\title{
Floods of
}

\section{January-February 1963 in}

California and Nevada

GEOLOGICAL SURVEY WATER-SUPPLY PAPER 1830-A

Prepared in cooperation with the States of California and Nevada and other agencies

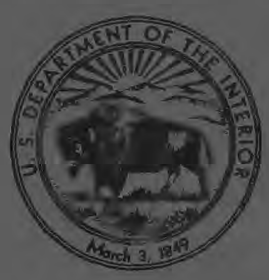




\section{Floods of}

January-February 1963 in California and Nevada

By L. E. YOUNG and E. E. HARRIS

FLOODS OF 1963 IN THE UNITED STATES

GEOLOGICAL SURVEY WATER-SUPPLY PAPER 1830-A

Prepared in cooperation with the States of California and Nevada and other agencies

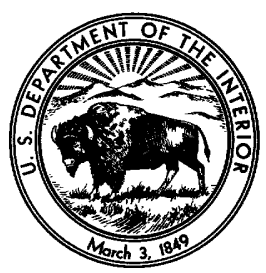




\title{
UNITED STATES DEPARTMENT OF THE INTERIOR
}

STEWART L. UDALL, Secretary

\section{GEOLOGIGAL SURVEY}

\author{
William T. Pecora, Director
}




\section{O N T E N T S}

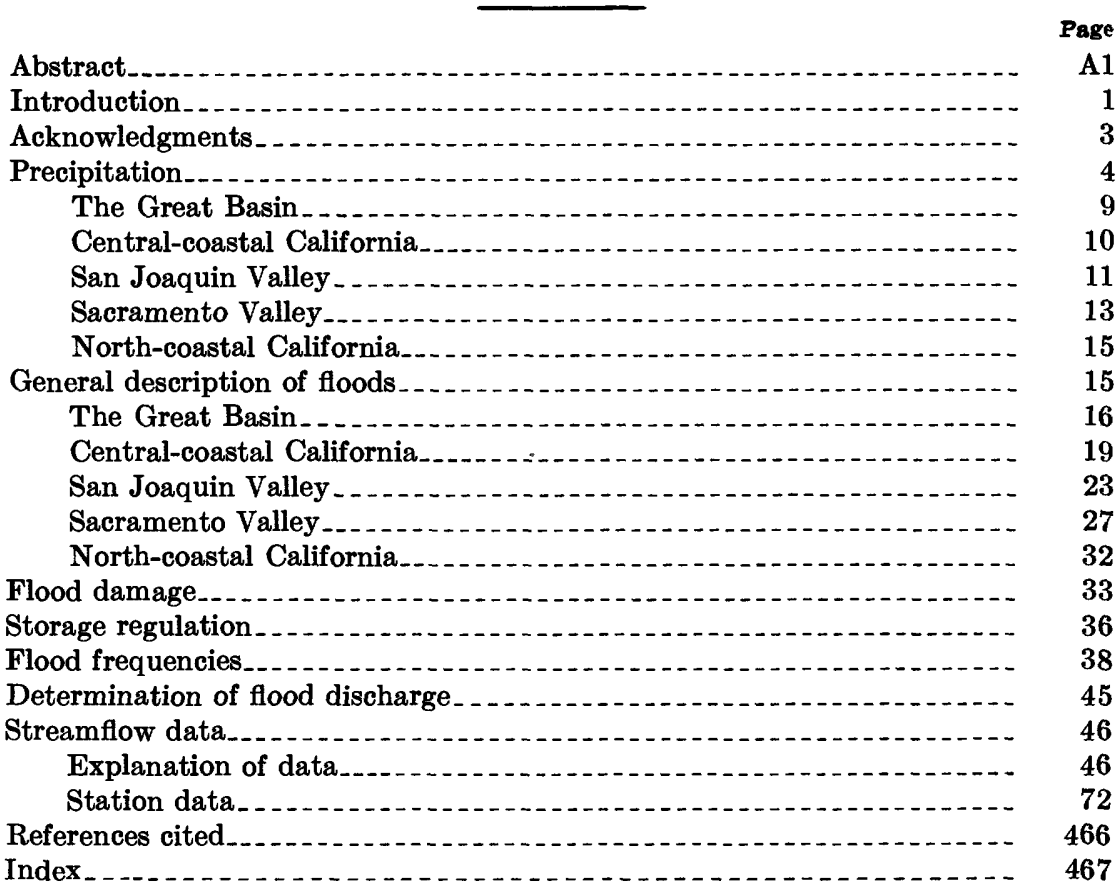

Plate 1. Map showing location of January-February 1963 flooddata sites . . . . . . In pocket

FIgURE 1. Map showing area described in this report _....... A2

2. Tsohyetal map for storm of January 29-February 1, 1963_ 6

3-8. Graphs showing cumulative precipitation at representative points:

3. In the Great Basin

4. In central-coastal California._... 10

5. In San Joaquin Valley _... 11

6. In Sacramento Valley

7. In north-coastal California

8. At Blue Canyon Weather Bureau Airport.

9. Discharge hydrographs at selected gaging stations in the

Great Basin, January 29-February 5, 1963 _...... 17 
10. Photograph showing Truckee River flooding in downtown Reno, Nev

1. Photograph showing gaging station on Truckee River at Vista, Nev., near time of flood crest

12. Discharge hydrographs at selected gaging stations in central-coastal California, January 29-February 5, 1963

13. Photograph showing Campbell police placing sandbags along San Tomas Aquina Creek.

14. Photograph showing flooding in Menlo Park, Calif......

15. Discharge hydrographs at selected gaging stations in the San Joaquin Valley, January 29-February 5, 1963_...

16. Discharge hydrographs at selected gaging stations in the Sacramento Valley, January 29-February 5, 1963.....

17. Photograph showing Marysville, Calif., during flood of January-February 1963 .........................

18. Photograph showing South Yuba River overflow damaging summer homes at Cisco, Calif . . . . . . . . . .

19. Discharge hydrographs at selected gaging stations in north-coastal California, January 29-February 5, 1963.

20. Photograph showing Napa River overflow near Edmonston Street Bridge in Napa, Calif ........

21-23. Graphs showing flood magnitude-frequency curves for selected gaging stations in-

21. The Great Basin and central-coastal California.

22. San Joaquin Valley ............................

23. Sacramento Valley and north-coastal California_

\section{TABLES}

Table 1. Precipitation at selected stations during January-February 1963.

2. Precipitation at selected stations during the storms of 1937, 1950, 1955, and 1963.

3. Flooded areas and flood damage in California and Nevada, January-February 1963.

4. Reduction of January-February 1963 flood discharge by storage regulation.

5. Annual peak stages and discharges . . .

6. Summary of flood stages and discharges... 50 


\title{
FLOODS OF 1963 IN THE UNITED STATES
}

\section{FLOODS OF JANUARY-FEBRUARY 1963 IN GALIFORNIA AND NEVADA}

\author{
By L. E. Young and E. E. Harris
}

\begin{abstract}
Flood-producing rains were associated with two warm frontal systems that crossed California and Nevada from the west on January 30 and 31. Most of the precipitation fell during a 72-hour period between January 29 and February 1. Three-day precipitation totals in excess of 20 inches were recorded at several places in Sierra Nevada and along the coast of California around Monterey Bay. The largest storm total was the 27.15 inches reported at Westfall Ranger Station in the Sierra National Forest, Calif. Ironically, the flood-producing storm ended a record-breaking 42-day winter drought in the area.

The floods of January-February 1963 in California and Nevada produced the greatest peak discharges in the history of recorded streamflow in some areas of the Sierra Nevada. Peak discharges in the American River basin were the most notable in this respect. For example, a peak of $121,000 \mathrm{cfs}$ (cubic feet per second) occurred on Middle Fork American River near Auburn, Calif., for which records have been kept since 1911 . This discharge not only exceeded the previously recorded high of $79,000 \mathrm{cfs}$, which occurred during the devastating 1955 floods, but also exceeded any previous flood peaks since the great deluge of December 1861-January 1862. Maximum peaks of record were also established in several other central Sierra Nevada River basins, including those of the Carson, Truckee, Stanislaus, Feather, and Yuba Rivers. The loss of 10 lives was attributed to the storm and floods, and total damage amounted to $\$ 18.5$ million.

This report presents a general description of the January-February 1963 floods, a discussion of the damage incurred, and a summary of peak stages and discharges at 623 sites. The storm precipitation and the regulation of floodflow by storage reservoirs are also discussed. A tabulation of annual peak stages and discharges for the period of record and flood-frequency curves based on these data are presented for selected gaging stations.
\end{abstract}

\section{INTRODUCTION}

The floods of January-February 1963 damaged large areas in central California and western Nevada (fig. 1). The most severely flooded areas were the basins of California and Nevada streams that 


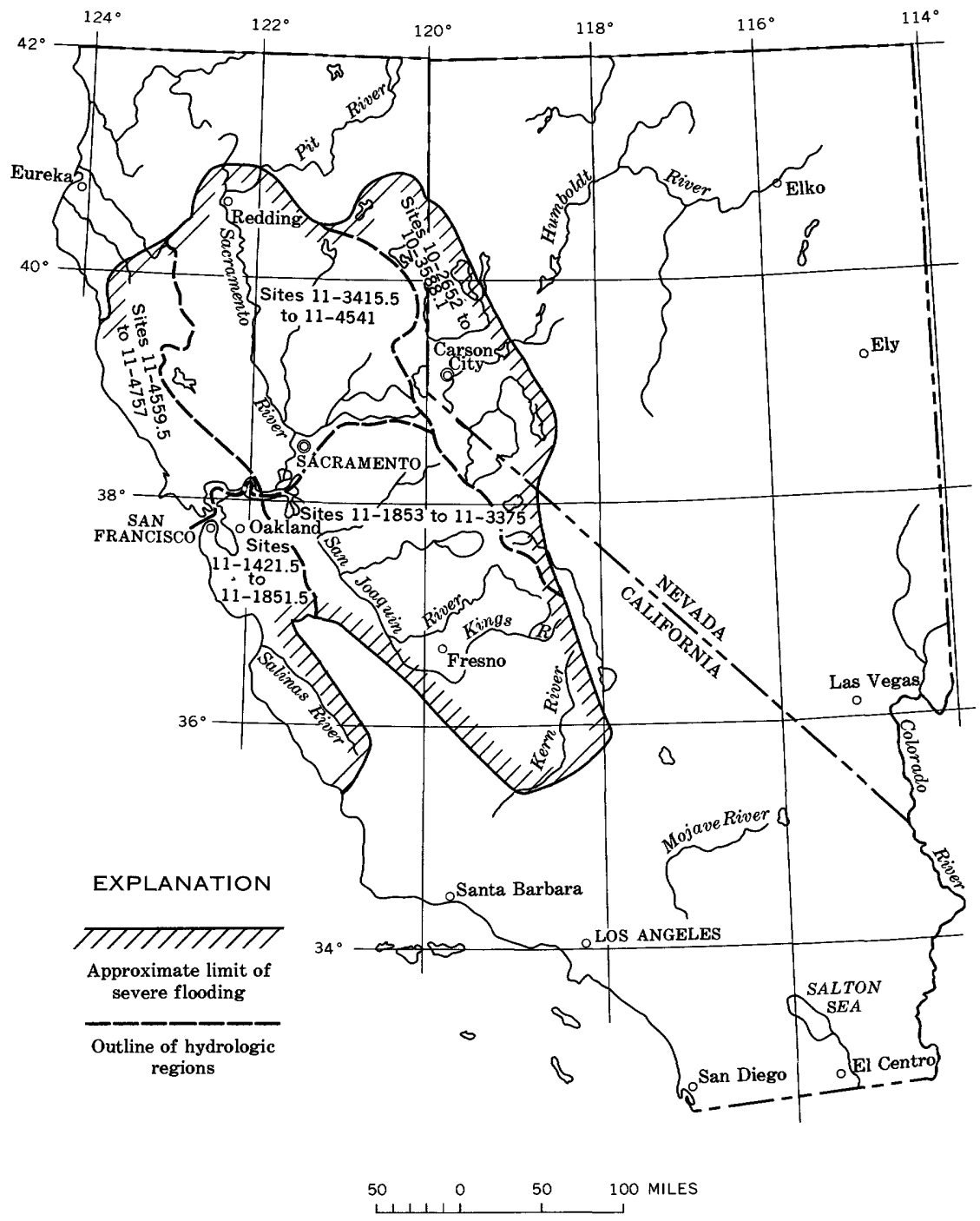

Figure 1.-Report area, hydrologic-region boundaries, and inclusive station numbers in each region.

have their source in the Sierra Nevada. Floods of lesser magnitude occurred along the central coast of California.

This report was prepared to provide detailed hydrologic data for use in flood-control planning, in design of structures to be built within the reach of floodwaters, and in any other studies involving flood hydrology. 
Flood-discharge information collected by the U.S. Geological Survey at the many stream-gaging stations (pl.1) throughout the flooded area is presented. This information includes data on stage and discharge throughout the period of flooding, a summary table of flood stages and discharges, and flood magnitude and frequency data for selected sites. Information on storm precipitation, flood damage, and storage regulation-a large part of which was provided by other agencies-is also included.

Pacific standard time, on a 24 -hour time basis, is used throughout this report. For example, 6:00 a.m. and 10:00 p.m. (Pacific standard time) are given as 0600 and 2200 hours, respectively.

To facilitate presentation of the data, the flooded area was divided into five regions, as outlined by the dashed lines in figure 1. These regions are the Great Basin, central-coastal California, San Joaquin Valley, Sacramento Valley, and north-coastal California. Nearly all items in this report are discussed individually for each of the regions, thus enabling the reader interested in only one region to readily obtain that individual information.

All sites where streamflow data are collected on a continuing basis are part of the nationwide stream-gaging network and, as such, have a network number. The numbers follow the downstream order used in Geological Survey publications on surface-water supply in the United States. These numbers appear wherever data for a network station are given in this report. For purposes of this report, numbers have also been assigned to miscellaneous sites, beginning with number one and following numerically in downstream order. Each site is shown on plate 1.

A preliminary open-file report on this flood of 1963 was released by the Geological Survey in March 1963 . The report, by S. E. Rantz and E. E. Harris, entitled "Floods of January-February 1963 in California and Nevada," contains the limited amount of flood data that was available on March 8, 1963. It consists mainly of data of peak discharges, a few typical flood hydrographs, information on storm precipitation, and preliminary storm-damage figures.

Special reports have been prepared for other notable floods that covered all or part of the area flooded during January-February 1963. The publications that contain this information are U.S. Geological Survey Water-Supply Papers 843; 1137-F, -H; 1260-D; 1650-A, -B; 1660-B; and 1790-B.

\section{ACKNOWLEDGMENTS}

The data in this report were collected as part of the cooperative programs between the U.S. Geological Survey and other Federal, 
State, county, and municipal agencies. The data were collected and compiled under the supervision of Walter Hofmann, district engineer of the Surface Water Branch in California, and G. F. Worts, Jr., district chief of the Water Resources Division in Nevada. The field surveys and office computations were coordinated by Harry Hulsing, area hydraulic specialist.

The cooperation of the U.S. Weather Bureau and the U.S. Army Corps of Engineers in providing precipitation data and estimates of flood damage is gratefully acknowledged.

\section{PRECIPITATION}

As late as January 27, 1963, California and western Nevada were having one of their worst winter droughts in a hundred years. The water year had started auspiciously with record-breaking rains in northern California in early October of 1962 . Very little precipitation was recorded, however, during the following months; and as December passed and January wore on without the usual winter storms, concern mounted for the water supply for the ensuing summer. The first rain of 1963 fell on January 28, terminating a record-breaking 42-day winter drought.

Intense precipitation on the evening of January 29 marked the arrival of a series of widespread storms. Two warm frontal systems were involved. The first frontal system crossed California and Nevada on January 30 and centered over the Yuba, American, and Truckee River basins; the second, which centered about 150 miles south over the Kaweah, Tule, and Kern River basins, swept across on January 31. Almost all the precipitation fell during a 72-hour period between January 29 and February 1 . The largest total was the 27.15 inches reported at Westfall Ranger Station in the Sierra National Forest, Calif. Table 1 lists storm totals at selected precipitation stations in the major hydrologic regions of the area.

The freezing level, or snowline, was above the 8,000-foot level during most of the storm and at times was as high as 11,000 feet. As a result, most storm precipitation occurred as rain; snow fell only in the extreme high Sierra Nevada. Very little snow had accumulated in the Sierra Nevada prior to this storm; accordingly, snowmelt was not a significant factor in this flood.

The isohyetal map (fig. 2) shows the generalized precipitation distribution for the storm period January 29-February 1. The map is based mainly on U.S. Weather Bureau precipitation records, supplemented wherever possible by additional data. This map shows that storm totals exceeded 20 inches in several areas in the Sierra Nevada and in the mountains along the central coast. 
TABLE 1.-Precipitation at selected stations during January-February 1963

\begin{tabular}{|c|c|c|c|c|c|c|c|c|}
\hline \multirow{3}{*}{ Precipitation station and subbasin } & \multirow{3}{*}{$\begin{array}{c}\text { Ante- } \\
\text { cedent } \\
\text { precipi- } \\
\text { tation } \\
\text { Jan. 1-28 } \\
\text { (inches) }\end{array}$} & \multicolumn{5}{|c|}{ Storm precipitation (inches) } & \multicolumn{2}{|c|}{$\begin{array}{l}\text { Total monthly } \\
\text { precipitation } \\
\text { (inches) }\end{array}$} \\
\hline & & \multicolumn{3}{|c|}{ January } & \multicolumn{2}{|c|}{ February } & \multirow{2}{*}{$\begin{array}{l}\text { Jan- } \\
\text { uary }\end{array}$} & \multirow{2}{*}{$\begin{array}{l}\text { Feb- } \\
\text { ruary }\end{array}$} \\
\hline & & 29 & 30 & 31 & 1 & 2 & & \\
\hline $\begin{array}{l}\text { The Great Basin: } \\
\text { Bridgeport (Walker River) } \\
\text { Woodfords (Carson River) } \\
\text { Mt. Rose (Truckee River) } \\
\text { Susanville (Honey Lake) }\end{array}$ & $\begin{array}{l}0 \\
.19 \\
0\end{array}$ & $0^{0} .02$ & $\begin{array}{r}1.68 \\
3.08 \\
2.48 \\
.55\end{array}$ & $\begin{array}{l}2.59 \\
\text { 3. } 92 \\
7.13 \\
1.27\end{array}$ & $\begin{array}{r}1.55 \\
2.34 \\
3.95 \\
.57\end{array}$ & $\begin{array}{l}0 \\
\text { Trace } \\
0 \\
.27\end{array}$ & $\begin{array}{r}4.27 \\
7.22 \\
10.27 \\
1.82\end{array}$ & $\begin{array}{l}1.68 \\
2.88 \\
4.69 \\
1.31\end{array}$ \\
\hline $\begin{array}{l}\text { Central-coastal California: } \\
\text { Big Sur State Park (Big Sur River) }\end{array}$ & Trace & & 4.66 & 9.23 & 6.29 & & 13.89 & 11.67 \\
\hline $\begin{array}{l}\text { Uvas Creek above Uvas Reservoir } \\
\text { (Uvas Creek) } \\
\text { Boulder Creek Locatelli Ranch (San }\end{array}$ & 0 & 1.0 & 7.2 & 7. 0 & .2 & 0 & 15.2 & 3. 0 \\
\hline $\begin{array}{l}\text { Lorenzo River) } \\
\text { San Joaquin Valley: }\end{array}$ & $\mathbf{0}$ & 2.37 & 8.77 & 7. 31 & .66 & 0 & 18.45 & 8. 76 \\
\hline $\begin{array}{l}\text { Packsaddle Canyon (Kern River) } \\
\text { Giant Forest (Kaweah River) } \\
\text { Huntington Lake (U pper San Joaquin }\end{array}$ & $\begin{array}{l}\mathbf{0} \\
\mathbf{0}\end{array}$ & $0^{.6}$ & $\begin{array}{l}3.2 \\
4.76\end{array}$ & $\begin{array}{l}5.9 \\
6.57\end{array}$ & $\begin{array}{l}1.9 \\
9.71\end{array}$ & 0.40 & $\begin{array}{l}9.7 \\
11.33\end{array}$ & $\begin{array}{l}\text { 3. } 2 \\
12.73\end{array}$ \\
\hline River) & 0 & 0 & 5.35 & 5.48 & 3. 09 & .02 & 10.83 & 5.63 \\
\hline $\begin{array}{l}\text { Yosemite National Park (Merced } \\
\text { River) }\end{array}$ & Trace & .03 & 4. 26 & 5.77 & 4.60 & .30 & 10.06 & 6.50 \\
\hline $\begin{array}{l}\text { Tiger Creek Powerhouse (Mokelumne } \\
\text { River) }\end{array}$ & $\mathbf{0}$ & .08 & 3. 67 & 3. 93 & 5.69 & .02 & 7.68 & 7.82 \\
\hline $\begin{array}{l}\text { Sacramento Valley: } \\
\text { Vollmers (Upper Sacramento River) } \\
\text { Stonyford Ranger Station (Stony Creek) -- }\end{array}$ & $\begin{array}{l}\text { Trace } \\
\text { Trace }\end{array}$ & $\begin{array}{l}.05 \\
.03\end{array}$ & $\begin{array}{r}1.76 \\
.63\end{array}$ & $\begin{array}{l}2.79 \\
1.79\end{array}$ & $\begin{array}{l}2.33 \\
1.41\end{array}$ & $0^{.53}$ & $\begin{array}{l}4.60 \\
2.45\end{array}$ & $\begin{array}{l}9.40 \\
4.70\end{array}$ \\
\hline $\begin{array}{l}\text { Brush Creek Ranger Station (Feather } \\
\text { River) }\end{array}$ & $\mathbf{0}$ & .11 & 2. 77 & 4.99 & 4. 79 & .40 & 7.87 & 8.05 \\
\hline $\begin{array}{l}\text { Blue Canyon (American and Bear } \\
\text { Rivers) }\end{array}$ & .35 & 1.37 & 5.26 & 8. 70 & 2.05 & .14 & 15.68 & 5.27 \\
\hline $\begin{array}{l}\text { Clearlake Highlands (Cache Creek) } \\
\text { North-coastal California: }\end{array}$ & $0^{.0}$ & 1.24 & 2.13 & 2.33 & .06 & .03 & 5.74 & 2. 24 \\
\hline $\begin{array}{l}\text { St. Helena 4 WSW (Napa River) } \\
\text { Kentfield (Corte Madera Creek) } \\
\text { Ukiah (Upper Russian River) } \\
\text { Cazadero (Lower Russian River) } \\
\text { Navarro } 1 \text { NW (Navarro River) }\end{array}$ & $\begin{array}{l}0 \\
.07 \\
0.07 \\
0\end{array}$ & $\begin{array}{r}.98 \\
.01 \\
.63 \\
1.13 \\
.95\end{array}$ & $\begin{array}{l}\text { 3. } 42 \\
\text { 3. } 94 \\
\text { 3. } 85 \\
6.58 \\
1.81\end{array}$ & $\begin{array}{l}\text { 4. } 41 \\
\text { 4. } 93 \\
\text { 3. } 20 \\
5.77 \\
2.42\end{array}$ & $\begin{array}{r}.63 \\
4.65 \\
.80 \\
.91 \\
.06\end{array}$ & $\begin{array}{l}0 \\
.06 \\
.09 \\
.08\end{array}$ & $\begin{array}{r}8.81 \\
8.95 \\
7.75 \\
13.48 \\
5.18\end{array}$ & $\begin{array}{l}\text { 3. } 51 \\
8.31 \\
\text { 3. } 22 \\
\text { 7. } 70 \\
2.23\end{array}$ \\
\hline
\end{tabular}

Figures 3-7 show cumulative precipitation for the 1963 storm at selected recording stations throughout the area. The graphs show that, except in the Boulder Creek area, the storm was most intense from about 0600 to 2400 hours January 31 , and that most of the precipitation fell during the 72-hour period trom 1<00 hours January 29 to 1200 hours February 1. In the Boulder Creek area the longest period of intense rain occurred between 0100 hours and 1100 hours January 30 ; a shorter period of high-intensity rain occurred between 1600 hours and 2100 hours January 31.

A comparison of 3-day storm precipitation totals for some of the notable storms in the area is given in table 2. The selected stations listed in the table are representative of the five hydrologic regions: Boca (Great Basin), Big Sur State Park (central-coastal California), Giant Forest (San Joaquin Valley), Blue Canyon Weather Bureau Airport (Sacramento Valley), Ukiah (north-coastal California). Because of extreme orographic influence, the actual magnitude of the precipitation for a given storm at these stations is not necessarily 


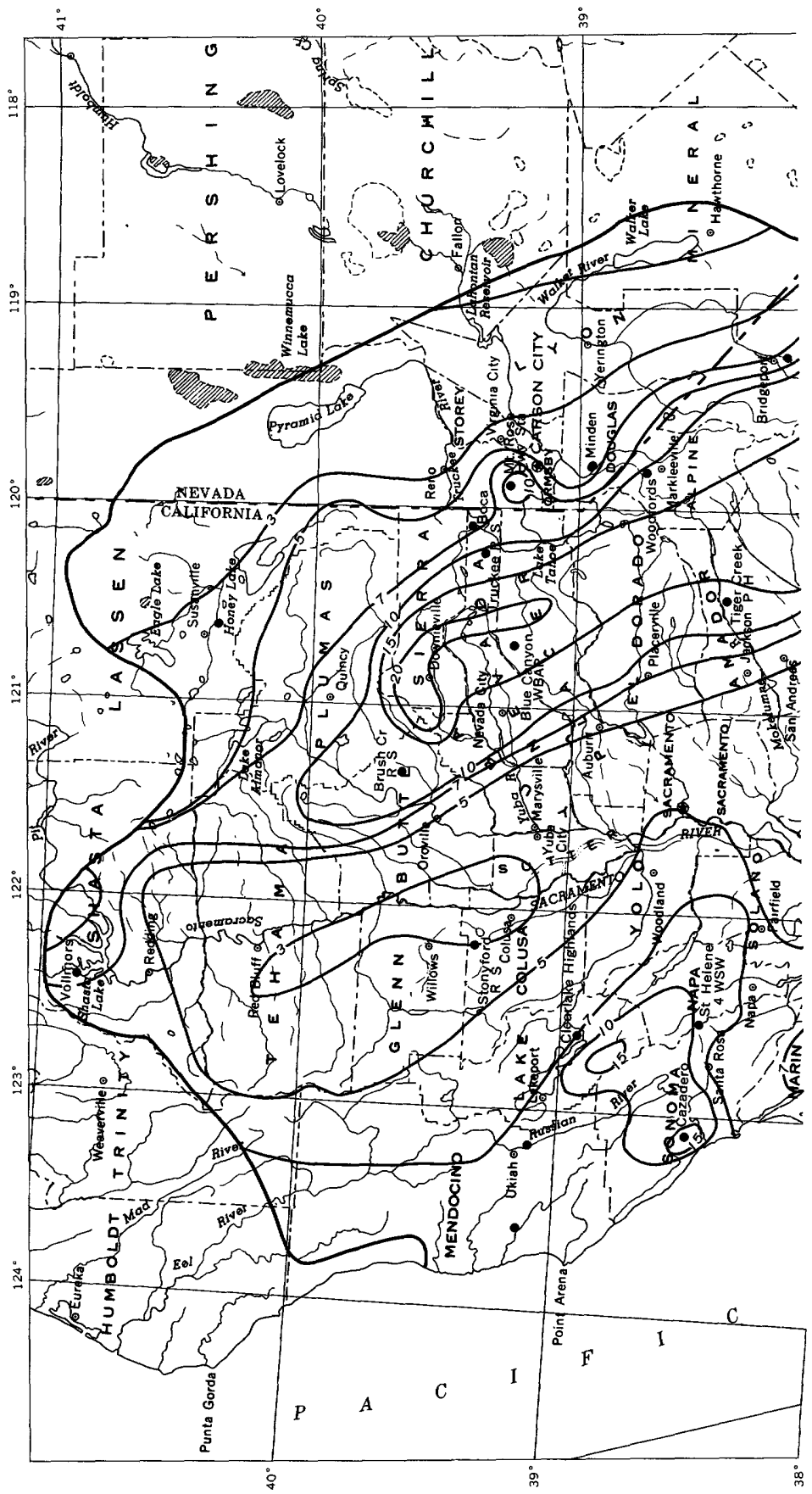




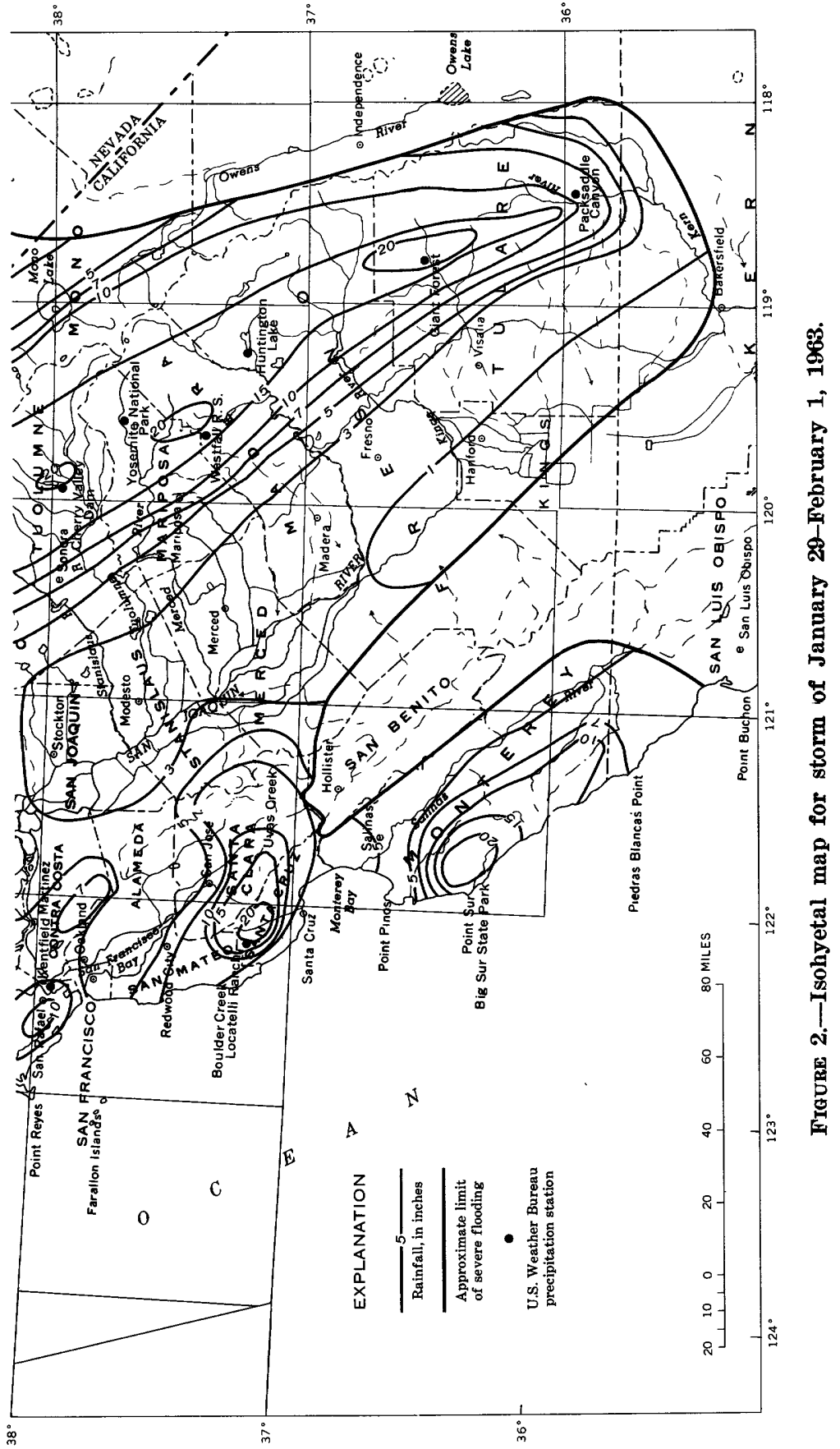


TABLE 2.-Precipitation at selected stations during the storms of 1937, 1950, 1955, and 1963

\begin{tabular}{|c|c|c|c|c|c|c|c|}
\hline \multicolumn{2}{|l|}{1837} & \multicolumn{2}{|l|}{1950} & \multicolumn{2}{|l|}{1955} & \multicolumn{2}{|l|}{1963} \\
\hline Period & $\begin{array}{c}\text { Pre- } \\
\text { cipi- } \\
\text { tation } \\
\text { (inches) }\end{array}$ & Period & $\begin{array}{c}\text { Pre- } \\
\text { cipi- } \\
\text { tation } \\
\text { (inches) }\end{array}$ & Period & $\begin{array}{c}\text { Pre- } \\
\text { cipi- } \\
\text { tation } \\
\text { (inches) }\end{array}$ & Period & $\begin{array}{c}\text { Pre- } \\
\text { cipi- } \\
\text { tation } \\
\text { (inches) }\end{array}$ \\
\hline \multicolumn{8}{|c|}{ Boca (Great Basin) } \\
\hline $\begin{array}{r}\text { Dec. } 1-9 . \\
10 \\
11 \\
12 \\
10-12\end{array}$ & $\begin{array}{l}0 \\
1.91 \\
1.45 \\
.40 \\
3.76\end{array}$ & $\begin{array}{r}\text { Nov. } 1-16 . \ldots \\
17 \\
18 \\
19 \\
17-19 \\
\end{array}$ & $\begin{array}{l}0.68 \\
.71 \\
1.54 \\
2.21 \\
4.46\end{array}$ & Dec. 1-21.... & $\begin{array}{l}6.17 \\
1.57 \\
2.25 \\
2.80 \\
6.62\end{array}$ & $\begin{array}{l}\text { Jan. 1-28 } 30 . \\
31 . \\
\text { Feb. 1 } \\
\text { Jan. } 30-\text { Feb. 1.. }\end{array}$ & $\begin{array}{l}0.49 \\
1.19 \\
2.35 \\
2.88 \\
6.42\end{array}$ \\
\hline
\end{tabular}

Big Sur State Park (central-coastal California)

\begin{tabular}{|c|c|c|c|c|c|c|c|}
\hline $\begin{array}{r}\text { Dec. } 1-9 . \\
10 \\
11 \\
12 \\
10-12\end{array}$ & $\begin{array}{r}0 \\
2.00 \\
4.45 \\
4.62 \\
11.07\end{array}$ & $\begin{array}{r}\text { Nov. 1-17. } \\
18 \\
19 \\
20 \\
18-20 \\
\end{array}$ & $\begin{array}{l}\text { 3. } 00 \\
2.10 \\
4.17 \\
2.25 \\
\mathbf{8 . 5 2}\end{array}$ & $\begin{array}{r}\text { Dec. } 1-21 \\
22 \\
23 \\
24 \\
22-24 \\
-\end{array}$ & $\begin{array}{r}8.05 \\
3.88 \\
7.50 \\
1.38 \\
12.76\end{array}$ & $\begin{array}{l}\text { Jan. 1-29. } \\
30 \\
31 \\
\text { Feb. } 1 . \\
\text { Jan. } 30-\text { Feb. 1... }\end{array}$ & \begin{aligned} \multicolumn{1}{l}{0} \\
4.66 \\
9.23 \\
6.29 \\
20.18\end{aligned} \\
\hline
\end{tabular}

Giant Forest (San Joaquin Valley)

\begin{tabular}{|c|c|c|c|c|c|c|c|}
\hline $\begin{array}{r}\text { Dec. } 1-9 \\
10 \\
11 \\
12 \\
10-12\end{array}$ & $\begin{array}{r}0.37 \\
8.26 \\
\text { 5. } 45 \\
2.20 \\
15.91\end{array}$ & $\begin{array}{r}\text { Nov. 1-17 } \\
18 \\
19 \\
20 \\
18-20\end{array}$ & $\begin{array}{r}1.76 \\
11.0 \\
\text { 3. } 52 \\
.14 \\
11.66\end{array}$ & $\begin{array}{r}\text { Dec. } 1-21 \\
22 \\
23 \\
24 \\
22-24\end{array}$ & $\begin{array}{r}6.59 \\
1.77 \\
11.04 \\
4.40 \\
17.21\end{array}$ & $\begin{array}{l}\text { Jan. } 1-29 \\
30 \\
\text { Feb. } 1 \\
\text { Jan. } 30-F e b .1\end{array}$ & 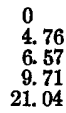 \\
\hline
\end{tabular}

Blue Canyon Weather Bureau Airport (Sacramento Valley)

\begin{tabular}{|c|c|c|c|c|c|c|c|}
\hline Dec. $1-9 \ldots \ldots . . . .$. & $\begin{array}{l}0.58 \\
\text { 5. } 27 \\
\text { 3. } 28 \\
.65 \\
9.20\end{array}$ & $\begin{array}{r}\text { Nov. 1-17 } \\
18 \\
19 \\
20 \\
18-20\end{array}$ & $\begin{array}{r}8.28 \\
6.80 \\
1.43 \\
8.56 \\
16.79\end{array}$ & $\begin{array}{r}\text { Dec. } 1-20 \\
21 \\
22 \\
23 \\
21-23\end{array}$ & $\begin{array}{r}21.13 \\
5.19 \\
7.44 \\
5.92 \\
18.55\end{array}$ & $\begin{array}{l}\text { Jan. 1-29. } \\
30 \\
\text { Feb. 1 } \\
\text { Jan. 30-Feb. 1.. }\end{array}$ & $\begin{array}{r}\text { 1. } 72 \\
\text { 5. } 26 \\
\text { 8. } 70 \\
2.05 \\
16.01\end{array}$ \\
\hline
\end{tabular}

Ukiah (north-coastal California)

\begin{tabular}{|c|c|c|c|c|c|c|c|}
\hline $\begin{array}{r}\text { Dec. } 1-9 . \ldots . \\
10 \\
11 \\
12 \\
10-12\end{array}$ & $\begin{array}{l}0.36 \\
4.26 \\
\text { 3. } 93 \\
.54 \\
8.73\end{array}$ & $\begin{array}{r}\text { Nov. } 1-15 \ldots \\
16 \\
17 \\
18 \\
16-18\end{array}$ & $\begin{array}{r}0.85 \\
1.84 \\
.23 \\
1.07 \\
\text { 3. } 14\end{array}$ & Dec. $1-20$. & $\begin{array}{r}11.28 \\
1.71 \\
\text { 3. } 98 \\
1.57 \\
7.26\end{array}$ & $\begin{array}{l}\text { Jan. 1-29... } \\
30 \\
\text { Feb. 1. } \\
\text { Jan. } 30-F e b .1\end{array}$ & $\begin{array}{r}0.70 \\
3.85 \\
3.20 \\
.80 \\
7.85\end{array}$ \\
\hline
\end{tabular}

indicative of the amount of precipitation over the entire region. However, at a given site the same general orographic influence should be effective for each storm; the storm differences at a site are representative of general differences in amounts of precipitation over large areas. Additional precipitation data for these and other major storms in the area are given in U.S. Weather Bureau reports and in the Geological Survey flood reports listed in the introduction of this report. The relations between the accumulated precipitation for the 1963 storm and for the severe storms of 1950, 1955, and 1962 at the Blue Canyon precipitation station are shown in figure 8. 


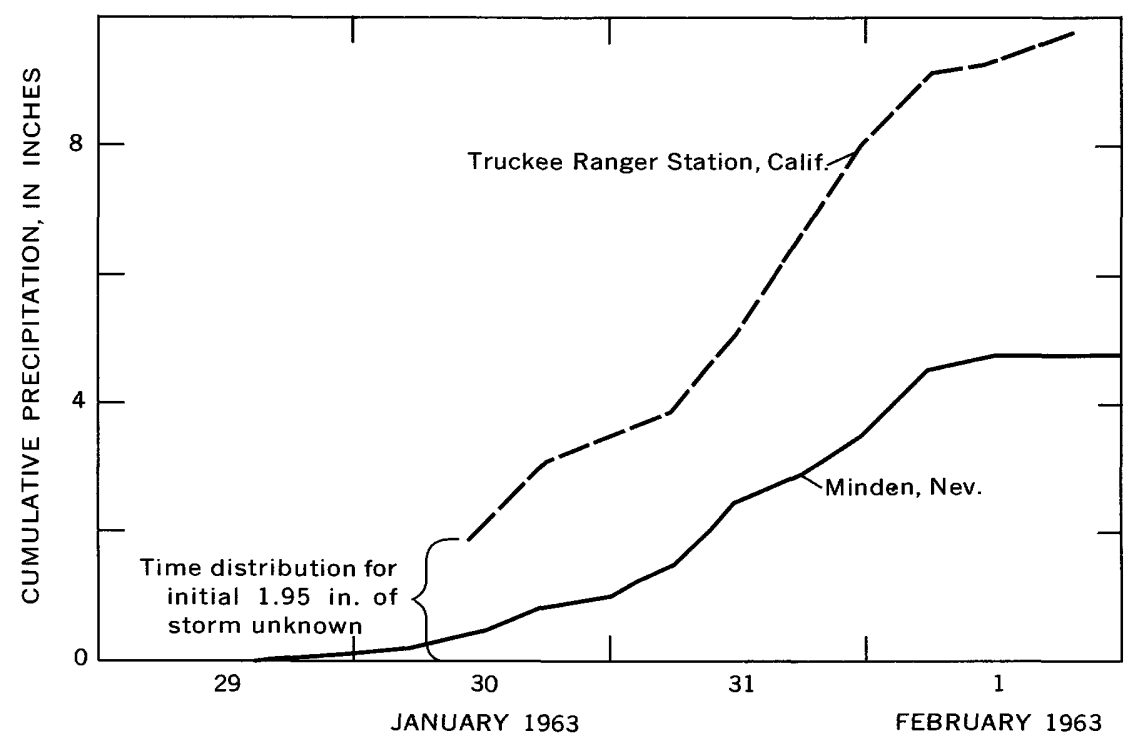

Figure 3.-Cumulative precipitation at representative points in the Great Basin.

All precipitation stations mentioned in the preceding paragraphs are shown on the isohyetal map (fig. 2).

\section{THE GREAT BASIN}

The storm centered over the Sierra Nevada and produced highintensity rainfall in the upper Truckee and the Carson River basins; in places, rain totaled as much as 20 inches. The storm decreased rapidly toward the east, and the Fallon area received only 0.62 inch of rain during the storm period.

The 4-day storm of January 29-February 1 established new maximum amounts of precipitation for 24, 48, 72, and 96 hours in Nevada. It moved across the Sierra Nevada from the Pacific Ocean and left a recordbreaking 7.13 inches of precipitation at Mount Rose Highway Station, Nev., in a 24 -hour period that ended at 1630 hours on January 31. An additional 3.95 inches was recorded during the following 24 hours for a 48-hour total of 11.08 inches. On January 30, 2.48 inches had been received. In the 72-hour period that began January 30, a record 13.56 inches of rain fell. Including the 0.02 inch received on January 29, a 4-day total of 13.58 inches was recorded. These amounts far exceed those previously recorded for similar periods in Nevada, according to the U.S. Weather Bureau. 


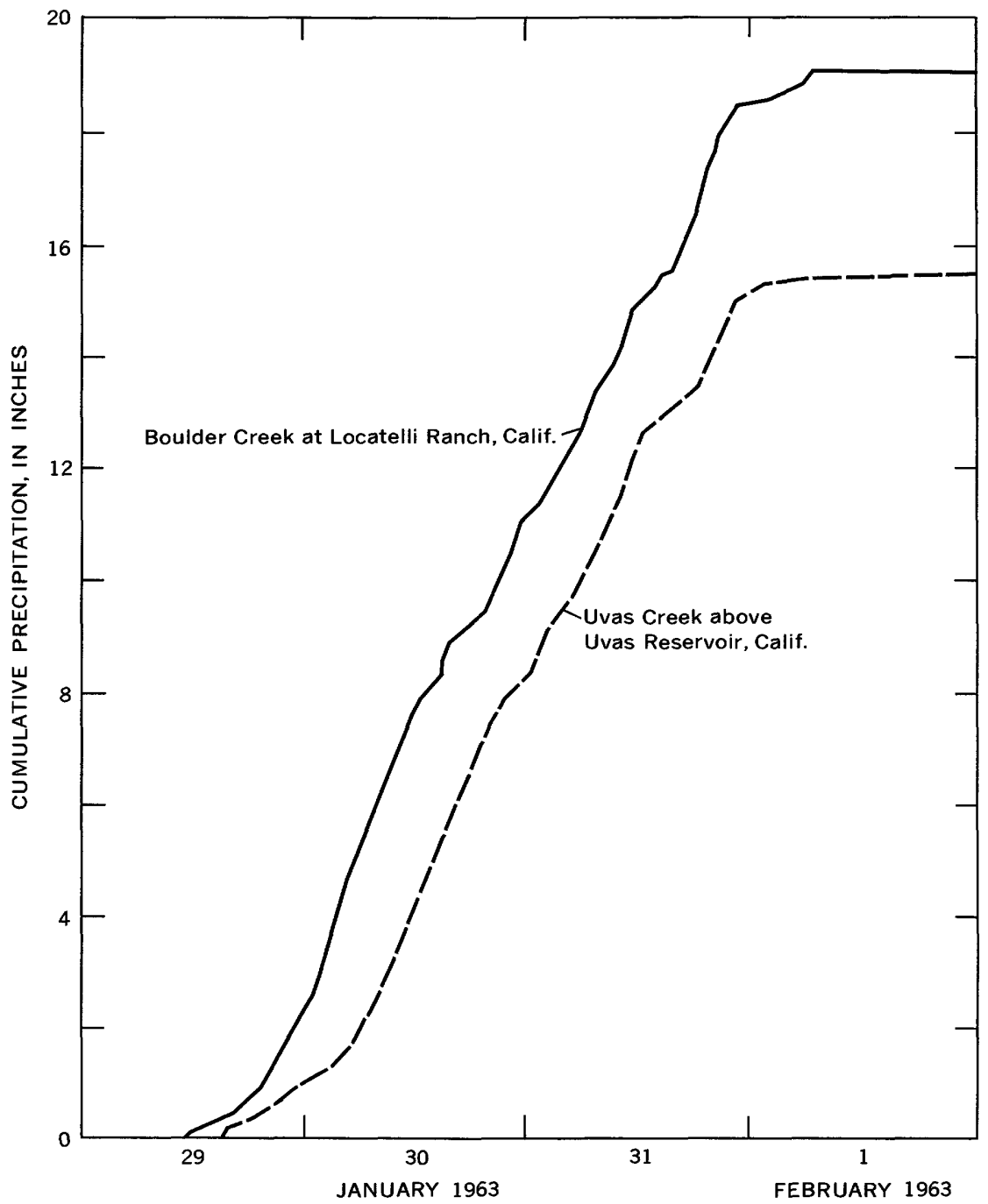

Frgure 4.-Cumulative precipitation at representative points in central-coastal California.

\section{CENTRAL-COASTAL CALIFORNIA}

Total storm precipitation in central-coastal California was heaviest in the Santa Lucia Range near Big Sur and in the Santa Cruz Mountains north of Santa Cruz; in places it exceeded 20 inches. Precipitation decreased rapidly to the east to less than 5 inches in the Salinas Valley and southeast of San Francisco Bay. The rate of rainfall 


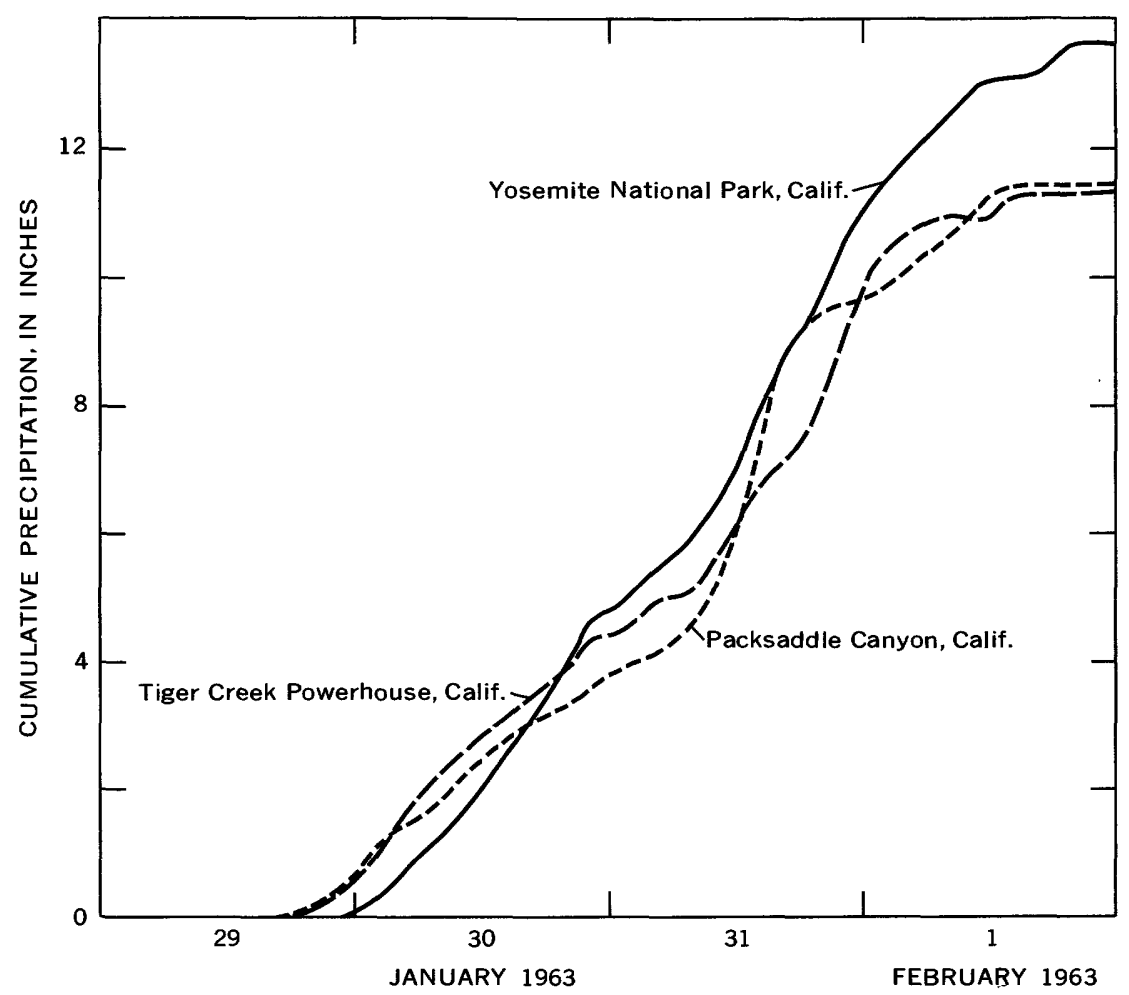

Frgure 5.-Cumulative precipitation at representative points in San Joaquin Valley.

was fairly uniform throughout the storm period, and hourly totals as high as 0.6 inch were recorded at Boulder Creek, about 12 miles north of Santa Cruz. The records of accumulated precipitation at Boulder Creek and at Uvas Creek Reservoir, about 4 miles southwest of Morgan Hill, are shown in figure 4.

A 24-hour precipitation of 9.23 inches was observed at Big Sur State Park in the Big Sur River basin; this total exceeded the previously observed maximum 24-hour measurement (8.05 in. Jan. 21, 1943) during the 50-year period of record. Neither figure necessarily represents the maximum 24-hour precipitation; each represents the precipitation catch in the 24 hours preceding the daily inspection of the rain gage.

\section{SAN JOAQUIN VALLEY}

As in most of California and western Nevada, the San Joaquin Valley and southern Sierra Nevada region had been affected by a winter drought for about 42 days prior to January 29. Rain began 


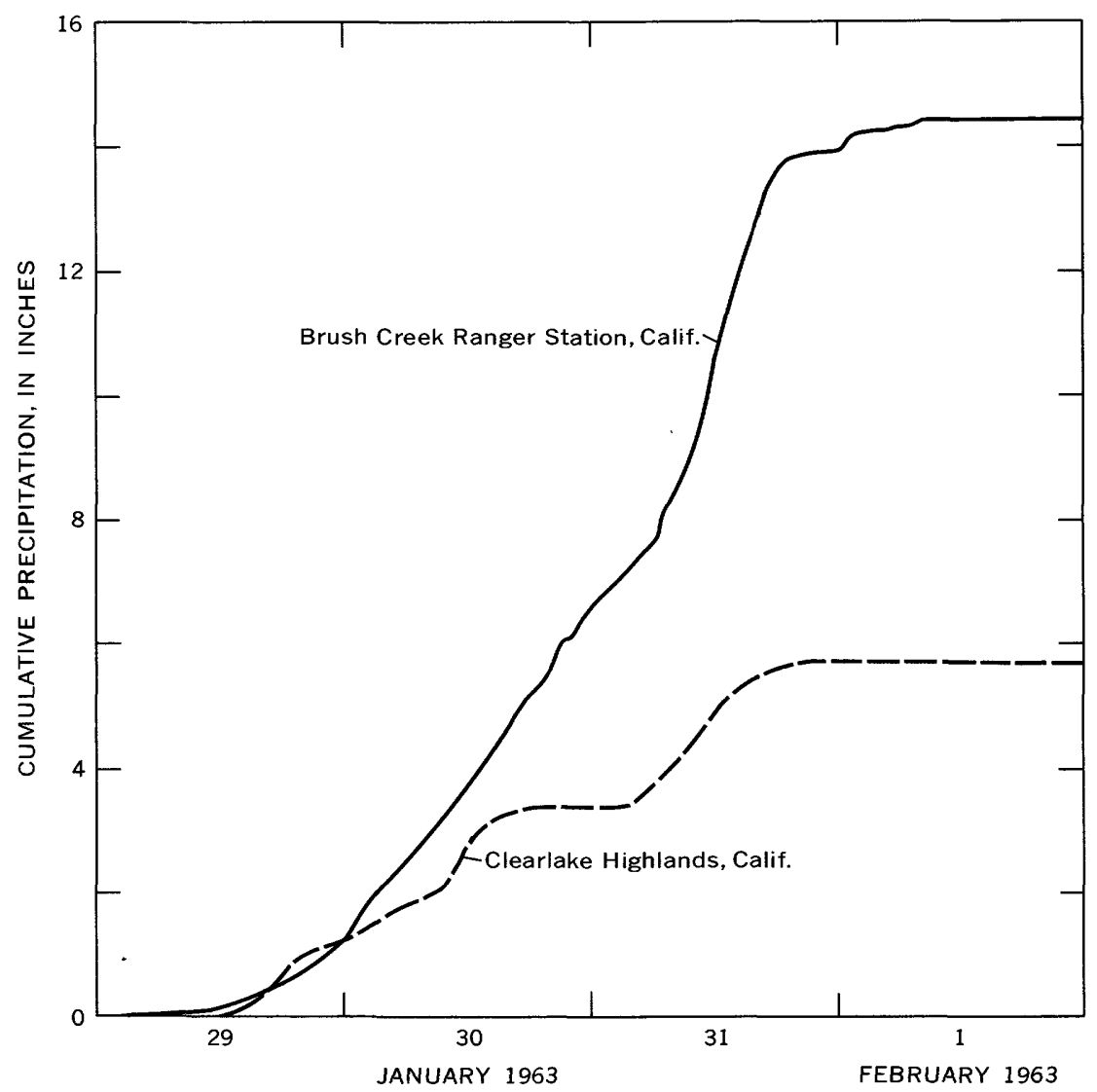

Figure 6.-Cumulative precipitation at representative points in the Sacramento Valley.

to fall late in the evening of January 29 and continued steadily through the early afternoon of February 1; the maximum intensity occurred between 1200 and 2400 hours January 31. Maximum hourly totals of 0.6 inch were registered at the Packsaddle Canyon rain gage in the Kern River basin. More than 12 inches of rainfall in one 24-hour period was recorded at Giant Forest in the Kaweah River basin. This amount exceeded the 11.04 inches recorded in December 1955 and indicates that hourly totals in excess of 0.6 inch must have occurred at this location.

Accumulated storm precipitation for selected stations in the area is shown in figure 5. Total storm precipitation ranged from less than 2 inches on the San Joaquin Valley floor to more than 20 inches in the Sierra Nevada. Rainfall in excess of 20 inches was reported at Cherry 
Valley Dam in the Tuolumne River basin, at the south entrance to Yosemite National Park in the Merced River basin, at Westfall Ranger Station in the Fresno River basin, and at Giant Forest in the Kaweah River basin.

\section{SACRAMENTO VALLEY}

The drought in the Sacramento Valley and adjacent mountains was ended by orographically influenced rains that began late in the evening of January 28 and that began to intensify in the early evening of January 29. The most intense precipitation occurred during the period from about 0600 to 2400 hours January 31 . Only small amounts fell after that time. Graphs of accumulated storm precipitation for Brush Creek Ranger Station in the Feather River basin and for Clearlake Highlands in the Cache Creek basin are shown in figure 6. A maximum hourly precipitation of 0.75 inch was registered at Brush Creek Ranger Station.

Total storm precipitation ranged from about 3 inches on the valley floor to more than 10 inches in the northern Coast Range to the west. Precipitation in the Sierra Nevada basins tributary to the Sacra-

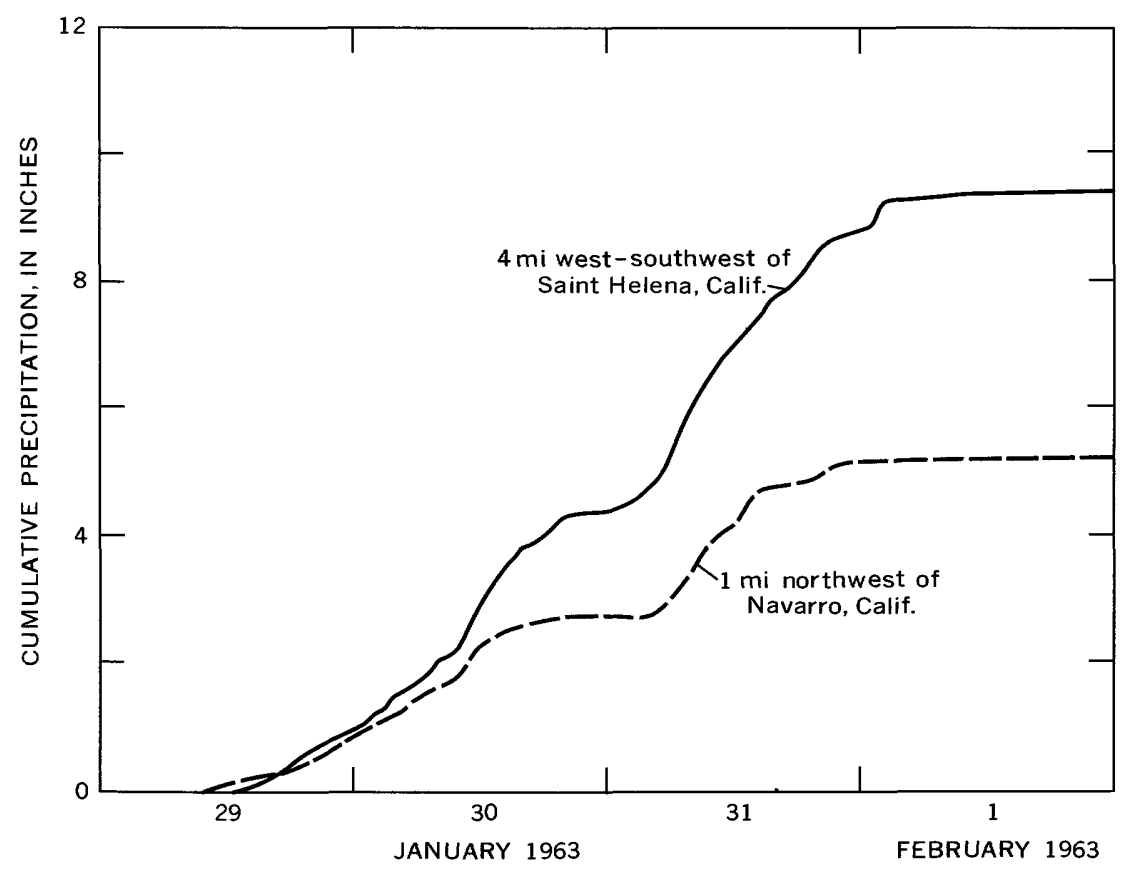

FIGURE 7.-Cumulative precipitation at representative points in north-coastal California. 


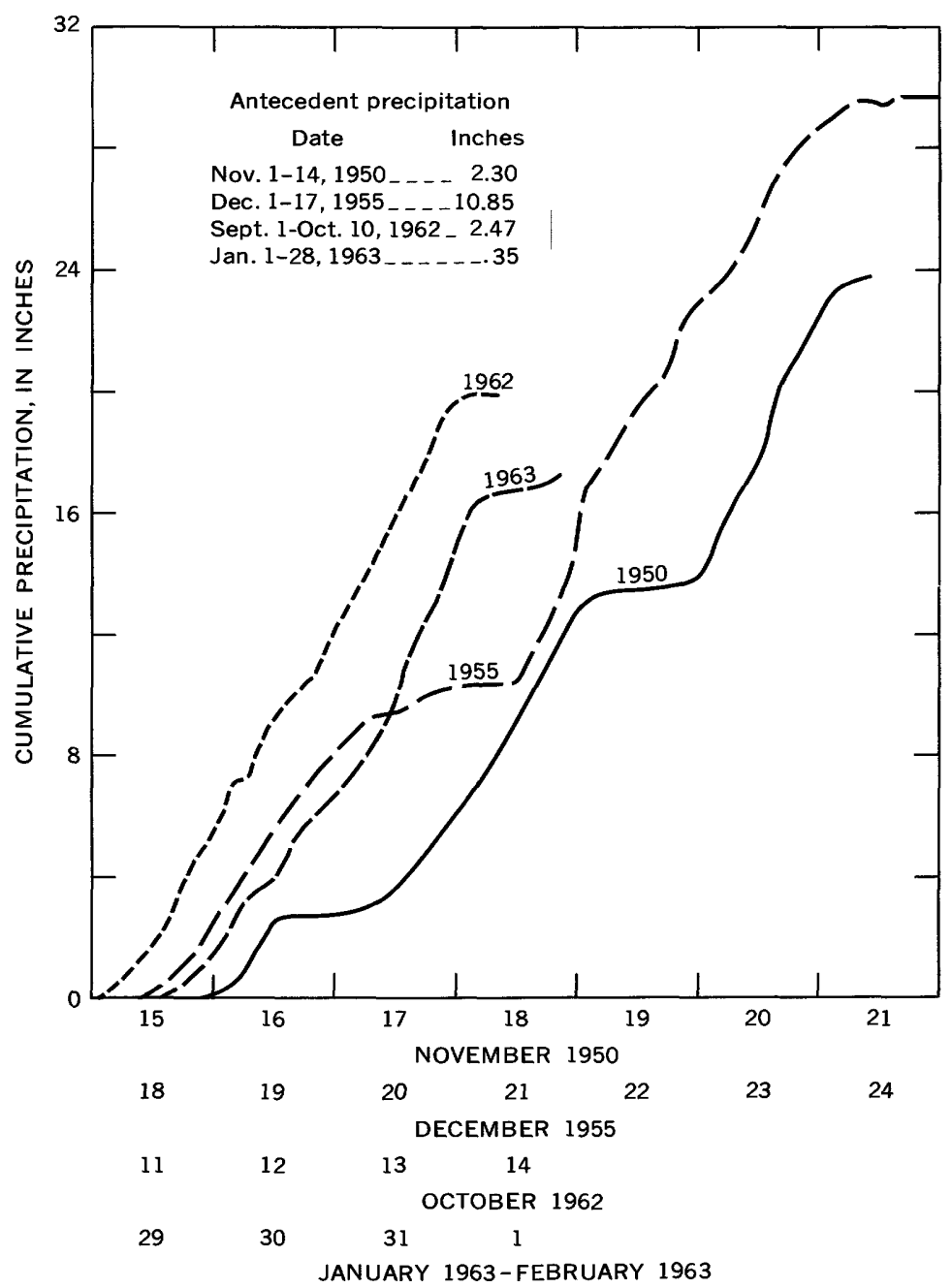

FIgURE 8.-Cumulative precipitation at Blue Canyon Weather Bureau Airport, Calif., for selected storms. (Altitude : $5,280 \mathrm{ft}$ above sea level.)

mento Valley ranged from about 5 inches in the western foothills to more than 20 inches in the American and the Feather River basins.

Cumulative-precipitation graphs for the storms of November 1950, December 1955, October 1962, and January-February 1963 at the Blue Canyon Weather Bureau Airport, on the north boundary of the American River basin, are given in figure 8. Total storm precipitation for the storms prior to 1963 was several inches greater than that for January-February 1963. However, the 1963 storm's intensity of 0.4- 
0.6 inch per hour for about 16 consecutive hours, preceded by about $81 / 2$ inches of steady rain in 36 hours, was greater than that during any previous storms. The maximum 24-hour precipitation in 1963 of 9.10 inches is exceeded only by that recorded during the 1955 storm of 9.31 inches.

\section{NORTH-COASTAL CALIFORNIA}

Storm precipitation in most of the north-coastal region was not unusually heavy, ranging from about 6 inches in the lowlands north of San Francisco Bay to more than 10 inches in the hills north of Golden Gate and in the vicinity of Cazadero, near the mouth of the Russian River.

Graphs of accumulated precipitation at St. Helena in the Napa River basin and at Navarro in the Navarro River basin are shown in figure 7. A maximum total hourly precipitation of 0.5 inch was recorded at St. Helena. Cazadero, generally a wet spot in this orographically influenced region, reported 6.58 inches of precipitation in 24 hours, as compared with 10.75 inches reported for a similar period in 1955 .

\section{GENERAL DESCRIPTION OF FLOODS}

At the highest altitudes, where the heaviest rainfall occurred, antecedent conditions were favorable for heavy runoff. Temperatures preceding the storm had been well below normal, and the ground was largely bare of snow and was frozen at altitudes greater than 4,000 feet above sea level on the west slope of the Sierra Nevada and 6,000 feet on the east slope. The runoff from the intense rainfall was therefore extremely heavy. Streams rose rapidly, and in large areas drought conditions quickly gave way to flooding. The rain-swollen rivers surged through hundreds of evacuated homes in northern California, pushed against hurriedly built sandbag dikes, in Reno, Nev., and blocked traffic on main east-west highway and rail routes across the Sierra Nevada. Hardest hit areas were in the basins of the American, Yuba, and Truckee Rivers. Flood peaks in many areas either reached record-breaking heights or rivaled the discharge peaks of the memorable floods of November 1950 and December 1955 .

Some generalizations can be made concerning the runoff patterns of the floods in the various hydrologic regions. The major flood peaks occurred on either January 31 or February 1. In the coastal basins north of San Francisco Bay, there was generally one minor stream rise, followed by the major peak. In the coastal basins south of San Francisco Bay, there were two major peaks, preceded by one or more minor rises. In the Sacramento and San Joaquin River basins, there was only a single major peak; in the Kern River and Tulare Lake basins, 
there were two major peaks. In the Great Basin there was generally a single major peak on all streams, but the smaller streams had one or more minor peaks that preceded that major rise.

The principal difference between this flood and those of 1950 and 1955 was the volume of storm runoff produced. Because the 1963 storm was of relatively short duration, the volume of runoff was not particularly noteworthy. Reservoir storage attained a high level, nevertheless, and provided the one bright aspect of what was otherwise a bleak outlook for the Sierra Nevada basins that depend on the mountain snowpack for their summer water supply.

The following sections present a brief description of the floods in each hydrologic region. Hydrologic-region boundaries are shown in figure 1 and on plate 1 . The basins of each region are discussed in the downstream order used by the Geological Survey for its annual reports of surface-water records.

\section{THE GREAT BASIN}

The Great Basin streams discussed in this section of the report are those that drain the east slope of the Sierra Nevada, from Owens Lake basin on the south to Honey Lake basin on the north. The major basins in this region are those of the Walker, Carson, and Truckee Rivers. The location of the flood-data sites is shown on plate 1.

Streams tributary to Owens Lake had only minor flooding during the January-February 1963 storm. Little damage of the area was reported.

In general, floods in the Walker River basin were of lesser magnitude than previous notable floods of record, such as those of December 1937 and November 1950. Locally, however, several streams had peak discharges larger than any previously recorded. Record discharge occurred on Buckeye Creek, on Little Walker River near Bridgeport and on East Walker River above Strosnider ditch near Mason, Nev. The flood hydrograph for Little Walker River near Bridgeport, Calif., is shown in figure 9 .

The runoff pattern during this flood was unusual in that the peak on the East Walker River reached Mason Valley before the peak on the West Walker River; normally the pattern is reversed. Most flood damage in the Walker River basin was to irrigation drains, ditches, and diversion structures. Valuable farmland adjacent to the streams was eroded.

Serious flooding also occurred in the Carson River basin. The heavy rains on frozen ground produced exceptionally high peak discharges in the upper basin at altitudes above 5,000 feet. The rapidly 


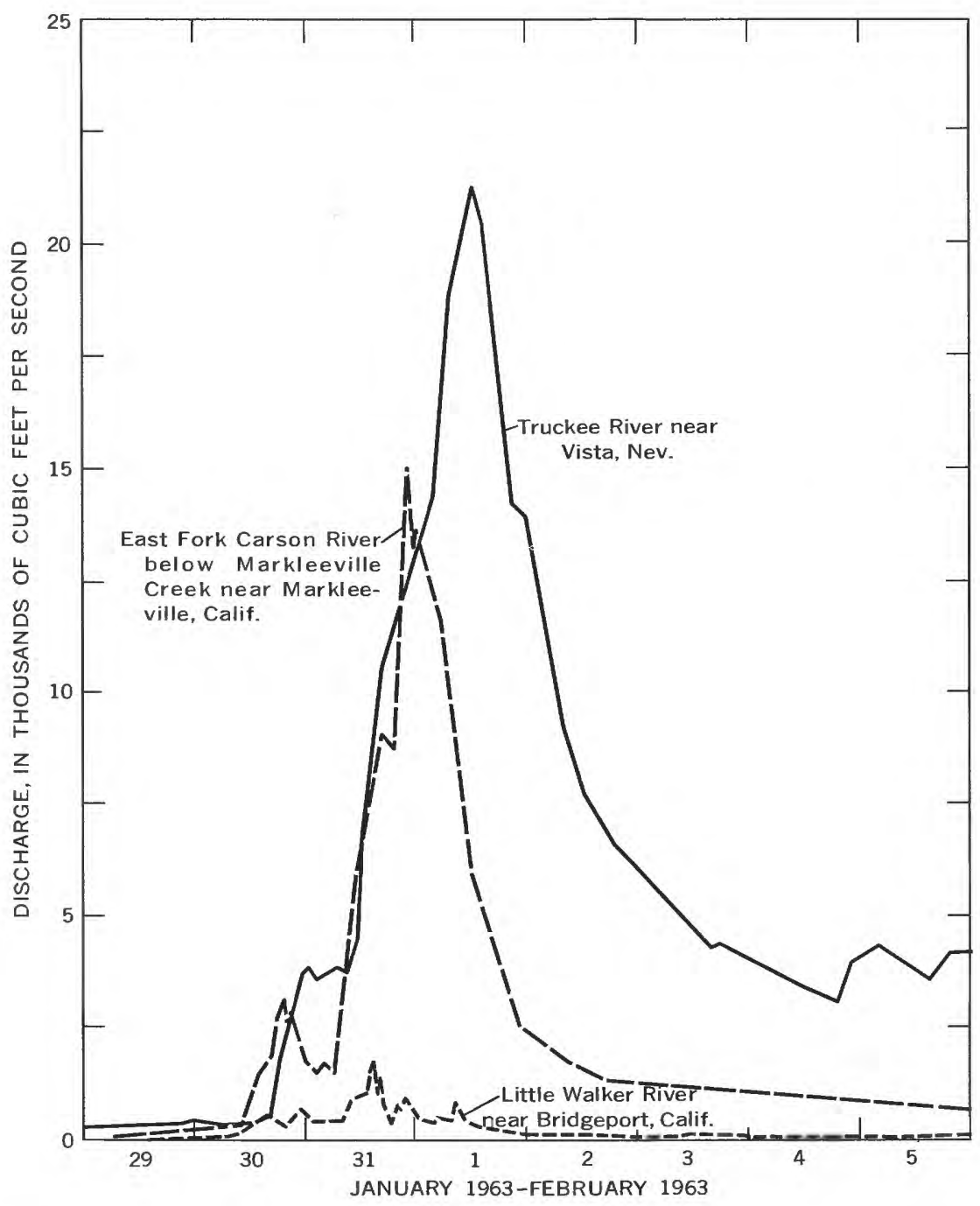

FIGURE 9.-Discharge hydrographs compiled from data collected at selected gaging stations in the Great Basin, January 29-February 5, 1963.

rising streams, carrying heavy debris loads, caused extensive damage to roads, bridges, and irrigation works near Minden and Gardenville, Nev. These communities were isolated for several days when U.S. Highway 395 and State Route 88 were inundated.

Peak discharges exceeded the maximum previously recorded at some places in the Carson River basin. The peak discharge on West Fork Carson River at Woodfords-the highest in at least 64 years-was 
possibly the highest ever known. The peak flow for Carson River near Carson City was 74 percent of that of the December 1955 flood. The flood hydrograph for East Fork Carson River below Markleeville Creek near Markleeville, Calif., is shown in figure 9.

The Truckee River basin sustained major flooding throughout. Peak flows exceeded previously recorded maximum flows at several gaging stations on both the main stem and the tributaries. Storage in the Lake Tahoe, Donner Lake, and Boca and Prosser Creek Reservoirs retarded much of the runoff, thereby lessening flood damage in the downstream urban areas.

The city of Reno had extensive flooding, and about 20 square blocks in the downtown area was inundated to depths of as much as 4 feet (fig. 10). Ten of Reno's 12 bridges had to be closed for an extended period of time. There was also extensive damage to roads, bridges, and irrigation structures in Washoe Valley and Truckee Meadows. Channel-rectification work done on the Truckee River main stem and on lower Steamboat Creek, after the flood of December 1955, expedited the rapid draining of Truckee Meadows. This rapid drainage is indicated by the sharpness of the peak recorded at Truckee River at

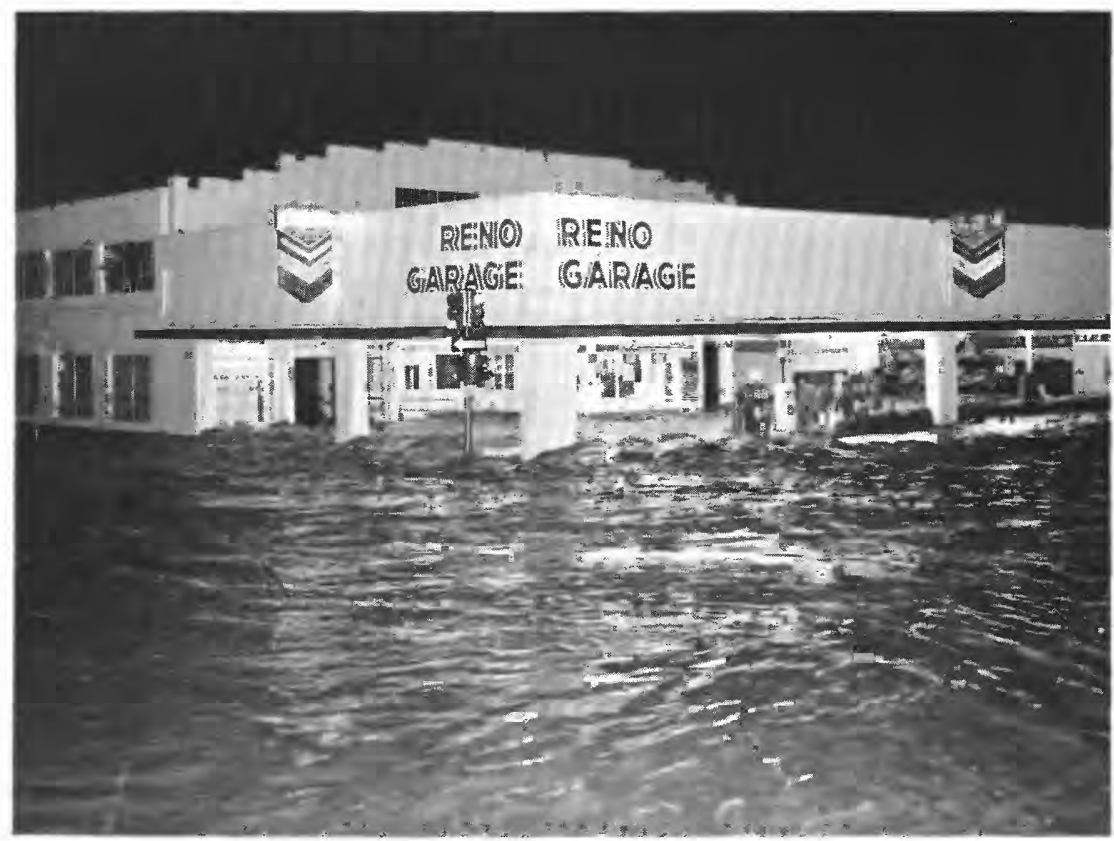

Figure 10.-Truckee River flooding in downtown Reno, Nev. Photograph by Nevada State Journal. 


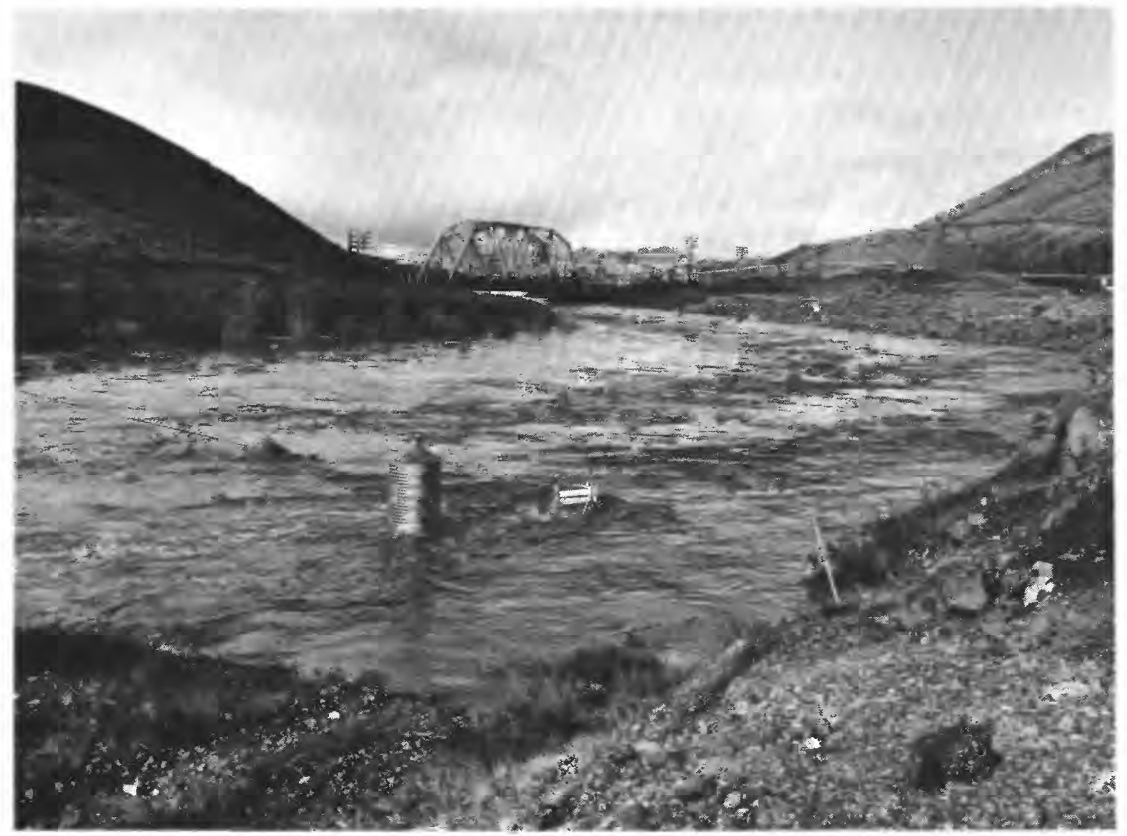

Figure 11.-Gaging station on Truckee River at Vista, Nev., at approximate time of flood crest.

Vista, Nev. (fig. 9). Figure 11 shows the Vista gaging station at the approximate time of peak discharge.

Some flooding occurred in the Honey Lake basin near Susanville, Calif. Peak discharges at Susan River at Susanville and Willow Creek near Susanville exceeded the maximum for the period of record, during which both the November 1950 and December 1955 floods occurred.

\section{CENTRAL-COASTAL CALIFORNIA}

The central-coastal California region consists of the Pacific slope drainage basins between the upper Salinas River on the south and the southern shores of San Francisco Bay on the north (pl. 1). The numbers shown on plate 1 are station numbers that correspond to those shown in the "Streamflow Data" section of this report.

The floods of January-February 1963 were of lesser magnitude than those of December 1955 and April 1958, as recorded at gaging stations throughout the central-coastal California subarea. Several stream peaks nearly equaled, but none exceeded, the record highs of 1955 and 1958.

In the Big Sur River basin, the heavy rainfall caused the Big Sur River to slightly exceed bankfull stage from the State park to the 
mouth. The peak discharge, $5,400 \mathrm{cfs}$ (cubic feet per second), closely approximated the highest recorded flow-that of April 1958. A brief flood threat existed at park headquarters when overflow from the Big Sur River reached the threshhold of the administration building, but the river receded, and there was no appreciable damage. California Highway 1 was closed to traffic just south of the Big Sur River because of a mud slide.

In the Carmel River basin the storm-fed river poured over the spillways of Los Padres and San Clemente Dams; and at the bridge on State Highway 1, the river rose to within 2 feet of the peak of the disastrous flood of April 1958. Hundreds of emergency workers placed sandbags on levees, cleared debris from bridge openings, and patrolled low-lying areas until the flood danger passed. Cooper bridge was washed out; it sustained the only serious damage in the basin.

In the Salinas River basin, heavy runoff occurred only in the downstream tributaries that enter the river from the west. The Nacimiento River was completely controlled by Nacimiento Reservoir, but the San Antonio River and the Arroyo Seco poured large quantities of water into the Salinas River. The discharge hydrograph for Arroyo Seco, whose peak discharge of $24,300 \mathrm{cfs}$ at the Soledad gaging station nearly equaled the peaks of the December 1955 and April 1958 floods, is shown in figure 12. The lower reaches of the Salinas River sustained minor flooding. The mouth of the river was choked by a sandbar, and at 0900 hours on February 1 the restricted flow went over the riverbanks; as a result some farmlands were inundated to a depth of 3 feet. An hour later the river broke through its sandbar constriction, and the water subsided.

In the Pajaro River basin the higher runoff rates all occurred in the tributaries entering the river from the north. Heavy damage to public facilities, roads, bridges, and residential, commercial, and agricultural properties resulted from flood inundation in this area. Chesbro and Uvas Reservoirs on Llagas and Uvas Creeks, respectively, reduced downstream peaks; but major flooding occurred in Gilroy, and minor flooding, in Morgan Hill. Water went over the banks of Miller Slough in Gilroy, closing Highway 101 and inundating the Walnut Lane subdivision and adjacent Gilroy High School. Families were evacuated; water was as much as 2 feet deep in some homes. In the lower reaches of the Pajaro River, the river was contained within its leveed banks.

In the San Lorenzo River basin, the river reached flood stage in the Felton-Ben Lomond area, and 70 homes were evacuated. At least one house was carried away by the river. In the city of Santa Cruz, the scene of major flooding in 1955, the San Lorenzo River, with a peak 


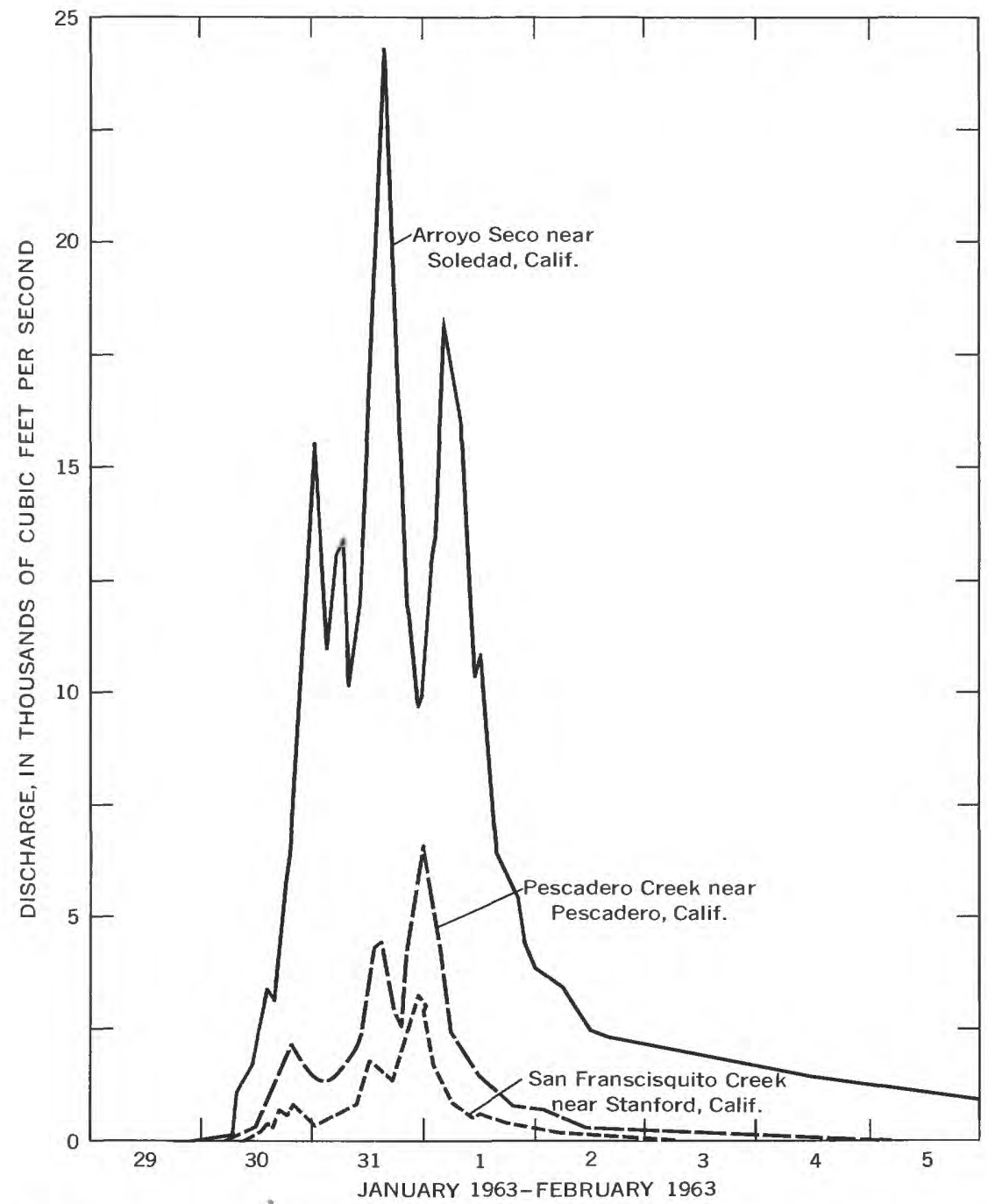

Figure 12.-Discharge hydrographs compiled from data collected at selected gaging stations in central-coastal California, January 29-February 5, 1963.

discharge of $13,000 \mathrm{cfs}$, was easily contained in the rectified channel between high levees. In nearby Soquel, Soquel Creek overflowed its banks and 15 homes and a trailer court had to be evacuated.

In the Santa Clara Valley, flood conditions were alleviated considerably in the Guadalupe River and Coyote Creek basins by the modifying effect of storage reservoirs, operated by the Santa Clara River Valley Water Conservation District. The Guadalupe River nearly 
overflowed its banks at several places in San Jose; downstream, merchants sandbagged their store fronts as a precautionary measure. The river subsided, however, and it did no damage to the city. Virtually the entire flow of Coyote Creek was stored in Coyote and Anderson Reservoirs. The effect of this storage in reducing potential flood damage in northwestern Santa Clara County is evident when one realizes that the only divide between Coyote Creek and the Guadalupe River, in their roughly parallel courses through the city of San Jose to San Francisco Bay, is formed by the natural leveelike silt banks of the streams. In the town of Alviso, at the mouth of the Guadalupe River, a high tide combined with the heavy runoff to fill the streets with water as much as 4 feet deep. About 150 residents were evacuated. All minor streams in the Santa Clara Valley were close to overtopping their banks. At least 100 families living along these streams left their homes and volunteer workers sandbagged banks of these streams and cleared drift from the bridge openings (fig. 13). Streambank revetments were destroyed, and streambank erosion was extensive.

North of the Santa Clara Valley and southeast of San Francisco Bay, there was extensive flooding but relatively minor damage. In

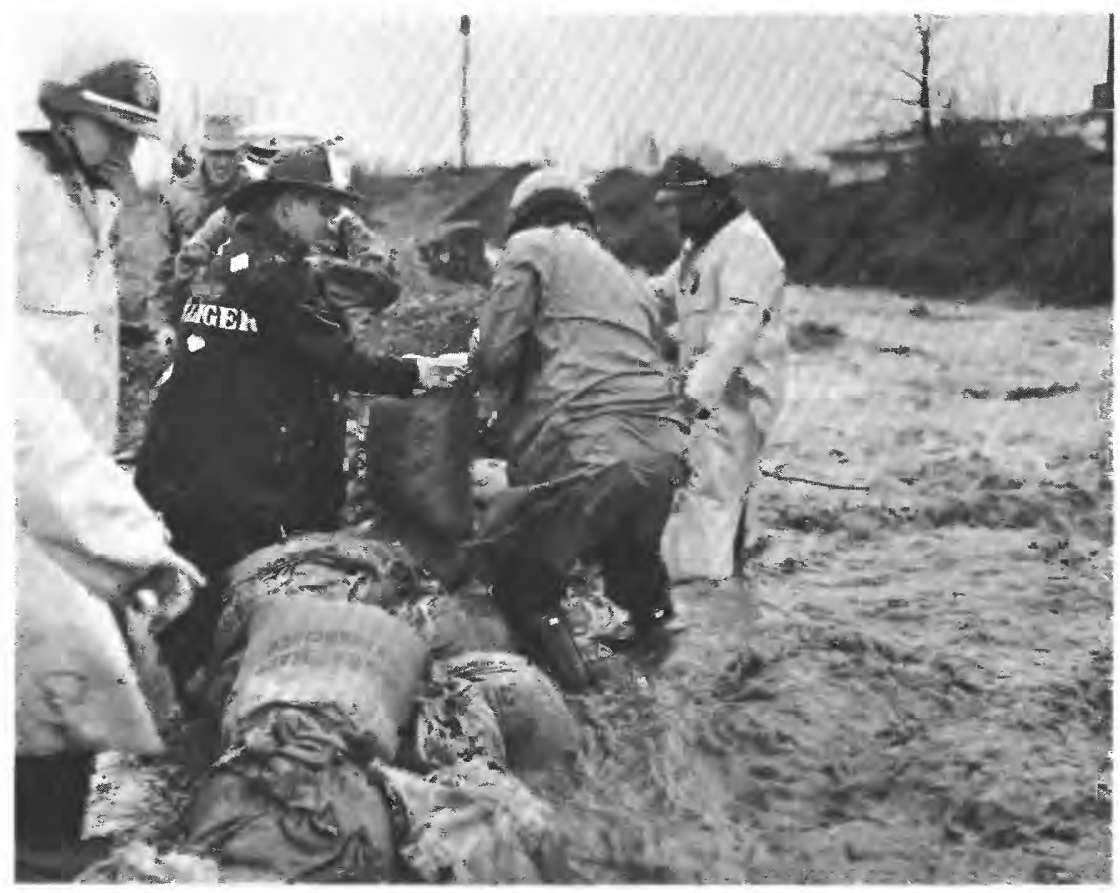

F'IGURE 13.-Campbell police placing sandbags along San Tomas Aquina Creek, Campbell, Calif. Photograph by San Jose Mercury-News. 


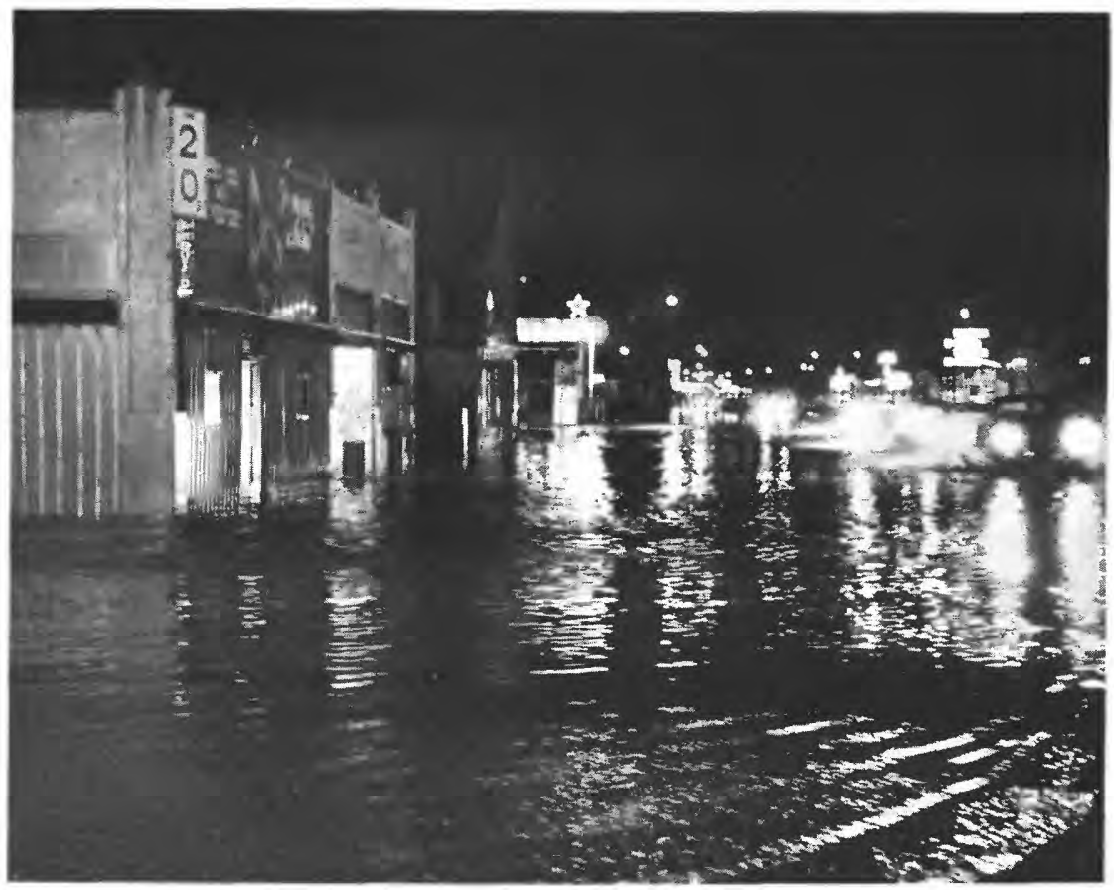

Figure 14.-Flooding in Menlo Park, Calif., caused by overtaxed storm sewers. Photograph by Palo Alto Times.

various areas streets and roads were closed by high water or slides, streambanks were eroded, agricultural land was inundated, and some houses were damaged by mud and water. Overtaxed storm sewers caused local flooding in many urban areas (fig. 14). Flood hydrographs for Pescadero Creek, on the coast south of San Francisco, and for San Francisquito Creek at Stanford, Calif.s are shown in figure 12.

\section{SAN JOAQUIN VALLEY}

The San Joaquin Valley region, as delineated in this report, consists of the southern half of the Central Valley and its tributary area. The major stream systems in the region are those of Buena Vista Lake, Tulare Lake, and the San Joaquin River basins. The gaging sites are shown on plate 1 , and the station numbers shown there are also listed in the tables presented in the "Streamflow Data" section of this report.

The magnitude of flood discharges varied widely throughout the San Joaquin Valley region. Flood peaks were among the highest of record in the upper Kern River basin and in the upper reaches of most 
Sierra Nevada streams; peak flows of the 1950 and 1955 floods were exceeded at several gaging stations.

The high peak flow from the upper basins was a result of the frozen ground and of the rise in freezing level to above 8,000 feet during the storm-a fact substantiated by the peak discharge of $89 \mathrm{cfs}$ at Budd Creek near Tuolumne Meadows (11-2747.3) in the Tuolumne River basin. This 2.94-square-mile drainage basin ranges in altitude from 8,560 feet above sea level at the gaged point to about 11,000 feet at the basin divide. Records of several other small streams in the region, gaged at the 6,000-8,000-foot level, also provide evidence of the heavy rainfall at the extremely high altitudes.

Peak discharges on the smaller streams whose headwaters are in the lower altitudes of the Sierra Nevada were not exceptionally high because of the lesser storm rainfall to the west of the high Sierra Nevada.

In the Kern River basin the instantaneous peak inflow to Isabella Reservoir of $26,000 \mathrm{cfs}$ (determined by the Corps of Engineers) slightly exceeded the peak inflow of the memorable flood of December 1955 . The peak outflow from the reservoir, however, was regulated to about $400 \mathrm{cfs}$, thereby preventing what would have been certain inundation in the city of Bakersfield. Heavy damage occurred in the sparsely settled basin upstream from Isabella Reservoir, where the flow was slightly less than was that of the 1955 flood. The Kern River Fish Hatchery was severely damaged, and the 20-mile length of road between Kernville and Johnsondale was deeply gouged in a number of places by the surging floodwaters. The discharge hydrograph for Kern River at Kernville is shown in figure 15.

In the Tule River basin, when the rapidly rising river endangered the town of Springville, many families prepared to evacuate their homes. However, the river receded and no damage was caused. Downstream from Springville the instantaneous peak inflow of the Tule River into Success Reservoir was 15,000 cfs (computed by the Corps of Engineers) ; the controlled outflow was 3,000 cfs. Although total damage in the basin was relatively light, widespread inundation would have occurred in and around Porterville if the recently built Success Reservoir had not been operative.

In the Kaweah River basin, flooding of the town of Three Rivers, on the main river, was narrowly averted. Emergency dikes, built by bulldozers, successfully confined the stream. Several families were evacuated, however, as a precautionary measure. The rampaging river and its tributaries, heavily laden with floating timbers and other debris, spilled over the banks in many places and did severe damage to roads and bridges. Newly built Terminus Reservoir, downstream 


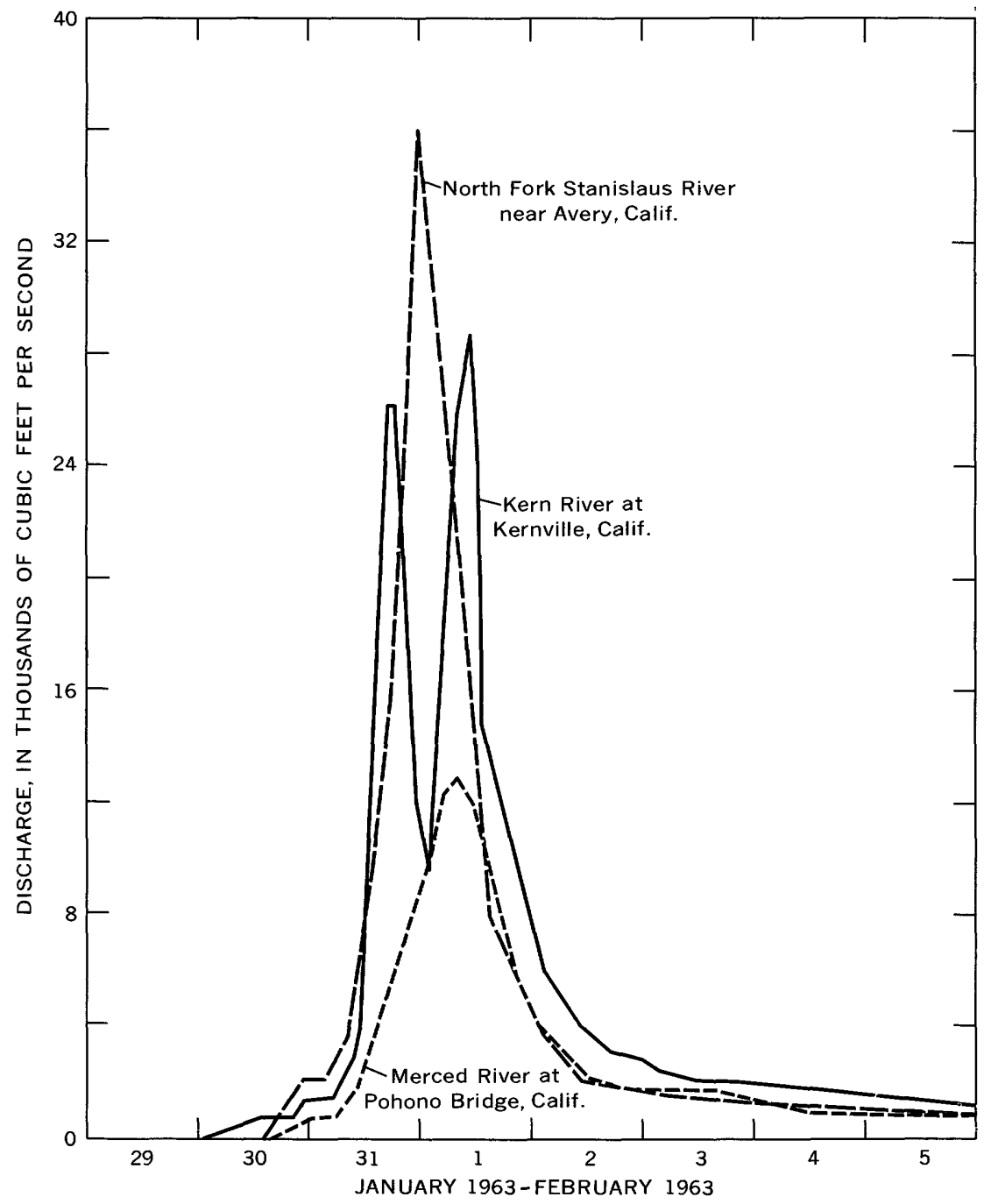

Figure 15.-Discharge hydrographs compiled from data collected at selected gaging stations in San Joaquin Valley, January 29-February 5, 1963.

on the Kaweah River, had an instantaneous peak inflow of 35,000 cfs (computed by the Corps of Engineers). The controlled outflow from the reservoir was only $5,000 \mathrm{cfs}$, and the downstream city of Visalia was therefore not inundated.

In the Kings River basin, roads and highways in the upper basin received the heaviest damage. At Pine Flat Reservoir, on the Kings River, a peak inflow of 58,000 cfs (computed by the Corps of Engi- 
neers) was reduced to an outflow of $20 \mathrm{cfs}$, and downstream areas were not flooded.

In the upper San Joaquin River basin, public-utility reservoirs, operated to generate hydroelectric power, contained much of the flow of the main river and its tributaries. This resulted in a peak inflow of only 31,000 cfs into Millerton Lake on the San Joaquin River. The outflow from Millerton Lake was reduced to $25 \mathrm{cfs}$, thereby increasing the ability of the lower river to carry the flow of its downstream tributaries.

In the lower San Joaquin River basin, roads and highways again received the most damage. Predicted flood stages on the Chowchilla and Fresno Rivers did not materialize; however, both streams inundated roads in some areas. None of the west-bank tributaries of the San Joaquin River were particularly hard hit by the storms, but water from Jacalitos and Los Gatos Creeks inundated part of State Highway 198 near Coalinga. The principal tributaries of the lower San Joaquin River are the Merced, Tuolumne, Stanislaus, Calaveras, Mokelumne, and Cosumnes Rivers. All, but the Cosumnes River, have large impounding reservoirs that were very effective in storing the floodwaters. Consequently, little inundation occurred downstream from these reservoirs, and damage was primarily to the highways and drainage structures in the upper reaches of the rivers. The flood hydrograph for Merced River at Pohono Bridge is shown in figure 15.

Peak discharge of North Fork Stanislaus River near Avery was 36,000 cfs (fig. 15); it was 32,000 cfs during the December 1955 flood. This peak discharge is the maximum for the periods of record, 1914-22 and 1928-63. Highland Creek, a tributary of the North Fork Stanislaus River, peaked at 9,860 cfs; during the floods of 1950 and 1955 it peaked at 8,800 cfs. Cole Creek, in the upper Mokelumne River basin, peaked at a slightly higher discharge than its peak of November 1950, which was the maximum discharge since the gage was established in 1927. Several reservoirs-the largest is Meloneswere instrumental in reducing floodflows on the lower Stanislaus River. As a result the peak discharge of the Stanislaus River at the gaging station below Goodwin Dam near Knights Ferry was only 11,800 cfs, as compared with the 1955 flood peak of $62,900 \mathrm{cfs}$.

The Cosumnes River has no large impounding basins; hence, it caused the most flood damage to the San Joaquin Valley floor. At Michigan Bar gaging station, the peak discharge was 39,400 cfs-only 2,600 cfs less than the flood peak of December 1955. Tributary streams below Michigan Bar contributed little discharge, and at McConnell gage downstream, the peak was only $26,200 \mathrm{cfs}$. The attenuation of the peak resulted from overbank storage in the reach between 
the gages; this overflow caused heavy damage to crops, agricultural lands, roads, and bridges.

In the delta of the San Joaquin Valley, the upper Marsh Creek basin was hardest hit by the flood. Two resorts received major damage, and bridges were wrecked. In the Brentwood area, downstream, there was little damage because of the effect of the newly built Marsh Creek flood-control dam.

\section{SACRAMENTO VALLEY}

The Sacramento Valley region includes the northern half of the Central Valley of California, which is drained by the Sacramento River and its tributaries. However, because the 1963 flood runoff was not extreme in any streams tributary to Shasta Lake, no discharge data for these streams are included in this report, other than data for gaging stations immediately upstream from Shasta Lake. Sites for which stage and discharge data are being published are shown on plate 1.

Several places in the Sierra Nevada in which streams are tributary to the Sacramento Valley received record breaking runoff. However, as in the San Joaquin Valley, the operation of flood-control facilities tremendously reduced the damage that would have otherwise resulted from the floods of January 31-February 1.

In the upper Sacramento River basin above Shasta Reservoir, runoff was relatively light. The peak inflow to Shasta Reservoir was only $72,000 \mathrm{cfs}$, as compared with a peak inflow of $193,000 \mathrm{cfs}$ in December 1955. The 1963 peak outflow from the reservoir was $13,500 \mathrm{cfs}$. In the 40-mile reach of river between Shasta Reservoir and Sacramento River gaging station near Red Bluff, tributary inflow was moderately heavy, and the peak discharge recorded at the Red Bluff gage was 76,700 cfs. Without the streamflow regulation afforded by Shasta Reservoir, the peak discharge at the Red Bluff gage would have exceeded 100,000 cfs. Only moderately heavy inflow to the Sacramento River occurred above Chico; therefore no flood-control problem occurred upstream from the confluence of the combined inflow of the Feather River, Sutter Bypass, and the Sacramento River.

Runoff in the Feather River basin was extremely high. As in most Sierra Nevada floods, the runoff originated chiefly at altitudes above 4,000 feet, but the runoff from the lower foothill areas during this flood seemed to be disproportionately small. In the high-altitude headwaters of the basin, the rampaging tributary streams overflowed roads and carried away several houses. Many families were trapped by the rapidly rising waters and, when helicopter rescue efforts failed, were rescued by boat. 
Record-high peaks occurred on the Middle Fork Feather River and on Spanish Creek. The discharge hydrograph for Middle Fork Feather River near Clio is shown in figure 16. Indian Creek near Crescent Mills had about the same record discharge that occurred there in 1907 . The 1907 flood was larger than any other that occurred during the period of continuous-discharge record collection, which began in 1930 .

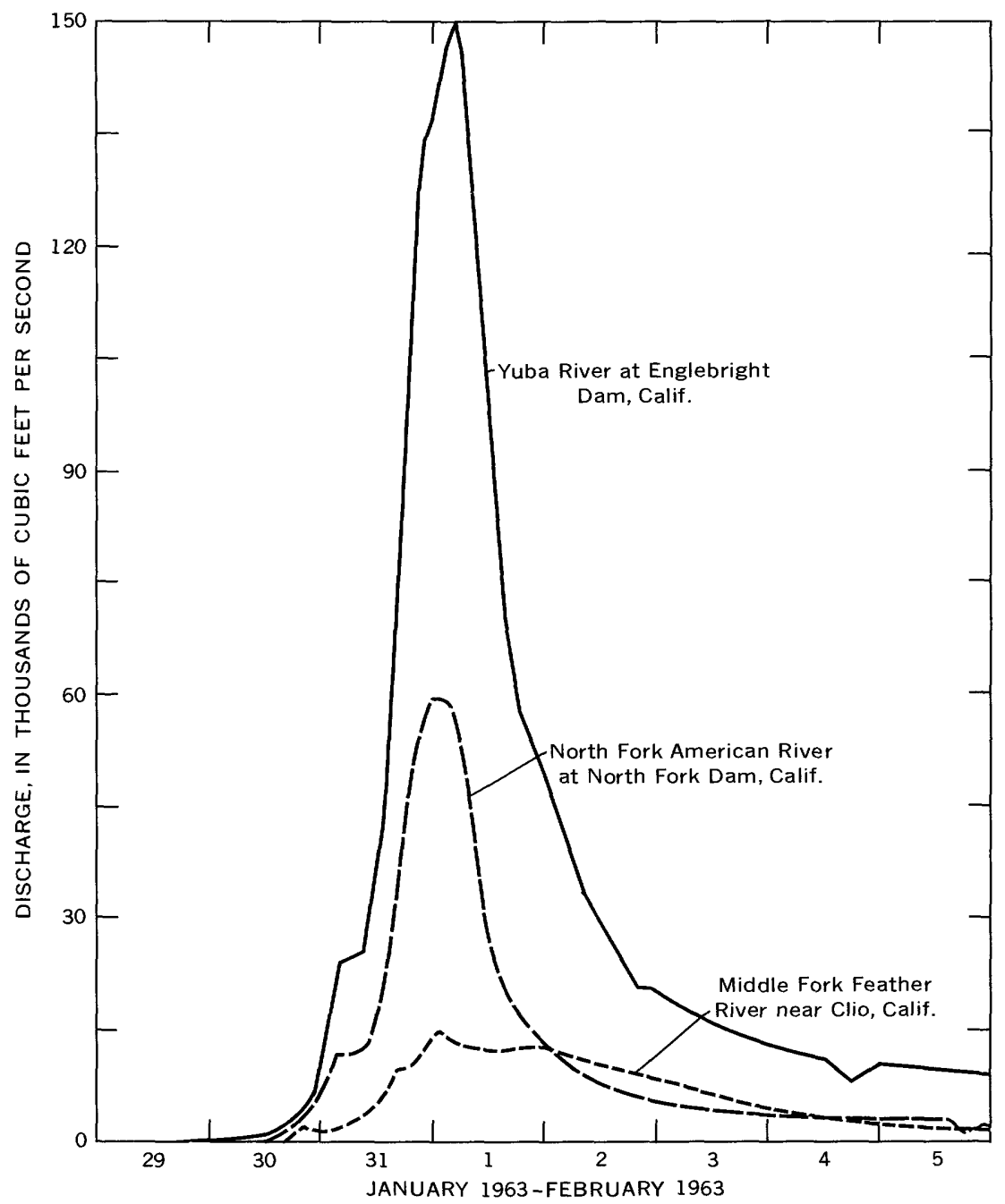

Figure 16.-Discharge hydrographs compiled from data collected at selected gaging stations in Sacramento Valley, January 29-February 5, 1963. 
Storm-caused landslides in the Feather River Canyon blocked Western Pacific Railroad tracks and U.S. Highway 40A. At Oroville, where the huge Oroville Dam was being constructed, the Feather River peaked at a stage only 1 foot lower than that of the disastrous flood of December 1955. Floodwaters toppled a $\$ 100,000$ temporary bridge at the damsite and damaged access roads and construction equipment.

Downstream from Oroville, in and around Yuba City and Marysville, at the junction of the Yuba and Feather Rivers, residents were very apprehensive. The apprehension was for good reason. Thirtyeight people in the area had drowned when a levee failed during the 1955 flood. Also, the Yuba River, over whose basin the storm centered, was reaching a recordbreaking peak discharge, which exceeded that of the 1955 flood. No levee failures occurred, however (fig. 17). The Feather River received only moderate inflow from drainage areas at lower altitudes. It crested at Marysville 4.4 feet lower than in 1955, and the danger passed. The discharge hydrograph for Yuba River at Englebright Dam is shown in figure 16. In the upper Yuba River basin, damage to roads and drainage structures was particularly heavy. In a 25 -mile length of State Highway 49 the road was reduced

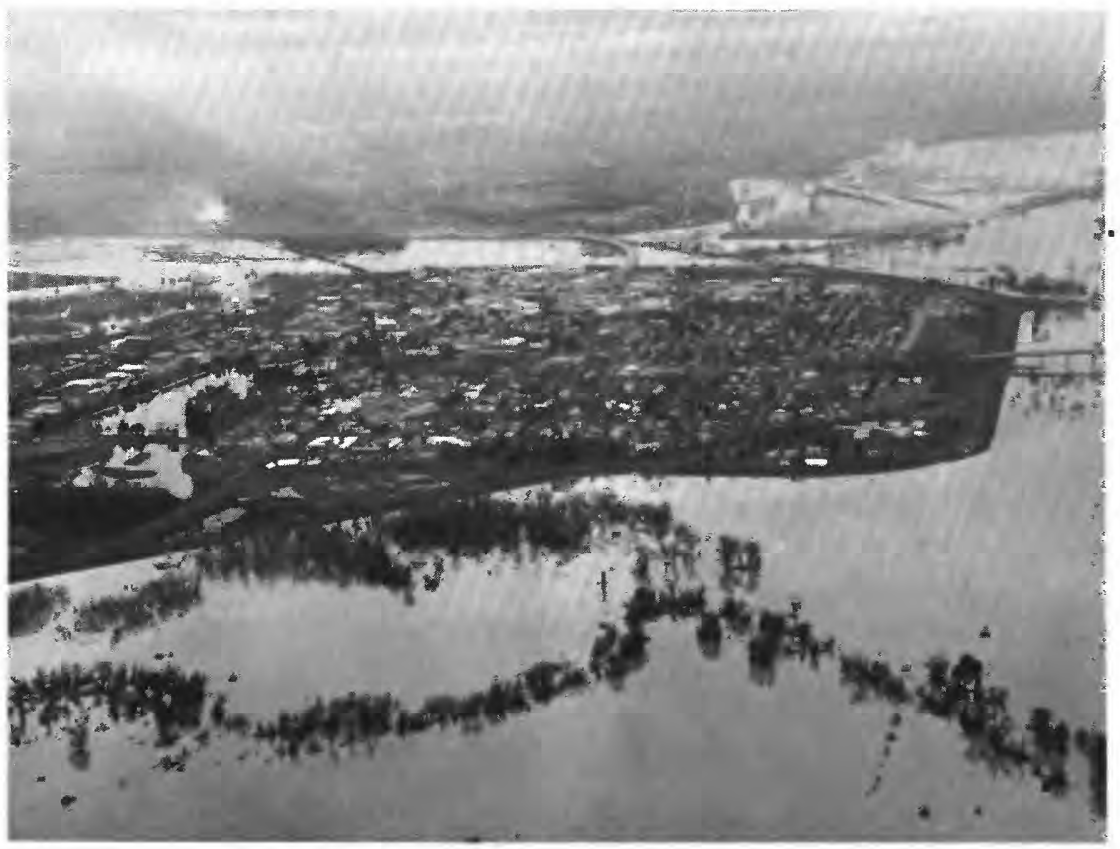

Figure 17.-Marysville, Calif., during flood of January-February, 1963. Photograph by U.S. Army Corps of Engineers. 


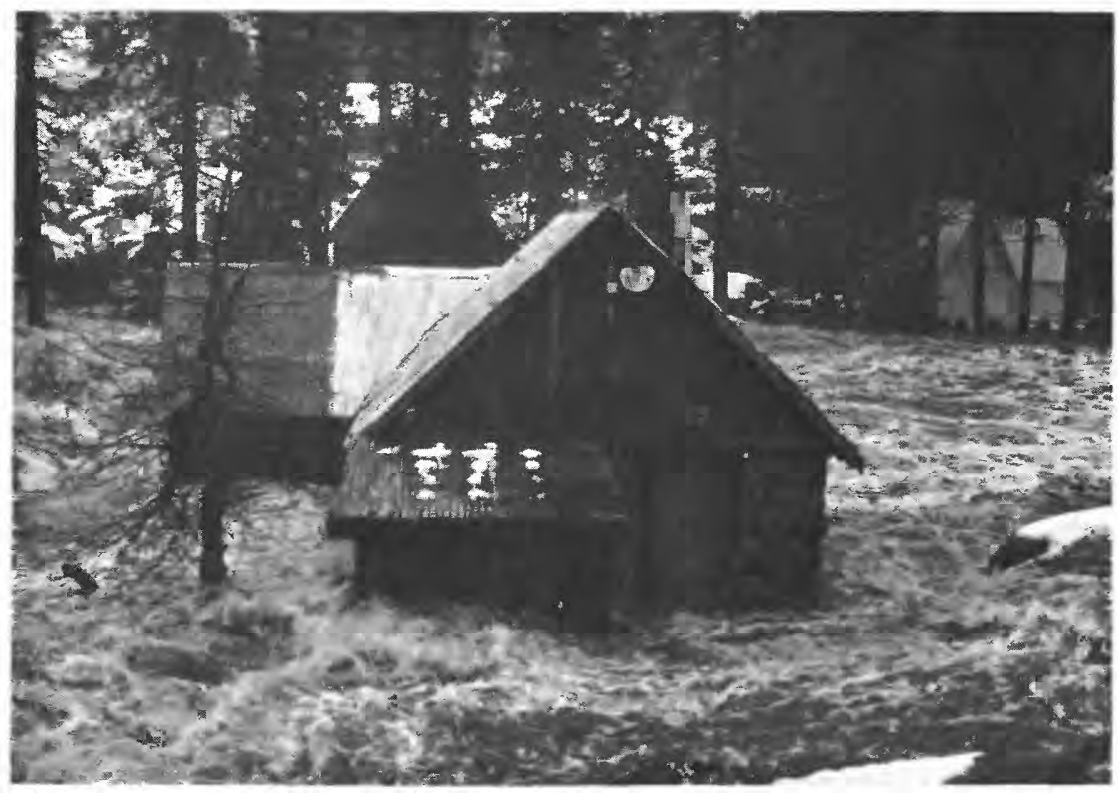

Frgure 18.-South Yuba River overflow damaging summer homes at Cisco, Calif. Photograph by Sacramento Bee.

to less than one lane wide in many places, and the bridge 12 miles west of Downieville was destroyed. U.S. Highway 40, which parallels the South Yuba River, was closed between the town of Cisco and Donner Lake because of flooding. At the resort settlement of Cisco Grove (fig. 18), widespread destruction of vacation homes was sustained as a result of severe flooding of the South Yuba River. Previous recordpeak discharges of the memorable floods of 1950 and 1955 were exceeded at many places in the North and South Yuba River basins.

On February 1 the Feather River peaked at $260,000 \mathrm{cfs}$ at the downstream gaging station at Nicolaus. Although the magnitude of this peak approached that of the disastrous $357,000 \mathrm{cfs}$ peak of December 1955, there were no levee failures or major flood problems on the lower Feather River. At the common junction of the Feather River, Sacramento River, and Sutter Bypass (carrying the Sacramento River overflow), the major part of the flow spilled, as usual, over the ungated Fremont Weir into Yolo Bypass. At the gaging station on Yolo Bypass near Woodland, the peak discharge was 163,000 cfs on February 2 and consisted mainly of Fremont Weir spill but also included all Cache Creek flow and westside lowland drainage through Knights Landing Ridge cut. Downstream from Fremont Weir, the maximum discharge of the Sacramento River at Verona was $69,400 \mathrm{cfs}$. 
Downstream from Verona the Sacramento River flow plus the large release down the American River from Folsom Reservoir necessitated the opening of the gates on the Sacramento Weir. On February 2 a peak discharge of 82,600 cfs passed over the Sacramento Weir into Yolo Bypass. Downstream from the Sacramento Weir and the American River, the Sacramento River peaked at Sacramento on February 1 at $98,100 \mathrm{cfs}$. It then receded slightly on February 2 because American River water that had been released flowed upstream to the Sacramento Weir.

In the American River basin the largest peak flows since the deluge of 1862 were recorded; recordbreaking peak discharges were common. In the upper basin the roaring tributary streams ruined roads. In other places roads, such as U.S. Highway 50 between Pacific House and Myers, were closed because of storm-caused landslides. The newly built Union Valley and Ice House Reservoirs in the Silver Creek basin substantially reduced flood peaks on the South Fork American River downstream from the mouth of Silver Creek.

Peak discharge of the North Fork American River far exceeded any previous flood of record and exceeded the great 1955 flood by $10,000 \mathrm{cfs}$ at the gage at North Fork Dam. The flood hydrograph for North Fork American River at North Fork Dam is shown in figure 16.

Probably the most striking flood peak recorded anywhere during the 1963 storm was at the gage on the Middle Fork American River near Auburn. The peak discharge at this site was 121,000 cfs from a 612 square-mile basin-a unit discharge of $198 \mathrm{cfs}$ per sq mi. The previous high recorded here since record collection began in 1911 was $79,000 \mathrm{cfs}$ during the devastating 1955 flood.

At Folsom Reservoir in the foothills, American River inflow reached a recordbreaking figure of $245,000 \mathrm{cfs}$ (determined by the Corps of Engineers). Controlled reservoir releases were increased from about $10,000 \mathrm{cfs}$ at the time of peak inflow to a maximum of $110,000 \mathrm{cfs}$ shortly after the peak inflow.

Tributary inflow to the Sacramento River from the west was moderately heavy. On Stony Creek the gaging station near Fruto recorded a peak discharge of $16,000 \mathrm{cfs}$. Little was added to this flow from the drainage area above Stony Gorge Reservoir; the reservoir did not fill until long after the peak flow had passed. In the upper Cache Creek basin, the small streams tributary to Clear Lake had peak discharges among the highest of record, although no new record highs were established. In the upper Putah Creek basin, Lake Berryessa retained virtually all the flow that reached it; the peak inflow was $86,000 \mathrm{cfs}$, and the controlled outflow, $10 \mathrm{cfs}$. 


\section{NORTH-COASTAL CALIFORNIA}

For purposes of this report the north-coastal California region consists of Pacific slope drainage basins that lie north of San Francisco Bay (pl. 1). The numbers representing gaging sites on plate 1 are also given in the "Streamflow Data" section of this report.

With the exception of the Napa River and Dry Creek (Russian River basin), the floods of January-February 1963 in the northcoastal region were of a much smaller magnitude than were the notable floods of December 1955. Larger floods have occurred, at least once or twice in the last three decades, on most of the streams in the area. The gaging station on the Napa River near St. Helena recorded a peak discharge only slightly less than the record 1955 peak, and a peak discharge slightly higher than the 1955 peak occurred at Dry Creek station near Cloverdale (Russian River basin). Flood hydrographs for these two stations are shown in figure 19.

The Napa River overflowed its banks and flooded downtown Napa. Floodwaters forced the evacuation of more than 200 persons. Muddy water, more than a foot deep, swirled through the downtown streets and created a serious health hazard when the sewage system became flooded. In other parts of the city, water was 3 feet deep in the streets (fig. 20). Roads were closed and bridges were in danger of being damaged or washed out when the river, in the environs of Napa, fanned out to half a mile wide. The swollen waters of Conn Creek, a tributary to the Napa River, poured over the spillway of Conn Dam and eroded part of State Highway 128 by the reservoir.

The small streams in Sonoma and Marin Counties also overflowed their banks, but damage was notable only in Sonoma Creek basin. High tides were generally a contributing factor to the flooding in the two counties.

In the Russian River basin, rainfall and the resulting runoff were heaviest in the lower part of the basin. At Guerneville the Russian River had the third highest peak in its recorded history and crested at 43.7 feet. This peak stage was exceeded only by those of the devastating floods of 1940 and 1955. Damage in the basin was confined mainly to the low-lying resort area near Guerneville, where 30 permanent residents were evacuated from flooded homes. The discharge hydrograph for Russian River near Guerneville is shown in figure 19. Damage in the upper Russian River basin was mitigated by the controlled release of water from Lake Mendocino, in which most of the runoff of the East Fork Russian River was stored.

The smaller coastal basins north of the Russian River and the upper Eel River basin had heavy runoff, but damage was minor. The maxi- 


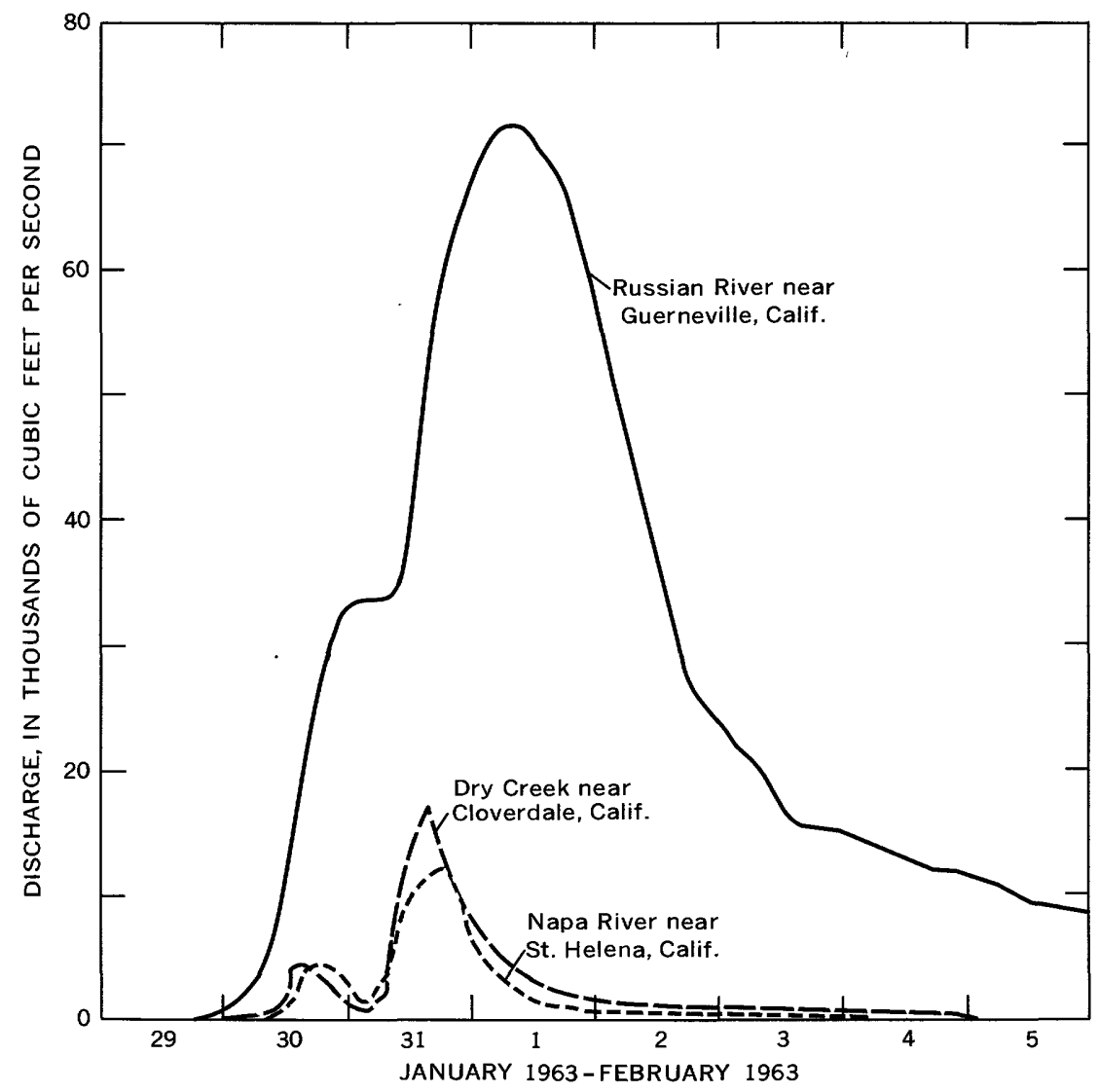

Figure 19.-Discharge hydrographs compiled from data collected at selected gaging stations in north-coastal California, January 29-February 5, 1963.

mum flood discharge at the gaging station on Garcia River near Point Arena was nearly as large as that of the memorable 1955 flood, but most other streams in this area had peak discharges that were much smaller than those in 1955 . The area is sparsely settled and contains no large flood plains; hence, damage was minor.

\section{FLOOD DAMAGE}

The deaths of 10 persons were attributed to the storm and floods of January-February 1963 in California and Nevada. Total damage in the report area amounted to about $\$ 18.5$ million, of which about $\$ 2.1$ million was incurred in headwater areas, as reported by the U.S. Forest Service. 


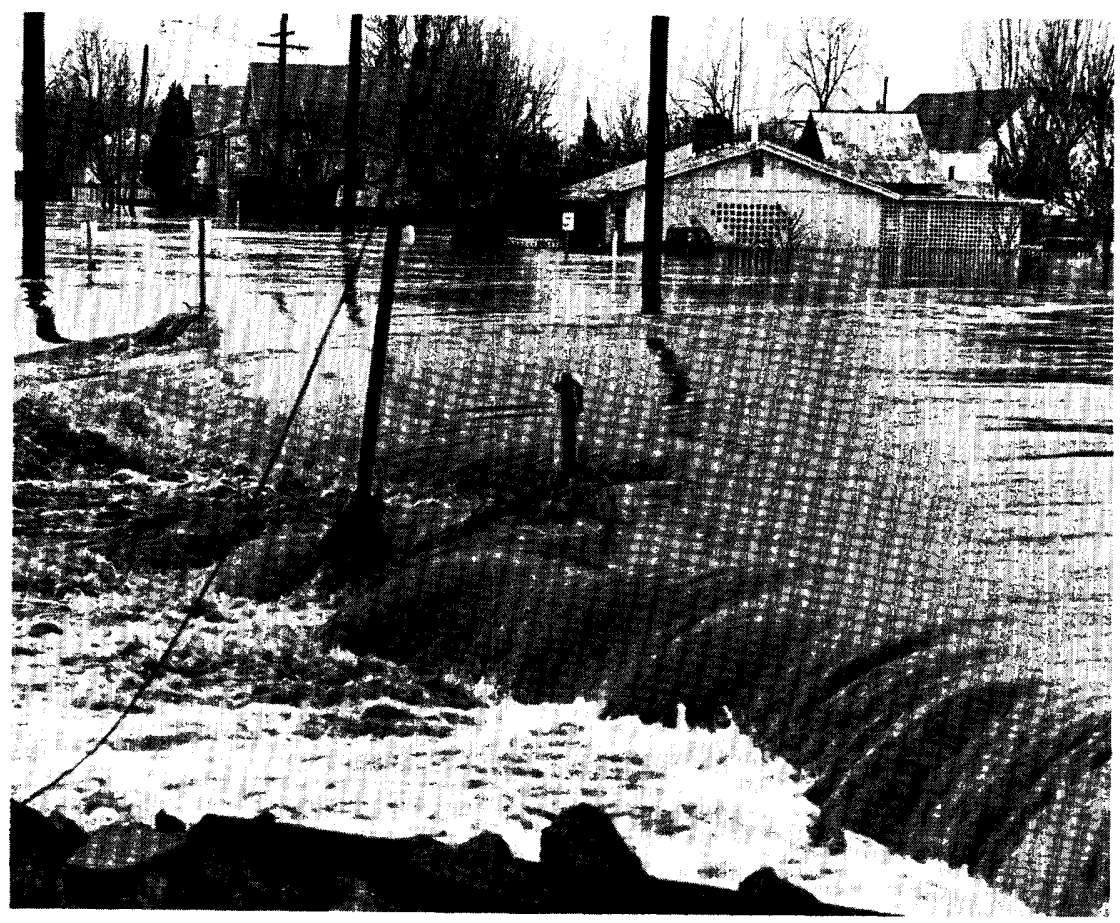

FIguRE 20.--Napa River overflow near Edmonston Street Bridge in Napa, Calif. Photograph by Oakland Tribune.

Surveys of flood damage were carried out by the U.S. Army Corps of Engineers, U.S. Soil Conservation Service, U.S. Forest Service, and other Federal, State, county, service, and private organizations. The Corps of Engineers assembled flood-damage data, most of which are presented in table 3.

Monetary losses resulting from the floods of January 31-February 1 were less than those incurred in such previous floods as those of November 1950 and December 1955, when peak discharges of similar magnitude were produced. Smaller losses were incurred from the 1963 flooding for two reasons. First, the floods of January 31-February 1 were of shorter duration than previous major floods, and most inflows to reservoirs in 1963 could consequently be controlled without spill. Second, more reservoirs had been constructed each successive year; therefore, by 1963 there was a larger amount of regulatory storage available for excess water.

Most of the $\$ 3.3$ million flood damage in the Great Basin occurred in Nevada. At the request of Governor Grant Sawyer of Nevada, the Federal government declared seven western Nevada counties a disaster 
TABLE 3.-Flooded areas and flood damage in California and Nevada, JanuaryFebruary 1963

[Compiled by Corps of Engineers]

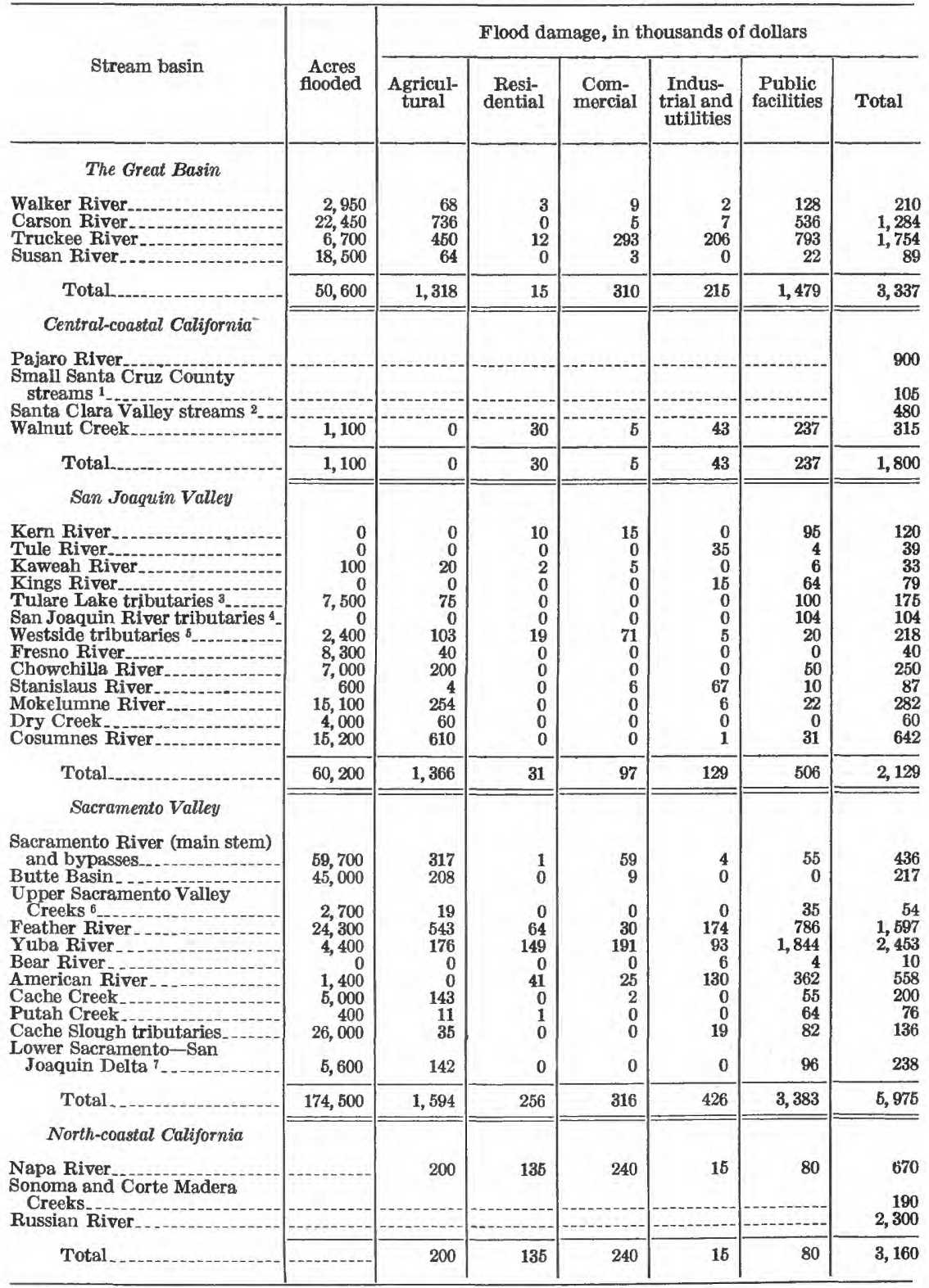

1 Includes Aptos and Soquel Creeks.

2 Includes Atherton, San Francisquito, and Coyote Creeks and the Guadalupe River.

3 Includes Los Gatos, Warthan, Jacalitos, Zapato-Chino, and Canoas Creeks.

4 Includes the Merced and Tuolumne Rivers and Littlejohn Creek.

5 Includes Marsh, Kellogg, Garzas, and Orestimba Creeks.

6 Includes Butte, Churn, Stony, and McClure Creeks and others.

7 Includes Tidal Tracts, Little Holland Tract, and Liberty Island. 
area. This area included Churchill, Douglas, Lyon, Mineral, Ormsby, Storey, and Washoe Counties. Damage was greatest in the Truckee River basin because of urbanization in and around Reno and Truckee Meadows. Flooding in the Carson and the Walker River basins and in the Honey Lake basin caused heavy damage to highways but primarily affected irrigation systems and ranch lands. Damage in the Walker, Carson, Truckee, and Susan River basins is summarized in table 3.

Flood damage in the central-coastal Califormia region was not excessive; it was confined mostly to lowland agricultural areas. However, damage to commercial, residential, industrial, and public-utilities properties was sustained in some areas, particularly in the upper Pajaro and lower Guadalupe River basins and the Walnut Creek basin.

In the San Joaquin Valley region, agricultural areas received the most flood damage. Parts most severely flooded consisted of foothill and mountain properties above the flood-control projects on the Kings, Kaweah, Tule, Kern, Chowchilla, Fresno, and Stanislaus Rivers, and on Orestimba Creek along the west side of the San Joaquin Valley.

A major part of the damage in the Sacramento Valley region was to public facilities, for which monetary losses were more than twice those for agricultural damage. Much of the public-facility damage was in the Yuba and Feather River basins. The damage required costly repairs to roads, railroad bridges, electric power systems, State park facilities, and fish-planting facilities, and to one dam in the Yuba River basin.

Major damage in the north-coastal California region was confined to the Napa and the Lower Russian River basins. Monetary losses were comparatively evenly divided among agricultural, residential, and commercial damages.

\section{STORAGE REGULATION}

Reservoir storage was effective in substantially reducing the magnitude of peak floodflow on many streams as was discussed in the foregoing general description of the floods and of the flood damage. This was true not only of those reservoirs constructed for purposes of flood control, but also of those whose primary function is water conservation or hydroelectric-power production. The major reservoirs in the floodaffected areas are listed in table 4, which gives data on peak inflow, peak outflow, storage space available, and storage space used (as compiled by the Corps of Engineers).

The most notable effect of upstream storage in the Great Basin region was in the Truckee River basin, where flood damage in the highly urbanized areas of Reno and Sparks, Nev., was less than it 
TABLE 4.-Reduction of January-February 1963 flood discharge by storage regulation

[Compiled by Corps of Engineers]

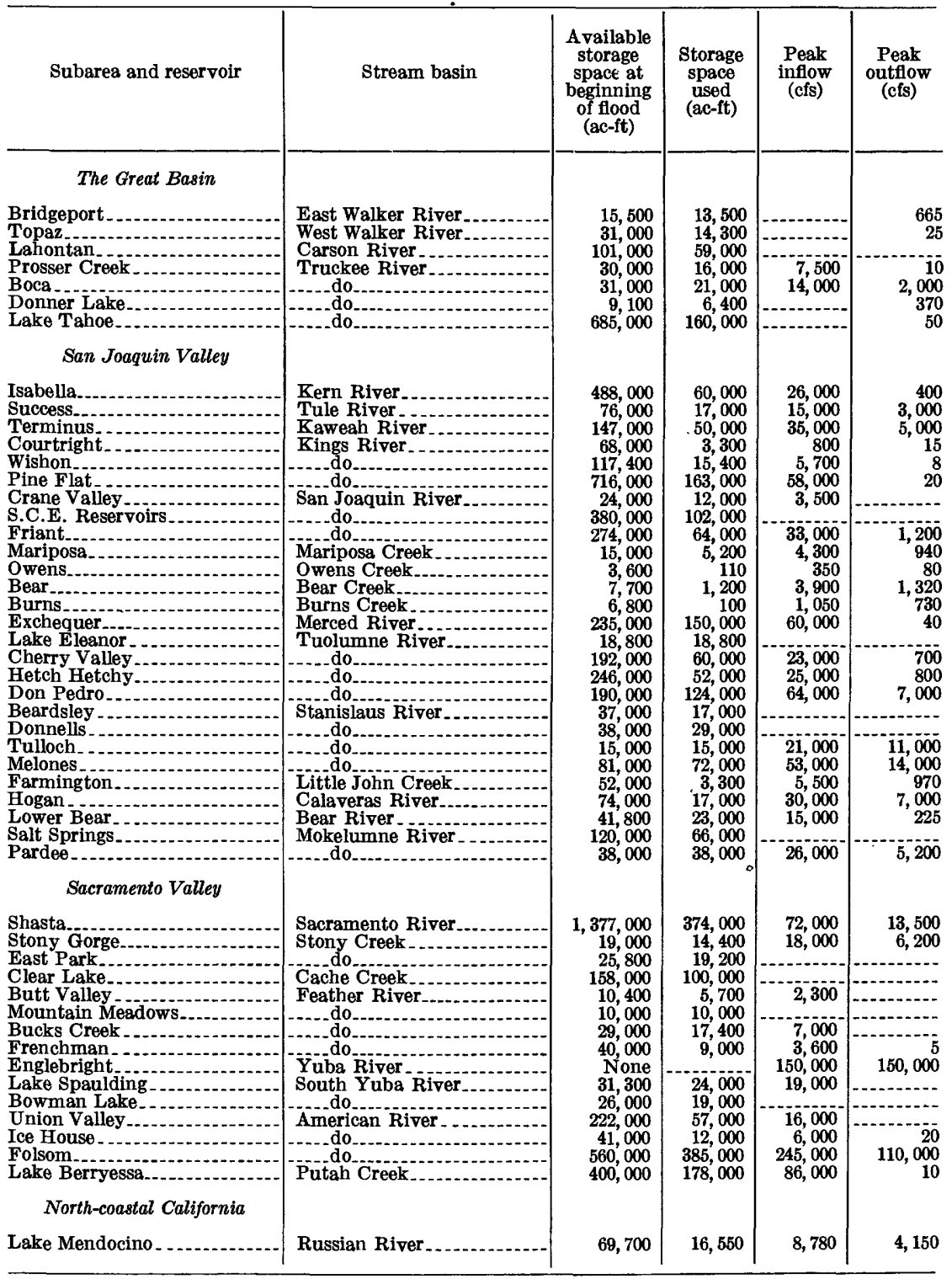

might have been without storage. During the period January 28February 4, Tahoe and Donner Lakes, and Boca and Prosser Creek Reservoirs stored a combined total of about 203,000 acre-feet of floodwater. The volume of runoff recorded for the Truckee River at Reno for this same period was 64,800 acre-feet, and the peak discharge of 
$18,400 \mathrm{cfs}$ was only slightly less than that of the disastrous flood of December 1955. The newly constructed Prosser Creek Reservoir began storing water on January 31,1963 , and accumulated a total of 16,000 acre-feet during the flood period. Had Prosser Creek Reservoir not been in operation, the flood peak of February 1 on the Truckee River in Reno would have exceeded that of 1955.

in central-coastal California the Nacimiento Reservoir, which contained all the heavy runoff from the Nacimiento River basin, was instrumental in preventing flood damage downstream along the Salinas River. Runoff from streams entering the Salinas Valley from the east was light, and floodflow damage from the additional discharge of the unregulated west-side tributaries was prevented by the large amount of natural storage afforded by the Salinas River channel (including the alluvial streambed).

In the upper Pajaro River basin, reservoirs on Uvas, Llagas, and Pacheco Creeks were effective, to a degree, in reducing floodflows. The several conservation reservoirs on streams tributary to San Francisco Bay, especially those on Santa Clara Valley streams, were instrumental in materially reducing flood peaks.

In the San Joaquin Valley region, all major reservoirs are on eastside streams that drain the Sierra Nevada. Floodflows were almost completely controlled by each reservoir, owing to the comparatively short duration of the high flows.

The large ( 1 million acre-ft capacity) Folsom Reservoir on the American River in the Sacramento Valley region effected the most notable regulation of floodflows. The 245,000 cfs peak inflow was reduced to a little more than $100,000 \mathrm{cfs}$ peak outflow by storage of 385,000 acre-feet of floodwater. Several smaller reservoirs in the American, Yuba, and Feather River basins also helped to reduce floodflows emanating from the Sierra Nevada. On the west side of the Sacramento Valley, Lake Berryessa (Putah Creek) and Clear Lake (Cache Creek) stored much water and prevented otherwise unavoidable inundation downstream.

Only a few reservoirs are available for storing floodwaters in the basins of the north-coastal California region. The relatively new Lake Mendocino (122,500 acre-ft capacity), near the mouth of the East Fork Russian River, stored sufficient runoff to appreciably reduce downstream flooding. Other reservoirs in this region are relatively small, and their flood-peak reduction was not noteworthy.

\section{FLOOD FREQUENCIES}

To illustrate the flood potential in the various hydrologic regions in California and Nevada, flood magnitude-frequency curves (figs. 
21-23) were prepared from annual flood peaks recorded at selected gaging stations. The annual flood peaks for each water year are listed in table 5. A water year is a consecutive 12-month period that ends September 30 of the stated year.

As applied to flood events, recurrence interval is the number of years, on the average, within which a given peak discharge will be equaled or exceeded once by the annual maximum discharge. This recurrence interval is inversely related to the chance of a specific flood discharge being equaled or exceeded in any one year. Thus, a flood with a 25 -year recurrence interval would have 1 change in 25 of being equaled or exceeded in any one year, or a 50-year flood would have 1 chance in 50 of being equaled or exceeded in any one year. Recurrence intervals, however, are average figures based on historical data; because of the erratic nature of flood events, the 50-year flood may not necessarily occur in any given 50-year period, or it may occur several times during that period. This relationship is accordingly true for a flood of any given recurrence interval.
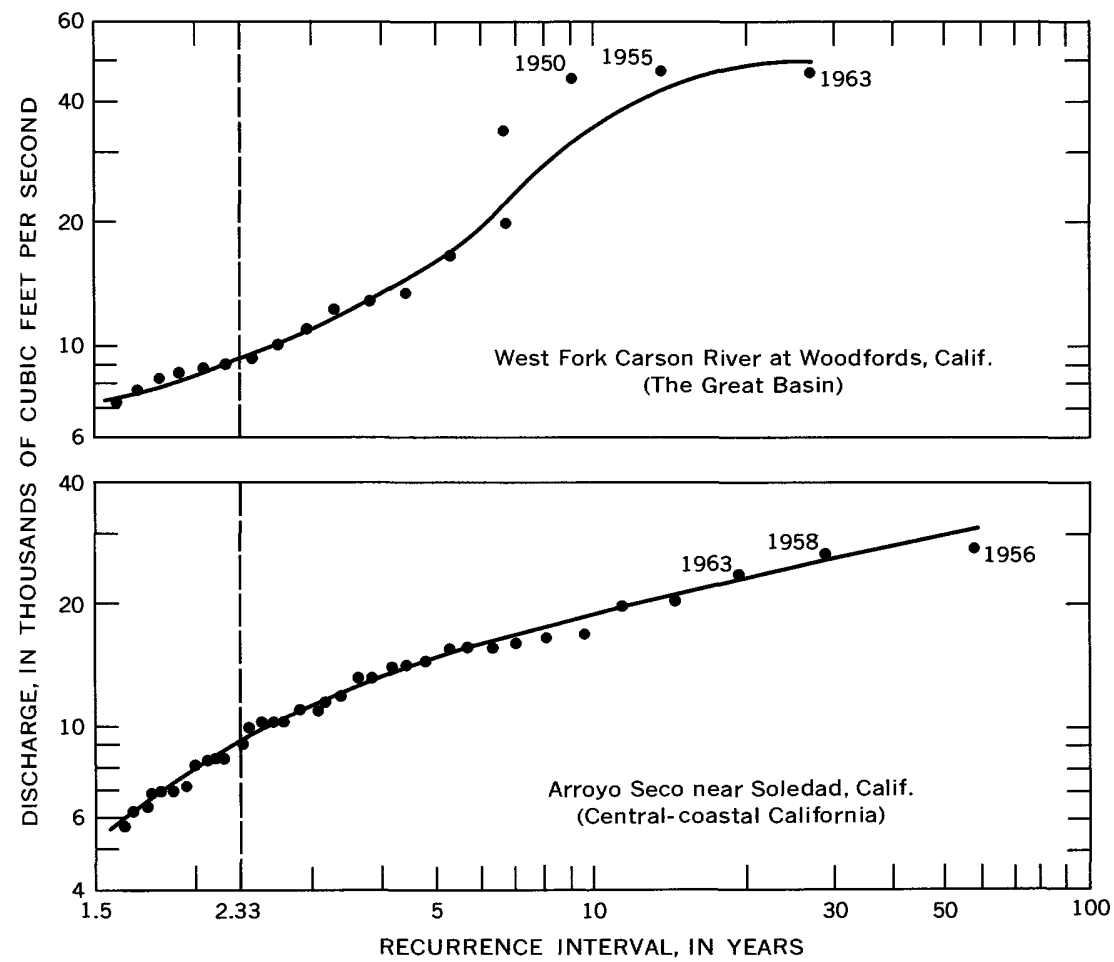

Frgure 21.-Flood magnitude-frequency curves for selected gaging stations in the Great Basin and central-coastal Califorina. 

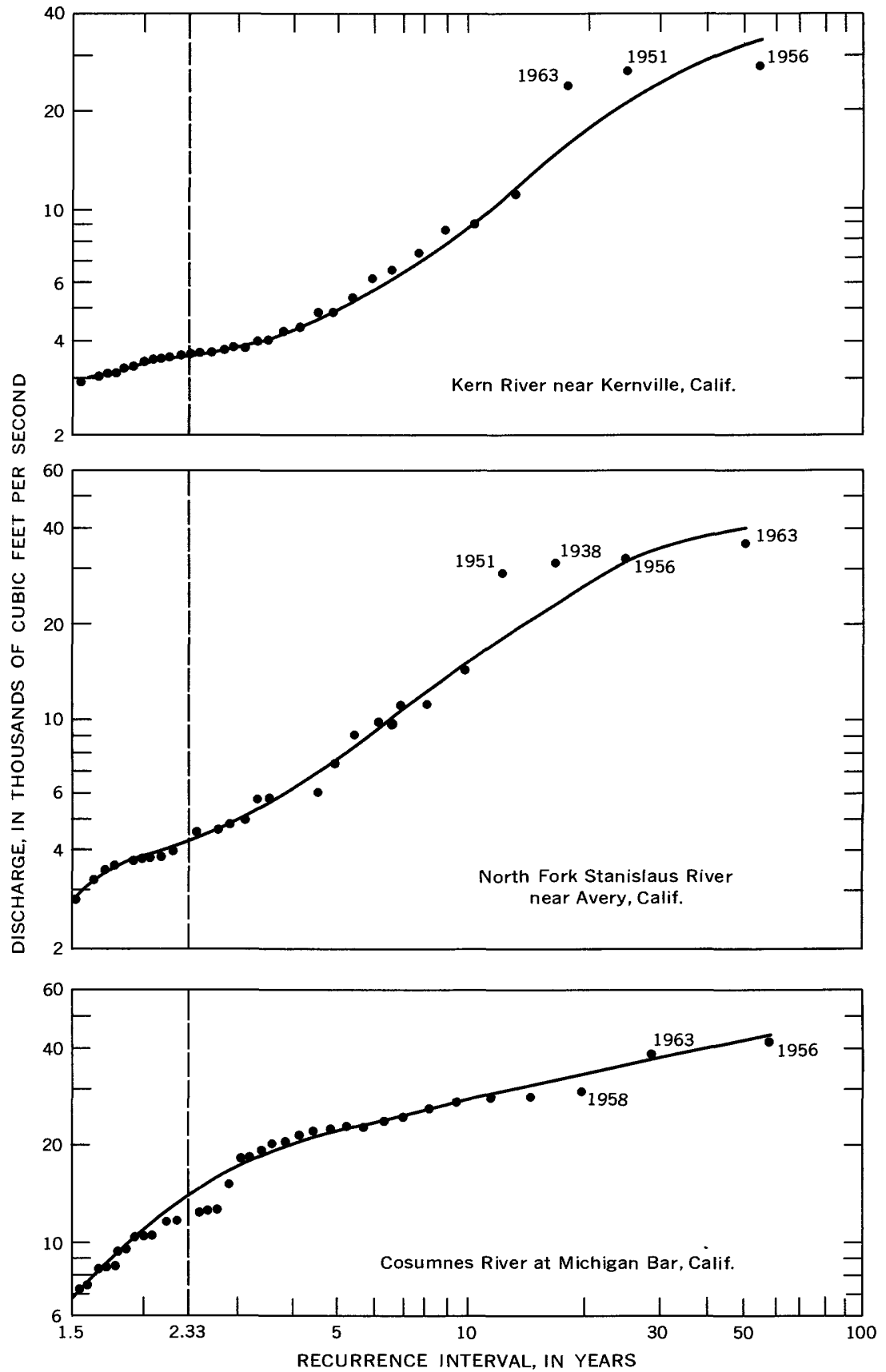

Figure 22.-Flood magnitude-frequency curves for selected gaging stations in San Joaquin Valley. 

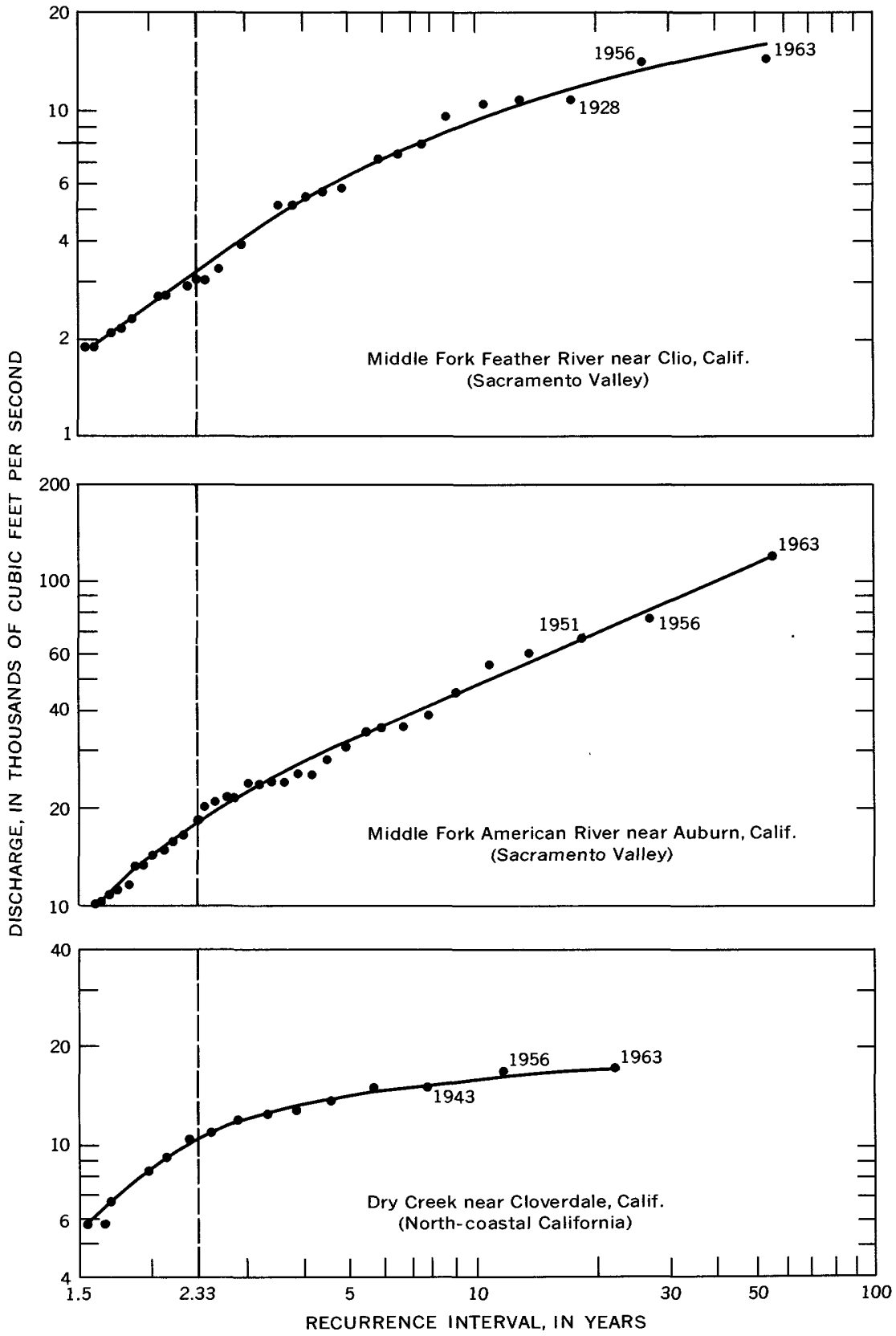

Frgure 23.-Flood magnitude-frequency curves for selected gaging stations in Sacramento Valley and north-coastal California. 
TABLE 5.-Annual peak stages and discharges

\begin{tabular}{c|c|c|c||c|c|c|c|}
\hline $\begin{array}{c}\text { Water } \\
\text { year }\end{array}$ & Date & $\begin{array}{c}\text { Gage } \\
\text { height } \\
\text { (feet) }\end{array}$ & $\begin{array}{c}\text { Dis- } \\
\text { charge } \\
\text { (cfs) }\end{array}$ & $\begin{array}{c}\text { Water } \\
\text { year }\end{array}$ & Date & $\begin{array}{c}\text { Gage } \\
\text { height } \\
\text { (foet) }\end{array}$ & $\begin{array}{c}\text { Dis- } \\
\text { charge } \\
\text { (cfs) }\end{array}$
\end{tabular}

Sta. 10-3100, West Fork Carson River at Woodfords, Calif.

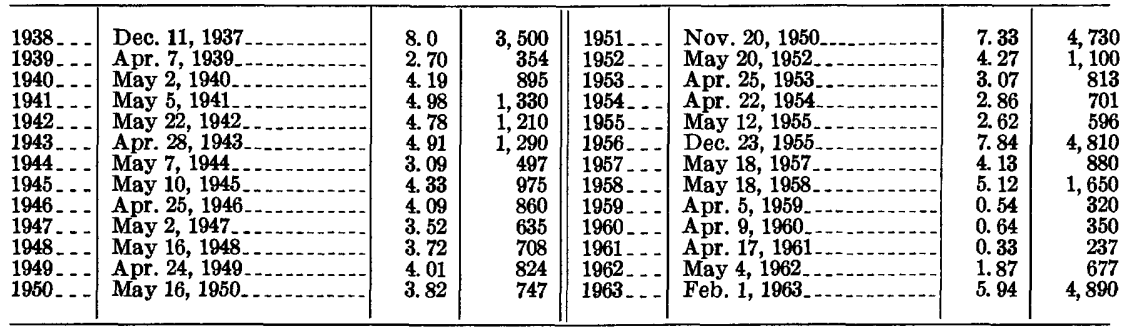

Sta. 11-1520, Arroyo Seco near Soledad, Calif.

\begin{tabular}{|c|c|c|c|c|c|c|c|}
\hline 19 & Jan. 13, 1906 . & 16. 4 & 10,800 & $1935 \ldots$ & Apr. 8, 1935. & 12.12 & 8,340 \\
\hline 1 & Mar. 23, 1907 & 16.3 & 10,700 & 1936 . & Feb. 13,1936 & 13. 70 & 11,100 \\
\hline 19 & Feb. 2, 1908 & 9.3 & 2,520 & 1937 & Feb. 13,1937 & 14. 42 & 12,200 \\
\hline 1909 & Jan. 26, 1909 & 14. 0 & 7,400 & 1938 & Feb. 11, 1938 & 16.5 & 16,000 \\
\hline 1910 & Mar. 21, 1910 & 10.8 & 3,710 & 1939 & Mar. $9,1939_{-}$ & 5. 96 & 1,380 \\
\hline 1911 & Mar. 6, 1911 & 20.0 & 17,300 & 1940. & Feb. 27, 1940 & 15. 0 & 13,600 \\
\hline 1912 & Mar. 12, 1912. & 7.6 & 1,350 & 1941 . & Apr. 4,1941 & 13. 0 & 10,600 \\
\hline 1913. & Jan. 15,1913 . & 8. 4 & 1,900 & 1942 & Jan. 24,1942 . & 11.10 & 14,100 \\
\hline & Jan. 25,1914 . & 20.5 & 17,500 & $1943 \ldots$ & Jan. 21, 1943 & 11.55 & 16,100 \\
\hline & Feb. 9, 1915_ & 12.2 & 7,200 & 1944 & Mar. 4, 1944 & 9. 20 & 7,100 \\
\hline 18 & Jan. 17, 1916 & 15.3 & 13,700 & 1945 & Feb. 2, 1945 & 12.55 & 21,100 \\
\hline 18 & Feb. 21, 1917 & 16.5 & 16,000 & $1946 \ldots$ & Dec. 21, 1945. & 10.47 & 11,600 \\
\hline 1 & Mar. 12, 1918. & 9.4 & 5,030 & 194 & 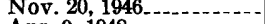 & 7.55 & 3,480 \\
\hline 1919 & Feb. 10, 1919 & 10.0 & 5,800 & & - & 5. & 972 \\
\hline 0. & Apr. $15,1920_{-}$ & 9.0 & 4,550 & -- & Mar. 3, 1949. & 7. 60 & 3,460 \\
\hline 1921 & Jan. 30, 1921. & 12.0 & 8,500 & 195 & Feb. 4, 1950 & 9.63 & 8,460 \\
\hline 1922 & Feb. 9, 1922 & 15.8 & 14,600 & $1951 \ldots$ & Nov. 19,1950 & 12.46 & 20,600 \\
\hline 1923 & Dec. 10, 1922 & 6.75 & 2,040 & $1952-$ & Jan. 14, 1952. & 11.32 & 15,000 \\
\hline 1924 & Jan. 27, 1924 & 6.70 & 1,900 & 1953 & Dec. 7,1952 & 9.80 & 9,050 \\
\hline 1 & Feb. 23, 1925 & 5.9 & 1,300 & 1954 & Feb. 13, 1954_ & 7. 33 & 3,120 \\
\hline 19 & Feb. 13, 1926_ & 12.0 & 8,500 & $1955 \ldots$ & Apr. 21, 1955. & 6.50 & 2,080 \\
\hline 1927 & Nov. 27,1926 & 16. 5 & 16,000 & 1956 & Dec. 23, 1955 . & 14. 30 & 27,700 \\
\hline 192 & Mar. 24, 1928 & 10.0 & 5,800 & $1957 \ldots$ & Feb. 25,1957 . & 8. 36 & 4,950 \\
\hline 1929 & Feb. 3, 1929 . & 9.5 & 5,150 & $1958 \ldots$ & 3,1958 & 14.40 & 28,300 \\
\hline 1950 & Mar. 4, 1950 & 9.03 & 4,590 & 195 & 16,1959 & 9.27 & 6,120 \\
\hline 1931 & Jan. 1,1931 & 5.35 & 810 & 196 & Feb. 1, 1960 & 11.56 & 6,580 \\
\hline 193 & Dec. 27,1931 & 13. 70 & 11,100 & $1961 \ldots$ & Dec. 1,1960 & 9. 15 & 2,600 \\
\hline 19 & Jan. $29,1933 \ldots$ & 7.31 & 2,340 & $1962---$ & Feb. $9,1962 \ldots$ & 12.77 & 10,300 \\
\hline & $-\cdots--$ & 11.01 & 7,110 & $1963 \ldots$ & Jan. $31,1963 \ldots$ & 15.55 & 24,300 \\
\hline
\end{tabular}

Sta. 11-1860, Kern River near Kernville, Calif.

\begin{tabular}{|c|c|c|c|c|c|c|c|}
\hline 101 & 12 & 4. & $\mathbf{3}, \mathbf{3 3 0}$ & 938 & 【ar. 2,1938 & 11. 38 & 7,0 \\
\hline & $24,25,191$ & 3. & & 39. & May 14,1939 & 7. 60 & \\
\hline & ne 4,1914 & 4. & 3,680 & 40 & May 25,1940 & 9.62 & \\
\hline & June 9,1915 & 4. 94 & 4,090 & 941 & June 14,1941 & 11. 14 & \\
\hline & Jan. 17,1916 & 8.8 & 11,500 & 1942 & June 6,1942 & 9.57 & 3,400 \\
\hline & June 17,1917 & 4. 70 & 3,800 & 1943 & Jan. 22,1943 & 12.57 & $8, \mathbf{3 1 0}$ \\
\hline & May 5,1918 & 2.79 & 1,850 & 1944 & June 8,1944 & 8. 54 & 2,310 \\
\hline & May 29,1919 & 5. 1 & 4,290 & 1945 & Feb. 2, 1945 & 10. & 5 , \\
\hline & May 21,1920 & 4. 49 & 3,560 & 1946. & May 9,1946 & 8. 78 & \\
\hline & June 8, 1921 & 3. & 3, & 1947. & Nov. $23,1946 \ldots$ & 9. & 2, \\
\hline 1922 & June 5,1922 & 9.83 & 3, & 19 & May 17,1948 & 7. & \\
\hline 1923. & May 17, 1923 & 8. 48 & 2,300 & 19 & May 28,1949 & 7. & \\
\hline & May 11,1924 & 6. & 80 & 19 & 1,19 & 8. & 2, \\
\hline 5. & June 13, 1925 & & 1,920 & 19 & 0 & 17. & 27,00 \\
\hline 1926. & May 20,1926 & 8 & 1,960 & 19 & May 30,1952 & 10. & 6,14 \\
\hline 1927. & Nov. 26,1926 & 10. & 4,420 & 19 & 27,1953 & 9. & 3,12 \\
\hline 1928. & May 30,1928 & 7. & 1,460 & 19 & 21,1954 & 8. & 2,60 \\
\hline 192 & May 25,1929 & 7. & 1,240 & 19 & June 8,1955 & 8. & 2,50 \\
\hline 19 & June 13,1930 & 8. & 1,730 & & 23,1955 & 17.55 & 27,200 \\
\hline 19 & May 7,1931 & 6. & 610 & 1957. & June $6,1957$. & 9.02 & 3,03 \\
\hline 19 & June 22,1932 & 9.38 & 3,030 & 19 & May $23,1958 \ldots$ & 9. 79 & 4,300 \\
\hline 19 & June 15,1933 . & 9.59 & 3,250 & & May 13,1959 & 5. 76 & 50 \\
\hline 195 & Apr. 20,1934 & 7.20 & 1,080 & & May 12,1960 & 6. 35 & 22 \\
\hline & June 8, 1935 & 9.68 & 2,920 & 19 & Aug. 24, 1961 & & 308 \\
\hline 198 & May 19, 1936. & 9. & 2,980 & 1962 & $22,1962 \ldots$ & 8. 77 & 2,700 \\
\hline & Feb. 6, 1937 & 12. & 8,600 & 1963 & Feb. 1, 1963 & 16.85 & 24,000 \\
\hline
\end{tabular}


TABLE 5.-Annual peak stages and discharges-Continued

\begin{tabular}{|c|c|c|c|c|c|c|c|}
\hline $\begin{array}{l}\text { Water } \\
\text { year }\end{array}$ & Date & $\begin{array}{c}\text { Gage } \\
\text { height } \\
\text { (feet) }\end{array}$ & $\begin{array}{c}\text { Dis- } \\
\text { charge } \\
\text { (cfs) }\end{array}$ & $\begin{array}{l}\text { Water } \\
\text { year }\end{array}$ & Date & $\begin{array}{c}\text { Gage } \\
\text { height } \\
\text { (feet) }\end{array}$ & $\begin{array}{c}\text { Dis- } \\
\text { charge } \\
\text { (cfs) }\end{array}$ \\
\hline
\end{tabular}

Sta. 11-2945, North Fork Stanislaus River near Avery, Calif.

\begin{tabular}{|c|c|c|c|c|c|c|c|}
\hline 1915 & Mav 11,1915 & 87 & 6210 & 1943 & Tan 211943 & 1065 & 11000 \\
\hline 1916 & May 6, 1916. & 6.6 & 2,760 & 1944 & May 15,1944 & $\begin{array}{r}\text { 10. 00 } \\
6.53\end{array}$ & 2,690 \\
\hline 1917. & Apr. 30,1917 & 6. 3 & 2,450 & 1945 & Feb. 2,1945 . & 10.7 & 11,300 \\
\hline 1918 & Apr. 30, May 1, 1918. & 5.8 & 1,960 & 1946 & Apr. 25,1946 & 7.30 & 3,730 \\
\hline 1919 & May 7, 1919 & 6.00 & 2,150 & 1947 . & May 3, 1947. & 6. 20 & 2,320 \\
\hline 1920 & May 23,1920 & 5.7 & 1,880 & 1948 & May 16, 1948 & 7.82 & 4,550 \\
\hline 1921. & May 13,1921 & 5.9 & 2,060 & 1949. & May 14,1949 & 7.12 & 3,470 \\
\hline 1922 & June 1,1922 & 7.5 & 3,780 & 1950 . & May 15,1950 & 7.35 & 3,800 \\
\hline 1929 & June 16, 1929 & 6. 80 & 3,000 & 1951 & Nov. 18,1950 & 13.8 & 29,000 \\
\hline 1930 & Apr. 24,1930 & 6. 18 & 2,230 & 1952 & May 27,1952 & 8.60 & 6,010 \\
\hline 1931. & Apr. 26,1931 & 4. 68 & 1,010 & 1953 & Apr. 27,1953 & 1008 & 9,980 \\
\hline 1932 & May 11,1932 & 7.90 & 4,690 & 1954 & Mar. 9,1954 & 9.20 & 7,400 \\
\hline 1933. & May 29,1933 & 7.31 & 3,580 & 1955 & May 22,1955 & 6. 33 & 2,480 \\
\hline 1934 & Mar. 29, 1934 & 5.88 & 2,000 & 1956. & Dec. 23,1955 & 14. 23 & 32,000 \\
\hline 1935 & May 23, 1935 & 7. 58 & 3,970 & 1957 & May 18,1957 & 11.18 & 14,300 \\
\hline 1936 & June 7,1936 & 8.50 & 5,810 & 1958 & May 18,1958 & 8. 63 & 6,070 \\
\hline 1937 & May 13,1937 & 8. 35 & 5,010 & 1959 & Feb. 16,1959 & 6.17 & 2,230 \\
\hline 1938 & Dec. 11,1937 & 14. 1 & 31,100 & 1960 & Feb. 8,1960 & 7.35 & 3,220 \\
\hline 1939 & Apr. 8, 1939. & 5.65 & 1,790 & 1961 . & Apr. 4, 1961. & 5. 73 & 1,320 \\
\hline 1940 & Mar. 26, 1940 & 9.82 & 9. 160 & 1962 & May 5, 1962 & 7.65 & 3,760 \\
\hline 1941 & May 11,1941 & 8. 60 & 5,760 & 1963 & Jan. 31, $1963 \ldots$ & 15. 00 & 36,000 \\
\hline 1942 & May $21,1942 \ldots$ & 8. 00 & 4,870 & & & & \\
\hline
\end{tabular}

Sta. 11-3350, Cosumnes River at Michigan Bar, Calif.

\begin{tabular}{|c|c|c|c|c|c|c|c|}
\hline 1907 & March 1907 & 16.3 & & 1936 & Feb. 22, 1936 & 9.95 & 18,200 \\
\hline 1908 . & Jan. $21,24,1908$ & & 2,200 & 1937 & Mar. 21, 1937 & 9. 50 & 15,300 \\
\hline 1909 & Jan. 13, $1909 \ldots$ & 12. 0 & 28,400 & 1938 & Feb. 11, 1938 & 10.06 & 19,300 \\
\hline 1910 & Mar. 21, 1910 & & 9,640 & 1939. & Mar. 9, 1939 & 5. 05 & 1,930 \\
\hline 18 & Jan. 31, 1911 & 12.0 & 28,400 & 1940 & Mar. 31, 1940 & 11. 66 & 26,200 \\
\hline 18 & Mar. 6, 1912 & & 1,700 & 1941 & Apr. 4, 1941 & 7.67 & 9,280 \\
\hline 13. & Jan. 18, 1913 & 5. 0 & 1,700 & 1942 & Jan. 27, 1942 & 11.28 & 24,500 \\
\hline 14 & Jan. 22, 1914 & 10.0 & 18,200 & 1943 & Mar. 10, 1943 & 10.90 & 22,900 \\
\hline 5 . & Feb. 2, 1915. & 7.5 & 8,200 & 1944 & Mar. 4, 1944 & 7.45 & 8,490 \\
\hline 19 & Mar. 20, 1916 & 8. 1 & 10,400 & 1945 & Feb. 2, 1945 & 10.51 & 21,100 \\
\hline 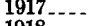 & Feb. 21, 1917 & 11.0 & 22,900 & 1946 & Dec. 23, 1945 & 8. 50 & 12,600 \\
\hline 19 & Mar. 12, 1918 & 8. 5 & 11,900 & 1947 & Mar. 10,1947 & 6. 06 & 3,930 \\
\hline 1 & Feb. 10, 1919 & 10.8 & 22,000 & 194 & Mar. 24, 1948 & 6. & 40 \\
\hline 1 & Mar. $1,21,1920$. & 6. 0 & 3,700 & 1949 & Mar. 3, 1949 & 8. 72 & 13,500 \\
\hline 1921 & Jan. 18, 1921 & 10.5 & 20,600 & 1950 & Feb. 4, 1950 . & 7. 44 & 8,360 \\
\hline $192-r \cdot r \cdot r \cdot r \cdot r$ & Feb. 9, 1922 & 8. 2 & 10,600 & 1951. & Nov. 18,1950 & 11.84 & 27,600 \\
\hline 1923 & Dec. 13,1922 & 8. 5 & 11,600 & 1952 & Jan. 12, 1952 & 8. & 12,500 \\
\hline 1 & Feb. 8, 1924 & 4.5 & 1,120 & 1953 & Apr. 27, 1953 & 6. & 4,080 \\
\hline 5 & Feb. 6, 1925. & 11.2 & 23,800 & 1954. & Mar. 30, 1954 & 6. & 3,860 \\
\hline 1926 & Feb. 12, 1926 & 6. 0 & 3,850 & 1955 & Jan. 1, 1955. & 6. & 360 \\
\hline 1927 & Apr. 3, 1927 & 8. 4 & 11,400 & 1956. & Dec. 23, 1955 & 14. 59 & 42,000 \\
\hline 1928 & Mar. 25, 1928 & 11. 0 & 22,900 & 19 & Mar. 5, 1957. & & 6,930 \\
\hline 1929 & Mar. 10, 1929 & 5. & 3,160 & 1958 & Apr. 3, 1958 & 12. 18 & 29,300 \\
\hline 19 & Mar. 5, 1930 & 6.80 & 6,090 & 1959 & Feb. 16,1959 & 6. & 4, 340 \\
\hline 18 & Feb. 18, 1931 & 4. & 1,620 & 1960 & Feb. 8, 1960 & & 11,200 \\
\hline 19 & Feb. 6, 1932 & 8. 24 & 10,600 & 1961 & Mar. 25, 1961 & & 486 \\
\hline 193 & May 30,1933 & 4. 28 & 890 & 1962 & Feb. 10, 19 & & 7,440 \\
\hline 193 & Jan. 1,1934 & $\begin{array}{r}7.15 \\
10.43\end{array}$ & 7,170 & 1963 & Feb. 1, 1963 . & 14. 11 & 39,400 \\
\hline & $\Omega$ & 10. & 20,100 & & & & \\
\hline
\end{tabular}

Sta. 11-3925, Middle Fork Feather River near Clio, Calif.

\begin{tabular}{|c|c|c|c|c|c|c|c|}
\hline 1926 & Feb. 4, 1926 & 5. 20 & 1,430 & 1945 & Feb. 3, 1945 & 8. 45 & 2,880 \\
\hline 1927 & Feb. 21,1927 & 11.80 & 10,600 & 1946 . & Dec. 29,1945 & 8.58 & 3,030 \\
\hline 1928 & Mar. 26, 1928 & 12.0 & 11,000 & 1947 & Feb. 12, 1947 & 8. 26 & 2,680 \\
\hline 1929 & Mar. 12, 1929 & 3. 68 & 590 & 1948 & Apr. 17, 1948 & 7.24 & 1,840 \\
\hline 1930. & Dec. 13,1929 & 6.82 & 2,260 & 1949 & Mar. 21,1949 & 6. 60 & 1,430 \\
\hline 1931 . & Mar. 18,1931 & 4. 47 & 925 & 1950 & Feb. 6, 1950 & 8. 26 & 2,680 \\
\hline 1932 . & Mar. 20,1932 . & 7.83 & 3,290 & 1951 & Nov. 20,1950 & 12. 58 & 7,170 \\
\hline 1933 & Mar. 12, 1933 & 4. 78 & 970 & 1952 & Apr. 6, 1952. & 13. 79 & 10,900 \\
\hline 1934 & $\operatorname{Jan} .4,1934$ & 4. 56 & 845 & 1953 & Jan. 9,1953 . & 9.15 & 3,050 \\
\hline 1935 & Apr. 9, 1935 & 9.93 & 5,650 & 1954 & Mar. 10,1954 & 8. 74 & 2,040 \\
\hline 1936 & Feb. 23,1936 & 9.55 & 5,200 & 1955 & Mar. 14,1955 & 7.32 & 1,100 \\
\hline 1937. & Mar. 13,1937 & 7.0 & 2,110 & 1956 & Dec. 23,1955 & 15. 77 & 14,400 \\
\hline 1938. & Apr. 20,1938 & 11. 6 & 7,300 & 1957 & Feb. 25, 1957 & 11. 51 & 5,130 \\
\hline 1939 & Mar. 31, 1939 & 5.09 & 582 & 1958 & Feb. 24,1958 & 11. 81 & 5,500 \\
\hline 1940 & Feb. 28,1940 & 12.03 & 8,070 & 1959 & Jan. 12,1959 & 7.37 & 1,220 \\
\hline 1941 & Feb. 10,1941 . & 7.95 & 2,280 & 1960 & Feb. 8, 1960 & 10.90 & 3,920 \\
\hline 1942 & Jan. 27, 1942_ & 10.65 & 5,800 & 1961 & Jan. 31, 1961 & 5.93 & 552 \\
\hline 1943 & $\operatorname{Jan} .23,1943$ & 13. 03 & 9,870 & 1962 & Feb. 13, 1962 & 8. 62 & 1,860 \\
\hline & Mar. 25, 1944 & 6.42 & 1,350 & 1963 & Feb. 1, 1963 & 16. 19 & 14,500 \\
\hline
\end{tabular}


TABLE 5.-Annual peak stages and discharges-Continued

\begin{tabular}{|c|c|c|c|c|c|c|c|}
\hline $\begin{array}{l}\text { Water } \\
\text { year }\end{array}$ & Date & $\begin{array}{c}\text { Gage } \\
\text { height } \\
\text { (feet) }\end{array}$ & $\begin{array}{c}\text { Dis- } \\
\text { charge } \\
\text { (cfs) }\end{array}$ & $\begin{array}{c}\text { Water } \\
\text { year }\end{array}$ & Date & $\begin{array}{c}\text { Gage } \\
\text { hoight } \\
\text { (feet) }\end{array}$ & $\begin{array}{c}\text { Dis- } \\
\text { (cfsarge }\end{array}$ \\
\hline
\end{tabular}

Sta. 11-4335, Middle Fork American River near Auburn, Calif.

\begin{tabular}{|c|c|c|c|c|c|c|c|}
\hline 1912 & May 30, 1912 & 7.4 & 5.350 & 1938 & Dec. 11,1937 & 27.3 & 47,900 \\
\hline 1913. & Apr. 26, 1913 & 8.1 & 6,460 & 1939 . & Apr. $4,8,1939$ & 9.05 & $.3,830$ \\
\hline 1914 & Jan. 1,1914 & 18. 0 & 26,400 & 1940. & Mar. 30,1940 & 23.2 & 35,600 \\
\hline 1915 & May 11,1915 & 16.0 & 22,000 & 1941 & Dec. 27,1940 . & 16. 9 & 18,400 \\
\hline 1916 & Mar. 20, 1916 & 13. 7 & 17,100 & 1942 & $\operatorname{Jan} .27,1942$. & 21. 60 & 32,300 \\
\hline 1917 & Feb. 25, 1917 . & 13. 0 & 15,600 & 1943 & Jan. 21,1943 & 28.0 & 58,000 \\
\hline 1918 & Apr. 10,1918 & 8. 0 & 6,100 & 1944 & May 8, 1944 & 11.1 & 6,440 \\
\hline 1919 & Fob. 11, 1919. & 17. 5 & 25,000 & 1945 & Feb. 2, 1945 & 23,90 & 40,400 \\
\hline 1920 & Apr. 16,1920 & 10.5 & 9,000 & 1946 & Dec. 29,1945 & 16. 62 & 16,300 \\
\hline 1921. & Jan. 18, 1921 . & 11.5 & 9,840 & 1947 & Feb. 12, 1947 & 14. 15 & 11. 600 \\
\hline 1922 & May 20, 1922. & 12.7 & 11,400 & 1948 & Apr. 17, 1948 & 13. 38 & 10,100 \\
\hline 1923. & Dec. 13,1922 & 17. 7 & 21,100 & 1949 & May 14, 1949 & 12. 70 & 8,700 \\
\hline 1924 & Feb. 8, 1924 & 8.3 & 5,100 & 1950 & Jan. 23, 1950. & 15. 60 & 14,900 \\
\hline 1925. & Feb. 6, 1925 & 25.0 & $\mathbf{3 6}, \mathbf{3 0 0}$ & 1951 . & Nov. 20,1950 & 34. 7 & 68,500 \\
\hline 1926 & Apr. 6, 1926. & 11.5 & 9,920 & 1952. & Feb. 2, 1952 . & 15.15 & 13,900 \\
\hline 1927. & Föb. 21, 1927 . & 21.5 & 29,200 & 1953. & Apr. 27,1953 & 18.55 & 22,300 \\
\hline 1928 & Mar. 25, 1928 & 35.6 & 62,000 & 1954. & Mar. 9, 1954 & 18. 65 & 22,600 \\
\hline 1929 & June 16,1929 & 11.3 & 12,000 & 1955 & May 13,1955 & 10.87 & 5,820 \\
\hline 1930 & Dec. 10,1929 & 9.8 & 8,180 & 1956 & Dec. 23, 1955 - & 33. 9 & 79,000 \\
\hline 1931 & Mar. 18,1931 & 10.88 & 6,110 & 1957. & May 18,1957 . & 19.55 & 26,400 \\
\hline 1932 & May 12,1932 & 12. 40 & 8,740 & 1958. & Feb. 25, 1958 & 18. 92 & 24,500 \\
\hline 1933 & May 30, $1933 \ldots$ & 11.6 & 6,770 & 1959 & Feb. 16, 1959 & 12.41 & 7,690 \\
\hline 1934 & Mar. 29, 1934. & 12.30 & 7,830 & 1960 & Feb. 8, 1960 & 22.74 & 36,700 \\
\hline 1935 & Apr. 8, 1935 & 19.5 & 25,000 & 1961 & Feb. 10, 1961 & 9.73 & 4,220 \\
\hline 1936 & Feb. 22,1936 & 19.4 & 24,700 & 1962. & Feb. 10,1962 & 15. 27 & 14,000 \\
\hline 1937 & Feb. 14, 1937 $\ldots$ & 13.5 & 10,600 & 1963. & Feb. 1, 1963 & 43. 1 & 121,000 \\
\hline
\end{tabular}

Sta. 11-4645, Dry Creek near Cloverdale, Calif.

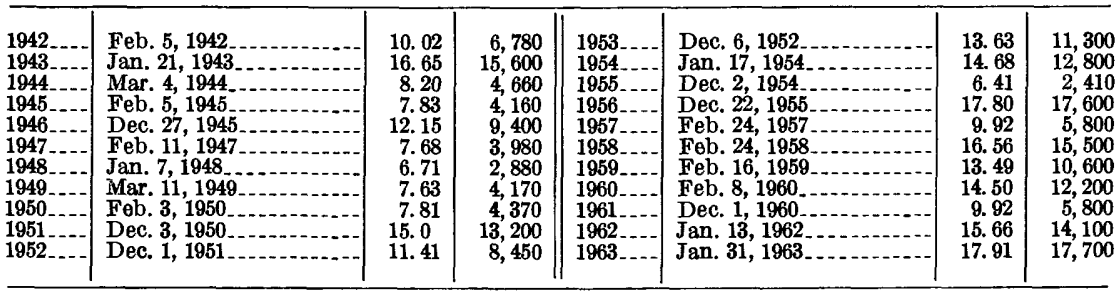

To fit a time scale to the annual flood peaks, plotting positions must be determined. The following formula for computing plotting positions was used:

$$
T=\frac{n+1}{m}
$$

in which $T$ is the plotting position or recurrence interval in years; $n$ is the number of years of record being considered; and $m$ is the order number of the flood, the highest flood of record being order number 1 , the second highest number 2, and so on. The graphs of figures 21-23 were drawn using the computed recurrence-intervals as abscissas and the discharges from table 5 as ordinates.

Use of a logarithmic discharge scale permits direct comparison of the characteristics of the curves for the various regions; the steeper the slope of the curve, the greater the variability, or comparative range in 
discharge, of annual flood peaks. The graphs show that the annual peaks for Arroyo Seco near Soledad, Calif., and Dry Creek near Cloverdale, Calif., have the least variability; those for Kern River near Kernville, Calif., and North Fork Stanislaus River near Avery, Calif., have the greatest variability.

For the flood magnitude-frequency data to be meaningful, a reasonably long period of continuous record of annual peak discharges must be available. Ideally, the period would be at least 50 and preferably 100 or more years. However, to present at least one set of data for each of the hydrologic regions defined in this report and to indicate the relative magnitude of the 1963 flood peaks, it was necessary to use some stations with less than 50 years of record. Frequency data based on these shorter periods may be biased because of the unusual flood activity in recent years in the area covered by this report.

The frequency curves included in this report are based solely on data for the period of continuous record at each gaging station. Lengths of record ranged from 22 years at Dry Creek near Cloverdale, Calif., to 58 years at Arroyo Seco near Soledad, Calif. When comprehensive flood-frequency studies are made in an area, historical data are sometimes used to adjust the upper end of the frequency curves. The data presented herein however would probably not be greatly altered by the available historical data for the rivers involved; therefore, the authors made no adjustments to the frequency curves.

\section{DETERMINATION OF FLOOD DISCHARGE}

The standard method used by the Geological Survey to determine discharge at a gaging station is to develop a stage-discharge relation from the current-meter discharge measurements made at various stages and then to apply this relation to records of stage. The record of stage is generally obtained from a water-stage-recorder installation that provides a continuous graphic or punch-tape record of stage. The reliability of the stage-discharge relation depends upon how adequately the discharge measurements define the entire range in stage. Short extensions of the high-water end of the stage-discharge-relation curve may be made on the basis of slope-conveyance studies, velocityarea studies, or by use of other hydrologic principles.

It was impossible to obtain current-meter measurements at or near the time of peak discharge at many of the gaging stations because the area of the 1963 flood was so extensive. Measuring facilities, such as cableways, were destroyed; also access roads and bridges were flooded or washed out. On some smaller streams the duration of the flood peaks was too short to permit measurement. The main difficulty was 
that the number of sites requiring flood measurements was far too great for the trained personnel available to measure the discharge by current meter during the short period that the streams were in flood.

For many gaging stations at which no high-water current-meter measurements were made, the peak discharge was obtained by slopearea, contracted-opening, culvert, or other types of indirect discharge measurements. These indirect measurements are based on field surveys of high-water profiles, channel geometry, and hydraulic-structure geometry, and are computed in accordance with established hydraulic principles. They are indirect only in the sense that the data are collected subsequent to the passage of the peak discharge. Indirect measurements were made at over 200 sites throughout the report area. A general description of the indirect-measurement methods used by the Geological Survey is given in Water-Supply Papers 773-E, 798, 816, and 843 ; more detailed information on the latest techniques is available in recent publications and reports of the Geological Survey, such as Circular 284, "Computation of Peak Discharge at Contractions," and open-file report, "Indirect Measurement of Peak Discharge Through Culverts."

\section{STREAMFLOW DATA}

\section{EXPLANATION OF DATA}

Maximum stages and discharges at the 623 continuous-record gaging stations, crest-stage stations, miscellaneous sites, and reservoir stations are summarized in table 6 . The derivation of the maximum data is explained in the station descriptions for each site in the "station data" section of this report. The peak-discharge values given in table 6 are for flow as it passed the gaging station or measuring site, and no adjustments have been made for storage, regulation, or diversion. For reservoir stations the maximum stage and contents are given.

At stations where the maximum discharge did not occur simultaneously with the maximum stage, the maximums are given on separate lines (sta. 10-2895, table 6). Under the heading "Maximum flood previously known," maximums during the period of gagingstation operation are listed first, and data on floods outside this period are given on the next line below, where such information is available (sta. 10-2905, table 6).

Peak discharges, in cubic feet per second per square mile, have been tabulated for all sites except those significantly affected by regulation or diversion and those for which the drainage-area figures were not available.

Following table 6, "Summary of flood stages and discharges," additional data are presented for each station where streamflow informa- 
tion was collected by the Geological Survey during the 1963 floods. In general, the information presented for each continuous-record gaging station is as follows: A description of the station, a tabulation of daily mean discharges for January and February 1963, and a tabulation of stages and discharges at selected intervals during the 3 or 4 days when most floodflow occurred. For the miscellaneous sites and crest-stage stations, only the station description is presented, because no information other than maximum stages and discharges is available.

The station description gives information relative to: Location of the gage; size of drainage area above the gage; nature of the gageheight record obtained during the period discussed in this report; datum of the gage; definition of the stage-discharge relation; maximum stage and discharge during the January-February 1963 flood; previous maximum during the period of record; available maximum data for floods outside the period of record; the effect of regulation and diversion; and maximum reservoir inflow and outflow, where available. Other pertinent general information is also given.

Daily mean discharges during the months of January and February 1963 are listed after the description of each gaging station. This 2month period shows antecedent conditions, floodflows, and most of the flood recession-enough information to allow adequate study of the flood hydrology.

The table of daily mean flow gives the discharge corresponding to the daily mean gage height unless (1) there were large or rapid changes in discharge during a day or (2) the gage-height record is from a digital-punch recorder. For the days that had large or rapid changes, discharge for the day is computed by subdividing the day and averaging the discharges from all the subdivided parts. For digitalpunch recorders the daily mean discharge is always the average of the several $(96$, for a recorder set to punch at 15 -minute intervals) discharges determined from each of the gage heights punched during the day.

Also shown in these tables are the monthly mean discharge, in cubic feet per second, and the volume of monthly runoff, in acre-feet and in inches. The monthly runoff in inches is not given for stations where regulation and (or) diversion significantly affected the runoff or where the drainage area was not determined.

The tables of stage and discharge at selected times-where such detailed definition is warranted-may be found after the daily-mean discharge tables. Enough detail is presented so that hydrographs for the flood period can be accurately constructed. 
Daily mean discharge, if computed from these flood detail sheets, may differ slightly from the daily mean discharge shown in the table of daily means. At a station where a digital-punch recorder is set to punch at 15-minute intervals, data for many of the 96 punches during the day were omitted from the table of stages and discharges. Only those data necessary to define the flood hydrograph with reasonable accuracy are included. Also, different methods of averaging data may result in slightly different daily mean values. Any resulting differences are of a minor nature but are pointed out for the information of the user. 



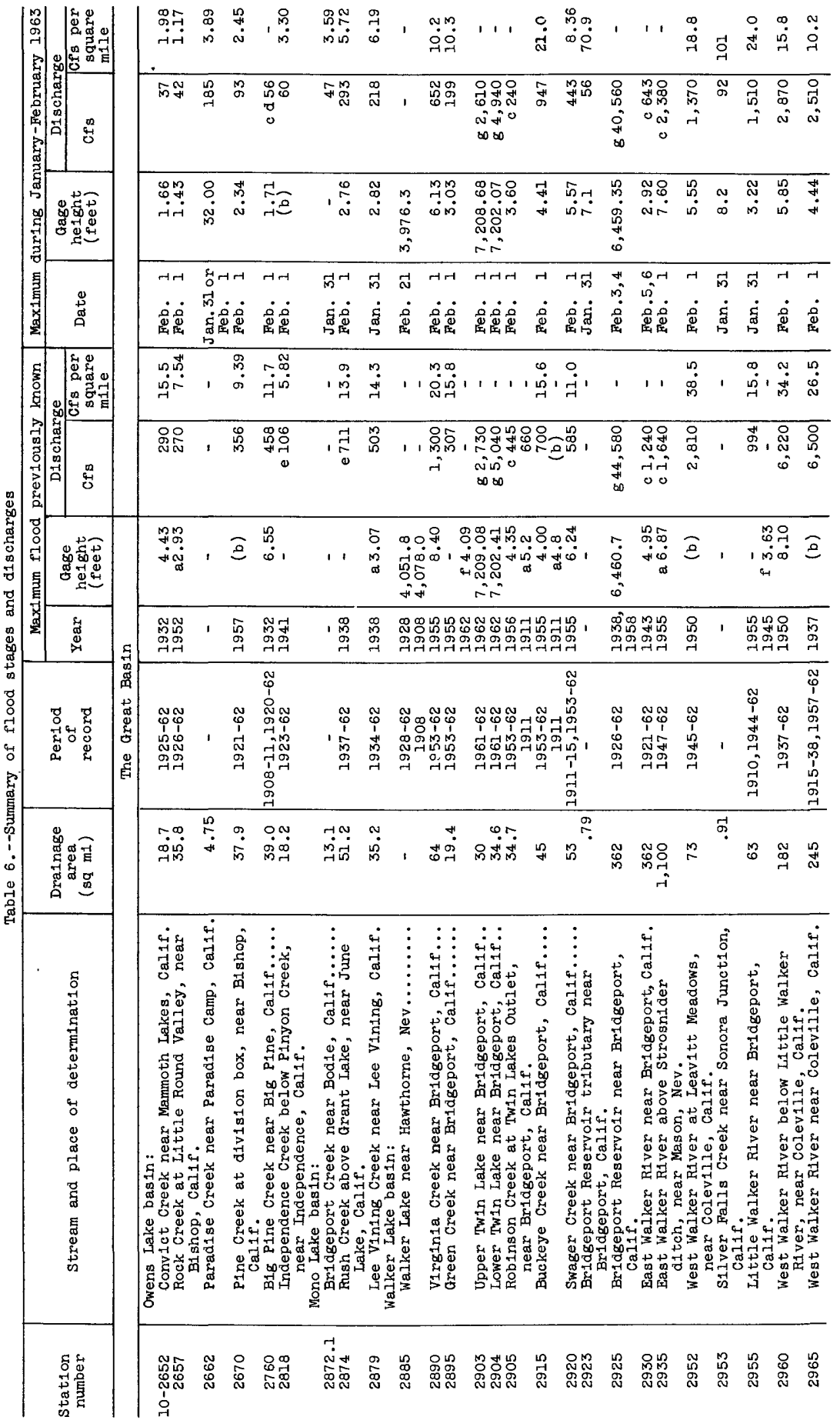




\begin{tabular}{|c|c|c|c|c|c|c|c|c|c|c|c|c|c|}
\hline & & & $\overrightarrow{7}$ & 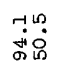 & 官官 & ت̇ & & $\stackrel{2}{\stackrel{0}{0}}$ & & ' ' & & & 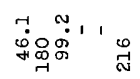 \\
\hline & 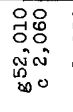 & $\begin{array}{l}\text { O } \\
\text { o } \\
i \\
i \\
0\end{array}$ & $\begin{array}{l}\stackrel{\mathcal{N}}{1} \\
\text { a }\end{array}$ & 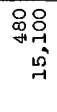 & 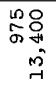 & 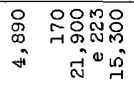 & 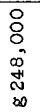 &, 9 & m & 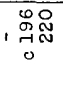 & $\begin{array}{l}8 \\
\text {-1 } \\
0 \\
0\end{array}$ & & 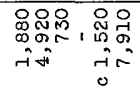 \\
\hline
\end{tabular}

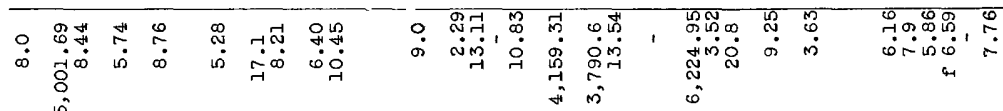

कू

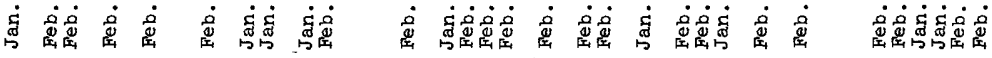

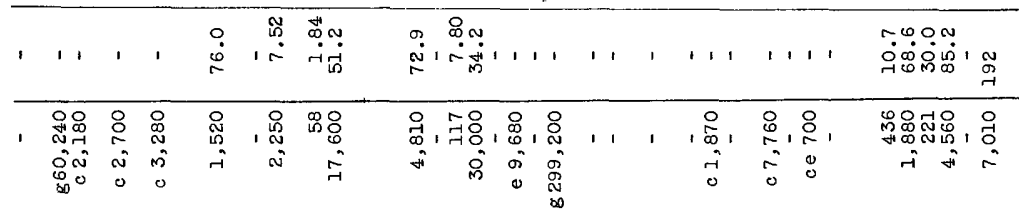

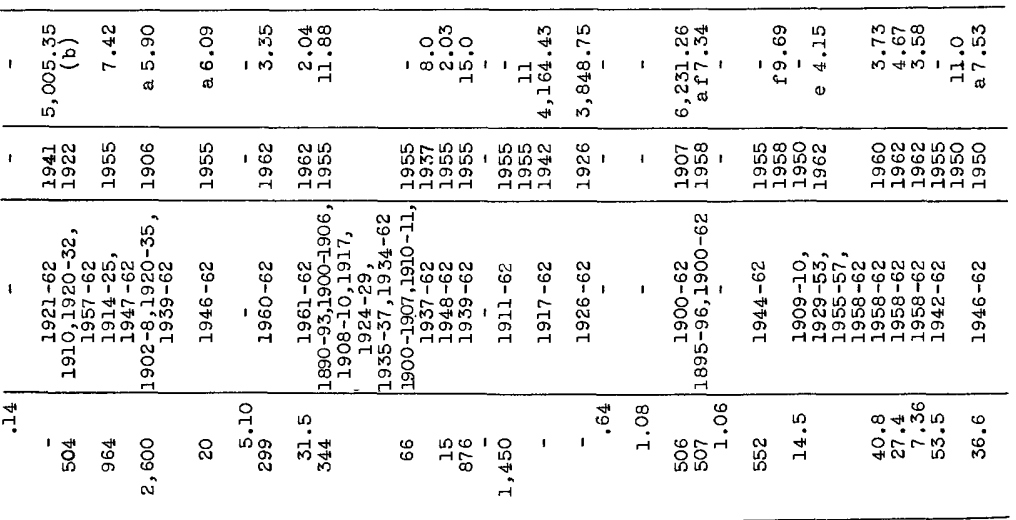

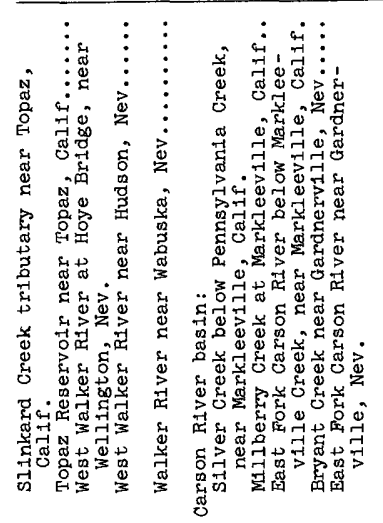

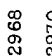

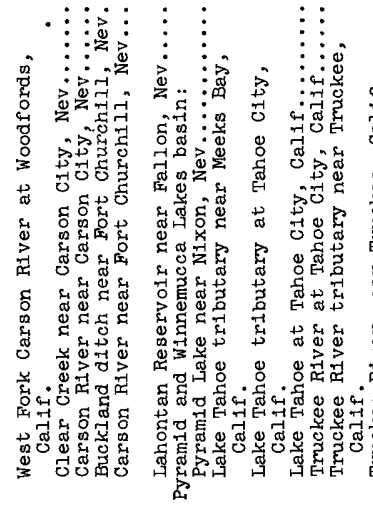

芹.

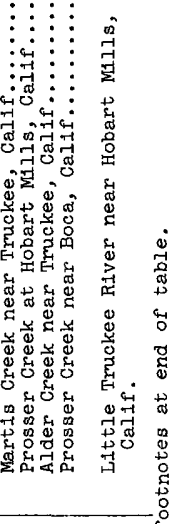

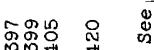




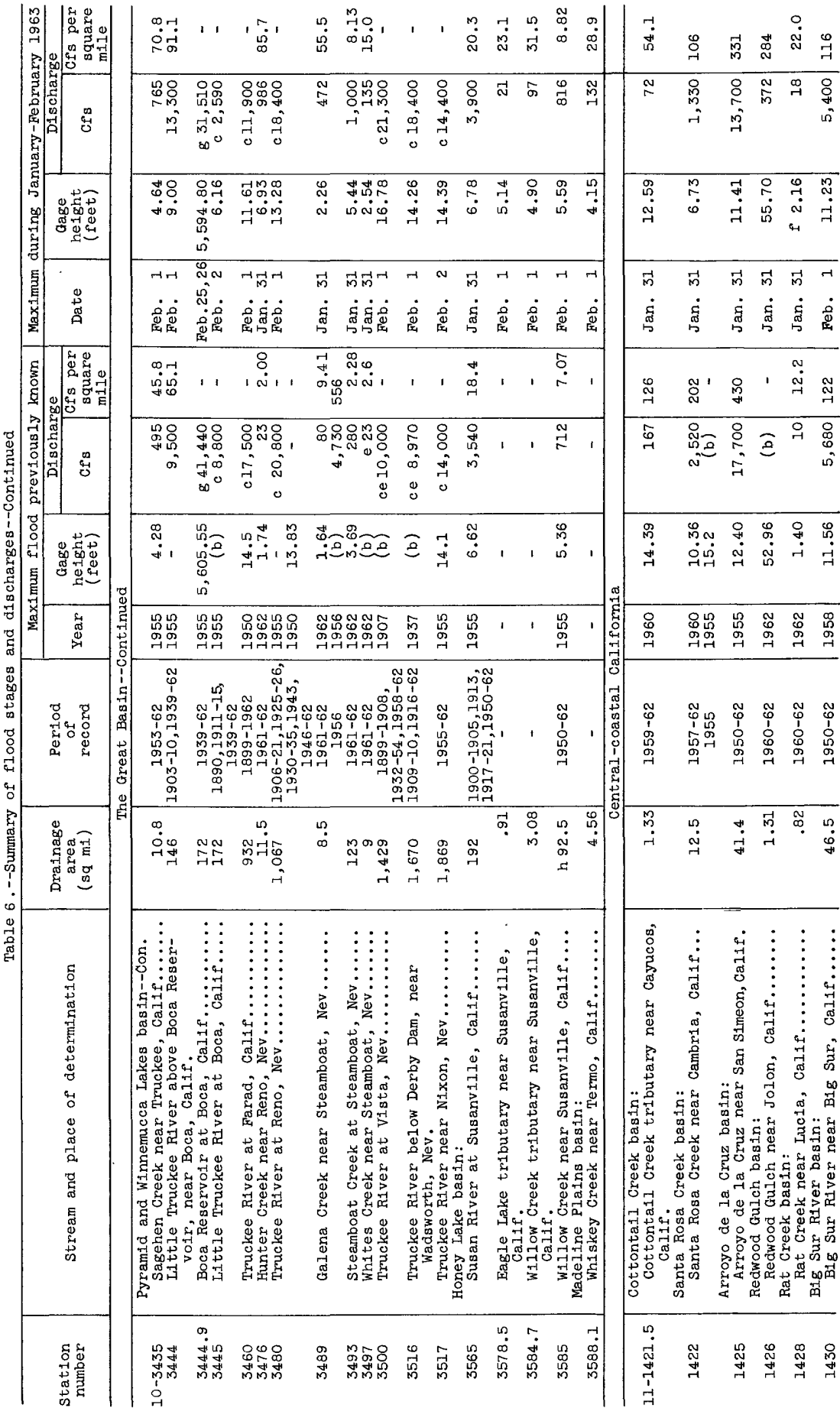




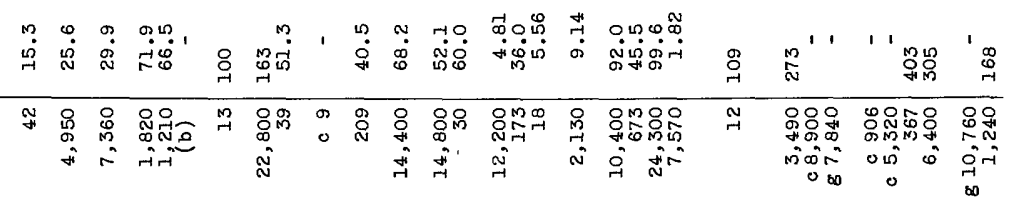

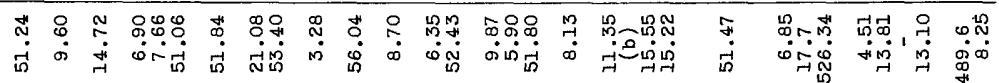

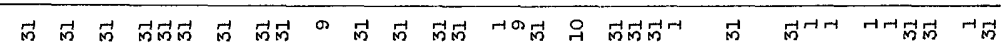

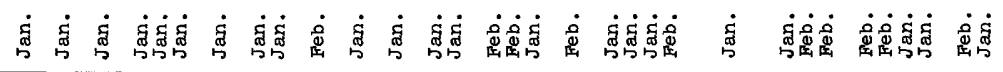

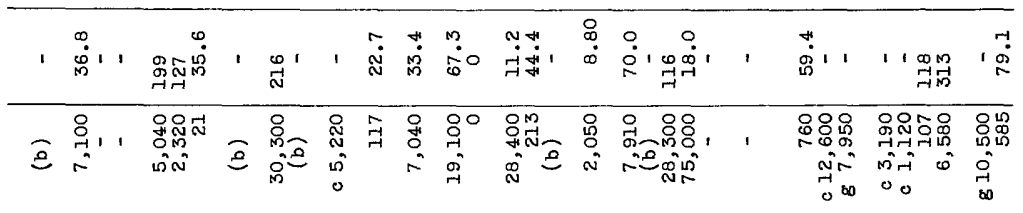

兽

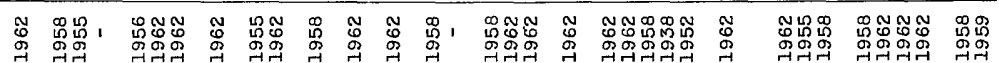

\begin{tabular}{|c|c|c|c|}
\hline 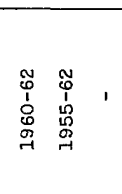 & 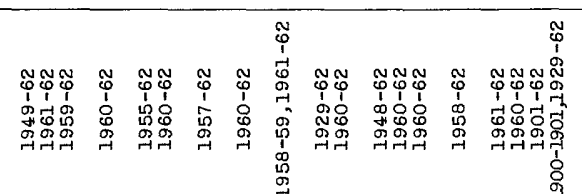 & 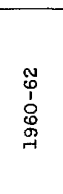 & 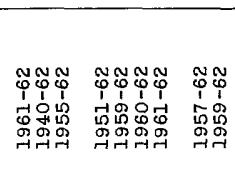 \\
\hline مُ & 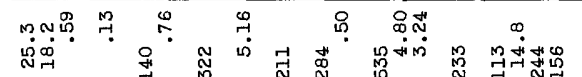 & $\vec{y}$ & 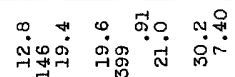 \\
\hline
\end{tabular}

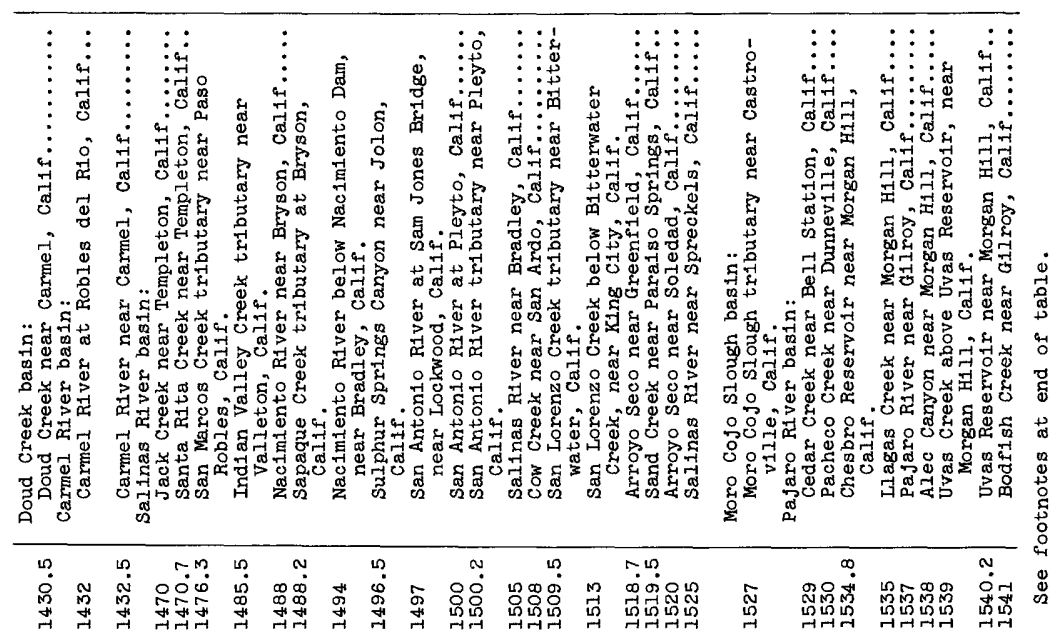




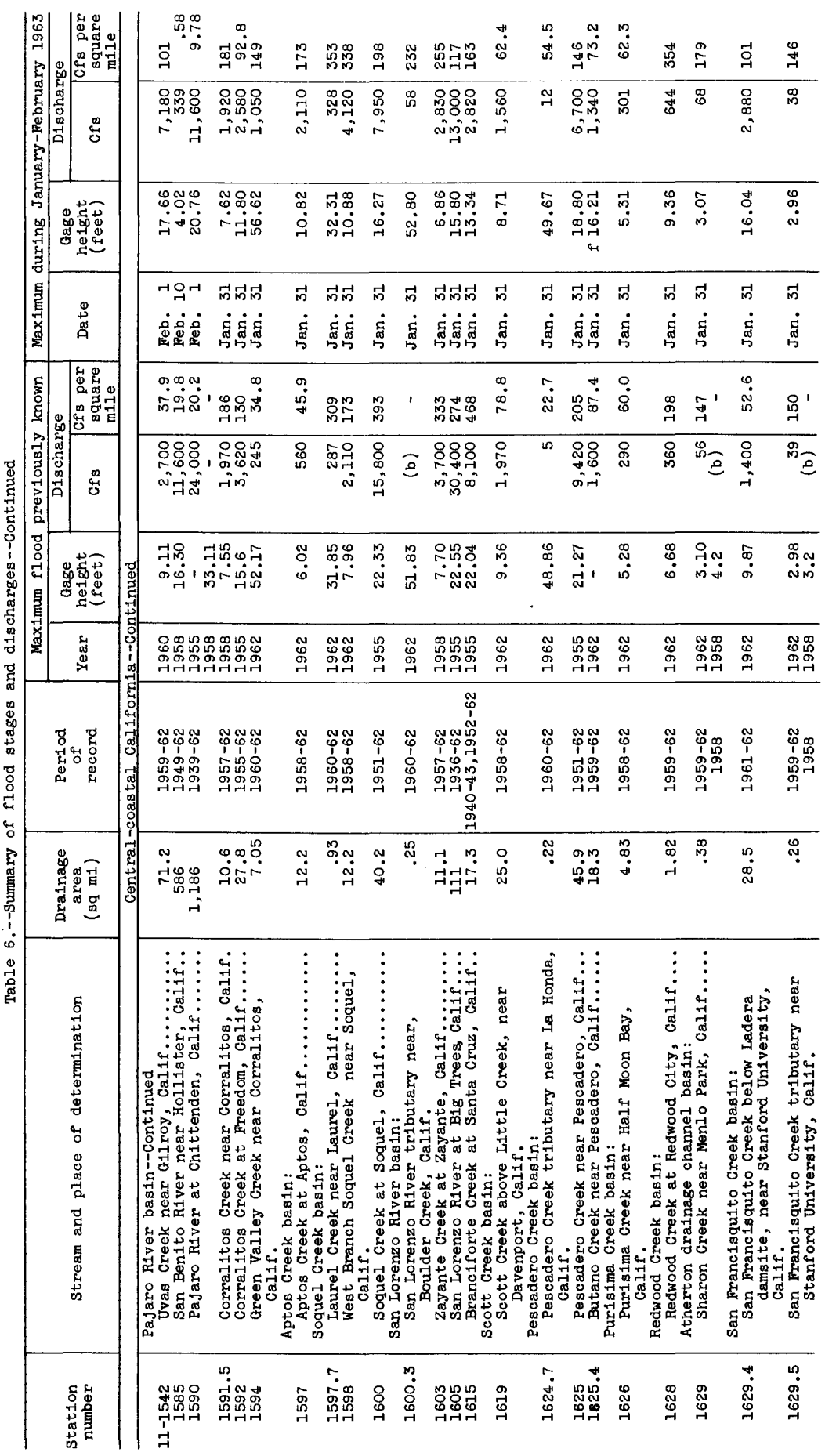




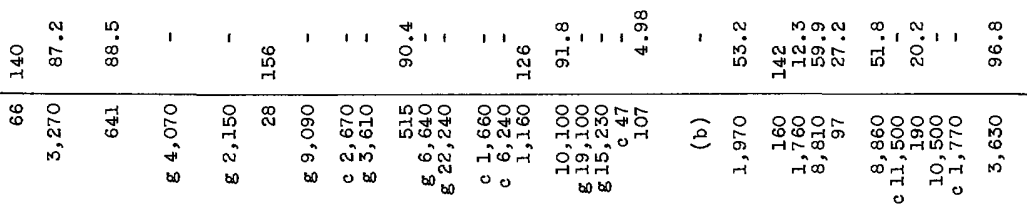

\&

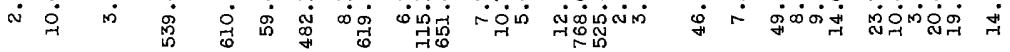

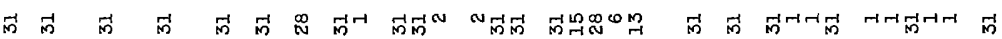

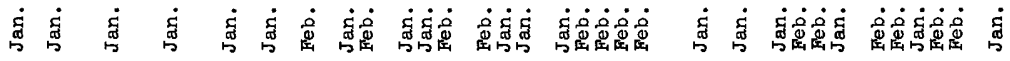

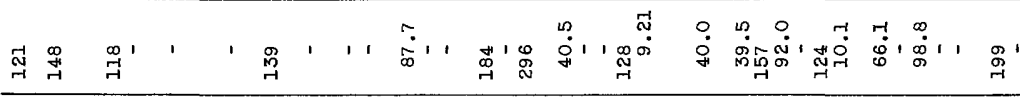

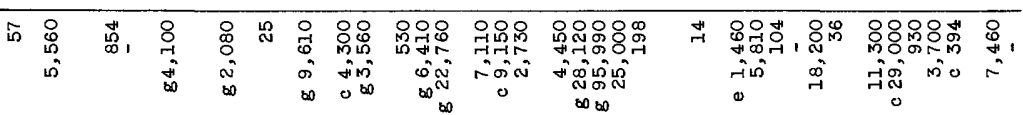

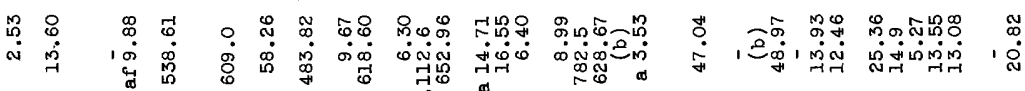

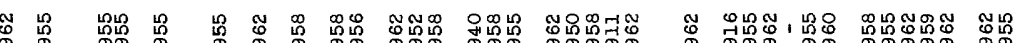

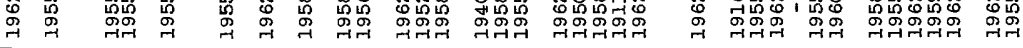

\begin{tabular}{|c|c|c|c|c|c|c|c|c|c|c|c|c|}
\hline 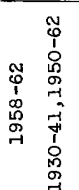 & 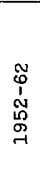 & 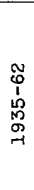 & $\begin{array}{ll}\tilde{o} & 0 \\
1 & 1 \\
0 & 1 \\
0 & 0 \\
0 & 0 \\
r-1 & 0\end{array}$ & 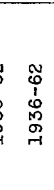 & 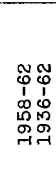 & 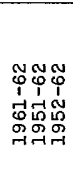 & 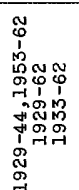 & 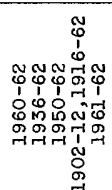 & 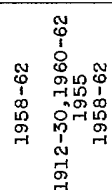 & 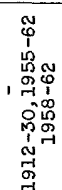 & 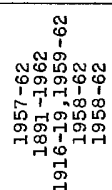 & $\begin{array}{l}0 \\
0 \\
0 \\
0 \\
0 \\
0 \\
0 \\
0 \\
0 \\
0 \\
0 \\
0 \\
0 \\
0\end{array}$ \\
\hline$\stackrel{4}{\dot{m}}$ & $\stackrel{\mathbb{N}}{\stackrel{\sim}{\sim}}$ & $m$ & $\underset{\sim}{\stackrel{\sim}{\sim}}$ & 量 & न & 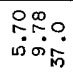 & 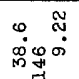 & 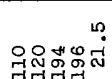 & $\stackrel{n}{?}: \stackrel{0}{\circ}$ & in & 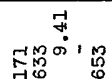 & \\
\hline
\end{tabular}

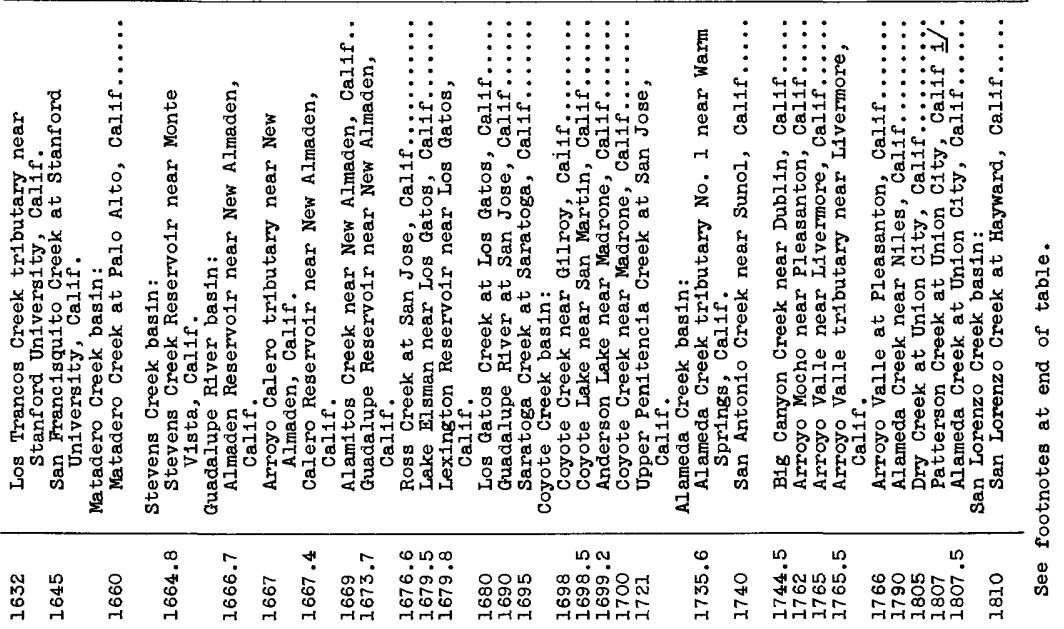




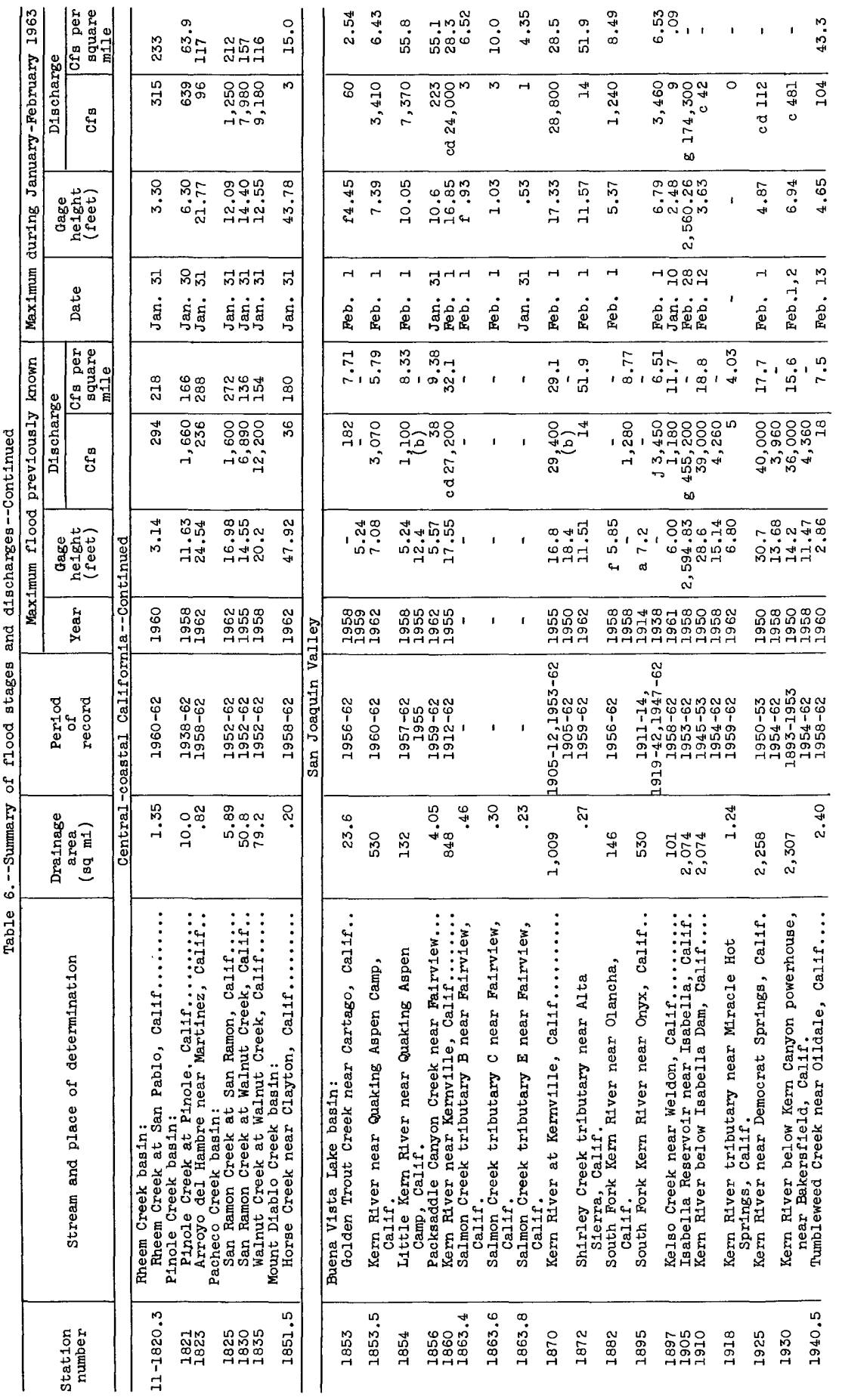




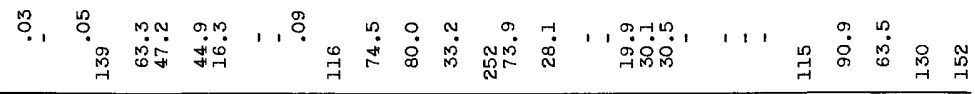

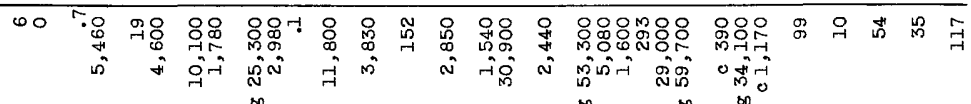

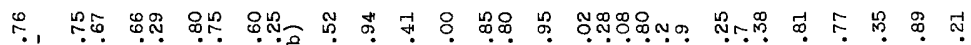

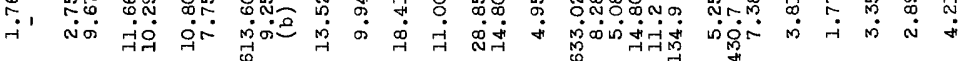

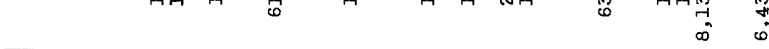

मु नન ન-

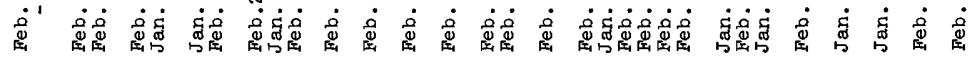

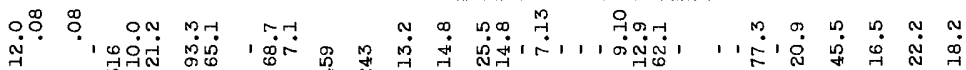

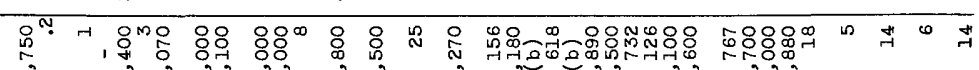

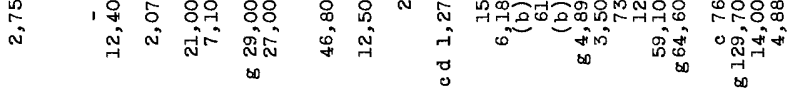

送

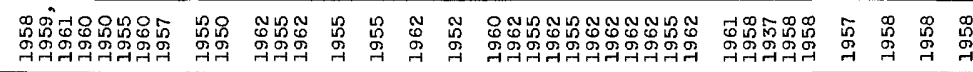

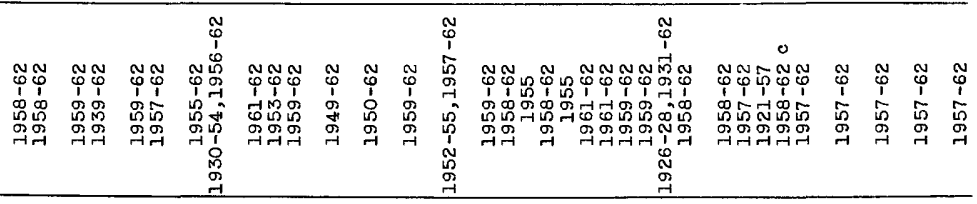

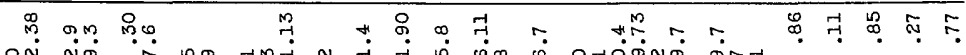

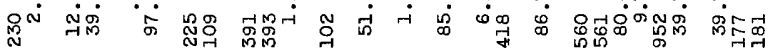

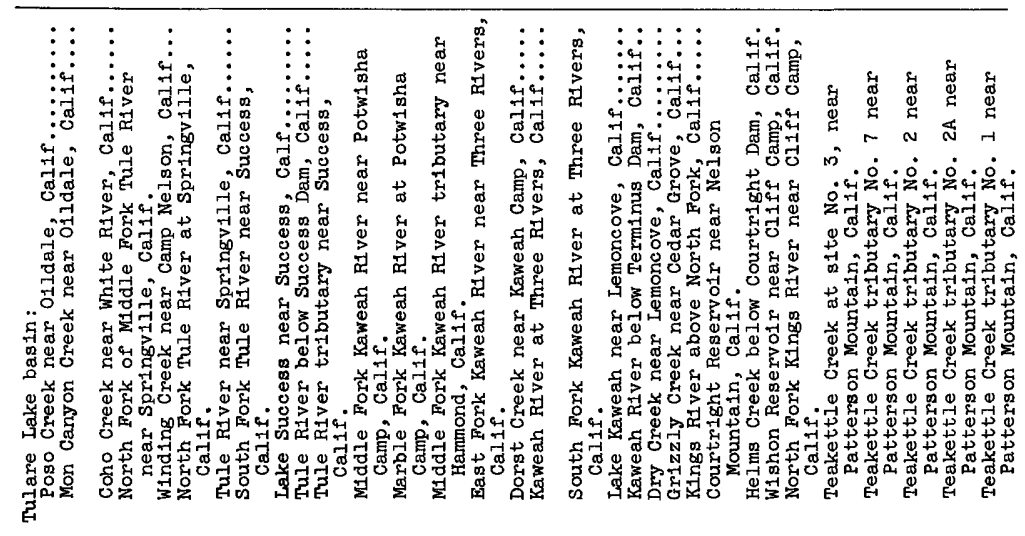

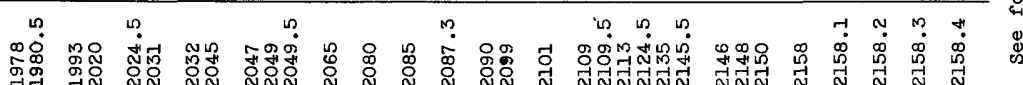




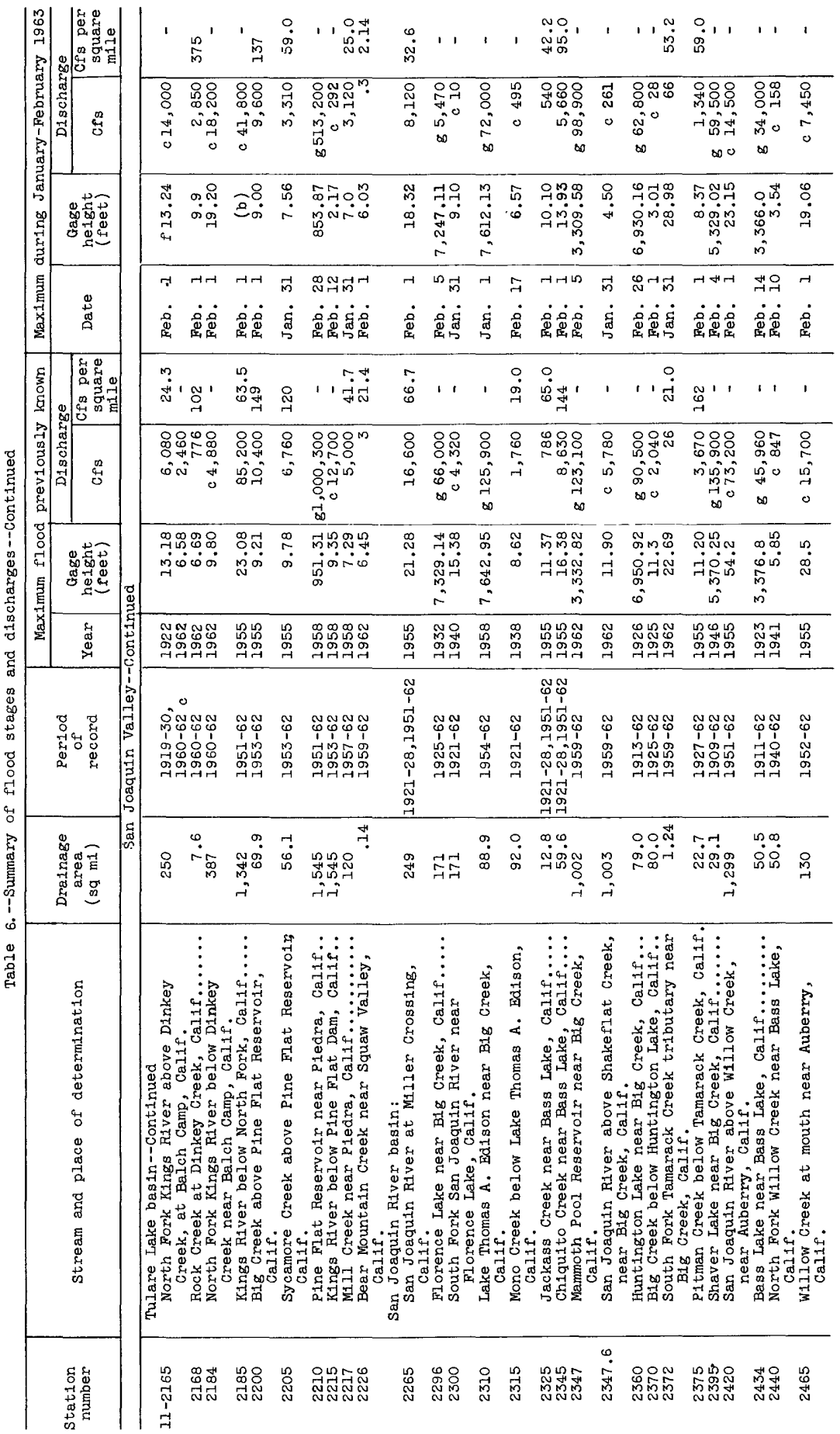




\begin{tabular}{|c|c|c|c|c|c|c|c|c|c|c|c|c|c|c|c|}
\hline 1 & $\begin{array}{l}0 \\
\dot{0}\end{array}$ & 11 & 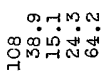 & 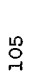 & $\underset{-}{\stackrel{-}{\prime \prime}}$ & 4 & 落 & 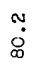 & 11 & 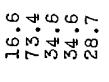 & $\stackrel{r}{\dot{H}}$ & $\stackrel{\infty}{\stackrel{\sigma}{\infty}}$ & $\begin{array}{l}\forall \dot{~} \\
\dot{m} \dot{\infty} \infty\end{array}$ & 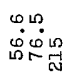 & ' $\left.{ }^{n}\right|^{n}$ \\
\hline $\begin{array}{l}8 \\
8 \\
m \\
0 \\
m\end{array}$ & $\underset{N}{\mathfrak{N}}$ & 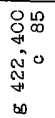 & 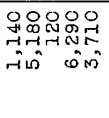 & $\begin{array}{l}\text { O } \\
\text { W } \\
\text { m }\end{array}$ & $\begin{array}{l}0 \\
\mathbb{N} \\
\text { N } \\
i-i\end{array}$ & $\begin{array}{l}\text { in } \\
\text { के } \\
\text { के }\end{array}$ & 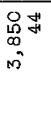 & $\begin{array}{l}\text { O } \\
\text { N } \\
\text { in }\end{array}$ & 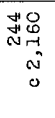 & 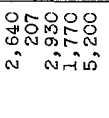 & $\begin{array}{l}8 \\
\text { O } \\
\text { in } \\
\sim\end{array}$ & $\begin{array}{l}\stackrel{\circ}{\circ} \\
\text { م } \\
\infty\end{array}$ & 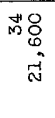 & 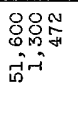 & 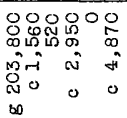 \\
\hline
\end{tabular}

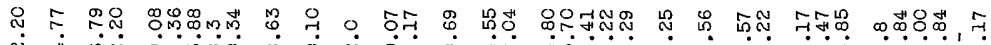
ले व

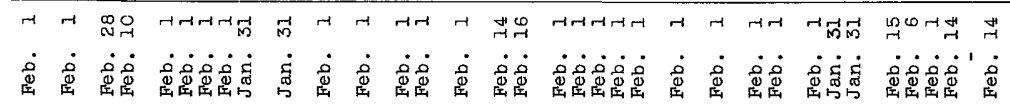

'

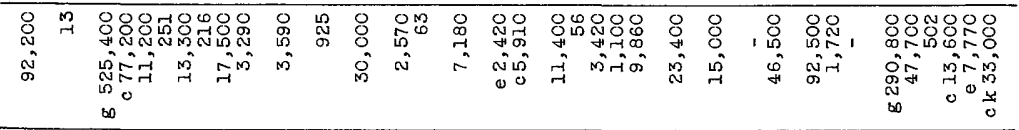

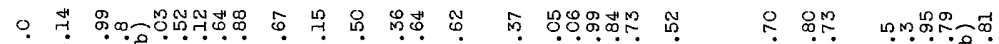

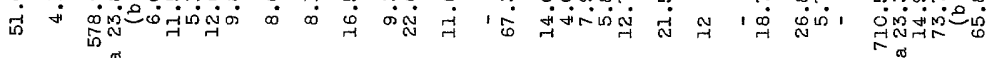

\begin{tabular}{|c|c|c|c|c|c|c|c|c|c|c|c|c|c|}
\hline 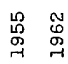 & 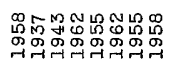 & $\begin{array}{l}\infty \\
\stackrel{\infty}{\infty} \\
\stackrel{\sim}{\sim}\end{array}$ & 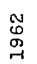 & 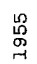 & 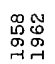 & 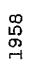 & 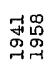 & 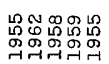 & 岇 & 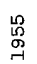 & ，总 & 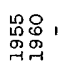 & 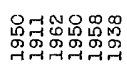 \\
\hline 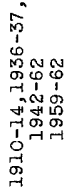 & 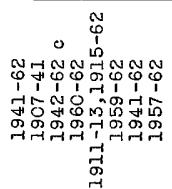 & $\begin{array}{l}0 \\
0 \\
1 \\
5 \\
5 \\
0 \\
\text { r. }\end{array}$ & 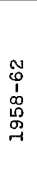 & 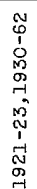 & 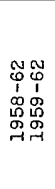 & $\begin{array}{l}0 \\
0 \\
1 \\
\infty \\
0 \\
0 \\
0 \\
\end{array}$ & 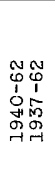 & 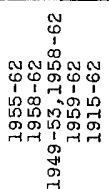 & $\begin{array}{l}N \\
0 \\
1 \\
0 \\
0 \\
-1 \\
0 \\
-1\end{array}$ & 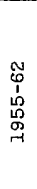 & 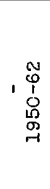 & 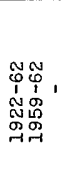 & 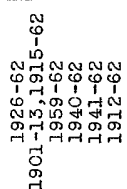 \\
\hline $\begin{array}{c}\overrightarrow{1} \\
\stackrel{\infty}{\sharp} \\
\overrightarrow{4}\end{array}$ & 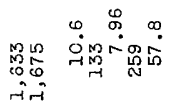 & $\stackrel{\varphi}{\dot{p}}$ & $\stackrel{m}{\sim}$ & $\stackrel{\text { }}{\stackrel{N}{N}}$ & 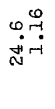 & $\infty_{\infty}^{\circ}$ & $\begin{array}{l}1 \text { O } \\
\text { O } \\
\text { की }\end{array}$ & 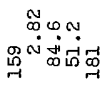 & $\underset{\mathrm{N}}{-1}$ & $\underset{-}{\stackrel{-}{-1}}$ & 号 & 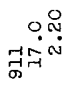 & 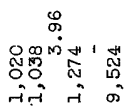 \\
\hline
\end{tabular}

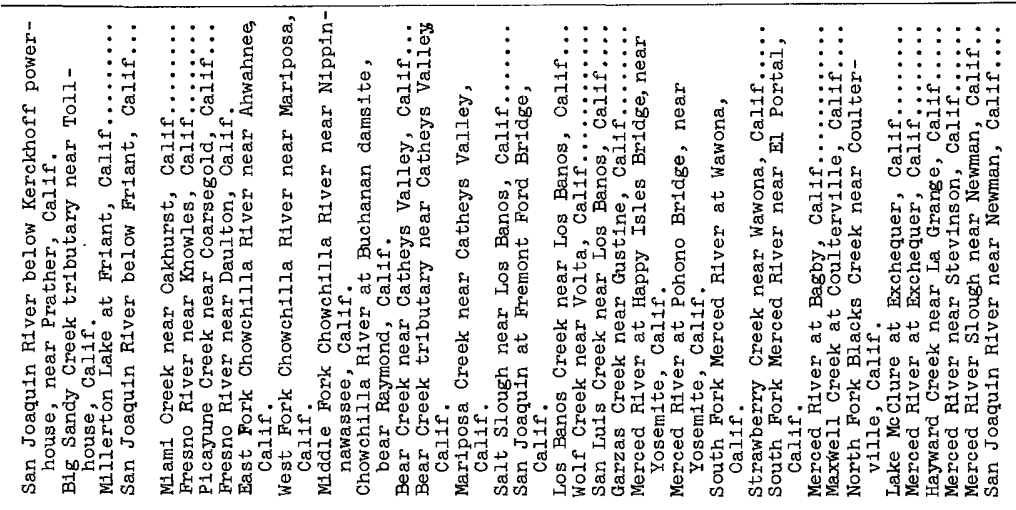

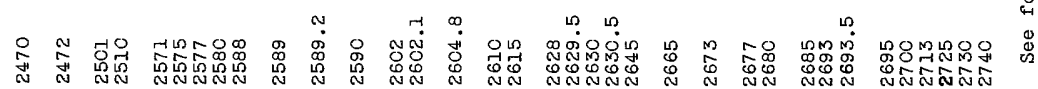




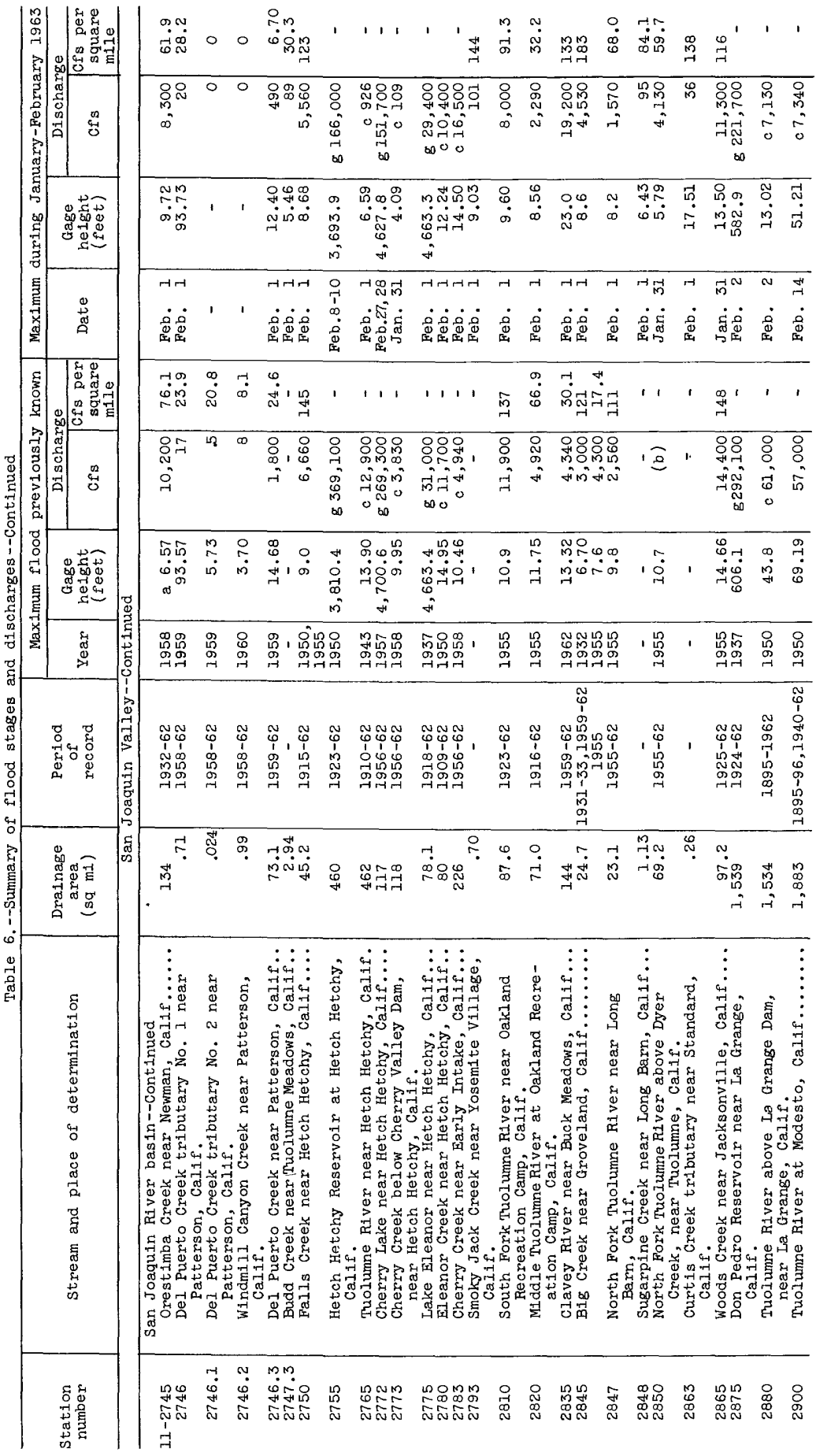




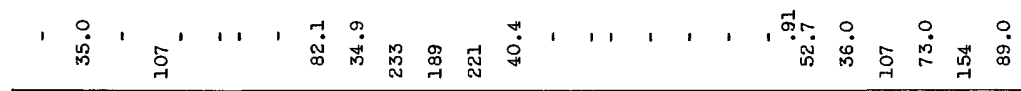

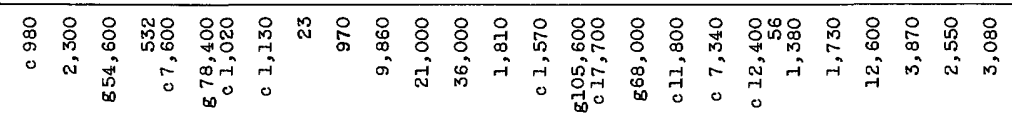
ஸึ

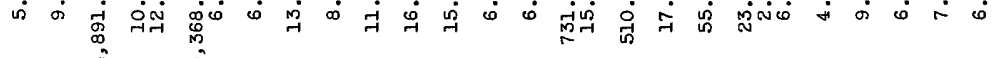

त

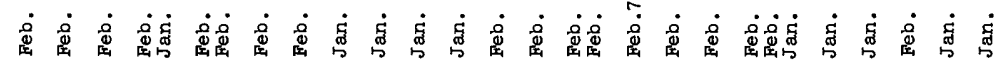

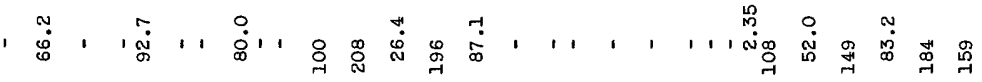

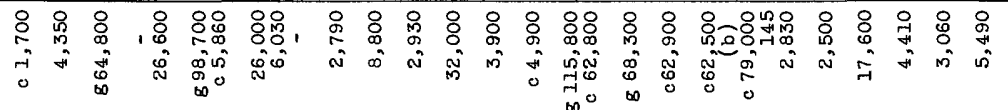

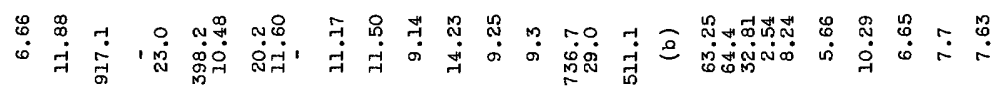

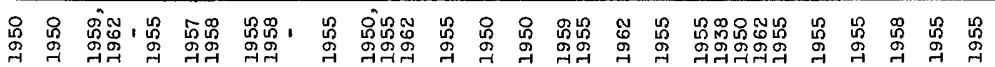
㵡

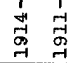

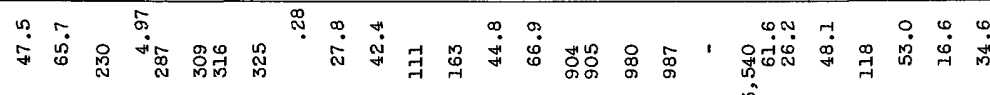

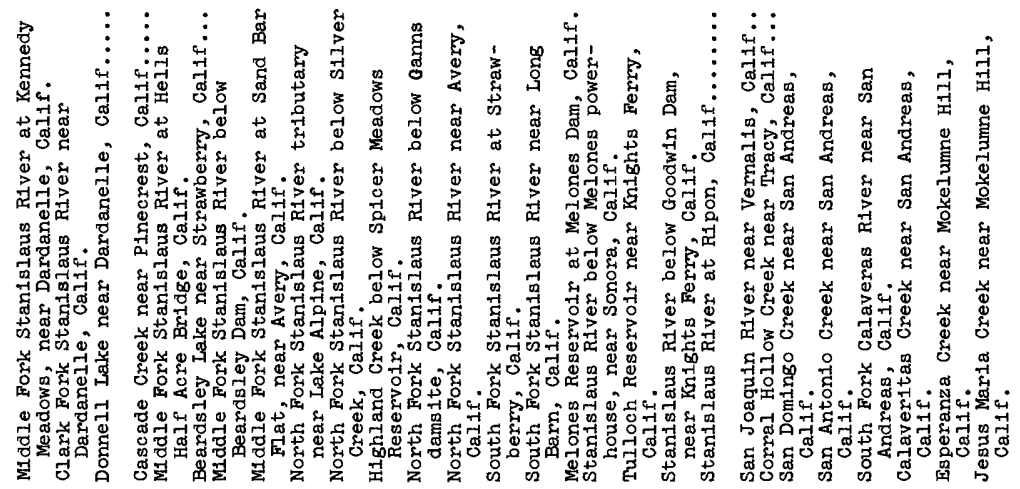

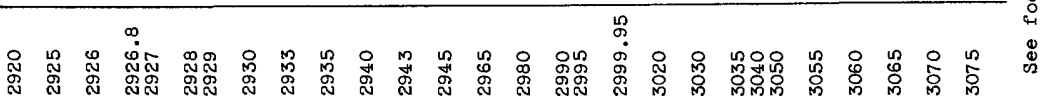




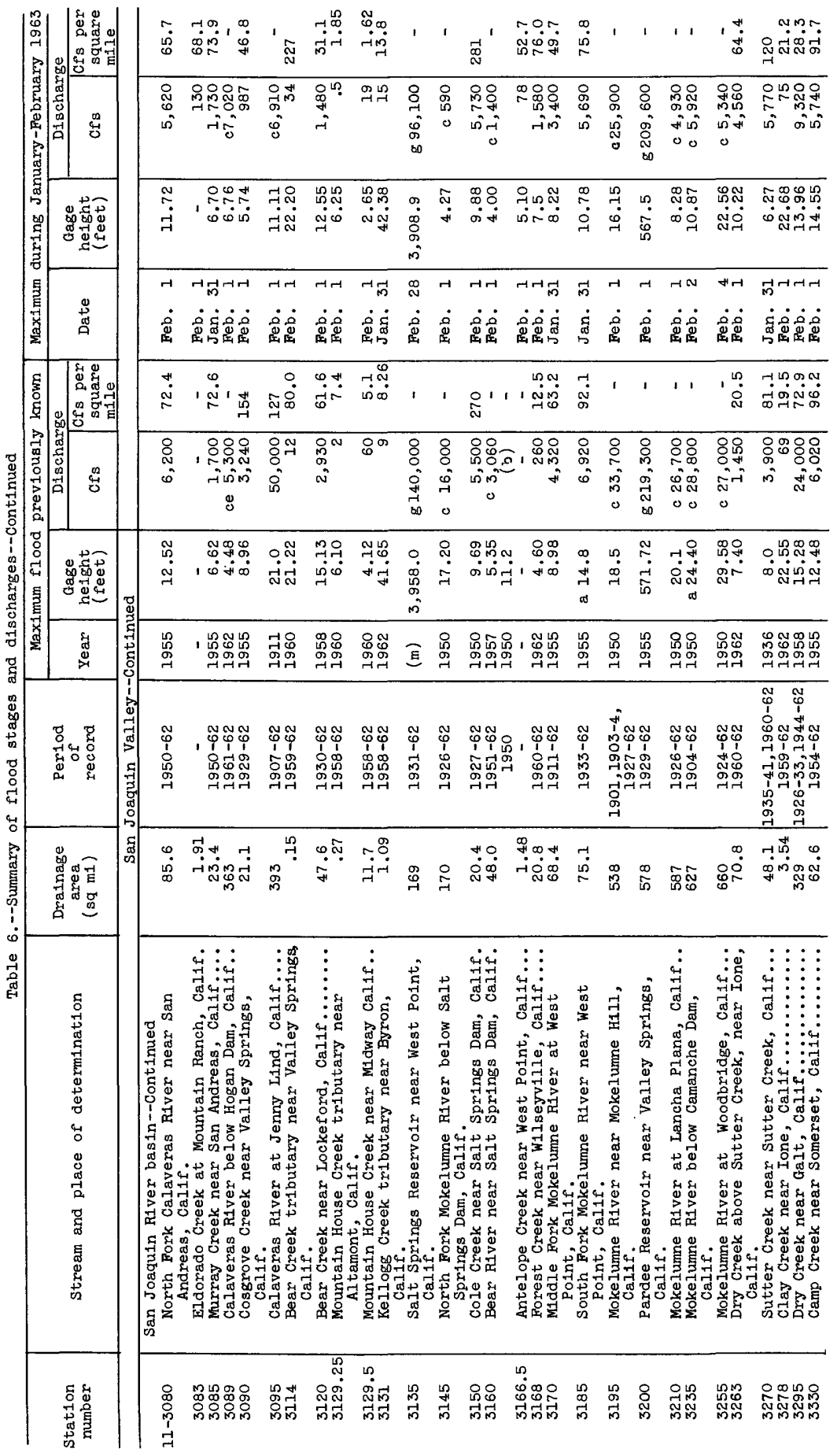


苜

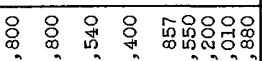
ते $\vec{r}$ के के min

นึ \# \&

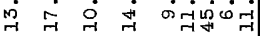

न

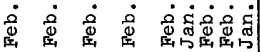

$\because \pi$ ก.

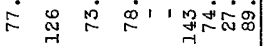
8 웅 은,

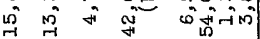

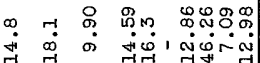

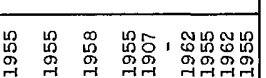
范

西

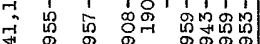

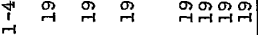
$\underset{r}{r-1}$

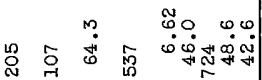

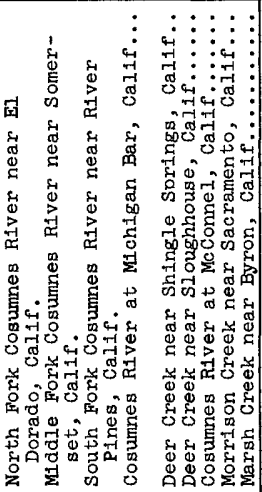

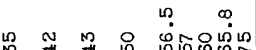

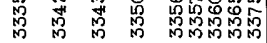

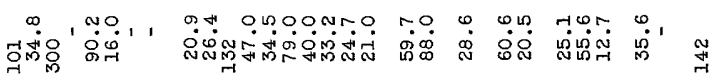

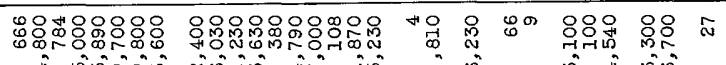

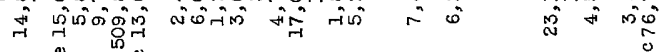
i in

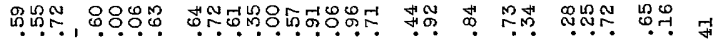
îंखि तi

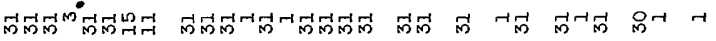

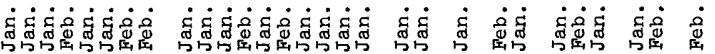

\begin{tabular}{|c|c|c|c|c|c|c|}
\hline 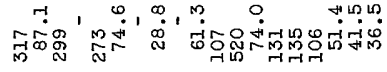 & 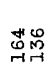 & 1 & $\begin{array}{l}\infty \\
\dot{n} \\
\operatorname{in} \\
\end{array}$ & ஸீட் & 常 & $\underset{\sim}{\stackrel{\infty}{N}}$ \\
\hline 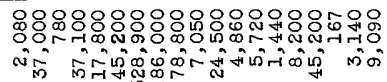 & 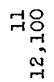 & I & $3 \widetilde{N}$ & 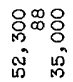 & $\begin{array}{l}88 \\
08 \\
0 .-1 \\
01-1\end{array}$ & 管 \\
\hline
\end{tabular}
iो

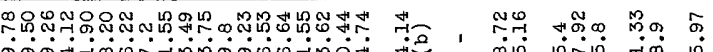

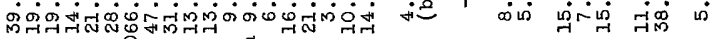
4

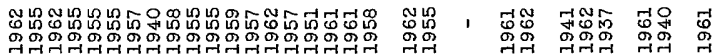

올.

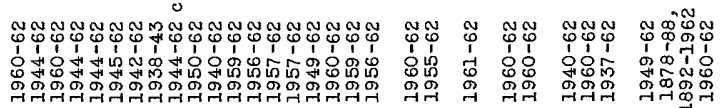

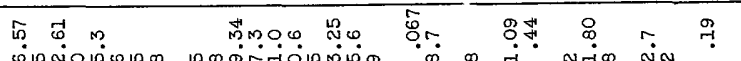

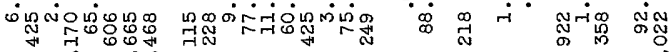

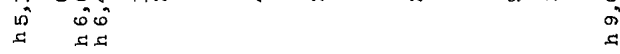

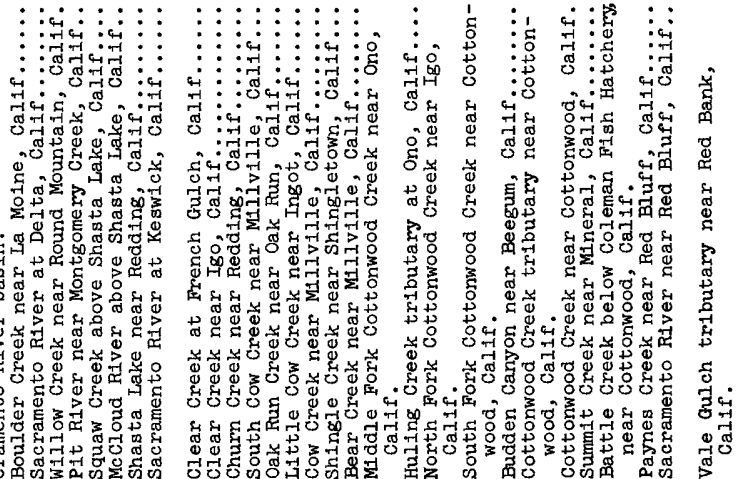
嵒 นด นด

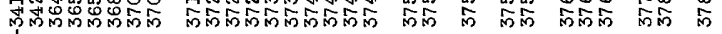
$\Rightarrow$ 


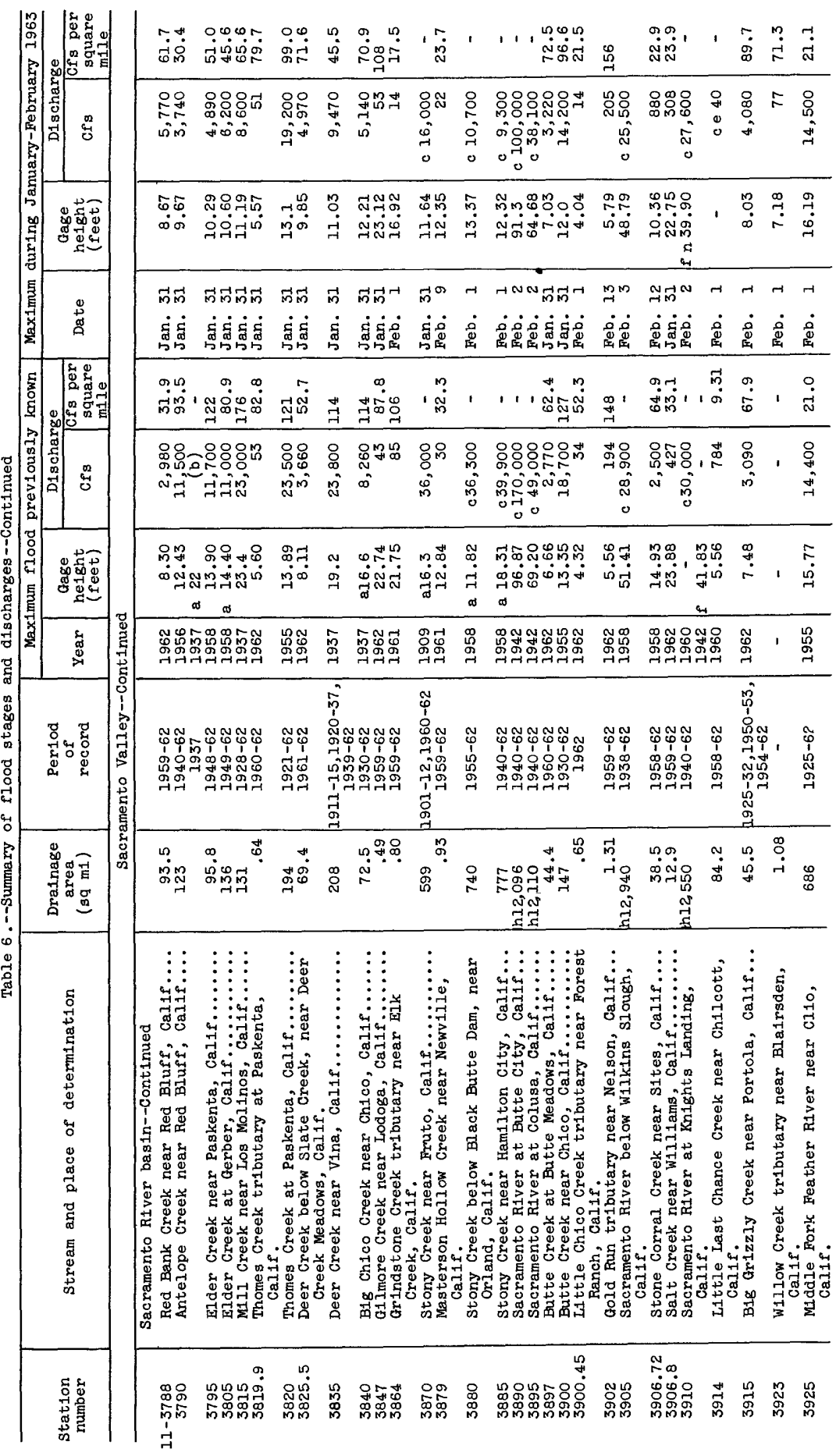




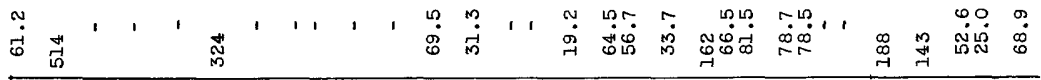

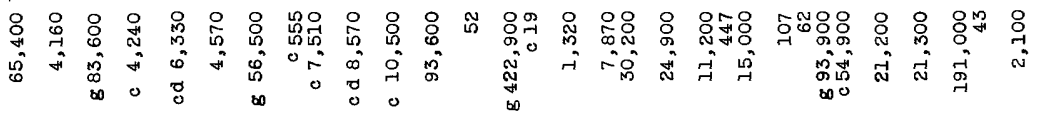
ำ

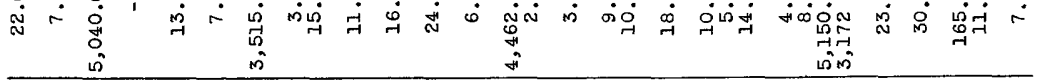

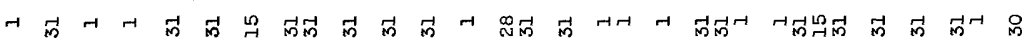

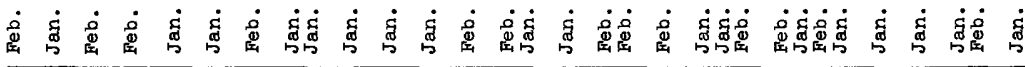

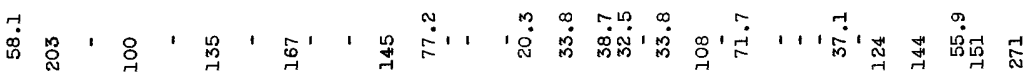

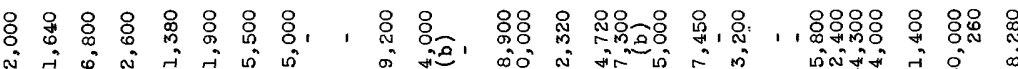

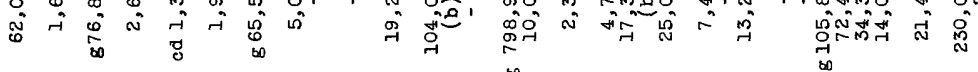

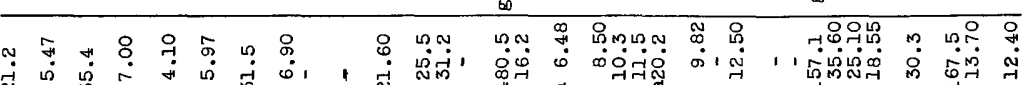

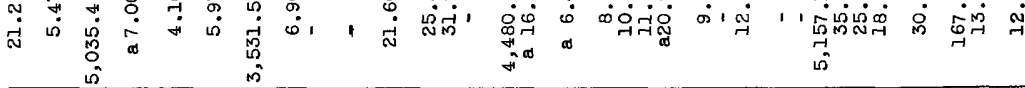

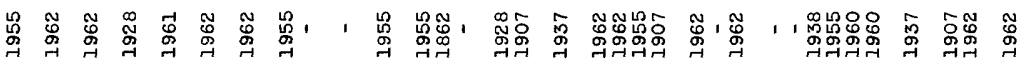

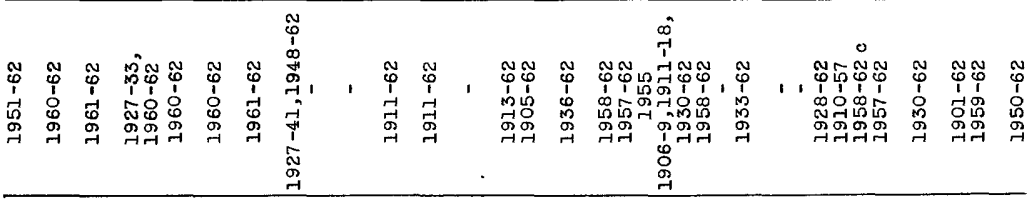

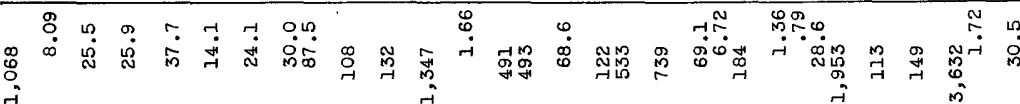

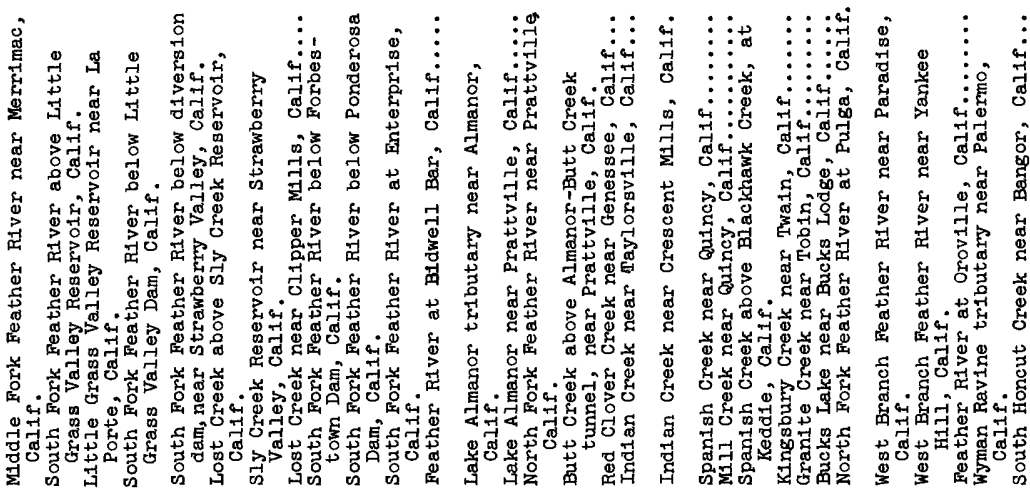

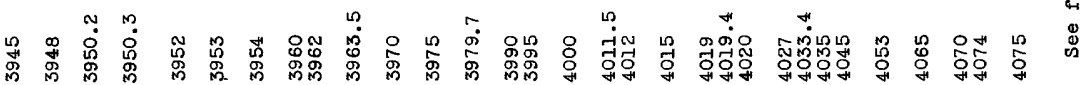




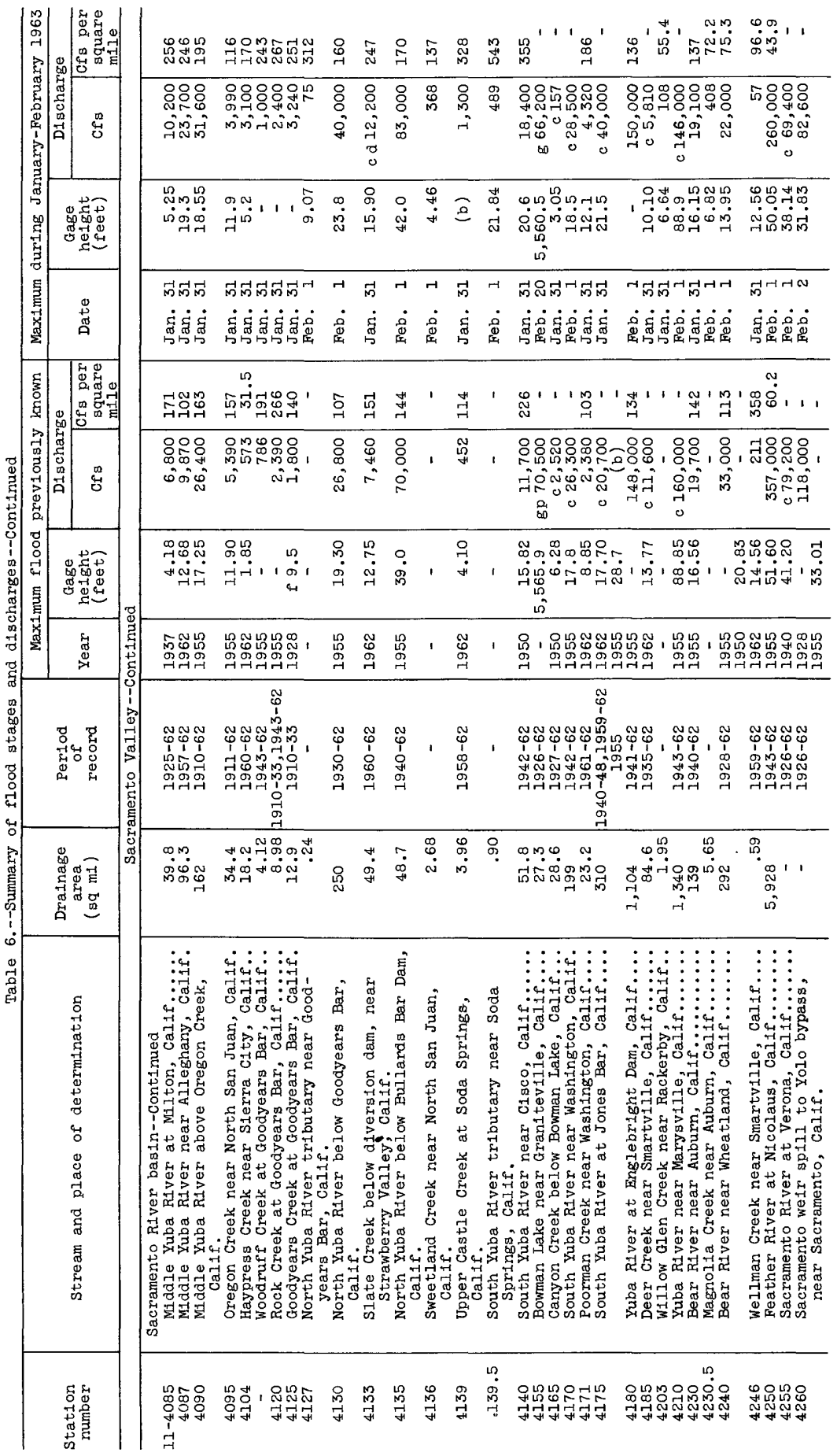




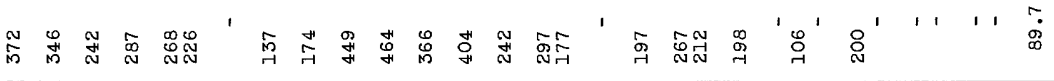

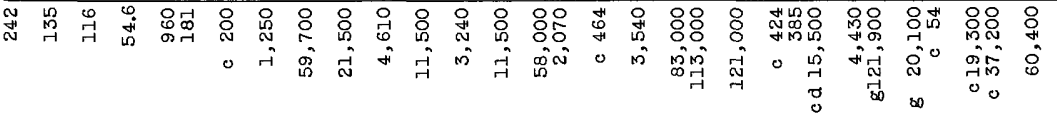

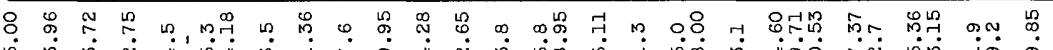

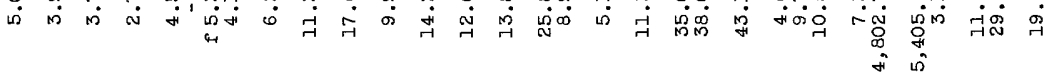

न मी की

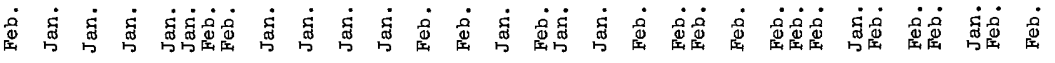

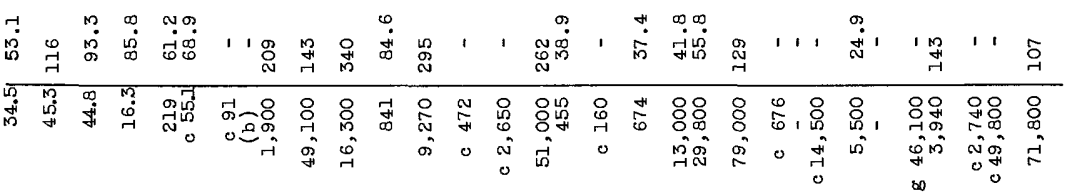

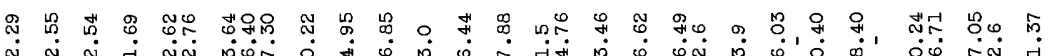

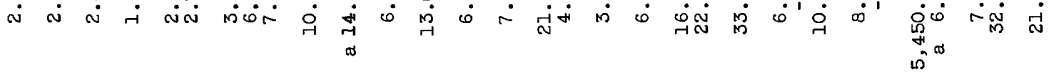

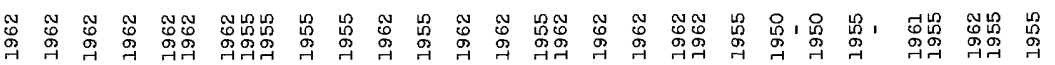

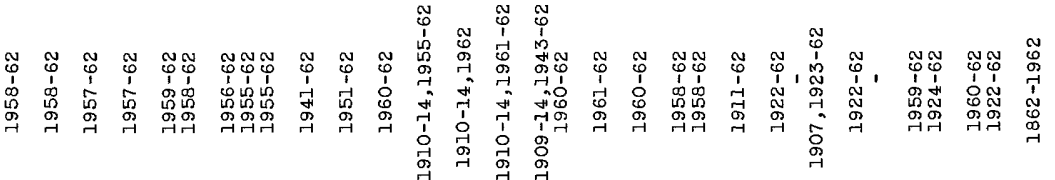

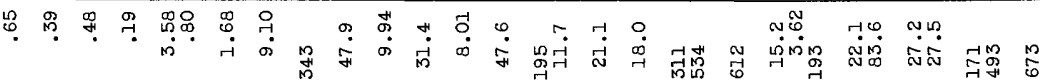

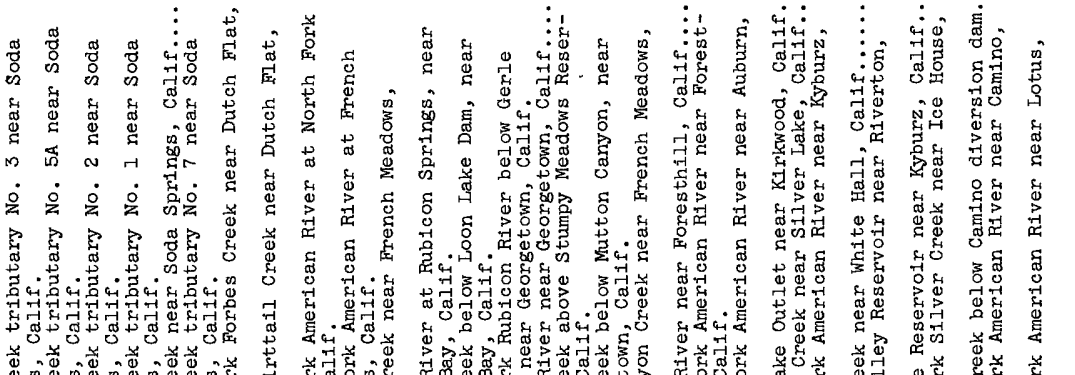

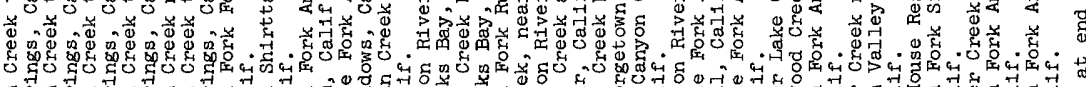

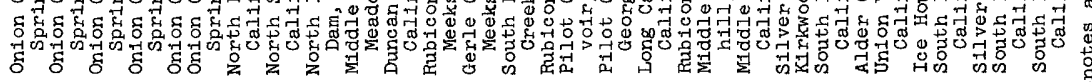




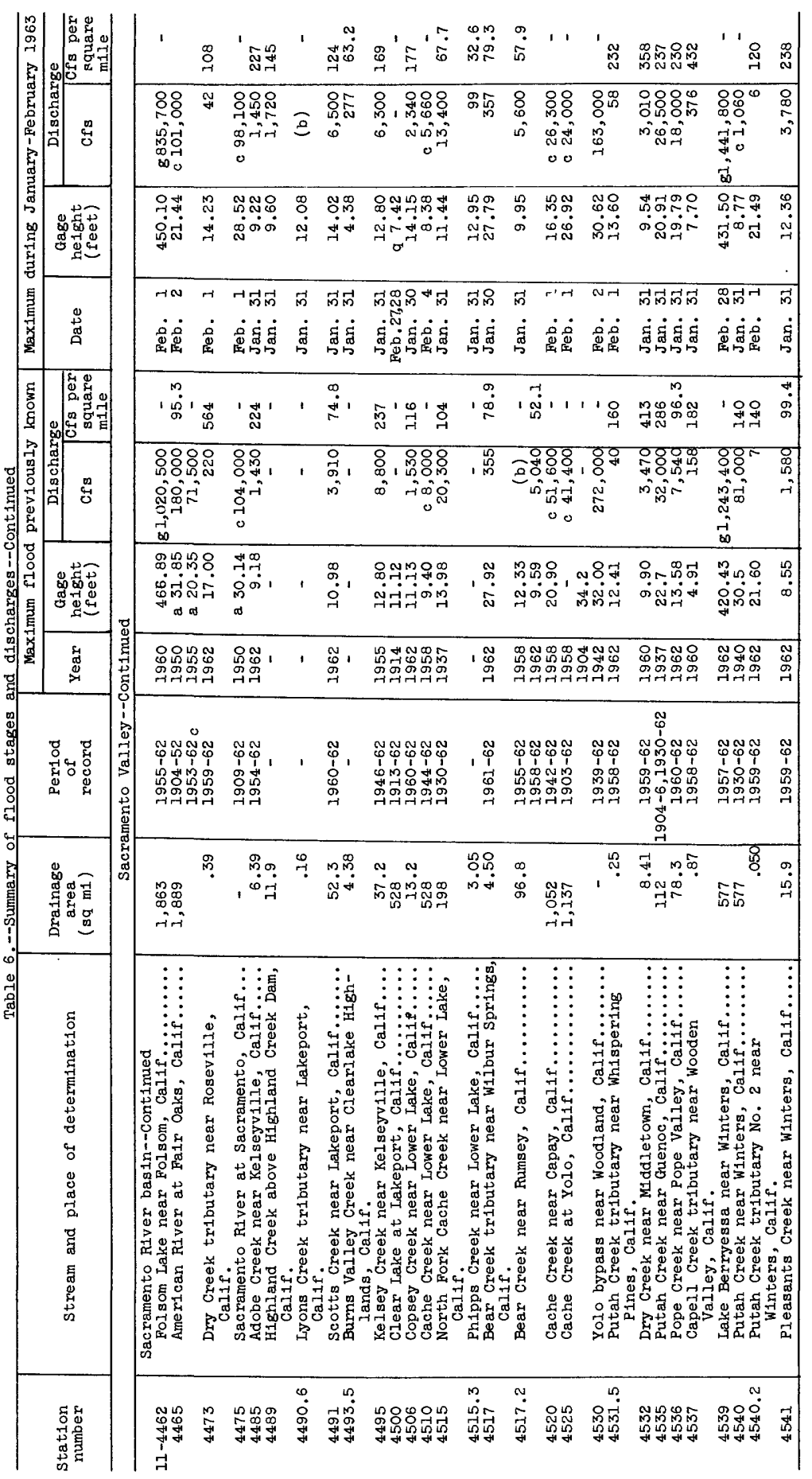




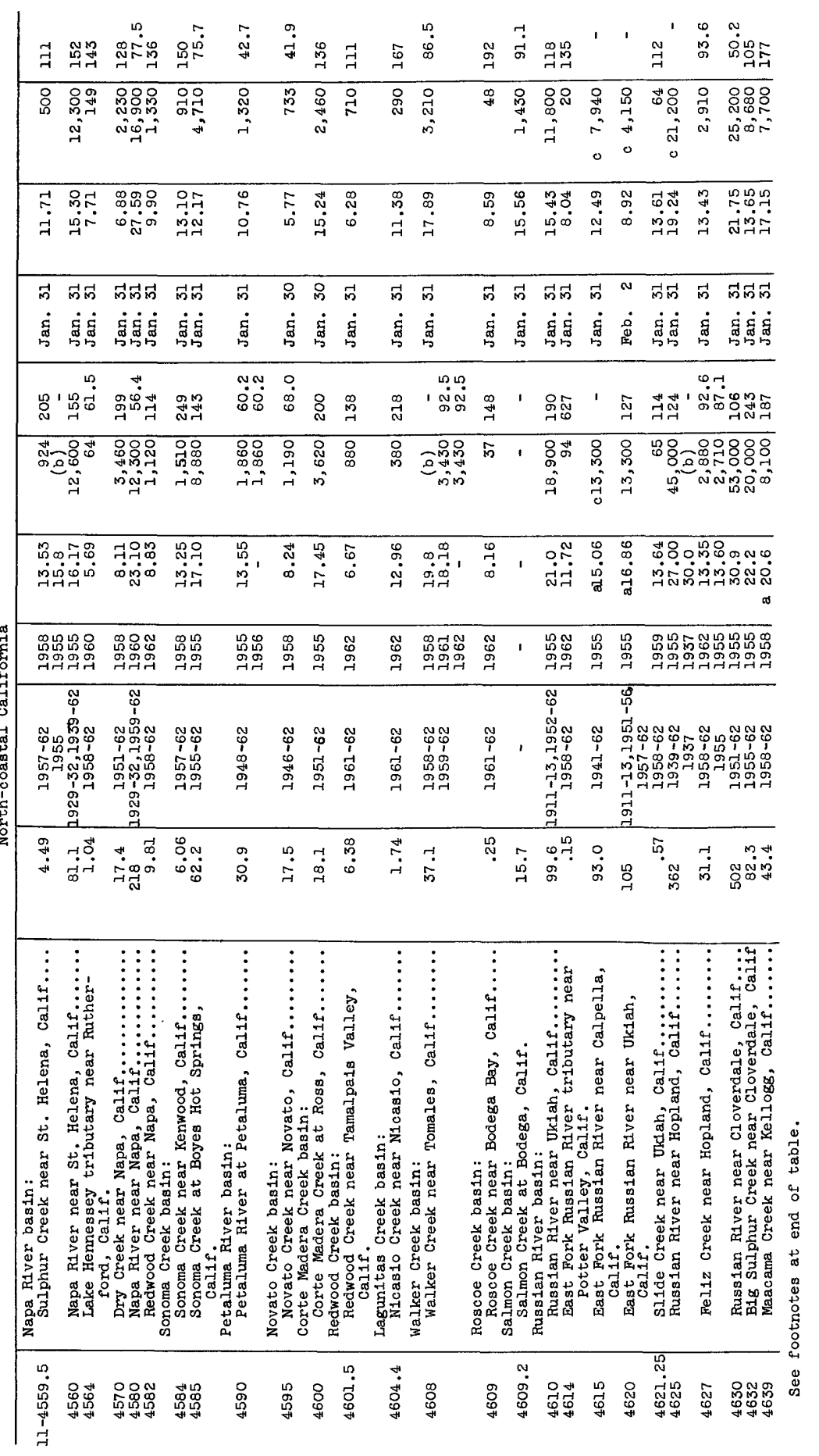




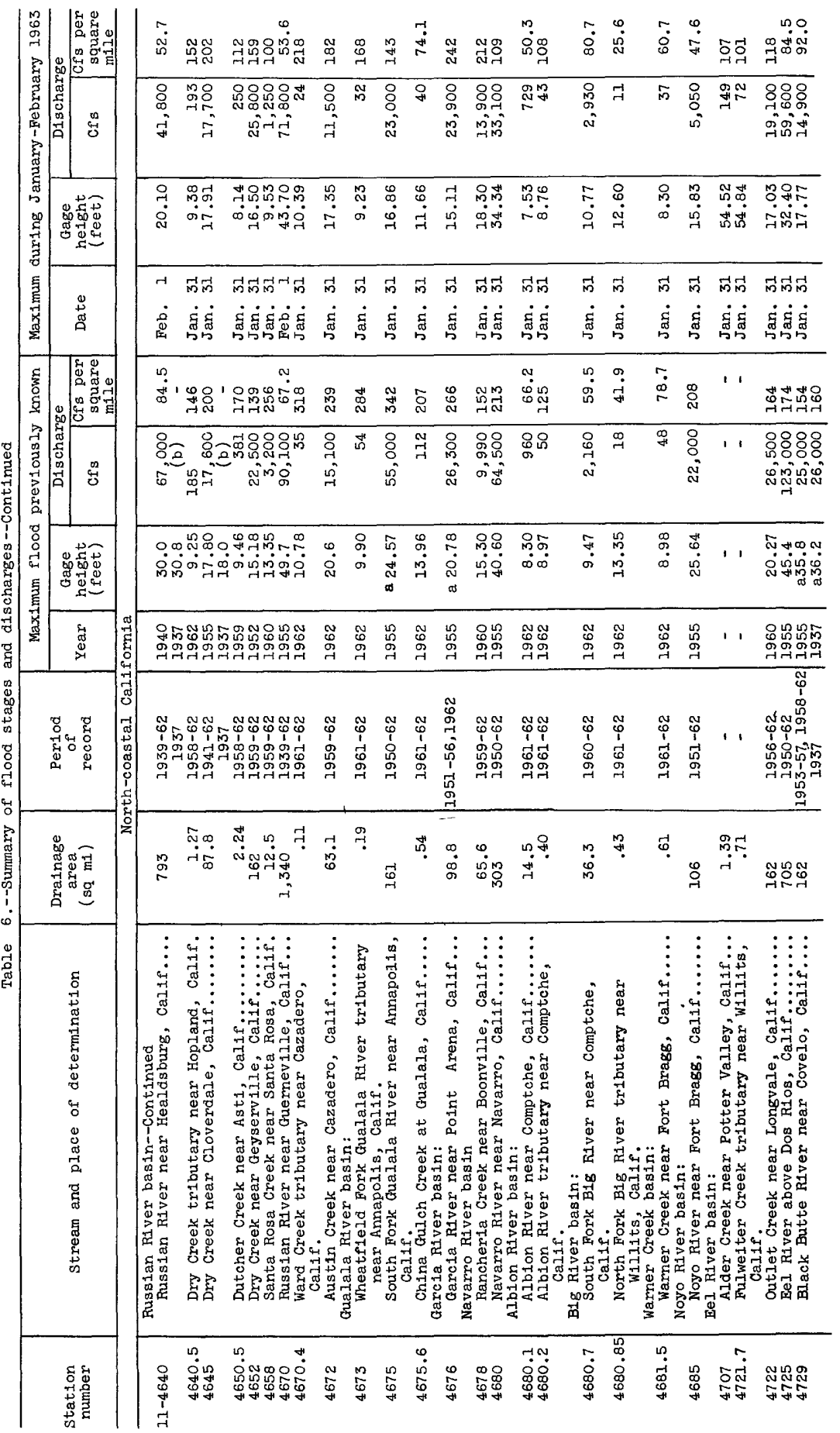




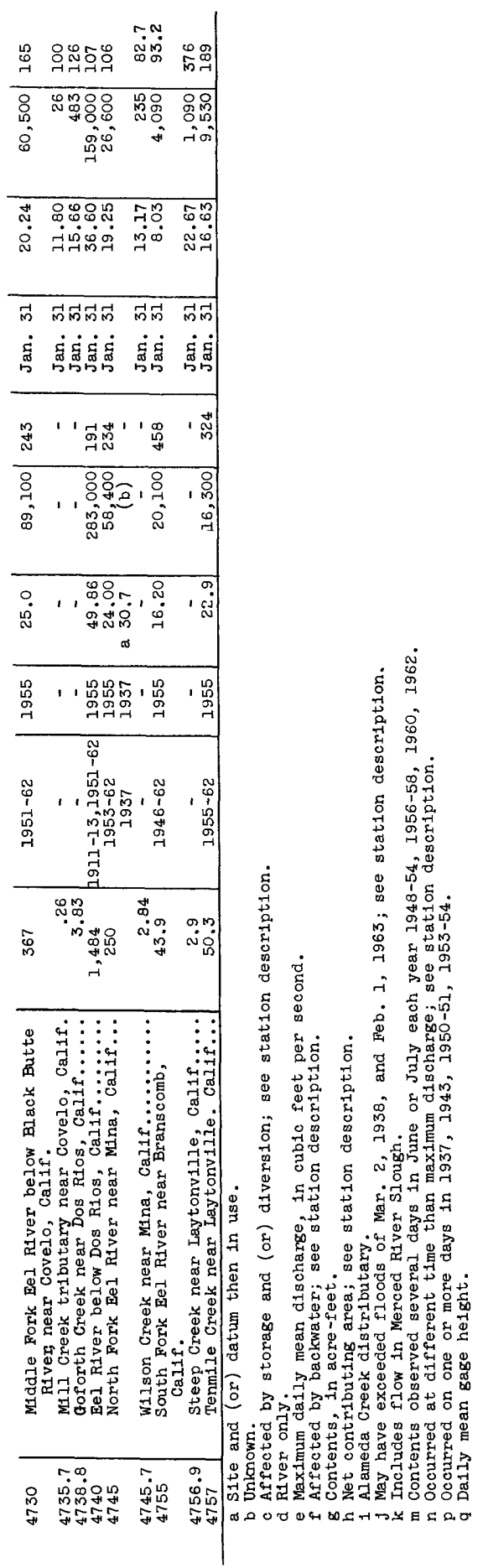




\section{STATION DATA}

THE GREAT BASIN

OWENS LAKE BASIN

10-2652. Convict Creek near Mammoth Lakes, Calif.

Location. --Lat $37^{\circ} 36^{\prime} 30^{\prime \prime}$, long $118^{\circ} 50^{\prime} 55^{\prime \prime}$, In NE $\frac{1}{4}$ sec.14, T.4 S., R.28 E., on right bank 1.1 miles downstream from Convict Lake, 2.0 miles upstream from U.S. Highway 395 , and 7.0 miles southeast of Mammoth Lakes (ranger station).

Drainage area. $--18.7 \mathrm{sq} \mathrm{mt}$.

Gage-helght record; --Water-stage recorder graph. Alt1tude of gage is $7,450 \mathrm{ft}$ (from topographic map).

Discharge record. --Stage-discharge relation defined by current-meter measurements.

Maxima.--January-February 1963: Discharge, 37 cfs 1600 hours Feb. 1 (gage helght, $1.66 \mathrm{ft})$

1925 to December 1962: Discharge, $290 \mathrm{cfs} J u n e$ 29, 1932 (gage height,

$4.43 \mathrm{ft}$ ).

Remarks.--Some regulation by Convict Lake above station. Records furnished by c1ty of Los Angeles, Department of Water and Power.

Mean discharge, in cublc feet per second, 1963

\begin{tabular}{|c|c|c|c|c|c|c|c|c|}
\hline Day & January & February & Day & January & February & Day & January & February \\
\hline $\begin{array}{c}1 \ldots \ldots \\
2 \ldots \ldots \\
3 \ldots \ldots \\
4 \ldots \ldots \\
6 \ldots \ldots \\
7 \ldots \ldots \\
9 \ldots \ldots \\
10 \ldots \ldots\end{array}$ & $\begin{array}{l}8.5 \\
8.5 \\
8.5 \\
8.5 \\
3.5 \\
8.5 \\
8.5 \\
8.5 \\
8.5 \\
\text { S.9 }\end{array}$ & $\begin{array}{l}33 \\
26 \\
23 \\
22 \\
21 \\
20 \\
20 \\
20 \\
19 \\
19\end{array}$ & $\begin{array}{l}11 \ldots \ldots \\
12 \ldots \ldots \\
13 \ldots \ldots \\
14 \ldots \ldots \\
15 \ldots \ldots \\
16 \ldots \ldots \\
17 \ldots \ldots \\
18 \ldots \ldots \\
19 \ldots \ldots \\
20 \ldots \ldots\end{array}$ & $\begin{array}{l}8.1 \\
5.1 \\
8.1 \\
8.1 \\
8.1 \\
8.1 \\
8.1 \\
7.7 \\
7.7 \\
7.3\end{array}$ & $\begin{array}{l}18 \\
17 \\
15 \\
15 \\
14 \\
14 \\
13 \\
13 \\
12 \\
12\end{array}$ & $\begin{array}{l}21 \ldots \ldots \\
22 \ldots \ldots \\
23 \ldots \ldots \\
24 \ldots \ldots \\
25 \ldots \ldots \\
26 \ldots \ldots \\
27 \ldots \ldots \\
28 \ldots \ldots \\
29 \ldots \ldots \\
30 \ldots \ldots \\
31 \ldots \ldots\end{array}$ & $\begin{array}{l}7.3 \\
7.3 \\
7.3 \\
7.3 \\
7.3 \\
7.3 \\
6.9 \\
6.9 \\
6.9 \\
12 \\
26\end{array}$ & $\begin{array}{c}11 \\
11 \\
11 \\
11 \\
10 \\
9.8 \\
9.8 \\
9.5 \\
\ldots--. \\
0-0 .\end{array}$ \\
\hline \multicolumn{7}{|l|}{$\begin{array}{l}\text { Monthly } \\
\text { Runoff, } \\
\text { Runoff, }\end{array}$} & $\begin{array}{r}8.62 \\
0.53 \\
530 \\
\end{array}$ & $\begin{array}{r}16.0 \\
0.89 \\
591 \\
\end{array}$ \\
\hline
\end{tabular}

Gage he1ght, in feet, and discharge, in cublc feet per second, at ind1cated t1me, 1963

\begin{tabular}{|c|c|c|c|c|c|c|c|c|c|c|c|}
\hline Date & Hour & $\begin{array}{c}\text { Cage } \\
\text { helght }\end{array}$ & $\begin{array}{l}\text { Dis- } \\
\text { charge }\end{array}$ & Date & Hour & $\begin{array}{c}\text { Gage } \\
\text { helght }\end{array}$ & $\begin{array}{c}\text { Dis- } \\
\text { charge }\end{array}$ & Date & Hour & $\begin{array}{c}\text { Gage } \\
\text { height }\end{array}$ & $\begin{array}{l}\text { D18- } \\
\text { charge }\end{array}$ \\
\hline $\begin{array}{r}\text { Jan. } \\
30\end{array}$ & $\begin{array}{l}2400 \\
0800 \\
1200 \\
1600 \\
2200 \\
2400\end{array}$ & $\begin{array}{l}1.14 \\
1.20 \\
1.24 \\
1.30 \\
1.35 \\
1.37\end{array}$ & $\begin{array}{l}6.9 \\
9.2 \\
11 \\
14 \\
16 \\
17\end{array}$ & Jan. 31 & $\begin{array}{l}0700 \\
1200 \\
1600 \\
2000 \\
2400\end{array}$ & $\begin{array}{l}1.40 \\
1.57 \\
1.59 \\
1.63 \\
1.63\end{array}$ & $\begin{array}{l}18 \\
29 \\
31 \\
34 \\
34\end{array}$ & Feb. 1 & $\begin{array}{l}1000 \\
1600 \\
1800 \\
2000 \\
2200 \\
2400\end{array}$ & $\begin{array}{l}1.65 \\
1.66 \\
1.47 \\
1.62 \\
1.56 \\
1.56\end{array}$ & $\begin{array}{l}36 \\
37 \\
22 \\
34 \\
28 \\
28\end{array}$ \\
\hline
\end{tabular}

10-2657. Rock Creek at Little Round Valley, near B1shop, Calif.

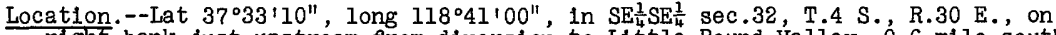
right bank just upstream from diversion to Little Round Valley, 0.6 mile south of Toms Place, and 20 miles northwest of B1 shop, Mono County.

Drainage area. $--35.8 \mathrm{sq} \mathrm{ml}$.

Gage-helght record.--Water-stage recorder graph. Alt1tude of gage 1s 7,450 ft

(from topographic map).

Discharge record.--D1scharge by computation of flow through 6-foot Parshall flume.

Maxima.--January-February 1963: Discharge, 42 cfs 1200 hours Feb. 1 (gage helght, $1.43 \mathrm{ft})$

1926 to December 1962: Discharge, 270 cfs July 26, 1952 (gage helght,

$2.93 \mathrm{ft}$, datum then in use).

Remarks.--Records furnished by clty of Los Angeles, Department of Water and Power. 
Mean discharge, in cublc feet per second, 1963, of Rock Creek at Little Round Valley, near Blshoo. Calif.

\begin{tabular}{|c|c|c|c|c|c|c|c|c|}
\hline Day & January & February & Day & January & February & Day & January & February \\
\hline $\begin{array}{c}1 \ldots \ldots \\
2 \ldots \ldots \\
3 \ldots \ldots \\
4 \ldots \ldots \\
5 \ldots \ldots \\
7 \ldots \ldots \\
8 \ldots \ldots \\
9 \ldots \ldots \\
10 \ldots \ldots\end{array}$ & $\begin{array}{c}11 \\
9.0 \\
8.2 \\
8.2 \\
8.7 \\
8.7 \\
7.9 \\
7.9 \\
7.9 \\
8.2\end{array}$ & $\begin{array}{l}37 \\
23 \\
18 \\
17 \\
15 \\
15 \\
14 \\
14 \\
14 \\
14\end{array}$ & $\begin{array}{l}11 \ldots \ldots \\
12 \ldots \ldots \\
13 \ldots \ldots \\
14 \ldots \ldots \\
15 \ldots \ldots \\
16 \ldots \ldots \\
17 \ldots \ldots \\
18 \ldots \ldots \\
19 \ldots \ldots \\
20 . \ldots \ldots\end{array}$ & $\begin{array}{r}7.7 \\
7.2 \\
7.2 \\
7.2 \\
7.2 \\
7.2 \\
7.7 \\
7.4 \\
11 \\
7.4\end{array}$ & $\begin{array}{l}14 \\
14 \\
13 \\
13 \\
13 \\
12 \\
12 \\
12 \\
12 \\
11\end{array}$ & $\begin{array}{l}21 \ldots \ldots \\
22 \ldots \ldots \\
23 \ldots \ldots \\
24 \ldots \ldots \\
25 \ldots \ldots \\
26 \ldots \ldots \\
27 \ldots \ldots \\
28 \ldots \ldots \\
29 \ldots \ldots \\
30 \ldots \ldots \\
31 \ldots \ldots\end{array}$ & $\begin{array}{l}7.0 \\
6.5 \\
6.2 \\
6.2 \\
6.5 \\
7.0 \\
7.2 \\
7.0 \\
6.5 \\
8.0 \\
19\end{array}$ & $\begin{array}{r}11 \\
11 \\
11 \\
11 \\
11 \\
11 \\
11 \\
10 \\
-\ldots-\end{array}$ \\
\hline $\begin{array}{l}\text { onthly } \\
\text { unoff, } \\
\text { unoff, }\end{array}$ & \multicolumn{6}{|c|}{ 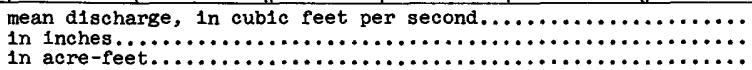 } & $\begin{array}{r}8.06 \\
0.26 \\
496\end{array}$ & $\begin{array}{r}14.1 \\
0.41 \\
781\end{array}$ \\
\hline
\end{tabular}

Gage height, in feet, and discharge, in cublc feet per second, at 1ndicated time, 1963

\begin{tabular}{|c|c|c|c|c|c|c|c|c|c|c|c|}
\hline Date & Hour & $\begin{array}{c}\text { Gage } \\
\text { he1ght }\end{array}$ & $\begin{array}{l}\text { D1s- } \\
\text { charge }\end{array}$ & Date & Hour & $\begin{array}{c}\text { Gage } \\
\text { helght }\end{array}$ & $\begin{array}{c}\text { Dis- } \\
\text { charge }\end{array}$ & Date & Hour & $\begin{array}{c}\text { Gage } \\
\text { he1ght }\end{array}$ & $\begin{array}{c}\text { Dis- } \\
\text { charge }\end{array}$ \\
\hline $\begin{array}{r}29 \\
30\end{array}$ & $\begin{array}{l}2400 \\
0400 \\
0600 \\
1400 \\
1600 \\
1800 \\
2000 \\
\end{array}$ & $\begin{array}{r}0.46 \\
.49 \\
.44 \\
.43 \\
.54 \\
.65 \\
.60 \\
\end{array}$ & $\begin{array}{l}7.0 \\
7.7 \\
6.5 \\
6.2 \\
9.0 \\
12 \\
11\end{array}$ & Jan. 30 & $\begin{array}{l}2200 \\
2400 \\
\\
0400 \\
0800 \\
1200 \\
1600 \\
2200\end{array}$ & $\begin{array}{r}0.55 \\
.53 \\
\\
.55 \\
.70 \\
.88 \\
1.00 \\
1.16\end{array}$ & $\begin{array}{l}9.2 \\
8.7 \\
\\
9.2 \\
14 \\
20 \\
24 \\
30\end{array}$ & $\begin{array}{l}\text { Jan. } 31 \\
\text { Feb. } 1\end{array}$ & $\begin{array}{l}2400 \\
\\
0800 \\
1200 \\
1600 \\
2000 \\
2400\end{array}$ & $\begin{array}{l}1.18 \\
1.37 \\
1.43 \\
1.35 \\
1.23 \\
1.12\end{array}$ & $\begin{array}{l}31 \\
40 \\
42 \\
39 \\
33 \\
29\end{array}$ \\
\hline
\end{tabular}

10-2662. Paradise Creek near Parad1se Camp, Callf.

(Crest-stage station)

Location.--Lat $37^{\circ} 27^{\prime} 45^{\prime \prime}$, long $118^{\circ} 34^{\prime} 35^{\prime \prime}$, in NE $\frac{1}{4} \mathrm{NW} \frac{1}{4}$ sec.4, T.6 S., R.31 E., at culvert on U.S. Highway $395,2.0$ miles southeast of Paradise Camp.

Dralnage area. $--4.75 \mathrm{sq} \mathrm{ml}$.

Gage-he1ght record.--Crest stages only. Alt1tude of gage is 4,800 ft (from topographlc map).

Discharge record.--Peak discharge by computation of flow through culvert.

Max1mum.--January-February 1963: Discharge, 185 cfs Jan. 31 or Feb. 1, 1963 (gage helght, $32.00 \mathrm{ft}$, from floodmarks).

10-2670. Pine Creek at division box, near Bishop, Calif.

Location.--Lat $37^{\circ} 25^{\prime} 00^{\prime \prime}$, long $118^{\circ} 37^{\prime} 15^{\prime \prime}$, in NW/ sec.19, T.6 S., R.31 E., on right bank 0.25 mile upstreám from division box (at Rovana), 1.9 miles west of Round

valley schoolhouse, and 13 miles northwest of Bishop.

Drainage area. $--37.9 \mathrm{sq} \mathrm{ml}$.

Gage-helght record:--Water-stage recorder graph. Alt1tude of gage is $5,280 \mathrm{ft}$ (from topographic map).

D1scharge record.--Discharge by computation of flow through 6-foot Parshall flume.

Maxima.--January-February 1963: D1scharge, $93 \mathrm{cfs} 1000$ hours Feb. 1 (gage he1ght, $2.34 \mathrm{ft}$ )

1921 to December 1962: Discharge, 356 cfs June 4, 1957.

Remarks.--Records furmished by city of Los Angeles, Department of Water and Power. 
Mean discharge, in cublc feet per second, 1963, of Pine Creek at division box, near

\begin{tabular}{|c|c|c|c|c|c|c|c|c|}
\hline Day & January & February & Day & Jamuary & February & Day & January & February \\
\hline $\begin{array}{c}1 \ldots \ldots \\
2 \ldots \ldots \\
3 \ldots \ldots \\
4 \ldots \ldots \\
5 \ldots \ldots \\
6 \ldots \ldots \\
7 \ldots \ldots \\
8 \ldots \ldots \\
10 \ldots \ldots\end{array}$ & $\begin{array}{l}23 \\
23 \\
22 \\
22 \\
23 \\
23 \\
23 \\
22 \\
22 \\
22\end{array}$ & $\begin{array}{l}73 \\
38 \\
31 \\
29 \\
28 \\
26 \\
26 \\
26 \\
26 \\
26\end{array}$ & $\begin{array}{l}11 \ldots \ldots \\
12 \ldots \ldots \\
13 \ldots \ldots \\
14 \ldots \ldots \\
15 \ldots \ldots \\
16 \ldots \ldots \\
17 \ldots \ldots \\
18 \ldots \ldots \\
19 \ldots \ldots \\
20 \ldots \ldots\end{array}$ & $\begin{array}{l}22 \\
20 \\
21 \\
22 \\
21 \\
21 \\
20 \\
20 \\
21 \\
21\end{array}$ & $\begin{array}{l}25 \\
25 \\
25 \\
24 \\
24 \\
25 \\
25 \\
24 \\
24 \\
24\end{array}$ & $\begin{array}{l}21 \ldots \ldots \\
22 \ldots \ldots \\
23 \ldots \ldots \\
24 \ldots \ldots \\
25 \ldots \ldots \\
26 \ldots \ldots \\
27 \ldots \ldots \\
28 \ldots \ldots \\
29 \ldots \ldots \\
30 \ldots \ldots \\
31 \ldots \ldots\end{array}$ & $\begin{array}{l}21 \\
21 \\
21 \\
21 \\
21 \\
21 \\
22 \\
21 \\
21 \\
29 \\
57\end{array}$ & $\begin{array}{r}24 \\
24 \\
24 \\
24 \\
24 \\
24 \\
24 \\
24 \\
--.-- \\
-.-2 \\
-.-2\end{array}$ \\
\hline $\begin{array}{l}\text { nthly } \\
\text { noff, } \\
\text { noff, }\end{array}$ & $\begin{array}{l}\text { Inch } \\
\text { acre }\end{array}$ & & & & & & $\begin{array}{r}22.9 \\
0.70 \\
1,410\end{array}$ & $\begin{array}{r}27.4 \\
0.75 \\
1,520\end{array}$ \\
\hline
\end{tabular}

Gage helght, In feet, and discharge, in cublc feet per second, at indicated time, 1963

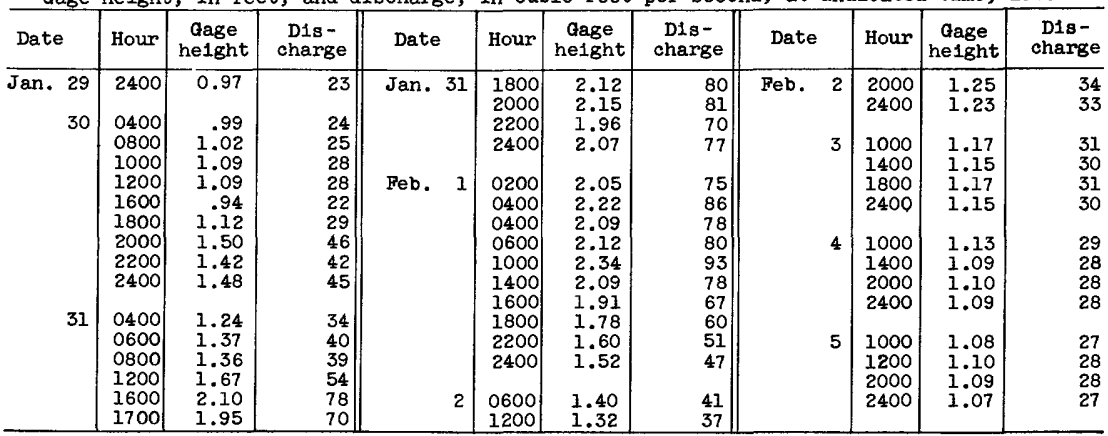

10-2760. Big Pine Creek near Big Pine, Calif.

Location.--Lat $37^{\circ} 08^{\prime} 40^{\prime \prime}$, long $118^{\circ} 18^{\prime} 55^{\prime \prime}$, in NW $\frac{1}{4}$ sec.25, T.9 S., R.33 E., on left bank 0.3 mile downstream from Little Pine Creek, 0.5 mile downstream from powerhouse No. 3 , and 2.2 miles southwest of Big PIne.

Drainage area. $--39.0 \mathrm{sq} \mathrm{ml}$.

Gage-helght record.--Water-stage recorder graphs. Altitude of gage is $4,550 \mathrm{ft}$ (from topographic map).

Discharge record.--Discharge by computation of flow through 6-foot Parshall flume (creek). D1scharge by computation of flow through 2-foot Parshall flumes for upper and lower Giroux ditches.

Maxima (creek only).--January-February 1963: Discharge, 56 cfs 0800 hours Feb. 1 (gage height, $1.71 \mathrm{ft}$ ).

1907-11, 1920 to December 1962: D1scharge, 458 cf's July 3, 1932 (gage helght, $6.55 \mathrm{ft})$.

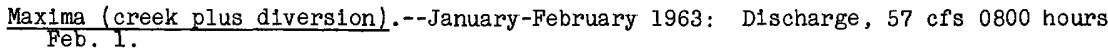

i930 to December 1962: Discharge, 458 cfs July 3, 1932.

Remarks.--Diversions for power and irrigation above station. Mean discharge figures and tabulation of discharge at indlcated times are the combined flow including the diversions. Records furnished by city of Los Angeles, Department of Water and Power. 
Combined mean discharge, In cub1c feet per second, of Big PIne Creek and upper and lower Giroux ditches near Big Pine, Calif.

\begin{tabular}{|c|c|c|c|c|c|c|c|c|}
\hline Day & January & February & Day & January & February & Day & January & February \\
\hline $\begin{array}{c}1 \ldots \ldots \\
2 \ldots \ldots \\
3 \ldots \ldots \\
4 \ldots \ldots \\
5 \ldots \ldots \\
6 \ldots \ldots \\
8 \ldots \ldots \\
9 \ldots \ldots \\
10 \ldots \ldots\end{array}$ & $\begin{array}{l}14 \\
15 \\
15 \\
14 \\
14 \\
14 \\
14 \\
13 \\
13 \\
13\end{array}$ & $\begin{array}{l}38 \\
19 \\
17 \\
16 \\
16 \\
15 \\
15 \\
15 \\
15 \\
15\end{array}$ & $\begin{array}{l}11 \ldots \ldots \\
12 \ldots \ldots \\
13 \ldots \ldots \\
14 \ldots \ldots \\
15 \ldots \ldots \\
16 \ldots \ldots \\
17 \ldots \ldots \\
18 \ldots \ldots \\
19 \ldots \ldots \\
20 \ldots \ldots\end{array}$ & $\begin{array}{l}13 \\
13 \\
13 \\
12 \\
12 \\
12 \\
11 \\
10 \\
11 \\
10\end{array}$ & $\begin{array}{l}14 \\
14 \\
13 \\
13 \\
12 \\
12 \\
12 \\
12 \\
12 \\
12\end{array}$ & $\begin{array}{l}21 \ldots \ldots \\
22 \ldots \ldots \\
23 \ldots \ldots \\
24 \ldots \ldots \\
25 \ldots \ldots \\
26 \ldots \ldots \\
27 \ldots \ldots \\
28 \ldots \ldots \\
29 \ldots \ldots \\
30 \ldots \ldots \\
31 \ldots \ldots\end{array}$ & $\begin{array}{l}11 \\
11 \\
11 \\
10 \\
10 \\
9.9 \\
10 \\
10 \\
11 \\
24 \\
38\end{array}$ & $\begin{array}{r}12 \\
12 \\
12 \\
12 \\
12 \\
12 \\
12 \\
12 \\
-----\end{array}$ \\
\hline \multicolumn{7}{|l|}{$\begin{array}{l}\text { Monthly } \\
\text { Runoff, } \\
\text { Runof'f, }\end{array}$} & $\begin{array}{r}13.3 \\
0.39 \\
817\end{array}$ & $\begin{array}{r}14.4 \\
0.38 \\
799 \\
\end{array}$ \\
\hline
\end{tabular}

Combined discharge, in cublc feet per second, at indicated time, 1963

\begin{tabular}{|c|c|c|c|c|c|c|c|c|c|c|c|}
\hline Date & Hour & $\begin{array}{c}\text { Gage } \\
\text { helght }\end{array}$ & $\begin{array}{l}\text { Dis- } \\
\text { charge }\end{array}$ & Date & Hour & $\begin{array}{c}\text { Gage } \\
\text { helght }\end{array}$ & $\begin{array}{l}\text { Dis - } \\
\text { charge }\end{array}$ & Date & Hour & $\begin{array}{c}\text { Gage } \\
\text { helght }\end{array}$ & $\begin{array}{c}\text { Dis- } \\
\text { charge }\end{array}$ \\
\hline $\begin{array}{r}29 \\
30\end{array}$ & $\begin{array}{l}2400 \\
0400 \\
0800 \\
1000 \\
1200 \\
1400 \\
1600 \\
1800 \\
2000 \\
2200 \\
2400\end{array}$ & $\begin{array}{l}- \\
\overline{-} \\
\overline{-} \\
- \\
- \\
- \\
- \\
- \\
-\end{array}$ & $\begin{array}{l}12 \\
14 \\
16 \\
23 \\
34 \\
28 \\
25 \\
32 \\
31 \\
39 \\
34 \\
\end{array}$ & Jan. 31 & $\begin{array}{l}0200 \\
0600 \\
0800 \\
1000 \\
1200 \\
1200 \\
1400 \\
1600 \\
1800 \\
2000 \\
2200 \\
2400\end{array}$ & $\begin{array}{l}\overline{-} \\
\overline{-} \\
\overline{-} \\
\overline{-} \\
\overline{-} \\
- \\
\overline{-} \\
-\end{array}$ & $\begin{array}{l}23 \\
31 \\
25 \\
34 \\
38 \\
32 \\
47 \\
56 \\
51 \\
46 \\
44 \\
48\end{array}$ & Feb. 1 & $\begin{array}{l}0200 \\
0600 \\
0800 \\
1000 \\
1000 \\
1200 \\
1600 \\
1800 \\
2200 \\
2400\end{array}$ & $\begin{array}{l}- \\
\overline{-} \\
\overline{-} \\
\overline{-} \\
\overline{-} \\
\overline{-}\end{array}$ & $\begin{array}{l}52 \\
48 \\
57 \\
57 \\
34 \\
35 \\
30 \\
27 \\
22 \\
22\end{array}$ \\
\hline
\end{tabular}

10-2818. Independence Creek below Pinyon Creek, near Independence, Calif.

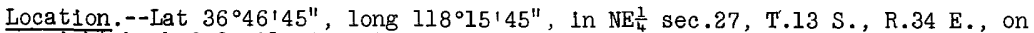
right bank $0.2 \mathrm{mlle}$ downstream from Pinyon Creek and 4.0 miles southwest of Independence.

Drainage area. $--18.2 \mathrm{sq} \mathrm{mi}$.

Gage-height record. --Water-stage recorder graph, except Jan. 31 to Feb. 12 . Altitude of gage is 5,300 ft (from topographic map).

Discharge record.--Discharge by computation of flow through 4-foot Parshall flume. Discharge Jan. 31 to Feb. 12 estimated on basis of unpublished records for station 4 miles downstream.

Maxima.--January-February 1963: Discharge, 60 cfs (estimated) 0100 hours Feb. 1 (gage height, unknown).

1923 to December 1962: Discharge, 106 cfs June 16, 1941.

Remarks.--Records furmished by city of Los Angeles, Department of Water and Power, and reviewed by Geological Survey.

Mean discharge, in cublc feet per second, 1963

\begin{tabular}{|c|c|c|c|c|c|c|c|c|}
\hline Day & January & February & Day & January & February & Day & January & Pebruary \\
\hline $\begin{array}{c}7 \ldots \ldots \\
2 \ldots \ldots \\
3 \ldots \ldots \\
4 \ldots \ldots \\
5 \ldots \ldots \\
6 \ldots \ldots \\
7 \ldots \ldots \\
9 \ldots \ldots \\
10 \ldots \ldots\end{array}$ & $\begin{array}{l}2.4 \\
2.6 \\
2.5 \\
2.3 \\
2.5 \\
2.5 \\
2.6 \\
2.6 \\
2.6 \\
2.5\end{array}$ & $\begin{array}{r}2 \\
26 \\
16 \\
12 \\
9.6 \\
8.7 \\
7.4 \\
6.9 \\
7.2 \\
7.9\end{array}$ & $\begin{array}{l}11 \ldots \ldots \\
12 \ldots \ldots \\
13 \ldots \ldots \\
14 \ldots \ldots \\
15 \ldots \ldots \\
16 \ldots \ldots \\
17 \ldots \ldots \\
18 \ldots \ldots \\
19 \ldots \ldots \\
20 \ldots \ldots\end{array}$ & $\begin{array}{l}2.5 \\
2.5 \\
2.5 \\
2.6 \\
2.6 \\
2.6 \\
2.6 \\
2.5 \\
2.4 \\
2.3\end{array}$ & $\begin{array}{l}6.5 \\
6.1 \\
5.5 \\
5.3 \\
5.2 \\
5.0 \\
4.9 \\
4.7 \\
4.5 \\
4.5\end{array}$ & $\begin{array}{l}21 \ldots \ldots \\
22 \ldots \ldots \\
23 \ldots \ldots \\
24 \ldots \ldots \\
25 \ldots \ldots \\
26 \ldots \ldots \\
27 \ldots \ldots \\
25 \ldots \ldots \\
29 \ldots \ldots \\
30 \ldots \ldots \\
31 \ldots \ldots\end{array}$ & $\begin{array}{l}2.2 \\
2.1 \\
2.0 \\
1.9 \\
1.8 \\
1.9 \\
1.9 \\
2.1 \\
2.1 \\
6.8 \\
24\end{array}$ & $\begin{array}{r}4.5 \\
4.5 \\
4.5 \\
4.5 \\
4.4 \\
4.5 \\
4.7 \\
4.7 \\
----- \\
----.-\end{array}$ \\
\hline \multicolumn{7}{|c|}{ 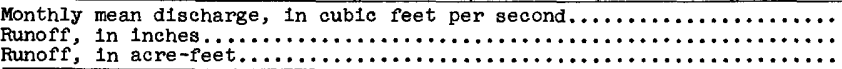 } & $\begin{array}{r}3.19 \\
0.20 \\
196\end{array}$ & $\begin{array}{r}8.29 \\
0.47 \\
461\end{array}$ \\
\hline
\end{tabular}




\section{MONO LAKE BASIN}

10-2872.1. Bridgeport Creek near Bodie, Cal1f.

(Miscellaneous site)

Location.--Lat $38^{\circ} 04^{\prime} 45^{\prime \prime}$, long $119^{\circ} 02^{\prime} 40^{\prime \prime}$, in NW/ sec.31, T.3 N., R.27 E., at culvert on Pole Line Road, 9.3 miles south of Bodle.

Drainage area. $--13.1 \mathrm{sq} \mathrm{mi}$.

Discharge record.--Peak discharge by slope-area measurement.

Maximum.--January-February 1963: Discharge, 46.9 cf's Jan. 31.

10-2874. Rush Creek above Grant Lake, near June Lake, Calif.

Location.--Lat $37^{\circ} 48^{1} 20^{\prime \prime}$, long $119^{\circ} 06^{\prime} 30^{\prime \prime}$, in NE $\frac{1}{4}$ sec.4, T.2 S., R.26 E., on left bank in narrows, 0.6 mile upstream from Grant Lake, and 2.7 miles northwest of town of June Lake.

Drainage area. $--51.2 \mathrm{sq} \mathrm{mi}$.

Gage-height record.--Water-stage recorder graph. Altitude of gage is 7,200 ft (from topographic map).

Discharge record.--Discharge by computation of flow through 15-foot Parshall flume.

Maxima.--January-February 1963: Discharge, 293 cfs 0100 hours Feb. 1 (gage he1ght, $2.76 \mathrm{ft})$ 1936 to December 1962: Da1ly mean discharge, 711 cfs June 28, 1938.

Remarks.--Flow regulated by Gem Lake, Lake Agnew, and Waugh Lake (combined capac1ty $, 23,400$ acre-ft), and by many natural lakes. Records furnished by city of Los Ángeles, Department of Water and Power.

Mean discharge, in cubic feet per second, 1963

\begin{tabular}{|c|c|c|c|c|c|c|c|c|}
\hline Day & January & February & Day & January & February & Day & January & February \\
\hline $\begin{array}{c}1 \ldots \ldots \\
2 \ldots \ldots \\
4 \ldots \ldots \\
5 \ldots \ldots \\
6 \ldots \ldots \\
7 \ldots \ldots \\
9 \ldots \ldots \\
10 \ldots \ldots\end{array}$ & $\begin{array}{l}55 \\
48 \\
39 \\
43 \\
50 \\
51 \\
54 \\
53 \\
45 \\
42\end{array}$ & $\begin{array}{r}249 \\
134 \\
109 \\
100 \\
95 \\
89 \\
84 \\
81 \\
79 \\
79\end{array}$ & $\begin{array}{l}11 \ldots \ldots \\
12 \ldots \ldots \\
13 \ldots \ldots \\
14 \ldots \ldots \\
15 \ldots \ldots \\
16 \ldots \ldots \\
17 \ldots \ldots \\
18 \ldots \ldots \\
19 \ldots \ldots \\
20 \ldots \ldots\end{array}$ & $\begin{array}{l}42 \\
47 \\
51 \\
55 \\
60 \\
60 \\
49 \\
45 \\
45 \\
40\end{array}$ & $\begin{array}{l}78 \\
76 \\
76 \\
74 \\
74 \\
72 \\
70 \\
70 \\
71 \\
70\end{array}$ & $\begin{array}{l}21 \ldots \ldots \\
22 \ldots \ldots \\
23 \ldots \ldots \\
24 \ldots \ldots \\
25 \ldots \ldots \\
26 \ldots \ldots \\
27 \ldots \ldots \\
28 \ldots \ldots \\
29 \ldots \ldots \\
30 \ldots \ldots \\
31 \ldots \ldots\end{array}$ & $\begin{array}{r}42 \\
55 \\
59 \\
60 \\
60 \\
60 \\
60 \\
60 \\
60 \\
86 \\
204\end{array}$ & $\begin{array}{r}69 \\
63 \\
40 \\
30 \\
34 \\
38 \\
33 \\
40 \\
-\ldots-- \\
-\ldots-\end{array}$ \\
\hline $\begin{array}{l}\text { Monthly } \\
\text { Runoff, } \\
\text { Runoff, }\end{array}$ & $\begin{array}{l}\text { an disc } \\
\text { inche } \\
\text { acre- }\end{array}$ & & & . & & & $\begin{array}{r}57.4 \\
1.29 \\
3,530\end{array}$ & $\begin{array}{r}77.8 \\
1.58 \\
4,320 \\
\end{array}$ \\
\hline
\end{tabular}

Gage height, in feet, and discharge, in cublc feet per second, at indicated time, 1963

\begin{tabular}{|c|c|c|c|c|c|c|c|c|c|c|c|}
\hline Date & Hour & $\begin{array}{c}\text { Gage } \\
\text { helght }\end{array}$ & $\begin{array}{c}\text { D1s- } \\
\text { charge }\end{array}$ & Date & Hour & $\begin{array}{c}\text { Gage } \\
\text { height }\end{array}$ & $\begin{array}{l}\text { D1s- } \\
\text { charge }\end{array}$ & Date & Hour & $\begin{array}{c}\text { Gage } \\
\text { he1ght }\end{array}$ & $\begin{array}{c}\text { Dis- } \\
\text { charge }\end{array}$ \\
\hline $\begin{array}{r}\text { Jan. } 29 \\
30\end{array}$ & $\begin{array}{l}2400 \\
0700 \\
0900 \\
1300 \\
1500 \\
1700 \\
1900 \\
2000 \\
2100 \\
2200 \\
2400 \\
0300\end{array}$ & $\begin{array}{l}1.19 \\
1.06 \\
1.06 \\
1.26 \\
1.33 \\
1.40 \\
1.48 \\
1.50 \\
1.55 \\
1.61 \\
1.61 \\
1.56\end{array}$ & $\begin{array}{r}76 \\
63 \\
63 \\
84 \\
91 \\
99 \\
108 \\
111 \\
117 \\
124 \\
124 \\
118\end{array}$ & Feb. 1 & $\begin{array}{l}0500 \\
0700 \\
0900 \\
1200 \\
1300 \\
1400 \\
1500 \\
1700 \\
1900 \\
2000 \\
2400 \\
0100 \\
0400\end{array}$ & $\begin{array}{l}1.69 \\
1.65 \\
1.96 \\
2.25 \\
2.26 \\
2.45 \\
2.59 \\
2.56 \\
2.64 \\
2.64 \\
2.75 \\
2.76 \\
2.74\end{array}$ & $\begin{array}{l}134 \\
129 \\
170 \\
212 \\
213 \\
242 \\
265 \\
260 \\
273 \\
273 \\
292 \\
293 \\
290\end{array}$ & Feb. I & $\begin{array}{l}0 \$ 00 \\
0900 \\
1200 \\
1500 \\
1800 \\
2100 \\
2400 \\
\\
0600 \\
1200 \\
1700 \\
2000 \\
2400\end{array}$ & $\begin{array}{l}2.71 \\
2.65 \\
2.54 \\
2.43 \\
2.27 \\
2.12 \\
1.97 \\
1.76 \\
1.63 \\
1.57 \\
1.60 \\
1.64\end{array}$ & $\begin{array}{l}285 \\
275 \\
257 \\
239 \\
215 \\
192 \\
171 \\
143 \\
126 \\
119 \\
123 \\
125\end{array}$ \\
\hline
\end{tabular}


10-2879. Lee Vining Creek near Lee Vining, Calif.

Location.--Lat $37^{\circ} 55^{\prime} 45^{\prime \prime}$, long $119^{\circ} 10^{\prime} 10^{\prime \prime}$, in SW $\frac{1}{4}$ sec.24, T.1 N., R.25 E., on right bank 0.8 mile upstream from Gibbs Canyon and 3.3 miles southwest of Lee Vining.

Drainage area. $-35.2 \mathrm{sq} \mathrm{ml}$.

Gage-height record.--Water-stage recorder graph. Alt1tude of gage is $7,400 \mathrm{ft}$ (from topographic map).

D1scharge record.--Stage-discharge relation defined by current-meter measurements .

Maxima.--January-February 1963: Discharge, 218 cfs 1300 hours Jan. 31 (gage he1ght, $2.82 \mathrm{ft})$.

1934 to December 1962: Discharge (observed), 503 cfs June 9, 1938 (gage

helght, $3.07 \mathrm{ft}$, datum then in use).

Remarks.--Flow regulated by Ellery, Saddlebag, and Tloga Lakes (combined capacity, 13,269 acre-ft) and several smail natural lakes. Records furnished by city of

Los Angeles, Department of Water and Power.

Mean discharge, in cubic feet per second, 1963

\begin{tabular}{|c|c|c|c|c|c|c|c|c|}
\hline Day & January & February & Day & January & February & Day & January & February \\
\hline $\begin{array}{c}1 \ldots \ldots \\
2 \ldots \ldots \\
3 \ldots \ldots \\
4 \ldots \ldots \\
5 \ldots \ldots \\
7 \ldots \ldots \\
8 \ldots \ldots \\
9 \ldots \ldots \\
10 \ldots \ldots\end{array}$ & $\begin{array}{l}32 \\
24 \\
24 \\
25 \\
22 \\
22 \\
22 \\
22 \\
22 \\
21\end{array}$ & $\begin{array}{r}122 \\
50 \\
56 \\
58 \\
47 \\
35 \\
36 \\
41 \\
72 \\
34\end{array}$ & $\begin{array}{l}11 \ldots \ldots \\
12 \ldots \ldots \\
13 \ldots \ldots \\
14 \ldots \ldots \\
15 \ldots \ldots \\
16 \ldots \ldots \\
17 \ldots \ldots \\
18 \ldots \ldots \\
19 \ldots \ldots \\
20 \ldots \ldots\end{array}$ & $\begin{array}{l}20 \\
23 \\
22 \\
23 \\
21 \\
26 \\
21 \\
21 \\
15 \\
17\end{array}$ & $\begin{array}{l}59 \\
50 \\
33 \\
30 \\
28 \\
28 \\
27 \\
26 \\
26 \\
26\end{array}$ & $\begin{array}{l}21 \ldots \ldots \\
22 \ldots \ldots \\
23 \ldots \ldots \\
24 \ldots \ldots \\
25 \ldots \ldots \\
26 \ldots \ldots \\
27 \ldots \ldots \\
25 \ldots \ldots \\
29 \ldots \ldots \\
30 \ldots \ldots \\
31 \ldots \ldots\end{array}$ & $\begin{array}{l}18 \\
18 \\
19 \\
20 \\
22 \\
22 \\
22 \\
23 \\
46 \\
35 \\
146\end{array}$ & $\begin{array}{r}26 \\
26 \\
26 \\
31 \\
26 \\
28 \\
30 \\
30 \\
-\ldots--- \\
-\ldots-.--\end{array}$ \\
\hline & $\operatorname{acr}$ & & & & & & $\begin{array}{r}27.0 \\
0.5 \mathrm{~s} \\
1,660\end{array}$ & $\begin{array}{r}39.6 \\
1.17 \\
2,200\end{array}$ \\
\hline
\end{tabular}

Gage height, In feet, and discharge, In cub1c feet per second, at ind1cated time, 1963

\begin{tabular}{|c|c|c|c|c|c|c|c|c|c|c|c|}
\hline Date & Hour & $\begin{array}{c}\text { Gage } \\
\text { he1ght }\end{array}$ & $\begin{array}{c}\text { D18- } \\
\text { charge }\end{array}$ & Date & Hour & $\begin{array}{c}\text { Gage } \\
\text { helght }\end{array}$ & $\begin{array}{c}\text { Dis- } \\
\text { charge }\end{array}$ & Date & Hour & $\begin{array}{c}\text { Gage } \\
\text { helght }\end{array}$ & $\begin{array}{c}\text { D1s- } \\
\text { charge }\end{array}$ \\
\hline $\begin{array}{r}\operatorname{Jan} .29 \\
30\end{array}$ & $\begin{array}{l}2400 \\
0500 \\
0500 \\
1000 \\
1100 \\
1400 \\
1500 \\
2400\end{array}$ & $\begin{array}{l}1.53 \\
1.55 \\
1.60 \\
1.69 \\
1.52 \\
1.60 \\
1.75 \\
1.65\end{array}$ & $\begin{array}{l}27 \\
28 \\
33 \\
42 \\
26 \\
33 \\
45 \\
35\end{array}$ & Jan. 31 & $\begin{array}{l}0600 \\
0800 \\
1000 \\
1200 \\
1300 \\
1600 \\
1500 \\
2200 \\
2400\end{array}$ & $\begin{array}{l}1.83 \\
2.30 \\
2.45 \\
2.75 \\
2.82 \\
2.77 \\
2.69 \\
2.74 \\
2.74\end{array}$ & $\begin{array}{r}55 \\
116 \\
146 \\
205 \\
218 \\
208 \\
192 \\
202 \\
202\end{array}$ & Feb. 1 & $\begin{array}{l}0400 \\
0800 \\
1200 \\
1600 \\
2400\end{array}$ & $\begin{array}{l}2.70 \\
2.73 \\
1.90 \\
2.08 \\
1.87\end{array}$ & $\begin{array}{r}194 \\
200 \\
62 \\
75 \\
59\end{array}$ \\
\hline
\end{tabular}

\section{WALKER LAKE BASIN}

10-2885. Walker Lake near Hawthorne, Nev .

Location.--Lat $38^{\circ} 35^{\prime} 05^{\prime \prime}$, long $118^{\circ} 42^{\prime} 15^{\prime \prime}$, in $\mathrm{NE} \frac{1}{4} \mathrm{NE} \frac{1}{4}$ sec.2, T.8 N., R.29 E., $5 \frac{1}{2}$ miles northwest of Hawthorme.

Gage-height record.--Elevations observed monthly. Datum of gage is at mean sea

level. Observations are referenced to bench mark, at U.S. Naval Depot, 5,053.41

ft above mean sea level, adjustment of 1912 .

Maxima.--January-February 1963: Elevation observed, 3,976.3 ft Feb. 21. 1928 to November 1962: Elevation observed, 4,051.8 ft Mar. 13, 1928 (Indian Service).

An elevation of $4,078.0 \mathrm{ft}$, adjustment of 1912 , was observed Sept. 27, 1908, by Geological Survey.

Elevation, in feet, November 1962 to March 1963
Nov. $13 \ldots \ldots \ldots 3,97 \mathrm{~s} .6$
Feb. $21 \ldots \ldots \ldots 3,976.3$
Jan. $23 \ldots \ldots \ldots .3,975.7$
Mar. $19 \ldots \ldots \ldots .3,976.2$ 


\section{0-2890. Virginia Creek near Bridgeport, Cal1f.}

Location.--Lat $38^{\circ} 11^{\prime} 30^{\prime \prime}$, long $119^{\circ} 12^{\prime} 30^{\prime \prime}$, near center of W $\frac{1}{2}$ sec.22, T.4 N., R.25 E., on right bank $1 \frac{1}{4}$ miles downstream from Clearwater Creek, 3 miles upstream from mouth, and $4 \frac{1}{2}$ miles southeast of Bridgeport.

Drainage area. --64 sq $\mathrm{mi}$, approximately.

Gage-height record.--Water-stage recorder graph, except Jan. 12-25. Altitude of gage is $6,700 \mathrm{f}^{\prime} \mathrm{t}$ (from topographic map).

Discharge record.--Stage-discharge relation defined by current-meter measurements below $86 \mathrm{cf}$ 's and by slope-area measurement at $652 \mathrm{cfs}$; affected by 1ce Jan. 6-11. Discharge for perlod of lce effect or no gage-height record estimated on basis of weather records and records for stations on nearby streams.

Maxima.--January-February 1963: Discharge, 652 cfs 0600 hours Feb. 1 (gage height, $6.13 \mathrm{ft})$.

1953 to December 1962: Discharge, 1,300 cfs Dec. 23, 1955 (gage helght,

$8.40 \mathrm{ft}$ ), from rating curve extended above $170 \mathrm{cfs}$ on basis of slope-area measurement of maximum flow.

Mean discharge, in cub1c feet per second, 1963

\begin{tabular}{|c|c|c|c|c|c|c|c|c|}
\hline Day & January & February & Day & January & February & Day & January & February \\
\hline $\begin{array}{c}1 \ldots \ldots \\
2 \ldots \ldots \\
4 \ldots \ldots \\
5 \ldots \ldots \\
6 \ldots \ldots \\
8 \ldots \ldots \\
9 \ldots \ldots \\
10 \ldots \ldots\end{array}$ & $\begin{array}{l}8.2 \\
7.9 \\
7.9 \\
8.2 \\
8.2 \\
7.6 \\
7.2 \\
6.5 \\
7.2 \\
7.6\end{array}$ & $\begin{array}{r}408 \\
100 \\
68 \\
49 \\
34 \\
26 \\
26 \\
22 \\
18 \\
18\end{array}$ & $\begin{array}{l}11 \ldots \ldots \\
12 \ldots \ldots \\
13 \ldots \ldots \\
14 \ldots \ldots \\
15 \ldots \ldots \\
16 \ldots \ldots \\
17 \ldots \ldots \\
18 \ldots \ldots \\
19 \ldots \ldots \\
20 \ldots \ldots\end{array}$ & $\begin{array}{l}7.2 \\
5.3 \\
5.9 \\
6.5 \\
6.5 \\
6.8 \\
6.5 \\
6.8 \\
5.4 \\
5.9\end{array}$ & $\begin{array}{l}17 \\
14 \\
16 \\
15 \\
13 \\
14 \\
13 \\
13 \\
14 \\
15\end{array}$ & $\begin{array}{l}21 \ldots \ldots \\
22 \ldots \ldots \\
23 \ldots \ldots \\
24 \ldots \ldots \\
25 \ldots \ldots \\
26 \ldots \ldots \\
27 \ldots \ldots \\
28 \ldots \ldots \\
29 \ldots \ldots \\
30 \ldots \ldots \\
31 \ldots \ldots\end{array}$ & $\begin{array}{r}6.2 \\
6.5 \\
7.6 \\
7.9 \\
7.6 \\
7.9 \\
7.6 \\
7.6 \\
8.6 \\
13 \\
234 \\
\end{array}$ & $\begin{array}{r}14 \\
13 \\
13 \\
14 \\
14 \\
17 \\
16 \\
14 \\
-----\end{array}$ \\
\hline jot't, & acre & & & & & & $\begin{array}{r}14.6 \\
0.26 \\
901 \\
\end{array}$ & $\begin{array}{r}36.7 \\
0.60 \\
2,040 \\
\end{array}$ \\
\hline
\end{tabular}

Gage height, in feet, and discharge, in cublc feet per second, at indicated time, 1963

\begin{tabular}{|c|c|c|c|c|c|c|c|c|c|c|c|}
\hline Date & Hour & $\begin{array}{c}\text { Gage } \\
\text { helght }\end{array}$ & $\begin{array}{l}\text { D1s- } \\
\text { charge }\end{array}$ & Date & Hour & $\begin{array}{c}\text { Gage } \\
\text { height }\end{array}$ & $\begin{array}{c}\text { D1s- } \\
\text { charge }\end{array}$ & Date & Hour & $\begin{array}{c}\text { Gage } \\
\text { helght }\end{array}$ & $\begin{array}{c}\text { D1s- } \\
\text { charge }\end{array}$ \\
\hline $\begin{array}{r}\text { Jan. } \\
30\end{array}$ & $\begin{array}{l}2400 \\
0900 \\
1500 \\
2400 \\
0700 \\
1200 \\
1300 \\
1500 \\
1700\end{array}$ & $\begin{array}{l}2.52 \\
2.52 \\
2.59 \\
2.77 \\
2.80 \\
3.28 \\
3.99 \\
4.95 \\
5.88\end{array}$ & $\begin{array}{r}10 \\
10 \\
13 \\
23 \\
\\
24 \\
67 \\
168 \\
349 \\
565\end{array}$ & $\begin{array}{l}\text { Jan. } 31 \\
\text { Feb. } 1\end{array}$ & $\begin{array}{l}2200 \\
2300 \\
2400 \\
\\
0600 \\
0900 \\
1300 \\
1600 \\
1500 \\
1900 \\
2400\end{array}$ & $\begin{array}{l}5.4 \mathrm{~S} \\
6.00 \\
5.85 \\
6.13 \\
5.88 \\
5.05 \\
5.05 \\
4.90 \\
4.70 \\
4.15\end{array}$ & $\begin{array}{l}465 \\
600 \\
54 \mathrm{~S} \\
652 \\
550 \\
315 \\
308 \\
269 \\
229 \\
130\end{array}$ & Feb. 2 & $\begin{array}{l}0800 \\
1600 \\
1800 \\
2400 \\
1200 \\
1800 \\
2400\end{array}$ & $\begin{array}{l}3.83 \\
4.00 \\
4.02 \\
3.66 \\
3.44 \\
3.97 \\
3.54\end{array}$ & $\begin{array}{r}87 \\
108 \\
110 \\
69 \\
48 \\
402 \\
57\end{array}$ \\
\hline
\end{tabular}

10-2895. Green Creek near Bridgeport, Callf.

Location.--Lat $38^{\circ} 10^{\prime} 25^{\prime \prime}$, long $119^{\circ} 14^{\prime} 00^{\prime \prime}$, in $\mathrm{NE} \frac{1}{4} \mathrm{SE} \frac{1}{4} \mathrm{sec} .29$, T.4 N., R.25 E., on right bank $130 \mathrm{ft}$ downstream from county road bridge and $5 \frac{1}{2}$ miles south of Bridgeport.

Drainage area. $--19.4 \mathrm{sq} \mathrm{ml}$.

Gage-helght record. --Water-stage recorder graph, except Jan. 1-8, Jan. 12 to Feb. 1. Altitude of gage is $6,850 \mathrm{ft}$ (from topographic map).

Discharge record.--Stage-discharge relation defined by current-meter measurements; affected by Ice Jan. 11. Discharge for Jan. 1-8 and Jan. 11 to Feb. 1 estimated on basis of weather records and records for nearby stations.

Maxima.--January-February 1963: Discharge, 199 cfs Feb. 1 (gage height, $3.03 \mathrm{ft}$ ). 1953 to December 1962: Discharge, $307 \mathrm{cfs}$ Dec. 23, 1955 , from rating curve extended above $220 \mathrm{cfs}$ on basls of slope-area measurement of maximum flow; gage height, $4.09 \mathrm{ft}$ Feb. 25, 1962 (backwater from 1ce) 
Mean discharge, in cubic feet per second, 1963, of Green Creek near Bridgeport, Calif.

\begin{tabular}{|c|c|c|c|c|c|c|c|c|}
\hline Day & January & February & Day & January & February & Day & January & February \\
\hline $\begin{array}{c}1 \ldots \ldots \\
2 \ldots \ldots \\
3 \ldots \ldots \\
4 \ldots \ldots \\
5 \ldots \ldots \\
6 \ldots \ldots \\
7 \ldots \ldots \\
8 \ldots \ldots \\
9 \ldots \ldots \\
10 \ldots \ldots\end{array}$ & $\begin{array}{l}5 \\
5 \\
6 \\
6 \\
5 \\
5 \\
4 \\
4 \\
4.1 \\
3.8\end{array}$ & $\begin{array}{r}110 \\
71 \\
44 \\
38 \\
29 \\
30 \\
28 \\
25 \\
20 \\
19\end{array}$ & $\begin{array}{l}11 \ldots \ldots \\
12 \ldots \ldots \\
13 \ldots \ldots \\
14 \ldots \ldots \\
15 \ldots \ldots \\
16 \ldots \ldots \\
17 \ldots \ldots \\
18 \ldots \ldots \\
19 \ldots \ldots \\
20 \ldots \ldots\end{array}$ & $\begin{array}{l}3.5 \\
3 \\
4 \\
4 \\
4 \\
4 \\
4 \\
4 \\
4 \\
4\end{array}$ & $\begin{array}{l}16 \\
13 \\
13 \\
12 \\
12 \\
12 \\
10 \\
11 \\
9.6 \\
11\end{array}$ & $\begin{array}{l}21 \ldots \ldots \\
22 \ldots \ldots \\
23 \ldots \ldots \\
24 \ldots \ldots \\
25 \ldots \ldots \\
26 \ldots \ldots \\
27 \ldots \ldots \\
28 \ldots \ldots \\
29 \ldots \ldots \\
30 \ldots \ldots \\
31 \ldots \ldots\end{array}$ & $\begin{array}{r}5 \\
5 \\
5 \\
5 \\
5 \\
5 \\
5 \\
6 \\
8 \\
10 \\
40\end{array}$ & $\begin{array}{c}11 \\
11 \\
9.6 \\
9.6 \\
11 \\
12 \\
12 \\
11 \\
\ldots .--. \\
-\ldots .--.\end{array}$ \\
\hline $\begin{array}{l}\text { nthly } \\
\text { noff, } \\
\text { noff, }\end{array}$ & $\begin{array}{l}\text { Inche } \\
\text { acre- }\end{array}$ & & & & & & $\begin{array}{r}5.98 \\
0.36 \\
368\end{array}$ & $\begin{array}{r}22.2 \\
1.19 \\
1,230\end{array}$ \\
\hline
\end{tabular}

10-2903. Upper Twin Lake near Bridgeport, Calif.

Location.--Lat $38^{\circ} 09^{\prime} 10^{\prime \prime}$, long $119^{\circ} 21^{\prime} 30^{\prime \prime}$, in $\mathrm{NE} \frac{1}{4} \mathrm{NE} \frac{1}{4}$ sec.6, T.3 N., R.24 E., on left bank, half a mile above outlet and $10 \frac{1}{2}$ miles southwest of Bridgeport.

Drainage area. $--30 \mathrm{sq} \mathrm{mi}$, approximately.

Gage-height record.--Water-stage recorder graph. Datum of gage is at mean sea leve1, datum of U.S. Indian Irrigation Service.

Contents record.--Contents computed from capac1ty table dated June 30, 1931.

Maxima.--January-February 1963: Contents, 2,610 acre-ft Feb. 1 (elevation, $7,208.68 \mathrm{ft})$.

1961 to December 1962: Contents, 2,730 acre-ft June 24, 1962 (elevation, $7,209.08 \mathrm{ft}$ ).

Remarks.--Contents regulated by dam at outlet. Figures given herein represent usable contents at 2400 hours.

Elevation, in feet, and contents, in acre-feet, at 2400 hours, 1963

\begin{tabular}{|c|c|c|c|c|c|c|c|c|c|}
\hline \multirow{2}{*}{ Day } & \multicolumn{2}{|c|}{ January } & \multicolumn{2}{|c|}{ February } & \multirow{2}{*}{ Day } & \multicolumn{2}{|c|}{ January } & \multicolumn{2}{|c|}{ February } \\
\hline & Elevation & Contents & Elevation & Contents & & Elevation & Contents & Elevation & Contents \\
\hline $\begin{array}{r}1 \\
2 \\
3 \\
4 \\
5 \\
6 \\
7 \\
8 \\
9 \\
10 \\
11 \\
12 \\
13 \\
14 \\
15\end{array}$ & $\begin{array}{l}7,206.89 \\
7,206.88 \\
7,206.88 \\
7,206.88 \\
7,206.88 \\
7,206.88 \\
7,206.88 \\
7,206.88 \\
7,206.87 \\
7,206.85 \\
7,206.83 \\
7,206.82 \\
7,206.82 \\
7,206.82 \\
7,206.82\end{array}$ & $\begin{array}{l}2,030 \\
2,030 \\
2,030 \\
2,030 \\
2,030 \\
2,030 \\
2,030 \\
2,030 \\
2,030 \\
2,020 \\
2,020 \\
2,010 \\
2,010 \\
2,010 \\
2,010\end{array}$ & $\begin{array}{l}7,208.68 \\
7,208.16 \\
7,207.87 \\
7,207.74 \\
7,207.66 \\
7,207.59 \\
7,207.54 \\
7,207.50 \\
7,207.46 \\
7,207.43 \\
7,207.39 \\
7,207.36 \\
7,207.34 \\
7,207.34 \\
7,207.33\end{array}$ & $\begin{array}{l}2,610 \\
2,440 \\
2,350 \\
2,310 \\
2,280 \\
2,260 \\
2,240 \\
2,230 \\
2,220 \\
2,210 \\
2,190 \\
2,190 \\
2,180 \\
2,180 \\
2,180\end{array}$ & $\begin{array}{l}16 \\
17 \\
18 \\
19 \\
20 \\
21 \\
22 \\
23 \\
24 \\
25 \\
26 \\
27 \\
28 \\
29 \\
30 \\
31\end{array}$ & $\begin{array}{l}7,206.82 \\
7,206.82 \\
7,206.82 \\
7,206.82 \\
7,206.82 \\
7,206.81 \\
7,206.81 \\
7,206.81 \\
7,206.81 \\
7,206.81 \\
7,206.81 \\
7,206.81 \\
7,206.80 \\
7,206.91 \\
7,207.48 \\
7,208.54\end{array}$ & $\begin{array}{l}2,010 \\
2,010 \\
2,010 \\
2,010 \\
2,010 \\
2,010 \\
2,010 \\
2,010 \\
2,010 \\
2,010 \\
2,010 \\
2,010 \\
2,010 \\
2,040 \\
2,220 \\
2,560\end{array}$ & $\begin{array}{c}7,207.32 \\
7,207.30 \\
7,207.30 \\
7,207.29 \\
7,207.26 \\
7,207.27 \\
7,207.26 \\
7,207.26 \\
7,207.27 \\
7,207.26 \\
7,207.25 \\
7,207.26 \\
7,207.26 \\
- \\
- \\
-\end{array}$ & $\begin{array}{l}2,170 \\
2,170 \\
2,170 \\
2,160 \\
2,150 \\
2,160 \\
2,150 \\
2,150 \\
2,160 \\
2,150 \\
2,150 \\
2,150 \\
2,150 \\
- \\
- \\
-\end{array}$ \\
\hline nar & e In cont & $8, \ln a$ & 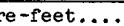 & & & - & +530 & - & -410 \\
\hline
\end{tabular}


10-2904. Lower Twin Lake near Bridgeport, Calif.

Location.--Lat $38^{\circ} 09^{1} 20^{\prime \prime}$, long $119^{\circ} 20^{\prime} 20^{\prime \prime}$, In SW $\frac{1}{4}$ SW $\frac{1}{4}$ sec.33, T.4 N., R.24 E., on right bank, 1.0 mile above outlet, and 10 miles southwest of Bridgeport.

Drainage area. --36 sq $\mathrm{ml}$, approximately.

Gage-height record.--Water-stage recorder graph. Datum of gage is at mean sea level, datum of U.S. Indian Irrigation Service.

Contents record.--Contents computed from capac1ty table dated June 30, 1931.

Maxima --January-February 1963: Contents, 4,940 acre-ft Feb. 1 (elevation, $7,202.07 \mathrm{ft}$ ).

1961 to December 1962: Contents, 5,040 acre-ft June 24, 25, 1962 (elevation, $7,202.41 \mathrm{ft}$ ).

Remarks.--Contents regulated by dam at outlet and by Upper Twin Lake. Figures given herein represent usable contents at 2400 hours.

Elevation, in feet, and contents, in acre-feet, at 2400 hours, 1963

\begin{tabular}{|c|c|c|c|c|c|c|c|c|c|}
\hline \multirow{2}{*}{ Day } & \multicolumn{2}{|c|}{ January } & \multicolumn{2}{|c|}{ February } & \multirow{2}{*}{ Day } & \multicolumn{2}{|c|}{ January } & \multicolumn{2}{|c|}{ February } \\
\hline & Elevation & Contents & Elevation & Contents & & Elevation & Contents & Elevation & Contents \\
\hline $\begin{array}{r}1 \\
2 \\
3 \\
4 \\
5 \\
6 \\
7 \\
\text { S } \\
9 \\
10 \\
11 \\
12 \\
13 \\
14 \\
15\end{array}$ & $\begin{array}{l}7,199.24 \\
7,199.27 \\
7,199.30 \\
7,199.34 \\
7,199.37 \\
7,199.41 \\
7,199.45 \\
7,199.48 \\
7,199.51 \\
7,199.54 \\
7,199.59 \\
7,199.64 \\
7,199.69 \\
7,199.73 \\
7,199.77\end{array}$ & $\begin{array}{l}3,700 \\
3,710 \\
3,720 \\
3,740 \\
3,750 \\
3,770 \\
3,780 \\
3,800 \\
3,810 \\
3,520 \\
3,850 \\
3,860 \\
3,880 \\
3,900 \\
3,920\end{array}$ & $\begin{array}{l}7,202.07 \\
7,201.99 \\
7,201.74 \\
7,201.48 \\
7,201.25 \\
7,201.14 \\
7,201.03 \\
7,200.95 \\
7,200.89 \\
7,200.85 \\
7,200.80 \\
7,200.76 \\
7,200.75 \\
7,200.70 \\
7,200.67\end{array}$ & $\begin{array}{l}4,940 \\
4,860 \\
4,750 \\
4,640 \\
4,550 \\
4,490 \\
4,440 \\
4,410 \\
4,380 \\
4,370 \\
4,350 \\
4,330 \\
4,330 \\
4,300 \\
4,290\end{array}$ & $\begin{array}{l}16 \\
17 \\
18 \\
19 \\
20 \\
21 \\
22 \\
23 \\
24 \\
25 \\
26 \\
27 \\
28 \\
29 \\
30 \\
31\end{array}$ & $\begin{array}{l}7,199.81 \\
7,199.86 \\
7,199.90 \\
7,199.93 \\
7,199.96 \\
7,200.00 \\
7,200.04 \\
7,200.07 \\
7,200.10 \\
7,200.13 \\
7,200.16 \\
7,200.18 \\
7,200.17 \\
7,200.28 \\
7,200.71 \\
7,201.51\end{array}$ & $\begin{array}{l}3,930 \\
3,950 \\
3,970 \\
3,950 \\
3,990 \\
4,010 \\
4,030 \\
4,040 \\
4,050 \\
4,070 \\
4,050 \\
4,090 \\
4,080 \\
4,130 \\
4,310 \\
4,650\end{array}$ & $\begin{array}{c}7,200.64 \\
7,200.62 \\
7,200.60 \\
7,200.59 \\
7,200.55 \\
7,200.57 \\
7,200.56 \\
7,200.55 \\
7,200.55 \\
7,200.56 \\
7,200.55 \\
7,200.55 \\
7,200.55 \\
- \\
-\end{array}$ & $\begin{array}{c}4,280 \\
4,270 \\
4,260 \\
4,260 \\
4,250 \\
4,250 \\
4,250 \\
4,240 \\
4,240 \\
4,250 \\
4,250 \\
4,240 \\
4,240 \\
= \\
= \\
-\end{array}$ \\
\hline s & In con & $s$, in a & fort & -2 & . & - & +970 & - & -410 \\
\hline
\end{tabular}

10-2905. Robinson Creek at Twin Lakes Outlet, near Bridgeport, Calif.

Location.--Lat $38^{\circ} 10^{\prime} 20^{\prime \prime}$, long $119^{\circ} 19^{\prime} 25^{\prime \prime}$, in $\mathrm{SE} \frac{1}{4} \mathrm{SE} \frac{1}{4}$ sec.28, T.4 N., R.24 E., on left bank a quarter of a mile downstream from Twin Lakes and 8 miles southwest of Bridgeport.

Drainage area. $--34.7 \mathrm{sq} \mathrm{mi}$.

Gage-height record.--Water-stage recorder graph. Altitude of gage is $7,050 \mathrm{ft}$ (from topographic map).

D1scharge record.--Stage-discharge relation defined by current-meter measurements; affected by Ice Jan. 12-28.

Maxima.--January-February 1963: D1scharge, $240 \mathrm{cfs} 2400$ hours Feb. 1 (gage height, $3.60 \mathrm{ft})$.

1953 to December 1962: Discharge, $445 \mathrm{cfs}$ June 29, 1956 (gage height, $4.35 \mathrm{ft}$ ).

Maximum discharge known, 660 cfs June 21, 1911 (gage height, $5.2 \mathrm{ft}$ ), at site $2 \frac{1}{2}$ miles downstream.

Remarks.--Flow regulated by Twin Lakes (see stations 10-2903,2904).

Mean discharge, in cublc feet per second, 1963

\begin{tabular}{|c|c|c|c|c|c|c|c|c|}
\hline Day & January & February & Day & January & February & Day & January & February \\
\hline $\begin{array}{r}1 \ldots \ldots \\
2 \ldots \ldots \\
3 \ldots \ldots \\
4 \ldots \ldots \\
5 \ldots \ldots \\
7 \ldots \ldots \\
8 \ldots \ldots \\
9 \ldots \ldots \\
10 \ldots \ldots\end{array}$ & $\begin{array}{l}4.8 \\
4.8 \\
5.1 \\
5.1 \\
5.4 \\
5.7 \\
6.0 \\
6.0 \\
5.4 \\
2.1\end{array}$ & $\begin{array}{r}198 \\
231 \\
190 \\
150 \\
115 \\
92 \\
76 \\
66 \\
57 \\
51\end{array}$ & $\begin{array}{l}11 \ldots \ldots \\
12 \ldots \ldots \\
13 \ldots \ldots \\
14 \ldots \ldots \\
15 \ldots \ldots \\
16 \ldots \ldots \\
17 \ldots \ldots \\
18 \ldots \ldots \\
19 \ldots \ldots \\
20 \ldots \ldots\end{array}$ & $\begin{array}{l}1.6 \\
1.2 \\
1.2 \\
1.6 \\
2.5\end{array}$ & $\begin{array}{l}47 \\
42 \\
40 \\
38 \\
35 \\
33 \\
31 \\
30 \\
28 \\
28\end{array}$ & $\begin{array}{l}21 \ldots \ldots \\
22 \ldots \ldots \\
23 \ldots \ldots \\
24 \ldots \ldots \\
25 \ldots \ldots \\
26 \ldots \ldots \\
27 \ldots \ldots \\
28 \ldots \ldots \\
29 \ldots \ldots \\
30 \ldots \ldots \\
31 \ldots \ldots\end{array}$ & $\begin{array}{l}2.5 \\
\\
3.0 \\
7.4 \\
21 \\
80\end{array}$ & $\begin{array}{r}27 \\
26 \\
25 \\
24 \\
24 \\
24 \\
24 \\
24 \\
----2 \\
------\end{array}$ \\
\hline $\begin{array}{l}\text { onthly } \\
\text { unoff, }\end{array}$ & $\begin{array}{l}\text { in d } \\
\text { acr }\end{array}$ & , & & & & & $\begin{array}{r}6.45 \\
396 \\
\end{array}$ & $\begin{array}{r}63.4 \\
3,520 \\
\end{array}$ \\
\hline
\end{tabular}


Gage he1ght, in feet, and discharge, in cublc feet per second, at indicated t1me, 1963, of Rob1nson Creek at Twin Lakes Outlet, near Bridgeport, Calif.

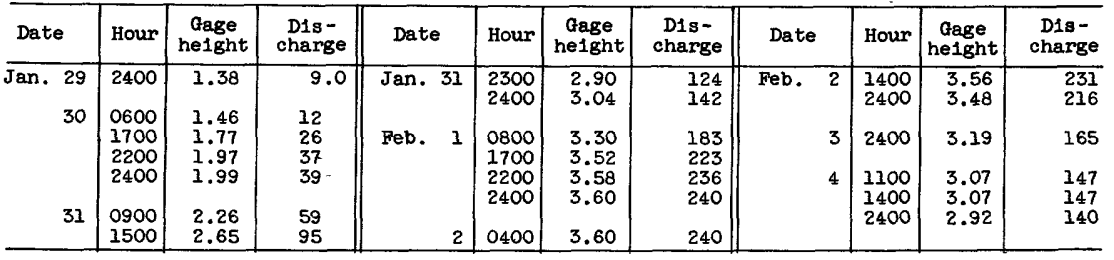

10-2915. Buckeye Creek near Bridgeport, Calif.

Location.--Lat $38^{\circ} 14^{\prime} 20^{\prime \prime}$, long $119^{\circ} 19^{\prime} 30^{\prime \prime}$, in $\mathrm{NE} \frac{1}{4} \mathrm{NE} \frac{1}{4} \sec .4$, T.4 N., R.24 E., on $r$ lght bank at Buckeye Hot Springs, $0.6 \mathrm{mile}$ downstream from Eagle Creek and $5 \frac{1}{2}$ miles southwest of Bridgeport.

Drainage area. $--45 \mathrm{sq} \mathrm{mi}$, approximately.

Gage-height record:--Water-stage recorder graph. Altitude of gage is $6,900 \mathrm{ft}$ (from topographic map).

Discharge record.--Stage-discharge relation defined by curirent-meter measurements below $360 \mathrm{cf}$ 's and by slope-area measurement at 700 cfs; affected by 1ce Jan. 1-29. Discharge for period of ice effect estimated on basis of weather records and records for Green Creek near Bridgeport, Calif.

Maxima.--January-February 1963: D1scharge, 947 cfs 0200 hours Feb. I (gage helght, $4.41 \mathrm{ft}$ )

1953 to December 1962: Discharge, $700 \mathrm{cfs}$ Dec. 23, 1955 (gage height, $4.00 \mathrm{ft}$ ).

Flood of June 21, 1911, reached an observed stage of $4.8 \mathrm{ft}$ (discharge not determined), at site half a mile downstream and at datum then in use.

Mean discharge, in cubic feet per second, 1963

\begin{tabular}{|c|c|c|c|c|c|c|c|c|}
\hline Day & January & February & Day & January & February & Day & J anuary & February \\
\hline $\begin{array}{c}1 \ldots \ldots \\
2 \ldots \ldots \\
4 \ldots \ldots \\
5 \ldots \ldots \\
7 \ldots \ldots \\
8 \ldots \ldots \\
9 \ldots \ldots \\
10 \ldots \ldots\end{array}$ & $\begin{array}{c}\text { s } \\
8 \\
8 \\
10 \\
11 \\
8 \\
7.5 \\
7.5 \\
7.5 \\
7.5\end{array}$ & $\begin{array}{r}452 \\
100 \\
74 \\
65 \\
55 \\
45 \\
41 \\
39 \\
34 \\
32\end{array}$ & $\begin{array}{l}11 \ldots \ldots \\
12 \ldots \ldots \\
13 \ldots \ldots \\
14 \ldots \ldots \\
15 \ldots \ldots \\
16 \ldots \ldots \\
17 \ldots \ldots \\
15 \ldots \ldots \\
19 \ldots \ldots \\
20 \ldots \ldots\end{array}$ & $\begin{array}{l}5 \\
4.5 \\
5 \\
6 \\
6 \\
6 \\
6 \\
6 \\
5.5 \\
6\end{array}$ & $\begin{array}{l}30 \\
27 \\
27 \\
26 \\
26 \\
25 \\
24 \\
24 \\
25 \\
26\end{array}$ & $\begin{array}{l}21 \ldots \ldots \\
22 \ldots \ldots \\
23 \ldots \ldots \\
24 \ldots \ldots \\
25 \ldots \ldots \\
26 \ldots \ldots \\
27 \ldots \ldots \\
28 \ldots \ldots \\
29 \ldots \ldots \\
30 \ldots \ldots \\
31 \ldots \ldots\end{array}$ & $\begin{array}{l}6 . \overline{5} \\
7 \\
7 \\
7 \\
6.5 \\
6 \\
6 \\
6.5 \\
14 \\
37 \\
509\end{array}$ & $\begin{array}{r}26 \\
25 \\
24 \\
25 \\
27 \\
31 \\
29 \\
29 \\
-\ldots-- \\
-\ldots-2\end{array}$ \\
\hline \multicolumn{7}{|l|}{$\begin{array}{l}\text { Monthly } \\
\text { Runoff, } \\
\text { Runoff, }\end{array}$} & $\begin{array}{r}24.2 \\
0.62 \\
1,490\end{array}$ & $\begin{array}{r}50.5 \\
1.17 \\
2,800\end{array}$ \\
\hline
\end{tabular}

Gage helght, in feet, and discharge, in cubic feet per second, at indicated time, 1963

\begin{tabular}{|c|c|c|c|c|c|c|c|c|c|c|c|}
\hline Date & Hour & $\begin{array}{c}\text { Gage } \\
\text { height }\end{array}$ & $\begin{array}{c}\text { Dis- } \\
\text { charge }\end{array}$ & Date & Hour & $\begin{array}{c}\text { Gage } \\
\text { helght }\end{array}$ & $\begin{array}{c}\text { DIs- } \\
\text { charge }\end{array}$ & Date & Hour & $\begin{array}{c}\text { Gage } \\
\text { helght }\end{array}$ & $\begin{array}{c}\text { D18- } \\
\text { charge }\end{array}$ \\
\hline $\begin{array}{r}\text { ran. } 29 \\
30\end{array}$ & $\begin{array}{l}2400 \\
0400 \\
0900 \\
1300 \\
2100 \\
2400 \\
\\
0200 \\
0600\end{array}$ & $\begin{array}{l}1.51 \\
1.44 \\
1.52 \\
1.54 \\
2.41 \\
2.40 \\
2.32 \\
2.53\end{array}$ & $\begin{array}{r}16 \\
13 \\
17 \\
15 \\
85 \\
91 \\
94 \\
130\end{array}$ & Peb. 1 & $\begin{array}{l}0700 \\
1400 \\
1800 \\
2000 \\
2100 \\
2400 \\
\\
0200 \\
0400 \\
1000 \\
\end{array}$ & $\begin{array}{l}3.26 \\
4.00 \\
4.08 \\
4.21 \\
4.17 \\
4.21 \\
4.41 \\
3.89 \\
3.73\end{array}$ & $\begin{array}{l}344 \\
700 \\
744 \\
521 \\
797 \\
821 \\
\\
947 \\
640 \\
560\end{array}$ & Feb. 1 & $\begin{array}{l}1600 \\
1900 \\
2400 \\
\\
0300 \\
1000 \\
1400 \\
1700 \\
2400\end{array}$ & $\begin{array}{l}3.02 \\
2.72 \\
2.45 \\
2.36 \\
2.24 \\
2.25 \\
2.25 \\
2.12\end{array}$ & $\begin{array}{r}262 \\
178 \\
126 \\
112 \\
94 \\
101 \\
101 \\
77\end{array}$ \\
\hline
\end{tabular}


10-2920. Swager Creek near Bridgeport, Cal1f.

Location.--Lat $38^{\circ} 17^{\prime} 00^{\prime \prime}$, long $11^{\circ} 17^{\prime} 50^{\prime \prime}$, in SE $\frac{1}{4} \mathrm{NW} \frac{1}{4} \sec .23, \mathrm{~T} .5 \mathrm{~N} ., \mathrm{R} .24 \mathrm{E}$, on right bank three-quarters of a mile downstream from Yaney Canyon and 4 miles northwest of Bridgeport.

Drainage area. - -53 sq $\mathrm{mi}$, approximately.

Gage-height record.--Water-stage recorder graph, except Jan. 1-10. Altitude of gage is 6,620 ft (from topographic map).

Discharge record.--Stage-discharge relation defined by current-meter measurements; affected by ice Jan. 11-28. Discharge for period of 1ce effect or no gage-he1ght record estimated on basis of weather records and records for stations on nearby streams. Maxima --January-February 1963: Discharge, $443 \mathrm{cfs} 1000$ hours Feb. 1 (gage height,

1911-15, 1953 to December 1962: Discharge, 585 cfs Dec. 23, 1955 (gage height, $6.24 \mathrm{ft}$ ), from rating curve extended above $175 \mathrm{cfs}$ on bas 1s of slopearea measurement of maximum flow.

Mean discharge, in cubic feet per second, 1963

\begin{tabular}{|c|c|c|c|c|c|c|c|c|}
\hline Day & January & February & Day & January & February & Day & January & Febmuary \\
\hline $\begin{array}{c}1 \ldots \ldots \\
2 \ldots \ldots \\
3 \ldots \ldots \\
4 \ldots \ldots \\
6 \ldots \ldots \\
7 \ldots \ldots \\
5 \ldots \ldots \\
9 \ldots \ldots \\
10 \ldots \ldots\end{array}$ & $\begin{array}{l}2.9 \\
3.2 \\
3.4 \\
4.1 \\
4.3 \\
4.1 \\
3.4 \\
3.4 \\
3.4 \\
3.6\end{array}$ & $\begin{array}{r}245 \\
48 \\
38 \\
34 \\
25 \\
20 \\
17 \\
15 \\
14 \\
16\end{array}$ & $\begin{array}{l}11 \ldots \ldots \\
12 \ldots \ldots \\
13 \ldots \ldots \\
14 \ldots \ldots \\
15 \ldots \ldots \\
16 \ldots \ldots \\
17 \ldots \ldots \\
18 \ldots \ldots \\
19 \ldots \ldots \\
20 \ldots \ldots\end{array}$ & $\begin{array}{l}3.8 \\
2.5 \\
1.8 \\
2.0 \\
2.5 \\
2.7 \\
2.7 \\
2.9 \\
2.5 \\
2.0\end{array}$ & $\begin{array}{l}14 \\
13 \\
13 \\
11 \\
10 \\
10 \\
9.8 \\
9.8 \\
10 \\
11\end{array}$ & $\begin{array}{l}21 \ldots \ldots \\
22 \ldots \ldots \\
23 \ldots \ldots \\
24 \ldots \ldots \\
25 \ldots \ldots \\
26 \ldots \ldots \\
27 \ldots \ldots \\
28 \ldots \ldots \\
29 \ldots \ldots \\
30 \ldots \ldots \\
31 \ldots \ldots\end{array}$ & $\begin{array}{l}2.2 \\
2.5 \\
2.7 \\
2.9 \\
2.7 \\
2.2 \\
2.5 \\
3.6 \\
4.9 \\
6.6 \\
67\end{array}$ & $\begin{array}{c}10 \\
9.4 \\
9.4 \\
9.8 \\
11 \\
12 \\
11 \\
10 \\
\ldots-.- \\
-\ldots-.\end{array}$ \\
\hline noff, & acre & & & & & & $\begin{array}{r}5.19 \\
0.11 \\
319\end{array}$ & $\begin{array}{r}23.9 \\
0.47 \\
1,330 \\
\end{array}$ \\
\hline
\end{tabular}

Gage helght, in feet, and discharge, in cublc feet per second, at indicated time, 1963

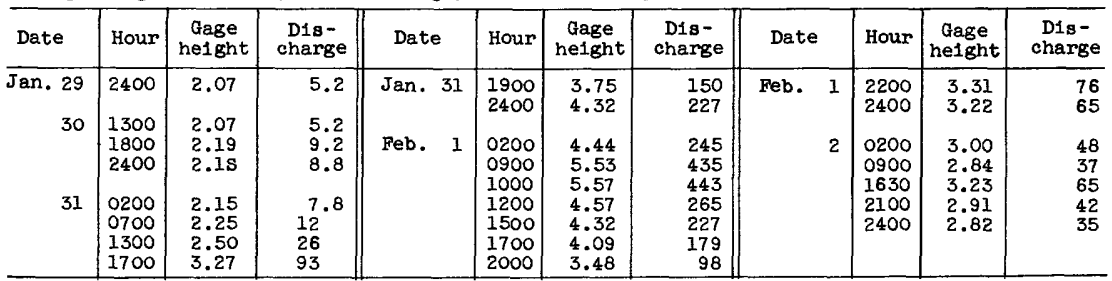

10-2923. Bridgeport Reservolr tributary near Bridgeport, Calif.

\section{(Crest-stage station)}

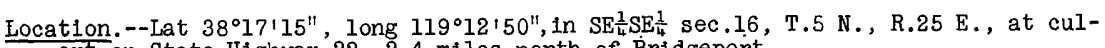
vert on State Highway' $22,2.4$ miles north of Bridgeport.

Drainage area. $--0.79 \mathrm{sq} \mathrm{mi}$.

Gage-helght record.--Crest stages only. Altitude of gage is 6,480 ft (from topographic mapl.

Discharge record.--Peak discharge by computation of flow through culvert.

Maximum.--January-February 1963: Discharge, 55.5 cfs Jan. 31 (gage he1ght, $7.1 \mathrm{ft}$ ). 
10-2925. Bridgeport Reservoir near Bridgeport, Calif.

Location. --Lat $38^{\circ} 19^{\prime} 30^{\prime \prime}$, 1ong $119^{\circ} 12^{\prime} 50^{\prime \prime}$, in $\mathrm{SE}_{\frac{1}{4}} \mathrm{NE} \frac{1}{4} \mathrm{sec} .34$, T.6 N., R.25 E., at Bridgeport Dam on East Walker River, $4 \frac{1}{2}$ miles north of Bridgeport.

Drainage area. $--362 \mathrm{sq} \mathrm{mi}$.

Gage-height record.-Float gage read once daily at about 0800 hours. Datum of gage is at mean sea level.

Contents record.--Contents computed from capacity table dated Nov. 13, 1939.

Maxima.--January-February 1963: Contents, 40,560 acre-ft Feb. 3, 4 (elevation, $6,459.35 \mathrm{ft} \mathrm{Feb} .31$.

1926 to December 1962: Contents, 44,580 acre-ft June 12, 1938, June 25, 26, 1958 (elevation, 6,460.7 ft).

Remarks.--Reservoir is formed by earthfill, rock-faced dam. Storage began Dec. 8, 1923. Dam completed in November 1924. Capacity, 42,460 acre-ft between elevations 6,415 ft (approximate elevation of bottom of reservoir) and 6,460 ft (crest of spillway). Elevation of sill of outlet gate, $6,412 \mathrm{ft}$. No dead storage. Figures given herein represent total contents. Elevations and capacity table furnished by Walker River Irrigation District.

Elevation, in feet, and contents, in acre-feet, 1963

\begin{tabular}{|c|c|c|c|c|c|c|c|c|c|}
\hline \multirow{2}{*}{ Day } & \multicolumn{2}{|c|}{ January } & \multicolumn{2}{|c|}{ February } & \multirow{2}{*}{ Day } & \multicolumn{2}{|c|}{ January } & \multicolumn{2}{|c|}{ February } \\
\hline & Elevation & Contents & Elevation & Contents & & Elevation & Contents & Elevation & Contents \\
\hline $\begin{array}{r}1 \\
2 \\
3 \\
4 \\
5 \\
6 \\
7 \\
8 \\
9 \\
10 \\
11 \\
12 \\
13 \\
14 \\
15\end{array}$ & $\begin{array}{l}6,453 \cdot 24 \\
6,453 \cdot 28 \\
6,453.31 \\
6,453 \cdot 34 \\
6,453.3 \mathrm{~s} \\
6,453 \cdot 42 \\
6,453.47 \\
6,453.51 \\
6,453.55 \\
6,453.59 \\
6,453.61 \\
6,453.62 \\
6,453.64 \\
6,453.66 \\
6,453.69\end{array}$ & $\begin{array}{l}25,210 \\
25,320 \\
25,320 \\
25,430 \\
25,540 \\
25,540 \\
25,650 \\
25,760 \\
25,570 \\
25,980 \\
25,980 \\
25,950 \\
26,090 \\
26,090 \\
26,200\end{array}$ & $\begin{array}{l}6,457 \cdot 59 \\
6,458 \cdot 34 \\
6,459 \cdot 35 \\
6,459 \cdot 34 \\
6,459 \cdot 24 \\
6,458 \cdot 98 \\
6,458 \cdot 71 \\
6,458 \cdot 38 \\
6,458 \cdot 18 \\
6,455 \cdot 08 \\
6,458 \cdot 11 \\
6,455.13 \\
6,458 \cdot 10 \\
6,458 \cdot 14 \\
6,458 \cdot 12\end{array}$ & $\begin{array}{l}35,700 \\
37,730 \\
40,560 \\
40,560 \\
40,270 \\
39,540 \\
38,710 \\
37,870 \\
37,320 \\
37,040 \\
37,040 \\
37,150 \\
37,040 \\
37,180 \\
37,040\end{array}$ & $\begin{array}{l}16 \\
17 \\
18 \\
19 \\
20 \\
21 \\
22 \\
23 \\
24 \\
25 \\
26 \\
27 \\
28 \\
29 \\
30 \\
31\end{array}$ & $\begin{array}{l}6,453.71 \\
6,453.74 \\
6,453.76 \\
6,453.78 \\
6,453.81 \\
6,453.85 \\
6,453.88 \\
6,453.91 \\
6,453.94 \\
6,453.97 \\
6,454.00 \\
6,454.03 \\
6,454.06 \\
6,454.09 \\
6,454.19 \\
6,454.96\end{array}$ & $\begin{array}{l}26,200 \\
26,310 \\
26,310 \\
26,420 \\
26,420 \\
26,530 \\
26,640 \\
26,640 \\
26,750 \\
26,750 \\
26,860 \\
26,950 \\
26,980 \\
27,090 \\
27,320 \\
29,040\end{array}$ & $\begin{array}{c}6,45 \mathrm{~S} .09 \\
6,45 \mathrm{~s} .06 \\
6,458.03 \\
6,458.01 \\
6,458.09 \\
6,458.20 \\
6,45 \mathrm{~s} .25 \\
6,458.34 \\
6,458.41 \\
6,458.49 \\
6,458.57 \\
6,45 \mathrm{~s} .65 \\
6,458.72 \\
- \\
- \\
-\end{array}$ & $\begin{array}{c}37,040 \\
36,900 \\
36,900 \\
36,760 \\
37,040 \\
37,320 \\
37,460 \\
37,730 \\
37,870 \\
38,150 \\
38,290 \\
38,570 \\
35,710 \\
- \\
- \\
-\end{array}$ \\
\hline & In con & s, In & & & . & - & $+3,940$ & - & $+9,670$ \\
\hline
\end{tabular}

10-2930. East Walker River near Bridgeport, Calif.

Location.--Lat $38^{\circ} 19^{\prime} 40^{\prime \prime}$, long $119^{\circ} 12^{\prime} 50^{\prime \prime}$, in SW $\frac{1}{4} \mathrm{NE} \frac{1}{4} \mathrm{sec} .34$, T.6 N., R.25 E., on right bank 1,500 ft downstream from Bridgeport Reservolr, 5 miles north of Bridgeport, and 10 miles upstream from Sweetwater Creek.

Drainage area. $--362 \mathrm{sq} \mathrm{mi}$.

Gage-height record.--Water-stage recorder graph. Altitude of gage is $6,400 \mathrm{ft}$ (from topographic map).

Discharge record.--Stage-discharge relation defined by current-meter measurements .

Maxima.--January-February 1963: Discharge, 643 cfs 1600 hours Feb. 5 to 0800 hours Feb: 6 (gage height, $2.92 \mathrm{ft}$ ). 1921 to December 1962: Discharge, 1,240 cfs Jan. 22, 1943; gage height, $4.95 \mathrm{ft}$ (top of surge).

Remarks.--Flow regulated by Bridgeport Reservoir (see station 10-2925).

Mean discharge, in cublc feet per second, 1963

\begin{tabular}{|c|c|c|c|c|c|c|c|c|}
\hline Day & January & Febrúary & Day & January & February & Day & January & February \\
\hline $\begin{array}{c}1 \ldots \ldots \\
2 \ldots \ldots \\
3 \ldots \ldots \\
4 \ldots \ldots \\
6 \ldots \ldots \\
7 \ldots \ldots \\
8 \ldots \ldots \\
10 \ldots \ldots \\
\end{array}$ & $\begin{array}{l}9.6 \\
9.6 \\
9.6 \\
9.6 \\
9.1 \\
9.6 \\
9.6 \\
10 \\
11 \\
11\end{array}$ & $\begin{array}{r}15 \\
91 \\
460 \\
545 \\
593 \\
639 \\
635 \\
565 \\
366 \\
201\end{array}$ & $\begin{array}{l}11 \ldots \ldots \\
12 \ldots \ldots \\
13 \ldots \ldots \\
14 \ldots \ldots \\
15 \ldots \ldots \\
16 \ldots \ldots \\
17 \ldots \ldots \\
18 \ldots \ldots \\
19 \ldots \ldots \\
20 \ldots \ldots\end{array}$ & $\begin{array}{l}11 \\
11 \\
11 \\
11 \\
11 \\
11 \\
11 \\
11 \\
11 \\
11\end{array}$ & $\begin{array}{r}164 \\
164 \\
167 \\
167 \\
167 \\
167 \\
167 \\
164 \\
84 \\
11\end{array}$ & $\begin{array}{l}21 \ldots \ldots \\
22 \ldots \ldots \\
23 \ldots \ldots \\
24 \ldots \ldots \\
25 \ldots \ldots \\
26 \ldots \ldots \\
27 \ldots \ldots \\
28 \ldots \ldots \\
29 \ldots \ldots \\
30 \ldots \ldots \\
31 \ldots \ldots\end{array}$ & $\begin{array}{l}11 \\
11 \\
11 \\
11 \\
11 \\
11 \\
10 \\
10 \\
10 \\
10 \\
11\end{array}$ & $\begin{array}{r}9.6 \\
9.6 \\
8.7 \\
8.7 \\
8.7 \\
5.7 \\
8.7 \\
9.1 \\
--.-2 \\
-.-1- \\
\end{array}$ \\
\hline $\begin{array}{l}\text { Monthly } \\
\text { Runoff, }\end{array}$ & cre & e in & foat & & & & $\begin{array}{r}10.5 \\
64.6\end{array}$ & $\begin{array}{r}200 \\
11,110\end{array}$ \\
\hline
\end{tabular}


10-2935. East Walker River above Strosnider ditch, near Mason, Nev.

Location.--Lat $38^{\circ} 48^{\prime} 50^{\prime \prime}$, Iong $119^{\circ} 02^{\prime} 50^{\prime \prime}$, in NW $\frac{1}{4}$ SE $\frac{1}{4}$ sec.14, T.11 N., R.26 E., on right bank 0.8 mile upstream from head of Strosnider ditch, 12 miles southeast of Mason, and $13 \frac{1}{2}$ miles southeast of Yerington.

Drainage area. $--1,100 \mathrm{sq} m i$, approximately.

Gage-height record.--Water-stage recorder graph, except Jan. 2-16. Datum of gage is 4,574.10 ft above mean sea level, datum of 1929 .

Discharge record.--Stage-discharge relation defined by current-meter measurements below 1,200 cfs and by slope-area measurement at 2,380 cfs; affected by ice Jan. $1,17-30$. Discharge for periods of ice effect or no gage-height record estimated on the basis of weather records and records for East Walker River near Bridgeport, Calif.

Maxima.--January-February 1963: Discharge, 2,380 cfs 2130 hours Feb. 1 (gage helght, $7.60 \mathrm{ft}$ ).

1947 to December 1962: Discharge, 1,640 cfs Dec. 24, 1955 (gage height, $6.87 \mathrm{ft}$ at site $400 \mathrm{ft}$ upstream at datum $0.56 \mathrm{ft}$ higher.

Remarks.--Flow partly affected by regulation of Bridgeport Reservoir.

Mean discharge, in cublc feet per second, 1963

\begin{tabular}{|c|c|c|c|c|c|c|c|c|}
\hline Day & January & February & Day & Jamuary & February & Day & January & February \\
\hline $\begin{array}{c}1 \ldots \ldots \\
2 \ldots \ldots \\
3 \ldots \ldots \\
4 \ldots \ldots \\
5 \ldots \ldots \\
7 \ldots \ldots \\
5 \ldots \ldots \\
9 \ldots \ldots \\
10 \ldots \ldots\end{array}$ & $\begin{array}{l}18 \\
18 \\
18 \\
35 \\
30 \\
23 \\
23 \\
23 \\
24 \\
25\end{array}$ & $\begin{array}{r}1,010 \\
806 \\
311 \\
571 \\
627 \\
671 \\
716 \\
716 \\
644 \\
399\end{array}$ & $\begin{array}{l}11 \ldots \ldots \\
12 \ldots \ldots \\
13 \ldots \ldots \\
14 \ldots \ldots \\
15 \ldots \ldots \\
16 \ldots \ldots \\
17 \ldots \ldots \\
18 \ldots \ldots \\
19 \ldots \ldots \\
20 \ldots \ldots\end{array}$ & $\begin{array}{l}18 \\
15 \\
16 \\
18 \\
20 \\
20 \\
24 \\
26 \\
20 \\
20\end{array}$ & $\begin{array}{l}262 \\
224 \\
213 \\
204 \\
193 \\
185 \\
153 \\
179 \\
178 \\
145\end{array}$ & $\begin{array}{l}21 \ldots \ldots \\
22 \ldots \ldots \\
23 \ldots \ldots \\
24 \ldots \ldots \\
25 \ldots \ldots \\
26 \ldots \ldots \\
27 \ldots \ldots \\
28 \ldots \ldots \\
29 \ldots \ldots \\
30 \ldots \ldots \\
31 \ldots \ldots\end{array}$ & $\begin{array}{r}21 \\
25 \\
30 \\
30 \\
30 \\
25 \\
25 \\
30 \\
35 \\
90 \\
157\end{array}$ & $\begin{array}{r}92 \\
79 \\
70 \\
66 \\
60 \\
55 \\
53 \\
49 \\
----\end{array}$ \\
\hline noff, & acre & $\ldots$ & & & & & $\begin{array}{r}30.1 \\
0.032 \\
1,850\end{array}$ & $\begin{array}{r}320 \\
0.30 \\
17,780\end{array}$ \\
\hline
\end{tabular}

Gage helght, in feet, and discharge, in cublc feet per second, at indicated time, 1963

\begin{tabular}{|c|c|c|c|c|c|c|c|c|c|c|c|}
\hline Date & Hour & $\begin{array}{c}\text { Gage } \\
\text { helght }\end{array}$ & $\begin{array}{c}\text { Dis- } \\
\text { charge }\end{array}$ & Date & Hour & $\begin{array}{c}\text { Gage } \\
\text { helght }\end{array}$ & $\begin{array}{l}\text { Dis- } \\
\text { charge }\end{array}$ & Date & Hour & $\begin{array}{c}\text { Gage } \\
\text { height }\end{array}$ & $\begin{array}{l}\text { D1s- } \\
\text { charge }\end{array}$ \\
\hline $\begin{array}{r}\text { Jan. } 30 \\
31\end{array}$ & $\begin{array}{l}2400 \\
0500 \\
1800 \\
2100 \\
2330 \\
2400 \\
\\
0230 \\
0330 \\
0430 \\
\end{array}$ & $\begin{array}{l}1.86 \\
1.84 \\
1.99 \\
2.75 \\
2.73 \\
2.79 \\
2.59 \\
2.71 \\
4.52\end{array}$ & $\begin{array}{l}122 \\
119 \\
142 \\
280 \\
276 \\
289 \\
\\
248 \\
272 \\
542\end{array}$ & Feb, 1 & $\begin{array}{l}0600 \\
1430 \\
2030 \\
2130 \\
2230 \\
2400 \\
\\
0230 \\
0400 \\
1000 \\
1300\end{array}$ & $\begin{array}{l}3.17 \\
4.58 \\
7.53 \\
7.60 \\
7.46 \\
7.17 \\
6.73 \\
6.63 \\
4.33 \\
3.53\end{array}$ & $\begin{array}{r}377 \\
764 \\
2,310 \\
2,380 \\
2,240 \\
2,000 \\
1,670 \\
1,610 \\
689 \\
467\end{array}$ & Feb, 2 & $\begin{array}{l}1700 \\
2000 \\
2400 \\
\\
0700 \\
1400 \\
1700 \\
2000 \\
2400\end{array}$ & $\begin{array}{l}3.04 \\
2.80 \\
2.60 \\
2.42 \\
2.37 \\
3.34 \\
3.67 \\
3.73\end{array}$ & $\begin{array}{l}346 \\
291 \\
250 \\
\\
215 \\
206 \\
419 \\
503 \\
519\end{array}$ \\
\hline
\end{tabular}

10-2952. West Walker River at Leavitt Meadows, near Coleville, Calif.

Location.--Iat $38^{\circ} 19^{\prime} 50^{\prime \prime}$, long $119^{\circ} 33^{\prime} 0^{\prime \prime}$, in NW $\frac{1}{4} \mathrm{NW} \frac{1}{4} \sec .34, \mathrm{~T} .6 \mathrm{~N}$, , R.22 E., on lef't bank at Leavitt Meadows Lodge, 500 ft upstream from Brownie'Creek, 0.9 mile downstream from Leavitt Creek, and $16 \frac{1}{2}$ miles south of Coleville.

Drainage area.--73 sq $\mathrm{mi}$, approximately.

Gage-height record.--Water-stage recorder graph except Jan. 16 to Feb. 28. Datum of gage is 7,111.32 ft above mean sea level (levels by Bureau of Reclamation).

Discharge record.--Stage-discharge relation defined by current-meter measurements; affected by 1ce Jan. 1-15. Discharge for period of lce effect or no gageheight record estimated on basis of weather records and records for nearby stations.

Maxima.--January-February 1963: Discharge, 1,370 cfs about 0700 hours Feb. 1 (gage height, $5.55 \mathrm{ft}$ ).

1945 to December 1962: Discharge, 2,810 cfs Nov. 21, 1950 (estimated on basis of records for West Walker River below Little Walker River, near coleville, Calif.). 
Mean discharge, In cubic feet per second, 1963, of West Walker River at Leav1tt Meadows, near Coleville, Calif.

\begin{tabular}{|c|c|c|c|c|c|c|c|c|}
\hline Day & January & February & Day & January & February & Day & January & February \\
\hline $\begin{array}{c}1 \ldots \ldots \\
2 \ldots \ldots \\
3 \ldots \ldots \\
4 \ldots \ldots \\
5 \ldots \ldots \\
7 \ldots \ldots \\
8 \ldots \ldots \\
9 \ldots \ldots \\
10 \ldots \ldots\end{array}$ & $\begin{array}{l}13 \\
13 \\
13 \\
14 \\
14 \\
13 \\
13 \\
13 \\
13 \\
10\end{array}$ & $\begin{array}{r}1,300 \\
420 \\
275 \\
200 \\
180 \\
150 \\
145 \\
140 \\
115 \\
100\end{array}$ & $\begin{array}{l}11 \ldots \ldots \\
12 \ldots \ldots \\
13 \ldots \ldots \\
14 \ldots \ldots \\
15 \ldots \ldots \\
16 \ldots \ldots \\
17 \ldots \ldots \\
18 \ldots \ldots \\
19 \ldots \ldots \\
20 \ldots \ldots\end{array}$ & $\begin{array}{r}8 \\
9 \\
10 \\
10 \\
10 \\
10 \\
10 \\
9 \\
9 \\
10\end{array}$ & $\begin{array}{l}95 \\
80 \\
80 \\
75 \\
75 \\
78 \\
70 \\
60 \\
60 \\
60\end{array}$ & $\begin{array}{l}21 \ldots \ldots \\
22 \ldots \ldots \\
23 \ldots \ldots \\
24 \ldots \ldots \\
25 \ldots \ldots \\
26 \ldots \ldots \\
27 \ldots \ldots \\
28 \ldots \ldots \\
29 \ldots \ldots \\
30 \ldots \ldots \\
31 \ldots \ldots\end{array}$ & $\begin{array}{r}10 \\
11 \\
11 \\
12 \\
11 \\
11 \\
10 \\
12 \\
16 \\
250 \\
1,000 \\
\end{array}$ & $\begin{array}{r}60 \\
56 \\
50 \\
55 \\
60 \\
60 \\
60 \\
60 \\
-\ldots-- \\
-\ldots-1 \\
\end{array}$ \\
\hline noff. & acre & & & & & & $\begin{array}{r}50.9 \\
0.80 \\
3,130 \\
\end{array}$ & $\begin{array}{r}151 \\
2.15 \\
8,370 \\
\end{array}$ \\
\hline
\end{tabular}

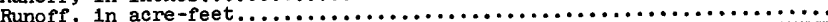

10-2953. Silver Falls Creek near Sonora Junction, Calif.

(Crest-stage station)

Location. --Lat $38^{\circ} 20^{\prime} 38^{\prime \prime}$, long $119^{\circ} 32^{\prime} 34^{\prime \prime}$, In $\mathrm{NW} \frac{1}{4} \mathrm{NE} \frac{1}{4}$ sec.27, T.6 N., R.22 E., at culvert of former State Highway $108,5.1$ miles west of Sonora Junction.

Drainage area. $-0.91 \mathrm{sq} \mathrm{mi}$.

Gage-height record.--Crest stages only. Alt1tude of gage is 7,120 ft (from topographic map).

Discharge record.--Peak discharge by computation of flow through culvert.

Maximum.--January-February 1963: Discharge, $92.5 \mathrm{cfs}$ Jan, 31 (gage height, $8.2 \mathrm{ft}$ ).

10-2955. Little Walker River near Bridgeport, Calif.

Location.--Lat $38^{\circ} 21^{1} 30^{\prime \prime}$, long $119^{\circ} 26^{1} 30^{\prime \prime}$, In NW $\frac{1}{4} N W \frac{1}{4}$ sec.22, T.6 N., R.23 E., on right bank three-quarters of a mile north of Sonora Junction, $1 \frac{1}{2}$ miles upstream from mouth, and 14 miles northwest of Bridgeport.

Drainage area.--63 sq mi, approximately.

Gage-helght record.--Water-stage recorder graph, except Jan. 12, 19-20. Alt1tude of gage is $6,790 \mathrm{f}^{\mathrm{t}} \mathrm{t}$ (from topographic map).

Discharge record.--Stage-discharge relation defined by current-meter measurements below $350 \mathrm{cf}$ 's and by slope-area measurement at 994 cfs; affected by 1 ce Jan. $1-11$, $13-18,21-28$, Feb. 15, $21,23,24$. Discharge for periods of 1ce effect or no gage-height record estimated on basis of weather records and records for nearby stations.

Maxima.--January-February 1963: Discharge, 1,510 cfs 1500 hours Jan. 31 (gage height, $3.22 \mathrm{ft}$ )

1910 ; 1944 to December 1962: Discharge, $994 \mathrm{cfs}$ Dec. 23, 1955; gage height. recorded, $3.63 \mathrm{ft}$ Jan. 3 , 1945 (backwater from 1ce).

Mean discharge, in cubic feet per second, 1963

\begin{tabular}{|c|c|c|c|c|c|c|c|c|}
\hline Day & January & February & Day & January & February & Day & January & Pebruary \\
\hline $\begin{array}{c}1 \ldots \ldots \\
3 \ldots \ldots \\
4 \ldots \ldots \\
5 \ldots \ldots \\
6 \ldots \ldots \\
7 \ldots \ldots \\
9 \ldots \ldots \\
10 \ldots \ldots\end{array}$ & $\begin{array}{r}9 \\
9 \\
9 \\
15 \\
17 \\
14 \\
12 \\
12 \\
12 \\
10\end{array}$ & $\begin{array}{r}365 \\
101 \\
74 \\
60 \\
54 \\
45 \\
40 \\
37 \\
33 \\
32\end{array}$ & $\begin{array}{l}11 \ldots \ldots \\
12 \ldots \ldots \\
13 \ldots \ldots \\
14 \ldots \ldots \\
15 \ldots \ldots \\
16 \ldots \ldots \\
17 \ldots \ldots \\
18 \ldots \ldots \\
19 \ldots \ldots \\
20 \ldots \ldots\end{array}$ & $\begin{array}{l}6 \\
5 \\
6 \\
7 \\
7 \\
7 \\
7 \\
7 \\
6 \\
7\end{array}$ & $\begin{array}{l}29 \\
27 \\
28 \\
25 \\
23 \\
24 \\
23 \\
23 \\
23 \\
23\end{array}$ & $\begin{array}{l}21 \ldots \ldots \\
22 \ldots \ldots \\
23 \ldots \ldots \\
24 \ldots \ldots \\
25 \ldots \ldots \\
26 \ldots \ldots \\
27 \ldots \ldots \\
28 \ldots \ldots \\
29 \ldots \ldots \\
30 \ldots \ldots \\
31 \ldots \ldots\end{array}$ & $\begin{array}{r}7 \\
7 \\
7 \\
8 \\
7 \\
7 \\
6 \\
7 \\
10 \\
237 \\
600\end{array}$ & $\begin{array}{r}22 \\
22 \\
22 \\
22 \\
24 \\
27 \\
25 \\
25 \\
-\ldots--\end{array}$ \\
\hline \multicolumn{9}{|c|}{ 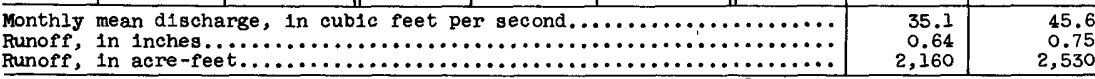 } \\
\hline
\end{tabular}


Gage height, in feet, and discharge, in cublc feet per second, at indicated time, 1963, of

\begin{tabular}{|c|c|c|c|c|c|c|c|c|c|c|c|}
\hline Date & Hour & $\begin{array}{c}\text { Gage } \\
\text { he1ght }\end{array}$ & $\begin{array}{l}\text { Dis- } \\
\text { charge }\end{array}$ & Date & Hour & $\begin{array}{c}\text { Gage } \\
\text { helght }\end{array}$ & $\begin{array}{l}\text { Dis - } \\
\text { charge }\end{array}$ & Date & Hour & $\begin{array}{c}\text { Gage } \\
\text { helght }\end{array}$ & $\begin{array}{c}\text { Dis- } \\
\text { charge }\end{array}$ \\
\hline $\begin{array}{r}29 \\
30\end{array}$ & $\begin{array}{l}2400 \\
\\
0800 \\
1500 \\
1700 \\
2100 \\
2300 \\
2400\end{array}$ & $\begin{array}{r}0.54 \\
.64 \\
2.16 \\
2.26 \\
1.96 \\
2.35 \\
2.10\end{array}$ & $\begin{array}{r}11 \\
15 \\
433 \\
503 \\
335 \\
574 \\
422\end{array}$ & $\operatorname{Jan} .31$ & $\begin{array}{l}1500 \\
1530 \\
1600 \\
1700 \\
1830 \\
2000 \\
2100 \\
2200 \\
2400\end{array}$ & $\begin{array}{l}3.22 \\
2.74 \\
3.12 \\
2.50 \\
1.83 \\
2.35 \\
2.30 \\
2.53\end{array}$ & $\begin{array}{r}1,510 \\
975 \\
1,400 \\
776 \\
350 \\
666 \\
631 \\
816 \\
474\end{array}$ & Feb. 1 & $\begin{array}{l}0830 \\
1100 \\
2100 \\
2400 \\
\\
0900 \\
1600 \\
2400\end{array}$ & $\begin{array}{r}2.33 \\
1.98 \\
1.28 \\
1.13 \\
.93 \\
1.08 \\
.83\end{array}$ & $\begin{array}{r}666 \\
438 \\
162 \\
126 \\
\\
88 \\
115 \\
72\end{array}$ \\
\hline 31 & $\begin{array}{l}0300 \\
0900 \\
1000 \\
1430\end{array}$ & $\begin{array}{l}1.80 \\
2.00 \\
2.39 \\
2.85 \\
\end{array}$ & $\begin{array}{r}272 \\
372 \\
624 \\
1,030\end{array}$ & Feb. 1 & $\begin{array}{l}0300 \\
0400 \\
0800\end{array}$ & $\begin{array}{l}1.86 \\
2.05 \\
2.08\end{array}$ & $\begin{array}{l}370 \\
480 \\
498\end{array}$ & 3 & $\begin{array}{l}1000 \\
1700 \\
2400\end{array}$ & $\begin{array}{r}.73 \\
1.00 \\
.77\end{array}$ & $\begin{array}{r}59 \\
100 \\
64\end{array}$ \\
\hline
\end{tabular}

10-2960. West Walker River below Little Walker River, near Coleville, Calif.

Location.--Lat $38^{\circ} 22: 45^{\prime \prime}$, long $119^{\circ} 27^{\prime} 00^{\prime \prime}$, in NW $\frac{1}{4} \mathrm{SE}_{\frac{1}{4}}$ sec.9, T.6 N., R.23 E., on left bank $100 \mathrm{ft}$ downstream from Little Walker River, $200 \mathrm{ft}$ upstream from bridge on U.S. Highway 395 , and 13 miles southeast of Coleville.

Drainage area. $--182 \mathrm{sq} \mathrm{mi}$.

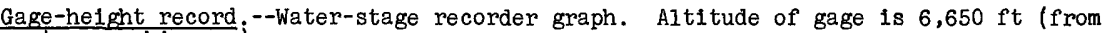
topographic mapi.

Discharge record.--Stage-discharge relation defined by current-meter measurements; affected by 1ce Jan. 1-28,30. Discharge for period of ice effect estimated on basis of weather records and records for nearby stations.

Maxima.--January-February 1963: Discharge, 2,870 cfs 0800 hours Feb. 1 (gage helght, $5.85 \mathrm{ft}$ )

1937 to December 1962: Discharge, 6,220 cfs November 1950 (gage height, $8.10 \mathrm{ft}$ ), from rating curve extended above $1,900 \mathrm{cfs}$ on basis of slope-area measurement of maximum flow.

Mean discharge, in cublc feet per second, 1963

\begin{tabular}{|c|c|c|c|c|c|c|c|c|}
\hline Day & January & February & Day & January & February & Day & January & February \\
\hline $\begin{array}{c}1 \ldots \ldots \\
2 \ldots \ldots \\
3 \ldots \ldots \\
4 \ldots \ldots \\
5 \ldots \ldots \\
6 \ldots \ldots \\
7 \ldots \ldots \\
8 \ldots \ldots \\
9 \ldots \ldots \\
10 \ldots \ldots\end{array}$ & $\begin{array}{l}25 \\
26 \\
28 \\
30 \\
32 \\
31 \\
26 \\
28 \\
30 \\
26\end{array}$ & $\begin{array}{r}2,040 \\
659 \\
462 \\
388 \\
313 \\
272 \\
235 \\
213 \\
186 \\
172\end{array}$ & $\begin{array}{l}11 \ldots \ldots \\
12 \ldots \ldots \\
13 \ldots \ldots \\
14 \ldots \ldots \\
15 \ldots \ldots \\
16 \ldots \ldots \\
17 \ldots \ldots \\
18 \ldots \ldots \\
19 \ldots \ldots \\
20 \ldots \ldots\end{array}$ & $\begin{array}{l}27 \\
25 \\
25 \\
25 \\
25 \\
25 \\
25 \\
26 \\
26 \\
27\end{array}$ & $\begin{array}{r}151 \\
136 \\
136 \\
120 \\
108 \\
110 \\
105 \\
101 \\
101 \\
97\end{array}$ & $\begin{array}{l}21 \ldots \ldots \\
22 \ldots \ldots \\
23 \ldots \ldots \\
24 \ldots \ldots \\
25 \ldots \ldots \\
26 \ldots \ldots \\
27 \ldots \ldots \\
28 \ldots \ldots \\
29 \ldots \ldots \\
30 \ldots \ldots \\
31 \ldots \ldots\end{array}$ & $\begin{array}{r}26 \\
28 \\
28 \\
28 \\
28 \\
27 \\
27 \\
27 \\
31 \\
381 \\
1,630\end{array}$ & $\begin{array}{r}97 \\
95 \\
90 \\
90 \\
95 \\
108 \\
110 \\
106 \\
----- \\
------\end{array}$ \\
\hline off, & $\operatorname{acr}$ & & & & & & $\begin{array}{r}90.3 \\
0.57 \\
5,550\end{array}$ & $\begin{array}{r}246 \\
1.41 \\
13,680 \\
\end{array}$ \\
\hline
\end{tabular}

Gage helght, in feet, and discharge, in cublc feet per second, at indicated time, 1963

\begin{tabular}{|c|c|c|c|c|c|c|c|c|c|c|c|}
\hline Date & Hour & $\begin{array}{c}\text { Gage } \\
\text { height }\end{array}$ & $\begin{array}{c}\text { D1s- } \\
\text { charge }\end{array}$ & Date & Hour & $\begin{array}{c}\text { Gage } \\
\text { helght }\end{array}$ & $\begin{array}{c}\text { Dis- } \\
\text { charge }\end{array}$ & Date & Hour & $\begin{array}{c}\text { Gage } \\
\text { height }\end{array}$ & $\begin{array}{c}\text { Dis- } \\
\text { charge }\end{array}$ \\
\hline $\begin{array}{r}\text { Jan. } 29 \\
30\end{array}$ & $\begin{array}{l}2400 \\
0800 \\
1000 \\
1200 \\
1730 \\
1800 \\
1830 \\
2100 \\
2300 \\
2400\end{array}$ & $\begin{array}{l}0.96 \\
1.09 \\
1.28 \\
1.87 \\
3.78 \\
3.68 \\
3.84 \\
3.34 \\
3.73 \\
3.58\end{array}$ & $\begin{array}{r}30 \\
28 \\
38 \\
88 \\
984 \\
922 \\
1,030 \\
739 \\
952 \\
866\end{array}$ & Jan. 31 & $\begin{array}{l}0300 \\
0600 \\
0630 \\
0900 \\
1100 \\
1200 \\
1230 \\
1530 \\
1830 \\
2400\end{array}$ & $\begin{array}{l}3.09 \\
3.65 \\
3.15 \\
3.57 \\
4.26 \\
5.36 \\
4.68 \\
5.71 \\
5.23 \\
5.70\end{array}$ & $\begin{array}{r}614 \\
904 \\
643 \\
860 \\
1,340 \\
2,300 \\
1,680 \\
2,700 \\
2,170 \\
2,690\end{array}$ & Feb. & $\begin{array}{l}0230 \\
0800 \\
0900 \\
1400 \\
1900 \\
2400 \\
\\
0300 \\
0700 \\
0900 \\
1900 \\
2400\end{array}$ & $\begin{array}{l}5.65 \\
5.85 \\
5.85 \\
4.73 \\
4.15 \\
3.65 \\
3.40 \\
3.20 \\
3.14 \\
3.10 \\
2.87\end{array}$ & $\begin{array}{r}2,630 \\
2,870 \\
2,870 \\
1,720 \\
1,250 \\
904 \\
770 \\
668 \\
638 \\
619 \\
516 \\
\end{array}$ \\
\hline
\end{tabular}


10-2965. West Walker River near Coleville, Calif.

Location.--Lat $38^{\circ} 30^{\prime} 55^{\prime \prime}$, long $119^{\circ} 27^{\prime} 15^{\prime \prime}$, In $\mathrm{NW} \frac{1}{4} \mathrm{NE} \frac{1}{4} \sec .28$, T.8 N., R.23 E., on left bank a quarter of a mile downstream from Rock Creek and 4 miles southeast of Coleville.

Drainage area. $--245 \mathrm{sq} \mathrm{mi}$.

Gage-helght record.--Water-stage recorder graph, except Jan. 12 to Feb. 4. Alt1tude of gage is $5,520 \mathrm{ft}$ (from topographic map).

Discharge record.--Stage-discharge relation defined by current-meter measurements; affected by 1ce Jan. 1-11. Discharge for perlod of no gage-helght record or period of ice effect estimated on basis of weather records and records for nearby stations. Maxima.--January-February 1963: Discharge, 2,510 cfs 0600 hours Feb. I (gage

1915-38, 1957 to December 1962: Discharge, 6,500 cf's Dec. 11, 1937, from slope-area measurement of maximum flow.

Mean discharge, in cubic feet per second, 1963

\begin{tabular}{|c|c|c|c|c|c|c|c|c|}
\hline Day & January & February & Day & January & February & Day & January & February \\
\hline $\begin{array}{c}1 \ldots \ldots \\
2 \ldots \ldots \\
3 \ldots \ldots \\
4 \ldots \ldots \\
5 \ldots \ldots \\
7 \ldots \ldots \\
8 \ldots \ldots \\
9 \ldots \ldots \\
10 \ldots \ldots\end{array}$ & $\begin{array}{l}35 \\
32 \\
36 \\
40 \\
39 \\
36 \\
30 \\
29 \\
32 \\
36\end{array}$ & $\begin{array}{r}2,220 \\
970 \\
780 \\
500 \\
338 \\
300 \\
250 \\
225 \\
195 \\
182\end{array}$ & $\begin{array}{l}11 \ldots \ldots \\
12 \ldots \ldots \\
13 \ldots \ldots \\
14 \ldots \ldots \\
15 \ldots \ldots \\
16 \ldots \ldots \\
17 \ldots \ldots \\
18 \ldots \ldots \\
19 \ldots \ldots \\
20 \ldots \ldots\end{array}$ & $\begin{array}{l}34 \\
23 \\
26 \\
29 \\
30 \\
30 \\
31 \\
30 \\
28 \\
30\end{array}$ & $\begin{array}{r}155 \\
135 \\
138 \\
121 \\
106 \\
108 \\
100 \\
95 \\
91 \\
93\end{array}$ & $\begin{array}{l}21 \ldots \ldots \\
22 \ldots \ldots \\
23 \ldots \ldots \\
24 \ldots \ldots \\
25 \ldots \ldots \\
26 \ldots \ldots \\
27 \ldots \ldots \\
28 \ldots \ldots \\
29 \ldots \ldots \\
30 \ldots \ldots \\
31 \ldots \ldots\end{array}$ & $\begin{array}{r}32 \\
32 \\
35 \\
36 \\
32 \\
30 \\
34 \\
32 \\
39 \\
350 \\
1,740\end{array}$ & $\begin{array}{r}91 \\
89 \\
87 \\
85 \\
89 \\
102 \\
104 \\
102 \\
--\ldots \\
-2---1\end{array}$ \\
\hline \multicolumn{7}{|l|}{$\begin{array}{l}\text { Monthly } \\
\text { Runoff, } \\
\text { Runoff, }\end{array}$} & $\begin{array}{r}97.7 \\
0.46 \\
6,010\end{array}$ & $\begin{array}{r}280 \\
1.19 \\
15,570\end{array}$ \\
\hline
\end{tabular}

10-2968. Slinkard Creek tributary near Topaz, Calif.

\section{(Crest-stage station)}

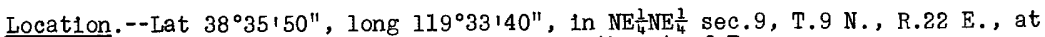
culvert on State Highway $89,3.4$ miles northwest of Topaz.

Drainage area. $--0.14 \mathrm{sq} \mathrm{ml}$.

Gage-he1ght record.--Crest stages only. Alt1tude of gage is $5,760 \mathrm{ft}$ (from topograph1c map).

Discharge record.--Peak discharge by computation of flow through culvert.

Maximum.--January-February 1963: Discharge, $22.0 \mathrm{cfs}$ Jan. 31 (gage helght, $8.0 \mathrm{ft}$ ). 
10-2970. Topaz Reservolr near Topaz, Calif.

Location.--Lat $38^{\circ} 41^{\prime} 35^{\prime \prime}$, long $119^{\circ} 31^{\prime} 10^{\prime \prime}$, in $\mathrm{NW} \frac{1}{4} \mathrm{NE} \frac{1}{4} \sec .33$, T.10 N., R.22 E., at outlet works of Topaz Reservoir, $5 \frac{1}{2}$ miles north of Topaz.

Gage-height record.--Float and staff gages read once daily at 0700 or 0800 hours. Datum of gage is at mean sea level (levels by Walker River Irrigation District).

Contents record.--Contents computed from capacity table dated Sept. 27, 1940.

Maxima.--January-February 1963: Contents observed, 52,010 acre-ft Feb. 28 (elevation, $5,001.69 \mathrm{ft}$ ).

1921 to December 1962: Contents observed, 60,240 acre-ft June 30, 1941 (elevation, $5,005.35 \mathrm{ft}$ ).

Remarks.--Topaz Reservoir, formerly known as Alkali Lake, was formed by the diversion of water from West Walker River through a feeder canal, and the construction of an outlet tunnel through a low saddle in rim of lake. Storage began about December 1921. Usable capac1ty, 59,440 acre-ft between elevations $4,972,3 \mathrm{ft}$ (lowest practical elevation for diversion through tunnel, bottom of outlet tunnel at elevation $4,970 \mathrm{ft}$ ) and $5,005 \mathrm{ft}$ ( $3 \mathrm{ft}$ below top of levee). Capacity of reservolr increased from about 45,000 acre-ft to 59,440 acre-ft in october 1937 by an earthfill, rock-faced levee at south end. Figures given herein represent usable contents. Elevations furmished by Walker River Irrigation District.

Elevation, in feet, and contents, in acre-feet, 1963

\begin{tabular}{|c|c|c|c|c|c|c|c|c|c|}
\hline \multirow{2}{*}{ Day } & \multicolumn{2}{|c|}{ January } & \multicolumn{2}{|c|}{ February } & \multirow{2}{*}{ Day } & \multicolumn{2}{|c|}{ January } & \multicolumn{2}{|c|}{ February } \\
\hline & Elevation & Contents & Elevation & Contents & & Elevation & Contents & Elevation & Contents \\
\hline $\begin{array}{r}1 \\
2 \\
3 \\
4 \\
5 \\
6 \\
7 \\
8 \\
9 \\
10 \\
11 \\
12 \\
13 \\
14\end{array}$ & $\begin{array}{l}4,988.34 \\
4,988.38 \\
4,988.43 \\
4,944.48 \\
4,985.54 \\
4,988.60 \\
4,988.65 \\
4,988.70 \\
4,988.76 \\
4,989.82 \\
4,988.87 \\
4,988.92 \\
4,983.95 \\
4,988.99 \\
4,989.02\end{array}$ & $\begin{array}{l}26,090 \\
26,160 \\
26,240 \\
26,330 \\
26,430 \\
26,540 \\
26,620 \\
26,710 \\
26,810 \\
26,920 \\
27,000 \\
27,090 \\
27,140 \\
27,210 \\
27,260\end{array}$ & $\begin{array}{l}4,994.04 \\
4,995.05 \\
4,996.02 \\
4,996.08 \\
4,997.03 \\
4,997.07 \\
4,998.01 \\
4,998.04 \\
4,998.07 \\
4,998.94 \\
4,999.18 \\
4,999.31 \\
4,999.57 \\
4,999.80 \\
4,999.97\end{array}$ & $\begin{array}{l}36,250 \\
38,190 \\
40,100 \\
40,220 \\
42,140 \\
42,220 \\
44,160 \\
44,220 \\
44,280 \\
46,100 \\
46,600 \\
46,880 \\
47,430 \\
47,920 \\
48,280\end{array}$ & $\begin{array}{l}16 \\
17 \\
18 \\
19 \\
20 \\
21 \\
22 \\
23 \\
24 \\
25 \\
26 \\
27 \\
28 \\
29 \\
30 \\
31\end{array}$ & $\begin{array}{l}4,989.05 \\
4,989.11 \\
4,989.16 \\
4,989.20 \\
4,989.25 \\
4,989.31 \\
4,989.36 \\
4,989.42 \\
4,989.48 \\
4,989.53 \\
4,989.59 \\
4,989.64 \\
4,989.69 \\
4,989.72 \\
4,989.79 \\
4,990.02\end{array}$ & $\begin{array}{l}27,320 \\
27,420 \\
27,510 \\
27,580 \\
27,660 \\
27,770 \\
27,850 \\
27,960 \\
28,060 \\
28,150 \\
28,250 \\
28,340 \\
28,430 \\
28,480 \\
28,600 \\
29,010\end{array}$ & $\begin{array}{c}5,000.12 \\
5,000.29 \\
5,000.42 \\
5,000.57 \\
5,000.71 \\
5,000.84 \\
5,000.96 \\
5,001.01 \\
5,001.10 \\
5,001.25 \\
5,001.44 \\
5,001.56 \\
5,001.69 \\
- \\
- \\
-\end{array}$ & $\begin{array}{c}48,600 \\
48,970 \\
49,250 \\
49,570 \\
49,870 \\
50,150 \\
50,410 \\
50,520 \\
50,720 \\
51,040 \\
51,460 \\
51,720 \\
52,010 \\
- \\
- \\
-\end{array}$ \\
\hline & 1 & & & & & & $+3,040$ & - & $+23,000$ \\
\hline
\end{tabular}

10-2975. West Walker River at Hoye bridge, near Wellington, Nev .

Location.--Iat $38^{\circ} 43^{\prime} 40^{\prime \prime}$, long $119^{\circ} 25^{\prime} 40^{\prime \prime}$, in $\mathrm{NE} \frac{1}{4} \mathrm{SE} \frac{1}{4} \sec .17$, T. $10 \mathrm{~N} ., \mathrm{R} .23 \mathrm{E}$., on left bank $20 \mathrm{ft}$ upstream from Hoye Bridge, 2 miles upstream from head of Saroni Canal, and 4 miles southwest of Wellington.

Drainage area. $--504 \mathrm{sq} \mathrm{ml}$.

Gage-height record:--Water-stage recorder graph. Altitude of gage is 4,980 ft (from topographic map).

D18charge record.--Stage-discharge relation defined by current-meter measurements; affected by 1ce Jan. 1-3, 7-9, 11-28. Discharge for periods of ice effect estimated on basis of weather records and records for nearby stations.

Maxima.--January-February 1963: Discharge, 2,060 cfs 1600 hours Feb. 1 (gage height, $8.44 \mathrm{ft}$ ). 1922 .

1910, 1920-23, 1924-32, 1957 to December 1962: Discharge, 2,180 cfs June 6,

Remarks.--Flow affected by regulation of Topaz Reservolr (see station 10-2970). 
Mean discharge, in cubic feet per second, 1963, of West Walker River at Hoye Bridge, near Wellington, Nev.

\begin{tabular}{|c|c|c|c|c|c|c|c|c|}
\hline Day & January & February & Day & January & February & Day & January & February \\
\hline $\begin{array}{c}1 \ldots \ldots \\
2 \ldots \ldots \\
3 \ldots \ldots \\
4 \ldots \ldots \\
5 \ldots \ldots \\
7 \ldots \ldots \\
8 \ldots \ldots \\
9 \ldots \ldots \\
10 \ldots \ldots\end{array}$ & $\begin{array}{l}21 \\
21 \\
22 \\
24 \\
24 \\
24 \\
23 \\
22 \\
23 \\
24\end{array}$ & $\begin{array}{r}1,590 \\
906 \\
262 \\
168 \\
109 \\
84 \\
70 \\
57 \\
49 \\
45\end{array}$ & $\begin{array}{l}11 \ldots \ldots \\
12 \ldots \ldots \\
13 \ldots \ldots \\
14 \ldots \ldots \\
15 \ldots \ldots \\
16 \ldots \ldots \\
17 \ldots \ldots \\
18 \ldots \ldots \\
19 \ldots \ldots \\
20 \ldots \ldots\end{array}$ & $\begin{array}{l}21 \\
19 \\
20 \\
21 \\
22 \\
23 \\
24 \\
24 \\
20 \\
21\end{array}$ & $\begin{array}{l}42 \\
39 \\
39 \\
38 \\
37 \\
36 \\
35 \\
34 \\
34 \\
34\end{array}$ & $\begin{array}{l}21 \ldots \ldots \\
22 \ldots \ldots \\
23 \ldots \ldots \\
24 \ldots \ldots \\
25 \ldots \ldots \\
26 \ldots \ldots \\
27 \ldots \ldots \\
28 \ldots \ldots \\
29 \ldots \ldots \\
30 \ldots \ldots \\
31 \ldots \ldots\end{array}$ & $\begin{array}{l}25 \\
22 \\
22 \\
22 \\
21 \\
20 \\
21 \\
21 \\
22 \\
27 \\
190 \\
\end{array}$ & 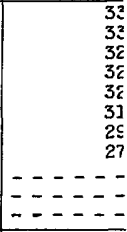 \\
\hline $\begin{array}{l}\text { nthly } \\
\text { inoff, } \\
\text { inoff, }\end{array}$ & $\begin{array}{l}\text { ean disc } \\
\text { n inches } \\
\text { n acre-f }\end{array}$ & & & & & & $\begin{array}{r}27.6 \\
0.06 \\
1,700 \\
\end{array}$ & $\begin{array}{r}141 \\
0.29 \\
7,850 \\
\end{array}$ \\
\hline
\end{tabular}

Gage height, in feet, and discharge, in cuble feet per second, at indicated time, 1963

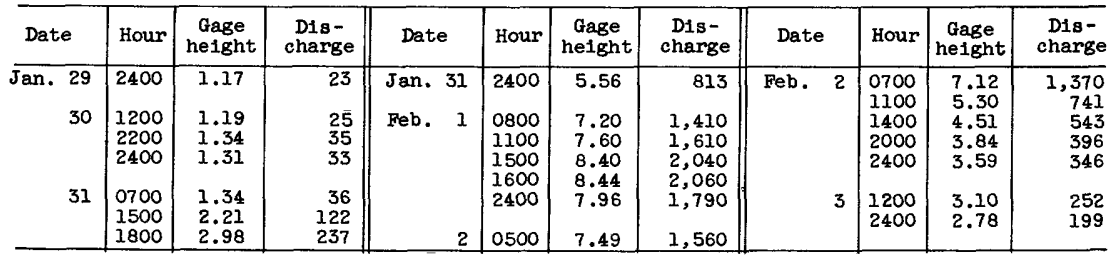

10-3000. West Walker River near Hudson, Nev.

Location. --Lat $38^{\circ} 48^{\prime} 35^{\prime \prime}$, long $119^{\circ} 13^{\prime} 35^{\prime \prime}$, in SE $\frac{1}{4} S W_{\frac{1}{4}}$ sec.18, T.11 N., R.25 E., on left bank half a mile upstream from Wilson Canyon and 3 miles southeast of Hudson

Drainage area. $--964 \mathrm{sq} \mathrm{mi}$.

Gage-height record.--Water-stage recorder graph. Altitude of gage is $4,670 \mathrm{ft}$ (from topographic map).

Discharge record.--Stage-discharge relation defined by current-meter measurements; affected by 1ce Jan. 1-4, 7-9, 11-28. Discharge for periods of 1ce effect estimated on basis of weather records and records for nearby stations.

Maxima.--January-Febmary 1963: D1scharge, 1,920 cfs 1000-1100 hours Feb. 2 (gage helght, $5.74 \mathrm{ft}$ )

1914-25, 1947 to December 1962: D1scharge, 2,700 cfs Dec. 24, 1955 (gage helght, $7.42 \mathrm{ft}$, from floodmarks).

Remarks.--Flow partly affected by regulation of Topaz Reservolr (see station $10-2970)$.

Mean discharge, in cub1c feet per second, 1963

\begin{tabular}{|c|c|c|c|c|c|c|c|c|}
\hline Day & January & February & Day & January & February & Day & January & February \\
\hline $\begin{array}{c}1 \ldots \ldots \\
2 \ldots \ldots \\
3 \ldots \ldots \\
4 \ldots \ldots \\
5 \ldots \ldots \\
6 \ldots \ldots \\
8 \ldots \ldots \\
9 \ldots \ldots \\
10 \ldots \ldots\end{array}$ & $\begin{array}{l}30 \\
30 \\
30 \\
31 \\
32 \\
31 \\
28 \\
27 \\
28 \\
30\end{array}$ & $\begin{array}{r}910 \\
1,530 \\
365 \\
209 \\
152 \\
120 \\
108 \\
94 \\
87 \\
82\end{array}$ & $\begin{array}{l}11 \ldots \ldots \\
12 \ldots \ldots \\
13 \ldots \ldots \\
14 \ldots \ldots \\
15 \ldots \ldots \\
16 \ldots \ldots \\
17 \ldots \ldots \\
18 \ldots \ldots \\
19 \ldots \ldots \\
20 \ldots \ldots\end{array}$ & $\begin{array}{l}27 \\
25 \\
26 \\
28 \\
28 \\
29 \\
30 \\
32 \\
28 \\
28\end{array}$ & $\begin{array}{l}78 \\
72 \\
64 \\
62 \\
59 \\
57 \\
55 \\
52 \\
50 \\
50\end{array}$ & $\begin{array}{l}21 \ldots \ldots \\
22 \ldots \ldots \\
23 \ldots \ldots \\
24 \ldots \ldots \\
25 \ldots \ldots \\
26 \ldots \ldots \\
27 \ldots \ldots \\
28 \ldots \ldots \\
29 \ldots \ldots \\
30 \ldots \ldots \\
31 \ldots \ldots\end{array}$ & $\begin{array}{r}32 \\
36 \\
32 \\
33 \\
32 \\
30 \\
29 \\
29 \\
30 \\
33 \\
108 \\
\end{array}$ & 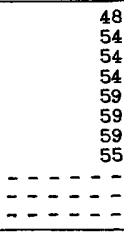 \\
\hline \multicolumn{7}{|l|}{$\begin{array}{l}\text { Monthly } \\
\text { Runoff, } \\
\text { Runoff, }\end{array}$} & $\begin{array}{r}32.3 \\
0.04 \\
1.990 \\
\end{array}$ & $\begin{array}{r}168 \\
0.18 \\
9,320 \\
\end{array}$ \\
\hline
\end{tabular}


Gage helght, in feet, and discharge, in cub1c feet per second, at indicated time, 1963, of

\begin{tabular}{|c|c|c|c|c|c|c|c|c|c|c|c|}
\hline Date & Hour & $\begin{array}{c}\text { Gage } \\
\text { he1ght }\end{array}$ & $\begin{array}{c}\text { Dis- } \\
\text { charge }\end{array}$ & Date & Hour & $\begin{array}{c}\text { Gage } \\
\text { height }\end{array}$ & $\begin{array}{c}\text { D1s- } \\
\text { charge }\end{array}$ & Date & Hour & $\begin{array}{c}\text { Gage } \\
\text { helght }\end{array}$ & $\begin{array}{c}\text { D1B- } \\
\text { charge }\end{array}$ \\
\hline $\begin{array}{r}\text { Jan. } 29 \\
30\end{array}$ & $\begin{array}{l}2400 \\
1700 \\
2400 \\
1700 \\
2200 \\
2400 \\
\end{array}$ & $\begin{array}{l}0.99 \\
1.03 \\
1.13 \\
1.40 \\
1.86 \\
1.94 \\
\end{array}$ & $\begin{array}{r}28 \\
33 \\
47 \\
100 \\
237 \\
266 \\
\end{array}$ & Feb. 1 & $\begin{array}{l}0700 \\
2100 \\
2400 \\
\\
0800 \\
1000 \\
1100 \\
1430\end{array}$ & $\begin{array}{l}3.06 \\
4.56 \\
4.76 \\
5.64 \\
5.74 \\
5.74 \\
5.61\end{array}$ & $\begin{array}{r}710 \\
1,330 \\
1,430 \\
1,870 \\
1,920 \\
1,920 \\
1,860\end{array}$ & $\mathrm{Feb} . \quad 2$ & $\begin{array}{l}1700 \\
2100 \\
2400 \\
\\
0700 \\
1500 \\
2400\end{array}$ & $\begin{array}{l}5.28 \\
3.02 \\
2.67 \\
2.28 \\
2.04 \\
1.88\end{array}$ & $\begin{array}{r}1,690 \\
698 \\
558 \\
\\
404 \\
311 \\
252\end{array}$ \\
\hline
\end{tabular}

10-3015. Walker River near Wabuska, Nev.

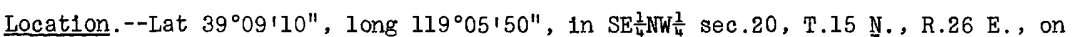
left bank $600 \mathrm{ft}$ upstream from timber bridge at Julian Ranch, $1 \frac{3}{4}$ miles downstream from Southerm Pacific Railroad bridge, 4.6 miles east of Wabuska, and 16 miles upstream from Weber Dam.

Drainage area. $--2,600 \mathrm{sq} \mathrm{mi}$, approximately.

Gage-helght record.--Water-stage recorder graph. Altitude of gage is $4,280 \mathrm{ft}$ (from topographic map).

Discharge record.--Stage-discharge relation defined by current-meter measurements; affected by 1ce Jan. 1-30. Discharge for period of ice effect. estimated on basis of weather records and records for nearby stations.

Maxima.--January-February 1963: Discharge, 1,690 cfs 1500 hours Feb. 3 (gage helght, $8.76 \mathrm{ft}$ ).

1902-8, 1920-35, 1939 to December 1962: Discharge observed, 3,280 cfs July 10, il, 1906 (gage helght, $5.90 \mathrm{ft}$ ) site and datum then in use.

Remarks.--Flow regulated by Bridgeport Reservolr and Topaz Reservolr (see stations $10-2925$ and $10-29701$.

Mean discharge, in cub1c feet per second, 1963

\begin{tabular}{|c|c|c|c|c|c|c|c|c|}
\hline Day & January & February & Day & January & February & Day & January & February \\
\hline $\begin{array}{c}1 \ldots \ldots \\
2 \ldots \ldots \\
3 \ldots \ldots \\
4 \ldots \ldots \\
5 \ldots \ldots \\
7 \ldots \ldots \\
8 \ldots \ldots \\
9 \ldots \ldots \\
10 \ldots \ldots\end{array}$ & $\begin{array}{l}38 \\
38 \\
38 \\
50 \\
48 \\
45 \\
45 \\
45 \\
47 \\
47\end{array}$ & $\begin{array}{r}279 \\
900 \\
1,470 \\
719 \\
643 \\
618 \\
618 \\
632 \\
630 \\
600\end{array}$ & $\begin{array}{l}11 \ldots \ldots \\
12 \ldots \ldots \\
13 \ldots \ldots \\
14 \ldots \ldots \\
15 \ldots \ldots \\
16 \ldots \ldots \\
17 \ldots \ldots \\
18 \ldots \ldots \\
19 \ldots \ldots \\
20 \ldots \ldots\end{array}$ & $\begin{array}{l}35 \\
25 \\
28 \\
30 \\
32 \\
33 \\
34 \\
40 \\
32 \\
33\end{array}$ & $\begin{array}{l}448 \\
352 \\
312 \\
302 \\
286 \\
273 \\
265 \\
258 \\
255 \\
255\end{array}$ & $\begin{array}{l}21 \ldots \ldots \\
22 \ldots \ldots \\
23 \ldots \ldots \\
24 \ldots \ldots \\
25 \ldots \ldots \\
26 \ldots \ldots \\
27 \ldots \ldots \\
28 \ldots \ldots \\
29 \ldots \ldots \\
30 \ldots \ldots \\
31 \ldots \ldots\end{array}$ & $\begin{array}{r}35 \\
40 \\
40 \\
40 \\
40 \\
38 \\
36 \\
50 \\
70 \\
100 \\
123\end{array}$ & $\begin{array}{r}213 \\
168 \\
149 \\
136 \\
131 \\
120 \\
115 \\
111 \\
------ \\
----1-\end{array}$ \\
\hline 10 & $\begin{array}{l}\text { inche } \\
\text { acre-1 }\end{array}$ & & & & & & $\begin{array}{r}44.4 \\
0.02 \\
2,730 \\
\end{array}$ & $\begin{array}{r}402 \\
0.16 \\
22,330 \\
\end{array}$ \\
\hline
\end{tabular}

Gage height, In feet, and discharge, in cub1c feet per second, at indicated t1me, 1963

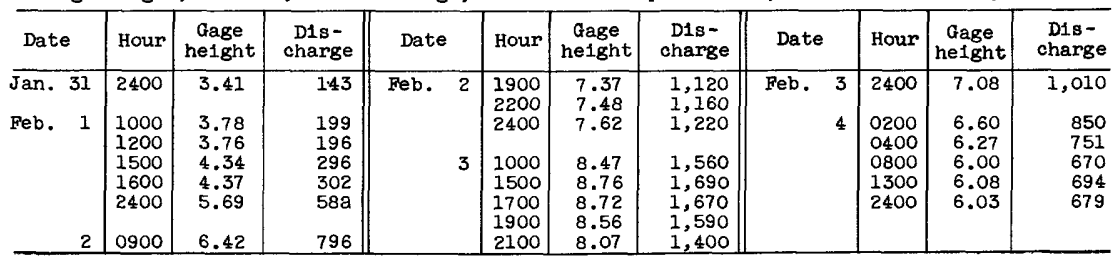




\section{CARSON RIVER BASIN}

10-3045. Silver Creek below Pennsylvania Creek, near Markleeville, Calif.

Location.--Lat $38^{\circ} 36^{\prime} 00^{\prime \prime}$, long $119^{\circ} 46^{\prime} 30^{\prime \prime}$, in $\mathrm{SE}_{\frac{1}{4}} \mathrm{NE} \frac{1}{4} \sec .28$, T.9 N., R.20 E., on left bank a quarter of a mile downstream from Pennsylvania Creek, 4 miles upstream from mouth, and $6 \frac{1}{2}$ miles south of Markleeville.

Drainage area.--20 sq $\mathrm{mi}$, approximately.

Gage-he1ght record.--Water-stage recorder graph, except Feb. 9-28. Altitude of gage is $6,500 \mathrm{ft}$ (from topographic map).

Discharge record.--Stage-discharge relation defined by current-meter measurements below $400 \mathrm{cfs}$ and by slope-area measurement at $2,220 \mathrm{cfs}$; affected by ice

Jan. 11-12, 19. Discharge for periods of no gage-helght record or period of ice effect estimated on basis of weather records and records for East Fork Carson River near Markleeville, Calif.

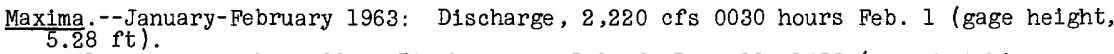

1946 to December 1962: Discharge, 1,520 cfs Dec. 23, 1955 (gage height, $6.09 \mathrm{ft}$, at site $30 \mathrm{ft}$ upstream at datum $1.00 \mathrm{ft}$ higher.

Mean discharge, in cublc feet per second, 1963

\begin{tabular}{|c|c|c|c|c|c|c|c|c|}
\hline Day & January & February & Day & January & February & Day & January & February \\
\hline $\begin{array}{r}1 \ldots \ldots \\
2 \ldots \ldots \\
4 \ldots \ldots \\
5 \ldots \ldots \\
6 \ldots \ldots \\
8 \ldots \ldots \\
9 \ldots \ldots \\
10 \ldots \ldots\end{array}$ & $\begin{array}{l}5.3 \\
5.3 \\
5.5 \\
5.7 \\
5.5 \\
5.1 \\
4.9 \\
4.9 \\
4.9 \\
4.9\end{array}$ & $\begin{array}{r}739 \\
151 \\
154 \\
115 \\
106 \\
88 \\
75 \\
55 \\
50 \\
45\end{array}$ & $\begin{array}{l}11 \ldots \ldots \\
12 \ldots \ldots \\
13 \ldots \ldots \\
14 \ldots \ldots \\
15 \ldots \ldots \\
16 \ldots \ldots \\
17 \ldots \ldots \\
18 \ldots \ldots \\
19 \ldots \ldots \\
20 \ldots \ldots\end{array}$ & $\begin{array}{l}4.2 \\
3.4 \\
2.8 \\
3.3 \\
4.0 \\
4.0 \\
3.8 \\
3.7 \\
3.4 \\
3.1\end{array}$ & $\begin{array}{l}40 \\
40 \\
35 \\
35 \\
35 \\
35 \\
30 \\
30 \\
30 \\
30\end{array}$ & $\begin{array}{l}21 \ldots \ldots \\
22 \ldots \ldots \\
23 \ldots \ldots \\
24 \ldots \ldots \\
25 \ldots \ldots \\
26 \ldots \ldots \\
27 \ldots \ldots \\
28 \ldots \ldots \\
29 \ldots \ldots \\
30 \ldots \ldots \\
31 \ldots \ldots\end{array}$ & $\begin{array}{r}3.3 \\
3.7 \\
3.8 \\
4.0 \\
4.0 \\
3.8 \\
3.7 \\
3.7 \\
3.8 \\
32 \\
553\end{array}$ & $\begin{array}{r}30 \\
25 \\
25 \\
25 \\
25 \\
25 \\
25 \\
25 \\
-\ldots--\end{array}$ \\
\hline \multicolumn{7}{|l|}{$\begin{array}{l}\text { Monthly } \\
\text { Runoff, } \\
\text { Runoff, }\end{array}$} & $\begin{array}{r}22.8 \\
1.31 \\
1,400\end{array}$ & $\begin{array}{r}75.8 \\
3.95 \\
4,210 \\
\end{array}$ \\
\hline
\end{tabular}

Gage height, in feet, and discharge, in cuble feet per second, at indicated time, 1963

\begin{tabular}{|c|c|c|c|c|c|c|c|c|c|c|c|}
\hline Date & Hour & $\begin{array}{c}\text { Gage } \\
\text { helght }\end{array}$ & $\begin{array}{l}\text { Dis- } \\
\text { charge }\end{array}$ & Date & Hour & $\begin{array}{c}\text { Gage } \\
\text { helght }\end{array}$ & $\begin{array}{l}\text { Dis- } \\
\text { charge }\end{array}$ & Date & Hour & $\begin{array}{c}\text { Gage } \\
\text { he1ght }\end{array}$ & $\begin{array}{c}\text { Dis- } \\
\text { charge }\end{array}$ \\
\hline $\begin{array}{r}\text { Jan. } 29 \\
30\end{array}$ & $\begin{array}{l}2400 \\
1100 \\
1800 \\
2400 \\
0300 \\
0800 \\
1300 \\
1600\end{array}$ & $\begin{array}{l}1.12 \\
1.50 \\
2.30 \\
2.20 \\
2.20 \\
2.76 \\
3.75 \\
3.70\end{array}$ & $\begin{array}{r}4.6 \\
14 \\
69 \\
59 \\
59 \\
146 \\
542 \\
515\end{array}$ & Feb. 1 & $\begin{array}{l}1800 \\
2000 \\
2100 \\
2400 \\
0030 \\
0100 \\
0200 \\
0300 \\
0530\end{array}$ & $\begin{array}{l}4.00 \\
4.00 \\
5.15 \\
4.85 \\
5.28 \\
4.60 \\
4.25 \\
3.85 \\
4.15\end{array}$ & $\begin{array}{r}695 \\
695 \\
2,000 \\
1,550 \\
\\
2,220 \\
1,480 \\
1,200 \\
946 \\
1,170\end{array}$ & Feb. I & $\begin{array}{l}0700 \\
0730 \\
1000 \\
1300 \\
1500 \\
2400 \\
\\
0700 \\
1000 \\
2400\end{array}$ & $\begin{array}{l}3.95 \\
4.17 \\
3.65 \\
2.90 \\
2.23 \\
1.73 \\
1.35 \\
1.28 \\
1.25\end{array}$ & $\begin{array}{r}1,050 \\
1,250 \\
892 \\
536 \\
321 \\
213 \\
\\
150 \\
140 \\
135\end{array}$ \\
\hline
\end{tabular}

10-3081. Millberry Creek at Markleeville, Calif.

(Crest-stage station)

Location.--Lat $38^{\circ} 42^{\prime} 00^{\prime \prime}$, long $119^{\circ} 47^{\prime} 00^{\prime \prime}$, In SW $\frac{1}{4} \mathrm{NE} \frac{1}{4} \sec .21$, T.10 N., R.20 E., at culvert on State Highway $4,89,0.4$ mile northwest of Markleevilie.

Drainage area. $--5.10 \mathrm{sq} \mathrm{mi}$.

Gage-height record.--Crest stages only. Altitude of gage is $5,600 \mathrm{ft}$ (from topographic map).

Discharge record.--Peak discharge by computation of flow through culvert.

Maximum.--January-February 1963: Discharge, $480 \mathrm{cfs}$ Jan. 31 (gage height, $17.1 \mathrm{ft}$ ). 
10-3082. East Fork Carson River below Markleeville Creek, near Markleeville, Calif.

Location.--Lat $38^{\circ} 42^{\prime} 50^{\prime \prime}$, long $119^{\circ} 45^{\prime} 50^{\prime \prime}$, in SW $\frac{1}{4} \mathrm{NE} \frac{1}{4}$ sec.15, T.10 N., R.20 E., on right bank 0.5 mile downstream from Markleeville Creek and $1 \frac{1}{2}$ miles northnortheast of Markleeville.

Drainage area. $--299 \mathrm{sq} \mathrm{mi}$.

Gage-height record.--Water-stage recorder graph, except Feb. 8-20, 26-28. Altitude of gage is $5,400 \mathrm{ft}$ (from topographic map).

D1scharge record.--Stage-discharge relation defined by current-meter measurements below $1,500 \mathrm{c}$ s and by slope-area measurement at 15,100 cfs; affected by ice Jan. 1-28. Discharge for perlods of no gage-height record or period of ice effect estimated on basis of weather records and records for nearby stations.

Maxima --January-February 1963: Discharge, 15,100 cfs 2200 hours Jan. 31 (gage helght, $8.21 \mathrm{ft}$ ).

1960 to December 1962: Discharge, 2,250 cfs May 5, 1962 (gage height, $3.35 \mathrm{ft}^{\mathrm{t}}$.

Mean discharge, in cublc feet per second, 1963

\begin{tabular}{|c|c|c|c|c|c|c|c|c|}
\hline Day & anuary & February & Day & January & February & Day & January & February \\
\hline $\begin{array}{r}1 \ldots \ldots \\
2 \ldots \ldots \\
3 \ldots \ldots \\
4 \ldots \ldots \\
5 \ldots \ldots \\
6 \ldots \ldots \\
7 \ldots \ldots \\
5 . \ldots . \\
90 . \ldots \\
10 . \ldots\end{array}$ & $\begin{array}{l}70 \\
70 \\
70 \\
70 \\
70 \\
65 \\
60 \\
60 \\
55 \\
50\end{array}$ & $\begin{array}{r}7,360 \\
1,680 \\
1,150 \\
910 \\
748 \\
673 \\
615 \\
560 \\
480 \\
420\end{array}$ & 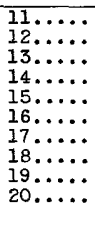 & $\begin{array}{l}35 \\
25 \\
30 \\
40 \\
50 \\
55 \\
60 \\
65 \\
55 \\
55\end{array}$ & $\begin{array}{l}390 \\
370 \\
360 \\
340 \\
320 \\
310 \\
300 \\
300 \\
290 \\
280\end{array}$ & $\begin{array}{l}21 \ldots \ldots \\
22 \ldots \ldots \\
23 \ldots \ldots \\
24 \ldots \ldots \\
25 \ldots \ldots \\
26 \ldots \ldots \\
27 \ldots \ldots \\
28 \ldots \ldots \\
29 \ldots \ldots \\
30 \ldots \ldots \\
31 \ldots \ldots\end{array}$ & $\begin{array}{r}55 \\
60 \\
60 \\
60 \\
60 \\
55 \\
55 \\
55 \\
58 \\
1,150 \\
6,310\end{array}$ & $\begin{array}{r}250 \\
270 \\
260 \\
255 \\
250 \\
230 \\
220 \\
215 \\
--.-15 \\
-.-10\end{array}$ \\
\hline \multicolumn{7}{|c|}{$\begin{array}{l}\text { nthly mean discharge, in cuble feet pe } \\
\text { noff, in inches....................... }\end{array}$} & $\begin{array}{r}293 \\
1.13 \\
1 \mathrm{~s}, 030\end{array}$ & $\begin{array}{r}710 \\
2.47 \\
39,410 \\
\end{array}$ \\
\hline
\end{tabular}

Gage height, In feet, and discharge, in cublc feet per second, at indicated time, 1963

\begin{tabular}{|c|c|c|c|c|c|c|c|c|c|c|c|}
\hline Date & Hour & $\begin{array}{c}\text { Gage } \\
\text { helght }\end{array}$ & $\begin{array}{c}\text { D1s- } \\
\text { charge }\end{array}$ & Date & Hour & $\begin{array}{c}\text { Gage } \\
\text { helght }\end{array}$ & $\begin{array}{c}\text { D1s- } \\
\text { charge }\end{array}$ & Date & Hour & $\begin{array}{c}\text { Gage } \\
\text { height }\end{array}$ & $\begin{array}{l}\text { D1s - } \\
\text { charge }\end{array}$ \\
\hline $\begin{array}{r}\text { Jan. } 29 \\
30\end{array}$ & $\begin{array}{l}2400 \\
0700 \\
1100 \\
1400 \\
1700 \\
1900 \\
2000 \\
2100 \\
2200 \\
2400\end{array}$ & $\begin{array}{l}0.85 \\
1.42 \\
1.60 \\
2.85 \\
3.15 \\
3.86 \\
3.86 \\
3.60 \\
3.65 \\
3.08\end{array}$ & $\begin{array}{r}64 \\
236 \\
322 \\
1,440 \\
1,850 \\
3,020 \\
3,020 \\
2,570 \\
2,650 \\
1,770\end{array}$ & Jan. 31 & $\begin{array}{l}0300 \\
0500 \\
0700 \\
1200 \\
1400 \\
1500 \\
1700 \\
1900 \\
2200 \\
2300 \\
2400\end{array}$ & $\begin{array}{l}2.61 \\
3.00 \\
2.88 \\
5.45 \\
5.82 \\
6.28 \\
6.37 \\
6.22 \\
8.21 \\
7.65 \\
7.80\end{array}$ & $\begin{array}{r}1,150 \\
1,650 \\
1,480 \\
6,580 \\
7,500 \\
8,840 \\
9,110 \\
8,660 \\
15,100 \\
13,100 \\
13,600\end{array}$ & Feb. I & $\begin{array}{l}0300 \\
0500 \\
0900 \\
1200 \\
1700 \\
2200 \\
2400 \\
0800 \\
1500 \\
2400\end{array}$ & $\begin{array}{l}7.50 \\
7.35 \\
6.20 \\
5.30 \\
4.40 \\
3.50 \\
3.30 \\
2.76 \\
2.50 \\
2.44\end{array}$ & $\begin{array}{r}12,600 \\
12,000 \\
3,600 \\
6,250 \\
4,300 \\
2,760 \\
2,460 \\
1,730 \\
1,420 \\
1,350\end{array}$ \\
\hline
\end{tabular}

10-3088. Bryant Creek near Gardnerville, Nev.

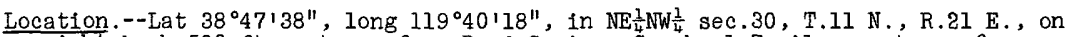
right bank $500 \mathrm{ft}$ upstream from Doud Springs Creek, 1.7 miles upstream from mouth, and 11 miles southeast of Gardnerville.

Drainage area. $--31.5 \mathrm{sq} \mathrm{mi}$.

Gage-height record.--Water-stage recorder graph, except Jan, 30 to Feb. 28. Datum of gage is $5,449.74 \mathrm{ft}$ above mean sea level, datum of 1929 , releveled 1940 (levels by Bureau of Reclamation).

Discharge record.--3tage-discharge relation defined by current-meter measurements below $63 \mathrm{cfs}$ and by slope-area measurement at $975 \mathrm{cfs}$. Discharge for period of no gage-height record estimated on basis of weather records and records for nearby stations.

Maxima.--January-February 1963: Discharge, 975 cfs Jan. 31 (gage height, $6.40 \mathrm{ft}$, from floodmarks).

1961 to December 1962: Discharge, 58 cfs Apr. 9, 1962 (gage height, $2.04 \mathrm{ft}$ ). 
Mean discharge, In cublc feet per second, 1963, of Bryant Creek near Gardnerville, Nev.

\begin{tabular}{|c|c|c|c|c|c|c|c|c|}
\hline Day & January & February & Day & January & February & Day & January & February \\
\hline $\begin{array}{c}1 \ldots \ldots \\
2 \ldots \ldots \\
3 \ldots \ldots \\
4 \ldots \ldots \\
5 \ldots \ldots \\
7 \ldots \ldots \\
8 \ldots \ldots \\
9 \ldots \ldots \\
10 \ldots \ldots\end{array}$ & $\begin{array}{l}2.4 \\
2.4 \\
2.4 \\
2.6 \\
2.6 \\
2.4 \\
2.3 \\
2.3 \\
2.6 \\
2.4\end{array}$ & $\begin{array}{l}\overline{-} \\
\overline{-} \\
\overline{-} \\
\overline{-} \\
\overline{-} \\
-\end{array}$ & $\begin{array}{l}11 \ldots \ldots \\
12 \ldots \ldots \\
13 \ldots \ldots \\
14 \ldots \ldots \\
15 \ldots \ldots \\
16 \ldots \ldots \\
17 \ldots \ldots \\
18 \ldots \ldots \\
19 \ldots \ldots \\
20 \ldots \ldots\end{array}$ & $\begin{array}{l}1.8 \\
1.5 \\
1.4 \\
1.5 \\
1.9 \\
2.4 \\
2.4 \\
2.4 \\
2.0 \\
1.8\end{array}$ & $\begin{array}{l}- \\
- \\
- \\
- \\
- \\
- \\
-\end{array}$ & $\begin{array}{l}21 \ldots \ldots \\
22 \ldots \ldots \\
23 \ldots \ldots \\
24 \ldots \ldots \\
25 \ldots \ldots \\
26 \ldots \ldots \\
27 \ldots \ldots \\
28 \ldots \ldots \\
29 \ldots \ldots \\
30 \ldots \ldots \\
31 \ldots \ldots\end{array}$ & $\begin{array}{r}2.1 \\
2.4 \\
2.6 \\
2.4 \\
2.4 \\
2.3 \\
2.4 \\
2.3 \\
2.4 \\
10 \\
300\end{array}$ & $\begin{array}{c}- \\
- \\
- \\
- \\
- \\
- \\
- \\
- \\
----\overline{-} \\
--\overline{-}-\overline{-} \\
----.\end{array}$ \\
\hline \multicolumn{7}{|l|}{$\begin{array}{l}\text { Monthly } \\
\text { Runoff, } \\
\text { Runoff, }\end{array}$} & $\begin{array}{r}12.1 \\
0.44 \\
743\end{array}$ & $\begin{array}{r}13.0 \\
0.43 \\
722\end{array}$ \\
\hline
\end{tabular}

10-3090. East Fork Carson R1ver near Gardnerville, Nev.

Location,--Lat $38^{\circ} 50^{\prime} 50^{\prime \prime}$, long $119^{\circ} 42^{\prime} 10^{\prime \prime}$, in SW $\frac{1}{4} \mathrm{NE} \frac{1}{4} \sec .2$, T. 11 N., R.20 E., on left bank 2 miles east of Mud Lake Reservoir, $4 \frac{1}{2}$ miles downstream from Bryant Creek, and 7 miles southeast of Gardnerville.

Drainage area. $--344 \mathrm{sq} \mathrm{ml}$.

Gage-he1ght record.--Water-stage recorder graph, except Jan. 1-14, Feb. 24-28. Datum of gage is 4,985.11 ft above mean sea level (levels by Bureau of Reclamation).

Discharge record.--Stage-discharge relation defined by current-meter measurements; affected by ice Jan. 15-29. D1scharge for periods of no gage-height record or

ice effect estimated on basis of weather records and records for nearby stations.

Maxima.--January-February 1963: Discharge, 13,400 efs 0800 hours Feb. 1 (gage height, $10.45 \mathrm{ft}$ ).

$1890-93,1900-1906,1908-10,1917,1924-28,1929,1935-37,1939$ to December 1962: Discharge, 17,600 cfs Dec. 23, 1955 (gage height, $11.88 \mathrm{ft}$ ), from rating curve extended above $6,000 \mathrm{cfs}$ on basis of slope-area measurements at gage helghts 9.66 and $11.88 \mathrm{ft}$.

Mean discharge, in cublc feet per second, 1963

\begin{tabular}{|c|c|c|c|c|c|c|c|c|}
\hline Day & January & February & Day & January & February & Day & January & February \\
\hline $\begin{array}{c}1 \ldots \ldots \\
2 \ldots \ldots \\
3 \ldots \ldots \\
4 \ldots \ldots \\
5 \ldots \ldots \\
7 \ldots \ldots \\
8 \ldots \ldots \\
9 \ldots \ldots \\
10 \ldots \ldots\end{array}$ & $\begin{array}{l}58 \\
59 \\
60 \\
65 \\
70 \\
72 \\
74 \\
72 \\
60 \\
54\end{array}$ & $\begin{array}{r}8,520 \\
1,820 \\
1,180 \\
1,030 \\
937 \\
764 \\
692 \\
630 \\
540 \\
480\end{array}$ & $\begin{array}{l}11 \ldots \ldots \\
12 \ldots \ldots \\
13 \ldots \ldots \\
14 \ldots \ldots \\
15 \ldots \ldots \\
16 \ldots \ldots \\
17 \ldots \ldots \\
18 \ldots \ldots \\
19 \ldots \ldots \\
20 \ldots \ldots\end{array}$ & $\begin{array}{l}52 \\
52 \\
57 \\
60 \\
63 \\
70 \\
74 \\
70 \\
60 \\
53\end{array}$ & $\begin{array}{l}421 \\
393 \\
402 \\
384 \\
355 \\
358 \\
336 \\
327 \\
319 \\
319\end{array}$ & $\begin{array}{l}21 \ldots \ldots \\
22 \ldots \ldots \\
23 \ldots \ldots \\
24 \ldots \ldots \\
25 \ldots \ldots \\
26 \ldots \ldots \\
27 \ldots \ldots \\
28 \ldots \ldots \\
29 \ldots \ldots \\
30 \ldots \ldots \\
31 \ldots \ldots\end{array}$ & $\begin{array}{r}58 \\
62 \\
70 \\
82 \\
83 \\
80 \\
75 \\
78 \\
80 \\
942 \\
5,040\end{array}$ & $\begin{array}{r}319 \\
315 \\
298 \\
280 \\
270 \\
250 \\
230 \\
240 \\
---\end{array}$ \\
\hline \multicolumn{7}{|l|}{$\begin{array}{l}\text { Monthly } \\
\text { Runoff, } \\
\text { Runoff, }\end{array}$} & $\begin{array}{r}255 \\
0.85 \\
15,680\end{array}$ & $\begin{array}{r}800 \\
2.42 \\
44,450 \\
\end{array}$ \\
\hline
\end{tabular}

Gage height, in feet, and discharge, in cubic feet per second, at Indlcated time, 1963

\begin{tabular}{|c|c|c|c|c|c|c|c|c|c|c|c|}
\hline Date & Hour & $\begin{array}{c}\text { Gage } \\
\text { height }\end{array}$ & $\begin{array}{l}\text { Dis- } \\
\text { charge }\end{array}$ & Date & Hour & $\begin{array}{c}\text { Gage } \\
\text { height }\end{array}$ & $\begin{array}{c}\text { Dis- } \\
\text { charge }\end{array}$ & Date & Hour & $\begin{array}{c}\text { Gage } \\
\text { height }\end{array}$ & $\begin{array}{c}\text { Dis - } \\
\text { charge }\end{array}$ \\
\hline $\begin{array}{r}\text { Jan. } 29 \\
30\end{array}$ & $\begin{array}{l}2400 \\
0500 \\
0900 \\
1430 \\
1500 \\
1700 \\
2100 \\
2200 \\
2400 \\
0400\end{array}$ & $\begin{array}{l}1.03 \\
1.06 \\
1.21 \\
1.96 \\
2.82 \\
3.75 \\
4.80 \\
4.74 \\
4.51 \\
3.49\end{array}$ & $\begin{array}{r}92 \\
98 \\
135 \\
421 \\
958 \\
1,700 \\
2,840 \\
2,770 \\
2,490 \\
1,460\end{array}$ & Feb. 1 & $\begin{array}{l}0700 \\
0800 \\
0900 \\
1400 \\
1600 \\
1800 \\
2030 \\
2400 \\
\\
0100 \\
0300 \\
0500\end{array}$ & $\begin{array}{r}3.91 \\
3.86 \\
4.01 \\
7.06 \\
7.94 \\
8.12 \\
7.85 \\
9.84 \\
\\
9.95 \\
10.12 \\
10.44\end{array}$ & $\begin{array}{r}1,850 \\
1,800 \\
1,950 \\
6,150 \\
7,850 \\
8,210 \\
7,670 \\
11,900 \\
12,100 \\
12,500 \\
13,300\end{array}$ & Feb. I & $\begin{array}{l}0700 \\
0800 \\
1300 \\
2400 \\
\\
0400 \\
1000 \\
1400 \\
2330 \\
2400\end{array}$ & $\begin{array}{r}10.00 \\
10.45 \\
7.40 \\
4.83 \\
4.30 \\
3.80 \\
3.58 \\
3.33 \\
3.19\end{array}$ & $\begin{array}{r}12,300 \\
13,400 \\
6,780 \\
2,880 \\
2,270 \\
1,760 \\
1,570 \\
1,370 \\
1,250\end{array}$ \\
\hline
\end{tabular}


10-3100. West Fork Carson River at Woodfords, Calif.

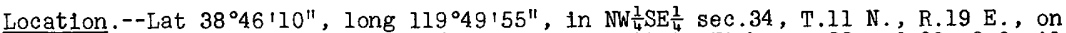
left bank $0.3 \mathrm{mile}$ downstream from bridge on State Highways 88 and $89,0.6 \mathrm{mile}$ southwest of Woodfords, and $3 \frac{3}{4}$ miles downstream from Willow Creek.

Drainage area. $--66 \mathrm{sq} \mathrm{ml}$, approximately.

Gage-helght record.--Water-stage recorder graph, except Jan. 16 to Feb. 28. Altitude of gage is $5,760 \mathrm{ft}$ (from river-profile map).

Discharge record.--Stage-discharge relation defined by current-meter measurements below $370 \mathrm{cfs}$ and by slope-area measurement at $4,890 \mathrm{cfs}$; affected by $1 \mathrm{ce}$ Jan. 10-15. Discharge for period of no gage-he1ght record or 1ce effect est1mated on basis of weather records and records for nearby stations.

Maxima.--January-February 1963: Discharge, 4,890 cfs Feb. 1 (gage he1ght, $9.0 \mathrm{ft}$ ). 1900-1907,1910-11, 1937 to December 1962: D1scharge, 4,810 cfs Dec. 23, 1955; gage he1ght $8.0 \mathrm{ft}$, from floodmarks, Dec. 11, 1937.

Mean discharge, in cub1c feet per second, 2963

\begin{tabular}{|c|c|c|c|c|c|c|c|c|}
\hline Day & January & February & Day & January & February & Day & January & February \\
\hline $\begin{array}{l}\ldots \ldots \\
3 \ldots \ldots \\
4 \ldots \ldots \\
5 \ldots \ldots \\
7 \ldots \ldots \\
8 \ldots \ldots \\
9 \ldots \ldots \\
10 \ldots \ldots\end{array}$ & $\begin{array}{l}24 \\
24 \\
25 \\
26 \\
26 \\
26 \\
24 \\
24 \\
25 \\
23\end{array}$ & $\begin{array}{r}3,000 \\
700 \\
400 \\
330 \\
300 \\
250 \\
220 \\
190 \\
160 \\
140\end{array}$ & $\begin{array}{l}11 \ldots \ldots \\
12 \ldots \ldots \\
13 \ldots \ldots \\
14 \ldots \ldots \\
15 \ldots \ldots \\
16 \ldots \ldots \\
17 \ldots \ldots \\
18 \ldots \ldots \\
19 \ldots \ldots \\
20 \ldots \ldots\end{array}$ & $\begin{array}{l}17 \\
16 \\
17 \\
20 \\
20 \\
21 \\
23 \\
23 \\
21 \\
20\end{array}$ & $\begin{array}{r}130 \\
110 \\
102 \\
102 \\
98 \\
93 \\
90 \\
86 \\
84 \\
82\end{array}$ & $\begin{array}{l}21 \ldots \ldots \\
22 \ldots \ldots \\
23 \ldots \ldots \\
24 \ldots \ldots \\
25 \ldots \ldots \\
26 \ldots \ldots \\
27 \ldots \ldots \\
28 \ldots \ldots \\
29 \ldots \ldots \\
30 \ldots \ldots \\
31 \ldots \ldots\end{array}$ & $\begin{array}{r}20 \\
21 \\
22 \\
23 \\
25 \\
26 \\
24 \\
23 \\
23 \\
300 \\
1,500\end{array}$ & $\begin{array}{r}82 \\
81 \\
78 \\
74 \\
70 \\
66 \\
60 \\
60 \\
-\ldots---\end{array}$ \\
\hline \multicolumn{7}{|l|}{$\begin{array}{l}\text { Monthly } \\
\text { Runoff, } \\
\text { Runoff, }\end{array}$} & $\begin{array}{r}79.1 \\
1.38 \\
4,860\end{array}$ & $\begin{array}{r}258 \\
4,08 \\
14,360 \\
\end{array}$ \\
\hline
\end{tabular}

10-3105. Clear Creek near Carson C1ty, Nev.

(Crest-stage station; gaging station, discontinued 1962)

Location. --Lat $39^{\circ} 06^{\prime} 50^{\prime \prime}$, long $119^{\circ} 47^{\prime} 50^{\prime \prime}$, In $\mathrm{NE} \frac{1}{4} \mathrm{NW} \frac{1}{4}$ sec.1, T.14 N., R.19 E., on left bank 3 miles upstream from mouth and $3 \frac{1}{2}$ miles southwest of Carson City.

Dralnage area.--15 sq $\mathrm{m} 1$, approximately.

Gage-helght record.--Crest stages only. Altitude of gage is 5,000 ft (from topographic map).

Discharge record.--Stage-discharge relation defined by current-meter measurements below 100 cr's.

Maxima.--January-February 1963: D1scharge, $170 \mathrm{cfs}$ Jan. 31 (gage he1ght, $2.29 \mathrm{ft}$ ). 1948 to December 1962: Discharge, $117 \mathrm{cfs}$ Dec. 23, 1955 (gage helght, $2.03 \mathrm{ft}$ ).

10-3110. Carson River near Carson City, Nev.

Location.--Lat $39^{\circ} 06^{\prime} 30^{\prime \prime}$, long $119^{\circ} 42^{\prime} 40^{\prime \prime}$, in SW $\frac{1}{4} N W^{\frac{1}{4}}$ sec.2, T. 14 N., R.20 E., on left bank 2 miles downstream from clear Creek, 3 miles upstream from bridge on road to Mexican Dam, and 5 miles southeast of Carson C1ty.

Dralnage area. $--876 \mathrm{sg} \mathrm{m}$.

Gage-he1ght record.--Water-stage recorder graph, except Jan. 3-4, 14, 16, 20. Datum of gage is 4,621.48 ft above mean sea level, datum of 1929 .

Discharge record.--Stage-discharge relation defined by current-meter measurements below $6,000 \mathrm{cfs}$; affected by 1ce Jan. 1-2,5-6, 10-13, 15, 19, 22-24. D1scharge for perlods of no gage-helght record or lce effect estimated on basis of weather records and records for station near Fort Churchill, Nev.

Maxima.--January-February 1963: Discharge, 21,900 cfs 2100 hours Feb. I (gage helght, 13.11 ft).

1939 to December 1962: Discharge, 30,000 cfs Dec. 24, 1955 (gage height, $15.0 \mathrm{ft}$, from floodmarks), from rating curve extended above $6,000 \mathrm{cfs}$ on basis of slope-area measurements at 8,500 and $30,000 \mathrm{cfs}$, computation of flow over dam at $15,500 \mathrm{cfs}$, and float measurement at $9,790 \mathrm{ft}$. 
Mean discharge, in cublc feet per second, 1963, of Carson River near Carson C1ty, Nev.

\begin{tabular}{|c|c|c|c|c|c|c|c|c|}
\hline Day & January & February & Day & January & February & Day & J anuary & February \\
\hline $\begin{array}{c}1 \ldots \ldots \\
3 \ldots \ldots \\
4 \ldots \ldots \\
5 \ldots \ldots \\
6 \ldots \ldots \\
8 \ldots \ldots \\
9 \ldots \ldots \\
10 \ldots \ldots\end{array}$ & $\begin{array}{l}102 \\
100 \\
109 \\
106 \\
104 \\
123 \\
141 \\
139 \\
135 \\
127\end{array}$ & $\begin{array}{r}12,200 \\
12,100 \\
4,370 \\
2,220 \\
1,820 \\
1,520 \\
1,250 \\
1,100 \\
972 \\
881\end{array}$ & $\begin{array}{l}11 \ldots \ldots \\
12 \ldots \ldots \\
13 \ldots \ldots \\
14 \ldots \ldots \\
15 \ldots \ldots \\
16 \ldots \ldots \\
17 \ldots \ldots \\
18 \ldots \ldots \\
19 \ldots \ldots \\
20 \ldots \ldots\end{array}$ & $\begin{array}{l}127 \\
133 \\
118 \\
120 \\
120 \\
127 \\
118 \\
114 \\
111 \\
113\end{array}$ & $\begin{array}{l}788 \\
711 \\
674 \\
711 \\
626 \\
580 \\
540 \\
509 \\
493 \\
482\end{array}$ & $\begin{array}{l}21 \ldots \ldots \\
22 \ldots \ldots \\
23 \ldots \ldots \\
24 \ldots \ldots \\
25 \ldots \ldots \\
26 \ldots \ldots \\
27 \ldots \ldots \\
28 \ldots \ldots \\
29 \ldots \ldots \\
30 \ldots \ldots \\
31 \ldots \ldots\end{array}$ & $\begin{array}{l}114 \\
113 \\
109 \\
109 \\
109 \\
107 \\
107 \\
107 \\
123 \\
184 \\
2,320\end{array}$ & $\begin{array}{r}472 \\
456 \\
416 \\
401 \\
382 \\
358 \\
335 \\
344 \\
---- \\
----- \\
----\end{array}$ \\
\hline $\begin{array}{l}\text { nthly } \\
\text { noff, } \\
\text { noff, }\end{array}$ & acre & & & & & & $\begin{array}{r}190 \\
0.25 \\
11,670 \\
\end{array}$ & $\begin{array}{r}1,704 \\
2.03 \\
94,630 \\
\end{array}$ \\
\hline
\end{tabular}

Gage helght, in feet, and discharge, in cublc feet per second, at indicated time, 1963

\begin{tabular}{|c|c|c|c|c|c|c|c|c|c|c|c|}
\hline Date & Hour & $\begin{array}{c}\text { Gage } \\
\text { helght }\end{array}$ & $\begin{array}{c}\text { Dis - } \\
\text { charge }\end{array}$ & Date & Hour & $\begin{array}{c}\text { Gage } \\
\text { helght }\end{array}$ & $\begin{array}{l}\text { Dis- } \\
\text { charge }\end{array}$ & Date & Hour & $\begin{array}{c}\text { Gage } \\
\text { helght }\end{array}$ & $\begin{array}{c}\text { Dis- } \\
\text { charge }\end{array}$ \\
\hline Jan. 29 & 2400 & 1.20 & 120 & Jan. 31 & 2400 & 5.44 & 3,510 & Feb. 2 & $\begin{array}{l}2000 \\
2400\end{array}$ & $\begin{array}{l}8.16 \\
7.58\end{array}$ & $\begin{array}{l}7,510 \\
6,550\end{array}$ \\
\hline 30 & $\begin{array}{l}1200 \\
1700 \\
2000 \\
2400\end{array}$ & $\begin{array}{l}1.32 \\
1.50 \\
1.63 \\
2.02\end{array}$ & $\begin{array}{l}149 \\
196 \\
238 \\
401\end{array}$ & Feb. 1 & $\begin{array}{l}0300 \\
0900 \\
1600 \\
1900 \\
2100\end{array}$ & $\begin{array}{r}5.68 \\
6.90 \\
12.34 \\
13.01 \\
13.11\end{array}$ & $\begin{array}{r}3,800 \\
5,500 \\
18,900 \\
21,500 \\
21,900\end{array}$ & 3 & $\begin{array}{l}0800 \\
1030 \\
2400\end{array}$ & $\begin{array}{l}6.45 \\
6.14 \\
4.67\end{array}$ & $\begin{array}{l}4,850 \\
4,420 \\
2,640\end{array}$ \\
\hline 31 & $\begin{array}{l}0400 \\
0600 \\
0900 \\
1900\end{array}$ & $\begin{array}{l}3.48 \\
3.91 \\
4.26 \\
5.08\end{array}$ & $\begin{array}{l}1,390 \\
1,810 \\
2,180 \\
3,090\end{array}$ & 2 & $\begin{array}{l}2400 \\
1000 \\
1600\end{array}$ & $\begin{array}{r}12.83 \\
10.25 \\
8.91\end{array}$ & $\begin{array}{r}20,800 \\
12,200 \\
8,920\end{array}$ & 4 & $\begin{array}{l}0300 \\
2400\end{array}$ & $\begin{array}{l}4.45 \\
4.05\end{array}$ & $\begin{array}{l}2,400 \\
1,960\end{array}$ \\
\hline
\end{tabular}

10-3119. Buckland ditch near Fort Churchill, Nev.

Location.--Lat $39^{\circ} 17^{\prime} 35^{\prime \prime}$, long $11^{\circ} 18^{\prime} 45^{\prime \prime}$, in $\mathrm{NW} \frac{1}{4} \mathrm{SE} \frac{1}{4} \sec .32$, T.17 N., R. $24 \mathrm{E}$, on left bank $200 \mathrm{ft}$ downstream from diversion, 2 miles west of Fort Churchili, and $4 \frac{1}{2}$ miles upstream from Weeks bridge on U.S. Highway 95 alternate.

Gage-height record.--Water-stage recorder graph, except Jan. 12-16, 19-24.

Discharge record.--Stage-discharge relation defined by current-meter measurements; affected by ice Jan. 2-3,11,17-18. Discharge for periods of ice effect or no gage-height record estimated from weather records and trend of flow.

Maximum.--January-February 1963: Daily discharge, $223 \mathrm{cf}$ s Feb. 3 . For maximum stage, see Carson River near Fort Churchill, which stage overflowed Buckland ditch at 0500 hours Feb. 2 to 1600 hours Feb. 3.

Remarks.--Flow is regulated by diversion gate about $200 \mathrm{ft}$ above station. Flow in excess of $240 \mathrm{cfs}$ is considered as part of Carson River near Fort Churchill.

Mean discharge, in cubic feet per second, 1963

\begin{tabular}{|c|c|c|c|c|c|c|c|c|}
\hline Day & January & February & Day & January & February & Day & January & February \\
\hline $\begin{array}{c}1 \ldots \ldots \\
2 \ldots \ldots \\
3 \ldots \ldots \\
5 \ldots \ldots \\
6 \ldots \ldots \\
7 \ldots \ldots \\
8 \ldots \ldots \\
9 \ldots \ldots \\
10 \ldots \ldots\end{array}$ & $\begin{array}{l}15 \\
16 \\
14 \\
13 \\
13 \\
11 \\
11 \\
11 \\
10 \\
12\end{array}$ & $\begin{array}{r}33 \\
208 \\
223 \\
18 \\
4.1 \\
3.1 \\
2.5 \\
2.3 \\
2.4 \\
3.6\end{array}$ & $\begin{array}{l}11 \ldots \ldots \\
12 \ldots \ldots \\
13 \ldots \ldots \\
14 \ldots \ldots \\
15 \ldots \ldots \\
16 \ldots \ldots \\
17 \ldots \ldots \\
18 \ldots \ldots \\
19 \ldots \ldots \\
20 \ldots \ldots\end{array}$ & $\begin{array}{l}9.0 \\
9.0 \\
10 \\
10 \\
12 \\
12 \\
13 \\
13 \\
12 \\
12\end{array}$ & $\begin{array}{l}2.8 \\
2.7 \\
2.0 \\
1.8 \\
1.6 \\
2.8 \\
6.6 \\
4.9 \\
2.7 \\
2.5\end{array}$ & $\begin{array}{l}21 \ldots \ldots \\
22 \ldots \ldots \\
23 \ldots \ldots \\
24 \ldots \ldots \\
25 \ldots \ldots \\
26 \ldots \ldots \\
27 \ldots \ldots \\
28 \ldots \ldots \\
29 \ldots \ldots \\
30 \ldots \ldots \\
31 \ldots \ldots\end{array}$ & $\begin{array}{l}13 \\
13 \\
14 \\
16 \\
16 \\
15 \\
12 \\
12 \\
15 \\
15 \\
17\end{array}$ & $\begin{array}{r}2.4 \\
1.9 \\
1.7 \\
1.5 \\
1.4 \\
1.4 \\
2.6 \\
9.3 \\
----- \\
-1---\end{array}$ \\
\hline
\end{tabular}


10-3120. Carson River near Fort Church111, Nev.

Location.--Lat $39^{\circ} 17130^{\prime \prime}$, long $11^{\circ} 18^{14} 0^{\prime \prime}$, In SW SE $\frac{1}{4}$ sec.32, T.17 N., R. 24 E., on right bank $400 \mathrm{ft}$ downstream from Buckland ditch, 2 miles west of Fort Churchill, and $4 \frac{1}{2}$ miles upstream from Weeks bridge on U.S. Highway 95 alternate.

Drainage area. $--1,450 \mathrm{sq} \mathrm{ml}$, approximately.

Gage-height record. --Water-stage recorder graph. Datum of gage is $4,214.70 \mathrm{ft}$ above mean sea level, datum of 1929, supplementary adjustment of 1956.

Discharge record.--Stage-discharge relation defined by current-meter measurements; affected by 1ce Jan. 1-28. Discharge for period of 1ce effect estimated on basis of weather records and gage helghts that were reconstructed for part of each day.

Maxtma.--January-February 1963: Discharge, 15,300 ofs 1300 hours Feb. 2 (gage height, $10.83 \mathrm{ft}$ ).

1911 to December 1962: Dally discharge, 9,680 cfs Dec. 26, 1955; gage he1ght, about $11 \mathrm{ft}$ in December 1955, from floodmarks.

Mean discharge, in cuble feet per second, 1963

\begin{tabular}{|c|c|c|c|c|c|c|c|c|}
\hline Day & Janúary & February & Day & January & February & Day & January & February \\
\hline $\begin{array}{c}1 \ldots \ldots \\
2 \ldots \ldots \\
3 \ldots \ldots \\
4 \ldots \ldots \\
5 \ldots \ldots \\
7 \ldots \ldots \\
8 \ldots \ldots \\
9 \ldots \ldots \\
10 \ldots \ldots\end{array}$ & $\begin{array}{l}72 \\
72 \\
72 \\
68 \\
68 \\
68 \\
68 \\
68 \\
68 \\
70\end{array}$ & $\begin{array}{r}3,390 \\
11,500 \\
8,430 \\
3,340 \\
2,040 \\
1,700 \\
1,400 \\
1,210 \\
1,080 \\
958\end{array}$ & $\begin{array}{l}11 \ldots \ldots \\
12 \ldots \ldots \\
13 \ldots \ldots \\
14 \ldots \ldots \\
15 \ldots \ldots \\
16 \ldots \ldots \\
17 \ldots \ldots \\
18 \ldots \ldots \\
19 \ldots \ldots \\
20 \ldots \ldots\end{array}$ & $\begin{array}{l}68 \\
60 \\
64 \\
66 \\
66 \\
68 \\
68 \\
68 \\
68 \\
68\end{array}$ & $\begin{array}{l}876 \\
766 \\
710 \\
696 \\
682 \\
612 \\
577 \\
538 \\
505 \\
487\end{array}$ & $\begin{array}{l}21 \ldots \ldots \\
22 \ldots \ldots \\
23 \ldots \ldots \\
24 \ldots \ldots \\
25 \ldots \ldots \\
26 \ldots \ldots \\
27 \ldots \ldots \\
28 \ldots \ldots \\
29 \ldots \ldots \\
30 \ldots \ldots \\
31 \ldots \ldots\end{array}$ & $\begin{array}{l}68 \\
70 \\
70 \\
70 \\
72 \\
72 \\
70 \\
72 \\
116 \\
131 \\
711\end{array}$ & $\begin{array}{r}474 \\
462 \\
444 \\
421 \\
409 \\
409 \\
415 \\
421 \\
---- \\
----\end{array}$ \\
\hline \multicolumn{7}{|l|}{$\begin{array}{l}\text { Monthly } \\
\text { Runoff, } \\
\text { Runoff, }\end{array}$} & $\begin{array}{r}92.9 \\
0.07 \\
5,710 \\
\end{array}$ & $\begin{array}{r}1,605 \\
1,15 \\
89,160 \\
\end{array}$ \\
\hline
\end{tabular}

Gage height, in feet, and discharge, in cubic feet per second, at indicated t1me, 1963

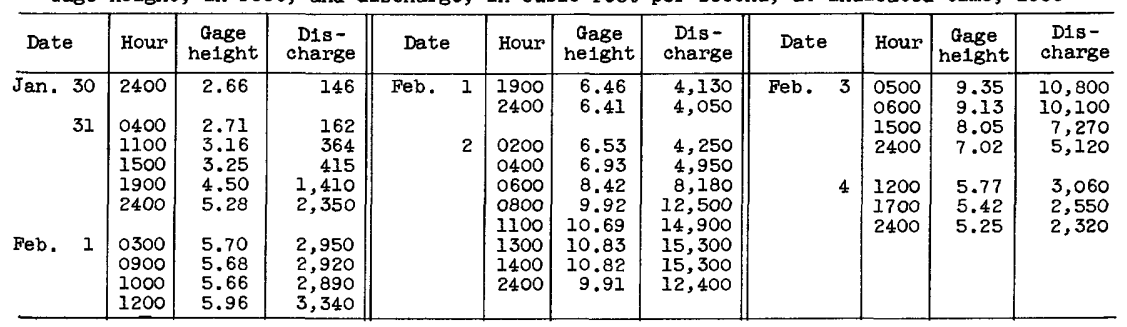

10-3121. Lahontan Reservoir near Fallon, Nev.

Location. --Lat $39^{\circ} 27^{\prime} 45^{\prime \prime}$, long $119^{\circ} 04^{\prime} 00^{\prime \prime}$, in SW $\frac{1}{4} \mathrm{SE}_{\frac{1}{4}} \mathrm{sec} .33$, T. 19 N., R.26 E., in outlet control house on upstream side of dam, 18 miles west of Falion.

Gage-height record.--Float tape with surface-contact detector read at 0800 hours dally. Datum of gage is at mean sea level (Bureau of Reclamation datum).

Contents record.-- Contents computed from capacity table furnished by U.S. Bureau of Reclamation.

Maxima.--January-February 1963: Contents observed, 248,000 acre-f't Feb. 11 (elevation, $4,159.31 \mathrm{ft}$ ).

1917 to December 1962: Contents observed (20-1nch flashboard on we1r), 299,200 acre-ft June 16, 1942 (elevation, 4,164.43 ft).

Remarks.--Reservolr is formed by earth and gravel-fill dam. Capacity, 273,600 acre-ft between elevations, 4,060.0 (invert of outlet conduit) and 4,162.0 ft (spillway crest). Surface area at spillway elevation, 10,000 acres. Figures given herein represent total contents and are computed from 0800 hour readings. Reservolr stores water from Carson River and from Truckee River at Derby Dam v1a Truckee Canal. Inflow is regulated by Lake Tahoe, Donner Lake, Boca Reservoir, and Derby Dam. Extensive Irrigation above reservolr in Carson and Truckee River basins. Records of dally elevation and contents furnished by Truckee-Carson Irrigation District. 
Contents, in acre-feet, at 0800 hours, 1963, of Lahontan Reservolr near Fallon, Nev.

\begin{tabular}{c|c|c||c|c|c||r|r|r}
\hline Day & January & February & Day & January & February & Day & January & February \\
\hline $1 \ldots \ldots$ & 171,000 & 192,700 & $11 \ldots \ldots$ & 180,100 & 248,000 & $21 \ldots \ldots$ & 183,900 & 241,600 \\
$2 \ldots \ldots$ & 172,400 & 199,800 & $12 \ldots \ldots$ & 180,400 & 247,600 & $22 \ldots \ldots$ & 184,500 & 240,900 \\
$3 \ldots \ldots$ & 173,200 & 221,900 & $13 \ldots \ldots$ & 180,600 & 247,000 & $23 \ldots \ldots$ & 184,700 & 240,700 \\
$4 \ldots \ldots$ & 173,900 & 238,300 & $14 \ldots \ldots$ & 280,500 & 246,300 & $24 \ldots \ldots$ & 185,300 & 240,000 \\
$5 \ldots \ldots$ & 175,700 & 243,600 & $15 \ldots \ldots$ & 181,100 & 245,700 & $25 \ldots \ldots$ & 185,900 & 239,600 \\
$6 \ldots \ldots$ & 176,100 & 245,500 & $16 \ldots \ldots$ & 181,500 & 244,700 & $26 \ldots \ldots$ & 186,400 & 238,900 \\
$7 \ldots \ldots$ & 177,100 & 246,800 & $17 \ldots \ldots$ & 182,000 & 243,900 & $27 \ldots \ldots$ & 186,700 & 238,200 \\
$8 \ldots \ldots$ & 178,000 & 247,500 & $18 \ldots \ldots$ & 182,600 & 242,900 & $28 \ldots \ldots$ & 187,300 & 238,200 \\
$9 \ldots \ldots$ & 178,800 & 247,700 & $19 \ldots \ldots$ & 183,100 & 242,600 & $29 \ldots \ldots$ & 187,900 & $--\ldots-\ldots-$ \\
$10 \ldots \ldots$ & 179,400 & 247,700 & $20 \ldots \ldots$ & 183,500 & 242,200 & $30 \ldots \ldots$ & 188,700 & $-\ldots-\ldots$ \\
\end{tabular}

\section{PYRAMID AND WINNEMUCCA LAKES BASIN}

10-3365. Pyramid Lake near Nixon, Nev.

Location.--Lat $39^{\circ} 50^{\prime} 30^{\prime \prime}$, long $119^{\circ} 28^{\prime} 00^{\prime \prime}$, in $\mathrm{SE} \frac{1}{4} \mathrm{SE} \frac{1}{4}$ sec.24, T.23 N., R.22 E., at southwest corner of concrete bridge No. $296 \mathrm{~B}, 150 \mathrm{ft}$ southwest of milepost 297 , 6 miles west of Nixon, and 11.5 miles south along Southern Pacific Railroad from station at Sutcliffe.

Gage-helght record.--Elevations observed monthly. Datum of gage is at mean sea level. 0bservations are referenced to bench mark N-21 of U.S. Coast and Geodetic Survey at elevation of $3,940.29 \mathrm{ft}$ above mean sea level, datum of 1929 , supplementary adjustment of 1956.

Maxima.--January-February 1963: Elevation observed, 3,790.6 ft, Feb. 8. 1926 to December 1962: Elevation observed, 3,848.75 ft June 1926.

Elevation, in feet, December 1962 to Apr11 1963

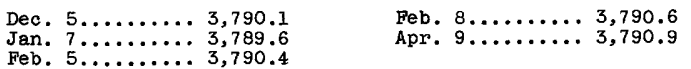

10-3366.35. Lake Tahoe tributary near Meeks Bay, Calif.

(Crest-stage station)

Location.--Lat $39^{\circ} 01^{\prime} 03^{\prime \prime}$, long $120^{\circ} 07^{\prime} 32^{\prime \prime}$, in $\mathrm{SE}_{\frac{1}{4}} \mathrm{NW} \frac{1}{4}$ sec.32, T.14 N., R.17 E., at culvert on State Highway $89,1.5$ miles south of Meeks Bay.

Drainage area. $--0.64 \mathrm{sq} \mathrm{mi}$.

Gage-height record.--Crest stages only. Altitude of gage is $6,360 \mathrm{ft}$ (from topographic map).

Discharge record.--Peak discharge by computation of flow through culvert.

Maximum.--January-February 1963: Discharge, $42.6 \mathrm{cfs} F \mathrm{Feb}$ 1 (gage height, $13.54 \mathrm{ft})$.

10-3366.8. Lake Tahoe tributary at Tahoe City, Calif.

(Crest-stage station)

Location.--Lat $39^{\circ} 10^{\prime} 25^{\prime \prime}$, long $120^{\circ} 07^{1} 45^{\prime \prime}$, in $\mathrm{NE} \frac{1}{4} \mathrm{SE} \frac{1}{4}$ sec.6, T.15 N., R.17 E., at culvert on State Highway 28 , at east edge of Tahoe City.

Drainage area. $--1.08 \mathrm{sq} \mathrm{mi}$.

Gage-helght renord.--Crest stages only. Altitude of gage is 6,260 ft (from topographic map).

Discharge record.--Discharge estimated on basis of flow through culvert.

Maximum.--January-February 1963: Discharge, 35 .cfs Jan. 31. 
10-3370. Lake Tahoe at Tahoe C1ty, Calif.

Location.--Lat $39^{\circ} 10^{\prime} 04^{\prime \prime}$, long $120^{\circ} 08^{\prime} 23^{\prime \prime}$, in NE $\frac{1}{4}$ sec.7, T.15 N., R.17 E., at Tahoe City, on pler $1,000 \mathrm{ft}$ east of dam at lake outlet.

Drainage area. $-506 \mathrm{sq} \mathrm{ml}$ at lake outlet.

Gage-height record.--Water-stage recorder graph. Datum of gage is 6,220.00 ft above mean sea level, datum of Bureau of Reclamation $(6,219.01 \mathrm{ft}$, datum of 1929).

Maxima.--January-February 1963: Elevation, 6,224.95 ft Feb. 20

i900 to December 1962: Elevation, $6,231.26 \mathrm{ft}$ July $14,15,17,18,1907$.

Remarks.--Lake levels regulated by a 17-gate concrete dam at outlet of lake; storage began about 1874. Figures given herein represent usable contents. Usable capacity, 744,600 acre-ft between elevations 6,223 ft (natural rim of lake) and $6,229.1 \mathrm{ft}$ (maximum permissible elevation by Federal Court decree). Increase in capacity within the range Indicated, about 120,000 acre-ft per foot of rise. All elevations are based on Bureau of Reclamation datum. One intermittent transmountain diversion from Echo Lake to South Fork American River for power and irrigation.

Elevation, in feet, at 2400 hours on indicated day, 1963

\begin{tabular}{|c|c|c|c|c|c|c|c|c|}
\hline Day & January & February & Day & January & February & Day & January & February \\
\hline $\begin{array}{l}1 \ldots \ldots \\
2 \ldots \ldots \\
4 \ldots \ldots \\
5 \ldots \ldots \\
6 \ldots \ldots \\
7 \ldots \ldots \\
9 \ldots \ldots \\
10 \ldots \ldots\end{array}$ & $\begin{array}{l}6,223.68 \\
6,223.68 \\
6,223.71 \\
6,223.70 \\
6,223.68 \\
6,223.67 \\
6,223.65 \\
6,223.65 \\
6,223.63 \\
6,223.62\end{array}$ & $\begin{array}{l}6,224.61 \\
6,224.68 \\
6,224.70 \\
6,224.74 \\
6,224.79 \\
6,224.81 \\
6,224.82 \\
6,224.84 \\
6,224.85 \\
6,224.87\end{array}$ & $\begin{array}{l}11 \ldots \ldots \\
12 \ldots \ldots \\
13 \ldots \ldots \\
14 \ldots \ldots \\
15 \ldots \ldots \\
16 \ldots \ldots \\
17 \ldots \ldots \\
18 \ldots \ldots \\
19 \ldots \ldots \\
20 \ldots \ldots\end{array}$ & $\begin{array}{l}6,223.65 \\
6,223.56 \\
6,223.57 \\
6,223.55 \\
6,223.56 \\
6,223.55 \\
6,223.55 \\
6,223.62 \\
6,223.52 \\
6,223.52\end{array}$ & $\begin{array}{l}6,224.87 \\
6,224.90 \\
6,224.92 \\
6,224.92 \\
6,224.93 \\
6,224.93 \\
6,224.94 \\
6,224.94 \\
6,224.94 \\
6,224.95\end{array}$ & $\begin{array}{l}21 \ldots \ldots \\
22 \ldots \ldots \\
23 \ldots \ldots \\
24 \ldots \ldots \\
25 \ldots \ldots \\
26 \ldots \ldots \\
27 \ldots \ldots \\
28 \ldots \ldots \\
29 \ldots \ldots \\
30 \ldots \ldots \\
31 \ldots \ldots\end{array}$ & $\begin{array}{l}6,223 \cdot 52 \\
6,223 \cdot 52 \\
6,223 \cdot 52 \\
6,223 \cdot 51 \\
6,223 \cdot 50 \\
6,223.50 \\
6,223.49 \\
6,223.49 \\
6,223.55 \\
6,223.80 \\
6,224.22\end{array}$ & $\begin{array}{r}6,224.94 \\
6,224.94 \\
6,224.94 \\
6,224.94 \\
6,224.94 \\
6,224.94 \\
6,224.94 \\
6,224.92 \\
------ \\
------ \\
------\end{array}$ \\
\hline
\end{tabular}

10-3375. Truckee River at Tahoe City, Callf.

Location. --Lat $39^{\circ} 10^{100 "}$, long $120^{\circ} 08^{1} 40^{\prime \prime}$, In NE $\frac{1}{4} N W \frac{1}{4}$ sec.7, T.15 N., R.17 E., at Tahoe city, on left bank $510 \mathrm{ft}$ downstream from dam at outlet of Lake Tahoe.

Drainage area. $--507 \mathrm{sq} \mathrm{mi}$.

Gage-helght record.--Water-stage recorder graph. Datum of gage is $6,216.75 \mathrm{ft}$ above mean sea level, datum of 1929 .

Discharge record.--Stage-discharge relation defined by current-meter measurements; affected by 1 ce Jan. $4-6,12,13$.

Maxima.--January-February 1963: Discharge, $196 \mathrm{cfs} 0300$ hours Feb. 1 (gage height, $3.52 \mathrm{ft}$ )

1895-96, 1900 to December 1962: Discharge, 1,870 cfs Apr. 5, 6, 1958 (gage helght, $7.30 \mathrm{ft}$, site and datum then in use); gage helght, $7.34 \mathrm{ft}$ Apr. 5, 1958, site and datum then in use (backwater from snow in channel).

Remarks.--Flow regulated by Lake Tahoe (operating capac1ty, 744,600 acre-ft).

Mean discharge, in cubic feet per second, 1963

\begin{tabular}{|c|c|c|c|c|c|c|c|c|}
\hline Day & January & February & Day & January & February & Day & January & February \\
\hline $\begin{array}{c}1 \ldots \ldots \\
2 \ldots \ldots \\
3 \ldots \ldots \\
4 \ldots \ldots \\
5 \ldots \ldots \\
7 \ldots \ldots \\
8 \ldots \ldots \\
9 \ldots \ldots \\
10 \ldots \ldots\end{array}$ & $\begin{array}{l}1.4 \\
1.4 \\
1.4 \\
34 \\
66 \\
66 \\
66 \\
65 \\
63 \\
59\end{array}$ & $\begin{array}{l}90 \\
19 \\
7.5 \\
4.8 \\
3.2 \\
2.8 \\
2.4 \\
2.4 \\
2.4 \\
2.4\end{array}$ & $\begin{array}{l}11 \ldots \ldots \\
12 \ldots \ldots \\
13 \ldots \ldots \\
14 \ldots \ldots \\
15 . \ldots \ldots \\
16 \ldots \ldots \\
17 \ldots \ldots \\
18 \ldots \ldots \\
19 \ldots \ldots \\
20 \ldots \ldots\end{array}$ & $\begin{array}{l}59 \\
60 \\
59 \\
47 \\
47 \\
47 \\
47 \\
48 \\
47 \\
39\end{array}$ & $\begin{array}{l}2.4 \\
2.4 \\
2.4 \\
2.4 \\
2.4 \\
2.4 \\
2.4 \\
2.4 \\
2.4 \\
2.4\end{array}$ & $\begin{array}{l}21 \ldots \ldots \\
22 \ldots \ldots \\
23 \ldots \ldots \\
24 \ldots \ldots \\
25 \ldots \ldots \\
26 \ldots \ldots \\
27 \ldots \ldots \\
28 \ldots \ldots \\
29 \ldots \ldots \\
30 \ldots \ldots \\
31 \ldots \ldots\end{array}$ & $\begin{array}{l}39 \\
39 \\
39 \\
39 \\
38 \\
36 \\
35 \\
34 \\
34 \\
52 \\
84\end{array}$ & $\begin{array}{r}2.0 \\
1.8 \\
1.8 \\
1.8 \\
1.8 \\
2.0 \\
2.4 \\
2.4 \\
-\ldots-.-1 \\
-1 .-1\end{array}$ \\
\hline $\begin{array}{l}\text { onthly } \\
\text { unoff, }\end{array}$ & acre & $=1$ & feet & & & & $\begin{array}{r}44.9 \\
2,760\end{array}$ & $\begin{array}{r}6.32 \\
351\end{array}$ \\
\hline
\end{tabular}


10-3379. Truckee River tributary near Truckee, Calif.

(Crest-stage station)

Location.--Lat $39^{\circ} 16^{\prime} 48^{\prime \prime}$, long $120^{\circ} 12^{\prime} 21^{\prime \prime}$, in SW $\frac{1}{4} \mathrm{NE} \frac{1}{4}$ sec.33, T.17 N., R.16 E., at culvert on State Highway $89,3.5$ miles southwest of Truckee.

Drainage area. $--1.06 \mathrm{sq} \mathrm{mi}$.

Gage-helght record.--Crest stages only. Altitude of gage is $5,960 \mathrm{ft}$ (from topographic mapl.

Discharge record.--Peak discharge by computation of flow through culvert.

Maximum.--January-February 1963: Discharge, $220 \mathrm{cfs}$ Jan. 31 (gage height, $20.8 \mathrm{ft}$ ).

10-3380. Truckee River near Truckee, Calif.

(Gaging station, discontinued 1961)

Location.--Lat $39^{\circ} 17^{\prime} 30^{\prime \prime}$, long $120^{\circ} 12^{\prime} 30^{\prime \prime}$, in $\mathrm{SW}_{\frac{1}{4}} \mathrm{NE} \frac{1}{4} \sec .28, \mathrm{~T} .17 \mathrm{~N} ., \mathrm{R} .16 \mathrm{E}$, on left bank 1.4 miles upstream from Donner Creek and 2.5 miles southwest of Truckee.

Drainage area. $--552 \mathrm{sq} \mathrm{m}$.

Gage-height record.--Maximum stage determined from floodmarks. Altitude of gage is $5,860 \mathrm{f}^{\prime} \mathrm{t}$ (from topographic map).

Discharge record.--Stage-discharge relation defined by current-meter measurements below $2,400 \mathrm{cfs}$ and by slope-area measurements at 6,480 and $7,760 \mathrm{cfs}$.

Maxima.--January-February 1963: Discharge, 11,000 cfs Feb. 1 (gage height, $9.25 \mathrm{ft}$ ). 1944 to December 1962: Discharge, 7,760 cfs Dec. 23, 1955 (gage height, $7.92 \mathrm{ft}$ ); gage height, 9.69 ft Apr. 3, 1958 (backwater from snow in channei).

Remarks.--Flow regulated by Lake Tahoe (see station 10-3366.8).

10-3385. Donner Creek at Donner Lake, near Truckee, Calif.

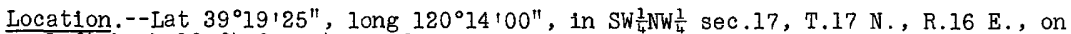
left bank $10 \mathrm{ft}$ downstream from bridge on Donner Memorial state Park road, 0.2 mile downstream from Donner Lake outlet, 0.7 mile upstream from Cold Creek, and $2 \frac{1}{2}$ miles west of Truckee.

Drainage area. $--14.5 \mathrm{sq} \mathrm{ml}$.

Gage-height record.--Water-stage recorder graph. Altitude of gage is $5,930 \mathrm{ft}$ (from topographic map).

Discharge record.--Stage-discharge relation defined by current-meter measurements.

Maxima --January-February 1963: Discharge, $381 \mathrm{cfs} 1600$ hours Feb. 7 (gage height, $3.63 \mathrm{ft})$.

1909-10, 1929-53, 1955-57, 1958 to December 1962: Daily discharge, $700 \mathrm{cfs}$

(estimated) Nov. 21, 1950; gage height observed, 4.15 ft Mar. 6, 1962 (backwater from ice).

Remarks.--Flow regulated by dam at outlet of Donner Lake (usable capacity, 9,500 acre-ft).

Mean discharge, in cubic feet per second, 1963

\begin{tabular}{|c|c|c|c|c|c|c|c|c|}
\hline Day & January & February & Day & January & February & Day & January & February \\
\hline $\begin{array}{c}1 \ldots \ldots \\
2 \ldots \ldots \\
3 \ldots \ldots \\
4 \ldots \ldots \\
6 \ldots \ldots \\
7 \ldots \ldots \\
5 \ldots \ldots \\
9 \ldots \ldots \\
10 \ldots \ldots\end{array}$ & $\begin{array}{l}33 \\
31 \\
30 \\
28 \\
28 \\
26 \\
25 \\
25 \\
24 \\
23\end{array}$ & $\begin{array}{r}86 \\
270 \\
263 \\
251 \\
252 \\
339 \\
260 \\
325 \\
286 \\
261\end{array}$ & $\begin{array}{l}11 \ldots \ldots \\
12 \ldots \ldots \\
13 \ldots \ldots \\
14 \ldots \ldots \\
15 \ldots \ldots \\
16 \ldots \ldots \\
17 \ldots \ldots \\
18 \ldots \ldots \\
19 \ldots \ldots \\
20 \ldots \ldots\end{array}$ & $\begin{array}{l}22 \\
20 \\
19 \\
15 \\
17 \\
17 \\
17 \\
16 \\
16 \\
14\end{array}$ & $\begin{array}{c}173 \\
3.3 \\
3.3 \\
3.1 \\
73 \\
130 \\
126 \\
121 \\
70 \\
2.1\end{array}$ & $\begin{array}{l}21 \ldots \ldots \\
22 \ldots \ldots \\
23 \ldots \ldots \\
24 \ldots \ldots \\
25 \ldots \ldots \\
26 \ldots \ldots \\
27 \ldots \ldots \\
28 \ldots \ldots \\
29 \ldots \ldots \\
30 \ldots \ldots \\
31 \ldots \ldots\end{array}$ & $\begin{array}{l}14 \\
14 \\
14 \\
14 \\
14 \\
13 \\
12 \\
12 \\
14 \\
23 \\
27\end{array}$ & 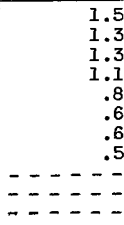 \\
\hline $\begin{array}{l}\text { onthly } \\
\text { unoff, }\end{array}$ & $\begin{array}{l}\text { an dis } \\
\text { acre- }\end{array}$ & , & $t$ & & & & $\begin{array}{r}20.0 \\
1,230\end{array}$ & $\begin{array}{r}118 \\
6,560 \\
\end{array}$ \\
\hline
\end{tabular}


10-3394. Mart1s Creek near Truckee, Calif.

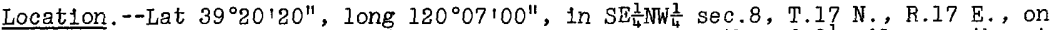
left bank three-quarters of a mile upstream from mouth and $3 \frac{1}{2}$ miles northeast of Truckee.

Drainage area. $--40.8 \mathrm{sq} \mathrm{mi}$.

Gage-he1ght record.--Water-stage recorder graph, except Feb. 22-28. Altitude of gage 1s 5,700 fit (from topograph1c map).

D1scharge record.--Stage-discharge relation defined by current-meter measurements below $500 \mathrm{cf}$ 's and by slope-area measurement of maximum flow; affected by 1 ce Jan. 1-28. D1scharge for perlods of 1ce effect or no gage-height record was estimated on basis of weather records and comparison with nearby streams:

Maxima.--January-February 1963: Discharge, 1,880 cfs 0500 hours Feb. I (gage helght, $6.16 \mathrm{ft}$ ).

1958 to December 1962: D1scharge, $436 \mathrm{cfs}$ Feb. 8, 1960 (gage he1ght, 3.73 ft).

Mean discharge, in cubic feet per second, 1963

\begin{tabular}{|c|c|c|c|c|c|c|c|c|}
\hline Day & January & February & Day & January & Pebruary & Day & January & February \\
\hline $\begin{array}{c}1 \ldots \ldots \\
2 \ldots \ldots \\
3 \ldots \ldots \\
4 \ldots \ldots \\
5 \ldots \ldots \\
6 \ldots \ldots \\
7 \ldots \ldots \\
9 \ldots \ldots \\
10 \ldots \ldots\end{array}$ & $\begin{array}{l}5 \\
5 \\
5 \\
5 \\
5 \\
4.5 \\
4.5 \\
4.5 \\
4 \\
4\end{array}$ & $\begin{array}{r}874 \\
219 \\
137 \\
114 \\
94 \\
74 \\
61 \\
54 \\
49 \\
60\end{array}$ & $\begin{array}{l}11 \ldots \ldots \\
12 \ldots \ldots \\
13 \ldots \ldots \\
14 \ldots \ldots \\
15 \ldots \ldots \\
16 \ldots \ldots \\
17 \ldots \ldots \\
15 \ldots \ldots \\
19 \ldots \ldots \\
20 \ldots \ldots\end{array}$ & $\begin{array}{l}3.5 \\
3.5 \\
3.5 \\
3.5 \\
4 \\
4 \\
4 \\
4 \\
4.5 \\
4.5\end{array}$ & $\begin{array}{l}49 \\
41 \\
61 \\
44 \\
38 \\
33 \\
34 \\
32 \\
31 \\
30\end{array}$ & $\begin{array}{l}21 \ldots \ldots \\
22 \ldots \ldots \\
23 \ldots \ldots \\
24 \ldots \ldots \\
25 \ldots \ldots \\
26 \ldots \ldots \\
27 \ldots \ldots \\
28 \ldots \ldots \\
29 \ldots \ldots \\
30 \ldots \ldots \\
31 \ldots \ldots\end{array}$ & $\begin{array}{l}5 \\
5 \\
5 \\
5 \\
6 \\
6 \\
6 \\
7 \\
7.0 \\
351 \\
903 \\
\end{array}$ & $\begin{array}{r}27 \\
25 \\
25 \\
25 \\
27 \\
27 \\
26 \\
25 \\
---.- \\
---.-\end{array}$ \\
\hline $\begin{array}{l}\text { Monthly } \\
\text { Runoff, } \\
\text { Runoff, }\end{array}$ & $\begin{array}{l}\text { mean disc } \\
\text { in inches } \\
\text { in acre-f }\end{array}$ & e, in & feet & econ & & & $\begin{array}{r}44.9 \\
1.27 \\
2,760\end{array}$ & $\begin{array}{r}83.4 \\
2.13 \\
4,630\end{array}$ \\
\hline
\end{tabular}

Gage height, in feet, and discharge, in cublc feet per second, at 1ndicated t1me, 1963

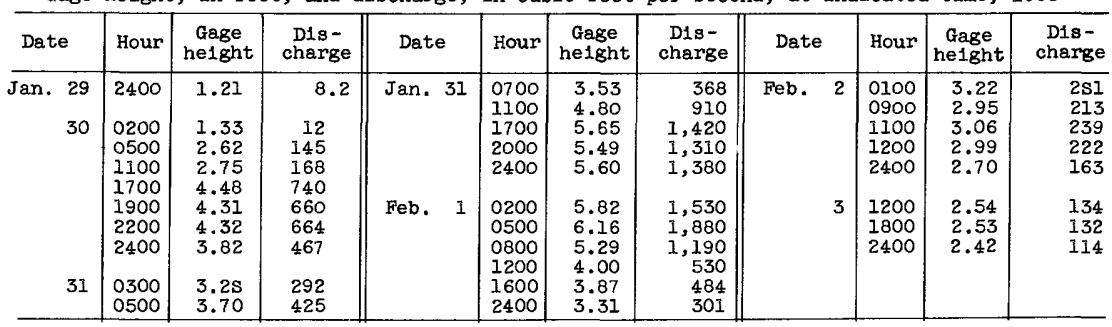

10-3397. Prosser Creek at Hobart M11ls, Cal1f.

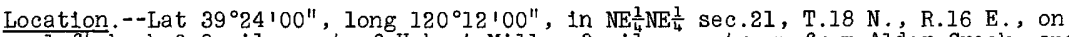
left -bank $0.8 \mathrm{mlle}$ west of Hobart M11ls, 3 miles upstream from Alder Creek, and 5 miles north of Truckee.

Dralnage area. $--27.4 \mathrm{sq} \mathrm{ml}$.

Gage-he1ght record.--None, gage was washed out in flood.

Discharge record.--Stage-discharge relation defined by current-meter measurements below $250 \mathrm{cfs}$ and by slope-area measurements at 1,880 and 4,920 cf's.

Maxima.--January-February 1963: D1scharge, 4,920 cfo Feb. 1 (gage height, 7.9 ft, from floodmarks).

1958 to December 1962: Discharge, 1,880 cfs Oct. 14, 1962 (gage he1ght, $4.67 \mathrm{ft}$ ). 
10-3399. Alder Creek near Truckee, Calif.

Location.--Lat $39^{\circ} 22^{\prime} 10^{\prime \prime}$, long $120^{\circ} 10^{\prime} 50^{\prime \prime}$, In $\mathrm{SE} \frac{1}{\frac{1}{4} \mathrm{NE} \frac{1}{4}}$ sec.34, T.18 N., R.16 E., on right bank 2 miles upstream from mouth and $2 \frac{1}{2}$ miles north of Truckee.

Dralnage area. $--7.36 \mathrm{sq} \mathrm{ml}$.

Gage-helght record.--Water-stage recorder graph. Altitude of gage is 5,800 ft (from topographic map).

Discharge record.--Stage-discharge relation defined by current-meter measurements below $250 \mathrm{cfs}$ and by measurement of maximum flow through culvert; affected by 1ce Jan. 1-19, 21, 22. Discharge for periods of 1ce effect estimated on the basis of weather records and reconstructed gage helghts.

Maxima --January-February 1963: Discharge, 730 cfs 2100 hours Jan. 31 (gage height, $5.86 \mathrm{ft}$ ).

1958 to December 1962: Discharge, 221 cf's 0ct. 13, 1962 (gage helght, $3.58 \mathrm{ft}$ ).

Mean discharge, in cubic feet per second, 1963

\begin{tabular}{|c|c|c|c|c|c|c|c|c|}
\hline Day & January & February & Day & January & February & Day & January & February \\
\hline $\begin{array}{c}1 \ldots \ldots \\
2 \ldots \ldots \\
4 \ldots \ldots \\
5 \ldots \ldots \\
6 \ldots \ldots \\
7 \ldots \ldots \\
8 \ldots \ldots \\
9 \ldots \ldots \\
10 \ldots\end{array}$ & $\begin{array}{l}3.7 \\
3.7 \\
3.7 \\
4.0 \\
4.6 \\
3.5 \\
3.0 \\
3.0 \\
3.0 \\
2.7\end{array}$ & $\begin{array}{r}348 \\
118 \\
92 \\
75 \\
59 \\
46 \\
37 \\
33 \\
28 \\
28\end{array}$ & $\begin{array}{l}11 \ldots \ldots \\
12 \ldots \ldots \\
13 \ldots \ldots \\
14 \ldots \ldots \\
15 \ldots \ldots \\
16 \ldots \ldots \\
17 \ldots \ldots \\
18 \ldots \ldots \\
19 \ldots \ldots \\
20 \ldots \ldots\end{array}$ & $\begin{array}{l}2.0 \\
1.4 \\
1.5 \\
1.8 \\
2.0 \\
2.0 \\
2.0 \\
2.0 \\
2.0 \\
2.2\end{array}$ & $\begin{array}{l}24 \\
22 \\
27 \\
22 \\
20 \\
19 \\
19 \\
18 \\
17 \\
16\end{array}$ & $\begin{array}{l}21 \ldots \ldots \\
22 \ldots \ldots \\
23 \ldots \ldots \\
24 \ldots \ldots \\
25 \ldots \ldots \\
26 \ldots \ldots \\
27 \ldots \ldots \\
28 \ldots \ldots \\
29 \ldots \ldots \\
30 \ldots \ldots \\
31 \ldots \ldots\end{array}$ & $\begin{array}{l}2.4 \\
2.5 \\
2.4 \\
2.2 \\
2.2 \\
2.2 \\
2.1 \\
2.2 \\
2.2 \\
30 \\
371\end{array}$ & $\begin{array}{r}15 \\
14 \\
13 \\
13 \\
14 \\
14 \\
12 \\
12 \\
-\ldots--1\end{array}$ \\
\hline \multicolumn{7}{|l|}{$\begin{array}{l}\text { Monthly } \\
\text { Runoff, } \\
\text { Runoff, }\end{array}$} & $\begin{array}{r}15.3 \\
2.40 \\
943 \\
\end{array}$ & $\begin{array}{r}42.0 \\
5.94 \\
2,330 \\
\end{array}$ \\
\hline
\end{tabular}

Gage height, in feet, and discharge, in cubic feet per second, at indicated time, 1963

\begin{tabular}{|c|c|c|c|c|c|c|c|c|c|c|c|}
\hline Date & Hour & $\begin{array}{c}\text { Gage } \\
\text { height }\end{array}$ & $\begin{array}{l}\text { Dis- } \\
\text { charge }\end{array}$ & Date & Hour & $\begin{array}{c}\text { Gage } \\
\text { height }\end{array}$ & $\begin{array}{l}\text { Dis- } \\
\text { charge }\end{array}$ & Date & Hour & $\begin{array}{c}\text { Gage } \\
\text { helght }\end{array}$ & $\begin{array}{l}\text { Dis- } \\
\text { charge }\end{array}$ \\
\hline $\begin{array}{r}29 \\
30\end{array}$ & $\begin{array}{l}2400 \\
0700 \\
1200 \\
1400 \\
2200 \\
2300 \\
2400\end{array}$ & $\begin{array}{l}2.26 \\
2.33 \\
2.46 \\
2.70 \\
2.98 \\
3.16 \\
3.18\end{array}$ & $\begin{array}{c}1.9 \\
3.3 \\
8.5 \\
30 \\
75 \\
114 \\
118\end{array}$ & Jan. 31 & $\begin{array}{l}09(1) 0 \\
1300 \\
1500 \\
1700 \\
1900 \\
2000 \\
2100 \\
2300 \\
2400\end{array}$ & $\begin{array}{l}3.48 \\
4.16 \\
4.45 \\
4.97 \\
5.25 \\
5.47 \\
5.86 \\
5.48 \\
5.42\end{array}$ & $\begin{array}{l}195 \\
369 \\
448 \\
564 \\
600 \\
660 \\
730 \\
661 \\
651\end{array}$ & Feb. I & $\begin{array}{l}0300 \\
0400 \\
0800 \\
1100 \\
1100 \\
1500 \\
1600 \\
1700 \\
2400\end{array}$ & $\begin{array}{l}5.46 \\
5.32 \\
3.69 \\
3.17 \\
3.26 \\
3.13 \\
3.06 \\
3.24 \\
2.93\end{array}$ & $\begin{array}{l}665 \\
643 \\
342 \\
236 \\
263 \\
233 \\
203 \\
257 \\
164\end{array}$ \\
\hline 31 & $\begin{array}{l}0300 \\
0600\end{array}$ & $\begin{array}{l}3.32 \\
3.34 \\
\end{array}$ & $\begin{array}{l}153 \\
158\end{array}$ & Feb. 1 & 0300 & & & & & & \\
\hline
\end{tabular}

10-3405. Prosser Creek near Boca, Cal1f.

Locat1on. --Lat $39^{\circ} 22^{\prime} 10^{\prime \prime}$, long $120^{\circ} 07^{\prime} 10^{\prime \prime}$, in SW $\frac{1}{4} \mathrm{NW} \frac{1}{4} \sec .32$, T.18 N., R.17 E., on left bank a quarter of a mile upstream from mouth and 2 miles southwest of Boca.

Drainage area. $--53.5 \mathrm{sq} \mathrm{ml}$.

Gage-height record.--Water-stage recorder graph, except Jan. 5-8, 21-23. Datum of gage is $5,572.66$ ft above mean sea level (levels by Bureau of Reclamation).

Discharge record.--Stage-discharge relation defined by current-meter measurements; affected by 1ce Jan. 1-4, 9-31. Discharge for perlod of ice effect or no gagehelght record estimated on basis of weather records and trend of adfacent flow.

Maxima.--January-February 1963: D1scharge, 1,520 cfs 1000 hours Feb. 6 (gage he1ght, $6.14 \mathrm{ft}$ ); gage he1ght, $6.59 \mathrm{ft}$ Jan. 31 (backwater from 1ce).

1942 to December 1962: Discharge, 4,560 cfs Dec. 23, 1955 (gage helght, $10.13 \mathrm{ft}$ ), from rating curve extended above $910 \mathrm{cfs}$ on basis of slope-area measurement of maximum flow; gage helght, $11.0 \mathrm{ft}$ Nov. 20, 1950, from floodmarks.

Remarks.--Flow regulated by Prosser Creek dam since Jan. 31, 1963. 
Mean discharge, in cublc feet per second, 1963, of Prosser Creek near Boca, Cal1f.

\begin{tabular}{|c|c|c|c|c|c|c|c|c|}
\hline Day & January & February & Day & January & February & Day & January & February \\
\hline $\begin{array}{r}1 \ldots \ldots \\
2 \ldots \ldots \\
3 \ldots \ldots \\
4 \ldots \ldots \\
5 \ldots \ldots \\
7 \ldots \ldots \\
8 \ldots \ldots \\
9 \ldots \ldots \\
10 \ldots \ldots\end{array}$ & $\begin{array}{l}26 \\
27 \\
29 \\
31 \\
31 \\
31 \\
31 \\
31 \\
31 \\
29\end{array}$ & $\begin{array}{r}112 \\
23 \\
28 \\
350 \\
1,210 \\
1,470 \\
873 \\
342 \\
266 \\
269\end{array}$ & $\begin{array}{l}11 \ldots \ldots \\
12 \ldots \ldots \\
13 \ldots \ldots \\
14 \ldots \ldots \\
15 \ldots \ldots \\
16 \ldots \ldots \\
17 \ldots \ldots \\
18 \ldots \ldots \\
19 \ldots \ldots \\
20 \ldots \ldots\end{array}$ & $\begin{array}{l}21 \\
18 \\
18 \\
23 \\
25 \\
27 \\
28 \\
28 \\
28 \\
27\end{array}$ & $\begin{array}{r}200 \\
11 \\
13 \\
12 \\
182 \\
312 \\
312 \\
145 \\
12 \\
12\end{array}$ & $\begin{array}{l}21 \ldots \ldots \\
22 \ldots \ldots \\
23 \ldots \ldots \\
24 \ldots \ldots \\
25 \ldots \ldots \\
26 \ldots \ldots \\
27 \ldots \ldots \\
28 \ldots \ldots \\
29 \ldots \ldots \\
30 \ldots \ldots \\
31 \ldots \ldots\end{array}$ & $\begin{array}{r}29 \\
30 \\
30 \\
30 \\
30 \\
29 \\
25 \\
27 \\
62 \\
225 \\
325\end{array}$ & $\begin{array}{r}12 \\
125 \\
219 \\
217 \\
164 \\
124 \\
108 \\
97 \\
---- \\
----1-\end{array}$ \\
\hline \multicolumn{7}{|c|}{ 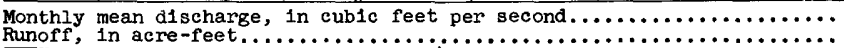 } & $\begin{array}{l}44.6 \\
2,740\end{array}$ & $\begin{array}{r}258 \\
14,320\end{array}$ \\
\hline
\end{tabular}

10-3420. Little Truckee River near Hobart Mills, Calif.

Location.--Lat $39^{\circ} 30^{\prime} 05^{\prime \prime}$, long $120^{\circ} 16^{\prime} 35^{\prime \prime}$, in NE $\frac{1}{4} \mathrm{NE} \frac{1}{4} \sec .14$, T.19 N., R.15 E., on right bank half a mile upstream from Independence Creek, and $7 \frac{1}{2}$ miles northwest of Hobart Mills.

Drainage area. $--36.6 \mathrm{sq} \mathrm{mi}$.

Gage-he1ght record.--Water-stage recorder graph. Altitude of gage is $6,290 \mathrm{ft}$ (from topographic map).

Discharge record.--Stage-discharge relation defined by current-meter measurements below I,100 cfs and by slope-area measurements at 7,010 cf's and 5,690 cf's (adJusted to present datum); affected by 1ce Jan. 1,2,5-28. Discharge for periods of ice effect estimated on basis of field notes, weather records, reconstructed gage-height record, and comparison with records for nearby stations.

Maxima.--January-February 1963: Discharge, 7,910 cfs 0300 hours Feb. 1 (gage helght, $7.76 \mathrm{ft}$ ).

1946 to December 1962: Discharge, 7,010 cfs Nov. 20, 1950 (gage height, $7.53 \mathrm{ft}$, at datum $0.15 \mathrm{ft}$ higher).

Mean discharge, in cubic feet per second, 1963

\begin{tabular}{|c|c|c|c|c|c|c|c|c|}
\hline Day & January & February & Day & January & February & Day & January & February \\
\hline $\begin{array}{c}\ldots \ldots \\
2 \ldots \ldots \\
3 \ldots \ldots \\
5 \ldots \ldots \\
6 \ldots \ldots \\
7 \ldots \ldots \\
9 \ldots \ldots \\
10 \ldots \ldots\end{array}$ & $\begin{array}{l}35 \\
35 \\
45 \\
41 \\
38 \\
38 \\
36 \\
34 \\
33 \\
31\end{array}$ & $\begin{array}{r}4,160 \\
770 \\
564 \\
503 \\
486 \\
342 \\
281 \\
241 \\
210 \\
201\end{array}$ & $\begin{array}{l}11 \ldots \ldots \\
12 \ldots \ldots \\
13 \ldots \ldots \\
14 \ldots \ldots \\
15 \ldots \ldots \\
16 \ldots \ldots \\
17 \ldots \ldots \\
18 \ldots \ldots \\
19 \ldots \ldots \\
20 \ldots \ldots\end{array}$ & $\begin{array}{l}25 \\
17 \\
18 \\
23 \\
24 \\
24 \\
24 \\
24 \\
22 \\
21\end{array}$ & $\begin{array}{l}180 \\
165 \\
170 \\
150 \\
132 \\
129 \\
118 \\
114 \\
108 \\
108\end{array}$ & $\begin{array}{l}21 \ldots \ldots \\
22 \ldots \ldots \\
23 \ldots \ldots \\
24 \ldots \ldots \\
25 \ldots \ldots \\
26 \ldots \ldots \\
27 \ldots \ldots \\
25 \ldots \ldots \\
29 \ldots \ldots \\
30 \ldots \ldots \\
31 \ldots \ldots\end{array}$ & $\begin{array}{r}22 \\
23 \\
25 \\
25 \\
25 \\
23 \\
21 \\
21 \\
25 \\
94 \\
2,400\end{array}$ & $\begin{array}{r}106 \\
101 \\
93 \\
92 \\
92 \\
94 \\
92 \\
83 \\
-\ldots-\end{array}$ \\
\hline \multicolumn{7}{|l|}{$\begin{array}{l}\text { Monthly } \\
\text { Runoff, } \\
\text { Runoff, }\end{array}$} & $\begin{array}{r}106 \\
3.35 \\
6,530\end{array}$ & $\begin{array}{r}353 \\
10.0 \\
19,610 \\
\end{array}$ \\
\hline
\end{tabular}

Gage helght, in feet, and discharge, in cuble feet per second, at indicated time, 1963

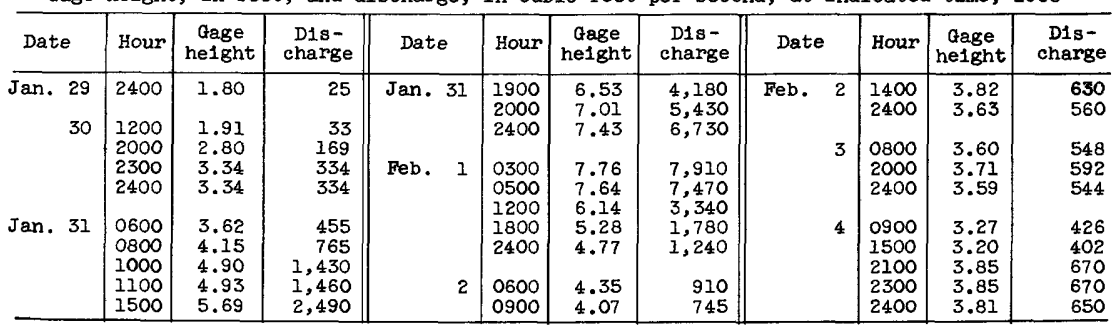


10-3435. Sagehen Creek near Truckee, Calif.

Location.--Lat $39^{\circ} 25^{\prime} 50^{\prime \prime}$, long $120^{\circ} 14^{\prime} 10^{\prime \prime}$, in $\mathrm{NE}_{\frac{1}{4}} \mathrm{NE} \frac{1}{4} \sec .7$, T.18 N., R.16 E., on left bank 2.2 miles upstream from bridge on State Highway 89 and 7.5 miles north of Truckee.

Drainage area. $--10.8 \mathrm{sq} \mathrm{mi}$.

Gage-height record.--Water-stage recorder graph, except Jan. 5-31. Altitude of gage is $6,320 \mathrm{f}^{\prime} \mathrm{f}$ (from topographic map).

Discharge record.--Stage-discharge relation defined by current-meter measurements below $70 \mathrm{cfs}$ and by slope-area measurement at $495 \mathrm{cfs}$. Discharge for period of no gage-height record estimated on basis of weather records and comparison with records for nearby streams.

Maxima.--January-February 1963: Discharge, 765 cfs (time unknown) Feb. I (gage height, $4.64 \mathrm{ft}$, from floodmarks).

1953 to December 1962: Discharge, $495 \mathrm{cfs}$ Dec. 23, 1955 (gage height, $4.28 \mathrm{ft}$ ).

Mean discharge, in cublc feet per second, 1963

\begin{tabular}{|c|c|c|c|c|c|c|c|c|}
\hline Day & January & February & Day & January & February & Day & January & Febmuary \\
\hline $\begin{array}{c}\ldots \ldots \\
2 \ldots \ldots \\
3 \ldots \ldots \\
4 \ldots \ldots \\
5 \ldots \ldots \\
6 \ldots \ldots \\
7 \ldots \ldots \\
9 \ldots \ldots \\
10 \ldots \ldots\end{array}$ & $\begin{array}{l}4.3 \\
4.1 \\
4.1 \\
4.3 \\
4.0 \\
3.8 \\
3.8 \\
3.5 \\
3.8 \\
3.6\end{array}$ & $\begin{array}{r}341 \\
115 \\
100 \\
95 \\
77 \\
64 \\
54 \\
50 \\
44 \\
47\end{array}$ & $\begin{array}{l}11 \ldots \ldots \\
12 \ldots \ldots \\
13 \ldots \ldots \\
14 \ldots \ldots \\
15 \ldots \ldots \\
16 \ldots \ldots \\
17 \ldots \ldots \\
18 \ldots \ldots \\
19 \ldots \ldots \\
20 \ldots \ldots\end{array}$ & $\begin{array}{l}2.5 \\
1.5 \\
1.8 \\
2.2 \\
2.4 \\
2.6 \\
2.5 \\
2.7 \\
2.6 \\
2.5\end{array}$ & $\begin{array}{l}39 \\
35 \\
37 \\
33 \\
29 \\
28 \\
26 \\
24 \\
24 \\
23\end{array}$ & $\begin{array}{l}21 \ldots \ldots \\
22 \ldots \ldots \\
23 \ldots \ldots \\
24 \ldots \ldots \\
25 \ldots \ldots \\
26 \ldots \ldots \\
27 \ldots \ldots \\
28 \ldots \ldots \\
29 \ldots \ldots \\
30 \ldots \ldots \\
31 \ldots \ldots\end{array}$ & $\begin{array}{l}2.6 \\
2.8 \\
2.8 \\
2.8 \\
2.8 \\
2.8 \\
2.7 \\
2.9 \\
3.0 \\
30 \\
370\end{array}$ & 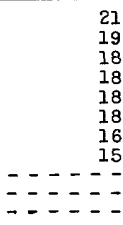 \\
\hline $\begin{array}{l}\text { Monthly } \\
\text { Runoff, } \\
\text { Runoff, }\end{array}$ & $\begin{array}{l}\text { an dis } \\
\text { inche } \\
\text { acre- }\end{array}$ & & & & & & $\begin{array}{r}15.7 \\
1.68 \\
968\end{array}$ & $\begin{array}{r}51.0 \\
4.92 \\
2,830\end{array}$ \\
\hline
\end{tabular}

10-3444. Iittle Truckee River above Boca Reservoir, near Boca, Calif.

Location. --Lat $39^{\circ} 26^{\prime} 10^{\prime \prime}$, long $120^{\circ} 05^{\prime} 00^{\prime \prime}$, in SW $\frac{1}{4} \mathrm{SW} \frac{1}{4} \mathrm{sec} .3, \mathrm{~T} .18 \mathrm{~N} ., \mathrm{R} .17 \mathrm{E}$., on left bank 1 mile upstream from Boca Reservolr, $1 \frac{4}{2}$ miles upstream 'from Dry Creek, and $3 \frac{1}{2}$ miles north of Boca.

Drainage area $--146 \mathrm{sq} \mathrm{mi}$.

Gage-height record.--Water-stage recorder graph. Datum of gage is $5,618.67 \mathrm{ft}$ above mean sea level (Bureau of Reclamation bench mark).

Discharge record.--Stage-discharge relation defined by current-meter measurements below $1,600 \mathrm{cfs}$ and by slope-area measurements at 4,100 and 13,300 cfs.

Maxima.--January-February 1963: Discharge, 13,300 cfs 0430 hours Feb. I (gage height, $9.00 \mathrm{ft}$ ).

1903-10, 1939 to December 1962: Discharge, about 9,500 cfs Dec. 23, 1955 (computed from change in contents of Boca Reservolr).

Mean discharge, in cublc feet per second, 1963

\begin{tabular}{|c|c|c|c|c|c|c|c|c|}
\hline Day & January & February & Day & January & February & Day & January & February \\
\hline $\begin{array}{c}1 \ldots \ldots \\
2 \ldots \ldots \\
3 \ldots \ldots \\
5 \ldots \ldots \\
6 \ldots \ldots \\
7 \ldots \ldots \\
8 \ldots \ldots \\
10 \ldots \ldots\end{array}$ & $\begin{array}{l}56 \\
57 \\
59 \\
62 \\
57 \\
53 \\
52 \\
51 \\
50 \\
47\end{array}$ & $\begin{array}{r}8,810 \\
1,750 \\
1,200 \\
1,080 \\
1,080 \\
759 \\
654 \\
630 \\
569 \\
576\end{array}$ & $\begin{array}{l}11 \ldots \ldots \\
12 \ldots \ldots \\
13 \ldots \ldots \\
14 \ldots \ldots \\
15 \ldots \ldots \\
16 \ldots \ldots \\
17 \ldots \ldots \\
18 \ldots \ldots \\
19 \ldots \ldots \\
20 \ldots \ldots\end{array}$ & $\begin{array}{l}27 \\
20 \\
15 \\
12 \\
10 \\
11 \\
11 \\
11 \\
11 \\
11\end{array}$ & $\begin{array}{l}527 \\
454 \\
520 \\
448 \\
400 \\
385 \\
370 \\
345 \\
330 \\
325\end{array}$ & $\begin{array}{l}21 \ldots \ldots \\
22 \ldots \ldots \\
23 \ldots \ldots \\
24 \ldots \ldots \\
25 \ldots \ldots \\
26 \ldots \ldots \\
27 \ldots \ldots \\
28 \ldots \ldots \\
29 \ldots \ldots \\
30 \ldots \ldots \\
31 \ldots \ldots\end{array}$ & $\begin{array}{r}12 \\
12 \\
13 \\
16 \\
16 \\
16 \\
16 \\
68 \\
109 \\
214 \\
4,750\end{array}$ & $\begin{array}{r}310 \\
295 \\
272 \\
272 \\
262 \\
267 \\
258 \\
244 \\
---- \\
-----\end{array}$ \\
\hline $\begin{array}{l}\text { nthly } \\
\text { anoff, } \\
\text { anoff, }\end{array}$ & \multicolumn{6}{|c|}{ 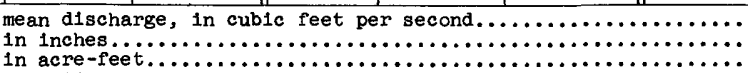 } & $\begin{array}{r}191 \\
1.51 \\
11,750\end{array}$ & $\begin{array}{r}835 \\
5.96 \\
46,400\end{array}$ \\
\hline
\end{tabular}


Gage height, in feet, and discharge, in cubic feet per second, at indicated time, 1963, of Little Truckee River above Boca Reservolr, near Boca, Calif.

\begin{tabular}{|c|c|c|c|c|c|c|c|c|c|c|c|}
\hline Date & Hour & $\begin{array}{c}\text { Gage } \\
\text { height }\end{array}$ & $\begin{array}{l}\text { Dis- } \\
\text { charge }\end{array}$ & Date & Hour & $\begin{array}{c}\text { Gage } \\
\text { helght }\end{array}$ & $\begin{array}{c}\text { Dis- } \\
\text { charge }\end{array}$ & Date & Hour & $\begin{array}{c}\text { Gage } \\
\text { he1ght }\end{array}$ & $\begin{array}{c}\text { Dis- } \\
\text { charge }\end{array}$ \\
\hline $\begin{array}{r}29 \\
30\end{array}$ & $\begin{array}{l}2400 \\
1100 \\
1300 \\
1500 \\
1800 \\
2000 \\
2400 \\
0300\end{array}$ & $\begin{array}{l}1.17 \\
1.25 \\
1.31 \\
1.52 \\
1.60 \\
1.73 \\
2.30 \\
3.40\end{array}$ & $\begin{array}{r}105 \\
126 \\
142 \\
218 \\
253 \\
315 \\
670 \\
1,960\end{array}$ & $\begin{array}{l}\text { Jan. } 31 \\
\text { Feb. } 1\end{array}$ & $\begin{array}{l}0600 \\
0800 \\
0900 \\
1300 \\
2400 \\
0430 \\
0700 \\
0800 \\
1200\end{array}$ & $\begin{array}{l}3.55 \\
4.20 \\
2.89 \\
4.00 \\
8.20 \\
9.00 \\
8.35 \\
7.62 \\
6.00\end{array}$ & $\begin{array}{r}2,240 \\
3,710 \\
1,270 \\
3,210 \\
12,500 \\
13,300 \\
12,700 \\
11,700 \\
8,640\end{array}$ & Feb. 1 & $\begin{array}{l}1500 \\
1800 \\
2400 \\
\\
0600 \\
1200 \\
1800 \\
2400\end{array}$ & $\begin{array}{l}5.31 \\
4.77 \\
3.92 \\
3.37 \\
3.09 \\
3.02 \\
2.90\end{array}$ & $\begin{array}{l}7,020 \\
5,540 \\
3,030 \\
1,910 \\
1,520 \\
1,430 \\
1,280\end{array}$ \\
\hline
\end{tabular}

10-3444.9. Boca Reservolr at Boca, Calif.

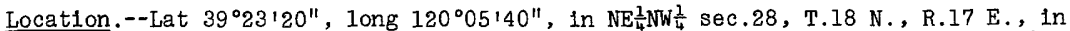
control house at Boca Dam, 1,800 ft upstream from mouth of Little Truckee River and a half a mile northwest of Boca.

Drainage area. --172 sq $\mathrm{ml}$.

Gage-helght record.--Pressure gage with mercury column read once dally at 0800 hours. Datum of gage is at mean sea level (levels by Bureau of Reclamation).

Contents record.--Contents computed from capacity table furnished by U.S. Bureau of Reclamation.

Maxima --January-February 1963: Contents, 31,510 acre-ft Feb. 26 (elevation, $5,594.80 \mathrm{f} t)$.

1939 to December 1962: Contents, 41,440 acre-ft Dec. 23, 1955 (elevation, $5,605.55 \mathrm{ft})$.

Remarks.--Reservolr is formed by earthfill, rock-faced dam. Storage began Dec. 8, 1938. Usable capac1ty, 40,900 acre-ft between elevations 5,521 (outlet s1l1) and $5,605 \mathrm{ft}$. Dead storage, 240 acre-ft. Figures given herein represent usable contents. Daliy elevations furnished by Washoe County Conservation District.

Elevation, in feet, and contents, in acre-feet, 1963

\begin{tabular}{|c|c|c|c|c|c|c|c|c|c|}
\hline \multirow{2}{*}{ Day } & \multicolumn{2}{|c|}{ January } & \multicolumn{2}{|c|}{ February } & \multirow{2}{*}{ Day } & \multicolumn{2}{|c|}{ January } & \multicolumn{2}{|c|}{ February } \\
\hline & Elevation & Contents & Elevation & Contents & & Elevation & Contents & Elevat1on & Contents \\
\hline $\begin{array}{r}1 \\
2 \\
3 \\
4 \\
5 \\
6 \\
7 \\
8 \\
9 \\
10 \\
11 \\
12 \\
13 \\
14 \\
15\end{array}$ & $\begin{array}{l}\mathbf{5}, 565.95 \\
\mathbf{5}, 565.23 \\
\mathbf{5}, 564.50 \\
5,563.88 \\
5,563.25 \\
\mathbf{5}, 562.70 \\
5,562.35 \\
5,562.30 \\
5,562.20 \\
\mathbf{5}, 562.30 \\
\mathbf{5}, 562.28 \\
5,562.20 \\
\mathbf{5}, 562.15 \\
\mathbf{5}, 562.18 \\
\mathbf{5}, 562.29\end{array}$ & $\begin{array}{r}11,600 \\
11,260 \\
10,880 \\
10,590 \\
10,280 \\
10,020 \\
9,860 \\
9,830 \\
9,790 \\
9,830 \\
9,830 \\
9,790 \\
9,760 \\
9,790 \\
9,830\end{array}$ & $\begin{array}{l}5,588.80 \\
5,594.60 \\
5,593.10 \\
5,591.95 \\
5,591.45 \\
5,590.70 \\
5,589.90 \\
5,589.20 \\
5,588.50 \\
5,587.80 \\
5,587.15 \\
5,587.65 \\
5,588.95 \\
5,590.30 \\
5,591.39\end{array}$ & $\begin{array}{l}26,550 \\
31,340 \\
30,070 \\
29,110 \\
28,700 \\
28,080 \\
27,430 \\
26,870 \\
26,310 \\
25,760 \\
25,260 \\
25,650 \\
26,670 \\
27,750 \\
28,650\end{array}$ & $\begin{array}{l}16 \\
17 \\
18 \\
19 \\
20 \\
21 \\
22 \\
23 \\
24 \\
25 \\
26 \\
27 \\
28 \\
29 \\
30 \\
31 \\
\end{array}$ & $\begin{array}{l}5,562.45 \\
5,562.50 \\
5,562.70 \\
5,562.70 \\
5,562.73 \\
5,562.85 \\
5,562.90 \\
5,563.00 \\
5,563.10 \\
5,563.15 \\
5,563.10 \\
5,563.05 \\
5,563.00 \\
5,562.97 \\
5,563.05 \\
5,565.45\end{array}$ & $\begin{array}{r}9,900 \\
9,930 \\
10,020 \\
10,020 \\
10,040 \\
10,090 \\
10,110 \\
10,160 \\
10,210 \\
10,240 \\
10,210 \\
10,180 \\
10,160 \\
10,140 \\
10,180 \\
10,360\end{array}$ & $\begin{array}{c}5,590.65 \\
5,590.10 \\
5,589.70 \\
5,590.32 \\
5,591.20 \\
5,591.98 \\
5,592.75 \\
5,593.45 \\
5,594.14 \\
5,594.78 \\
5,594.80 \\
5,594.70 \\
5,594.20 \\
- \\
- \\
-\end{array}$ & $\begin{array}{c}28,040 \\
27,590 \\
27,270 \\
26,950 \\
28,490 \\
29,150 \\
29,780 \\
30,360 \\
30,960 \\
31,510 \\
31,510 \\
31,430 \\
31,000 \\
- \\
- \\
-\end{array}$ \\
\hline \multicolumn{6}{|c|}{ 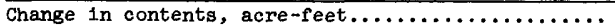 } & - & $-1,600$ & - & $+20,640$ \\
\hline
\end{tabular}


10-3445. Little Truckee River at Boca, Calif.

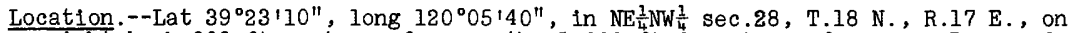
right bank $800 \mathrm{ft}$ upstream from mouth, 1,000 ft downstream from Boca Dam, and a third of a mile northwest of Boca.

Drainage area. $--172 \mathrm{sq} \mathrm{mi}$.

Gage-height record:--Water-stage recorder graph. Altitude of gage is $5,500 \mathrm{ft}$ (from topographic map).

Discharge record.--Stage-discharge relation defined by current-meter measurements below 1,500 cfs.

Maxima.--January-February 1963: Discharge, 2,590 cfs 0015 hours Feb. 2 (gage height, $6.16 \mathrm{ft}$ ).

$1890,1911-15,1939$ to December 1962: Discharge, 8,800 cfs Dec. 24, 1955, from records of Washoe County Water Conservation District.

Remarks.--Flow regulated by Boca Reservoir (see station 10-3444.9). Independence Lake (capacity, about 17,500 acre-ft), and one transmountain diversion to Sierra Valley.

Mean discharge, in cublc feet per second, 1963

\begin{tabular}{|c|c|c|c|c|c|c|c|c|}
\hline Day & January & February & Day & January & February & Day & $J$ anuary & February \\
\hline $\begin{array}{r}1 \ldots \ldots \\
2 \ldots \ldots \\
3 \ldots \ldots \\
4 \ldots \ldots \\
5 \ldots \ldots \\
6 \ldots \ldots \\
7 \ldots \ldots \\
8 \ldots \ldots \\
9 \ldots \ldots \\
10 \ldots \ldots\end{array}$ & $\begin{array}{r}247 \\
247 \\
245 \\
243 \\
190 \\
151 \\
104 \\
73 \\
56 \\
43\end{array}$ & $\begin{array}{r}1,040 \\
2,360 \\
1,820 \\
1,530 \\
1,340 \\
1,160 \\
1,000 \\
921 \\
902 \\
902\end{array}$ & $\begin{array}{l}11 \ldots \ldots \\
12 \ldots \ldots \\
13 \ldots \ldots \\
14 \ldots \ldots \\
15 \ldots \ldots \\
16 \ldots \ldots \\
17 \ldots \ldots \\
18 \ldots \ldots \\
19 \ldots \ldots \\
20 \ldots \ldots\end{array}$ & $\begin{array}{l}43 \\
41 \\
28 \\
23 \\
23 \\
23 \\
23 \\
22 \\
22 \\
22\end{array}$ & $\begin{array}{r}655 \\
1.2 \\
.8 \\
498^{.8} \\
670 \\
554 \\
239 \\
1 \\
1.1\end{array}$ & $\begin{array}{l}21 \ldots \ldots \\
22 \ldots \ldots \\
23 \ldots \ldots \\
24 \ldots \ldots \\
25 \ldots \ldots \\
26 \ldots \ldots \\
27 \ldots \ldots \\
28 \ldots \ldots \\
29 \ldots \ldots \\
30 \ldots \ldots \\
31 \ldots \ldots\end{array}$ & $\begin{array}{r}23 \\
23 \\
23 \\
23 \\
39 \\
48 \\
48 \\
48 \\
48 \\
36 \\
5\end{array}$ & $\begin{array}{c}1.3 \\
1.2 \\
1.0 \\
1.0 \\
200 \\
296 \\
405 \\
470 \\
\ldots--.- \\
---.-\end{array}$ \\
\hline \multicolumn{7}{|c|}{ 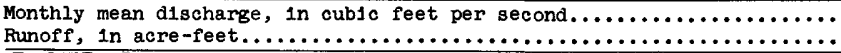 } & $\begin{array}{r}72.0 \\
4,430\end{array}$ & $\begin{array}{r}606 \\
33,660 \\
\end{array}$ \\
\hline
\end{tabular}

10-3460. Truckee River at Farad, Calif.

Location.--Lat $39^{\circ} 25^{\prime} 4^{\prime \prime}$, long $120^{\circ} 01^{\prime} 59^{\prime \prime}$, in NE $\frac{1}{4}$ sec.12, T.18 N., R.17 E., on left bank 0.7 mile downstream from Farad powerplant, 2.5 miles north of Floriston, 3.4 miles downstream from Bronco Creek, and 3.5 miles upstream from CaliforniaNevada State line.

Drainage area. $--932 \mathrm{sq} \mathrm{mi}$.

Gage-height record.--Water-stage recorder graph. Datum of gage is $5,153.21 \mathrm{ft}$ above mean sea level (Bureau of Reclamation bench mark).

Discharge record.--Stage-discharge relation defined by current-meter measurements below $600 \mathrm{cfs}$ and by slope-area measurements at 14,400 and 17,500 cfs.

Maxima.--January-February 1963: Discharge, 11,900 cfs 0600 hours Feb. 1 (gage height, $11.61 \mathrm{ft}$ ).

1899 to December 1962: Discharge, 17,500 cfs Nov. 21, 1950 (gage height, $14.5 \mathrm{ft}$, from floodmarks).

Remarks.--Flow regulated by Lake Tahoe, Prosser Creek and Boca Reservoirs, Donner and Independence Lakes, and by several powerplants.

Mean discharge, in cublc feet per second, 1963

\begin{tabular}{|c|c|c|c|c|c|c|c|c|}
\hline Day & January & February & Day & January & February & Day & January & February \\
\hline $\begin{array}{r}1 \ldots \ldots \\
2 \ldots \ldots \\
3 \ldots \ldots \\
4 \ldots \ldots \\
5 \ldots \ldots \\
6 \ldots \ldots \\
7 \ldots \ldots \\
9 \ldots \ldots \\
10 \ldots \ldots\end{array}$ & $\begin{array}{l}405 \\
410 \\
418 \\
418 \\
404 \\
382 \\
340 \\
300 \\
285 \\
264\end{array}$ & $\begin{array}{l}7,960 \\
4,560 \\
3,530 \\
3,230 \\
3,820 \\
3,820 \\
2,980 \\
2,200 \\
1,920 \\
1,860\end{array}$ & $\begin{array}{l}11 \ldots \ldots \\
12 \ldots \ldots \\
13 \ldots \ldots \\
14 \ldots \ldots \\
15 \ldots \ldots \\
16 \ldots \ldots \\
17 \ldots \ldots \\
18 \ldots \ldots \\
19 \ldots \ldots \\
20 \ldots \ldots\end{array}$ & $\begin{array}{l}234 \\
200 \\
192 \\
204 \\
208 \\
211 \\
213 \\
213 \\
210 \\
198 \\
\end{array}$ & $\begin{array}{r}1,620 \\
506 \\
492 \\
447 \\
904 \\
1,400 \\
1,290 \\
912 \\
428 \\
334\end{array}$ & $\begin{array}{l}21 \ldots \ldots \\
22 \ldots \ldots \\
23 \ldots \ldots \\
24 \ldots \ldots \\
25 \ldots \ldots \\
26 \ldots \ldots \\
27 \ldots \ldots \\
22 \ldots \ldots \\
29 \ldots \ldots \\
30 \ldots \ldots \\
31 \ldots \ldots\end{array}$ & $\begin{array}{r}200 \\
200 \\
194 \\
194 \\
199 \\
207 \\
199 \\
197 \\
202 \\
696 \\
4,800\end{array}$ & $\begin{array}{r}324 \\
368 \\
459 \\
455 \\
560 \\
640 \\
705 \\
770 \\
----- \\
----- \\
--.-\end{array}$ \\
\hline $\begin{array}{l}\text { onthly } \\
\text { anoff, }\end{array}$ & $n$ disc & $e, 1$ & $100 \mathrm{~s}$ & & & & $\begin{array}{r}419 \\
25,7 a 0 \\
\end{array}$ & $\begin{array}{r}1,732 \\
96,200 \\
\end{array}$ \\
\hline
\end{tabular}


Gage height, in feet, and discharge, in cublc feet per second, at indicated time, 1963, of Truckee River at Farad, Calif.

\begin{tabular}{|c|c|c|c|c|c|c|c|c|c|c|c|}
\hline Date & Hour & $\begin{array}{c}\text { Gage } \\
\text { he1ght }\end{array}$ & $\begin{array}{c}\text { Dis- } \\
\text { charge }\end{array}$ & Date & Hour & $\begin{array}{c}\text { Gage } \\
\text { helght }\end{array}$ & $\begin{array}{c}\text { DIs- } \\
\text { charge }\end{array}$ & Date & dour & $\begin{array}{c}\text { Gage } \\
\text { helght }\end{array}$ & $\begin{array}{c}\text { D18- } \\
\text { charge }\end{array}$ \\
\hline $\begin{array}{r}\operatorname{Jan} . \\
30\end{array}$ & $\begin{array}{l}2400 \\
\\
0900 \\
1600 \\
1700 \\
1800 \\
1900 \\
2400 \\
0500\end{array}$ & $\begin{array}{l}1.89 \\
\\
2.03 \\
2.72 \\
3.50 \\
4.02 \\
4.44 \\
4.94 \\
4.49\end{array}$ & $\begin{array}{r}212 \\
256 \\
520 \\
920 \\
1,240 \\
1,540 \\
1,940 \\
1,580 \\
\end{array}$ & Feb. 1 & $\begin{array}{l}1000 \\
1300 \\
1500 \\
1700 \\
1900 \\
2200 \\
2400 \\
0600 \\
0800\end{array}$ & $\begin{array}{r}5.37 \\
6.73 \\
7.73 \\
9.13 \\
9.91 \\
10.70 \\
11.09 \\
11.61 \\
10.62\end{array}$ & $\begin{array}{r}2,390 \\
4,000 \\
5,370 \\
7,460 \\
8,750 \\
10,160 \\
10,870 \\
11,900 \\
10,020\end{array}$ & Feb. 1 & $\begin{array}{l}1000 \\
1200 \\
1400 \\
2000 \\
2400 \\
1200 \\
2400\end{array}$ & $\begin{array}{l}9.43 \\
8.33 \\
7.68 \\
8.19 \\
7.85 \\
7.05 \\
6.60\end{array}$ & $\begin{array}{l}6,240 \\
5,300 \\
6,040 \\
5,540 \\
4,420 \\
3,840\end{array}$ \\
\hline
\end{tabular}

10-3476. Hunter Creek near Reno, Nev.

Location.--Lat $39^{\circ} 29^{1} 2^{\prime \prime}$, long $119^{\circ} 53^{\prime} 55^{\prime \prime}$, in SW $\frac{1}{4} \mathrm{SW} \frac{1}{4} \sec .19$, T.19 N., R.19 E., on right bank $1 \frac{1}{4}$ miles upstream from Hunter Creek Reservolr and 5 miles southwest of Reno.

Drainage area.--11.5 sq mi, approximately.

Gage-height record.--Water-stage recorder graph, except Feb. 2-13, for wh1ch graph is doubtful. Aititude of gage is $5,070 \mathrm{ft}$ (from topographic map).

Discharge record.--Stage-discharge relation defined by current-meter measurements below $50 \mathrm{cf}$ 's and by slope-area measurement of peak flow; affected by ice

Jan. 11-15. D1scharge for perlods of 1ce effect or doubtful gage helght estimated on basis of weather records and comparison with records for nearby streams.

Maxima.--January-February 1963: Discharge, 986 ofs about 1430 hours Jan. 31 (gage helght, $6.93 \mathrm{ft}$ ).

1961 to December 1962: Discharge, $23 \mathrm{cf}$ 's May 8, oct. 13, 1962; gage height, 1.74 May 8,1962 .

Mean discharge, in cublc feet per second, 1963

\begin{tabular}{|c|c|c|c|c|c|c|c|c|}
\hline Day & January & February & Day & January & February & Day & January & February \\
\hline $\begin{array}{c}1 \ldots \ldots \\
2 \ldots \ldots \\
3 \ldots \ldots \\
4 \ldots \ldots \\
6 \ldots \ldots \\
7 \ldots \ldots \\
8 \ldots \ldots \\
9 \ldots \ldots \\
10 \ldots \ldots\end{array}$ & $\begin{array}{l}4.2 \\
4.2 \\
4.4 \\
4.4 \\
4.2 \\
4.2 \\
4.4 \\
4.2 \\
4.2 \\
4.2\end{array}$ & $\begin{array}{r}110 \\
30 \\
17 \\
17 \\
18 \\
16 \\
14 \\
12 \\
10 \\
11\end{array}$ & $\begin{array}{l}11 \ldots \ldots \\
12 \ldots \ldots \\
13 \ldots \ldots \\
14 \ldots \ldots \\
15 \ldots \ldots \\
16 \ldots \ldots \\
17 \ldots \ldots \\
18 \ldots \ldots \\
19 \ldots \ldots \\
20 \ldots \ldots\end{array}$ & $\begin{array}{l}3.6 \\
3.2 \\
3.6 \\
4.1 \\
4.3 \\
4.4 \\
4.2 \\
4.2 \\
4.2 \\
4\end{array}$ & $\begin{array}{l}11 \\
10 \\
10 \\
9.2 \\
8.9 \\
8.5 \\
8.1 \\
7.8 \\
7.8 \\
7\end{array}$ & $\begin{array}{l}21 \ldots \ldots \\
22 \ldots \ldots \\
23 \ldots \ldots \\
24 \ldots \ldots \\
25 \ldots \ldots \\
26 \ldots \ldots \\
27 \ldots \ldots \\
28 \ldots \ldots \\
29 \ldots \ldots \\
30 \ldots \ldots \\
31 \ldots \ldots\end{array}$ & $\begin{array}{l}4.2 \\
4.2 \\
4 \\
4 \\
4 \\
3.8 \\
4 \\
3.8 \\
3.8 \\
46 \\
230\end{array}$ & $\begin{array}{r}6.6 \\
6.6 \\
6.3 \\
6.6 \\
6.6 \\
6.6 \\
6.6 \\
6.6 \\
-.-.-1 \\
-1 .-1\end{array}$ \\
\hline \multicolumn{7}{|c|}{ 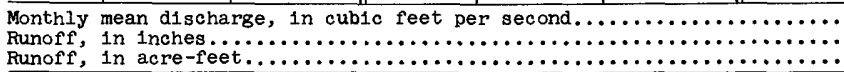 } & $\begin{array}{r}12.7 \\
1.27 \\
782\end{array}$ & $\begin{array}{r}14.1 \\
1.28 \\
785\end{array}$ \\
\hline
\end{tabular}

Gage he1ght, in feet, and d1scharge, in cub1c feet per second, at indicated t1me, 1963

\begin{tabular}{|c|c|c|c|c|c|c|c|c|c|c|c|}
\hline Date & Hour & $\begin{array}{c}\text { Gage } \\
\text { he1ght }\end{array}$ & $\begin{array}{c}\text { D1s- } \\
\text { charge }\end{array}$ & Date & Hour & $\begin{array}{c}\text { Gage } \\
\text { helght }\end{array}$ & $\begin{array}{l}\text { Dis- } \\
\text { charge }\end{array}$ & Date & Hour & $\begin{array}{c}\text { Gage } \\
\text { helght }\end{array}$ & $\begin{array}{c}\text { D1s - } \\
\text { charge }\end{array}$ \\
\hline $\begin{array}{r}\text { Jan. } 29 \\
30\end{array}$ & $\begin{array}{l}2400 \\
1100 \\
1400 \\
1600 \\
2000 \\
2400 \\
0300\end{array}$ & $\begin{array}{l}1.59 \\
1.65 \\
1.93 \\
2.65 \\
2.56 \\
2.08 \\
2.05\end{array}$ & $\begin{array}{c}4.0 \\
5.6 \\
25 \\
121 \\
123 \\
57 \\
54\end{array}$ & Jan. 31 & $\begin{array}{l}0900 \\
0930 \\
1130 \\
1130 \\
1300 \\
1330 \\
1400 \\
1430 \\
1500\end{array}$ & $\begin{array}{l}2.35 \\
2.68 \\
2.70 \\
2.96 \\
3.05 \\
3.80 \\
4.50 \\
6.93 \\
6.20\end{array}$ & $\begin{array}{r}91 \\
143 \\
146 \\
193 \\
210 \\
360 \\
500 \\
986 \\
840\end{array}$ & $\begin{array}{l}\text { Jan. } 31 \\
\text { Feb. } 1\end{array}$ & $\begin{array}{l}1530 \\
1830 \\
2200 \\
2400 \\
\\
0700 \\
1200 \\
2400\end{array}$ & $\begin{array}{l}5.25 \\
2.70 \\
3.10 \\
3.03 \\
2.06 \\
1.76 \\
1.52\end{array}$ & \begin{tabular}{r|r}
658 \\
219 \\
282 \\
271 \\
\\
123 \\
80 \\
47
\end{tabular} \\
\hline
\end{tabular}


10-3480. Truckee River at Reno, Nev.

Location.--Lat $39^{\circ} 31^{1} 55^{\prime \prime}$, long $119^{\circ} 47^{\prime} 05^{\prime \prime}$, in NW $\frac{1}{4}$ sec.7, T.19 N., R.20 E., on left bank $400 \mathrm{ft}$ downstream from Kletzke Lane bridge, half a mile east of Reno, and 5 miles upstream from Steamboat Creek.

Drainage area. $--1,067 \mathrm{sq} \mathrm{m1.}$

Gage-he1ght record.--Water-stage recorder graph, except Jan. 1-9. Datum of gage is $4,431.97 \mathrm{ft}$ above mean sea level (levels by Corps of Englneers).

Discharge record.--Stage-discharge relation defined by current-meter measurements below 14,000 cfs. Affected by 1ce Jan. 10-29. Discharge for Jan. 31, Feb. 1-4 computed by using rate of change of stage as a factor. D1scharge for periods of 1 ce effect or no gage-height record estimated on basis of weather records and comparison with records for station at V1sta.

Maxima.--January-February 1963: Discharge, 18,400 cf's 0430 hours Feb. 1 (gage helght, $13.28 \mathrm{ft}$ ); gage he1ght, $13.33 \mathrm{ft} 0500$ hours Feb. 1 .

$1906-21,1925-26,1930-35$, 1943, 1946 to December 1962: Discharge, 20,800 cf's Dec. 23, 1955; gage he1ght, 13.83 ft Nov. 21, 1950.

Remarks.--Flow regulated by Lake Tahoe, Prosser Creek and Boca Reservoirs, Donner and Independence Lakes, and by several powerplants.

Mean discharge, in cublc feet per second, 1963

\begin{tabular}{|c|c|c|c|c|c|c|c|c|}
\hline Day & January & February & Day & January & February & Day & January & February \\
\hline $\begin{array}{c}1 \ldots \ldots \\
3 \ldots \ldots \\
4 \ldots \ldots \\
5 \ldots \ldots \\
6 \ldots \ldots \\
8 \ldots \ldots \\
9 \ldots \ldots \\
10 \ldots \ldots\end{array}$ & $\begin{array}{l}220 \\
220 \\
225 \\
245 \\
235 \\
235 \\
230 \\
220 \\
215 \\
205\end{array}$ & $\begin{array}{r}11,480 \\
5,350 \\
3,850 \\
3,400 \\
3,960 \\
3,960 \\
3,330 \\
2,520 \\
2,300 \\
2,270\end{array}$ & $\begin{array}{l}11 \ldots \ldots \\
12 \ldots \ldots \\
13 \ldots \ldots \\
14 \ldots \ldots \\
15 \ldots \ldots \\
16 \ldots \ldots \\
17 \ldots \ldots \\
18 \ldots \ldots \\
19 \ldots \ldots \\
20 \ldots \ldots\end{array}$ & $\begin{array}{l}150 \\
145 \\
150 \\
160 \\
170 \\
160 \\
160 \\
155 \\
150 \\
155\end{array}$ & $\begin{array}{r}2,150 \\
610 \\
520 \\
495 \\
750 \\
1,710 \\
1,570 \\
1,290 \\
456 \\
370\end{array}$ & $\begin{array}{l}21 \ldots \ldots \\
22 \ldots \ldots \\
23 \ldots \ldots \\
24 \ldots \ldots \\
25 \ldots \ldots \\
26 \ldots \ldots \\
27 \ldots \ldots \\
28 \ldots \ldots \\
29 \ldots \ldots \\
30 \ldots \ldots \\
31 \ldots \ldots\end{array}$ & $\begin{array}{l}160 \\
160 \\
160 \\
150 \\
155 \\
155 \\
155 \\
180 \\
190 \\
987 \\
7,210\end{array}$ & $\begin{array}{r}307 \\
295 \\
447 \\
452 \\
510 \\
647 \\
692 \\
800 \\
---- \\
----\end{array}$ \\
\hline \multicolumn{7}{|l|}{$\begin{array}{l}\text { Monthly } \\
\text { Runoff, } \\
\text { Runoff, }\end{array}$} & $\begin{array}{r}434 \\
0.47 \\
26,710\end{array}$ & $\begin{array}{r}2,018 \\
1.97 \\
112,000\end{array}$ \\
\hline
\end{tabular}

Gage height, in feet, and discharge, in cublc feet per second, at indicated time, 1963

\begin{tabular}{|c|c|c|c|c|c|c|c|c|c|c|c|}
\hline Date & Hour & $\begin{array}{c}\text { Gage } \\
\text { height }\end{array}$ & $\begin{array}{c}\text { D1s- } \\
\text { charge }\end{array}$ & Date & Hour & $\begin{array}{c}\text { Gage } \\
\text { helght }\end{array}$ & $\begin{array}{l}\text { Dis- } \\
\text { charge }\end{array}$ & Date & Hour & $\begin{array}{c}\text { Gage } \\
\text { helght }\end{array}$ & $\begin{array}{l}\text { Dis- } \\
\text { charge }\end{array}$ \\
\hline an. $\begin{array}{r}29 \\
30\end{array}$ & $\begin{array}{l}2400 \\
0500 \\
1000 \\
1200 \\
1330 \\
1500 \\
1600 \\
1700 \\
1800 \\
1900 \\
2030 \\
2100 \\
2230 \\
2400 \\
0200 \\
0430 \\
0700 \\
0900\end{array}$ & $\begin{array}{l}2.11 \\
2.16 \\
2.31 \\
2.52 \\
2.53 \\
2.86 \\
3.95 \\
4.85 \\
5.07 \\
5.07 \\
5.23 \\
5.90 \\
6.31 \\
6.03 \\
5.71 \\
6.05 \\
5.75 \\
6.15\end{array}$ & $\begin{array}{r}176 \\
191 \\
242 \\
324 \\
328 \\
475 \\
1,130 \\
1,870 \\
2,070 \\
2,070 \\
2,220 \\
2,840 \\
3,240 \\
2,960 \\
2,640 \\
2,980 \\
2,680 \\
3,080\end{array}$ & Jan. 31 & $\begin{array}{l}1100 \\
1200 \\
1500 \\
1700 \\
2100 \\
2400 \\
0230 \\
0430 \\
0500 \\
0530 \\
0930 \\
1200 \\
1600 \\
1730 \\
1800 \\
1900 \\
2030 \\
2130 \\
2400\end{array}$ & $\begin{array}{r}7.75 \\
8.53 \\
9.32 \\
10.25 \\
10.91 \\
12.06 \\
12.74 \\
13.28 \\
13.33 \\
13.23 \\
12.13 \\
10.93 \\
9.14 \\
8.80 \\
8.82 \\
8.82 \\
9.10 \\
9.10 \\
8.97\end{array}$ & $\begin{array}{r}6,240 \\
7,280 \\
8,540 \\
11,000 \\
12,100 \\
15,900 \\
17,000 \\
18,400 \\
17,500 \\
16,700 \\
13,400 \\
10,300 \\
7,080 \\
6,800 \\
6,840 \\
6,840 \\
7,370 \\
7,370 \\
7,120\end{array}$ & Feb. 2 & $\begin{array}{l}0700 \\
1100 \\
1800 \\
2400 \\
0800 \\
1200 \\
1430 \\
1600 \\
2400 \\
1100 \\
1200 \\
1230 \\
1800 \\
1900 \\
2000 \\
2400\end{array}$ & $\begin{array}{l}8.21 \\
7.88 \\
7.47 \\
7.23 \\
6.91 \\
6.83 \\
6.68 \\
6.77 \\
6.64 \\
6.31 \\
6.13 \\
6.28 \\
6.13 \\
6.15 \\
6.80 \\
6.97\end{array}$ & $\begin{array}{l}5,770 \\
5,240 \\
4,640 \\
4,310 \\
3,900 \\
3,810 \\
3,640 \\
3,740 \\
3,590 \\
3,240 \\
3,060 \\
3,210 \\
3,060 \\
3,080 \\
3,770 \\
3,970\end{array}$ \\
\hline
\end{tabular}


10-3489. Galena Creek near Steamboat, Nev.

Location.--Lat $39^{\circ} 21^{\prime} 45^{\prime \prime}$, long $119^{\circ} 49^{\prime} 30^{\prime \prime}$, in SW $\frac{1}{4} S W^{\frac{1}{4}}$ sec.2, T.17 N., R.19 E., on right bank, I mile upstream from Jones Creek, $3 \frac{1}{2}$ miles upstream from mouth, and 12 miles south of Reno.

Drainage area. $--8.5 \mathrm{sq} \mathrm{mi}$, approximately.

Gage-height record.--Water-stage recorder graph, except Feb. 2, 3, 7-14. Altitude of gage is $5,580 \mathrm{ft}$ (from topograph1c map).

Discharge record.--Stage-discharge relation defined by current-meter measurements below $50 \mathrm{cfs}$ and by slope-area measurement of maximum flow; affected by ice Jan. $11-16, \mathrm{Feb} .23,24,27,28$. Discharge for periods of lce effect or no gageheight record estimated on basis of weather records and comparison with records for nearby streams.

Maxima.--January-February 1963: Discharge, 472 cfs 2000 hours Jan. 31 (gage he1ght, $2.26 \mathrm{ftl}$.

1961 to December 1962: Discharge, $80 \mathrm{cfs}$ June 10, 1962 (gage height,1.64 ft). Flood of July 20,1956 , reached a discharge of $4,730 \mathrm{cfs}$.

Mean discharge, in cublc feet per second, 1963

\begin{tabular}{|c|c|c|c|c|c|c|c|c|}
\hline Day & January & February & Day & January & February & Day & January & February \\
\hline $\begin{array}{c}1 \ldots \ldots \\
2 \ldots \ldots \\
4 \ldots \ldots \\
5 \ldots \ldots \\
6 \ldots \ldots \\
8 \ldots \ldots \\
9 \ldots \ldots \\
10 \ldots \ldots\end{array}$ & $\begin{array}{l}1.2 \\
1.3 \\
1.3 \\
1.3 \\
1.2 \\
1.2 \\
1.2 \\
1.2 \\
1.2 \\
1.2\end{array}$ & $\begin{array}{c}100 \\
37 \\
30 \\
21 \\
14 \\
12 \\
10 \\
7.0 \\
5.4 \\
4.0\end{array}$ & $\begin{array}{l}11 \ldots \ldots \\
12 \ldots \ldots \\
13 \ldots \ldots \\
14 \ldots \ldots \\
15, \ldots \ldots \\
16 \ldots \ldots \\
17 \ldots \ldots \\
18 \ldots \ldots \\
19 \ldots \ldots \\
20 \ldots \ldots\end{array}$ & $\begin{array}{r}1.0 \\
.8 \\
.9 \\
1.0 \\
1.1 \\
1.3 \\
1.2 \\
1.2 \\
1.2 \\
1.2\end{array}$ & $\begin{array}{l}3.4 \\
2.8 \\
2.5 \\
2.2 \\
2.2 \\
2.2 \\
2.2 \\
2.1 \\
2.4 \\
2.3\end{array}$ & $\begin{array}{l}21 \ldots \ldots \\
22 \ldots \ldots \\
23 \ldots \ldots \\
24 \ldots \ldots \\
25 \ldots \ldots \\
26 \ldots \ldots \\
27 \ldots \ldots \\
28 \ldots \ldots \\
29 \ldots \ldots \\
30 \ldots \ldots \\
31 \ldots \ldots\end{array}$ & $\begin{array}{r}1.2 \\
1.2 \\
1.2 \\
1.2 \\
1.2 \\
1.2 \\
1.2 \\
1.2 \\
1.3 \\
3.5 \\
130\end{array}$ & $\begin{array}{r}2.4 \\
2.1 \\
1.9 \\
2.1 \\
2.8 \\
3.0 \\
2.6 \\
2.4 \\
---- \\
--.-1 \\
--.-1\end{array}$ \\
\hline \multicolumn{7}{|l|}{$\begin{array}{l}\text { Monthly } \\
\text { Runoff, } \\
\text { Runoff, }\end{array}$} & $\begin{array}{r}5.41 \\
0.73 \\
332 \\
\end{array}$ & $\begin{array}{r}10.1 \\
1.24 \\
563 \\
\end{array}$ \\
\hline
\end{tabular}

Gage height, in feet, and discharge, in cublc feet per second, at indicated time, 1963

\begin{tabular}{|c|c|c|c|c|c|c|c|c|c|c|c|}
\hline Date & Hour & $\begin{array}{c}\text { Gage } \\
\text { helght }\end{array}$ & $\begin{array}{l}\text { Dis- } \\
\text { charge }\end{array}$ & Date & Hour & $\begin{array}{c}\text { Gage } \\
\text { helght }\end{array}$ & $\begin{array}{c}\text { D1s- } \\
\text { charge }\end{array}$ & Date & Hour & $\begin{array}{c}\text { Gage } \\
\text { helght }\end{array}$ & $\begin{array}{l}\text { Dis- } \\
\text { charge }\end{array}$ \\
\hline $\begin{array}{r}\text { Jan. } 30 \\
31\end{array}$ & $\begin{array}{l}2400 \\
0200 \\
0400 \\
0500 \\
0800 \\
1000 \\
1400 \\
1500 \\
1900 \\
2000\end{array}$ & $\begin{array}{l}1.22 \\
1.13 \\
1.22 \\
1.20 \\
1.38 \\
1.42 \\
1.77 \\
2.02 \\
2.25 \\
2.26\end{array}$ & $\begin{array}{r}5.3 \\
3.1 \\
5.3 \\
4.6 \\
12.6 \\
15.5 \\
77 \\
209 \\
458 \\
472\end{array}$ & $\begin{array}{l}\text { Jan. } 31 \\
\text { Feb. } 1\end{array}$ & $\begin{array}{l}2100 \\
2200 \\
2300 \\
2400 \\
0100 \\
0200 \\
0400 \\
0500 \\
0600 \\
0700\end{array}$ & $\begin{array}{l}2.04 \\
1.85 \\
1.63 \\
1.25 \\
1.55 \\
1.81 \\
1.64 \\
1.25 \\
1.12 \\
.90\end{array}$ & $\begin{array}{r}317 \\
205 \\
136 \\
63 \\
\\
165 \\
393 \\
338 \\
215 \\
165 \\
90\end{array}$ & Feb. 1 & $\begin{array}{l}0800 \\
0900 \\
1000 \\
1200 \\
1300 \\
1400 \\
1500 \\
1600 \\
2400\end{array}$ & $\begin{array}{r}0.58 \\
.56 \\
.69 \\
.62 \\
.57 \\
.79 \\
.48 \\
.50 \\
.46\end{array}$ & $\begin{array}{l}34 \\
11 \\
53 \\
40 \\
32 \\
76 \\
26 \\
36 \\
37\end{array}$ \\
\hline
\end{tabular}

10-3493. Steamboat Creek at Steamboat, Nev.

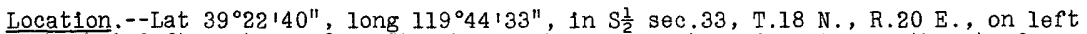
bank 250 ft upstream from Steamboat ditch, a quarter of a mile southwest of Steamboat, and 11 miles southwest of Reno.

Drainage area. $--123 \mathrm{sq} \mathrm{m}$.

Gage-height record.--Water-stage recorder graph. Altitude of gage is 4,600 $\mathrm{ft}$ (from topographic map).

Discharge record.--Stage-discharge relation defined by current-meter measurements below 400 cf's.

Maxima -- January-February 1963: Discharge, 1,000 cfs 2000 hours Jan. 31 (gage hel ght, $5.44 \mathrm{ft}$ ).

1961 to December 1962: Discharge, $280 \mathrm{cfs}$ Feb. 9, 1962 (gage he1ght, $3.69 \mathrm{ft}$ ).

Remarks.--Flow partly regulated by Washoe Lake. 
Mean discharge, in cublc feet per second, 1963, of Steamboat Creek at Steamboat, Nev.

\begin{tabular}{|c|c|c|c|c|c|c|c|c|}
\hline Day & January & February & Day & Jamuary & February & Day & January & February \\
\hline $\begin{array}{c}\ldots \ldots \\
2 \ldots \ldots \\
3 \ldots \ldots \\
4 \ldots \ldots \\
5 \ldots \ldots \\
6 \ldots \ldots \\
8 \ldots \ldots \\
9 \ldots \ldots \\
10 \ldots \ldots\end{array}$ & $\begin{array}{l}3.4 \\
3.3 \\
3.8 \\
4.4 \\
4.0 \\
3.6 \\
3.6 \\
3.8 \\
4.0 \\
3.6\end{array}$ & $\begin{array}{r}19 \\
76 \\
57 \\
48 \\
47 \\
37 \\
33 \\
27 \\
22 \\
22\end{array}$ & $\begin{array}{l}11 \ldots \ldots \\
12 \ldots \ldots \\
13 \ldots \ldots \\
14 \ldots \ldots \\
15 \ldots \ldots \\
16 \ldots \ldots \\
17 \ldots \ldots \\
18 \ldots \ldots \\
19 \ldots \ldots \\
20 \ldots \ldots\end{array}$ & $\begin{array}{l}2.4 \\
1.9 \\
2.7 \\
3.8 \\
4.6 \\
4.6 \\
4.0 \\
3.6 \\
3.6 \\
3.6\end{array}$ & $\begin{array}{l}19 \\
15 \\
12 \\
11 \\
10 \\
9.6 \\
9.2 \\
8.9 \\
8.6 \\
8.2\end{array}$ & $\begin{array}{l}21 \ldots \ldots \\
22 \ldots \ldots \\
23 \ldots \ldots \\
24 \ldots \ldots \\
25 \ldots \ldots \\
26 \ldots \ldots \\
27 \ldots \ldots \\
28 \ldots \ldots \\
29 \ldots \ldots \\
30 \ldots \ldots \\
31 \ldots \ldots\end{array}$ & $\begin{array}{r}3.6 \\
3.8 \\
3.8 \\
3.6 \\
3.4 \\
3.3 \\
3.3 \\
3.3 \\
3.8 \\
105 \\
473\end{array}$ & $\begin{array}{r}7.8 \\
7.5 \\
7.2 \\
7.0 \\
7.5 \\
7.5 \\
7.2 \\
7.0 \\
-7--. \\
--.--\end{array}$ \\
\hline $\begin{array}{l}\text { Monthly } \\
\text { Runoff, } \\
\text { Runoff, }\end{array}$ & $\begin{array}{l}\text { an dis } \\
\text { inche } \\
\text { acre }\end{array}$ & & & & & & $\begin{array}{r}22.0 \\
0.21 \\
1,350\end{array}$ & $\begin{array}{r}34.2 \\
0.29 \\
1,900\end{array}$ \\
\hline
\end{tabular}

Gage height, in feet, and discharge, in cubic feet per second, at indicated time, 1963

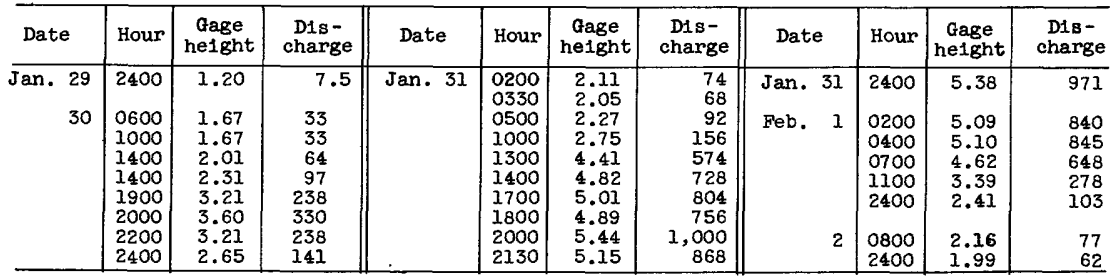

10-3497. Whites Creek near Steamboat, Nev.

Location.--Lat $39^{\circ} 23^{\prime} 05^{\prime \prime}$, long $119^{\circ} 50^{\prime} 20^{\prime \prime}$, in SE $\frac{1}{4} N W \frac{1}{4}$ sec.34, T.18 N., R.19 E., on left bank 4 miles above Steamboat ditch and 10 miles south of Reno.

Drainage area. $--9 \mathrm{sq} \mathrm{mi}$, approximately.

Gage-height record.--Water-stage recorder graph. Altitude of gage is $5,955 \mathrm{ft}$ (from topographic map).

Discharge record.--Stage-discharge relation defined by current-meter measurements below $30 \mathrm{cf}$ 's and by slope-area measurement of maximum flow.

Maxima.--January-February 1963: Discharge, 135 cfs 1700 hours Jan. 31 (gage height, $2.54 \mathrm{ft}$ ).

1961 to December 1962: Da1ly discharge, 23 cfs June 10, 1962.

Mean discharge, in cublc feet per second, 1963

\begin{tabular}{|c|c|c|c|c|c|c|c|c|}
\hline Day & January & February & Day & January & February & Day & January & February \\
\hline $\begin{array}{c}\ldots \ldots \\
2 \ldots \ldots \\
3 \ldots \ldots \\
4 \ldots \ldots \\
5 \ldots \ldots \\
7 \ldots \ldots \\
8 \ldots \ldots \\
9 \ldots \ldots \\
10 \ldots \ldots\end{array}$ & $\begin{array}{l}3.1 \\
3.1 \\
3.1 \\
3.8 \\
3.6 \\
3.6 \\
3.6 \\
3.6 \\
3.6 \\
3.6\end{array}$ & $\begin{array}{l}34 \\
15 \\
13 \\
10 \\
10 \\
9.8 \\
8.8 \\
8.4 \\
7.9 \\
7.4\end{array}$ & $\begin{array}{l}11 \ldots \ldots \\
12 \ldots \ldots \\
13 \ldots \ldots \\
14 \ldots \ldots \\
15 \ldots \ldots \\
16 \ldots \ldots \\
17 \ldots \ldots \\
18 \ldots \ldots \\
19 \ldots \ldots \\
20 \ldots \ldots\end{array}$ & $\begin{array}{l}3.0 \\
2.7 \\
2.9 \\
2.9 \\
2.9 \\
2.9 \\
2.9 \\
2.9 \\
2.9 \\
2.9\end{array}$ & $\begin{array}{l}6.4 \\
6.0 \\
6.0 \\
5.7 \\
5.3 \\
5.3 \\
5.3 \\
5.3 \\
5.3 \\
5.3\end{array}$ & $\begin{array}{l}21 \ldots \ldots \\
22 \ldots \ldots \\
23 \ldots \ldots \\
24 \ldots \ldots \\
25 \ldots \ldots \\
26 \ldots \ldots \\
27 \ldots \ldots \\
28 \ldots \ldots \\
29 \ldots \ldots \\
30 \ldots \ldots \\
31 \ldots \ldots\end{array}$ & $\begin{array}{l}2.7 \\
2.7 \\
2.7 \\
2.7 \\
2.7 \\
2.7 \\
2.7 \\
2.7 \\
2.7 \\
6.0 \\
57\end{array}$ & $\begin{array}{r}5.3 \\
5.3 \\
5.3 \\
5.0 \\
5.0 \\
5.3 \\
5.0 \\
5.3 \\
----- \\
-----\end{array}$ \\
\hline $\begin{array}{l}\text { nthly } \\
\text { inoff, } \\
\text { inoff, }\end{array}$ & $\begin{array}{l}\text { an disc } \\
\text { Inches } \\
\text { acre-f }\end{array}$ & $\ldots \ldots$ & & & & & $\begin{array}{r}4.87 \\
0.62 \\
299 \\
\end{array}$ & $\begin{array}{r}7.92 \\
0.92 \\
440\end{array}$ \\
\hline
\end{tabular}

Gage height, in feet, and discharge, in cublc feet per second, at indicated time, 1963

\begin{tabular}{|c|c|c|c|c|c|c|c|c|c|c|c|}
\hline Date & Hour & $\begin{array}{c}\text { Gage } \\
\text { helght }\end{array}$ & $\begin{array}{c}\text { Dis- } \\
\text { charge }\end{array}$ & Date & Hour & $\begin{array}{c}\text { Gage } \\
\text { helght }\end{array}$ & $\begin{array}{l}\text { D1s- } \\
\text { charge }\end{array}$ & Date & Hour & $\begin{array}{c}\text { Gage } \\
\text { helght }\end{array}$ & $\begin{array}{l}\text { D1s- } \\
\text { charge }\end{array}$ \\
\hline $\begin{array}{r}\text { Jan. } 29 \\
30\end{array}$ & $\begin{array}{l}2400 \\
0800 \\
1300 \\
2200 \\
2400 \\
0400\end{array}$ & $\begin{array}{l}1.47 \\
3.50 \\
3.50 \\
1.72 \\
1.77 \\
1.67\end{array}$ & $\begin{array}{c}2.7 \\
3.3 \\
3.3 \\
13 \\
16 \\
9.8\end{array}$ & Jan. 31 & $\begin{array}{l}0900 \\
1100 \\
1200 \\
1300 \\
1400 \\
1500 \\
1700 \\
1800\end{array}$ & $\begin{array}{l}1.75 \\
1.95 \\
2.15 \\
2.35 \\
2.40 \\
2.34 \\
2.54 \\
2.45\end{array}$ & $\begin{array}{r}15 \\
32 \\
58 \\
93 \\
103 \\
91 \\
135 \\
114\end{array}$ & $\begin{array}{l}\text { Jan. } 31 \\
\text { Feb. } 1\end{array}$ & $\begin{array}{l}1900 \\
2000 \\
2400 \\
1200 \\
2400\end{array}$ & $\begin{array}{l}2.43 \\
2.47 \\
2.38 \\
\\
2.08 \\
1.93\end{array}$ & $\begin{array}{r}110 \\
97 \\
71 \\
25 \\
13\end{array}$ \\
\hline
\end{tabular}


10-3500. Truckee River at Vista, Nev.

Location.--Lat $39^{\circ} 31^{1} \mathrm{05}^{\prime \prime}$, long $119^{\circ} 40^{\prime} 58^{\prime \prime}$, in NW $\mathrm{NE} \frac{1}{4} \sec .13$, T.19 N., R.20 E., on left bank $800 \mathrm{ft}$ downstream from Southern Pacific railroad bridge, 0.9 mile southeast of Vista, $1 \frac{1}{2}$ miles downstream from Steamboat Creek, and 4 miles southeast of Sparks.

Drainage area. $--1,429 \mathrm{sq} \mathrm{mi}$.

Gage-height record.--Water-stage recorder graph. Datum of gage is 4,368.33 ft above mean sea level, datum of 1929, supplementary adjustment of 1956 .

Discharge record.--Stage-discharge relation defined by current-meter measurements below $5,000 \mathrm{cfs}$ and by slope-area measurement of maximum flow; affected by ice Jan. $12-15$.

Maxima.--January-February 1963: Discharge, 21,300 cfs 1200 hours Feb. 1 (gage height, $16.78 \mathrm{ft}$ ).

1899-1908, 1932-54, 1958 to December 1962: Daily discharge, about $10,000 \mathrm{cfs}$

Mar. 18, 1907 (estimated on basis of discharge at Farad and at Reno).

Flood of Dec. 23, 1955, probably equaled or exceeded that of Mer. 18, 1907

Remarks.--Flow regulated by Lake Tahoe, Boca Reservolr, and other lakes (combined capacity, 800,000 acre-ft). Several powerplants and many diversions above station.

Mean discharge, in cubic feet per second, 1963

\begin{tabular}{|c|c|c|c|c|c|c|c|c|}
\hline Day & January & February & Day & January & February & Day & January & February \\
\hline $\begin{array}{r}1 \ldots . . \\
2 \ldots . \\
3 \ldots \ldots \\
4 \ldots \ldots \\
5 \ldots \ldots \\
6 \ldots \ldots \\
7 \ldots \ldots \\
8 \ldots \ldots \\
10 \ldots \ldots\end{array}$ & $\begin{array}{l}493 \\
490 \\
484 \\
499 \\
490 \\
466 \\
440 \\
398 \\
375 \\
355\end{array}$ & $\begin{array}{r}17,400 \\
8,640 \\
4,880 \\
3,600 \\
4,050 \\
4,030 \\
3,270 \\
2,260 \\
2,010 \\
2,040\end{array}$ & 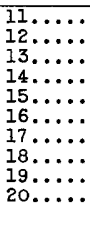 & $\begin{array}{l}308 \\
255 \\
270 \\
280 \\
280 \\
284 \\
280 \\
276 \\
265 \\
265\end{array}$ & $\begin{array}{r}1,910 \\
762 \\
619 \\
604 \\
676 \\
1,450 \\
1,300 \\
1,060 \\
544 \\
457\end{array}$ & $\begin{array}{l}21 \ldots \ldots \\
22, \ldots \ldots \\
23 \ldots \ldots \\
24 \ldots \ldots \\
25, \ldots \ldots \\
26 \ldots \ldots \\
27 \ldots \ldots \\
28 \ldots \ldots \\
29 \ldots \ldots \\
30 \ldots \ldots \\
31 \ldots \ldots\end{array}$ & $\begin{array}{r}269 \\
275 \\
273 \\
273 \\
269 \\
282 \\
282 \\
291 \\
299 \\
884 \\
7,150\end{array}$ & $\begin{array}{r}408 \\
388 \\
499 \\
511 \\
526 \\
656 \\
670 \\
776 \\
-0 .- \\
-0 .-0\end{array}$ \\
\hline & & & & & & & $\begin{array}{r}574 \\
0.46 \\
35,310 \\
\end{array}$ & $\begin{array}{r}2,357 \\
1.72 \\
130,900\end{array}$ \\
\hline
\end{tabular}

Gage height, in feet, and discharge, in cubic feet per second, at indicated time, 1963

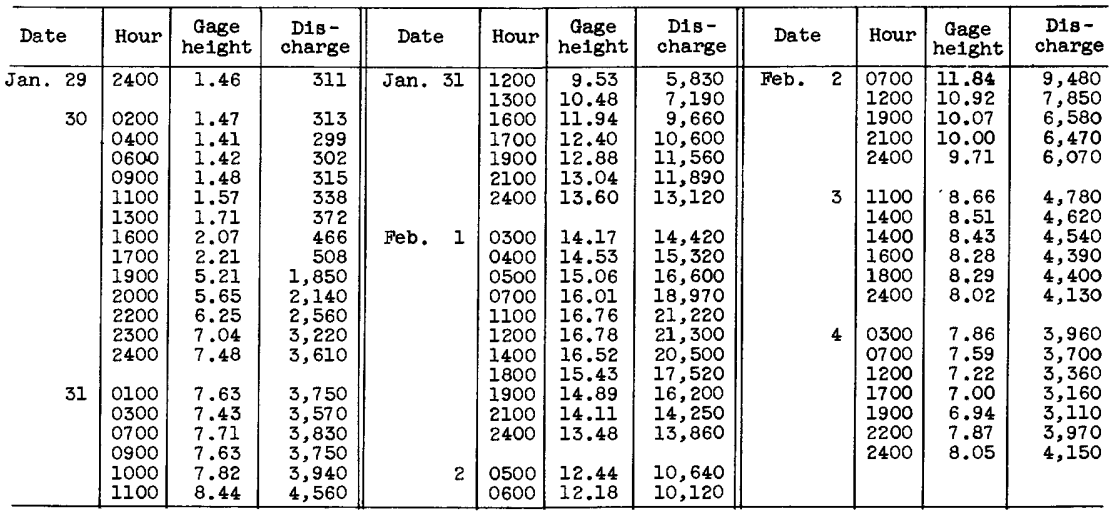


10-3516. Truckee River below Derby Dam, near Wadsworth, Nev.

Location.--Lat $39^{\circ} 35^{\prime} 05^{\prime \prime}$, long $119^{\circ} 26^{\prime} 25^{\prime \prime}$, in $\mathrm{NW} \frac{1}{4} \mathrm{SE} \frac{1}{4} \sec .19$, T.20 N., R.23 E., on right bank 1,500 ft downstream from Derby Dam, $3 \frac{4}{4}$ miles downstream from Ciark, and 9 miles southwest of Wadsworth.

Drainage area. $--1,670 \mathrm{sq} \mathrm{mi}$.

Gage-height record:--Water-stage recorder graph. Altitude of gage is $4,200 \mathrm{ft}$ (from topographic map).

Discharge record.--Stage-discharge relation defined by current-meter measurements below 1,500 cfs and by slope-area measurement of maximum flow.

Maxima.--January-February 1963: Discharge, 18,400 efs 1600 hours Feb. 1 (gage height, $14.26 \mathrm{ft}^{\prime}$ ).

1909-10, 1916 to December 1962: Daily discharge recorded, 8,970 cfs Dec. 13, 1937.

Remarks.--Flow regulated by Lake Tahoe, Boca Reservoir, other lakes, powerplants, many diversions for irrigation, and by Derby Dam. Truckee Canal diverts water at Derby Dam out of basin to Lahontan Reservoir.

Mean discharge, in cubic feet per second, 1963

\begin{tabular}{|c|c|c|c|c|c|c|c|c|}
\hline Day & January & February & Day & January & February & Day & January & February \\
\hline $\begin{array}{c}1 \ldots \ldots \\
2 \ldots \ldots \\
3 \ldots \ldots \\
4 \ldots \ldots \\
5 \ldots \ldots \\
6 \ldots \ldots \\
7 \ldots \ldots \\
9 \ldots \ldots \\
10 \ldots \ldots\end{array}$ & $\begin{array}{r}2.0 \\
1.5 \\
1.0 \\
.9 \\
.8 \\
.7 \\
.6 \\
.6 \\
.6 \\
.6\end{array}$ & $\begin{array}{r}14,700 \\
7,760 \\
3,240 \\
2,420 \\
2,530 \\
2,560 \\
2,370 \\
1,810 \\
1,750 \\
1,710\end{array}$ & $\begin{array}{l}11 \ldots \ldots \\
12 \ldots \ldots \\
13 \ldots \ldots \\
14 \ldots \ldots \\
15 \ldots \ldots \\
16 \ldots \ldots \\
17 \ldots \ldots \\
18 \ldots \ldots \\
19 \ldots \ldots \\
20 \ldots \ldots\end{array}$ & $\begin{array}{l}0.6 \\
.6 \\
.7 \\
.8 \\
.8 \\
.8 \\
.8 \\
.8 \\
.8 \\
.8\end{array}$ & $\begin{array}{r}1,710 \\
1,050 \\
612 \\
630 \\
540 \\
1,320 \\
1,280 \\
1,190 \\
655 \\
528\end{array}$ & $\begin{array}{l}21 \ldots \ldots \\
22 \ldots \ldots \\
23 \ldots \ldots \\
24 \ldots \ldots \\
25 \ldots \ldots \\
26 \ldots \ldots \\
27 \ldots \ldots \\
28 \ldots \ldots \\
29 \ldots \ldots \\
30 \ldots \ldots \\
31 \ldots \ldots\end{array}$ & $\begin{array}{r}0.8 \\
.8 \\
.8 \\
.8 \\
.8 \\
.8 \\
.8 \\
1.0 \\
1.5 \\
14 \\
4,400\end{array}$ & $\begin{array}{r}422 \\
327 \\
394 \\
462 \\
492 \\
585 \\
528 \\
630 \\
---- \\
-----\end{array}$ \\
\hline \multicolumn{7}{|l|}{$\begin{array}{l}\text { Monthly } \\
\text { Runoff, } \\
\text { Runoff, }\end{array}$} & $\begin{array}{r}143 \\
0.10 \\
8,800 \\
\end{array}$ & $\begin{array}{r}1,936 \\
1.21 \\
107,500 \\
\end{array}$ \\
\hline
\end{tabular}

Gage height, in feet, and discharge, in cublc feet per second, at indicated time, 1963

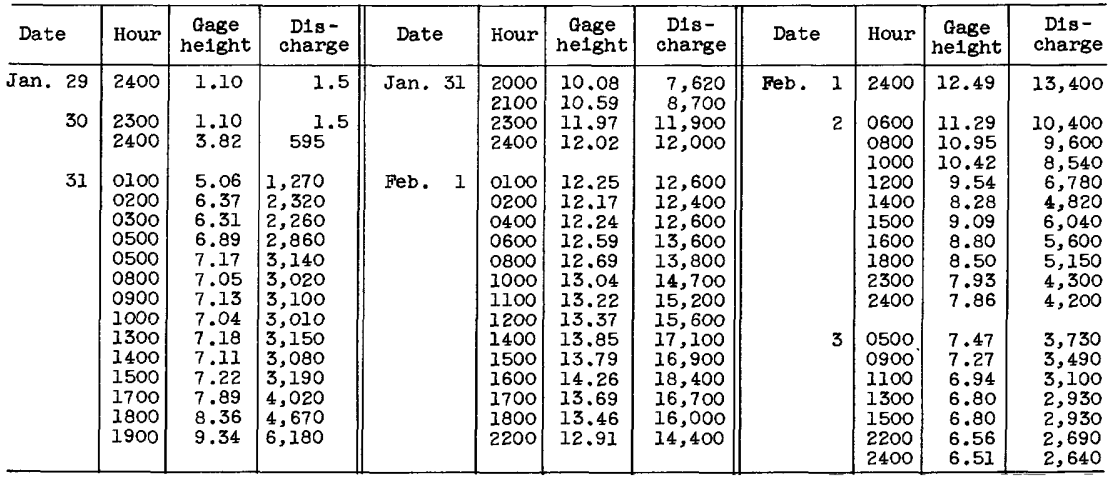


10-3517. Truckee River near N1xon, Nev.

Location.--Lat $39^{\circ} 46^{\prime} 40^{\prime \prime}$, long $119^{\circ} 20^{\prime} 10^{\prime \prime}$, in SW $\frac{1}{4} \mathrm{NW} \frac{1}{4}$ sec.18, T.22 N., R.24 E., on right bank $1 \mathrm{mile}$ upstream from Pyramid Indian Reservation diversion dam, 4 miles south of $\mathrm{N} 1 \mathrm{xon}$, and 13 miles upstream from mouth.

Drainage area. $--1,869 \mathrm{sq} \mathrm{m} 1$.

Gage-he1ght record.--Water-stage recorder graph. Alt1tude of gage is 3,940 ft (from topographic map).

Discharge record.--Stage-discharge relation defined by current-meter measurements below $10,300 \mathrm{cfs}$ and by computation of flow (14,000 $\mathrm{cfs})$ over dam; affected by 1ce Jan. 1-27. Discharge for perlod of lce effect estimated on basis of eng1neers' notes, reconstructed gage-helght graph, weather records, and comparison with records for upstream stations.

Maxima.--January-February 1963: D1scharge, 14,400 cfs 0130 hours Feb. 2 (gage height, $14.39 \mathrm{ft}$ ).

1955 to December 1962: Discharge, 14,000 cfs Dec. 24, 1955 (gage he1ght, $14.1 \mathrm{ft}$, from floodmarks), by flow-over-dam measurement of peak flow.

Remarks.--Flow regulated by Lake Tahoe, Boca Reservolr, other lakes, powerplants, and many diversions for irrigation. Truckee Canal often diverts practically

a11 flow at Derby Dam about 25 m1les upstream out of basin to Lahontan Reservolr. Severa1 diversions for 1rrigation between station and Truckee Canal. One 1rrigation canal diverts between station and mouth of river.

Mean discharge, in cublc feet per second, 1963

\begin{tabular}{|c|c|c|c|c|c|c|c|c|}
\hline Day & January & February & Day & January & February & Day & January & February \\
\hline $\begin{array}{r}1 \ldots \ldots \\
2 \ldots \ldots \\
4 \ldots \ldots \\
5 \ldots \ldots \\
6 \ldots \ldots \\
7 \ldots \ldots \\
9 \ldots \ldots \\
10 \ldots \ldots\end{array}$ & $\begin{array}{l}30 \\
29 \\
29 \\
28 \\
28 \\
28 \\
28 \\
27 \\
26 \\
25\end{array}$ & $\begin{array}{r}9,460 \\
11,600 \\
5,460 \\
3,550 \\
3,730 \\
3,980 \\
3,840 \\
2,660 \\
2,240 \\
2,130\end{array}$ & $\begin{array}{l}11 \ldots \ldots \\
12 \ldots \ldots \\
13 \ldots \ldots \\
14 \ldots \ldots \\
15 \ldots \ldots \\
16 \ldots \ldots \\
17 \ldots \ldots \\
18 \ldots \ldots \\
19 \ldots \ldots \\
20 \ldots \ldots\end{array}$ & $\begin{array}{l}24 \\
21 \\
22 \\
23 \\
24 \\
24 \\
24 \\
24 \\
24 \\
24\end{array}$ & $\begin{array}{r}2,160 \\
1,540 \\
792 \\
780 \\
676 \\
1,120 \\
1,410 \\
1,350 \\
974 \\
635\end{array}$ & $\begin{array}{l}21 \ldots \ldots \\
22 \ldots \ldots \\
23 \ldots \ldots \\
24 \ldots \ldots \\
25 \ldots \ldots \\
26 \ldots \ldots \\
27 \ldots \ldots \\
28 \ldots \ldots \\
29 \ldots \ldots \\
30 \ldots \ldots \\
31 \ldots \ldots\end{array}$ & $\begin{array}{r}24 \\
24 \\
24 \\
25 \\
25 \\
26 \\
27 \\
28 \\
28 \\
29 \\
1,370\end{array}$ & $\begin{array}{r}538 \\
444 \\
475 \\
565 \\
590 \\
670 \\
709 \\
770 \\
----- \\
--\overline{-}---\end{array}$ \\
\hline $\begin{array}{l}\text { nthly } \\
\text { noff, } \\
\text { noff, }\end{array}$ & acre & & & & & & $\begin{array}{r}69.1 \\
0.04 \\
4,250\end{array}$ & $\begin{array}{r}2,316 \\
1.29 \\
128,600 \\
\end{array}$ \\
\hline
\end{tabular}

Gage height, in feet, and discharge, in cub1c feet per second, at indicated time, 1963

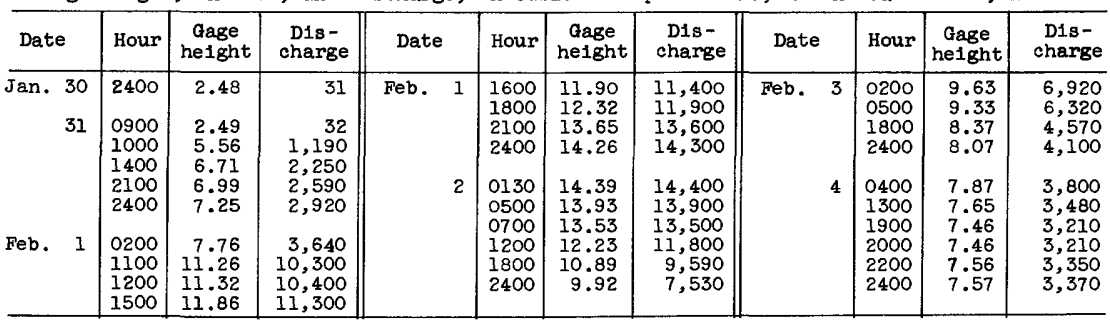




\section{HONEY LAKE BASIN}

10-3565. Susan River at Susanville, Calif.

Location.--Lat $40^{\circ} 25^{\prime} 05^{\prime \prime}$, long $120^{\circ} 40^{\prime} 15^{\prime \prime}$, in NE⿺ sec.31, T.30 N., R.12 E., on left bank 0.5 mile west of Susanville and 1.1 miles upstream from Piute Creek.

Drainage area. $--192 \mathrm{sq} \mathrm{mi}$.

Gage-height record.--Water-stage recorder graph. Datum of gage is $4,225.72 \mathrm{ft}$ above mean sea level, datum of 1929.

Discharge record.--Stage-discharge relation defined by current-meter measurements below $840 \mathrm{cfs}$ and by slope-area measurement at $3,540 \mathrm{cfs}$; affected by ice Jan. $1-19,21-30$.

Maxima.--January-February 1963: Discharge, 3,900 cf's 2300 hours Jan. 31 (gage helght, $6.78 \mathrm{ft}$ ).

$1900-1905,1913,1917-21,1950$ to December 1962: Discharge, 3,540 cfs Dec. 23, 1955 (gage height, $6.62 \mathrm{ft}$ ).

Remarks.--Floodflow regulated by McCoy Flat Reservoir, Hog Flat Reservoir, and Lake Levitt (combined usable capacity, 39,300 acre-ft).

Mean discharge, in cubic feet per second," 1963

\begin{tabular}{|c|c|c|c|c|c|c|c|c|}
\hline Day & January & February & Day & January & February & Day & January & February \\
\hline $\begin{array}{c}1 \ldots \ldots \\
2 \ldots \ldots \\
3 \ldots \ldots \\
4 \ldots \ldots \\
5 \ldots \ldots \\
7 \ldots \ldots \\
8 \ldots \ldots \\
9 \ldots \ldots \\
10 \ldots \ldots\end{array}$ & $\begin{array}{l}45 \\
45 \\
45 \\
40 \\
40 \\
40 \\
35 \\
35 \\
30 \\
30\end{array}$ & $\begin{array}{r}1,840 \\
678 \\
585 \\
530 \\
494 \\
446 \\
406 \\
342 \\
318 \\
318\end{array}$ & $\begin{array}{l}11 \ldots \ldots \\
12 \ldots \ldots \\
13 \ldots \ldots \\
14 \ldots \ldots \\
15 \ldots \ldots \\
16 \ldots \ldots \\
17 \ldots \ldots \\
18 \ldots \ldots \\
19 \ldots \ldots \\
20 \ldots \ldots\end{array}$ & $\begin{array}{l}30 \\
25 \\
25 \\
30 \\
30 \\
30 \\
30 \\
25 \\
25 \\
25\end{array}$ & $\begin{array}{l}290 \\
270 \\
233 \\
183 \\
161 \\
151 \\
145 \\
134 \\
129 \\
126\end{array}$ & $\begin{array}{l}21 \ldots \ldots \\
22 \ldots \ldots \\
23 \ldots \ldots \\
24 \ldots \ldots \\
25 \ldots \ldots \\
26 \ldots \ldots \\
27 \ldots \ldots \\
28 \ldots \ldots \\
29 \ldots \ldots \\
30 \ldots \ldots \\
31 \ldots \ldots\end{array}$ & $\begin{array}{r}25 \\
25 \\
25 \\
25 \\
25 \\
25 \\
25 \\
25 \\
25 \\
30 \\
1,560\end{array}$ & $\begin{array}{r}121 \\
109 \\
101 \\
96 \\
93 \\
84 \\
81 \\
77 \\
--2- \\
--2--\end{array}$ \\
\hline \multicolumn{7}{|c|}{ 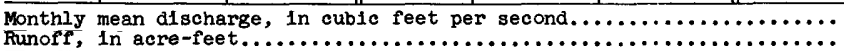 } & $\begin{array}{r}798 \\
4,910\end{array}$ & $\begin{array}{r}305 \\
16,940\end{array}$ \\
\hline
\end{tabular}

Gage helght, in feet, and discharge, in cublc feet per second, at indicated time, 1963

\begin{tabular}{|c|c|c|c|c|c|c|c|c|c|c|c|}
\hline Date & Hour & $\begin{array}{c}\text { Gage } \\
\text { height }\end{array}$ & $\begin{array}{l}\text { DIs- } \\
\text { charge }\end{array}$ & Date & Hour & $\begin{array}{c}\text { Gage } \\
\text { helght }\end{array}$ & $\begin{array}{c}\text { Dis- } \\
\text { charge }\end{array}$ & Date & Hour & $\begin{array}{c}\text { Gage } \\
\text { height }\end{array}$ & $\begin{array}{c}\text { D1s- } \\
\text { charge }\end{array}$ \\
\hline $\begin{array}{r}\text { Jan. } 30 \\
31\end{array}$ & $\begin{array}{l}2400 \\
0900 \\
0930 \\
1000 \\
1100 \\
1200 \\
1500\end{array}$ & $\begin{array}{l}1.61 \\
1.75 \\
4.59 \\
4.15 \\
4.71 \\
5.10 \\
5.77\end{array}$ & $\begin{array}{r}32 \\
39 \\
834 \\
585 \\
917 \\
1,240 \\
2,040\end{array}$ & Feb. 1 & $\begin{array}{l}1700 \\
1800 \\
2100 \\
2300 \\
2400 \\
\\
0100 \\
0200\end{array}$ & $\begin{array}{l}6.47 \\
6.63 \\
6.42 \\
6.78 \\
6.75 \\
\\
6.70 \\
6.72\end{array}$ & $\begin{array}{l}3,240 \\
3,570 \\
3,140 \\
3,900 \\
3,830 \\
3,720 \\
3,760\end{array}$ & Feb. 1 & $\begin{array}{l}0500 \\
0800 \\
1300 \\
1700 \\
2100 \\
2400\end{array}$ & $\begin{array}{l}6.08 \\
5.50 \\
5.17 \\
5.32 \\
4.92 \\
4.61\end{array}$ & $\begin{array}{r}2,510 \\
1,680 \\
1,310 \\
1,460 \\
1,080 \\
847\end{array}$ \\
\hline
\end{tabular}

10-3578.5. Eagle Lake tributary near Susanville, Calif.

Location.--Lat $40^{\circ} 44^{\prime} 10^{\prime \prime}$, long $120^{\circ} 42^{\prime} 20^{\prime \prime}$, in SW $\frac{1}{4}$ sec.11, T.33 N., R.11 E., on State Highway $139,22.2$ miles north of Susanville.

Drainage area. $--0.91 \mathrm{sq} \mathrm{ml}$.

Gage-he1ght record - Water-stage recorder graph and crest-stage gage. Altitude of gage $185,170 \mathrm{ft}$ (from topographic map).

Discharge record.--Stage-discharge relation defined by computation of flow through culvert.

Maxima.--January-February 1963: Discharge, 21 cfs 1630 hours Feb. I (gage height, $5.14 \mathrm{ft}$ )

October to December 1962: Discharge, 14 cfs 0ct. 13, 1962 (gage height, $6.01 \mathrm{ft}$, culvert partly plugged). 
Mean discharge, in cubic feet per second, 1963, of Eagle Lake tributary near Susanville, Calif.

\begin{tabular}{|c|c|c|c|c|c|c|c|c|}
\hline Day & January & February & Day & January & February & Day & January & February \\
\hline $\begin{array}{c}1 \ldots \ldots \\
2 \ldots \ldots \\
3 \ldots \ldots \\
4 \ldots \ldots \\
5 \ldots \ldots \\
6 \ldots \ldots \\
8 \ldots \ldots \\
9 \ldots \ldots \\
10 \ldots \ldots\end{array}$ & $\begin{array}{l}0 \\
0 \\
0 \\
0 \\
0 \\
0 \\
0 \\
0 \\
0 \\
0\end{array}$ & $\begin{array}{r}4.3 \\
.6 \\
.4 \\
.4 \\
.3 \\
.2 \\
.2 \\
.2 \\
.2 \\
.2\end{array}$ & $\begin{array}{l}11 \ldots \ldots \\
12 \ldots \ldots \\
13 \ldots \ldots \\
14 \ldots \ldots \\
15 \ldots \ldots \\
16 \ldots \ldots \\
17 \ldots \ldots \\
18 \ldots \ldots \\
19 \ldots \ldots \\
20 \ldots \ldots\end{array}$ & $\begin{array}{l}0 \\
0 \\
0 \\
0 \\
0 \\
0 \\
0 \\
0 \\
0 \\
0\end{array}$ & $\begin{array}{l}0.1 \\
.1 \\
.2 \\
.1 \\
0 \\
0 \\
0 \\
0 \\
0 \\
0\end{array}$ & $\begin{array}{l}21 \ldots \ldots \\
22 \ldots \ldots \\
23 \ldots \ldots \\
24 \ldots \ldots \\
25 \ldots \ldots \\
26 \ldots \ldots \\
27 \ldots \ldots \\
28 \ldots \ldots \\
29 \ldots \ldots \\
30 \ldots \ldots \\
31 \ldots \ldots\end{array}$ & $\begin{array}{l}0 \\
0 \\
0 \\
0 \\
0 \\
0 \\
0 \\
0 \\
0 \\
0 \\
.1 \\
6.4\end{array}$ & $\begin{array}{r}0 \\
0 \\
0 \\
0 \\
0 \\
0 \\
0 \\
0 \\
0----\end{array}$ \\
\hline \multicolumn{9}{|c|}{ 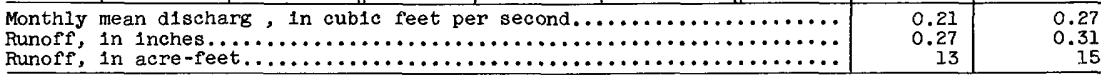 } \\
\hline
\end{tabular}

Gage height, in feet, and discharge, in cublc feet per second, at indicated t1me, 1963

\begin{tabular}{|c|c|c|c|c|c|c|c|c|c|c|c|}
\hline Date & Hour & $\begin{array}{c}\text { Gage } \\
\text { helght }\end{array}$ & $\begin{array}{c}\text { D1s- } \\
\text { charge }\end{array}$ & Date & Hour & $\begin{array}{c}\text { Gage } \\
\text { height }\end{array}$ & $\begin{array}{c}\text { D1s- } \\
\text { charge }\end{array}$ & Date & Hour & $\begin{array}{c}\text { Gage } \\
\text { he1ght }\end{array}$ & $\begin{array}{c}\text { D1s - } \\
\text { charge }\end{array}$ \\
\hline $\begin{array}{r}30 \\
31\end{array}$ & $\begin{array}{l}2400 \\
0430 \\
0530 \\
0630 \\
0700 \\
1030 \\
1100 \\
1300 \\
1400 \\
1600 \\
1700 \\
1800\end{array}$ & $\begin{array}{l}2.91 \\
3.00 \\
3.22 \\
3.82 \\
4.22 \\
4.58 \\
4.55 \\
3.91 \\
3.71 \\
3.86 \\
4.08 \\
3.76\end{array}$ & $\begin{array}{r}0.5 \\
.7 \\
1.8 \\
6.2 \\
11 \\
14 \\
14 \\
7.1 \\
5.2 \\
6.6 \\
9.0 \\
5.6\end{array}$ & $\begin{array}{l}\text { Jan. } 31 \\
\text { Feb. } 1\end{array}$ & $\begin{array}{l}2000 \\
2400 \\
0030 \\
0100 \\
0115 \\
0130 \\
0200 \\
0230 \\
0500 \\
0800 \\
1100 \\
1400\end{array}$ & $\begin{array}{l}3.80 \\
3.69 \\
3.82 \\
4.83 \\
4.99 \\
4.60 \\
4.01 \\
3.73 \\
3.22 \\
3.03 \\
2.99 \\
3.01\end{array}$ & $\begin{array}{r}6.0 \\
5.0 \\
6.2 \\
17 \\
19 \\
15 \\
8.2 \\
5.4 \\
1.8 \\
.9 \\
.7 \\
.8\end{array}$ & Feb. 1 & $\begin{array}{l}1415 \\
1430 \\
1445 \\
1505 \\
1530 \\
1550 \\
1600 \\
1630 \\
1700 \\
1730 \\
1800 \\
2000 \\
2400\end{array}$ & $\begin{array}{l}3.11 \\
3.58 \\
4.50 \\
4.91 \\
4.58 \\
4.35 \\
4.41 \\
5.14 \\
4.68 \\
4.09 \\
3.75 \\
3.28 \\
2.90\end{array}$ & $\begin{array}{l}1.2 \\
4.1 \\
14 \\
18 \\
14 \\
12 \\
13 \\
21 \\
16 \\
9.1 \\
5.6 \\
2.1 \\
.4\end{array}$ \\
\hline
\end{tabular}

10-3584.7. Willow Creek tributary near Susanville, Calif.

(Crest-stage station)

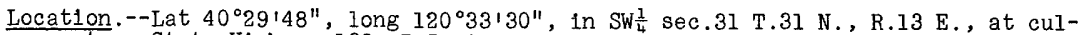
vert on State Highway $139,7.5$ miles northeast of Susanville.

Drainage area. $--3.08 \mathrm{sq} \mathrm{mi}$.

Gage-helght record.--Crest stages only. Alt1tude of gage is $4,890 \mathrm{ft}$ (from topographic map).

Discharge record.--Maximum discharge by computation of flow through culvert.

Maxima.--January-February 1963: Discharge, $97 \mathrm{cfs} F \mathrm{Feb}$. 1 (gage height, $4.90 \mathrm{ft}$ ). July to December 1962: Discharge, 50 cfs Oct. 13,1962 (gage height, $3.81 \mathrm{ft}$ ).

10-3585. Willow Creek near Susanv1lle, Calif.

Location.--Lat $40^{\circ} 29^{\prime}$, long $120^{\circ} 32^{\prime}$, in NW $\frac{1}{4}$ sec.5, T.30 N., R.13 E., on left bank 4 miles upstream from Peters Valley Creek and 8 miles northeast of Susanville.

Drainage area. $--92.5 \mathrm{sq} \mathrm{ml}$, excludes that of Eagle Lake basin.

Gage-he1ght record.--Water-stage recorder graph. Datum of gage is 4,836.27 $\mathrm{ft}$ above mean sea level, unadjusted.

Dlscharge record.--Stage-discharge relation defined by current-meter measurements. $\frac{\text { Maxima }}{5.5}$--January-February 1963: D1scharge, 816 cfs 1600 hours Feb. 1 (gage height, 1950 to December 1962: Discharge, 712 cfs Dec. 23, 1955 (gage height, $5.36 \mathrm{ft}$ ). 
Mean discharge, in cublc feet per second, 1963, of Wlllow Creek near Susanville, Calif.

\begin{tabular}{|c|c|c|c|c|c|c|c|c|}
\hline Day & January & February & Day & January & February & Day & January & February \\
\hline $\begin{array}{c}1 \ldots \ldots \\
2 \ldots \ldots \\
3 \ldots \ldots \\
4 \ldots \ldots \\
5 \ldots \ldots \\
6 \ldots \ldots \\
7 \ldots \ldots \\
9 \ldots \ldots \\
10 \ldots \ldots\end{array}$ & $\begin{array}{l}28 \\
28 \\
29 \\
30 \\
30 \\
30 \\
30 \\
30 \\
30 \\
31\end{array}$ & $\begin{array}{l}751 \\
596 \\
380 \\
260 \\
199 \\
158 \\
133 \\
119 \\
106 \\
104\end{array}$ & $\begin{array}{l}11 \ldots \ldots \\
12 \ldots \ldots \\
13 \ldots \ldots \\
14 \ldots \ldots \\
15 \ldots \ldots \\
16 \ldots \ldots \\
17 \ldots \ldots \\
18 \ldots \ldots \\
19 \ldots \ldots \\
20 \ldots \ldots\end{array}$ & $\begin{array}{l}26 \\
26 \\
28 \\
26 \\
26 \\
25 \\
26 \\
26 \\
24 \\
25\end{array}$ & $\begin{array}{l}95 \\
85 \\
81 \\
76 \\
68 \\
63 \\
58 \\
54 \\
50 \\
48\end{array}$ & $\begin{array}{l}21 \ldots \ldots \\
22 \ldots \ldots \\
23 \ldots \ldots \\
24 \ldots \ldots \\
25 \ldots \ldots \\
26 \ldots \ldots \\
27 \ldots \ldots \\
28 \ldots \ldots \\
29 \ldots \ldots \\
30 \ldots \ldots \\
31 \ldots \ldots\end{array}$ & $\begin{array}{l}25 \\
25 \\
25 \\
25 \\
26 \\
24 \\
18 \\
15 \\
15 \\
16 \\
343 \\
\end{array}$ & $\begin{array}{r}46 \\
45 \\
41 \\
39 \\
38 \\
37 \\
36 \\
35 \\
-\ldots-- \\
---- \\
-\end{array}$ \\
\hline & $\operatorname{acr}$ & & & & & & $\begin{array}{r}35.8 \\
0.45 \\
2,200\end{array}$ & $\begin{array}{r}136 \\
1.53 \\
7,540\end{array}$ \\
\hline
\end{tabular}

Gage he1ght, in feet, and discharge, in cubic feet per second, at indicated time, 1963

\begin{tabular}{|c|c|c|c|c|c|c|c|c|c|c|c|}
\hline Date & Hour & $\begin{array}{c}\text { Gage } \\
\text { height }\end{array}$ & $\begin{array}{l}\text { Dis- } \\
\text { charge }\end{array}$ & Date & Hour & $\begin{array}{c}\text { Gage } \\
\text { height }\end{array}$ & $\begin{array}{l}\text { D1s- } \\
\text { charge }\end{array}$ & Date & Hour & $\begin{array}{c}\text { Gage } \\
\text { he1ght }\end{array}$ & $\begin{array}{l}\text { Dis- } \\
\text { charge }\end{array}$ \\
\hline $\begin{array}{r}\text { Jan. } 30 \\
31\end{array}$ & $\begin{array}{l}2400 \\
0200 \\
0600 \\
0700 \\
1000 \\
1300 \\
1800\end{array}$ & $\begin{array}{l}2.50 \\
2.69 \\
2.98 \\
3.11 \\
4.08 \\
4.66 \\
5.03\end{array}$ & $\begin{array}{r}26 \\
40 \\
68 \\
82 \\
260 \\
436 \\
572\end{array}$ & $\begin{array}{l}\text { Jan. } 31 \\
\text { Feb. } 1\end{array}$ & $\begin{array}{l}2300 \\
2400 \\
\\
0200 \\
0400 \\
0600 \\
1400 \\
1600\end{array}$ & $\begin{array}{l}5.28 \\
5.34 \\
5.49 \\
5.42 \\
5.40 \\
5.49 \\
5.59\end{array}$ & $\begin{array}{l}676 \\
703 \\
771 \\
739 \\
730 \\
771 \\
816\end{array}$ & Feb. 1 & $\begin{array}{l}2000 \\
2400 \\
\\
0600 \\
1200 \\
1800 \\
2400\end{array}$ & $\begin{array}{l}5.41 \\
5.34 \\
\\
5.23 \\
5.11 \\
4.98 \\
4.84\end{array}$ & $\begin{array}{l}735 \\
703 \\
\\
654 \\
600 \\
541 \\
478\end{array}$ \\
\hline
\end{tabular}

\section{MADELINE PLAINS BASIN}

10-3588.1. Whiskey Creek near Termo, Calif.

(Crest-stage station)

Location:--Lat $40^{\circ} 49^{\prime} 15^{\prime \prime}$, long $120^{\circ} 35^{1} 00^{\prime \prime}$, in NW $\frac{1}{4} \mathrm{SE} \frac{1}{4} \sec .11, \mathrm{~T} .34$ N., R.12 E., 7.4 miles west of Termo.

Drainage area. $--4.56 \mathrm{sq} \mathrm{mi}$.

Gage-height record.--Crest stages only. Altitude of gage is 5,300 ft (from topographic map).

Discharge record.--Maximum discharge by slope-area measurement.

Maxima.--January-Febmuary 1963: Discharge, $132 \mathrm{cfs}$ Feb. 1 (gage height, 4.15 ft). July to December 1962: Discharge, 96 cfs Oct. 13, 1962 (gage height, $4.15 \mathrm{ft}$.

\section{CENTRAL-COASTAL CALIFORNIA}

\section{COTTONTAIL CREEK BASIN}

11-1421.5. Cottonta1l Creek tributary near Cayucos, Calif.

(Crest-stage station)

Location.--Lat $35^{\circ} 28^{\prime} 55^{\prime \prime}$, long $120^{\circ} 52^{\prime} 25^{\prime \prime}$, in $\mathrm{SE} \frac{1}{4} \mathrm{SE} \frac{1}{4}$ sec.22. T.28 S., R.10 E., at culvert on county road 2.8 miles northeast of Cayucos.

Drainage area. $--1.33 \mathrm{sq} \mathrm{mi}$.

Gage-height record.--Crest stages only. Altitude of gage is $250 \mathrm{ft}$ (from topographic map).

Discharge record.--Stage-discharge relation defined by current-meter measurements below $9 \mathrm{cf}$ and by computation of flow through culvert at $167 \mathrm{cfs}$.

Max1ma.--January-February 1963: Discharge, $72 \mathrm{cfs}$ Jan. 31 (gage height, $12.59 \mathrm{ft}$ ). 1959 to December 1962: Discharge, $167 \mathrm{cfs}$ Feb. 1, 1960 ?gage height. $14.39 \mathrm{ft}$ ). 


\section{SANTA ROSA CREEK BASTN}

11-1422. Santa Rosa Creek near Cambria, Calif.

Location.--Lat $35^{\circ} 34^{\prime} 35^{\prime \prime}$, long $120^{\circ} 59^{\prime} 50^{\prime \prime}$, In $\mathrm{NE} \frac{1}{4} \sec .21$, T.27 S., R.9 E., on left bank 4.8 miles east of Cambria.

Drainage area. $--12.5 \mathrm{sq} \mathrm{mi}$.

Gage-height record.--Water-stage recorder graph, except Feb. 8-18. Datum of gage is $264.03 \mathrm{f}^{\prime} \mathrm{t}$ above mean sea level, datum of 1929 , supplementary adjustment of 1960.

Discharge record.--Stage-discharge relation defined by current-meter measurements . Discharge for $\mathrm{Feb}$. 8-18 estimated on basis of records for nearby stations.

Maxima.--January-February 1963: Discharge, 1,330 cfs 0900 hours Jan. 31 (gage helght, $6.73 \mathrm{ft}$ ).

1957 to December 1962: Discharge, 2,520 cfs Feb. 1, 1960 (gage height, $10.36 \mathrm{ft}$ ), from rating curve extended above $390 \mathrm{cfs}$ on basis of slope-area measurement of peak flow.

Flood of December 1955 reached a stage of $15.2 \mathrm{ft}$ (from floodmarks).

Mean discharge, in cublc feet per second, 1963

\begin{tabular}{|c|c|c|c|c|c|c|c|c|}
\hline Day & January & February & Day & January & February & Day & January & February \\
\hline $\begin{array}{c}1 \ldots \ldots \\
2 \ldots \ldots \\
3 \ldots \ldots \\
5 \ldots \ldots \\
6 \ldots \ldots \\
7 \ldots \ldots \\
9 \ldots \ldots \\
10 \ldots \ldots\end{array}$ & $\begin{array}{l}0.7 \\
.7 \\
.7 \\
.7 \\
.7 \\
.6 \\
.6 \\
.6 \\
.6 \\
.6\end{array}$ & $\begin{array}{r}518 \\
64 \\
36 \\
25 \\
19 \\
17 \\
14 \\
13 \\
180 \\
300\end{array}$ & $\begin{array}{l}11 \ldots \ldots \\
12 \ldots \ldots \\
13 \ldots \ldots \\
14 \ldots \ldots \\
15 \ldots \ldots \\
16 \ldots \ldots \\
17 \ldots \ldots \\
18 \ldots \ldots \\
19 \ldots \ldots \\
20 \ldots \ldots\end{array}$ & $\begin{array}{r}0.6 \\
.6 \\
.6 \\
.6 \\
.6 \\
.6 \\
.6 \\
.6 \\
.6 \\
.5\end{array}$ & $\begin{array}{r}150 \\
80 \\
260 \\
100 \\
70 \\
55 \\
44 \\
35 \\
30 \\
27\end{array}$ & $\begin{array}{l}21 \ldots \ldots \\
22 \ldots \ldots \\
23 \ldots \ldots \\
24 \ldots \ldots \\
25 \ldots \ldots \\
26 \ldots \ldots \\
27 \ldots \ldots \\
28 \ldots \ldots \\
29 \ldots \ldots \\
30 \ldots \ldots \\
31 \ldots \ldots\end{array}$ & $\begin{array}{r}0.5 \\
.5 \\
.5 \\
.5 \\
.5 \\
.5 \\
.5 \\
.5 \\
132^{.6} \\
498\end{array}$ & $\begin{array}{r}24 \\
22 \\
20 \\
19 \\
17 \\
15 \\
14 \\
13 \\
-----\end{array}$ \\
\hline $\begin{array}{l}\text { inthiy } \\
\text { inoff, } \\
\text { inoff, }\end{array}$ & $\begin{array}{l}\text { disc } \\
\text { Inches } \\
\text { acre-f }\end{array}$ & & & & & & $\begin{array}{r}20.9 \\
1.92 \\
1,280\end{array}$ & $\begin{array}{r}77.9 \\
6.49 \\
4,330 \\
\end{array}$ \\
\hline
\end{tabular}

Gage height, in feet, and discharge, in cubic feet per second, at Indicated time, 1963

\begin{tabular}{|c|c|c|c|c|c|c|c|c|c|c|c|}
\hline Date & Hour & $\begin{array}{c}\text { Gage } \\
\text { helght }\end{array}$ & $\begin{array}{l}\text { Dis- } \\
\text { charge }\end{array}$ & Date & Hour & $\begin{array}{c}\text { Gage } \\
\text { helght }\end{array}$ & $\begin{array}{l}\text { Dis- } \\
\text { charge }\end{array}$ & Date & Hour & $\begin{array}{c}\text { Gage } \\
\text { height }\end{array}$ & $\begin{array}{c}\text { D1s- } \\
\text { charge }\end{array}$ \\
\hline $\begin{array}{r}\text { Jan. } 29 \\
30\end{array}$ & $\begin{array}{l}2400 \\
0500 \\
0700 \\
0700 \\
0900 \\
1100 \\
1200 \\
1400 \\
1600 \\
1700 \\
2100 \\
2200 \\
2300 \\
2400\end{array}$ & $\begin{array}{l}2.45 \\
2.65 \\
3.20 \\
3.61 \\
3.43 \\
3.52 \\
3.65 \\
3.44 \\
3.42 \\
3.84 \\
4.20 \\
4.50 \\
5.18 \\
5.09\end{array}$ & $\begin{array}{r}3.1 \\
9.9 \\
49 \\
105 \\
77 \\
90 \\
113 \\
79 \\
76 \\
153 \\
255 \\
345 \\
592 \\
556\end{array}$ & Jan. 31 & $\begin{array}{l}0100 \\
0200 \\
0500 \\
0700 \\
0800 \\
0900 \\
0900 \\
1000 \\
1100 \\
1200 \\
1300 \\
1500 \\
1700 \\
2000 \\
2200\end{array}$ & $\begin{array}{l}4.49 \\
4.66 \\
4.10 \\
5.00 \\
6.42 \\
5.80 \\
6.73 \\
6.24 \\
6.50 \\
5.36 \\
4.79 \\
4.23 \\
4.13 \\
4.18 \\
5.13\end{array}$ & $\begin{array}{r}342 \\
401 \\
255 \\
520 \\
1,160 \\
850 \\
1,330 \\
1,070 \\
1,200 \\
664 \\
447 \\
264 \\
234 \\
249 \\
572\end{array}$ & $\begin{array}{l}\text { Jan. } 31 \\
\text { Feb. } 1\end{array}$ & $\begin{array}{l}2400 \\
0100 \\
0200 \\
0300 \\
0300 \\
0400 \\
0500 \\
0600 \\
0700 \\
0800 \\
1000 \\
1200 \\
1800 \\
2400\end{array}$ & $\begin{array}{l}4.84 \\
5.07 \\
6.48 \\
6.39 \\
6.50 \\
6.44 \\
5.90 \\
5.45 \\
5.82 \\
6.61 \\
5.23 \\
4.50 \\
3.82 \\
3.53\end{array}$ & $\begin{array}{r}464 \\
548 \\
1,190 \\
1,150 \\
1,200 \\
1,170 \\
900 \\
700 \\
860 \\
1,260 \\
612 \\
345 \\
148 \\
92\end{array}$ \\
\hline
\end{tabular}

\section{ARROYO DE LA CRUZ BASIN}

11-1425. Arroyo de la Cruz near San Simeon, Calif.

Location.--Lat $35^{\circ} 43^{\prime} 25^{\prime \prime}$, long $121^{\circ} 17^{\prime} 00^{\prime \prime}$, in Pledra Blanca Grant, on right bank 1.7 miles upstream from mouth and 7 miles northwest of town of San Simeon, San Luis Obispo County.

Drainage area. $--41.4 \mathrm{sq} \mathrm{ml}$.

Gage-height record ${ }^{--W a t e r-s t a g e ~ r e c o r d e r ~ g r a p h . ~ A l t i t u d e ~ o f ~ g a g e ~ i s ~} 22 \mathrm{ft}$ (from topographic mapj.

Discharge record.--Stage-discharge relation defined by current-meter measurements .

Maxima.--January-February 1963: Discharge, 13,700 cfs 1000 hours Jan. 31 (gage height, $11.41 \mathrm{ft}$ ).

1950 to December 1962: Discharge, 17,700 cfs Dec. 23, 1955 (gage height, $12.40 \mathrm{ft}$ ), from rating curve extended above $7,600 \mathrm{cfs}$ on basis of slope-area measurement of peak flow. 
Mean discharge, in cubic feet per second, 1963, of Arroyo de la Cruz near San Simeon, Calif.

\begin{tabular}{|c|c|c|c|c|c|c|c|c|}
\hline Day & January & February & Day & January & February & Day & January & February \\
\hline $\begin{array}{c}1 \ldots \ldots \\
2 \ldots \ldots \\
3 \ldots \ldots \\
4 \ldots \ldots \\
6 \ldots \ldots \\
7 \ldots \ldots \\
8 \ldots \ldots \\
9 \ldots \ldots \\
10 \ldots \ldots\end{array}$ & $\begin{array}{l}5.6 \\
5.3 \\
4.7 \\
4.4 \\
3.9 \\
3.3 \\
3.1 \\
3.1 \\
3.1 \\
2.9\end{array}$ & $\begin{array}{r}, 220 \\
710 \\
343 \\
214 \\
153 \\
118 \\
96 \\
84 \\
770 \\
1,070\end{array}$ & $\begin{array}{l}11 \ldots \ldots \\
12 \ldots \ldots \\
13 \ldots \ldots \\
14 \ldots \ldots \\
15 \ldots \ldots \\
16 \ldots \ldots \\
17 \ldots \ldots \\
18 \ldots \ldots \\
19 \ldots \ldots \\
20 \ldots \ldots\end{array}$ & $\begin{array}{l}2.8 \\
2.2 \\
2.1 \\
1.9 \\
1.9 \\
1.9 \\
1.9 \\
1.9 \\
1.7 \\
1.6\end{array}$ & $\begin{array}{l}457 \\
283 \\
912 \\
458 \\
290 \\
221 \\
180 \\
146 \\
124 \\
112\end{array}$ & $\begin{array}{l}21 \ldots \ldots \\
22 \ldots \ldots \\
23 \ldots \ldots \\
24 \ldots \ldots \\
25 \ldots \ldots \\
26 \ldots \ldots \\
27 \ldots \ldots \\
28 \ldots \ldots \\
29 \ldots \ldots \\
30 \ldots \ldots \\
31 \ldots \ldots\end{array}$ & $\begin{array}{r}1.6 \\
1.6 \\
1.5 \\
1.5 \\
1.5 \\
1.4 \\
1.4 \\
1.4 \\
2.2 \\
2,670 \\
6,870\end{array}$ & $\begin{array}{r}94 \\
85 \\
77 \\
70 \\
64 \\
59 \\
55 \\
50 \\
----- \\
-----\end{array}$ \\
\hline $\begin{array}{l}\text { nthly } \\
\text { inoff, } \\
\text { inoff, }\end{array}$ & $\begin{array}{l}\text { Inche } \\
\text { acre- }\end{array}$ & & & & & & $\begin{array}{r}310 \\
8.63 \\
19,070 \\
\end{array}$ & $\begin{array}{r}411 \\
10.34 \\
22,840 \\
\end{array}$ \\
\hline
\end{tabular}

Gage height, in feet, and discharge, in cublc feet per second, at indicated time, 1963

\begin{tabular}{|c|c|c|c|c|c|c|c|c|c|c|c|}
\hline Date & Hour & $\begin{array}{c}\text { Gage } \\
\text { helght }\end{array}$ & $\begin{array}{c}\text { DIs- } \\
\text { charge }\end{array}$ & Date & Hour & $\begin{array}{c}\text { Gage } \\
\text { helght }\end{array}$ & $\begin{array}{l}\text { DIs- } \\
\text { charge }\end{array}$ & Date & Hour & $\begin{array}{c}\text { Gage } \\
\text { helght }\end{array}$ & $\begin{array}{l}\text { D1s- } \\
\text { charge }\end{array}$ \\
\hline $\begin{array}{r}\operatorname{Jan} .29 \\
30\end{array}$ & $\begin{array}{l}2400 \\
0200 \\
0300 \\
0400 \\
0600 \\
0800 \\
1000 \\
1200 \\
1400 \\
1600 \\
1900 \\
2100 \\
2200 \\
2400\end{array}$ & $\begin{array}{l}2.28 \\
2.28 \\
5.10 \\
5.37 \\
5.07 \\
6.33 \\
7.88 \\
7.08 \\
6.33 \\
6.08 \\
7.32 \\
7.88 \\
7.77 \\
9.53\end{array}$ & $\begin{array}{r}9.7 \\
99.7 \\
1,100 \\
1,300 \\
1,080 \\
2,240 \\
4,440 \\
3,190 \\
2,240 \\
1,980 \\
3,530 \\
4,440 \\
4,250 \\
7,830\end{array}$ & Jan. 31 & $\begin{array}{l}0100 \\
0400 \\
0600 \\
0800 \\
0900 \\
1000 \\
1300 \\
1400 \\
1600 \\
1800 \\
2000 \\
2200 \\
2300 \\
2400\end{array}$ & $\begin{array}{r}9.73 \\
8.13 \\
7.52 \\
9.00 \\
10.55 \\
11.41 \\
10.17 \\
10.37 \\
8.37 \\
7.56 \\
6.91 \\
7.90 \\
9.20 \\
9.50\end{array}$ & $\begin{array}{r}8,330 \\
4,890 \\
3,850 \\
6,600 \\
10,700 \\
13,700 \\
9,560 \\
10,200 \\
5,340 \\
3,920 \\
2,950 \\
4,480 \\
7,000 \\
7,750\end{array}$ & Feb. 1 & $\begin{array}{l}0100 \\
0300 \\
0600 \\
0900 \\
1200 \\
1500 \\
1900 \\
2400 \\
\\
1800 \\
2400\end{array}$ & $\begin{array}{r}9.34 \\
10.55 \\
8.88 \\
8.03 \\
7.00 \\
6.20 \\
5.69 \\
5.10 \\
4.16 \\
3.97\end{array}$ & $\begin{array}{r}7,350 \\
10,700 \\
6,360 \\
4,710 \\
3,080 \\
2,100 \\
1,590 \\
1,100 \\
\\
540 \\
447\end{array}$ \\
\hline
\end{tabular}

\section{REDWOOD GULCH BASIN}

11-1426. Redwood Gulch near Jolon, Calif.

(Crest-stage station)

Location.--Lat $35^{\circ} 50112^{\prime \prime}$, long $121^{\circ} 231^{\prime \prime} 5^{\prime \prime}$, in NE $\frac{1}{4}$ sec.23, T.24 S., R.5 E., at culvert on State Highway 1,15 miles west of Jolon.

Drainage area. $--1.31 \mathrm{sq} \mathrm{m} 1$.

Gage-height record.--Crest stages only. Altitude of gage is $510 \mathrm{ft}$ (from topographic map).

Discharge record.--Maximum discharge by computation of flow through culvert.

Maxima.--January-February 1963: Discharge, 372 cfs Jan. 31 (gage height, $55.70 \mathrm{ft}$ ). 1960 to December 1962: Discharge, not determined, occurred Feb. 9, 1962

(gage height, $52.96 \mathrm{ft}$ ).

\section{RAT CREEK BASIN}

11-1428. Rat Creek near Lucia, Calif.

Location. --Lat $36^{\circ} 05^{\prime} 32^{\prime \prime}$, long $121^{\circ} 37^{\prime} 03^{\prime \prime}$, in SW $\frac{1}{4} \mathrm{NE} \frac{1}{4}$ sec.22, T.21 S., R.3 E., on left bank at culvert on State Highway 1 and 6.2 miles northwest of Lucia.

Drainage area. $--0.82 \mathrm{sq} \mathrm{mi}$.

Gage-height record.--Water-stage recorder graph, except Feb. 13-17. Altitude of gage is $190 \mathrm{ft}$ (from topographic map).

Discharge record.--Stage-discharge relation defined by current-meter measurements below $2 \mathrm{cf}$ 's and by computation of flow through culvert at $23 \mathrm{cfs}$. Discharge for $\mathrm{Feb}$. 13-17 estimated on basis of records for nearby stations. Stage-discharge indefinite Feb. 3-12; discharge estimated on basis of records for nearby stations.

Maxima.--January-February 1963: Discharge, 18 cf's 1145 hours Jan. 31 (gage height, $1.89 \mathrm{ft}$ ); gage height, $2.16 \mathrm{ft} 0810$ hours Jan. 31 (log jam) 1960 to December 1962: Discharge, $10 \mathrm{cfs} \mathrm{Feb}$. 10, 1962 (gage height, $1.40 \mathrm{ft}$ ). 
Mean discharge, in cubic feet per second, 1963, of Rat Creek near Luc1a, Callf.

\begin{tabular}{l} 
Day \\
\hline $1 \ldots \ldots$
\end{tabular}

Gage height, In feet, and discharge, in cublc feet per second, at Indicated time, 1963

\begin{tabular}{|c|c|c|c|c|c|c|c|c|c|c|c|}
\hline Date & Hour & $\begin{array}{c}\text { Gage } \\
\text { helght }\end{array}$ & $\begin{array}{c}\text { D1s- } \\
\text { charge }\end{array}$ & Date & Hour & $\begin{array}{c}\text { Gage } \\
\text { helght }\end{array}$ & $\begin{array}{l}\text { DIs- } \\
\text { charge }\end{array}$ & Date & Hour & $\begin{array}{c}\text { Gage } \\
\text { he1ght }\end{array}$ & $\begin{array}{c}\text { D1s- } \\
\text { charge }\end{array}$ \\
\hline $\begin{array}{r}\text { Jan. } \\
30\end{array}$ & $\begin{array}{l}2400 \\
0500 \\
0600 \\
0900 \\
1100 \\
1400 \\
1500 \\
1900 \\
2200 \\
2300\end{array}$ & $\begin{array}{r}0.47 \\
.57 \\
.56 \\
.88 \\
.83 \\
1.12 \\
1.12 \\
1.41 \\
1.37 \\
1.32 \\
\end{array}$ & $\begin{array}{r}0.1 \\
.2 \\
.2 \\
3.2 \\
2.6 \\
6.2 \\
6.2 \\
10 \\
9.8 \\
9.0\end{array}$ & $\begin{array}{r}\text { Jan. } 30 \\
31\end{array}$ & $\begin{array}{l}2400 \\
0600 \\
0700 \\
0800 \\
0800 \\
0900 \\
1100 \\
1145 \\
1400 \\
1500 \\
\end{array}$ & $\begin{array}{l}1.35 \\
1.50 \\
1.63 \\
1.72 \\
1.70 \\
1.64 \\
1.83 \\
1.89 \\
1.67 \\
1.67\end{array}$ & $\begin{array}{l}9.5 \\
12 \\
14 \\
15 \\
15 \\
14 \\
17 \\
18 \\
15 \\
15 \\
\end{array}$ & Feb. 1 & $\begin{array}{l}1900 \\
2200 \\
2400 \\
\\
0300 \\
0400 \\
0500 \\
1000 \\
1800 \\
2400\end{array}$ & $\begin{array}{l}1.47 \\
1.43 \\
1.50 \\
1.64 \\
1.61 \\
1.64 \\
1.52 \\
1.30 \\
1.20\end{array}$ & $\begin{array}{c}11 \\
11 \\
12 \\
14 \\
14 \\
14 \\
12 \\
8.7 \\
7.3\end{array}$ \\
\hline
\end{tabular}

\section{BIG SUR RIVER BASIN}

11-1430. Big Sur River near Big Sur, Calif.

Location.--Lat $36^{\circ} 14^{\prime} 45^{\prime \prime}$, long $121^{\circ} 46^{\prime} 20^{\prime \prime}$, in SW $\frac{1}{4}$ SW $\frac{1}{4}$ sec.29, T.19 S., R.2 E., on right bank at downstream side of bridge, 0.4 mile upstream from Post Creek and 2.6 miles southeast of Big Sur.

Drainage area. $--46.5 \mathrm{sq} \mathrm{ml}$.

Gage-height record ; - Water-8tage recorder graph. Altitude of gage is $400 \mathrm{ft}$ (from topographic map).

Discharge record.--Stage-discharge relation defined by current-meter measurements below 1,400 cfs and by slope-area measurement at gage he1ght $11.05 \mathrm{ft}$.

Maxima.--January-February 1963: Discharge, 5,400 cfs 0100 hours Feb. 1 (gage hel ght, $11.23 \mathrm{ft}$ ).

1950 to December 1962: Discharge, 5,680 cfs Apr. 2, 1958 (gage height, $11.56 \mathrm{ft}^{\mathrm{t}}$.

Mean discharge, in cuble feet per second, 1963

\begin{tabular}{|c|c|c|c|c|c|c|c|c|}
\hline Day & January & February & Day & January & February & Day & January & February \\
\hline $\begin{array}{c}1 \ldots \ldots \\
2 \ldots \ldots \\
3 \ldots \ldots \\
4 \ldots \ldots \\
6 \ldots \ldots \\
7 \ldots \ldots \\
8 \ldots \ldots \\
9 \ldots \ldots \\
10 \ldots\end{array}$ & $\begin{array}{l}31 \\
30 \\
29 \\
29 \\
29 \\
27 \\
26 \\
26 \\
26 \\
26\end{array}$ & $\begin{array}{r}3,250 \\
1,360 \\
822 \\
570 \\
438 \\
347 \\
297 \\
261 \\
417 \\
763\end{array}$ & $\begin{array}{l}11 \ldots \ldots \\
12 \ldots \ldots \\
13 \ldots \ldots \\
14 \ldots \ldots \\
15 \ldots \ldots \\
16 \ldots \ldots \\
17 \ldots \ldots \\
18 \ldots \ldots \\
19 \ldots \ldots \\
20 \ldots \ldots\end{array}$ & $\begin{array}{l}25 \\
25 \\
25 \\
25 \\
24 \\
24 \\
23 \\
22 \\
22 \\
22\end{array}$ & $\begin{array}{l}615 \\
493 \\
585 \\
529 \\
454 \\
394 \\
343 \\
303 \\
270 \\
247\end{array}$ & $\begin{array}{l}21 \ldots \ldots \\
22 \ldots \ldots \\
23 \ldots \ldots \\
24 \ldots \ldots \\
25 \ldots \ldots \\
26 \ldots \ldots \\
27 \ldots \ldots \\
28 \ldots \ldots \\
29 \ldots \ldots \\
30 \ldots \ldots \\
31 \ldots \ldots\end{array}$ & $\begin{array}{r}21 \\
21 \\
21 \\
21 \\
21 \\
21 \\
21 \\
21 \\
29 \\
1,240 \\
3,830\end{array}$ & $\begin{array}{r}220 \\
202 \\
188 \\
172 \\
164 \\
152 \\
147 \\
141 \\
-.--- \\
--.-1-\end{array}$ \\
\hline $\begin{array}{l}\text { noff, } \\
\text { noff, }\end{array}$ & $\begin{array}{l}\text { Inche } \\
\text { acre- }\end{array}$ & & & & & & $\begin{array}{r}187 \\
4.63 \\
11,470\end{array}$ & $\begin{array}{r}505 \\
11.31 \\
28,050 \\
\end{array}$ \\
\hline
\end{tabular}


Gage height, in feet, and discharge, in cublc feet per second, at indicated time, 1963, of $\mathrm{BIg}$ Sur River near Big Sur, Calif.

\begin{tabular}{|c|c|c|c|c|c|c|c|c|c|c|c|}
\hline Date & Hour & $\begin{array}{c}\text { Gage } \\
\text { height }\end{array}$ & $\begin{array}{l}\text { D18- } \\
\text { charge }\end{array}$ & Date & Hour & $\begin{array}{c}\text { Gage } \\
\text { helght }\end{array}$ & $\begin{array}{c}\text { Dis- } \\
\text { charge }\end{array}$ & Date & Hour & $\begin{array}{c}\text { Gage } \\
\text { he1ght }\end{array}$ & $\begin{array}{c}\text { D1s - } \\
\text { charge }\end{array}$ \\
\hline $\begin{array}{r}29 \\
30\end{array}$ & $\begin{array}{l}2400 \\
0300 \\
0600 \\
1000 \\
1200 \\
1600 \\
1800 \\
1900 \\
2100\end{array}$ & $\begin{array}{l}3.15 \\
3.65 \\
4.30 \\
5.48 \\
5.56 \\
6.66 \\
7.01 \\
7.75 \\
8.90\end{array}$ & $\begin{array}{r}80 \\
154 \\
310 \\
820 \\
860 \\
1,500 \\
1,750 \\
2,300 \\
3,250 \\
\end{array}$ & Jan. 30 & $\begin{array}{l}2300 \\
2400 \\
0300 \\
0500 \\
0700 \\
1000 \\
1300 \\
1600 \\
2000\end{array}$ & $\begin{array}{r}8.62 \\
8.64 \\
9.13 \\
8.87 \\
9.09 \\
9.98 \\
10.52 \\
9.62 \\
9.07\end{array}$ & $\begin{array}{l}3,000 \\
3,020 \\
3,460 \\
3,220 \\
3,420 \\
4,220 \\
4,710 \\
3,900 \\
3,400\end{array}$ & $\begin{array}{l}\text { Jan. } 31 \\
\text { Feb. } 1\end{array}$ & $\begin{array}{l}2200 \\
2400 \\
\\
0100 \\
0300 \\
0600 \\
0900 \\
1200 \\
1800 \\
2400\end{array}$ & $\begin{array}{r}9.75 \\
10.90 \\
11.23 \\
11.00 \\
9.70 \\
8.90 \\
8.50 \\
7.57 \\
7.01 \\
\end{array}$ & $\begin{array}{l}4,020 \\
5,070 \\
5,400 \\
5,170 \\
3,970 \\
3,320 \\
3,000 \\
2,260 \\
1,840\end{array}$ \\
\hline
\end{tabular}

DOUD CREEK BASIN

11-1430.5. Doud Creek near Carmel, Calif.

(Crest-stage station)

Location.--Lat $36^{\circ} 25^{\prime} 18^{\prime \prime}$, long $121^{\circ} 54^{\prime} 40^{\prime \prime}$, in San Jose y Sur Chiquito Grant at culvert on State Highway $1,9.3$ miles south of Carmel.

Drainage area. $--2.75 \mathrm{sq} \mathrm{mt}$.

Gage-height record.--Crest-stages only. Altitude of gage is $50 \mathrm{ft}$ (from topographic map).

Discharge record.--Maximum discharge by computation of flow through culvert.

Maxima --January-February 1963: Discharge, $42 \mathrm{cfs} J a n .31$ (gage he1ght, $51.24 \mathrm{ft}$ ). 1960 to December 1962: Discharge, not determined, occurred oct. 13, 1962

(gage helght, $50.95 \mathrm{ft}$ ).

\section{CARMEL RIVER BASIN}

11-1432. Carmel River at Robles del Rio, Callf.

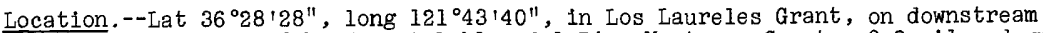
side of county road bridge at Robles del Rio, Monterey County, 0.2 miles downstream from Hitchcock Canyon and 11 miles southeast of town of Carmel.

Drainage area. --193 sq $\mathrm{mi}$.

Gage-helght record.--Water-stage recorder graph, except Feb. 20-24. Altitude of gage is $270 \mathrm{ft}$ (from topographic map).

Discharge record.--Stage-discharge relation defined by current-meter measurements. Discharge for Feb. 20-24 estimated on basis of weather records and records for Carmel River near Carmel.

Maxima:--January-February 1963: Discharge, 4,950 cfs 1600 hours Jan. 31 (gage helght, $9.60 \mathrm{ft}$ ).

1957 to December 1962: D1scharge, 7,100 cfs Apr. 2, 1958 (gage helght, $10.50 \mathrm{ft}$ ).

Flood of Dec. 23, 1955, reached a stage of $11.7 \mathrm{ft}$, from floodmarks (discharge, $6,930 \mathrm{cfs}$ on basis of slope-area measurement of peak flow).

Remarks.--Flow slightly regulated by Los Padres Reservolr (capacity, 3,000 acre-ft) and San Clemente Reservoir (capacity, 1,600 acre-ft).

Mean discharge, In cublc feet per second, 1963

\begin{tabular}{|c|c|c|c|c|c|c|c|c|}
\hline Day & January & February & Day & January & February & Day & January & February \\
\hline $\begin{array}{c}1 \ldots \ldots \\
2 \ldots \ldots \\
3 \ldots \ldots \\
4 \ldots \ldots \\
5 \ldots \ldots \\
6 \ldots \ldots \\
8 \ldots \ldots \\
9 \ldots \ldots \\
10 \ldots \ldots\end{array}$ & $\begin{array}{l}12 \\
1.1 \\
10 \\
1.1 \\
8.8 \\
7.0 \\
7.0 \\
6.4 \\
7.7 \\
6.7\end{array}$ & $\begin{array}{r}2,900 \\
1,110 \\
660 \\
437 \\
299 \\
210 \\
158 \\
139 \\
220 \\
717\end{array}$ & $\begin{array}{l}11 \ldots \ldots \\
12 \ldots \ldots \\
13 \ldots \ldots \\
14 \ldots \ldots \\
15 \ldots \ldots \\
16 \ldots \ldots \\
17 \ldots \ldots \\
18 \ldots \ldots \\
19 \ldots \ldots \\
20 \ldots \ldots\end{array}$ & $\begin{array}{l}5.6 \\
4.6 \\
4.6 \\
4.1 \\
5.4 \\
4.6 \\
4.6 \\
4.1 \\
4.1 \\
3.3\end{array}$ & $\begin{array}{l}666 \\
521 \\
539 \\
497 \\
433 \\
388 \\
353 \\
308 \\
274 \\
243\end{array}$ & $\begin{array}{l}21 \ldots \ldots \\
22 \ldots \ldots \\
23 \ldots \ldots \\
24 \ldots \ldots \\
25 \ldots \ldots \\
26 \ldots \ldots \\
27 \ldots \ldots \\
28 \ldots \ldots \\
29 \ldots \ldots \\
30 \ldots \ldots \\
31 \ldots \ldots\end{array}$ & $\begin{array}{r}3.3 \\
2.9 \\
3.1 \\
2.9 \\
2.7 \\
2.7 \\
2.7 \\
2.7 \\
2.7 \\
922 \\
3,670\end{array}$ & $\begin{array}{r}230 \\
210 \\
200 \\
180 \\
167 \\
155 \\
150 \\
138 \\
----- \\
----1\end{array}$ \\
\hline $\begin{array}{l}\text { lonthiy } \\
\text { unoff, } \\
\text { unoff, }\end{array}$ & $\begin{array}{l}\text { an dis } \\
\text { Inche } \\
\text { acre- }\end{array}$ & & & & & & $\begin{array}{r}153 \\
0.92 \\
9,420 \\
\end{array}$ & $\begin{array}{r}246 \\
24,81 \\
\end{array}$ \\
\hline
\end{tabular}


Gage height, in feet, and discharge, in cubic feet per second, at indicated t1me, 1963, of Carmel River at Robles del Rio, Calif.

\begin{tabular}{|c|c|c|c|c|c|c|c|c|c|c|c|}
\hline Date & Hour & $\begin{array}{c}\text { Gage } \\
\text { helght }\end{array}$ & $\begin{array}{l}\text { D1s- } \\
\text { charge }\end{array}$ & Date & Hour & $\begin{array}{c}\text { Gage } \\
\text { helght }\end{array}$ & $\begin{array}{l}\text { Dis- } \\
\text { charge }\end{array}$ & Date & Hour & $\begin{array}{c}\text { Gage } \\
\text { helght }\end{array}$ & $\begin{array}{c}\text { Dis- } \\
\text { charge }\end{array}$ \\
\hline $\begin{array}{r}\operatorname{Jan} .29 \\
30\end{array}$ & $\begin{array}{l}2400 \\
0400 \\
0700 \\
1000 \\
1100 \\
1200 \\
1300 \\
1500 \\
1900\end{array}$ & $\begin{array}{l}2.83 \\
2.83 \\
2.98 \\
3.15 \\
3.20 \\
4.50 \\
5.25 \\
6.16 \\
7.45 \\
\end{array}$ & $\begin{array}{r}3.8 \\
3.8 \\
8.0 \\
16 \\
18 \\
245 \\
500 \\
936 \\
1,950\end{array}$ & Jan. 30 & $\begin{array}{l}2200 \\
2400 \\
\\
0200 \\
0400 \\
0700 \\
1000 \\
1300 \\
1600 \\
2100\end{array}$ & $\begin{array}{l}8.45 \\
8.75 \\
8.48 \\
8.48 \\
8.33 \\
8.54 \\
9.26 \\
9.60 \\
8.63\end{array}$ & $\begin{array}{l}3,130 \\
3,580 \\
\\
3,170 \\
3,170 \\
2,950 \\
3,260 \\
4,340 \\
4,950 \\
3,400\end{array}$ & $\begin{array}{l}\text { Jan. } 31 \\
\text { Feb. } 1\end{array}$ & $\begin{array}{l}2200 \\
2400 \\
0200 \\
0300 \\
0600 \\
1200 \\
1800 \\
2400\end{array}$ & $\begin{array}{l}8.56 \\
8.77 \\
9.28 \\
9.29 \\
8.93 \\
8.17 \\
7.53 \\
7.06\end{array}$ & $\begin{array}{l}3,290 \\
3,610 \\
4,370 \\
4,390 \\
3,850 \\
2,710 \\
2,030 \\
1,590\end{array}$ \\
\hline
\end{tabular}

11-1432.5 Carmel River near Carmel, Calif.

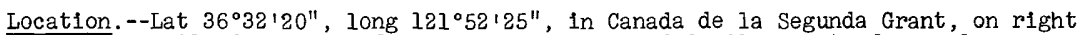
bank 0.3 mile downstream from Potrero Canyon and 3 miles east of Carmel.

Drainage area. $--246 \mathrm{sq} \mathrm{mi}$.

Gage-height record ${ }^{--W a t e r-s t a g e ~ r e c o r d e r ~ g r a p h . ~ A l t i t u d e ~ o f ~ g a g e ~ i s ~} 45 \mathrm{ft}$ (from topographic mapj.

Discharge record.--Stage-discharge relation defined by current-meter measurements.

Maxima.--January-February 1963: Discharge, 7,360 cf's 1800 hours Jan. 31 (gage height, $14.72 \mathrm{ft}$ ).

August to December 1962: Discharge, $2.0 \mathrm{cfs}$ Dec. 2, 1962 (gage height, 2.89ft).

Remarks.--Flow slightly regulated by Los Padres Reservoir (capacity, 3,000 acre-ft) and San Clemente Reservoir (capacity, 1,600 acre-ft).

Mean discharge, in cublc feet per second, 1963

\begin{tabular}{|c|c|c|c|c|c|c|c|c|}
\hline Day & January & February & Day & January & February & Day & $J$ anuary & February \\
\hline $\begin{array}{r}1 \ldots \ldots \\
2 \ldots \ldots \\
3 \ldots \ldots \\
4 \ldots \ldots \\
5 \ldots \ldots \\
7 \ldots \ldots \\
8 \ldots \ldots \\
9 \ldots \ldots \\
10 \ldots \ldots\end{array}$ & $\begin{array}{r}0.6 \\
.6 \\
.6 \\
.6 \\
.6 \\
.6 \\
.6 \\
.6 \\
.6 \\
.6\end{array}$ & $\begin{array}{r}4,270 \\
1,370 \\
757 \\
562 \\
435 \\
359 \\
305 \\
271 \\
318 \\
817\end{array}$ & $\begin{array}{l}11 \ldots \ldots \\
12 \ldots \ldots \\
13 \ldots \ldots \\
14 \ldots \ldots \\
15 \ldots \ldots \\
16 \ldots \ldots \\
17 \ldots \ldots \\
18 \ldots \ldots \\
19 \ldots \ldots \\
20 \ldots \ldots\end{array}$ & $\begin{array}{l}0.8 \\
1.0 \\
1.2 \\
1.5 \\
1.7 \\
2.0 \\
2.4 \\
2.5 \\
2.8 \\
3.0\end{array}$ & $\begin{array}{l}710 \\
562 \\
594 \\
555 \\
487 \\
431 \\
398 \\
359 \\
319 \\
291\end{array}$ & $\begin{array}{l}21 \ldots \ldots \\
22 \ldots \ldots \\
23 \ldots \ldots \\
24 \ldots \ldots \\
25 \ldots \ldots \\
26 \ldots \ldots \\
27 \ldots \ldots \\
28 \ldots \ldots \\
29 \ldots \ldots \\
30 \ldots \ldots \\
31 \ldots \ldots\end{array}$ & $\begin{array}{r}3.2 \\
3.5 \\
3.9 \\
3.9 \\
3.9 \\
3.0 \\
2.2 \\
2.8 \\
3.0 \\
293 \\
5,000\end{array}$ & $\begin{array}{r}276 \\
255 \\
230 \\
213 \\
204 \\
186 \\
173 \\
171 \\
---- \\
-----\end{array}$ \\
\hline $\begin{array}{l}\text { Monthly } \\
\text { Runoff, } \\
\text { Runoff, }\end{array}$ & $\begin{array}{l}\text { mean diso } \\
\text { In inches } \\
\text { in acre-1 }\end{array}$ & 3 & & & & & $\begin{array}{r}172 \\
0.81 \\
10,610\end{array}$ & $\begin{array}{r}568 \\
2.41 \\
31,560 \\
\end{array}$ \\
\hline
\end{tabular}

Gage he1ght, in feet, and discharge, in cublc feet per second, at indicated t1me, 1963

\begin{tabular}{|c|c|c|c|c|c|c|c|c|c|c|c|}
\hline Date & Hour & $\begin{array}{c}\text { Gage } \\
\text { helght }\end{array}$ & $\begin{array}{c}\text { Dis- } \\
\text { charge }\end{array}$ & Date & Hour & $\begin{array}{c}\text { Gage } \\
\text { helght }\end{array}$ & $\begin{array}{c}\text { DIs- } \\
\text { charge }\end{array}$ & Date & Hour & $\begin{array}{c}\text { Gage } \\
\text { he1ght }\end{array}$ & $\begin{array}{l}\text { Dis - } \\
\text { charge }\end{array}$ \\
\hline $\begin{array}{r}\operatorname{Jan} . \\
30\end{array}$ & $\begin{array}{l}2400 \\
0100 \\
0300 \\
0700 \\
1200 \\
1800 \\
1900 \\
2100 \\
2400\end{array}$ & $\begin{array}{l}4.06 \\
3.98 \\
3.97 \\
3.97 \\
4.04 \\
4.11 \\
6.35 \\
7.90 \\
9.18\end{array}$ & \begin{tabular}{|r|}
6.7 \\
4.1 \\
3.9 \\
3.9 \\
6.0 \\
8.5 \\
530 \\
1,240 \\
2,030
\end{tabular} & Jan. 31 & $\begin{array}{l}0900 \\
1000 \\
1100 \\
1300 \\
1600 \\
1800 \\
2000 \\
2200 \\
2300 \\
2400\end{array}$ & $\begin{array}{l}12.20 \\
11.88 \\
11.83 \\
12.30 \\
13.50 \\
14.72 \\
14.34 \\
13.25 \\
12.90 \\
12.90\end{array}$ & $\begin{array}{l}4,520 \\
4,200 \\
4,160 \\
4,630 \\
5,950 \\
7,360 \\
6,910 \\
5,680 \\
5,290 \\
5,290\end{array}$ & Feb. & $\begin{array}{l}0800 \\
1000 \\
1300 \\
1400 \\
1600 \\
1800 \\
2200 \\
2400 \\
0500\end{array}$ & $\begin{array}{r}13.76 \\
12.75 \\
11.45 \\
10.95 \\
10.42 \\
10.00 \\
9.41 \\
9.15 \\
8.62\end{array}$ & $\begin{array}{l}6,240 \\
5,120 \\
3,820 \\
3,360 \\
2,940 \\
2,600 \\
2,190 \\
2,000 \\
1,670\end{array}$ \\
\hline 31 & $\begin{array}{l}0300 \\
0400 \\
0600 \\
0700\end{array}$ & $\begin{array}{l}11.90 \\
12.00 \\
11.92 \\
12.27\end{array}$ & $\begin{array}{l}4,220 \\
4,320 \\
4,240 \\
4,600\end{array}$ & Feb. 1 & $\begin{array}{l}0100 \\
0200 \\
0400 \\
0600\end{array}$ & $\begin{array}{l}12.80 \\
13.10 \\
13.80 \\
14.30\end{array}$ & $\begin{array}{l}5,180 \\
5,510 \\
6,280 \\
6,860\end{array}$ & & $\begin{array}{l}1400 \\
1700 \\
2400\end{array}$ & $\begin{array}{l}7.84 \\
7.62 \\
7.30\end{array}$ & $\begin{array}{r}1,210 \\
1,100 \\
940\end{array}$ \\
\hline
\end{tabular}




\section{SALINAS RIVER BASIN}

11-1470. Jack Creek near Templeton, Calif.

Location.--Lat $35^{\circ} 34^{\prime}$, long $120^{\circ} 48^{\prime}$, in Paso de Robles Grant, on left bank 1.4 miles upstream from mouth, 1.8 miles northwest of oakdale School, and 5.6 miles west of Templeton, San Luis Obispo County.

Drainage area. $--25.3 \mathrm{sq} \mathrm{mi}$.

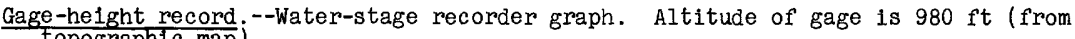
topographic map).

Discharge record.--Stage-discharge relation defined by current-meter measurements.

Maxima.--January-February 1963: Discharge, 1,820 cfs 1200 hours Jan. 31 (gage height, $6.90 \mathrm{ft}$ ).

1949 to December 1962: Discharge, 5,040 cf's Jan. 25, 1956 (gage height, $9.56 \mathrm{ft}$ ), from rating curve extended above $1,500 \mathrm{cf}$ 's on basis of slope-area measurement of peak flow.

Mean discharge, in cub1c feet per second, 1963

\begin{tabular}{|c|c|c|c|c|c|c|c|c|}
\hline Day & January & February & Day & January & February & Day & January & February \\
\hline $\begin{array}{c}1 \ldots \ldots \\
2 \ldots \ldots \\
3 \ldots \ldots \\
4 \ldots \ldots \\
5 \ldots \ldots \\
7 \ldots \ldots \\
5 \ldots \ldots \\
9 \ldots \ldots \\
10 \ldots \ldots\end{array}$ & $\begin{array}{r}0.2 \\
.2 \\
.2 \\
.2 \\
.2 \\
.2 \\
.2 \\
.2 \\
.2 \\
.2\end{array}$ & $\begin{array}{r}709 \\
109 \\
50 \\
30 \\
22 \\
17 \\
14 \\
12 \\
245 \\
461\end{array}$ & $\begin{array}{l}11 \ldots \ldots \\
12 \ldots \ldots \\
13 \ldots \ldots \\
14 \ldots \ldots \\
15 \ldots \ldots \\
16 \ldots \ldots \\
17 \ldots \ldots \\
18 \ldots \ldots \\
19 \ldots \ldots \\
20 \ldots \ldots\end{array}$ & $\begin{array}{l}0.2 \\
.2 \\
.2 \\
.2 \\
.2 \\
.2 \\
.2 \\
.2 \\
.2 \\
.2\end{array}$ & $\begin{array}{r}142 \\
78 \\
128 \\
94 \\
60 \\
47 \\
37 \\
30 \\
27 \\
23\end{array}$ & $\begin{array}{l}21 \ldots \ldots \\
22 \ldots \ldots \\
23 \ldots \ldots \\
24 \ldots \ldots \\
25 \ldots \ldots \\
26 \ldots \ldots \\
27 \ldots \ldots \\
28 \ldots \ldots \\
29 \ldots \ldots \\
30 \ldots \ldots \\
31 \ldots \ldots\end{array}$ & $\begin{array}{r}0.2 \\
.2 \\
.2 \\
.2 \\
.2 \\
.3 \\
.3 \\
.3 \\
128 \\
905\end{array}$ & $\begin{array}{r}20 \\
15 \\
16 \\
15 \\
13 \\
12 \\
11 \\
11 \\
-\ldots---\end{array}$ \\
\hline \multicolumn{7}{|c|}{ 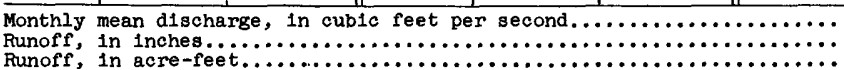 } & $\begin{array}{r}33.5 \\
1.53 \\
2,060\end{array}$ & $\begin{array}{r}87.5 \\
3.60 \\
4,560\end{array}$ \\
\hline
\end{tabular}

Gage height, in feet, and discharge, in cubic feet per second, at indicated time, 1963

\begin{tabular}{|c|c|c|c|c|c|c|c|c|c|c|c|}
\hline Date & Hour & $\begin{array}{c}\text { Gage } \\
\text { he1ght }\end{array}$ & $\begin{array}{l}\text { D18- } \\
\text { charge }\end{array}$ & Date & Hour & $\begin{array}{c}\text { Gage } \\
\text { height }\end{array}$ & $\begin{array}{l}\text { Dis- } \\
\text { charge }\end{array}$ & Date & Hour & $\begin{array}{c}\text { Gage } \\
\text { helght }\end{array}$ & $\begin{array}{c}\text { Dis- } \\
\text { charge }\end{array}$ \\
\hline $\begin{array}{r}\text { Jan. } 29 \\
30\end{array}$ & $\begin{array}{l}2400 \\
0100 \\
0600 \\
0700 \\
0900 \\
1000 \\
1300 \\
1600 \\
1700 \\
2000 \\
2300 \\
2400\end{array}$ & $\begin{array}{l}1.51 \\
1.84 \\
1.95 \\
2.05 \\
2.25 \\
3.31 \\
3.86 \\
3.48 \\
3.46 \\
3.92 \\
4.34 \\
4.90\end{array}$ & $\begin{array}{r}1.0 \\
1.2 \\
2.1 \\
3.8 \\
8.4 \\
102 \\
215 \\
132 \\
128 \\
230 \\
352 \\
565\end{array}$ & Jan. 31 & $\begin{array}{l}0100 \\
0400 \\
0600 \\
0500 \\
0900 \\
1100 \\
1200 \\
1500 \\
1700 \\
1800 \\
2000 \\
2100 \\
2200\end{array}$ & $\begin{array}{l}5.33 \\
5.20 \\
4.97 \\
5.30 \\
6.10 \\
6.75 \\
6.90 \\
5.42 \\
5.00 \\
4.94 \\
4.99 \\
5.04 \\
5.25\end{array}$ & $\begin{array}{r}780 \\
715 \\
600 \\
765 \\
1,210 \\
1,700 \\
1,820 \\
826 \\
615 \\
585 \\
610 \\
635 \\
740\end{array}$ & $\begin{array}{l}\text { Jan. } 31 \\
\text { Feb. } 1\end{array}$ & $\begin{array}{l}2300 \\
2400 \\
\\
0200 \\
0400 \\
0600 \\
0500 \\
0900 \\
1200 \\
1400 \\
1700 \\
2400\end{array}$ & $\begin{array}{l}5.78 \\
5.94 \\
5.78 \\
6.60 \\
5.90 \\
5.46 \\
5.66 \\
5.15 \\
4.72 \\
4.33 \\
3.77\end{array}$ & $\begin{array}{r}1,020 \\
1,110 \\
1,020 \\
1,550 \\
1,090 \\
848 \\
955 \\
690 \\
479 \\
349 \\
193\end{array}$ \\
\hline
\end{tabular}

11-1470.7. Santa Rita Creek near Templeton, Calif.

Location.--Iat $35^{\circ} 31^{\prime} 26^{\prime \prime}$, long $120^{\circ} 45^{\prime} 54^{\prime \prime}$, in Asuncion Grant, on left bank 1.6 miles upstream from Paso Robles Creek and 4 miles west of Templeton, San Luis Ob1spo County.

Drainage area. $--18.2 \mathrm{sq} \mathrm{mi}$.

Gage-height record; --Water-stage recorder graph. Alt1tude of gage is $860 \mathrm{ft}$ (from topographic map).

Discharge record.--Stage-discharge relation defined by current-meter measurements .

Maxima.--January-February 1963: Discharge, 1,210 cfs 1030 hours Jan. 31 (gage height, $7.66 \mathrm{ft}$ ).

1961 to December 1962: Maximum discharge, 2,320 cfs Feb. 9, 1962 (gage height, $9.15 \mathrm{ft}$ ). 
Mean discharge, in cubic feet per second, 1963, of Santa Rita Creek near Templeton, Calif.

\begin{tabular}{|c|c|c|c|c|c|c|c|c|}
\hline Day & January & Febmuary & Day & January & February & Day & January & Pebruary \\
\hline $\begin{array}{c}1 \ldots \ldots \\
2 \ldots \ldots \\
4 \ldots \ldots \\
5 \ldots \ldots \\
6 \ldots \ldots \\
7 \ldots \ldots \\
9 \ldots \ldots \\
10 \ldots \ldots\end{array}$ & $\begin{array}{r}0.2 \\
.2 \\
.2 \\
.2 \\
.2 \\
.2 \\
.2 \\
.2 \\
.2 \\
.2\end{array}$ & $\begin{array}{c}607 \\
107 \\
42 \\
25 \\
17 \\
12 \\
10 \\
8.6 \\
223 \\
411\end{array}$ & $\begin{array}{l}11 \ldots \ldots \\
12 \ldots \ldots \\
13 \ldots \ldots \\
14 \ldots \ldots \\
15 \ldots \ldots \\
16 \ldots \ldots \\
17 \ldots \ldots \\
18 \ldots \ldots \\
19 \ldots \ldots \\
20 \ldots \ldots\end{array}$ & $\begin{array}{r}0.2 \\
.2 \\
.2 \\
.2 \\
.2 \\
.3 \\
.3 \\
.3 \\
.3 \\
.3\end{array}$ & $\begin{array}{r}145 \\
75 \\
179 \\
117 \\
70 \\
51 \\
36 \\
29 \\
22 \\
18\end{array}$ & $\begin{array}{l}21 \ldots \ldots \\
22 \ldots \ldots \\
23 \ldots \ldots \\
24 \ldots \ldots \\
25 \ldots \ldots \\
26 \ldots \ldots \\
27 \ldots \ldots \\
28 \ldots \ldots \\
29 \ldots \ldots \\
30 \ldots \ldots \\
31 \ldots \ldots\end{array}$ & $\begin{array}{r}0.3 \\
.3 \\
.3 \\
.3 \\
.3 \\
.3 \\
.3 \\
.3 \\
.5 \\
81 \\
523\end{array}$ & 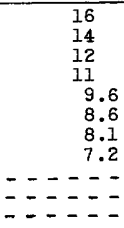 \\
\hline \multicolumn{7}{|c|}{ 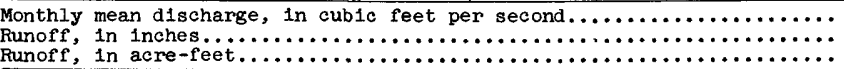 } & $\begin{array}{r}19.7 \\
1.25 \\
1,210\end{array}$ & $\begin{array}{r}81.8 \\
4.68 \\
4,540\end{array}$ \\
\hline
\end{tabular}

Gage height, in feet, and discharge, in cubic feet per second, at indicated time, 1963

\begin{tabular}{|c|c|c|c|c|c|c|c|c|c|c|c|}
\hline Date & Hour & $\begin{array}{c}\text { Gage } \\
\text { height }\end{array}$ & $\begin{array}{l}\text { Dis- } \\
\text { charge }\end{array}$ & Date & Hour & $\begin{array}{c}\text { Gage } \\
\text { helght }\end{array}$ & $\begin{array}{l}\text { D1s- } \\
\text { charge }\end{array}$ & Date & Hour & $\begin{array}{c}\text { Gage } \\
\text { helght }\end{array}$ & $\begin{array}{l}\text { D1s- } \\
\text { charge }\end{array}$ \\
\hline $\begin{array}{r}\text { Jan. } \\
30\end{array}$ & $\begin{array}{l}2400 \\
1000 \\
1100 \\
1200 \\
1300 \\
1500 \\
1700 \\
1900 \\
2100 \\
2300 \\
2400\end{array}$ & $\begin{array}{l}3.63 \\
3.77 \\
5.26 \\
5.68 \\
5.35 \\
5.05 \\
4.66 \\
4.48 \\
4.68 \\
4.76 \\
4.95\end{array}$ & $\begin{array}{r}1.5 \\
5.9 \\
205 \\
319 \\
228 \\
157 \\
89 \\
65 \\
92 \\
104 \\
137\end{array}$ & Jan. 31 & $\begin{array}{l}0100 \\
0300 \\
0400 \\
0600 \\
0700 \\
0800 \\
0900 \\
1030 \\
1100 \\
1300 \\
1500 \\
1700\end{array}$ & $\begin{array}{l}4.95 \\
5.94 \\
5.63 \\
5.53 \\
5.40 \\
5.48 \\
6.25 \\
7.66 \\
7.52 \\
7.60 \\
6.62 \\
5.94\end{array}$ & $\begin{array}{r}157 \\
419 \\
324 \\
294 \\
260 \\
280 \\
530 \\
1,210 \\
1,120 \\
1,170 \\
678 \\
419\end{array}$ & $\begin{array}{l}\text { Jan. } 31 \\
\text { Feb. } 1\end{array}$ & $\begin{array}{l}1900 \\
2000 \\
2300 \\
2400 \\
\\
0100 \\
0200 \\
0500 \\
0800 \\
1000 \\
1400 \\
1700 \\
2400 \\
\end{array}$ & $\begin{array}{l}5.68 \\
5.68 \\
5.82 \\
6.20 \\
\\
6.55 \\
6.57 \\
7.47 \\
6.87 \\
7.15 \\
6.24 \\
5.77 \\
5.12 \\
\end{array}$ & $\begin{array}{r}339 \\
339 \\
381 \\
510 \\
\\
650 \\
658 \\
1,090 \\
785 \\
925 \\
526 \\
366 \\
193 \\
\end{array}$ \\
\hline
\end{tabular}

11-1476.3. San Marcos Creek tributary near Paso Robles, Calif.

\section{(Crest-stage station)}

Location.--Lat $35^{\circ} 41^{\prime} 20^{\prime \prime}$, long $120^{\circ} 47^{\prime} 50^{\prime \prime}$, in NW $\frac{1}{4} N W \frac{1}{4} \sec .9$, T.26 S., R.11 E., at culvert on county road, 7.3 miles northwest of Paso Robles.

Drainage area. $--0.59 \mathrm{sq} \mathrm{mi}$.

Gage-height record.--Crest stages only. Altitude of gage is $950 \mathrm{ft}$ (from topographic map).

D1scharge record, --Stage-discharge relation not defined.

Maxima.--January-February 1963: Discharge, not determined, occurred Jan. 31 (gage height, $51.06 \mathrm{ft}$ ).

1959 to December 1962: Discharge, $21 \mathrm{cfs}$ Feb. 14, 1962 (gage height, 51.54 ft), by computation of flow through culvert.

11-1485.5. Indian Valley Creek tributary near Valleton, Calif.

(Crest-stage station)

Location.--Lat $36^{\circ} 01^{\prime} 25^{\prime \prime}$, long $120^{\circ} 39^{\prime} 10^{\prime \prime}$, in SW $\frac{1}{4}$ sec.11, T.22 S., R.12 E., at culvert on Indian Valley Road, 9.2 miles northeast of Valleton.

Drainage area. $--0.13 \mathrm{sq} \mathrm{mi}$.

Gage-height record.--Crest stages only. Altitude of gage is 1,660 ft (from topographic map).

Discharge record.--Maximum discharge by computation of flow through culvert.

Maxima.--January-February 1963: Discharge, 13 cfs Jan. 31 (gage he1ght, $51.84 \mathrm{ft}$ ). 1960 to December 1962: Discharge, not determined, occurred Feb. 9, 1962 (gage height, $51.27 \mathrm{ft}$ ). 
11-1488. Nacimiento River near Bryson, Calif.

Location.--Lat $35^{\circ} 48^{\prime} 06^{\prime \prime}$, long $121^{\circ} 06^{\prime} 50^{\prime \prime}$, in NW $\frac{1}{4}$ sec.33, T.24 S., R.8 E., on right bank 0.6 mile upstream from Turtle Creek, 1.6 miles west of Bryson, and 10 miles southwest of Lockwood.

Drainage area. $--140 \mathrm{sq} \mathrm{mi}$.

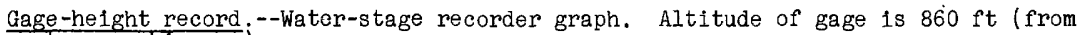
topographic map).

Discharge record.--Stage-discharge relation defined by current-meter measurements.

Maxima.--January-February 1963: Discharge, 22,800 cfs 1400 hours Jan. 31 (gage helght, $21.08 \mathrm{ft}$ ).

1955 to December 1962: Discharge, 30,300 cfs Dec. 23, 1955 (gage he1ght, $24.63 \mathrm{ft}$ ), from rating curve extended above 13,000 $\mathrm{cfs}$ on basis of slope-area measurement of maximum flow.

Mean discharge, in cubic feet per second, 1963

\begin{tabular}{|c|c|c|c|c|c|c|c|c|}
\hline Day & January & February & Day & January & February & Day & January & February \\
\hline $\begin{array}{c}1 \ldots \ldots \\
2 \ldots \ldots \\
4 \ldots \ldots \\
5 \ldots \ldots \\
6 \ldots \ldots \\
7 \ldots \ldots \\
8 \ldots \ldots \\
9 \ldots \ldots \\
10 \ldots \ldots\end{array}$ & $\begin{array}{l}18 \\
18 \\
17 \\
17 \\
16 \\
15 \\
14 \\
14 \\
14 \\
14\end{array}$ & $\begin{array}{r}8,370 \\
1,940 \\
902 \\
509 \\
328 \\
239 \\
194 \\
156 \\
1,610 \\
3,730\end{array}$ & $\begin{array}{l}11 \ldots \ldots \\
12 \ldots \ldots \\
13 \ldots \ldots \\
14 \ldots \ldots \\
15 \ldots \ldots \\
16 \ldots \ldots \\
17 \ldots \ldots \\
18 \ldots \ldots \\
19 \ldots \ldots \\
20 \ldots \ldots\end{array}$ & $\begin{array}{l}13 \\
12 \\
12 \\
11 \\
11 \\
11 \\
11 \\
11 \\
11 \\
11\end{array}$ & $\begin{array}{r}1,730 \\
758 \\
1,710 \\
1,100 \\
630 \\
407 \\
286 \\
212 \\
156 \\
121\end{array}$ & $\begin{array}{l}21 \ldots \ldots \\
22 \ldots \ldots \\
23 \ldots \ldots \\
24 \ldots \ldots \\
25 \ldots \ldots \\
26 \ldots \ldots \\
27 \ldots \ldots \\
28 \ldots \ldots \\
29 \ldots \ldots \\
30 \ldots \ldots \\
31 \ldots \ldots\end{array}$ & $\begin{array}{r}10 \\
9.8 \\
9.8 \\
9.8 \\
9.8 \\
9.8 \\
9.8 \\
9.8 \\
13 \\
4,700 \\
13,600 \\
\end{array}$ & $\begin{array}{r}91 \\
67 \\
52 \\
38 \\
31 \\
24 \\
21 \\
17 \\
-\ldots-\ldots \\
--\ldots--1\end{array}$ \\
\hline \multicolumn{7}{|l|}{$\begin{array}{l}\text { Monthly } \\
\text { Runoff, } \\
\text { Runoff, }\end{array}$} & $\begin{array}{r}602 \\
4.96 \\
37,020\end{array}$ & $\begin{array}{r}908 \\
6.76 \\
50,440 \\
\end{array}$ \\
\hline
\end{tabular}

Gage height, in feet, and discharge, in cublc feet per second, at indicated time, 1963

\begin{tabular}{|c|c|c|c|c|c|c|c|c|c|c|c|}
\hline Date & Hour & $\begin{array}{c}\text { Gage } \\
\text { helght }\end{array}$ & $\begin{array}{c}\text { Dis- } \\
\text { charge }\end{array}$ & Date & Hour & $\begin{array}{c}\text { Gage } \\
\text { helght }\end{array}$ & $\begin{array}{l}\text { D1s- } \\
\text { charge }\end{array}$ & Date & Hour & $\begin{array}{c}\text { Gage } \\
\text { he 1ght }\end{array}$ & $\begin{array}{l}\text { D1s- } \\
\text { charge }\end{array}$ \\
\hline $\begin{array}{r}\operatorname{Jan} .29 \\
30\end{array}$ & $\begin{array}{l}2400 \\
0300 \\
0400 \\
0500 \\
0700 \\
0900 \\
1000 \\
1100 \\
1200 \\
1300 \\
1500 \\
1700 \\
2100\end{array}$ & $\begin{array}{r}4.37 \\
4.61 \\
6.42 \\
6.98 \\
7.77 \\
9.40 \\
10.50 \\
10.90 \\
10.85 \\
10.90 \\
10.52 \\
11.55 \\
14.40 \\
\end{array}$ & $\begin{array}{r}25 \\
\\
55 \\
700 \\
1,030 \\
1,580 \\
3,120 \\
4,370 \\
4,890 \\
4,830 \\
4,890 \\
4,400 \\
5,830 \\
10,200 \\
\end{array}$ & Jan. 30 & $\begin{array}{l}2300 \\
2400 \\
\\
0200 \\
0400 \\
0600 \\
0800 \\
1100 \\
1200 \\
1400 \\
1700 \\
2000 \\
2200 \\
2400 \\
\end{array}$ & $\begin{array}{l}15.60 \\
15.53 \\
14.98 \\
15.07 \\
14.83 \\
15.83 \\
19.50 \\
19.66 \\
21.08 \\
17.00 \\
13.55 \\
12.65 \\
13.30\end{array}$ & $\begin{array}{r}12,200 \\
12,100 \\
11,200 \\
11,300 \\
10,900 \\
12,600 \\
19,600 \\
19,900 \\
22,800 \\
14,700 \\
8,880 \\
7,480 \\
8,480 \\
\end{array}$ & Feb. 1 & $\begin{array}{l}0500 \\
0800 \\
1100 \\
1500 \\
1700 \\
2000 \\
2400 \\
\\
0600 \\
1200 \\
1800 \\
2400\end{array}$ & $\begin{array}{r}16.72 \\
15.94 \\
14.00 \\
11.70 \\
11.00 \\
10.20 \\
9.42 \\
8.64 \\
8.07 \\
7.63 \\
7.26\end{array}$ & $\begin{array}{r}14,200 \\
12,800 \\
9,600 \\
6,050 \\
5,020 \\
4,000 \\
3,140 \\
2,320 \\
1,820 \\
1,460 \\
1,200\end{array}$ \\
\hline
\end{tabular}

11-1488.2. Sapaque Creek tributary at Bryson, Calif.

(Crest-stage station)

Location.--Lat $35^{\circ} 48^{\prime} 50^{\prime \prime}$, long $121^{\circ} 05^{\prime} 25^{\prime \prime}$, in $N{ }^{\frac{1}{4}} \mathrm{SE} \frac{1}{4}$ sec.27, T.24 S., R. 8 E., at culvert on county road, 0.4 mile north' of Bryson.

Drainage area. $--0.76 \mathrm{sq} \mathrm{mi}$.

Gage-height record.--Crest stages only. Altitude of gage is $990 \mathrm{ft}$ (from topographic map).

Discharge record.--Maximum discharge by computation of flow through culvert.

Maxima --January-February 1963: Discharge, $39 \mathrm{cfs}$ Jan. 31 (gage height, $53.40 \mathrm{ft}$ ). 1960 to December 1962: Discharge, not determined, occurred Feb. 9, 1962 (gage height, 52.22 (t). 
11-1494. Nacimiento River below Nacimiento Dam, near Bradley, Calif.

Location.--Lat $35^{\circ} 45^{\prime} 41^{\prime \prime}$, long $120^{\circ} 51^{\prime} 16^{\prime \prime}$, in $\mathrm{NE} \frac{1}{4} \mathrm{NE} \frac{1}{4} \mathrm{sec} .14$, T.25 S., R.10 E., on lef't bank 2.2 miles below Nacimiento Dam and 7.6 miles southwest of Bradrey.

Drainage area. $--322 \mathrm{sq} \mathrm{mi}$.

Gage-height record. - Water-stage recorder graph, except Jan. 1-7. Datum of gage is $597 \mathrm{ft}$ above mean sea level (Corps of Engineers bench mark).

Discharge record.--Stage-discharge relation defined by current-meter measurements . Discharge for Jan. 1-7 estimated on basis of recorded range in stage.

Maxima --January-February 1963: Discharge, 8.7 cfs 1500 hours Feb. 9 (gage height, $3.28 \mathrm{ft}$ ).

1957 to December 1962: Discharge, 5,220 cfs Apr. 7, 1958 (gage height, $10.28 \mathrm{ft}$ )

Remarks.--Flow regulated by Nacimiento Dam (usable capacity, 340,000 acre-ft).

Mean discharge, in cub1c feet per second, 1963

\begin{tabular}{|c|c|c|c|c|c|c|c|c|}
\hline Day & January & February & Day & January & February & Day & January & February \\
\hline $\begin{array}{c}\ldots \ldots \\
2 \ldots \ldots \\
3 \ldots \ldots \\
4 \ldots \ldots \\
6 \ldots \ldots \\
7 \ldots \ldots \\
8 \ldots \ldots \\
9 \ldots \ldots \\
10 \ldots \ldots\end{array}$ & $\begin{array}{l}0 \\
0 \\
0 \\
0 \\
0 \\
0 \\
0 \\
0 \\
0 \\
0\end{array}$ & $\begin{array}{r}1.4 \\
.5 \\
.2 \\
.2 \\
.2 \\
.2 \\
.2 \\
.2 \\
2.7 \\
1.4\end{array}$ & $\begin{array}{l}11 \ldots \ldots \\
12 \ldots \ldots \\
13 \ldots \ldots \\
14 \ldots \ldots \\
15 \ldots \ldots \\
16 \ldots \ldots \\
17 \ldots \ldots \\
18 \ldots \ldots \\
19 \ldots \ldots \\
20 \ldots \ldots\end{array}$ & $\begin{array}{l}0 \\
0 \\
0 \\
0 \\
0 \\
0 \\
0 \\
0 \\
0 \\
0\end{array}$ & $\begin{array}{l}0.4 \\
.3 \\
.5 \\
.3 \\
.2 \\
.2 \\
.2 \\
.1 \\
.1 \\
.1\end{array}$ & $\begin{array}{l}21 \ldots \ldots \\
22 \ldots \ldots \\
23 \ldots \ldots \\
24 \ldots \ldots \\
25 \ldots \ldots \\
26 \ldots \ldots \\
27 \ldots \ldots \\
28 \ldots \ldots \\
29 \ldots \ldots \\
30 \ldots \ldots \\
31 \ldots \ldots\end{array}$ & $\begin{array}{l}0 \\
0 \\
0 \\
0 \\
0 \\
0 \\
0 \\
0 \\
0 \\
.1 \\
1.1\end{array}$ & $\begin{array}{r}0.1 \\
.1 \\
.1 \\
.1 \\
.1 \\
.1 \\
.1 \\
.1 \\
----- \\
---.--\end{array}$ \\
\hline $\begin{array}{l}\text { nthly } \\
\text { anoff, }\end{array}$ & $\begin{array}{l}\text { an d1 } \\
\text { acre }\end{array}$ & , & feet $p$ & & & & $\begin{array}{r}0.04 \\
2.4 \\
\end{array}$ & $\begin{array}{r}0.37 \\
21 \\
\end{array}$ \\
\hline
\end{tabular}

11-1496.5. Sulphur Springs Canyon near Jolon, Calif.

(Crest-stage station)

Location.--Lat $36^{\circ} 01^{\prime} 10^{\prime \prime}$, long $121^{\circ} 14^{\prime} 15^{\prime \prime}$, in Hunter Liggett Military Reservation, at culvert on Sulphur Springs Road, 4.8 miles northwest of Jolon.

Drainage area $--5.16 \mathrm{sq} \mathrm{mi}$.

Gage-height record.--Crest stages only. Altitude of gage is 1,070 ft (from topographic map).

Discharge record.--Stage-discharge relation defined by computation of flow through culvert at 29 and $209 \mathrm{cfs}$.

Maxima.--January-February 1963: Discharge, 209 cfs Jan. 31 (gage height, $56.04 \mathrm{ft}$ ). 1960 to December 1962: Discharge, $117 \mathrm{cfs}$ Feb. 9, 1962 (gage height, $54.22 \mathrm{ft}^{\prime}$ ).

11-1497. San Antonio River at Sam Jones Bridge, near Lockwood, Calif.

Location.--Lat $35^{\circ} 54^{\prime} 45^{\prime \prime}$, long $121^{\circ} 07^{\prime} 50^{\prime \prime}$, in Los 0jitos Grant, on downstream side of Sam Jones Bridge, 300 ft downstream from China Gulch and 3.5 miles southwest of Lockwood, Monterey County.

Drainage area. $--211 \mathrm{sq} \mathrm{mi}$.

Gage-height record:--Water-stage recorder graph. Alt1tude of gage is $860 \mathrm{ft}$ (from topographic map).

Discharge record.--Stage-discharge relation defined by current-meter measurements.

Maxima.--January-February 1963: Discharge, 14,400 cfs 1700 hours Jan. 31 (gage height, $8.70 \mathrm{ft}$ ).

1958-59, 1961 to December 1962: Discharge, 7,040 cf's Feb. 9, 1962 (gage height, $7.01 \mathrm{ft}$ ). 
Mean discharge, in cubic feet per second, 1963, of San Antonio River at Sam Jones Bridge, near Lockwood, Calif.

\begin{tabular}{|c|c|c|c|c|c|c|c|c|}
\hline Day & January & February & Day & January & February & Day & January & February \\
\hline $\begin{array}{c}1 \ldots \ldots \\
2 \ldots \ldots \\
3 \ldots \ldots \\
4 \ldots \ldots \\
6 \ldots \ldots \\
7 \ldots \ldots \\
8 \ldots \ldots \\
9 \ldots \ldots \\
10 \ldots \ldots\end{array}$ & $\begin{array}{l}12 \\
12 \\
12 \\
12 \\
12 \\
12 \\
11 \\
10 \\
10 \\
10\end{array}$ & $\begin{array}{r}5,710 \\
1,130 \\
640 \\
491 \\
363 \\
290 \\
235 \\
208 \\
412 \\
1,140\end{array}$ & $\begin{array}{l}11 \ldots \ldots \\
12 \ldots \ldots \\
13 \ldots \ldots \\
14 \ldots \ldots \\
15 \ldots \ldots \\
16 \ldots \ldots \\
17 \ldots \ldots \\
18 \ldots \ldots \\
19 \ldots \ldots \\
20 \ldots \ldots\end{array}$ & $\begin{array}{l}9.8 \\
9.2 \\
9.2 \\
9.2 \\
8.6 \\
8.6 \\
8.0 \\
8.0 \\
8.0 \\
8.0\end{array}$ & $\begin{array}{l}720 \\
461 \\
942 \\
750 \\
523 \\
426 \\
375 \\
334 \\
296 \\
279\end{array}$ & $\begin{array}{l}21 \ldots \ldots \\
22 \ldots \ldots \\
23 \ldots \ldots \\
24 \ldots \ldots \\
25 \ldots \ldots \\
26 \ldots \ldots \\
27 \ldots \ldots \\
28 \ldots \ldots \\
29 \ldots \ldots \\
30 \ldots \ldots \\
31 \ldots \ldots\end{array}$ & $\begin{array}{r}8.0 \\
8.0 \\
8.0 \\
8.0 \\
8.6 \\
8.6 \\
8.6 \\
8.6 \\
9.8 \\
1,530 \\
7,480 \\
\end{array}$ & 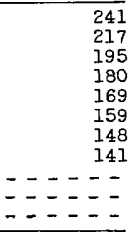 \\
\hline & $\begin{array}{l}\text { inche } \\
\text { acre- }\end{array}$ & & & & & & $\begin{array}{r}300 \\
1.64 \\
18,420 \\
\end{array}$ & $\begin{array}{r}613 \\
3.03 \\
34,070 \\
\end{array}$ \\
\hline
\end{tabular}

Gage height, in feet, and discharge, in cubic feet per second, at indicated t1me, 1963

\begin{tabular}{|c|c|c|c|c|c|c|c|c|c|c|c|}
\hline Date & Hour & $\begin{array}{c}\text { Gage } \\
\text { height }\end{array}$ & $\begin{array}{c}\text { Dis- } \\
\text { charge }\end{array}$ & Date & Hour & $\begin{array}{c}\text { Gage } \\
\text { helght }\end{array}$ & $\begin{array}{l}\text { Dis- } \\
\text { charge }\end{array}$ & Date & Hour & $\begin{array}{c}\text { Gage } \\
\text { helght }\end{array}$ & $\begin{array}{c}\text { Dis - } \\
\text { charge }\end{array}$ \\
\hline 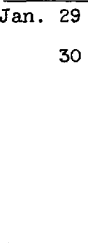 & $\begin{array}{l}2400 \\
0400 \\
0700 \\
0700 \\
0800 \\
1000 \\
1400 \\
1800 \\
2000 \\
2100 \\
2400\end{array}$ & $\begin{array}{l}2.73 \\
2.75 \\
2.82 \\
3.40 \\
4.12 \\
4.50 \\
5.26 \\
5.32 \\
5.73 \\
5.80 \\
6.33\end{array}$ & $\begin{array}{r}16 \\
18 \\
25 \\
155 \\
572 \\
940 \\
2,070 \\
2,190 \\
3,030 \\
3,200 \\
4,690\end{array}$ & Jan. 31 & $\begin{array}{l}0100 \\
0300 \\
0500 \\
0800 \\
0800 \\
1100 \\
1300 \\
1400 \\
1600 \\
1600 \\
1700 \\
2000\end{array}$ & $\begin{array}{l}6.41 \\
6.40 \\
6.21 \\
6.72 \\
6.60 \\
7.10 \\
7.90 \\
7.33 \\
8.52 \\
8.32 \\
8.70 \\
7.36\end{array}$ & $\begin{array}{r}4,930 \\
4,900 \\
4,330 \\
5,860 \\
5,500 \\
7,100 \\
10,400 \\
7,920 \\
13,500 \\
12,500 \\
14,400 \\
8,040\end{array}$ & $\begin{array}{l}\text { Jan. } 31 \\
\text { Feb. } 1\end{array}$ & $\begin{array}{l}2400 \\
0100 \\
0300 \\
0600 \\
0700 \\
1100 \\
1500 \\
1800 \\
2400\end{array}$ & $\begin{array}{l}6.48 \\
6.48 \\
7.01 \\
8.28 \\
8.18 \\
6.64 \\
6.07 \\
5.73 \\
5.22\end{array}$ & $\begin{array}{r}5,140 \\
5,140 \\
6,780 \\
12,300 \\
11,800 \\
5,620 \\
3,910 \\
3,030 \\
1,990\end{array}$ \\
\hline
\end{tabular}

11-1500. San Antonio River at Pleyto, Calif.

Location.--Lat $35^{\circ} 51^{\prime} 55^{\prime \prime}$, long $120^{\circ} 59^{\prime} 30^{\prime \prime}$, In Pleyto Grant, on downstream side of left abutment of highway bridge at old townsite of Pleyto, Monterey County,

1.1 miles downstream from Cooperhead Creek and 15 miles west of Bradley.

Drainage area. $--284 \mathrm{sq} \mathrm{ml}$.

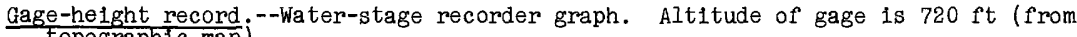
topographic mapj.

Discharge record.--Stage-discharge relation defined by current-meter measurements .

Maxima.--January-February 1963: Discharge, 14,800 cf's 1900 hours Jan. 31 (gage helght, $6.35 \mathrm{ft}$ ).

1929 to December 1962: Discharge, 19,100 cf's Apr. 3, 1958 (gage helght, $6.44 \mathrm{ft}$ ), from rating curve extended above $4,500 \mathrm{cfs}$.

Mean discharge, in cubic feet per second, 1963

\begin{tabular}{|c|c|c|c|c|c|c|c|c|}
\hline Day & January & February & Day & January & February & Day & January & February \\
\hline $\begin{array}{c}1 \ldots \ldots \\
2 \ldots \ldots \\
3 \ldots \ldots \\
4 \ldots \ldots \\
6 \ldots \ldots \\
7 \ldots \ldots \\
8 \ldots \ldots \\
10 \ldots \ldots\end{array}$ & $\begin{array}{l}9.0 \\
9.0 \\
10 \\
9.0 \\
10 \\
10 \\
10 \\
9.0 \\
9.0 \\
10\end{array}$ & $\begin{array}{r}5,780 \\
1,400 \\
708 \\
465 \\
353 \\
286 \\
248 \\
222 \\
277 \\
1,100\end{array}$ & $\begin{array}{l}11 \ldots \ldots \\
12 \ldots \ldots \\
13 \ldots \ldots \\
14 \ldots \ldots \\
15 \ldots \ldots \\
16 \ldots \ldots \\
17 \ldots \ldots \\
18 \ldots \ldots \\
19 \ldots \ldots \\
20 \ldots \ldots\end{array}$ & $\begin{array}{l}10 \\
10 \\
9.0 \\
10 \\
10 \\
10 \\
10 \\
11 \\
11 \\
10\end{array}$ & $\begin{array}{l}919 \\
570 \\
871 \\
841 \\
582 \\
475 \\
406 \\
361 \\
318 \\
301\end{array}$ & $\begin{array}{l}21 \ldots \ldots \\
22 \ldots \ldots \\
23 \ldots \ldots \\
24 \ldots \ldots \\
25 \ldots \ldots \\
26 \ldots \ldots \\
27 \ldots \ldots \\
28 \ldots \ldots \\
29 \ldots \ldots \\
30 \ldots \ldots \\
31 \ldots \ldots\end{array}$ & $\begin{array}{r}9.0 \\
9.0 \\
8.1 \\
7.2 \\
6.3 \\
4.5 \\
5.4 \\
4.5 \\
3.6 \\
517 \\
6,110\end{array}$ & $\begin{array}{r}262 \\
235 \\
225 \\
216 \\
203 \\
177 \\
164 \\
164 \\
----- \\
--.---\end{array}$ \\
\hline \multicolumn{7}{|l|}{$\begin{array}{l}\text { Monthly } \\
\text { Runoff, } \\
\text { Runoff, }\end{array}$} & $\begin{array}{r}222 \\
0.90 \\
13,650 \\
\end{array}$ & $\begin{array}{r}647 \\
2.37 \\
35,960 \\
\end{array}$ \\
\hline
\end{tabular}


Gage height, In feet, and discharge, in cublc feet per second, at indicated time, 1963, of San Antonio River at Pleyto, Calif.

\begin{tabular}{|c|c|c|c|c|c|c|c|c|c|c|c|}
\hline Date & Hour & $\begin{array}{c}\text { Gage } \\
\text { height }\end{array}$ & $\begin{array}{l}\text { Dis- } \\
\text { charge }\end{array}$ & Date & Hour & $\begin{array}{c}\text { Gage } \\
\text { height }\end{array}$ & $\begin{array}{l}\text { Dis- } \\
\text { charge }\end{array}$ & Date & Hour & $\begin{array}{c}\text { Gage } \\
\text { height }\end{array}$ & $\begin{array}{l}\text { D1s- } \\
\text { charge }\end{array}$ \\
\hline $\begin{array}{r}\text { Jan. } 29 \\
30\end{array}$ & $\begin{array}{l}2400 \\
1400 \\
1400 \\
1600 \\
1800 \\
2000 \\
2200 \\
2400 \\
0400\end{array}$ & $\begin{array}{l}1.16 \\
1.28 \\
2.60 \\
3.35 \\
3.88 \\
3.97 \\
3.90 \\
4.31 \\
4.98\end{array}$ & $\begin{array}{r}7.6 \\
17 \\
378 \\
844 \\
1,330 \\
1,440 \\
1,360 \\
1,910 \\
3,170\end{array}$ & Jan. 31 & $\begin{array}{l}0600 \\
0700 \\
1000 \\
1300 \\
1500 \\
1700 \\
1900 \\
2100 \\
2300 \\
2400\end{array}$ & $\begin{array}{l}4.95 \\
4.87 \\
5.17 \\
5.30 \\
5.70 \\
6.05 \\
6.35 \\
6.06 \\
5.90 \\
5.64\end{array}$ & $\begin{array}{r}3,100 \\
2,910 \\
3,710 \\
3,980 \\
6,390 \\
10,200 \\
14,800 \\
10,900 \\
9,100 \\
6,710\end{array}$ & Feb. 1 & $\begin{array}{l}0300 \\
0600 \\
0900 \\
1200 \\
1600 \\
2000 \\
2400 \\
\\
0800 \\
1600 \\
2400\end{array}$ & $\begin{array}{l}5.31 \\
5.73 \\
6.08 \\
5.75 \\
5.17 \\
4.75 \\
4.40 \\
\\
3.95 \\
3.64 \\
3.39\end{array}$ & $\begin{array}{r}4,610 \\
7,470 \\
11,200 \\
7,650 \\
4,040 \\
2,870 \\
2,180 \\
1,500 \\
1,140 \\
932\end{array}$ \\
\hline
\end{tabular}

11-1500.2. San Antonio River tributary near Pleyto, Calif.

(Crest-stage station)

Location. --Lat $35^{\circ} 50^{\prime} 35^{\prime \prime}$, long $120^{\circ} 57^{\prime} 45^{\prime \prime}$, in Hunter Liggett Military Reservation, at culvert, 2.1 miles southeast of Pleyto.

Drainage area $--0.50 \mathrm{sq} \mathrm{ml}$.

Gage-height record.--Crest stages only. Altitude of gage is $740 \mathrm{ft}$ (from topographic map).

D1scharge record.--Maximum discharge by computation of flow through culvert.

Maxima.--January-February 1963: Discharge, $30 \mathrm{cfs}$ Jan. 31 (gage height, $52.43 \mathrm{ft}$ ). i960 to December 1962: No flow.

11-1505. Salinas River near Bradley, Calif.

Location.--Lat $35^{\circ} 55^{\prime} 40^{\prime \prime}$, long $120^{\circ} 52^{\prime} 00^{\prime \prime}$, in $\mathrm{NE} \frac{1}{4} \mathrm{sec} .15$, T.23 S., R.10 E., on left bank 6 miles northwest of Bradley and 7 miles downstream from San Antonio River.

Drainage area. $--2,535 \mathrm{sq} \mathrm{mi}$.

Gage-he1ght record ; -Water-stage recorder graph. Altitude of gage is $450 \mathrm{ft}$ (from topographic map).

Discharge record.--Stage-discharge relation defined by current-meter measurements.

Maxima.--January-February 1963: Discharge, 12,200 efs 0300 hours Feb. I (gage height $9.87 \mathrm{ft}$ ).

1948 to December 1962: Discharge, 28,400 cfs Apr. 3, 1958 (gage helght, $12.53 \mathrm{ft}$ )

Remarks.--Flow slightly regulated by Salinas Reservoir (usable capacity, 26,000 acre-ft) and Nac1miento Reservoir (usable capacity, 340,000 acre-ft).

Mean discharge, in cubic feet per second, 1963

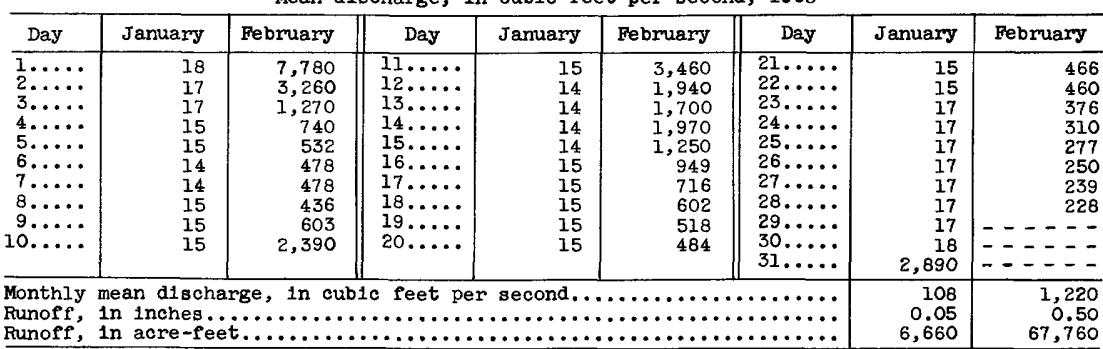


Gage height, in feet, and discharge, in cubic feet per second, at indicated time, 1963, of Salinas River near Bradley, Calif.

\begin{tabular}{|c|c|c|c|c|c|c|c|c|c|c|c|}
\hline Date & Hour & $\begin{array}{c}\text { Gage } \\
\text { height }\end{array}$ & $\begin{array}{l}\text { Dis- } \\
\text { charge }\end{array}$ & Date & Hour & $\begin{array}{c}\text { Gage } \\
\text { height }\end{array}$ & $\begin{array}{l}\text { D1s- } \\
\text { charge }\end{array}$ & Date & Hour & $\begin{array}{c}\text { Gage } \\
\text { height }\end{array}$ & $\begin{array}{l}\text { Dis- } \\
\text { charge }\end{array}$ \\
\hline $\begin{array}{r}\text { Jan. } 30 \\
31\end{array}$ & $\begin{array}{l}2400 \\
0500 \\
0600 \\
0800 \\
1200 \\
1600 \\
2100 \\
2400\end{array}$ & $\begin{array}{l}3.70 \\
3.71 \\
4.70 \\
5.50 \\
6.50 \\
7.50 \\
8.10 \\
9.25\end{array}$ & $\begin{array}{r}27 \\
29 \\
490 \\
1,120 \\
2,340 \\
4,170 \\
5,670 \\
9,600\end{array}$ & Feb. 1 & $\begin{array}{l}0200 \\
0300 \\
0500 \\
0700 \\
0900 \\
1100 \\
1400 \\
1700 \\
2100\end{array}$ & $\begin{array}{l}9.85 \\
9.87 \\
9.22 \\
8.50 \\
8.14 \\
8.08 \\
8.50 \\
9.10 \\
8.32\end{array}$ & $\begin{array}{r}12,100 \\
12,200 \\
9,480 \\
6,850 \\
5,770 \\
5,620 \\
6,850 \\
9,000 \\
6,260\end{array}$ & Feb. 1 & $\begin{array}{l}2400 \\
0600 \\
1200 \\
1800 \\
2400\end{array}$ & $\begin{array}{l}8.09 \\
7.54 \\
6.84 \\
6.40 \\
6.06\end{array}$ & $\begin{array}{l}5,650 \\
4,270 \\
2,880 \\
2,190 \\
1,730\end{array}$ \\
\hline
\end{tabular}

11-1508. Cow Creek near San Ardo, Calif.

Location. --Lat $36^{\circ} 10^{\prime} 40^{\prime \prime}$, long $120^{\circ} 47^{\prime} 45^{\prime \prime}$, in San Lorenzo Grant, on right bank at culvert on Peach Tree Valley Road, 12.5 miles northeast of San Ardo, Monterey County.

Drainage area. $--4.80 \mathrm{sq} \mathrm{mi}$.

Gage-height record.--Water-stage recorder graph, except Feb. 2-9. Alt1tude of gage is $1,340 \mathrm{f}^{\prime} \mathrm{t}$ (frrom topographic map).

Discharge record.--Stage-discharge relation defined by current-meter measurements below $21 \mathrm{cf}$ 's and by computation of peak flow through culvert at 173 and $213 \mathrm{cf}$. Discharge for Feb. 2-9 estimated on basis of weather records.

Maxima --January-February 1963: Discharge, $173 \mathrm{cfs}$, time unknown, Feb. 9 (gage helght, $5.90 \mathrm{ft}$, from floodmarks).

1960 to December 1962: Discharge, $213 \mathrm{cfs}$ Feb. 15, 1962 (gage height, $6.96 \mathrm{ft}$ ).

Mean discharge, in cubic feet per second, 1963

\begin{tabular}{|c|c|c|c|c|c|c|c|c|}
\hline Day & January & February & Day & January * & February & Day & January & February \\
\hline $\begin{array}{c}1 \ldots \ldots \\
2 \ldots \ldots \\
3 \ldots \ldots \\
4 \ldots \ldots \\
5 \ldots \ldots \\
6 \ldots \ldots \\
7 \ldots \ldots \\
8 \ldots \ldots \\
9 \ldots \ldots \\
10 \ldots \ldots\end{array}$ & $\begin{array}{l}0 \\
0 \\
0 \\
0 \\
0 \\
0 \\
0 \\
0 \\
0 \\
0\end{array}$ & $\begin{array}{l}0.2 \\
0 \\
0 \\
0 \\
0 \\
0 \\
0 \\
0 \\
34 \\
1.5\end{array}$ & $\begin{array}{l}11 \ldots \ldots \\
12 \ldots \ldots \\
13 \ldots \ldots \\
14 \ldots \ldots \\
15 \ldots \ldots \\
16 \ldots \ldots \\
17 \ldots \ldots \\
18 \ldots \ldots \\
19 \ldots \ldots \\
20 \ldots \ldots\end{array}$ & $\begin{array}{l}0 \\
0 \\
0 \\
0 \\
0 \\
0 \\
0 \\
0 \\
0 \\
0\end{array}$ & $\begin{array}{l}0 \\
2.7 \\
8.5 \\
0 \\
0 \\
0 \\
0 \\
0 \\
0 \\
0\end{array}$ & $\begin{array}{l}21 \ldots \ldots \\
22 \ldots \ldots \\
23 \ldots \ldots \\
24 \ldots \ldots \\
25 \ldots \ldots \\
26 \ldots \ldots \\
27 \ldots \ldots \\
28 \ldots \ldots \\
29 \ldots \ldots \\
30 \ldots \ldots \\
31 \ldots \ldots\end{array}$ & $\begin{array}{l}0 \\
0 \\
0 \\
0 \\
0 \\
0 \\
0 \\
0 \\
0 \\
0 \\
9.2\end{array}$ & $\begin{array}{r}0 \\
0 \\
0 \\
0 \\
0 \\
0 \\
0 \\
0 \\
------\end{array}$ \\
\hline \multicolumn{7}{|l|}{$\begin{array}{l}\text { Monthly } \\
\text { Runoff, } \\
\text { Runoff, }\end{array}$} & $\begin{array}{r}0.30 \\
0.07 \\
18 \\
\end{array}$ & $\begin{array}{r}1.68 \\
0.36 \\
93 \\
\end{array}$ \\
\hline
\end{tabular}

Gage height, in feet, and discharge, in cubic feet per second, at indicated time, 1963

\begin{tabular}{|c|c|c|c|c|c|c|c|c|c|c|c|}
\hline Date & Hour & $\begin{array}{c}\text { Gage } \\
\text { helght }\end{array}$ & $\begin{array}{l}\text { Dis - } \\
\text { charge }\end{array}$ & Date & Hour & $\begin{array}{c}\text { Gage } \\
\text { he1ght }\end{array}$ & $\begin{array}{l}\text { Dis- } \\
\text { charge }\end{array}$ & Date & Hour & $\begin{array}{c}\text { Gage } \\
\text { helght }\end{array}$ & $\begin{array}{l}\text { Dis- } \\
\text { charge }\end{array}$ \\
\hline $\begin{array}{rr}\operatorname{Jan} . & 30 \\
31\end{array}$ & $\begin{array}{l}2400 \\
0900 \\
1000 \\
\end{array}$ & $\begin{array}{l}0 \\
0 \\
1.39 \\
\end{array}$ & $\begin{array}{r}0 \\
0 \\
27 \\
\end{array}$ & Jan. 31 & $\begin{array}{l}1100 \\
1200 \\
1300 \\
1700\end{array}$ & $\begin{array}{r}1.28 \\
1.38 \\
1.82 \\
.85 \\
\end{array}$ & $\begin{array}{l}23 \\
26 \\
40 \\
10\end{array}$ & Jan. 31 & $\begin{array}{l}1900 \\
2400\end{array}$ & $\begin{array}{r}0.62 \\
.45\end{array}$ & $\begin{array}{r}3.6 \\
.4\end{array}$ \\
\hline
\end{tabular}

11-1509.5. San Lorenzo Creek tributary near Bitterwater, Calif.

(Crest-stage station)

Location.--Lat $36^{\circ} 17^{\prime} 30^{\prime \prime}$, long $120^{\circ} 58^{\prime} 10^{\prime \prime}$, in $\mathrm{NE} \frac{1}{4} \operatorname{SW} \frac{1}{4}$ sec.11, T.19 S., R.9 E., at

culvert on Lonoak Road, 6.4 miles south of Bitterwater.

Drainage area. $--3.24 \mathrm{sq} \mathrm{mi}$.

Gage-height record.--Crest stages only. Altitude of gage is $820 \mathrm{ft}$ (from topographic map).

Discharge record.--Maximum discharge by computation of flow through culvert.

Maxima.--January-February 1963: Discharge, $18 \mathrm{cfs}$ Jan. 31 (gage height, $51.80 \mathrm{ft}$ ). 1960 to December 1962: Discharge not determined, occurred Feb. 15, 1962

(gage height, $51.37 \mathrm{ft}$ ). 
11-1513. San Lorenzo Creek below Bitterwater Creek, near King City, Calif.

Location:--Lat $36^{\circ} 16^{\prime} 05^{\prime \prime}$, long $121^{\circ} 03^{\prime} 50^{\prime \prime}$, in NW $\frac{1}{4}$ sec. 24 , T.19 S., R.8 E., on left bank 1.2 miles downstream from Bitterwater Creek, 5 miles northeast of King City, and 10 miles upstream from mouth.

Drainage area. $--233 \mathrm{sq} \mathrm{ml}$.

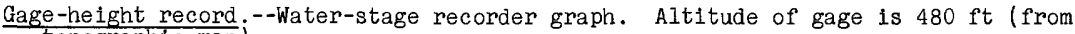
topographic map).

Discharge record.--Stage-discharge relation defined by current-meter measurements below $800 \mathrm{cf}$.

Maxima.--January-February 1963: Discharge, 2,130 cfs 0200 hours Feb. 10 (gage helght, $8.13 \mathrm{ft}$ ).

1958 to December 1962: Discharge, 2,050 cfs Feb. 9, 1962 (gage height, $8.02 \mathrm{ft}$, from floodmarks j.

Mean discharge, in cub1c feet per second, 1963

\begin{tabular}{|c|c|c|c|c|c|c|c|c|}
\hline Day & January & February & Day & January & February & Day & January & February \\
\hline $\begin{array}{c}1 \ldots \ldots \\
2 \ldots \ldots \\
3 \ldots \ldots \\
4 \ldots \ldots \\
5 \ldots \ldots \\
7 \ldots \ldots \\
8 \ldots \ldots \\
9 \ldots \ldots \\
10 \ldots \ldots\end{array}$ & $\begin{array}{l}0.2 \\
.2 \\
.2 \\
.2 \\
.2 \\
.2 \\
.2 \\
.2 \\
.2 \\
.2\end{array}$ & $\begin{array}{c}193 \\
33 \\
15 \\
10 \\
7.8 \\
7.0 \\
5.6 \\
4.9 \\
234 \\
518\end{array}$ & $\begin{array}{l}11 \ldots \ldots \\
12 \ldots \ldots \\
13 \ldots \ldots \\
14 \ldots \ldots \\
15 \ldots \ldots \\
16 \ldots \ldots \\
17 \ldots \ldots \\
18 \ldots \ldots \\
19 \ldots \ldots \\
20 \ldots \ldots\end{array}$ & $\begin{array}{l}0.2 \\
.2 \\
.2 \\
.2 \\
.2 \\
.2 \\
.2 \\
.2 \\
.2 \\
.2\end{array}$ & $\begin{array}{c}58 \\
24 \\
338 \\
138 \\
27 \\
19 \\
15 \\
12 \\
8.7 \\
7.0\end{array}$ & $\begin{array}{l}21 \ldots \ldots \\
22 \ldots \ldots \\
23 \ldots \ldots \\
24 \ldots \ldots \\
25 \ldots \ldots \\
26 \ldots \ldots \\
27 \ldots \ldots \\
25 \ldots \ldots \\
29 \ldots \ldots \\
30 \ldots \ldots \\
31 \ldots \ldots\end{array}$ & $\begin{array}{r}0.2 \\
.2 \\
.2 \\
.2 \\
.2 \\
.2 \\
.2 \\
.2 \\
.3 \\
4.4 \\
325\end{array}$ & $\begin{array}{r}5.2 \\
4.4 \\
3.3 \\
2.8 \\
2.2 \\
2.0 \\
1.8 \\
1.6 \\
--.--1 \\
-.--.-\end{array}$ \\
\hline $\begin{array}{l}\text { thly } \\
\text { toff, } \\
\text { loff, }\end{array}$ & $\begin{array}{l}\text { an di } \\
\text { Inch } \\
\text { acre }\end{array}$ & & & & & & $\begin{array}{r}10.8 \\
0.05 \\
665\end{array}$ & $\begin{array}{r}60.6 \\
0.27 \\
3,370\end{array}$ \\
\hline
\end{tabular}

Gage height, in feet, and discharge, in cubic feet per second, at indicated time, 1963

\begin{tabular}{|c|c|c|c|c|c|c|c|c|c|c|c|}
\hline Date & Hour & $\begin{array}{c}\text { Gage } \\
\text { height }\end{array}$ & $\begin{array}{c}\text { Dis- } \\
\text { charge }\end{array}$ & Date & Hour & $\begin{array}{c}\text { Gage } \\
\text { height }\end{array}$ & $\begin{array}{c}\text { Dis- } \\
\text { charge }\end{array}$ & Date & Hour & $\begin{array}{c}\text { Gage } \\
\text { height }\end{array}$ & $\begin{array}{c}\text { Dis- } \\
\text { charge }\end{array}$ \\
\hline $\begin{array}{r}\text { Jan. } 30 \\
31\end{array}$ & $\begin{array}{l}2400 \\
0700 \\
1000 \\
1100 \\
1500 \\
1500 \\
1600 \\
1700 \\
1900 \\
2100 \\
2400 \\
0200 \\
0500\end{array}$ & $\begin{array}{l}3.89 \\
3.93 \\
4.02 \\
4.58 \\
4.76 \\
5.93 \\
5.81 \\
6.11 \\
6.30 \\
6.10 \\
5.47 \\
5.12 \\
4.75\end{array}$ & $\begin{array}{r}16 \\
19 \\
26 \\
123 \\
188 \\
685 \\
650 \\
826 \\
940 \\
820 \\
507 \\
\\
342 \\
206\end{array}$ & Feb. 1 & $\begin{array}{l}0800 \\
1100 \\
1700 \\
2400 \\
\\
2400 \\
\\
0400 \\
0600 \\
1100 \\
1400 \\
1500 \\
1800 \\
1900 \\
2000\end{array}$ & $\begin{array}{l}4.54 \\
4.45 \\
4.73 \\
4.37 \\
3.54 \\
\\
3.54 \\
3.58 \\
3.59 \\
3.78 \\
3.76 \\
3.93 \\
5.45 \\
521\end{array}$ & $\begin{array}{r}148 \\
125 \\
198 \\
105 \\
4.9 \\
\\
4.9 \\
6.5 \\
7.0 \\
17 \\
16 \\
27 \\
494 \\
384\end{array}$ & Feb. 9 & $\begin{array}{l}2200 \\
2300 \\
2400 \\
\\
0100 \\
0200 \\
0200 \\
0300 \\
0400 \\
0500 \\
0800 \\
1100 \\
1600 \\
2200 \\
2400\end{array}$ & $\begin{array}{l}6.78 \\
7.58 \\
7.23 \\
8.01 \\
7.97 \\
8.13 \\
7.03 \\
6.30 \\
6.03 \\
5.35 \\
4.85 \\
4.44 \\
4.16 \\
4.12\end{array}$ & $\begin{array}{r}1,230 \\
1,750 \\
1,500 \\
2,050 \\
2,020 \\
2,130 \\
1,380 \\
940 \\
785 \\
460 \\
255 \\
148 \\
93 \\
87\end{array}$ \\
\hline
\end{tabular}

11-1518.7. Arroyo Seco near Greenfield, Calif.

Location.--Lat $36^{\circ} 14^{\prime} 15^{\prime \prime}$, long $121^{\circ} 28^{\prime} 50^{\prime \prime}$, in $\mathrm{NE} \frac{1}{4} \mathrm{SE} \frac{1}{4} \sec .36$, T.19 S., R.4 E., on right bank 0.6 mile downstream from Rocky Creek and 14.5 miles southwest of Greenfleld.

Drainage area. --113 so $\mathrm{mi}$.

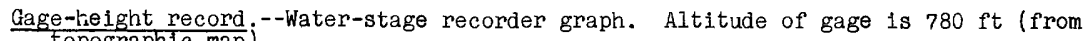
topographic map)

D1scharge record.--Stage-discharge relation defined by current-meter measurements.

Maxima.--January-February 1963: Discharge, 10,400 cfs 1300 hours Jan. 31 (gage helght, $11.35 \mathrm{ft}$ ).

1961 to December 1962: Discharge, 7,910 cfs Feb. 9, 1962 (gage height, 10.23 ft $)$, from rating curve extended above $960 \mathrm{cfs}$. 
Mean discharge, in cublc feet per second, 1963, of Arroyo Seco near Greenfield, Calif.

\begin{tabular}{|c|c|c|c|c|c|c|c|c|}
\hline Day & January & February & Day & January & February & Day & January & February \\
\hline $\begin{array}{l}1 \ldots \ldots \\
2 \ldots \ldots \\
3 \ldots \ldots \\
4 \ldots \ldots \\
5 \ldots \ldots \\
6 \ldots \ldots \\
8 \ldots \ldots \\
9 \ldots \ldots \\
0 \ldots \ldots\end{array}$ & $\begin{array}{l}22 \\
21 \\
21 \\
21 \\
20 \\
20 \\
20 \\
20 \\
20 \\
19\end{array}$ & $\begin{array}{r}4,980 \\
1,520 \\
915 \\
665 \\
524 \\
432 \\
373 \\
325 \\
677 \\
1,490\end{array}$ & $\begin{array}{l}11 \ldots \ldots \\
12 \ldots \ldots \\
13 \ldots \ldots \\
14 \ldots \ldots \\
15 \ldots \ldots \\
16 \ldots \ldots \\
17 \ldots \ldots \\
18 \ldots \ldots \\
19 \ldots \ldots \\
20 \ldots \ldots\end{array}$ & $\begin{array}{l}19 \\
19 \\
18 \\
18 \\
18 \\
18 \\
18 \\
18 \\
18 \\
17\end{array}$ & $\begin{array}{l}965 \\
690 \\
883 \\
725 \\
608 \\
524 \\
453 \\
404 \\
359 \\
325\end{array}$ & $\begin{array}{l}21 \ldots \ldots \\
22 \ldots \ldots \\
23 \ldots \ldots \\
24 \ldots \ldots \\
25 \ldots \ldots \\
26 \ldots \ldots \\
27 \ldots \ldots \\
28 \ldots \ldots \\
29 \ldots \ldots \\
30 \ldots \ldots \\
31 \ldots \ldots\end{array}$ & $\begin{array}{r}17 \\
17 \\
17 \\
17 \\
17 \\
17 \\
17 \\
17 \\
20 \\
3,760 \\
7,360\end{array}$ & $\begin{array}{r}293 \\
270 \\
248 \\
229 \\
211 \\
196 \\
186 \\
172 \\
--.-- \\
-----\end{array}$ \\
\hline $20 \mathrm{f}$ & cr & & & & & & $\begin{array}{r}376 \\
3.84 \\
23,130\end{array}$ & $\begin{array}{r}702 \\
6.46 \\
38,960 \\
\end{array}$ \\
\hline
\end{tabular}

Gage height, in feet, and discharge, in cublc feet per second, at indicated time, 1963

\begin{tabular}{|c|c|c|c|c|c|c|c|c|c|c|c|c|}
\hline Date & Hour & $\begin{array}{c}\text { Gage } \\
\text { helght }\end{array}$ & $\begin{array}{c}\text { Dis- } \\
\text { charge }\end{array}$ & Date & Hour & $\begin{array}{c}\text { Gage } \\
\text { he1ght }\end{array}$ & $\begin{array}{l}\text { Dis- } \\
\text { charge }\end{array}$ & Date & & Hour & $\begin{array}{c}\text { Gage } \\
\text { helght }\end{array}$ & $\begin{array}{l}\text { Dis- } \\
\text { charge }\end{array}$ \\
\hline $\begin{array}{r}29 \\
30\end{array}$ & $\begin{array}{l}2400 \\
0100 \\
0200 \\
0600 \\
1000 \\
1100 \\
1300 \\
1500 \\
1700 \\
2100 \\
2400\end{array}$ & $\begin{array}{r}2.27 \\
2.35 \\
4.30 \\
5.70 \\
7.35 \\
7.57 \\
7.23 \\
8.96 \\
8.84 \\
10.54 \\
9.40\end{array}$ & $\begin{array}{r}37 \\
44 \\
505 \\
1,300 \\
2,980 \\
3,260 \\
2,830 \\
5,390 \\
5,170 \\
8,590 \\
6,200\end{array}$ & Feb. 1 & $\begin{array}{l}0200 \\
0500 \\
1000 \\
1100 \\
1300 \\
1600 \\
1800 \\
2000 \\
2100 \\
2400 \\
0100\end{array}$ & $\begin{array}{r}10.10 \\
9.32 \\
10.80 \\
10.70 \\
11.35 \\
10.00 \\
9.30 \\
8.90 \\
8.90 \\
10.00 \\
10.60\end{array}$ & $\begin{array}{r}7,620 \\
6,060 \\
9,160 \\
8,940 \\
10,400 \\
7,400 \\
6,020 \\
5,340 \\
5,340 \\
7,400 \\
8,720\end{array}$ & Feb. & 1 & $\begin{array}{l}0200 \\
0500 \\
0700 \\
1000 \\
1400 \\
1800 \\
2400 \\
\\
0400 \\
0800 \\
1200 \\
1800 \\
2400\end{array}$ & $\begin{array}{r}10.75 \\
10.00 \\
9.35 \\
8.75 \\
7.92 \\
7.30 \\
6.50 \\
6.12 \\
5.82 \\
5.58 \\
5.29 \\
5.06\end{array}$ & $\begin{array}{l}9,050 \\
7,400 \\
6,110 \\
5,100 \\
3,840 \\
3,070 \\
2,250 \\
1,880 \\
1,640 \\
1,440 \\
1,240 \\
1,110\end{array}$ \\
\hline
\end{tabular}

11-1519.5. Sand Creek near Paraiso Springs, Calif.

(Crest-stage station)

Location.--Lat $36^{\circ} 15^{\prime} 48^{\prime \prime}$, long $121^{\circ} 25^{\prime} 48^{\prime \prime}$, in NW $\frac{1}{4}$ SE $\frac{1}{4}$ sec.21, T.19 S., R.5 E., at culvert on Jamesburg road, 5.8 miles southwest of Paraiso Springs.

Drainage area $--14.8 \mathrm{sq} \mathrm{mi}$.

Gage-height record.--No record, station destroyed. Altitude of gage is $720 \mathrm{ft}$ (f'rom topographic map).

Discharge record.--Maximum discharge by slope-area measurement.

Maxima.--January-February 1963: Discharge, 673 cfs Jan. 31.

i960 to December 1962: Discharge not determined, occurred Feb. 13, 1962 (gage height, $51.94 \mathrm{ft}^{\mathrm{t}}$ ).

11-1520. Arroyo Seco near Soledad, Calif.

Location.--Lat $36^{\circ} 16^{\prime} 50^{\prime \prime}$, long $121^{\circ} 19^{\prime} 20^{\prime \prime}$, in SW $\frac{1}{4} N E \frac{1}{4}$ sec.16, T.19 S., R. 6 E., on lef't bank just downstream drom bridge, 1.5 miles downstream from Vaquero Creek and 10 miles south of Soledad.

Drainage area. $--244 \mathrm{sq} \mathrm{mi}$.

Gage-height record --Water-stage recorder graph. Datum of gage is $342.20 \mathrm{ft}$ above mean sea level (Corps of Engineers bench mark).

Discharge record.--Stage-discharge relation defined by current-meter measurements below $12,000 \mathrm{cfs}$ and by slope-area measurement at $27,700 \mathrm{cfs}$.

Maxima.--January-February 1963: Discharge, 24,300 cf's 1530 hours Jan. 31 (gage height, $15.55 \mathrm{ft}$ ).

1901 to December 1962: Discharge, 28,300 cfs Apr. 3, 1958 (gage height, $14.40 \mathrm{ft}$, at datum $2.00 \mathrm{ft}^{\prime}$ higher), from rating curve extended above 12,000 cfs on basis of slope-area measurement at $27,700 \mathrm{cfs}$. 
Mean discharge, in cubic feet per second, 1963, of Arroyo Seco near Soledad, Calif.

\begin{tabular}{|c|c|c|c|c|c|c|c|c|}
\hline Day & January & February & Day & January & February & Day & January & February \\
\hline $\begin{array}{c}1 \ldots \ldots \\
2 \ldots \ldots \\
3 \ldots \ldots \\
4 \ldots \ldots \\
6 \ldots \ldots \\
7 \ldots \ldots \\
8 \ldots \ldots \\
9 \ldots \ldots \\
10 \ldots \ldots\end{array}$ & $\begin{array}{l}31 \\
29 \\
28 \\
28 \\
27 \\
26 \\
26 \\
25 \\
26 \\
26\end{array}$ & $\begin{array}{r}10,200 \\
2,700 \\
1,980 \\
1,490 \\
1,110 \\
830 \\
649 \\
522 \\
1,110 \\
2,920\end{array}$ & $\begin{array}{l}11 \ldots \ldots \\
12 \ldots \ldots \\
13 \ldots \ldots \\
14 \ldots \ldots \\
15 \ldots \ldots \\
16 \ldots \ldots \\
17 \ldots \ldots \\
18 \ldots \ldots \\
19 \ldots \ldots \\
20 \ldots \ldots\end{array}$ & $\begin{array}{l}25 \\
25 \\
24 \\
23 \\
23 \\
23 \\
23 \\
22 \\
22 \\
22\end{array}$ & $\begin{array}{r}1,740 \\
1,230 \\
1,600 \\
1,340 \\
1,050 \\
830 \\
667 \\
515 \\
440 \\
394\end{array}$ & $\begin{array}{l}21 \ldots \ldots \\
22 \ldots \ldots \\
23 \ldots \ldots \\
24 \ldots \ldots \\
25 \ldots \ldots \\
26 \ldots \ldots \\
27 \ldots \ldots \\
28 \ldots \ldots \\
29 \ldots \ldots \\
30 \ldots \ldots \\
31 \ldots \ldots\end{array}$ & $\begin{array}{r}21 \\
21 \\
20 \\
20 \\
20 \\
20 \\
20 \\
20 \\
20 \\
3,580 \\
14,500\end{array}$ & $\begin{array}{r}350 \\
320 \\
293 \\
270 \\
250 \\
233 \\
220 \\
208 \\
----- \\
------\end{array}$ \\
\hline $\begin{array}{l}\text { Monthly } \\
\text { Runoff, } \\
\text { Runoff, }\end{array}$ & $\begin{array}{l}\text { mean disc } \\
\text { in Inches } \\
\text { in acre-f }\end{array}$ & $=1$ & eet & 2. & & & $\begin{array}{r}605 \\
2.86 \\
37,220 \\
\end{array}$ & $\begin{array}{r}1,266 \\
5,40 \\
70,340\end{array}$ \\
\hline
\end{tabular}

Gage he1ght, In feet, and discharge, in cub1c feet per second, at ind1cated t1me, 1963

\begin{tabular}{|c|c|c|c|c|c|c|c|c|c|c|c|}
\hline Date & Hour & $\begin{array}{c}\text { Gage } \\
\text { helght }\end{array}$ & $\begin{array}{c}\text { D1s- } \\
\text { charge }\end{array}$ & Date & Hour & $\begin{array}{c}\text { Gage } \\
\text { helght }\end{array}$ & $\begin{array}{c}\text { D1s- } \\
\text { charge }\end{array}$ & Date & Hour & $\begin{array}{c}\text { Gage } \\
\text { he1ght }\end{array}$ & $\begin{array}{l}\text { D1s- } \\
\text { charge }\end{array}$ \\
\hline $\begin{array}{r}\operatorname{Jan} .29 \\
30\end{array}$ & $\begin{array}{l}2400 \\
0300 \\
0400 \\
0500 \\
0700 \\
0700 \\
0800 \\
1000 \\
1200 \\
1400 \\
1600 \\
1800 \\
2000 \\
2200 \\
2400 \\
0300\end{array}$ & $\begin{array}{r}3.08 \\
3.13 \\
3.50 \\
3.85 \\
4.12 \\
5.50 \\
7.27 \\
8.15 \\
8.80 \\
9.55 \\
9.35 \\
10.50 \\
11.15 \\
12.45 \\
13.53 \\
12.35\end{array}$ & $\begin{array}{r}26 \\
29 \\
60 \\
96 \\
127 \\
370 \\
1,080 \\
1,700 \\
2,400 \\
3,450 \\
3,150 \\
5,260 \\
6,950 \\
11,200 \\
15,500 \\
10,800\end{array}$ & Feb. 1 & $\begin{array}{l}0500 \\
0600 \\
0800 \\
1000 \\
1200 \\
1400 \\
1530 \\
1700 \\
1900 \\
2100 \\
2300 \\
2400 \\
\\
0200 \\
0300 \\
0400 \\
0700 \\
0900\end{array}$ & $\begin{array}{l}12.95 \\
13.02 \\
12.18 \\
12.65 \\
13.70 \\
14.80 \\
15.55 \\
14.60 \\
13.40 \\
12.50 \\
12.03 \\
12.13 \\
13.05 \\
13.70 \\
14.24 \\
13.65 \\
12.93\end{array}$ & $\begin{array}{r}13,200 \\
13,500 \\
10,200 \\
12,000 \\
16,200 \\
20,900 \\
24,300 \\
20,000 \\
15,000 \\
11,400 \\
9,710 \\
10,100 \\
13,600 \\
16,200 \\
18,400 \\
16,000 \\
13,100\end{array}$ & Feb. & $\begin{array}{l}1100 \\
1200 \\
1400 \\
1600 \\
1900 \\
2200 \\
2400 \\
\\
0600 \\
1200 \\
1600 \\
1900 \\
2200 \\
2400\end{array}$ & $\begin{array}{r}12.22 \\
12.37 \\
11.52 \\
11.00 \\
10.52 \\
10.08 \\
9.84 \\
9.38 \\
9.18 \\
9.12 \\
9.08 \\
8.97 \\
8.98\end{array}$ & $\begin{array}{r}10,400 \\
10,900 \\
8,060 \\
6,500 \\
5,300 \\
4,310 \\
3,830 \\
\\
2,910 \\
2,520 \\
2,430 \\
2,370 \\
2,210 \\
2,220\end{array}$ \\
\hline
\end{tabular}

11-1525. Salinas River near Spreckels, Calif.

Location.--Lat $36^{\circ} 37^{\prime} 50^{\prime \prime}$, long $121^{\circ} 40^{\prime} 40^{\prime \prime}$, in El Toro Grant, on first pier near left end of bridge on Salinas-Monterey highway, 0.5 mile upstream from Toro

Creek, 2 miles west of Spreckels, Monterey County, and 4 miles south of Salinas.

Drainage area. $--4,156 \mathrm{sq} \mathrm{mi}$.

Gage-height record.--Water-stage recorder graph. Datum of gage is $19.87 \mathrm{ft}$ above mean sea leve1, datum of 1929, supplementary adjustment of 1955 .

Discharge record.--Stage-discharge relation defined by current-meter measurements.

Maxima.--January-February 1963: Discharge, 7,570 cf's 0700 hours Feb. 1 (gage height, $15.22 \mathrm{ft}$ ).

1900-1901, 1929 to December 1962: Discharge, 75,000 cfs Feb. 12, 1938 (gage height, $25.0^{\prime} \mathrm{ft}$ ), from rating curve extended above $26,000 \mathrm{cfs}$ on basis of velocity-area studies; maximum gage height, $26.85 \mathrm{ft}$ Jan. 16, 1952 , from floodmarks.

Remarks.-Flow slightly regulated by Nacimiento Reservoir (usable capacity, 340,000 acre-ft).

Mean discharge, in cub1c feet per second, 1963

\begin{tabular}{|c|c|c|c|c|c|c|c|c|}
\hline Day & January & February & Day & January & February & Day & January & February \\
\hline $\begin{array}{c}1 \ldots \ldots \\
2 \ldots \ldots \\
3 \ldots \ldots \\
4 \ldots \ldots \\
5 \ldots \ldots \\
7 \ldots \ldots \\
8 \ldots \ldots \\
9 \ldots \ldots \\
10 \ldots \ldots\end{array}$ & $\begin{array}{l}5.2 \\
5.2 \\
5.1 \\
5.0 \\
4.9 \\
4.9 \\
5.0 \\
4.8 \\
4.7 \\
4.7\end{array}$ & $\begin{array}{r}6,590 \\
6,250 \\
5,030 \\
2,780 \\
1,810 \\
1,300 \\
1,060 \\
876 \\
760 \\
921\end{array}$ & $\begin{array}{l}11 \ldots \ldots \\
12 \ldots \ldots \\
13 \ldots \ldots \\
14 \ldots \ldots \\
15 \ldots \ldots \\
16 \ldots \ldots \\
17 \ldots \ldots \\
18 \ldots \ldots \\
19 \ldots \ldots \\
20 \ldots \ldots\end{array}$ & $\begin{array}{l}4.4 \\
4.4 \\
4.3 \\
4.3 \\
4.2 \\
4.1 \\
3.8 \\
3.7 \\
3.6 \\
3.3\end{array}$ & $\begin{array}{r}2,730 \\
2,790 \\
2,630 \\
2,350 \\
2,110 \\
1,820 \\
1,400 \\
1,090 \\
939 \\
790\end{array}$ & $\begin{array}{l}21 \ldots \ldots \\
22 \ldots \ldots \\
23 \ldots \ldots \\
24 \ldots \ldots \\
25 \ldots \ldots \\
26 \ldots \ldots \\
27 \ldots \ldots \\
28 \ldots \ldots \\
29 \ldots \ldots \\
30 \ldots \ldots \\
31 \ldots \ldots\end{array}$ & $\begin{array}{r}3.4 \\
3.2 \\
2.9 \\
3.1 \\
2.9 \\
2.8 \\
2.7 \\
2.7 \\
2.8 \\
4.3 \\
1,280\end{array}$ & $\begin{array}{r}724 \\
688 \\
610 \\
526 \\
470 \\
425 \\
384 \\
351 \\
-.--- \\
-.--.\end{array}$ \\
\hline noff, & $\begin{array}{l}\text { Inche } \\
\text { acre- }\end{array}$ & & & & & & $\begin{array}{r}45.2 \\
0.01 \\
2,780\end{array}$ & $\begin{array}{r}1,793 \\
0.44 \\
99,580\end{array}$ \\
\hline
\end{tabular}


Gage helght, in feet, and discharge, in cublc feet per second, at Indicated time, I963, of Salinas River near Spreckels, Calif.

\begin{tabular}{|c|c|c|c|c|c|c|c|c|c|c|c|}
\hline Date & Hour & $\begin{array}{c}\text { Gage } \\
\text { helght }\end{array}$ & $\begin{array}{l}\text { Dis- } \\
\text { charge }\end{array}$ & Date & Hour & $\begin{array}{c}\text { Gage } \\
\text { he1ght }\end{array}$ & $\begin{array}{l}\text { D1s- } \\
\text { charge }\end{array}$ & Date & Hour & $\begin{array}{c}\text { Gage } \\
\text { helght }\end{array}$ & $\begin{array}{c}\text { D1s- } \\
\text { charge }\end{array}$ \\
\hline an. $\begin{array}{r}30 \\
31\end{array}$ & $\begin{array}{l}2400 \\
0100 \\
0900 \\
1300 \\
1700 \\
1700 \\
1800 \\
1900 \\
2100 \\
2400\end{array}$ & $\begin{array}{r}6.10 \\
6.10 \\
6.09 \\
6.14 \\
6.14 \\
7.95 \\
11.00 \\
12.00 \\
12.65 \\
13.03\end{array}$ & $\begin{array}{r}6.4 \\
6.4 \\
6.1 \\
7.8 \\
7.8 \\
355 \\
2,900 \\
4,200 \\
5,110 \\
5,650\end{array}$ & Feb. 2 & $\begin{array}{l}0400 \\
0600 \\
0700 \\
0800 \\
1000 \\
1300 \\
1400 \\
1500 \\
1900 \\
2100 \\
2400\end{array}$ & $\begin{array}{l}14.76 \\
15.16 \\
15.22 \\
15.17 \\
14.73 \\
14.00 \\
13.94 \\
14.11 \\
14.86 \\
14.91 \\
14.62\end{array}$ & $\begin{array}{l}6,820 \\
7,470 \\
7,570 \\
7,490 \\
6,770 \\
5,600 \\
5,520 \\
5,780 \\
6,980 \\
7,060 \\
6,590\end{array}$ & Feb. 2 & $\begin{array}{l}0500 \\
0700 \\
0800 \\
1000 \\
1300 \\
1500 \\
1700 \\
2100 \\
2400\end{array}$ & $\begin{array}{l}12.72 \\
12.70 \\
12.80 \\
13.33 \\
13.96 \\
14.00 \\
13.92 \\
13.38 \\
13.23\end{array}$ & $\begin{array}{l}5,210 \\
5,180 \\
5,320 \\
6,130 \\
7,140 \\
7,200 \\
7,070 \\
6,210 \\
5,970\end{array}$ \\
\hline Feb. $\quad 2$ & 0200 & 14.35 & 6,160 & 2 & 0300 & 13.11 & 5,780 & & & & \\
\hline
\end{tabular}

\section{MORO COJO SLOUGH BASIN}

11-1527. Moro Cojo Slough tributary near Castroville, Calif.

(Crest-stage station)

Location.--Iat $36^{\circ} 46^{\prime} 30^{\prime \prime}$, long $121^{\circ} 43^{\prime} 05^{\prime \prime}$, In Bolsa de las Escorpinas Grant, at culvert on State Highway 156, 1.8 miles northeast of Castroville.

Drainage area. $--0.11 \mathrm{sq} \mathrm{mi}$.

Gage-helght record.--Crest stages only. Alt1tude of gage is 35 ft (from topographic map).

Discharge record.--Maximum discharge by computation of flow through culvert.

Maxima.--January-February 1963: Discharge, 12 cfs Jan. 31 (gage helght, 51.47 ft). 1960 to December 1962: Discharge not determined, occurred Feb. 13, 1962

(gage helght, $50.62 \mathrm{ft}$ ).

\section{PAJARO RIVER BASIN}

11-1529. Cedar Creek near Bell Station, Calif.

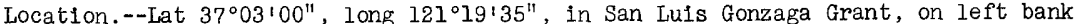
$0.5 \mathrm{mile}$ upstream from Hagerman Canyon and $1.3 \mathrm{miles}$ northwest of Bell Station, Santa Clara County.

Dra inage area. $--12.8 \mathrm{sq} \mathrm{mi}$.

Gage-helght record.--Water-stage recorder graph. Altitude of gage is $390 \mathrm{ft}$ (from topographic mapi.

Discharge record.--Stage-discharge relation defined by current-meter measurements below $260 \mathrm{cfs}$.

Maxima.--January-February 1963: Discharge, 3,490 cfs 1300 hours Jan. 31 (gage height, $6.85 \mathrm{ft}$ ).

1961 to December 1962: Discharge, $760 \mathrm{cfs}$ Feb. 15, 1962 (gage height, $4.30 \mathrm{ft}$ ).

Mean discharge, in cub1c feet per second, 1963

\begin{tabular}{|c|c|c|c|c|c|c|c|c|}
\hline Day & January & February & Day & January & February & Day & January & February \\
\hline $\begin{array}{c}\ldots \ldots \\
2 \ldots \ldots \\
3 \ldots \ldots \\
4 \ldots \ldots \\
5 \ldots \ldots \\
6 \ldots \ldots \\
8 \ldots \ldots \\
9 \ldots \ldots \\
10 \ldots \ldots\end{array}$ & $\begin{array}{l}0 \\
0 \\
0 \\
0 \\
0 \\
0 \\
0 \\
0 \\
0 \\
0\end{array}$ & $\begin{array}{c}447 \\
40 \\
13 \\
5.8 \\
3.3 \\
2.4 \\
1.8 \\
1.4 \\
20 \\
34\end{array}$ & $\begin{array}{l}11 \ldots \ldots \\
12 \ldots \ldots \\
13 \ldots \ldots \\
14 \ldots \ldots \\
15 \ldots \ldots \\
16 \ldots \ldots \\
17 \ldots \ldots \\
18 \ldots \ldots \\
19 \ldots \ldots \\
20 \ldots \ldots\end{array}$ & $\begin{array}{l}0 \\
0 \\
0 \\
0 \\
0 \\
0 \\
0 \\
0 \\
0 \\
0\end{array}$ & $\begin{array}{r}12 \\
31 \\
176 \\
53 \\
22 \\
13 \\
8.3 \\
5.8 \\
4.4 \\
3.7\end{array}$ & $\begin{array}{l}21 \ldots \ldots \\
22 \ldots \ldots \\
23 \ldots \ldots \\
24 \ldots \ldots \\
25 \ldots \ldots \\
26 \ldots \ldots \\
27 \ldots \ldots \\
28 \ldots \ldots \\
29 \ldots \ldots \\
30 \ldots \ldots \\
31 \ldots \ldots\end{array}$ & $\begin{array}{r}0 \\
0 \\
0 \\
0 \\
0 \\
0 \\
0 \\
0 \\
0 \\
45 \\
832\end{array}$ & $\begin{array}{r}3.3 \\
2.9 \\
2.4 \\
2.2 \\
2.1 \\
1.9 \\
1.8 \\
1.7 \\
----- \\
------\end{array}$ \\
\hline $\begin{array}{l}\text { inor', } \\
\text { anoff, }\end{array}$ & acre-1 & & & & & & $\begin{array}{r}28.3 \\
2.55 \\
1,740\end{array}$ & $\begin{array}{r}32.7 \\
2.66 \\
1,820 \\
\end{array}$ \\
\hline
\end{tabular}


Gage height, in feet, and discharge, in cublc feet per second, at Indicated time, 1963, of Cedar Creek near Bell Station, Callf.

\begin{tabular}{|c|c|c|c|c|c|c|c|c|c|c|c|}
\hline Date & Hour & $\begin{array}{c}\text { Gage } \\
\text { height }\end{array}$ & $\begin{array}{c}\text { D1s- } \\
\text { charge }\end{array}$ & Date & Hour & $\begin{array}{c}\text { Gage } \\
\text { height }\end{array}$ & $\begin{array}{c}\text { D1s - } \\
\text { charge }\end{array}$ & Date & Hour & $\begin{array}{c}\text { Gage } \\
\text { height }\end{array}$ & $\begin{array}{c}\text { D1s- } \\
\text { charge }\end{array}$ \\
\hline $\begin{array}{r}\text { Jan. } 29 \\
30\end{array}$ & $\begin{array}{l}2400 \\
1200 \\
1700 \\
1800 \\
2000 \\
2100 \\
2200 \\
2400 \\
\\
\\
0200 \\
0300\end{array}$ & $\begin{array}{l}1.26 \\
1.40 \\
1.38 \\
2.11 \\
3.14 \\
3.12 \\
3.37 \\
2.98 \\
2.81 \\
3.33\end{array}$ & $\begin{array}{c}0.3 \\
1.1 \\
1.0 \\
25 \\
192 \\
186 \\
264 \\
151 \\
113 \\
253\end{array}$ & Jan. 31 & $\begin{array}{l}0700 \\
1000 \\
1100 \\
1200 \\
1300 \\
1400 \\
1500 \\
1600 \\
1800 \\
1900 \\
2000 \\
2100\end{array}$ & $\begin{array}{l}2.89 \\
3.86 \\
3.67 \\
4.77 \\
6.85 \\
4.77 \\
4.34 \\
4.30 \\
3.55 \\
3.40 \\
3.42 \\
5.00\end{array}$ & $\begin{array}{r}130 \\
480 \\
390 \\
1,070 \\
3,490 \\
1,150 \\
838 \\
810 \\
410 \\
350 \\
358 \\
1,340\end{array}$ & Jan. 31 & $\begin{array}{l}2200 \\
2300 \\
2400 \\
0200 \\
0400 \\
0700 \\
1200 \\
1800 \\
2400\end{array}$ & $\begin{array}{l}6.65 \\
6.23 \\
5.50 \\
4.86 \\
4.21 \\
3.86 \\
3.16 \\
2.64 \\
2.39\end{array}$ & $\begin{array}{r}3,210 \\
2,660 \\
1,820 \\
1,220 \\
747 \\
550 \\
262 \\
121 \\
76\end{array}$ \\
\hline
\end{tabular}

11-1530. Pacheco Creek near Dunneville, Calif.

Location.--Lat $36^{\circ} 58^{\prime} 50^{\prime \prime}$, long $121^{\circ} 22^{\prime} 45^{\prime \prime}$, in Ausaymas y San Felipe Grant, on right bank $350 \mathrm{ft}$ downstream from private road bridge and 3.3 miles northeast of Dunneville, Santa Clara County.

Drainage area. $--146 \mathrm{sq} \mathrm{mi}$.

Gage-height record.--Water-stage recorder graph, except 0200 to 1000 hours Feb. 1 , for which graph was reconstructed on basis of outside high-water mark. Datum of gage is $230.70 \mathrm{ft}$ above mean sea level, datum of 1947.

Discharge record.--Stage-discharge relation defined by current-meter measurements below 1,400 cfs and by slope-area measurement at 12,600 cf8.

Maxima.--January-February 1963: Discharge, 8,900 cfs 0500 hours Feb. I (gage height, $17.7 \mathrm{ft}$ ).

1940 to December 1962: Discharge, 12,600 cfs Dec. 23, 1955 (gage height, $21.0 \mathrm{ft}$, from floodmarks), from rating curve extended above 820 cfs on basis of slope-area measurement of maximum flow.

Remarks.--Flow regulated by Pacheco Lake (capacity, 6,150 acre-ft).

Mean discharge, in cub1c feet per second, 1963

\begin{tabular}{|c|c|c|c|c|c|c|c|c|}
\hline Day & January & February & Day & January & February & Day & January & February \\
\hline $\begin{array}{c}1 \ldots \ldots \\
2 \ldots \ldots \\
4 \ldots \ldots \\
5 \ldots \ldots \\
6 \ldots \ldots \\
7 \ldots \ldots \\
9 \ldots \ldots \\
10 \ldots \ldots\end{array}$ & $\begin{array}{l}0 \\
0 \\
0 \\
0 \\
0 \\
0 \\
0 \\
0 \\
0 \\
0\end{array}$ & $\begin{array}{r}3,630 \\
513 \\
199 \\
98 \\
60 \\
39 \\
27 \\
19 \\
56 \\
395\end{array}$ & $\begin{array}{l}11 \ldots \ldots \\
12 \ldots \ldots \\
13 \ldots \ldots \\
14 \ldots \ldots \\
15 \ldots \ldots \\
16 \ldots \ldots \\
17 \ldots \ldots \\
18 \ldots \ldots \\
19 \ldots \ldots \\
20 \ldots \ldots\end{array}$ & $\begin{array}{l}0 \\
0 \\
0 \\
0 \\
0 \\
0 \\
0 \\
0 \\
0 \\
0\end{array}$ & $\begin{array}{r}134 \\
162 \\
1,180 \\
491 \\
211 \\
129 \\
92 \\
67 \\
52 \\
41\end{array}$ & $\begin{array}{l}21 \ldots \ldots \\
22 \ldots \ldots \\
23 \ldots \ldots \\
24 \ldots \ldots \\
25 \ldots \ldots \\
26 \ldots \ldots \\
27 \ldots \ldots \\
28 \ldots \ldots \\
29 \ldots \ldots \\
30 \ldots \ldots \\
31 \ldots \ldots\end{array}$ & $\begin{array}{r}0 \\
0 \\
0 \\
0 \\
0 \\
0 \\
0 \\
0 \\
0 \\
0 \\
549\end{array}$ & 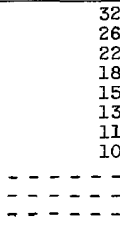 \\
\hline $\begin{array}{l}\text { Ionthly } \\
\text { tunoff', } \\
\text { tunoff', }\end{array}$ & \multicolumn{6}{|c|}{ 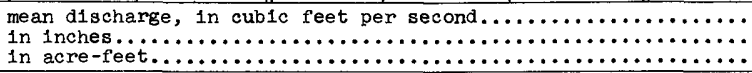 } & $\begin{array}{r}17.7 \\
0.14 \\
1,090\end{array}$ & $\begin{array}{r}276 \\
1.97 \\
15,360 \\
\end{array}$ \\
\hline
\end{tabular}

Gage he1ght, in feet, and discharge, in cublc feet per second, at indicated time, 1963

\begin{tabular}{|c|c|c|c|c|c|c|c|c|c|c|c|}
\hline Date & Hour & $\begin{array}{c}\text { Gage } \\
\text { helght }\end{array}$ & $\begin{array}{l}\text { D1s- } \\
\text { charge }\end{array}$ & Date & Hour & $\begin{array}{c}\text { Gage } \\
\text { helght }\end{array}$ & $\begin{array}{c}\text { D1s- } \\
\text { charge }\end{array}$ & Date & Hour & $\begin{array}{c}\text { Gage } \\
\text { helght }\end{array}$ & $\begin{array}{c}\text { Dis - } \\
\text { charge }\end{array}$ \\
\hline $\begin{array}{r}30 \\
31\end{array}$ & $\begin{array}{l}2400 \\
1100 \\
1200 \\
1300 \\
1400 \\
1500 \\
1600 \\
1700 \\
1900 \\
2200\end{array}$ & $\begin{array}{c}- \\
- \\
5.30 \\
8.12 \\
8.65 \\
10.42 \\
9.70 \\
8.55 \\
7.40 \\
6.73\end{array}$ & $\begin{array}{r}0 \\
0 \\
0 \\
93 \\
1,090 \\
1,370 \\
2,500 \\
2,000 \\
1,310 \\
745 \\
469\end{array}$ & $\begin{array}{l}\text { Jan. } 31 \\
\text { Feb. } 1\end{array}$ & $\begin{array}{l}2300 \\
2400 \\
0100 \\
0200 \\
0300 \\
0400 \\
0500 \\
0600 \\
0800 \\
0900\end{array}$ & $\begin{array}{r}7.12 \\
8.80 \\
9.75 \\
13.10 \\
14.95 \\
16.50 \\
17.70 \\
16.60 \\
14.85 \\
14.05\end{array}$ & $\begin{array}{r}623 \\
1,460 \\
2,040 \\
4,520 \\
6,160 \\
7,700 \\
8,900 \\
7,800 \\
6,070 \\
5,350\end{array}$ & Feb. 1 & $\begin{array}{l}1000 \\
1200 \\
1400 \\
1600 \\
1900 \\
2400 \\
\\
0600 \\
1200 \\
1800 \\
2400\end{array}$ & $\begin{array}{r}13.00 \\
11.70 \\
10.67 \\
9.40 \\
8.50 \\
7.90 \\
7.17 \\
6.66 \\
6.35 \\
6.10\end{array}$ & $\begin{array}{r}4,440 \\
3,400 \\
2,680 \\
1,820 \\
1,280 \\
980 \\
\\
643 \\
444 \\
342 \\
267 \\
\end{array}$ \\
\hline
\end{tabular}


11-1534.8. Chesbro Reservoir near Morgan Hill, Calif.

Location.--Lat $37^{\circ} 07^{\prime} 00^{\prime \prime}$, long $121^{\circ} 41^{\prime} 34^{\prime \prime}$, near southwest boundary of 0 jo de Agua de la Coche Grant, at left end of dam on Llagas Creek, 2.5 miles west of Morgan Hill, Santa Clara County.

Drainage area. $--19.4 \mathrm{sq} \mathrm{ml}$.

Gage-helght record.--Staff gage read once da1ly, except Jan. 4, 6, 7, 13-17, 19, $21,23-27$, Feb. 5, 16 . Datum of gage is at mean sea level (levels by South Santa Clara Valley Water Conservation District).

Contents record.--Contents computed from capacity table dated Oct. 20, 1955. Contents for periods of no gage-helght record were estimated.

Maxima.--January-February 1963: Contents, 7,840 acre-ft 1200 hours Feb. I (elevation, $526.34 \mathrm{ft}$ ).

1955 to December 1962: Contents observed, 7,950 acre-ft Apr. 3, 1958 (elevation, $526.8 \mathrm{ft})$.

Remarks.--Reservoir is formed by earth and rockfill dam completed in 1955 . Capac1ty, 7,500 acre-ft between elevations 465 (elevation of outlet gates) and 525 ft' (crest of spillway). Records furmished by South Santa Clara Valley Water Conservation District.

Elevation, in feet, and contents, in acre-feet, at 0800 hours, 1963

\begin{tabular}{|c|c|c|c|c|c|c|c|c|c|}
\hline \multirow{2}{*}{ Day } & \multicolumn{2}{|c|}{ January } & \multicolumn{2}{|c|}{ February } & \multirow{2}{*}{ Day } & \multicolumn{2}{|c|}{ January } & \multicolumn{2}{|c|}{ February } \\
\hline & Elevation & Contents & Elevation & Contents & & Elevation & Contents & Elevation & Contents \\
\hline $\begin{array}{r}1 \\
2 \\
3 \\
4 \\
5 \\
6 \\
7 \\
8 \\
9 \\
10 \\
11 \\
12 \\
13 \\
14 \\
15\end{array}$ & $\begin{array}{c}479.1 \\
479.2 \\
479.3 \\
- \\
479.4 \\
- \\
- \\
479.6 \\
479.6 \\
479.7 \\
479.8 \\
479.8 \\
- \\
- \\
-\end{array}$ & $\begin{array}{l}446 \\
452 \\
458 \\
461 \\
464 \\
468 \\
472 \\
476 \\
476 \\
482 \\
488 \\
488 \\
490 \\
492 \\
494\end{array}$ & $\begin{array}{c}526.3 \\
526.1 \\
526.0 \\
525.6 \\
- \\
525.5 \\
525.5 \\
525.5 \\
525.4 \\
525.4 \\
525.4 \\
525.3 \\
525.5 \\
525.5 \\
525.4\end{array}$ & $\begin{array}{l}7,820 \\
7,780 \\
7,750 \\
7,650 \\
7,640 \\
7,620 \\
7,620 \\
7,620 \\
7,600 \\
7,610 \\
7,600 \\
7,580 \\
7,620 \\
7,620 \\
7,600\end{array}$ & $\begin{array}{l}16 \\
17 \\
18 \\
19 \\
20 \\
21 \\
22 \\
23 \\
24 \\
25 \\
26 \\
27 \\
28 \\
29 \\
30 \\
31\end{array}$ & $\begin{array}{c}- \\
- \\
480.0 \\
- \\
480.1 \\
\overline{-} \\
480.1 \\
- \\
- \\
- \\
- \\
- \\
480.3 \\
480.3 \\
481.4 \\
510.0\end{array}$ & $\begin{array}{r}496 \\
498 \\
500 \\
503 \\
506 \\
506 \\
506 \\
508 \\
510 \\
512 \\
514 \\
516 \\
515 \\
518 \\
584 \\
4,300\end{array}$ & $\begin{array}{c}- \\
525.1 \\
524.9 \\
524.6 \\
524.4 \\
524.0 \\
523.5 \\
523.3 \\
522.4 \\
522.4 \\
522.6 \\
521.6 \\
520.7 \\
- \\
- \\
-\end{array}$ & $\begin{array}{c}7,560 \\
7,520 \\
7,480 \\
7,410 \\
7,360 \\
7,280 \\
7,170 \\
7,130 \\
6,930 \\
6,930 \\
6,970 \\
6,750 \\
6,550 \\
- \\
- \\
-\end{array}$ \\
\hline 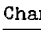 & in conte & $\mathrm{s}$, in a & - feet & & & - & $+3,860$ & - & $+2,250$ \\
\hline
\end{tabular}

11-1535. Llagas Creek near Morgan Hill, Calif.

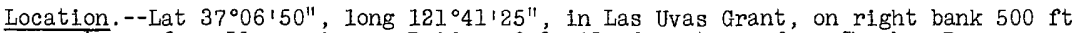
upstream from Llagas Avenue Bridge, 0.3 mile downstream from Chesbro Dam,

0.3 mile upstream from small tributary, and 2.3 miles west of Morgan Hili, Santa Clara County.

Drainage area. $--19.6 \mathrm{sq} \mathrm{m} 1$.

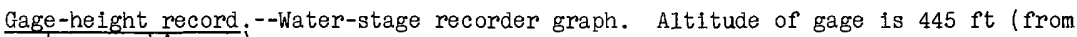
topographic map).

Discharge record. --Stage-discharge relation defined by current-meter measurements .

Maxima --January-February 1963: Discharge, 906 cfs 1100 hours Feb. I (gage height, $4.51 \mathrm{ft}$ )

1951 to December 1962: Discharge, 3,190 cfs Apr. 2, 1958 (gage helght,

$8.45 \mathrm{ft}$ ), from rating curve extended above $1,600 \mathrm{cfs}$ on bas is of computation of maximum flow over dam.

Remarks.--Flow regulated by Chesbro Reservolr (see station 11-1534.8). 
Mean discharge, in cubic feet per second, 1963, of Llagas Creek near Morgan H1ll, Cal1f.

\begin{tabular}{|c|c|c|c|c|c|c|c|c|}
\hline Day & January & February & Day & January & February & Day & January & February \\
\hline $\begin{array}{c}\ldots \ldots \\
2 \ldots \ldots \\
3 \ldots \ldots \\
4 \ldots \ldots \\
5 \ldots \ldots \\
6 \ldots \ldots \\
7 \ldots \ldots \\
9 \ldots \ldots \\
10 \ldots \ldots\end{array}$ & $\begin{array}{l}1.0 \\
.7 \\
.6 \\
.5 \\
.7 \\
.7 \\
.7 \\
.7 \\
.7 \\
.7\end{array}$ & $\begin{array}{r}566 \\
403 \\
198 \\
131 \\
96 \\
75 \\
60 \\
52 \\
68 \\
91\end{array}$ & $\begin{array}{l}11 \ldots \ldots \\
12 \ldots \ldots \\
13 \ldots \ldots \\
14 \ldots \ldots \\
15 \ldots \ldots \\
16 \ldots \ldots \\
17 \ldots \ldots \\
18 \ldots \ldots \\
19 \ldots \ldots \\
20 \ldots \ldots\end{array}$ & $\begin{array}{l}0.7 \\
1.1 \\
1.1 \\
1.1 \\
1.1 \\
1.1 \\
1.1 \\
1.1 \\
1.1 \\
1.1\end{array}$ & $\begin{array}{r}84 \\
84 \\
118 \\
106 \\
89 \\
83 \\
83 \\
83 \\
83 \\
83\end{array}$ & $\begin{array}{l}21 \ldots \ldots \\
22 \ldots \ldots \\
23 \ldots \ldots \\
24 \ldots \ldots \\
25 \ldots \ldots \\
26 \ldots \ldots \\
27 \ldots \ldots \\
28 \ldots \ldots \\
29 \ldots \ldots \\
30 \ldots \ldots \\
31 \ldots \ldots\end{array}$ & $\begin{array}{l}1.1 \\
1.0 \\
1.0 \\
1.0 \\
1.0 \\
1.0 \\
1.0 \\
1.0 \\
1.1 \\
11 \\
24\end{array}$ & $\begin{array}{r}83 \\
83 \\
83 \\
83 \\
83 \\
83 \\
82 \\
82 \\
\ldots-\ldots \\
-\ldots-\ldots\end{array}$ \\
\hline \multicolumn{7}{|c|}{ 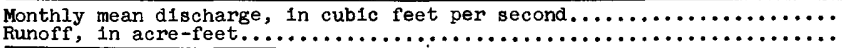 } & $\begin{array}{r}1.99 \\
123\end{array}$ & $\begin{array}{r}118 \\
6,540\end{array}$ \\
\hline
\end{tabular}

Gage height, in feet, and discharge, in cublc feet per second, at indicated time, 1963

\begin{tabular}{|c|c|c|c|c|c|c|c|c|c|c|c|}
\hline Date & Hour & $\begin{array}{c}\text { Gage } \\
\text { he1ght }\end{array}$ & $\begin{array}{l}\text { Dis- } \\
\text { charge }\end{array}$ & Date & Hour & $\begin{array}{c}\text { Gage } \\
\text { helght }\end{array}$ & $\begin{array}{c}\text { D1s- } \\
\text { charge }\end{array}$ & Date & Hour & $\begin{array}{c}\text { Gage } \\
\text { helght }\end{array}$ & $\begin{array}{c}\text { Dis- } \\
\text { charge }\end{array}$ \\
\hline $\begin{array}{r}\text { Jan. } 29 \\
30\end{array}$ & $\begin{array}{l}2400 \\
0500 \\
0800 \\
1100 \\
1400 \\
1600 \\
1700 \\
1900 \\
2000 \\
2400 \\
0200 \\
0600 \\
0700\end{array}$ & $\begin{array}{r}0.94 \\
.96 \\
1.05 \\
1.20 \\
1.35 \\
1.24 \\
1.37 \\
1.27 \\
1.37 \\
1.21 \\
1.34 \\
1.33 \\
1.39 \\
\end{array}$ & $\begin{array}{l}1.3 \\
1.6 \\
4.0 \\
11 \\
21 \\
13 \\
22 \\
15 \\
22 \\
11 \\
20 \\
19 \\
23 \\
\end{array}$ & Jan. 31 & $\begin{array}{l}0900 \\
1000 \\
3100 \\
1300 \\
1400 \\
2400 \\
\\
0400 \\
0500 \\
0600 \\
0700 \\
0900 \\
1100 \\
1700 \\
2400\end{array}$ & $\begin{array}{l}1.35 \\
1.49 \\
1.94 \\
1.56 \\
1.35 \\
1.22 \\
1.16 \\
2.44 \\
3.27 \\
3.76 \\
4.38 \\
4.51 \\
4.17 \\
3.83\end{array}$ & $\begin{array}{c}21 \\
31 \\
82 \\
38 \\
21 \\
12 \\
\\
8.8 \\
165 \\
377 \\
559 \\
840 \\
906 \\
737 \\
587 \\
\end{array}$ & Feb. 2 & $\begin{array}{l}0600 \\
1200 \\
1800 \\
2300 \\
2400 \\
\\
0400 \\
0900 \\
0900 \\
1200 \\
1800 \\
2400\end{array}$ & $\begin{array}{l}3.56 \\
3.32 \\
3.09 \\
2.84 \\
2.85 \\
2.61 \\
2.57 \\
2.74 \\
2.66 \\
2.52 \\
2.40\end{array}$ & $\begin{array}{l}479 \\
393 \\
323 \\
254 \\
257 \\
\\
200 \\
192 \\
230 \\
211 \\
181 \\
157\end{array}$ \\
\hline
\end{tabular}

11-1537. Pajaro River near Gilroy, Calif.

Location.--Lat $36^{\circ} 56^{\prime} 5^{\prime \prime}$, long $121^{\circ} 30^{\prime} 40^{\prime \prime}$, on boundary between Las Animas and Llano del Tequisquita Grants, on center pier on downstream side of highway bridge on Bolsa Road, 0.9 mile downstream from Llagas Creek and 4.7 miles southeast of Gilroy, Santa Clara County.

Drainage area. --399 sq $\mathrm{mi}$.

Gage-height record --Water-stage recorder graph. Datum of gage is $123.88 \mathrm{ft}$ above mean sea level (levels by Corps of Engineers).

Discharge record.--Stage-discharge relation defined by current-meter measurements below 2,100 cis.

Maxima.--January-February 1963: Discharge, 5,320 cfs 0500 hours Heb. I (gage helght, $13.81 \mathrm{ft}$ ).

1959 to December 1962: Discharge, 1,120 cfs Feb. 15, 1962 (gage height, $9.00 \mathrm{ft}$ ).

Remarks.--Flow regulated by Pacheco Lake (capacity, 6,150 acre-ft), Chesbro Reservo1r (see station 11-1534.8), and San Felipe Lake

Mean discharge, in cublc feet per second, 1963

\begin{tabular}{|c|c|c|c|c|c|c|c|c|}
\hline Day & January & February & Day & January & February & Day & January & Pebruary \\
\hline $\begin{array}{c}1 \ldots \ldots \\
2 \ldots \ldots \\
3 \ldots \ldots \\
4 \ldots \ldots \\
5 \ldots \ldots \\
6 \ldots \ldots \\
7 \ldots \ldots \\
8 \ldots \ldots \\
9 \ldots \ldots \\
10 \ldots \ldots\end{array}$ & $\begin{array}{l}0.1 \\
.1 \\
.1 \\
.1 \\
.1 \\
.2 \\
.4 \\
.6 \\
.3 \\
.2\end{array}$ & $\begin{array}{r}4,170 \\
2,090 \\
1,160 \\
792 \\
538 \\
358 \\
230 \\
139 \\
103 \\
234\end{array}$ & $\begin{array}{l}11 \ldots \ldots \\
12 \ldots \ldots \\
13 \ldots \ldots \\
14 \ldots \ldots \\
15 \ldots \ldots \\
16 \ldots \ldots \\
17 \ldots \ldots \\
18 \ldots \ldots \\
19 \ldots \ldots \\
20 \ldots \ldots\end{array}$ & $\begin{array}{r}0.5 \\
.3 \\
.2 \\
1.4 \\
.5 \\
.3 \\
.6 \\
.8 \\
.3 \\
.4\end{array}$ & $\begin{array}{l}285 \\
290 \\
983 \\
828 \\
629 \\
462 \\
338 \\
238 \\
172 \\
125\end{array}$ & $\begin{array}{l}21 \ldots \ldots \\
22 \ldots \ldots \\
23 \ldots \ldots \\
24 \ldots \ldots \\
25 \ldots \ldots \\
26 \ldots \ldots \\
27 \ldots \ldots \\
25 \ldots \ldots \\
29 \ldots \ldots \\
30 \ldots \ldots \\
31 \ldots \ldots\end{array}$ & $\begin{array}{r}0.2 \\
.4 \\
.4 \\
.5 \\
.4 \\
.2 \\
.4 \\
.3 \\
.3 \\
85^{.3} \\
2,480\end{array}$ & $\begin{array}{r}95 \\
77 \\
68 \\
62 \\
56 \\
51 \\
48 \\
45 \\
-\ldots--1 \\
-\ldots-\ldots\end{array}$ \\
\hline $\begin{array}{l}\text { onthly } \\
\text { unoff, }\end{array}$ & $\begin{array}{l}n \text { disc } \\
\text { acre-1 }\end{array}$ & , in & feet & onona & & & $\begin{array}{r}83.1 \\
5,110 \\
\end{array}$ & $\begin{array}{r}524 \\
29, \cup 90 \\
\end{array}$ \\
\hline
\end{tabular}


Gage height, in feet, and discharge, in cubic feet per second, at indicated time, 1963, of Pajaro River near Gilroy, Calif.

\begin{tabular}{|c|c|c|c|c|c|c|c|c|c|c|c|}
\hline Date & Hour & $\begin{array}{c}\text { Gage } \\
\text { helght }\end{array}$ & $\begin{array}{l}\text { Dis- } \\
\text { charge }\end{array}$ & Date & Hour & $\begin{array}{c}\text { Gage } \\
\text { height }\end{array}$ & $\begin{array}{l}\text { Dis- } \\
\text { charge }\end{array}$ & Date & Hour & $\begin{array}{c}\text { Cage } \\
\text { helght }\end{array}$ & $\begin{array}{l}\text { D1s - } \\
\text { charge }\end{array}$ \\
\hline $\begin{array}{r}\text { Jan. } 29 \\
30\end{array}$ & $\begin{array}{l}2400 \\
0700 \\
0900 \\
1100 \\
1300 \\
1500 \\
1800 \\
2100 \\
2400 \\
0200\end{array}$ & $\begin{array}{l}2.40 \\
2.50 \\
2.63 \\
2.86 \\
3.35 \\
3.96 \\
4.95 \\
6.27 \\
8.00 \\
8.85\end{array}$ & $\begin{array}{r}0.6 \\
1.0 \\
1.5 \\
2.9 \\
7.9 \\
20 \\
63 \\
226 \\
720 \\
1,090\end{array}$ & Feb. 1 & $\begin{array}{l}0800 \\
1000 \\
1200 \\
1400 \\
1700 \\
1900 \\
2200 \\
2300 \\
2400 \\
\\
0300 \\
0400\end{array}$ & $\begin{array}{r}9.35 \\
9.70 \\
10.40 \\
10.76 \\
12.56 \\
13.07 \\
13.15 \\
12.98 \\
13.01 \\
13.65 \\
13.79\end{array}$ & $\begin{array}{l}1,350 \\
1,550 \\
2,000 \\
2,260 \\
3,870 \\
4,430 \\
4,530 \\
4,330 \\
4,360 \\
5,130 \\
5,300\end{array}$ & Feb. 1 & $\begin{array}{l}0500 \\
0700 \\
0900 \\
1500 \\
1800 \\
2400 \\
\\
0600 \\
1200 \\
1800 \\
2400\end{array}$ & $\begin{array}{r}13.81 \\
13.75 \\
13.50 \\
12.39 \\
11.98 \\
11.41 \\
10.92 \\
10.49 \\
10.06 \\
9.60\end{array}$ & $\begin{array}{l}5,320 \\
5,250 \\
4,950 \\
3,680 \\
3,270 \\
2,780 \\
2,390 \\
2,060 \\
1,770 \\
1,490\end{array}$ \\
\hline
\end{tabular}

11-1538. Alec Canyon near Morgan H1ll, Calif.

(Crest-stage station)

Location.--Lat $37^{\circ} 05^{1} 00^{\prime \prime}$, long $121^{\circ} 47^{\prime} 05^{\prime \prime}$, in $\mathrm{SE}_{\frac{1}{4}} \mathrm{SE} \frac{1}{4} \mathrm{sec} .6$, T.10 S., R.2 E., at culvert on Croy Creek Road, 8.0 miles southwest of Morgan Hill.

Drainage area. $-0.91 \mathrm{sq} \mathrm{mi}$.

Gage-height record.--No record; station destroyed. Altitude of gage is $960 \mathrm{ft}$ (from topographic map).

Discharge record.--Maximum discharge by computation of flow through culvert and flow over road embankment.

Maxima.--January-February 1963: Discharge, 367 cfs Jan. 31.

1960 to December 1962: Discharge, $107 \mathrm{cfs}$ Feb. 14, 1962 (gage height, 55.07ft).

11-1539. Uvas Creek above Uvas Reservoir, near Morgan H1ll, Calif.

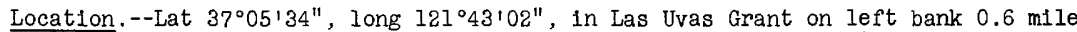
downstream from Little Uvas Creek, 0.9 mile upstream from Hay Canyon, and

4.4 miles southwest of Morgan Hili, Santa Clara County.

Drainage area. $--21.0 \mathrm{sq} \mathrm{mi}$.

Gage-height record.--Water-stage recorder graph. Altitude of gage is $500 \mathrm{ft}$ (from topographic map).

Discharge record.--Stage-dishcarge relation defined by current-meter measurements.

Maxima.--January-February 1963: Discharge, 6,400 cfs 1130 hours Jan. 31 (gage height, $13.10 \mathrm{ft}$ ).

1961 to December 1962: Discharge, 6,580 cfs 0ct. 13, 1962 (gage height, $13.18 \mathrm{ft}$ ).

Mean discharge, in cublc feet per second, 196:

\begin{tabular}{|c|c|c|c|c|c|c|c|c|}
\hline Day & January & February & Day & January & February & Day & Jamuary & February \\
\hline $\begin{array}{c}1 \ldots \ldots \\
2 \ldots \ldots \\
3 \ldots \ldots \\
4 \ldots \ldots \\
6 \ldots \ldots \\
7 \ldots \ldots \\
8 \ldots \ldots \\
9 \ldots \ldots \\
10 \ldots \ldots\end{array}$ & $\begin{array}{l}7.2 \\
7.0 \\
7.0 \\
6.8 \\
6.6 \\
6.4 \\
5.9 \\
5.9 \\
5.7 \\
5.5\end{array}$ & $\begin{array}{r}1,150 \\
300 \\
180 \\
134 \\
107 \\
91 \\
79 \\
70 \\
88 \\
125\end{array}$ & $\begin{array}{l}11 \ldots \ldots \\
12 \ldots \ldots \\
13 \ldots \ldots \\
14 \ldots \ldots \\
15 \ldots \ldots \\
16 \ldots \ldots \\
17 \ldots \ldots \\
18 \ldots \ldots \\
19 \ldots \ldots \\
20 \ldots \ldots\end{array}$ & $\begin{array}{l}5.3 \\
5.1 \\
4.9 \\
4.9 \\
5.1 \\
5.1 \\
5.1 \\
4.9 \\
4.9 \\
4.9\end{array}$ & $\begin{array}{r}96 \\
119 \\
320 \\
169 \\
128 \\
98 \\
90 \\
78 \\
70 \\
62\end{array}$ & $\begin{array}{l}21 \ldots \ldots \\
22 \ldots \ldots \\
23 \ldots \ldots \\
24 \ldots \ldots \\
25 \ldots \ldots \\
26 \ldots \ldots \\
27 \ldots \ldots \\
25 \ldots \ldots \\
29 \ldots \ldots \\
30 \ldots \ldots \\
31 \ldots \ldots\end{array}$ & $\begin{array}{r}4.9 \\
4.3 \\
4.6 \\
4.5 \\
4.6 \\
4.6 \\
4.5 \\
4.8 \\
6.3 \\
1,700 \\
3,390\end{array}$ & $\begin{array}{r}57 \\
52 \\
4 \mathrm{~S} \\
45 \\
42 \\
40 \\
36 \\
34 \\
---- \\
-----\end{array}$ \\
\hline $\begin{array}{l}\text { hofhy, } \\
\text { hoff, }\end{array}$ & acr & & & & & & $\begin{array}{r}169 \\
9.29 \\
10,410 \\
\end{array}$ & $\begin{array}{r}140 \\
6.92 \\
7,760 \\
\end{array}$ \\
\hline
\end{tabular}


Gage height, In feet, and discharge, in cubic feet per second, at indicated time, 1963, of Uvas Creek above Uvas Reservoir, near Morgan H1ll, Calif.

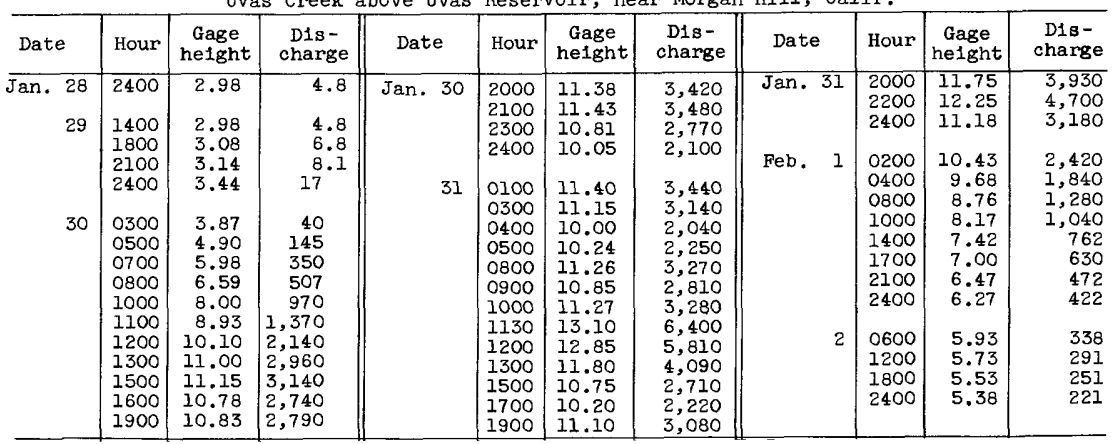

11-1540.2. Uvas Reservoir near Morgan Hill, Calif.

Location.--Lat $37^{\circ} 04^{\prime} 02^{\prime \prime}$, long $121^{\circ} 41^{\prime} 25^{\prime \prime}$, in Las Uvas Grant, at center of dam on Uvas Creek, 4.8 miles' southwest of Morgan Hill, Santa Clara County.

Drainage area. $--30.2 \mathrm{sq} \mathrm{mi}$.

Gage-height record.--Staff gage read once daily, except Jan. 4, 6, 7, 13, 17, 19, $21,23,26,27$. Datum of gage is at mean sea level (levels by South Santá Clára Vailey Water Conservation District).

Contents record.--Contents computed from capacity table dated Dec. 8, 1955 . Contents for periods of no gage-height record were interpolated.

Maxima.--January-February 1963: Contents, 10,760 acre-ft 0800 hours Feb. 1 (elevation, $489.6 \mathrm{ft}$ ).

1957 to December 1962: Contents observed, 10,500 acre-ft Apr. 1, 1958 (elevation, $488.9 \mathrm{ft}$ ).

Remarks.--Reservolr is formed by earth and rockfill dam completed in 1957. Capac1ty, 10,000 acre-ft between elevations 410 (hydraulic gate valves) and $487.5 \mathrm{ft}$

(crest of spillway). Records furnished by South Santa Clara Valley Water Conservation District.

Elevation, in feet, and contents, in acre-feet, at 0800 hours, 1963

\begin{tabular}{|c|c|c|c|c|c|c|c|c|c|}
\hline \multirow{2}{*}{ Day } & \multicolumn{2}{|c|}{ January } & \multicolumn{2}{|c|}{ February } & \multirow{2}{*}{ Day } & \multicolumn{2}{|c|}{ January } & \multicolumn{2}{|c|}{ February } \\
\hline & Elevation & Contents & Elevation & Contents & & Elevation & Contents & Elevation & Contents \\
\hline $\begin{array}{r}1 \\
2 \\
3 \\
4 \\
5 \\
6 \\
7 \\
8 \\
9 \\
10 \\
11 \\
12 \\
13 \\
14 \\
15\end{array}$ & $\begin{array}{c}436.1 \\
436.3 \\
436.4 \\
\overline{6} \\
436.7 \\
- \\
\overline{-} \\
437.1 \\
437.3 \\
437.4 \\
437.5 \\
437.7 \\
\overline{-} \\
437.7 \\
438.0\end{array}$ & $\begin{array}{l}1,190 \\
1,200 \\
1,210 \\
1,220 \\
1,240 \\
1,250 \\
1,260 \\
1,270 \\
1,280 \\
1,290 \\
1,300 \\
1,320 \\
1,320 \\
1,320 \\
1,340\end{array}$ & $\begin{array}{l}489.6 \\
488.2 \\
488.0 \\
487.4 \\
487.4 \\
487.4 \\
487.4 \\
487.4 \\
487.4 \\
487.7 \\
487.8 \\
487.6 \\
488.2 \\
487.9 \\
487.8\end{array}$ & $\begin{array}{r}10,760 \\
10,250 \\
10,180 \\
9,960 \\
9,960 \\
9,960 \\
9,960 \\
9,960 \\
9,960 \\
10,070 \\
10,110 \\
10,040 \\
10,250 \\
10,140 \\
10,110\end{array}$ & $\begin{array}{l}16 \\
17 \\
18 \\
19 \\
20 \\
21 \\
22 \\
23 \\
24 \\
25 \\
26 \\
27 \\
28 \\
29 \\
30 \\
31\end{array}$ & $\begin{array}{c}438.2 \\
- \\
438.2 \\
- \\
438.4 \\
- \\
438.5 \\
- \\
438.7 \\
438.8 \\
- \\
- \\
439.0 \\
439.1 \\
441.1 \\
477.5\end{array}$ & $\begin{array}{l}1,360 \\
1,360 \\
1,360 \\
1,360 \\
1,370 \\
1,380 \\
1,380 \\
1,390 \\
1,400 \\
1,400 \\
1,410 \\
1,410 \\
1,420 \\
1,430 \\
1,610 \\
7,250\end{array}$ & $\begin{array}{c}487.4 \\
487.4 \\
487.5 \\
487.5 \\
487.5 \\
487.5 \\
487.5 \\
487.5 \\
487.5 \\
487.5 \\
487.5 \\
487.5 \\
487.4 \\
- \\
- \\
-\end{array}$ & $\begin{array}{r}9,960 \\
9,960 \\
10,000 \\
10,000 \\
10,000 \\
10,000 \\
10,000 \\
10,000 \\
10,000 \\
10,000 \\
10,000 \\
10,000 \\
9,960 \\
- \\
- \\
-\end{array}$ \\
\hline \multicolumn{6}{|c|}{ 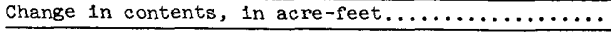 } & - & $+6,070$ & - & $+2,710$ \\
\hline
\end{tabular}


11-1541. Bodfish Creek near Gilroy, Cal1f.

Location.--Lat $37^{\circ} 00^{\prime} 15^{\prime \prime}$, long $121^{\circ} 40^{\prime} 00^{\prime \prime}$, In Las Animas Grant, on left bank just upstream from Whitehurst Creek, 2.7 miles upstream from mouth and 5.1 miles west of city limits of Gilroy, Santa Clara County.

Drainage area, $--7.40 \mathrm{sq} \mathrm{ml}$.

Gage-he1ght record.--Water-stage recorder graph, except Feb. 2-6. Altitude of gage is 360 ft (from topographic map).

Discharge record.--Stage-discharge relation defined by current-meter measurements below $580 \mathrm{cfs}$. Discharge for Feb. 2-6 estimated on basis of one discharge measurement and records for nearby stations.

Maxima.--January-February 1963: Discharge 1,240 cfs 1200 hours Jan. 31 (gage helght, $8.25 \mathrm{ft}$ )

1959 to December 1962: Discharge, $585 \mathrm{cfs}$ Feb. 1, 1959 (gage height, $6.35 \mathrm{ft}$ ).

Mean discharge, in cuble feet per second, 1963

\begin{tabular}{|c|c|c|c|c|c|c|c|c|}
\hline Day & January & February & Day & January & February & Day & January & February \\
\hline $\begin{array}{r}1 \ldots \ldots \\
2 \ldots \ldots \\
3 \ldots \ldots \\
4 \ldots \ldots \\
5 \ldots \ldots \\
6 \ldots \ldots \\
8 \ldots \ldots \\
9 \ldots \ldots \\
10 \ldots \ldots\end{array}$ & $\begin{array}{l}0.6 \\
.6 \\
.6 \\
.5 \\
.5 \\
.5 \\
.5 \\
.5 \\
.4 \\
.4\end{array}$ & $\begin{array}{r}228 \\
34 \\
15 \\
9.8 \\
7.3 \\
6.6 \\
5.9 \\
5.5 \\
9.1 \\
17\end{array}$ & $\begin{array}{l}11 \ldots \ldots \\
12 \ldots \ldots \\
13 \ldots \ldots \\
14 \ldots \ldots \\
15 \ldots \ldots \\
16 \ldots \ldots \\
17 \ldots \ldots \\
18 \ldots \ldots \\
19 \ldots \ldots \\
20 \ldots \ldots\end{array}$ & $\begin{array}{l}0.4 \\
.4 \\
.4 \\
.4 \\
.4 \\
.4 \\
.3 \\
.3 \\
.3 \\
.3\end{array}$ & $\begin{array}{l}14 \\
23 \\
83 \\
27 \\
18 \\
14 \\
11 \\
8.3 \\
7.3 \\
6.6\end{array}$ & $\begin{array}{l}21 \ldots \ldots \\
22 \ldots \ldots \\
23 \ldots \ldots \\
24 \ldots \ldots \\
25 \ldots \ldots \\
26 \ldots \ldots \\
27 \ldots \ldots \\
28 \ldots \ldots \\
29 \ldots \ldots \\
30 \ldots \ldots \\
31 \ldots \ldots\end{array}$ & $\begin{array}{r}0.3 \\
.3 \\
.3 \\
.3 \\
.3 \\
.3 \\
.3 \\
.3 \\
.4 \\
165^{.4} \\
505\end{array}$ & $\begin{array}{r}5.5 \\
5.2 \\
4.9 \\
4.4 \\
4.1 \\
3.8 \\
3.5 \\
3.3 \\
---.- \\
----- \\
----\end{array}$ \\
\hline \multicolumn{7}{|l|}{$\begin{array}{l}\text { Monthly } \\
\text { Runoff, } \\
\text { Runoff, }\end{array}$} & $\begin{array}{r}22.0 \\
3.43 \\
1,350\end{array}$ & $\begin{array}{r}20.9 \\
2.94 \\
1,160 \\
\end{array}$ \\
\hline
\end{tabular}

Gage height, in feet, and discharge, in cubic feet per second, at indicated time, 1963

\begin{tabular}{|c|c|c|c|c|c|c|c|c|c|c|c|}
\hline Date & Hour & $\begin{array}{c}\text { aage } \\
\text { height }\end{array}$ & $\begin{array}{c}\text { Dis- } \\
\text { charge }\end{array}$ & Date & Hour & $\begin{array}{c}\text { Gage } \\
\text { height }\end{array}$ & $\begin{array}{c}\text { Dis- } \\
\text { charge }\end{array}$ & Date & Hour & $\begin{array}{c}\text { Gage } \\
\text { helght }\end{array}$ & $\begin{array}{c}\text { Dis- } \\
\text { charge }\end{array}$ \\
\hline $\begin{array}{r}29 \\
30\end{array}$ & $\begin{array}{l}2400 \\
0400 \\
0600 \\
1000 \\
1200 \\
1400 \\
1600 \\
1700 \\
1800 \\
2000 \\
2100\end{array}$ & $\begin{array}{l}2.60 \\
2.74 \\
2.92 \\
3.44 \\
4.04 \\
4.61 \\
4.37 \\
4.83 \\
5.90 \\
5.64 \\
6.04\end{array}$ & $\begin{array}{c}2.7 \\
6.9 \\
14 \\
46 \\
108 \\
190 \\
153 \\
228 \\
455 \\
390 \\
492 \\
\end{array}$ & $\begin{array}{r}\text { Jan. } 30 \\
31\end{array}$ & $\begin{array}{l}2400 \\
0200 \\
0500 \\
0700 \\
0900 \\
1000 \\
1100 \\
1200 \\
1300 \\
1400 \\
1600\end{array}$ & $\begin{array}{l}5.17 \\
5.58 \\
4.86 \\
5.50 \\
6.50 \\
6.35 \\
7.90 \\
8.25 \\
7.98 \\
6.72 \\
5.87\end{array}$ & $\begin{array}{r}294 \\
376 \\
234 \\
360 \\
630 \\
585 \\
1,100 \\
1,240 \\
1,130 \\
696 \\
448\end{array}$ & $\begin{array}{l}\text { Jan. } 31 \\
\text { Feb. } 1\end{array}$ & $\begin{array}{l}1800 \\
1900 \\
2200 \\
2400 \\
\\
0100 \\
0500 \\
0900 \\
1100 \\
1700 \\
2100 \\
2400\end{array}$ & $\begin{array}{l}5.25 \\
5.25 \\
5.84 \\
5.94 \\
5.86 \\
5.25 \\
5.14 \\
4.84 \\
4.29 \\
3.84 \\
3.65\end{array}$ & $\begin{array}{r}310 \\
310 \\
440 \\
465 \\
\\
445 \\
310 \\
288 \\
230 \\
142 \\
84 \\
65\end{array}$ \\
\hline
\end{tabular}

11-1542. Uvas Creek near Gilroy, Cal1f.

Location.--Lat $36^{\circ} 59^{\prime} 35^{\prime \prime}$, long $121^{\circ} 34^{\prime} 20^{\prime \prime}$, in Las Anlmas Grant, on left bank $400 \mathrm{ft}$ upstream from county road bridge, $0.4 \mathrm{mile}$ southwest of G1lroy, Santa Clara County, and 3.9 miles downstream from Bodf'lsh Creek.

Drainage area. $--71.2 \mathrm{sq} \mathrm{mi}$.

Gage-height record ${ }^{--W a t e r-s t a g e ~ r e c o r d e r ~ g r a p h . ~ A l t i t u d e ~ o f ~ g a g e ~ i s ~} 190 \mathrm{ft}$ (from topographic map).

Discharge record. --Stage-discharge relation defined by current-meter measurements below $2,500 \mathrm{c}$ 's.

Maxima.--January-February 1963: Discharge, 7,180 cfs 0230 hours Feb. 1 (gage height, $17.66 \mathrm{ft}$ ).

1959 to December 1962: Discharge, 2,700 cfs Feb. 8, 1960 (gage height,

$9.11 \mathrm{ft}$ ), from rating curve extended above $400 \mathrm{cfs}$.

Remarks.--Flow regulated by Uvas Reservolr (see station 11-1540.2). 
Mean discharge, in cublc feet per second, 1963, of Uvas Creek near G1lroy, Calif.

\begin{tabular}{|c|c|c|c|c|c|c|c|c|}
\hline Day & January & February & Day & January & February & Day & January & February \\
\hline $\begin{array}{c}1 \ldots \ldots \\
2 \ldots \ldots \\
4 \ldots \ldots \\
5 \ldots \ldots \\
6 \ldots \ldots \\
7 \ldots \ldots \\
8 \ldots \ldots \\
9 \ldots \ldots \\
10 \ldots \ldots\end{array}$ & $\begin{array}{l}0 \\
0 \\
0 \\
0 \\
0 \\
0 \\
0 \\
0 \\
0 \\
0\end{array}$ & $\begin{array}{r}3,910 \\
1,260 \\
720 \\
494 \\
374 \\
287 \\
238 \\
195 \\
190 \\
314\end{array}$ & $\begin{array}{l}11 \ldots \ldots \\
12 \ldots \ldots \\
13 \ldots \ldots \\
14 \ldots \ldots \\
15 \ldots \ldots \\
16 \ldots \ldots \\
17 \ldots \ldots \\
18 \ldots \ldots \\
19 \ldots \ldots \\
20 \ldots \ldots\end{array}$ & $\begin{array}{l}0 \\
0 \\
0 \\
0 \\
0 \\
0 \\
0 \\
0 \\
0 \\
0\end{array}$ & $\begin{array}{l}287 \\
266 \\
873 \\
578 \\
414 \\
335 \\
272 \\
225 \\
190 \\
162\end{array}$ & $\begin{array}{l}21 \ldots \ldots \\
22 \ldots \ldots \\
23 \ldots \ldots \\
24 \ldots \ldots \\
25 \ldots \ldots \\
26 \ldots \ldots \\
27 \ldots \ldots \\
28 \ldots \ldots \\
29 \ldots \ldots \\
30 \ldots \ldots \\
31 \ldots \ldots\end{array}$ & $\begin{array}{r}0 \\
0 \\
0 \\
0 \\
0 \\
0 \\
0 \\
0 \\
0 \\
315 \\
2,410\end{array}$ & $\begin{array}{r}134 \\
117 \\
103 \\
89 \\
76 \\
62 \\
64 \\
56 \\
-\ldots-.\end{array}$ \\
\hline & $\operatorname{cre}$ & & & & & & $\begin{array}{r}87.9 \\
1.42 \\
5,400\end{array}$ & $\begin{array}{r}439 \\
6.42 \\
24,370\end{array}$ \\
\hline
\end{tabular}

Gage height, in feet, and discharge, in cubic feet per second, at Indicated time, 1963

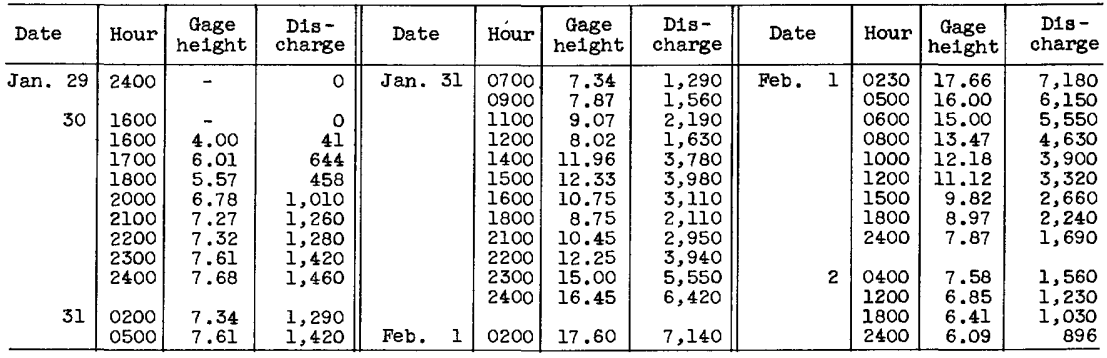

11-1585. San Benito River near Hollister, Calif.

Location. --Lat $36^{\circ} 47^{\prime} 17^{\prime \prime}$, long $121^{\circ} 22^{\prime} 11^{\prime \prime}$, In SW $\frac{1}{4}$ sec.24, T.13 S., R.5 E., on left bank $1,500 \mathrm{ft}$ downstream from Bird Creek, 0.9 mile downstream from Tres Pinos

Creek, 2.7 miles west of Tres Pinos, and 4.8 miles southeast of Hollister.

Drainage area. $--586 \mathrm{sq} \mathrm{mi}$.

Gage-height record ${ }^{--W a t e r-s t a g e ~ r e c o r d e r ~ g r a p h . ~ A l t i t u d e ~ o f ~ g a g e ~ i s ~} 370 \mathrm{ft}$ (from topographic mapi).

Discharge record.--Stage-discharge relation defined by current-meter measurements.

Maxima.--January-February 1963: Discharge, $339 \mathrm{cfs} 2000$ hours Feb. 10 (gage height, $4.02 \mathrm{ft}$ ).

1949 to December 1962: Discharge, 11,600 cfs Apr. 3, 1958 (gage height, 16.30 $\mathrm{ft})$, from rating curve extended above $1,200 \mathrm{cfs}$ on basis of flood-routing study.

Remarks.--Flow regulated by Hernandez Dam since December 1961 (capacity, 18,700 acre-ft).

Mean discharge, in cublc feet per second, 1963

\begin{tabular}{|c|c|c|c|c|c|c|c|c|}
\hline Day & January & February & Day & January & February & Day & January & February \\
\hline $\begin{array}{c}1 \ldots \ldots \\
2 \ldots \ldots \\
3 \ldots \ldots \\
4 \ldots \ldots \\
5 \ldots \ldots \\
7 \ldots \ldots \\
8 \ldots \ldots \\
9 \ldots \ldots \\
10 \ldots \ldots\end{array}$ & $\begin{array}{l}0.1 \\
.1 \\
.1 \\
.1 \\
.1 \\
0 \\
0 \\
0 \\
0 \\
0\end{array}$ & $\begin{array}{l}43 \\
22 \\
12 \\
11 \\
7.0 \\
5.2 \\
3.4 \\
2.5 \\
4.3 \\
63\end{array}$ & $\begin{array}{l}11 \ldots \ldots \\
12 \ldots \ldots \\
13 \ldots \ldots \\
14 \ldots \ldots \\
15 \ldots \ldots \\
16 \ldots \ldots \\
17 \ldots \ldots \\
18 \ldots \ldots \\
19 \ldots \ldots \\
20 \ldots \ldots\end{array}$ & $\begin{array}{l}0 \\
0 \\
0 \\
0 \\
.1 \\
.1 \\
.1 \\
.1 \\
.1 \\
.1\end{array}$ & $\begin{array}{c}100 \\
39 \\
36 \\
39 \\
7.7 \\
4.3 \\
3.9 \\
3.4 \\
3 \\
2.3\end{array}$ & $\begin{array}{l}21 \ldots \ldots \\
22 \ldots \ldots \\
23 \ldots \ldots \\
24 \ldots \ldots \\
25 \ldots \ldots \\
26 \ldots \ldots \\
27 \ldots \ldots \\
28 \ldots \ldots \\
29 \ldots \ldots \\
30 \ldots \ldots \\
31 \ldots \ldots\end{array}$ & $\begin{array}{r}0.1 \\
.1 \\
.1 \\
.1 \\
.1 \\
.1 \\
.1 \\
.1 \\
.1 \\
.4 \\
4.5\end{array}$ & $\begin{array}{r}2.1 \\
1.9 \\
1.9 \\
1.9 \\
1.7 \\
1.6 \\
1.4 \\
1.0 \\
-.---1 \\
---1--1\end{array}$ \\
\hline $\begin{array}{l}\text { onthly } \\
\text { unoff, }\end{array}$ & $\begin{array}{l}\text { an disc } \\
\text { acre-f }\end{array}$ & In & feet & econd. & & & $\begin{array}{r}0.22 \\
14 \\
\end{array}$ & $\begin{array}{r}15.2 \\
844 \\
\end{array}$ \\
\hline
\end{tabular}


11-1590. Pajaro River at Chittenden, Calif.

Location.--Lat $36^{\circ} 54^{\prime} 01^{\prime \prime}$, long $121^{\circ} 35^{\prime} 48^{\prime \prime}$, in Salsipuedes Grant, on downstream side of right bank pier of State highway bridge, 0.6 mile downstream from Pescadero Creek, 0.6 mile southeast of Chittenden, Santa Cruz County, and 2.3 miles downstream from San Benito River.

Drainage area. $--1,186 \mathrm{sq} \mathrm{mi}$.

Gage-height record.--Water-stage recorder graph. Datum of gage is $81.77 \mathrm{ft}$ above mean sea leve1, datum of 1929, supplementary adjustment of 1955 .

Discharge record.--Stage-discharge relation defined by current-meter measurements.

Maxima.--January-February 1963: Discharge, 11,600 cfs 0900 hours Feb. 1 (gage height, $20.76 \mathrm{ft}$ ).

1939 to December 1962: Discharge, $24,000 \mathrm{cfs}$ Dec. 24, 1955, from rating curve extended above $8,300 \mathrm{cfs}$ on basis of slope-conveyance study; maximum gage height, $33.11 \mathrm{ft}$ Apr. 3, 1958 .

Flood in February 1938 reached a stage of $31.3 \mathrm{ft}$, from floodmarks .

Remarks.--Flow slightly regulated by Pacheco Lake (capacity, 6,150 acre-ft), Chesbro and Uvas Reservoirs (see stations $11-1534.8$ and $11-1540.2$ ), and San Felipe Iake.

Mean discharge, in cuble feet per second, 1963

\begin{tabular}{|c|c|c|c|c|c|c|c|c|}
\hline Day & January & February & Day & January & February & Day & January & February \\
\hline $\begin{array}{c}1 \ldots \ldots \\
2 \ldots \ldots \\
3 \ldots \ldots \\
4 \ldots \ldots \\
5 \ldots \ldots \\
7 \ldots \ldots \\
8 \ldots \ldots \\
9 \ldots \ldots \\
10 \ldots \ldots\end{array}$ & $\begin{array}{l}1.5 \\
1.4 \\
1.2 \\
1.2 \\
1.2 \\
1.2 \\
1.2 \\
1.2 \\
1.4 \\
1.4\end{array}$ & $\begin{array}{r}9,580 \\
3,750 \\
1,550 \\
960 \\
664 \\
488 \\
362 \\
268 \\
199 \\
336\end{array}$ & $\begin{array}{l}11 \ldots \ldots \\
12 \ldots \ldots \\
13 \ldots \ldots \\
14 \ldots \ldots \\
15 \ldots \ldots \\
16 \ldots \ldots \\
17 \ldots \ldots \\
18 \ldots \ldots \\
19 \ldots \ldots \\
20 \ldots \ldots\end{array}$ & $\begin{array}{l}1.5 \\
1.5 \\
1.5 \\
1.6 \\
1.7 \\
1.8 \\
2.0 \\
2.1 \\
2.2 \\
2.4\end{array}$ & $\begin{array}{r}396 \\
358 \\
1,940 \\
1,630 \\
1,130 \\
876 \\
693 \\
544 \\
436 \\
355\end{array}$ & $\begin{array}{l}21 \ldots \ldots \\
22 \ldots \ldots \\
23 \ldots \ldots \\
24 \ldots \ldots \\
25 \ldots \ldots \\
26 \ldots \ldots \\
27 \ldots \ldots \\
28 \ldots \ldots \\
29 \ldots \ldots \\
30 \ldots \ldots \\
31 \ldots \ldots\end{array}$ & $\begin{array}{r}2.4 \\
2.2 \\
2.1 \\
2.1 \\
2.1 \\
2.2 \\
2.2 \\
2.4 \\
3.1 \\
60 \\
4,550\end{array}$ & $\begin{array}{r}270 \\
222 \\
194 \\
172 \\
152 \\
137 \\
129 \\
118 \\
----- \\
----- \\
----\end{array}$ \\
\hline \multicolumn{7}{|c|}{ 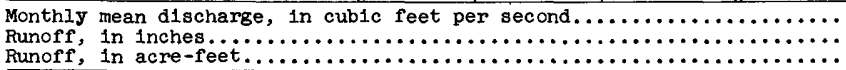 } & $\begin{array}{r}150 \\
0.15 \\
9,250\end{array}$ & $\begin{array}{r}997 \\
0.88 \\
55,360\end{array}$ \\
\hline
\end{tabular}

Gage height, in feet, and discharge, in cubic feet per second, at indicated t1me, 1963

\begin{tabular}{|c|c|c|c|c|c|c|c|c|c|c|c|}
\hline Date & Hour & $\begin{array}{c}\text { Gage } \\
\text { helght }\end{array}$ & $\begin{array}{c}\text { Dis - } \\
\text { charge }\end{array}$ & Date & Hour & $\begin{array}{c}\text { Gage } \\
\text { helght }\end{array}$ & $\begin{array}{c}\text { Dis- } \\
\text { charge }\end{array}$ & Date & Hour & $\begin{array}{c}\text { Gage } \\
\text { helght }\end{array}$ & $\begin{array}{c}\text { D1s- } \\
\text { charge }\end{array}$ \\
\hline $\begin{array}{r}\text { Jan. } 29 \\
30\end{array}$ & $\begin{array}{l}2400 \\
0400 \\
0800 \\
1100 \\
1600 \\
1700 \\
1800 \\
1900 \\
2000 \\
2200 \\
2300\end{array}$ & $\begin{array}{l}3.61 \\
3.65 \\
3.75 \\
3.86 \\
3.91 \\
4.26 \\
4.41 \\
4.41 \\
5.60 \\
5.32 \\
7.20\end{array}$ & $\begin{array}{c}4.1 \\
5.0 \\
7.6 \\
11 \\
13 \\
30 \\
39 \\
39 \\
149 \\
117 \\
425\end{array}$ & $\begin{array}{r}\mathrm{Jan} .30 \\
31\end{array}$ & $\begin{array}{l}2400 \\
0200 \\
0500 \\
0800 \\
1100 \\
1300 \\
1500 \\
2000 \\
2400 \\
0400\end{array}$ & $\begin{array}{r}8.40 \\
10.25 \\
11.95 \\
12.70 \\
13.65 \\
15.10 \\
15.45 \\
17.58 \\
18.30 \\
20.00\end{array}$ & $\begin{array}{r}760 \\
1,530 \\
2,470 \\
2,990 \\
3,720 \\
4,990 \\
5,310 \\
7,500 \\
8,360 \\
10,500\end{array}$ & Feb. 1 & $\begin{array}{l}0600 \\
0800 \\
0900 \\
1000 \\
1800 \\
2100 \\
2400 \\
\\
0600 \\
1200 \\
1800 \\
2400\end{array}$ & $\begin{array}{l}20.40 \\
20.75 \\
20.76 \\
20.65 \\
18.53 \\
17.51 \\
16.55 \\
14.60 \\
13.32 \\
12.33 \\
11.48\end{array}$ & $\begin{array}{r}11,100 \\
11,600 \\
11,600 \\
11,400 \\
8,640 \\
7,410 \\
6,350 \\
4,540 \\
3,460 \\
2,730 \\
2,190 \\
\end{array}$ \\
\hline
\end{tabular}

11-1591.5. Corralitos Creek near Corralitos, Calif.

Location.--Lat $37^{\circ} 00^{\prime} 20^{\prime \prime}$, long $121^{\circ} 48^{\prime} 25^{\prime \prime}$, in Los Corralitos Grant, on left bank $0.5 \mathrm{~m} j \mathrm{le}$ downstream from Mormon Gulch, 1.2 miles upstream from Corralitos, Santa Cruz County, and 7 miles northwest of Watsonville.

Drainage area. $--10.6 \mathrm{sq} \mathrm{mL}$.

Gage-height record.--Water-stage recorder graph, except Feb. 2-4. Alt1tude of gage is $310 \mathrm{ft}^{\prime}$ (from topographic map).

Discharge record.--Stage-discharge relation defined by current-meter measurements below $430 \mathrm{cfs}$. Discharge for $\mathrm{Feb}$. 2-4 estimated on basis of normal recession.

Maxima.--January-February 1963: Discharge, 1,920 cfs 1130 hours Jan. 31 (gage height, $7.62 \mathrm{ft}$ ).

1957 to December 1962: D1scharge, 1,970 cfs Apr. 2, 1958 (gage height, $7.55 \mathrm{ft}$ ), from rating curve extended above $430 \mathrm{cfs}$ on basis of estimate of flow over dam. 
Mean discharge, in cubic feet per second, 1963, of Corralitos Creek near Corral1tos, Cal1f.

\begin{tabular}{|c|c|c|c|c|c|c|c|c|}
\hline Day & January & Febmuary & Day & January & February & Day & January & February \\
\hline $\begin{array}{c}\ldots \ldots \\
2 \ldots \ldots \\
3 \ldots \ldots \\
4 \ldots \ldots \\
5 \ldots \ldots \\
7 \ldots \ldots \\
8 \ldots \ldots \\
9 \ldots \ldots \\
10 \ldots \ldots\end{array}$ & $\begin{array}{l}1.8 \\
1.4 \\
1.4 \\
1.4 \\
1.4 \\
1.4 \\
1.4 \\
1.2 \\
1.4 \\
1.0\end{array}$ & $\begin{array}{r}467 \\
131 \\
79 \\
58 \\
44 \\
35 \\
30 \\
27 \\
38 \\
67\end{array}$ & $\begin{array}{l}11 \ldots \ldots \\
12 \ldots \ldots \\
13 \ldots \ldots \\
14 \ldots \ldots \\
15 \ldots \ldots \\
16 \ldots \ldots \\
17 \ldots \ldots \\
18 \ldots \ldots \\
19 \ldots \ldots \\
20 \ldots \ldots\end{array}$ & $\begin{array}{r}0.8 \\
.8 \\
.6 \\
.6 \\
1.2 \\
1.2 \\
1.2 \\
1.2 \\
1.2 \\
1.2\end{array}$ & $\begin{array}{r}49 \\
50 \\
124 \\
67 \\
51 \\
42 \\
37 \\
30 \\
27 \\
24\end{array}$ & $\begin{array}{l}21 \ldots \ldots \\
22 \ldots \ldots \\
23 \ldots \ldots \\
24 \ldots \ldots \\
25 \ldots \ldots \\
26 \ldots \ldots \\
27 \ldots \ldots \\
28 \ldots \ldots \\
29 \ldots \ldots \\
30 \ldots \ldots \\
31 \ldots \ldots\end{array}$ & $\begin{array}{r}1.2 \\
.6 \\
.4 \\
.4 \\
.3 \\
.3 \\
.2 \\
.3 \\
4.5 \\
426 \\
997\end{array}$ & $\begin{array}{r}22 \\
20 \\
18 \\
16 \\
15 \\
14 \\
15 \\
15 \\
-\ldots--\end{array}$ \\
\hline $\begin{array}{l}\text { onthly } \\
\text { anoff, } \\
\text { noff, }\end{array}$ & $\begin{array}{l}\text { Inches } \\
\text { acre-f }\end{array}$ & & & & & & $\begin{array}{r}46.9 \\
5.10 \\
2,890\end{array}$ & $\begin{array}{r}57.6 \\
5.66 \\
3,200 \\
\end{array}$ \\
\hline
\end{tabular}

Gage height, in feet, and discharge, in cublc feet per second, at indicated time, 1963

\begin{tabular}{|c|c|c|c|c|c|c|c|c|c|c|c|}
\hline Date & Hour & $\begin{array}{c}\text { Gage } \\
\text { he1ght }\end{array}$ & $\begin{array}{l}\text { Dis- } \\
\text { charge }\end{array}$ & Date & Hour & $\begin{array}{c}\text { Gage } \\
\text { helght }\end{array}$ & $\begin{array}{c}\text { Dis- } \\
\text { charge }\end{array}$ & Date & Hour & $\begin{array}{c}\text { Gage } \\
\text { helght }\end{array}$ & $\begin{array}{l}\text { Dis- } \\
\text { charge }\end{array}$ \\
\hline $\begin{array}{r}\text { an. } 29 \\
30\end{array}$ & $\begin{array}{l}2400 \\
\\
0300 \\
0600 \\
0900 \\
1000 \\
1200 \\
1400 \\
1600 \\
1800 \\
1900 \\
2000 \\
2100 \\
\end{array}$ & $\begin{array}{l}1.42 \\
1.86 \\
2.38 \\
2.96 \\
4.00 \\
5.00 \\
4.40 \\
4.74 \\
5.31 \\
5.31 \\
6.02 \\
5.95 \\
\end{array}$ & $\begin{array}{r}24 \\
51 \\
92 \\
157 \\
325 \\
600 \\
420 \\
522 \\
709 \\
709 \\
999 \\
968 \\
\end{array}$ & Jan. 30 & $\begin{array}{l}2200 \\
2400 \\
\\
0200 \\
0300 \\
0500 \\
0600 \\
0800 \\
0900 \\
1000 \\
1130 \\
1200 \\
1300\end{array}$ & $\begin{array}{l}5.90 \\
5.31 \\
5.86 \\
5.72 \\
5.00 \\
5.02 \\
5.96 \\
5.84 \\
6.25 \\
7.62 \\
7.60 \\
6.40\end{array}$ & $\begin{array}{r}945 \\
709 \\
\\
927 \\
868 \\
600 \\
607 \\
972 \\
918 \\
1,110 \\
1,920 \\
1,900 \\
1,180\end{array}$ & Jan. 31 & $\begin{array}{l}1500 \\
1800 \\
1900 \\
2300 \\
2200 \\
2400 \\
\\
0400 \\
0800 \\
1200 \\
1800 \\
2400\end{array}$ & $\begin{array}{l}5.70 \\
5.01 \\
5.13 \\
6.34 \\
7.17 \\
6.40 \\
5.29 \\
4.83 \\
4.19 \\
3.54 \\
3.16\end{array}$ & $\begin{array}{r}860 \\
604 \\
646 \\
1,150 \\
1,600 \\
I, 180 \\
\\
702 \\
549 \\
368 \\
244 \\
183\end{array}$ \\
\hline
\end{tabular}

11-1592. Corralitos Creek at Freedom, Cal1f.

Location. --Lat $36^{\circ} 56^{\prime} 22^{\prime \prime}$, long $121^{\circ} 46^{\prime} 10^{\prime \prime}$, in Los Corralitos Grant, on right bank just upstream from Green Valley Road bridge, 0.25 mile north of Freedom, Santa Cruz County, and 2.3 miles north of Watsonville.

Drainage area. $--27.8 \mathrm{sq} \mathrm{mi}$.

Gage-height record.--Water-stage recorder graph, except Feb. 4-6. Altitude of gage is 80 f't (from topographic map).

Discharge record.--Stage-discharge relation defined by current-meter measurements below $790 \mathrm{cfs}$ and contracted-opening measurement at $3,620 \mathrm{cfs}$. Discharge for Feb. 4-6 estimated on basis of one discharge measurement, normal recession, and records for station near Corralitos.

Maxima.--January-February 1963: Discharge, 2,580 cf's 1400 hours Jan. 31 (gage height, $11.80 \mathrm{ft}$ ).

1955 to December 1962: Discharge, 3,620 cfs Dec. 22, 1955 (gage height, $15.6 \mathrm{ft}$, from floodmarks), on basis of contracted-opening measurement of maximum flow.

Mean discharge, in cub1c feet per second, 1963

\begin{tabular}{|c|c|c|c|c|c|c|c|c|}
\hline Day & January & February & Day & January & February & Day & January & February \\
\hline $\begin{array}{c}\ldots \ldots \\
2 \ldots \ldots \\
3 \ldots \ldots \\
5 \ldots \ldots \\
6 \ldots \ldots \\
7 \ldots \ldots \\
9 \ldots \ldots \\
10 \ldots \ldots\end{array}$ & $\begin{array}{l}0.2 \\
.2 \\
.4 \\
.3 \\
1.4 \\
.1 \\
0 \\
0 \\
0 \\
0\end{array}$ & $\begin{array}{r}1,090 \\
350 \\
159 \\
103 \\
72 \\
52 \\
40 \\
28 \\
54 \\
143\end{array}$ & $\begin{array}{l}11 \ldots \ldots \\
12 \ldots \ldots \\
13 \ldots \ldots \\
14 \ldots \ldots \\
15 \ldots \ldots \\
16 \ldots \ldots \\
17 \ldots \ldots \\
18 \ldots \ldots \\
19 \ldots \ldots \\
20 \ldots \ldots\end{array}$ & $\begin{array}{l}0 \\
0 \\
0 \\
.1 \\
.1 \\
.1 \\
.1 \\
.3 \\
.2 \\
0 .\end{array}$ & $\begin{array}{r}91 \\
101 \\
402 \\
197 \\
125 \\
95 \\
78 \\
62 \\
52 \\
44\end{array}$ & $\begin{array}{l}21 \ldots \ldots \\
22 \ldots \ldots \\
23 \ldots \ldots \\
24 \ldots \ldots \\
25 \ldots \ldots \\
26 \ldots \ldots \\
27 \ldots \ldots \\
28 \ldots \ldots \\
29 \ldots \ldots \\
30 \ldots \ldots \\
31 \ldots \ldots\end{array}$ & $\begin{array}{r}0 \\
0 \\
0 \\
0 \\
0 \\
0 \\
0 \\
0 \\
0 \\
600 \\
1,490\end{array}$ & $\begin{array}{r}40 \\
33 \\
30 \\
25 \\
22 \\
20 \\
21 \\
20 \\
-\ldots--\end{array}$ \\
\hline $\begin{array}{l}\text { onthly } \\
\text { unoff, } \\
\text { unoff, }\end{array}$ & $\begin{array}{l}\text { an dis } \\
\text { Inche } \\
\text { acre- }\end{array}$ & $\ldots \ldots$ & 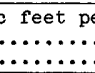 & & & & $\begin{array}{r}67.5 \\
2.80 \\
4,150\end{array}$ & $\begin{array}{r}127 \\
4.75 \\
7,040 \\
\end{array}$ \\
\hline
\end{tabular}


Gage height, In feet, and discharge, in cubic feet per second, at indicated time, 1963, of Corralitos Creek at Freedom, Cal1f.

\begin{tabular}{|c|c|c|c|c|c|c|c|c|c|c|c|}
\hline Date & Hour & $\begin{array}{c}\text { Gage } \\
\text { helght }\end{array}$ & $\begin{array}{c}\text { D1s- } \\
\text { charge }\end{array}$ & Date & Hour & $\begin{array}{c}\text { Gage } \\
\text { height }\end{array}$ & $\begin{array}{c}\text { Dis- } \\
\text { charge }\end{array}$ & Date & Hour & $\begin{array}{c}\text { Gage } \\
\text { height }\end{array}$ & $\begin{array}{c}\text { Dis- } \\
\text { charge }\end{array}$ \\
\hline $\begin{array}{r}\operatorname{Jan} .29 \\
30\end{array}$ & $\begin{array}{l}2400 \\
0200 \\
0300 \\
0600 \\
0900 \\
1200 \\
1400 \\
1600 \\
2000 \\
2200 \\
2300 \\
2400 \\
0200\end{array}$ & $\begin{array}{l}1.45 \\
1.47 \\
2.32 \\
2.84 \\
3.62 \\
5.50 \\
6.20 \\
5.65 \\
7.02 \\
7.98 \\
8.05 \\
7.75 \\
6.92\end{array}$ & $\begin{array}{c}0.1 \\
3.2 \\
81 \\
82 \\
207 \\
690 \\
900 \\
735 \\
1,150 \\
1,430 \\
1,460 \\
1,370 \\
1,120\end{array}$ & Jan. 31 & $\begin{array}{l}0300 \\
0400 \\
0600 \\
0800 \\
1000 \\
1100 \\
1200 \\
1400 \\
1500 \\
1600 \\
1700 \\
1900 \\
2000 \\
2200 \\
2400\end{array}$ & $\begin{array}{r}7.77 \\
7.65 \\
6.36 \\
6.90 \\
8.30 \\
8.62 \\
9.85 \\
11.80 \\
10.00 \\
8.10 \\
7.52 \\
6.87 \\
7.00 \\
8.70 \\
11.08\end{array}$ & $\begin{array}{r}1,370 \\
1,340 \\
948 \\
1,110 \\
1,530 \\
1,630 \\
2,000 \\
2,580 \\
2,040 \\
1,470 \\
1,300 \\
1,100 \\
1,140 \\
1,650 \\
2,360\end{array}$ & Feb. 1 & $\begin{array}{l}0200 \\
0500 \\
0700 \\
1100 \\
1500 \\
1900 \\
2400 \\
\\
0600 \\
1200 \\
1800 \\
2400\end{array}$ & $\begin{array}{l}9.70 \\
7.85 \\
7.30 \\
6.70 \\
5.88 \\
5.48 \\
5.00 \\
4.69 \\
4.42 \\
4.22 \\
4.05\end{array}$ & $\begin{array}{r}1,950 \\
1,400 \\
1,230 \\
1,050 \\
804 \\
684 \\
540 \\
424 \\
335 \\
269 \\
215\end{array}$ \\
\hline
\end{tabular}

11-1594. Green Valley Creek near Corral1tos, Cal1f.

(Crest-stage station)

Location. --Lat $36^{\circ} 58^{\prime} 37^{\prime \prime}$, long $121^{\circ} 46^{\prime} 31^{\prime \prime}$, in Los Corralitos Grant, at culvert on Green valley road, 1.9 miles southeast of Corralitos.

Drainage area. $--7.05 \mathrm{sq} \mathrm{m}$.

Gage-helght record.--Crest stages only. Altitude of gage is $165 \mathrm{ft}$ (from topographic map).

Discharge record.--Maximum discharge by computation of flow through culvert.

Maxima.--January-February 1963: D1scharge, 1,050 cfs Jan. 31 (gage he1ght, $56.62 \mathrm{ft}^{\mathrm{t}}$ ).

1960 to December 1962: D1scharge, $245 \mathrm{cfs}$ Feb. 9, 1962 (gage height, 52.17 $f t)$, by slope-area measurement of peak flow.

\section{APTOS CREEK BASIN}

11-1597. Aptos Creek at Aptos, Cal1f.

Locat1on.--Lat $36^{\circ} 58^{\prime} 35^{\prime \prime}$, long $121^{\circ} 54^{\prime} 05^{\prime \prime}$, In Aptos Grant, on left bank at Aptos, Santa Cruz County, 0.6 mlle upstream from mouth.

Drainage area. $--12.2 \mathrm{sq} \mathrm{mi}$.

Gage-helght record.--Water-stage recorder graph, except Feb. 14, 21-26. Alt1tude of gage is $10 \mathrm{f}^{t}$ (from topographic map).

D1scharge record.--Stage-d1scharge relation defined by current-meter measurements below $980 \mathrm{cfs}$. D1scharge for Feb. 14,21-26 estimated on basis of reconstructed gage-helght graph.

Maxima.--January-February 1963: D1scharge, 2,110 cf's 1200 hours Jan. 31 (gage height, $10.82 \mathrm{ft}$ ).

1958 to December 1962: D1scharge, $560 \mathrm{cfs}$ Feb. 14, 1962 (gage he1ght, $6.02 \mathrm{ft}$ ).

Mean discharge, in cubic feet per second, 1963

\begin{tabular}{|c|c|c|c|c|c|c|c|c|}
\hline Day & January & February & Day & January & February & Day & January & February \\
\hline $\begin{array}{c}1 \ldots \ldots \\
2 \ldots \ldots \\
3 \ldots \ldots \\
4 \ldots \ldots \\
6 \ldots \ldots \\
7 \ldots \ldots \\
8 \ldots \ldots \\
9 \ldots \ldots \\
10 \ldots \ldots\end{array}$ & $\begin{array}{l}3.7 \\
3.4 \\
3.1 \\
3.1 \\
3.1 \\
3.1 \\
3.1 \\
3.1 \\
2.9 \\
2.9\end{array}$ & $\begin{array}{r}425 \\
121 \\
78 \\
52 \\
39 \\
22 \\
16 \\
12 \\
29 \\
73\end{array}$ & $\begin{array}{l}11 \ldots \ldots \\
12 \ldots \ldots \\
13 \ldots \ldots \\
14 \ldots \ldots \\
15 \ldots \ldots \\
16 \ldots \ldots \\
17 \ldots \ldots \\
18 \ldots \ldots \\
19 \ldots \ldots \\
20 \ldots \ldots\end{array}$ & $\begin{array}{l}3.1 \\
3.4 \\
3.6 \\
4.0 \\
4.0 \\
4.0 \\
4.0 \\
4.0 \\
4.0 \\
4.0\end{array}$ & $\begin{array}{r}52 \\
39 \\
155 \\
77 \\
54 \\
53 \\
53 \\
54 \\
56 \\
51\end{array}$ & $\begin{array}{l}21 \ldots \ldots \\
22 \ldots \ldots \\
23 \ldots \ldots \\
24 \ldots \ldots \\
25 \ldots \ldots \\
26 \ldots \ldots \\
27 \ldots \ldots \\
28 \ldots \ldots \\
29 \ldots \ldots \\
30 \ldots \ldots \\
31 \ldots \ldots\end{array}$ & $\begin{array}{r}4.0 \\
4.0 \\
3.6 \\
3.6 \\
3.6 \\
3.6 \\
4.0 \\
4.0 \\
6.5 \\
446 \\
861\end{array}$ & $\begin{array}{r}45 \\
40 \\
37 \\
29 \\
24 \\
20 \\
17 \\
13 \\
--\ldots-\end{array}$ \\
\hline $\begin{array}{l}\text { onthly } \\
\text { anoff, } \\
\text { inoff, }\end{array}$ & acre & & & & & & $\begin{array}{r}45.6 \\
4.31 \\
2,800\end{array}$ & $\begin{array}{r}62.0 \\
5.29 \\
3,440 \\
\end{array}$ \\
\hline
\end{tabular}

$793-2850-66-10$ 
Gage height, in feet, and discharge, in cubic feet per second, at indicated time, 1963, of

\begin{tabular}{|c|c|c|c|c|c|c|c|c|c|c|c|}
\hline Date & Hour & $\begin{array}{c}\text { Gage } \\
\text { height }\end{array}$ & $\begin{array}{c}\text { Dis- } \\
\text { charge }\end{array}$ & Date & Hour & $\begin{array}{c}\text { Gage } \\
\text { height }\end{array}$ & $\begin{array}{l}\text { D1s- } \\
\text { charge }\end{array}$ & Date & Hour & $\begin{array}{c}\text { Gage } \\
\text { helght }\end{array}$ & $\begin{array}{c}\text { Dis- } \\
\text { charge }\end{array}$ \\
\hline $\begin{array}{r}\operatorname{Jan} .29 \\
30\end{array}$ & $\begin{array}{l}2400 \\
0300 \\
0500 \\
0600 \\
0900 \\
1000 \\
1100 \\
1200 \\
1600 \\
2000 \\
2300 \\
2400\end{array}$ & $\begin{array}{l}3.38 \\
3.65 \\
4.18 \\
4.68 \\
5.58 \\
6.19 \\
6.73 \\
6.83 \\
5.61 \\
5.91 \\
6.88 \\
6.73\end{array}$ & $\begin{array}{r}24 \\
47 \\
121 \\
227 \\
450 \\
603 \\
759 \\
789 \\
458 \\
533 \\
804 \\
759\end{array}$ & $\operatorname{Jan} .31$ & $\begin{array}{l}0100 \\
0200 \\
0300 \\
0700 \\
0800 \\
1000 \\
1100 \\
1200 \\
1300 \\
1400 \\
.1700 \\
2000 \\
2100\end{array}$ & $\begin{array}{r}6.49 \\
6.59 \\
6.80 \\
5.77 \\
6.46 \\
7.65 \\
9.50 \\
10.82 \\
9.04 \\
7.62 \\
6.41 \\
5.70 \\
6.21\end{array}$ & $\begin{array}{r}687 \\
717 \\
780 \\
498 \\
678 \\
1,040 \\
1,650 \\
2,110 \\
1,490 \\
1,030 \\
663 \\
480 \\
608\end{array}$ & $\begin{array}{l}\text { Jan. } 31 \\
\text { Feb. } 1\end{array}$ & $\begin{array}{l}2300 \\
2400 \\
\\
0100 \\
0200 \\
0400 \\
0600 \\
1200 \\
1900 \\
2400\end{array}$ & $\begin{array}{l}7.40 \\
7.58 \\
7.17 \\
7.02 \\
6.51 \\
6.01 \\
5.05 \\
4.73 \\
4.43\end{array}$ & $\begin{array}{r}960 \\
1,010 \\
891 \\
846 \\
693 \\
558 \\
318 \\
239 \\
169\end{array}$ \\
\hline
\end{tabular}

\section{SOQUEL CREEK BASIN}

11-1597.7. Laurel Creek near Laure1, Calif.

(Crest-stage station)

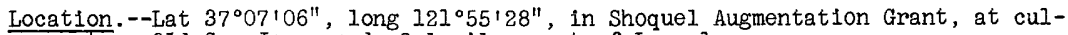
vert on 0ld San Jose road, 2.1 miles east of Laurel.

Drainage area. $--0.93 \mathrm{sq} \mathrm{ml}$.

Gage-helght record.--Crest stages only. Altitude of gage is 1,530 ft (from topograph1c map).

Discharge record. --Maximum discharge by computation of flow through culvert.

Maxima.--January-February 1963: Discharge, 328 cfs Jan. 31 (gage height, $32.31 \mathrm{ft}$ ). i960 to December 1962: Discharge, $287 \mathrm{cfs}$ 0ct. 13, 1962 (gage height, $31.85 \mathrm{ft})$.

11-1598. West Branch Soque1 Creek near Soquel, Callf.

Location.--Lat $37^{\circ} 03^{\prime} 05^{\prime \prime}$, long $121^{\circ} 56^{\prime} 20^{\prime \prime}$, in $\mathrm{NW} \frac{1}{4}$ sec.23, T.10 S., R.1 W., on left bank 0.5 mile upstream from Soquel Creek and 4.5 miles north of Soquel.

Drainage area. $--12.2 \mathrm{sq} \mathrm{mi}$.

Gage-height record.--Water-stage recorder graph, except Feb. 16-27. Altitude of gage is 220 ft (from topographic map).

Discharge record.--Stage-discharge relation defined by current-meter measurements below $740 \mathrm{cfs}$ and by slope-area measurement at $2,110 \mathrm{cfs}$. Discharge for

Feb. 16-27 estimated on basis of weather records and records for soquel Creek at Soquel.

Maxima.--January-February 1963: Discharge, 4,120 cfs 1200 hours Jan. 31 (gage helght, $10.88 \mathrm{ft}$ ).

1958 to December 1962: Discharge 2,110 cfs 0ct. 13, 1962 (gage height, $7.96 \mathrm{ft})$.

Mean d1scharge, in cubic feet per second, 1963

\begin{tabular}{|c|c|c|c|c|c|c|c|c|}
\hline Day & January & February & Day & January & February & Day & January & February \\
\hline $\begin{array}{r}1 \ldots . . \\
2 \ldots . . \\
3 \ldots \ldots \\
4 \ldots \ldots \\
5 \ldots \ldots \\
7 \ldots \ldots \\
8 \ldots \ldots \\
9 \ldots \ldots \\
10 . \ldots .\end{array}$ & $\begin{array}{l}5.2 \\
5.2 \\
5.2 \\
5.2 \\
5.2 \\
5.0 \\
5.0 \\
5.0 \\
4.8 \\
4.8\end{array}$ & $\begin{array}{r}648 \\
164 \\
84 \\
59 \\
44 \\
35 \\
29 \\
27 \\
121 \\
182\end{array}$ & 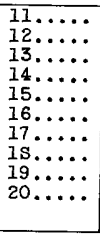 & $\begin{array}{l}4.8 \\
4.5 \\
4.8 \\
4.8 \\
4.8 \\
4.8 \\
4.8 \\
4.8 \\
4.8 \\
4.5\end{array}$ & $\begin{array}{r}118 \\
123 \\
300 \\
136 \\
80 \\
6 \mathrm{~s} \\
60 \\
50 \\
46 \\
42\end{array}$ & $\begin{array}{l}21 \ldots \ldots \\
22 \ldots \ldots \\
23 \ldots \ldots \\
24 \ldots \\
25 \ldots \\
26 \ldots \\
27 \ldots \ldots \\
28 \ldots \\
29 \ldots \ldots \\
30 \ldots \ldots \\
31 \ldots \ldots \\
\end{array}$ & $\begin{array}{r}4.5 \\
4.5 \\
4.3 \\
4.3 \\
4.3 \\
4.3 \\
4.3 \\
4.3 \\
7.3 \\
746 \\
1,910 \\
\end{array}$ & $\begin{array}{r}38 \\
35 \\
32 \\
28 \\
25 \\
22 \\
20 \\
18 \\
--1- \\
-0 .- \\
\end{array}$ \\
\hline & & & & & & & $\begin{array}{r}90.2 \\
8.52 \\
5,550 \\
\end{array}$ & $\begin{array}{r}94.1 \\
8.03 \\
5,220 \\
\end{array}$ \\
\hline
\end{tabular}


Gage height, in feet, and discharge, in cublc feet per second, at indicated time, 1963, of

\begin{tabular}{|c|c|c|c|c|c|c|c|c|c|c|c|}
\hline Date & Hour & $\begin{array}{c}\text { Gage } \\
\text { helght }\end{array}$ & $\begin{array}{l}\text { Dis - } \\
\text { charge }\end{array}$ & Date & Hour & $\begin{array}{c}\text { Gage } \\
\text { helght }\end{array}$ & $\begin{array}{l}\text { Dls- } \\
\text { charge }\end{array}$ & Date & Hour & $\begin{array}{c}\text { Gage } \\
\text { height }\end{array}$ & $\begin{array}{c}\text { Dis- } \\
\text { charge }\end{array}$ \\
\hline $\begin{array}{r}\operatorname{Jan} \cdot 28 \\
29\end{array}$ & $\begin{array}{l}2400 \\
1500 \\
1800 \\
2100 \\
2300 \\
2400\end{array}$ & $\begin{array}{l}2.62 \\
2.62 \\
2.69 \\
2.89 \\
3.02 \\
3.15\end{array}$ & $\begin{array}{l}4.3 \\
4.3 \\
6.0 \\
11 \\
23 \\
34\end{array}$ & $\operatorname{Jan}, 30$ & $\begin{array}{l}1500 \\
1600 \\
1900 \\
2100 \\
2300 \\
2400\end{array}$ & $\begin{array}{l}5.22 \\
6.00 \\
5.42 \\
6.85 \\
6.78 \\
6.48\end{array}$ & $\begin{array}{r}580 \\
970 \\
680 \\
1,440 \\
1,400 \\
1,230\end{array}$ & Jan. 31 & $\begin{array}{l}1400 \\
1500 \\
1700 \\
1900 \\
2200 \\
2400\end{array}$ & $\begin{array}{l}8.15 \\
7.29 \\
6.60 \\
8.02 \\
8.84 \\
7.30\end{array}$ & $\begin{array}{l}2,240 \\
1,690 \\
1,300 \\
2,150 \\
2,690 \\
1,700\end{array}$ \\
\hline 30 & $\begin{array}{l}0200 \\
0300 \\
0500 \\
0800 \\
0900 \\
1000 \\
1100 \\
1200 \\
1300\end{array}$ & $\begin{array}{l}3.45 \\
3.75 \\
4.32 \\
4.68 \\
5.19 \\
6.26 \\
7.01 \\
6.97 \\
6.00\end{array}$ & $\begin{array}{r}69 \\
114 \\
248 \\
358 \\
566 \\
1,110 \\
1,530 \\
1,500 \\
970\end{array}$ & 31 & $\begin{array}{l}0100 \\
0300 \\
0400 \\
0500 \\
0700 \\
0800 \\
1000 \\
1100 \\
1200 \\
1300\end{array}$ & $\begin{array}{r}6.30 \\
7.24 \\
6.00 \\
6.48 \\
6.00 \\
6.93 \\
8.00 \\
9.00 \\
10.88 \\
9.50\end{array}$ & $\begin{array}{r}1,140 \\
1,660 \\
970 \\
1,230 \\
970 \\
1,480 \\
2,140 \\
2,800 \\
4,120 \\
3,150\end{array}$ & Feb. 1 & $\begin{array}{l}0300 \\
0500 \\
0800 \\
1200 \\
1800 \\
2400 \\
\\
0600 \\
1200 \\
2400\end{array}$ & $\begin{array}{l}6.18 \\
5.74 \\
5.54 \\
5.06 \\
4.72 \\
4.47 \\
\\
4.30 \\
4.07 \\
3.92\end{array}$ & $\begin{array}{r}1,070 \\
840 \\
740 \\
507 \\
372 \\
291 \\
\\
200 \\
139 \\
104\end{array}$ \\
\hline
\end{tabular}

11-1600. Soquel Creek at Soquel, Calif.

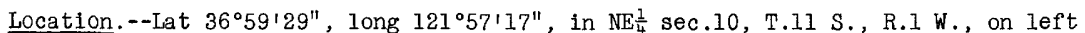
bank 0.2 mile upstream from highway bridge in town of Soquel and $0.4 \mathrm{mile}$ downstream from Bates Creek.

Drainage area. $--40.2 \mathrm{sq} \mathrm{mi}$.

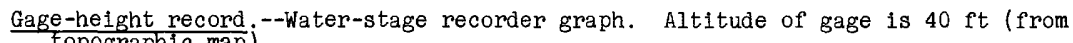
topographic map ).

Discharge record.--Stage-discharge relation defined by current-meter measurements below 2,900 cfs and by slope-area measurements at 5,120 and 15,800 cfs.

Maxima.--January-February 1963: Discharge, 7,950 cfs 1300 hours Jan. 31 (gage helght, $16.27 \mathrm{ft}$ ).

1951 to December 1962: Discharge, 15,800 cfs Dec. 23, 1955 (gage height, $22.33 \mathrm{ft}$ ), from rating curve extended above $2,900 \mathrm{cfs}$ on basis of slope-area measurement of maximum flow.

Mean discharge, in cublc feet per second, 1963

\begin{tabular}{|c|c|c|c|c|c|c|c|c|}
\hline Day & January & February & Day & January & February & Day & January & February \\
\hline $\begin{array}{c}\ldots \ldots \\
2 \ldots \ldots \\
3 \ldots \ldots \\
4 \ldots \ldots \\
5 \ldots \ldots \\
7 \ldots \ldots \\
8 \ldots \ldots \\
9 \ldots \ldots \\
10 \ldots \ldots\end{array}$ & $\begin{array}{l}16 \\
15 \\
15 \\
15 \\
14 \\
14 \\
14 \\
13 \\
13 \\
13\end{array}$ & $\begin{array}{r}2,110 \\
558 \\
315 \\
206 \\
156 \\
126 \\
106 \\
93 \\
262 \\
424\end{array}$ & $\begin{array}{l}11 \ldots \ldots \\
12 \ldots \ldots \\
13 \ldots \ldots \\
14 \ldots \ldots \\
15 \ldots \ldots \\
16 \ldots \ldots \\
17 \ldots \ldots \\
18 \ldots \ldots \\
19 \ldots \ldots \\
20 \ldots \ldots\end{array}$ & $\begin{array}{l}13 \\
13 \\
12 \\
12 \\
12 \\
12 \\
11 \\
11 \\
12 \\
11\end{array}$ & $\begin{array}{l}238 \\
235 \\
743 \\
304 \\
229 \\
195 \\
178 \\
149 \\
140 \\
126\end{array}$ & $\begin{array}{l}21 \ldots \ldots \\
22 \ldots \ldots \\
23 \ldots \ldots \\
24 \ldots \ldots \\
25 \ldots \ldots \\
26 \ldots \ldots \\
27 \ldots \ldots \\
28 \ldots \ldots \\
29 \ldots \ldots \\
30 \ldots \ldots \\
31 \ldots \ldots\end{array}$ & $\begin{array}{r}10 \\
9.7 \\
9.3 \\
9.3 \\
9.3 \\
9.3 \\
9.3 \\
9.3 \\
9.3 \\
1,880 \\
4,150\end{array}$ & $\begin{array}{r}126 \\
110 \\
98 \\
91 \\
86 \\
79 \\
73 \\
69 \\
----\end{array}$ \\
\hline \multicolumn{7}{|c|}{$\begin{array}{l}\text { Monthly } \\
\text { Runoff, } \\
\text { Runoff, }\end{array}$} & $\begin{array}{r}206 \\
5.90 \\
12,650 \\
\end{array}$ & $\begin{array}{r}272 \\
7.06 \\
15,130 \\
\end{array}$ \\
\hline
\end{tabular}

Gage height, in feet, and discharge, in cubic feet per second, at indicated time, 1963

\begin{tabular}{|c|c|c|c|c|c|c|c|c|c|c|c|}
\hline Date & Hour & $\begin{array}{c}\text { Gage } \\
\text { height }\end{array}$ & $\begin{array}{l}\text { Dis- } \\
\text { charge }\end{array}$ & Date & Hour & $\begin{array}{c}\text { Gage } \\
\text { height }\end{array}$ & $\begin{array}{c}\text { D1s- } \\
\text { charge }\end{array}$ & Date & Hour & $\begin{array}{c}\text { Gage } \\
\text { height }\end{array}$ & $\begin{array}{c}\text { Dis- } \\
\text { charge }\end{array}$ \\
\hline Jan. 29 & 2400 & 3.12 & 9.3 & Jan. 30 & 2400 & 10.92 & 3,340 & Jan. 31 & 2400 & 13.42 & 5,230 \\
\hline 30 & $\begin{array}{l}0200 \\
0400 \\
0600 \\
0700 \\
0800 \\
1100 \\
1200 \\
1300 \\
1400 \\
1600 \\
1800 \\
2100 \\
2300 \\
\end{array}$ & $\begin{array}{r}4.08 \\
5.10 \\
6.25 \\
7.00 \\
7.14 \\
9.89 \\
11.03 \\
11.00 \\
11.35 \\
8.40 \\
9.54 \\
9.17 \\
11.02 \\
\end{array}$ & $\begin{array}{r}105 \\
328 \\
743 \\
1,080 \\
1,150 \\
2,680 \\
3,420 \\
3,400 \\
3,640 \\
1,790 \\
2,470 \\
2,250 \\
3,410 \\
\end{array}$ & 31 & $\begin{array}{l}0100 \\
0200 \\
0400 \\
0500 \\
0600 \\
0700 \\
1000 \\
1300 \\
1600 \\
1700 \\
1900 \\
2100 \\
2300\end{array}$ & $\begin{array}{r}10.75 \\
10.23 \\
10.67 \\
10.60 \\
9.42 \\
9.35 \\
12.56 \\
16.27 \\
11.82 \\
11.47 \\
10.27 \\
12.00 \\
13.43\end{array}$ & $\begin{array}{l}3,220 \\
2,890 \\
3,170 \\
3,120 \\
2,400 \\
2,360 \\
4,540 \\
7,950 \\
3,970 \\
3,730 \\
2,910 \\
4,100 \\
5,230 \\
\end{array}$ & Feb. 1 & $\begin{array}{l}0100 \\
0200 \\
0300 \\
0800 \\
0900 \\
1200 \\
1800 \\
2400 \\
\\
0300 \\
1000 \\
1800 \\
2400 \\
\end{array}$ & $\begin{array}{r}13.30 \\
12.00 \\
11.05 \\
9.10 \\
8.90 \\
8.30 \\
7.30 \\
6.50 \\
6.20 \\
5.83 \\
5.45 \\
5.30 \\
\end{array}$ & $\begin{array}{r}5,130 \\
4,100 \\
3,440 \\
2,210 \\
2,090 \\
1,730 \\
1,230 \\
855 \\
\\
720 \\
572 \\
438 \\
388 \\
\end{array}$ \\
\hline
\end{tabular}




\section{SAN IORENZO RIVER BASIN}

11-1600.3. San Lorenzo River tributary near Boulder Creek, Calif.

(Crest-stage station)

Location. --Lat $37^{\circ} 10^{\prime} 10^{\prime \prime}$, long $122^{\circ} 08^{\prime} 05^{\prime \prime}$, in $\mathrm{NE} \frac{1}{4} \mathrm{NE} \frac{1}{4} \mathrm{sec} .12$, T.9 S., R.3 W., at culvert on State Highway $9,3.2$ miles north of Boulder Creek.

Drainage area. $--0.25 \mathrm{sq} \mathrm{ml}$.

Gage-height record.--Crest stages only. Altitude of gage is $560 \mathrm{ft}$ (from topographic map).

Discharge record.--Maximum discharge by computation of flow through culvert.

Maxima --January-February 1963: Discharge, $58 \mathrm{cfs}$ Jan. 31 (gage height, $52.80 \mathrm{ft}$ ). 1960 to December 1962: Discharge not determined, occurped Feb. 9, 1962 (gage height, $51.83 \mathrm{ft}$ ).

11-1603. Zayante Creek at Zayante, Calif.

Location.--Lat $37^{\circ} 05^{\prime} 10^{\prime \prime}$, long $122^{\circ} 02^{\prime} 45^{\prime \prime}$, in SE $\frac{1}{4}$ sec.2, T.10 S., R.2 W., on left bank at Zayante Road bridge in town of Zayante, 0.4 mile upstream from Lompico Creek, 2.0 miles east of Ben Lomond, and 3.2 miles upstream from mouth.

Drainage area. $--11.1 \mathrm{sq} \mathrm{mi}$.

Gage-height record.--Water-stage recorder graph, except Jan. 6, 25-27, 29, 30, Feb. 1-5. Alt1tude of gage is $390 \mathrm{ft}$ (from topographic map).

Discharge record.--Stage-discharge relation defined by current-meter measurements below 1,200 cfs and by slope-area measurement at 3,700 cfs. Discharge for periods of no gage-height record estimated on basis of two discharge measurements, weather records, and records for West Branch Soque1 Creek near Soquel.

Maxima.--January-February 1963: Discharge, 2,830 cfs 1200 hours Jan. 31 (gage height, $6.86 \mathrm{ft}$ ).

1957 to December 1962: Discharge, 3,700 cfs Apr. 2, 1958 (gage height $7.70 \mathrm{ft}$ )

Mean discharge, in cubic feet per second, 1963

\begin{tabular}{|c|c|c|c|c|c|c|c|c|}
\hline Day & January & February & Day & January & February & Day & January & February \\
\hline $\begin{array}{r}1 \ldots \ldots \\
3 \ldots \ldots \\
4 \ldots \ldots \\
5 \ldots \ldots \\
6 \ldots \ldots \\
8 \ldots \ldots \\
9 \ldots \ldots \\
10 \ldots \ldots\end{array}$ & $\begin{array}{l}2.7 \\
2.7 \\
2.7 \\
2.6 \\
2.6 \\
2.6 \\
2.4 \\
2.2 \\
2.2 \\
2.2\end{array}$ & $\begin{array}{r}500 \\
100 \\
45 \\
35 \\
30 \\
27 \\
23 \\
21 \\
60 \\
109\end{array}$ & $\begin{array}{l}11 \ldots \ldots \\
12 \ldots \ldots \\
13 \ldots \ldots \\
14 \ldots \ldots \\
15 \ldots \ldots \\
16 \ldots \ldots \\
17 \ldots \ldots \\
18 \ldots \ldots \\
19 \ldots \ldots \\
20 \ldots \ldots\end{array}$ & $\begin{array}{l}2.1 \\
2.0 \\
2.0 \\
2.0 \\
2.0 \\
2.0 \\
2.0 \\
2.0 \\
2.0 \\
1.9\end{array}$ & $\begin{array}{r}65 \\
71 \\
139 \\
74 \\
56 \\
46 \\
38 \\
33 \\
30 \\
27\end{array}$ & $\begin{array}{l}21 \ldots \ldots \\
22 \ldots \ldots \\
23 \ldots \ldots \\
24 \ldots \ldots \\
25 \ldots \ldots \\
26 \ldots \ldots \\
27 \ldots \ldots \\
28 \ldots \ldots \\
29 \ldots \ldots \\
30 \ldots \ldots \\
31 \ldots \ldots\end{array}$ & $\begin{array}{r}1.9 \\
1.9 \\
1.9 \\
1.9 \\
1.9 \\
1.8 \\
1.8 \\
1.9 \\
10 \\
150 \\
1,400\end{array}$ & $\begin{array}{r}24 \\
22 \\
20 \\
19 \\
18 \\
16 \\
16 \\
14 \\
---1 \\
----1\end{array}$ \\
\hline \multicolumn{7}{|l|}{$\begin{array}{l}\text { Monthly } \\
\text { Runoff, } \\
\text { Runoff, }\end{array}$} & $\begin{array}{r}52.3 \\
5.43 \\
3,210\end{array}$ & $\begin{array}{r}59.9 \\
5.62 \\
3,330\end{array}$ \\
\hline
\end{tabular}

11-1605. San Lorenzo River at Big Trees, Calif.

Location.--Lat $37^{\circ} 01^{\prime} 40^{\prime \prime}$, long $122^{\circ} 03^{\prime} 30^{\prime \prime}$, in Canada del Rincon Grant, on right bank 0.5 mile south of Big Trees station on Southern Pacific Railroad, 1.6 miles downstream from Zayante Creek, and 4 miles north of Santa Cruz, Santa Cruz County.

Drainage area.--111 sq mi.

Gage-height record. - Water-stage recorder graph, except 0200 hours Jan. 30 to 1600 hours Feb. 1. Datum of gage is $217.0 \mathrm{ft}$ above mean sea level (levels by Topographic Division).

Discharge record.--Stage-discharge relation defined by current-meter measurements. Discharge for Jan. 30 to Feb. 1 estimated on basis of records for nearby stations.

Maxima.--January-February 1963: Discharge, 13,000 cfs about 1300 hours Jan. 31 (gage height, $15.80 \mathrm{ft}$, from floodmarks).

1936 to December 1962: Discharge, 30,400 cfs Dec. 23, 1955 (gage helght, $22.55 \mathrm{ft}$ ), from rating curve extended above $11,000 \mathrm{cfs}$ on basis of slope-area measurement of maximum flow. 
Mean discharge, in cubic feet per second, 1963, of San Lorenzo River at Big Trees, Cal1f.

\begin{tabular}{|c|c|c|c|c|c|c|c|c|}
\hline Day & January & February & Day & January & February & Day & January & February \\
\hline $\begin{array}{c}\ldots \ldots \\
2 \ldots \ldots \\
3 \ldots \ldots \\
4 \ldots \ldots \\
5 \ldots \ldots \\
6 \ldots \ldots \\
7 \ldots \ldots \\
8 \ldots \ldots \\
9 \ldots \ldots \\
10 \ldots \ldots\end{array}$ & $\begin{array}{l}40 \\
40 \\
39 \\
38 \\
37 \\
36 \\
35 \\
35 \\
34 \\
34\end{array}$ & $\begin{array}{r}3,900 \\
1,130 \\
675 \\
475 \\
365 \\
303 \\
279 \\
259 \\
779 \\
1,290\end{array}$ & $\begin{array}{l}11 \ldots \ldots \\
12 \ldots \ldots \\
13 \ldots \ldots \\
14 \ldots \ldots \\
15 \ldots \ldots \\
16 \ldots \ldots \\
17 \ldots \ldots \\
18 \ldots \ldots \\
19 \ldots \ldots \\
20 \ldots \ldots\end{array}$ & $\begin{array}{l}33 \\
32 \\
31 \\
31 \\
32 \\
38 \\
32 \\
31 \\
31 \\
29\end{array}$ & $\begin{array}{r}742 \\
648 \\
1,250 \\
731 \\
539 \\
447 \\
383 \\
324 \\
294 \\
280\end{array}$ & $\begin{array}{l}21 \ldots \ldots \\
22 \ldots \ldots \\
23 \ldots \ldots \\
24 \ldots \ldots \\
25 \ldots \ldots \\
26 \ldots \ldots \\
27 \ldots \ldots \\
28 \ldots \ldots \\
29 \ldots \ldots \\
30 \ldots \ldots \\
31 \ldots \ldots\end{array}$ & $\begin{array}{r}29 \\
29 \\
29 \\
29 \\
29 \\
29 \\
29 \\
28 \\
67 \\
3,600 \\
7,400\end{array}$ & $\begin{array}{r}260 \\
250 \\
240 \\
220 \\
200 \\
180 \\
170 \\
160 \\
-\ldots-.-1 \\
-\ldots-\ldots\end{array}$ \\
\hline \multicolumn{7}{|c|}{ 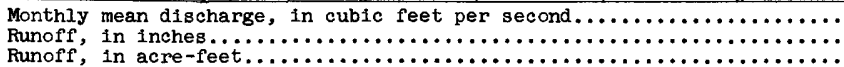 } & $\begin{array}{r}387 \\
4.02 \\
23,770\end{array}$ & $\begin{array}{r}599 \\
5.62 \\
33,270\end{array}$ \\
\hline
\end{tabular}

11-1615. Branciforte Creek at Santa Cruz, Cal1f.

Location. - -Lat 36 58:00", long $122^{\circ} 01^{\prime} 00^{\prime \prime}$, on right bank in Santa Cruz, Santa Cruz County, $15 \mathrm{ft}$ downstream from Market Street bridge and $1.0 \mathrm{mile}$ upstream from mouth.

Drainage area. $--17.3 \mathrm{sq} \mathrm{mi}$.

Gage-height record - Water-stage recorder graph; Datum of gage is $11.22 \mathrm{ft}$ above mean sea level (levels by Corps of Englneers).

D1scharge record.--Stage-discharge relation defined by current-meter measurements.

Maxima.--January-February 1963: Discharge, 2,820 cfs 1200 hours Jan. 31 (gage helght, $13.34 \mathrm{ft}$ ).

$1940-43,1952$ to December 1962: D1scharge, 8,100 cfs Dec. 22, 1955 (gage helght, $22.04 \mathrm{ft}$ ), from rating curve extended above $530 \mathrm{cfs}$ on basis of slopearea measurement of maximum flow.

Mean discharge, in cubic feet per second, 1963

\begin{tabular}{|c|c|c|c|c|c|c|c|c|}
\hline Day & January & February & Day & January & February & Day & January & February \\
\hline $\begin{array}{c}\ldots \ldots \\
2 \ldots \ldots \\
3 \ldots \ldots \\
4 \ldots \ldots \\
5 \ldots \ldots \\
6 \ldots \ldots \\
8 \ldots \ldots \\
9 \ldots \ldots \\
10 \ldots \ldots\end{array}$ & $\begin{array}{l}4.0 \\
3.8 \\
3.5 \\
3.5 \\
3.5 \\
3.3 \\
3.3 \\
3.3 \\
3.3 \\
3.0\end{array}$ & $\begin{array}{r}502 \\
127 \\
62 \\
42 \\
31 \\
24 \\
21 \\
20 \\
154 \\
247\end{array}$ & $\begin{array}{l}11 \ldots \ldots \\
12 \ldots \ldots \\
13 \ldots \ldots \\
14 \ldots \ldots \\
15 \ldots \ldots \\
16 \ldots \ldots \\
17 \ldots \ldots \\
18 \ldots \ldots \\
19 \ldots \ldots \\
20 \ldots \ldots\end{array}$ & $\begin{array}{l}3.0 \\
2.8 \\
2.8 \\
2.8 \\
2.8 \\
3.0 \\
3.0 \\
3.0 \\
3.0 \\
2.8\end{array}$ & $\begin{array}{r}92 \\
164 \\
445 \\
113 \\
68 \\
50 \\
37 \\
28 \\
22 \\
18\end{array}$ & $\begin{array}{l}21 \ldots \ldots \\
22 \ldots \ldots \\
23 \ldots \ldots \\
24 \ldots \ldots \\
25 \ldots \ldots \\
26 \ldots \ldots \\
27 \ldots \ldots \\
28 \ldots \ldots \\
29 \ldots \ldots \\
30 \ldots \ldots \\
31 \ldots \ldots\end{array}$ & $\begin{array}{r}2.8 \\
3.3 \\
3.5 \\
3.5 \\
3.5 \\
3.3 \\
3.3 \\
3.0 \\
11 \\
1,040 \\
1,220\end{array}$ & 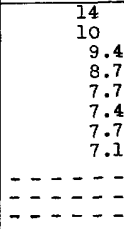 \\
\hline \multicolumn{7}{|c|}{ 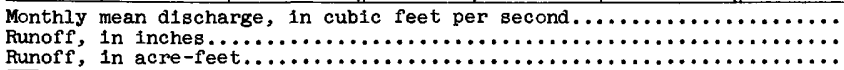 } & $\begin{array}{r}76.2 \\
5.07 \\
4,680\end{array}$ & $\begin{array}{r}83.5 \\
5.03 \\
4,640\end{array}$ \\
\hline
\end{tabular}

Gage he1ght, in feet, and discharge, in cublc feet per second, at indicated t1me, 1963

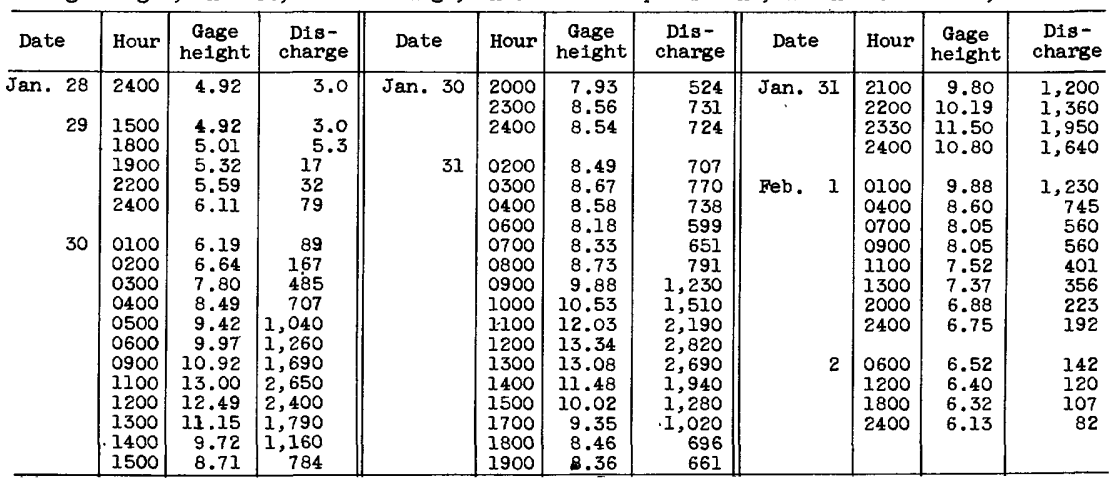




\section{SCOTT CREEK BASIN}

11-1619. Scott Creek above Little Creek, near Davenport, Calif.

Location.--Lat 37 $33^{\circ} 50^{\prime \prime}$, long $122^{\circ} 13^{\prime} 45^{\prime \prime}$, in Agua Puerco y las Trancas Grant, on right bank $600 \mathrm{ft}$ upstream from little Creek, 2.0 miles upstream from mouth, and 4.2 miles north of Davenport, Santa Cruz County.

Drainage area. $--25.0 \mathrm{sq} \mathrm{mi}$.

Gage-he1ght record; - Water-stage recorder graph. Altitude of gage is $30 \mathrm{ft}$ (from topographic mapj.

Discharge record.--Stage-discharge relation defined by current-meter measurements below $650 \mathrm{cfs}$ and by slope-area measurement at 1,060 cfs.

Maxima.--January-February 1963: D1scharge, 1,560 cfs 1300 hours Jan. 31 (gage helght, $8.71 \mathrm{ft}^{\prime}$ ).

1958 to December 1962: D1scharge, 1,970 cfs Feb. 13, 1962 (gage he1ght, $9.36 \mathrm{ft})$.

Mean discharge, in cub1c feet per second, 1963

\begin{tabular}{|c|c|c|c|c|c|c|c|c|}
\hline Day & January & February & Day & January & February & Day & January & February \\
\hline $\begin{array}{c}1 \ldots \ldots \\
2 \ldots \ldots \\
3 \ldots \ldots \\
5 \ldots \ldots \\
6 \ldots \ldots \\
7 \ldots \ldots \\
8 \ldots \ldots \\
9 \ldots \ldots \\
10 \ldots \ldots\end{array}$ & $\begin{array}{l}12 \\
12 \\
13 \\
14 \\
14 \\
14 \\
14 \\
13 \\
12 \\
14\end{array}$ & $\begin{array}{r}644 \\
303 \\
184 \\
151 \\
125 \\
105 \\
93 \\
95 \\
388 \\
444\end{array}$ & $\begin{array}{l}11 \ldots \ldots \\
12 \ldots \ldots \\
13 \ldots \ldots \\
14 \ldots \ldots \\
15 \ldots \ldots \\
16 \ldots \ldots \\
17 \ldots \ldots \\
18 \ldots \ldots \\
19 \ldots \ldots \\
20 \ldots \ldots\end{array}$ & $\begin{array}{l}14 \\
13 \\
13 \\
13 \\
14 \\
14 \\
13 \\
13 \\
12 \\
11\end{array}$ & $\begin{array}{l}267 \\
297 \\
376 \\
246 \\
197 \\
172 \\
148 \\
128 \\
116 \\
105\end{array}$ & $\begin{array}{l}21 \ldots \ldots \\
22 \ldots \ldots \\
23 \ldots \ldots \\
24 \ldots \ldots \\
25 \ldots \ldots \\
26 \ldots \ldots \\
27 \ldots \ldots \\
28 \ldots \ldots \\
29 \ldots \ldots \\
30 \ldots \ldots \\
31 \ldots \ldots\end{array}$ & $\begin{array}{r}12 \\
14 \\
12 \\
11 \\
11 \\
11 \\
10 \\
10 \\
13 \\
400 \\
1,030\end{array}$ & $\begin{array}{r}95 \\
90 \\
83 \\
77 \\
74 \\
70 \\
65 \\
62 \\
---- \\
-0-\end{array}$ \\
\hline \multicolumn{7}{|l|}{$\begin{array}{l}\text { Monthly } \\
\text { Runoff, } \\
\text { Runoff, }\end{array}$} & $\begin{array}{r}57.9 \\
2.67 \\
3,560\end{array}$ & $\begin{array}{r}186 \\
7.74 \\
10,310\end{array}$ \\
\hline
\end{tabular}

Gage height, in feet, and discharge, in cubic feet per second, at indicated time, 1963

\begin{tabular}{|c|c|c|c|c|c|c|c|c|c|c|c|}
\hline Date & Hour & $\begin{array}{c}\text { Gage } \\
\text { helght }\end{array}$ & $\begin{array}{l}\text { Dis- } \\
\text { charge }\end{array}$ & Date & Hour & $\begin{array}{c}\text { Gage } \\
\text { helght }\end{array}$ & $\begin{array}{l}\text { Dis- } \\
\text { charge }\end{array}$ & Date & Hour & $\begin{array}{c}\text { Gage } \\
\text { helght }\end{array}$ & $\begin{array}{l}\text { D1s- } \\
\text { charge }\end{array}$ \\
\hline $\begin{array}{r}\text { Jan. } 28 \\
29\end{array}$ & $\begin{array}{l}2400 \\
1300 \\
1500 \\
1700 \\
2000 \\
2400 \\
0300 \\
0600 \\
0600 \\
0800 \\
1000 \\
1200 \\
1400 \\
1600 \\
1800\end{array}$ & $\begin{array}{l}2.59 \\
2.59 \\
2.63 \\
2.69 \\
2.84 \\
3.00 \\
\\
2.75 \\
3.59 \\
3.57 \\
4.21 \\
5.05 \\
5.79 \\
6.00 \\
5.57 \\
6.11\end{array}$ & $\begin{array}{l}9.7 \\
{ }^{9.7} \\
11 \\
13 \\
20 \\
29 \\
\\
40 \\
137 \\
134 \\
244 \\
415 \\
593 \\
645 \\
538 \\
673\end{array}$ & Jan. 30 & $\begin{array}{l}2100 \\
2200 \\
2400 \\
0200 \\
0400 \\
0600 \\
0700 \\
0800 \\
0900 \\
1100 \\
1300 \\
1400 \\
1500 \\
1700 \\
1900 \\
2000\end{array}$ & $\begin{array}{l}5.48 \\
5.57 \\
6.26 \\
6.85 \\
6.44 \\
6.44 \\
6.30 \\
6.50 \\
7.06 \\
7.45 \\
8.71 \\
8.53 \\
8.00 \\
6.90 \\
6.52 \\
7.00\end{array}$ & $\begin{array}{r}515 \\
538 \\
71.8 \\
\\
895 \\
772 \\
772 \\
730 \\
790 \\
961 \\
1,100 \\
1,560 \\
1,490 \\
1,290 \\
910 \\
796 \\
940\end{array}$ & $\begin{array}{l}\text { Jan. } 31 \\
\text { Feb. } 1\end{array}$ & $\begin{array}{l}2200 \\
2300 \\
2400 \\
\\
0200 \\
0400 \\
0900 \\
1200 \\
1800 \\
2400 \\
\\
0600 \\
1200 \\
1800 \\
2400\end{array}$ & $\begin{array}{l}8.22 \\
8.16 \\
8.47 \\
7.21 \\
6.40 \\
6.10 \\
5.70 \\
5.28 \\
5.07 \\
4.82 \\
4.45 \\
4.19 \\
4.04\end{array}$ & $\begin{array}{r}1,370 \\
1,350 \\
1,470 \\
1,010 \\
760 \\
670 \\
570 \\
466 \\
419 \\
\\
364 \\
290 \\
240 \\
213\end{array}$ \\
\hline
\end{tabular}

PESCADERO CREEK BASIN

11-1624.7. Pescadero Creek tributary near La Honda, Calif.

(Crest-stage station)

Location.--Lat $37^{\circ} 16^{\prime} 40^{\prime \prime}$, long $122^{\circ} 17^{\prime} 35^{\prime \prime}$, in NW $\frac{1}{4} \mathrm{SW} \frac{1}{4}$ sec.34, T.7 S., R.4 W., at culvert on Pescadero road, 3.0 miles southwest of La Honda.

Drainage area. $--0.22 \mathrm{sq} \mathrm{ml}$.

Gage-height record.--Crest stages only. Altitude of gage is $240 \mathrm{ft}$ (from topographic mapl.

Discharge record.--Maximum discharge by computation of flow through culvert.

Max1ma.--January-February 1963: Discharge, $12 \mathrm{cfs}$ Jan. 31 (gage he1ght, $49.67 \mathrm{ft}$ ). 1960 to December 1962: Discharge, 5.0 cfs Feb. 14, 1962 (gage height, $48.86 \mathrm{ft})$. 
11-1625. Pescadero Creek near Pescadero, Cal1f.

Location.--Lat $37^{\circ} 15^{\prime} 40^{\prime \prime}$, long $122^{\circ} 19^{\prime} 40^{\prime \prime}$, in SW $\frac{1}{4}$ sec.5, T.8 S., R.4 W., on left bank at downstream side of highway bridge, 3.0 miles east of Pescadero and 5.3 miles upstream from mouth.

Drainage area. $--45.9 \mathrm{sq} \mathrm{m}$.

Gage-helght record.--Water-stage recorder graph, except Feb. 3-6, 10-24, 27, 28. Datum of gage is 62.3 ft above mean sea level, datum of 1929 .

D1scharge record.--Stage-discharge relation defined by current-meter measurements below 1,400 cfs and by slope-area measurement at 9,420 cfs. Discharge for periods of no gage-helght record estimated on basis of one discharge measurement and records for Scott Creek above Little Creek, near Davenport and Purisima Creek near Half Moon Bay.

Maxima,--January-February 1963: Discharge, 6,700 cfs 2400 hours Jan. 31 (gage he1 ght, $18.80 \mathrm{ft}$ ).

1951 to December 1962: Discharge, 9,420 cfs Dec. 23, 1955 (gage height, $21.27 \mathrm{ft}$ ), from rating curve extended above $2,700 \mathrm{cfs}$ on basis of slope-area measurement of maximum flow.

Mean discharge, in cubic feet per second, 1963

\begin{tabular}{|c|c|c|c|c|c|c|c|c|}
\hline Day & January & February & Day & January & February & Day & January & February \\
\hline $\begin{array}{c}1 \ldots \ldots \\
2 \ldots \ldots \\
3 \ldots \ldots \\
4 \ldots \ldots \\
5 \ldots \ldots \\
7 \ldots \ldots \\
8 \ldots \ldots \\
9 \ldots \ldots \\
10 \ldots \ldots\end{array}$ & $\begin{array}{c}11 \\
9.8 \\
10 \\
9.8 \\
9.4 \\
8.7 \\
8.3 \\
8.3 \\
8.3 \\
8.0\end{array}$ & $\begin{array}{r}2,180 \\
475 \\
250 \\
180 \\
160 \\
130 \\
107 \\
101 \\
319 \\
450\end{array}$ & $\begin{array}{l}11 \ldots \ldots \\
12 \ldots \ldots \\
13 \ldots \ldots \\
14 \ldots \ldots \\
15 \ldots \ldots \\
16 \ldots \ldots \\
17 \ldots \ldots \\
18 \ldots \ldots \\
19 \ldots \ldots \\
20 \ldots \ldots\end{array}$ & $\begin{array}{l}8.0 \\
7.6 \\
8.0 \\
8.0 \\
8.0 \\
7.6 \\
7.6 \\
7.3 \\
6.9 \\
6.6\end{array}$ & $\begin{array}{l}350 \\
300 \\
400 \\
280 \\
200 \\
175 \\
160 \\
145 \\
130 \\
120\end{array}$ & $\begin{array}{l}21 \ldots \ldots \\
22 \ldots \ldots \\
23 \ldots \ldots \\
24 \ldots \ldots \\
25 \ldots \ldots \\
26 \ldots \ldots \\
27 \ldots \ldots \\
28 \ldots \ldots \\
29 \ldots \ldots \\
30 \ldots \ldots \\
31 \ldots \ldots\end{array}$ & $\begin{array}{r}6.2 \\
6.2 \\
6.2 \\
6.2 \\
5.9 \\
5.5 \\
5.5 \\
5.3 \\
6.1 \\
790 \\
2,930\end{array}$ & $\begin{array}{r}110 \\
100 \\
90 \\
80 \\
73 \\
69 \\
65 \\
62 \\
-\ldots--\end{array}$ \\
\hline unoff, & $\begin{array}{l}\text { inche } \\
\text { acre }\end{array}$ & & & & & & $\begin{array}{r}127 \\
3.17 \\
7,820 \\
\end{array}$ & $\begin{array}{r}259 \\
5.84 \\
14,400 \\
\end{array}$ \\
\hline
\end{tabular}

Gage height, in feet, and discharge, in cublc feet per second, at indicated t1me, 1963

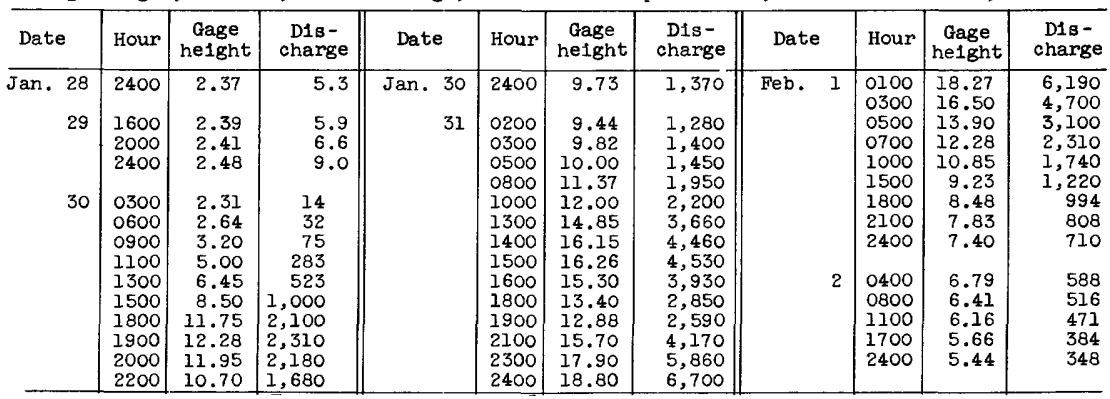

11-1625.4. Butano Creek near Pescadero, Calif.

Location.--Lat $37^{\circ} 14^{\prime} 01^{\prime \prime}$, long $122^{\circ} 21^{\prime} 56^{\prime \prime}$, In Butano Grant, on right bank $0.15 \mathrm{mile}$ below unnamed tributary and 1.7 miles southeast of Pescadero, San Mateo County.

Drainage area. $--18.3 \mathrm{sq} \mathrm{mi}$.

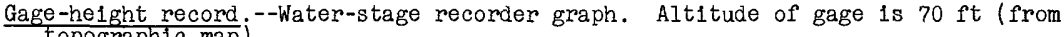
topographic map).

Discharge record.--Stage-discharge relation defined by current-meter measurements.

Max1ma.--January-February 1963: Discharge, 1,340 cfs 2400 hours Jan. 31; gage

helght, $16.21 \mathrm{ft} 1350$ hours Jan. 31 (backwater from mudflow).

1959 to December 1962: Discharge, 1,600 cfs Feb. 13, 1962.

Cooperation.--Records furnished by California Department of Water Resources. 
Mean discharge, in cubic feet per second, 1963, of Butano Creek near Pescadero, Calif.

\begin{tabular}{|c|c|c|c|c|c|c|c|c|}
\hline Day & January & February & Day & January & February & Day & January & February \\
\hline $\begin{array}{c}1 \ldots \ldots \\
2 \ldots \ldots \\
4 \ldots \ldots \\
5 \ldots \ldots \\
6 \ldots \ldots \\
8 \ldots \ldots \\
9 \ldots \ldots \\
10 \ldots \ldots\end{array}$ & $\begin{array}{l}8.1 \\
7.9 \\
7.6 \\
7.2 \\
6.8 \\
6.6 \\
6.4 \\
6.0 \\
5.8 \\
5.6\end{array}$ & $\begin{array}{r}552 \\
167 \\
107 \\
96 \\
73 \\
47 \\
42 \\
37 \\
124 \\
209\end{array}$ & $\begin{array}{l}11 \ldots \ldots \\
12 \ldots \ldots \\
13 \ldots \ldots \\
14 \ldots \ldots \\
15 \ldots \ldots \\
16 \ldots \ldots \\
17 \ldots \ldots \\
18 \ldots \ldots \\
19 \ldots \ldots \\
20 \ldots \ldots\end{array}$ & $\begin{array}{l}5.4 \\
5.4 \\
5.4 \\
5.4 \\
5.4 \\
5.4 \\
5.4 \\
5.4 \\
5.2 \\
5.0\end{array}$ & $\begin{array}{r}118 \\
105 \\
223 \\
136 \\
103 \\
87 \\
75 \\
64 \\
54 \\
48\end{array}$ & $\begin{array}{l}21 \ldots \ldots \\
22 \ldots \ldots \\
23 \ldots \ldots \\
24 \ldots \ldots \\
25 \ldots \ldots \\
26 \ldots \ldots \\
27 \ldots \ldots \\
28 \ldots \ldots \\
29 \ldots \ldots \\
30 \ldots \ldots \\
31 \ldots \ldots\end{array}$ & $\begin{array}{r}5.0 \\
4.9 \\
4.5 \\
4.3 \\
4.3 \\
4.3 \\
4.3 \\
4.2 \\
4.8 \\
333 \\
884\end{array}$ & $\begin{array}{r}43 \\
39 \\
36 \\
33 \\
31 \\
29 \\
27 \\
26 \\
-\ldots \\
-\ldots-\ldots\end{array}$ \\
\hline $\begin{array}{l}\text { nthly } \\
\text { anoff, } \\
\text { anoff, }\end{array}$ & $\begin{array}{l}\text { Inches } \\
\text { acre-1 }\end{array}$ & & & & & & $\begin{array}{r}44.5 \\
2.80 \\
2,740 \\
\end{array}$ & $\begin{array}{r}97.5 \\
5.55 \\
5,420 \\
\end{array}$ \\
\hline
\end{tabular}

\section{PURISIMA CREEK BASIN}

11-1626. Purisima Creek near Half Moon Bay, Calif.

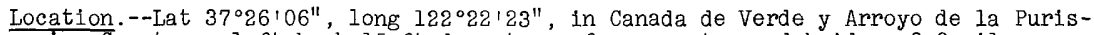
Ima Grant, on left bank $15 \mathrm{ft}$ downstream from county road bridge, 3.6 miles southeast of Half Moon Bay, San Mateo County, and 4.0 miles upstream from mouth.

Drainage area. $--4.83 \mathrm{sq} \mathrm{mi}$.

Gage-height record - -Water-stage recorder graph, except Feb. 2-28. Altitude of gage is $380 \mathrm{ft}^{-}$(from topographic map).

Discharge record.--Stage-discharge relation defined by current-meter measurements below $65 \mathrm{cf}$ 's and by slope-area measurement at $290 \mathrm{cf}$ s. Discharge for Feb. 2-28 estimated on basis of one discharge measurement and records for Scott Creek above Little Creek, near Davenport.

Maxima.--January-February 1963: Discharge, 301 cfs 2200 hours Jan. 31 (gage height, $5.31 \mathrm{ft}$ ).

1958 to December 1962: Discharge, 290 cfs Oct. 13, 1962 (gage height, $5.28 \mathrm{ft})$.

Mean discharge, in cubic feet per second, 1963

\begin{tabular}{|c|c|c|c|c|c|c|c|c|}
\hline Day & January & February & Day & January & Febmuary & Day & J anuary & February \\
\hline $\begin{array}{r}1 \ldots \ldots \\
2 \ldots \ldots \\
3 \ldots \ldots \\
4 \ldots \ldots \\
6 \ldots \ldots \\
7 \ldots \ldots \\
8 \ldots \ldots \\
10 \ldots \ldots\end{array}$ & $\begin{array}{l}2.0 \\
2.0 \\
1.8 \\
1.8 \\
1.8 \\
1.6 \\
1.6 \\
1.4 \\
1.4 \\
1.4\end{array}$ & $\begin{array}{l}87 \\
40 \\
20 \\
15 \\
10 \\
9.0 \\
8.5 \\
8.0 \\
20 \\
35\end{array}$ & $\begin{array}{l}11 \ldots \ldots \\
12 \ldots \ldots \\
13 \ldots \ldots \\
14 \ldots \ldots \\
15 \ldots \ldots \\
16 \ldots \ldots \\
17 \ldots \ldots \\
18 \ldots \ldots \\
19 \ldots \ldots \\
20 \ldots \ldots\end{array}$ & $\begin{array}{l}1.4 \\
1.3 \\
1.3 \\
1.3 \\
1.3 \\
1.3 \\
1.3 \\
1.3 \\
1.3 \\
1.1\end{array}$ & $\begin{array}{l}30 \\
22 \\
32 \\
25 \\
18 \\
15 \\
12 \\
11 \\
10 \\
9.0\end{array}$ & $\begin{array}{l}21 \ldots \ldots \\
22 \ldots \ldots \\
23 \ldots \ldots \\
24 \ldots \ldots \\
25 \ldots \ldots \\
26 \ldots \ldots \\
27 \ldots \ldots \\
28 \ldots \ldots \\
29 \ldots \ldots \\
30 \ldots \ldots \\
31 \ldots \ldots\end{array}$ & $\begin{array}{r}1.1 \\
1.1 \\
1.1 \\
1.1 \\
1.1 \\
1.1 \\
1.1 \\
1.1 \\
1.2 \\
19 \\
122\end{array}$ & $\begin{array}{r}8.5 \\
8.0 \\
7.5 \\
7.0 \\
6.5 \\
6.0 \\
5.5 \\
5.2 \\
--.-1 \\
--.-1\end{array}$ \\
\hline \multicolumn{7}{|c|}{ 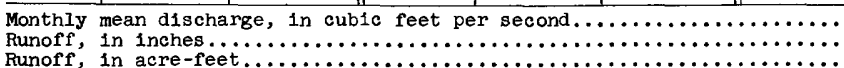 } & $\begin{array}{r}5.83 \\
1.39 \\
358\end{array}$ & $\begin{array}{r}17.5 \\
3.78 \\
973\end{array}$ \\
\hline
\end{tabular}

Gage height, in feet, and discharge, in cub1c feet per second, at indicated time, 1963

\begin{tabular}{|c|c|c|c|c|c|c|c|c|c|c|c|}
\hline Date & Hour & $\begin{array}{c}\text { Gage } \\
\text { he1ght }\end{array}$ & $\begin{array}{c}\text { Dis- } \\
\text { charge }\end{array}$ & Date & Hour & $\begin{array}{c}\text { Gage } \\
\text { height }\end{array}$ & $\begin{array}{l}\text { D1s- } \\
\text { charge }\end{array}$ & Date & Hour & $\begin{array}{c}\text { Gage } \\
\text { helght }\end{array}$ & $\begin{array}{c}\text { Dis- } \\
\text { charge }\end{array}$ \\
\hline $\begin{array}{r}\text { Jan. } \\
28\end{array}$ & $\begin{array}{l}2400 \\
1500 \\
1800 \\
2400\end{array}$ & $\begin{array}{l}3.48 \\
3.48 \\
3.50 \\
3.50\end{array}$ & $\begin{array}{l}1.1 \\
1.1 \\
1.4 \\
1.4\end{array}$ & Jan. 30 & $\begin{array}{l}1500 \\
1700 \\
1900 \\
2400\end{array}$ & $\begin{array}{l}3.94 \\
4.10 \\
4.06 \\
4.17\end{array}$ & $\begin{array}{l}23 \\
37 \\
33 \\
44\end{array}$ & $\operatorname{Jan} .31$ & $\begin{array}{l}2000 \\
2100 \\
2200 \\
2400\end{array}$ & $\begin{array}{l}5.21 \\
5.14 \\
5.31 \\
4.94\end{array}$ & $\begin{array}{l}266 \\
243 \\
301 \\
184\end{array}$ \\
\hline 30 & $\begin{array}{l}0300 \\
0500 \\
1000\end{array}$ & $\begin{array}{l}3.47 \\
3.54 \\
3.69\end{array}$ & $\begin{array}{l}2.0 \\
3.9 \\
8.9\end{array}$ & 31 & $\begin{array}{l}0900 \\
1200 \\
1600 \\
1900\end{array}$ & $\begin{array}{l}4.41 \\
4.73 \\
4.59 \\
4.78\end{array}$ & $\begin{array}{r}75 \\
134 \\
105 \\
145\end{array}$ & Feb. 1 & $\begin{array}{l}0300 \\
1300 \\
2400\end{array}$ & $\begin{array}{l}4.66 \\
4.40 \\
4.21\end{array}$ & $\begin{array}{r}119 \\
73 \\
48\end{array}$ \\
\hline
\end{tabular}


REDWOOD CREEK BASIN

11-1628. Redwood Creek at Redwood C1ty, Calif.

Location.--Lat $37^{\circ} 26^{\prime} 58^{\prime \prime}$, long $122^{\circ} 13^{\prime} 57^{\prime \prime}$, in Pulgas Grant, at Menlo Country Club, on right bank, $200 \mathrm{ft}$ upstream from Alameda de las Pulgas Bridge and $2.5 \mathrm{miles}$ south of Redwood City Post Office, San Mateo County.

Dralnage area. $--1.82 \mathrm{sq} \mathrm{mi}$.

Gage-height record.--Water-stage recorder graph, except Jan. 30 to Feb. 1, for which. graph was reconstructed on basis of fragmentary gage-height record and records for nearby stations. Datum of gage is $83.92 \mathrm{ft}$ above mean sea level, datum of 1929 .

Discharge record.--Stage-discharge relation defined by current-meter measurements below $170 \mathrm{cf}$ 's and by average of two indirect measurements of maximum flow.

Maxima.--January-February 1963: Discharge, 644 cf's 1830 hours Jan. 31 (gage height, $9.36 \mathrm{ft}$ ).

1959 to December 1962: Discharge, $360 \mathrm{cf}$ ' Mar. 5, 1962 (gage height, $6.68 \mathrm{ft}$ ).

Mean discharge, in cublc feet per second, 1963

\begin{tabular}{|c|c|c|c|c|c|c|c|c|}
\hline Day & January & February & Day & January & February & Day & January & February \\
\hline $\begin{array}{l}1 \ldots \ldots \\
2 \ldots \ldots \\
3 \ldots \ldots \\
4 \ldots \ldots \\
5 \ldots \ldots \\
7 \ldots \ldots \\
8 \ldots \ldots \\
9 \ldots \ldots \\
10 \ldots \ldots\end{array}$ & $\begin{array}{r}0.2 \\
.2 \\
.2 \\
.2 \\
.1 \\
.1 \\
.1 \\
.1 \\
.1 \\
.1\end{array}$ & $\begin{array}{r}24 \\
4.1 \\
2.2 \\
1.6 \\
1.3 \\
1.0 \\
.9 \\
.8 \\
14.8 \\
5.7\end{array}$ & $\begin{array}{l}11 \ldots \ldots \\
12 \ldots \ldots \\
13 \ldots \ldots \\
14 \ldots \ldots \\
15 \ldots \ldots \\
16 \ldots \ldots \\
17 \ldots \ldots \\
15 \ldots \ldots \\
19 \ldots \ldots \\
20 \ldots \ldots\end{array}$ & $\begin{array}{l}0.1 \\
.1 \\
.1 \\
.1 \\
.1 \\
.1 \\
.1 \\
.1 \\
.1 \\
.1\end{array}$ & $\begin{array}{l}1.9 \\
7.1 \\
7.3 \\
2.2 \\
1.7 \\
1.9 \\
1.5 \\
1.1 \\
.9 \\
.8\end{array}$ & $\begin{array}{l}21 \ldots \ldots \\
22 \ldots \ldots \\
23 \ldots \ldots \\
24 \ldots \ldots \\
25 \ldots \ldots \\
26 \ldots \ldots \\
27 \ldots \ldots \\
28 \ldots \ldots \\
29 \ldots \ldots \\
30 \ldots \ldots \\
31 \ldots \ldots\end{array}$ & $\begin{array}{r}0.1 \\
.1 \\
.1 \\
.1 \\
.1 \\
.1 \\
.1 \\
.1 \\
37^{.4} \\
151\end{array}$ & $\begin{array}{r}0.8 \\
.7 \\
.6 \\
.6 \\
.6 \\
.5 \\
.4 \\
.4 \\
--.-.-\end{array}$ \\
\hline \multicolumn{7}{|c|}{ 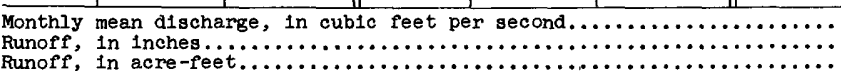 } & $\begin{array}{r}7.15 \\
4.53 \\
440\end{array}$ & $\begin{array}{r}3.09 \\
1.77 \\
172\end{array}$ \\
\hline
\end{tabular}

Gage height, in feet, and discharge, in cublc feet per second, at indicated time, 1963

\begin{tabular}{|c|c|c|c|c|c|c|c|c|c|c|c|}
\hline Date & Hour & $\begin{array}{c}\text { Qage } \\
\text { helght }\end{array}$ & $\begin{array}{l}\text { Dis- } \\
\text { charge }\end{array}$ & Date & Hour & $\begin{array}{c}\text { Gage } \\
\text { helght }\end{array}$ & $\begin{array}{c}\text { Dis- } \\
\text { charge }\end{array}$ & Date & Hour & $\begin{array}{c}\text { Gage } \\
\text { helght }\end{array}$ & $\begin{array}{c}\text { Dis- } \\
\text { charge }\end{array}$ \\
\hline $\begin{array}{r}\text { Jan: } 28 \\
29\end{array}$ & $\begin{array}{l}2400 \\
1500 \\
1800 \\
2000 \\
2300 \\
2400 \\
\\
0200 \\
0400 \\
0500 \\
0600 \\
0900\end{array}$ & $\begin{array}{l}1.02 \\
1.00 \\
1.32 \\
1.14 \\
1.06 \\
1.17 \\
1.15 \\
1.47 \\
1.41 \\
1.67 \\
1.89\end{array}$ & $\begin{array}{r}0.1 \\
.1 \\
1.9 \\
.5 \\
.2 \\
.7 \\
.6 \\
3.6 \\
2.8 \\
7.8 \\
13\end{array}$ & $\operatorname{Jan} .30$ & $\begin{array}{l}1100 \\
1300 \\
1500 \\
1800 \\
2200 \\
2400 \\
\\
0400 \\
1000 \\
1400 \\
1400 \\
1500 \\
1600\end{array}$ & $\begin{array}{l}3.93 \\
2.95 \\
3.85 \\
3.10 \\
2.28 \\
2.75 \\
2.30 \\
5.25 \\
3.22 \\
3.40 \\
3.05 \\
4.80\end{array}$ & $\begin{array}{r}99 \\
48 \\
94 \\
54 \\
24 \\
40 \\
\\
25 \\
210 \\
59 \\
68 \\
52 \\
167\end{array}$ & Jan. 31 & $\begin{array}{l}1800 \\
1830 \\
1900 \\
2200 \\
2400 \\
\\
0300 \\
0600 \\
1200 \\
1800 \\
2400\end{array}$ & $\begin{array}{l}8.00 \\
9.36 \\
9.00 \\
5.30 \\
3.70 \\
2.25 \\
2.80 \\
2.06 \\
1.74 \\
1.59\end{array}$ & $\begin{array}{r}505 \\
644 \\
608 \\
215 \\
85 \\
\\
24 \\
42 \\
18 \\
9.5 \\
6.0\end{array}$ \\
\hline
\end{tabular}

\section{ATHERTON DRAINAGE CHANNEL BASIN}

11-1629. Sharon Creek near Menlo Park, Calif.

Location.--Lat $37^{\circ} 25^{\prime} 45^{\prime \prime}$, long $122^{\circ} 13^{\prime} 02^{\prime \prime}$, in Pulgas Grant, at Atherton city boundary, 900 ft upstream from Atherton drainage channel and 2.6 miles southwest of Menio Park, San Mateo County.

Drainage area $--0.38 \mathrm{sq} \mathrm{mi}$.

Gage-height record.--Water-stage recorder graph. Datum of gage is $146.18 \mathrm{ft}$ above mean sea leve1, datum of 1929.

Discharge record.--Stage-discharge relation defined by current-meter measurements below $21 \mathrm{cf}$ 's and by slope-area measurement at $68 \mathrm{cfs}$.

Maxima.--January-February 1963: Discharge, 68 cf's 1900 hours Jan. 31 (gage heIght, $3.07 \mathrm{ft}$ ).

1958 to December 1962: Discharge, $56 \mathrm{cfs}$ Mar. 5, 1962 (gage height, $3.10 \mathrm{ft}$, from floodmarks), from rating curve extended above $18 \mathrm{cfs}$ on basis of slopearea measurement of peak flow.

Flood of Apr. 2, 1958, reached a stage of about $4.2 \mathrm{ft}$, from floodmarks. 
Mean discharge, in cubic feet per second, 1963, of Sharon Creek near Menlo Park, Cal1f.

\begin{tabular}{|c|c|c|c|c|c|c|c|c|}
\hline Day & January & February & Day & J anuary & February & Day & January & February \\
\hline $\begin{array}{c}\ldots \ldots \\
2 \ldots \ldots \\
3 \ldots \ldots \\
4 \ldots \ldots \\
6 \ldots \ldots \\
7 \ldots \ldots \\
8 \ldots \ldots \\
10 \ldots \ldots\end{array}$ & $\begin{array}{l}0.03 \\
.03 \\
.03 \\
.03 \\
.02 \\
.02 \\
.02 \\
.02 \\
.02 \\
.03\end{array}$ & $\begin{array}{r}3.70 \\
1.07 \\
.62 \\
.06 \\
.12 \\
.09 \\
.09 \\
.05 \\
5.02 \\
.58\end{array}$ & $\begin{array}{l}11 \ldots \ldots \\
12 \ldots \ldots \\
13 \ldots \ldots \\
14 \ldots \ldots \\
15 \ldots \ldots \\
16 \ldots \ldots \\
17 \ldots \ldots \\
18 \ldots \ldots \\
19 \ldots \ldots \\
20 \ldots \ldots\end{array}$ & $\begin{array}{l}0.35 \\
0 \\
0 \\
0 \\
0 \\
0 \\
.01 \\
.01 \\
.03 \\
0 .\end{array}$ & $\begin{array}{l}0.10 \\
1.86 \\
.54 \\
.07 \\
.04 \\
.05 \\
.02 \\
.02 \\
.09 \\
.02\end{array}$ & $\begin{array}{l}21 \ldots \ldots \\
22 \ldots \ldots \\
23 \ldots \ldots \\
24 \ldots \ldots \\
25 \ldots \ldots \\
26 \ldots \ldots \\
27 \ldots \ldots \\
28 \ldots \ldots \\
29 \ldots \ldots \\
30 \ldots \ldots \\
31 \ldots \ldots\end{array}$ & $\begin{array}{l}0 \\
0 \\
0 \\
0 \\
.01 \\
.01 \\
.01 \\
.01 \\
.08 \\
6.25 \\
19.2\end{array}$ & $\begin{array}{r}0.39 \\
.02 \\
.01 \\
.01 \\
.01 \\
.01 \\
.02 \\
.01 \\
---- \\
----0 \\
-----\end{array}$ \\
\hline noff, & $\begin{array}{l}\text { inche } \\
\text { acre- }\end{array}$ & & & & & & $\begin{array}{r}0.846 \\
2.57 \\
52\end{array}$ & $\begin{array}{r}0.525 \\
1.44 \\
29 \\
\end{array}$ \\
\hline
\end{tabular}

Gage he1ght, in feet, and discharge, in cublc feet per second, at indicated time, 1963

\begin{tabular}{|c|c|c|c|c|c|c|c|c|c|c|c|}
\hline Date & Hour & $\begin{array}{c}\text { Gage } \\
\text { he1ght }\end{array}$ & $\begin{array}{l}\text { Dis- } \\
\text { charge }\end{array}$ & Date & Hour & $\begin{array}{c}\text { Gage } \\
\text { height }\end{array}$ & $\begin{array}{l}\text { Dis- } \\
\text { charge }\end{array}$ & Date & Hour & $\begin{array}{c}\text { Gage } \\
\text { helght }\end{array}$ & $\begin{array}{c}\text { D1s- } \\
\text { charge }\end{array}$ \\
\hline $\begin{array}{r}\text { Jan. } 29 \\
30\end{array}$ & $\begin{array}{l}2400 \\
0100 \\
0200 \\
0300 \\
0400 \\
0500 \\
0600 \\
0700 \\
0800 \\
0900 \\
1000 \\
1100 \\
1200 \\
1300 \\
1400 \\
1500 \\
1600 \\
1700 \\
1800 \\
1900 \\
2000\end{array}$ & $\begin{array}{l}1.22 \\
1.17 \\
1.14 \\
1.21 \\
1.61 \\
1.55 \\
1.66 \\
1.69 \\
1.64 \\
1.84 \\
2.03 \\
2.12 \\
2.03 \\
1.73 \\
2.00 \\
2.09 \\
2.00 \\
1.85 \\
1.59 \\
1.62 \\
1.62\end{array}$ & $\begin{array}{c}0.28 \\
.16 \\
.11 \\
.24 \\
3.28 \\
2.42 \\
4.08 \\
4.62 \\
3.84 \\
8.23 \\
15.1 \\
18.8 \\
15.1 \\
5.42 \\
13.9 \\
17.4 \\
13.9 \\
8.68 \\
2.98 \\
3.44 \\
3.44\end{array}$ & Jan. 30 & $\begin{array}{l}2100 \\
2200 \\
2300 \\
2400 \\
0100 \\
0200 \\
0300 \\
0400 \\
0500 \\
0600 \\
0700 \\
0800 \\
0900 \\
1000 \\
1100 \\
1200 \\
1300 \\
1400 \\
1500 \\
1600 \\
1700\end{array}$ & $\begin{array}{l}1.50 \\
1.42 \\
1.38 \\
1.51 \\
1.44 \\
1.37 \\
1.39 \\
1.40 \\
1.84 \\
2.04 \\
2.03 \\
1.81 \\
2.08 \\
2.56 \\
2.41 \\
2.13 \\
1.79 \\
1.63 \\
1.80 \\
2.22 \\
2.31\end{array}$ & $\begin{array}{c}1.77 \\
1.07 \\
.88 \\
1.89 \\
1.20 \\
.82 \\
.91 \\
.96 \\
8.38 \\
15.5 \\
15.1 \\
7.48 \\
17.0 \\
38.8 \\
31.5 \\
19.1 \\
6.92 \\
3.60 \\
7.20 \\
22.9 \\
26.9\end{array}$ & Feb. 1 & $\begin{array}{l}1800 \\
1900 \\
2000 \\
2100 \\
2200 \\
2300 \\
2400 \\
\\
0100 \\
0200 \\
0300 \\
0400 \\
0500 \\
0600 \\
0700 \\
0800 \\
0900 \\
1000 \\
1100 \\
1300 \\
1500 \\
1800 \\
2400\end{array}$ & $\begin{array}{l}2.66 \\
3.07 \\
2.51 \\
2.69 \\
2.34 \\
2.03 \\
1.79 \\
1.71 \\
1.66 \\
1.62 \\
1.57 \\
1.90 \\
1.95 \\
1.87 \\
1.71 \\
1.66 \\
1.65 \\
1.61 \\
1.54 \\
1.52 \\
1.48 \\
1.45\end{array}$ & $\begin{array}{c}44.0 \\
68.0 \\
36.3 \\
45.6 \\
28.2 \\
15.1 \\
6.92 \\
\\
5.00 \\
4.08 \\
3.44 \\
2.70 \\
10.3 \\
12.1 \\
9.32 \\
5.00 \\
4.08 \\
3.92 \\
3.28 \\
2.28 \\
2.02 \\
1.54 \\
1.27\end{array}$ \\
\hline
\end{tabular}

\section{SAN FRANCISQUITO CREEK BASIN}

11-1629.4. San Francisquito Creek below Ladera damsite, near Stanford University, Calif.

Location.--Lat $37^{\circ} 24^{\prime} 24^{\prime \prime}$, long $122^{\circ} 12^{\prime} 11^{\prime \prime}$, on north boundary of El Corte de Madera Grant, 1.2 miles upstream from Los Trancos Creek, $0.5 \mathrm{mile}$ northwest of Ladera School, and 2.3 miles southwest of Stanford University Post Office, Santa Clara County.

Drainage area. $--28.5 \mathrm{sq} \mathrm{ml}$.

Gage-height record.--Digital-recorder tape punched at 15-minute intervals. Alt1tude of gage is $180 \mathrm{ft}$ (from topographic map).

Discharge record.--Stage-discharge relation defined by current-meter measurements below 620 cf's.

Maxima.--January-February 1963: Discharge, 2,880 cfs 2230 hours Jan. 31 (gage height, $16.04 \mathrm{ft}$ ).

1961 to December 1962: Discharge, 1,400 cfs 0ct. 13, 1962 (gage height, $9.87 \mathrm{ft}$ ).

Remarks.--Flow slightly regulated by Searsville Lake (capac1ty, 952 acre ft). 
Mean discharge, in cublc feet per second, 1963, of San Franclsquito Creek below Iadera damsite, near Stanford University, Calif.

\begin{tabular}{|c|c|c|c|c|c|c|c|c|}
\hline Day & January & February & Day & January & February & Day & January & February \\
\hline $\begin{array}{c}3 \ldots \\
2 \ldots \ldots \\
3 \ldots \ldots \\
4 \ldots \ldots \\
5 \ldots \ldots \\
6 \ldots \ldots \\
7 \ldots \ldots \\
8 \ldots \ldots \\
9 \ldots \ldots \\
10 \ldots \ldots\end{array}$ & $\begin{array}{r}0.9 \\
7.4 \\
.6 \\
.4 \\
.4 \\
.4 \\
.4 \\
.4 \\
.5 \\
.4\end{array}$ & $\begin{array}{r}866 \\
227 \\
99 \\
47 \\
35 \\
27 \\
23 \\
20 \\
185 \\
221\end{array}$ & $\begin{array}{l}11 \ldots \ldots \\
12 \ldots \ldots \\
13 \ldots \ldots \\
14 \ldots \ldots \\
15 \ldots \ldots \\
16 \ldots \ldots \\
17 \ldots \ldots \\
18 \ldots \ldots \\
19 \ldots \ldots \\
20 \ldots \ldots\end{array}$ & $\begin{array}{r}0.3 \\
.3 \\
.3 \\
.3 \\
.3 \\
.3 \\
.5 \\
.4 \\
.3 \\
.3\end{array}$ & $\begin{array}{r}69 \\
74 \\
187 \\
59 \\
43 \\
37 \\
33 \\
26 \\
23 \\
19\end{array}$ & $\begin{array}{l}21 \ldots \ldots \\
22 \ldots \ldots \\
23 \ldots \ldots \\
24 \ldots \ldots \\
25 \ldots \ldots \\
26 \ldots \ldots \\
27 \ldots \ldots \\
28 \ldots \ldots \\
29 \ldots \ldots \\
30 \ldots \ldots \\
31 \ldots \ldots\end{array}$ & $\begin{array}{r}0.3 \\
.3 \\
.4 \\
.4 \\
.3 \\
.4 \\
.3 \\
.4 \\
.4 \\
335 \\
1,560\end{array}$ & $\begin{array}{c}14 \\
13 \\
11 \\
10 \\
9.7 \\
10 \\
12 \\
11 \\
\ldots \ldots \\
-\ldots-.- \\
-\ldots-\ldots\end{array}$ \\
\hline noff, & $\begin{array}{l}\text { Inche } \\
\text { acre- }\end{array}$ & & & & & & $\begin{array}{r}61.7 \\
2.50 \\
3,790\end{array}$ & $\begin{array}{r}86.1 \\
3.15 \\
4,780 \\
\end{array}$ \\
\hline
\end{tabular}

Gage height, in feet, and discharge, in cublc feet per second, at indicated time, 1963

\begin{tabular}{|c|c|c|c|c|c|c|c|c|c|c|c|}
\hline Date & Hour & $\begin{array}{c}\text { Gage } \\
\text { helght }\end{array}$ & $\begin{array}{l}\text { D1s- } \\
\text { charge }\end{array}$ & Date & Hour & $\begin{array}{c}\text { Gage } \\
\text { helght }\end{array}$ & $\begin{array}{c}\text { D1s - } \\
\text { charge }\end{array}$ & Date & Hour & $\begin{array}{c}\text { Gage } \\
\text { helght }\end{array}$ & $\begin{array}{c}\text { Dls- } \\
\text { charge }\end{array}$ \\
\hline $\begin{array}{r}\text { Jan. } 29 \\
30\end{array}$ & $\begin{array}{l}2400 \\
0200 \\
0400 \\
0600 \\
1000 \\
1200 \\
1400 \\
1600 \\
1800 \\
1830 \\
2000 \\
2200 \\
2400\end{array}$ & $\begin{array}{l}2.51 \\
2.51 \\
2.78 \\
2.74 \\
3.38 \\
4.67 \\
5.29 \\
6.34 \\
7.32 \\
8.13 \\
7.34 \\
7.00 \\
6.44\end{array}$ & $\begin{array}{c}0.4 \\
\\
3.4 \\
3.6 \\
2.9 \\
31 \\
259 \\
378 \\
588 \\
800 \\
981 \\
805 \\
730 \\
608\end{array}$ & Feb. 1 & $\begin{array}{l}0200 \\
0400 \\
0600 \\
0800 \\
1000 \\
1200 \\
1400 \\
1600 \\
1800 \\
2000 \\
2230 \\
2400 \\
0200\end{array}$ & $\begin{array}{r}6.56 \\
6.24 \\
6.66 \\
7.89 \\
8.50 \\
11.94 \\
12.06 \\
10.32 \\
11.62 \\
13.97 \\
16.04 \\
13.85 \\
11.34\end{array}$ & $\begin{array}{r}632 \\
568 \\
655 \\
926 \\
1,070 \\
1,900 \\
1,920 \\
1,510 \\
1,820 \\
2,380 \\
2,880 \\
2,350 \\
1,750\end{array}$ & Feb. $\quad l$ & $\begin{array}{l}0400 \\
0800 \\
1000 \\
1200 \\
1800 \\
2200 \\
2400 \\
\\
0600 \\
1200 \\
1800 \\
2400\end{array}$ & $\begin{array}{l}9.80 \\
8.49 \\
6.29 \\
6.56 \\
5.81 \\
5.30 \\
5.12 \\
\\
4.76 \\
4.50 \\
4.29 \\
4.24\end{array}$ & $\begin{array}{r}3,380 \\
1,070 \\
578 \\
633 \\
482 \\
380 \\
344 \\
\\
277 \\
224 \\
175 \\
140\end{array}$ \\
\hline
\end{tabular}

11-1629.5. San Francisquito Creek tributary near Stanford University, Calif.

Location.--Lat $37^{\circ} 24^{\prime} 43^{\prime \prime}$, long $122^{\circ} 11^{\prime} 52^{\prime \prime}$, in Pulgas Grant, on left bank $130 \mathrm{ft}$ upstream from mouth, $200 \mathrm{ft}$ downstream from ranch road bridge, $0.4 \mathrm{mile}$ west of gate at Alpine Road, and 1.8 miles southwest of Stanford University Post office, Santa Clara County.

Drainage area. $--0.26 \mathrm{sq} \mathrm{mi}$.

Gage-height record.--Water-stage recorder graph. Datum of gage is $174.73 \mathrm{ft}$ above mean sea level, datum of 1929.

Discharge record.--Stage-discharge relation defined by current-meter measurements below $16 \mathrm{cf}$ s and by slope-area measurement at $39 \mathrm{cfs}$.

Maxima.--January-February 1963: Discharge, 38 cfs 2145 hours Jan. 31 (gage he1ght, $2.96 \mathrm{ft})$

1958 to December 1962: Discharge, $39 \mathrm{cfs}$ Mar. 5, 1962 (gage height, $2.98 \mathrm{ft}$ ). Flood of Apr. 2, 1958, reached a stage of $3.2 \mathrm{ft}$, from floodmarks.

Mean discharge, in cubic feet per second, 1963

\begin{tabular}{|c|c|c|c|c|c|c|c|c|}
\hline Day & January & February & Day & January & February & Day & January & February \\
\hline $\begin{array}{c}\ldots \ldots \\
2 \ldots \ldots \\
3 \ldots \ldots \\
4 \ldots \ldots \\
5 \ldots \ldots \\
7 \ldots \ldots \\
8 \ldots \ldots \\
9 \ldots \ldots \\
10 \ldots \ldots\end{array}$ & $\begin{array}{l}0 \\
0 \\
0 \\
0 \\
0 \\
0 \\
0 \\
0 \\
0 \\
0\end{array}$ & $\begin{array}{r}2.56 \\
.41 \\
.24 \\
.14 \\
.03 \\
.02 \\
.01 \\
.01 \\
3.46 \\
.59\end{array}$ & $\begin{array}{l}11 \ldots \ldots \\
12 \ldots \ldots \\
13 \ldots \ldots \\
14 \ldots \ldots \\
15 \ldots \ldots \\
16 \ldots \ldots \\
17 \ldots \ldots \\
18 \ldots \ldots \\
19 \ldots \ldots \\
20 \ldots \ldots\end{array}$ & $\begin{array}{l}0 \\
0 \\
0 \\
0 \\
0 \\
0 \\
0 \\
0 \\
0 \\
0\end{array}$ & $\begin{array}{r}0.18 \\
1.45 \\
.71 \\
.18 \\
.07 \\
.11 \\
.05 \\
.01 \\
.01 \\
.01\end{array}$ & $\begin{array}{l}21 \ldots \ldots \\
22 \ldots \ldots \\
23 \ldots \ldots \\
24 \ldots \ldots \\
25 \ldots \ldots \\
26 \ldots \ldots \\
27 \ldots \ldots \\
28 \ldots \ldots \\
29 \ldots \ldots \\
30 \ldots \ldots \\
31 \ldots \ldots\end{array}$ & $\begin{array}{l}0 \\
0 \\
0 \\
0 \\
0 \\
0 \\
0 \\
0 \\
0 \\
1.30 \\
11.9\end{array}$ & $\begin{array}{r}0.01 \\
.01 \\
.01 \\
.01 \\
.01 \\
.01 \\
.01 \\
0 \\
----- \\
---.--\end{array}$ \\
\hline $\begin{array}{l}\text { onthly } \\
\text { anoff, } \\
\text { anoff, }\end{array}$ & $\begin{array}{l}\text { Inche } \\
\text { acre- }\end{array}$ & $\ldots$ & & & & & $\begin{array}{r}0.426 \\
1.89 \\
26\end{array}$ & $\begin{array}{r}0.369 \\
i .48 \\
20 \\
\end{array}$ \\
\hline
\end{tabular}


Gage height, in feet, and discharge, in cubic feet per second, at indicated time, 1963, of

\begin{tabular}{|c|c|c|c|c|c|c|c|c|c|c|c|}
\hline Date & Hour & $\begin{array}{c}\text { Gage } \\
\text { height }\end{array}$ & $\begin{array}{l}\text { Dis- } \\
\text { charge }\end{array}$ & Date & Hour & $\begin{array}{l}\text { Gage } \\
\text { helght }\end{array}$ & $\begin{array}{l}\text { Dis- } \\
\text { charge }\end{array}$ & Date & Hour & $\begin{array}{c}\text { Gage } \\
\text { height }\end{array}$ & $\begin{array}{c}\text { Dis - } \\
\text { charge }\end{array}$ \\
\hline $\begin{array}{r}\operatorname{Tan} .29 \\
30\end{array}$ & $\begin{array}{l}2400 \\
0600 \\
0700 \\
0800 \\
0900 \\
1000 \\
1100 \\
1200 \\
1400 \\
1500 \\
1600 \\
1700 \\
1800 \\
1900 \\
2000 \\
2200\end{array}$ & $\begin{array}{l}0.68 \\
1.18 \\
1.24 \\
1.28 \\
1.23 \\
1.41 \\
1.62 \\
1.72 \\
1.46 \\
1.93 \\
1.83 \\
1.69 \\
1.58 \\
1.43 \\
1.47 \\
1.32\end{array}$ & $\begin{array}{l}0 \\
.19 \\
.34 \\
.44 \\
.31 \\
.94 \\
2.45 \\
3.62 \\
1.22 \\
7.08 \\
5.22 \\
3.22 \\
2.08 \\
1.04 \\
1.28 \\
.56\end{array}$ & $\begin{array}{r}\operatorname{Jan} .30 \\
31\end{array}$ & $\begin{array}{l}2400 \\
0100 \\
0300 \\
0400 \\
0500 \\
0600 \\
0800 \\
0900 \\
1000 \\
1030 \\
1100 \\
1200 \\
1300 \\
1400 \\
1500 \\
1600\end{array}$ & $\begin{array}{l}1.27 \\
1.42 \\
1.30 \\
1.29 \\
1.42 \\
1.90 \\
1.78 \\
1.65 \\
2.35 \\
2.45 \\
2.20 \\
2.26 \\
1.90 \\
1.68 \\
1.66 \\
1.90\end{array}$ & $\begin{array}{r}0.41 \\
.99 \\
.50 \\
.47 \\
.99 \\
6.45 \\
4.43 \\
2.76 \\
17.8 \\
20.8 \\
13.6 \\
15.3 \\
6.45 \\
3.10 \\
2.87 \\
6.45\end{array}$ & Jan. 31 & $\begin{array}{l}1700 \\
1800 \\
1900 \\
2000 \\
2145 \\
2300 \\
2400 \\
\\
0200 \\
0430 \\
0600 \\
0800 \\
1200 \\
1800 \\
2400\end{array}$ & $\begin{array}{l}2.36 \\
2.26 \\
2.94 \\
2.51 \\
2.96 \\
2.45 \\
2.02 \\
1.68 \\
1.58 \\
2.06 \\
1.80 \\
1.49 \\
1.38 \\
1.33\end{array}$ & $\begin{array}{c}18.1 \\
15.3 \\
37.7 \\
22.7 \\
38.5 \\
20.8 \\
9.03 \\
3.10 \\
2.08 \\
10.0 \\
4.70 \\
1.41 \\
.79 \\
.60\end{array}$ \\
\hline
\end{tabular}

11-1632. Los Trancos Creek tributary near Stanford University, Calif.

Location.--Iat $37^{\circ} 24^{\prime} 18^{\prime \prime}$, long $122^{\circ} 11^{\prime} 09^{\prime \prime}$, in El Corte de Madera Grant, on right bank $350 \mathrm{ft}$ east of wooden water tanks, 0.4 mile east of Ladera, 0.6 mile upstream from mouth, and 1.7 miles southwest of Stanford University Post office, Santa Clara County.

Drainage area. $--0.47 \mathrm{sq} \mathrm{mi}$.

Gage-height record.--Water-stage recorder graph. Datum of gage is $269.13 \mathrm{ft}$ above mean sea leve1, datum of 1929.

Discharge record.--Stage-discharge relation defined by current-meter measurements below $8 \mathrm{cf}$ 's and by slope-area measurement at $64 \mathrm{cfs}$.

Maxima --January-February 1963: Discharge, $66 \mathrm{cfs} 1830$ hours Jan. 31 (gage helght, $2.63 \mathrm{ft})$.

1958 to December 1962: Discharge, $57 \mathrm{cfs}$ Mar. 5, 1962 (gage height, $2.53 \mathrm{ft}$ ).

Mean discharge, in cubic feet per second, 1963

\begin{tabular}{|c|c|c|c|c|c|c|c|c|}
\hline Day & January & February & Day & January & February & Day & January & February \\
\hline $\begin{array}{c}1 \ldots \ldots \\
2 \ldots \ldots \\
3 \ldots \ldots \\
4 \ldots \ldots \\
5 \ldots \ldots \\
6 \ldots \ldots \\
7 \ldots \ldots \\
9 \ldots \ldots \\
10 \ldots \ldots\end{array}$ & $\begin{array}{l}0 \\
0 \\
0 \\
0 \\
0 \\
0 \\
0 \\
0 \\
0 \\
0\end{array}$ & $\begin{array}{r}2.86 \\
.20 \\
.07 \\
.02 \\
.07 \\
.01 \\
.01 \\
0 . \\
4.51 \\
.57\end{array}$ & $\begin{array}{l}11 \ldots \ldots \\
12 \ldots \ldots \\
13 \ldots \ldots \\
14 \ldots \ldots \\
15 \ldots \ldots \\
16 \ldots \ldots \\
17 \ldots \ldots \\
18 \ldots \ldots \\
19 \ldots \ldots \\
20 \ldots \ldots\end{array}$ & $\begin{array}{l}0 \\
0 \\
0 \\
0 \\
0 \\
0 \\
0 \\
0 \\
0 \\
0\end{array}$ & $\begin{array}{l}0.30 \\
.76 \\
.91 \\
.09 \\
.03 \\
.02 \\
.02 \\
.01 \\
.01 \\
.01\end{array}$ & $\begin{array}{l}21 \ldots \ldots \\
22 \ldots \ldots \\
23 \ldots \ldots \\
24 \ldots \ldots \\
25 \ldots \ldots \\
26 \ldots \ldots \\
27 \ldots \ldots \\
28 \ldots \ldots \\
29 \ldots \ldots \\
30 \ldots \ldots \\
31 \ldots \ldots\end{array}$ & $\begin{array}{l}0 \\
0 \\
0 \\
0 \\
0 \\
0 \\
0 \\
0 \\
0 \\
16.9\end{array}$ & $\begin{array}{c}0.01 \\
0 \\
0 \\
0 \\
0 \\
0 \\
0 \\
0 \\
-\ldots--. \\
-\ldots---\end{array}$ \\
\hline $\begin{array}{l}\text { onthly } \\
\text { inoff, } \\
\text { unoff, }\end{array}$ & $\begin{array}{l}\text { an disc } \\
\text { inches } \\
\text { acre-f }\end{array}$ & $\cdots$ & $\cdots \cdots$ & $\cdots \cdots$ & & $\ldots \ldots$ & $\begin{array}{r}0.555 \\
1.36 \\
34 \\
\end{array}$ & $\begin{array}{r}0.372 \\
0.83 \\
21 \\
\end{array}$ \\
\hline
\end{tabular}

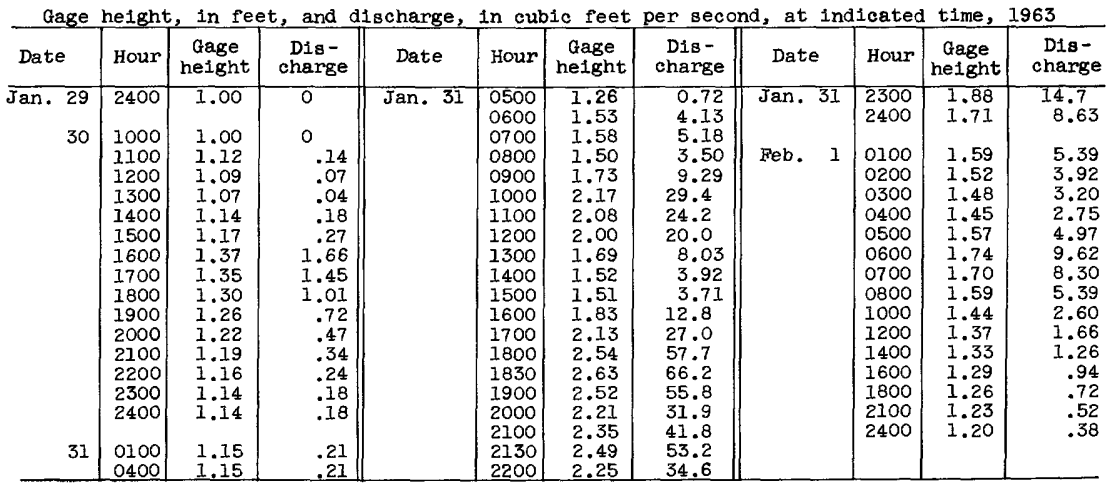


11-1645. San Francisquito Creek at Stanford University, Calif.

Location.--Lat $37^{\circ} 25^{\prime} 2^{\prime \prime}$, long $122^{\circ} 11^{\prime} 18^{\prime \prime}$, in San Franclsquito Grant at golf course, on right bank 1.1 miles downstream from Los Trancos Creek and 1.1 miles west of Stanford University Post Office, Santa Clara County.

Drainage area. $--37.5 \mathrm{sq} \mathrm{mi}$.

Gage-he1ght record; --Water-stage recorder graph. Altitude of gage is 120 ft (from topographic map)

Discharge record.--Stage-discharge relation defined by current-meter measurements .

Maxima.--January-February 1963: Discharge, 3,270 cfs 2300 hours Jan. 31 (gage helght, $9.28 \mathrm{ft}$ in gage well; $10.07 \mathrm{ft}$, from outslde gage).

1930-41, 1950 to December 1962: Discharge, 5,560 cfs Dec. 22, 1955 (gage height, $13.60 \mathrm{ft}$ ).

Remarks.--Flow slightly regulated by Searsville Lake (capac1ty, 952 acre-ft).

Mean discharge, in cub1c feet per second, 1963

\begin{tabular}{|c|c|c|c|c|c|c|c|c|}
\hline Day & January & February & Day & January & February & Day & January & February \\
\hline $\begin{array}{c}1 \ldots \ldots \\
2 \ldots \ldots \\
3 \ldots \ldots \\
4 \ldots \ldots \\
5 \ldots \ldots \\
6 \ldots \ldots \\
7 \ldots \ldots \\
9 \ldots \ldots \\
10 . \ldots .\end{array}$ & $\begin{array}{l}0.3 \\
4.0 \\
.2 \\
.2 \\
.2 \\
.2 \\
.2 \\
.2 \\
.2 \\
.2\end{array}$ & $\begin{array}{r}555 \\
201 \\
88 \\
45 \\
31 \\
19 \\
11 \\
13 \\
159 \\
190\end{array}$ & 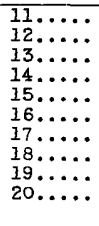 & $\begin{array}{l}0.2 \\
.2 \\
.1 \\
.2 \\
.1 \\
.1 \\
.2 \\
.1 \\
.1 \\
.1\end{array}$ & $\begin{array}{r}69 \\
76 \\
167 \\
70 \\
49 \\
47 \\
42 \\
26 \\
19 \\
21\end{array}$ & $\begin{array}{l}21 \ldots \ldots \\
22 \ldots \ldots \\
23 \ldots \ldots \\
24 \ldots \ldots \\
25, \ldots \ldots \\
26 \ldots \ldots \\
27 \ldots \ldots \\
28 \ldots \ldots \\
29 . \ldots \ldots \\
31 \ldots \ldots \\
31 \ldots \ldots\end{array}$ & $\begin{array}{r}0.1 \\
.1 \\
.1 \\
.1 \\
.1 \\
.1 \\
.1 \\
.1 \\
285^{.1} \\
1,420\end{array}$ & $\begin{array}{r}15 \\
15 \\
13 \\
12 \\
11 \\
11 \\
12 \\
13 \\
-1 \\
-0 .-1\end{array}$ \\
\hline 7 & 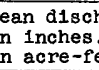 & & & & & & $\begin{array}{r}55.3 \\
1.70 \\
3,400\end{array}$ & $\begin{array}{r}82.1 \\
2.28 \\
4,560\end{array}$ \\
\hline
\end{tabular}

Gage height, In feet, and discharge, in cublc feet per second, at indicated t1me, 1963

\begin{tabular}{|c|c|c|c|c|c|c|c|c|c|c|c|}
\hline Date & Hour & $\begin{array}{c}\text { Gage } \\
\text { he1ght }\end{array}$ & $\begin{array}{l}\text { D1s- } \\
\text { charge }\end{array}$ & Date & Hour & $\begin{array}{c}\text { Gage } \\
\text { he1ght }\end{array}$ & $\begin{array}{l}\text { Dis- } \\
\text { charge }\end{array}$ & Date & Hour & $\begin{array}{c}\text { Gage } \\
\text { he1ght }\end{array}$ & $\begin{array}{c}\text { Dis- } \\
\text { charge }\end{array}$ \\
\hline $\begin{array}{r}\text { Jan. } 29 \\
30\end{array}$ & $\begin{array}{l}2400 \\
0800 \\
1000 \\
1200 \\
1300 \\
1400 \\
1500 \\
1700 \\
1800 \\
2000 \\
2300 \\
2400\end{array}$ & $\begin{array}{r}0.26 \\
.34 \\
.41 \\
.40 \\
2.52 \\
3.34 \\
3.25 \\
4.26 \\
4.15 \\
4.62 \\
4.02 \\
3.90\end{array}$ & $\begin{array}{c}0.2 \\
0.6 \\
1.2 \\
1.1 \\
214 \\
405 \\
383 \\
701 \\
663 \\
828 \\
617 \\
575\end{array}$ & Jan. 31 & $\begin{array}{l}100 \\
0200 \\
0500 \\
0600 \\
0700 \\
1000 \\
1300 \\
1500 \\
1700 \\
1800 \\
2200 \\
2300 \\
2400\end{array}$ & $\begin{array}{l}3.83 \\
3.88 \\
3.76 \\
3.82 \\
4.00 \\
4.72 \\
6.82 \\
6.69 \\
6.00 \\
6.25 \\
9.00 \\
9.28 \\
9.00\end{array}$ & $\begin{array}{r}551 \\
568 \\
528 \\
547 \\
610 \\
868 \\
1,830 \\
1,760 \\
1,410 \\
1,540 \\
3,100 \\
3,270 \\
3,100\end{array}$ & Feb. 1 & $\begin{array}{l}0200 \\
0600 \\
0900 \\
1000 \\
1300 \\
1400 \\
1800 \\
2400 \\
1300 \\
2000 \\
2400\end{array}$ & $\begin{array}{l}6.92 \\
5.05 \\
4.77 \\
3.71 \\
3.78 \\
3.77 \\
3.39 \\
2.99 \\
2.27 \\
2.06 \\
1.96\end{array}$ & $\begin{array}{r}1,890 \\
1,000 \\
888 \\
513 \\
534 \\
531 \\
418 \\
318 \\
176 \\
138 \\
121\end{array}$ \\
\hline
\end{tabular}

\section{MATADERO CREEK BASIN}

11-1660. Matadero Creek at Palo Alto, Calif.

Location.--Lat $37^{\circ} 25^{\prime} 10^{\prime \prime}$, long $122^{\circ} 08^{\prime} 10^{\prime \prime}$, in Rinconada de San Francisquito Grant, on right bank on Ash Street, $150 \mathrm{ft}$ upstream from Lambert Avenue Bridge and 2.1 miles southeast of post of fice at Palo Alto, Santa Clara County.

Dra1nage area, $--7.24 \mathrm{sq} \mathrm{mi}$.

Gage-height record, --Water-stage recorder graph. Altitude of gage is $25 \mathrm{ft}$ (from topographic map).

Discharge record.--Stage-discharge relation defined by current-meter measurements below $60 \mathrm{cfs}$ and by critical-depth determination at $340 \mathrm{cfs}$.

Maxima.--January-February 1963: Discharge, 641 cfs 2000 hours Jan. 31 (gage height, $3.97 \mathrm{ft}$ ).

1952 to December 1962: Discharge, $854 \mathrm{cfs}$ Dec. 22, 1955, from rating curve extended above $390 \mathrm{cfs}$ on bas $1 \mathrm{~s}$ of slope-area measurement of maximum flow; maximum gage height, $9.88 \mathrm{ft}$ Dec. 23, 1955; site and datum then in use (backwater from culvert). 
Mean discharge, in cublc feet per second, 1963, of Matadero Creek at Palo Alto, Cal1f.

\begin{tabular}{|c|c|c|c|c|c|c|c|c|}
\hline Day & January & February & Day & January & February & Day & January & February \\
\hline $\begin{array}{c}\ldots \ldots \\
2 \ldots \ldots \\
3 \ldots \ldots \\
4 \ldots \ldots \\
5 \ldots \ldots \\
7 \ldots \ldots \\
8 \ldots \ldots \\
10 \ldots \ldots\end{array}$ & $\begin{array}{l}0 \\
0 \\
0 \\
0 \\
0 \\
0 \\
0 \\
0 \\
0 \\
0\end{array}$ & $\begin{array}{r}57 \\
4.5 \\
1.7 \\
.8 \\
.4 \\
0 \\
0 \\
0 \\
51 \\
13\end{array}$ & $\begin{array}{l}11 \ldots \ldots \\
12 \ldots \ldots \\
13 \ldots \ldots \\
14 \ldots \ldots \\
15 \ldots \ldots \\
16 \ldots \ldots \\
17 \ldots \ldots \\
18 \ldots \ldots \\
19 \ldots \ldots \\
20 \ldots \ldots\end{array}$ & $\begin{array}{l}0 \\
0 \\
0 \\
0 \\
0 \\
0 \\
0 \\
0 \\
0 \\
0\end{array}$ & $\begin{array}{r}2.1 \\
7.0 \\
13 \\
1.9 \\
1.0 \\
1.2 \\
.4 \\
.1 \\
.3\end{array}$ & $\begin{array}{l}21 \ldots \ldots \\
22 \ldots \ldots \\
23 \ldots \ldots \\
24 \ldots \ldots \\
25 \ldots \ldots \\
26 \ldots \ldots \\
27 \ldots \ldots \\
28 \ldots \ldots \\
29 \ldots \ldots \\
30 \ldots \ldots \\
31 \ldots \ldots\end{array}$ & $\begin{array}{c}0 \\
0 \\
0 \\
0 \\
0 \\
0 \\
0 \\
0 \\
{ }^{4.1} .1 \\
200\end{array}$ & 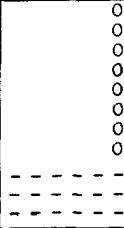 \\
\hline \multicolumn{7}{|l|}{$\begin{array}{l}\text { Monthly } \\
\text { Runoff, } \\
\text { Runoff, }\end{array}$} & $\begin{array}{r}7.78 \\
1.24 \\
478 \\
\end{array}$ & $\begin{array}{r}5.55 \\
0.80 \\
308 \\
\end{array}$ \\
\hline
\end{tabular}

Gage helght, in feet, and discharge, in cubic feet per second, at indicated time, 1963

\begin{tabular}{|c|c|c|c|c|c|c|c|c|c|c|c|}
\hline Date & Hour & $\begin{array}{c}\text { Gage } \\
\text { height }\end{array}$ & $\begin{array}{l}\text { Dis- } \\
\text { charge }\end{array}$ & Date & Hour & $\begin{array}{c}\text { Gage } \\
\text { helght }\end{array}$ & $\begin{array}{l}\text { Dis - } \\
\text { charge }\end{array}$ & Date & Hour & $\begin{array}{c}\text { Gage } \\
\text { he1ght }\end{array}$ & $\begin{array}{l}\text { Dis- } \\
\text { charge }\end{array}$ \\
\hline in. $\begin{array}{r}29 \\
30\end{array}$ & $\begin{array}{l}2400 \\
0200 \\
0300 \\
0500 \\
0600 \\
0800 \\
1000 \\
1100 \\
1300 \\
1600 \\
2100 \\
2300 \\
2400 \\
0200\end{array}$ & $\begin{array}{r}0.26 \\
.21 \\
.26 \\
.42 \\
.57 \\
.57 \\
1.17 \\
1.21 \\
1.30 \\
1.84 \\
1.03 \\
.87 \\
.87 \\
.91 \\
\end{array}$ & $\begin{array}{r}0.2 \\
.1 \\
.2 \\
2.1 \\
6.0 \\
6.0 \\
43 \\
47 \\
56 \\
131 \\
31 \\
20 \\
20 \\
23 \\
\end{array}$ & Jan. 31 & $\begin{array}{l}0500 \\
0700 \\
0800 \\
0900 \\
1000 \\
1100 \\
1200 \\
1300 \\
1400 \\
1500 \\
1600 \\
1800 \\
1900 \\
2000 \\
2100 \\
2200\end{array}$ & $\begin{array}{l}0.85 \\
1.28 \\
1.53 \\
1.51 \\
1.65 \\
2.41 \\
2.85 \\
2.91 \\
2.46 \\
1.92 \\
1.70 \\
1.84 \\
2.83 \\
3.97 \\
3.82 \\
3.25\end{array}$ & $\begin{array}{r}19 \\
54 \\
84 \\
82 \\
102 \\
237 \\
342 \\
358 \\
247 \\
143 \\
110 \\
131 \\
338 \\
641 \\
596 \\
442\end{array}$ & $\begin{array}{l}\text { Jan. } 31 \\
\text { Feb. } 1\end{array}$ & $\begin{array}{l}2300 \\
2400 \\
0100 \\
0300 \\
0500 \\
0600 \\
0900 \\
1000 \\
1100 \\
1200 \\
1400 \\
1800 \\
1900 \\
2100 \\
2400\end{array}$ & $\begin{array}{l}3.28 \\
2.76 \\
2.15 \\
1.56 \\
1.34 \\
1.33 \\
1.45 \\
1.45 \\
1.33 \\
1.15 \\
1.01 \\
.82 \\
.78 \\
.73 \\
.66\end{array}$ & $\begin{array}{r}450 \\
320 \\
185 \\
89 \\
61 \\
60 \\
74 \\
74 \\
60 \\
42 \\
30 \\
17 \\
15 \\
12 \\
9.4 \\
\end{array}$ \\
\hline
\end{tabular}

\section{STEVENS CREEK BASIN}

11-1664.8. Stevens Creek Reservoir near Monte Vista, Calif.

Location.--Lat $37^{\circ} 17^{\prime} 55^{\prime \prime}$, long $122^{\circ} 04^{\prime} 34^{\prime \prime}$, In NW/ $\frac{1}{4}$ sec.27, T.7 S., R.2 W., at center of dam on Stevens Creek, 2.0 miles southwest of Monte Vista.

Drainage area. $--17.3 \mathrm{sq} \mathrm{mi}$.

Gage-height record. --Staff gage read once da1ly, except Feb. 5, 6. Datum of gage is at mean sea ievel (levels by Santa Clara valley Water Conservation District).

Contents record.--Contents computed from capacity table dated 0ct. 1, 1961. Contents for Feb. 5, 6 interpolated.

Maxima --January-February 1963: Contents, 4,070 acre-ft time unknown Jan. 31 (elevation, $539.48 \mathrm{ft}$, from floodmarks).

1935 to December 1962: Contents observed, 4,100 acre-ft Dec. 26, 1955 (elevation, $538.61 \mathrm{ft}$ ).

Remarks.--Reservoir is formed by earthfill dam completed in 1936. Capacity, 3,860 acre-tt between elevations $444.9 \mathrm{ft}$ (invert of outlet tunnel) and $537.14 \mathrm{ft}$

(crest of spillway). Records furnished by Santa Clara Valley Water Conservation District. 
Elevation, in feet, and contents, in acre-feet, at 2400 hours, 1963, of Stevens Creek

\begin{tabular}{|c|c|c|c|c|c|c|c|c|c|}
\hline \multirow{2}{*}{ Day } & \multicolumn{2}{|c|}{ Januaxy } & \multicolumn{2}{|c|}{ February } & \multirow{2}{*}{ Day } & \multicolumn{2}{|c|}{ January } & \multicolumn{2}{|c|}{ February } \\
\hline & Elevat1on & Contents & Elevation & Contents & & Elevation & Contents & Elevation & Contents \\
\hline $\begin{array}{r}1 \\
2 \\
3 \\
4 \\
5 \\
6 \\
7 \\
8 \\
9 \\
10 \\
11 \\
12 \\
13 \\
14 \\
15\end{array}$ & $\begin{array}{c}526.33 \\
526.34 \\
526.36 \\
526.36 \\
- \\
- \\
526.37 \\
526.36 \\
526.36 \\
526.36 \\
526.36 \\
526.35 \\
526.33 \\
526.31 \\
526.30\end{array}$ & $\begin{array}{l}2,950 \\
2,950 \\
2,950 \\
2,950 \\
2,950 \\
2,950 \\
2,950 \\
2,950 \\
2,950 \\
2,950 \\
2,950 \\
2,950 \\
2,950 \\
2,950 \\
2,940\end{array}$ & $\begin{array}{l}538.05 \\
537.70 \\
537.53 \\
536.76 \\
536.48 \\
536.91 \\
537.30 \\
537.32 \\
537.44 \\
537.46 \\
537.40 \\
537.53 \\
537.51 \\
537.42 \\
537.34\end{array}$ & $\begin{array}{l}3,940 \\
3,910 \\
3,900 \\
3,830 \\
3,800 \\
3,840 \\
3,880 \\
3,880 \\
3,890 \\
3,890 \\
3,890 \\
3,900 \\
3,890 \\
3,890 \\
3,880\end{array}$ & $\begin{array}{l}16 \\
17 \\
18 \\
19 \\
20 \\
21 \\
22 \\
23 \\
24 \\
25 \\
26 \\
27 \\
28 \\
29 \\
30 \\
31\end{array}$ & $\begin{array}{l}526.30 \\
526.29 \\
526.28 \\
526.27 \\
526.25 \\
526.23 \\
526.22 \\
526.22 \\
526.21 \\
526.20 \\
526.19 \\
526.18 \\
526.17 \\
526.31 \\
535.00 \\
538.65\end{array}$ & $\begin{array}{l}2,940 \\
2,940 \\
2,940 \\
2,940 \\
2,940 \\
2,940 \\
2,940 \\
2,940 \\
2,940 \\
2,940 \\
2,940 \\
2,940 \\
2,930 \\
2,950 \\
3,670 \\
4,030\end{array}$ & $\begin{array}{c}537.25 \\
536.92 \\
536.08 \\
535.07 \\
535.20 \\
535.86 \\
536.48 \\
537.03 \\
537.29 \\
537.31 \\
537.32 \\
537.31 \\
537.28 \\
- \\
- \\
-\end{array}$ & $\begin{array}{c}3,870 \\
3,840 \\
3,770 \\
3,680 \\
3,690 \\
3,750 \\
3,800 \\
3,850 \\
3,880 \\
3,880 \\
3,880 \\
3,880 \\
3,870 \\
- \\
- \\
-\end{array}$ \\
\hline $\tan$ & In conte & 3 , In & & & & $\rightarrow$ & $+1,080$ & - & -160 \\
\hline
\end{tabular}

\section{GUADALUPE RIVER BASIN}

11-1666.7. Almaden Reservoir near New Almaden, Calif.

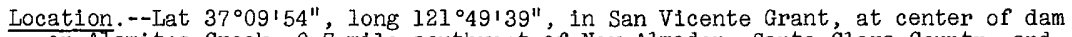
on Alamitos Creek, 0.7 mile southwest of New Almaden, Santa Clara County, and 7 miles south of Edenvale.

Drainage area. $--12.0 \mathrm{sq} \mathrm{mi}$.

Gage-height record.--Staff gage read once daily. Datum of gage is at mean sea

level (levels by Santa Clara Valley Water Conservation District).

Contents record.--Contents computed from capacity table dated Nov. 1, 1960 .

Maxima.--January-February 1963: Contents, 2,150 acre-ft, time unknown, Jan. 31 (elevation, $610.24 \mathrm{ft}$, from floodmarks).

1936 to December 1962: Contents observed, 2,080 acre-ft Apr. 1, 1941, Dec. 23, 1955 (elevation, $609.0 \mathrm{ft}$ ).

Remarks.--Reservoir is formed by earthfill dam completed in 1936. Capacity, 1,960 acre-ft between elevations $533.1 \mathrm{ft}$ (Invert of outlet tunnel) and $607 \mathrm{ft}$ (crest of spillway). Up to $100 \mathrm{cfs}$ diverted to Calero Reservoir at times. Records furnished by Santa Clara Valley Water Conservation District.

Elevation, in feet, and contents, in acre-feet, at 2400 hours, 1963, Almaden Reservoir near New Almaden, Calif.

\begin{tabular}{|c|c|c|c|c|c|c|c|c|c|}
\hline \multirow{2}{*}{ Day } & \multicolumn{2}{|c|}{ January } & \multicolumn{2}{|c|}{ February } & \multirow{2}{*}{ Day } & \multicolumn{2}{|c|}{ January } & \multicolumn{2}{|c|}{ February } \\
\hline & Elevation & Contents & Elevation & Contents & & Elevation & Contents & Elevation & Contents \\
\hline $\begin{array}{r}1 \\
2 \\
3 \\
4 \\
5 \\
6 \\
7 \\
8 \\
9 \\
10 \\
11 \\
12 \\
13 \\
14 \\
15\end{array}$ & $\begin{array}{l}568.32 \\
568.64 \\
568.93 \\
569.73 \\
570.45 \\
570.03 \\
569.86 \\
570.07 \\
570.30 \\
570.47 \\
570.64 \\
570.80 \\
570.94 \\
571.07 \\
571.25\end{array}$ & $\begin{array}{l}390 \\
397 \\
403 \\
419 \\
435 \\
425 \\
421 \\
426 \\
431 \\
435 \\
439 \\
443 \\
447 \\
450 \\
454\end{array}$ & $\begin{array}{l}607.85 \\
607.19 \\
607.01 \\
606.58 \\
605.90 \\
603.99 \\
601.85 \\
599.45 \\
598.11 \\
597.14 \\
595.44 \\
594.40 \\
594.57 \\
594.28 \\
592.95\end{array}$ & $\begin{array}{l}2,010 \\
1,970 \\
1,960 \\
1,930 \\
1,900 \\
1,770 \\
1,660 \\
1,530 \\
1,460 \\
1,410 \\
1,320 \\
1,270 \\
1,280 \\
1,260 \\
1,200\end{array}$ & $\begin{array}{l}16 \\
17 \\
18 \\
19 \\
20 \\
21 \\
22 \\
23 \\
24 \\
25 \\
26 \\
27 \\
28 \\
29 \\
30 \\
31\end{array}$ & $\begin{array}{l}571.41 \\
571.55 \\
571.69 \\
571.73 \\
571.85 \\
571.97 \\
572.06 \\
569.99 \\
567.25 \\
566.55 \\
566.71 \\
566.89 \\
567.03 \\
567.70 \\
596.25 \\
609.60\end{array}$ & $\begin{array}{r}458 \\
461 \\
465 \\
446 \\
468 \\
471 \\
473 \\
424 \\
369 \\
355 \\
358 \\
362 \\
365 \\
378 \\
1,360 \\
2,120\end{array}$ & $\begin{array}{c}591.12 \\
588.67 \\
588.33 \\
590.05 \\
592.21 \\
594.10 \\
595.79 \\
597.28 \\
598.62 \\
600.18 \\
600.97 \\
601.99 \\
602.20 \\
- \\
- \\
-\end{array}$ & $\begin{array}{r}1,110 \\
1,110 \\
992 \\
1,060 \\
1,170 \\
1,260 \\
1,340 \\
1,420 \\
1,490 \\
1,570 \\
1,610 \\
1,670 \\
1,680 \\
- \\
- \\
-\end{array}$ \\
\hline han & In conte & , in & $-f e c t$ & & & - & $+1,736$ & - & -440 \\
\hline
\end{tabular}


11-1667. Arroyo Calero tributary near New Almaden, Calif.

(Crest-stage station)

Location.--Lat $37^{\circ} 10^{\prime} 40^{\prime \prime}$, long $121^{\circ} 45^{\prime} 30^{\prime \prime}$, in Pueblo Lands of San Jose Grant, at culvert on McKean Road, 3.7 miles east of New Almaden.

Drainage area. $--0.18 \mathrm{sq} \mathrm{mi}$.

Gage-height record.--Crest stages only. Altitude of gage is $510 \mathrm{ft}^{\prime}$ (from topographic map).

Discharge record. --Maximum discharge by computation of flow through culvert.

Maxima.--January-February 1963: Discharge, $28 \mathrm{cfs}$ Jan. 31 (gage height, $59.83 \mathrm{ft}$ ). 1960 to December 1962: Discharge, $25 \mathrm{cfs}$ Oct. 13, 1962 (gage height, $58.26 \mathrm{ft}\}$.

11-1667.4. Calero Reservolr near New Almaden, Calif.

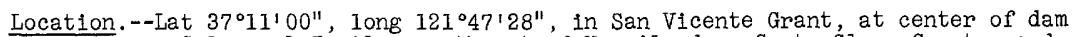
on Arroyo Calero, 1.7 mlles northeast of New Almaden, Santa Clara County, and 6 miles southeast of Edenvale.

Drainage area. $--6.95 \mathrm{sq} \mathrm{mi}$.

Gage-height record.--Staff gage read once daily, except Jan. 4-6. Datum of gage is at mean sea level (levels by Santa Clara Valiey Water Conservation District).

Contents record.--Contents for Jan. 4-6 interpolated.

Maxima.--January-February 1963: Contents, 9,090 acre-ft 2400 hours Feb. 28 (elevation, $482.15 \mathrm{ft}$ )

1936 to December 1962: Contents observed, 9,610 acre-ft Apr. 3, 1958 (elevation, $483.82 \mathrm{ft}$ ).

Remarks.--Reservoir is formed by earthfill dam completed to crest elevation 482.55 $\mathrm{ft}$ in 1936 and raised to $483.90 \mathrm{ft}$ in 1962. Capacity, 9,630 acre-ft between elevations $393.7 \mathrm{ft}$ (center of outlet tunnel) and $483.90^{\prime} \mathrm{ft}$ (crest of spillway). Up to 100 cfs diverted from Almaden Reservoir to Calero Reservoir at times. Records furnished by Santa Clara Valley Water Conservation District.

Elevation, in feet, and contents, in acre-feet, at 2400 hours, 1963

\begin{tabular}{|c|c|c|c|c|c|c|c|c|c|}
\hline \multirow{2}{*}{ Day } & \multicolumn{2}{|c|}{ January } & \multicolumn{2}{|c|}{ February } & \multirow{2}{*}{ Day } & \multicolumn{2}{|c|}{ Jantary } & \multicolumn{2}{|c|}{ February } \\
\hline & Elevation & Contents & Elevation & Contents & & Elevation & Contents & Elevation & Contents \\
\hline $\begin{array}{r}1 \\
2 \\
3 \\
4 \\
5 \\
6 \\
7 \\
8 \\
9 \\
10 \\
11 \\
12 \\
13 \\
14 \\
15\end{array}$ & $\begin{array}{c}448.27 \\
448.09 \\
447.83 \\
- \\
- \\
- \\
447.69 \\
447.69 \\
447.68 \\
447.67 \\
447.66 \\
447.65 \\
447.64 \\
447.63 \\
447.62\end{array}$ & $\begin{array}{l}2,220 \\
2,200 \\
2,170 \\
2,170 \\
2,160 \\
2,160 \\
2,160 \\
2,160 \\
2,150 \\
2,150 \\
2,150 \\
2,150 \\
2,150 \\
2,150 \\
2,150\end{array}$ & $\begin{array}{l}467.66 \\
468.74 \\
469.74 \\
470.71 \\
471.65 \\
472.51 \\
473.35 \\
474.17 \\
475.04 \\
475.88 \\
476.70 \\
477.52 \\
478.32 \\
479.08 \\
479.82\end{array}$ & $\begin{array}{l}5,170 \\
5,400 \\
5,610 \\
5,850 \\
6,100 \\
6,330 \\
6,560 \\
6,780 \\
7,010 \\
7,250 \\
7,480 \\
7,720 \\
7,940 \\
8,160 \\
8,370\end{array}$ & $\begin{array}{l}16 \\
17 \\
18 \\
19 \\
20 \\
21 \\
22 \\
23 \\
24 \\
25 \\
26 \\
27 \\
28 \\
29 \\
30 \\
31\end{array}$ & $\begin{array}{l}447.60 \\
447.59 \\
447.62 \\
447.64 \\
447.64 \\
447.64 \\
447.65 \\
448.06 \\
448.61 \\
448.78 \\
448.78 \\
448.78 \\
448.78 \\
448.83 \\
453.75 \\
465.75\end{array}$ & $\begin{array}{l}2,150 \\
2,140 \\
2,150 \\
2,150 \\
2,150 \\
2,150 \\
2,150 \\
2,200 \\
2,260 \\
2,280 \\
2,280 \\
2,280 \\
2,280 \\
2,280 \\
2,860 \\
4,770\end{array}$ & $\begin{array}{c}480.58 \\
481.34 \\
481.79 \\
481.93 \\
481.96 \\
481.98 \\
482.00 \\
482.00 \\
482.01 \\
482.02 \\
482.03 \\
482.04 \\
482.15 \\
- \\
- \\
-\end{array}$ & $\begin{array}{c}8,600 \\
8,840 \\
8,970 \\
9,020 \\
9,030 \\
9,030 \\
9,040 \\
9,040 \\
9,040 \\
9,050 \\
9,050 \\
9,050 \\
9,090 \\
- \\
- \\
-\end{array}$ \\
\hline Wing & In conter & 5 , in acr & $=-2$. & & & - & $+2,540$ & - & $+4,320$ \\
\hline
\end{tabular}


11-1669. Alamitos Creek near New Almaden, Calif.

Location.--Iat $37^{\circ} 13^{\prime} 21^{\prime \prime}$, long $121^{\circ} 51^{\prime} 00^{\prime \prime}$, In Pueblo Lands of San Jose Grant, on lef't bank at Greystone Bridge, 1.1 miles downstream from Arroyo Calero, 3.4 miles southwest of Edenvale, and 3.5 miles northwest of New Almaden, Santa Clara County.

Dra Inage area. $--31.9 \mathrm{sq} \mathrm{ml}$.

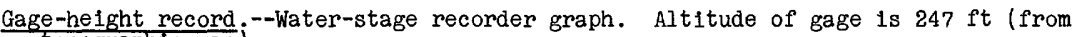
topographic map).

Discharge record.--Stage-discharge relation defined by current-meter measurements below $440 \mathrm{cf}$ 's and by slope-area measurement at $2,280 \mathrm{cfs}$.

Maxima.--January-February 1963: D1scharge, 2,670 cfs 1200 hours Jan. 31 (gage helght, $8.17 \mathrm{ft}$ ).

1958 to December 1962: Discharge, 4,300 cfs Apr. 2, 1958 (gage height, $9.67 \mathrm{ft}$ ), from rating curve extended above $330 \mathrm{cfs}$ on basis of computed outflow from Almaden and Calero Reservoirs.

Remarks.-Flow regulated by Almaden and Calero Reservolrs (see stations 11-1666.7 and 1667.4$)$.

Mean discharge, in cublc feet per second, 1963

\begin{tabular}{|c|c|c|c|c|c|c|c|c|}
\hline Day & January & February & Day & January & February & Day & January & February \\
\hline $\begin{array}{c}1 \ldots \ldots \\
2 \ldots \ldots \\
3 \ldots \ldots \\
4 \ldots \ldots \\
5 \ldots \ldots \\
7 \ldots \ldots \\
8 \ldots \ldots \\
9 \ldots \ldots \\
10 \ldots \ldots\end{array}$ & $\begin{array}{r}18 \\
18 \\
18 \\
14 \\
6.0 \\
5.2 \\
4.9 \\
4.7 \\
4.7 \\
4.4\end{array}$ & $\begin{array}{r}1,130 \\
274 \\
106 \\
39 \\
23 \\
18 \\
15 \\
13 \\
28 \\
26\end{array}$ & $\begin{array}{l}11 \ldots \ldots \\
12 \ldots \ldots \\
13 \ldots \ldots \\
14 \ldots \ldots \\
15 \ldots \ldots \\
16 \ldots \ldots \\
17 \ldots \ldots \\
15 \ldots \ldots \\
19 \ldots \ldots \\
20 . \ldots \ldots\end{array}$ & $\begin{array}{l}4.4 \\
4.4 \\
4.2 \\
4.4 \\
4.4 \\
4.4 \\
4.7 \\
5.2 \\
5.4 \\
5.4\end{array}$ & $\begin{array}{l}17 \\
16 \\
39 \\
21 \\
17 \\
14 \\
14 \\
12 \\
11 \\
9.8\end{array}$ & $\begin{array}{l}21 \ldots \ldots \\
22 \ldots \ldots \\
23 \ldots \ldots \\
24 \ldots \ldots \\
25 \ldots \ldots \\
26 \ldots \ldots \\
27 \ldots \ldots \\
28 \ldots \ldots \\
29 \ldots \ldots \\
30 \ldots \ldots \\
31 \ldots \ldots\end{array}$ & $\begin{array}{r}5.4 \\
5.7 \\
5.7 \\
5.4 \\
5.2 \\
5.4 \\
5.7 \\
5.7 \\
5.4 \\
432 \\
1,670\end{array}$ & $\begin{array}{r}9.1 \\
8.4 \\
8.1 \\
7.7 \\
7.4 \\
7.0 \\
6.7 \\
6.3 \\
---.- \\
-.-1-\end{array}$ \\
\hline $\begin{array}{l}\text { onthly } \\
\text { unoff, } \\
\text { unoff, }\end{array}$ & $\begin{array}{l}\text { Inche } \\
\text { acre- }\end{array}$ & & & & & & $\begin{array}{r}74.1 \\
2.68 \\
4,550\end{array}$ & $\begin{array}{r}68.0 \\
2.22 \\
3,780 \\
\end{array}$ \\
\hline
\end{tabular}

Gage height, in feet, and discharge, in cuble feet per second, at indicated t1me, 1963

\begin{tabular}{|c|c|c|c|c|c|c|c|c|c|c|c|}
\hline Date & Hour & $\begin{array}{c}\text { Gage } \\
\text { helght }\end{array}$ & $\begin{array}{c}\text { Dis- } \\
\text { charge }\end{array}$ & Date & Hour & $\begin{array}{c}\text { Gage } \\
\text { helght }\end{array}$ & $\begin{array}{c}\text { D1s- } \\
\text { charge }\end{array}$ & Date & Hour & $\begin{array}{c}\text { Gage } \\
\text { helght }\end{array}$ & $\begin{array}{c}\mathrm{Dls}- \\
\text { charge }\end{array}$ \\
\hline $\begin{array}{r}\text { Jan. } 29 \\
30\end{array}$ & $\begin{array}{l}2400 \\
0600 \\
0800 \\
1000 \\
1100 \\
1200 \\
1400 \\
1500 \\
1700 \\
1900 \\
2400 \\
0100\end{array}$ & $\begin{array}{l}2.32 \\
2.36 \\
2.41 \\
2.61 \\
3.25 \\
4.40 \\
5.96 \\
6.22 \\
5.67 \\
5.00 \\
4.58 \\
4.75\end{array}$ & $\begin{array}{c}7.0 \\
8.4 \\
10 \\
22 \\
127 \\
490 \\
1,120 \\
1,250 \\
987 \\
710 \\
553 \\
770\end{array}$ & Feb. 1 & $\begin{array}{l}0400 \\
0600 \\
0700 \\
0700 \\
0900 \\
1000 \\
1200 \\
1400 \\
1700 \\
2200 \\
2400 \\
0300 \\
0500\end{array}$ & $\begin{array}{l}4.50 \\
5.18 \\
5.00 \\
6.00 \\
6.87 \\
6.94 \\
8.17 \\
7.45 \\
6.84 \\
7.50 \\
7.00 \\
6.60 \\
6.08\end{array}$ & $\begin{array}{r}670 \\
946 \\
870 \\
1,350 \\
1,840 \\
1,880 \\
2,670 \\
2,200 \\
1,820 \\
2,240 \\
1,920 \\
1,680 \\
1,390\end{array}$ & Feb. 1 & $\begin{array}{l}0900 \\
1500 \\
2400 \\
1000 \\
1700 \\
1700 \\
2400 \\
\\
0300 \\
0300 \\
1900 \\
2000 \\
2400\end{array}$ & $\begin{array}{l}5.80 \\
5.05 \\
4.30 \\
\\
3.68 \\
3.58 \\
3.62 \\
3.42 \\
\\
3.35 \\
3.28 \\
3.06 \\
2.98 \\
2.97\end{array}$ & $\begin{array}{r}1,240 \\
890 \\
595 \\
\\
249 \\
219 \\
231 \\
173 \\
154 \\
135 \\
81 \\
66 \\
64\end{array}$ \\
\hline
\end{tabular}

11-1673.7. Guadalupe Reservoir near New Almaden, Calif.

Location.--Lat $37^{\circ} 11^{\prime} 57^{\prime \prime}$, long $121^{\circ} 52^{\prime} 42^{\prime \prime}$, in Los Capitancillos Grant, at center of dam on Guadalupe Creek, 3.6 miles northwest of New Almaden, Santa Clara County, and 5.0 miles southeast of Los Gatos.

Dralnage area. $--5.94 \mathrm{sq} \mathrm{ml}$.

Gage-height record.--Staff gage read once daily. Datum of gage is at mean sea level (levels by Santa clara valley Water Conservation District).

Contents record.--Contents computed from capacity table dated 0ct. 1, 1960 .

Maxima.--January-February 1963: Contents, 3,610 acre-ft, time unknown, Feb. 1 (elevation, $619.26 \mathrm{ft}$, from floodmarks).

1936 to December 1962: Contents observed, 3,560 acre-ft Feb. 23, 1956 (elevation, $618.60 \mathrm{ft}$ ).

Remarks.--Reservolr is formed by eartheill dam completed in 1936. Capacity, 3,460 acre-ft between elevations $506.8 \mathrm{ft}$ (Invert of outlet tunnel) and 617.0 ft (crest of splilway). Records furmished by Santa Clara Valley Water Conservation District.

$793-2850-66-11$ 
Elevation, in feet, and contents, in acre-feet, at 2400 hours, 1963, of Guadalupe Reservoir

\begin{tabular}{|c|c|c|c|c|c|c|c|c|c|}
\hline \multirow{2}{*}{ Day } & \multicolumn{2}{|c|}{ January } & \multicolumn{2}{|c|}{ February } & \multirow{2}{*}{ Day } & \multicolumn{2}{|c|}{ January } & \multicolumn{2}{|c|}{ February } \\
\hline & Elevation & Contents & Elevation & Contents & & Elevation & Contents & Elevation & Contents \\
\hline $\begin{array}{r}1 \\
2 \\
3 \\
4 \\
5 \\
6 \\
7 \\
8 \\
9 \\
10 \\
11 \\
12 \\
13 \\
14 \\
15\end{array}$ & $\begin{array}{l}595.87 \\
595.76 \\
595.88 \\
595.52 \\
594.90 \\
594.25 \\
593.43 \\
592.56 \\
591.64 \\
590.68 \\
589.63 \\
588.58 \\
587.66 \\
586.76 \\
585.82\end{array}$ & $\begin{array}{l}2,210 \\
2,200 \\
2,210 \\
2,190 \\
2,160 \\
2,130 \\
2,080 \\
2,040 \\
1,990 \\
1,940 \\
1,890 \\
1,840 \\
1,790 \\
1,750 \\
1,700\end{array}$ & $\begin{array}{l}617.00 \\
617.76 \\
617.14 \\
617.62 \\
617.76 \\
617.62 \\
617.70 \\
617.67 \\
617.76 \\
617.65 \\
617.60 \\
617.76 \\
617.79 \\
617.69 \\
617.64\end{array}$ & $\begin{array}{l}3,460 \\
3,510 \\
3,470 \\
3,500 \\
3,510 \\
3,500 \\
3,510 \\
3,500 \\
3,510 \\
3,500 \\
3,500 \\
3,510 \\
3,510 \\
3,500 \\
3,500\end{array}$ & $\begin{array}{l}16 \\
17 \\
18 \\
19 \\
20 \\
21 \\
22 \\
23 \\
24 \\
25 \\
26 \\
27 \\
28 \\
29 \\
30 \\
31 \\
\end{array}$ & $\begin{array}{l}585.35 \\
584.75 \\
583.86 \\
582.99 \\
582.06 \\
581.59 \\
581.00 \\
579.94 \\
578.75 \\
577.56 \\
576.43 \\
575.26 \\
574.16 \\
573.79 \\
580.00 \\
615.50\end{array}$ & $\begin{array}{l}1,680 \\
1,650 \\
1,610 \\
1,570 \\
1,520 \\
1,500 \\
1,480 \\
1,430 \\
1,380 \\
1,330 \\
1,280 \\
1,230 \\
1,190 \\
1,170 \\
1,430 \\
3,370\end{array}$ & $\begin{array}{c}617.59 \\
617.57 \\
617.55 \\
617.54 \\
617.52 \\
617.50 \\
617.49 \\
617.50 \\
617.51 \\
617.49 \\
617 \cdot 49 \\
617.50 \\
617.50 \\
- \\
- \\
-\end{array}$ & $\begin{array}{c}3,500 \\
3,500 \\
3,500 \\
3,500 \\
3,490 \\
3,490 \\
3,490 \\
3,490 \\
3,490 \\
3,490 \\
3,490 \\
3,490 \\
3,490 \\
- \\
- \\
- \\
\end{array}$ \\
\hline & 11 & & & & & - & $+1,160$ & - & +120 \\
\hline
\end{tabular}

11-1676.6. Ross Creek at San Jose, Calif.

Location.--Lat $37^{\circ} 14^{\prime} 55^{\prime \prime}$, long $121^{\circ} 54^{\prime} 49^{\prime \prime}$, in SE⿺ $\frac{1}{4}$ sec.12, T.8 S., R.1 E., on left bank, $100 \mathrm{ft}$ downstream from Lone Hill Creek, 500 ft upstream from Harwood Avenue, and at south city limits of San Jose.

Drainage area. $--5.70 \mathrm{sq} \mathrm{ml}$

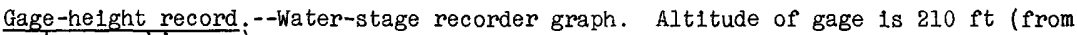
topographic map).

Discharge record.--Stage-discharge relation defined by current-meter measurements .

Maxima.--January-February 1963: Discharge, 515 cfs 1200 hours Jan. 31 (gage helght, $6.25 \mathrm{ft})$

1961 to December 1962: D1scharge, 530 cfs Oct. 13, 1962 (gage helght, $6.30 \mathrm{ft}$ ).

Mean discharge, in cubic feet per second, 1963

\begin{tabular}{|c|c|c|c|c|c|c|c|c|}
\hline Day & January & February & Day & January & February & Day & January & February \\
\hline $\begin{array}{c}1 \ldots \ldots \\
2 \ldots \ldots \\
3 \ldots \ldots \\
5 \ldots \ldots \\
6 \ldots \ldots \\
7 \ldots \ldots \\
8 \ldots \ldots \\
9 \ldots \ldots \\
10 \ldots \ldots\end{array}$ & $\begin{array}{r}1.4 \\
1.4 \\
1.2 \\
.5 \\
1.0 \\
.9 \\
.3 \\
0.3 \\
0.2\end{array}$ & $\begin{array}{c}71 \\
18 \\
6.6 \\
4.9 \\
3.7 \\
2.6 \\
2.0 \\
1.9 \\
19 \\
7.3\end{array}$ & $\begin{array}{l}11 \ldots \ldots \\
12 \ldots \ldots \\
13 \ldots \ldots \\
14 \ldots \ldots \\
15 \ldots \ldots \\
16 \ldots \ldots \\
17 \ldots \ldots \\
18 \ldots \ldots \\
19 \ldots \ldots \\
20 \ldots \ldots\end{array}$ & $\begin{array}{l}0 \\
0 \\
0 \\
0 \\
0 \\
0 \\
0 \\
.3 \\
0 \\
0\end{array}$ & $\begin{array}{r}2.2 \\
12 \\
24 \\
5.8 \\
4.7 \\
3.4 \\
2.3 \\
1.4 \\
2.2 \\
.9\end{array}$ & $\begin{array}{l}21 \ldots \ldots \\
22 \ldots \ldots \\
23 \ldots \ldots \\
24 \ldots \ldots \\
25 \ldots \ldots \\
26 \ldots \ldots \\
27 \ldots \ldots \\
28 \ldots \ldots \\
29 \ldots \ldots \\
30 \ldots \ldots \\
31 \ldots \ldots\end{array}$ & $\begin{array}{c}0.6 \\
0.3 \\
0.1 \\
0 \\
0 \\
0 \\
1.3 \\
164 \\
295\end{array}$ & $\begin{array}{r}0.9 \\
.7 \\
.5 \\
.5 \\
.5 \\
.4 \\
.4 \\
.4 \\
-2 \\
---.-\end{array}$ \\
\hline \multicolumn{7}{|l|}{$\begin{array}{l}\text { Monthly } \\
\text { Runoff, } \\
\text { Runoff, }\end{array}$} & $\begin{array}{r}15.1 \\
3.06 \\
931 \\
\end{array}$ & $\begin{array}{r}7.15 \\
1.31 \\
397 \\
\end{array}$ \\
\hline
\end{tabular}

Gage height, in feet, and discharge, in cub1c feet per second, at ind1cated time, 1963

\begin{tabular}{|c|c|c|c|c|c|c|c|c|c|c|c|}
\hline Date & Hour & $\begin{array}{c}\text { Gage } \\
\text { helght }\end{array}$ & $\begin{array}{l}\text { D1s- } \\
\text { charge }\end{array}$ & Date & Hour & $\begin{array}{c}\text { Gage } \\
\text { helght }\end{array}$ & $\begin{array}{c}\text { D1s- } \\
\text { charge }\end{array}$ & Date & Hour & $\begin{array}{c}\text { Gage } \\
\text { he1ght }\end{array}$ & $\begin{array}{c}\text { Dis- } \\
\text { charge }\end{array}$ \\
\hline $\begin{array}{r}\text { Jan. } 28 \\
29\end{array}$ & $\begin{array}{l}2400 \\
0600 \\
1700 \\
1700 \\
1800 \\
1900 \\
2000 \\
2100 \\
2100 \\
2300 \\
2400\end{array}$ & $\begin{array}{l}2.27 \\
2.10 \\
1.88 \\
2.78 \\
2.72 \\
2.92 \\
2.79 \\
2.80 \\
2.93 \\
2.93 \\
2.98\end{array}$ & $\begin{array}{l}0.1 \\
0 \\
0 \\
3.8 \\
2.9 \\
6.6 \\
4.0 \\
4.1 \\
7.0 \\
7.0 \\
8.6\end{array}$ & $\operatorname{Jan} \cdot 30$ & $\begin{array}{l}1400 \\
1500 \\
1600 \\
1700 \\
1800 \\
1900 \\
2000 \\
2100 \\
2200 \\
2300 \\
2400\end{array}$ & $\begin{array}{l}5.45 \\
6.11 \\
5.90 \\
5.50 \\
5.00 \\
4.90 \\
4.80 \\
5.50 \\
4.80 \\
4.75 \\
5.16\end{array}$ & $\begin{array}{l}300 \\
475 \\
416 \\
312 \\
209 \\
192 \\
175 \\
312 \\
175 \\
167 \\
238\end{array}$ & Jan. 31 & $\begin{array}{l}1000 \\
1100 \\
1200 \\
1300 \\
1400 \\
1700 \\
1800 \\
1900 \\
2100 \\
2200 \\
2400\end{array}$ & $\begin{array}{l}5.35 \\
6.00 \\
6.25 \\
6.00 \\
5.35 \\
5.05 \\
5.62 \\
5.89 \\
5.34 \\
5.58 \\
4.70\end{array}$ & $\begin{array}{l}277 \\
444 \\
515 \\
444 \\
277 \\
218 \\
343 \\
413 \\
275 \\
333 \\
159\end{array}$ \\
\hline 30 & $\begin{array}{l}0100 \\
0300 \\
0700 \\
0900 \\
1100 \\
1200 \\
1300 \\
\end{array}$ & $\begin{array}{l}3.03 \\
2.98 \\
3.42 \\
3.55 \\
4.52 \\
5.45 \\
5.75\end{array}$ & $\begin{array}{c}10 \\
8.6 \\
29 \\
38 \\
133 \\
300 \\
377 \\
\end{array}$ & 32 & $\begin{array}{l}0030 \\
0100 \\
0200 \\
0300 \\
0400 \\
0600 \\
0800 \\
0900\end{array}$ & $\begin{array}{l}5.00 \\
5.60 \\
5.00 \\
5.00 \\
4.72 \\
5.27 \\
5.62 \\
5.20 \\
\end{array}$ & $\begin{array}{l}209 \\
338 \\
209 \\
209 \\
162 \\
260 \\
343 \\
246 \\
\end{array}$ & Feb. 1 & $\begin{array}{l}0300 \\
0500 \\
0800 \\
0900 \\
1200 \\
1700 \\
2400\end{array}$ & $\begin{array}{l}4.22 \\
4.03 \\
4.53 \\
4.13 \\
3.79 \\
3.65 \\
3.45\end{array}$ & $\begin{array}{r}96 \\
77 \\
i 34 \\
87 \\
55 \\
45 \\
31\end{array}$ \\
\hline
\end{tabular}


11-1679.5. Lake Elsman near Los Gatos, Calif.

Location.--Lat $37^{\circ} 07^{\prime} 51^{\prime \prime}$, long $121^{\circ} 55^{\prime} 47^{\prime \prime}$, In SE $\frac{1}{4}$ sec.23, T.9 S., R.1 W., at center of Austrian Dam on Los Gatos Creek and' 7.3 miles southeast of Los Gatos.

Drainage area. $--9.78 \mathrm{sq} \mathrm{ml}$.

Gage-height record.--Staff gage read once daily. Datum of gage is at mean sea level (levels by San Jose Waterworks).

Contents record.--Contents computed from capacity table No. 1 .

Maxima.--January-February 1963: Contents observed, 6,640 acre-ft 0800 hours Jan. 31 (elevation, $1,115.1 \mathrm{ft}$ ).

1951 to December 1962: Contents observed, 6,410 acre-ft Jan. 12, 1952 (elevation, 1,112.6 ft).

Remarks.--Reservoir is formed by earthfill dam completed in 1951. Usable capac1ty, 6,090 acre-ft between elevations $944 \mathrm{ft}$ (elevation of outlet gates) and $1,110 \mathrm{ft}$ (crest of splilway). Dead storage, 60 acre-ft. Records fumlshed by San Jose Waterworks.

Elevation, in feet, and contents, in acre-feet, at 2400 hours, 1963

\begin{tabular}{c|r|r|r|r||r|r|r|r|r}
\hline \multirow{2}{*}{ Day } & \multicolumn{2}{|c|}{ January } & \multicolumn{2}{|c|}{ February } & \multirow{2}{*}{ Day } & \multicolumn{2}{c}{ January } & \multicolumn{3}{c}{ February } \\
\cline { 2 - 7 } & Elevat1on & Contents & Elevat1on & Contents & & Elevation & Contents & Elevation & Contents \\
\hline 1 & $1,110.5$ & 6,200 & $1,112.9$ & 6,430 & 16 & $1,110.4$ & 6,190 & $1,110.5$ & 6,200 \\
2 & $1,110.4$ & 6,190 & $1,111.4$ & 6,290 & 17 & $1,110.4$ & 6,190 & $1,110.4$ & 6,190 \\
3 & $1,110.3$ & 6,180 & $1,111.2$ & 6,270 & 18 & $1,110.4$ & 6,190 & $1,110.4$ & 6,190 \\
4 & $1,110.3$ & 6,180 & $1,111.1$ & 6,260 & 19 & $1,110.4$ & 6,190 & $1,110.3$ & 6,180 \\
5 & $1,110.3$ & 6,180 & $1,111.1$ & 6,260 & 20 & $1,110.5$ & 6,200 & $1,110.3$ & 6,180 \\
6 & $1,110.3$ & 6,180 & $1,111.2$ & 6,270 & 21 & $1,110.5$ & 6,200 & $1,110.2$ & 6,170 \\
7 & $1,110.3$ & 6,180 & $1,110.7$ & 6,220 & 22 & $.1,110.5$ & 6,200 & $1,110.2$ & 6,170 \\
8 & $1,110.3$ & 6,180 & $1,110.3$ & 6,180 & 23 & $1,110.5$ & 6,200 & $1,110.1$ & 6,160 \\
9 & $1,110.3$ & 6,180 & $1,110.6$ & 6,210 & 24 & $1,110.4$ & 6,190 & $1,110.0$ & 6,150 \\
10 & $1,110.4$ & 6,190 & $1,110.7$ & 6,220 & 25 & $1,110.4$ & 6,190 & $1,110.1$ & 6,160 \\
11 & $1,110.4$ & 6,190 & $1,110.6$ & 6,210 & 26 & $1,110.4$ & 6,190 & $1,110.3$ & 6,180 \\
12 & $1,110.3$ & 6,180 & $1,110.9$ & 6,240 & 27 & $1,110.4$ & 6,190 & $1,110.5$ & 6,200 \\
13 & $1,110.4$ & 6,190 & $1,111.0$ & 6,250 & 28 & $1,110.4$ & 6,190 & $1,110.7$ & 6,220 \\
14 & $1,110.4$ & 6,190 & $1,110.8$ & 6,230 & 29 & $1,110.1$ & 6,160 & - & - \\
15 & $1,110.4$ & 6,190 & $1,110.6$ & 6,210 & 30 & $1,114.0$ & 6,540 & - & - \\
& & & & 31 & $1,114.9$ & 6,630 & - & - \\
\hline
\end{tabular}

11-1679.8. Lexington Reservoir near Los Gatos, Calif.

Location.--Lat $37^{\circ} 12^{1} 06^{\prime \prime}$, long $121^{\circ} 59^{\prime} 17^{\prime \prime}$, in SE $\frac{1}{4}$ sec.29, T.8 S., R.1 W., at center of dam on Los Gatos Creek and 1.7 miles south of Los Gatos.

Drainage area. $--37.0 \mathrm{sq} \mathrm{mi}$.

Gage-helght record.--Staff gage read once daily, except Feb. 4. Datum of gage is at mean sea level (levels by Santa Clara Valley Water Conservation District).

Contents record.--Contents computed from capacity table dated 0ct. 1, 1960 . Contents for Feb. 3, 4 estimated on basis of valve change made on Feb. 5 .

Maxima.--January-February 1963: Contents, 22,240 acre-ft, time unknown, Feb. 2 (elevation, 651.84 ft, from floodmarks).

1952 to December 1962: Contents observed, 22,760 acre-ft Apr. 13, 1958 (elevation, $652.96 \mathrm{ft}$ ).

Remarks.--Reservoir is formed by earthfill dam completed in 1952. Capacity, 21,430 acre-ft between elevations $519 \mathrm{ft}$ (invert at outlet tunnel) and $650 \mathrm{ft}$ (crest of spillway). Dead storage, 31 acre-ft. Records furnished by Santa Clara Valley Water Conservation District. 
Elevation, in feet, and contents, in acre-feet, at 2400 hours, 1963, of Lexington Reservo1r near Los Gatos, Cal1f.

\begin{tabular}{|c|c|c|c|c|c|c|c|c|c|}
\hline \multirow{2}{*}{ Day } & \multicolumn{2}{|c|}{ January } & \multicolumn{2}{|c|}{ February } & \multirow{2}{*}{ Day } & \multicolumn{2}{|c|}{ January } & \multicolumn{2}{|c|}{ February } \\
\hline & Elevation & Contents & Elevation & Contents & & Elevation & Contents & Elevation & Contents \\
\hline $\begin{array}{r}1 \\
2 \\
3 \\
4 \\
5 \\
6 \\
7 \\
8 \\
9 \\
10 \\
11 \\
12 \\
13 \\
14 \\
15\end{array}$ & $\begin{array}{l}612.08 \\
612.14 \\
612.13 \\
611.65 \\
610.92 \\
610.15 \\
609.37 \\
608.57 \\
607.77 \\
607.22 \\
606.68 \\
606.11 \\
605.55 \\
604.93 \\
604.35\end{array}$ & $\begin{array}{l}8,830 \\
8,850 \\
8,840 \\
8,730 \\
8,550 \\
8,360 \\
8,180 \\
8,000 \\
7,830 \\
7,700 \\
7,580 \\
7,460 \\
7,330 \\
7,190 \\
7,080\end{array}$ & $\begin{array}{c}650.14 \\
651.00 \\
- \\
- \\
650.19 \\
650.56 \\
650.58 \\
650.54 \\
650.74 \\
650.79 \\
650.68 \\
650.90 \\
650.91 \\
650.78 \\
650.70\end{array}$ & $\begin{array}{l}21,490 \\
21,870 \\
21,600 \\
21,320 \\
21,520 \\
21,680 \\
21,690 \\
21,670 \\
21,760 \\
21,780 \\
21,730 \\
21,830 \\
21,830 \\
21,780 \\
21,740\end{array}$ & $\begin{array}{l}16 \\
17 \\
18 \\
19 \\
20 \\
21 \\
22 \\
23 \\
24 \\
25 \\
26 \\
27 \\
28 \\
29 \\
30 \\
31\end{array}$ & $\begin{array}{l}603.85 \\
603.40 \\
602.84 \\
602.16 \\
601.41 \\
600.60 \\
599.79 \\
599.14 \\
598.44 \\
597.75 \\
596.97 \\
596.30 \\
595.65 \\
596.08 \\
611.50 \\
642.50\end{array}$ & $\begin{array}{r}6,980 \\
6,880 \\
6,770 \\
6,630 \\
6,480 \\
6,320 \\
6,160 \\
6,040 \\
5,920 \\
5,790 \\
5,650 \\
5,530 \\
5,420 \\
5,490 \\
8,600 \\
18,380\end{array}$ & $\begin{array}{c}650.63 \\
650.55 \\
650.52 \\
650.49 \\
650.46 \\
650.44 \\
650.41 \\
650.45 \\
650.46 \\
650.42 \\
650.40 \\
650.44 \\
650.47 \\
- \\
- \\
-\end{array}$ & $\begin{array}{c}21,710 \\
21,670 \\
21,660 \\
21,650 \\
21,630 \\
21,630 \\
21,610 \\
21,630 \\
21,630 \\
21,620 \\
21,610 \\
21,630 \\
21,640 \\
= \\
- \\
-\end{array}$ \\
\hline $1 \mathrm{ar}$ & In cont & , In ac & & & & - & $+9,560$ & - & $+3,260$ \\
\hline
\end{tabular}

11-1680. Los Gatos Creek at Los Gatos, Calif.

Location.--Lat $37^{\circ} 12^{\prime} 30^{\prime \prime}$, long $121^{\circ} 59^{\prime} 15^{\prime \prime}$, in NE $\frac{1}{4}$ sec.29, T.8 S., R.1 W., on left bank $0.3 \mathrm{mile}$ downstream from Trout Creek, 0.5 mile downstream from Lexington Reservoir, and 1.0 mile south of Los Gatos.

Drainage area. $--38.6 \mathrm{sq} \mathrm{mi}$.

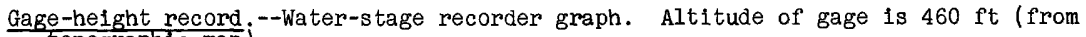
topographic mapj.

Discharge record. --Stage-discharge relation defined by current-meter measurements.

Maxima.--January-February 1963: Discharge, 1,660 cfs 0300 hours Feb. 2 (gage helght, $7.77 \mathrm{ft}$ ).

$1929-44,1953$ to December 1962: D1scharge, 7,110 cfs Feb. 27, 1940 (gage

height, 14.71 ft, site and datum then in use), from rating curve extended above 2,300 cfs.

Remarks.--Flow regulated by Lake Elsman and Lexington Reservoir (see stations $11-1679.5$ and $11-1679.8)$.

Mean discharge, in cubic feet per second, 1963

\begin{tabular}{|c|c|c|c|c|c|c|c|c|}
\hline Day & January & February & Day & January & February & Day & January & February \\
\hline $\begin{array}{c}1 \ldots \ldots \\
3 \ldots \ldots \\
4 \ldots \ldots \\
5 \ldots \ldots \\
6 \ldots \ldots \\
8 \ldots \ldots \\
9 \ldots \ldots \\
10 \ldots \ldots\end{array}$ & $\begin{array}{c}4.3 \\
4.3 \\
21 \\
89 \\
112 \\
109 \\
109 \\
108 \\
108 \\
80\end{array}$ & $\begin{array}{r}530 \\
1,130 \\
687 \\
560 \\
239 \\
202 \\
281 \\
278 \\
306 \\
473\end{array}$ & $\begin{array}{l}11 \ldots \ldots \\
12 \ldots \ldots \\
13 \ldots \ldots \\
14 \ldots \ldots \\
15 \ldots \ldots \\
16 \ldots \ldots \\
17 \ldots \ldots \\
18 \ldots \ldots \\
19 \ldots \ldots \\
20 \ldots \ldots\end{array}$ & $\begin{array}{l}71 \\
82 \\
82 \\
80 \\
80 \\
71 \\
68 \\
73 \\
82 \\
86\end{array}$ & $\begin{array}{l}374 \\
328 \\
560 \\
486 \\
378 \\
314 \\
270 \\
229 \\
202 \\
185\end{array}$ & $\begin{array}{l}21 \ldots \ldots \\
22 \ldots \ldots \\
23 \ldots \ldots \\
24 \ldots \ldots \\
25 \ldots \ldots \\
26 \ldots \ldots \\
27 \ldots \ldots \\
28 \ldots \ldots \\
29 \ldots \ldots \\
30 \ldots \ldots \\
31 \ldots \ldots\end{array}$ & $\begin{array}{r}91 \\
87 \\
82 \\
81 \\
81 \\
81 \\
75 \\
75 \\
47 \\
66 \\
241 \\
\end{array}$ & $\begin{array}{r}160 \\
141 \\
122 \\
114 \\
112 \\
81 \\
75 \\
72 \\
-\ldots- \\
--1-2\end{array}$ \\
\hline $\begin{array}{l}\text { onthly } \\
\text { anoff, }\end{array}$ & 8 & $\theta$ & & & & & $\begin{array}{r}81.5 \\
5,010\end{array}$ & $\begin{array}{r}317 \\
17,630\end{array}$ \\
\hline
\end{tabular}


Gage height, in feet, and discharge, in cubic feet per second, at ind1cated t1me, 1963, of Los Gatos Creek at Los Gatos, Cal1f.

\begin{tabular}{|c|c|c|c|c|c|c|c|c|c|c|c|}
\hline Date & Hour & $\begin{array}{c}\text { Gage } \\
\text { he1ght }\end{array}$ & $\begin{array}{l}\text { D1s- } \\
\text { charge }\end{array}$ & Date & Hour & $\begin{array}{c}\text { Gage } \\
\text { helght }\end{array}$ & $\begin{array}{c}\text { Dis- } \\
\text { charge }\end{array}$ & Date & Hour & $\begin{array}{c}\text { Gage } \\
\text { helght }\end{array}$ & $\begin{array}{l}\text { D1s- } \\
\text { charge }\end{array}$ \\
\hline $\begin{array}{r}\text { Jan. } 29 \\
30\end{array}$ & $\begin{array}{l}2400 \\
0100 \\
0800 \\
1000 \\
1100 \\
1200 \\
1200 \\
1400 \\
1600 \\
1800 \\
1900 \\
2000 \\
2100 \\
2300 \\
2400 \\
0200\end{array}$ & $\begin{array}{l}3.73 \\
3.72 \\
3.84 \\
4.05 \\
4.42 \\
4.47 \\
4.55 \\
4.57 \\
4.84 \\
4.47 \\
4.43 \\
4.52 \\
4.50 \\
4.57 \\
4.64 \\
4.83\end{array}$ & $\begin{array}{r}21 \\
20 \\
26 \\
41 \\
77 \\
83 \\
94 \\
96 \\
139 \\
83 \\
79 \\
90 \\
87 \\
96 \\
106 \\
137 \\
\end{array}$ & Feb. 1 & $\begin{array}{l}0500 \\
0600 \\
0800 \\
0900 \\
1200 \\
1400 \\
1500 \\
1600 \\
1700 \\
1800 \\
1900 \\
2000 \\
2200 \\
2400 \\
0600 \\
1400 \\
1600\end{array}$ & $\begin{array}{l}4.87 \\
5.00 \\
5.20 \\
5.22 \\
5.62 \\
5.46 \\
5.46 \\
5.37 \\
5.42 \\
5.47 \\
5.53 \\
5.45 \\
5.49 \\
5.44 \\
5.26 \\
5.24 \\
6.14\end{array}$ & $\begin{array}{l}145 \\
170 \\
216 \\
221 \\
342 \\
288 \\
288 \\
262 \\
276 \\
291 \\
311 \\
285 \\
297 \\
282 \\
\\
232 \\
226 \\
560\end{array}$ & Feb. 1 & $\begin{array}{l}2000 \\
2400 \\
0100 \\
0300 \\
0400 \\
0700 \\
0900 \\
1400 \\
1600 \\
1600 \\
1700 \\
1700 \\
1800 \\
2000 \\
2400\end{array}$ & $\begin{array}{l}7.00 \\
7.68 \\
7.50 \\
7.77 \\
7.50 \\
7.35 \\
6.90 \\
6.72 \\
6.65 \\
6.48 \\
6.47 \\
7.22 \\
7.15 \\
7.00 \\
6.68\end{array}$ & $\begin{array}{r}1,070 \\
1,580 \\
1,440 \\
1,660 \\
1,440 \\
1,330 \\
1,000 \\
883 \\
840 \\
739 \\
734 \\
1,230 \\
1,180 \\
1,070 \\
858\end{array}$ \\
\hline
\end{tabular}

11-1690. Guadalupe River at San Jose, Calif.

Location.--Lat $37^{\circ} 20^{\prime} 00^{\prime \prime}$, long $121^{\circ} 54^{\prime} 00^{\prime \prime}$, at San Jose, Santa Clara County, on right bank $100 \mathrm{ft}$ downstream from Los Gatos Creek.

Drainage area. $--146 \mathrm{sq} \mathrm{ml}$.

Gage-height record --Water-stage recorder graph. Datum of gage is $72.00 \mathrm{ft}$ above mean sea level (levels by Corps of Englneers).

Discharge record.--Stage-discharge relation defined by current-meter measurements.

Maxima.--January-February 1963: Discharge, 6,240 cfs 1400 hours Jan. 31 (gage helght, $10.79 \mathrm{ft}$ ).

1929 to December 1962: Discharge, 9,150 cfs Apr. 2, 1958 (gage height, $16.55 \mathrm{ft})$.

Remarks.--Flow regulated by Calero, Almaden, Guadalupe, and Lexington Reservolrs, and Lake Elsman, described elswhere in this report.

Mean discharge, in cubic feet per second, 1963

\begin{tabular}{|c|c|c|c|c|c|c|c|c|}
\hline Day & January & February & Day & January & February & Day & January & February \\
\hline $\begin{array}{r}1 \ldots \ldots \\
2 \ldots \ldots \\
3 \ldots \ldots \\
4 \ldots \ldots \\
5 \ldots \ldots \\
6 \ldots \ldots \\
7 \ldots \ldots \\
8 \ldots \ldots \\
9 \ldots \ldots \\
10 . \ldots\end{array}$ & $\begin{array}{l}0 \\
4.3 \\
1.5 \\
0 \\
0 \\
0 \\
0 \\
0 \\
.7 \\
1.3\end{array}$ & $\begin{array}{r}2,580 \\
1,350 \\
924 \\
571 \\
366 \\
94 \\
160 \\
241 \\
349 \\
450\end{array}$ & $\begin{array}{l}11 \ldots . . \\
12 \ldots \\
13 \ldots . \\
14 \ldots \\
15 \ldots \\
16 \ldots \\
17 \ldots \ldots \\
18 \ldots . \\
19 . \ldots . \\
20 . \ldots\end{array}$ & $\begin{array}{l}0.8 \\
0 \\
0 \\
.8 \\
1.4 \\
1.6 \\
1.9 \\
1.9 \\
1.6 \\
0\end{array}$ & $\begin{array}{r}333 \\
304 \\
615 \\
440 \\
319 \\
266 \\
213 \\
160 \\
118 \\
98\end{array}$ & $\begin{array}{l}21 \ldots \ldots \\
22 \ldots \ldots \\
23 \ldots \ldots \\
24 \ldots \ldots \\
25 \ldots \ldots \\
26 \ldots \ldots \\
27 \ldots \ldots \\
28 \ldots \ldots \\
29 \ldots \ldots \\
30 \ldots \ldots \\
31 \ldots \ldots\end{array}$ & $\begin{array}{c}1.9 \\
2.3 \\
2.3 \\
2.5 \\
2.0 \\
1.1 \\
0 \\
5.1 \\
5.8 \\
1,450 \\
4,370\end{array}$ & $\begin{array}{c}81 \\
61 \\
48 \\
33 \\
38 \\
26 \\
16 \\
9.6 \\
-0 .-1\end{array}$ \\
\hline $1 y$ & & & $t$ & & & & $\begin{array}{r}189 \\
11,620\end{array}$ & $\begin{array}{r}367 \\
20,360\end{array}$ \\
\hline
\end{tabular}

Gage height, in feet, and discharge, in cublc feet per second, at indicated time, 1963

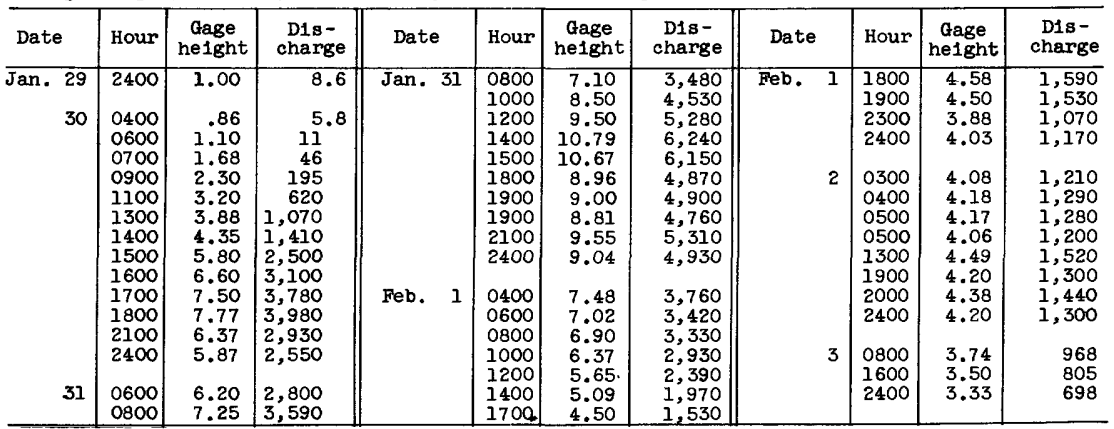


11-1695. Saratoga Creek at Saratoga, Calif.

Location.--Lat $37^{\circ} 15^{\prime} 15^{\prime \prime}$, long $122^{\circ} 02^{\prime} 25^{\prime \prime}$, in Quito Grant, on right bank on downstream side of private road bridge, 0.5 mile southwest of Saratoga, Santa Clara County, and 0.7 mile downstream from diversion dam.

Drainage area. $--9.22 \mathrm{sq} \mathrm{ml}$.

Gage-height record.--Water-stage recorder graph, except Feb. 6-8, 16-25. Altitude of gage is $500 \mathrm{ft}$ (from topographic map).

Discharge record.--Stage-discharge relation defined by current-meter measurements. Discharge for periods of no gage-height record estimated on basis of weather records and records for San Francisquito Creek below Ladera damsite, near Stanford University .

Maxima.--January-February 1963: Discharge, 1,160 cfs 1200 hours Jan. 31 (gage helght, $5.68 \mathrm{ft}$ ).

1933 to December 1962: Discharge, 2,730 cfs Dec. 22, 1955 (gage height, $6.40 \mathrm{ft})$, from rating curve extended above $510 \mathrm{cfs}$ on basis of slope-area measurement of maximum flow.

Mean discharge, in cublc feet per second, 1963

\begin{tabular}{|c|c|c|c|c|c|c|c|c|}
\hline Day & January & Febmuary & Day & January & February & Day & January & February \\
\hline $\begin{array}{c}\ldots \ldots \\
2 \ldots \ldots \\
3 \ldots \ldots \\
4 \ldots \ldots \\
5 \ldots \ldots \\
6 \ldots \ldots \\
7 \ldots \ldots \\
9 \ldots \ldots \\
10 \ldots \ldots\end{array}$ & $\begin{array}{r}0.6 \\
.2 \\
.2 \\
.2 \\
.2 \\
.2 \\
.2 \\
.2 \\
.2 \\
.2\end{array}$ & $\begin{array}{r}365 \\
149 \\
99 \\
72 \\
60 \\
51 \\
30 \\
23 \\
44 \\
58\end{array}$ & $\begin{array}{l}11 \ldots \ldots \\
12 \ldots \ldots \\
13 \ldots \ldots \\
14 \ldots \ldots \\
15 \ldots \ldots \\
16 \ldots \ldots \\
17 \ldots \ldots \\
18 \ldots \ldots \\
19 \ldots \ldots \\
20 \ldots \ldots\end{array}$ & $\begin{array}{l}0.2 \\
.4 \\
.2 \\
.2 \\
.2 \\
.2 \\
.1 \\
.2 \\
.1 \\
.2\end{array}$ & $\begin{array}{l}47 \\
45 \\
72 \\
49 \\
39 \\
35 \\
32 \\
30 \\
27 \\
25\end{array}$ & $\begin{array}{l}21 \ldots \ldots \\
22 \ldots \ldots \\
23 \ldots \ldots \\
24 \ldots \ldots \\
25 \ldots \ldots \\
26 \ldots \ldots \\
27 \ldots \ldots \\
28 \ldots \ldots \\
29 \ldots \ldots \\
30 \ldots \ldots \\
31 \ldots \ldots\end{array}$ & $\begin{array}{r}0.2 \\
.2 \\
.2 \\
.2 \\
.2 \\
.2 \\
.2 \\
.2 \\
1.3 \\
276 \\
651\end{array}$ & 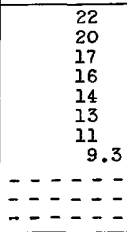 \\
\hline \multicolumn{7}{|l|}{$\begin{array}{l}\text { Monthly } \\
\text { Runoff, } \\
\text { Runoff, }\end{array}$} & $\begin{array}{r}30.1 \\
3.77 \\
1,850\end{array}$ & $\begin{array}{r}52.7 \\
5.95 \\
2,930\end{array}$ \\
\hline
\end{tabular}

Gage height, in feet, and discharge, in cub1c feet per second, at indicated t1me, 1963

\begin{tabular}{|c|c|c|c|c|c|c|c|c|c|c|c|}
\hline Date & Hour & $\begin{array}{c}\text { Gage } \\
\text { height }\end{array}$ & $\begin{array}{l}\text { Dis- } \\
\text { charge }\end{array}$ & Date & Hour & $\begin{array}{c}\text { Gage } \\
\text { he1ght }\end{array}$ & $\begin{array}{l}\text { Dis- } \\
\text { charge }\end{array}$ & Date & Hour & $\begin{array}{c}\text { Gage } \\
\text { helght }\end{array}$ & $\begin{array}{l}\text { Dis - } \\
\text { charge }\end{array}$ \\
\hline $\begin{array}{r}\text { Jan. } 29 \\
30\end{array}$ & $\begin{array}{l}2400 \\
0300 \\
0800 \\
0900 \\
1100 \\
1300 \\
1600 \\
1800 \\
1900 \\
2000 \\
2300 \\
2400 \\
\end{array}$ & $\begin{array}{l}1.81 \\
1.92 \\
2.28 \\
2.40 \\
3.38 \\
4.05 \\
4.65 \\
4.31 \\
4.48 \\
4.26 \\
4.10 \\
4.13 \\
\end{array}$ & $\begin{array}{r}7.5 \\
13 \\
37 \\
49 \\
211 \\
408 \\
638 \\
499 \\
567 \\
481 \\
425 \\
436\end{array}$ & $\operatorname{Jan}, 31$ & $\begin{array}{l}0100 \\
0400 \\
0500 \\
0900 \\
1100 \\
1200 \\
1300 \\
1400 \\
1500 \\
1600 \\
1800 \\
2000 \\
2200\end{array}$ & $\begin{array}{l}4.27 \\
4.24 \\
4.48 \\
4.42 \\
5.15 \\
5.68 \\
5.40 \\
5.00 \\
5.00 \\
4.45 \\
5.10 \\
4.48 \\
4.37\end{array}$ & $\begin{array}{r}485 \\
474 \\
567 \\
543 \\
865 \\
1,160 \\
990 \\
795 \\
795 \\
567 \\
840 \\
567 \\
523\end{array}$ & $\begin{array}{l}\text { Jan. } 31 \\
\text { Feb. } 1\end{array}$ & $\begin{array}{l}2400 \\
0100 \\
0100 \\
0300 \\
0500 \\
0800 \\
1100 \\
1500 \\
2000 \\
2400\end{array}$ & $\begin{array}{l}5.00 \\
5.10 \\
4.82 \\
4.41 \\
4.15 \\
4.05 \\
3.51 \\
3.66 \\
3.42 \\
3.31\end{array}$ & $\begin{array}{l}795 \\
\\
840 \\
714 \\
539 \\
443 \\
408 \\
325 \\
284 \\
221 \\
194\end{array}$ \\
\hline
\end{tabular}

\section{COYOTE CREEK BASIN}

11-1698. Coyote Creek near Gilroy, Calif.

Location. --Lat $37^{\circ} 04^{\prime} 27^{\prime \prime}$, long $121^{\circ} 29^{\prime} 55^{\prime \prime}$, in SW $\frac{1}{4}$ sec.11, T.10 S., R.4 E., on right bank 1.1 miles downstream from Bear Creek, 4.6 miles upstream from Coyóte Creek Dam, and 6 miles northeast of Gilroy.

Drainage area. $--110 \mathrm{sq} \mathrm{m} 1$.

Gage-helght record.--Water-stage recorder graph, except Feb. 2-12, 14-21. Alt1tude of gage is $870 \mathrm{ft}$ (from topographic map).

Discharge record.--Stage-discharge relation defined by current-meter measurements below $3,200 \mathrm{cfs}$ and by slope-area measurement at $10,100 \mathrm{cfs}$. Discharge for periods of no gage-height record estimated on basis of two discharge measurements and records for San Lorenzo Creek at Hayward. $\frac{\text { Maxima }}{\text { height, } 12.60 \mathrm{ft} \text { ). }}$. 12 anuary-February 1963: Discharge, 10,100 cfs 2300 hours Jan. 31 (gage

1960 to December 1962: Discharge, 4,450 cfs Feb. 15, 1962 (gage height, $8.99 \mathrm{ft}$ ). 
Mean discharge, In cuble feet per second, 1963, of Coyote Creek near Gilroy, Calif.

\begin{tabular}{|c|c|c|c|c|c|c|c|c|}
\hline Day & January & February & Day & January & February & Day & January & February \\
\hline $\begin{array}{c}\ldots \ldots \\
3 \ldots \ldots \\
4 \ldots \ldots \\
5 \ldots \ldots \\
6 \ldots \ldots \\
8 \ldots \ldots \\
9 \ldots \ldots \\
10 \ldots \ldots\end{array}$ & $\begin{array}{l}2.1 \\
2.1 \\
2.1 \\
2.1 \\
2.4 \\
2.1 \\
2.1 \\
1.8 \\
1.8 \\
1.8\end{array}$ & $\begin{array}{r}3,180 \\
500 \\
300 \\
200 \\
150 \\
110 \\
95 \\
90 \\
510 \\
450\end{array}$ & $\begin{array}{l}11 \ldots \ldots \\
12 \ldots \ldots \\
13 \ldots \ldots \\
14 \ldots \ldots \\
15 \ldots \ldots \\
16 \ldots \ldots \\
17 \ldots \ldots \\
18 \ldots \ldots \\
19 \ldots \ldots \\
20 \ldots \ldots\end{array}$ & $\begin{array}{l}1.8 \\
1.2 \\
1.0 \\
1.0 \\
1.0 \\
1.2 \\
1.2 \\
1.2 \\
1.2 \\
1.2\end{array}$ & $\begin{array}{r}300 \\
600 \\
1,030 \\
500 \\
300 \\
180 \\
130 \\
95 \\
70 \\
55\end{array}$ & $\begin{array}{l}21 \ldots \ldots \\
22 \ldots \ldots \\
23 \ldots \ldots \\
24 \ldots \ldots \\
25 \ldots \ldots \\
26 \ldots \ldots \\
27 \ldots \ldots \\
28 \ldots \ldots \\
29 \ldots \ldots \\
30 \ldots \ldots \\
31 \ldots \ldots\end{array}$ & $\begin{array}{r}1.5 \\
1.2 \\
1.2 \\
1.5 \\
1.5 \\
1.5 \\
1.8 \\
1.8 \\
2.1 \\
546 \\
5,490\end{array}$ & $\begin{array}{r}48 \\
42 \\
36 \\
30 \\
28 \\
27 \\
24 \\
21 \\
---- \\
--\ldots\end{array}$ \\
\hline $\begin{array}{l}\text { Monthly } \\
\text { Runoff, } \\
\text { Runoff, }\end{array}$ & $\begin{array}{l}\text { Inches } \\
\text { acre- }\end{array}$ & 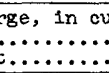 & $\ldots$ & & 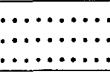 & 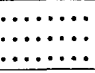 & $\begin{array}{r}196 \\
2.06 \\
12,060 \\
\end{array}$ & $\begin{array}{r}325 \\
3.08 \\
18,050 \\
\end{array}$ \\
\hline
\end{tabular}

Gage height, In feet, and discharge, in cuble feet per second, at indicated time, 1963

\begin{tabular}{|c|c|c|c|c|c|c|c|c|c|c|c|}
\hline Date & Hour & $\begin{array}{c}\text { Gage } \\
\text { helght }\end{array}$ & $\begin{array}{l}\text { Dis - } \\
\text { charge }\end{array}$ & Date & Hour & $\begin{array}{c}\text { Gage } \\
\text { helght }\end{array}$ & $\begin{array}{l}\text { Dis- } \\
\text { charge }\end{array}$ & Date & Hour & $\begin{array}{c}\text { Gage } \\
\text { helght }\end{array}$ & $\begin{array}{l}\text { D1s- } \\
\text { charge }\end{array}$ \\
\hline $\begin{array}{r}\text { an. } 29 \\
30\end{array}$ & $\begin{array}{l}2400 \\
0400 \\
0600 \\
1100 \\
1400 \\
1600 \\
1800 \\
1900 \\
2000 \\
2100 \\
2200 \\
2300\end{array}$ & $\begin{array}{l}4.16 \\
4.19 \\
4.22 \\
4.44 \\
4.72 \\
6.00 \\
6.65 \\
7.19 \\
7.40 \\
7.39 \\
7.76 \\
7.59\end{array}$ & $\begin{array}{r}2.7 \\
3.6 \\
4.6 \\
13 \\
31 \\
390 \\
945 \\
1,570 \\
1,830 \\
1,820 \\
2,330 \\
2,090\end{array}$ & $\begin{array}{r}\text { Jan. } 30 \\
31\end{array}$ & $\begin{array}{l}2400 \\
0100 \\
0200 \\
0300 \\
0400 \\
0500 \\
1000 \\
1100 \\
1300 \\
1400 \\
1300 \\
21500\end{array}$ & $\begin{array}{r}7.69 \\
7.34 \\
7.71 \\
7.61 \\
7.69 \\
7.57 \\
8.65 \\
9.29 \\
12.25 \\
11.30 \\
9.95 \\
10.60\end{array}$ & $\begin{array}{l}2,230 \\
1,750 \\
2,260 \\
2,110 \\
2,230 \\
2,060 \\
3,800 \\
4,990 \\
9,610 \\
8,210 \\
6,080 \\
7,120\end{array}$ & Jan. 31 & $\begin{array}{l}2200 \\
2300 \\
2400 \\
\\
0200 \\
0400 \\
0600 \\
1200 \\
1400 \\
2100 \\
2400\end{array}$ & $\begin{array}{r}12.59 \\
12.60 \\
11.98 \\
\\
10.98 \\
9.83 \\
9.11 \\
8.20 \\
7.86 \\
6.98 \\
6.78\end{array}$ & $\begin{array}{r}10,100 \\
10,100 \\
9,230 \\
\\
7,620 \\
5,640 \\
4,270 \\
2,460 \\
1,900 \\
821 \\
639\end{array}$ \\
\hline
\end{tabular}

11-1698.5. Coyote Lake near San Martin, Calif.

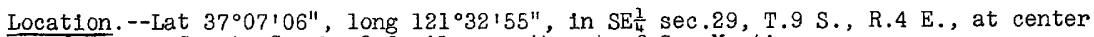
of dam on Coyote Creek, 3.8 miles northeast of San Martin.

Drainage area. $--120 \mathrm{sq} \mathrm{mi}$.

Gage-height record.--Staff gage read once dally, except Jan. 15-20, 23, 25-27, 29, Feb. 17. Datum of gage is at mean sea level' (levels by Santa Clara valley Water Conservation District\}.

Contents record.--Contents computed from capacity table dated oct. 1, 1961. Contents for periods of no elevation record interpolated.

Maxima.--January-February 1963: Contents observed, 19,100 acre-f't 0800 hours Feb. 15 (elevation, $768.05 \mathrm{ft}$ ).

1936 to December 1962: Contents observed, 28,120 acre-ft Dec. 8, 1950 (elevation, $782.5 \mathrm{ft}$ ).

Remarks.--Reservo1r is formed by rockf1ll and earthf11l dam completed in 1936. Capacity, 24,510 acre-ft between elevations $693.3 \mathrm{ft}$ (invert of outlet tunnel) and 777 ft (crest of spillway). Records furnished by Santa Clara Valley Water Conservation District.

Elevation, in feet, and contents, in acre-feet, at 0800 hours, 1963

\begin{tabular}{|c|c|c|c|c|c|c|c|c|c|}
\hline \multirow{2}{*}{ Day } & \multicolumn{2}{|c|}{ January } & \multicolumn{2}{|c|}{ February } & \multirow{2}{*}{ Day } & \multicolumn{2}{|c|}{ January } & \multicolumn{2}{|c|}{ February } \\
\hline & Elevation & Contents & Elevation & Contents & & Elevation & Contents & Elevation & Contents \\
\hline $\begin{array}{r}1 \\
2 \\
3 \\
4 \\
5 \\
6 \\
7 \\
8 \\
9 \\
10 \\
11 \\
12 \\
13 \\
14 \\
15\end{array}$ & $\begin{array}{c}709.72 \\
709.80 \\
709.87 \\
709.93 \\
709.99 \\
710.05 \\
710.10 \\
710.16 \\
710.22 \\
710.27 \\
710.32 \\
710.36 \\
710.41 \\
710.45 \\
-\end{array}$ & $\begin{array}{l}473 \\
477 \\
480 \\
483 \\
486 \\
490 \\
494 \\
499 \\
505 \\
509 \\
513 \\
516 \\
521 \\
524 \\
528\end{array}$ & $\begin{array}{l}761.02 \\
765.55 \\
766.68 \\
765.22 \\
764.47 \\
763.79 \\
763.31 \\
763.08 \\
762.75 \\
763.05 \\
763.18 \\
763.39 \\
764.74 \\
767.65 \\
768.05\end{array}$ & $\begin{array}{l}15,240 \\
17,660 \\
17,750 \\
17,480 \\
17,080 \\
16,710 \\
16,460 \\
16,340 \\
16,160 \\
16,320 \\
16,390 \\
16,500 \\
17,220 \\
18,870 \\
19,100\end{array}$ & $\begin{array}{l}16 \\
17 \\
18 \\
19 \\
20 \\
21 \\
22 \\
23 \\
24 \\
25 \\
26 \\
27 \\
28 \\
29 \\
30 \\
31 \\
\end{array}$ & $\begin{array}{c}- \\
- \\
- \\
- \\
\overline{-} \\
710.75 \\
710.78 \\
\overline{-} \\
705.98 \\
- \\
- \\
\overline{7} \\
707.10 \\
\overline{-} \\
707.54 \\
724.65\end{array}$ & $\begin{array}{r}531 \\
535 \\
538 \\
542 \\
545 \\
549 \\
552 \\
426 \\
300 \\
313 \\
326 \\
339 \\
352 \\
362 \\
372 \\
2,390 \\
\end{array}$ & $\begin{array}{c}767.95 \\
- \\
767.43 \\
767.05 \\
766.60 \\
766.15 \\
765.68 \\
765.21 \\
764.64 \\
764.10 \\
763.58 \\
763.21 \\
762.88 \\
- \\
- \\
-\end{array}$ & $\begin{array}{c}19,040 \\
18,900 \\
18,750 \\
18,530 \\
18,270 \\
18,010 \\
17,750 \\
17,480 \\
17,170 \\
16,880 \\
16,600 \\
16,410 \\
16,230 \\
- \\
- \\
-\end{array}$ \\
\hline 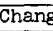 & In conve & 21 & & & & - & $+1,928$ & - & $+13,840$ \\
\hline
\end{tabular}


11-1699.2. Anderson Lake near Madrone, Calif.

Location.--Lat $37^{\circ} 09^{\prime} 56^{\prime \prime}$, long $121^{\circ} 37^{\prime} 42^{\prime \prime}$, in southeast comer of La Laguna Seca Grant, at center of dam on Coyote Creek, 2.5 miles northeast of Madrone, Santa Clara County.

Drainage area. $--194 \mathrm{sq} \mathrm{mi}$.

Gage-he1ght record.--Staff gage read once da1ly, except Jan. 5, 6. Datum of gage is at mean sea level (levels by Santa Clara Valley Water Conservation District).

Contents record.--Contents computed from capac1ty table dated oct. 1, 1961 . Contents for Jan. 5, 6 interpolated.

Maxima.--January-February 1963: Contents observed, 15,230 acre-ft 0800 hours

Feb. 28 (elevation, $525.84 \mathrm{ft}$ ).

1950 to December 1962: Contents, 95,990 acre-ft Apr. 3, 1958 (elevation, $628.67 \mathrm{ft}$, from floodmarks).

Remarks.--Reservoir is formed by earthfill and rockfill dam completed in 1950. Capacity, 91,310 acre-ft between elevations $439 \mathrm{ft}$ (invert of outlet tunnei) and $625 \mathrm{ft}$ (crest of sp111way). Records furnished by Santa Clara Valley Water Conservation District.

Elevation, in feet, and contents, in acre-feet, at 0800 hours, 1963

\begin{tabular}{|c|c|c|c|c|c|c|c|c|c|}
\hline \multirow{2}{*}{ Day } & \multicolumn{2}{|c|}{ January } & \multicolumn{2}{|c|}{ February } & \multirow{2}{*}{ Day } & \multicolumn{2}{|c|}{ January } & \multicolumn{2}{|c|}{ Pebruary } \\
\hline & Elevation & Contents & Elevation & Contents & & Elevation & Contents & Elevation & Contents \\
\hline $\begin{array}{r}1 \\
2 \\
3 \\
4 \\
5 \\
6 \\
7 \\
8 \\
9 \\
10 \\
11 \\
12 \\
13 \\
14 \\
15\end{array}$ & $\begin{array}{c}446.47 \\
446.43 \\
446.38 \\
446.33 \\
- \\
- \\
446.15 \\
446.09 \\
446.03 \\
445.98 \\
445.89 \\
445.82 \\
445.75 \\
445.67 \\
445.62\end{array}$ & $\begin{array}{l}205 \\
203 \\
201 \\
199 \\
197 \\
194 \\
192 \\
190 \\
187 \\
185 \\
182 \\
179 \\
176 \\
173 \\
171\end{array}$ & $\begin{array}{l}486.51 \\
492.80 \\
496.52 \\
499.98 \\
502.08 \\
504.34 \\
505.50 \\
506.23 \\
506.88 \\
507.89 \\
508.87 \\
509.64 \\
510.59 \\
512.58 \\
514.13\end{array}$ & $\begin{array}{r}4,200 \\
5,340 \\
6,110 \\
6,890 \\
7,430 \\
8,010 \\
8,320 \\
8,530 \\
8,720 \\
9,020 \\
9,300 \\
9,530 \\
9,820 \\
10,460 \\
10,960\end{array}$ & $\begin{array}{l}16 \\
17 \\
18 \\
19 \\
20 \\
21 \\
22 \\
23 \\
24 \\
25 \\
26 \\
27 \\
28 \\
29 \\
30 \\
31\end{array}$ & $\begin{array}{l}445.56 \\
445.50 \\
445.44 \\
445.34 \\
445.26 \\
445.21 \\
445.13 \\
449.47 \\
449.80 \\
449.76 \\
449.74 \\
449.69 \\
449.64 \\
449.58 \\
449.65 \\
464.05\end{array}$ & $\begin{array}{r}168 \\
166 \\
164 \\
160 \\
156 \\
154 \\
151 \\
325 \\
338 \\
336 \\
336 \\
334 \\
332 \\
329 \\
332 \\
1,360\end{array}$ & $\begin{array}{c}515.44 \\
516.61 \\
517.71 \\
518.77 \\
519.71 \\
520.55 \\
521.46 \\
522.29 \\
523.18 \\
523.98 \\
524.82 \\
525.34 \\
525.84 \\
- \\
- \\
-\end{array}$ & $\begin{array}{c}11,400 \\
11,810 \\
12,190 \\
12,570 \\
12,900 \\
13,210 \\
13,550 \\
13,860 \\
14,200 \\
14,500 \\
14,820 \\
15,020 \\
15,230 \\
- \\
- \\
-\end{array}$ \\
\hline & In cor & 1 & & & & 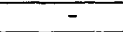 & $+1,154$ & - & $+13,870$ \\
\hline
\end{tabular}

11-1700. Coyote Creek near Madrone, Calif.

Location.--Lat $37^{\circ} 10^{\prime} 06^{\prime \prime}$, long $121^{\circ} 38^{\prime} 55^{\prime \prime}$, near southeast comer of La Laguna Seca Grant, on right bank 1.2 miles downstream from Anderson Dam and 1.8 miles northeast of Madrone, Santa Clara County.

Drainage area $--196 \mathrm{sq} \mathrm{ml}$.

Gage-height record.--Water-stage recorder graph. Altitude of gage is $375 \mathrm{ft}$ (from topographic map).

Discharge record.--Stage-discharge relation defined by current-meter measurements.

Maxima.--January-February 1963: Discharge, 47 cfs 1300-1500 hour8 Feb. 6 (gage helght, $2.28 \mathrm{ft}$ ).

$1902-12,1916$ to December 1962: Discharge, 25,000 cfs probably Mar. 7, 1911

(record furnished by Duryea, Haehi \& Gilman).

Remarks.--Flow regulated by Coyote and Anderson Lakes (see stations $11-1698.5$ and

11-1699.2). 
Mean discharge, in cubic feet per second, 1963, of Coyote Creek near Madrone, Calif.

\begin{tabular}{|c|c|c|c|c|c|c|c|c|}
\hline Day & January & February & Day & January & February & Day & January & February \\
\hline $\begin{array}{r}1 \ldots \ldots \\
2 \ldots \ldots \\
3 \ldots \ldots \\
4 \ldots \ldots \\
5 \ldots \ldots \\
6 \ldots \ldots \\
7 \ldots \ldots \\
8 \ldots \ldots \\
9 \ldots \ldots \\
10 \ldots \ldots\end{array}$ & $\begin{array}{r}1.0 \\
1.0 \\
1.0 \\
1.0 \\
1.0 \\
1.0 \\
1.0 \\
1.0 \\
1.0 \\
.9\end{array}$ & $\begin{array}{r}2.1 \\
.8 \\
.6 \\
.6 \\
.5 \\
24^{.5} \\
42 \\
43 \\
27 \\
3.0\end{array}$ & $\begin{array}{l}11 \ldots \ldots \\
12 \ldots \ldots \\
13 \ldots \ldots \\
14 \ldots \ldots \\
15 \ldots \ldots \\
16 \ldots \ldots \\
17 \ldots \ldots \\
18 \ldots \ldots \\
19 \ldots \ldots \\
20 \ldots \ldots\end{array}$ & $\begin{array}{l}0.8 \\
.8 \\
.8 \\
.9 \\
.9 \\
.9 \\
.9 \\
.9 \\
.9 \\
.9\end{array}$ & $\begin{array}{l}2.2 \\
31 \\
9.6 \\
19 \\
45 \\
34 \\
30 \\
30 \\
26 \\
26\end{array}$ & $\begin{array}{l}21 \ldots \ldots \\
22 \ldots \ldots \\
23 \ldots \ldots \\
24 \ldots \ldots \\
25 \ldots \ldots \\
26 \ldots \ldots \\
27 \ldots \ldots \\
28 \ldots \ldots \\
29 \ldots \ldots \\
30 \ldots \ldots \\
31 \ldots \ldots\end{array}$ & $\begin{array}{r}0.9 \\
.9 \\
1.0 \\
1.0 \\
1.0 \\
.7 \\
.6 \\
.6 \\
.8 \\
5.6 \\
12\end{array}$ & $\begin{array}{r}26 \\
26 \\
26 \\
26 \\
26 \\
26 \\
26 \\
26 \\
----- \\
---- \\
---\end{array}$ \\
\hline $\begin{array}{l}\text { onthly } \\
\text { unoff, }\end{array}$ & $\begin{array}{l}\text { in disc } \\
\text { acre-f }\end{array}$ & , In & feet & & & & $\begin{array}{r}1.41 \\
87 \\
\end{array}$ & $1,21,6$ \\
\hline
\end{tabular}

11-1721. Upper Penttencla Creek at San Jose, Calif.

Location.--Lat $37^{\circ} 23^{\prime} 43^{\prime \prime}$, long $121^{\circ} 49^{\prime} 38^{\prime \prime}$, on north boundary of San Jose Pala Grant, on left bank at downstream side of county road bridge, 0.1 mile upstream from

Dutard Creek, near northeast limits of San Jose, Santa Clara County.

Drainage area. $--21.5 \mathrm{sq} \mathrm{mi}$.

Gage-helght record $j^{--W a t e r-s t a g e ~ r e c o r d e r ~ g r a p h . ~ A l t i t u d e ~ o f ~ g a g e ~ i s ~} 270 \mathrm{ft}$ (from topographic map).

Discharge record.--Stage-discharge relation defined by current-meter measurements .

Maxima.--January-February 1963: Discharge, $107 \mathrm{cfs} 0300$ hours Feb. 13 (gage height, $3.26 \mathrm{ft}$ )

1961 to December 1962: Discharge, $198 \mathrm{cfs}$ Feb. 16, 1962 (gage height, $3.53 \mathrm{ft}$, at site 0.4 mile downstream at different datum.

Remarks.-Flow partly regulated by Cherry Flat Reservoir (capacity, 500 acre-ft).

Mean discharge, in cubic feet per second, 1963

\begin{tabular}{|c|c|c|c|c|c|c|c|c|}
\hline Day & January & February & Day & January & February & Day & January & February \\
\hline $\begin{array}{c}1 \ldots \ldots \\
2 \ldots \ldots \\
3 \ldots \ldots \\
5 \ldots \ldots \\
6 \ldots \ldots \\
8 \ldots \ldots \\
9 \ldots \ldots \\
10 \ldots \ldots\end{array}$ & $\begin{array}{l}0.3 \\
.3 \\
.3 \\
.3 \\
.3 \\
.3 \\
.3 \\
.3 \\
.3 \\
.3\end{array}$ & $\begin{array}{r}27 \\
8.1 \\
3.8 \\
2.6 \\
1.8 \\
1.4 \\
1.1 \\
.9 \\
2.4 \\
4.9\end{array}$ & $\begin{array}{l}11 \ldots \ldots \\
12 \ldots \ldots \\
13 \ldots \ldots \\
14 \ldots \ldots \\
15 \ldots \ldots \\
16 \ldots \ldots \\
17 \ldots \ldots \\
18 \ldots \ldots \\
19 \ldots \ldots \\
20 \ldots \ldots\end{array}$ & $\begin{array}{l}0.2 \\
.3 \\
.3 \\
.3 \\
.3 \\
.3 \\
.3 \\
.3 \\
.3 \\
.3\end{array}$ & $\begin{array}{l}3.4 \\
6.2 \\
48 \\
15 \\
6.2 \\
4.2 \\
3.6 \\
2.6 \\
2.3 \\
1.7\end{array}$ & $\begin{array}{l}21 \ldots \ldots \\
22 \ldots \ldots \\
23 \ldots \ldots \\
24 \ldots \ldots \\
25 \ldots \ldots \\
26 \ldots \ldots \\
27 \ldots \ldots \\
25 \ldots \ldots \\
29 \ldots \ldots \\
30 \ldots \ldots \\
31 \ldots \ldots\end{array}$ & $\begin{array}{r}0.3 \\
.3 \\
.3 \\
.3 \\
.3 \\
.3 \\
.3 \\
.3 \\
.4 \\
2.6 \\
16\end{array}$ & $\begin{array}{r}1.4 \\
1.2 \\
.9 \\
.8 \\
.8 \\
.8 \\
.8 \\
1.2 \\
---.-\end{array}$ \\
\hline $\begin{array}{l}\text { loff,' } \\
\text { noff, }\end{array}$ & $\begin{array}{l}\text { Inche } \\
\text { acre- }\end{array}$ & & & & & & $\begin{array}{r}0.88 \\
0.05 \\
54\end{array}$ & $\begin{array}{r}5.54 \\
0.27 \\
308\end{array}$ \\
\hline
\end{tabular}

Gage height, in feet, and discharge, in cublc feet per second, at indicated time, 1963

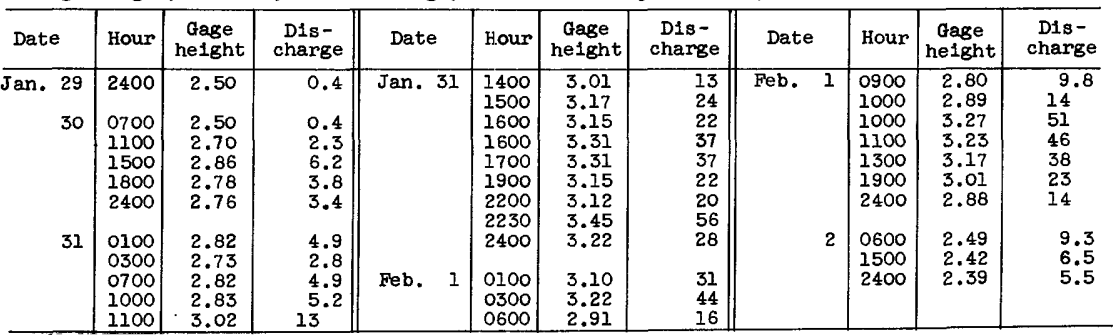




\section{ALAMEDA CREEK BASIN}

11-1735.6. Alameda Creek tributary No. I near Warm Springs, Calif.

(Crest-stage station)

Location.--Lat $37^{\circ} 31^{\prime} 14^{\prime \prime}$, long $121^{\circ} 50^{\prime} 48^{\prime \prime}$, In NW $\frac{1}{4} \mathrm{NE} \frac{1}{4}$ sec.10, T.5 S., R.I E., at culvert on Calaveras road, 5 miles northeast of Warm Springs.

Drainage area. $--0.35 \mathrm{sq} \mathrm{mi}$.

Gage-height record.--Crest stages only. Altitude of gage is $530 \mathrm{ft}$ (from topographic map).

Discharge record.--Stage-discharge relation not defined.

Maxima.--January-February 1963: Discharge, not determined, occurred Jan. 31 (gage helght, $46.24 \mathrm{ft}$ ).

1958 to December 1962: Discharge, 14 cfs Feb. 14, 1962 (gage height, $47.04 \mathrm{ft}$ ), by computation of flow through culvert.

11-1740. San Antonio Creek near Sunol, Cal1f.

Location.--Lat $37^{\circ} 34^{\prime} 39^{\prime \prime}$, long $121^{\circ} 51^{\prime} 24^{\prime \prime}$, in Valle de San Jose Grant, on right bank 0.4 mile upstream from Calaveras Road Bridge, $0.85 \mathrm{mile}$ above mouth, and 2 miles southeast of Sunol, Alameda County.

Drainage area. $--37.0 \mathrm{sq} \mathrm{mi}$.

Gage-height record. --Water-stage recorder graph. Datum of gage is $271.56 \mathrm{ft}$ above mean sea level, levels by city of San Francisco.

Discharge record.--Stage-discharge relation defined by current-meter measurements below $170 \mathrm{cfs}$ and by slope-area measurement at $1,970 \mathrm{cfs}$.

Maxima.--January-February 1963: D1scharge, 1,970 cfs 2330 hours Jan. 31 (gage height $7.16 \mathrm{ft}$ ).

$1912-30,1960$ to December 1962: Da1ly discharge, 1,460 cfs Jan. 3, 1916

Flood of Dec. 23, 1955, 5,810 cfs (by slope-area measurement of maximum flow).

Mean discharge, in cubic feet per second, 1963

\begin{tabular}{|c|c|c|c|c|c|c|c|c|}
\hline Day & January & February & Day & January & February & Day & January & February \\
\hline $\begin{array}{r}1 \ldots \ldots \\
2 \ldots \ldots \\
3 \ldots \ldots \\
5 \ldots \ldots \\
6 \ldots \ldots \\
7 \ldots \ldots \\
8 \ldots \ldots \\
10 \ldots \ldots\end{array}$ & $\begin{array}{l}0.4 \\
.4 \\
.4 \\
.4 \\
.4 \\
.4 \\
.4 \\
.4 \\
.4 \\
.4\end{array}$ & $\begin{array}{c}362 \\
64 \\
31 \\
18 \\
12 \\
9.2 \\
7.2 \\
5.7 \\
5.8 \\
13\end{array}$ & $\begin{array}{l}11 \ldots \ldots \\
12 \ldots \ldots \\
13 \ldots \ldots \\
14 \ldots \ldots \\
15 \ldots \ldots \\
16 \ldots \ldots \\
17 \ldots \ldots \\
18 \ldots \ldots \\
19 \ldots \ldots \\
20 \ldots \ldots\end{array}$ & $\begin{array}{r}0.4 \\
.4 \\
.4 \\
.4 \\
.4 \\
.4 \\
.4 \\
.4 \\
.4 \\
.4\end{array}$ & $\begin{array}{c}7.2 \\
18 \\
163 \\
57 \\
29 \\
21 \\
17 \\
13 \\
11 \\
9.6\end{array}$ & $\begin{array}{l}21 \ldots \ldots \\
22 \ldots \ldots \\
23 \ldots \ldots \\
24 \ldots \ldots \\
25 \ldots \ldots \\
26 \ldots \ldots \\
27 \ldots \ldots \\
28 \ldots \ldots \\
29 \ldots \ldots \\
30 \ldots \ldots \\
31 \ldots \ldots\end{array}$ & $\begin{array}{r}0.4 \\
.4 \\
.4 \\
.4 \\
.4 \\
.4 \\
.4 \\
.4 \\
.4 \\
1.5 \\
390\end{array}$ & 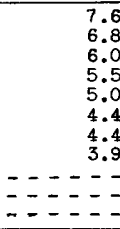 \\
\hline \multicolumn{7}{|c|}{ 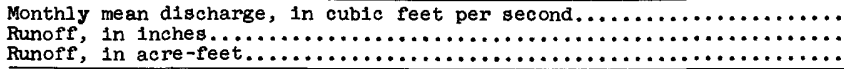 } & $\begin{array}{r}13.0 \\
0.41 \\
800\end{array}$ & $\begin{array}{r}32.8 \\
0.93 \\
1,820\end{array}$ \\
\hline
\end{tabular}

Gage height, in feet, and discharge, in cubic feet per second, at indicated time, 1963

\begin{tabular}{|c|c|c|c|c|c|c|c|c|c|c|c|}
\hline Date & Hour & $\begin{array}{c}\text { Gage } \\
\text { he1ght }\end{array}$ & $\begin{array}{l}\text { Dis- } \\
\text { charge }\end{array}$ & Date & Hour & $\begin{array}{c}\text { Gage } \\
\text { height }\end{array}$ & $\begin{array}{l}\text { Dis- } \\
\text { charge }\end{array}$ & Date & Hour & $\begin{array}{c}\text { Gage } \\
\text { helght }\end{array}$ & $\begin{array}{l}\text { Dis- } \\
\text { charge }\end{array}$ \\
\hline $\begin{array}{r}\text { an. } 30 \\
31\end{array}$ & $\begin{array}{l}2400 \\
0200 \\
0400 \\
1000 \\
1200 \\
1300 \\
1400 \\
1700 \\
1800\end{array}$ & $\begin{array}{l}3.14 \\
3.14 \\
3.36 \\
3.42 \\
3.70 \\
4.07 \\
5.15 \\
4.58 \\
4.56\end{array}$ & $\begin{array}{c}4.4 \\
4.4 \\
14 \\
17 \\
43 \\
109 \\
513 \\
263 \\
256 \\
\end{array}$ & Feb. 1 & $\begin{array}{l}1900 \\
2000 \\
2100 \\
2200 \\
2330 \\
2400 \\
\\
0100 \\
0300 \\
0600\end{array}$ & $\begin{array}{l}4.70 \\
5.80 \\
6.93 \\
6.58 \\
7.16 \\
6.84 \\
6.00 \\
5.30 \\
4.77\end{array}$ & $\begin{array}{r}308 \\
900 \\
1,770 \\
1,460 \\
1,970 \\
1,690 \\
1,030 \\
600 \\
336\end{array}$ & Feb. 1 & $\begin{array}{l}0800 \\
1200 \\
1800 \\
2400 \\
\\
0600 \\
1200 \\
1800 \\
2400\end{array}$ & $\begin{array}{l}5.00 \\
4.61 \\
4.26 \\
4.06 \\
3.93 \\
3.82 \\
3.73 \\
3.68\end{array}$ & $\begin{array}{r}435 \\
274 \\
159 \\
106 \\
\\
78 \\
59 \\
47 \\
41\end{array}$ \\
\hline
\end{tabular}


11-1744.5. Big Canyon Creek near Dublin, Calif.

(Crest-stage station)

Location.--Lat $37^{\circ} 43^{\prime} 15^{\prime \prime}$, long $121^{\circ} 56^{\prime} 25^{\prime \prime}$, in San Ramon Grant, at culvert on State Highway 21, 1.4 miles north of Dublin.

Drainage area. $--1.13 \mathrm{sq} \mathrm{mi}$.

Gage-height record.--Crest stages only. Altitude of gage is $420 \mathrm{ft}$ (from topographic map).

Discharge record.--Stage-discharge relation defined by current-meter measurements below $7 \mathrm{cf}$ 's and by slope-area measurements at 124 and $140 \mathrm{cfs}$.

Maxima.--January-February 1963: Discharge, $160 \mathrm{cfs}$ Jan. 31 (gage height, $49.36 \mathrm{ft}$ ). 1958 to December 1962: Discharge, $104 \mathrm{cfs}$ 0ct. 13, 1962 (gage height, $48.97 \mathrm{ft}$ ).

11-1762. Arroyo Mocho near Pleasanton, Calif.

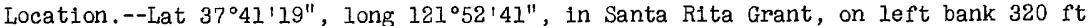
downstream from Santa Rita Road, 0.7 mile upstream from Tassa Jara Creek, and 1.8 miles north of Pleasanton, Alameda County.

Drainage area. $--143 \mathrm{sq} \mathrm{mi}$.

Gage-height record. --Water-stage recorder graph. Datum of gage is $328.55 \mathrm{ft}$ above mean sea level (levels by Alameda County Flood Control and Water Conservation District).

Discharge record.--Stage-discharge relation defined by current-meter measurements below $41 \mathrm{cfs}$ and by slope-area measurement at $1,760 \mathrm{cfs}$.

Maxima.--January-February 1963: Discharge, 1,760 cfs 0130 hours Feb. I (gage height, $8.60 \mathrm{ft}$ ).

September-December 1962: Discharge, 296 cfs Oct. 13, 1962 (gage height, $3.50 \mathrm{ft}$ ).

Mean discharge, in cubic feet per second, 1963

\begin{tabular}{|c|c|c|c|c|c|c|c|c|}
\hline Day & January & February & Day & January & February & Day & January & February \\
\hline $\begin{array}{r}1 \ldots \ldots \\
2 \ldots \ldots \\
4 \ldots \ldots \\
5 \ldots \ldots \\
6 \ldots \ldots \\
7 \ldots \ldots \\
8 \ldots \ldots \\
10 \ldots \ldots\end{array}$ & $\begin{array}{l}3.3 \\
2.1 \\
0 \\
0 \\
0 \\
0 \\
0 \\
0 \\
0 \\
0\end{array}$ & $\begin{array}{c}926 \\
62 \\
4.3 \\
1.4 \\
2.1 \\
1.9 \\
1.9 \\
1.2 \\
0 \\
1.2\end{array}$ & $\begin{array}{l}11 \ldots \ldots \\
12 \ldots \ldots \\
13 \ldots \ldots \\
14 \ldots \ldots \\
15 \ldots \ldots \\
16 \ldots \ldots \\
17 \ldots \ldots \\
18 \ldots \ldots \\
19 \ldots \ldots \\
20 \ldots \ldots\end{array}$ & $\begin{array}{l}0 \\
8.8 \\
40 \\
29 \\
.4 \\
.4 \\
2.4 \\
15 \\
26 \\
41\end{array}$ & $\begin{array}{c}0.4 \\
20 \\
241 \\
33 \\
3.3 \\
.1 \\
0 \\
0 \\
0 \\
0\end{array}$ & $\begin{array}{l}21 \ldots \ldots \\
22 \ldots \ldots \\
23 \ldots \ldots \\
24 \ldots \ldots \\
25 \ldots \ldots \\
26 \ldots \ldots \\
27 \ldots \ldots \\
28 \ldots \ldots \\
29 \ldots \ldots \\
30 \ldots \ldots \\
31 \ldots \ldots\end{array}$ & $\begin{array}{c}30 \\
1.3 \\
.4 \\
0 \\
0 \\
0 \\
0 \\
0 \\
0 \\
9.9 \\
374\end{array}$ & $\begin{array}{r}0 \\
0 \\
0 \\
0 \\
0 \\
0 \\
0 \\
0 \\
--1--1\end{array}$ \\
\hline \multicolumn{7}{|l|}{$\begin{array}{l}\text { Monthly } \\
\text { Runoff, } \\
\text { Runoff, }\end{array}$} & $\begin{array}{r}18.8 \\
0.15 \\
1,160\end{array}$ & $\begin{array}{r}46.4 \\
0.34 \\
2,580\end{array}$ \\
\hline
\end{tabular}

Gage height, in feet, and discharge, in cublc feet per second, at indicated time, 1963

\begin{tabular}{|c|c|c|c|c|c|c|c|c|c|c|c|}
\hline Date & Hour & $\begin{array}{c}\text { Gage } \\
\text { helght }\end{array}$ & $\begin{array}{c}\text { Dis- } \\
\text { charge }\end{array}$ & Date & Hour & $\begin{array}{c}\text { aage } \\
\text { helght }\end{array}$ & $\begin{array}{c}\text { D1s- } \\
\text { charge }\end{array}$ & Date & Hour & $\begin{array}{c}\text { Gage } \\
\text { helght }\end{array}$ & $\begin{array}{c}\text { D1s- } \\
\text { charge }\end{array}$ \\
\hline $\begin{array}{r}\text { Jan. } 29 \\
30\end{array}$ & $\begin{array}{l}2400 \\
1600 \\
1600 \\
1900 \\
2400 \\
\\
0500 \\
0900 \\
1100\end{array}$ & $\begin{array}{l}1.05 \\
1.05 \\
1.52 \\
2.03 \\
1.85 \\
1.70 \\
1.70 \\
1.85\end{array}$ & $\begin{array}{c}0 \\
0 \\
6.6 \\
41 \\
25 \\
14 \\
14 \\
25 \\
\end{array}$ & Feb. 1 & $\begin{array}{l}1200 \\
1300 \\
1500 \\
1600 \\
1900 \\
2100 \\
2400 \\
0130\end{array}$ & $\begin{array}{l}2.02 \\
3.24 \\
3.41 \\
3.26 \\
5.78 \\
6.30 \\
8.34 \\
8.60\end{array}$ & $\begin{array}{r}40 \\
237 \\
274 \\
241 \\
914 \\
1,070 \\
1,680 \\
1,760\end{array}$ & Feb. 1 & $\begin{array}{l}0500 \\
0900 \\
1600 \\
2100 \\
2400 \\
0600 \\
1200 \\
2400\end{array}$ & $\begin{array}{l}7.80 \\
6.10 \\
4.40 \\
3.25 \\
2.87 \\
2.40 \\
2.10 \\
1.66\end{array}$ & $\begin{array}{r}1,520 \\
1,190 \\
515 \\
239 \\
161 \\
\\
84 \\
48 \\
12\end{array}$ \\
\hline
\end{tabular}


11-1765. Arroyo Valle near Livermore, Calif.

Location.--Lat $37^{\circ} 37^{\prime} 24^{\prime \prime}$, long $121^{\circ} 45^{\prime} 28^{\prime \prime}$, in Valle de San Jose Grant, on right bank $900 \mathrm{ft}$ downstream from highway bridge, 1.1 miles upstream from Dry Creek, 4.1 miles south of Livermore, Alameda County, and 6.9 miles southeast of Pleasanton.

Drainage area $--147 \mathrm{sq} \mathrm{ml}$.

Gage-helght record; --Water-stage recorder graph. Alt1tude of gage is $500 \mathrm{ft}$ (from topographic map) .

Discharge record.--Stage-discharge relation defined by current-meter measurements .

Maxima.--January-February 1963: Discharge, 8,810 cfs 0130 hours Feb. 1 (gage helght, $9.34 \mathrm{ft}$ ).

$1912-30,1955$ to December 1962: Discharge, 18,200 cfs Dec. 23, 1955 (gage helght, $13.93 \mathrm{ft}$, from floodmarks), on basis of contracted-opening and slope-area measurement of peak flow.

Mean discharge, in cublc feet per second, 1963

\begin{tabular}{|c|c|c|c|c|c|c|c|c|}
\hline Day & January & February & Day & January & February & Day & January & February \\
\hline $\begin{array}{c}1 \ldots \ldots \\
3 \ldots \ldots \\
4 \ldots \ldots \\
5 \ldots \ldots \\
6 \ldots \ldots \\
7 \ldots \ldots \\
9 \ldots \ldots \\
9 \ldots \ldots \\
10 \ldots \ldots\end{array}$ & $\begin{array}{r}0.4 \\
.8 \\
.9 \\
1.1 \\
1.2 \\
1.2 \\
1.4 \\
1.4 \\
1.4 \\
1.4\end{array}$ & $\begin{array}{r}, 560 \\
472 \\
167 \\
93 \\
59 \\
41 \\
31 \\
26 \\
23 \\
45\end{array}$ & $\begin{array}{l}11 \ldots \ldots \\
12 \ldots \ldots \\
13 \ldots \ldots \\
14 \ldots \ldots \\
15 \ldots \ldots \\
16 \ldots \ldots \\
17 \ldots \ldots \\
15 \ldots \ldots \\
19 \ldots \ldots \\
20 \ldots \ldots\end{array}$ & $\begin{array}{l}1.6 \\
1.4 \\
1.4 \\
1.4 \\
1.2 \\
1.2 \\
1.2 \\
1.2 \\
1.2 \\
1.2\end{array}$ & $\begin{array}{r}55 \\
44 \\
537 \\
314 \\
159 \\
105 \\
75 \\
55 \\
42 \\
34\end{array}$ & $\begin{array}{l}21 \ldots \ldots \\
22 \ldots \ldots \\
23 \ldots \ldots \\
24 \ldots \ldots \\
25 \ldots \ldots \\
26 \ldots \ldots \\
27 \ldots \ldots \\
28 \ldots \ldots \\
29 \ldots \ldots \\
30 \ldots \ldots \\
31 \ldots \ldots\end{array}$ & $\begin{array}{r}1.2 \\
1.4 \\
1.2 \\
1.2 \\
.9 \\
.9 \\
1.4 \\
1.4 \\
1.3 \\
1.8 \\
1,420\end{array}$ & $\begin{array}{r}29 \\
26 \\
21 \\
20 \\
18 \\
16 \\
15 \\
15 \\
--.-- \\
--.--\end{array}$ \\
\hline $\begin{array}{l}\text { nthiy } \\
\text { anoff, } \\
\text { anoff, }\end{array}$ & $\begin{array}{l}\text { Inche } \\
\text { acre- }\end{array}$ & & & & & & $\begin{array}{r}47.0 \\
0.37 \\
2,890 \\
\end{array}$ & $\begin{array}{r}218 \\
1.54 \\
12,090 \\
\end{array}$ \\
\hline
\end{tabular}

Gage helght, in feet, and discharge, in cublc feet per second, at indicated t1me, 1963

\begin{tabular}{|c|c|c|c|c|c|c|c|c|c|c|c|}
\hline Date & Hour & $\begin{array}{c}\text { Gage } \\
\text { helght }\end{array}$ & $\begin{array}{l}\text { Dis- } \\
\text { charge }\end{array}$ & Date & Hour & $\begin{array}{c}\text { Gage } \\
\text { helght }\end{array}$ & $\begin{array}{c}\text { Dis- } \\
\text { charge }\end{array}$ & Date & Hour & $\begin{array}{c}\text { Gage } \\
\text { helght }\end{array}$ & $\begin{array}{l}\text { Dis - } \\
\text { charge }\end{array}$ \\
\hline $\begin{array}{r}30 \\
31\end{array}$ & $\begin{array}{l}2400 \\
0300 \\
0300 \\
0900 \\
0900 \\
1000 \\
1400 \\
1500 \\
1600 \\
1700 \\
1900\end{array}$ & $\begin{array}{l}2.22 \\
\\
2.25 \\
3.06 \\
3.21 \\
3.46 \\
3.35 \\
3.68 \\
4.00 \\
4.78 \\
5.32 \\
6.00\end{array}$ & $\begin{array}{r}1.6 \\
2.2 \\
82 \\
114 \\
183 \\
151 \\
262 \\
420 \\
982 \\
1,590 \\
2,510\end{array}$ & Jan. 30 & $\begin{array}{l}2200 \\
2400 \\
0100 \\
0130 \\
0700 \\
1400 \\
2000 \\
2400 \\
0800 \\
1400\end{array}$ & $\begin{array}{l}7.95 \\
8.60 \\
9.25 \\
9.34 \\
6.85 \\
5.85 \\
5.09 \\
4.71 \\
4.16 \\
3.91\end{array}$ & $\begin{array}{r}6,000 \\
7,290 \\
\text { s, 610 } \\
\text { s, s10 } \\
3,920 \\
2,300 \\
1,320 \\
919 \\
\\
511 \\
370\end{array}$ & Feb. 2 & $\begin{array}{l}2100 \\
2400 \\
\\
0800 \\
1800 \\
2400 \\
1200 \\
2400\end{array}$ & $\begin{array}{l}3.68 \\
3.62 \\
3.44 \\
3.30 \\
3.23 \\
3.10 \\
3.00\end{array}$ & $\begin{array}{r}262 \\
238 \\
\\
177 \\
137 \\
120 \\
\\
90 \\
71\end{array}$ \\
\hline
\end{tabular}

11-1765.5. Arroyo Valle tributary near Livermore, Calif.

(Crest-stage station)

Location.--Lat $37^{\circ} 38^{\prime} 4^{\prime \prime}$, long $121^{\circ} 47^{\prime} 55^{\prime \prime}$, in Valle de San Jose Grant, at culvert on Vineyard Avenue, 2.5 miles southwest of Livermore.

Drainage area. $--3.57 \mathrm{sq} \mathrm{ml}$.

Gage-helght record.--Crest stages only. Alt1tude of gage is $430 \mathrm{ft}$ (from topographic map).

Discharge record.--Maximum discharge by computation of flow through culvert.

Maxima.--January-February 1963: Discharge, $97 \mathrm{cfs}$ Jan. 31 (gage height, $14.03 \mathrm{ft}$ ). 1958 to December 1962: Discharge, $36 \mathrm{cfs} \mathrm{Feb.} \mathrm{8,} 1960$ (gage helght, $12.46 \mathrm{ft}$ ). 
11-1766. Arroyo Va1le at Pleasanton, Cal1f.

Location.--Iat $37^{\circ} 40^{\prime} 02^{\prime \prime}$, long $121^{\circ} 53^{\prime} 02^{\prime \prime}$, In Valle de San Jose Grant, on right bank $0.4 \mathrm{mile}$ northwest of' Pleasanton, Alameda County, and $5.8 \mathrm{miles}$ west of Livermore.

Drainage area. $--171 \mathrm{sq} \mathrm{ml}$.

Gage-helght record;--Water-stage recorder graph. Alt1tude of gage is $350 \mathrm{ft}$ (from topographic mapi).

Discharge record.--Stage-discharge relation defined by current-meter measurements below 1,900 cfs.

Maxima,--January-February 1963: Discharge, 8,860 cfs 0400 hours Feb. I (gage heIght, $23.70 \mathrm{ft}$ ).

1957 to December 1962: Discharge, Il,300 cfs Apr. 3, 1958 (gage helght, $25.36 \mathrm{ft}$ ).

Mean d1scharge, in cub1c feet per second, 1963

\begin{tabular}{|c|c|c|c|c|c|c|c|c|}
\hline Day & January & February & Day & January & February & Day & January & February \\
\hline $\begin{array}{c}1 \ldots \ldots \\
2 \ldots \ldots \\
3 \ldots \ldots \\
5 \ldots \ldots \\
6 \ldots \ldots \\
7 \ldots \ldots \\
8 \ldots \ldots \\
9 \ldots \ldots \\
10 \ldots \ldots\end{array}$ & $\begin{array}{l}0 \\
0 \\
0 \\
0 \\
0 \\
0 \\
0 \\
0 \\
0 \\
0\end{array}$ & $\begin{array}{r}4,360 \\
680 \\
229 \\
109 \\
64 \\
44 \\
30 \\
14 \\
9.8 \\
9.8\end{array}$ & $\begin{array}{l}11 \ldots \ldots \\
12 \ldots \ldots \\
13 \ldots \ldots \\
14 \ldots \ldots \\
15 \ldots \ldots \\
16 \ldots \ldots \\
17 \ldots \ldots \\
15 \ldots \ldots \\
19 \ldots \ldots \\
20 \ldots \ldots\end{array}$ & $\begin{array}{l}0 \\
0 \\
0 \\
0 \\
0 \\
0 \\
0 \\
0 \\
0 \\
0\end{array}$ & $\begin{array}{r}36 \\
38 \\
385 \\
498 \\
206 \\
105 \\
72 \\
53 \\
40 \\
28\end{array}$ & $\begin{array}{l}21 \ldots \ldots \\
22 \ldots \ldots \\
23 \ldots \ldots \\
24 \ldots \ldots \\
25 \ldots \ldots \\
26 \ldots \ldots \\
27 \ldots \ldots \\
28 \ldots \ldots \\
29 \ldots \ldots \\
30 \ldots \ldots \\
31 \ldots \ldots\end{array}$ & $\begin{array}{r}0 \\
0 \\
0 \\
0 \\
0 \\
0 \\
0 \\
0 \\
0 \\
0 \\
454\end{array}$ & 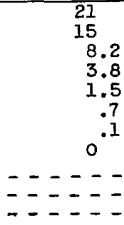 \\
\hline $\begin{array}{l}\text { onthly } \\
\text { unoff, } \\
\text { unoff, }\end{array}$ & $\begin{array}{l}\text { 1nches } \\
\text { acre-1 }\end{array}$ & & & & & & $\begin{array}{r}14.6 \\
0.10 \\
900\end{array}$ & $\begin{array}{r}252 \\
1.54 \\
14,010\end{array}$ \\
\hline
\end{tabular}

Gage height, in feet, and discharge, in cubic feet per second, at 1nd1cated time, 1963

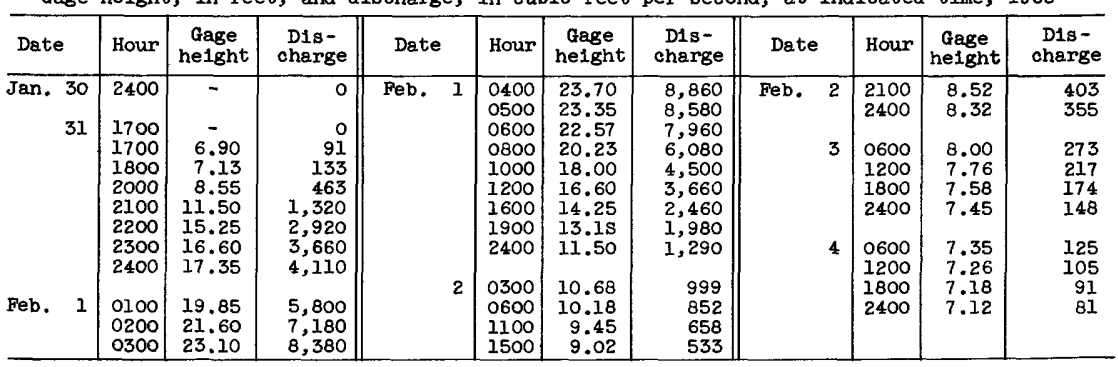

11-1790. Alameda Creek near N1les, Calif.

Location.--Lat $37^{\circ} 35^{\prime} 14^{\prime \prime}$, long $121^{\circ} 57^{\prime} 35^{\prime \prime}$, in NW $\frac{1}{4}$ sec.15, T.4 S., R.I W., on right bank 0.3 mile downstream from rallroad bridge and 1.2 mfles northeast of N1les.

Drainage area. $--633 \mathrm{sq} \mathrm{mi}$.

Qage-he1ght record.--Water-stage recorder graph. Datum of gage is $85.65 \mathrm{ft}$ above mean sea level, datum of 1929 .

Discharge record.--Stage-discharge relation defined by current-meter measurements .

Maxima.--January-February 1963: D1scharge, 11,500 cfs 0800 hours Feb. 1 (gage helght, $10.48 \mathrm{ft}$ ).

$14.9 \mathrm{ft})$.

Remarks.--Flow regulated by Calaveras Reservoir since 1925 (capacity, 96,800 acre-ft). 
Mean discharge, in cubic feet per second, 1963, of Alameda Creek near Niles, Cal1f.

\begin{tabular}{|c|c|c|c|c|c|c|c|c|}
\hline Day & January & February & Day & January & February & Day & January & February \\
\hline $\begin{array}{c}1 \ldots \ldots \\
2 \ldots \ldots \\
3 \ldots \ldots \\
4 \ldots \ldots \\
5 \ldots \ldots \\
6 \ldots \ldots \\
7 \ldots \ldots \\
8 \ldots \ldots \\
9 \ldots \ldots \\
10 \ldots \ldots\end{array}$ & $\begin{array}{l}5.6 \\
5.6 \\
5.4 \\
3.7 \\
2.7 \\
2.3 \\
2.3 \\
2.3 \\
2.3 \\
2.2\end{array}$ & $\begin{array}{r}7,890 \\
1,910 \\
581 \\
218 \\
122 \\
78 \\
57 \\
42 \\
37 \\
129\end{array}$ & $\begin{array}{l}11 \ldots \ldots \\
12 \ldots \ldots \\
13 \ldots \ldots \\
14 \ldots \ldots \\
15 \ldots \ldots \\
16 \ldots \ldots \\
17 \ldots \ldots \\
18 \ldots \ldots \\
19 \ldots \ldots \\
20 \ldots \ldots\end{array}$ & $\begin{array}{l}2.0 \\
1.8 \\
16 \\
40 \\
17 \\
5.2 \\
3.4 \\
3.2 \\
14 \\
37\end{array}$ & $\begin{array}{r}57 \\
142 \\
1,210 \\
766 \\
324 \\
174 \\
126 \\
89 \\
78 \\
60\end{array}$ & $\begin{array}{l}21 \ldots \ldots \\
22 \ldots \ldots \\
23 \ldots \ldots \\
24 \ldots \ldots \\
25 \ldots \ldots \\
26 \ldots \ldots \\
27 \ldots \ldots \\
28 \ldots \ldots \\
29 \ldots \ldots \\
30 \ldots \ldots \\
31 \ldots \ldots\end{array}$ & $\begin{array}{r}41 \\
19 \\
6.0 \\
3.9 \\
3.2 \\
2.5 \\
2.3 \\
2.0 \\
2.2 \\
6.7 \\
1,820\end{array}$ & $\begin{array}{r}47 \\
41 \\
32 \\
28 \\
24 \\
22 \\
19 \\
17 \\
-----\end{array}$ \\
\hline
\end{tabular}

Gage height, in feet, and discharge, in cublc feet per second, at 1ndicated time, 1963

\begin{tabular}{|c|c|c|c|c|c|c|c|c|c|c|c|}
\hline Date & Hour & $\begin{array}{c}\text { Gage } \\
\text { helght }\end{array}$ & $\begin{array}{l}\text { D1s- } \\
\text { charge }\end{array}$ & Date & Hour & $\begin{array}{c}\text { Gage } \\
\text { height }\end{array}$ & $\begin{array}{c}\text { D1s- } \\
\text { charge }\end{array}$ & Date & Hour & $\begin{array}{c}\text { Gage } \\
\text { helght }\end{array}$ & $\begin{array}{c}\text { Dis- } \\
\text { charge }\end{array}$ \\
\hline $\begin{array}{r}\text { Jan. } 29 \\
30\end{array}$ & $\begin{array}{l}2400 \\
0300 \\
0800 \\
2300 \\
2400\end{array}$ & $\begin{array}{l}2.29 \\
2.30 \\
2.36 \\
2.68 \\
2.80\end{array}$ & $\begin{array}{l}2.5 \\
2.6 \\
3.4 \\
13 \\
19\end{array}$ & Feb. 1 & $\begin{array}{l}2300 \\
2330 \\
2400 \\
\\
0200 \\
0400 \\
0600\end{array}$ & $\begin{array}{r}10.14 \\
10.30 \\
10.17 \\
10.35 \\
9.99 \\
10.10\end{array}$ & $\begin{array}{l}10,500 \\
11,000 \\
10,600 \\
11,200 \\
10,100 \\
10,400\end{array}$ & Feb. & $\begin{array}{l}0600 \\
1300 \\
1600 \\
1800 \\
2100 \\
2400\end{array}$ & $\begin{array}{l}6.30 \\
5.74 \\
5.50 \\
5.48 \\
5.26 \\
5.06\end{array}$ & $\begin{array}{l}2,360 \\
1,670 \\
1,420 \\
1,400 \\
1,190 \\
1,030\end{array}$ \\
\hline 31 & $\begin{array}{l}0100 \\
0300 \\
1100 \\
1300 \\
1400 \\
1700 \\
1800 \\
1900 \\
2000 \\
2100 \\
2200\end{array}$ & $\begin{array}{r}3.39 \\
3.52 \\
3.48 \\
3.64 \\
3.78 \\
5.35 \\
5.80 \\
6.93 \\
6.80 \\
7.80 \\
10.00\end{array}$ & $\begin{array}{r}93 \\
126 \\
115 \\
161 \\
209 \\
1,270 \\
1,740 \\
3,290 \\
3,080 \\
4,880 \\
10,200\end{array}$ & 2 & $\begin{array}{l}0800 \\
1000 \\
1200 \\
1400 \\
1600 \\
1800 \\
2000 \\
2200 \\
2400 \\
0200\end{array}$ & $\begin{array}{r}10.48 \\
10.06 \\
9.30 \\
8.83 \\
8.22 \\
7.80 \\
7.48 \\
7.18 \\
6.92 \\
6.75\end{array}$ & $\begin{array}{r}11,500 \\
10,300 \\
8,400 \\
7,230 \\
5,780 \\
4,880 \\
4,240 \\
3,700 \\
3,270 \\
3,000\end{array}$ & 5 & $\begin{array}{l}0600 \\
1200 \\
1800 \\
2400 \\
\\
1200 \\
2400 \\
\\
1200 \\
2400\end{array}$ & $\begin{array}{l}4.65 \\
4.40 \\
4.23 \\
4.00 \\
3.78 \\
3.62 \\
3.50 \\
3.40\end{array}$ & $\begin{array}{r}705 \\
530 \\
423 \\
300 \\
\\
209 \\
154 \\
\\
120 \\
96\end{array}$ \\
\hline
\end{tabular}

11-1805. Dry Creek at Union City, Calif.

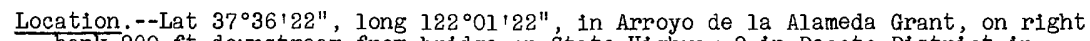
bank 900 ft downstream from bridge on State Highway 9 in Decoto District in Union City, Alameda County, and 1.7 miles upstream from mouth.

Drainage area. $--9.41 \mathrm{sq} \mathrm{mi}$.

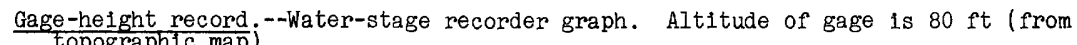
topographic map $j$.

Discharge record.--Stage-discharge relation defined by current-meter measurements.

Maxima.--January-February 1963: Discharge, 190 efs 2000 hours Jan. 31 (gage height, $3.20 \mathrm{ft})$.

1916-19, 1959 to December 1962: Discharge, 930 cfs Oct. 13, 1962 (gage

height, $5.27 \mathrm{ft}$, from outside gage), from rating curve extended above $140 \mathrm{cfs}$ on basis of slope-area measurement of maximum flow.

Mean discharge, In cub1c feet per second, 1963

\begin{tabular}{|c|c|c|c|c|c|c|c|c|}
\hline Day & January & February & Day & January & February & Day & January & February \\
\hline $\begin{array}{c}1 \ldots \ldots \\
2 \ldots \ldots \\
4 \ldots \ldots \\
5 \ldots \ldots \\
6 \ldots \ldots \\
7 \ldots \ldots \\
9 \ldots \ldots \\
10 \ldots \ldots\end{array}$ & $\begin{array}{l}0.1 \\
.1 \\
.1 \\
0.1 \\
0.1 \\
0 \\
0.1 \\
0 \\
0\end{array}$ & $\begin{array}{r}64 \\
21 \\
13 \\
8.0 \\
5.7 \\
5.5 \\
3.1 \\
2.7 \\
11 \\
12\end{array}$ & $\begin{array}{l}11 \ldots \ldots \\
12 \ldots \ldots \\
13 \ldots \ldots \\
14 \ldots \ldots \\
15 . \ldots \ldots \\
16 \ldots \ldots \\
17 \ldots \ldots \\
18 \ldots \ldots \\
19 \ldots \ldots \\
20 \ldots \ldots\end{array}$ & $\begin{array}{l}0 \\
0 \\
0 \\
0 \\
0 \\
0 \\
0 \\
0 \\
0 \\
0\end{array}$ & $\begin{array}{l}5.6 \\
21 \\
40 \\
18 \\
12 \\
9.6 \\
8.8 \\
6.0 \\
5.2 \\
4.2\end{array}$ & $\begin{array}{l}21 \ldots \ldots \\
22 \ldots \ldots \\
23 \ldots \ldots \\
24 \ldots \ldots \\
25 \ldots \ldots \\
26 \ldots \ldots \\
27 \ldots \ldots \\
28 \ldots \ldots \\
29 \ldots \ldots \\
30 \ldots \ldots \\
31 \ldots \ldots\end{array}$ & $\begin{array}{l}0 \\
0 \\
0 \\
0 \\
0 \\
0 \\
0 \\
0 \\
0 \\
1.5 \\
56\end{array}$ & $\begin{array}{r}3.4 \\
3.1 \\
2.7 \\
2.4 \\
2.0 \\
1.8 \\
1.7 \\
1.6 \\
--.--1 \\
-1-0 .-1\end{array}$ \\
\hline \multicolumn{7}{|c|}{ 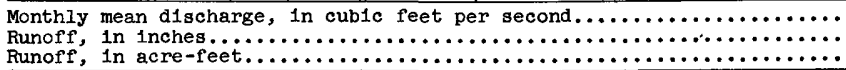 } & $\begin{array}{r}1.87 \\
0.23 \\
115 \\
\end{array}$ & $\begin{array}{r}10.5 \\
1.17 \\
585\end{array}$ \\
\hline
\end{tabular}


Gage height, in feet, and discharge, in cuble feet per second, at indicated time, 1963, of Dry Creek at Union City, Calif.

\begin{tabular}{|c|c|c|c|c|c|c|c|c|c|c|c|}
\hline Date & Hour & $\begin{array}{c}\text { Gage } \\
\text { height }\end{array}$ & $\begin{array}{l}\text { Dis - } \\
\text { charge }\end{array}$ & Date & Hour & $\begin{array}{c}\text { Gage } \\
\text { height }\end{array}$ & $\begin{array}{l}\text { D1s- } \\
\text { charge }\end{array}$ & Date & Hour & $\begin{array}{c}\text { Gage } \\
\text { height }\end{array}$ & $\begin{array}{c}\text { Dis- } \\
\text { charge }\end{array}$ \\
\hline an. $\begin{array}{r}30 \\
31\end{array}$ & $\begin{array}{l}2400 \\
0800 \\
1100 \\
1100 \\
1200 \\
1300 \\
1600 \\
1700\end{array}$ & $\begin{array}{l}1.67 \\
1.70 \\
2.00 \\
2.30 \\
2.25 \\
2.35 \\
2.28 \\
2.85\end{array}$ & $\begin{array}{c}3.0 \\
3.4 \\
15 \\
40 \\
35 \\
46 \\
38 \\
121\end{array}$ & Feb. 1 & $\begin{array}{l}1800 \\
1900 \\
2000 \\
2200 \\
2400 \\
\\
0400 \\
0500 \\
0600\end{array}$ & $\begin{array}{l}2.63 \\
3.10 \\
3.20 \\
3.00 \\
2.80 \\
\\
2.47 \\
2.47 \\
2.75\end{array}$ & $\begin{array}{r}84 \\
168 \\
190 \\
148 \\
112 \\
\\
61 \\
61 \\
104\end{array}$ & Feb. 1 & $\begin{array}{l}0700 \\
1200 \\
1800 \\
2400 \\
1200 \\
2400\end{array}$ & $\begin{array}{l}2.85 \\
2.44 \\
2.29 \\
2.20 \\
\\
2.08 \\
1.94\end{array}$ & $\begin{array}{r}121 \\
57 \\
39 \\
30 \\
\\
21 \\
12\end{array}$ \\
\hline
\end{tabular}

11-1807. Patterson Creek at Union City, Calif.

Location. --Lat $37^{\circ} 35^{\prime} 03^{\prime \prime}$, long $122^{\circ} 02^{\prime} 56^{\prime \prime}$, in Portero de Los Cerritos Grant, on right bank $75 \mathrm{ft}$ upstream from bridge on State Highway 17 (Nimitz Freeway), $0.3 \mathrm{mile}$ below effiuence, and $1.9 \mathrm{miles}$ southeast of Alvarado District in Union City, Alameda County.

Gage-he1ght record.--Water-stage recorder graph, except 0700-1500 hours Feb. I for which graph was reconstructed on basis of two staff-gage readings and floodmarks. Datum of gage is $4.90 \mathrm{ft}^{\mathrm{t}}$ above mean sea level, datum of 1929 .

Discharge record.--Stage-discharge relation defined by current-meter measurements .

Maxima.--January-February 1963: Discharge, 10,500 cf's about 1000 hours Feb. 1 (gage height, $20.4 \mathrm{ft}$, from floodmarks).

1958 to December 1962: Discharge, 3,700 cfs Feb. 16, 1959 (gage height, $13.55 \mathrm{ft})$.

Remarks.--This stream is a distributary of Alameda Creek (see Remarks for Alameda Creek near Niles, $11-1790)$.

Mean discharge, in cubic feet per second, 1963

\begin{tabular}{|c|c|c|c|c|c|c|c|c|}
\hline Day & January & February & Day & January & February & Day & $J$ anuary & February \\
\hline $\begin{array}{c}1 \ldots \ldots \\
2 \ldots \ldots \\
4 \ldots \ldots \\
5 \ldots \ldots \\
6 \ldots \ldots \\
8 \ldots \ldots \\
9 \ldots \ldots \\
10 \ldots \ldots\end{array}$ & $\begin{array}{l}0 \\
0 \\
0 \\
0 \\
0 \\
0 \\
0 \\
0 \\
0 \\
0\end{array}$ & $\begin{array}{r}7,340 \\
1,660 \\
494 \\
162 \\
71 \\
14 \\
4.1 \\
2.0 \\
8.2 \\
64\end{array}$ & $\begin{array}{l}11 \ldots \ldots \\
12 \ldots \ldots \\
13 \ldots \ldots \\
14 \ldots \ldots \\
15 \ldots \ldots \\
16 \ldots \ldots \\
17 \ldots \ldots \\
18 \ldots \ldots \\
19 \ldots \ldots \\
20 \ldots \ldots\end{array}$ & $\begin{array}{l}0 \\
0 \\
0 \\
0 \\
0 \\
0 \\
0 \\
0 \\
0 \\
0\end{array}$ & $\begin{array}{r}13 \\
17 \\
808 \\
631 \\
272 \\
138 \\
80 \\
45 \\
27 \\
22\end{array}$ & $\begin{array}{l}21 \ldots \ldots \\
22 \ldots \ldots \\
23 \ldots \ldots \\
24 \ldots \ldots \\
25 \ldots \ldots \\
26 \ldots \ldots \\
27 \ldots \ldots \\
28 \ldots \ldots \\
29 \ldots \ldots \\
30 \ldots \ldots \\
31 \ldots \ldots\end{array}$ & $\begin{array}{r}0 \\
0 \\
0 \\
0 \\
0 \\
0 \\
0 \\
0 \\
0 \\
0 \\
575\end{array}$ & $\begin{array}{r}6.4 \\
2.5 \\
1.0 \\
.8 \\
.5 \\
.2 \\
.2 \\
.1 \\
-\ldots-.-\end{array}$ \\
\hline $\begin{array}{l}\text { onthly } \\
\text { anoff, }\end{array}$ & $\begin{array}{l}\text { n disc } \\
\text { acre-f }\end{array}$ & , 1 & eet & $\sigma_{1}$ & & & $\begin{array}{r}18.5 \\
1,140\end{array}$ & $\begin{array}{r}424 \\
23,570\end{array}$ \\
\hline
\end{tabular}

Gage height, in feet, and discharge, in cubic feet per second, at indicated time, 1963

\begin{tabular}{|c|c|c|c|c|c|c|c|c|c|c|c|}
\hline Date & Hour & $\begin{array}{c}\text { Gage } \\
\text { helght }\end{array}$ & $\begin{array}{l}\text { Dis- } \\
\text { charge }\end{array}$ & Date & Hour & $\begin{array}{c}\text { Gage } \\
\text { he1ght }\end{array}$ & $\begin{array}{c}\text { Dis- } \\
\text { charge }\end{array}$ & Date & Hour & $\begin{array}{c}\text { Gage } \\
\text { height }\end{array}$ & $\begin{array}{c}\text { Dis- } \\
\text { charge }\end{array}$ \\
\hline $\begin{array}{r}\text { Jan. } 30 \\
31\end{array}$ & $\begin{array}{l}2400 \\
1200 \\
1300 \\
1400 \\
1500 \\
1700 \\
1800 \\
1900 \\
2000 \\
2200 \\
2400 \\
0100\end{array}$ & $\begin{array}{r}- \\
- \\
4.80 \\
5.48 \\
5.89 \\
6.13 \\
6.45 \\
7.50 \\
10.50 \\
13.15 \\
16.90 \\
18.70\end{array}$ & $\begin{array}{c}0 \\
0 \\
5.0 \\
28 \\
56 \\
77 \\
109 \\
280 \\
1,220 \\
2,710 \\
5,920 \\
8,100\end{array}$ & Feb. 1 & $\begin{array}{l}0300 \\
0500 \\
0600 \\
1000 \\
1300 \\
1500 \\
1700 \\
1900 \\
2200 \\
2400 \\
0200 \\
0500 \\
0800\end{array}$ & $\begin{array}{l}19.58 \\
19.57 \\
19.43 \\
20.40 \\
19.10 \\
18.05 \\
16.60 \\
15.30 \\
13.85 \\
13.29 \\
13.10 \\
12.47 \\
11.70\end{array}$ & $\begin{array}{r}9,300 \\
9,290 \\
9,090 \\
10,500 \\
8,630 \\
7,260 \\
5,600 \\
4,370 \\
3,200 \\
2,800 \\
2,670 \\
2,260 \\
1,800\end{array}$ & Feb. 2 & $\begin{array}{l}1000 \\
1200 \\
1800 \\
2400 \\
\\
0600 \\
1200 \\
1800 \\
2400 \\
\\
0600 \\
1200 \\
2400\end{array}$ & $\begin{array}{r}11.52 \\
11.12 \\
10.38 \\
9.58 \\
8.88 \\
8.24 \\
7.78 \\
7.36 \\
7.03 \\
6.79 \\
6.33\end{array}$ & $\begin{array}{r}1,700 \\
1,500 \\
1,170 \\
863 \\
\\
629 \\
450 \\
340 \\
252 \\
193 \\
155 \\
96\end{array}$ \\
\hline
\end{tabular}


11-1807.5. Alameda Creek at Union City, Cal1f.

Location.--Lat $37^{\circ} 35^{\prime} 46^{\prime \prime}$, long $122^{\circ} 03^{\prime} 15^{\prime \prime}$, in Arroyo de la Alameda Grant, on left bank $5 \mathrm{ft}$ downstream from bridge on Baker Road, 1 mile downstream from Dry Creek, and 1.4 miles east of Alvarado District in Union City, Alameda County.

Drainage area. --653 sq mi.

Gage-height record.--Water-stage recorder graph, except 0100 hours Feb. 1 to 0300 hours Feb. 2, for which graph was reconstructed on basis of several staffgage readings and floodmarks. Datum of gage is at mean sea level (levels by Alameda County Flood Control and Water Conservation District).

Discharge record. --Stage-discharge relation defined by current-meter measurements.

Maxima --January-February 1963: Discharge, 1,770 cfs about 1000 hours Feb. 1 (gage height, $19.25 \mathrm{ft}$, from floodmarks).

1958 to December 1962: Discharge, $394 \mathrm{cfs}$ Feb. 15, 1962 (gage height, $13.08 \mathrm{ft}$ ).

Remarks.-For total flow in Alameda Creek, add flow of Patterson Creek at Union City (see Remarks for Alameda Creek near Niles, 11-1790).

Mean d1scharge, in cuble feet per second, 1963

\begin{tabular}{|c|c|c|c|c|c|c|c|c|}
\hline Day & January & Febmuary & Day & January & February & Day & January & February \\
\hline $\begin{array}{r}1 \ldots \ldots \\
2 \ldots \ldots \\
3 \ldots \ldots \\
4 \ldots \ldots \\
5 \ldots \ldots \\
7 \ldots \ldots \\
8 \ldots \ldots \\
9 \ldots \ldots \\
10 \ldots \ldots\end{array}$ & $\begin{array}{l}0 \\
0 \\
0 \\
0 \\
0 \\
0 \\
0 \\
0 \\
0 \\
0\end{array}$ & $\begin{array}{c}1,280 \\
298 \\
7.7 \\
0 \\
0 \\
0 \\
0 \\
0 \\
0 \\
0\end{array}$ & $\begin{array}{l}11 \ldots \ldots \\
12 \ldots \ldots \\
13 \ldots \ldots \\
14 \ldots \ldots \\
15 \ldots \ldots \\
16 \ldots \ldots \\
17 \ldots \ldots \\
18 \ldots \ldots \\
19 \ldots \ldots \\
20 \ldots \ldots\end{array}$ & $\begin{array}{l}0 \\
0 \\
0 \\
0 \\
0 \\
0 \\
0 \\
0 \\
0 \\
0\end{array}$ & $\begin{array}{r}0 \\
0 \\
47 \\
20 \\
0 \\
0 \\
0 \\
0 \\
0 \\
0\end{array}$ & $\begin{array}{l}21 \ldots \ldots \\
22 \ldots \ldots \\
23 \ldots \ldots \\
24 \ldots \ldots \\
25 \ldots \ldots \\
26 \ldots \ldots \\
27 \ldots \ldots \\
28 \ldots \ldots \\
29 \ldots \ldots \\
30 \ldots \ldots \\
31 \ldots \ldots\end{array}$ & $\begin{array}{l}0 \\
0 \\
0 \\
0 \\
0 \\
0 \\
0 \\
0 \\
0 \\
0 \\
98\end{array}$ & $\begin{array}{r}0 \\
0 \\
0 \\
0 \\
0 \\
0 \\
0 \\
0 \\
0 \\
--1--1\end{array}$ \\
\hline $\begin{array}{l}\text { onthly } \\
\text { unoff, }\end{array}$ & $\begin{array}{l}\text { an disch } \\
\text { acre-fe }\end{array}$ & $\begin{array}{l}e, \text { In } \\
\ldots . .\end{array}$ & feet $p$ & econo & & & $\begin{array}{l}3.2 \\
194\end{array}$ & $\begin{array}{r}59.0 \\
3,280\end{array}$ \\
\hline
\end{tabular}

Gage helght, In feet, and discharge, in cubic feet per second, at 1ndicated time, 1963

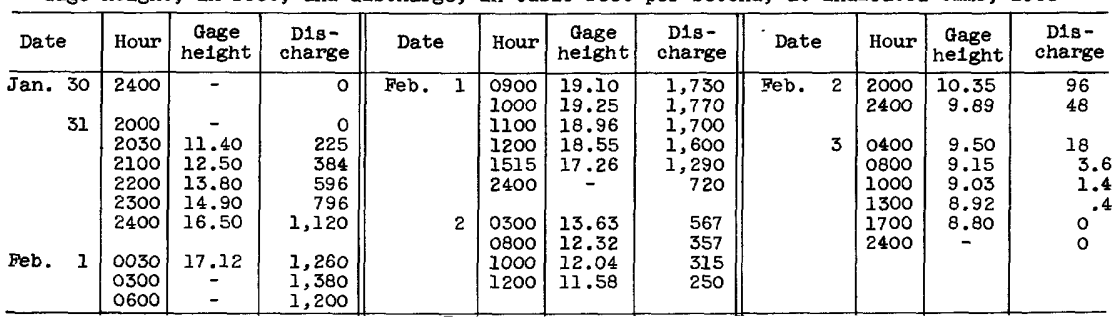

\section{SAN LORENZO CREEK BASIN}

11-1810. San Lorenzo Creek at Hayward, Calif.

Location.--Lat $37^{\circ} 41^{\prime} 11^{\prime \prime}$, long $122^{\circ} 03^{\prime} 44^{\prime \prime}$, in San Lorenzo Grant, on right bank at bridge on B Street, just outside city ilmits of Hayward, Alameda County, 0.5 mile downstream from Crow Creek.

Drainage area. $--37.5 \mathrm{sq} \mathrm{mi}$.

Gage-height record. - Water-stage recorder graph. Datum of gage is $133.16 \mathrm{ft}$ above mean sea level, datum of 1929 .

Discharge record.--Stage-discharge relation defined by current-meter measurements .

Maxima.--January-February 1963: Discharge, 3,630 cfs 2100 hours Jan. 31 (gage height, $14.38 \mathrm{ft}$ ).

$1939-40$, 1946 to December 1962: Discharge, 7,460 cfs 0ct. 13, 1962 (gage height, $19.73 \mathrm{ft}$, from floodmarks), from rating curve extended above $2,700 \mathrm{cfs}$ on basis of slope-area measurement of maximum flow; maximum gage height, 20.82 $\mathrm{ft}$, from floodmarks, Dec. 22, 1955. 
Mean discharge, in cublc feet per second, 1963, of San Lorenzo Creek at Hayward, Cal1f.

\begin{tabular}{|c|c|c|c|c|c|c|c|c|}
\hline Day & January & February & Day & January & February & Day & January & February \\
\hline $\begin{array}{c}1 \ldots \ldots \\
2 \ldots \ldots \\
3 \ldots \ldots \\
4 \ldots \ldots \\
5 \ldots \ldots \\
6 \ldots \ldots \\
7 \ldots \ldots \\
9 \ldots \ldots \\
10 \ldots \ldots\end{array}$ & $\begin{array}{l}5.3 \\
5.3 \\
5.1 \\
4.8 \\
4.2 \\
4.6 \\
4.6 \\
4.6 \\
4.4 \\
3.8\end{array}$ & $\begin{array}{r}639 \\
175 \\
88 \\
63 \\
45 \\
38 \\
32 \\
31 \\
74 \\
66\end{array}$ & $\begin{array}{l}11 \ldots \ldots \\
12 \ldots \ldots \\
13 \ldots \ldots \\
14 \ldots \ldots \\
15 \ldots \ldots \\
16 \ldots \ldots \\
17 \ldots \ldots \\
18 \ldots \ldots \\
19 \ldots \ldots \\
20 \ldots \ldots\end{array}$ & $\begin{array}{l}3.0 \\
3.0 \\
3.0 \\
3.1 \\
3.1 \\
3.2 \\
3.4 \\
3.2 \\
3.0 \\
2.7\end{array}$ & $\begin{array}{r}35 \\
91 \\
152 \\
67 \\
50 \\
47 \\
39 \\
32 \\
31 \\
27\end{array}$ & $\begin{array}{l}21 \ldots \ldots \\
22 \ldots \ldots \\
23 \ldots \ldots \\
24 \ldots \ldots \\
25 \ldots \ldots \\
26 \ldots \ldots \\
27 \ldots \ldots \\
28 \ldots \ldots \\
29 \ldots \ldots \\
30 \ldots \ldots \\
31 \ldots \ldots\end{array}$ & $\begin{array}{r}9.0 \\
8.4 \\
2.5 \\
2.5 \\
2.5 \\
2.5 \\
2.7 \\
3.0 \\
5.0 \\
67 \\
806\end{array}$ & $\begin{array}{r}25 \\
22 \\
21 \\
20 \\
19 \\
18 \\
18 \\
17 \\
----\end{array}$ \\
\hline $\begin{array}{l}\text { thly } \\
\text { off, } \\
\text { off, }\end{array}$ & $\begin{array}{l}\text { Inch } \\
\text { acre }\end{array}$ & & & & & & $\begin{array}{r}31.9 \\
0.98 \\
1,960 \\
\end{array}$ & $\begin{array}{r}70.8 \\
1.97 \\
3,930 \\
\end{array}$ \\
\hline
\end{tabular}

Gage height, in feet, and discharge, in cubic feet per second, at indicated time, 1963

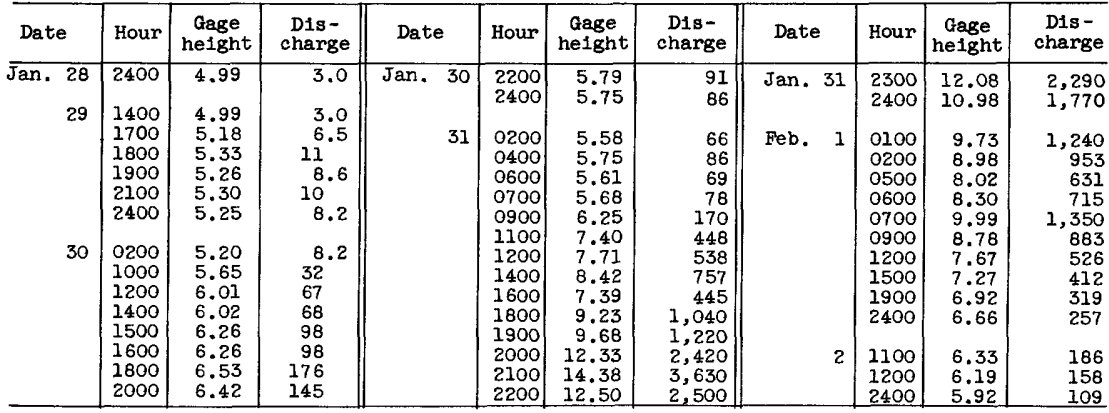

\section{RHEEM CREEK BASIN}

11-1820.3. Rheem Creek at San Pablo, Calif.

Location.--Lat $37^{\circ} 58^{\prime} 32^{\prime \prime}$, long $122^{\circ} 21^{1} 00^{\prime \prime}$, in San Pablo Grant, on left bank 0.6 mile downstream from San Pablo Avenue in San Pablo, Contra Costa County, and $0.9 \mathrm{mile}$ upstream from mouth.

Drainage area. $--1.35 \mathrm{sq} \mathrm{mi}$.

Gage-he1ght record.--Water-stage recorder graph, except Jan. 25-30, Feb. 1-4.

Datum of gage Is $21.37 \mathrm{ft}$ above mean sea leve1 (levels by Corps of Engineers).

Discharge record.--Stage-discharge relation defined by current-meter measurements below $140 \mathrm{crs}$ and by slope-area measurement at $315 \mathrm{cfs}$. Discharge for periods of no gage-helght record estimated on basis of fragmentary gage-height record, recorded range in stage, normal recession, and weather records.

Maxima. - January-February. 1963: Discharge, 315 cfs 0715 hours Jan. 31 (gage height, $3.30 \mathrm{ft}$ ).

1960 to December 1962: Discharge, $294 \mathrm{cfs}$ Dec. 1, 1960 (gage height, $3.14 \mathrm{ft}$ ).

Mean discharge, in cublc feet per second, 1963

\begin{tabular}{|c|c|c|c|c|c|c|c|c|}
\hline Day & January & February & Day & January & February & Day & $\mathrm{J}$ anuary & February \\
\hline $\begin{array}{c}1 \ldots \ldots \\
2 \ldots \ldots \\
3 \ldots \ldots \\
4 \ldots \ldots \\
5 \ldots \ldots \\
6 \ldots \ldots \\
7 \ldots \ldots \\
8 \ldots \ldots \\
10 \ldots \ldots \\
\end{array}$ & $\begin{array}{l}0.1 \\
.1 \\
.1 \\
.1 \\
.1 \\
.1 \\
.3 \\
.7 \\
.2 \\
.1\end{array}$ & $\begin{array}{r}20 \\
5.0 \\
1.0 \\
.8 \\
.6 \\
.4 \\
.4 \\
1.4 \\
23 \\
3.0\end{array}$ & $\begin{array}{l}11 \ldots \ldots \\
12 \ldots \ldots \\
13 \ldots \ldots \\
14 \ldots \ldots \\
15 \ldots \ldots \\
16 \ldots \ldots \\
17 \ldots \ldots \\
18 \ldots \ldots \\
19 \ldots \ldots \\
20 \ldots \ldots\end{array}$ & $\begin{array}{r}0.1 \\
.1 \\
.1 \\
.1 \\
.1 \\
.1 \\
.1 \\
.1 \\
.1 \\
.1\end{array}$ & $\begin{array}{r}0.9 \\
28 \\
6.5 \\
.9 \\
.6 \\
.7 \\
.4 \\
.4 \\
.4 \\
.3\end{array}$ & $\begin{array}{l}21 \ldots \ldots \\
22 \ldots \ldots \\
23 \ldots \ldots \\
24 \ldots \ldots \\
25 \ldots \ldots \\
26 \ldots \ldots \\
27 \ldots \ldots \\
28 \ldots \ldots \\
29 \ldots \ldots \\
30 \ldots \ldots \\
31 \ldots \ldots\end{array}$ & $\begin{array}{r}0.2 \\
.1 \\
.1 \\
.1 \\
.1 \\
.1 \\
.1 \\
.1 \\
5.0 \\
40 \\
85\end{array}$ & $\begin{array}{r}0.3 \\
.3 \\
.3 \\
.3 \\
.3 \\
.2 \\
.2 \\
.1 \\
----- \\
--0--\end{array}$ \\
\hline of' $\mathrm{f}$, & $\begin{array}{l}\text { Inch } \\
\text { acre }\end{array}$ & & & & & & $\begin{array}{r}4.32 \\
3.69 \\
265\end{array}$ & $\begin{array}{r}3.45 \\
2.66 \\
192\end{array}$ \\
\hline
\end{tabular}


Gage height, in feet, and discharge, in cubic feet per second, at indicated time, 1963, of

\begin{tabular}{|c|c|c|c|c|c|c|c|c|c|c|c|}
\hline Date & Hour & $\begin{array}{c}\text { Gage } \\
\text { he1ght }\end{array}$ & $\begin{array}{c}\text { Dis- } \\
\text { charge }\end{array}$ & Date & Hour & $\begin{array}{c}\text { Gage } \\
\text { height }\end{array}$ & $\begin{array}{c}\text { Dis- } \\
\text { charge }\end{array}$ & Date & Hour & $\begin{array}{c}\text { Gage } \\
\text { helght }\end{array}$ & $\begin{array}{l}\text { Dis- } \\
\text { charge }\end{array}$ \\
\hline Jan. 30 & $\begin{array}{l}1100 \\
1115 \\
1130 \\
1330 \\
1530 \\
1700 \\
1730 \\
1800 \\
1830 \\
1900 \\
2000 \\
2130 \\
2330 \\
2400 \\
\\
0100 \\
0200\end{array}$ & $\begin{array}{r}2.09 \\
2.00 \\
2.12 \\
1.23 \\
.74 \\
1.55 \\
1.85 \\
2.45 \\
1.47 \\
1.63 \\
1.00 \\
.87 \\
.57 \\
.83 \\
1.44 \\
.91 \\
\end{array}$ & $\begin{array}{r}152 \\
142 \\
156 \\
61 \\
23 \\
93 \\
126 \\
195 \\
84 \\
101 \\
41 \\
31 \\
15 \\
29 \\
\\
82 \\
34 \\
\end{array}$ & Jan. 31 & $\begin{array}{l}0300 \\
0400 \\
0500 \\
0600 \\
0700 \\
0715 \\
0800 \\
0830 \\
0930 \\
1000 \\
1130 \\
1200 \\
1400 \\
1430 \\
1500 \\
1600 \\
1700\end{array}$ & $\begin{array}{l}1.29 \\
1.05 \\
1.68 \\
1.36 \\
2.45 \\
3.30 \\
1.98 \\
1.55 \\
2.37 \\
1.83 \\
1.44 \\
1.61 \\
.90 \\
1.22 \\
2.72 \\
1.40 \\
.92 \\
\end{array}$ & $\begin{array}{r}66 \\
46 \\
107 \\
74 \\
195 \\
315 \\
150 \\
103 \\
196 \\
133 \\
91 \\
109 \\
40 \\
68 \\
240 \\
86 \\
42\end{array}$ & Jan. 31 & \begin{tabular}{|l|}
1730 \\
1900 \\
2000 \\
2030 \\
2100 \\
2300 \\
2400 \\
0230 \\
0300 \\
0400 \\
0430 \\
0600 \\
0800 \\
0900 \\
2400
\end{tabular} & $\begin{array}{r}0.87 \\
1.50 \\
.96 \\
.89 \\
.94 \\
.65 \\
.58 \\
.45 \\
1.20 \\
1.01 \\
1.57 \\
.87 \\
.52 \\
.47 \\
-\end{array}$ & $\begin{array}{r}38 \\
97 \\
46 \\
40 \\
44 \\
23 \\
18 \\
\\
12 \\
66 \\
50 \\
105 \\
38 \\
15 \\
13 \\
8.0\end{array}$ \\
\hline
\end{tabular}

\section{PINOLE CREEK BASIN}

11-1821. Pinole Creek at Pinole, Calif.

Location.--Lat $37^{\circ} 58^{\prime} 21^{\prime \prime}$, long $122^{\circ} 14^{\prime} 43^{\prime \prime}$, in Pinole Grant, on left bank 0.2 mile downstream from county bridge on Pinole valley Road, $0.8 \mathrm{mile}$ upstream from Pinole clty boundary, Contra Costa County.

Drainage area. $--10.0 \mathrm{sq} \mathrm{ml}$.

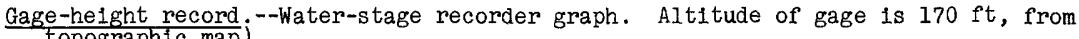
topographic mapj).

Discharge record.--Stage-discharge relation defined by current-meter measurements .

Maxima --January-February 1963: Discharge, 639 cfs 1800 hours Jan. 30 (gage he1ght, $6.30 \mathrm{ft})$.

1938 to December 1962: Discharge, 1,660 cfs Apr. 2, 1958 (gage height, $11.63 \mathrm{ft}$ ).

Remarks.--Records furnished by East Bay Municipal Utility District.

Mean discharge, in cubic feet per second, 1963

\begin{tabular}{|c|c|c|c|c|c|c|c|c|}
\hline Day & January & February & Day & January & February & Day & January & February \\
\hline $\begin{array}{c}1 \ldots \ldots \\
2 \ldots \ldots \\
3 \ldots \ldots \\
5 \ldots \ldots \\
6 \ldots \ldots \\
7 \ldots \ldots \\
9 \ldots \ldots \\
10 \ldots \ldots\end{array}$ & $\begin{array}{r}1.0 \\
1.0 \\
1.0 \\
.8 \\
.8 \\
.8 \\
.8 \\
.8 \\
.8 \\
.8\end{array}$ & $\begin{array}{c}191 \\
38 \\
20 \\
13 \\
9.4 \\
7.1 \\
6.3 \\
5.8 \\
63 \\
22\end{array}$ & $\begin{array}{l}11 \ldots \ldots \\
12 \ldots \ldots \\
13 \ldots \ldots \\
14 \ldots \ldots \\
15 \ldots \ldots \\
16 \ldots \ldots \\
17 \ldots \ldots \\
18 \ldots \ldots \\
19 \ldots \ldots \\
20 \ldots \ldots\end{array}$ & $\begin{array}{l}0.8 \\
.8 \\
.8 \\
.8 \\
.8 \\
.8 \\
.8 \\
.8 \\
.8 \\
.7\end{array}$ & $\begin{array}{l}9.0 \\
50 \\
49 \\
14 \\
10 \\
9.4 \\
7.7 \\
6.6 \\
6.0 \\
5.6\end{array}$ & $\begin{array}{l}21 \ldots \ldots \\
22 \ldots \ldots \\
23 \ldots \ldots \\
24 \ldots \ldots \\
25 \ldots \ldots \\
26 \ldots \ldots \\
27 \ldots \ldots \\
28 \ldots \ldots \\
29 \ldots \ldots \\
30 \ldots \ldots \\
31 \ldots \ldots\end{array}$ & $\begin{array}{r}0.7 \\
.7 \\
.7 \\
.8 \\
.8 \\
.8 \\
.8 \\
.8 \\
2.1 \\
190 \\
352\end{array}$ & $\begin{array}{r}5.2 \\
5.1 \\
4.8 \\
4.7 \\
4.5 \\
4.2 \\
4.1 \\
4.1 \\
-.--- \\
---.--\end{array}$ \\
\hline $\begin{array}{l}\text { Monthly } \\
\text { Runoff, } \\
\text { Runoff, }\end{array}$ & $\begin{array}{l}\text { an discl } \\
\text { Inches } \\
\text { acre-f }\end{array}$ & - & . & & & & $\begin{array}{r}18.3 \\
2.11 \\
1,120 \\
\end{array}$ & $\begin{array}{r}20.7 \\
2.16 \\
1,150 \\
\end{array}$ \\
\hline
\end{tabular}

Gage he1ght, in feet, and discharge, in cublc feet per second, at indicated time, 1963

\begin{tabular}{|c|c|c|c|c|c|c|c|c|c|c|c|}
\hline Date & Hour & $\begin{array}{c}\text { Gage } \\
\text { helght }\end{array}$ & $\begin{array}{c}\text { D1s- } \\
\text { charge }\end{array}$ & Date & Hour & $\begin{array}{c}\text { Gage } \\
\text { helght }\end{array}$ & $\begin{array}{l}\text { Dis- } \\
\text { charge }\end{array}$ & Date & Hour & $\begin{array}{c}\text { Gage } \\
\text { helght }\end{array}$ & $\begin{array}{c}\text { D18- } \\
\text { charge }\end{array}$ \\
\hline $\begin{array}{r}\text { Jan. } 29 \\
30\end{array}$ & $\begin{array}{l}2400 \\
0100 \\
0200 \\
0600 \\
0900 \\
1000 \\
1200 \\
1500 \\
1600 \\
1800 \\
2100 \\
2300 \\
2400\end{array}$ & $\begin{array}{l}1.92 \\
1.88 \\
1.91 \\
2.38 \\
2.40 \\
2.50 \\
3.50 \\
4.50 \\
4.47 \\
6.30 \\
4.15 \\
3.55 \\
3.48\end{array}$ & $\begin{array}{c}7.1 \\
6.0 \\
6.8 \\
32 \\
34 \\
41 \\
170 \\
344 \\
339 \\
639 \\
285 \\
179 \\
167\end{array}$ & Jan. 31 & $\begin{array}{l}0100 \\
0300 \\
0400 \\
0600 \\
0700 \\
0900 \\
1000 \\
1100 \\
1200 \\
1400 \\
1500 \\
1600 \\
1700 \\
2000\end{array}$ & $\begin{array}{l}3.52 \\
3.37 \\
3.43 \\
4.33 \\
4.52 \\
4.59 \\
5.14 \\
5.07 \\
5.28 \\
4.42 \\
6.02 \\
5.20 \\
4.85 \\
5.57\end{array}$ & $\begin{array}{l}174 \\
150 \\
159 \\
316 \\
347 \\
358 \\
439 \\
428 \\
463 \\
331 \\
589 \\
449 \\
397 \\
512\end{array}$ & $\begin{array}{l}\text { Jan. } 31 \\
\text { Feb. I }\end{array}$ & $\begin{array}{l}2100 \\
2200 \\
2400 \\
0200 \\
0530 \\
0700 \\
1200 \\
1800 \\
2400 \\
0600 \\
1200 \\
1800 \\
2400\end{array}$ & $\begin{array}{l}4.90 \\
4.65 \\
3.88 \\
3.54 \\
5.70 \\
4.25 \\
3.34 \\
2.97 \\
2.72 \\
2.57 \\
2.45 \\
2.31 \\
2.29\end{array}$ & $\begin{array}{r}404 \\
367 \\
238 \\
\\
177 \\
534 \\
302 \\
146 \\
92 \\
59 \\
\\
47 \\
37 \\
27 \\
26\end{array}$ \\
\hline
\end{tabular}


11-1823. Arroyo del Hambre near Martinez, Calif.

(Crest-stage station)

Location.--Lat $37^{\circ} 58^{\prime} 10^{\prime \prime}$, long $122^{\circ} 10^{\prime} 05^{\prime \prime}$, in SW! sec.35, T.2 N., R.3 W., at culvert on Alhambra Valley road, 2.8 miles southwest of Martinez.

Drainage area. $--0.82 \mathrm{sq} \mathrm{mi}$.

Gage-height record.--Crest stages only. Altitude of gage is $570 \mathrm{ft}$ (from topographic mapl.

Discharge record.--Stage-discharge relation defined by current-meter measurements below $7 \mathrm{cf}$ 's and by computation of flow through culvert at 102,122 , and $236 \mathrm{cfs}$.

Maxima.--January-February 1963: Discharge, $96 \mathrm{cfs} J a n .31$ (gage height, $21.77 \mathrm{ft}$ ). 1958 to December 1962: Discharge, $236 \mathrm{cfs}$ Feb. 14, 1962 (gage helight, $24.54 \mathrm{ft}$ )

\section{PACHECO CREEK BASIN}

11-1825. San Ramon Creek at San Ramon, Calif.

Location. --Lat $37^{\circ} 46^{\prime} 20^{\prime \prime}$, long $121^{\circ} 59^{\prime} 40^{\prime \prime}$, in sec.8, T.2 S., R.I W., on right bank $0.2 \mathrm{mile}$ downstream from Bollinger Creek and 1.0 mile southwest of San Ramon.

Drainage area. $--5.89 \mathrm{sq} \mathrm{mi}$.

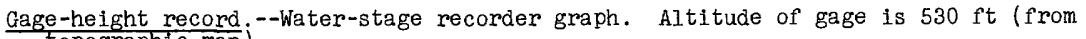
topographic map).

Discharge record.--Stage-discharge relation defined by current-meter measurements below $90 \mathrm{cfs}$ and by computation of flow through culvert at 1,240 and $1,600 \mathrm{cfs}$.

Maxima.--January-February 1963: Discharge, 1,250 cfs 1930 hours Jan. 31 (gage height, $12.09 \mathrm{ft}$ ).

1952 to December 1962: Discharge, 1,600 cfs 0ct. 13, 1962 (gage height, $16.98 \mathrm{ft}$ ).

Mean discharge, in cubic feet per second, 1963

\begin{tabular}{|c|c|c|c|c|c|c|c|c|}
\hline Day & January & February & Day & January & February & Day & January & February \\
\hline $\begin{array}{c}1 \ldots \ldots \\
2 \ldots \ldots \\
3 \ldots \ldots \\
4 \ldots \ldots \\
5 \ldots \ldots \\
7 \ldots \ldots \\
5 \ldots \ldots \\
9 \ldots \ldots \\
10 \ldots \ldots\end{array}$ & $\begin{array}{l}1.4 \\
1.2 \\
1.2 \\
1.1 \\
1.1 \\
1.1 \\
1.1 \\
1.1 \\
1.1 \\
1.1\end{array}$ & $\begin{array}{r}151 \\
34 \\
20 \\
16 \\
14 \\
12 \\
12 \\
12 \\
17 \\
13\end{array}$ & $\begin{array}{l}11 \ldots \ldots \\
12 \ldots \ldots \\
13 \ldots \ldots \\
14 \ldots \ldots \\
15 \ldots \ldots \\
16 \ldots \ldots \\
17 \ldots \ldots \\
18 \ldots \ldots \\
19 \ldots \ldots \\
20 \ldots \ldots\end{array}$ & $\begin{array}{l}1.0 \\
1.0 \\
1.0 \\
1.0 \\
1.0 \\
1.0 \\
1.0 \\
1.0 \\
1.0 \\
1.0\end{array}$ & $\begin{array}{r}10 \\
26 \\
21 \\
12 \\
11 \\
11 \\
9.6 \\
8.9 \\
8.5 \\
8.1\end{array}$ & $\begin{array}{l}21 \ldots \ldots \\
22 \ldots \ldots \\
23 \ldots \ldots \\
24 \ldots \ldots \\
25 \ldots \ldots \\
26 \ldots \ldots \\
27 \ldots \ldots \\
28 \ldots \ldots \\
29 \ldots \ldots \\
30 \ldots \ldots \\
31 \ldots \ldots\end{array}$ & $\begin{array}{r}1.0 \\
1.0 \\
1.0 \\
1.1 \\
1.1 \\
1.1 \\
1.1 \\
1.1 \\
1.5 \\
33 \\
327\end{array}$ & $\begin{array}{r}7.7 \\
7.3 \\
7.0 \\
6.6 \\
7.0 \\
6.6 \\
6.2 \\
5.7 \\
----- \\
--.--\end{array}$ \\
\hline \multicolumn{7}{|c|}{ 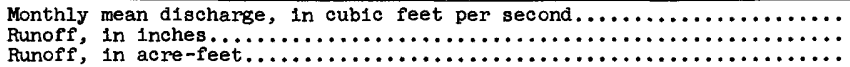 } & $\begin{array}{r}12.6 \\
2.47 \\
777\end{array}$ & $\begin{array}{r}17.2 \\
3.04 \\
954\end{array}$ \\
\hline
\end{tabular}

Gage height, in feet, and discharge, in cublc feet per second, at indicated time, 1963

\begin{tabular}{|c|c|c|c|c|c|c|c|c|c|c|c|}
\hline Date & Hour & $\begin{array}{c}\text { Gage } \\
\text { helght }\end{array}$ & $\begin{array}{c}\text { Dis- } \\
\text { charge }\end{array}$ & Date & Hour & $\begin{array}{c}\text { Gage } \\
\text { helght }\end{array}$ & $\begin{array}{c}\text { Dis- } \\
\text { charge }\end{array}$ & Date & Hour & $\begin{array}{c}\text { Gage } \\
\text { height }\end{array}$ & $\begin{array}{l}\text { D18- } \\
\text { charge }\end{array}$ \\
\hline $\begin{array}{r}29 \\
30\end{array}$ & $\begin{array}{l}2400 \\
0600 \\
0600 \\
1000 \\
1300 \\
1300 \\
1400 \\
1500 \\
1500 \\
1600 \\
1700 \\
1800 \\
2000 \\
2200 \\
2400 \\
0200 \\
0300\end{array}$ & $\begin{array}{l}1.88 \\
1.89 \\
1.99 \\
2.13 \\
2.45 \\
2.42 \\
2.45 \\
2.63 \\
2.77 \\
3.04 \\
2.87 \\
2.93 \\
2.57 \\
2.72 \\
2.52 \\
2.62 \\
2.60\end{array}$ & $\begin{array}{c}2.4 \\
2.6 \\
5.7 \\
12 \\
33 \\
30 \\
33 \\
50 \\
66 \\
101 \\
79 \\
87 \\
44 \\
60 \\
39 \\
49 \\
49 \\
47\end{array}$ & Jan. 31 & $\begin{array}{l}0500 \\
0700 \\
0800 \\
0900 \\
1000 \\
1200 \\
1200 \\
1300 \\
1400 \\
1500 \\
1600 \\
1700 \\
1700 \\
1800 \\
1930 \\
2000 \\
2100 \\
2300 \\
2400 \\
\end{array}$ & $\begin{array}{r}2.41 \\
2.57 \\
3.00 \\
3.11 \\
3.36 \\
4.36 \\
3.99 \\
4.19 \\
3.53 \\
3.52 \\
5.85 \\
7.51 \\
5.63 \\
8.00 \\
12.09 \\
7.90 \\
8.87 \\
5.15 \\
4.07\end{array}$ & $\begin{array}{r}29 \\
44 \\
96 \\
110 \\
146 \\
303 \\
243 \\
275 \\
172 \\
170 \\
519 \\
736 \\
488 \\
800 \\
1,250 \\
787 \\
904 \\
421 \\
256 \\
\end{array}$ & Feb. 1 & $\begin{array}{l}0100 \\
0200 \\
0400 \\
0500 \\
0600 \\
0700 \\
0800 \\
1000 \\
1400 \\
1800 \\
2400 \\
0600 \\
1200 \\
1800 \\
2400\end{array}$ & $\begin{array}{l}3.65 \\
3.55 \\
3.43 \\
5.00 \\
6.62 \\
4.11 \\
3.70 \\
3.07 \\
2.90 \\
2.85 \\
2.75 \\
2.53 \\
2.38 \\
2.35 \\
2.32\end{array}$ & $\begin{array}{r}190 \\
175 \\
157 \\
400 \\
621 \\
263 \\
197 \\
105 \\
83 \\
77 \\
64 \\
40 \\
27 \\
25 \\
22\end{array}$ \\
\hline
\end{tabular}


11-1830. San Ramon Creek at Walnut Creek, Calif.

Location.--Lat $37^{\circ} 53^{\prime} 04^{\prime \prime}$, long $122^{\circ} 03^{\prime} 00^{\prime \prime}$, on boundary between Arroyo de las Nueces y Bolbones and San Ramon Grants, on left bank 0.3 mile downstream from small tributary, 1.1 miles south of town of Walnut Creek, Contra Costa County, and 1.2 miles upstream from confluence with Las Trampas Creek.

Drainage area. $--50.8 \mathrm{sq} \mathrm{mi}$.

Gage-height record.--Water-stage recorder graph, except 0100 to 1000 hours Feb. 1. Altitude of gage is $170 \mathrm{ft}$ (from topographic map).

Discharge record.--Stage-discharge relation defined by current-meter measurements below 2,200 cfs and by computed discharge at 6,530 cfs. Discharge for perlod of no gage -height record estimated on basis of normal recession and records for San Ramon Creek at San Ramon.

Maxima.--January-February 1963: Discharge, 7,980 cfs 2100 hours Jan. 31 (gage height, $14.40 \mathrm{ft}$ ).

1952 to December 1962: Discharge, 6,890 cfs Dec. 23, 1955 (gage height, $14.55 \mathrm{ft}$ ), from rating curve extended above $570 \mathrm{cfs}$ on basis of slope-area measurement of maximum flow.

Mean discharge, in cubic feet per second, 1963

\begin{tabular}{|c|c|c|c|c|c|c|c|c|}
\hline Day & Jamuary & February & Day & January & February & Day & January & February \\
\hline $\begin{array}{c}1 \ldots \ldots \\
3 \ldots \ldots \\
4 \ldots \ldots \\
5 \ldots \ldots \\
6 \ldots \ldots \\
7 \ldots \ldots \\
8 \ldots \ldots \\
9 \ldots \ldots \\
10 \ldots\end{array}$ & $\begin{array}{r}3.1 \\
3.4 \\
3.1 \\
2.9 \\
2.8 \\
2.8 \\
2.9 \\
2.9 \\
2.8 \\
5.5\end{array}$ & $\begin{array}{r}1,140^{\circ} \\
132 \\
62 \\
45 \\
36 \\
31 \\
26 \\
25 \\
69 \\
77\end{array}$ & $\begin{array}{l}11 \ldots \ldots \\
12 \ldots \ldots \\
13 \ldots \ldots \\
14 \ldots \ldots \\
15 \ldots \ldots \\
16 \ldots \ldots \\
17 \ldots \ldots \\
18 \ldots \ldots \\
19 \ldots \ldots \\
20 \ldots \ldots\end{array}$ & $\begin{array}{l}9.9 \\
3.1 \\
2.6 \\
2.8 \\
2.5 \\
2.3 \\
1.3 \\
1.9 \\
1.8 \\
1.5\end{array}$ & $\begin{array}{r}30 \\
192 \\
192 \\
41 \\
31 \\
29 \\
28 \\
23 \\
20 \\
19\end{array}$ & $\begin{array}{l}21 \ldots \ldots \\
22 \ldots \ldots \\
23 \ldots \ldots \\
24 \ldots \ldots \\
25 \ldots \ldots \\
26 \ldots \ldots \\
27 \ldots \ldots \\
28 \ldots \ldots \\
29 \ldots \ldots \\
30 \ldots \ldots \\
31 \ldots \ldots\end{array}$ & $\begin{array}{r}1.9 \\
1.8 \\
1.7 \\
3.4 \\
2.2 \\
1.9 \\
1.8 \\
1.9 \\
2.5 \\
354 \\
2,950\end{array}$ & $\begin{array}{r}18 \\
17 \\
16 \\
15 \\
15 \\
14 \\
14 \\
13 \\
--1 \\
-0\end{array}$ \\
\hline \multicolumn{7}{|l|}{$\begin{array}{l}\text { Monthly } \\
\text { Runoff', } \\
\text { Runoff, }\end{array}$} & $\begin{array}{r}109 \\
2.48 \\
6,710\end{array}$ & $\begin{array}{r}84.6 \\
1.73 \\
4,700 \\
\end{array}$ \\
\hline
\end{tabular}

Gage height, in feet, and discharge, in cub1c feet per second, at indicated time, 1963

\begin{tabular}{|c|c|c|c|c|c|c|c|c|c|c|c|}
\hline Date & Hour & $\begin{array}{c}\text { Gage } \\
\text { height }\end{array}$ & $\begin{array}{l}\text { D1s- } \\
\text { charge }\end{array}$ & Date & Hour & $\begin{array}{c}\text { Gage } \\
\text { helght }\end{array}$ & $\begin{array}{c}\text { Dis- } \\
\text { charge }\end{array}$ & Date & Hour & $\begin{array}{c}\text { Gage } \\
\text { helght }\end{array}$ & $\begin{array}{l}\text { D1s- } \\
\text { charge }\end{array}$ \\
\hline $\begin{array}{r}\operatorname{Jan} .20 \\
29\end{array}$ & $\begin{array}{l}2400 \\
1000 \\
1200 \\
1400 \\
1800 \\
1900 \\
2100 \\
2300 \\
2400 \\
\\
0400 \\
0800 \\
1000 \\
1100 \\
1200 \\
1300 \\
1500 \\
1600 \\
\end{array}$ & $\begin{array}{l}1.24 \\
1.23 \\
1.29 \\
1.25 \\
1.30 \\
1.31 \\
1.46 \\
1.37 \\
1.64 \\
1.64 \\
1.85 \\
1.97 \\
2.20 \\
2.80 \\
3.38 \\
5.00 \\
5.70\end{array}$ & \begin{tabular}{|r|}
1.7 \\
1.6 \\
2.3 \\
1.8 \\
2.5 \\
2.6 \\
5.6 \\
3.6 \\
11 \\
11 \\
19 \\
25 \\
40 \\
106 \\
212 \\
740 \\
1,040 \\
\end{tabular} & Jan. 30 & $\begin{array}{l}1700 \\
1800 \\
2000 \\
2200 \\
2400 \\
0100 \\
0500 \\
0700 \\
0900 \\
1100 \\
1300 \\
1400 \\
1500 \\
1600 \\
1800 \\
1900 \\
2000 \\
2100\end{array}$ & $\begin{array}{r}5.82 \\
5.55 \\
5.00 \\
4.68 \\
4.23 \\
4.31 \\
3.95 \\
4.37 \\
5.28 \\
7.18 \\
8.62 \\
9.03 \\
8.47 \\
8.98 \\
13.00 \\
14.00 \\
14.05 \\
14.40\end{array}$ & $\begin{array}{r}1,090 \\
973 \\
740 \\
613 \\
456 \\
\\
484 \\
360 \\
505 \\
852 \\
1,750 \\
2,650 \\
2,940 \\
2,550 \\
2,910 \\
6,500 \\
7,540 \\
7,600 \\
7,980\end{array}$ & Feb. 1 & $\begin{array}{l}2200 \\
2300 \\
2400 \\
\\
0600 \\
0700 \\
0900 \\
1100 \\
1300 \\
1400 \\
1600 \\
2000 \\
2400 \\
\\
0600 \\
1200 \\
1800 \\
2400\end{array}$ & $\begin{array}{c}13.77 \\
12.40 \\
10.65 \\
- \\
- \\
- \\
5.57 \\
5.00 \\
4.74 \\
4.34 \\
3.75 \\
3.44 \\
3.10 \\
2.92 \\
2.73 \\
2.60\end{array}$ & $\begin{array}{r}7,290 \\
5,900 \\
4,250 \\
\\
800 \\
1,400 \\
1,300 \\
902 \\
740 \\
636 \\
494 \\
303 \\
226 \\
\\
155 \\
124 \\
96 \\
79\end{array}$ \\
\hline
\end{tabular}


11-1835. Walnut Creek at Walnut Creek, Cal1f.

Location.--Lat $37^{\circ} 54^{\prime} 21^{\prime \prime}$, long $122^{\circ} 03^{\prime} 22^{\prime \prime}$, In Arroyo de las Nueces y Bolbones Grant, on right bank at Southern Pacific Railroad bridge at town of Walnut Creek, Contra Costa County, 0.7 mile downstream from confluence of San Ramon and Las Trampas Creeks.

Drainage area,$--79.2 \mathrm{sq} \mathrm{ml}$.

Gage-height record.--Water-stage recorder graph, except Feb. 5. Altitude of gage is $120 \mathrm{ft}$ (from topographic map).

Discharge record.--Stage-discharge relation defined by current-meter measurements below $3,200 \mathrm{c}$ s. Discharge for Feb. 5 estimated on basis of normal recession.

Max1ma.--January-February 1963: Discharge, 9,180 cfs 2000 hours Jan. 31 (gage helght, $12.55 \mathrm{ft}$ ).

1952 to December 1962: Discharge, $12,200 \mathrm{cfs}$ Apr. 2, 1958 (gage helght, $20.2 \mathrm{ft}$ ).

Remarks.--Flow slightly regulated by storage in Lafayette Reservoir.

Mean discharge, in cuble feet per second, 1963

\begin{tabular}{|c|c|c|c|c|c|c|c|c|}
\hline Day & January & February & Day & January & February & Day & January & February \\
\hline $\begin{array}{r}1 \ldots \ldots \\
2 \ldots \ldots \\
3 \ldots \ldots \\
4 \ldots \ldots \\
5 \ldots \ldots \\
7 \ldots \ldots \\
5 \ldots \ldots \\
9 \ldots \ldots \\
10 \ldots \ldots\end{array}$ & $\begin{array}{l}5.9 \\
6.6 \\
5.9 \\
5.9 \\
5.6 \\
5.3 \\
5.3 \\
5.9 \\
5.0 \\
7.1\end{array}$ & $\begin{array}{r}1,590 \\
213 \\
110 \\
77 \\
64 \\
53 \\
48 \\
46 \\
140 \\
133\end{array}$ & $\begin{array}{l}11 \ldots \ldots \\
12 \ldots \ldots \\
13 \ldots \ldots \\
14 \ldots \ldots \\
15 \ldots \ldots \\
16 \ldots \ldots \\
17 \ldots \ldots \\
15 \ldots \ldots \\
19 \ldots \ldots \\
20 \ldots \ldots\end{array}$ & $\begin{array}{r}16 \\
5.0 \\
4.4 \\
4.4 \\
3.9 \\
4.4 \\
3.9 \\
5.0 \\
3.9 \\
3.7\end{array}$ & $\begin{array}{r}54 \\
286 \\
318 \\
57 \\
64 \\
59 \\
54 \\
44 \\
41 \\
38\end{array}$ & $\begin{array}{l}21 \ldots \ldots \\
22 \ldots \ldots \\
23 \ldots \ldots \\
24 \ldots \ldots \\
25 \ldots \ldots \\
26 \ldots \ldots \\
27 \ldots \ldots \\
28 \ldots \ldots \\
29 \ldots \ldots \\
30 \ldots \ldots \\
31 \ldots \ldots\end{array}$ & $\begin{array}{r}5.0 \\
5.0 \\
4.1 \\
6.5 \\
5.3 \\
4.4 \\
4.1 \\
4.1 \\
34 \\
998 \\
3,540\end{array}$ & $\begin{array}{r}35 \\
33 \\
32 \\
31 \\
30 \\
29 \\
27 \\
27 \\
-\ldots--\end{array}$ \\
\hline \multicolumn{7}{|c|}{ 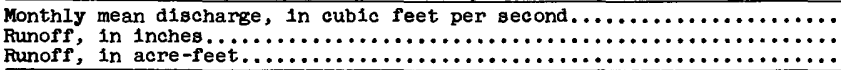 } & $\begin{array}{r}152 \\
2,22 \\
9,370 \\
\end{array}$ & $\begin{array}{r}134 \\
1.77 \\
7,460 \\
\end{array}$ \\
\hline
\end{tabular}

Gage height, In feet, and discharge, in cublc feet per second, at indicated time, 1963

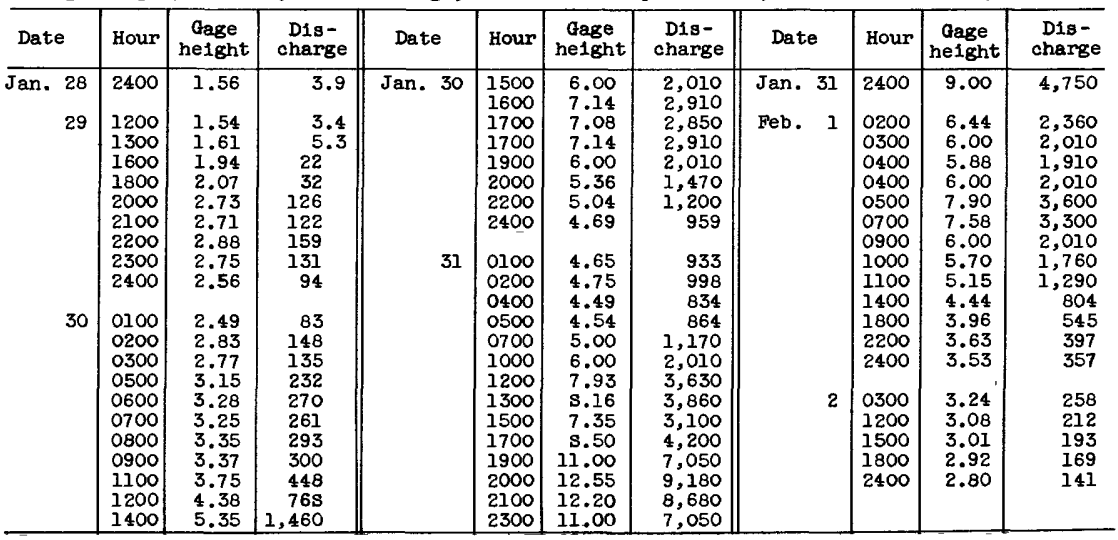




\section{MOUNT DIABLO CREEK BASIN}

11-1851.5. Horse Creek near Clayton, Calif.

(Crest-stage station)

Location. --Lat $37^{\circ} 54^{\prime} 55^{\prime \prime}$, long $121^{\circ} 53^{\prime} 25^{\prime \prime}$, in SWl sec.20, T.I N., R.I E., at culvert on county road, 3.0 miles southeast of Clayton.

Drainage area. $--0.20 \mathrm{sq} \mathrm{mi}$.

Gage-height record.--Crest stages only. Altitude of gage is $800 \mathrm{ft}$ (from topographic map).

Discharge record. --Stage-discharge relation defined by current-meter measurements below $5 \mathrm{cfs}$ and by computation of flow through culvert at $36 \mathrm{cfs}$.

Maxima.--January-February 1963: D1scharge, $2.7 \mathrm{cfs}$ Jan. 31 (gage height, $43.78 \mathrm{ft}$ ). ig58 to December 1962: Discharge, 36 cfs oct. 13, ig62 (gage height, $47.92 \mathrm{ft}$ ).

\section{SAN JOAQUIN VAILEY}

\section{BUENA VISTA LAKE BASIN}

11-1853. Golden Trout Creek near Cartago, Calif.

Location.--Lat $36^{\circ} 22^{\prime} 20^{\prime \prime}$, long $118^{\circ} 17^{\prime} 15^{\prime \prime}$, in NW $\frac{1}{4} S_{W} \frac{1}{4}$ sec.10, T.18 S., R.34 E., on right bank 0.5 mile upstream from Tunnel Ranger Station and 15 miles west of Cartago.

Drainage area. $--23.6 \mathrm{sq} \mathrm{mi}$.

Gage-he1ght record.--Water-stage recorder graph. Alt1tude of gage is $8,940 \mathrm{ft}$ (from topographic map).

Discharge record.--Stage-discharge relation defined by current-meter measurements; affected by 1 ce most of period Jan. 5 to Feb. 3.

Maxima.--January-February 1963: Discharge, about 60 efs 1800 hours Feb. I (gage helght, $4.45 \mathrm{ft}$, backwater from ice).

October 1956 to December 1962: Discharge, 182 cfs May 31, 1958 (gage height, $4.05 \mathrm{ft}$ ); gage helght, $5.24 \mathrm{ft}$ Feb. 12, 1959 .

Mean discharge, in cubic feet per second, 1963

\begin{tabular}{|c|c|c|c|c|c|c|c|c|}
\hline Day & January & February & Day & January & February & Day & January & February \\
\hline $\begin{array}{c}1 \ldots \ldots \\
2 \ldots \ldots \\
3 \ldots \ldots \\
4 \ldots \ldots \\
5 \ldots \ldots \\
6 \ldots \ldots \\
7 \ldots \ldots \\
9 \ldots \ldots \\
9 \ldots \ldots \\
10 \ldots \ldots\end{array}$ & $\begin{array}{l}8.7 \\
8.7 \\
8.7 \\
9.0 \\
8.7 \\
8.7 \\
8.7 \\
8.7 \\
8.7 \\
8.7\end{array}$ & $\begin{array}{l}40 \\
25 \\
15 \\
10 \\
9.7 \\
9.5 \\
9.5 \\
9.2 \\
9.2 \\
9.2\end{array}$ & $\begin{array}{l}11 \ldots \ldots \\
12 \ldots \ldots \\
13 \ldots \ldots \\
14 \ldots \ldots \\
15 \ldots \ldots \\
16 \ldots \ldots \\
17 \ldots \ldots \\
18 \ldots \ldots \\
19 \ldots \ldots \\
20 \ldots \ldots\end{array}$ & $\begin{array}{l}8.7 \\
8.0 \\
7.0 \\
8.0 \\
8.7 \\
8.7 \\
8.7 \\
8.4 \\
8.4 \\
8.4\end{array}$ & $\begin{array}{l}9.2 \\
9.0 \\
9.0 \\
9.0 \\
9.2 \\
8.7 \\
8.7 \\
8.7 \\
8.7 \\
8.7\end{array}$ & $\begin{array}{l}21 \ldots \ldots \\
22 \ldots \ldots \\
23 \ldots \ldots \\
24 \ldots \ldots \\
25 \ldots \ldots \\
26 \ldots \ldots \\
27 \ldots \ldots \\
28 \ldots \ldots \\
29 \ldots \ldots \\
30 \ldots \ldots \\
31 \ldots \ldots\end{array}$ & $\begin{array}{c}8.2 \\
8.2 \\
8.2 \\
8.2 \\
8.2 \\
8.2 \\
8.2 \\
5.2 \\
8.2 \\
12 \\
25\end{array}$ & $\begin{array}{r}8.7 \\
8.7 \\
8.7 \\
8.7 \\
8.7 \\
9.0 \\
9.0 \\
9.0 \\
--.-- \\
-.-1\end{array}$ \\
\hline \multicolumn{7}{|l|}{$\begin{array}{l}\text { Monthly } \\
\text { Runoff, } \\
\text { Runoff, }\end{array}$} & $\begin{array}{r}9.07 \\
0.44 \\
558\end{array}$ & $\begin{array}{r}10.9 \\
0.48 \\
606\end{array}$ \\
\hline
\end{tabular}

11-1853.5. Kern River near Quaking Aspen Camp, Calif.

Location. --Lat $36^{\circ} 08^{\prime} 05^{\prime \prime}$, long $118^{\circ} 25^{\prime} 45^{\prime \prime}$, in SW $\frac{1}{4}$ SW $\frac{1}{4}$ sec.32, T.20 S., R.33 E., on right bank 0.4 mile upstream from Littie Kern River and 6.8 miles east of Quaking Aspen Camp.

Drainage area. $--530 \mathrm{sq} \mathrm{ms}$.

Gage-height record. --Water-stage recorder graph. Datum of gage is $4,693 \mathrm{ft}$ above mean sea level (river-profile survey).

Discharge record.--Stage-discharge relation defined by current-meter measurements below $2,300 \mathrm{c}$ is and by slope-area measurement at $2,930 \mathrm{cfs}$; affected by $1 \mathrm{ce}$ Jan. 1 and Jan. 11-23.

Maxima.--January-February 1963: Discharge, 3,410 cf's 0800 hours Feb. I (gage helght, $7.39 \mathrm{ft}$ ).

1960 to December 1962: Discharge, 3,070 cfs June 22, 1962 (gage height, $7.08 \mathrm{ft})$. 
Mean discharge, in cublc feet per second, 1963, of Kern River near Quaking Aspen Camp, Calif.

\begin{tabular}{|c|c|c|c|c|c|c|c|c|}
\hline Day & January & February & Day & January & February & Day & January & February \\
\hline $\begin{array}{c}1 \ldots \ldots \\
3 \ldots \ldots \\
4 \ldots \ldots \\
5 \ldots \ldots \\
6 \ldots \ldots \\
8 \ldots \ldots \\
9 \ldots \ldots \\
10 \ldots \ldots\end{array}$ & $\begin{array}{l}116 \\
116 \\
116 \\
116 \\
114 \\
114 \\
112 \\
112 \\
114 \\
112\end{array}$ & $\begin{array}{r}2,600 \\
1,200 \\
761 \\
596 \\
498 \\
446 \\
421 \\
407 \\
396 \\
407\end{array}$ & $\begin{array}{l}11 \ldots \ldots \\
12 \ldots \ldots \\
13 \ldots \ldots \\
14 \ldots \ldots \\
15 \ldots \ldots \\
16 \ldots \ldots \\
17 \ldots \ldots \\
18 \ldots \ldots \\
19 \ldots \ldots \\
20 \ldots \ldots\end{array}$ & $\begin{array}{r}110 \\
96 \\
83 \\
93 \\
109 \\
109 \\
107 \\
105 \\
105 \\
101\end{array}$ & $\begin{array}{l}368 \\
348 \\
337 \\
324 \\
309 \\
309 \\
294 \\
288 \\
288 \\
288\end{array}$ & $\begin{array}{l}21 \ldots \ldots \\
22 \ldots \ldots \\
23 \ldots \ldots \\
24 \ldots \ldots \\
25 \ldots \ldots \\
26 \ldots \ldots \\
27 \ldots \ldots \\
28 \ldots \ldots \\
29 \ldots \ldots \\
30 \ldots \ldots \\
31 \ldots \ldots\end{array}$ & $\begin{array}{r}109 \\
112 \\
109 \\
107 \\
105 \\
105 \\
103 \\
105 \\
112 \\
265 \\
1,630\end{array}$ & $\begin{array}{r}294 \\
291 \\
288 \\
288 \\
294 \\
306 \\
315 \\
315 \\
---2 \\
----2\end{array}$ \\
\hline \multicolumn{9}{|c|}{ 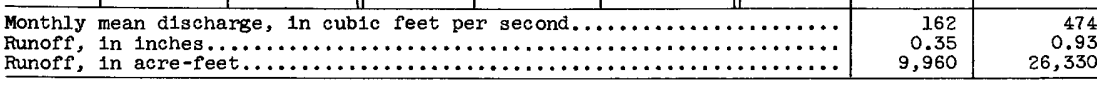 } \\
\hline
\end{tabular}

Gage height, in feet, and discharge, in cubic feet per second, at indicated t1me, 1963

\begin{tabular}{|c|c|c|c|c|c|c|c|c|c|c|c|}
\hline Date & Hour & $\begin{array}{c}\text { Gage } \\
\text { helght }\end{array}$ & $\begin{array}{l}\text { D18- } \\
\text { charge }\end{array}$ & Date & Hour & $\begin{array}{c}\text { Gage } \\
\text { height }\end{array}$ & $\begin{array}{l}\text { D1s- } \\
\text { charge }\end{array}$ & Date & Hour & $\begin{array}{c}\text { Gage } \\
\text { helght }\end{array}$ & $\begin{array}{c}\text { D1s- } \\
\text { charge }\end{array}$ \\
\hline $\begin{array}{r}\mathbf{J a n} .29 \\
30\end{array}$ & $\begin{array}{l}2400 \\
0600 \\
1200 \\
1800 \\
2400\end{array}$ & $\begin{array}{l}2.40 \\
2.50 \\
2.73 \\
3.20 \\
3.52\end{array}$ & $\begin{array}{l}143 \\
165 \\
221 \\
365 \\
478\end{array}$ & Jan. 31 & $\begin{array}{l}1200 \\
1600 \\
1800 \\
2000 \\
2400\end{array}$ & $\begin{array}{l}5.40 \\
7.23 \\
6.97 \\
6.50 \\
5.54\end{array}$ & $\begin{array}{l}1,550 \\
3,230 \\
2,950 \\
2,480 \\
1,660\end{array}$ & Feb. 1 & $\begin{array}{l}2000 \\
2400 \\
\\
0800 \\
1600 \\
2400\end{array}$ & $\begin{array}{l}6.16 \\
5.64 \\
5.00 \\
4.59 \\
4.39\end{array}$ & $\begin{array}{r}2,170 \\
1,740 \\
1,270 \\
1,010 \\
894\end{array}$ \\
\hline 31 & $\begin{array}{l}0400 \\
0600 \\
0800 \\
\end{array}$ & $\begin{array}{l}3.95 \\
3.90 \\
4.12\end{array}$ & $\begin{array}{l}670 \\
645 \\
755\end{array}$ & Feb. 1 & $\begin{array}{l}0400 \\
0800 \\
1200 \\
1600\end{array}$ & $\begin{array}{l}6.60 \\
7.39 \\
7.07 \\
6.68\end{array}$ & $\begin{array}{l}2,580 \\
3,410 \\
3,060 \\
2,660\end{array}$ & 3 & $\begin{array}{l}1200 \\
2400\end{array}$ & $\begin{array}{l}4.08 \\
3.97\end{array}$ & $\begin{array}{l}735 \\
680\end{array}$ \\
\hline
\end{tabular}

11-1854. Little Kern River near Quaking Aspen Camp, Calif.

Location.--Lat $36^{\circ} 08^{\prime} 05^{\prime \prime}$, long $118^{\circ} 26^{\prime} 10^{\prime \prime}$, in $\mathrm{SE} \frac{1}{4} \mathrm{SE} \frac{1}{4}$ sec.31, T.20 S., R.33 E., on left bank $600 \mathrm{ft}$ upstream from mouth and 5 miles east of Quaking Aspen Camp.

Drainage area. $--132 \mathrm{sq} \mathrm{m} 1$.

Gage-helght record. --Water-stage recorder graph. Datum of gage is 4,695 ft above mean sea level (river-profile survey).

Discharge record.--Stage-discharge relation defined by current-meter measurements below $870 \mathrm{cf}$ 's and by slope-area measurement at $7,370 \mathrm{cfs}$; affected by ice Jan. 4-28.

Maxima.--January-February 1963: Discharge, 7,370 cfs 0900 hours Feb. 1 (gage he1ght, $9.19 \mathrm{ft}$, from recorder graph; $10.05 \mathrm{ft}$, from floodmarks).

1957 to December 1962: Discharge, i, 100 cfs May 19, ig58 (gage height, $5.24 \mathrm{ft}$ ).

The fiood of Dec. 23, 1955, reached a stage of $12.4 \mathrm{ft}$, from floodmarks (discharge not determined).

Mean discharge, in cubic feet per second, 1963

\begin{tabular}{|c|c|c|c|c|c|c|c|c|}
\hline Day & January & February & Day & January & February & Day & January & February \\
\hline $\begin{array}{c}1 \ldots \ldots \\
2 \ldots \ldots \\
3 \ldots \ldots \\
4 \ldots \ldots \\
5 \ldots \ldots \\
6 \ldots \ldots \\
7 \ldots \ldots \\
9 \ldots \ldots \\
10 \ldots \ldots\end{array}$ & $\begin{array}{l}12 \\
12 \\
13 \\
12 \\
12 \\
11 \\
11 \\
11 \\
11 \\
11\end{array}$ & $\begin{array}{r}, 480 \\
1,520 \\
689 \\
492 \\
406 \\
360 \\
318 \\
294 \\
290 \\
304\end{array}$ & $\begin{array}{l}11 \ldots \ldots \\
12 \ldots \ldots \\
13 \ldots \ldots \\
14 \ldots \ldots \\
15 \ldots \ldots \\
16 \ldots \ldots \\
17 \ldots \ldots \\
18 \ldots \ldots \\
19 \ldots \ldots \\
20 \ldots \ldots\end{array}$ & $\begin{array}{r}11 \\
10 \\
9 \\
10 \\
10 \\
10 \\
10 \\
10 \\
10 \\
10\end{array}$ & $\begin{array}{l}266 \\
239 \\
227 \\
219 \\
203 \\
193 \\
183 \\
171 \\
166 \\
164\end{array}$ & $\begin{array}{l}21 \ldots \ldots \\
22 \ldots \ldots \\
23 \ldots \ldots \\
24 \ldots \ldots \\
25 \ldots \ldots \\
26 \ldots \ldots \\
27 \ldots \ldots \\
28 \ldots \ldots \\
29 \ldots \ldots \\
30 \ldots \ldots \\
31 \ldots \ldots\end{array}$ & $\begin{array}{r}10 \\
10 \\
11 \\
12 \\
12 \\
12 \\
12 \\
12 \\
13 \\
239 \\
2,070\end{array}$ & $\begin{array}{r}159 \\
152 \\
147 \\
145 \\
147 \\
147 \\
150 \\
147 \\
----- \\
---- \\
---\end{array}$ \\
\hline \multicolumn{7}{|c|}{ 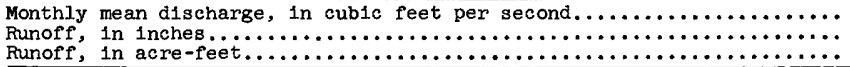 } & $\begin{array}{r}84.8 \\
0.74 \\
5,210 \\
\end{array}$ & $\begin{array}{r}442 \\
3.49 \\
24,550 \\
\end{array}$ \\
\hline
\end{tabular}


Gage helght, in feet, and discharge, in cubic feet per second, at indicated time, 1963 , of Little Kern River near Quaking Aspen Camp, Calif.

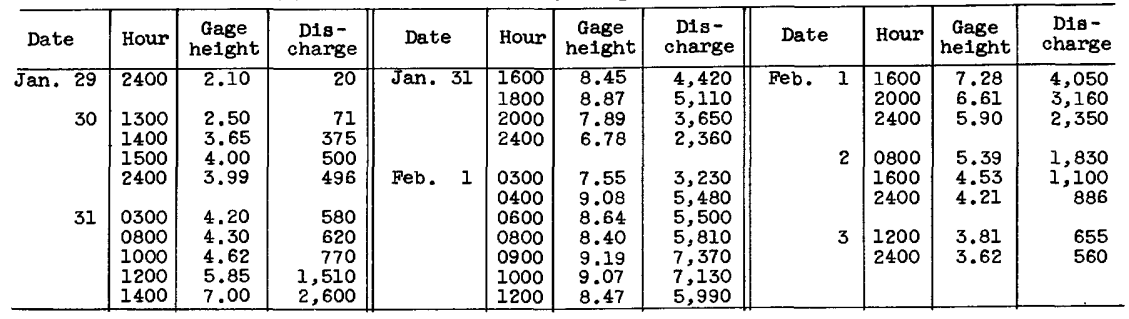

11-1856. Packsaddle Canyon Creek near Fairview, Calif.

Location.--Lat $35^{\circ} 56^{\prime} 40^{\prime \prime}$, long $118^{\circ} 28^{\prime} 30^{\prime \prime}$, in sec.12, T.23 S., R.32 E., on right bank 1.8 miles northeast of Falrview.

Drainage area. $--4.05 \mathrm{sq} \mathrm{mi}$.

Gage-height record.--Water-stage recorder graph, except Feb. 11-13. Altitude of gage is 3,600 ft above mean sea level (from topographic map).

Discharge record.--Stage-discharge relation defined by current-meter measurements below $19 \mathrm{cfs}$ and by computation of flow through culvert and over highway. Discharge on Feb. 11-13 estimated on basis of partial gage-height record.

Maxima --January-February 1963: Discharge, 223 cf's 1615 hours Jan. 31 (gage helght, $9.91 \mathrm{ft}$ in gage well; $10.6 \mathrm{ft}$, from floodmarks).

1959 to December 1962: Discharge, $38 \mathrm{cfs}$ (revised) Feb. 8, 1962 (gage height, $5.57 \mathrm{ft}$ ).

Mean discharge, in cublc feet per second, 1963

\begin{tabular}{|c|c|c|c|c|c|c|c|c|}
\hline Day & January & February & Day & January & February & Day & January & Pebruary \\
\hline $\begin{array}{c}\ldots \ldots \\
2 \ldots \ldots \\
3 \ldots \ldots \\
4 \ldots \ldots \\
6 \ldots \ldots \\
7 \ldots \ldots \\
8 \ldots \ldots \\
9 \ldots \ldots \\
10 \ldots \ldots\end{array}$ & $\begin{array}{l}0 \\
0 \\
0 \\
0 \\
0 \\
0 \\
0 \\
0 \\
0 \\
0\end{array}$ & $\begin{array}{r}53 \\
9.4 \\
3.8 \\
2.6 \\
1.2 \\
.6 \\
.4 \\
.2 \\
1.3 \\
3.5\end{array}$ & $\begin{array}{l}11 \ldots \ldots \\
12 \ldots \ldots \\
13 \ldots \ldots \\
14 \ldots \ldots \\
15 \ldots \ldots \\
16 \ldots \ldots \\
17 \ldots \ldots \\
18 \ldots \ldots \\
19 \ldots \ldots \\
20 \ldots \ldots\end{array}$ & $\begin{array}{l}0 \\
0 \\
0 \\
0 \\
0 \\
0 \\
0 \\
0 \\
0 \\
0\end{array}$ & $\begin{array}{r}3.0 \\
2.5 \\
2.0 \\
1.6 \\
1.3 \\
.9 \\
.8 \\
.6 \\
.4 \\
.3\end{array}$ & $\begin{array}{l}21 \ldots \ldots \\
22 \ldots \ldots \\
23 \ldots \ldots \\
24 \ldots \ldots \\
25 \ldots \ldots \\
26 \ldots \ldots \\
27 \ldots \ldots \\
28 \ldots \ldots \\
29 \ldots \ldots \\
30 \ldots \ldots \\
31 \ldots \ldots\end{array}$ & $\begin{array}{l}0 \\
0 \\
0 \\
0 \\
0 \\
0 \\
0 \\
0 \\
0 \\
59^{.2}\end{array}$ & $\begin{array}{r}0.2 \\
.2 \\
.1 \\
0.1 \\
0 \\
0 \\
0 \\
--.1 \\
--.--\end{array}$ \\
\hline \multicolumn{7}{|l|}{$\begin{array}{l}\text { Monthly } \\
\text { Runoff, } \\
\text { Runoff, }\end{array}$} & $\begin{array}{r}1.91 \\
0.54 \\
117\end{array}$ & $\begin{array}{r}3.22 \\
0.83 \\
179\end{array}$ \\
\hline
\end{tabular}

Gage height, in feet, and discharge, in cubic feet per second, at indicated time, 1963

\begin{tabular}{|c|c|c|c|c|c|c|c|c|c|c|c|}
\hline Date & Hour & $\begin{array}{c}\text { Gage } \\
\text { height }\end{array}$ & $\begin{array}{l}\text { Dis- } \\
\text { charge }\end{array}$ & Date & Hour & $\begin{array}{c}\text { Gage } \\
\text { height }\end{array}$ & $\begin{array}{l}\text { D1g- } \\
\text { charge }\end{array}$ & Date & Hour & $\begin{array}{c}\text { Gage } \\
\text { he1ght }\end{array}$ & $\begin{array}{c}\mathrm{D} 1 \mathrm{~g}- \\
\text { charge }\end{array}$ \\
\hline $\begin{array}{r}\text { Jan. } 29 \\
30\end{array}$ & $\begin{array}{l}2400 \\
2000 \\
2100 \\
2400\end{array}$ & $\begin{array}{l}- \\
- \\
3.73 \\
3.80 \\
3.90\end{array}$ & $\begin{array}{l}0 \\
0 \\
1.4 \\
2.0 \\
3\end{array}$ & Jan. 31 & $\begin{array}{l}1615 \\
1800 \\
1900 \\
2000 \\
2200 \\
2400\end{array}$ & $\begin{array}{l}9.91 \\
9.43 \\
9.27 \\
7.93 \\
6.00 \\
5.43\end{array}$ & $\begin{array}{r}223 \\
146 \\
139 \\
101 \\
49 \\
35\end{array}$ & Feb. 1 & $\begin{array}{l}1200 \\
1400 \\
1700 \\
1900 \\
2400\end{array}$ & $\begin{array}{l}7.19 \\
6.55 \\
5.71 \\
5.40 \\
4.86\end{array}$ & $\begin{array}{l}81 \\
64 \\
41 \\
34 \\
22\end{array}$ \\
\hline 31 & $\begin{array}{l}0700 \\
0900 \\
1000 \\
1100 \\
1200 \\
1300 \\
1400 \\
1500 \\
1600\end{array}$ & $\begin{array}{l}3.89 \\
4.04 \\
4.29 \\
4.78 \\
5.77 \\
7.00 \\
7.94 \\
9.69 \\
9.52\end{array}$ & $\begin{array}{r}3.0 \\
5.0 \\
9.0 \\
20 \\
43 \\
76 \\
101 \\
178 \\
152\end{array}$ & Feb. 1 & $\begin{array}{l}0200 \\
0300 \\
0400 \\
0500 \\
0600 \\
0800 \\
0900 \\
1100\end{array}$ & $\begin{array}{l}5.22 \\
5.29 \\
5.60 \\
6.53 \\
6.48 \\
7.33 \\
7.88 \\
7.60\end{array}$ & $\begin{array}{r}30 \\
32 \\
39 \\
63 \\
62 \\
85 \\
100 \\
91\end{array}$ & 2 & $\begin{array}{l}0200 \\
0400 \\
0700 \\
1130 \\
1430 \\
2400\end{array}$ & $\begin{array}{l}4.60 \\
4.52 \\
4.42 \\
4.30 \\
4.15 \\
4.02\end{array}$ & $\begin{array}{r}16 \\
14 \\
12 \\
9.2 \\
6.7 \\
4.7\end{array}$ \\
\hline
\end{tabular}


11-1860. Kern River near Kernville, Calif.

Location. --Lat $35^{\circ} 56^{\prime} 00^{\prime \prime}$, long $118^{\circ} 29^{\prime} 10^{\prime \prime}$, in $\mathrm{NE} \frac{1}{4}$ sec.14, T.23 S., R.32 E., on left bank 3 miles upstream 'from Salmon Creek and 15 miles north of Kernvilie.'

Drainage area. $--848 \mathrm{sq} \mathrm{mi}$.

Gage-height reciord; - Water-stage recorder graph. Datum of gage is $3,542.3 \mathrm{ft}$ above mean sea level (river-profile survey).

Discharge record.--Stage-discharge relation defined by current-meter measurements below 6,000 cfs and extended above on basis of computed flow over dam.

Maxima (river only).--January-February 1963: Discharge, 24,000 cfs 1030 hours Feb. I (gage helght, $16.85 \mathrm{ft}$ ).

1912 to December 1962: Discharge, 27,200 cfs Dec. 23, 1955 (gage helght, $17.55 \mathrm{ft}$ ). $\frac{\text { Maxima (river and cana1).--January-February 1963: Discharge, 24,600 cfs } 1030 \text { hours }}{\text { Feb. } 1 \text {. }}$

1912 to December 1962: Discharge, 27,400 cfs Nov. 19, 1950, Dec. 23, 1955.

Remarks.--Kern River No. 3 Canal diverts up to 620 cfs 1 mile above station. Mean discharge figures and tabulation of discharge at indicated times are the combined flow of Kern River and Kern River No. 3 Canal.

Mean discharge, in cubic feet per second, 1963

\begin{tabular}{|c|c|c|c|c|c|c|c|c|}
\hline Day & January & February & Day & January & February & Day & January & February \\
\hline $\begin{array}{c}1 \ldots \ldots \\
2 \ldots \ldots \\
3 \ldots \ldots \\
4 \ldots \ldots \\
6 \ldots \ldots \\
7 \ldots \ldots \\
9 \ldots \ldots \\
10 \ldots \ldots\end{array}$ & $\begin{array}{l}155 \\
153 \\
156 \\
156 \\
155 \\
155 \\
152 \\
151 \\
152 \\
153\end{array}$ & $\begin{array}{r}12,600 \\
3,510 \\
1,900 \\
1,420 \\
1,140 \\
986 \\
895 \\
846 \\
828 \\
977\end{array}$ & $\begin{array}{l}11 \ldots \ldots \\
12 \ldots \ldots \\
13 \ldots \ldots \\
14 \ldots \ldots \\
15 \ldots \ldots \\
16 \ldots \ldots \\
17 \ldots \ldots \\
18 \ldots \ldots \\
19 \ldots \ldots \\
20 \ldots \ldots\end{array}$ & $\begin{array}{l}151 \\
136 \\
114 \\
124 \\
147 \\
147 \\
145 \\
140 \\
141 \\
136\end{array}$ & $\begin{array}{l}839 \\
773 \\
745 \\
733 \\
668 \\
648 \\
607 \\
564 \\
553 \\
546\end{array}$ & $\begin{array}{l}21 \ldots \ldots \\
22 \ldots \ldots \\
23 \ldots \ldots \\
24 \ldots \ldots \\
25 \ldots \ldots \\
26 \ldots \ldots \\
27 \ldots \ldots \\
28 \ldots \ldots \\
29 \ldots \ldots \\
30 \ldots \ldots \\
31 \ldots \ldots\end{array}$ & $\begin{array}{l}143 \\
148 \\
146 \\
143 \\
142 \\
140 \\
141 \\
141 \\
149 \\
709 \\
7,140\end{array}$ & $\begin{array}{r}544 \\
534 \\
519 \\
514 \\
515 \\
526 \\
541 \\
535 \\
----\end{array}$ \\
\hline \multicolumn{7}{|l|}{$\begin{array}{l}\text { Monthly } \\
\text { Runoff, } \\
\text { Runoff, }\end{array}$} & $\begin{array}{r}389 \\
0.53 \\
23,920 \\
\end{array}$ & $\begin{array}{r}1,286 \\
1,58 \\
71,420 \\
\end{array}$ \\
\hline
\end{tabular}

Gage helght, In feet, and discharge, in cubic feet per second, at indicated time, 1963

\begin{tabular}{|c|c|c|c|c|c|c|c|c|c|c|c|}
\hline Date & Hour & $\begin{array}{c}\text { Gage } \\
\text { helght }\end{array}$ & $\begin{array}{l}\text { Dis- } \\
\text { charge }\end{array}$ & Date & Hour & $\begin{array}{c}\text { Gage } \\
\text { helght }\end{array}$ & $\begin{array}{c}\text { Dis- } \\
\text { charge }\end{array}$ & Date & Hour & $\begin{array}{c}\text { Gage } \\
\text { helght }\end{array}$ & $\begin{array}{l}\text { Dis- } \\
\text { charge }\end{array}$ \\
\hline an. $\begin{array}{r}29 \\
30\end{array}$ & $\begin{array}{l}2400 \\
0800 \\
0900 \\
1000 \\
1100 \\
1200 \\
1400 \\
1500 \\
1700 \\
1800 \\
1900 \\
2000 \\
2400 \\
0200 \\
\end{array}$ & $\begin{array}{l}- \\
- \\
\overline{-} \\
\overline{-} \\
\overline{-} \\
\overline{-} \\
\overline{-} \\
- \\
-\end{array}$ & $\begin{array}{r}185 \\
550 \\
557 \\
614 \\
632 \\
647 \\
675 \\
720 \\
742 \\
905 \\
1,170 \\
1,270 \\
1,270 \\
1,310 \\
\end{array}$ & Jan. 31 & $\begin{array}{l}0400 \\
0600 \\
0700 \\
1000 \\
1100 \\
1200 \\
1300 \\
1400 \\
1500 \\
1700 \\
1800 \\
1900 \\
2100 \\
2400 \\
0200\end{array}$ & $\begin{array}{c}- \\
- \\
- \\
- \\
- \\
- \\
11.00 \\
11.94 \\
13.28 \\
14.96 \\
15.42 \\
15.43 \\
13.66 \\
11.57 \\
11.05\end{array}$ & $\begin{array}{r}1,440 \\
1,320 \\
1,320 \\
1,660 \\
2,160 \\
3,760 \\
6,770 \\
8,650 \\
11,900 \\
17,100 \\
18,800 \\
18,800 \\
13,100 \\
8,220 \\
7,180\end{array}$ & Feb. 1 & $\begin{array}{l}0300 \\
0400 \\
0500 \\
0700 \\
0900 \\
1030 \\
1200 \\
1500 \\
1800 \\
2100 \\
2400 \\
0500 \\
1000 \\
1600 \\
2400\end{array}$ & $\begin{array}{c}11.29 \\
11.95 \\
13.35 \\
15.35 \\
16.02 \\
16.85 \\
15.45 \\
13.70 \\
11.98 \\
10.80 \\
10.18 \\
- \\
- \\
-\end{array}$ & $\begin{array}{r}7,660 \\
8,980 \\
12,300 \\
18,500 \\
21,200 \\
24,600 \\
18,900 \\
13,300 \\
9,060 \\
6,700 \\
5,580 \\
4,350 \\
3,450 \\
2,850 \\
2,390\end{array}$ \\
\hline
\end{tabular}


11-1863.4. Salmon Creek tributary B near Falrview, Calif.

Location.--Lat $35^{\circ} 54^{\prime} 05^{\prime \prime}$, long $118^{\circ} 23^{\prime} 00^{\prime \prime}$, in $\mathrm{SE}_{\frac{1}{4}} \mathrm{NE} \frac{1}{4}$ sec.26, T.23 S., R.33 E., on left bank 0.15 mile upstream from junction with Salmon Creek, 6.4 miles east of Falrview, and 10.3 miles north of Kernville.

Dreinage area. $--0.46 \mathrm{sq} \mathrm{mi}$.

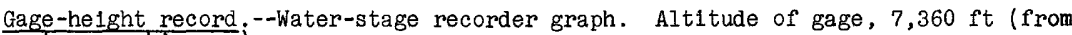
topographic map).

Discharge record.--Stage-discharge relation defined by computation of flow over $120^{\circ} \mathrm{V}$-notch weir.

Maximum.--January-February 1963: Discharge, $3.1 \mathrm{cfs} 1000$ hours Feb. I (gage height, $0.87 \mathrm{ft}$ ); gage helght, $0.93 \mathrm{ft}$, backwater from debris.

Remarks.--Gage-helght record furnished by U.S. Forest Service.

11-1863.6. Salmon Creek tributary C near Fairview, Calif.

Location.--Lat $35^{\circ} 54^{\prime} 15^{\prime \prime}$, long $118^{\circ} 23^{\prime} 30^{\prime \prime}$, in $\mathrm{NE} \frac{1}{4} \mathrm{NW} \frac{1}{4}$ sec.26, T.23 S., R.33 E., on left bank, 0.1 mile upstream from junction with Salmon Creek, 6.0 miles east of Falrview, and 10.5 miles north of Kernville.

Drainage area $--0.30 \mathrm{sq} \mathrm{mi}$.

Gage-helght record.--Water-stage recorder graph, except 0600 hours Jan. 12 to Jan. 15. Altitude of gage is $7,200 \mathrm{ft}$ (from topographic map).

Discharge record.--Stage-discharge relation defined by computation of flow over $120^{\circ}$ $V$-notch weir; affected by ice Jan. 11. Discharge for Jan. 12-15 estimated on basis of records for Salmon Creek tributaries $B$ and $E$, recorded range in stage, and weather records.

Maximum.--January-February 1963: Discharge, 2.7 cfs 0400 and 0830 hours Feb. 1 (gage helght, $1.03 \mathrm{ft}$ ).

Remarks.--Gage-height record furnished by U.S. Forest Service.

11-1863.8. Salmon Creek tributary E near Fairview, Calif.

Location.--Lat $35^{\circ} 54^{\prime} 15^{\prime \prime}$, long $118^{\circ} 23^{\prime} 45^{\prime \prime}$, in NW $\frac{1}{4} \mathrm{NW} \frac{1}{4}$ sec.26, T.23 S., R.33 E., on left bank 0.2 mile upstream from junction with Salmon Creek, 5.7 miles east of Falrview, and 10.5 miles north of Kernville.

Drainage area. $-0.23 \mathrm{sq} \mathrm{mi}$.

Gage-he1ght record.--Water-stage recorder graph. Alt1tude of gage is $7,200 \mathrm{ft}$ (from topographic map).

Discharge record.--Stage-discharge relation defined by computation of flow over $120^{\circ} \mathrm{V}$-notch weir.

Maximum.--January-February 1963: Discharge, 0.9 cfs 1230 hours Jan. 31 (gage helght, $0.53 \mathrm{ft}$ ).

Remarks.--Gage-height record furnished by U.S. Forest Service. 
11-1870. Kerm River at Kernville, Calif.

Location.--Lat $35^{\circ} 45^{\prime} 15^{\prime \prime}$, long $118^{\circ} 25^{\prime} 25^{\prime \prime}$, in $\mathrm{NE} \frac{1}{4} \mathrm{SW}_{\frac{1}{4}} \sec .15$, T.25 S., R.33 E., on right bank $300 \mathrm{ft}$ downstream from highway bridge at new town of Kernville, 1.1 miles upstream from Caldwell Creek, 8.9 miles upstream from Isabelia Dam, and 41 miles northeast of Bakersfield.

Drainage area. $--1,009 \mathrm{sq} \mathrm{mi}$.

Gage-height record.--Water-stage recorder graph. Datum of gage is $2,621.57 \mathrm{ft}$ above mean sea level (levels by Corps of Engineers).

Discharge record.--Stage-discharge relation defined by current-meter measurements below 7,200 cfs and by slope-area measurement at $28,800 \mathrm{cfs}$.

Maxima.--January-February 1963: Discharge, 28,800 cfs 1100hours Feb; 1 (gage height, $16.76 \mathrm{ft}$ in gage well; $17.33 \mathrm{ft}$ outside, from floodmarks). 1905-12, 1953 to December 1962: Discharge, 29,400 cfs Dec. 23, 1955 (gage height, $16.20 \mathrm{ft}$ in gage. well; $16.8 \mathrm{ft}$ outside, from floodmarks).

Maximum stage known since at least 1905, 18.4 ft Nov. 19, 1950 (discharge not determined).

Mean discharge, in cubic feet per second, 1963

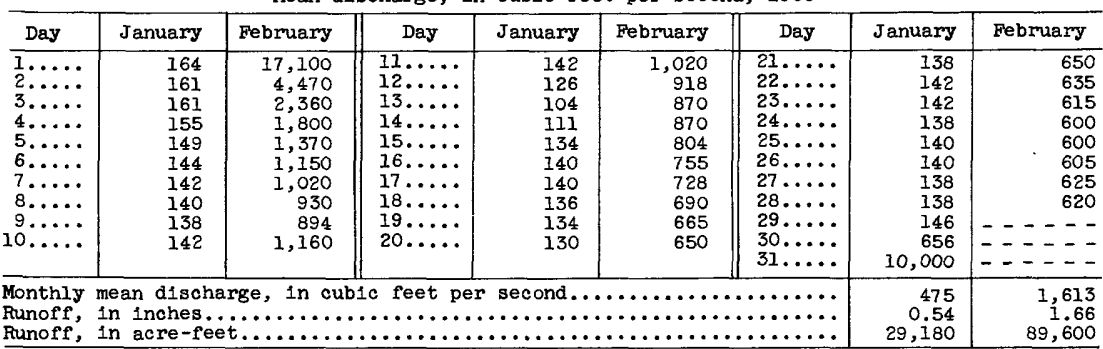

Gage height, in feet, and discharge, in cublc feet per second, at indicated time, 1963

\begin{tabular}{|c|c|c|c|c|c|c|c|c|c|c|c|}
\hline Date & Hour & $\begin{array}{c}\text { Gage } \\
\text { he1ght }\end{array}$ & $\begin{array}{l}\text { Dis - } \\
\text { charge }\end{array}$ & Date & Hour & $\begin{array}{c}\text { Gage } \\
\text { helght }\end{array}$ & $\begin{array}{c}\text { Dis - } \\
\text { charge }\end{array}$ & Date & Hour & $\begin{array}{c}\text { Gage } \\
\text { height }\end{array}$ & $\begin{array}{c}\text { Dis- } \\
\text { charge }\end{array}$ \\
\hline $\begin{array}{r}\text { Jan. } 28 \\
29\end{array}$ & $\begin{array}{l}2400 \\
1000 \\
1400 \\
2100 \\
2400\end{array}$ & $\begin{array}{l}3.92 \\
3.86 \\
3.92 \\
3.96 \\
4.07\end{array}$ & $\begin{array}{l}146 \\
134 \\
146 \\
155 \\
179\end{array}$ & Jan. 31 & $\begin{array}{l}0700 \\
1000 \\
1200 \\
1300 \\
1400 \\
1600 \\
1800\end{array}$ & $\begin{array}{r}7.10 \\
8.15 \\
9.85 \\
11.35 \\
13.00 \\
14.68 \\
16.26\end{array}$ & $\begin{array}{r}1,810 \\
2,840 \\
5,250 \\
8,280 \\
12,850 \\
19,000 \\
26,200\end{array}$ & Feb. I & $\begin{array}{l}1100 \\
1200 \\
1500 \\
1800 \\
2100 \\
2400\end{array}$ & $\begin{array}{l}16.76 \\
16.45 \\
14.90 \\
13.30 \\
12.00 \\
11.00\end{array}$ & $\begin{array}{r}28,800 \\
27,200 \\
20,200 \\
14,500 \\
10,600 \\
8,180\end{array}$ \\
\hline 30 & $\begin{array}{l}0200 \\
0600 \\
0900 \\
1400 \\
1600\end{array}$ & $\begin{array}{l}4.15 \\
4.73 \\
5.32 \\
5.73 \\
5.66\end{array}$ & $\begin{array}{l}202 \\
384 \\
624 \\
826 \\
790\end{array}$ & & $\begin{array}{l}1900 \\
2100 \\
2300 \\
2400\end{array}$ & $\begin{array}{l}16.25 \\
15.00 \\
13.35 \\
12.75\end{array}$ & $\begin{array}{l}26,200 \\
20,400 \\
14,000 \\
12,100\end{array}$ & 2 & $\begin{array}{l}0400 \\
1000 \\
1800 \\
2400\end{array}$ & $\begin{array}{l}9.94 \\
8.95 \\
8.14 \\
7.76\end{array}$ & $\begin{array}{l}6,010 \\
4,320 \\
3,190 \\
2,740\end{array}$ \\
\hline 31 & $\begin{array}{l}2200 \\
2400 \\
0100 \\
0400 \\
0600\end{array}$ & $\begin{array}{l}5.88 \\
6.62 \\
6.67 \\
6.74 \\
6.89\end{array}$ & $\begin{array}{r}913 \\
1,420 \\
1,460 \\
1,510 \\
1,630\end{array}$ & Feb. 1 & $\begin{array}{l}0200 \\
0400 \\
0500 \\
0600 \\
0700 \\
0900\end{array}$ & $\begin{array}{l}11.90 \\
12.35 \\
13.00 \\
14.75 \\
15.60 \\
16.15\end{array}$ & $\begin{array}{r}9,650 \\
10,900 \\
12,800 \\
19,300 \\
23,000 \\
25,700\end{array}$ & 3 & $\begin{array}{l}0400 \\
0800 \\
1000 \\
1200 \\
2400\end{array}$ & $\begin{array}{l}7.53 \\
7.40 \\
7.37 \\
7.41 \\
7.21\end{array}$ & $\begin{array}{l}2,480 \\
2,350 \\
2,320 \\
2,360 \\
2,160\end{array}$ \\
\hline
\end{tabular}

11-1872. Shirley Creek tributary near Alta Sierra, Cal1f.

(Crest-stage station)

Location.--Lat $35^{\circ} 43^{\prime} 15^{\prime \prime}$, long $118^{\circ} 29^{\prime} 55^{\prime \prime}$, in SW $\frac{1}{4}$ sec.25, T.25 S., R.32 E., 3 miles east of Alta Sierra.

Drainage area. $--0.27 \mathrm{sq} \mathrm{mi}$.

Gage-height record.--Crest stages only. Altitude of gage is 4,120 ft (from topographic map).

Discharge record.--Maximum discharge by computation of flow through culvert.

Maxima.--January-February 1963: Discharge, $14 \mathrm{cfs}$ Feb. 1 (gage height, $11.57 \mathrm{ft}$ ). i959 to December 1962: Discharge, $14 \mathrm{cf}$. Feb. 8, 1962 (gage height, $11.51 \mathrm{ft}$ ). 
11-1882. South Fork Kern River near Olancha, Calif.

Location.--Lat $36^{\circ} 11^{\prime} 00^{\prime \prime}$, long $118^{\circ} 07140^{\prime \prime}$, in NW $\frac{1}{4} S W \frac{1}{4} \sec .18$, T.20 S., R.36 E., on left bank $50 \mathrm{ft}$ upstream from small unnamed left bank tributary, 2.0 miles downstream from Snake Creek, and 9.7 miles southwest of 0lancha.

Drainage area. $--146 \mathrm{sq} \mathrm{mi}$.

Gage-height record --Water-stage recorder graph. Altitude of gage is 7,840 ft (from topographic map)

Discharge record.--Stage-discharge relation defined by current-meter measurements; affected by Ice Jan. 1-29, Feb. 26-28.

Maxima.--January-February 1963: Discharge, 1,240 cfs 1300 hours Feb. 1 (gage helght, $5.37 \mathrm{ft}$ )

October 1956 to December 1962: Discharge, 1,280 cfs May 10, 1958 (gage height, $5.50 \mathrm{ft}$ ); gage height, $5.85 \mathrm{ft}$ Apr. 18, 1958 (backwater from ice).

Mean discharge, in cubic feet per second, 1963

\begin{tabular}{|c|c|c|c|c|c|c|c|c|}
\hline Day & January & February & Day & January & February & Day & January & February \\
\hline $\begin{array}{c}1 \ldots \ldots \\
3 \ldots \ldots \\
4 \ldots \ldots \\
5 \ldots \ldots \\
6 \ldots \ldots \\
8 \ldots \ldots \\
9 \ldots \ldots \\
10 \ldots \ldots\end{array}$ & $\begin{array}{l}6 \\
6 \\
6 \\
6 \\
6 \\
6 \\
6 \\
6 \\
6 \\
6\end{array}$ & $\begin{array}{r}880 \\
482 \\
222 \\
155 \\
136 \\
120 \\
105 \\
93 \\
89 \\
70\end{array}$ & $\begin{array}{l}11 \ldots \ldots \\
12 \ldots \ldots \\
13 \ldots \ldots \\
14 \ldots \ldots \\
15 \ldots \ldots \\
16 \ldots \ldots \\
17 \ldots \ldots \\
18 \ldots \ldots \\
19 \ldots \ldots \\
20 \ldots \ldots\end{array}$ & $\begin{array}{l}6 \\
6 \\
5 \\
6 \\
6 \\
6 \\
6 \\
6 \\
6 \\
6\end{array}$ & $\begin{array}{l}76 \\
75 \\
70 \\
73 \\
63 \\
62 \\
60 \\
56 \\
58 \\
62\end{array}$ & $\begin{array}{l}21 \ldots \ldots \\
22 \ldots \ldots \\
23 \ldots \ldots \\
24 \ldots \ldots \\
25 \ldots \ldots \\
26 \ldots \ldots \\
27 \ldots \ldots \\
28 \ldots \ldots \\
29 \ldots \ldots \\
30 \ldots \ldots \\
31 \ldots \ldots\end{array}$ & $\begin{array}{r}5 \\
5 \\
6 \\
6 \\
6 \\
6 \\
6 \\
6 \\
6 \\
13 \\
178\end{array}$ & $\begin{array}{r}65 \\
55 \\
51 \\
54 \\
56 \\
56 \\
54 \\
54 \\
----- \\
---- \\
---\end{array}$ \\
\hline $\begin{array}{l}\text { Monthly } \\
\text { Runoff, } \\
\text { Runoff, }\end{array}$ & $\begin{array}{l}\text { an disch } \\
\text { n inches } \\
\text { n acre-fe }\end{array}$ & $e$, in & & & & & $\begin{array}{r}11.7 \\
0.09 \\
718 \\
\end{array}$ & $\begin{array}{r}121 \\
0.86 \\
6,730 \\
\end{array}$ \\
\hline
\end{tabular}

Gage height, in feet, and discharge, in cuble feet per second, at indicated time, 1963

\begin{tabular}{|c|c|c|c|c|c|c|c|c|c|c|c|}
\hline Date & Hour & $\begin{array}{c}\text { Gage } \\
\text { helght }\end{array}$ & $\begin{array}{c}\text { Dis - } \\
\text { charge }\end{array}$ & Date & Hour & $\begin{array}{c}\text { Gage } \\
\text { height }\end{array}$ & $\begin{array}{c}\text { D1s - } \\
\text { charge }\end{array}$ & Date & Hour & $\begin{array}{c}\text { Gage } \\
\text { helght }\end{array}$ & $\begin{array}{l}\text { Dis- } \\
\text { charge }\end{array}$ \\
\hline an. $\begin{array}{r}30 \\
31\end{array}$ & $\begin{array}{l}2400 \\
0600 \\
1200 \\
1800 \\
2100 \\
2400\end{array}$ & $\begin{array}{l}1.86 \\
2.25 \\
2.82 \\
3.21 \\
3.31 \\
3.77\end{array}$ & $\begin{array}{r}43 \\
82 \\
170 \\
258 \\
282 \\
424\end{array}$ & Feb. 1 & $\begin{array}{l}0200 \\
0300 \\
0500 \\
1000 \\
1300 \\
1800 \\
2400\end{array}$ & $\begin{array}{l}3.65 \\
4.60 \\
4.11 \\
4.83 \\
5.37 \\
5.20 \\
4.38\end{array}$ & $\begin{array}{r}382 \\
790 \\
554 \\
918 \\
1,240 \\
1,140 \\
680\end{array}$ & Feb. 2 & $\begin{array}{l}1200 \\
1800 \\
2400 \\
\\
0800 \\
1600 \\
2400\end{array}$ & $\begin{array}{l}3.43 \\
3.90 \\
3.55 \\
2.92 \\
3.01 \\
2.89\end{array}$ & $\begin{array}{l}314 \\
470 \\
350 \\
\\
190 \\
210 \\
184\end{array}$ \\
\hline Feb. 1 & 0100 & 3.87 & 460 & $\underline{2}$ & 0600 & 3.67 & 390 & & & & \\
\hline
\end{tabular}

11-1895. South Fork Kern River near Onyx, Calif.

Location.--Lat $35^{\circ} 44^{\prime}$, long $118^{\circ} 10^{\prime}$, in SW $\frac{1}{4}$ sec.24, T.25 S., R.35 E., on left bank three-quarters of a mile north of State Highway $178,1.4$ miles upstream from Canebrake creek, and 5 miles northeast of Onyx.

Drainage area. $--530 \mathrm{sq} \mathrm{mi}$.

Gage-height record.--Water-stage recorder graph. Altitude of gage is 2,900 ft (from topographic map).

Discharge record.--Stage-discharge relation defined by current-meter measurements .

Maxima,-January-February 1963: Discharge, 3,460 cfs at 1500 hours Feb. 1 (gage heIght, $6.79 \mathrm{ft}$ ).

1911-14, 1919-42, 1947 to December 1962: Discharge, 3,450 cfs Mar. 2, 1938 (gage helght, $6.69 \mathrm{ft}$ ), but may have been exceeded by flood of Jan. 25, 1914 (observed maximum gage height, $7.2 \mathrm{ft}$ and rising, at site $140 \mathrm{ft}$ upstream at same datum). 
Mean discharge, in cuble feet per second, 1963, of South Fork Kerm River near Onyx, Cal1f.

\begin{tabular}{|c|c|c|c|c|c|c|c|c|}
\hline Day & January & February & Day & January & February & Day & January & February \\
\hline $\begin{array}{c}1 \ldots \ldots \\
2 \ldots \ldots \\
4 \ldots \ldots \\
5 \ldots \ldots \\
6 \ldots \ldots \\
7 \ldots \ldots \\
9 \ldots \ldots \\
10 \ldots \ldots\end{array}$ & $\begin{array}{l}21 \\
23 \\
23 \\
22 \\
21 \\
23 \\
23 \\
23 \\
21 \\
23\end{array}$ & $\begin{array}{r}2,420 \\
1,370 \\
642 \\
411 \\
324 \\
272 \\
235 \\
220 \\
226 \\
339\end{array}$ & $\begin{array}{l}11 \ldots \ldots \\
12 \ldots \ldots \\
13 \ldots \ldots \\
14 \ldots \ldots \\
15 \ldots \ldots \\
16 \ldots \ldots \\
17 \ldots \ldots \\
18 \ldots \ldots \\
19 \ldots \ldots \\
20 \ldots \ldots\end{array}$ & $\begin{array}{l}24 \\
18 \\
12 \\
16 \\
19 \\
19 \\
19 \\
18 \\
19 \\
15\end{array}$ & $\begin{array}{l}238 \\
208 \\
192 \\
190 \\
178 \\
165 \\
155 \\
146 \\
142 \\
142\end{array}$ & $\begin{array}{l}21 \ldots \ldots \\
22 \ldots \ldots \\
23 \ldots \ldots \\
24 \ldots \ldots \\
25 \ldots \ldots \\
26 \ldots \ldots \\
27 \ldots \ldots \\
28 \ldots \ldots \\
29 \ldots \ldots \\
30 \ldots \ldots \\
31 \ldots \ldots\end{array}$ & $\begin{array}{r}17 \\
18 \\
18 \\
19 \\
18 \\
18 \\
18 \\
18 \\
21 \\
108 \\
1,150\end{array}$ & $\begin{array}{r}142 \\
137 \\
129 \\
123 \\
123 \\
125 \\
131 \\
129 \\
---1- \\
----1-\end{array}$ \\
\hline \multicolumn{7}{|c|}{ 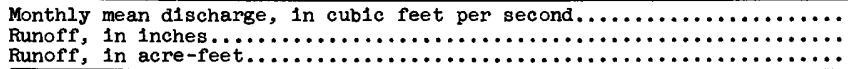 } & $\begin{array}{r}58.9 \\
0.13 \\
3,620\end{array}$ & $\begin{array}{r}330 \\
0.65 \\
18,360\end{array}$ \\
\hline
\end{tabular}

Gage height, in feet, and discharge, in cublc feet per second, at indicated time, 1963

\begin{tabular}{|c|c|c|c|c|c|c|c|c|c|c|c|}
\hline Date & Hour & $\begin{array}{c}\text { Gage } \\
\text { height }\end{array}$ & $\begin{array}{l}\text { Dis- } \\
\text { charge }\end{array}$ & Date & Hour & $\begin{array}{c}\text { Gage } \\
\text { he1ght }\end{array}$ & $\begin{array}{l}\text { Dis- } \\
\text { charge }\end{array}$ & Date & Hour & $\begin{array}{c}\text { Gage } \\
\text { height }\end{array}$ & $\begin{array}{c}\text { Dis- } \\
\text { charge }\end{array}$ \\
\hline an. $\begin{array}{r}29 \\
30\end{array}$ & $\begin{array}{l}2400 \\
0100 \\
0600 \\
0700 \\
0900 \\
1000 \\
1300 \\
1400 \\
1700 \\
1900 \\
2300 \\
2400\end{array}$ & $\begin{array}{l}1.78 \\
1.91 \\
1.98 \\
2.03 \\
2.46 \\
2.52 \\
2.57 \\
2.53 \\
2.69 \\
2.73 \\
2.78 \\
2.93\end{array}$ & $\begin{array}{r}23 \\
34 \\
40 \\
45 \\
106 \\
117 \\
127 \\
119 \\
153 \\
162 \\
175 \\
214\end{array}$ & Feb. 1 & $\begin{array}{l}0400 \\
0900 \\
1200 \\
1400 \\
1600 \\
2100 \\
2300 \\
2400 \\
\\
0400 \\
0500 \\
0700 \\
1200\end{array}$ & $\begin{array}{l}2.97 \\
3.22 \\
3.86 \\
4.63 \\
5.74 \\
6.15 \\
6.16 \\
6.04 \\
5.22 \\
5.16 \\
5.37 \\
5.80\end{array}$ & $\begin{array}{r}226 \\
307 \\
593 \\
1,090 \\
2,070 \\
2,560 \\
2,570 \\
2,410 \\
1,580 \\
1,520 \\
1,710 \\
2,140\end{array}$ & Feb. I & $\begin{array}{l}1300 \\
1500 \\
1900 \\
2000 \\
2100 \\
2400 \\
\\
0200 \\
0500 \\
1000 \\
1600 \\
2100 \\
2400\end{array}$ & $\begin{array}{l}6.02 \\
6.79 \\
6.69 \\
6.59 \\
6.32 \\
6.07 \\
5.85 \\
5.72 \\
5.00 \\
4.40 \\
4.12 \\
4.13\end{array}$ & $\begin{array}{r}2,390 \\
3,460 \\
3,320 \\
3,160 \\
2,780 \\
2,450 \\
2,200 \\
2,050 \\
1,390 \\
920 \\
742 \\
748\end{array}$ \\
\hline
\end{tabular}

11-1897. Kelso Creek near Weldon, Cal1f.

Location.--Lat $35^{\circ} 34^{\prime} 10^{\prime \prime}$, long $118^{\circ} 15^{\prime} 05^{\prime \prime}$, in NW $\frac{1}{4}$ sec. 20 , T.27 S., R.35 E., on left bank 0.5 mile upstream from Woolstaff Creek and 7 miles southeast of Weldon.

Drainage area. $--101 \mathrm{sq} \mathrm{mi}$.

Gage-he1ght record.--Water-stage recorder graph, except Jan. 20-23, Feb. 1-3. Alt1tude of gage is $3,180 \mathrm{ft}$ (from topographic map).

Discharge record.--Stage-discharge relation defined by current-meter measurements below $2 \mathrm{cf}$, weir computations at 2.2 and $6.2 \mathrm{cfs}$, and slope-area measurement at $1,180 \mathrm{cfs}$. Discharge Jan. $20-23, \mathrm{Feb}, 1-3$, estimated on basis of recorded range in stage and weather records.

Maxima.--January-February 1963: Discharge, 9.1 cfs 1330 hours Jan. 10 (gage helght, $2.48 \mathrm{ft})$.

1958 to December 1962: Discharge, 1,180 cfs Aug. 23, 1961 (gage height, $6.00 \mathrm{ft}$ ). 
11-1905. Isabella Reservoir near Isabella, Calif.

Location.--Lat $35^{\circ} 38^{1} 50^{\prime \prime}$, long $118^{\circ} 28^{\prime} 50^{\prime \prime}$, in SW $\frac{1}{4}$ sec.19, T.26 S., R.33 E., in main control tower near left abutment of main dam on Kern River, 1.5 miles north of new town of Isabella and 2.8 miles upstream from Erskine Creek.

Drainage area. $--2,074 \mathrm{sq} \mathrm{mi}$.

Gage-height record.--Water-stage recorder graph. Datum of gage is at mean sea level (levels by Corps of Engineers).

Contents record.--Contents computed from capacity table dated Aug. 25, 1954.

Maxima.--January-February 1963: Computed bihourly inflow, 24,400 cfs 1000 to 1200 hours Feb. 1 ; outflow, 570 cfs 1400 hours Jan. 30 ; contents, 174,300 acre-ft 2400 hours Feb. 28 (elevation, 2,560.26 ft).

1953 to December 1962: Contents, 455,200 acre-ft June 28, 1958 (elevation, $2,594.83 \mathrm{ft})$.

Remarks.--Reservoir is formed by earthfill dam with sidehill spillway and auxiliary earthfill dam, completed in 1954; regulation of discharge from reservoir began Apr. 15, 1954. Usable capacity, 569,700 acre-ft between elevations 2,470.0 ft (invert of main outlet) and $2,605.5 \mathrm{ft}$ (splliway crest) above mean sea level. Dead storage, 326 acre-ft. Surcharge flood control storage, 271,800 acre-ft between ungated spillway crest and elevation 2,627.0 ft (maximum design spillway flood pool). Figures given herein represent total contents. Records furnished by Corps of Engineers.

Elevation, in feet, and contents, in acre-feet, at 2400 hours, 1963

\begin{tabular}{|c|c|c|c|c|c|c|c|c|c|}
\hline \multirow{2}{*}{ Day } & \multicolumn{2}{|c|}{ January } & \multicolumn{2}{|c|}{ February } & \multirow{2}{*}{ Day } & \multicolumn{2}{|c|}{ January } & \multicolumn{2}{|c|}{ February } \\
\hline & Elevation & Contents & Elevation & Contents & & Elevation & Contents & Elevat1on & Contents \\
\hline $\begin{array}{l}1 \\
2 \\
3 \\
4 \\
5 \\
6 \\
7 \\
8 \\
9 \\
10 \\
11 \\
12 \\
13 \\
14 \\
15\end{array}$ & $\begin{array}{l}2,541.53 \\
2,541.53 \\
2,541.52 \\
2,541.52 \\
2,541.51 \\
2,541.50 \\
2,541.50 \\
2,541.49 \\
2,541.48 \\
2,541.46 \\
2,541.46 \\
2,541.45 \\
2,541.44 \\
2,541.43 \\
2,541.42\end{array}$ & $\begin{array}{l}82,850 \\
82,850 \\
82,810 \\
82,810 \\
82,770 \\
82,740 \\
82,740 \\
82,700 \\
82,660 \\
82,590 \\
82,590 \\
82,550 \\
82,520 \\
52,480 \\
82,440\end{array}$ & $\begin{array}{l}2,551.90 \\
2,554.17 \\
2,555.16 \\
2,555.80 \\
2,556.27 \\
2,556.64 \\
2,556.94 \\
2,557.21 \\
2,557.47 \\
2,557.84 \\
2,558.13 \\
2,558.35 \\
2,558.59 \\
2,558.79 \\
2,558.97\end{array}$ & $\begin{array}{l}127,800 \\
139,500 \\
144,800 \\
148,400 \\
151,000 \\
153,000 \\
154,800 \\
156,300 \\
157,800 \\
159,900 \\
161,600 \\
162,900 \\
164,300 \\
165,500 \\
166,500\end{array}$ & $\begin{array}{l}16 \\
17 \\
18 \\
19 \\
20 \\
21 \\
22 \\
23 \\
24 \\
25 \\
26 \\
27 \\
25 \\
29 \\
30 \\
31\end{array}$ & $\begin{array}{l}2,541 \cdot 41 \\
2,541 \cdot 41 \\
2,541 \cdot 40 \\
2,541.39 \\
2,541.39 \\
2,541.38 \\
2,541.35 \\
2,541.38 \\
2,541.38 \\
2,541.37 \\
2,541.37 \\
2,541.36 \\
2,541.35 \\
2,541.37 \\
2,541.54 \\
2,545.28\end{array}$ & $\begin{array}{l}82,410 \\
82,410 \\
82,370 \\
52,340 \\
82,340 \\
\mathrm{~s} 2,300 \\
82,300 \\
82,300 \\
82,300 \\
82,260 \\
82,260 \\
82,230 \\
82,190 \\
82,260 \\
82,890 \\
97,580\end{array}$ & $\begin{array}{c}2,559.32 \\
2,559.26 \\
2,559.39 \\
2,559.49 \\
2,559.61 \\
2,559.71 \\
2,559.79 \\
2,559.87 \\
2,559.95 \\
2,560.02 \\
2,560.10 \\
2,560.19 \\
2,560.26 \\
- \\
-\end{array}$ & $\begin{array}{c}167,400 \\
165,300 \\
169,000 \\
169,600 \\
170,300 \\
171,000 \\
171,400 \\
171,900 \\
172,400 \\
172,800 \\
173,300 \\
173,900 \\
174,300 \\
- \\
- \\
-\end{array}$ \\
\hline Gitare & in conte & , in ac & & & & - & $+14,730$ & - & $+76,720$ \\
\hline
\end{tabular}

Average inflow, in cubic feet per second, for bihourly periods ending at indicated

\begin{tabular}{|c|c|c|c|c|c|c|c|c|}
\hline Date & Hour & Inflow & Date & Hour & Inflow & Date & Hour & Inflow \\
\hline $\operatorname{Jan} .31$ & $\begin{array}{l}0200 \\
0400 \\
0600 \\
0800 \\
1000 \\
1200 \\
1400 \\
1600 \\
1800 \\
2000 \\
2200 \\
2400 \\
\end{array}$ & $\begin{array}{r}1,330 \\
1,320 \\
1,770 \\
2,460 \\
2,470 \\
3,830 \\
4,280 \\
9,100 \\
14,500 \\
22,700 \\
17,800 \\
13,400 \\
\end{array}$ & Feb. 1 & $\begin{array}{l}0200 \\
0400 \\
0600 \\
0800 \\
1000 \\
1200 \\
1400 \\
1600 \\
1800 \\
2000 \\
2200 \\
2400 \\
\end{array}$ & $\begin{array}{r}11,300 \\
8,580 \\
10,100 \\
15,600 \\
24,100 \\
24,400 \\
20,200 \\
20,200 \\
16,400 \\
13,400 \\
11,100 \\
11,000 \\
\end{array}$ & Feb. 2 & $\begin{array}{l}0200 \\
0400 \\
0600 \\
0800 \\
1000 \\
1200 \\
1400 \\
1600 \\
1800 \\
2000 \\
2200 \\
2400 \\
\end{array}$ & $\begin{array}{l}9,480 \\
9,180 \\
7,230 \\
7,550 \\
6,610 \\
5,990 \\
8,550 \\
4,220 \\
4,220 \\
4,220 \\
3,900 \\
3,900 \\
\end{array}$ \\
\hline
\end{tabular}


11-1910. Kern River below Isabella Dam, Cal1f.

Location.--Lat $35^{\circ} 38^{\prime} 30^{\prime \prime}$, long $118^{\circ} 28^{\prime} 55^{\prime \prime}$, in S $\frac{1}{2} \mathrm{NW} \frac{1}{4} \sec .30$, T.26 S., R.33 E., on right bank $200 \mathrm{ft}$ downstream from highway bridge, 0.6 mile downstream from Isabella Dam, and 1.6 miles southwest of Isabella.

Drainage area. $--2,074 \mathrm{sq} \mathrm{mi}$.

Gage-helght record. - Water-stage recorder graph. Datum of gage is 2,435.07 ft above mean sea leveI (levels by Corps of Engineers).

Discharge record,--Stage-discharge relation defined by current-meter measurements .

Maxima --January-February 1963: Discharge, 42 cfs 0930 hours Feb. 12 (gage height, $3.63 \mathrm{ft})$

1945-53 (prior to regulation by Isabella Reservolr): Discharge, 39,000 cfs Nov. 19, 1950 (gage height, $28.6 \mathrm{ft}$, from floodmark), from rating curve extended above $1,100 \mathrm{cfs}$ on basis of slope-area measurement of maximum flow.

1954 to December 1962: Discharge, 4,260 cfs June 28, 1958 (gage height, $15.14 \mathrm{ft}$ ).

Remarks.--Flow regulated by Isabella Reservoir beginning Apr. 15, 1954.

11-1918. Kern River tributary near Miracle Hot Springs, Calif.

$$
\text { (Crest-stage station) }
$$

Location. --Lat $35^{\circ} 33^{\prime} 15^{\prime \prime}$, long $118^{\circ} 34^{\prime} 45^{\prime \prime}$, in NW $\frac{1}{4}$ sec. 30 , T.27 S., R.32 E., on State Highway $178,3.5$ miles southwest of Miracle Hot Springs.

Drainage area. $--1.21 \mathrm{sq} \mathrm{mi}$.

Gage-height record.--Crest stages only. Datum of gage is 2,453.4 ft.

Discharge record.--Stage-discharge relation defined by current-meter measurements below $0.7 \mathrm{cfs}$ and by computation of flow through culvert at 1.0 and $5.0 \mathrm{cfs}$.

Maxima.--January-February 1963: No flow.

1959 to December 1962: Discharge, $5.0 \mathrm{cfs}$ Feb. 8, 1962 (gage height, $6.80 \mathrm{ft}$ ).

11-1925. Kern River near Democrat Springs, Calif.

Location.--Lat $35^{\circ} 31^{1} 20^{\prime \prime}$, long $118^{\circ} 40^{\prime} 40^{\prime \prime}$, in $\mathrm{NE} \frac{1}{4} \mathrm{SE} \frac{1}{4}$ sec.6, T.28 S., R.31 E., on left bank 1.0 mile southwest of Democrat Springs and 2.1 miles upstream from Cow Creek.

Drainage area. $--2,258 \mathrm{sq} \mathrm{mi}$.

Gage-height record.--Water-stage recorder graph. Altitude of gage is 1,850 $\mathrm{ft}$ (from topographic map).

D1scharge record. --Stage-discharge relation defined by current-meter measurements.

Maxima (river only).--January-February 1963: Discharge, 112 cfs 1430 hours Feb. I (gage helght, $4.87 \mathrm{ft}$ ).

1950-53 (prior to regulation by Isabella Reservolr): Discharge, 40,000 cfs

Nov. 19, 1950 (gage helght, $30.7 \mathrm{ft}$ ), from rating curve extended above $8,700 \mathrm{cfs}$ on basis of computation of peak flow over dam (basic data for computation furnished by Southern California Edison Co. $)$.

1954 to December 1962: Discharge, 3,960 cfs June 12, 1958 (gage height, $13.68 \mathrm{ft})$.

Maxima (river and conduit).--January-February 1963: D1scharge, 486 cfs 2200 hours Jan, 30

1950 to December 1962: Discharge, 40,000 cf's Nov. 19, 1950.

Remarks.--Flow regulated by Isabella Reservoir (see station 11-1905). Kern River No. 1 conduit diverts up to 412 cfs above station. Mean discharge figures are the combined flow of Kerm River and Kern River No. 1 conduit. 
Mean d1scharge, in cublc feet per second, 1963, of Kerm R1ver near Democrat Springs,

\begin{tabular}{|c|c|c|c|c|c|c|c|c|}
\hline Day & January & February & Day & January & February & Day & January & February \\
\hline $\begin{array}{c}1 \ldots \ldots \\
3 \ldots \ldots \\
4 \ldots \ldots \\
5 \ldots \ldots \\
7 \ldots \ldots \\
8 \ldots \ldots \\
9 \ldots \ldots \\
10 \ldots \ldots\end{array}$ & $\begin{array}{l}179 \\
182 \\
183 \\
191 \\
186 \\
181 \\
180 \\
178 \\
176 \\
178\end{array}$ & $\begin{array}{l}444 \\
373 \\
354 \\
351 \\
350 \\
351 \\
350 \\
353 \\
367 \\
434\end{array}$ & $\begin{array}{l}11 \ldots \ldots \\
12 \ldots \ldots \\
13 \ldots \ldots \\
14 \ldots \ldots \\
15 \ldots \ldots \\
16 \ldots \ldots \\
17 \ldots \ldots \\
18 \ldots \ldots \\
19 \ldots \ldots \\
20 \ldots \ldots\end{array}$ & $\begin{array}{l}177 \\
176 \\
148 \\
138 \\
161 \\
171 \\
170 \\
161 \\
161 \\
157\end{array}$ & $\begin{array}{l}431 \\
423 \\
430 \\
429 \\
424 \\
422 \\
420 \\
419 \\
418 \\
418\end{array}$ & $\begin{array}{l}21 \ldots \ldots \\
22 \ldots \ldots \\
23 \ldots \ldots \\
24 \ldots \ldots \\
25 \ldots \ldots \\
26 \ldots \ldots \\
27 \ldots \ldots \\
28 \ldots \ldots \\
29 \ldots \ldots \\
30 \ldots \ldots \\
31 \ldots \ldots\end{array}$ & $\begin{array}{l}159 \\
165 \\
168 \\
166 \\
167 \\
167 \\
166 \\
164 \\
166 \\
250 \\
439\end{array}$ & $\begin{array}{r}417 \\
418 \\
415 \\
417 \\
419 \\
415 \\
417 \\
416 \\
----- \\
------\end{array}$ \\
\hline onthly & dis & , & & & & & $\begin{array}{r}181 \\
11,130 \\
\end{array}$ & $\begin{array}{r}403 \\
22,400 \\
\end{array}$ \\
\hline
\end{tabular}

11-1930. Kern River below Kern Canyon powerhouse, near Bakersfleld, Calif.

Location.--Lat $35^{\circ} 26^{\prime} 10^{\prime \prime}$, long $118^{\circ} 48^{\prime} 50^{\prime \prime}$, in NW $\frac{1}{4} \mathrm{SE} \frac{1}{4}$ sec.1, T.29 S., R.29 E., on left bank 1 mile downstream from Kerm Canyon powerhouse, 1.3 miles upstream from Cottonwood Creek, and 11 miles northeast of Bakersfield.

Drainage area. $--2,307 \mathrm{sq} \mathrm{mi}$.

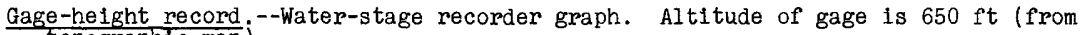
topographic map).

Discharge record.--Stage-discharge pelation defined by current-meter measurements .

Maxima.--January-February 1963: Discharge, $481 \mathrm{cfs} 2200$ hours Feb. 1 to 0300 hours Feb. 2 (gage height, $6.94 \mathrm{ft}$ ).

1893-1953 (prior to regulation by Isabella Reservole): Discharge, 36,000 cfs Nov. 19, 1950 (gage height, $14.2 \mathrm{ft}$, at site 11 miles downstream at datum then in use).

1954 to December 1962: Discharge, 4,360 cfs June 12, 1958 (gage helght, $11.47 \mathrm{ft}$ ).

Remarks.--Flow regulated by Isabella Reservoir since 1954 (see station 11-1905).

Mean discharge, in cubic feet per second, 1963

\begin{tabular}{|c|c|c|c|c|c|c|c|c|}
\hline Day & January & February & Day & January & February & Day & January & February \\
\hline $\begin{array}{c}1 \ldots \ldots \\
2 \ldots \ldots \\
3 \ldots \ldots \\
4 \ldots \ldots \\
5 \ldots \ldots \\
7 \ldots \ldots \\
5 \ldots \ldots \\
9 \ldots \ldots \\
10 \ldots \ldots\end{array}$ & $\begin{array}{l}174 \\
187 \\
182 \\
189 \\
191 \\
157 \\
184 \\
180 \\
180 \\
182\end{array}$ & $\begin{array}{l}465 \\
433 \\
376 \\
366 \\
362 \\
362 \\
366 \\
366 \\
369 \\
415\end{array}$ & $\begin{array}{l}11 \ldots \ldots \\
12 \ldots \ldots \\
13 \ldots \ldots \\
14 \ldots \ldots \\
15 \ldots \ldots \\
16 \ldots \ldots \\
17 \ldots \ldots \\
18 \ldots \ldots \\
19 \ldots \ldots \\
20 \ldots \ldots\end{array}$ & $\begin{array}{l}184 \\
180 \\
155 \\
146 \\
162 \\
176 \\
176 \\
172 \\
166 \\
166\end{array}$ & $\begin{array}{l}453 \\
445 \\
449 \\
449 \\
441 \\
437 \\
433 \\
429 \\
425 \\
422\end{array}$ & $\begin{array}{l}21 \ldots \ldots \\
22 \ldots \ldots \\
23 \ldots \ldots \\
24 \ldots \ldots \\
25 \ldots \ldots \\
26 \ldots \ldots \\
27 \ldots \ldots \\
28 \ldots \ldots \\
29 \ldots \ldots \\
30 \ldots \ldots \\
31 \ldots \ldots\end{array}$ & $\begin{array}{l}168 \\
168 \\
170 \\
170 \\
166 \\
170 \\
166 \\
170 \\
178 \\
237 \\
415\end{array}$ & $\begin{array}{r}422 \\
422 \\
422 \\
422 \\
422 \\
422 \\
422 \\
422 \\
---- \\
-----\end{array}$ \\
\hline $\begin{array}{l}\text { onthly } \\
\text { unoff, }\end{array}$ & 100 & 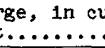 & & & & & $11, \frac{184}{310}$ & 23,0916 \\
\hline
\end{tabular}

11-1940.5. Tumbleweed Creek near O1ldale, Callf.

(Crest-stage station)

Location.--Iat $35^{\circ} 27^{\prime} 55^{\prime \prime}$, long $119^{\circ} 01^{\prime} 30^{\prime \prime}$, in NW $\frac{1}{4}$ sec.25, T.28 S., R.27 E., 3.2 miles north of oildale.

Drainage area. $--2.40 \mathrm{sq} \mathrm{ml}$.

Gage-height record.--Crest stages only. Altitude of gage is $765 \mathrm{ft}$ (from topographic map).

Discharge record.--Maximum discharge by computation of flow through culvert.

Maxima.--Januapy-February 1963: Discharge, $104 \mathrm{cfs}$ Feb. 13 (gage height, $4.65 \mathrm{ft}$, from high-water profile) 1958 to December 1962: Discharge, $18 \mathrm{cfs}$ Nov. 5, 1960 (gage height, $2.86 \mathrm{ft}$ ). 


\section{TULARE LAKE BASIN}

11-1978. Poso Creek near Oildale, Calif.

Location.--Lat $35^{\circ} 30^{\prime} 50^{\prime \prime}$, long $118^{\circ} 54^{\prime} 15^{\prime \prime}$, in SW $\frac{1}{4}$ SW $\frac{1}{4}$ sec.6, T.28 S., R.29 E., opposite mouth of Hillvale Canyon, on highway bridge 10 miles northeast of Oildale and 12 miles northeast of Bakersfield.

Drainage area. $--230 \mathrm{sq} \mathrm{mi}$.

Gage-height record ${ }^{--W a t e r-s t a g e ~ r e c o r d e r ~ g r a p h . ~ A l t i t u d e ~ o f ~ g a g e ~ i s ~} 700 \mathrm{ft}$ (from topographic map).

Discharge record.--Stage-discharge relation defined by current-meter measurements below $50 \mathrm{cfs}$ and by computation of peak flow at 2,750 cfs by Kern County Land Co.

Maxima.--January-February 1963: Discharge, $5.8 \mathrm{cfs} 0200$ hours Feb. 14 (gage height, $1.76 \mathrm{ft})$.

1958 to December 1962: The flood of Apr. 4, 1958, reached a stage of $8.6 \mathrm{ft}$, from floodmarks (discharge 2,750 cfs, furnished by Kern County Land Co.).

11-1980.5. Mon Canyon Creek near 01ldale, Calif.

(Crest-stage station)

Location.--Lat $35^{\circ} 31^{\prime} 45^{\prime \prime}$, long $118^{\circ} 58^{\prime} 25^{\prime \prime}$, in NW $\frac{1}{4} \mathrm{NW} \frac{1}{4}$ sec.4, T.28 S., R.28 E., on county road, 8 miles northeast of 0ildále.

Drainage area. $--2.38 \mathrm{sq} \mathrm{ml}$.

Gage-height record.--Crest stages only. Altitude of gage is $640 \mathrm{ft}^{\mathrm{t}}$ (from topographic map).

Discharge record. --Maximum discharge estimated.

Maxima --January-February 1963: No significant flow.

1958 to December 1962: Discharge, $0.2 \mathrm{cfs}$ Feb. 16, 1959, and Dec. 2, 1961 (gage heights not determined).

11-1993. Coho Creek near White River, Calif.

(Crest-stage station)

Location.--Lat $35^{\circ} 49^{\prime} 50^{\prime \prime}$, long $118^{\circ} 51^{\prime} 35^{\prime \prime}$, in $\mathrm{NE} \frac{1}{4} \mathrm{NE} \frac{1}{4} \sec .20$, T.24 S., R. $29 \mathrm{E}$, on county road, 1.6 miles northeast of white River.

Drainage area. $--12.9 \mathrm{sq} \mathrm{mi}$.

Gage-height record.--Crest stages only. Altitude of gage is 1,090 ft (from topographic map).

Discharge record. --Maximum discharge estimated.

Maxima.--January-February 1963: Discharge, $0.7 \mathrm{cfs} F \mathrm{Fb} .1$ (gage height, $2.75 \mathrm{ft}$ ). 1959 to December 1962: Discharge, I cfs Nov. 11, 1960 (gage height not determined). 
11-2020. North Fork of Middle Fork Tule River near Springville, Calif.

Location.--Lat $36^{\circ} 10^{\prime} 29^{\prime \prime}$, long $118^{\circ} 41 / 41^{\prime \prime}$, in sec.23, T.20 S., R.30 E. (unsurveyed), on right bank 1.2 miles upstream from mouth, 2.2 miles downstream from Hossack

Creek, and 7.4 miles northeast of Springvilie.

Drainage area. $--39.3 \mathrm{sq} \mathrm{mi}$.

Gage-helght record - Water-stage recorder graph. Altitude of gage is 2,920 ft (from topographic map).

Discharge record.--Stage-discharge relation defined by current-meter measurements below $340 \mathrm{cfs}$ and by critical-depth determination at $5,460 \mathrm{cfs}$.

Maxima --January-February 1963: Discharge, 5,460 cfs 0500 hours Feb. I (gage height, $9.67 \mathrm{ft}$ ).

1939 to December 1962: Discharge, 12,400 cfs Dec. 23, 1955 (gage height, $12.47 \mathrm{ft}$, from floodmarks), from rating curve extended above $100 \mathrm{cfs}$ on basis of critical-depth determination; gage helght, $13.06 \mathrm{ft}$ Nov. 19, 1950, from floodmarks.

Remarks.--Pacific Gas \& Electric Co. conduit diverts 2.5 miles upstream from station. All figures are the combined flow of North Fork of Middle Fork Tule River and Pacific Gas \& Electric Co. conduit, although diversion is insignificant during floodflow.

Mean discharge, in cub1c feet per second, 1963

\begin{tabular}{|c|c|c|c|c|c|c|c|c|}
\hline Day & January & February & Day & January & February & Day & January & February \\
\hline $\begin{array}{c}1 \ldots \ldots \\
2 \ldots \ldots \\
4 \ldots \ldots \\
5 \ldots \ldots \\
6 \ldots \ldots \\
7 \ldots \ldots \\
9 \ldots \ldots \\
10 \ldots \ldots\end{array}$ & $\begin{array}{l}13 \\
13 \\
13 \\
13 \\
13 \\
13 \\
13 \\
13 \\
13 \\
13\end{array}$ & $\begin{array}{r}, 390 \\
424 \\
206 \\
143 \\
115 \\
98 \\
92 \\
83 \\
80 \\
99\end{array}$ & $\begin{array}{l}11 \ldots \ldots \\
12 \ldots \ldots \\
13 \ldots \ldots \\
14 \ldots \ldots \\
15 \ldots \ldots \\
16 \ldots \ldots \\
17 \ldots \ldots \\
18 \ldots \ldots \\
19 \ldots \ldots \\
20 \ldots \ldots\end{array}$ & $\begin{array}{l}13 \\
13 \\
12 \\
13 \\
13 \\
13 \\
13 \\
13 \\
13 \\
13\end{array}$ & $\begin{array}{l}86 \\
76 \\
74 \\
74 \\
69 \\
64 \\
60 \\
57 \\
56 \\
56\end{array}$ & $\begin{array}{l}21 \ldots \ldots \\
22 \ldots \ldots \\
23 \ldots \ldots \\
24 \ldots \ldots \\
25 \ldots \ldots \\
26 \ldots \ldots \\
27 \ldots \ldots \\
28 \ldots \ldots \\
29 \ldots \ldots \\
30 \ldots \ldots \\
31 \ldots \ldots\end{array}$ & $\begin{array}{r}13 \\
13 \\
13 \\
13 \\
13 \\
13 \\
13 \\
13 \\
15 \\
161 \\
1,590\end{array}$ & $\begin{array}{r}54 \\
52 \\
50 \\
49 \\
48 \\
49 \\
48 \\
47 \\
---- \\
--.-- \\
-2\end{array}$ \\
\hline $\begin{array}{l}\text { onthly } \\
\text { unoff, } \\
\text { anoff, }\end{array}$ & $\begin{array}{l}\text { Inches } \\
\text { acre-f }\end{array}$ & & & & & & $\begin{array}{r}65.7 \\
2.01 \\
4,220 \\
\end{array}$ & $\begin{array}{r}171 \\
4.54 \\
9,520 \\
\end{array}$ \\
\hline
\end{tabular}

Gage helght, in feet, and discharge, in cuble feet per second, at indicated t1me, 1963

\begin{tabular}{|c|c|c|c|c|c|c|c|c|c|c|c|}
\hline Date & Hour & $\begin{array}{c}\text { Gage } \\
\text { helght }\end{array}$ & $\begin{array}{c}\text { D1s- } \\
\text { charge }\end{array}$ & Date & Hour & $\begin{array}{c}\text { Gage } \\
\text { height }\end{array}$ & $\begin{array}{c}\text { Dis- } \\
\text { charge }\end{array}$ & Date & Hour & $\begin{array}{c}\text { Gage } \\
\text { helght }\end{array}$ & $\begin{array}{c}\text { Dis- } \\
\text { charge }\end{array}$ \\
\hline $\begin{array}{r}\text { Jan. } 29 \\
30\end{array}$ & $\begin{array}{l}2400 \\
0300 \\
0400 \\
0800 \\
1200 \\
1300 \\
1500 \\
1500 \\
2000 \\
2300 \\
2400\end{array}$ & $\begin{array}{l}- \\
- \\
\overline{-} \\
\overline{-} \\
\overline{-} \\
\overline{-} \\
\overline{-}\end{array}$ & $\begin{array}{r}46 \\
66 \\
80 \\
157 \\
271 \\
267 \\
155 \\
161 \\
167 \\
159 \\
190\end{array}$ & Jan. 31 & $\begin{array}{l}0200 \\
0300 \\
0500 \\
0600 \\
0700 \\
1100 \\
1400 \\
1600 \\
1700 \\
1800 \\
2200 \\
2300 \\
2400\end{array}$ & $\begin{array}{c}- \\
- \\
- \\
- \\
- \\
6.15 \\
8.16 \\
9.32 \\
9.54 \\
8.40 \\
6.48 \\
5.95 \\
6.15\end{array}$ & $\begin{array}{r}254 \\
261 \\
427 \\
310 \\
322 \\
876 \\
2,990 \\
4,840 \\
5,220 \\
3,350 \\
1,110 \\
751 \\
876\end{array}$ & Feb. 1 & $\begin{array}{l}0300 \\
0400 \\
0500 \\
0600 \\
0700 \\
0500 \\
1000 \\
1400 \\
1700 \\
2400 \\
1200 \\
2400\end{array}$ & $\begin{array}{l}7.55 \\
9.25 \\
9.67 \\
8.75 \\
8.80 \\
9.00 \\
8.31 \\
7.06 \\
6.35 \\
5.35 \\
4.66 \\
4.29\end{array}$ & $\begin{array}{r}2,150 \\
4,720 \\
5,460 \\
4,140 \\
4,220 \\
4,560 \\
3,440 \\
1,930 \\
1,370 \\
691 \\
\\
367 \\
272 \\
\end{array}$ \\
\hline
\end{tabular}

11-2024.5. Winding Creek near Camp Nelson, Calif.

(Crest-stage station)

Location.--Lat $36^{\circ} 09^{\prime} 35^{\prime \prime}$, long $118^{\circ} 40^{\prime} 30^{\prime \prime}$, in sec.25, T.20 S., R.30 E., on State Highway 190, 4 miles northwest of Camp NeIson.

Drainage area. $--0.30 \mathrm{sq} \mathrm{mi}$.

Gage-helght record.--Crest stages only. Altitude of gage is 3,500 ft (from topographic map).

Discharge record.--Stage-discharge relation defined by current-meter measurements below 0.9 and by computation of flow through culvert at $19 \mathrm{cfs}$.

Maxima.--January-February 1963: D1scharge, $19 \mathrm{cfs}$ Feb. 1 (gage he1ght, $11.66 \mathrm{ft}$, from high-water profile). 1959 to December 1962: Discharge, $3 \mathrm{cfs}$ (estimated) Feb. 1, 1960 (gage height, $10.66 \mathrm{ft}$ ). 
11-2031. North Fork Tule River at Springville, Calif.

Location.--Lat $36^{\circ} 08^{\prime} 22^{\prime \prime}$, long $118^{\circ} 48^{\prime} 15^{\prime \prime}$, in SE $\frac{1}{4}$ sec.35, T.20 S., R.29 E., on left bank 0.1 mile upstream from Middle Fork Tule River, three-quarters of a mile northeast of Springville, and 12.9 miles northeast of Porterville.

Drainage area. $--97.6 \mathrm{sq} \mathrm{m} 1$.

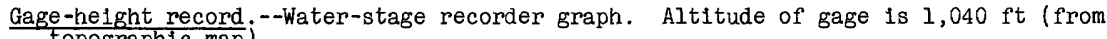
topographic map) .

Discharge record.--Stage-discharge relation defined by current-meter measurements below $2,500 \mathrm{cfs}$.

Maxima.--January-February 1963: Discharge, 4,600 cf's 1600 hours Jan. 31 (gage height, $10.29 \mathrm{ft}$ ).

1957 to December 1962: Discharge, 2,070 cfs May 19, 1957 (gage height, $9.27 \mathrm{ft}$.

Remarks.--Records furnished by California Department of Water Resources and reviewed by Geological Survey.

Mean discharge, in cublc feet per second, 1963

\begin{tabular}{|c|c|c|c|c|c|c|c|c|}
\hline Day & January & February & Day & January & February & Day & January & February \\
\hline $\begin{array}{c}1 \ldots \ldots \\
2 \ldots \ldots \\
3 \ldots \ldots \\
5 \ldots \ldots \\
6 \ldots \ldots \\
7 \ldots \ldots \\
5 \ldots \ldots \\
10 \ldots \ldots\end{array}$ & $\begin{array}{l}1.4 \\
1.3 \\
1.1 \\
.7 \\
.6 \\
.5 \\
.5 \\
.5 \\
.5 \\
.5\end{array}$ & $\begin{array}{r}2,000 \\
396 \\
153 \\
92 \\
72 \\
60 \\
50 \\
43 \\
42 \\
153\end{array}$ & $\begin{array}{l}11 \ldots \ldots \\
12 \ldots \ldots \\
13 \ldots \ldots \\
14 \ldots \ldots \\
15 \ldots \ldots \\
16 \ldots \ldots \\
17 \ldots \ldots \\
15 \ldots \ldots \\
19 \ldots \ldots \\
20 \ldots \ldots\end{array}$ & $\begin{array}{l}0.5 \\
.5 \\
.5 \\
.5 \\
.5 \\
.5 \\
.5 \\
.5 \\
.5 \\
.8\end{array}$ & $\begin{array}{r}104 \\
83 \\
73 \\
75 \\
72 \\
60 \\
54 \\
45 \\
45 \\
42\end{array}$ & $\begin{array}{l}21 \ldots \ldots \\
22 \ldots \ldots \\
23 \ldots \ldots \\
24 \ldots \ldots \\
25 \ldots \ldots \\
26 \ldots \ldots \\
27 \ldots \ldots \\
28 \ldots \ldots \\
29 \ldots \ldots \\
30 \ldots \ldots \\
31 \ldots \ldots\end{array}$ & $\begin{array}{r}1.0 \\
1.0 \\
1.1 \\
.9 \\
.7 \\
.6 \\
.6 \\
.6 \\
127 \\
1,770\end{array}$ & $\begin{array}{r}41 \\
3 \mathrm{~S} \\
35 \\
34 \\
32 \\
30 \\
29 \\
27 \\
--- \\
-\ldots--\end{array}$ \\
\hline $\begin{array}{l}\text { onthly } \\
\text { unoff, } \\
\text { unoff }\end{array}$ & $\begin{array}{l}\text { an di } \\
\text { Inch } \\
\text { acre }\end{array}$ & & & & & & $\begin{array}{r}61.5 \\
0.73 \\
3,800\end{array}$ & $\begin{array}{r}143 \\
1.53 \\
7,960\end{array}$ \\
\hline
\end{tabular}

Gage height, in feet, and discharge, in cublc feet per second, at indicated time, 1963

\begin{tabular}{|c|c|c|c|c|c|c|c|c|c|c|c|}
\hline Date & Hour & $\begin{array}{c}\text { Gage } \\
\text { helght }\end{array}$ & $\begin{array}{l}\text { Dis - } \\
\text { charge }\end{array}$ & Date & Hour & $\begin{array}{c}\text { Gage } \\
\text { helght }\end{array}$ & $\begin{array}{c}\text { D1s - } \\
\text { charge }\end{array}$ & Date & Hour & $\begin{array}{c}\text { Gage } \\
\text { helght }\end{array}$ & $\begin{array}{c}\text { Dis- } \\
\text { charge }\end{array}$ \\
\hline $\begin{array}{r}\text { Jan. } 29 \\
30\end{array}$ & $\begin{array}{l}2400 \\
0900 \\
1000 \\
1400 \\
1500 \\
1600 \\
1900 \\
2400 \\
0300 \\
0500\end{array}$ & $\begin{array}{l}4.13 \\
4.42 \\
5.15 \\
5.45 \\
6.40 \\
6.47 \\
6.15 \\
6.21 \\
6.12 \\
6.52\end{array}$ & $\begin{array}{r}5.5 \\
15 \\
64 \\
96 \\
309 \\
333 \\
242 \\
251 \\
296 \\
444\end{array}$ & Feb. 1 & $\begin{array}{l}1000 \\
1200 \\
1400 \\
1600 \\
1800 \\
2100 \\
2400 \\
\\
0100 \\
0400 \\
0500 \\
0600\end{array}$ & $\begin{array}{r}6.88 \\
7.73 \\
9.60 \\
10.29 \\
9.98 \\
9.00 \\
8.28 \\
8.12 \\
8.62 \\
9.20 \\
9.90\end{array}$ & $\begin{array}{r}612 \\
1,160 \\
3,370 \\
4,600 \\
4,020 \\
2,490 \\
1,660 \\
1,500 \\
2,020 \\
2,760 \\
3,870\end{array}$ & Feb. 1 & $\begin{array}{l}0800 \\
0900 \\
1200 \\
1700 \\
2400 \\
\\
0600 \\
1200 \\
1800 \\
2400\end{array}$ & $\begin{array}{l}9.39 \\
9.52 \\
8.52 \\
8.00 \\
7.29 \\
\\
6.91 \\
6.60 \\
6.35 \\
6.18\end{array}$ & $\begin{array}{r}3,040 \\
3,240 \\
2,260 \\
1,390 \\
849 \\
\\
509 \\
380 \\
293 \\
242\end{array}$ \\
\hline
\end{tabular}

11-2032. Tule River near Springville, Callf.

Location.--Lat $36^{\circ} 05^{\prime} 41^{\prime \prime}$, long $118^{\circ} 50^{\prime} 09^{\prime \prime}$, in SE $\frac{1}{4} S W \frac{1}{4}$ sec.15, T.21 S., R.29 E., on left bank $15 \mathrm{ft}$ upstream from highway bridge, 2 miles southwest of Springville, and 4 miles downstream from North Fork.

Drainage area. $--225 \mathrm{sq} \mathrm{mi}$.

Gage-helght record.--Water-stage recorder graph. Altitude of gage is $800 \mathrm{ft}$ (from topographic map).

Discharge record.--Stage-discharge relation defined by current-meter measurements below 7,400 cfs.

Maxima.--January-February 1963: Discharge, 10,100 cfs 1800 hours Jan. 31 (gage helght, $10.80 \mathrm{ft}$ ).

1955 to December 1962: Discharge, about 21,000 cf's December 1955 (gage helght, $13.7 \mathrm{ft}$, from floodmarks), from drainage-area-runoff comparison. 
Mean discharge, in cublc feet per second, 1963, of Thle River near Springville, Cal1f.

\begin{tabular}{|c|c|c|c|c|c|c|c|c|}
\hline Day & January & February & Day & January & February & Day & January & February \\
\hline $\begin{array}{c}1 \ldots \ldots \\
2 \ldots \ldots \\
3 \ldots \ldots \\
4 \ldots \ldots \\
5 \ldots \ldots \\
7 \ldots \ldots \\
8 \ldots \ldots \\
9 \ldots \ldots \\
10 \ldots \ldots\end{array}$ & $\begin{array}{l}17 \\
17 \\
18 \\
16 \\
16 \\
16 \\
16 \\
16 \\
17 \\
18\end{array}$ & $\begin{array}{r}4,930 \\
1,130 \\
599 \\
400 \\
292 \\
241 \\
215 \\
191 \\
161 \\
427\end{array}$ & $\begin{array}{l}11 \ldots \ldots \\
12 \ldots \ldots \\
13 \ldots \ldots \\
14 \ldots \ldots \\
15 \ldots \ldots \\
16 \ldots \ldots \\
17 \ldots \ldots \\
18 \ldots \ldots \\
19 \ldots \ldots \\
20 \ldots \ldots\end{array}$ & $\begin{array}{l}17 \\
18 \\
15 \\
15 \\
15 \\
17 \\
15 \\
14 \\
16 \\
17\end{array}$ & $\begin{array}{l}330 \\
257 \\
237 \\
241 \\
221 \\
191 \\
174 \\
161 \\
148 \\
145\end{array}$ & $\begin{array}{l}21 \ldots \ldots \\
22 \ldots \ldots \\
23 \ldots \ldots \\
24 \ldots \ldots \\
25 \ldots \ldots \\
26 \ldots \ldots \\
27 \ldots \ldots \\
28 \ldots \ldots \\
29 \ldots \ldots \\
30 \ldots \ldots \\
31 \ldots \ldots\end{array}$ & $\begin{array}{r}17 \\
17 \\
17 \\
17 \\
16 \\
16 \\
16 \\
16 \\
16 \\
477 \\
4,110\end{array}$ & $\begin{array}{r}139 \\
131 \\
123 \\
115 \\
110 \\
105 \\
105 \\
100 \\
---- \\
---.-\end{array}$ \\
\hline & acre-f & & & & & & $\begin{array}{r}163 \\
0.84 \\
10,040\end{array}$ & $\begin{array}{r}415 \\
1.92 \\
23,050\end{array}$ \\
\hline
\end{tabular}

Gage height, in feet, and discharge, in cublc feet per second, at indicated time, 1963

\begin{tabular}{|c|c|c|c|c|c|c|c|c|c|c|c|}
\hline Date & Hour & $\begin{array}{c}\text { Gage } \\
\text { height }\end{array}$ & $\begin{array}{l}\text { Dis- } \\
\text { charge }\end{array}$ & Date & Hour & $\begin{array}{c}\text { Gage } \\
\text { helght }\end{array}$ & $\begin{array}{c}\text { D1s- } \\
\text { charge }\end{array}$ & Date & Hour & $\begin{array}{c}\text { Gage } \\
\text { helght }\end{array}$ & $\begin{array}{l}\text { Dis- } \\
\text { charge }\end{array}$ \\
\hline $\begin{array}{r}\text { Jan. } 28 \\
29\end{array}$ & $\begin{array}{l}2400 \\
1200 \\
1400 \\
2400 \\
0700 \\
0800 \\
1000 \\
1200 \\
1400 \\
1600 \\
2100 \\
2400\end{array}$ & $\begin{array}{l}3.08 \\
3.09 \\
3.04 \\
3.13 \\
3.34 \\
3.72 \\
4.17 \\
4.54 \\
4.83 \\
5.22 \\
4.86 \\
4.87\end{array}$ & $\begin{array}{r}16 \\
17 \\
13 \\
20 \\
47 \\
477 \\
1325 \\
529 \\
724 \\
1,060 \\
748 \\
756\end{array}$ & Feb. 1 & $\begin{array}{l}0200 \\
0500 \\
0900 \\
1100 \\
1200 \\
1400 \\
1600 \\
1800 \\
2000 \\
2200 \\
2400 \\
0100 \\
0400\end{array}$ & $\begin{array}{r}4.85 \\
5.18 \\
6.00 \\
6.56 \\
7.39 \\
9.24 \\
10.38 \\
10.80 \\
9.33 \\
8.13 \\
7.27 \\
7.17 \\
8.00\end{array}$ & $\begin{array}{r}740 \\
1,020 \\
1,840 \\
2,430 \\
3,500 \\
6,650 \\
9,090 \\
10,100 \\
6,830 \\
4,640 \\
3,330 \\
3,190 \\
4,430\end{array}$ & Feb. 1 & $\begin{array}{l}0600 \\
0700 \\
0900 \\
1100 \\
1600 \\
1900 \\
2400 \\
\\
0600 \\
1200 \\
1800 \\
2400\end{array}$ & $\begin{array}{r}10.20 \\
9.95 \\
10.04 \\
9.55 \\
7.65 \\
6.95 \\
6.14 \\
5.69 \\
5.32 \\
5.05 \\
4.89\end{array}$ & $\begin{array}{r}8,690 \\
8,140 \\
8,340 \\
7,280 \\
3,880 \\
2,880 \\
1,870 \\
1,390 \\
1,040 \\
810 \\
693\end{array}$ \\
\hline
\end{tabular}

11-2045. South Fork Tule River near Success, Calif.

Location.--Lat $36^{\circ} 02^{\prime} 30^{\prime \prime}$, long $118^{\circ} 51^{\prime} 25^{\prime \prime}$, In NW $\frac{1}{4}$ SW $\frac{1}{4}$ sec.4, T.22 S., R.29 E., on left bank $0.5 \mathrm{mile}$ upstream from Crew Creek, $4 \mathrm{miles}$ southeast of Success, and 5 miles upstream from mouth.

Drainage area. --109 sq $\mathrm{m} 1$.

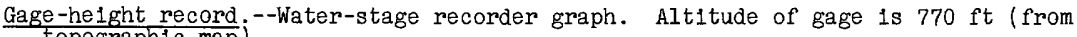
topographic map) .

D1scharge record.--Stage-discharge relation defined by current-meter measurements below $3,100 \mathrm{cfs}$ and by slope-area measurement at 7,100 cf's.

Maxima $7.75 \mathrm{ft})$

1930-54, 1956 to December 1962: Discharge, 7,100 cfs Nov. 19, 1950 (gage he1ght, $11.36 \mathrm{ft}$ ).

Mean discharge, in cublc feet per second, 1963

\begin{tabular}{|c|c|c|c|c|c|c|c|c|}
\hline Day & January & February & Day & January & February & Day & January & February \\
\hline $\begin{array}{c}1 \ldots \ldots \\
3 \ldots \ldots \\
4 \ldots \ldots \\
5 \ldots \ldots \\
6 \ldots \ldots \\
8 \ldots \ldots \\
9 \ldots \ldots \\
10 \ldots\end{array}$ & $\begin{array}{l}1.8 \\
1.8 \\
1.9 \\
1.9 \\
2.5 \\
5.0 \\
5.0 \\
5.0 \\
4.7 \\
4.7\end{array}$ & $\begin{array}{r}932 \\
208 \\
94 \\
63 \\
48 \\
38 \\
35 \\
31 \\
31 \\
103\end{array}$ & $\begin{array}{l}11 \ldots \ldots \\
12 \ldots \ldots \\
13 \ldots \ldots \\
14 \ldots \ldots \\
15 \ldots \ldots \\
16 \ldots \ldots \\
17 \ldots \ldots \\
18 \ldots \ldots \\
19 \ldots \ldots \\
20 \ldots \ldots\end{array}$ & $\begin{array}{l}4.1 \\
1.9 \\
1.6 \\
1.1 \\
1.3 \\
1.8 \\
1.8 \\
1.6 \\
2.3 \\
3.6\end{array}$ & $\begin{array}{l}91 \\
68 \\
62 \\
68 \\
57 \\
47 \\
41 \\
37 \\
34 \\
33\end{array}$ & $\begin{array}{l}21 \ldots \ldots \\
22 \ldots \ldots \\
23 \ldots \ldots \\
24 \ldots \ldots \\
25 \ldots \ldots \\
26 \ldots \ldots \\
27 \ldots \ldots \\
28 \ldots \ldots \\
29 \ldots \ldots \\
30 \ldots \ldots \\
31 \ldots \ldots\end{array}$ & $\begin{array}{r}3.6 \\
3.9 \\
3.9 \\
4.1 \\
4.7 \\
4.7 \\
4.7 \\
4.7 \\
4.7 \\
87 \\
493\end{array}$ & $\begin{array}{r}31 \\
30 \\
27 \\
25 \\
23 \\
23 \\
23 \\
21 \\
-\ldots-.--\end{array}$ \\
\hline \multicolumn{7}{|l|}{$\begin{array}{l}\text { Monthly } \\
\text { Runoff, } \\
\text { Runoff, }\end{array}$} & $\begin{array}{r}21.8 \\
0.23 \\
1,340\end{array}$ & $\begin{array}{r}83.0 \\
0.79 \\
4,610 \\
\end{array}$ \\
\hline
\end{tabular}


Gage height, in feet, and discharge, in cub1c feet per second, at indicated time, I963, of South Fork Tule River near Success, Calif.

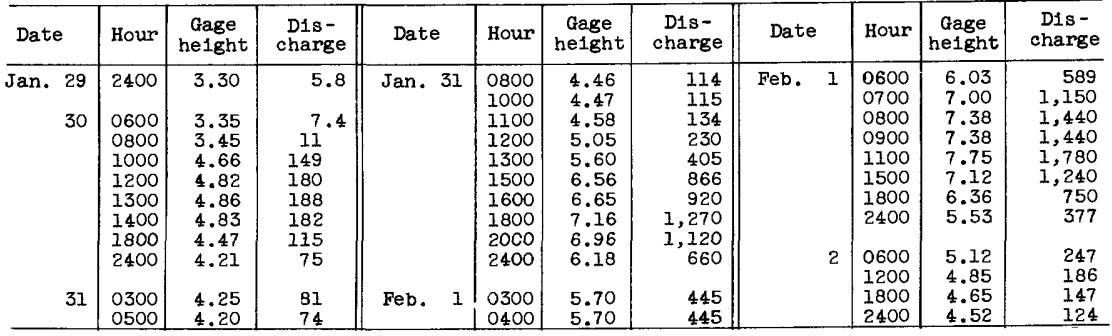

11-2047. Lake Success near Success, Cal1f.

(Formerly published as Success Reservoir near Success, Calif.

Location.--Lat $36^{\circ} 03^{\prime} 40^{\prime \prime}$, long $118^{\circ} 55^{\prime} 18^{\prime \prime}$, in $\mathrm{SE} \frac{1}{4} \mathrm{NW} \frac{1}{4}$ sec.35, T.21 S., R.28 E., in control tower near right abutment of Success Dam on Tule River, 5 miles east of Porterville.

Drainage area. $--391 \mathrm{sq} \mathrm{mi}$.

Gage-he1ght record.--Water-stage recorder graph. Datum of gage is at mean sea level, datum of 1929 (levels by Corps of Engineers).

Contents record.--Contents computed from capacity table dated 0ct. 16, 1962.

Maxima,--January-February 1963: Computed bihourly inflow, 12,100 efs 0800 to 1000 hours Feb. 1. Contents, 25,300 acre-ft 2000 hours Feb. 2 to 1800 hours Feb. 3 (elevation, $613.60 \mathrm{ft}$ ).

1961 to December 1962: Contents, 29,000 acre-ft June 4-21, 1962; elevation, 617.52 ft June 7,8 .

Remarks.--Lake is formed by earthfill dam and dike. Storage began November 1961. Usable capacity, 83,900 acre-ft, between elevations $559.0 \mathrm{ft}$ (invert of outlet structure) and $652.5 \mathrm{ft}$ (spillway crest). Spillway design flood pool elevation, $686.8 \mathrm{ft}$ (capac1ty, 205,500 acre-ft). No dead storage. Records furnished by Corps of Engineers.

Elevation, in feet, and contents, in acre-feet, at 2400 hours, 1963

\begin{tabular}{|c|c|c|c|c|c|c|c|c|c|}
\hline \multirow{2}{*}{ Day } & \multicolumn{2}{|c|}{ January } & \multicolumn{2}{|c|}{ February } & \multirow{2}{*}{ Day } & \multicolumn{2}{|c|}{ January } & \multicolumn{2}{|c|}{ February } \\
\hline & Elevation & Contents & Elevation & Contents & & Elevation & Contents & Elevation & Contents \\
\hline $\begin{array}{r}1 \\
2 \\
3 \\
4 \\
5 \\
6 \\
7 \\
8 \\
9 \\
10 \\
11 \\
12 \\
13 \\
14 \\
15\end{array}$ & $\begin{array}{l}588.90 \\
588.91 \\
588.91 \\
588.90 \\
588.88 \\
588.87 \\
588.86 \\
588.87 \\
588.88 \\
588.88 \\
588.89 \\
588.88 \\
588.87 \\
588.87 \\
588.87\end{array}$ & $\begin{array}{l}7,730 \\
7,740 \\
7,740 \\
7,730 \\
7,720 \\
7,720 \\
7,710 \\
7,720 \\
7,720 \\
7,720 \\
7,730 \\
7,720 \\
7,720 \\
7,720 \\
7,720\end{array}$ & $\begin{array}{l}612.07 \\
613.57 \\
613.43 \\
612.90 \\
612.17 \\
611.19 \\
610.05 \\
608.84 \\
607.69 \\
607.38 \\
606.79 \\
605.88 \\
604.87 \\
603.85 \\
602.65\end{array}$ & $\begin{array}{l}23,900 \\
25,300 \\
25,200 \\
24,700 \\
24,000 \\
23,200 \\
22,200 \\
21,200 \\
20,200 \\
20,000 \\
19,500 \\
18,800 \\
18,000 \\
17,200 \\
16,300\end{array}$ & $\begin{array}{l}16 \\
17 \\
18 \\
19 \\
20 \\
21 \\
22 \\
23 \\
24 \\
25 \\
26 \\
27 \\
28 \\
29 \\
30 \\
31\end{array}$ & $\begin{array}{l}588.88 \\
588.88 \\
588.89 \\
588.88 \\
588.88 \\
588.88 \\
588.88 \\
588.88 \\
588.88 \\
588.88 \\
588.88 \\
588.88 \\
588.88 \\
588.91 \\
589.76 \\
598.46\end{array}$ & $\begin{array}{r}7,720 \\
7,720 \\
7,730 \\
7,720 \\
7,720 \\
7,720 \\
7,720 \\
7,720 \\
7,720 \\
7,720 \\
7,720 \\
7,720 \\
7,720 \\
7,740 \\
8,180 \\
13,400\end{array}$ & $\begin{array}{c}601.30 \\
599.86 \\
599.60 \\
599.87 \\
600.05 \\
600.35 \\
600.75 \\
601.16 \\
601.55 \\
601.97 \\
602.32 \\
602.69 \\
603.05 \\
- \\
- \\
-\end{array}$ & $\begin{array}{c}15,300 \\
14,300 \\
14,100 \\
14,300 \\
14,500 \\
14,700 \\
14,900 \\
15,200 \\
15,500 \\
15,800 \\
16,100 \\
16,300 \\
16,600 \\
- \\
- \\
-\end{array}$ \\
\hline an & In cont & , in a & & & & - & $+5,670$ & - & $+3,200$ \\
\hline
\end{tabular}


Average inflow, in cublc feet per second, for bihourly perlods ending at indicated time, 1963, of Lake Success near Success, Cal1f.

\begin{tabular}{|c|c|c|c|c|c|c|c|c|}
\hline Date & Hour & Inflow & Date & Hour & Inflow & Date & Hour & Inflow \\
\hline Jan. 30 & $\begin{array}{l}0200 \\
0400 \\
0600 \\
0800 \\
1000 \\
1200 \\
1400 \\
1600 \\
1800 \\
2000 \\
2200 \\
2400 \\
\\
0200 \\
0400 \\
0600 \\
0800\end{array}$ & $\begin{array}{r}44 \\
44 \\
14 \\
44 \\
44 \\
165 \\
415 \\
637 \\
681 \\
689 \\
729 \\
723 \\
638 \\
632 \\
753 \\
856\end{array}$ & $\begin{array}{l}\text { Jan. } 31 \\
\text { Feb. } 1\end{array}$ & $\begin{array}{l}1000 \\
1200 \\
1400 \\
1600 \\
1800 \\
2000 \\
2200 \\
2400 \\
\\
0200 \\
0400 \\
0600 \\
0800 \\
1000 \\
1200 \\
1400 \\
1600\end{array}$ & $\begin{array}{r}1,160 \\
1,550 \\
2,630 \\
4,770 \\
8,110 \\
12,000 \\
8,130 \\
6,450 \\
4,400 \\
4,120 \\
5,260 \\
8,690 \\
12,100 \\
8,090 \\
8,550 \\
6,910\end{array}$ & Feb. 1 & $\begin{array}{l}1800 \\
2000 \\
2200 \\
2400 \\
\\
0200 \\
0400 \\
0600 \\
0800 \\
1000 \\
1200 \\
1400 \\
1600 \\
1800 \\
2000 \\
2200 \\
2400\end{array}$ & $\begin{array}{r}5,090 \\
3,870 \\
3,170 \\
2,810 \\
2,240 \\
2,240 \\
1,490 \\
1,540 \\
1,450 \\
1,320 \\
1,150 \\
1,140 \\
984 \\
1,030 \\
984 \\
814\end{array}$ \\
\hline
\end{tabular}

11-2049. Tule River below Success Dam, Calif.

Location.--Lat $36^{\circ} 03^{\prime} 23^{\prime \prime}$, long $118^{\circ} 55^{\prime} 22^{\prime \prime}$, in SW $\frac{1}{4} 8 e c .35$, T.21 S., R.28 E. on right bank $i, 000 \mathrm{ft}$ downstream from Success Dam and 5 miles east of Portervilie.

Drainage area. $--393 \mathrm{sq} \mathrm{mi}$.

Gage-height record.--Water-stage recorder graph. Datum of gage is $536.00 \mathrm{ft}$ above mean sea level, datum of 1929 (levels by Corps of Engineers).

Discharge record.--Stage-discharge relation defined by current-meter measurements below 1,200 cis.

Max1ma.--January-February 1963: Discharge, 2,980 cfs 1600 hours Jan. 31 (gage he1ght, $9.25 \mathrm{ft}$ )

1953 to December 1962: Discharge, 27,000 cfs Dec. 23, 1955 (gage height, $21.65 \mathrm{ft}$, at site $0.5 \mathrm{mile}$ downstream and datum then in use).

Remarks.--FIow regulated by Lake Success beginning Nov. 23, 1961.

Mean discharge, in cubic feet per second, 1963

\begin{tabular}{|c|c|c|c|c|c|c|c|c|}
\hline Day & January & February & Day & January & February & Day & January & February \\
\hline $\begin{array}{c}1 \ldots \ldots \\
2 \ldots \ldots \\
4 \ldots \ldots \\
5 \ldots \ldots \\
6 \ldots \ldots \\
8 \ldots \ldots \\
9 \ldots \ldots \\
10 \ldots \ldots\end{array}$ & $\begin{array}{l}13 \\
13 \\
14 \\
17 \\
17 \\
16 \\
15 \\
13 \\
12 \\
12\end{array}$ & $\begin{array}{l}768 \\
675 \\
740 \\
680 \\
680 \\
720 \\
740 \\
735 \\
720 \\
680\end{array}$ & $\begin{array}{l}11 \ldots \ldots \\
12 \ldots \ldots \\
13 \ldots \ldots \\
14 \ldots \ldots \\
15 \ldots \ldots \\
16 \ldots \ldots \\
17 \ldots \ldots \\
18 \ldots \ldots \\
19 \ldots \ldots \\
20 \ldots \ldots\end{array}$ & $\begin{array}{l}12 \\
12 \\
12 \\
11 \\
10 \\
10 \\
10 \\
11 \\
12 \\
12\end{array}$ & $\begin{array}{r}680 \\
710 \\
725 \\
710 \\
745 \\
760 \\
750 \\
317 \\
90 \\
101\end{array}$ & $\begin{array}{l}21 \ldots \ldots \\
22 \ldots \ldots \\
23 \ldots \ldots \\
24 \ldots \ldots \\
25 \ldots \ldots \\
26 \ldots \ldots \\
27 \ldots \ldots \\
28 \ldots \ldots \\
29 \ldots \ldots \\
30 \ldots \ldots \\
31 \ldots \ldots\end{array}$ & $\begin{array}{r}12 \\
12 \\
12 \\
12 \\
13 \\
14 \\
14 \\
14 \\
14 \\
143 \\
1,360\end{array}$ & $\begin{array}{r}64 \\
25 \\
14 \\
9.9 \\
6.9 \\
4.3 \\
3.5 \\
3.6 \\
-----. \\
--.--\end{array}$ \\
\hline $\begin{array}{l}\text { Monthly } \\
\text { Runoff, }\end{array}$ & \multicolumn{6}{|c|}{ 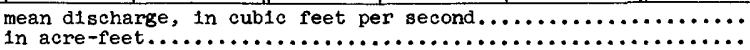 } & $\begin{array}{r}60.5 \\
3,720\end{array}$ & 25,500 \\
\hline
\end{tabular}

Gage he1ght, in feet, and discharge, in cub1c feet per second, at indicated t1me, 1963

\begin{tabular}{|c|c|c|c|c|c|c|c|c|c|c|c|}
\hline Date & Hour & $\begin{array}{c}\text { Gage } \\
\text { helght }\end{array}$ & $\begin{array}{l}\text { D1s- } \\
\text { charge }\end{array}$ & Date & Hour & $\begin{array}{c}\text { Gage } \\
\text { helght }\end{array}$ & $\begin{array}{l}\text { D1s- } \\
\text { charge }\end{array}$ & Date & Hour & $\begin{array}{c}\text { Gage } \\
\text { he1ght }\end{array}$ & $\begin{array}{c}\text { D1s - } \\
\text { charge }\end{array}$ \\
\hline $\begin{array}{r}\text { Jan. } 29 \\
30\end{array}$ & $\begin{array}{l}2400 \\
1600 \\
1700 \\
1800 \\
1900 \\
2000 \\
2400\end{array}$ & $\begin{array}{l}2.21 \\
2.19 \\
4.52 \\
4.70 \\
4.71 \\
6.25 \\
6.25\end{array}$ & $\begin{array}{r}14 \\
13 \\
149 \\
176 \\
178 \\
602 \\
602\end{array}$ & $\operatorname{Jan} .31$ & $\begin{array}{l}0900 \\
0900 \\
1200 \\
1400 \\
1500 \\
1600 \\
1600 \\
1800 \\
1900\end{array}$ & $\begin{array}{l}6.26 \\
7.85 \\
7.91 \\
7.91 \\
8.81 \\
8.81 \\
9.25 \\
9.14 \\
9.16\end{array}$ & $\begin{array}{r}607 \\
1,560 \\
1,610 \\
1,610 \\
2,450 \\
2,450 \\
2,980 \\
2,850 \\
2,870\end{array}$ & $\begin{array}{l}\text { Jan. } 31 \\
\text { Feb. } 2\end{array}$ & $\begin{array}{l}2000 \\
2100 \\
2100 \\
2400 \\
1200 \\
1300 \\
1400 \\
2400\end{array}$ & $\begin{array}{l}7.45 \\
7.47 \\
6.97 \\
6.90 \\
7.02 \\
6.18 \\
6.14 \\
6.17\end{array}$ & $\begin{array}{r}1,260 \\
1,280 \\
962 \\
920 \\
992 \\
572 \\
556 \\
568\end{array}$ \\
\hline
\end{tabular}


11-2049.5. Tule River tributary near Success, Calif.

(Crest-stage station)

Location.--Lat $36^{\circ} 03^{\prime} 27^{\prime \prime}$, long $118^{\circ} 54^{\prime} 48^{\prime \prime}$, in $\mathrm{NE} \frac{1}{4} \mathrm{SE} \frac{1}{4} \mathrm{sec} .35$, T.21 S., R.28 E., on State Highway $190,1.8$ miles south of Success.

Drainage area. $--1.13 \mathrm{sq} \mathrm{ml}$.

Gage-helght record.--Crest stages only. Altitude of gage is $630 \mathrm{ft}$ (from topographic map).

Discharge record.--Maximum discharge by computation of flow through culvert.

Maxima.--January-February 1963: D1scharge, $0.1 \mathrm{cfs} F e b .1$ (gage he1ght not determined)

1959 to December 1962: Discharge, 8 cfs Mar. 6, 1962 (gage height, $11.76 \mathrm{ft}$ ).

11-2065. Middle Fork Kaweah River near Potwisha Camp, Calif.

Location. --Lat $36^{\circ} 30^{\prime} 45^{\prime \prime}$, long $118^{\circ} 47^{\prime} 25^{\prime \prime}$, in NW/ sec.25, T.16 S., R.29 E., on right bank $0.7 \mathrm{mlle}$ southeast of Potwisha Camp and 0.9 mile upstream from confluence with Marble Fork Kaweah River.

Drainage area. $--102 \mathrm{sq} \mathrm{mi}$.

Gage-he1ght record.--Water-stage recorder graph. Altitude of gage is 2,100 ft (from topographic map).

D1scharge record.--Stage-discharge relation defined by current-meter measurements below $920 \mathrm{cfs}$ and by slope-area measurements at 17,500 and 46,800 cfs.

Maxima,--January-February 1963: D1scharge, 11,800 cfs 0330 hours Feb. 1 (gage height, $13.52 \mathrm{ft}$ ).

1949 to December 1962: Discharge, 46,800 cfs Dec. 23, 1955 (gage height, $29.0 \mathrm{ft}$, from floodmarks, at datum 0.70 ft higher), by slope-area measurement of maximum flow.

Remarks.--Middle Fork Kaweah River No. 3 condult diverts 0.5 mile above station. AIl discharge figures are the combined flow of Middle Fork Kaweah River and Middle Fork Kawea River No. 3 conduit, although diversion is insignificant during floodflow.

Mean discharge, in cub1c feet per second, 1963

\begin{tabular}{|c|c|c|c|c|c|c|c|c|}
\hline Day & January & February & Day & January & February & Day & $J$ anuary & February \\
\hline $\begin{array}{c}1 \ldots \ldots \\
2 \ldots \ldots \\
3 \ldots \ldots \\
4 \ldots \ldots \\
5 \ldots \ldots \\
7 \ldots \ldots \\
8 \ldots \ldots \\
9 \ldots \ldots \\
10 \ldots \ldots\end{array}$ & $\begin{array}{l}13 \\
13 \\
13 \\
13 \\
13 \\
13 \\
13 \\
13 \\
13 \\
13\end{array}$ & $\begin{array}{r}5,650 \\
1,090 \\
596 \\
388 \\
303 \\
260 \\
231 \\
214 \\
202 \\
253\end{array}$ & $\begin{array}{l}11 \ldots \ldots \\
12 \ldots \ldots \\
13 \ldots \ldots \\
14 \ldots \ldots \\
15 \ldots \ldots \\
16 \ldots \ldots \\
17 \ldots \ldots \\
18 \ldots \ldots \\
19 \ldots \ldots \\
20 \ldots \ldots\end{array}$ & $\begin{array}{l}13 \\
9.3 \\
10 \\
22 \\
15 \\
13 \\
12 \\
13 \\
12 \\
12\end{array}$ & $\begin{array}{l}203 \\
177 \\
175 \\
169 \\
151 \\
141 \\
132 \\
139 \\
141 \\
135\end{array}$ & $\begin{array}{l}21 \ldots \ldots \\
22 \ldots \ldots \\
23 \ldots \ldots \\
24 \ldots \ldots \\
25 \ldots \ldots \\
26 \ldots \ldots \\
27 \ldots \ldots \\
25 \ldots \ldots \\
29 \ldots \ldots \\
30 \ldots \ldots \\
31 \ldots \ldots\end{array}$ & $\begin{array}{r}12 \\
12 \\
12 \\
13 \\
12 \\
12 \\
12 \\
12 \\
15 \\
648 \\
3,600\end{array}$ & $\begin{array}{r}132 \\
127 \\
121 \\
122 \\
122 \\
134 \\
150 \\
141 \\
---1- \\
---1-\end{array}$ \\
\hline \multicolumn{7}{|l|}{$\begin{array}{l}\text { Monthly } \\
\text { Runoff, } \\
\text { Runoff, }\end{array}$} & $\begin{array}{r}149 \\
1.68 \\
9,170\end{array}$ & $\begin{array}{r}422 \\
4.31 \\
23,460\end{array}$ \\
\hline
\end{tabular}

Gage he1ght, in feet, and discharge, in cubsc feet per second, at indicated time, 1963

\begin{tabular}{|c|c|c|c|c|c|c|c|c|c|c|c|}
\hline Date & Hour & $\begin{array}{c}\text { Gage } \\
\text { he1ght }\end{array}$ & $\begin{array}{c}\text { Dis- } \\
\text { charge }\end{array}$ & Date & Hour & $\begin{array}{c}\text { Gage } \\
\text { helght }\end{array}$ & $\begin{array}{c}\text { Dis- } \\
\text { charge }\end{array}$ & Date & Hour & $\begin{array}{c}\text { Gage } \\
\text { helght }\end{array}$ & $\begin{array}{c}\text { D1s- } \\
\text { charge }\end{array}$ \\
\hline $\begin{array}{r}\text { Jan. } \\
30\end{array}$ & $\begin{array}{l}2400 \\
0100 \\
0200 \\
0300 \\
0400 \\
0500 \\
0700 \\
1100 \\
1300 \\
1400 \\
1800 \\
2000 \\
2100 \\
2200 \\
2400 \\
0200\end{array}$ & $\begin{array}{l}- \\
\overline{-} \\
\overline{-} \\
\overline{-} \\
\overline{-} \\
\overline{-} \\
\overline{-} \\
\overline{-} \\
-\end{array}$ & $\begin{array}{r}29 \\
72 \\
115 \\
177 \\
297 \\
404 \\
546 \\
937 \\
854 \\
937 \\
754 \\
701 \\
777 \\
765 \\
946 \\
1,120\end{array}$ & Feb. 1 & $\begin{array}{l}0300 \\
0400 \\
0800 \\
1000 \\
1300 \\
1400 \\
1500 \\
1600 \\
1700 \\
1800 \\
1900 \\
2100 \\
2300 \\
2400 \\
0100 \\
0200 \\
0330\end{array}$ & $\begin{array}{c}- \\
- \\
- \\
- \\
9.32 \\
10.12 \\
10.88 \\
12.11 \\
13.13 \\
12.08 \\
12.41 \\
11.00 \\
10.12 \\
10.22 \\
10.80 \\
12.25 \\
13.52\end{array}$ & $\begin{array}{r}1,060 \\
1,280 \\
1,050 \\
1,700 \\
2,760 \\
3,840 \\
5,160 \\
7,780 \\
10,600 \\
7,700 \\
8,530 \\
5,400 \\
3,830 \\
3,990 \\
5,000 \\
8,130 \\
11,800 \\
\end{array}$ & Feb. 1 & $\begin{array}{l}0500 \\
0600 \\
0700 \\
0500 \\
1000 \\
1300 \\
1400 \\
1700 \\
2000 \\
2400 \\
0200 \\
1000 \\
1300 \\
2200 \\
2400\end{array}$ & $\begin{array}{r}12.73 \\
11.55 \\
11.95 \\
11.39 \\
12.15 \\
11.60 \\
11.00 \\
10.00 \\
8.96 \\
8.26 \\
7.97 \\
7.40 \\
7.22 \\
6.98 \\
6.85\end{array}$ & $\begin{array}{r}9,390 \\
6,560 \\
7,380 \\
6,150 \\
7,880 \\
6,600 \\
5,400 \\
3,640 \\
2,330 \\
1,680 \\
1,440 \\
1,070 \\
978 \\
858 \\
799\end{array}$ \\
\hline
\end{tabular}


11-2080. Marble Fork Kaweah Rlver at Potwlsha Camp, Cal1f.

Location. --Lat $36^{\circ} 31^{\prime} 10^{\prime \prime}$, long $118^{\circ} 48^{\prime} 10^{\prime \prime}$, in $\mathrm{SE}_{\frac{1}{4}} \mathrm{sec} .23$, T.16 S., R.29 E., on left bank 0.1 mile north of Potwisha Camp and 0.3 mile upstream from confluence with Middle Fork Kaweah River.

Drainage area. $--51.4 \mathrm{sq} \mathrm{ml}$.

Gage-height record.--Water-stage recorder graph, except Jan. 1-7. Altitude of gage is 2,150 f't (from topographic map).

Discharge record.--Stage-discharge relation defined by current-meter measurements below $250 \mathrm{cf}$ 's and by slope-area measurement at $12,500 \mathrm{cfs}$. Discharge for Jan. 1-7 estimated on basis of recorded range in stage.

Maxima.--January-Pebruary 1963: Discharge, 3,830 cfs 0500 hours Feb. I (gage height, $9.94 \mathrm{ft})$.

1950 to December 1962: Discharge, 12,500 cfs Dec. 23, 1955 (gage height, $13.4 \mathrm{ft}$ ), from rating curve extended above 1,100 $\mathrm{cfs}$ on basis of slope-area measurement of maximum flow.

Remarks.--Marble Fork Kaweah River No. 3 conduit diverts 0.3 mile above station. All discharge figures are the combined flow of Marble Fork Kaweah River and Marble Fork Kaweah River No. 3 conduit, although diversion is insignificant during floodflow.

Mean discharge, in cubic feet per second, 1963

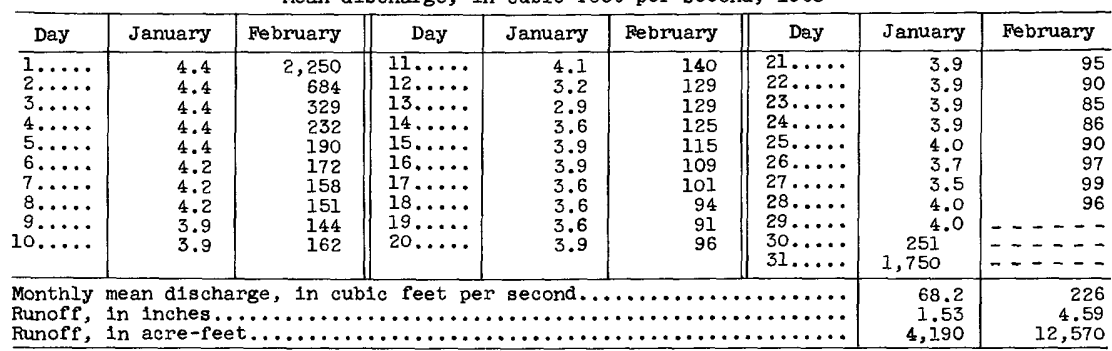

Gage height, in feet, and discharge, in cublc feet per second, at indicated t1me, 1963

\begin{tabular}{|c|c|c|c|c|c|c|c|c|c|c|c|}
\hline Date & Hour & $\begin{array}{c}\text { Gage } \\
\text { helght }\end{array}$ & $\begin{array}{c}\text { Dis- } \\
\text { charge }\end{array}$ & Date & Hour & $\begin{array}{c}\text { Gage } \\
\text { helght }\end{array}$ & $\begin{array}{c}\text { Dis- } \\
\text { charge }\end{array}$ & Pate & Hour & $\begin{array}{c}\text { Gage } \\
\text { helght }\end{array}$ & $\begin{array}{l}\text { Dis- } \\
\text { charge }\end{array}$ \\
\hline $\begin{array}{r}\text { Jan. } 29 \\
30\end{array}$ & $\begin{array}{l}2400 \\
0500 \\
0600 \\
0700 \\
0900 \\
1100 \\
1400 \\
1500 \\
1600 \\
1700 \\
1900 \\
2100 \\
2300 \\
2400\end{array}$ & $\begin{array}{l}- \\
- \\
- \\
- \\
- \\
- \\
- \\
- \\
- \\
- \\
- \\
-\end{array}$ & $\begin{array}{c}8.7 \\
22 \\
52 \\
82 \\
126 \\
167 \\
393 \\
469 \\
551 \\
517 \\
423 \\
399 \\
418 \\
517\end{array}$ & $\mathrm{~J}$ an. 31 & $\begin{array}{l}0100 \\
0400 \\
0700 \\
0800 \\
1100 \\
1400 \\
1500 \\
1600 \\
1700 \\
1800 \\
1900 \\
2100 \\
2300 \\
2400\end{array}$ & $\begin{array}{c}- \\
- \\
- \\
- \\
- \\
- \\
- \\
9.15 \\
9.44 \\
9.10 \\
9.06 \\
8.64 \\
8.16 \\
8.46\end{array}$ & $\begin{array}{r}647 \\
676 \\
1,080 \\
942 \\
1,540 \\
2,640 \\
3,280 \\
2,840 \\
3,180 \\
2,770 \\
2,720 \\
2,260 \\
1,830 \\
2,080\end{array}$ & Feb. I & $\begin{array}{l}0200 \\
0400 \\
0500 \\
0600 \\
0700 \\
1100 \\
1400 \\
2400 \\
\\
0700 \\
0800 \\
1000 \\
1400 \\
2400\end{array}$ & $\begin{array}{l}9.23 \\
9.29 \\
9.94 \\
9.56 \\
9.00 \\
8.84 \\
8.14 \\
6.67 \\
5.98 \\
5.95 \\
5.80 \\
5.39 \\
4.90\end{array}$ & $\begin{array}{r}3,000 \\
3,070 \\
3,830 \\
3,370 \\
2,750 \\
2,590 \\
1,960 \\
1,090 \\
793 \\
781 \\
721 \\
568 \\
421\end{array}$ \\
\hline
\end{tabular}


11-2085. Middle Fork Kaweah River tributary near Hammond, Calif.

\section{(Crest-stage station)}

Location.--Lat $36^{\circ} 29^{\prime} 35^{\prime \prime}$, long $118^{\circ} 49^{\prime} 30^{\prime \prime}$, In NW $\frac{1}{4} \mathrm{SW} \frac{1}{4}$ sec.34, T.16 S., R.29 E., on State Highway 198, 2.7 miles northeast of Hammond.

Drainage area. $--1.90 \mathrm{sq} \mathrm{mi}$.

Gage-height record.--Crest stages only. Alt1tude of gage is 1,700 ft (from topo- * graphic map).

Discharge record.--Stage-discharge relation defined by current-meter measurements below $2.3 \mathrm{cfs}$ and by computation of flow through culvert at $8.7,17,24$, and $152 \mathrm{cfs}$.

Maxima.--January-February 1963: Discharge, $152 \mathrm{cfs}$ Feb. 1 (gage he1ght, $18.41 \mathrm{ft}$, from high-water profile).

1959 to December 1962: D1scharge, 25 cf's Mar. 1962 (gage he1ght, $12.08 \mathrm{ft}$ ).

\section{1-2087.3. East Fork Kaweah River near Three Rivers, Calif.}

Location.--Lat $36^{\circ} 27^{\prime} 05^{\prime \prime}$, long $118^{\circ} 47^{\prime} 15^{\prime \prime}$, in NW $\frac{1}{4}$ sec.14, T.17 S., R.29 E., on left bank just downstream from diversion dam and 6.6 miles east' of Three Rivers.

Drainage area. $--85.8 \mathrm{sq} \mathrm{mi}$.

Gage-height record.-Water-stage recorder graph. Altitude of gage is $2,500 \mathrm{ft}$ (from topographic map).

Discharge record.--Stage-discharge relation defined by current-meter measurements.

Maxima (river only).--January-February 1963: Discharge, 2,850 cfs 0500 hours Feb. I (gage helght, $11.00 \mathrm{ft}$ ).

1952-55, 1957 to December 1962: Discharge, 1,270 cfs May 27, 1952 (gage height, $5.59 \mathrm{ft}$, site and datum then in use).

Maxima (river and condult).--January-February 1963: Discharge, 2,850 cfs 0500 hour's Feb. 1 .

1952-55, 1957 to December 1962: Discharge, 1,300 cfs May 27, 1952.

Remarks.--East Fork Kaweah River No. 1 conduit diverts from left bank of river near diversion dam. Mean discharge figures are the combined flow of East Fork Kaweah River and East Fork Kaweah River No. 1 condult, although diversion is insigniflcant during floodflow. Records furnished by Southern California Edison Co. and reviewed by Geological Survey.

Mean discharge, in cubic feet per second, 1963

\begin{tabular}{|c|c|c|c|c|c|c|c|c|}
\hline Day & January & February & Day & January & February & Day & January & February \\
\hline $\begin{array}{r}1 . \ldots . \\
2 \ldots \\
3 \ldots \ldots \\
4 \ldots \ldots \\
5 \ldots \ldots \\
6 \ldots \ldots \\
7 \ldots \ldots \\
9 \ldots \ldots \\
10 \ldots \ldots\end{array}$ & $\begin{array}{l}10 \\
10 \\
10 \\
10 \\
10 \\
10 \\
10 \\
10 \\
10 \\
10\end{array}$ & $\begin{array}{r}1,920 \\
665 \\
282 \\
212 \\
167 \\
131 \\
117 \\
113 \\
142 \\
159\end{array}$ & $\begin{array}{l}11 \ldots \ldots \\
12 \ldots \ldots \\
13 \ldots \ldots \\
14 \ldots \ldots \\
15 \ldots \ldots \\
16 \ldots \ldots \\
17 \ldots \ldots \\
18 \ldots \ldots \\
19 . \ldots .\end{array}$ & $\begin{array}{l}9.7 \\
7.0 \\
5.0 \\
7.5 \\
8.8 \\
8.9 \\
9.1 \\
9.2 \\
7.2 \\
7.2\end{array}$ & $\begin{array}{r}118 \\
105 \\
104 \\
96 \\
86 \\
80 \\
74 \\
72 \\
71 \\
71\end{array}$ & $\begin{array}{l}21 \ldots \ldots \\
22, \ldots . \\
23 \ldots \ldots \\
24 \ldots \ldots \\
25 \ldots \ldots \\
26 \ldots \ldots \\
27 \ldots \ldots \\
28 \ldots \ldots \\
29 \ldots \ldots \\
30 \ldots \ldots \\
31 \ldots \ldots\end{array}$ & $\begin{array}{r}8.0 \\
8.9 \\
8.9 \\
9.1 \\
9.0 \\
8.8 \\
8.8 \\
8.8 \\
10 \\
435 \\
1,390\end{array}$ & $\begin{array}{r}69 \\
67 \\
67 \\
66 \\
69 \\
71 \\
73 \\
73 \\
- \\
-0 .-0\end{array}$ \\
\hline $\begin{array}{l}\text { unoff, } \\
\text { unoff, }\end{array}$ & acre $-f$ & & & & & & $\begin{array}{r}67.3 \\
0.90 \\
4,140 \\
\end{array}$ & $\begin{array}{r}191 \\
2.31 \\
10,590 \\
\end{array}$ \\
\hline
\end{tabular}


11-2090. Dorst Creek near Kaweah Camp, Calif.

(Crest-stage station)

Location.--Lat $36^{\circ} 38^{\prime} 45^{\prime \prime}$, long $118^{\circ} 48^{\prime} 15^{\prime \prime}$, in $\mathrm{SE} \frac{1}{4} \mathrm{SW} \frac{1}{4} \sec .2, \mathrm{~T} .15 \mathrm{~S} ., \mathrm{R} .29 \mathrm{E}$. ,

6 miles northwest of Kaweah Camp.

Drainage area. $--6.11 \mathrm{sq} \mathrm{mi}$.

Gage-height record.--Crest stages only. Altitude of gage is 6,700 ft (from topographic map).

Discharge record.--Stage-discharge relation defined by current-meter measurements below $55 \mathrm{cfs}$ and by computation of flow through culvert at 108,156, and 1,540 cfs.

Maxima.--January-February 1963: Discharge, 1,540 cfs Feb. 1 (gage he1ght, $28.85 \mathrm{ft}$ ). 1959 to December 1962: Discharge, 156 of ${ }^{2}$ May 12, 1960 (gage height, $21.70 \mathrm{ft})$.

11-2099. Kaweah River at Three Rivers, Calif.

Location. --Lat $36^{\circ} 26^{\prime} 38^{\prime \prime}$, long $118^{\circ} 54^{\prime} 09^{\prime \prime}$, in SW $\frac{1}{4} S W^{\frac{1}{4}}$ sec.13, T.17 S., R.28 E., on right bank opposite schoolhouse in Three Rivers, 0.25 mile downstream from North Fork Kaweah River.

Drainage area. $--418 \mathrm{sq} \mathrm{mi}$.

Gage-he1ght record.--Water-stage recorder graph, except Feb. 2-18, 24-28. Datum of gage is $809.62 \mathrm{ft}$ above mean sea leve1, datum of 1929.

Discharge record.--Stage-discharge relation defined by current-meter measurements below 6,000 cfs and by slope-area measurement at $30,900 \mathrm{cfs}$. Discharge Feb. 2-18, 24-28, estimated on basis of 2 discharge measurements, 11 outside gage-height observations, and comparison with South Fork Kaweah at Three Rivers.

Maxima.--January-February 1963: Discharge, 30,900 cfs 0400 hours Feb. 1 (gage helght, $13.68 \mathrm{ft}$, from recorder graph; $14.80 \mathrm{ft}$, from high-water profile).

1958 to December 1962: Discharge, 6,180 cfs Feb. 9, 1962 (gage height, $8.12 \mathrm{ft})$.

Flood of December 23, 1955, reached a stage of $17.9 \mathrm{ft}$, from floodmarks.

Mean discharge, in cub1c feet per second, 1963

\begin{tabular}{|c|c|c|c|c|c|c|c|c|}
\hline Day & January & February & Day & January & February & Day & January & February \\
\hline $\begin{array}{r}1 \ldots \ldots \\
2 \ldots \ldots \\
3 \ldots \ldots \\
5 \ldots \ldots \\
6 \ldots \ldots \\
7 \ldots \ldots \\
5 \ldots \ldots \\
9 \ldots \ldots \\
10 \ldots \ldots\end{array}$ & $\begin{array}{l}37 \\
37 \\
38 \\
38 \\
38 \\
37 \\
36 \\
36 \\
36 \\
36\end{array}$ & $\begin{array}{r}17,700 \\
4,000 \\
1,900 \\
1,500 \\
990 \\
950 \\
880 \\
820 \\
740 \\
1,500\end{array}$ & $\begin{array}{l}11 \ldots \ldots \\
12, \ldots \ldots \\
13 \ldots \ldots \\
14 \ldots \ldots \\
15 \ldots \ldots \\
16, \ldots \ldots \\
17 \ldots \ldots \\
18 \ldots \ldots \\
19 \ldots \ldots \\
20 \ldots \ldots\end{array}$ & $\begin{array}{l}36 \\
32 \\
21 \\
22 \\
33 \\
34 \\
35 \\
33 \\
28 \\
29\end{array}$ & $\begin{array}{l}900 \\
500 \\
740 \\
700 \\
600 \\
550 \\
510 \\
490 \\
478 \\
464\end{array}$ & $\begin{array}{l}21 \ldots \ldots \\
22 \ldots \ldots \\
23 \ldots \ldots \\
24 \ldots \ldots \\
25 \ldots \ldots \\
26 \ldots \ldots \\
27 \ldots \ldots \\
28 \ldots \ldots \\
29 \ldots \ldots \\
30 \ldots \ldots \\
31 \ldots \ldots\end{array}$ & $\begin{array}{r}35 \\
36 \\
35 \\
35 \\
35 \\
34 \\
34 \\
33 \\
36 \\
1,740 \\
12,400 \\
\end{array}$ & $\begin{array}{r}451 \\
424 \\
406 \\
400 \\
400 \\
410 \\
430 \\
430 \\
----7- \\
------ \\
\end{array}$ \\
\hline $\begin{array}{l}\text { horf, } \\
\text { noff, }\end{array}$ & acre- & & & & & & $\begin{array}{r}488 \\
1.35 \\
30,000 \\
\end{array}$ & $\begin{array}{r}1,449 \\
3.61 \\
80,460 \\
\end{array}$ \\
\hline
\end{tabular}

Qage he1ght, in feet, and discharge, in cub1c feet per second, at indicated time, 1963

\begin{tabular}{|c|c|c|c|c|c|c|c|c|c|c|c|}
\hline Date & Hour & $\begin{array}{c}\text { Gage } \\
\text { he1ght }\end{array}$ & $\begin{array}{l}\text { D1s- } \\
\text { charge }\end{array}$ & Date & Hour & $\begin{array}{c}\text { Gage } \\
\text { helght }\end{array}$ & $\begin{array}{c}\text { DIs- } \\
\text { charge }\end{array}$ & Date & Hour & $\begin{array}{c}\text { Gage } \\
\text { he1ght }\end{array}$ & $\begin{array}{l}\text { D1a- } \\
\text { charge }\end{array}$ \\
\hline $\begin{array}{r}\text { Jan. } 29 \\
30\end{array}$ & $\begin{array}{l}2400 \\
0300 \\
0500 \\
0600 \\
0700 \\
0500 \\
1000 \\
1100 \\
1600 \\
1700 \\
2100 \\
2200 \\
2300 \\
2400 \\
0200\end{array}$ & $\begin{array}{l}2.38 \\
2.74 \\
3.15 \\
3.25 \\
5.30 \\
5.78 \\
6.04 \\
6.40 \\
7.30 \\
7.37 \\
7.11 \\
7.07 \\
7.09 \\
7.21 \\
7.77\end{array}$ & $\begin{array}{r}55 \\
86 \\
131 \\
142 \\
660 \\
984 \\
1,230 \\
1,680 \\
3,200 \\
3,340 \\
2,820 \\
2,750 \\
2,780 \\
3,020 \\
4,220\end{array}$ & Jan. 31 & $\begin{array}{l}0300 \\
0500 \\
0600 \\
0800 \\
0900 \\
1000 \\
1100 \\
1200 \\
1400 \\
1500 \\
1600 \\
1700 \\
1700 \\
2000 \\
2100 \\
2300 \\
2400\end{array}$ & $\begin{array}{r}7.88 \\
7.83 \\
8.05 \\
8.30 \\
8.26 \\
8.38 \\
9.00 \\
9.27 \\
9.17 \\
12.50 \\
13.20 \\
13.05 \\
13.38 \\
12.20 \\
11.58 \\
10.75 \\
10.42\end{array}$ & $\begin{array}{r}4,500 \\
4,380 \\
4,920 \\
5,600 \\
5,480 \\
5,340 \\
7,900 \\
8,980 \\
8,580 \\
24,300 \\
28,200 \\
27,300 \\
29,100 \\
22,600 \\
19,500 \\
15,400 \\
13,900\end{array}$ & Feb, 1 & $\begin{array}{l}0100 \\
0200 \\
0300 \\
0400 \\
0600 \\
0700 \\
1000 \\
1200 \\
1300 \\
1500 \\
1900 \\
2200 \\
2400\end{array}$ & $\begin{array}{r}10.66 \\
12.45 \\
12.90 \\
13.68 \\
12.75 \\
12.19 \\
11.68 \\
11.60 \\
11.25 \\
10.42 \\
9.20 \\
8.52 \\
8.14\end{array}$ & $\begin{array}{r}15,000 \\
24,000 \\
26,500 \\
30,900 \\
25,800 \\
23,000 \\
20,700 \\
20,300 \\
18,900 \\
15,300 \\
10,600 \\
8,170 \\
6,920\end{array}$ \\
\hline
\end{tabular}


11-2101. South Fork Kaweah River at Three Rivers, Calif.

Location.--Lat $36^{\circ} 25^{\prime} 00^{\prime \prime}$, long $118^{\circ} 54^{\prime} 48^{\prime \prime}$, in SE $\frac{1}{4}$ sec.26, T.17 S., R.28 E., on right bank $200 \mathrm{ft}$ upstream from unnamed tributary, 0.5 mile upstream from mouth, and 1.8 miles southwest of Three Rivers.

Drainage area. $--86.7 \mathrm{sq} \mathrm{ml}$.

Gage-height record.--Water-stage recorder graph. Datum of gage is $807.22 \mathrm{ft}$ above mean sea level, datum of 1929 .

Discharge record.--Stage-discharge relation defined by current-meter measurements.

Maxima.--January-February 1963: Discharge, 2,440 cfs 1000 hours Feb. 1 (gage helght, $4.95 \mathrm{ft}$ ).

1958 to December 1962: Discharge, $618 \mathrm{cfs}$ Feb. 10, 1962 (gage height, $3.71 \mathrm{ft}$ ).

Flood in December 1955 reached a stage of $9.5 \mathrm{ft}$, from floodmarks.

Mean discharge, in cubic feet per second, 1963

\begin{tabular}{|c|c|c|c|c|c|c|c|c|}
\hline Day & January & February & Day & January & February & Day & January & February \\
\hline $\begin{array}{c}1 \ldots \ldots \\
2 \ldots \ldots \\
3 \ldots \ldots \\
5 \ldots \ldots \\
6 \ldots \ldots \\
7 \ldots \ldots \\
9 \ldots \ldots \\
10 \ldots \ldots\end{array}$ & $\begin{array}{l}3.1 \\
3.1 \\
3.1 \\
3.1 \\
3.1 \\
3.1 \\
2.8 \\
2.8 \\
2.8 \\
2.8\end{array}$ & $\begin{array}{r}1,400 \\
433 \\
398 \\
155 \\
116 \\
97 \\
85 \\
80 \\
81 \\
162\end{array}$ & $\begin{array}{l}11 \ldots \ldots \\
12 \ldots \ldots \\
13 \ldots \ldots \\
14 \ldots \ldots \\
15 \ldots \ldots \\
16 \ldots \ldots \\
17 \ldots \ldots \\
18 \ldots \ldots \\
19 \ldots \ldots \\
20 \ldots \ldots\end{array}$ & $\begin{array}{l}2.8 \\
2.8 \\
2.6 \\
2.4 \\
2.4 \\
2.4 \\
2.4 \\
2.6 \\
2.8 \\
2.8\end{array}$ & $\begin{array}{r}101 \\
85 \\
78 \\
74 \\
65 \\
60 \\
55 \\
51 \\
49 \\
49\end{array}$ & $\begin{array}{l}21 \ldots \ldots \\
22 \ldots \ldots \\
23 \ldots \ldots \\
24 \ldots \ldots \\
25 \ldots \ldots \\
26 \ldots \ldots \\
27 \ldots \ldots \\
28 \ldots \ldots \\
29 \ldots \ldots \\
30 \ldots \ldots \\
31 \ldots \ldots\end{array}$ & $\begin{array}{r}3.1 \\
3.1 \\
3.1 \\
3.1 \\
3.1 \\
3.1 \\
3.1 \\
3.1 \\
3.4 \\
101 \\
957\end{array}$ & $\begin{array}{r}49 \\
47 \\
46 \\
43 \\
43 \\
44 \\
46 \\
46 \\
---- \\
--2-\end{array}$ \\
\hline \multicolumn{7}{|l|}{$\begin{array}{l}\text { Monthly } \\
\text { Runoff, } \\
\text { Runoff, }\end{array}$} & $\begin{array}{r}36.8 \\
0.49 \\
2,270 \\
\end{array}$ & $\begin{array}{r}144 \\
1.73 \\
8,010 \\
\end{array}$ \\
\hline
\end{tabular}

Gage height, in feet, and discharge, in cublc feet per second, at indicated time, 1963

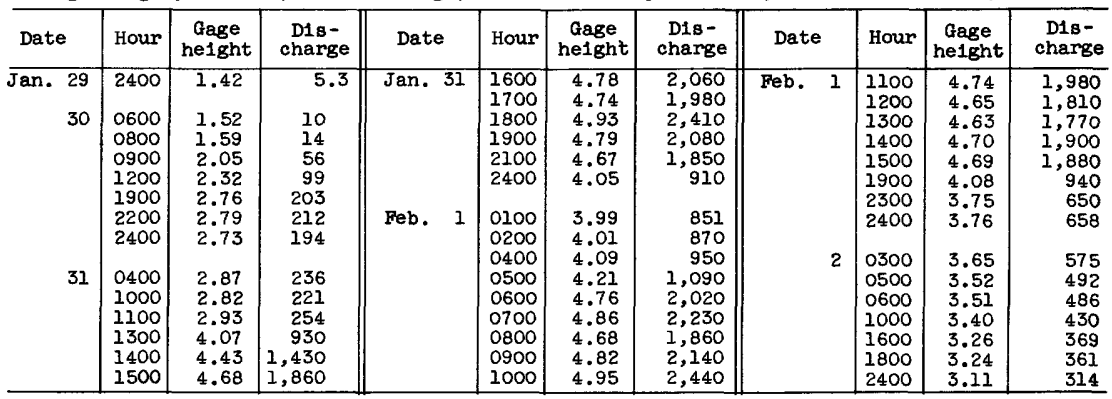


11-2109. Lake Kaweah near Lemoncove, Calif.

(Formerly published as Terminus Reservoir near Lemoncove, Calif.)

Location.--Lat $36^{\circ} 24153^{\prime \prime}, 119^{\circ} 00^{\prime} 07^{\prime \prime}$, In SE $\frac{1}{4}$ SW $\frac{1}{4}$ Sec.25, T.17 S., R.27 E., in control tower near left abutment of Terminus Dam on Kaweah River, 2.1 miles northeast of Lemoncove.

Drainage area. $--560 \mathrm{sq} \mathrm{mi}$.

Gage-helght record.--Water-stage recorder graph. Datum of gage is at mean sea level (levels by Corps of Engineers).

Contents record.--Contents computed from capacity table dated october 1955.

Maxima --January-February 1963: Computed bihourly inflow, 33,500 cf's 0400 to 0600 hours Feb. 1; outflow, 5,090 cfs 1800 hours Jan. 31; contents, 53,300 acre-ft 1200 hours Feb. 2 (elevation, $633.02 \mathrm{ft}$ ).

october 1961 to December 1962: Contents, 4,890 acre-ft May 20, 1962 (elevation, $559.2 \mathrm{ft})$.

Remarks.--Reservoir is formed by earthfill dam and earthfill auxiliary dam. Usable capac1ty, 149,400 acre-ft between elevations $520.0 \mathrm{ft}$ (invert of outlet structure) and $694.0 \mathrm{ft}$ (spillway crest). Dead storage, 166 acre-ft. .Spillway design flood pool elevation, 745.1 ft (capacity, 266,000 acre-ft). Records furnished by Corps of Engineers.

Elevation, in feet, and contents, in acre-feet, at 2400 hours, 1963

\begin{tabular}{|c|c|c|c|c|c|c|c|c|c|}
\hline \multirow{2}{*}{ Day } & \multicolumn{2}{|c|}{ January } & \multicolumn{2}{|c|}{ February } & \multirow{2}{*}{ Day } & \multicolumn{2}{|c|}{ January } & \multicolumn{2}{|c|}{ February } \\
\hline & Elevation & Contents & Elevation & Contents & & Elevation & Contents & Elevation & Contents \\
\hline $\begin{array}{r}1 \\
2 \\
3 \\
4 \\
5 \\
6 \\
7 \\
8 \\
9 \\
10 \\
11 \\
12 \\
13 \\
14 \\
15\end{array}$ & $\begin{array}{l}551.65 \\
551.64 \\
551.64 \\
551.64 \\
551.63 \\
551.63 \\
551.62 \\
551.62 \\
551.62 \\
551.63 \\
551.64 \\
551.65 \\
551.59 \\
551.53 \\
551.56\end{array}$ & $\begin{array}{l}3,240 \\
3,240 \\
3,240 \\
3,240 \\
3,240 \\
3,240 \\
3,230 \\
3,230 \\
3,230 \\
3,240 \\
3,240 \\
3,240 \\
3,230 \\
3,220 \\
3,220\end{array}$ & $\begin{array}{l}630.90 \\
632.55 \\
629.70 \\
625.35 \\
619.24 \\
612.20 \\
604.50 \\
594.70 \\
582.19 \\
571.35 \\
568.35 \\
570.00 \\
571.02 \\
571.37 \\
570.98\end{array}$ & $\begin{array}{r}50,900 \\
52,800 \\
49,500 \\
44,800 \\
38,600 \\
32,100 \\
25,900 \\
19,500 \\
13,000 \\
8,580 \\
7,550 \\
8,110 \\
8,460 \\
8,590 \\
8,450\end{array}$ & $\begin{array}{l}16 \\
17 \\
18 \\
19 \\
20 \\
21 \\
22 \\
23 \\
24 \\
25 \\
26 \\
27 \\
28 \\
29 \\
30 \\
31\end{array}$ & $\begin{array}{l}551.63 \\
551.67 \\
551.68 \\
551.67 \\
551.64 \\
551.64 \\
551.69 \\
551.71 \\
551.74 \\
551.74 \\
551.70 \\
551.65 \\
551.62 \\
551.64 \\
557.42 \\
598.29\end{array}$ & $\begin{array}{r}3,240 \\
3,240 \\
3,240 \\
3,240 \\
3,240 \\
3,240 \\
3,250 \\
3,250 \\
3,260 \\
3,260 \\
3,250 \\
3,240 \\
3,230 \\
3,240 \\
4,460 \\
21,700\end{array}$ & $\begin{array}{c}570.26 \\
569.74 \\
569.64 \\
569.78 \\
569.83 \\
569.80 \\
569.65 \\
569.53 \\
569.53 \\
569.59 \\
569.67 \\
569.73 \\
569.63 \\
- \\
- \\
-\end{array}$ & $\begin{array}{c}8,200 \\
8,020 \\
7,980 \\
8,030 \\
8,050 \\
8,040 \\
7,990 \\
7,950 \\
7,950 \\
7,970 \\
7,990 \\
8,010 \\
7,980 \\
- \\
- \\
-\end{array}$ \\
\hline Chan & in conten & , In $a c$ & feet. & 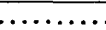 & $\ldots$ & - & $+18,460$ & - & $-13,720$ \\
\hline
\end{tabular}

Average inflow, in cublc feet per second, for bihourly periods ending at indicated t1me, 1963

\begin{tabular}{|c|c|c|c|c|c|c|c|c|}
\hline Date & Hour & Inflow & Date & Hour & Infllow & Date & Hour & Inflow \\
\hline Jan. 30 & $\begin{array}{l}0200 \\
0400 \\
0600 \\
0800 \\
1000 \\
1200 \\
1400 \\
1600 \\
1800 \\
2000 \\
2200 \\
2400 \\
\\
0200 \\
0400 \\
0600 \\
0800\end{array}$ & $\begin{array}{r}32 \\
49 \\
85 \\
91 \\
332 \\
794 \\
1,500 \\
1,630 \\
2,920 \\
3,020 \\
2,910 \\
2,810 \\
2,700 \\
3,520 \\
4,030 \\
4,220\end{array}$ & $\begin{array}{l}\text { Jan. } 31 \\
\text { Feb. } 1\end{array}$ & $\begin{array}{l}1000 \\
1200 \\
1400 \\
1600 \\
1800 \\
2000 \\
2200 \\
2400 \\
\\
0200 \\
0400 \\
0600 \\
0800 \\
1000 \\
1200 \\
1400 \\
1600\end{array}$ & $\begin{array}{r}4,720 \\
5,240 \\
9,990 \\
19,000 \\
28,300 \\
27,600 \\
18,700 \\
18,400 \\
14,400 \\
24,700 \\
33,500 \\
30,700 \\
24,900 \\
19,700 \\
19,900 \\
14,400\end{array}$ & Feb. 1 & $\begin{array}{l}1800 \\
2000 \\
2200 \\
2400 \\
0200 \\
0400 \\
0600 \\
0800 \\
1000 \\
1200 \\
1400 \\
1600 \\
1800 \\
2000 \\
2200 \\
2400\end{array}$ & $\begin{array}{r}12,800 \\
9,540 \\
8,760 \\
6,540 \\
6,990 \\
6,220 \\
5,180 \\
4,430 \\
4,080 \\
3,570 \\
3,540 \\
3,290 \\
3,150 \\
3,080 \\
2,940 \\
2,880\end{array}$ \\
\hline
\end{tabular}


11-2109.5. Kaweah River below Terminus Dam, Calif.

Location.--Lat $36^{\circ} 24151^{\prime \prime}$, long $119^{\circ} 00142^{\prime \prime}$, in $\mathrm{SE}_{\frac{1}{4}} \mathrm{SE}_{\frac{1}{4}} \mathrm{sec} .26$, T.17 S., R.27 E., $0.6 \mathrm{mile}$ downstream from Terminus Dam and 2.2 miles northeast of Lemoncove.

Drainage area. $--561 \mathrm{sq} \mathrm{mi}$.

Gage-he1ght record;-Water-stage recorder graph. Datum of gage is $495.90 \mathrm{ft}$ above mean sea level (levels by Corps of Engineers).

Discharge record.--Stage-discharge relation defined by current-meter measurements below $3,600 \mathrm{c}$ 's

Maxima.--January-February 1963: Discharge, 5,080 cfs 1800 hours Jan. 31 (gage height, $8.28 \mathrm{ft}$ ).

1961 to December 1962: Discharge, 3,500 cfs Feb. 10, 1962 (gage height, $7.26 \mathrm{ft}$ ).

Remarks.--Flow regulated by Lake Kaweah (see station No. 11-2109).

Mean discharge, in cublc feet per second, 1963

\begin{tabular}{|c|c|c|c|c|c|c|c|c|}
\hline Day & January & February & Day & January & February & Day & January & February \\
\hline $\begin{array}{c}1 \ldots \ldots \\
2 \ldots \ldots \\
3 \ldots \ldots \\
4 \ldots \ldots \\
6 \ldots \ldots \\
7 \ldots \ldots \\
8 \ldots \ldots \\
9 \ldots \ldots \\
10 \ldots \ldots\end{array}$ & $\begin{array}{l}9.8 \\
9.8 \\
9.3 \\
9.3 \\
18 \\
29 \\
29 \\
28 \\
27 \\
27\end{array}$ & $\begin{array}{l}3,670 \\
3,010 \\
3,720 \\
3,820 \\
4,420 \\
4,330 \\
3,910 \\
4,010 \\
4,040 \\
3,450\end{array}$ & $\begin{array}{l}11 \ldots \ldots \\
12 \ldots \ldots \\
13 \ldots \ldots \\
14 \ldots \ldots \\
15 \ldots \ldots \\
16 \ldots \ldots \\
17 \ldots \ldots \\
18 \ldots \ldots \\
19 \ldots \ldots \\
20 \ldots \ldots\end{array}$ & $\begin{array}{l}27 \\
26 \\
26 \\
22 \\
17 \\
18 \\
23 \\
27 \\
28 \\
27\end{array}$ & $\begin{array}{r}1,440 \\
495 \\
568 \\
676 \\
720 \\
720 \\
644 \\
537 \\
498 \\
498\end{array}$ & $\begin{array}{l}21 \ldots \ldots \\
22 \ldots \ldots \\
23 \ldots \ldots \\
24 \ldots \ldots \\
25 \ldots \ldots \\
26 \ldots \ldots \\
27 \ldots \ldots \\
28 \ldots \ldots \\
29 \ldots \ldots \\
30 \ldots \ldots \\
31 \ldots \ldots\end{array}$ & $\begin{array}{r}27 \\
26 \\
25 \\
26 \\
29 \\
32 \\
33 \\
31 \\
29 \\
726 \\
3,570 \\
\end{array}$ & $\begin{array}{r}495 \\
495 \\
476 \\
448 \\
436 \\
448 \\
479 \\
495 \\
----- \\
----- \\
-\end{array}$ \\
\hline $\begin{array}{l}\text { nthly } \\
\text { noff, }\end{array}$ & acr & & & & & & $\begin{array}{r}161 \\
9,900\end{array}$ & $\begin{array}{r}1,748 \\
97,090\end{array}$ \\
\hline
\end{tabular}

Gage he1ght, in feet, and discharge, in cublc feet per second, at indicated time, 1963

\begin{tabular}{|c|c|c|c|c|c|c|c|c|c|c|c|}
\hline Date & Hour & $\begin{array}{c}\text { Gage } \\
\text { height }\end{array}$ & $\begin{array}{c}\text { D1s- } \\
\text { charge }\end{array}$ & Date & Hour & $\begin{array}{c}\text { Gage } \\
\text { height }\end{array}$ & $\begin{array}{l}\text { Dis- } \\
\text { charge }\end{array}$ & Date & Hour & $\begin{array}{c}\text { Gage } \\
\text { helght }\end{array}$ & $\begin{array}{l}\text { D1s- } \\
\text { charge }\end{array}$ \\
\hline $\begin{array}{r}\operatorname{Jan} .29 \\
30\end{array}$ & $\begin{array}{l}2400 \\
0900 \\
1000 \\
1100 \\
1200 \\
1300 \\
1400 \\
1500 \\
1600 \\
1800 \\
2400\end{array}$ & $\begin{array}{r}0.66 \\
.67 \\
.92 \\
.95 \\
1.90 \\
3.92 \\
3.82 \\
3.80 \\
5.71 \\
5.83 \\
5.91\end{array}$ & $\begin{array}{r}29 \\
29 \\
45 \\
48 \\
145 \\
608 \\
572 \\
565 \\
1,670 \\
1,780 \\
1,850\end{array}$ & Jan. 31 & $\begin{array}{l}0200 \\
0300 \\
0700 \\
0800 \\
0900 \\
1000 \\
1200 \\
1300 \\
1400 \\
1500 \\
1800 \\
2100\end{array}$ & $\begin{array}{l}5.94 \\
6.39 \\
6.48 \\
6.89 \\
7.23 \\
7.66 \\
7.70 \\
7.46 \\
7.50 \\
7.93 \\
8.28 \\
8.10\end{array}$ & $\begin{array}{l}1,880 \\
2,310 \\
2,400 \\
2,890 \\
3,320 \\
3,980 \\
4,040 \\
3,660 \\
3,720 \\
4,450 \\
5,080 \\
4,760\end{array}$ & $\begin{array}{l}\text { Jan. } 31 \\
\text { Feb. } 1\end{array}$ & $\begin{array}{l}2200 \\
2400 \\
\\
0600 \\
0800 \\
0900 \\
1600 \\
1800 \\
2200 \\
2400\end{array}$ & $\begin{array}{l}7.63 \\
7.67 \\
7.90 \\
7.38 \\
7.70 \\
7.85 \\
6.58 \\
6.60 \\
6.46\end{array}$ & $\begin{array}{l}3,930 \\
3,990 \\
4,400 \\
3,530 \\
4,040 \\
4,310 \\
2,520 \\
2,540 \\
2,380\end{array}$ \\
\hline
\end{tabular}

11-2113. Dry Creek near Lemoncove, Calif.

Location.--Lat $36^{\circ} 25^{\prime} 30^{\prime \prime}$, long $119^{\circ} 01120^{\prime \prime}$, in NW $\frac{1}{4} N W \frac{1}{4}$ sec. 26 , T.17 S., R.27 E., on left bank $400 \mathrm{ft}$ downstream from Pogue Canyon, 1.3 miles upstream from mouth, and 2.8 miles north of Lemoncove.

Drainage area. $--80.4 \mathrm{sq} \mathrm{mi}$.

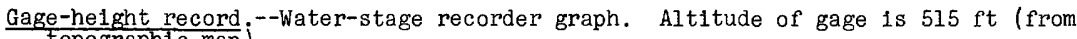
topographic mapj.

Discharge record.--Stage-discharge relation defined by current-meter measurements.

Maxima.--January-February 1963: Discharge, 1,600 cf's 0700 hours Feb. I (gage height, $5.08 \mathrm{ft}$ ).

1959 to December 1962: D1scharge, $732 \mathrm{cfs}$ Feb. 11, 1962 (gage height, $4.37 \mathrm{ft}$ ). 
Mean discharge, in cublc feet per second, 1963, of Dry Creek near Lemoncove, Calif.

\begin{tabular}{|c|c|c|c|c|c|c|c|c|}
\hline Day & January & February & Day & J anuary & February & Day & January & February \\
\hline $\begin{array}{c}1 \ldots \ldots \\
2 \ldots \ldots \\
3 \ldots \ldots \\
4 \ldots \ldots \\
5 \ldots \ldots \\
6 \ldots \ldots \\
8 \ldots \ldots \\
9 \ldots \ldots \\
10 \ldots \ldots\end{array}$ & $\begin{array}{l}0 \\
0 \\
0 \\
0 \\
0 \\
0 \\
0 \\
0 \\
0 \\
0\end{array}$ & $\begin{array}{c}647 \\
78 \\
31 \\
18 \\
9.6 \\
6.4 \\
4.0 \\
2.8 \\
4.0 \\
130\end{array}$ & $\begin{array}{l}11 \ldots \ldots \\
12 \ldots \ldots \\
13 \ldots \ldots \\
14 \ldots \ldots \\
15 \ldots \ldots \\
16 \ldots \ldots \\
17 \ldots \ldots \\
18 \ldots \ldots \\
19 \ldots \ldots \\
20 \ldots \ldots\end{array}$ & $\begin{array}{l}0 \\
0 \\
0 \\
0 \\
0 \\
0 \\
0 \\
0 \\
0 \\
0\end{array}$ & $\begin{array}{l}50 \\
31 \\
28 \\
27 \\
21 \\
17 \\
14 \\
11 \\
8.5 \\
7.4\end{array}$ & $\begin{array}{l}21 \ldots \ldots \\
22 \ldots \ldots \\
23 \ldots \ldots \\
24 \ldots \ldots \\
25 \ldots \ldots \\
26 \ldots \ldots \\
27 \ldots \ldots \\
28 \ldots \ldots \\
29 \ldots \ldots \\
30 \ldots \ldots \\
31 \ldots \ldots\end{array}$ & $\begin{array}{c}0 \\
0 \\
0 \\
0 \\
0 \\
0 \\
0 \\
0 \\
0 \\
1.0 \\
466\end{array}$ & $\begin{array}{r}7.4 \\
6.4 \\
6.4 \\
6.4 \\
5.5 \\
5.5 \\
4.7 \\
4.7 \\
-.--. \\
--.-1 \\
-.-1-.\end{array}$ \\
\hline & acre-f & & & & & & $\begin{array}{r}15.1 \\
0.22 \\
926\end{array}$ & $\begin{array}{r}42.6 \\
0.55 \\
2,370 \\
\end{array}$ \\
\hline
\end{tabular}

Gage he1ght, in feet, and d1scharge, In cub1c feet per second, at 1ndicated t1me, 1963

\begin{tabular}{|c|c|c|c|c|c|c|c|c|c|c|c|}
\hline Date & Hour & $\begin{array}{c}\text { Gage } \\
\text { he1ght }\end{array}$ & $\begin{array}{l}\text { D1s- } \\
\text { charge }\end{array}$ & Date & Hour & $\begin{array}{c}\text { Gage } \\
\text { helght }\end{array}$ & $\begin{array}{l}\text { D1s- } \\
\text { charge }\end{array}$ & Date & Hour & $\begin{array}{c}\text { Gage } \\
\text { he1ght }\end{array}$ & $\begin{array}{l}\text { D1s- } \\
\text { charge }\end{array}$ \\
\hline $\begin{array}{r}\operatorname{Jan} . \\
30 \\
31\end{array}$ & $\begin{array}{l}2400 \\
2300 \\
2400 \\
0400 \\
0500 \\
0900 \\
1200 \\
1300\end{array}$ & $\begin{array}{c}- \\
- \\
2.77 \\
2.92 \\
2.94 \\
2.95 \\
3.04 \\
3.09\end{array}$ & $\begin{array}{r}0 \\
0 \\
60 \\
93 \\
98 \\
101 \\
125 \\
139\end{array}$ & Feb. 1 & $\begin{array}{l}1400 \\
1500 \\
1600 \\
1700 \\
1800 \\
2000 \\
2400 \\
\\
0200 \\
0300\end{array}$ & $\begin{array}{l}3.25 \\
3.64 \\
4.50 \\
4.86 \\
4.91 \\
4.76 \\
3.98 \\
\\
3.75 \\
3.68\end{array}$ & $\begin{array}{r}192 \\
353 \\
810 \\
1,340 \\
1,420 \\
1,270 \\
606 \\
\\
460 \\
418\end{array}$ & Feb. 1 & $\begin{array}{l}0400 \\
0500 \\
0600 \\
0700 \\
0800 \\
1100 \\
1400 \\
1900 \\
2200 \\
2400\end{array}$ & $\begin{array}{l}3.73 \\
4.25 \\
4.90 \\
5.08 \\
4.95 \\
4.33 \\
3.89 \\
3.44 \\
3.23 \\
3.13\end{array}$ & $\begin{array}{r}448 \\
810 \\
1,410 \\
1,600 \\
1,460 \\
874 \\
544 \\
290 \\
202 \\
162\end{array}$ \\
\hline
\end{tabular}

11-2124.5. Grizzly Creek near Cedar Grove, Calif.

\section{(Crest-stage station)}

Location.--Iat $36^{\circ} 48^{\prime} 10^{\prime \prime}$, long $118^{\circ} 44^{\prime} 35^{\prime \prime}$, in NW $\frac{1}{4} \mathrm{SE} \frac{1}{4} \sec .8$, T.13 S., R.30 E., on State Highway $180,4.1$ miles east of Cédar Grove.

Drainage area. $--9.73 \mathrm{sq} \mathrm{mi}$.

Gage-height record.--Crest stages only. Altitude of gage is 4,210 ft (from topographic map).

Discharge record.--Stage-discharge relation defined by current-meter measurements below $22 \mathrm{cfs}$ and by computation of flow through culvert at 49, 126, and $293 \mathrm{cfs}$.

Maxima --January-February 1963: Discharge, $293 \mathrm{cfs}$ Feb. 1 (gage helght, $14.80 \mathrm{ft}$ ). i959 to December 1962: Discharge, 126 cfs May 1962 (gage height, $12.98 \mathrm{ft}$, from high-water profile).

11-2135. Kings Rlver above North Fork, Callf.

Location.--Lat $36^{\circ} 51^{\prime} 45^{\prime \prime}$, long $119^{\circ} 07^{\prime} 25^{\prime \prime}$, in NE $\frac{1}{4}$ sec.27, T.12 S., R.26 E., on left bank at Rogers Crossing, 0.9 mile upstream from North Fork and 2.9 miles south of Balch Camp.

Drainage area. $--952 \mathrm{sq} \mathrm{mi}$.

Gage-helght record.--Water-stage recorder graph, except 1200 hours Jan. 12 to 1000 hours Jan. 29, and 0500 hours Feb. 2 to 1400 hours Feb. 3, for which graph was reconstructed on basis of adjacent record. Datum of gage is $1,003.5 \mathrm{ft}$ above mean sea level (river-profile survey).

Discharge record.--Stage-discharge relation defined by current-meter measurements below 8,000 cfs and by slope-area measurement at 59,100 cfs. Discharge for Jan. 12-29 estimated on basis of record for station below North Fork and recorded range in stage.

Maxima.--January-February 1963: Dlscharge, 29,000 cfs 0500 hours Feb. I (gage helght, $10.85 \mathrm{ft}$, from recorder graph; il.2 ft, from floodmarks).

$1926-28,1931$ to December 1962: Discharge, 59,100 cfs Dec. 23, 1955 (gage height, $16.26 \mathrm{ft}$ ). 
Mean discharge, in cubic feet per second, 1963, of Kings River above North Fork, Calif.

\begin{tabular}{|c|c|c|c|c|c|c|c|c|}
\hline Day & January & February & Day & January & February & Day & January & February \\
\hline $\begin{array}{c}1 \ldots \ldots \\
2 \ldots \ldots \\
3 \ldots \ldots \\
4 \ldots \ldots \\
5 \ldots \ldots \\
7 \ldots \ldots \\
8 \ldots \ldots \\
9 \ldots \ldots \\
10 \ldots \ldots\end{array}$ & $\begin{array}{l}113 \\
111 \\
114 \\
116 \\
111 \\
108 \\
106 \\
104 \\
102 \\
104\end{array}$ & $\begin{array}{r}18,900 \\
4,510 \\
2,670 \\
2,110 \\
1,770 \\
1,510 \\
1,340 \\
1,260 \\
1,170 \\
1,530\end{array}$ & $\begin{array}{l}11 \ldots \ldots \\
12 \ldots \ldots \\
13 \ldots \ldots \\
14 \ldots \ldots \\
15 \ldots \ldots \\
16 \ldots \ldots \\
17 \ldots \ldots \\
18 \ldots \ldots \\
19 \ldots \ldots \\
20 \ldots \ldots\end{array}$ & $\begin{array}{r}104 \\
100 \\
80 \\
70 \\
80 \\
80 \\
90 \\
90 \\
85 \\
85\end{array}$ & $\begin{array}{r}1,180 \\
1,060 \\
1,070 \\
1,000 \\
904 \\
865 \\
800 \\
770 \\
776 \\
734\end{array}$ & $\begin{array}{l}21 \ldots \ldots \\
22 \ldots \ldots \\
23 \ldots \ldots \\
24 \ldots \ldots \\
25 \ldots \ldots \\
26 \ldots \ldots \\
27 \ldots \ldots \\
28 \ldots \ldots \\
29 \ldots \ldots \\
30 \ldots \ldots \\
31 \ldots \ldots\end{array}$ & $\begin{array}{r}90 \\
90 \\
90 \\
95 \\
95 \\
95 \\
100 \\
100 \\
101 \\
1,440 \\
11,700\end{array}$ & $\begin{array}{r}729 \\
707 \\
707 \\
690 \\
696 \\
729 \\
764 \\
758 \\
----- \\
--.--\end{array}$ \\
\hline \multicolumn{7}{|c|}{ 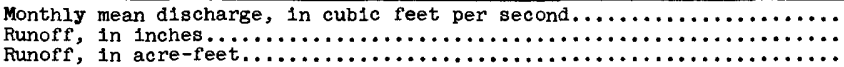 } & $\begin{array}{r}514 \\
0.62 \\
31,630 \\
\end{array}$ & $\begin{array}{r}1,847 \\
2.02 \\
102,600 \\
\end{array}$ \\
\hline
\end{tabular}

Gage height, in feet, and discharge, in cubic feet per second, at indicated t1me, 1963

\begin{tabular}{|c|c|c|c|c|c|c|c|c|c|c|c|}
\hline Date & Hour & $\begin{array}{c}\text { Gage } \\
\text { height }\end{array}$ & $\begin{array}{l}\text { Dis- } \\
\text { charge }\end{array}$ & Date & Hour & $\begin{array}{c}\text { Gage } \\
\text { helght }\end{array}$ & $\begin{array}{c}\text { Dis- } \\
\text { charge }\end{array}$ & Date & Hour & $\begin{array}{c}\text { Gage } \\
\text { height }\end{array}$ & $\begin{array}{l}\text { Dis- } \\
\text { charge }\end{array}$ \\
\hline $\begin{array}{r}\text { Jan. } 29 \\
30\end{array}$ & $\begin{array}{l}2400 \\
0400 \\
0800 \\
1200 \\
1800 \\
2200 \\
2400\end{array}$ & $\begin{array}{l}0.80 \\
1.04 \\
1.04 \\
3.03 \\
4.27 \\
4.37 \\
4.58\end{array}$ & $\begin{array}{r}140 \\
188 \\
585 \\
1,170 \\
2,700 \\
2,870 \\
3,260\end{array}$ & Jan. 31 & $\begin{array}{l}1200 \\
1400 \\
1600 \\
1700 \\
1800 \\
2000 \\
2300 \\
2400\end{array}$ & $\begin{array}{l}6.68 \\
7.88 \\
9.60 \\
9.80 \\
9.75 \\
9.02 \\
7.72 \\
7.78\end{array}$ & $\begin{array}{r}9,740 \\
14,800 \\
22,900 \\
23,800 \\
23,600 \\
20,100 \\
14,100 \\
14,400\end{array}$ & Feb. 1 & $\begin{array}{l}0700 \\
1000 \\
1200 \\
1600 \\
1800 \\
2100 \\
2400\end{array}$ & $\begin{array}{r}10.57 \\
10.07 \\
9.30 \\
7.92 \\
7.51 \\
6.59 \\
5.93\end{array}$ & $\begin{array}{r}27,600 \\
25,200 \\
21,400 \\
15,200 \\
13,500 \\
9,860 \\
7,450\end{array}$ \\
\hline 31 & $\begin{array}{l}0300 \\
0500 \\
0900\end{array}$ & $\begin{array}{l}5.12 \\
5.14 \\
5.44\end{array}$ & $\begin{array}{l}4,470 \\
4,520 \\
5,360\end{array}$ & Feb. 1 & $\begin{array}{l}0300 \\
0400 \\
0500\end{array}$ & $\begin{array}{r}9.45 \\
10.61 \\
10.85\end{array}$ & $\begin{array}{l}22,200 \\
27,800 \\
29,000\end{array}$ & 2 & $\begin{array}{l}0600 \\
1200 \\
2400\end{array}$ & $\begin{array}{l}5.20 \\
4.75 \\
4.20\end{array}$ & $\begin{array}{l}5,210 \\
4,080 \\
2,990\end{array}$ \\
\hline
\end{tabular}

11-2145.5. Courtright Reservoir near Nelson Mountain, Calif.

Location.--Lat $37^{\circ} 04^{\prime} 40^{\prime \prime}$, long $118^{\circ} 58^{\prime} 05^{\prime \prime}$, in NW $\frac{1}{4}$ sec.7, T.10 S., R.28 E., at left end of dam on Helms Creek, 2.5 miles upstream from mouth, 4.6 miles east of Nelson Mountain, and 9.7 miles west of Blackcap Mountain.

Drainage area. $--39.7 \mathrm{sq} \mathrm{mi}$.

Gage-height record.--Water-stage recorder graph. Datum of gage is at mean sea level (levels by Pacific Gas \& Electric Co.).

Contents record.--Contents computed from capacity table dated Apr. 13, 1957.

Maxima.--January-February 1963: Contents, 59,700 acre-ft 2400 hours Feb. 28 (elevation, $8,134.9 \mathrm{ft}$ ).

1958 to December 1962: Contents, 64,600 acre-ft July 14-24, 1962; maximum elevation, $8,139.80$ ft July 18,1962 .

Remarks.--Reservoir is formed by rockfill dam completed in 1958. Usable capacity, 129,900 acre-ft between elevations $7,902 \mathrm{ft}$ (invert of tunnei) and $8,188 \mathrm{ft}$

(crest of dam).

Elevation, in feet, and contents, in acre-feet, at 2400 hours, 1963

\begin{tabular}{|c|c|c|c|c|c|c|c|c|c|}
\hline \multirow{2}{*}{ Day } & \multicolumn{2}{|c|}{ January } & \multicolumn{2}{|c|}{ February } & \multirow{2}{*}{ Day } & \multicolumn{2}{|c|}{ January } & \multicolumn{2}{|c|}{ February } \\
\hline & Elevation & Contents & Elevation & Contents & & Elevation & Contents & Elevation & Contents \\
\hline $\begin{array}{r}1 \\
2 \\
3 \\
4 \\
5 \\
6 \\
7 \\
8 \\
9 \\
10 \\
11 \\
12 \\
13 \\
14 \\
15\end{array}$ & $\begin{array}{l}8,134.8 \\
8,134.8 \\
8,134.8 \\
8,134.8 \\
8,134.7 \\
8,134.7 \\
8,134.7 \\
8,134.7 \\
8,134.6 \\
8,134.6 \\
8,134.6 \\
8,134.6 \\
8,134.5 \\
8,134.0 \\
8,132.9\end{array}$ & $\begin{array}{l}59,600 \\
59,600 \\
59,500 \\
59,500 \\
59,500 \\
59,500 \\
59,400 \\
59,400 \\
59,400 \\
59,300 \\
59,300 \\
59,300 \\
59,300 \\
58,700 \\
57,700\end{array}$ & $\begin{array}{l}8,132.8 \\
8,133.3 \\
8,133.5 \\
8,133.7 \\
8,133.8 \\
8,133.9 \\
8,134.0 \\
8,134.1 \\
8,134.2 \\
8,134.3 \\
8,134.3 \\
8,134.4 \\
8,134.5 \\
8,134.5 \\
8,134.6\end{array}$ & $\begin{array}{l}57,600 \\
58,100 \\
58,300 \\
58,500 \\
58,600 \\
58,700 \\
58,800 \\
58,800 \\
58,900 \\
59,000 \\
59,100 \\
59,200 \\
59,200 \\
59,300 \\
59,300\end{array}$ & $\begin{array}{l}16 \\
17 \\
18 \\
19 \\
20 \\
21 \\
22 \\
23 \\
24 \\
25 \\
26 \\
27 \\
28 \\
29 \\
30 \\
31\end{array}$ & $\begin{array}{l}8,132.3 \\
8,132.2 \\
8,132.2 \\
8,132.2 \\
8,132.2 \\
8,131.7 \\
8,130.5 \\
8,130.0 \\
8,130.0 \\
8,130.0 \\
8,130.0 \\
8,129.9 \\
8,129.9 \\
8,130.0 \\
8,130.8 \\
8,131.4\end{array}$ & $\begin{array}{l}57,100 \\
57,100 \\
57,100 \\
57,000 \\
57,000 \\
56,500 \\
55,500 \\
55,000 \\
55,000 \\
54,900 \\
54,900 \\
54,900 \\
54,900 \\
55,000 \\
55,700 \\
56,300\end{array}$ & $\begin{array}{c}8,134.6 \\
8,134.6 \\
8,134.6 \\
8,134.6 \\
8,134.7 \\
8,134.7 \\
8,134.7 \\
8,134.7 \\
8,134.7 \\
8,134.8 \\
8,134.8 \\
8,134.8 \\
8,134.9 \\
- \\
- \\
-\end{array}$ & $\begin{array}{c}59,300 \\
59,400 \\
59,400 \\
59,400 \\
59,400 \\
59,400 \\
59,500 \\
59,500 \\
59,500 \\
59,500 \\
59,600 \\
59,600 \\
59,700 \\
- \\
- \\
-\end{array}$ \\
\hline Chang & in conte & , in $a$ & & & & - & $-3,300$ & - & $+3,400$ \\
\hline
\end{tabular}


11-2146. Helms Creek below Courtright Dam, Calif.

Location.--Lat $37^{\circ} 04^{\prime} 40^{\prime \prime}$, long $118^{\circ} 58^{\prime} 05^{\prime \prime}$, in NW $\frac{1}{4}$ sec.7, T.10 S., R.28 E., on left bank $500 \mathrm{ft}$ downstream from Courtright 'Dam, 2.5 miles upstream from North Fork Kings River, and 17 miles southeast of town of Huntington Lake.

Drainage area. $--39.7 \mathrm{sq} \mathrm{mi}$.

Gage-height record.--Water-stage recorder graph. Altitude of gage is $7,840 \mathrm{ft}$ (from Pacific Gas \& Electric Co. Survey).

Discharge record.--Stage-discharge relation defined by current-meter measurements.

Maxima.--January-February 1963: Discharge, 390 cfs 1300 hours Jan. 14 (gage height, $5 . \overline{2} 5 \mathrm{ft}$ ).

1958 to December 1962: Discharge, 767 cfs June 2, 1961 (gage height, $6.52 \mathrm{ft}$ ).

Remarks. - Flow regulated by Courtright Reservoir (see station 11-2145.5).

Mean discharge, in cubic feet per second, 1963

\begin{tabular}{|c|c|c|c|c|c|c|c|c|}
\hline Day & January & February & Day & January & February & Day & January & February \\
\hline $\begin{array}{c}1 \ldots \ldots \\
2 \ldots \ldots \\
3 \ldots \ldots \\
4 \ldots \\
5 \ldots \\
6 \ldots \ldots \\
7 \ldots \ldots \\
8 \ldots \ldots \\
9 \ldots \ldots \\
10 \ldots \ldots\end{array}$ & $\begin{array}{l}14 \\
14 \\
14 \\
14 \\
14 \\
14 \\
14 \\
14 \\
14 \\
14\end{array}$ & $\begin{array}{l}19 \\
14 \\
14 \\
14 \\
14 \\
14 \\
14 \\
14 \\
14 \\
14\end{array}$ & $\begin{array}{l}11 \ldots \ldots \\
12 \ldots \ldots \\
13 \ldots \ldots \\
14 \ldots \ldots \\
15 \ldots \ldots \\
16 \ldots \ldots \\
17 \ldots \ldots \\
18 \ldots \ldots \\
19 \ldots \ldots\end{array}$ & $\begin{array}{r}14 \\
14 \\
14 \\
198 \\
384 \\
214 \\
14 \\
14 \\
14 \\
13\end{array}$ & $\begin{array}{l}14 \\
14 \\
14 \\
14 \\
14 \\
14 \\
14 \\
14 \\
14 \\
14\end{array}$ & $\begin{array}{l}21 \ldots \ldots \\
22 \ldots \ldots \\
23 \ldots \ldots \\
24 \ldots \ldots \\
25 \ldots \ldots \\
26 \ldots \ldots \\
27 \ldots \ldots \\
28 \ldots \ldots \\
29 \ldots \ldots \\
30 \ldots \ldots \\
31 \ldots \ldots\end{array}$ & $\begin{array}{r}169 \\
388 \\
185 \\
13 \\
13 \\
13 \\
13 \\
13 \\
13 \\
14 \\
17\end{array}$ & $\begin{array}{r}14 \\
14 \\
14 \\
14 \\
14 \\
14 \\
14 \\
14 \\
14 \\
\ldots----\end{array}$ \\
\hline $\begin{array}{l}\text { nthly } \\
\text { unoff, }\end{array}$ & $\begin{array}{l}\text { in disc } \\
\text { acre-f }\end{array}$ & $\ldots$ & $e$ & & & & $\begin{array}{r}60.8 \\
3,740\end{array}$ & $\begin{array}{r}14.2 \\
787\end{array}$ \\
\hline
\end{tabular}

11-2148. Wishon Reservoir near Cliff Camp, Calif.

Location.--Lat $37^{\circ} 00^{\prime} 20^{\prime \prime}$, long $118^{\circ} 58^{\prime} 00^{\prime \prime}$, in NW $\frac{1}{4}$ sec.6, T.1I S., R.28 E., on right end of dam on North Fork Kings River, 1.2 miles north of Cliff Camp, 1.3 miles upstream from Cliff Camp gaging station, and 20 miles southeast of town of Big Creek.

Drainage area $--177 \mathrm{sq} \mathrm{mi}$.

Gage-height record. --Water-stage recorder graph. Datum of gage is at mean sea level (levels by Pacific Gas \& Electric Co.).

Contents record.--Contents computed from capacity table dated Apr. 13, 1957.

Maxima:--January-February 1963: Contents, 34,100 acre-ft 2400 hours Feb. 28 (elevation, $6,430.7 \mathrm{ft}$ ).

1957 to December 1962: Contents, 129,700 acre-ft July 29, 1958 (elevation, $6,551.1 \mathrm{ft})$.

Remarks.--Reservoir is formed by rockfill dam completed in 1957. Capacity, 128,600 acre-ft between elevations 6,317 ft (bottom of slide gates) and 6,550 ft (operating crest of spillway gates). Water is diverted to Haas powerhouse for power.

Elevation, in feet, and contents in acre-feet, at 2400 hours, 1963

\begin{tabular}{|c|c|c|c|c|c|c|c|c|c|}
\hline \multirow{2}{*}{ Day } & \multicolumn{2}{|c|}{ January } & \multicolumn{2}{|c|}{ February } & \multirow{2}{*}{ Day } & \multicolumn{2}{|c|}{ January } & \multicolumn{2}{|c|}{ February } \\
\hline & Elevation & Contents & Elevation & Contents & & Elevation & Contents & Elevation & Contents \\
\hline $\begin{array}{r}1 \\
2 \\
3 \\
4 \\
5 \\
6 \\
7 \\
8 \\
9 \\
10 \\
11 \\
12 \\
13 \\
14 \\
15\end{array}$ & $\begin{array}{l}6,381 \cdot 1 \\
6,381 \cdot 1 \\
6,381 \cdot 2 \\
6,381 \cdot 2 \\
6,381 \cdot 2 \\
6,381 \cdot 2 \\
6,381 \cdot 2 \\
6,381 \cdot 2 \\
6,381 \cdot 2 \\
6,381 \cdot 3 \\
6,380 \cdot 7 \\
6,380 \cdot 8 \\
6,380 \cdot 8 \\
6,381 \cdot 8 \\
6,383 \cdot 6\end{array}$ & $\begin{array}{r}9,990 \\
9,990 \\
10,000 \\
10,000 \\
10,000 \\
10,000 \\
10,000 \\
10,000 \\
10,000 \\
10,000 \\
9,830 \\
9,830 \\
9,830 \\
10,300 \\
11,000\end{array}$ & $\begin{array}{l}6,411.0 \\
6,413.6 \\
6,415.1 \\
6,416.2 \\
6,417.2 \\
6,418.0 \\
6,418.8 \\
6,419.8 \\
6,420.5 \\
6,421.3 \\
6,421.9 \\
6,422.5 \\
6,423.2 \\
6,423.8 \\
6,424.2\end{array}$ & $\begin{array}{l}23,700 \\
25,100 \\
25,800 \\
26,400 \\
26,900 \\
27,300 \\
27,700 \\
28,200 \\
28,600 \\
29,000 \\
29,400 \\
29,700 \\
30,100 \\
30,400 \\
30,600\end{array}$ & $\begin{array}{l}16 \\
17 \\
18 \\
19 \\
20 \\
21 \\
22 \\
23 \\
24 \\
25 \\
26 \\
27 \\
28 \\
29 \\
30 \\
31\end{array}$ & $\begin{array}{l}6,384.2 \\
6,383.4 \\
6,382.9 \\
6,382.8 \\
6,382.8 \\
6,383.3 \\
6,385.3 \\
6,386.0 \\
6,385.9 \\
6,385.7 \\
6,385.7 \\
6,385.8 \\
6,385.2 \\
6,385.0 \\
6,386.6 \\
6,397.4\end{array}$ & $\begin{array}{l}11,300 \\
10,900 \\
10,700 \\
10,700 \\
10,700 \\
10,900 \\
11,700 \\
12,000 \\
12,000 \\
11,900 \\
11,900 \\
11,900 \\
11,700 \\
11,600 \\
12,300 \\
17,200\end{array}$ & $\begin{array}{c}6,424.7 \\
6,425.0 \\
6,425.5 \\
6,425.9 \\
6,426.4 \\
6,426.9 \\
6,427.3 \\
6,427.8 \\
6,428.3 \\
6,428.8 \\
6,429.4 \\
6,430.0 \\
6,430.7 \\
- \\
- \\
-\end{array}$ & $\begin{array}{c}30,800 \\
31,100 \\
31,300 \\
31,500 \\
31,800 \\
32,000 \\
32,300 \\
32,500 \\
32,800 \\
33,100 \\
33,400 \\
33,800 \\
34,100 \\
- \\
- \\
-\end{array}$ \\
\hline Ian & In $c$ & in a & -feet. & & & - & $+7,210$ & - & $+16,900$ \\
\hline
\end{tabular}


11-2150. North Fork Kings River near Cliff Camp, Calif.

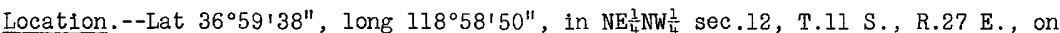
right bank at Cliff Camp Bridge, 1 mile northwest of Cliff Camp, 1.2 miles downstream from Wishon Dam, and 2 miles downstream from Woodchuck Creek.

Dralnage area. $--181 \mathrm{sq} \mathrm{mi}$.

Gage-height record.--Water-stage recorder graph. Datum of gage is $6,143.95 \mathrm{ft}$ above mean sea level, adjustment of 1912 (levels by San Joaquin Light and Power Corp.).

Discharge record.--Stage-discharge relation defined by current-meter measurements .

Maxima.--January-February 1963: Discharge, 1,170 cfs 2400 hours Jan. 31 (gage helght, $7.38 \mathrm{ft}$ ).

1921-57 (prior to regulation by Wishon Reservoir): Discharge, 14,000 cfs

Dec. 11, 1937 (gage height, $18.0 \mathrm{ft}$, from floodmarks), from rating curve extended above $4,200 \mathrm{cf}$ 's on basis of velocity-area studies.

1957 to December 1962: Discharge, 4,880 cfs May 28, 1958 (gage height, $11.75 \mathrm{ft})$.

Remarks.--Flow regulated by Wishon Reservolr since Dec. 5, 1957 (see station

II-2148) and Courtright Reservoir since 0ct. 17, 1958 (see station 11-2145.5).

Mean discharge, in cubic feet per second, 1963

\begin{tabular}{|c|c|c|c|c|c|c|c|c|}
\hline Day & January & February & Day & January & February & Day & January & February \\
\hline $\begin{array}{c}\ldots \ldots \\
2 \ldots \ldots \\
3 \ldots \ldots \\
4 \ldots \ldots \\
6 \ldots \ldots \\
7 \ldots \ldots \\
9 \ldots \ldots \\
10 \ldots \ldots\end{array}$ & $\begin{array}{l}7.6 \\
7.5 \\
7.5 \\
7.5 \\
7.5 \\
7.5 \\
7.5 \\
7.5 \\
7.5 \\
7.5\end{array}$ & $\begin{array}{c}301 \\
41 \\
26 \\
21 \\
18 \\
16 \\
15 \\
12 \\
9.2 \\
19\end{array}$ & $\begin{array}{l}11 \ldots \ldots \\
12 \ldots \ldots \\
13 \ldots \ldots \\
14 \ldots \ldots \\
15 \ldots \ldots \\
16 \ldots \ldots \\
17 \ldots \ldots \\
18 \ldots \ldots \\
19 \ldots \ldots \\
20 \ldots \ldots\end{array}$ & $\begin{array}{l}7.6 \\
7.6 \\
7.6 \\
7.6 \\
7.6 \\
7.6 \\
7.6 \\
7.6 \\
7.6 \\
7.6\end{array}$ & $\begin{array}{l}13 \\
9.4 \\
14 \\
13 \\
9.0 \\
7.8 \\
6.9 \\
6.7 \\
8.2 \\
8.0\end{array}$ & $\begin{array}{l}21 \ldots \ldots \\
22 \ldots \ldots \\
23 \ldots \ldots \\
24 \ldots \ldots \\
25 \ldots \ldots \\
26 \ldots \ldots \\
27 \ldots \ldots \\
28 \ldots \ldots \\
29 \ldots \ldots \\
30 \ldots \ldots \\
31 \ldots \ldots\end{array}$ & $\begin{array}{r}7.6 \\
7.6 \\
7.6 \\
7.6 \\
7.6 \\
7.6 \\
7.6 \\
7.8 \\
8.2 \\
101 \\
527\end{array}$ & $\begin{array}{r}7.8 \\
7.5 \\
7.1 \\
6.9 \\
6.9 \\
7.3 \\
7.3 \\
7.1 \\
--.-1 \\
--.-1\end{array}$ \\
\hline $\begin{array}{l}\text { onthly } \\
\text { anoff }\end{array}$ & \multicolumn{6}{|c|}{$\begin{array}{l}\text { mean discharge, in cubic feet per second } \ldots \ldots \ldots \ldots \ldots \ldots \ldots \ldots \ldots \ldots \ldots \\
\text { in acre-feet. } \ldots \ldots \ldots \ldots \ldots \ldots \ldots \ldots \ldots \ldots \ldots \ldots\end{array}$} & $\begin{array}{r}27.4 \\
1,680\end{array}$ & $\begin{array}{r}22.6 \\
1,250\end{array}$ \\
\hline
\end{tabular}

Gage he1ght, in feet, and discharge, in cubic feet per second, at indicated time, 1963

\begin{tabular}{|c|c|c|c|c|c|c|c|c|c|c|c|}
\hline Date & Hour & $\begin{array}{c}\text { Gage } \\
\text { helght }\end{array}$ & $\begin{array}{c}\text { Dis- } \\
\text { charge }\end{array}$ & Date & Hour & $\begin{array}{c}\text { Gage } \\
\text { height }\end{array}$ & $\begin{array}{c}\text { Dis- } \\
\text { charge }\end{array}$ & Date & Hour & $\begin{array}{c}\text { Gage } \\
\text { helght }\end{array}$ & $\begin{array}{c}\text { Dis- } \\
\text { charge }\end{array}$ \\
\hline $\begin{array}{r}\operatorname{Jan} .29 \\
30\end{array}$ & $\begin{array}{l}2400 \\
0600 \\
0800 \\
1300 \\
1400 \\
1600 \\
1900 \\
2100 \\
2200 \\
2400\end{array}$ & $\begin{array}{l}2.76 \\
2.75 \\
2.83 \\
3.50 \\
3.90 \\
4.42 \\
4.22 \\
4.76 \\
4.82 \\
4.59\end{array}$ & $\begin{array}{c}9.2 \\
{ }^{9.0} \\
11 \\
57 \\
108 \\
200 \\
161 \\
273 \\
287 \\
236\end{array}$ & Jan. 31 & $\begin{array}{l}0200 \\
0400 \\
0600 \\
0800 \\
1000 \\
1200 \\
1400 \\
1600 \\
1900 \\
2000 \\
2200\end{array}$ & $\begin{array}{l}4.48 \\
5.55 \\
4.97 \\
5.40 \\
5.34 \\
5.57 \\
6.20 \\
6.72 \\
5.60 \\
5.97 \\
5.55\end{array}$ & $\begin{array}{l}212 \\
480 \\
323 \\
435 \\
417 \\
486 \\
700 \\
908 \\
495 \\
615 \\
480\end{array}$ & $\begin{array}{l}\text { Jan. } 31 \\
\text { Feb. } 1\end{array}$ & $\begin{array}{l}2400 \\
0400 \\
0600 \\
0800 \\
1000 \\
1200 \\
1400 \\
1800 \\
2400\end{array}$ & $\begin{array}{l}7.38 \\
\\
5.40 \\
4.98 \\
5.37 \\
4.70 \\
4.47 \\
4.14 \\
3.84 \\
3.57\end{array}$ & $\begin{array}{r}1,170 \\
435 \\
325 \\
426 \\
260 \\
210 \\
147 \\
100 \\
65\end{array}$ \\
\hline
\end{tabular}

11-2158. Teakettle Creek at site No. 3, near Patterson Mountain, Calif.

Location. --Lat $36^{\circ} 57140^{\prime \prime}$, long $11^{\circ} 01^{\prime} 35^{\prime \prime}$, in $\mathrm{NE} \frac{1}{4} \mathrm{sec} .21$, T.11 S., R.27 E., 1.6 miles east of Patterson Mountain, 1.8 miles upstream from mouth, and' 2.9 miles north of Black Rock Reservoir.

Drainage area. $--0.86 \mathrm{sq} \mathrm{mi}$.

Gage-height record.--Water-stage recorder graph. Datum of gage is 6,705.4 ft above mean sea level.

Discharge record. --Stage-discharge relation defined by computation of flow over $90^{\circ}$ sharp-crested $V$-notch weir and sharp-crested Cippoletti weir.

Maxima.-January-February 1963: Discharge, 99.0 cfs 0132 hours Feb. 1 (gage height, $3.81 \mathrm{ft}$ ).

1957 to December 1962: Discharge, $18.4 \mathrm{cfs} F e b .16,1958$ (gage height, $6.24 \mathrm{ft}$, at datum $4.00 \mathrm{ft}$ lower.

Remarks.--Records furnished by U.S. Forest Service. 
Mean discharge, in cubic feet per second, 1963, of Teakettle Creek at site No. 3 near Patterson Mountain, Calif.

\begin{tabular}{|c|c|c|c|c|c|c|c|c|}
\hline Day & January & February & Day & January & February & Day & January & February \\
\hline $\begin{array}{c}1 \ldots \ldots \\
2 \ldots \ldots \\
4 \ldots \ldots \\
5 \ldots \ldots \\
6 \ldots \ldots \\
8 \ldots \ldots \\
9 \ldots \ldots \\
10 \ldots \ldots\end{array}$ & $\begin{array}{l}0.28 \\
.28 \\
.29 \\
.28 \\
.28 \\
.27 \\
.27 \\
.27 \\
.27 \\
.27\end{array}$ & $\begin{array}{c}46.7 \\
6.05 \\
4.28 \\
3.66 \\
3.21 \\
2.85 \\
2.67 \\
2.46 \\
2.51 \\
2.59\end{array}$ & $\begin{array}{l}11 \ldots \ldots \\
12 \ldots \ldots \\
13 \ldots \ldots \\
14 \ldots \ldots \\
15 \ldots \ldots \\
16 \ldots \ldots \\
17 \ldots \ldots \\
18 \ldots \ldots \\
19 \ldots \ldots \\
20 \ldots \ldots\end{array}$ & $\begin{array}{l}0.26 \\
.22 \\
.20 \\
.26 \\
.25 \\
.25 \\
.25 \\
.25 \\
.24 \\
.24\end{array}$ & $\begin{array}{l}2.30 \\
2.21 \\
2.23 \\
2.11 \\
2.02 \\
1.93 \\
1.84 \\
1.81 \\
1.80 \\
1.82\end{array}$ & $\begin{array}{l}21 \ldots \ldots \\
22 \ldots \ldots \\
23 \ldots \ldots \\
24 \ldots \ldots \\
25 \ldots \ldots \\
26 \ldots \ldots \\
27 \ldots \ldots \\
28 \ldots \ldots \\
29 \ldots \ldots \\
30 \ldots \ldots \\
31 \ldots \ldots\end{array}$ & $\begin{array}{r}0.24 \\
.24 \\
.24 \\
.26 \\
.28 \\
.28 \\
.28 \\
.27 \\
.27 \\
22.2 \\
36.4\end{array}$ & $\begin{array}{r}1.75 \\
1.68 \\
1.66 \\
1.65 \\
1.64 \\
1.65 \\
1.62 \\
1.56 \\
-.-1-. \\
-.--.-\end{array}$ \\
\hline $\begin{array}{l}\text { onthly } \\
\text { dnoffe, } \\
\text { anoff, }\end{array}$ & $\begin{array}{l}\text { ean a1 } \\
\text { inch } \\
n \text { acre }\end{array}$ & & & & & & $\begin{array}{r}2.13 \\
2.86 \\
131 \\
\end{array}$ & $\begin{array}{r}3.94 \\
4.77 \\
219 \\
\end{array}$ \\
\hline
\end{tabular}

Gage height, in feet, and discharge, in cublc feet per second, at indicated time, 1963

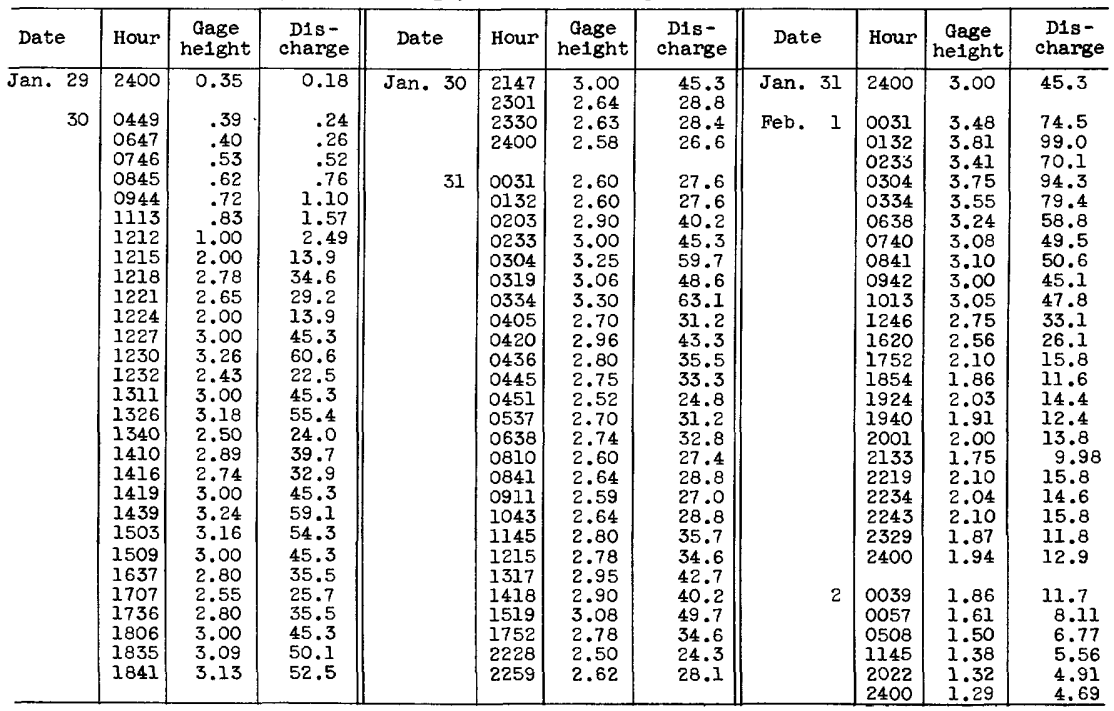

11-2158.1. Teakettle Creek tributary No. 7 near Patterson Mountain, Calif.

Location.--Lat $36^{\circ} 57^{\prime} 45^{\prime \prime}$, long $119^{\circ} 01^{\prime} 20^{\prime \prime}$, in NW $\frac{1}{4} N W^{\frac{1}{4}}$ sec.22, T.1I S., R.27 E., $0.3 \mathrm{mile}$ upstream from junction with Teakettle Creek, 1.9 miles east of Patterson Mountain, and 3.0 miles north of Black Rock Reservoir.

Drainage area. $--0.11 \mathrm{sq} \mathrm{mi}$.

Gage-height record.--Water-stage recorder graph. Altitude of gage is $6,800 \mathrm{f} t$ (from topographic map)

Discharge record.--Stage-discharge relation defined by computation of flow over $90^{\circ}$ sharp-crested $v$-notch weir.

Maxima.--January-February 1963: Discharge, 10.3 cfs 0430 hours Jan. 31 (gage helght, $\left.1.77 \mathrm{ft}^{\prime}\right)$.

1957 to December 1962: Discharge, $5.01 \mathrm{cfs}$ Dec. 16, 1957 (gage height, $5.33 \mathrm{ft}$, at datum $4.00 \mathrm{ft}$ lower).

Remarks.--Records furnished by U.S. Forest Service. 
Mean discharge, in cublc feet per second, 1963, of Teakettle Creek tributary No. 7 near Patterson Mountain, Calif.

\begin{tabular}{|c|c|c|c|c|c|c|c|c|}
\hline Day & January & February & Day & January & February & Day & January & February \\
\hline $\begin{array}{c}1 \ldots \ldots \\
2 \ldots \ldots \\
3 \ldots \ldots \\
4 \ldots \ldots \\
5 \ldots \ldots \\
7 \ldots \ldots \\
8 \ldots \ldots \\
9 \ldots \ldots \\
10 \ldots \ldots\end{array}$ & $\begin{array}{l}0.01 \\
.01 \\
.01 \\
.01 \\
.01 \\
.01 \\
.01 \\
.01 \\
.01 \\
.01\end{array}$ & $\begin{array}{r}5.14 \\
1.10 \\
.73 \\
.58 \\
.47 \\
.39 \\
.34 \\
.31 \\
.41 \\
.52\end{array}$ & $\begin{array}{l}11 \ldots \ldots \\
12 \ldots \ldots \\
13 \ldots \ldots \\
14 \ldots \ldots \\
15 \ldots \ldots \\
16 \ldots \ldots \\
17 \ldots \ldots \\
18 \ldots \ldots \\
19 \ldots \ldots \\
20 \ldots \ldots\end{array}$ & $\begin{array}{l}0.01 \\
.01 \\
.01 \\
.01 \\
.01 \\
.01 \\
.01 \\
.01 \\
.01 \\
.01\end{array}$ & $\begin{array}{l}0.41 \\
.36 \\
.41 \\
.38 \\
.32 \\
.31 \\
.28 \\
.27 \\
.26 \\
.26\end{array}$ & $\begin{array}{l}21 \ldots \ldots \\
22 \ldots \ldots \\
23 \ldots \ldots \\
24 \ldots \ldots \\
25 \ldots \ldots \\
26 \ldots \ldots \\
27 \ldots \ldots \\
28 \ldots \ldots \\
29 \ldots \ldots \\
30 \ldots \ldots \\
31 \ldots \ldots\end{array}$ & $\begin{array}{l}0.01 \\
.01 \\
.01 \\
.01 \\
.01 \\
.01 \\
.01 \\
.01 \\
.01 \\
.61 \\
8.02\end{array}$ & $\begin{array}{r}0.25 \\
.24 \\
.22 \\
.21 \\
.20 \\
.19 \\
.19 \\
.18 \\
---.- \\
----.- \\
---.-\end{array}$ \\
\hline \multicolumn{7}{|c|}{ 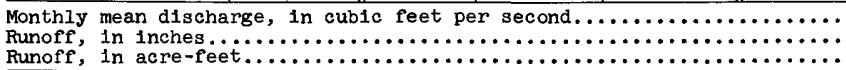 } & $\begin{array}{l}0.29 \\
3.02 \\
17.7\end{array}$ & $\begin{array}{l}0.53 \\
5.05 \\
29.6\end{array}$ \\
\hline
\end{tabular}

Gage height, in feet, and discharge, in cublc feet per second, at indicated time, 1963

\begin{tabular}{|c|c|c|c|c|c|c|c|c|c|c|c|}
\hline Date & Hour & $\begin{array}{c}\text { Gage } \\
\text { height }\end{array}$ & $\begin{array}{l}\text { Dis- } \\
\text { charge }\end{array}$ & Date & Hour & $\begin{array}{c}\text { Gage } \\
\text { helght }\end{array}$ & $\begin{array}{c}\text { Dis- } \\
\text { charge }\end{array}$ & Date & Hour & $\begin{array}{c}\text { Gage } \\
\text { height }\end{array}$ & $\begin{array}{c}\text { D1s- } \\
\text { charge }\end{array}$ \\
\hline $\begin{array}{r}\text { Jan. } 29 \\
30\end{array}$ & $\begin{array}{l}2400 \\
0705 \\
0901 \\
1301 \\
1331 \\
1456 \\
1603 \\
1716 \\
1808 \\
1902 \\
2107 \\
2217 \\
2342 \\
2400 \\
0130 \\
0151 \\
\end{array}$ & $\begin{array}{l}0.14 \\
.17 \\
.25 \\
.48 \\
.49 \\
.45 \\
.47 \\
.57 \\
.63 \\
.68 \\
.91 \\
1.01 \\
1.06 \\
1.31 \\
1.48 \\
1.64 \\
\end{array}$ & $\begin{array}{r}0.02 \\
.03 \\
.08 \\
.40 \\
.43 \\
.34 \\
.38 \\
.63 \\
.79 \\
.94 \\
1.96 \\
2.58 \\
2.87 \\
4.89 \\
\\
6.59 \\
8.48\end{array}$ & Jan. 31 & $\begin{array}{l}0210 \\
0310 \\
0430 \\
0623 \\
0811 \\
0935 \\
1018 \\
1154 \\
1306 \\
1422 \\
1522 \\
1558 \\
1631 \\
1932 \\
2017 \\
2117 \\
2400\end{array}$ & $\begin{array}{l}1.52 \\
1.68 \\
1.77 \\
1.53 \\
1.66 \\
1.60 \\
1.62 \\
1.62 \\
1.66 \\
1.62 \\
1.68 \\
1.64 \\
1.67 \\
1.49 \\
1.55 \\
1.46 \\
1.76\end{array}$ & $\begin{array}{c}7.02 \\
8.96 \\
10.3 \\
7.17 \\
8.72 \\
8.02 \\
8.28 \\
8.28 \\
8.74 \\
8.28 \\
8.96 \\
8.56 \\
8.94 \\
6.72 \\
7.34 \\
6.32 \\
10.1\end{array}$ & Feb. 1 & $\begin{array}{l}0137 \\
0206 \\
0627 \\
0728 \\
0938 \\
1137 \\
1327 \\
1452 \\
1547 \\
1804 \\
1902 \\
2140 \\
2400 \\
\\
0602 \\
1159 \\
1534 \\
2400\end{array}$ & $\begin{array}{r}1.71 \\
1.67 \\
1.54 \\
1.59 \\
1.49 \\
1.34 \\
1.13 \\
1.10 \\
1.11 \\
.99 \\
.99 \\
.90 \\
.84 \\
.75 \\
.70 \\
.69 \\
.65\end{array}$ & $\begin{array}{l}9.47 \\
8.94 \\
7.31 \\
7.88 \\
6.72 \\
5.16 \\
3.39 \\
3.15 \\
3.23 \\
2.42 \\
2.42 \\
1.90 \\
1.61 \\
1.22 \\
1.02 \\
1.01 \\
.85\end{array}$ \\
\hline
\end{tabular}

11-2158.2. Teakettle Creek tributary No. 2 near Patterson Mountain, Calif.

Location.--Lat $36^{\circ} 57^{\prime} 3^{\prime \prime}$, long $119^{\circ} 02^{\prime} 00^{\prime \prime}$, in SE $\frac{1}{4} N W_{4}^{\frac{1}{4}}$ sec.21, T.11 S., R.27 E., $0.8 \mathrm{mile}$ upstream from junction with Téakettle Creek, 1.2 miles east of

Patterson Mountain, and 2.8 miles north of Black Rock Reservoir.

Drainage area. $--0.85 \mathrm{sq} \mathrm{mi}$.

Gage-height record. - Water-stage recorder graph. Datum of gage is 6,905.4 ft above mean sea level.

Discharge record.--Stage-discharge relation defined by computation of flow over sharp-crested $90^{\circ} \mathrm{V}$-notch weir and sharp-crested Cippoletti weir.

Maxima.--January-February 1963: Discharge, $53.7 \mathrm{cfs} 0507$ hours Jan. 31 (gage height, $3.35 \mathrm{ft}^{\prime}$ ).

1957 to December 1962: Discharge, 13.6 cfs May 30, 1958 (gage height, $3.98 \mathrm{ft}$, at datum $2.00 \mathrm{ft}$ lower).

Remarks.--Records furnished by U.S. Forest Service.

Mean discharge, in cubic feet per second, 1963

\begin{tabular}{|c|c|c|c|c|c|c|c|c|}
\hline Day & January & February & Day & January & February & Day & January & February \\
\hline $\begin{array}{c}1 \ldots \ldots \\
2 \ldots \ldots \\
4 \ldots \ldots \\
5 \ldots \ldots \\
6 \ldots \ldots \\
7 \ldots \ldots \\
9 \ldots \ldots \\
10 \ldots \ldots\end{array}$ & $\begin{array}{l}0.20 \\
.21 \\
.21 \\
.20 \\
.20 \\
.20 \\
.20 \\
.20 \\
.20 \\
.19\end{array}$ & $\begin{array}{r}25.1 \\
5.64 \\
3.70 \\
3.11 \\
2.59 \\
2.29 \\
2.18 \\
1.97 \\
2.08 \\
1.88\end{array}$ & $\begin{array}{l}11 \ldots \ldots \\
12 \ldots \ldots \\
13 \ldots \ldots \\
14 \ldots \ldots \\
15 \ldots \ldots \\
16 \ldots \ldots \\
17 \ldots \ldots \\
18 \ldots \ldots \\
19 \ldots \ldots \\
20 \ldots \ldots\end{array}$ & $\begin{array}{r}0.17 \\
.15 \\
.16 \\
.18 \\
.18 \\
.18 \\
.17 \\
.18 \\
.17 \\
.17\end{array}$ & $\begin{array}{l}1.76 \\
1.72 \\
1.67 \\
1.62 \\
1.58 \\
1.53 \\
1.46 \\
1.43 \\
1.41 \\
1.42\end{array}$ & $\begin{array}{l}21 \ldots \ldots \\
22 \ldots \ldots \\
23 \ldots \ldots \\
24 \ldots \ldots \\
25 \ldots \ldots \\
26 \ldots \ldots \\
27 \ldots \ldots \\
28 \ldots \ldots \\
29 \ldots \ldots \\
30 \ldots \ldots \\
31 \ldots \ldots\end{array}$ & $\begin{array}{r}0.18 \\
.20 \\
.20 \\
.20 \\
.20 \\
.20 \\
.19 \\
.19 \\
.19 \\
7.11 \\
27.5\end{array}$ & $\begin{array}{r}1.38 \\
1.32 \\
1.30 \\
1.30 \\
1.31 \\
1.33 \\
1.31 \\
1.26 \\
---.-- \\
-1 .-1-\end{array}$ \\
\hline \multicolumn{7}{|l|}{$\begin{array}{l}\text { Monthly } \\
\text { Runoff, } \\
\text { Runoff, }\end{array}$} & $\begin{array}{l}1.29 \\
1.75 \\
79.5 \\
\end{array}$ & $\begin{array}{r}2.734 \\
3.35 \\
152 \\
\end{array}$ \\
\hline
\end{tabular}


Gage height, in feet, and discharge, in cubic feet per second, at indicated time, 1963, of

\begin{tabular}{|c|c|c|c|c|c|c|c|c|c|c|c|}
\hline Date & Hour & $\begin{array}{c}\text { Gage } \\
\text { height }\end{array}$ & $\begin{array}{l}\text { Dis- } \\
\text { charge }\end{array}$ & Date & Hour & $\begin{array}{c}\text { Gage } \\
\text { helght }\end{array}$ & $\begin{array}{l}\text { Dis- } \\
\text { charge }\end{array}$ & Date & Hour & $\begin{array}{c}\text { Gage } \\
\text { helght }\end{array}$ & $\begin{array}{l}\text { Dis- } \\
\text { charge }\end{array}$ \\
\hline $\begin{array}{r}\text { Jan. } 29 \\
30\end{array}$ & $\begin{array}{l}2400 \\
0327 \\
0526 \\
0802 \\
1207 \\
1231 \\
1240 \\
1300 \\
1334 \\
1410 \\
1507 \\
1525 \\
1555 \\
1646 \\
1916 \\
2124 \\
2224\end{array}$ & $\begin{array}{r}0.30 \\
.34 \\
.37 \\
.47 \\
.72 \\
1.01 \\
1.73 \\
2.42 \\
1.86 \\
1.83 \\
2.01 \\
2.24 \\
2.05 \\
2.27 \\
1.75 \\
2.18 \\
2.31\end{array}$ & $\begin{array}{c}0.13 \\
.17 \\
.21 \\
.38 \\
1.11 \\
2.53 \\
9.65 \\
22.2 \\
11.5 \\
11.1 \\
14.0 \\
18.3 \\
14.8 \\
19.0 \\
9.93 \\
17.2 \\
19.8\end{array}$ & Jan. 30 & $\begin{array}{l}2354 \\
2400 \\
\\
0229 \\
0259 \\
0501 \\
0507 \\
0605 \\
0638 \\
0647 \\
1111 \\
1301 \\
1322 \\
1444 \\
1508 \\
1554 \\
1743 \\
1921\end{array}$ & $\begin{array}{l}1.95 \\
2.01 \\
2.41 \\
2.67 \\
2.36 \\
3.35 \\
3.26 \\
3.01 \\
2.33 \\
2.47 \\
2.72 \\
2.70 \\
2.93 \\
2.85 \\
2.93 \\
2.61 \\
2.34\end{array}$ & $\begin{array}{l}13.1 \\
14.0 \\
22.0 \\
28.4 \\
21.0 \\
53.7 \\
48.9 \\
38.2 \\
20.2 \\
23.4 \\
29.8 \\
29.4 \\
35.7 \\
33.4 \\
35.8 \\
26.8 \\
20.4\end{array}$ & $\begin{array}{l}\text { Jan. } 31 \\
\text { Feb. } 1\end{array}$ & $\begin{array}{l}2036 \\
2256 \\
2400 \\
\\
0153 \\
0526 \\
0817 \\
1013 \\
1304 \\
1616 \\
2103 \\
2400 \\
0621 \\
1151 \\
1745 \\
2400\end{array}$ & $\begin{array}{l}2.25 \\
3.00 \\
3.26 \\
3.31 \\
3.00 \\
2.74 \\
2.53 \\
2.21 \\
2.01 \\
1.76 \\
1.64 \\
1.46 \\
1.35 \\
1.29 \\
1.23\end{array}$ & $\begin{array}{c}18.6 \\
38.1 \\
49.3 \\
51.8 \\
38.1 \\
30.4 \\
25.0 \\
17.7 \\
14.0 \\
10.1 \\
8.42 \\
6.36 \\
5.24 \\
4.71 \\
4.19\end{array}$ \\
\hline
\end{tabular}

11-2158.3. Teakettle Creek tributary No. 2A near Patterson Mountain, Calif.

Location. --Lat $36^{\circ} 57^{\prime} 25^{\prime \prime}$, long $119^{\circ} 01^{\prime} 50^{\prime \prime}$, in NW $\frac{1}{4} \mathrm{SE} \frac{1}{4} \sec .21$, T.11 S., R.27 E., $0.1 \mathrm{mile}$ upstream from junction w1th Teakettle Creek tributary No. 2, 1.3 miles east of Patterson Mountain, and 2.6 miles north of Black Rock Reservoir.

Drainage area. $--0.27 \mathrm{sq} \mathrm{ml}$.

Gage-he1ght record --Water-stage recorder graph. Datum of gage is 6,924 ft above mean sea level (levels by U.S. Forest Service).

D1scharge record.--Stage-discharge relation defined by computation of flow over $90^{\circ}$ sharp-crested V-notch weir. Maxima - -January-February 1963: D1scharge, $34.7 \mathrm{cfs} 0145$ hours Feb. 1 (gage height,

1957 to December 1962: D1scharge, $5.54 \mathrm{cfs}$ May 22, 1958 (gage he1ght, $5.38 \mathrm{ft}$, at datum $4.00 \mathrm{ft}$ lower).

Remarks.--Records furnished by U.S. Forest Service.

Mean discharge, in cubic feet per second, 1963

\begin{tabular}{|c|c|c|c|c|c|c|c|c|}
\hline Day & January & February & Day & January & February & Day & January & February \\
\hline $\begin{array}{c}\ldots \ldots \\
2 \ldots \ldots \\
3 \ldots \ldots \\
4 \ldots \ldots \\
5 \ldots \ldots \\
7 \ldots \ldots \\
s \ldots \ldots \\
9 \ldots \ldots \\
10 \ldots \ldots\end{array}$ & $\begin{array}{l}0.04 \\
.04 \\
.04 \\
.04 \\
.04 \\
.04 \\
.04 \\
.04 \\
.04 \\
.04\end{array}$ & $\begin{array}{r}11.7 \\
1.96 \\
1.31 \\
1.08 \\
.88 \\
.78 \\
.72 \\
.69 \\
.78 \\
.73\end{array}$ & $\begin{array}{l}11 \ldots \ldots \\
12 \ldots \ldots \\
13 \ldots \ldots \\
14 \ldots \ldots \\
15 \ldots \ldots \\
16 \ldots \ldots \\
17 \ldots \ldots \\
18 \ldots \ldots \\
19 \ldots \ldots \\
20 \ldots \ldots\end{array}$ & $\begin{array}{l}0.04 \\
.04 \\
.03 \\
.03 \\
.03 \\
.03 \\
.03 \\
.03 \\
.03 \\
.03\end{array}$ & $\begin{array}{r}0.66 \\
.62 \\
.63 \\
.63 \\
.59 \\
.57 \\
.54 \\
.53 \\
.53 \\
.54\end{array}$ & $\begin{array}{l}21 \ldots \ldots \\
22 \ldots \ldots \\
23 \ldots \ldots \\
24 \ldots \ldots \\
25 \ldots \ldots \\
26 \ldots \ldots \\
27 \ldots \ldots \\
28 \ldots \ldots \\
29 \ldots \ldots \\
30 \ldots \ldots \\
31 \ldots \ldots\end{array}$ & $\begin{array}{r}0.03 \\
.03 \\
.03 \\
.04 \\
.04 \\
.04 \\
.04 \\
.04 \\
.04 \\
2.40 \\
14.1\end{array}$ & 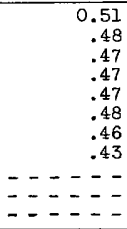 \\
\hline \multicolumn{7}{|l|}{$\begin{array}{l}\text { Monthly } \\
\text { Runoff, } \\
\text { Runoff, }\end{array}$} & $\begin{array}{l}0.57 \\
2.42 \\
34.8\end{array}$ & $\begin{array}{l}1.08 \\
4.17 \\
60.0\end{array}$ \\
\hline
\end{tabular}


Gage height, in feet, and discharge, in cublc feet per second, at 1ndicated t1me, 1963, of Teakettle Creek tributary No. 2 A near Patterson Mountain, Calif.

\begin{tabular}{|c|c|c|c|c|c|c|c|c|c|c|c|}
\hline Date & Hour & $\begin{array}{c}\text { Gage } \\
\text { he1ght }\end{array}$ & $\begin{array}{c}\text { Dis- } \\
\text { charge }\end{array}$ & Date & Hour & $\begin{array}{c}\text { Gage } \\
\text { height }\end{array}$ & $\begin{array}{c}\text { Dis - } \\
\text { charge }\end{array}$ & Date & Hour & $\begin{array}{c}\text { Gage } \\
\text { helght }\end{array}$ & $\begin{array}{l}\text { Dis- } \\
\text { charge }\end{array}$ \\
\hline $\begin{aligned} \text { Jan. } & 29 \\
& 30\end{aligned}$ & $\begin{array}{l}2400 \\
0511 \\
0904 \\
0943 \\
0955 \\
1033 \\
1118 \\
1154 \\
1203 \\
1239 \\
1556 \\
1723 \\
1843 \\
1919 \\
2206 \\
2400\end{array}$ & $\begin{array}{r}0.18 \\
.22 \\
.36 \\
.37 \\
.43 \\
.53 \\
.63 \\
.58 \\
.60 \\
.80 \\
1.25 \\
1.34 \\
1.22 \\
1.24 \\
1.59 \\
1.52\end{array}$ & $\begin{array}{l}0.04 \\
.06 \\
.19 \\
.21 \\
.30 \\
.52 \\
.78 \\
.64 \\
.69 \\
1.45 \\
4.30 \\
5.19 \\
4.10 \\
4.27 \\
7.88 \\
7.04\end{array}$ & Jan. 31 & $\begin{array}{l}0500 \\
0630 \\
0900 \\
1000 \\
1130 \\
1200 \\
1415 \\
1430 \\
1600 \\
1630 \\
1700 \\
1730 \\
1800 \\
1936 \\
2130 \\
2354 \\
2400\end{array}$ & $\begin{array}{l}1.91 \\
1.74 \\
1.99 \\
1.95 \\
2.06 \\
2.02 \\
2.22 \\
2.13 \\
2.38 \\
2.29 \\
2.40 \\
2.29 \\
2.32 \\
2.02 \\
1.76 \\
2.53 \\
2.35\end{array}$ & $\begin{array}{c}12.4 \\
9.79 \\
13.7 \\
13.1 \\
15.0 \\
14.3 \\
18.0 \\
16.3 \\
21.4 \\
19.5 \\
21.9 \\
19.5 \\
20.1 \\
14.3 \\
10.1 \\
25.0 \\
20.7\end{array}$ & Feb. $l$ & $\begin{array}{l}0400 \\
0500 \\
0615 \\
0730 \\
0800 \\
0900 \\
0951 \\
1200 \\
1430 \\
1630 \\
2000 \\
2400 \\
\\
0614 \\
0854 \\
1533 \\
1813\end{array}$ & $\begin{array}{l}2.42 \\
2.22 \\
2.08 \\
1.95 \\
2.00 \\
1.86 \\
1.87 \\
1.62 \\
1.42 \\
1.32 \\
1.22 \\
1.12 \\
.94 \\
.90 \\
.88 \\
.85\end{array}$ & $\begin{array}{r}22.3 \\
18.0 \\
15.3 \\
13.1 \\
13.9 \\
11.6 \\
11.7 \\
8.25 \\
5.95 \\
4.97 \\
4.09 \\
3.30 \\
2.13 \\
1.92 \\
1.84 \\
1.65\end{array}$ \\
\hline 31 & $\begin{array}{l}0100 \\
0200\end{array}$ & $\begin{array}{l}1.55 \\
1.57 \\
\end{array}$ & $\begin{array}{l}7.40 \\
7.64 \\
\end{array}$ & Feb. 1 & $\begin{array}{l}0145 \\
0200\end{array}$ & $\begin{array}{l}2.89 \\
2.80\end{array}$ & $\begin{array}{l}34.7 \\
31.9\end{array}$ & & & & \\
\hline
\end{tabular}

11-2158.4. Teakettle Creek tributary No. 1 near Patterson Mountain, Cal1f.

Location.--Lat $36^{\circ} 57^{\prime} 00^{\prime \prime}$, long $119^{\circ} 01^{\prime} 10^{\prime \prime}$, in NW $\frac{1}{4} N W \frac{1}{4}$ sec.27, T.11 S., R.27 E., $0.2 \mathrm{mi}$ le upstream from confluence with 'Teakettle Creek, 2.1 miles north of Black Rock Reservoir, and 2.2 miles east of Patterson Mountain.

Drainage area. $--0.77 \mathrm{sq} \mathrm{mi}$.

Gage-height record;-Water-stage recorder graph. Datum of gage is $6,407.7 \mathrm{ft}$ above mean sea leveI (levels by U.S. Forest Service).

D1scharge record.--Stage-discharge relation defined by computation of flow over $90^{\circ}$ sharp-crested $V$-notch weir, and sharp-crested Cippoletti weir.

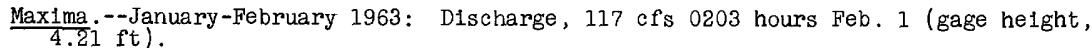

1957 to December 1962: Discharge, 13.7 cfs May 22, 1958 (gage he1ght,5.99 ft, at datum $4.00 \mathrm{ft}$ lower).

Remarks.--Records furnished by U.S. Forest Service.

Mean discharge, in cubic feet per second, 1963

\begin{tabular}{|c|c|c|c|c|c|c|c|c|}
\hline Day & January & February & Day & January & February & Day & January & February \\
\hline $\begin{array}{c}\ldots \ldots \\
2 \ldots \ldots \\
3 \ldots \ldots \\
4 \ldots \ldots \\
5 \ldots \ldots \\
7 \ldots \ldots \\
8 \ldots \ldots \\
9 \ldots \ldots \\
10 \ldots \ldots\end{array}$ & $\begin{array}{l}0.20 \\
.20 \\
.20 \\
.20 \\
.20 \\
.19 \\
.19 \\
.19 \\
.19 \\
.20\end{array}$ & $\begin{array}{r}37.2 \\
7.08 \\
4.54 \\
3.67 \\
3.02 \\
2.67 \\
2.40 \\
2.18 \\
2.36 \\
2.52\end{array}$ & $\begin{array}{l}13 \ldots \ldots \\
12 \ldots \ldots \\
13 \ldots \ldots \\
14 \ldots \ldots \\
15 \ldots \ldots \\
16 \ldots \ldots \\
17 \ldots \ldots \\
18 \ldots \ldots \\
19 \ldots \ldots \\
20 \ldots \ldots\end{array}$ & $\begin{array}{r}0.20 \\
.17 \\
.18 \\
.19 \\
.19 \\
.19 \\
.19 \\
.19 \\
.18 \\
.19\end{array}$ & $\begin{array}{l}2.14 \\
2.02 \\
2.10 \\
2.00 \\
1.88 \\
1.81 \\
1.75 \\
1.69 \\
1.66 \\
1.67\end{array}$ & $\begin{array}{l}21 \ldots \ldots \\
22 \ldots \ldots \\
23 \ldots \ldots \\
24 \ldots \ldots \\
25 \ldots \ldots \\
26 \ldots \ldots \\
27 \ldots \ldots \\
28 \ldots \ldots \\
29 \ldots \ldots \\
30 \ldots \ldots \\
31 \ldots \ldots\end{array}$ & $\begin{array}{r}0.19 \\
.19 \\
.19 \\
.19 \\
.19 \\
.18 \\
.18 \\
.18 \\
.18 \\
5.71 \\
30.6\end{array}$ & $\begin{array}{r}1.62 \\
1.56 \\
1.50 \\
1.47 \\
1.46 \\
1.46 \\
1.44 \\
1.37 \\
---.-- \\
--.--.-\end{array}$ \\
\hline \multicolumn{7}{|l|}{$\begin{array}{l}\text { Monthly } \\
\text { Runoff, } \\
\text { Runoff, }\end{array}$} & $\begin{array}{l}1.35 \\
2.02 \\
82.9\end{array}$ & $\begin{array}{r}3.51 \\
4.75 \\
195\end{array}$ \\
\hline
\end{tabular}


Gage height, in feet, and discharge, in cubic feet per second, at Indicated time, 1963, of Teakettle Creek tributary No. I near Patterson Mountain, Calif.

\begin{tabular}{|c|c|c|c|c|c|c|c|c|c|c|c|}
\hline Date & Hour & $\begin{array}{c}\text { Gage } \\
\text { height }\end{array}$ & $\begin{array}{l}\text { Dis- } \\
\text { charge }\end{array}$ & Date & Hour & $\begin{array}{c}\text { Gage } \\
\text { helght }\end{array}$ & $\begin{array}{l}\text { D1s- } \\
\text { charge }\end{array}$ & Date & Hour & $\begin{array}{c}\text { Gage } \\
\text { he1ght }\end{array}$ & $\begin{array}{l}\text { D1s- } \\
\text { charge }\end{array}$ \\
\hline $\begin{array}{r}\text { Jan. } 29 \\
30\end{array}$ & $\begin{array}{l}2400 \\
0312 \\
0413 \\
0458 \\
0559 \\
0853 \\
0954 \\
1055 \\
1155 \\
1235 \\
1422 \\
1629 \\
1730 \\
1902 \\
2003 \\
2103 \\
2106 \\
2122 \\
2158\end{array}$ & $\begin{array}{r}0.28 \\
.28 \\
.31 \\
.37 \\
.41 \\
.64 \\
.75 \\
1.01 \\
1.61 \\
1.65 \\
1.62 \\
1.76 \\
1.74 \\
1.84 \\
1.70 \\
1.76 \\
2.01 \\
2.05 \\
1.90\end{array}$ & $\begin{array}{c}0.10 \\
.11 \\
.14 \\
.21 \\
.27 \\
.83 \\
1.22 \\
2.55 \\
8.10 \\
8.61 \\
8.22 \\
10.1 \\
9.89 \\
11.3 \\
9.34 \\
10.1 \\
14.0 \\
14.8 \\
12.3\end{array}$ & $\begin{array}{r}\operatorname{Jan} . \\
30 \\
31\end{array}$ & $\begin{array}{l}2400 \\
0045 \\
0300 \\
0500 \\
0651 \\
0800 \\
1100 \\
1200 \\
1230 \\
1409 \\
1457 \\
1530 \\
1600 \\
1700 \\
1745 \\
1800 \\
2000 \\
2121 \\
2200\end{array}$ & $\begin{array}{l}2.04 \\
2.05 \\
2.25 \\
2.48 \\
2.36 \\
2.56 \\
2.70 \\
2.74 \\
2.92 \\
3.03 \\
3.10 \\
3.24 \\
3.20 \\
3.28 \\
3.20 \\
3.24 \\
2.54 \\
2.37 \\
2.41\end{array}$ & $\begin{array}{l}14.6 \\
14.8 \\
18.6 \\
23.7 \\
20.9 \\
25.7 \\
29.5 \\
30.4 \\
35.4 \\
39.5 \\
42.5 \\
49.3 \\
46.8 \\
51.3 \\
46.8 \\
49.3 \\
25.1 \\
21.1 \\
22.0\end{array}$ & $\operatorname{Jan} .31$ & $\begin{array}{l}2345 \\
2357 \\
2400 \\
0203 \\
0304 \\
0506 \\
0810 \\
1013 \\
1317 \\
1620 \\
1924 \\
2400 \\
\\
0230 \\
0430 \\
0630 \\
1130 \\
1700 \\
2400\end{array}$ & $\begin{array}{l}3.39 \\
3.49 \\
3.43 \\
4.21 \\
3.90 \\
3.32 \\
2.98 \\
2.74 \\
2.32 \\
2.10 \\
1.96 \\
1.79 \\
1.70 \\
1.62 \\
1.56 \\
1.49 \\
1.44 \\
1.37\end{array}$ & $\begin{array}{c}57.5 \\
63.2 \\
59.6 \\
117 \\
91.1 \\
53.1 \\
37.5 \\
30.4 \\
20.0 \\
15.6 \\
13.1 \\
10.6 \\
\\
9.35 \\
8.18 \\
7.56 \\
6.69 \\
6.15 \\
5.44\end{array}$ \\
\hline
\end{tabular}

11-2165. North Fork Kings River above Dinkey Creek, at Balch Camp, Calif.

Location.--Lat $36^{\circ} 54^{\prime} 10^{\prime \prime}$, long $119^{\circ} 07^{\prime} 15^{\prime \prime}$, in NW $\frac{1}{4}$ sec.10, T.12 S., R.26 E., on left bank $100 \mathrm{ft}$ downstream from bridge at Balch Camp, $200 \mathrm{ft}$ upstream from Dinkey Creek, and 9.3 miles east of Trimmer.

Drainage area. $--250 \mathrm{sq} \mathrm{mi}$.

Gage-helght record.--Water-stage recorder graph. Altitude of gage is 1,240 ft (from river-profile map).

Discharge record.--Stage-discharge relation defined by current-meter measurements below 890 cfs. Backwater from Dinkey Creek Jan. 31 to Feb. 2.

Maxima.--January-February 1963: Discharge, 14,000 cfs 0200 hours Feb. 1 (gage height, $13.24 \mathrm{ft}$, backwater from Dinkey Creek).

1919-30 (prior to regulation by Wishon and Courtright Reservolrs): Discharge, 6,080 cfs June 4, 1922 (gage height, $13.18 \mathrm{ft}$ ).

1960 to December 1962: Discharge, 2,460 cfs June 27, 1962 (gage height, $6.58 \mathrm{ft})$.

Remarks.--Flow regulated by Courtright and Wishon Reservolrs (see stations 11-2i45.5 and 11-2148), Black Rock Reservoir (capacity, 1,000 acre-ft), Balch afterbay (capacity, 125 acre-ft), and Haas and Balch powerplants. Diversion from Balch afterbay to Kings River powerhouse began Mar. 1, 1962 .

Mean discharge, in cubic feet per second, 1963

\begin{tabular}{|c|c|c|c|c|c|c|c|c|}
\hline Day & January & February & Day & January & February & Day & January & February \\
\hline $\begin{array}{r}1 \ldots . . \\
2 \ldots \ldots \\
3 \ldots \ldots \\
4 \ldots \ldots \\
5 \ldots \ldots \\
6 \ldots \ldots \\
7 \ldots \ldots \\
8 \ldots \ldots \\
9 \ldots \ldots \\
10 . \ldots .\end{array}$ & $\begin{array}{r}8.0 \\
8.0 \\
8.0 \\
8.2 \\
8.2 \\
8.0 \\
8.0 \\
9.5 \\
13 \\
9.8\end{array}$ & $\begin{array}{r}, 700 \\
110 \\
25 \\
14 \\
11 \\
7.9 \\
5.4 \\
6.3 \\
7.8 \\
26\end{array}$ & 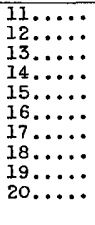 & $\begin{array}{l}7.7 \\
8.0 \\
7.7 \\
7.7 \\
7.7 \\
7.7 \\
7.7 \\
7.7 \\
7.7 \\
7.7\end{array}$ & $\begin{array}{l}11 \\
8.1 \\
15 \\
11 \\
8.1 \\
7.2 \\
6.4 \\
5.9 \\
6.1 \\
7.2\end{array}$ & $\begin{array}{l}21 \ldots \ldots \\
22 \ldots \ldots \\
23 \ldots \ldots \\
24 \ldots \ldots \\
25 \ldots \ldots \\
26 \ldots \ldots \\
27 \ldots \ldots \\
28 \ldots \ldots \\
29 \ldots \ldots \\
30 \ldots \ldots \\
31 \ldots \ldots\end{array}$ & $\begin{array}{r}7.7 \\
7.7 \\
7.7 \\
7.5 \\
7.3 \\
7.7 \\
7.7 \\
7.7 \\
9.0 \\
84 \\
4,000\end{array}$ & $\begin{array}{r}6.8 \\
6.4 \\
6.3 \\
5.9 \\
7.2 \\
9.5 \\
9.8 \\
10 \\
-0 . \\
-0.0\end{array}$ \\
\hline $\begin{array}{l}\text { nthly } \\
\text { noff, }\end{array}$ & dis & $\ldots$ & & & & & $\begin{array}{r}139 \\
8,570 \\
\end{array}$ & $\begin{array}{r}181 \\
10,040 \\
\end{array}$ \\
\hline
\end{tabular}


11-2168. Rock Creek at Dinkey Creek, Calif.

Location.--Lat $37^{\circ} 05^{\prime} 25^{\prime \prime}$, long $119^{\circ} 09^{\prime} 40^{\prime \prime}$, in SE $\frac{1}{4} \mathrm{NW} \frac{1}{4} \sec .5$, T.10 S., R.26 E., on right bank 0.4 mile northwest of town of Dinkey Creek and 0.5 mile upstream from mouth.

Drainage area. $--7.6 \mathrm{sq} \mathrm{mi}$.

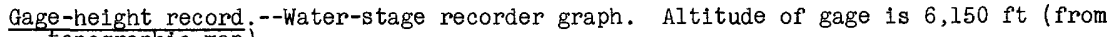
topographic mapj.

Discharge record.--Stage-discharge relation defined by current-meter measurements below $140 \mathrm{cfs}$ and by slope-area measurement at $2,850 \mathrm{cfs}$.

Maxima.--January-February 1963: Discharge, 2,850 cfs 0100 hours Feb. 1 (gage helght, $8.68 \mathrm{ft}$, from recorder graph; $9.9 \mathrm{ft}$, from floodmarks).

1960 to December 1962: Discharge, $776 \mathrm{cf}$ ' Feb. 9, 1962 (gage helght, $6.69 \mathrm{ft}$.

Mean discharge, in cub1c feet per second, 1963

\begin{tabular}{|c|c|c|c|c|c|c|c|c|}
\hline Day & January & February & Day & January & February & Day & January & February \\
\hline $\begin{array}{c}1 \ldots \ldots \\
2 \ldots \ldots \\
3 \ldots \ldots \\
5 \ldots \ldots \\
6 \ldots \ldots \\
7 \ldots \ldots \\
9 \ldots \ldots \\
10 \ldots \ldots\end{array}$ & $\begin{array}{r}0.2 \\
.2 \\
.3 \\
.3 \\
.3 \\
.3 \\
.3 \\
.3 \\
.3 \\
.3\end{array}$ & $\begin{array}{r}746 \\
96 \\
54 \\
43 \\
36 \\
32 \\
30 \\
26 \\
25 \\
28\end{array}$ & $\begin{array}{l}11 \ldots \ldots \\
12 \ldots \ldots \\
13 \ldots \ldots \\
14 \ldots \ldots \\
15 \ldots \ldots \\
16 \ldots \ldots \\
17 \ldots \ldots \\
18 \ldots \ldots \\
19 \ldots \ldots \\
20 \ldots \ldots\end{array}$ & $\begin{array}{r}0.3 \\
.2 \\
.1 \\
.1 \\
.2 \\
.2 \\
.2 \\
.2 \\
.2 \\
.2\end{array}$ & $\begin{array}{l}26 \\
23 \\
25 \\
25 \\
21 \\
19 \\
17 \\
16 \\
18 \\
20\end{array}$ & $\begin{array}{l}21 \ldots \ldots \\
22 \ldots \ldots \\
23 \ldots \ldots \\
24 \ldots \ldots \\
25 \ldots \ldots \\
26 \ldots \ldots \\
27 \ldots \ldots \\
28 \ldots \ldots \\
29 \ldots \ldots \\
30 \ldots \ldots \\
31 \ldots \ldots\end{array}$ & $\begin{array}{r}0.2 \\
.2 \\
.2 \\
.2 \\
.2 \\
.2 \\
.2 \\
.2 \\
155^{.2} \\
1,010\end{array}$ & $\begin{array}{r}19 \\
17 \\
15 \\
16 \\
17 \\
19 \\
19 \\
17 \\
----\end{array}$ \\
\hline \multicolumn{7}{|l|}{$\begin{array}{l}\text { Monthly } \\
\text { Runoff, } \\
\text { Runoff, }\end{array}$} & $\begin{array}{r}37.8 \\
5.73 \\
2,320 \\
\end{array}$ & $\begin{array}{r}52.3 \\
7.17 \\
2,910 \\
\end{array}$ \\
\hline
\end{tabular}

Gage height, in feet, and discharge, In cub1c feet per second, at indicated time, 1963

\begin{tabular}{|c|c|c|c|c|c|c|c|c|c|c|c|}
\hline Date & Hour & $\begin{array}{c}\text { Gage } \\
\text { helght }\end{array}$ & $\begin{array}{c}\text { D1s- } \\
\text { charge }\end{array}$ & Date & Hour & $\begin{array}{c}\text { Gage } \\
\text { helght }\end{array}$ & $\begin{array}{c}\text { D1s- } \\
\text { charge }\end{array}$ & Date & Hour & $\begin{array}{c}\text { Gage } \\
\text { he1ght }\end{array}$ & $\begin{array}{l}\text { Dis- } \\
\text { charge }\end{array}$ \\
\hline $\begin{array}{r}\text { Jan. } 29 \\
30\end{array}$ & $\begin{array}{l}2400 \\
0200 \\
0900 \\
1200 \\
1400 \\
1500 \\
1800 \\
2000 \\
2100 \\
2200\end{array}$ & $\begin{array}{l}1.92 \\
1.93 \\
2.35 \\
2.92 \\
2.94 \\
3.63 \\
4.44 \\
5.61 \\
6.33 \\
6.93\end{array}$ & $\begin{array}{r}0.2 \\
1.3 \\
11.8 \\
12 \\
44 \\
119 \\
384 \\
675 \\
1,030\end{array}$ & Feb. 1 & $\begin{array}{l}2300 \\
2400 \\
0500 \\
1200 \\
1700 \\
2000 \\
2200 \\
2400 \\
0100\end{array}$ & $\begin{array}{l}6.53 \\
5.75 \\
6.48 \\
6.61 \\
7.77 \\
6.90 \\
6.90 \\
8.14 \\
8.68\end{array}$ & $\begin{array}{r}778 \\
432 \\
750 \\
826 \\
1,730 \\
1,010 \\
1,010 \\
2,130 \\
2,850\end{array}$ & Feb. 1 & $\begin{array}{l}0400 \\
0600 \\
1200 \\
1800 \\
2400 \\
\\
0600 \\
1200 \\
1800 \\
2400\end{array}$ & $\begin{array}{l}7.07 \\
6.54 \\
6.00 \\
5.17 \\
4.63 \\
4.31 \\
4.11 \\
4.11 \\
3.91\end{array}$ & $\begin{array}{r}1,130 \\
784 \\
530 \\
258 \\
153 \\
\\
107 \\
84 \\
84 \\
65\end{array}$ \\
\hline
\end{tabular}

11-2184. North Fork Kings River below Dinkey Creek, near Balch Camp, Calif.

Location.--Lat $36^{\circ} 52^{\prime} 50^{\prime \prime}$, long $119^{\circ} 07^{\prime} 40^{\prime \prime}$, in NW $\frac{1}{4}$ sec.22, T.12 S., R.26 E., on right bank 1.1 miles upstream from mouth, 1.7 miles south of Balch Camp, 2.1 miles downstream from Dinkey Creek, and 9 miles east of Trimmer.

Drainage area. $--387 \mathrm{sq} \mathrm{ml}$.

Gage-helght record.--Water-stage recorder graph. Altitude of gage is $1,035 \mathrm{ft}$ (from river-proflie map).

Discharge record.--Stage-discharge relation defined by current-meter measurements below I,900 cfs.

Maxima --January-February 1963: Discharge, 18,200 cfs 0200 hours Feb. I (gage height, $19.20 \mathrm{ft}^{\mathrm{t}}$.

1960 to December 1962: Discharge, 4,880 cf's Feb. 9, 1962 (gage height, $9.80 \mathrm{ft}^{\prime}$ ).

Remarks.--Flow regulated by Courtright and Wishon Reservolrs (see stations 11-2145.5 and il-2148), Black Rock Reservoir (capacity, 1,000 acre-ft), Balch afterbay

(capacity, 125 acre-ft), and Haas and Balch powerplants. Diversion from Balch abterbay to Kings River powerhouse began Mar. 1, 1962. 
Mean discharge, in cubic feet per second, 1963, of North Fork Kings River below Dinkey Creek, near Balch Camp, Calif.

\begin{tabular}{|c|c|c|c|c|c|c|c|c|}
\hline Day & January & February & Day & January & February & Day & $J$ anuary & February \\
\hline $\begin{array}{r}1 \ldots \ldots \\
2 \ldots \ldots \\
4 \ldots \ldots \\
5 \ldots \ldots \\
6 \ldots \ldots \\
8 \ldots \ldots \\
9 \ldots \ldots \\
10 \ldots \ldots\end{array}$ & $\begin{array}{l}19 \\
19 \\
20 \\
20 \\
20 \\
19 \\
19 \\
19 \\
23 \\
22\end{array}$ & $\begin{array}{r}7,920 \\
1,560 \\
752 \\
542 \\
450 \\
393 \\
367 \\
352 \\
354 \\
560\end{array}$ & $\begin{array}{l}11 \ldots \ldots \\
12 \ldots \ldots \\
13 \ldots \ldots \\
14 \ldots \ldots \\
15 \ldots \ldots \\
16 \ldots \ldots \\
17 \ldots \ldots \\
18 \ldots \ldots \\
19 \ldots \ldots \\
20 \ldots \ldots\end{array}$ & $\begin{array}{l}19 \\
19 \\
16 \\
15 \\
17 \\
17 \\
17 \\
17 \\
17 \\
17\end{array}$ & $\begin{array}{l}414 \\
326 \\
360 \\
375 \\
301 \\
277 \\
246 \\
228 \\
230 \\
234\end{array}$ & $\begin{array}{l}21 \ldots \ldots \\
22 \ldots \ldots \\
23 \ldots \ldots \\
24 \ldots \ldots \\
25 \ldots \ldots \\
26 \ldots \ldots \\
27 \ldots \ldots \\
28 \ldots \ldots \\
29 \ldots \ldots \\
30 \ldots \ldots \\
31 \ldots \ldots\end{array}$ & $\begin{array}{r}17 \\
18 \\
18 \\
18 \\
18 \\
19 \\
19 \\
19 \\
21 \\
855 \\
6,980\end{array}$ & $\begin{array}{r}240 \\
225 \\
212 \\
212 \\
226 \\
240 \\
250 \\
242 \\
------ \\
-----\end{array}$ \\
\hline \multicolumn{7}{|l|}{$\begin{array}{l}\text { Monthly } \\
\text { Runoff, }\end{array}$} & $\begin{array}{r}270 \\
16,610\end{array}$ & $\begin{array}{r}646 \\
35,880\end{array}$ \\
\hline
\end{tabular}

Gage height, In feet, and discharge, in cubic feet per second, at indicated time, 1963

\begin{tabular}{|c|c|c|c|c|c|c|c|c|c|c|c|}
\hline Date & Hour & $\begin{array}{c}\text { Gage } \\
\text { helght }\end{array}$ & $\begin{array}{l}\text { Dis- } \\
\text { charge }\end{array}$ & Date & Hour & $\begin{array}{c}\text { Gage } \\
\text { he1ght }\end{array}$ & $\begin{array}{l}\text { Dis- } \\
\text { charge }\end{array}$ & Date & Hour & $\begin{array}{c}\text { Gage } \\
\text { helght }\end{array}$ & $\begin{array}{c}\text { Dis- } \\
\text { charge }\end{array}$ \\
\hline $\begin{array}{r}\text { Jan. } 29 \\
30\end{array}$ & $\begin{array}{l}2400 \\
0400 \\
0700 \\
1000 \\
1200 \\
1400 \\
1500 \\
1900 \\
2000 \\
2100 \\
2400 \\
0200\end{array}$ & $\begin{array}{l}1.00 \\
1.44 \\
2.37 \\
3.10 \\
3.60 \\
4.72 \\
5.00 \\
6.45 \\
6.50 \\
6.62 \\
8.10 \\
8.05\end{array}$ & $\begin{array}{r}35 \\
61 \\
166 \\
300 \\
430 \\
828 \\
940 \\
1,750 \\
1,780 \\
1,860 \\
3,100 \\
2,950\end{array}$ & Feb. 1 & $\begin{array}{l}0300 \\
0400 \\
0600 \\
0700 \\
1000 \\
1200 \\
1500 \\
1700 \\
1800 \\
2100 \\
2300 \\
2400 \\
0100\end{array}$ & $\begin{array}{r}8.95 \\
8.90 \\
10.60 \\
10.37 \\
11.65 \\
11.90 \\
14.85 \\
15.62 \\
15.00 \\
11.55 \\
11.70 \\
13.80 \\
15.00\end{array}$ & $\begin{array}{r}3,760 \\
3,710 \\
5,460 \\
5,210 \\
6,680 \\
6,980 \\
10,800 \\
11,900 \\
11,000 \\
6,560 \\
6,740 \\
9,340 \\
11,000\end{array}$ & Feb. 1 & $\begin{array}{l}0200 \\
0600 \\
0900 \\
1000 \\
1700 \\
2000 \\
2400 \\
\\
0400 \\
0700 \\
1000 \\
1300 \\
1800 \\
2400\end{array}$ & $\begin{array}{r}19.20 \\
15.00 \\
12.68 \\
12.70 \\
10.00 \\
9.00 \\
7.85 \\
7.00 \\
6.48 \\
6.10 \\
5.80 \\
5.52 \\
5.07\end{array}$ & $\begin{array}{r}18,200 \\
11,000 \\
7,920 \\
7,940 \\
4,800 \\
3,800 \\
2,780 \\
\\
2,100 \\
1,740 \\
1,510 \\
1,340 \\
1,200 \\
975\end{array}$ \\
\hline
\end{tabular}

11-2185. Kings River below North Fork, Calif.

Location.--Lat $36^{\circ} 52^{\prime} 30^{\prime \prime}$, long $119^{\circ} 08^{\prime} 30^{\prime \prime}$, in NE $\frac{1}{4}$ sec.21, T.12 S., R.26 E., on right bank downstream from North Fork, 2.4 miles southwest of Balch Camp and 8.5 miles southeast of Trimmer.

Drainage area $--1,342$ sq $\mathrm{mi}$.

Gage-height record.--Water-stage recorder graph. Datum of gage is $942.42 \mathrm{ft}$ above mean sea level (levels by Corps of Engineers).

Discharge record.--Stage-discharge relation defined by current-meter measurements below 18,000 cfs and by slope-area measurement at $85,200 \mathrm{cfs}$.

Maxima.--January-February 1963: Discharge, 41,800 efs 0300 hours Feb. 1. i951 to December 1962: Discharge, 85,200 cf's Dec. 23, 1955 (gage height, $23.08 \mathrm{ft})$.

Remarks.--Flow affected by Courtright Reservoir (see station 11-2145.5) and Wishon Reservoir (see station 11-2148). Records include flow diverted to Kings River powerplant. Records of diversion to Kings River powerplant furnished by Pacific Gas and Electric Co.

Mean discharge, in cublc feet per second, 1963

\begin{tabular}{|c|c|c|c|c|c|c|c|c|}
\hline Day & January & February & Day & January & February & Day & January & February \\
\hline $\begin{array}{c}1 \ldots \ldots \\
2 \ldots \ldots \\
3 \ldots \ldots \\
4 \ldots \ldots \\
5 \ldots \ldots \\
7 \ldots \ldots \\
8 \ldots \ldots \\
9 \ldots \ldots \\
10 \ldots \ldots\end{array}$ & $\begin{array}{l}127 \\
127 \\
132 \\
132 \\
129 \\
127 \\
122 \\
181 \\
127 \\
122\end{array}$ & $\begin{array}{r}26,300 \\
7,170 \\
4,280 \\
2,740 \\
2,430 \\
2,160 \\
1,870 \\
1,900 \\
1,970 \\
2,480\end{array}$ & $\begin{array}{l}11 \ldots \ldots \\
12 \ldots \ldots \\
13 \ldots \ldots \\
14 \ldots \ldots \\
15 \ldots \ldots \\
16 \ldots \ldots \\
17 \ldots \ldots \\
18 \ldots \ldots \\
19 \ldots \ldots \\
20 \ldots \ldots\end{array}$ & $\begin{array}{r}193 \\
115 \\
97 \\
193 \\
235 \\
302 \\
303 \\
191 \\
185 \\
102\end{array}$ & $\begin{array}{l}1,660 \\
1,500 \\
1,570 \\
1,580 \\
1,430 \\
1,290 \\
1,090 \\
1,110 \\
1,150 \\
1,150\end{array}$ & $\begin{array}{l}21 \ldots \ldots \\
22 \ldots \ldots \\
23 \ldots \ldots \\
24 \ldots \ldots \\
25 \ldots \ldots \\
26 \ldots \ldots \\
27 \ldots \ldots \\
28 \ldots \ldots \\
29 \ldots \ldots \\
30 \ldots \ldots \\
31 \ldots \ldots\end{array}$ & $\begin{array}{r}190 \\
159 \\
288 \\
161 \\
176 \\
113 \\
113 \\
279 \\
206 \\
3,210 \\
20,000\end{array}$ & $\begin{array}{r}1,280 \\
1,090 \\
1,080 \\
1,040 \\
961 \\
974 \\
1,020 \\
1,030 \\
-\ldots--- \\
-1---\end{array}$ \\
\hline $\begin{array}{l}\text { Monthly } \\
\text { Runoff, }\end{array}$ & $\begin{array}{l}n \text { disc } \\
\text { acre-f }\end{array}$ & 3 & 1e & -2 & & & $\begin{array}{r}908 \\
55,810\end{array}$ & $\begin{array}{r}2,689 \\
149,400\end{array}$ \\
\hline
\end{tabular}


Gage height, in feet, and discharge, in cublc feet per second, at indicated time, 1963, of

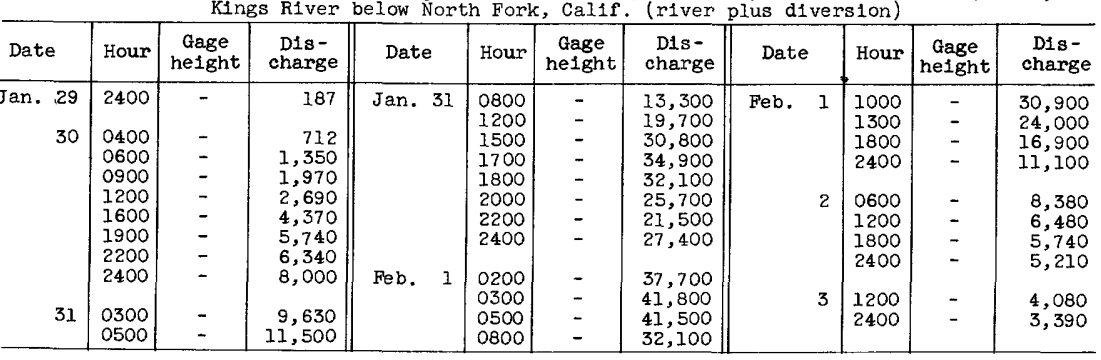

11-2200. Big Creek above Pine Flat Reservolr, Calif.

Location.--Lat $36^{\circ} 55^{\prime} 05^{\prime \prime}$, long $119^{\circ} 14^{\prime} 45^{\prime \prime}$, in $\mathrm{NE} \frac{1}{4}$ sec.4, T.12 S., R.25 E., on right bank 2.4 miles upstream from mouth and' 2.7 miles northeast of Trimmer.

Drainage area. $--69.9 \mathrm{sq} \mathrm{ml}$.

Gage-he1ght record.--Water-stage recorder graph. Datum of gage is 962.04 ft above mean sea level (levels by Corps of Engineers).

Discharge record.--Stage-discharge relation defined by current-meter measurements below $1,300 \mathrm{c}$ 's and by slope-area measurement at 10,400 cfs.

Maxima.--January-February 1963: D1scharge, 9,600 cfs 0230 hours Feb. 1 (gage helght, $9.00 \mathrm{ft}$ ).

1953 to December 1962: D1scharge, 10,400 cfs Dec. 23, 1955 (gage he1ght, $9.21 \mathrm{ft}$.

Mean discharge, in cublc feet per second, 1963

\begin{tabular}{|c|c|c|c|c|c|c|c|c|}
\hline Day & January & February & Day & January & February & Day & January & February \\
\hline $\begin{array}{c}1 \ldots \ldots \\
2 \ldots \ldots \\
3 \ldots \ldots \\
4 \ldots \ldots \\
5 \ldots \ldots \\
6 \ldots \ldots \\
7 \ldots \ldots \\
9 \ldots \ldots \\
10 \ldots \ldots\end{array}$ & $\begin{array}{l}3.2 \\
3.2 \\
3.2 \\
3.2 \\
3.2 \\
3.2 \\
3.2 \\
3.2 \\
3.2 \\
3.6\end{array}$ & $\begin{array}{r}2,370 \\
267 \\
114 \\
79 \\
60 \\
51 \\
44 \\
39 \\
41 \\
406\end{array}$ & $\begin{array}{l}11 \ldots \ldots \\
12 \ldots \ldots \\
13 \ldots \ldots \\
14 \ldots \ldots \\
15 \ldots \ldots \\
16 \ldots \ldots \\
17 \ldots \ldots \\
18 \ldots \ldots \\
19 \ldots \ldots \\
20 \ldots \ldots\end{array}$ & $\begin{array}{l}3.8 \\
3.8 \\
3.0 \\
2.6 \\
3.4 \\
3.6 \\
3.4 \\
3.4 \\
3.6 \\
3.4\end{array}$ & $\begin{array}{r}130 \\
86 \\
100 \\
113 \\
80 \\
67 \\
58 \\
53 \\
50 \\
47\end{array}$ & $\begin{array}{l}21 \ldots \ldots \\
22 \ldots \ldots \\
23 \ldots \ldots \\
24 \ldots \ldots \\
25 \ldots \ldots \\
26 \ldots \ldots \\
27 \ldots \ldots \\
28 \ldots \ldots \\
29 \ldots \ldots \\
30 \ldots \ldots \\
31 \ldots \ldots\end{array}$ & $\begin{array}{r}3.4 \\
3.6 \\
3.8 \\
3.8 \\
3.8 \\
3.6 \\
3.6 \\
3.6 \\
5.2 \\
519 \\
3,200\end{array}$ & $\begin{array}{r}45 \\
42 \\
39 \\
37 \\
36 \\
34 \\
34 \\
32 \\
-\ldots--- \\
-\ldots-2\end{array}$ \\
\hline \multicolumn{7}{|l|}{$\begin{array}{l}\text { Monthly } \\
\text { Runoff, } \\
\text { Runoff, }\end{array}$} & $\begin{array}{r}123 \\
2.05 \\
7,580\end{array}$ & $\begin{array}{r}163 \\
2.45 \\
9,030 \\
\end{array}$ \\
\hline
\end{tabular}

Gage height, in feet, and discharge, in cublc feet per second, at indicated time, 1963

\begin{tabular}{|c|c|c|c|c|c|c|c|c|c|c|c|}
\hline Date & Hour & $\begin{array}{c}\text { Gage } \\
\text { height }\end{array}$ & $\begin{array}{c}\text { D1s- } \\
\text { charge }\end{array}$ & Date & Hour & $\begin{array}{c}\text { Gage } \\
\text { helght }\end{array}$ & $\begin{array}{c}\text { D1s- } \\
\text { charge }\end{array}$ & Date & Hour & $\begin{array}{c}\text { Gage } \\
\text { height }\end{array}$ & $\begin{array}{l}\text { D1s- } \\
\text { charge }\end{array}$ \\
\hline $\begin{array}{r}29 \\
30\end{array}$ & $\begin{array}{l}2400 \\
0300 \\
0400 \\
0600 \\
0900 \\
1200 \\
1300 \\
1500 \\
1700 \\
1800 \\
1900 \\
2000 \\
2200\end{array}$ & $\begin{array}{l}1.43 \\
1.58 \\
1.65 \\
2.09 \\
3.19 \\
4.12 \\
4.24 \\
4.37 \\
4.39 \\
4.53 \\
4.57 \\
4.65 \\
5.08\end{array}$ & $\begin{array}{r}12 \\
18 \\
22 \\
52 \\
223 \\
580 \\
640 \\
712 \\
724 \\
808 \\
832 \\
885 \\
1,200\end{array}$ & $\begin{array}{r}\text { Jan. } 30 \\
31\end{array}$ & $\begin{array}{l}2400 \\
0100 \\
0300 \\
0800 \\
1200 \\
1400 \\
1500 \\
1600 \\
1800 \\
2000 \\
2100 \\
2300 \\
2400\end{array}$ & $\begin{array}{l}5.48 \\
5.60 \\
5.51 \\
6.30 \\
6.88 \\
8.02 \\
8.46 \\
8.22 \\
6.83 \\
6.25 \\
5.78 \\
5.54 \\
5.87\end{array}$ & $\begin{array}{l}1,580 \\
1,700 \\
1,610 \\
2,640 \\
3,660 \\
6,360 \\
7,680 \\
6,960 \\
3,560 \\
2,560 \\
1,920 \\
1,640 \\
2,020\end{array}$ & Feb. 1 & $\begin{array}{l}0100 \\
0230 \\
0500 \\
0700 \\
0900 \\
1100 \\
1500 \\
1900 \\
2400 \\
\\
0600 \\
1200 \\
1800 \\
2400\end{array}$ & $\begin{array}{l}7.00 \\
9.00 \\
7.37 \\
6.29 \\
5.63 \\
5.29 \\
4.82 \\
4.36 \\
3.93 \\
3.52 \\
3.23 \\
3.03 \\
2.86\end{array}$ & $\begin{array}{r}3,900 \\
9,600 \\
4,680 \\
2,620 \\
1,740 \\
1,390 \\
1,000 \\
706 \\
492 \\
\\
333 \\
236 \\
181 \\
147\end{array}$ \\
\hline
\end{tabular}


11-2205. Sycamore Creek above Pine Flat Reservolr, Calif.

Location.--Lat $36^{\circ} 55^{\prime} 15^{\prime \prime}$, long $119^{\circ} 18^{\prime} 30^{\prime \prime}$, in NW $\frac{1}{4}$ sec.1, T.12 S., R.24 E., on right bank 0.1 mile downstream from Little Dry Creek, 1.7 miles northwest of 'Trimmer, and 4.8 miles upstream from mouth.

Drainage area. $--56.1 \mathrm{sq} \mathrm{mi}$.

Gage-height record.--Water-stage recorder graph, except Jan. 18-29. Datum of gage is 1,141.96 ft above mean sea level (levels by Corps of Engineers).

Discharge record.--Stage-discharge relation defined by current-meter measurements below 1,400 cf's and by slope-area measurement at 6,760 cfs. Discharge for Jan. 18-29 estimated on basis of records for nearby streams.

Maxima.--January-February 1963: Discharge, 3,310 cf's 1330 hours Jan. 31 (gage height, $7.56 \mathrm{ft}$ ).

1953 to December 1962: Discharge, 6,760 cfs Dec. 24, 1955 (gage height, $9.78 \mathrm{ft})$.

Mean discharge, in cuble feet per second, 1963

\begin{tabular}{|c|c|c|c|c|c|c|c|c|}
\hline Day & January & February & Day & January & February & Day & January & February \\
\hline $\begin{array}{c}1 \ldots \ldots \\
2 \ldots \ldots \\
4 \ldots \ldots \\
5 \ldots \ldots \\
6 \ldots \ldots \\
7 \ldots \ldots \\
8 \ldots \ldots \\
10 \ldots \ldots\end{array}$ & $\begin{array}{r}0.4 \\
.4 \\
.4 \\
.4 \\
.4 \\
.4 \\
.4 \\
.4 \\
.4 \\
.4\end{array}$ & $\begin{array}{c}744 \\
79 \\
33 \\
20 \\
13 \\
9.5 \\
7.3 \\
5.6 \\
30 \\
458\end{array}$ & $\begin{array}{l}11 \ldots \ldots \\
12 \ldots \ldots \\
13 \ldots \ldots \\
14 \ldots \ldots \\
15 \ldots \ldots \\
16 \ldots \ldots \\
17 \ldots \ldots \\
18 \ldots \ldots \\
19 \ldots \ldots \\
20 \ldots \ldots\end{array}$ & $\begin{array}{l}0.5 \\
.5 \\
.5 \\
.6 \\
.6 \\
.5 \\
.4 \\
.4 \\
.4 \\
.4\end{array}$ & $\begin{array}{l}57 \\
39 \\
60 \\
67 \\
31 \\
22 \\
18 \\
15 \\
15 \\
13\end{array}$ & $\begin{array}{l}21 \ldots \ldots \\
22 \ldots \ldots \\
23 \ldots \ldots \\
24 \ldots \ldots \\
25 \ldots \ldots \\
26 \ldots \ldots \\
27 \ldots \ldots \\
28 \ldots \ldots \\
29 \ldots \ldots \\
30 \ldots \ldots \\
31 \ldots \ldots\end{array}$ & $\begin{array}{r}0.4 \\
.4 \\
.4 \\
.4 \\
.4 \\
.4 \\
.4 \\
.4 \\
.4 \\
248^{.4} \\
1,280\end{array}$ & $\begin{array}{r}11 \\
11 \\
10 \\
9.5 \\
8.7 \\
8.7 \\
8.7 \\
8.0 \\
---- \\
-----\end{array}$ \\
\hline $\begin{array}{l}\text { nthly } \\
\text { noff, } \\
\text { noff, }\end{array}$ & $\begin{array}{l}\text { inche } \\
\text { acre- }\end{array}$ & $\ldots$ & & & & & $\begin{array}{r}49.7 \\
1.01 \\
3,060\end{array}$ & $\begin{array}{r}64.7 \\
1.19 \\
3,590 \\
\end{array}$ \\
\hline
\end{tabular}

Gage height, in feet, and discharge, in cubic feet per second, at indicated time, 1963

\begin{tabular}{|c|c|c|c|c|c|c|c|c|c|c|c|}
\hline Date & Hour & $\begin{array}{c}\text { Gage } \\
\text { helght }\end{array}$ & $\begin{array}{l}\text { Dis- } \\
\text { charge }\end{array}$ & Date & Hour & $\begin{array}{c}\text { Gage } \\
\text { helght }\end{array}$ & $\begin{array}{c}\text { Dis- } \\
\text { charge }\end{array}$ & Date & Hour & $\begin{array}{c}\text { Gage } \\
\text { height }\end{array}$ & $\begin{array}{c}\text { D1s- } \\
\text { charge }\end{array}$ \\
\hline $\begin{array}{r}29 \\
30\end{array}$ & $\begin{array}{l}2400 \\
0830 \\
0900 \\
1100 \\
1200 \\
1300 \\
1500 \\
1630 \\
1800 \\
2000 \\
2200 \\
2300 \\
2400 \\
0200\end{array}$ & $\begin{array}{r}0.74 \\
\\
.74 \\
2.69 \\
3.45 \\
3.43 \\
3.33 \\
2.66 \\
2.41 \\
2.69 \\
3.57 \\
4.04 \\
4.24 \\
4.30 \\
4.02\end{array}$ & $\begin{array}{l}{ }^{0.4} \\
261^{.4} \\
402 \\
398 \\
372 \\
257 \\
213 \\
261 \\
435 \\
602 \\
700 \\
735 \\
594\end{array}$ & Feb. 1 & $\begin{array}{l}0400 \\
0800 \\
0900 \\
1100 \\
1300 \\
1330 \\
1400 \\
1500 \\
1700 \\
1800 \\
2200 \\
2300 \\
2400 \\
0100 \\
0300\end{array}$ & $\begin{array}{l}4.00 \\
4.41 \\
5.10 \\
5.38 \\
7.39 \\
7.56 \\
7.47 \\
7.54 \\
6.00 \\
4.90 \\
3.59 \\
3.46 \\
3.44 \\
3.97 \\
6.93\end{array}$ & $\begin{array}{r}582 \\
795 \\
1,250 \\
1,450 \\
3,140 \\
3,310 \\
3,220 \\
3,290 \\
1,900 \\
1,110 \\
441 \\
405 \\
400 \\
\\
570 \\
2,690\end{array}$ & Feb. 1 & $\begin{array}{l}0400 \\
0500 \\
0700 \\
1000 \\
1400 \\
1800 \\
2000 \\
2400 \\
\\
0300 \\
0600 \\
0900 \\
1200 \\
1800 \\
2400\end{array}$ & $\begin{array}{l}6.70 \\
6.13 \\
4.79 \\
3.85 \\
3.15 \\
2.48 \\
2.30 \\
2.14 \\
1.92 \\
1.77 \\
1.67 \\
1.59 \\
1.48 \\
1.41\end{array}$ & $\begin{array}{r}2,480 \\
2,000 \\
1,020 \\
522 \\
330 \\
225 \\
193 \\
163 \\
121 \\
95 \\
80 \\
69 \\
54 \\
44\end{array}$ \\
\hline
\end{tabular}


11-2210. Pine Flat Reservoir near Pledra, Calif.

Location.--Lat $36^{\circ} 49^{\prime} 55^{\prime \prime}$, long $119^{\circ} 19^{\prime} 25^{\prime \prime}$, In NE⿺ sec.2, T.13 S., R.24 E., near center of Pine Flat Dam on Kings River, 1.9 miles upstream from Mill Creek, 3.5 miles northeast of Piedra, and 16 miles northeast of Sanger.

Drainage area. $--1,545 \mathrm{sq} \mathrm{mi}$.

Gage-height record.--Water-stage recorder graph. Datum of gage is at mean sea level (levels by Corps of Engineers).

Contents record.--Contents computed from capacity table dated Jan. 1, 1956.

Maxima.--January-February 1963: Computed bihourly inflow, 56,800 cfs 0200 to 0400 hours Feb. 1. Contents, 513,200 acre-ft 2400 hours Feb. 28 (elevation, $853.87 \mathrm{ft}$ ).

i951 to December 1962: Contents, 1,000,300 acre-ft June 28, 1958 (elevation, $951.31 \mathrm{ft}$ ).

Remarks.--Reservoir formed by gravity-type concrete dam; regulation began Dec. 4, 1951. Capacity, 1,013,400 acre-ft between elevations $565.5 \mathrm{ft}$ (bottom of lower tier of river outlets) and $953.5 \mathrm{ft}$ (top of spillway gates) above mean sea level. No dead storage. Reservoir is used for flood control and conservation storage. Records furnished by Corps of Engineers.

Elevation, in feet, and contents, in acre-feet, at 2400 hours, 1963

\begin{tabular}{|c|c|c|c|c|c|c|c|c|c|}
\hline \multirow{2}{*}{ Day } & \multicolumn{2}{|c|}{ January } & \multicolumn{2}{|c|}{ February } & \multirow{2}{*}{ Day } & \multicolumn{2}{|c|}{ January } & \multicolumn{2}{|c|}{ February } \\
\hline & Elevation & Contents & Elevation & Contents & & Elevation & Contents & Elevation & Contents \\
\hline $\begin{array}{r}1 \\
2 \\
3 \\
4 \\
5 \\
6 \\
7 \\
8 \\
9 \\
10 \\
11 \\
12 \\
13 \\
14 \\
15\end{array}$ & $\begin{array}{l}790.91 \\
790.85 \\
790.81 \\
790.75 \\
790.69 \\
790.61 \\
790.55 \\
790.49 \\
790.43 \\
790.34 \\
790.32 \\
790.27 \\
790.17 \\
790.13 \\
790.11\end{array}$ & $\begin{array}{l}257,700 \\
287,600 \\
287,400 \\
287,300 \\
287,100 \\
286,800 \\
286,600 \\
286,500 \\
286,300 \\
286,000 \\
285,900 \\
285,800 \\
285,500 \\
285,400 \\
285,300\end{array}$ & $\begin{array}{l}827.97 \\
832.13 \\
\mathrm{~S} 34.46 \\
835.96 \\
\mathrm{~s} 37.21 \\
838.34 \\
839.30 \\
840.25 \\
841.34 \\
843.22 \\
844.18 \\
844.88 \\
845.75 \\
846.60 \\
847.27\end{array}$ & $\begin{array}{l}412,300 \\
427,700 \\
436,500 \\
442,200 \\
447,000 \\
451,300 \\
455,000 \\
458,700 \\
463,000 \\
470,300 \\
474,100 \\
476,900 \\
480,300 \\
483,700 \\
486,400\end{array}$ & $\begin{array}{l}16 \\
17 \\
18 \\
19 \\
20 \\
21 \\
22 \\
23 \\
24 \\
25 \\
26 \\
27 \\
28 \\
29 \\
30 \\
31\end{array}$ & $\begin{array}{l}790.12 \\
790.73 \\
790.10 \\
790.04 \\
789.92 \\
789.86 \\
789.78 \\
789.79 \\
789.73 \\
789.70 \\
789.64 \\
789.58 \\
789.63 \\
789.78 \\
792.24 \\
809.20\end{array}$ & $\begin{array}{l}285,300 \\
285,400 \\
285,300 \\
285,100 \\
284,700 \\
284,600 \\
284,300 \\
284,300 \\
284,200 \\
284,100 \\
283,900 \\
283,700 \\
283,900 \\
284,300 \\
291,800 \\
346,300\end{array}$ & $\begin{array}{c}847.87 \\
848.37 \\
848.91 \\
849.45 \\
850.00 \\
850.62 \\
851.12 \\
851.60 \\
852.08 \\
852.53 \\
852.97 \\
853.42 \\
853.87 \\
- \\
- \\
-\end{array}$ & $\begin{array}{c}488,800 \\
490,800 \\
493,000 \\
495,200 \\
497,400 \\
499,900 \\
501,900 \\
503,900 \\
505,900 \\
507,700 \\
509,500 \\
511,400 \\
513,200 \\
- \\
- \\
-\end{array}$ \\
\hline \multicolumn{6}{|c|}{ Change in contents, in acre-feet................ } & - & $+58,400$ & - & $+166,900$ \\
\hline
\end{tabular}

Average inflow, in cuble feet per second, for bihourly periods ending at indicated time, 1963

\begin{tabular}{|c|c|c|c|c|c|c|c|c|}
\hline Date & Hour & Inflow & Date & Hour & Inflow & Date & Hour & Inflow \\
\hline Jan. 30 & $\begin{array}{l}0200 \\
0400 \\
0600 \\
0800 \\
1000 \\
1200 \\
1400 \\
1600 \\
1800 \\
2000 \\
2200 \\
2400 \\
\\
0200 \\
0400 \\
0600 \\
0800\end{array}$ & $\begin{array}{r}400 \\
707 \\
1,450 \\
2,000 \\
1,450 \\
4,660 \\
3,260 \\
5,700 \\
4,820 \\
6,730 \\
8,400 \\
8,400 \\
11,800 \\
10,500 \\
13,900 \\
15,700\end{array}$ & Feb. 1 & $\begin{array}{l}1000 \\
1200 \\
1400 \\
1600 \\
1800 \\
2000 \\
2200 \\
2400 \\
\\
0200 \\
0400 \\
0600 \\
0800 \\
1000 \\
1200 \\
1400 \\
1600\end{array}$ & $\begin{array}{l}19,000 \\
28,400 \\
41,800 \\
38,400 \\
48,200 \\
42,200 \\
32,800 \\
27,300 \\
42,900 \\
56,800 \\
56,400 \\
43,700 \\
43,900 \\
34,600 \\
24,900 \\
27,900\end{array}$ & Feb. 1 & $\begin{array}{l}1800 \\
2000 \\
2200 \\
2400 \\
\\
0200 \\
0400 \\
0600 \\
0800 \\
1000 \\
1200 \\
1400 \\
1600 \\
1800 \\
2000 \\
2200 \\
2400\end{array}$ & $\begin{array}{r}21,600 \\
17,700 \\
16,400 \\
12,900 \\
12,300 \\
10,700 \\
9,430 \\
7,860 \\
9,680 \\
6,620 \\
7,360 \\
6,550 \\
6,120 \\
5,900 \\
5,900 \\
5,240 \\
\end{array}$ \\
\hline
\end{tabular}


11-2215. Kings River below Pine Flat Dam, Calif.

Location.--Lat $36^{\circ} 49^{\prime} 50^{\prime \prime}$, long $119^{\circ} 20^{\prime} 05^{\prime \prime}$, in NW $\frac{1}{4}$ sec.2, T.13S., R.24 E., on right bank $3,200 \mathrm{ft}$ downstream from Pine Flat Dam and 2.9 miles northeast of Pledra.

Drainage area. $--1,545 \mathrm{sq} \mathrm{mi}$.

Gage-height record.--Water-stage recorder graph. Datum of gage is $556.97 \mathrm{ft}$ above mean sea level (levels by Corps of Engineers).

Discharge record.--Stage-discharge relation defined by current-meter measurements.

Maxima.--January-February 1963: Discharge, 292 cfs 1900 hours Feb. 12 (gage height, $2.17 \mathrm{ft}$ ).

1953 to December 1962: Discharge, 12,700 cfs May 3, 1958 (gage height, $9.35 \mathrm{ft})$.

Remarks.--Plow completely regulated by Pine Flat, Wishon, and Courtright Reservoirs.

11-2217. Mill Creek near Piedra, Calif.

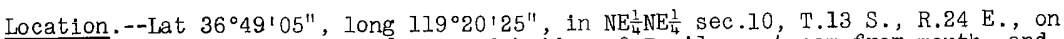
left bank $150 \mathrm{ft}$ upstream from road bridge, $0.7 \mathrm{mile}$ upstream from mouth, and 2.3 miles east of Piedra.

Drainage area $--120 \mathrm{sq} \mathrm{mi}$.

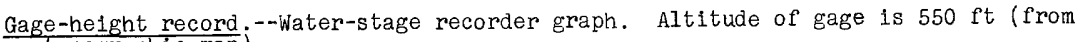
topographic map).

Discharge record.--Stage-discharge relation defined by current-meter measurements below $1,200 \mathrm{cfs}$.

Maxima.--January-February 1963: Discharge, 3,120 cfs 1700 hours Jan. 31 (gage height, $6.68 \mathrm{ft}$, from recorder graph; $7.0 \mathrm{ft}$, from floodmarks).

1957 to December 1962: Discharge, 5,000 cfs Mar. 22, 1958 (gage height, $7.29 \mathrm{ft})$.

Mean discharge, in cub1c feet per second, 1963

\begin{tabular}{|c|c|c|c|c|c|c|c|c|}
\hline Day & January & February & Day & January & Febmuary & Day & January & Febmuary \\
\hline $\begin{array}{c}1 \ldots \ldots \\
2 \ldots \ldots \\
3 \ldots \ldots \\
4 \ldots \ldots \\
5 \ldots \ldots \\
6 \ldots \ldots \\
7 \ldots \ldots \\
9 \ldots \ldots \\
10 \ldots \ldots\end{array}$ & $\begin{array}{l}0 \\
0 \\
0 \\
0 \\
0 \\
0 \\
0 \\
0 \\
0 \\
0\end{array}$ & $\begin{array}{r}784 \\
153 \\
65 \\
41 \\
30 \\
24 \\
21 \\
18 \\
25 \\
537\end{array}$ & $\begin{array}{l}11 \ldots \ldots \\
12 \ldots \ldots \\
13 \ldots \ldots \\
14 \ldots \ldots \\
15 \ldots \ldots \\
16 \ldots \ldots \\
17 \ldots \ldots \\
18 \ldots \ldots \\
19 \ldots \ldots \\
20 \ldots \ldots\end{array}$ & $\begin{array}{l}0 \\
0 \\
0 \\
0 \\
0 \\
0 \\
0 \\
0 \\
0 \\
0\end{array}$ & $\begin{array}{r}120 \\
77 \\
74 \\
70 \\
54 \\
45 \\
40 \\
34 \\
31 \\
28\end{array}$ & $\begin{array}{l}21 \ldots \ldots \\
22 \ldots \ldots \\
23 \ldots \ldots \\
24 \ldots \ldots \\
25 \ldots \ldots \\
26 \ldots \ldots \\
27 \ldots \ldots \\
28 \ldots \ldots \\
29 \ldots \ldots \\
30 \ldots \ldots \\
31 \ldots \ldots\end{array}$ & $\begin{array}{r}0 \\
0 \\
0 \\
0 \\
0 \\
0 \\
0 \\
0 \\
0 \\
51 \\
1,040 \\
\end{array}$ & 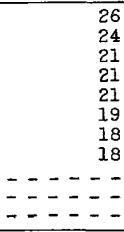 \\
\hline \multicolumn{7}{|l|}{$\begin{array}{l}\text { Monthly } \\
\text { Runoff, } \\
\text { Runoff, }\end{array}$} & $\begin{array}{r}35.2 \\
0.34 \\
2,160\end{array}$ & $\begin{array}{r}87.1 \\
0.76 \\
4,840 \\
\end{array}$ \\
\hline
\end{tabular}

Gage height, in feet, and discharge, in cubic feet per second, at indicated time, 1963

\begin{tabular}{|c|c|c|c|c|c|c|c|c|c|c|c|}
\hline Date & Hour & $\begin{array}{c}\text { Gage } \\
\text { height }\end{array}$ & $\begin{array}{l}\text { Dis- } \\
\text { charge }\end{array}$ & Date & Hour & $\begin{array}{c}\text { Gage } \\
\text { height }\end{array}$ & $\begin{array}{c}\text { D1s- } \\
\text { charge }\end{array}$ & Date & Hour & $\begin{array}{c}\text { Gage } \\
\text { helght }\end{array}$ & $\begin{array}{c}\text { D1s- } \\
\text { charge }\end{array}$ \\
\hline $\begin{array}{r}\text { Jan. } 29 \\
30\end{array}$ & $\begin{array}{l}2400 \\
0600 \\
0700 \\
1100 \\
1300 \\
2400 \\
\\
0300 \\
0800 \\
1100 \\
1200\end{array}$ & $\begin{array}{c}- \\
- \\
2.47 \\
2.64 \\
2.88 \\
3.53 \\
\\
3.82 \\
3.84 \\
3.92 \\
4.23\end{array}$ & $\begin{array}{c}0 \\
0 \\
3.5 \\
11 \\
31 \\
159 \\
\\
263 \\
271 \\
304 \\
452\end{array}$ & Feb. 1 & $\begin{array}{l}1300 \\
1400 \\
1500 \\
1600 \\
1700 \\
1900 \\
2100 \\
2400 \\
\\
0300 \\
0400 \\
0600\end{array}$ & $\begin{array}{l}4.92 \\
5.53 \\
6.10 \\
6.63 \\
6.68 \\
6.10 \\
5.45 \\
4.47 \\
4.50 \\
4.61 \\
5.35\end{array}$ & $\begin{array}{r}926 \\
1,510 \\
2,220 \\
3,030 \\
3,120 \\
2,220 \\
1,430 \\
806 \\
\\
610 \\
687 \\
1,320\end{array}$ & Feb. 1 & $\begin{array}{l}0800 \\
1200 \\
1700 \\
1800 \\
2400 \\
\\
0600 \\
1200 \\
1800 \\
2400\end{array}$ & $\begin{array}{l}5.47 \\
4.94 \\
4.38 \\
4.26 \\
3.89 \\
3.62 \\
3.43 \\
3.31 \\
3.20\end{array}$ & $\begin{array}{r}1,450 \\
942 \\
538 \\
468 \\
291 \\
187 \\
132 \\
105 \\
87\end{array}$ \\
\hline
\end{tabular}


11-2226. Bear Mountain Creek near Squaw Valley, Calif.

(Crest-stage station)

Location.--Lat $36^{\circ} 43^{\prime} 52^{\prime \prime}$, long $119^{\circ} 16^{\prime} 53^{\prime \prime}$, in NW $\frac{1}{4} \mathrm{NW}_{\frac{1}{4}}$ sec.8, T.14 S., R.25 E., on State Highway $180,1.0^{\circ}$ mile west of Squaw Valley, Calif'.

Drainage area. $--0.14 \mathrm{sq} \mathrm{ml}$.

Gage-height record.--Crest stages only. Altitude of gage is $1,600 \mathrm{ft}$ (from topographic map).

Discharge record.--Maximum discharge by computation of flow through culvert.

Maxima.--January-February 1963: Discharge, 0.3 cfs (estimated) Feb. 1 (gage height, $6.03 \mathrm{ft}$, from high-water profile).

1959 to December 1962: Discharge, $3.0 \mathrm{cfs}$ Feb. 10, 1962 (gage height, $6.45 \mathrm{ft}$ ).

\section{SAN JOAQUIN RIVER BASIN}

11-2265. San Joaquin River at Miller Crossing, Calif.

Location.--Lat $37^{\circ} 30^{\prime} 35^{\prime \prime}$, long $119^{\circ} 11^{\prime} 50^{\prime \prime}$, in $\mathrm{NE}_{\frac{1}{4}} \sec .11$, T.5 S., R.25 E., on right bank 2.4 miles downstream from North Fork San Joaquin River, 4.6 miles east of Clover Meadow ranger station, and 23 miles northeast of town of Bass Lake.

Drainage area. $--249 \mathrm{sq}$ mí.

Gage-height record:--Water-stage recorder graph. Altitude of gage is $4,570 \mathrm{ft}$ (from topographic map).

Discharge record.--Stage-discharge relation defined by current-meter measurements.

Maxima.--January-February 1963: Discharge, 8,120 cfs 0100 hours Feb. 1 (gage height, $18.32 \mathrm{ft})$.

1921-28, 1951 to December 1962: Discharge, 16,600 cfs Dec. 23, 1955 (gage height, $21.28 \mathrm{ft}$ ), from rating curve extended above $5,100 \mathrm{cfs}$ on basis of contracted-opening measurement of maximum flow.

Mean discharge, in cub1c feet per second, 1963

\begin{tabular}{|c|c|c|c|c|c|c|c|c|}
\hline Day & January & February & Day & January & February & Day & January & February \\
\hline $\begin{array}{r}1 \ldots \ldots \\
3 \ldots \ldots \\
4 \ldots \ldots \\
5 \ldots \ldots \\
6 \ldots \ldots \\
7 \ldots \ldots \\
9 \ldots \ldots \\
10 \ldots \ldots\end{array}$ & 33 & $\begin{array}{c}5,350 \\
1,570 \\
970 \\
780 \\
626 \\
555 \\
514 \\
496 \\
436 \\
439\end{array}$ & 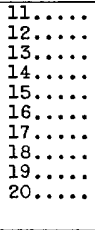 & 33 & $\begin{array}{l}382 \\
352 \\
409 \\
388 \\
320 \\
305 \\
278 \\
270 \\
270 \\
284\end{array}$ & $\begin{array}{l}21 \ldots \ldots \\
22 \ldots \ldots \\
23 \ldots \ldots \\
24 \ldots \ldots \\
25 \ldots \ldots \\
26 \ldots \ldots \\
27 \ldots \ldots \\
28 \ldots \ldots \\
29 \ldots \ldots \\
30 \ldots \ldots \\
31 \ldots \ldots\end{array}$ & $\begin{array}{r}44 \\
248 \\
2,710\end{array}$ & $\begin{array}{r}300 \\
286 \\
268 \\
278 \\
305 \\
358 \\
373 \\
332 \\
-.---.-\end{array}$ \\
\hline & & & & & & & $\begin{array}{r}127 \\
0.57 \\
7,790 \\
\end{array}$ & $\begin{array}{r}625 \\
2.56 \\
34,700 \\
\end{array}$ \\
\hline
\end{tabular}

Gage he1ght, in feet, and discharge, in cub1c feet per second, at indicated time, 1963

\begin{tabular}{|c|c|c|c|c|c|c|c|c|c|c|c|}
\hline Date & Hour & $\begin{array}{c}\text { Gage } \\
\text { he1ght }\end{array}$ & $\begin{array}{c}\text { Dis- } \\
\text { charge }\end{array}$ & Date & Hour & $\begin{array}{c}\text { Gage } \\
\text { helght }\end{array}$ & $\begin{array}{c}\text { Dis- } \\
\text { charge }\end{array}$ & Date & Hour & $\begin{array}{c}\text { Gage } \\
\text { helght }\end{array}$ & $\begin{array}{l}\text { D1s- } \\
\text { charge }\end{array}$ \\
\hline $\begin{array}{r}\text { Jan. } 29 \\
30\end{array}$ & $\begin{array}{l}2400 \\
0200 \\
0400 \\
0600 \\
0800 \\
1000 \\
1200 \\
1600 \\
1900 \\
2000 \\
2200 \\
2400 \\
0300 \\
\end{array}$ & $\begin{array}{r}9.21 \\
9.21 \\
9.24 \\
9.20 \\
9.24 \\
9.35 \\
9.46 \\
10.35 \\
11.22 \\
11.88 \\
12.15 \\
12.68 \\
12.25 \\
\end{array}$ & $\begin{array}{r}49 \\
49 \\
50 \\
48 \\
50 \\
57 \\
64 \\
170 \\
346 \\
548 \\
650 \\
900 \\
\end{array}$ & Feb. 1 & $\begin{array}{l}0500 \\
0600 \\
0700 \\
0800 \\
1100 \\
1200 \\
1600 \\
2000 \\
2200 \\
2300 \\
2400 \\
\\
0100 \\
0300 \\
0600 \\
\end{array}$ & $\begin{array}{l}12.98 \\
12.79 \\
13.53 \\
13.29 \\
14.00 \\
14.46 \\
15.74 \\
15.94 \\
17.61 \\
17.23 \\
17.50 \\
18.32 \\
18.00 \\
17.72\end{array}$ & $\begin{array}{r}1,080 \\
964 \\
1,440 \\
1,270 \\
1,810 \\
2,240 \\
3,730 \\
4,000 \\
6,660 \\
5,970 \\
6,460 \\
8,120 \\
7,440 \\
6,880 \\
\end{array}$ & Feb. 1 & $\begin{array}{l}0700 \\
1000 \\
1400 \\
2400 \\
\\
0500 \\
1200 \\
1400 \\
1600 \\
1800 \\
2400\end{array}$ & $\begin{array}{l}17.90 \\
17.34 \\
16.36 \\
14.69 \\
14.00 \\
13.51 \\
13.42 \\
13.42 \\
13.38 \\
13.12\end{array}$ & $\begin{array}{l}7,240 \\
6,170 \\
4,590 \\
2,470 \\
1,810 \\
1,430 \\
1,360 \\
1,360 \\
1,340 \\
1,160\end{array}$ \\
\hline
\end{tabular}


11-2296. Florence Lake near Big Creek, Calif.

Location.--Lat $37^{\circ} 16^{\prime} 25^{\prime \prime}$, long $118^{\circ} 58^{\prime} 20^{\prime \prime}$, in NW $\frac{1}{4}$ sec.1, T.8 S., R.27 E., in gatehouse of Ward tunnel intake, near dam on South Fork San Joaquin River, 16 miles northeast of town of Big Creek.

Drainage area.--17l sq $\mathrm{mi}$.

Gage-height record.--Water-stage recorder graph. Datum of gage is at mean sea level (levels by Southern California Edison Co.).

Contents record.--Contents computed from capacity table dated Aug. 26, 1926.

Maxima.--January-February 1963: Contents, 5,470 acre-ft 1000 hours Feb. 5 (elevation, 7,247.11 ft)

1925 to December 1962: Contents, 66,000 acre-ft July 3, 1932 (elevation, $7,329.14 \mathrm{ft})$.

Remarks.--Lake is formed by multiple-arch concrete dam; storage began in April 1925 Usabie capacity, 64,400 acre-ft between elevations $7,220.9 \mathrm{ft}$ (throat of venturl tube in Ward tunnel intake) and $7,327.5 \mathrm{ft}$ (top of spillway drum gates) above mean sea level. Additional storage of 168 acre-ft is not available for diversion. Water is diverted through Ward tunnel to Huntington Lake and used for power development in Big Creek plants. Figures given herein represent usable contents. Records furnished by Southern California Edison Co.

Elevation, in feet, and contents, in acre-feet, at 2400 hours, 1963

\begin{tabular}{|c|c|c|c|c|c|c|c|c|c|}
\hline \multirow{2}{*}{ Day } & \multicolumn{2}{|c|}{ January } & \multicolumn{2}{|c|}{ February } & \multirow{2}{*}{ Day } & \multicolumn{2}{|c|}{ January } & \multicolumn{2}{|c|}{ February } \\
\hline & Elevation & Contents & Elevation & Contents & & Elevation & Contents & Elevation & Contents \\
\hline $\begin{array}{r}1 \\
2 \\
3 \\
4 \\
5 \\
6 \\
7 \\
8 \\
9 \\
10 \\
11 \\
12 \\
13 \\
14 \\
15\end{array}$ & $\begin{array}{l}7,224.08 \\
7,224.08 \\
7,224.10 \\
7,224.12 \\
7,224.13 \\
7,224.15 \\
7,224.15 \\
7,224.14 \\
7,224.13 \\
7,224.12 \\
7,224.09 \\
7,224.05 \\
7,224.01 \\
7,224.00 \\
7,223.97\end{array}$ & $\begin{array}{l}207 \\
207 \\
208 \\
210 \\
211 \\
212 \\
212 \\
211 \\
211 \\
210 \\
208 \\
204 \\
201 \\
201 \\
199\end{array}$ & $\begin{array}{l}7,241.66 \\
7,243.98 \\
7,245.30 \\
7,246.60 \\
7,246.26 \\
7,245.84 \\
7,244.73 \\
7,243.50 \\
7,242.06 \\
7,240.45 \\
7,238.53 \\
7,236.31 \\
7,233.85 \\
7,231.15 \\
7,227.50\end{array}$ & $\begin{array}{r}3,510 \\
4,300 \\
4,780 \\
5,270 \\
5,140 \\
4,980 \\
4,570 \\
4,130 \\
3,640 \\
3,120 \\
2,580 \\
2,060 \\
1,550 \\
1,070 \\
556\end{array}$ & $\begin{array}{l}16 \\
17 \\
18 \\
19 \\
20 \\
21 \\
22 \\
23 \\
24 \\
25 \\
26 \\
27 \\
28 \\
29 \\
30 \\
31\end{array}$ & $\begin{array}{l}7,223.95 \\
7,223.94 \\
7,223.92 \\
7,223.91 \\
7,223.91 \\
7,223.90 \\
7,223.93 \\
7,223.95 \\
7,223.98 \\
7,224.00 \\
7,224.02 \\
7,224.04 \\
7,224.05 \\
7,224.12 \\
7,225.90 \\
7,232.98\end{array}$ & $\begin{array}{l}197 \\
196 \\
195 \\
194 \\
194 \\
194 \\
196 \\
197 \\
199 \\
201 \\
202 \\
204 \\
204 \\
210 \\
370 \\
1,390\end{array}$ & $\begin{array}{c}7,225.74 \\
7,225.44 \\
7,225.34 \\
7,225.33 \\
7,225.38 \\
7,225.43 \\
7,225.39 \\
7,225.31 \\
7,225.34 \\
7,225.43 \\
7,225.53 \\
7,225.52 \\
7,225.43 \\
- \\
- \\
-\end{array}$ & $\begin{array}{c}354 \\
324 \\
314 \\
313 \\
318 \\
323 \\
319 \\
311 \\
314 \\
323 \\
333 \\
332 \\
323 \\
- \\
- \\
-\end{array}$ \\
\hline Whan & in 0 & - In a & & & & - & $+1,180$ & - & $-1,070$ \\
\hline
\end{tabular}

11-2300. South Fork San Joaquin River near Florence Lake, Calif.

Location.--Lat $37^{\circ} 16^{\prime} 20^{\prime \prime}$, long $118^{\circ} 57^{\prime} 50^{\prime \prime}$, in SE $\frac{1}{4}$ sec.36, T.7 S., R.27 E., on left bank just downstream from spillway of Florence Lake Dam and 6 miles upstream from Bear Creek.

Drainage area. $--171 \mathrm{sq} \mathrm{mi}$.

Gage-height record.--Water-stage recorder graph. Altitude of gage is $7,200 \mathrm{ft}$ (from topographic map).

Discharge record.--Stage-discharge relation defined by current-meter measurements.

Maxima.--January-February 1963: Discharge, $9.9 \mathrm{cfs} 1430$ hours Jan. 31 (gage height, $9.10 \mathrm{ft})$.

1921 to December 1962: Discharge, 4,320 cfs June 6, 1940 (gage helght, $15.38 \mathrm{ft}$ ).

Remarks.--Flow regulated by Florence Lake since 1925 (see station 11-2296). 
Mean discharge, in cubic feet per second, 1963, of South Fork San Joaquin River near Florence Lake, Calif.

\begin{tabular}{|c|c|c|c|c|c|c|c|c|}
\hline Day & January & February & Day & January & Febmuary & Day & January & February \\
\hline $\begin{array}{c}1 \ldots \ldots \\
2 \ldots \ldots \\
3 \ldots \ldots \\
4 \ldots \ldots \\
5 \ldots \ldots \\
7 \ldots \ldots \\
8 \ldots \ldots \\
9 \ldots \ldots \\
10 \ldots \ldots\end{array}$ & $\begin{array}{l}3.1 \\
3.1 \\
3.1 \\
3.1 \\
3.1 \\
3.1 \\
3.1 \\
3.1 \\
3.1 \\
3.1\end{array}$ & $\begin{array}{l}5.6 \\
3.9 \\
3.9 \\
3.9 \\
3.9 \\
3.8 \\
3.8 \\
3.8 \\
3.8 \\
3.8\end{array}$ & $\begin{array}{l}11 \ldots \ldots \\
12 \ldots \ldots \\
13 \ldots \ldots \\
14 \ldots \ldots \\
15 \ldots \ldots \\
16 \ldots \ldots \\
17 \ldots \ldots \\
18 \ldots \ldots \\
19 \ldots \ldots \\
20 \ldots \ldots\end{array}$ & $\begin{array}{l}3.1 \\
3.1 \\
3.1 \\
3.1 \\
3.1 \\
3.1 \\
3.1 \\
3.1 \\
3.1 \\
3.1\end{array}$ & $\begin{array}{l}3.7 \\
3.6 \\
3.7 \\
3.4 \\
3.3 \\
3.1 \\
3.1 \\
3.1 \\
3.1 \\
3.1\end{array}$ & $\begin{array}{l}21 \ldots \ldots \\
22 \ldots \ldots \\
23 \ldots \ldots \\
24 \ldots \ldots \\
25 \ldots \ldots \\
26 \ldots \ldots \\
27 \ldots \ldots \\
28 \ldots \ldots \\
29 \ldots \ldots \\
30 \ldots \ldots \\
31 \ldots \ldots\end{array}$ & $\begin{array}{l}3.1 \\
3.1 \\
3.1 \\
3.1 \\
3.1 \\
3.1 \\
3.1 \\
3.1 \\
3.1 \\
5.3 \\
7.4\end{array}$ & $\begin{array}{r}3.1 \\
3.1 \\
3.1 \\
3.1 \\
3.1 \\
3.1 \\
3.1 \\
3.1 \\
---- \\
---1 \\
---1\end{array}$ \\
\hline $\begin{array}{l}\text { onthly } \\
\text { unoff, }\end{array}$ & acr & , & 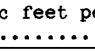 & & & & $\begin{array}{r}3.31 \\
204 \\
\end{array}$ & $\begin{array}{r}3.51 \\
195 \\
\end{array}$ \\
\hline
\end{tabular}

11-2310. Lake Thomas A. Edison near Big Creek, Calif.

Location.--Lat $37^{\circ} 22^{\prime} 10^{\prime \prime}$, long $118^{\circ} 59^{\prime} 15^{\prime \prime}$, in sec.26, T.6 S., R.27 E. (unsurveyed), in outlet works of dam on Mono Creek at lower end of Vermilion Valley, 18.1 miles northeast of town of Big Creek.

Drainage area. $--88.9 \mathrm{sq} \mathrm{mi}$.

Gage-height record.-Water-stage recorder graph. Datum of gage is at mean sea level (levels by Southern California Edison Co.).

Contents record.--Contents computed from capacity table dated July 22, 1955.

Maxima --January-February 1963: Contents, 72,000 acre-ft 0000 hours Jan. I (elevation, 7,612.13 ft).

1954 to December 1962: Contents, 125,900 acre-ft Aug. 18, 1958 (elevation, $7,642.95 \mathrm{ft})$.

Remarks.--Lake is formed by earthfill dam; dam completed and storage began on oct. 12, 1954. Usable capacity, 125,000 acre-ft between elevations 7,508.9 ft (invert of outlet works) and $7,642.5 \mathrm{ft}$ (top of gates in service spiliway) above mean sea level. Water is released for diversion to Ward tunnel via Mono Creek diversion works. Figures given herein represent usable contents.

Records furnished by Southern California Edison Co.

Elevation, in feet, and contents, in acre-feet, at 2400 hours, 1963

\begin{tabular}{|c|c|c|c|c|c|c|c|c|c|}
\hline \multirow{2}{*}{ Day } & \multicolumn{2}{|c|}{ January } & \multicolumn{2}{|c|}{ February } & \multirow{2}{*}{ Day } & \multicolumn{2}{|c|}{ January } & \multicolumn{2}{|c|}{ February } \\
\hline & Elevation & Contents & Elevation & Contents & & Elevation & Contents & Elevation & Contents \\
\hline $\begin{array}{r}1 \\
2 \\
3 \\
4 \\
5 \\
6 \\
7 \\
8 \\
9 \\
10 \\
11 \\
12 \\
13 \\
14 \\
15\end{array}$ & $\begin{array}{l}7,611.84 \\
7,611.53 \\
7,611.24 \\
7,610.95 \\
7,610.66 \\
7,610.35 \\
7,610.08 \\
7,609.78 \\
7,609.48 \\
7,609.18 \\
7,608.87 \\
7,608.56 \\
7,608.25 \\
7,607.96 \\
7,607.66\end{array}$ & $\begin{array}{l}71,500 \\
71,000 \\
70,600 \\
70,100 \\
69,700 \\
69,200 \\
68,700 \\
68,300 \\
67,800 \\
67,300 \\
66,900 \\
66,400 \\
65,900 \\
65,400 \\
65,000\end{array}$ & $\begin{array}{l}7,604.22 \\
7,604.30 \\
7,604.32 \\
7,604.14 \\
7,603.92 \\
7,603.70 \\
7,603.48 \\
7,603.25 \\
7,603.03 \\
7,602.80 \\
7,602.54 \\
7,602.29 \\
7,602.07 \\
7,601.80 \\
7,601.54\end{array}$ & $\begin{array}{l}59,800 \\
59,900 \\
60,000 \\
59,700 \\
59,400 \\
59,100 \\
58,700 \\
58,400 \\
58,100 \\
57,800 \\
57,400 \\
57,000 \\
56,700 \\
56,300 \\
56,000\end{array}$ & $\begin{array}{l}16 \\
17 \\
18 \\
19 \\
20 \\
21 \\
22 \\
23 \\
24 \\
25 \\
26 \\
27 \\
28 \\
29 \\
30 \\
31\end{array}$ & $\begin{array}{l}7,607.36 \\
7,607.05 \\
7,606.73 \\
7,606.44 \\
7,606.15 \\
7,605.86 \\
7,605.56 \\
7,605.27 \\
7,604.95 \\
7,604.65 \\
7,604.34 \\
7,604.04 \\
7,603.76 \\
7,603.55 \\
7,603.76 \\
7,603.95\end{array}$ & $\begin{array}{l}64,500 \\
64,100 \\
63,600 \\
63,100 \\
62,700 \\
62,300 \\
61,800 \\
61,400 \\
60,900 \\
60,500 \\
60,000 \\
59,600 \\
59,200 \\
58,900 \\
59,200 \\
59,400\end{array}$ & $\begin{array}{c}7,601.72 \\
7,600.57 \\
7,600.03 \\
7,599.48 \\
7,599.95 \\
7,595.41 \\
7,597.87 \\
7,597.31 \\
7,596.78 \\
7,596.36 \\
7,596.16 \\
7,595.94 \\
7,595.72 \\
- \\
- \\
-\end{array}$ & $\begin{array}{c}55,400 \\
54,600 \\
53,800 \\
53,000 \\
52,300 \\
51,600 \\
50,800 \\
50,100 \\
49,300 \\
48,800 \\
48,500 \\
48,200 \\
47,900 \\
- \\
- \\
-\end{array}$ \\
\hline & Dit con & In & & & & - & $-12,600$ & - & $-11,500$ \\
\hline
\end{tabular}


11-2315. Mono Creek below Lake Thomas A. Edison, Calif.

Location.--Lat $37^{\circ} 21^{1} 40^{\prime \prime}$, long $118^{\circ} 59125^{\prime \prime}$, in SW $\frac{1}{4}$ sec.35, T.6 S. R. R.27 E.

(unsurveyed), on left bank 0.6 mile upstream from diversion dam, 1 mile down-

stream from Lake Thomas A. Edison, and 1.9 miles northeast of Mono Hot Springs.

Drainage area. $--92.0 \mathrm{sq} \mathrm{mi}$.

Gage-helght record.--Water-stage recorder graph, except Jan. 31 to Feb. 5. Altitude of gage is 7,400 ft (from topographic map).

Discharge record.--Stage-discharge relation defined by current-meter measurements. Discharge for Jan. 31 to Feb. 5 estimated on basis of recorded range in stage and record of gate changes for Lake Thomas A. Edison.

Maxima.--January-February 1963: Discharge, 495 cfs 1630-2100 hours Feb. 17 (gage height, $6.57 \mathrm{ft}$ ).

1921 to December 1962: Discharge, 1,760 ofs June 2, 1938 (gage height, $8.62 \mathrm{ft})$.

Remarks.--Flow regulated by Lake Thomas A. Edison since 1954 (see station 11-2310).

Mean discharge, in cubic feet per second, 1963

\begin{tabular}{|c|c|c|c|c|c|c|c|c|}
\hline Day & January & February & Day & Januery & February & Day & January & February \\
\hline $\begin{array}{c}1 \ldots \ldots \\
2 \ldots \ldots \\
3 \ldots \ldots \\
4 \ldots \ldots \\
5 \ldots \ldots \\
6 \ldots \ldots \\
8 \ldots \ldots \\
9 \ldots \ldots \\
10 \ldots \ldots\end{array}$ & $\begin{array}{l}241 \\
238 \\
238 \\
234 \\
234 \\
234 \\
234 \\
234 \\
234 \\
234\end{array}$ & $\begin{array}{r}20 \\
20 \\
130 \\
230 \\
230 \\
230 \\
230 \\
230 \\
230 \\
230\end{array}$ & $\begin{array}{l}11 \ldots \ldots \\
12 \ldots \ldots \\
13 \ldots \ldots \\
14 \ldots \ldots \\
15, \ldots \ldots \\
16 \ldots \ldots \\
17 \ldots \ldots \\
18 \ldots \ldots \\
19 \ldots \ldots \\
20 \ldots \ldots\end{array}$ & $\begin{array}{l}234 \\
230 \\
230 \\
230 \\
230 \\
230 \\
230 \\
230 \\
230 \\
230\end{array}$ & $\begin{array}{l}230 \\
230 \\
230 \\
227 \\
227 \\
343 \\
425 \\
400 \\
405 \\
400\end{array}$ & $\begin{array}{l}21 \ldots \ldots \\
22 \ldots \ldots \\
23 \ldots \ldots \\
24 \ldots \ldots \\
25 \ldots \ldots \\
26 \ldots \ldots \\
27 \ldots \ldots \\
28 \ldots \ldots \\
29 \ldots \ldots \\
30 \ldots \ldots \\
31 \ldots \ldots\end{array}$ & $\begin{array}{l}227 \\
227 \\
227 \\
227 \\
227 \\
223 \\
223 \\
223 \\
223 \\
192 \\
115\end{array}$ & $\begin{array}{r}400 \\
400 \\
400 \\
400 \\
328 \\
195 \\
198 \\
198 \\
---- \\
-.-1\end{array}$ \\
\hline $\begin{array}{l}\text { onthly } \\
\text { unoff, }\end{array}$ & $\begin{array}{l}\text { in } \mathrm{dech} \\
\text { acre-fe }\end{array}$ & e, in & feet & second & & & $\begin{array}{r}226 \\
13,870 \\
\end{array}$ & $\begin{array}{r}265 \\
14,710 \\
\end{array}$ \\
\hline
\end{tabular}

11-2325. Jackass .Creek near Bass Lake, Calif.

Location.--Lat $37^{\circ} 29^{1} 20^{\prime \prime}$, long $119^{\circ} 18^{1} 10^{\prime \prime}$, in SW $\frac{1}{4}$ sec.13, T.5 S., R.24 E., on left bank 1.6 miles east of Jackass Meadow, 10 miles upstream from West Fork, and 18 miles northeast of town of Bass Lake.

Drainage area. $--12.8 \mathrm{sq} \mathrm{mi}$.

Gage-height record - Water-stage recorder graph. Altitude of gage is $6,900 \mathrm{ft}$ (from topographic map).

Discharge record.--Stage-discharge relation defined by current-meter measurements; affected by ice Feb. 13-18.

Maxima --January-February 1963: Discharge, 540 cfs 0600 hours Feb. I (gage height, $10.10 \mathrm{ft})$.

1921-28, 1951 to December 1962: Discharge recorded, 786 cfs Dec. 23, 1955 (gage height, $11.37 \mathrm{ft}$ ).

Mean discharge, in cubic feet per second, 1963

\begin{tabular}{|c|c|c|c|c|c|c|c|c|}
\hline Day & January & February & Day & January & Febmary & Day & January & February \\
\hline $\begin{array}{c}1 \ldots \ldots \\
2 \ldots \ldots \\
3 \ldots \ldots \\
5 \ldots \ldots \\
6 \ldots \ldots \\
7 \ldots \ldots \\
9 \ldots \ldots \\
10 \ldots \ldots\end{array}$ & $\begin{array}{l}0.1 \\
.1 \\
.1 \\
.1 \\
.1 \\
.1 \\
.1 \\
.1 \\
.1\end{array}$ & $\begin{array}{r}391 \\
120 \\
65 \\
50 \\
43 \\
40 \\
38 \\
37 \\
32 \\
31\end{array}$ & $\begin{array}{l}11 \ldots \ldots \\
12 \ldots \ldots \\
13 \ldots \ldots \\
14 \ldots \ldots \\
15 \ldots \ldots \\
16 \ldots \ldots \\
17 \ldots \ldots \\
18 \ldots \ldots \\
19 \ldots \ldots \\
20 \ldots \ldots\end{array}$ & $\begin{array}{l}0.1 \\
0 \\
0 \\
0 \\
0 \\
0 \\
0 \\
0 \\
0 \\
0\end{array}$ & $\begin{array}{l}30 \\
24 \\
23 \\
26 \\
26 \\
22 \\
21 \\
19 \\
18 \\
21\end{array}$ & $\begin{array}{l}21 \ldots \ldots \\
22 \ldots \ldots \\
23 \ldots \ldots \\
24 \ldots \ldots \\
25 \ldots \ldots \\
26 \ldots \ldots \\
27 \ldots \ldots \\
28 \ldots \ldots \\
29 \ldots \ldots \\
30 \ldots \ldots \\
31 \ldots \ldots\end{array}$ & $\begin{array}{c}0 \\
0 \\
0 \\
0 \\
0 \\
0 \\
0 \\
0 \\
0 \\
103^{.4}\end{array}$ & $\begin{array}{r}22 \\
20 \\
20 \\
22 \\
24 \\
28 \\
30 \\
26 \\
-\ldots-\ldots\end{array}$ \\
\hline \multicolumn{7}{|c|}{ 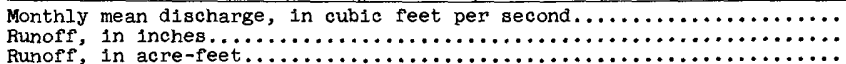 } & $\begin{array}{r}3.36 \\
0.30 \\
207\end{array}$ & $\begin{array}{r}45.3 \\
3.69 \\
2,520 \\
\end{array}$ \\
\hline
\end{tabular}


Gage helght, in feet, and discharge, in cublc feet per second, at Indicated time, 1963, of Jackass Creek near Bass Lake, Calif.

\begin{tabular}{|c|c|c|c|c|c|c|c|c|c|c|c|}
\hline Date & Hour & $\begin{array}{c}\text { Gage } \\
\text { he1ght }\end{array}$ & $\begin{array}{l}\text { Dis- } \\
\text { charge }\end{array}$ & Date & Hour & $\begin{array}{c}\text { Gage } \\
\text { helght }\end{array}$ & $\begin{array}{c}\text { Dis- } \\
\text { charge }\end{array}$ & Date & Hour & $\begin{array}{c}\text { Gage } \\
\text { helght }\end{array}$ & $\begin{array}{l}\text { Dis- } \\
\text { charge }\end{array}$ \\
\hline $\begin{array}{r}\operatorname{Jan} . \\
30\end{array}$ & $\begin{array}{l}2400 \\
1300 \\
1800 \\
2100 \\
2400 \\
0800\end{array}$ & $\begin{array}{l}4.91 \\
4.91 \\
5.00 \\
5.10 \\
5.31 \\
6.07\end{array}$ & $\begin{array}{c}0 \\
0 \\
.1 \\
.9 \\
4.1 \\
27\end{array}$ & Feb. 1 & $\begin{array}{l}1600 \\
2100 \\
2200 \\
2300 \\
2400 \\
\\
0300 \\
0600\end{array}$ & $\begin{array}{r}6.95 \\
8.48 \\
8.80 \\
9.00 \\
9.19 \\
9.95 \\
10.10\end{array}$ & $\begin{array}{r}80 \\
257 \\
305 \\
335 \\
364 \\
510 \\
540\end{array}$ & Feb. 1 & $\begin{array}{l}1200 \\
1900 \\
2400 \\
1000 \\
1600 \\
2400\end{array}$ & $\begin{array}{l}9.54 \\
8.58 \\
7.98 \\
7.22 \\
7.29 \\
6.96\end{array}$ & $\begin{array}{r}428 \\
272 \\
190 \\
103 \\
110 \\
81\end{array}$ \\
\hline
\end{tabular}

11-2345. Chiquito Creek near Bass Lake, Calif.

Location -- Lat $37^{\circ} 24145^{\prime \prime}$, long $119^{\circ} 22^{\prime} 50^{\prime \prime}$, in $\mathrm{NE}_{\frac{1}{4}}$ sec.18, T.6 S., R.24 E., on right bank 0.5 mile downstream from Beasore Creek, 0.6 mile southwest of Arnold Meadow, and 12 miles northeast of town of Bass Lake.

Drainage area. $--59.6 \mathrm{sq} \mathrm{mi}$.

Gage-he1ght record.--Water-stage recorder graph. Altitude of gage is $4,800 \mathrm{ft}$ (from topographic map).

Discharge record.--Stage-discharge relation defined by current-meter measurements below $1,100 \mathrm{cfs}$ and by slope-area measurement at 8,630 cfs; affected by $1 \mathrm{ce}$ Jan. 31 .

Maxima.--January-February 1963: Discharge, 5,660 cfs 0200 hours Feb. I (gage helght, $13.93 \mathrm{ft}$ ).

1921-28, 1951 to December 1962: Discharge, 8,630 cfs Dec. 23, 1955 (gage height, $16.38 \mathrm{ft}$ ).

Mean discharge, in cublc feet per second, 1963

\begin{tabular}{|c|c|c|c|c|c|c|c|c|}
\hline Day & January & February & Day & January & February & Day & January & February \\
\hline $\begin{array}{c}1 \ldots \ldots \\
3 \ldots \ldots \\
4 \ldots \ldots \\
5 \ldots \ldots \\
6 \ldots \ldots \\
8 \ldots \ldots \\
9 \ldots \ldots \\
10 \ldots \ldots\end{array}$ & $\begin{array}{l}7.6 \\
7.6 \\
8.0 \\
8.4 \\
8.0 \\
8.0 \\
8.9 \\
8.9 \\
8.9 \\
8.0\end{array}$ & $\begin{array}{r}2,960 \\
528 \\
287 \\
227 \\
194 \\
173 \\
160 \\
154 \\
152 \\
169\end{array}$ & $\begin{array}{l}11 \ldots \ldots \\
12 \ldots \ldots \\
13 \ldots \ldots \\
14 \ldots \ldots \\
15 \ldots \ldots \\
16 \ldots \ldots \\
17 \ldots \ldots \\
18 \ldots \ldots \\
19 \ldots \ldots \\
20 \ldots \ldots\end{array}$ & $\begin{array}{l}7.6 \\
6.4 \\
6.0 \\
6.0 \\
6.4 \\
6.4 \\
6.4 \\
6.4 \\
6.4 \\
6.4\end{array}$ & $\begin{array}{l}139 \\
127 \\
139 \\
139 \\
119 \\
115 \\
104 \\
100 \\
100 \\
104\end{array}$ & $\begin{array}{l}21 \ldots \ldots \\
22 \ldots \ldots \\
23 \ldots \ldots \\
24 \ldots \ldots \\
25 \ldots \ldots \\
26 \ldots \ldots \\
27 \ldots \ldots \\
28 \ldots \ldots \\
29 \ldots \ldots \\
30 \ldots \ldots \\
31 \ldots \ldots\end{array}$ & $\begin{array}{r}6.4 \\
7.2 \\
8.4 \\
8.9 \\
8.9 \\
5.9 \\
8.4 \\
11 \\
8.4 \\
91 \\
1,750\end{array}$ & $\begin{array}{r}106 \\
98 \\
95 \\
98 \\
106 \\
115 \\
115 \\
108 \\
-\ldots-- \\
---1\end{array}$ \\
\hline & acre & 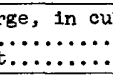 & & & & & $\begin{array}{r}67.6 \\
1.31 \\
4,150 \\
\end{array}$ & $\begin{array}{r}251 \\
4.39 \\
13,950 \\
\end{array}$ \\
\hline
\end{tabular}

Gage height, in feet, and discharge, in cubic feet per second, at indicated time, 1963

\begin{tabular}{|c|c|c|c|c|c|c|c|c|c|c|c|}
\hline Date & Hour & $\begin{array}{c}\text { Gage } \\
\text { helght }\end{array}$ & $\begin{array}{l}\text { Dis- } \\
\text { charge }\end{array}$ & Date & Hour & $\begin{array}{c}\text { Gage } \\
\text { helght }\end{array}$ & $\begin{array}{c}\text { Dis- } \\
\text { charge }\end{array}$ & Date & Hour & $\begin{array}{c}\text { Gage } \\
\text { height }\end{array}$ & $\begin{array}{c}\text { Dis- } \\
\text { charge }\end{array}$ \\
\hline $\begin{array}{r}\operatorname{Jan} .29 \\
30\end{array}$ & $\begin{array}{l}2400 \\
0300 \\
0900 \\
1300 \\
1500 \\
1900 \\
2200 \\
2300 \\
2400\end{array}$ & $\begin{array}{l}4.80 \\
4.83 \\
5.03 \\
5.35 \\
5.55 \\
5.65 \\
6.05 \\
6.44 \\
6.58\end{array}$ & $\begin{array}{r}11 \\
13 \\
30 \\
74 \\
110 \\
129 \\
219 \\
332 \\
374\end{array}$ & Jan. 31 & $\begin{array}{l}0500 \\
0700 \\
0900 \\
1100 \\
1700 \\
1800 \\
2000 \\
2100 \\
2200 \\
2300 \\
2400\end{array}$ & $\begin{array}{r}7.25 \\
7.64 \\
7.52 \\
8.35 \\
11.37 \\
11.56 \\
11.00 \\
11.31 \\
11.89 \\
11.74 \\
12.51\end{array}$ & $\begin{array}{r}627 \\
773 \\
854 \\
1,120 \\
3,100 \\
3,260 \\
2,800 \\
3,050 \\
3,570 \\
3,430 \\
4,190\end{array}$ & Feb. 1 & $\begin{array}{l}0500 \\
0900 \\
1500 \\
2400 \\
\\
0300 \\
0500 \\
1000 \\
1100 \\
1700 \\
2400\end{array}$ & $\begin{array}{r}12.78 \\
11.96 \\
9.85 \\
7.96 \\
7.58 \\
7.39 \\
7.00 \\
6.90 \\
6.70 \\
6.47\end{array}$ & $\begin{array}{r}4,460 \\
3,640 \\
1,930 \\
920 \\
\\
747 \\
671 \\
515 \\
450 \\
410 \\
341\end{array}$ \\
\hline 31 & $\begin{array}{l}0100 \\
0300\end{array}$ & $\begin{array}{l}6.60 \\
6.64\end{array}$ & $\begin{array}{l}350 \\
392\end{array}$ & Feb. 1 & 0200 & 13.93 & & & & & \\
\hline
\end{tabular}


11-2347. Mammoth Pool Reservolr near Big Creek, Calif.

Location.--Lat $37^{\circ} 19^{\prime} 45^{\prime \prime}$, long $119^{\circ} 19^{\prime} 15^{\prime \prime}$, in SW $\frac{1}{4}$ sec.11, T.7 S., R.24 E., in gatehouse of power tunnel intake near dam on San Joaquin River, 10 miles northwest of town of Big Creek.

Drainage area. $--1,002 \mathrm{sq} \mathrm{ml}$.

Gage-he1ght record.--Water-stage recorder graph. Datum of gage is at mean sea level (levels by Southerm Californla Edison Co.).

Contents record.--Contents computed from capacity table dated Nov. 6, 1959.

Maxima.--January-February 1963: Contents, 98,900 acre-ft 0300 hours Feb. 5 (elevation, $3,309.58 \mathrm{ft}$ ).

1959 to December 1962: Contents, 123,100 acre-ft May 6, 1962 (elevation, $3,332.82 \mathrm{ft}$ ).

Remarks.--Reservolr is formed by an earthfill dam; storage began oct. 8, 1959. Usable capacity, 119,900 acre-ft between elevations 3,100.00 ft (invert of power tunnel) and $3,330.00 \mathrm{ft}$ (crest of spillway) above mean sea level. Additional storage of 2,780 acre-ft is not available for release. Water is diverted through tunnel for power development; water is returned to river 8.5 miles downstream from dam. Figures given herein represent usable contents. Records furnished by Southerm California Edison Co.

Elevation, in feet, and contents, in acre-feet, at 2400 hours, 1963

\begin{tabular}{|c|c|c|c|c|c|c|c|c|c|}
\hline \multirow{2}{*}{ Day } & \multicolumn{2}{|c|}{ January } & \multicolumn{2}{|c|}{ February } & \multirow{2}{*}{ Day } & \multicolumn{2}{|c|}{ January } & \multicolumn{2}{|c|}{ February } \\
\hline & Elevation & Contents & Elevation & Contents & & Elevation & Contents & Elevation & Contents \\
\hline $\begin{array}{r}1 \\
2 \\
3 \\
4 \\
5 \\
6 \\
7 \\
8 \\
9 \\
10 \\
11 \\
12 \\
13 \\
14 \\
15\end{array}$ & $\begin{array}{l}3,203.52 \\
3,201.98 \\
3,201.49 \\
3,200.83 \\
3,200.12 \\
3,200.49 \\
3,200.23 \\
3,199.97 \\
3,199.54 \\
3,199.07 \\
3,198.37 \\
3,197.64 \\
3,196.46 \\
3,195.62 \\
3,194.95\end{array}$ & $\begin{array}{l}23,100 \\
22,300 \\
22,000 \\
21,500 \\
21,500 \\
21,600 \\
21,500 \\
21,400 \\
21,200 \\
21,000 \\
20,700 \\
20,400 \\
19,900 \\
19,600 \\
19,300\end{array}$ & $\begin{array}{l}3,300.30 \\
3,307.35 \\
3,309.12 \\
3,309.56 \\
3,309.11 \\
3,308.17 \\
3,306.96 \\
3,305.55 \\
3,304.07 \\
3,302.93 \\
3,301.23 \\
3,299.25 \\
3,297.68 \\
3,296.22 \\
3,294.10\end{array}$ & $\begin{array}{l}90,100 \\
96,700 \\
95,400 \\
98,900 \\
95,400 \\
97,500 \\
96,300 \\
95,000 \\
93,600 \\
92,500 \\
90,900 \\
89,100 \\
87,600 \\
86,300 \\
84,400\end{array}$ & $\begin{array}{l}16 \\
17 \\
18 \\
19 \\
20 \\
21 \\
22 \\
23 \\
24 \\
25 \\
26 \\
27 \\
28 \\
29 \\
30 \\
31\end{array}$ & $\begin{array}{l}3,194.04 \\
3,192.59 \\
3,192.72 \\
3,192.93 \\
3,193.27 \\
3,193.24 \\
3,193.31 \\
3,193.62 \\
3,193.94 \\
3,193.97 \\
3,194.35 \\
3,193.56 \\
3,194.14 \\
3,194.60 \\
3,202.00 \\
3,250.00\end{array}$ & $\begin{array}{l}19,000 \\
18,400 \\
18,500 \\
18,500 \\
18,700 \\
18,700 \\
15,700 \\
18,800 \\
18,900 \\
18,900 \\
19,100 \\
18,900 \\
19,000 \\
19,200 \\
22,300 \\
49,300\end{array}$ & $\begin{array}{c}3,291.73 \\
3,259.14 \\
3,256.44 \\
3,283.64 \\
3,280.77 \\
3,277.94 \\
3,275.00 \\
3,271.81 \\
3,265.62 \\
3,265.49 \\
3,262.55 \\
3,259.69 \\
3,256.55 \\
- \\
- \\
-\end{array}$ & $\begin{array}{c}82,200 \\
79,900 \\
77,600 \\
75,200 \\
72,800 \\
70,400 \\
68,000 \\
65,400 \\
62,900 \\
60,500 \\
58,300 \\
56,200 \\
53,900 \\
- \\
- \\
-\end{array}$ \\
\hline and & In conte & $1 n$ & 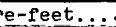 & 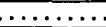 & & 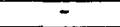 & $+26,100$ & 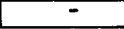 & $+4,600$ \\
\hline
\end{tabular}

11-2347.6. San Joaquin River above Shakeflat Creek, near Big Creek, Calif.

Location.--Lat $37^{\circ} 19^{1} 05^{\prime \prime}$, long $119^{\circ} 19^{14} 40^{\prime \prime}$, In SW $\frac{1}{4}$ sec.14, T.7 S., R.24 E., on right bank $1,500 \mathrm{ft}$ upstream from Shakeflat Creek, 4,900 ft downstream from Mammoth Pool dam, and 10 miles northwest of town of Big Creek.

Drainage area. $--1,003 \mathrm{sq} \mathrm{ml}$.

Gage-height record.--Water-stage recorder graph. Datum of gage is $2,865.50 \mathrm{ft}$ above mean sea level (levels by Southerm Califormla Edison Co.).

D1scharge record. --Stage-discharge relation defined by current-meter measurements.

Maxima.--January-February 1963: Discharge, 261 cfs 2130 hours Jan. 31 (gage height, $4.50 \mathrm{ft}$ ).

1959 to December 1962: Discharge, 5,780 cfs May 6, 1962 (gage he1ght, $11.90 \mathrm{ft}$ ).

Remarks.--Flow regulated by Mammoth Pool Reservolr (see station 11-2347); slightly regulated by Florence Lake and Lake Thomas A. Edison (see stations 11-2296 and $11-2310)$. 
Mean discharge, in cublc feet per second, 1963, of San Joaquin R1ver above Shakeflat Creek, near B1g Creek, Calif.

\begin{tabular}{|c|c|c|c|c|c|c|c|c|}
\hline Day & January & February & Day & January & February & Day & January & February \\
\hline $\begin{array}{c}1 \ldots \ldots \\
2 \ldots \ldots \\
3 \ldots \ldots \\
4 \ldots \ldots \\
5 \ldots \ldots \\
6 \ldots \ldots \\
7 \ldots \ldots \\
9 \ldots \ldots \\
10 \ldots \ldots\end{array}$ & $\begin{array}{l}11 \\
11 \\
11 \\
11 \\
11 \\
11 \\
11 \\
11 \\
11 \\
11\end{array}$ & $\begin{array}{l}75 \\
39 \\
62 \\
61 \\
60 \\
37 \\
14 \\
14 \\
15 \\
18\end{array}$ & $\begin{array}{l}11 \ldots \ldots \\
12 \ldots \ldots \\
13 \ldots \ldots \\
14 \ldots \ldots \\
15 \ldots \ldots \\
16 \ldots \ldots \\
17 \ldots \ldots \\
18 \ldots \ldots \\
19 \ldots \ldots \\
20 \ldots \ldots\end{array}$ & $\begin{array}{l}11 \\
11 \\
10 \\
10 \\
11 \\
11 \\
11 \\
11 \\
11 \\
11\end{array}$ & $\begin{array}{l}9.0 \\
4.9 \\
16 \\
15 \\
13 \\
13 \\
13 \\
13 \\
13 \\
12\end{array}$ & $\begin{array}{l}21 \ldots \ldots \\
22 \ldots \ldots \\
23 \ldots \ldots \\
24 \ldots \ldots \\
25 \ldots \ldots \\
26 \ldots \ldots \\
27 \ldots \ldots \\
28 \ldots \ldots \\
29 \ldots \ldots \\
30 \ldots \ldots \\
31 \ldots \ldots\end{array}$ & $\begin{array}{r}11 \\
11 \\
11 \\
11 \\
11 \\
11 \\
11 \\
11 \\
12 \\
59 \\
105\end{array}$ & $\begin{array}{r}12 \\
12 \\
12 \\
12 \\
12 \\
11 \\
11 \\
11 \\
-\ldots-\ldots\end{array}$ \\
\hline $\begin{array}{l}\text { onthly } \\
\text { unoff, }\end{array}$ & $\begin{array}{l}\text { n disc } \\
\text { acre }-f\end{array}$ & 3 & Sn & & & & $\begin{array}{r}15.5 \\
956\end{array}$ & $\begin{array}{r}21.8 \\
1,210 \\
\end{array}$ \\
\hline
\end{tabular}

11-2360. Huntington Lake near Big Creek, Calif.

Location. --Lat $37^{\circ} 14^{\prime} 05^{\prime \prime}$, long $119^{\circ} 12^{\prime} 40^{\prime \prime}$, in SW $\frac{1}{4}$ sec.14, T.8 S., R.25 E., in gate tower of dam 1 on Big Creek, 2 miles northeast of town of Big Creek.

Drainage area. $--79.0 \mathrm{sq} \mathrm{m}$.

Gage-height record.--Water-stage recorder graph. Datum of gage is at mean sea level (levels by Southern California Edison Co.).

Contents record.--Contents computed from capacity table dated Sept. 24, 1946.

Maxima.--January-February 1963: Contents, 62,800 acre-ft 0100 hours Feb. 26 (elevation, $6,930.16 \mathrm{ft}$ )

1913 to December 1962: Contents, 90,500 acre-ft May 31, 1926 (elevation, $6,950.92 \mathrm{ft})$.

Remarks.--Lake is formed by four dams; storage began Apr. 11, 1913. Dams were raised in 1914 and again in 1917. Usable capacity, 89,200 acre-ft between elevations $6,819.9 \mathrm{ft}$ (invert of outlet tunnel No.1) and $6,950 \mathrm{ft}$ (splliway crest at dam 1) above mean sea level. Additional storage of 600 acre-ft is not available for release. Water is used for power development in Big Creek plants. Figures given herein represent usable contents. Records fumished by Southern California Edison Co.

Elevation, in feet, and contents, in acre-feet, at 2400 hours, 1963

\begin{tabular}{|c|c|c|c|c|c|c|c|c|c|}
\hline \multirow{2}{*}{ Day } & \multicolumn{2}{|c|}{ January } & \multicolumn{2}{|c|}{ February } & \multirow{2}{*}{ Day } & \multicolumn{2}{|c|}{ January } & \multicolumn{2}{|c|}{ February } \\
\hline & Elevation & Contents & Elevation & Contents & & Elevation & Contents & Elevation & Contents \\
\hline $\begin{array}{r}1 \\
2 \\
3 \\
4 \\
5 \\
6 \\
7 \\
8 \\
9 \\
10 \\
11 \\
12 \\
13 \\
14 \\
15\end{array}$ & $\begin{array}{l}6,923.65 \\
6,923.43 \\
6,923.37 \\
6,923.24 \\
6,923.39 \\
6,923.67 \\
6,923.76 \\
6,923.74 \\
6,923.58 \\
6,923.42 \\
6,923.16 \\
6,922.93 \\
6,922.74 \\
6,922.46 \\
6,922.23\end{array}$ & $\begin{array}{l}55,000 \\
54,700 \\
54,600 \\
54,500 \\
54,700 \\
55,000 \\
55,100 \\
55,100 \\
54,900 \\
54,700 \\
54,400 \\
54,100 \\
53,900 \\
53,600 \\
53,300\end{array}$ & $\begin{array}{l}6,926.67 \\
6,926.63 \\
6,926.24 \\
6,926.22 \\
6,926.21 \\
6,926.55 \\
6,926.86 \\
6,927.18 \\
6,927.55 \\
6,927.85 \\
6,928.10 \\
6,928.37 \\
6,928.71 \\
6,928.93 \\
6,929.14\end{array}$ & $\begin{array}{l}58,500 \\
58,500 \\
58,000 \\
58,000 \\
58,000 \\
58,400 \\
58,800 \\
59,100 \\
59,600 \\
59,900 \\
60,200 \\
60,600 \\
61,000 \\
61,200 \\
61,500\end{array}$ & $\begin{array}{l}16 \\
17 \\
18 \\
19 \\
20 \\
21 \\
22 \\
23 \\
24 \\
25 \\
26 \\
27 \\
28 \\
29 \\
30 \\
31\end{array}$ & $\begin{array}{l}6,922.06 \\
6,921.83 \\
6,921.61 \\
6,921.61 \\
6,921.78 \\
6,921.61 \\
6,921.38 \\
6,921.13 \\
6,920.85 \\
6,920.59 \\
6,920.91 \\
6,921.12 \\
6,920.91 \\
6,920.78 \\
6,921.35 \\
6,923.68\end{array}$ & $\begin{array}{l}53,100 \\
52,900 \\
52,600 \\
52,600 \\
52,800 \\
52,600 \\
52,400 \\
52,100 \\
51,800 \\
51,500 \\
51,800 \\
52,100 \\
51,800 \\
51,700 \\
51,300 \\
55,000\end{array}$ & $\begin{array}{c}6,929.26 \\
6,929.35 \\
6,929.44 \\
6,929.49 \\
6,929.57 \\
6,929.69 \\
6,929.77 \\
6,929.87 \\
6,930.02 \\
6,930.15 \\
6,929.94 \\
6,929.73 \\
6,929.45 \\
- \\
-\end{array}$ & $\begin{array}{c}61,600 \\
61,800 \\
61,900 \\
61,900 \\
62,000 \\
62,200 \\
62,300 \\
62,400 \\
62,600 \\
62,700 \\
62,500 \\
62,200 \\
61,900 \\
= \\
= \\
=\end{array}$ \\
\hline \multicolumn{6}{|c|}{ 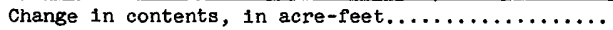 } & - & +300 & - & $+6,900$ \\
\hline
\end{tabular}


11-2370. Big Creek below Huntington Lake, Calif.

Location: -Lat $37^{\circ} 13^{\prime} 10^{\prime \prime}$, long $119^{\circ} 12150^{\prime \prime}$, in NW $\frac{1}{4}$ sec.23, T.8 S., R.25 E., on right bank $i, 200 \mathrm{ft}$ upstream from Grouse Creek and 1 mile downstream from Huntington Lake.

Drainage area. $--80 \mathrm{sq} \mathrm{m} 1$.

Gage-helght record:--Water-stage recorder graph. Altitude of gage is $6,600 \mathrm{ft}$ (from topographic map).

Discharge record.--Stage-discharge relation defined by current-meter measurements.

Maxima.--January-February 1963: Discharge, 28 cfs 0200 hours Feb. 1 (gage helght, $3.01 \mathrm{ft}$ ).

1925 to December 1962: Discharge, 2,040 cfs June 23, 1925 (gage height,

$11.3 \mathrm{ft}$, present datum), siphon splilways operating at Huntington Lake.

Remarks.--Flow regulated by Huntington Lake since 1913 (see station 11-2360).

Mean discharge, in cubic feet per second, 1963

\begin{tabular}{|c|c|c|c|c|c|c|c|c|}
\hline Day & January & February & Day & Jamuary & February & Day & January & February \\
\hline $\begin{array}{c}1 \ldots \ldots \\
2 \ldots \ldots \\
3 \ldots \ldots \\
5 \ldots \ldots \\
6 \ldots \ldots \\
7 \ldots \ldots \\
9 \ldots \ldots \\
10 \ldots \ldots\end{array}$ & $\begin{array}{l}1.6 \\
1.6 \\
1.6 \\
1.6 \\
1.6 \\
1.6 \\
1.5 \\
1.5 \\
1.5 \\
1.5\end{array}$ & $\begin{array}{r}14 \\
4.9 \\
3.6 \\
3.1 \\
2.8 \\
2.6 \\
2.5 \\
2.4 \\
2.6 \\
3.0\end{array}$ & $\begin{array}{l}11 \ldots \ldots \\
12 \ldots \ldots \\
13 \ldots \ldots \\
14 \ldots \ldots \\
15 \ldots \ldots \\
16 \ldots \ldots \\
17 \ldots \ldots \\
18 \ldots \ldots \\
19 \ldots \ldots \\
20 \ldots \ldots\end{array}$ & $\begin{array}{l}1.5 \\
1.5 \\
1.5 \\
1.5 \\
1.5 \\
1.5 \\
1.5 \\
1.5 \\
1.5 \\
1.5\end{array}$ & $\begin{array}{l}2.6 \\
2.5 \\
2.8 \\
2.7 \\
2.6 \\
2.4 \\
2.4 \\
2.4 \\
2.4 \\
2.4\end{array}$ & $\begin{array}{l}21 \ldots \ldots \\
22 \ldots \ldots \\
23 \ldots \ldots \\
24 \ldots \ldots \\
25 \ldots \ldots \\
26 \ldots \ldots \\
27 \ldots \ldots \\
28 \ldots \ldots \\
29 \ldots \ldots \\
30 \ldots \ldots \\
31 \ldots \ldots\end{array}$ & $\begin{array}{l}1.5 \\
1.5 \\
1.5 \\
1.5 \\
1.5 \\
1.5 \\
1.5 \\
1.5 \\
1.6 \\
4.8 \\
13\end{array}$ & $\begin{array}{r}2.3 \\
2.3 \\
2.2 \\
2.2 \\
2.2 \\
2.2 \\
2.1 \\
2.1 \\
----- \\
----.-\end{array}$ \\
\hline \multicolumn{7}{|c|}{ 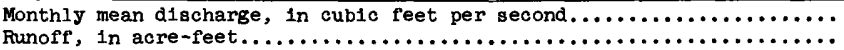 } & $\begin{array}{r}2.00 \\
123 \\
\end{array}$ & $\begin{array}{r}3.01 \\
167 \\
\end{array}$ \\
\hline
\end{tabular}

11-2372. South Fork Tamarack Creek tributary near B1g Creek, Cal1f.

(Crest-stage station)

Location.--Lat $37^{\circ} 10^{1} 40^{\prime \prime}$, long $119^{\circ} 12^{\prime} 10^{\prime \prime}$, in SW $\frac{1}{4} N W \frac{1}{4}$ sec.1, T.9 S., R.25 E., on State Highway $168,2.8$ miles southeast of Big Creek.

Drainage area. $--1.24 \mathrm{sq} \mathrm{mi}$.

Gage-helght record.--Crest stages only. Altitude of gage is 7,200 ft (from topographic map).

Discharge record.--Stage-discharge relation defined by current-meter measurements below $8.7 \mathrm{cfs}$ and by computation of flow through culvert at 26 and $66 \mathrm{cfs}$.

Maxima.--January-February 1963: D1scharge, $66 \mathrm{cfs}$ Jan. 31 (gage he1ght, $28.98 \mathrm{ft}$, from high-water profile).

1959 to December 1962: D1scharge, 26 ofs May 6, 1962 (gage he1ght, $22.69 \mathrm{ft}$ ).

11-2375. Pitman Creek below Tamarack Creek, Calif.

Location.--Lat $37^{\circ} 11^{\prime} 55^{\prime \prime}$, long $119^{\circ} 12^{\prime} 45^{\prime \prime}$, in NW $\frac{1}{4}$ sec.35, T.8 S., R.25 E., on right bank $0.8 \mathrm{mile}$ downstream from confluence of Tamarack Creek and South Fork Tamarack Creek, 1.4 miles upstream from mouth, and 1.9 miles east of town of Big Creek.

Dra1nage area. $--22.7 \mathrm{sq} \mathrm{m} 1$.

Gage-height record. - Water-stage recorder graph. Altitude of gage is 7,005 ft (from Southerm California Edison Co. contour map).

Discharge record.--Stage-discharge relation defined by current-meter measurements: af'fected by 1ce Jan. 1-30, Feb. 15-28.

Maxima - -January-February 1963: D1scharge, 1,340 cf's 0400-0500 hours Feb. 1 (gage he1ght, $8.37 \mathrm{ft}$ ).

1927 to December 1962: Discharge, 3,670 cf's Dec. 23, 1955 (gage height, 11.20 $\mathrm{ft}$ ), from rating curve extended above $1,100 \mathrm{cfs}$ on basis of slope-area measurement at 3,220 cfs. 
Mean discharge, in cubic feet per second, 1963, of P1tman Creek below Tamarack Creek, Calif.

\begin{tabular}{|c|c|c|c|c|c|c|c|c|}
\hline Day & January & February & Day & January & February & Day & January & February \\
\hline $\begin{array}{c}1 \ldots \ldots \\
2 \ldots \ldots \\
3 \ldots \ldots \\
4 \ldots \ldots \\
5 \ldots \ldots \\
6 \ldots \ldots \\
7 \ldots \ldots \\
8 \ldots \ldots \\
10 \ldots .\end{array}$ & 0.3 & $\begin{array}{r}925 \\
220 \\
113 \\
88 \\
75 \\
67 \\
64 \\
61 \\
56 \\
51\end{array}$ & $\begin{array}{l}11 \ldots \ldots \\
12 \ldots \ldots \\
13 \ldots \ldots \\
14 \ldots \ldots \\
15 \ldots \ldots \\
16, \ldots \\
17 \ldots \ldots \\
18, \ldots \ldots \\
19 . \ldots .\end{array}$ & 0.3 & $\begin{array}{l}48 \\
42 \\
39 \\
40 \\
37 \\
32 \\
28 \\
26 \\
31 \\
31\end{array}$ & $\begin{array}{l}21 \ldots \ldots \\
22 \ldots \ldots \\
23 \ldots \ldots \\
24 \ldots \ldots \\
25 \ldots \\
26 \ldots \\
27 \ldots \ldots \\
28 \ldots \\
29 \ldots \\
30 \ldots \\
31 \ldots \ldots \\
\end{array}$ & $450^{3.0}$ & $\begin{array}{r}33 \\
30 \\
25 \\
29 \\
36 \\
42 \\
44 \\
39 \\
-0 .\end{array}$ \\
\hline & acre & & & & & & $\begin{array}{r}14.9 \\
0.76 \\
916\end{array}$ & $\begin{array}{r}84.0 \\
3.85 \\
4,670\end{array}$ \\
\hline
\end{tabular}

Gage helght, in feet, and discharge, in cubic feet per second, at indicated time, 1963

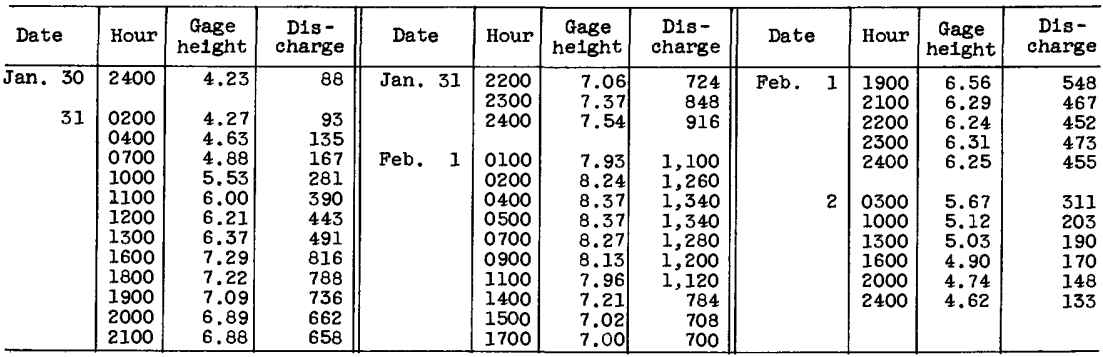

11-2395. Shaver Lake near B1g Creek, Cal1f.

Location. --Lat $37^{\circ} 08^{1} 40^{\prime \prime}$, long $119^{\circ} 18^{\prime} 10^{\prime \prime}$, in SE $\frac{1}{4}$ sec.13, T.9 S., R.24 E., near center of dam on Stevenson Creek, 6 mlies southwest of town of Big Creek.

Drainage area. $--29.1 \mathrm{sq} \mathrm{mi}$.

Gage-helght record.--Water-stage recorder graph. Datum of gage is at mean sea level (levels by Southerm California Edison Co.).

Contents record.--Contents computed from capacity table dated Mar. 28, 1928.

Maxima:--January-February 1963: Contents, 59,500 acre-ft 1900 hours Feb. 4 (elevation, $5,329.02 \mathrm{ft}$ ).

1909 to December 1962: Contents, 135,900 acre-ft July 5, 1946 (elevation, $5,370.25 \mathrm{ft}$ ).

Remarks.--Lake is formed by concrete-arch dam; dam completed Nov, 18, 1927. Usable capacity, 135,300 acre-ft between elevations 5,255 ft (trashrack foundation) and $5,370 \mathrm{ft}$ (crest of spillway) above mean sea level. Water is recelved from Pitman Creek (since Feb. 22, 1928) and Huntington Lake (since Apr. 21, 1928) through Huntington-Shaver condult and released for power development in Big Creek plants. Figures given herein represent usable contents. Records furnished by Southerm California Edison Co.

Elevation, in feet, and contents, in acre-feet, at 2400 hours, 1963

\begin{tabular}{|c|c|c|c|c|c|c|c|c|c|}
\hline \multirow{2}{*}{ Day } & \multicolumn{2}{|c|}{ January } & \multicolumn{2}{|c|}{ February } & \multirow{2}{*}{ Day } & \multicolumn{2}{|c|}{ January } & \multicolumn{2}{|c|}{ February } \\
\hline & Elevation & Contents & Elevation & Contents & & Elevation & Contents & Elevation & Contents \\
\hline $\begin{array}{r}1 \\
2 \\
3 \\
4 \\
5 \\
6 \\
7 \\
8 \\
9 \\
10 \\
11 \\
12 \\
13 \\
14 \\
15\end{array}$ & $\begin{array}{l}5,323.38 \\
5,323.11 \\
5,323.00 \\
5,322.90 \\
5,322.90 \\
5,322.90 \\
5,322.90 \\
5,322.90 \\
5,322.90 \\
5,322.90 \\
5,322.82 \\
5,322.71 \\
5,322.59 \\
5,322.38 \\
5,322.37\end{array}$ & $\begin{array}{l}51,400 \\
51,000 \\
50,900 \\
50,700 \\
50,700 \\
50,700 \\
50,700 \\
50,700 \\
50,700 \\
50,700 \\
50,600 \\
50,500 \\
50,300 \\
50,000 \\
50,000\end{array}$ & $\begin{array}{l}\mathbf{5}, 328.05 \\
5,328.57 \\
5,328.85 \\
5,328.92 \\
5,328.64 \\
\mathbf{5}, 328.31 \\
5,327.97 \\
5,327.59 \\
5,327.35 \\
5,327.07 \\
5,326.75 \\
5,326.48 \\
5,326.37 \\
5,326.04 \\
5,325.76\end{array}$ & $\begin{array}{l}58,000 \\
58,800 \\
59,200 \\
59,300 \\
58,900 \\
58,400 \\
57,900 \\
57,400 \\
57,000 \\
56,600 \\
56,100 \\
55,800 \\
55,600 \\
55,100 \\
54,700\end{array}$ & $\begin{array}{l}16 \\
17 \\
18 \\
19 \\
20 \\
21 \\
22 \\
23 \\
24 \\
25 \\
26 \\
27 \\
28 \\
29 \\
30 \\
31 \\
\end{array}$ & $\begin{array}{l}5,322.31 \\
5,322.02 \\
5,321.83 \\
5,321.70 \\
5,321.70 \\
5,321.67 \\
5,321.63 \\
5,321.61 \\
5,321.58 \\
5,321.54 \\
5,321.54 \\
5,321.52 \\
5,321.51 \\
5,321.59 \\
5,322.99 \\
5,325.87\end{array}$ & $\begin{array}{l}49,900 \\
49,500 \\
49,300 \\
49,100 \\
49,100 \\
49,100 \\
49,000 \\
49,000 \\
48,900 \\
48,900 \\
48,900 \\
48,800 \\
48,800 \\
48,900 \\
50,800 \\
54,900 \\
\end{array}$ & $\begin{array}{c}5,325.47 \\
5,325.06 \\
5,324.73 \\
5,324.36 \\
5,324.06 \\
5,323.83 \\
5,323.67 \\
5,323.38 \\
5,322.87 \\
5,322.46 \\
5,322.02 \\
5,321.43 \\
5,321.01 \\
- \\
- \\
-\end{array}$ & $\begin{array}{c}54,300 \\
53,700 \\
53,300 \\
52,700 \\
52,300 \\
52,000 \\
51,800 \\
51,400 \\
50,700 \\
50,100 \\
49,500 \\
48,700 \\
48,200 \\
- \\
- \\
-\end{array}$ \\
\hline he $>2+2$ & In & 100,110 & & & & - & $+3,500$ & - & $-6,700$ \\
\hline
\end{tabular}


11-2420. San Joaquin River above Willow Creek, near Auberry, Calif.

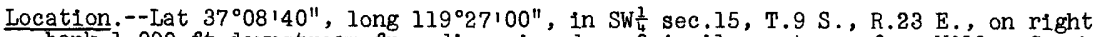
bank $1,000 \mathrm{ft}$ downstream from diversion dam, 0.4 mile upstream from Willow Creek, and 4.2 miles northeast of Auberry.

Drainage area. $--1,299 \mathrm{sq} \mathrm{ml}$.

Gage-height record --Water-stage recorder graph. Datum of gage is $1,175.54 \mathrm{ft}$ above mean sea level (levels by Southem California Edison Co.).

Discharge record.--Stage-discharge relation defined by current-meter measurements.

Maxima.--January-February 1963: Discharge, 14,500 cfs 0200 hours Feb. I (gage height, $23.15 \mathrm{ft}$ ).

1951 to December 1962: Discharge, 73,200 cfs Dec. 23, 1955 (gage height, $54.2 \mathrm{ft}$, from floodmarks), from rating curve extended above $7,000 \mathrm{cfs}$ on basis of computed flow over dam.

Remarks :-Flow regulated by nine powerplants and six reservoirs (combined capacity, about 559,900 acre-ft).

Mean discharge, in cublc feet per second, 1963

\begin{tabular}{|c|c|c|c|c|c|c|c|c|}
\hline Day & January & February & Day & January & February & Day & January & February \\
\hline $\begin{array}{r}\ldots \ldots \\
2 \ldots \ldots \\
3 \ldots \ldots \\
4 \ldots \ldots \\
5 \ldots \ldots \\
6 \ldots \ldots \\
8 \ldots \ldots \\
9 \ldots \ldots \\
10 \ldots \ldots\end{array}$ & $\begin{array}{l}20 \\
20 \\
20 \\
20 \\
20 \\
20 \\
20 \\
20 \\
20 \\
20\end{array}$ & $\begin{array}{r}3,670 \\
16 \\
6.0 \\
4.9 \\
18 \\
3.7 \\
3.7 \\
3.7 \\
3.8 \\
5.3\end{array}$ & $\begin{array}{l}11 \ldots \ldots \\
12 \ldots \ldots \\
13 \ldots \ldots \\
14 \ldots \ldots \\
15 \ldots \ldots \\
16 \ldots \ldots \\
17 \ldots \ldots \\
19 \ldots \ldots \\
19 \ldots \ldots \\
20 \ldots \ldots\end{array}$ & $\begin{array}{l}20 \\
20 \\
20 \\
21 \\
21 \\
21 \\
21 \\
21 \\
21 \\
21\end{array}$ & $\begin{array}{l}7.2 \\
7.3 \\
5.1 \\
4.0 \\
4.0 \\
3.9 \\
3.9 \\
3.9 \\
3.8 \\
3.8\end{array}$ & $\begin{array}{l}21 \ldots \ldots \\
22 \ldots \ldots \\
23 \ldots \ldots \\
24 \ldots \ldots \\
25 \ldots \ldots \\
26 \ldots \ldots \\
27 \ldots \ldots \\
28 \ldots \ldots \\
29 \ldots \ldots \\
30 \ldots \ldots \\
31 \ldots \ldots\end{array}$ & $\begin{array}{r}21 \\
21 \\
21 \\
20 \\
20 \\
20 \\
20 \\
20 \\
20 \\
12 \\
2,410\end{array}$ & $\begin{array}{r}3.8 \\
3.8 \\
3.8 \\
3.8 \\
3.7 \\
3.7 \\
3.7 \\
3.7 \\
----- \\
--1--.-\end{array}$ \\
\hline $\begin{array}{l}\text { MonthIy } \\
\text { Runoff, }\end{array}$ & dis & , & & & & & $\begin{array}{r}97.2 \\
5,970\end{array}$ & $\begin{array}{r}136 \\
7,580\end{array}$ \\
\hline
\end{tabular}

11-2434. Bass Lake near Bass Lake, Cal1f.

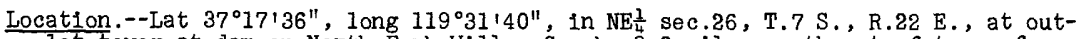
let tower at dam on North Fork Willow Creek, 2.2 miles southeast of town of Bass Lake and 5 miles north of town of North Fork.

Drainage area. $--50.5 \mathrm{sq} \mathrm{m} 1$.

Gage-height record.--Water-stage recorder graph. Datum of gage is at mean sea level (levels by Pacific Gas \& Electric Co.).

Contents record.--Contents computed from capacity table dated July 8, 1937.

Maxima.--January-February 1963: Contents, 34,000 acre-ft 1600 hours Feb. 14 (elevation, $3,366.0 \mathrm{ft})$.

1911 to December 1962: Contents, 45,960 acre-ft June 17, 1923 (elevation, $3,376.8 \mathrm{f} t$ ).

Remarks.--Reservoir formed by earthfill and rockfill dam; completed in 1901 and raised in 1910. Since 1910, usable contents 45,100 acre-ft between elevations, $3,280.22 \mathrm{ft}$ (invert of outlet conduit No. 3 ) and $3,376.40 \mathrm{ft}$ (top of spillway gates) above mean sea level. Additional storage of 300 acre-ft not available for release. Records show contents at 2400 hours. Records furnished by Pacific Gas \& Electric Co. 
Contents, in acre-feet, at 2400 hours, 1963, of Bass Lake near Bass Lake, Calif.

\begin{tabular}{|c|c|c|c|c|c|c|c|c|}
\hline Day & January & Pebruary & Day & Jamuary & February & Day & January & February \\
\hline $\begin{array}{c}\ldots \ldots \\
2 \ldots \ldots \\
3 \ldots \ldots \\
5 \ldots \ldots \\
6 \ldots \ldots \\
7 \ldots \ldots \\
8 \ldots \ldots \\
10 \ldots \ldots\end{array}$ & $\begin{array}{l}20,600 \\
20,600 \\
20,600 \\
20,600 \\
20,700 \\
20,700 \\
20,700 \\
20,700 \\
20,700 \\
20,700\end{array}$ & $\begin{array}{l}31,300 \\
32,600 \\
32,900 \\
33,000 \\
33,100 \\
33,100 \\
33,100 \\
33,300 \\
33,300 \\
33,500\end{array}$ & $\begin{array}{l}11 \ldots \ldots \\
12 \ldots \ldots \\
13 \ldots \ldots \\
14 \ldots \ldots \\
15 \ldots \ldots \\
16 \ldots \ldots \\
17 \ldots \ldots \\
18 \ldots \ldots \\
19 \ldots \ldots \\
20 \ldots \ldots\end{array}$ & $\begin{array}{l}20,700 \\
20,800 \\
20,800 \\
20,800 \\
20,800 \\
20,800 \\
20,800 \\
20,800 \\
20,800 \\
20,900\end{array}$ & $\begin{array}{l}33,500 \\
33,500 \\
33,500 \\
33,700 \\
34,000 \\
33,900 \\
33,800 \\
33,700 \\
33,600 \\
33,400\end{array}$ & $\begin{array}{l}21 \ldots \ldots \\
22 \ldots \ldots \\
23 \ldots \ldots \\
24 \ldots \ldots \\
25 \ldots \ldots \\
26 \ldots \ldots \\
27 \ldots \ldots \\
28 \ldots \ldots \\
29 \ldots \ldots \\
30 \ldots \ldots \\
31 \ldots \ldots\end{array}$ & $\begin{array}{l}20,900 \\
20,900 \\
20,900 \\
20,900 \\
20,900 \\
20,900 \\
21,000 \\
21,000 \\
21,000 \\
22,100 \\
25,700\end{array}$ & $\begin{array}{r}33,300 \\
33,100 \\
33,000 \\
32,800 \\
32,600 \\
32,600 \\
32,500 \\
32,400 \\
------ \\
---- \\
--\end{array}$ \\
\hline & & & & & & & $+5,130$ & $+6,730$ \\
\hline
\end{tabular}

11-2440. North Fork Willow Creek near Bass Lake, Calif.

Location.--Lat $37^{\circ} 17^{\prime} 20^{\prime \prime}$, long $119^{\circ} 31^{\prime} 45^{\prime \prime}$, in SE $\frac{1}{4}$ sec.26, T.7 S., R.22 E., on right bank $1,500 \mathrm{ft}$ downstream from Bass Lake spillway and 2.5 miles southeast of town of Bass Lake.

Drainage area. $--50.8 \mathrm{sq} \mathrm{ml}$.

Gage-height record.--Water-stage recorder graph. Altitude of gage is $3,200 \mathrm{ft}$ (from topographic map).

Discharge record.--Stage-discharge relation defined by current-meter measurements.

Maxima --January-February 1963: Discharge, 158 cfs 0330 hours Feb. 10 (gage height, $3.54 \mathrm{ft}^{\mathrm{t}}$ ).

1940 to December 1962: Discharge, 847 cfs Feb. 11, 1941 (gage height, $5.85 \mathrm{ft}$ ).

Remarks.--Flow regulated by Bass Lake (see station 11-2434). Diversion by Pacific Gas \& Electric Co. conduit No. 3 near Bass Lake of 5,570 acre-ft during flood period.

Mean discharge, In cub1c feet per second, 1963

\begin{tabular}{|c|c|c|c|c|c|c|c|c|}
\hline Day & January & February & Day & January & February & Day & January & February \\
\hline 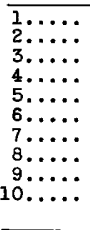 & $\begin{array}{l}0.2 \\
.2 \\
.2 \\
.2 \\
.2 \\
.2 \\
.2 \\
.2 \\
.2 \\
.2\end{array}$ & $\begin{array}{r}15 \\
1.5 \\
1.0 \\
.9 \\
.8 \\
.8 \\
32.7 \\
150 \\
152\end{array}$ & $\begin{array}{l}11 \ldots . . \\
12 \ldots . \\
13 \ldots \\
14, \ldots \\
15 . \ldots \\
16 . \ldots \\
17 \ldots \\
18 . \ldots \\
19 . \ldots \\
20 . \ldots\end{array}$ & $\begin{array}{l}0.2 \\
.2 \\
.2 \\
.3 \\
.8 \\
.8 \\
.8 \\
.8 \\
.8 \\
.8\end{array}$ & $\begin{array}{r}146 \\
148 \\
154 \\
35 \\
1.0 \\
.9 \\
.9 \\
.8 \\
.8 \\
.8\end{array}$ & $\begin{array}{l}21 \ldots \ldots \\
22 \ldots \ldots \\
23 \ldots \ldots \\
24 \ldots \ldots \\
25 \ldots \ldots \\
26 \ldots \\
27 \ldots \ldots \\
28 \ldots \\
29 \ldots \\
30 \ldots \\
31 \ldots \ldots\end{array}$ & $\begin{array}{r}0.8 \\
.8 \\
.8 \\
.8 \\
.5 \\
.2 \\
.2 \\
.2 \\
.3 \\
7.6 \\
24\end{array}$ & $\begin{array}{r}0.8 \\
.8 \\
.7 \\
.7 \\
.7 \\
.7 \\
.7 \\
.7 \\
-.7 \\
-.-0\end{array}$ \\
\hline $\begin{array}{l}\text { nthly } \\
\text { noff, }\end{array}$ & & & & & & & $\begin{array}{r}1.42 \\
87\end{array}$ & $\begin{array}{r}30.3 \\
1,680 \\
\end{array}$ \\
\hline
\end{tabular}


11-2465. W1llow Creek at mouth, near Auberry, Callf.

Location.--Lat $37^{\circ} 09^{\prime} 10^{\prime \prime}$, long $19^{\circ} 27^{\prime} 30^{\prime \prime}$, in NE $\frac{1}{4}$ sec.16, T.9 S., R.23 E., on left bank 40 ft upstream from bridge, 0.4 mile upstream from mouth, 1.3 miles downstream from Whiskey Creek, and 4.3 miles northeast of Auberry.

Dralnage area. $--130 \mathrm{sq} \mathrm{mi}$.

Gage-helght record. - Water-stage recorder graph. Datum of gage is 1,174.69 $\mathrm{ft}$ above mean sea level (levels by Southern California Edison Co.).

D1scharge record.--Stage-discharge relation defined by current-meter measurements.

Maxima.--January-February 1963: Discharge, 7,450 cfs 0200-0300 hours Feb. 1 (gage helght, $19.06 \mathrm{ft}$ ).

1952 to December 1962: Discharge, 15,700 cfs Dec. 23, 1955 (gage helght, $28.5 \mathrm{ft}$, from floodmarks), from rating curve extended above $4,700 \mathrm{cfs}$.

Remarks.--Flow regulated by Bass Lake (see station 11-2434) and diversion into Paclfic Gas \& Electric Co. conduit No. 1.

Mean discharge, in cubic feet per second, 1963

\begin{tabular}{|c|c|c|c|c|c|c|c|c|}
\hline Day & January & February & Day & January & February & Day & January & February \\
\hline $\begin{array}{r}1 \ldots \ldots \\
2 \ldots \ldots \\
3 \ldots \ldots \\
4 \ldots \ldots \\
5 \ldots \ldots \\
7 \ldots \ldots \\
8 \ldots \ldots \\
9 \ldots \ldots \\
10 \ldots \ldots\end{array}$ & $\begin{array}{l}1.7 \\
1.8 \\
1.9 \\
2.0 \\
2.0 \\
2.0 \\
1.9 \\
1.8 \\
1.8 \\
1.8\end{array}$ & $\begin{array}{r}3,640 \\
514 \\
218 \\
149 \\
65 \\
34 \\
28 \\
24 \\
26 \\
280\end{array}$ & $\begin{array}{l}11 \ldots \ldots \\
12 \ldots \ldots \\
13 \ldots \ldots \\
14 \ldots \ldots \\
15 \ldots \ldots \\
16 \ldots \ldots \\
17 \ldots \ldots \\
18 \ldots \ldots \\
19 \ldots \ldots \\
20 \ldots \ldots\end{array}$ & $\begin{array}{l}1.9 \\
1.9 \\
1.5 \\
1.5 \\
1.9 \\
1.9 \\
1.9 \\
1.9 \\
1.9 \\
1.9\end{array}$ & $\begin{array}{r}108 \\
63 \\
98 \\
133 \\
84 \\
52 \\
44 \\
42 \\
35 \\
32\end{array}$ & $\begin{array}{l}21 \ldots \ldots \\
22 \ldots \ldots \\
23 \ldots \ldots \\
24 \ldots \ldots \\
25 \ldots \ldots \\
26 \ldots \ldots \\
27 \ldots \ldots \\
28 \ldots \ldots \\
29 \ldots \ldots \\
30 \ldots \ldots \\
31 \ldots \ldots\end{array}$ & $\begin{array}{r}1.9 \\
1.9 \\
2.0 \\
2.0 \\
2.0 \\
2.0 \\
2.0 \\
1.7 \\
1.8 \\
434 \\
3,200\end{array}$ & $\begin{array}{r}30 \\
28 \\
25 \\
23 \\
22 \\
22 \\
21 \\
20 \\
---.--\end{array}$ \\
\hline $\begin{array}{l}\text { onthly } \\
\text { unoff, }\end{array}$ & $\begin{array}{l}a d \\
a c r\end{array}$ & e, in & feet $p$ & & & & $\begin{array}{r}119 \\
7,320\end{array}$ & $\begin{array}{r}209 \\
11,620\end{array}$ \\
\hline
\end{tabular}

Gage he1ght, in feet, and discharge, in cub1c feet per second, at indicated time, 1963

\begin{tabular}{|c|c|c|c|c|c|c|c|c|c|c|c|}
\hline Date & Hour & $\begin{array}{c}\text { Gage } \\
\text { helght }\end{array}$ & $\begin{array}{c}\text { D1s - } \\
\text { charge }\end{array}$ & Date & Hour & $\begin{array}{c}\text { Gage } \\
\text { height }\end{array}$ & $\begin{array}{c}\text { Dis- } \\
\text { charge }\end{array}$ & Date & Hour & $\begin{array}{c}\text { Gage } \\
\text { height }\end{array}$ & $\begin{array}{c}\text { D1s- } \\
\text { charge }\end{array}$ \\
\hline $\begin{array}{r}\operatorname{Jan} .29 \\
30\end{array}$ & $\begin{array}{l}2400 \\
0200 \\
0400 \\
0500 \\
0800 \\
1000 \\
1300 \\
1500 \\
1600 \\
1700 \\
1800 \\
2100 \\
2400 \\
0100 \\
0500 \\
0700\end{array}$ & $\begin{array}{r}4.25 \\
4.41 \\
4.64 \\
4.80 \\
5.38 \\
5.76 \\
6.38 \\
6.89 \\
7.20 \\
8.65 \\
9.35 \\
10.45 \\
10.75 \\
10.95 \\
10.74 \\
11.34\end{array}$ & $\begin{array}{r}4.1 \\
6.2 \\
10 \\
14 \\
39 \\
65 \\
129 \\
205 \\
265 \\
650 \\
913 \\
1,440 \\
1,600 \\
1,720 \\
1,590 \\
1,950\end{array}$ & Feb. 1 & $\begin{array}{l}0800 \\
0900 \\
1000 \\
1300 \\
1400 \\
1500 \\
1600 \\
1700 \\
2000 \\
2200 \\
2300 \\
2400 \\
\\
0100 \\
0200 \\
0300 \\
0500 \\
0800\end{array}$ & $\begin{array}{l}11.82 \\
12.72 \\
13.27 \\
15.79 \\
15.91 \\
16.55 \\
16.50 \\
16.16 \\
13.00 \\
12.15 \\
13.00 \\
16.45 \\
18.55 \\
19.06 \\
19.06 \\
17.35 \\
13.96\end{array}$ & $\begin{array}{l}2,240 \\
2,780 \\
3,140 \\
4,900 \\
4,990 \\
5,440 \\
5,400 \\
5,160 \\
2,950 \\
2,440 \\
2,950 \\
5,370 \\
7,040 \\
7,450 \\
7,450 \\
6,080 \\
3,620\end{array}$ & Feb. I & $\begin{array}{l}0900 \\
1100 \\
1200 \\
1300 \\
1400 \\
1600 \\
2000 \\
2200 \\
2400 \\
\\
0500 \\
0800 \\
1200 \\
1800 \\
1900 \\
2000 \\
2100 \\
2400\end{array}$ & $\begin{array}{r}13.38 \\
14.33 \\
13.85 \\
13.85 \\
13.00 \\
11.68 \\
10.46 \\
10.02 \\
9.72 \\
8.84 \\
8.45 \\
8.00 \\
7.39 \\
7.33 \\
7.36 \\
7.21 \\
6.98\end{array}$ & $\begin{array}{r}3,220 \\
3,880 \\
3,550 \\
3,550 \\
2,950 \\
2,160 \\
1,440 \\
1,220 \\
1,080 \\
\\
711 \\
587 \\
453 \\
301 \\
289 \\
295 \\
265 \\
220 \\
\end{array}$ \\
\hline
\end{tabular}


11-2470. San Joaquin River below Kerckhoff powerhouse, near Prather, Calif.

Location. - Lat $37^{\circ} 04^{\prime} 45^{\prime \prime}$, long $119^{\circ} 33^{\prime} 35^{\prime \prime}$, in NW $\frac{1}{4}$ sec.10, T.10 S., R.22 E., on left bank 1.1 miles downstream from Kerckhoff powerhouse, 1.4 miles upstream from Blg Sandy Creek, and 3.8 miles southeast of Prather.

Drainage area. $--1,481 \mathrm{sq} \mathrm{ml}$.

Gage-helght record. -Water-stage recorder graph. Datum of gage is $563.4 \mathrm{ft}$ above mean sea level (levels by Bureau of Reclamation).

Discharge record.--Stage-discharge relation defined by current-meter measurements.

Maxima --January-February 1963: Discharge, 30,300 cfs 0500 hours Feb. 1 (gage helght, $32.20 \mathrm{ft}$ ).

1910-14, 1936-37, 1942 to December 1962: Discharge, 92,200 cfs Dec. 23, 1955 (gage helght, $51.0 \mathrm{ft}$, from floodmarks), from rating curve extended above $20,000 \mathrm{cf}$ 's on basis of records for San Joaquin RIver above Willow Creek, near Auberry, and Willow Creek at mouth, near Auberry.

Remarks.-Flow regulated by 12 powerplants and 8 reservolrs with total usable capacity of about 609,300 acre-ft.

Mean discharge, in cublc feet per second, 1963

\begin{tabular}{|c|c|c|c|c|c|c|c|c|}
\hline Day & January & February & Day & January & February & Day & January & February \\
\hline $\begin{array}{c}1 \ldots \ldots \\
2 \ldots \ldots \\
3 \ldots \ldots \\
4 \ldots \ldots \\
5 \ldots \ldots \\
7 \ldots \ldots \\
8 \ldots \ldots \\
9 \ldots \ldots \\
10 \ldots \ldots\end{array}$ & $\begin{array}{l}521 \\
599 \\
647 \\
644 \\
535 \\
301 \\
357 \\
413 \\
484 \\
566\end{array}$ & $\begin{array}{r}11,600 \\
4,030 \\
3,720 \\
3,660 \\
3,600 \\
3,580 \\
3,530 \\
3,350 \\
3,470 \\
4,020\end{array}$ & $\begin{array}{l}11 \ldots \ldots \\
12 \ldots \ldots \\
13 \ldots \ldots \\
14 \ldots \ldots \\
15 \ldots \ldots \\
16 \ldots \ldots \\
17 \ldots \ldots \\
15 \ldots \ldots \\
19 \ldots \ldots \\
20 \ldots \ldots\end{array}$ & $\begin{array}{r}651 \\
731 \\
637 \\
1,130 \\
499 \\
624 \\
1,000 \\
755 \\
358 \\
72\end{array}$ & $\begin{array}{l}3,710 \\
3,600 \\
3,650 \\
3,640 \\
3,600 \\
3,590 \\
3,560 \\
3,540 \\
3,500 \\
3,500\end{array}$ & $\begin{array}{l}21 \ldots \ldots \\
22 \ldots \ldots \\
23 \ldots \ldots \\
24 \ldots \ldots \\
25 \ldots \ldots \\
26 \ldots \ldots \\
27 \ldots \ldots \\
28 \ldots \ldots \\
29 \ldots \ldots \\
30 \ldots \ldots \\
31 \ldots \ldots\end{array}$ & $\begin{array}{r}440 \\
465 \\
310 \\
622 \\
508 \\
235 \\
206 \\
440 \\
657 \\
1,780 \\
9,200 \\
\end{array}$ & $\begin{array}{r}3,470 \\
3,500 \\
3,460 \\
3,450 \\
3,440 \\
3,410 \\
3,400 \\
3,360 \\
------ \\
----. \\
\end{array}$ \\
\hline $\begin{array}{l}\text { inthly } \\
\text { inoff, }\end{array}$ & \multicolumn{6}{|c|}{ 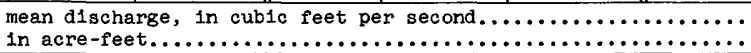 } & $\begin{array}{r}861 \\
52,930 \\
\end{array}$ & $\begin{array}{r}3,855 \\
214,100 \\
\end{array}$ \\
\hline
\end{tabular}

Gage height, in feet, and discharge, In cubic feet per second, at indicated time, 1963

\begin{tabular}{|c|c|c|c|c|c|c|c|c|c|c|c|}
\hline Date & Hour & $\begin{array}{c}\text { Gage } \\
\text { he1.ght }\end{array}$ & $\begin{array}{l}\text { D1s- } \\
\text { charge }\end{array}$ & Date & Hour & $\begin{array}{c}\text { Gage } \\
\text { he1ght }\end{array}$ & $\begin{array}{l}\text { Dis- } \\
\text { charge }\end{array}$ & Date & Hour & $\begin{array}{c}\text { Gage } \\
\text { helght }\end{array}$ & $\begin{array}{l}\text { Dis- } \\
\text { charge }\end{array}$ \\
\hline $\begin{array}{r}\operatorname{Jan} \cdot 30 \\
31\end{array}$ & $\begin{array}{l}2400 \\
0100 \\
0200 \\
0300 \\
0500 \\
0700 \\
1000 \\
1100 \\
1200 \\
1300 \\
1400 \\
1500 \\
1600\end{array}$ & $\begin{array}{l}17.06 \\
16.65 \\
16.75 \\
17.32 \\
17.32 \\
17.14 \\
17.22 \\
17.72 \\
17.88 \\
18.22 \\
23.00 \\
26.32 \\
24.50\end{array}$ & $\begin{array}{r}5,140 \\
4,790 \\
4,870 \\
5,370 \\
5,370 \\
5,210 \\
5,280 \\
5,730 \\
5,870 \\
6,180 \\
11,800 \\
17,200 \\
14,100\end{array}$ & Feb. 1 & $\begin{array}{l}1700 \\
1900 \\
2100 \\
2200 \\
2400 \\
0100 \\
0200 \\
0300 \\
0400 \\
0500 \\
0600 \\
0700 \\
0800\end{array}$ & $\begin{array}{l}26.10 \\
26.30 \\
25.00 \\
23.68 \\
16.20 \\
14.56 \\
21.08 \\
23.95 \\
27.00 \\
32.20 \\
28.90 \\
28.50 \\
25.00\end{array}$ & $\begin{array}{r}16,800 \\
17,200 \\
14,800 \\
12,800 \\
4,430 \\
3,170 \\
9,230 \\
13,200 \\
18,600 \\
30,300 \\
22,600 \\
21,700 \\
14,800\end{array}$ & Feb. 1 & $\begin{array}{l}0900 \\
1000 \\
1100 \\
1200 \\
1200 \\
1300 \\
1400 \\
1600 \\
1800 \\
2000 \\
2100 \\
2200 \\
2400\end{array}$ & $\begin{array}{l}22.50 \\
22.20 \\
19.70 \\
25.00 \\
26.38 \\
25.00 \\
23.60 \\
23.10 \\
18.86 \\
18.60 \\
16.92 \\
16.28 \\
16.52\end{array}$ & $\begin{array}{r}11,100 \\
10,700 \\
7,660 \\
14,800 \\
17,400 \\
14,800 \\
12,700 \\
12,000 \\
6,800 \\
6,540 \\
5,010 \\
4,500 \\
4,690\end{array}$ \\
\hline
\end{tabular}

11-2472. Big Sandy Creek tributary near Tollhouse, Calif.

(Crest-stage station)

Location:--Lat $37^{\circ} 01^{\prime} 55^{\prime \prime}$, long $119^{\circ} 26^{\prime} 50^{\prime \prime}$, in $\mathrm{SW}_{4} \mathrm{NE}_{\frac{1}{4}} \sec .27$, T.10 S., R.23 E., $2.8 \mathrm{miles}$ west of Tolihouse.

Drainage area. $-0.46 \mathrm{sq} \mathrm{ml}$.

Gage-helght record.--Crest stages only. Altitude of gage is 1,900 ft (from topographic map).

Discharge record.--Stage-discharge relation defined by current-meter measurements below 15 cf's.

Maxima.--January-February 1963: Discharge, $23 \mathrm{cfs} F e b .1$ (gage height, $4.77 \mathrm{ft}$ ). 1959 to December 1962: Discharge, $13 \mathrm{cfs}$ Feb. 15, 1962 (gage height,
$4.14 \mathrm{ft}$ ). 
11-2501. Millerton Lake at Friant, Calif.

Location.--Lat $37^{\circ} 00^{\prime} 00^{\prime \prime}$, long $119^{\circ} 42^{\prime} 10^{\prime \prime}$, in SW $\frac{1}{4}$ sec.5, T.11 S., R.21 E., near center of Friant Dam on San Joaquin River, Immediately upstream from Cottonwood Creek, and 0.9 mile northeast of Friant.

Drainage area. $--1,633 \mathrm{sq} \mathrm{mi}$.

Gage-helght record.--Water-stage recorder graph. Datum of gage is at mean sea level (levels by Bureau of Reclamation).

Maxima.--January-February 1963: Contents, 422,400 acre-ft 2400 hours Feb. 28 (elevation, $556.79 \mathrm{ft}$ \}.

1941 to December 1962: Contents, 525,400 acre-ft June 23, 1958 (elevation, $578,99 \mathrm{ft}$ ).

Remarks. --Reservolr is formed by gravity-type concrete dam with spillway near center, completed in December 1942. Usable capacity, 503,200 acre-ft between elevations $375.4 \mathrm{ft}$ (1nvert of river outlet) and 578.0 ft (top of drum-type sp111way gates) above mean sea level. Not avallable for release, 17,400 acre-ft.

Records show total contents. Records of contents furmished by Bureau of Reclamation.

\begin{tabular}{|c|c|c|c|c|c|c|c|c|c|}
\hline \multirow{2}{*}{ Day } & \multicolumn{2}{|c|}{ January } & \multicolumn{2}{|c|}{ February } & \multirow{2}{*}{ Day } & \multicolumn{2}{|c|}{ January } & \multicolumn{2}{|c|}{ February } \\
\hline & Elevation & Contents & Elevation & Contents & & Elevation & Contents & Elevation & Contents \\
\hline $\begin{array}{r}1 \\
2 \\
3 \\
4 \\
5 \\
6 \\
7 \\
8 \\
9 \\
10 \\
11 \\
12 \\
13 \\
14 \\
15\end{array}$ & $\begin{array}{l}501.35 \\
501.88 \\
502.25 \\
502.58 \\
502.95 \\
503.11 \\
503.27 \\
503.50 \\
503.74 \\
504.08 \\
504.42 \\
504.84 \\
505.21 \\
505.93 \\
506.21\end{array}$ & $\begin{array}{l}219.6 \\
221.2 \\
222.3 \\
223.3 \\
224.4 \\
224.9 \\
225.4 \\
226.1 \\
226.8 \\
227.8 \\
228.9 \\
230.2 \\
231.3 \\
233.5 \\
234.4\end{array}$ & $\begin{array}{l}524.63 \\
526.29 \\
527.67 \\
525.98 \\
530.72 \\
532.30 \\
533.84 \\
535.31 \\
536.95 \\
538.89 \\
540.42 \\
541.72 \\
543.09 \\
544.44 \\
545.72\end{array}$ & $\begin{array}{l}295.5 \\
301.4 \\
306.4 \\
311.2 \\
317.6 \\
323.5 \\
329.2 \\
334.8 \\
341.1 \\
348.6 \\
354.6 \\
359.7 \\
365.2 \\
370.6 \\
375.8\end{array}$ & $\begin{array}{l}16 \\
17 \\
18 \\
19 \\
20 \\
21 \\
22 \\
23 \\
24 \\
25 \\
26 \\
27 \\
28 \\
29 \\
30 \\
31 \\
\end{array}$ & $\begin{array}{l}506.53 \\
507.13 \\
507.57 \\
507.78 \\
507.79 \\
508.00 \\
508.27 \\
508.40 \\
508.81 \\
509.02 \\
509.18 \\
509.26 \\
509.45 \\
509.78 \\
510.98 \\
517.48\end{array}$ & $\begin{array}{l}235.4 \\
237.2 \\
238.6 \\
239.3 \\
239.3 \\
240.0 \\
240.8 \\
241.2 \\
242.5 \\
243.2 \\
243.7 \\
243.9 \\
244.5 \\
245.6 \\
249.4 \\
270.8\end{array}$ & $\begin{array}{c}546.95 \\
548.14 \\
549.15 \\
550.02 \\
550.83 \\
551.64 \\
552.38 \\
553.07 \\
553.76 \\
554.36 \\
554.97 \\
555.78 \\
556.79 \\
- \\
- \\
-\end{array}$ & $\begin{array}{r}380.8 \\
355.7 \\
389.9 \\
393.5 \\
396.9 \\
400.3 \\
403.4 \\
406.4 \\
409.3 \\
411.9 \\
414.5 \\
418.0 \\
422.4 \\
- \\
- \\
-\end{array}$ \\
\hline Cha & se in con & ts, & 0 & & & - & +52.1 & - & +151.6 \\
\hline
\end{tabular}

11-2510. San Joaquin River below Friant, Calif.

Location.--Lat $36^{\circ} 59104^{\prime \prime}$, long $119^{\circ} 43^{1} 24^{\prime \prime}$, In SW $\frac{1}{4}$ sec.7, T.11 S., R.21 E., on left bank 0.5 mile west of Friant, 1.5 miles downstream from Cottonwood Creek, 2 miles downstream from Friant Dam, and at mile 268.1.

Drainage area. $--1,675 \mathrm{sq} \mathrm{ml}$.

Gage-height record.-Water-stage recorder graph. Datum of gage is $294.00 \mathrm{ft}$ above mean sea level (levels by Bureau of Reclamation).

Discharge record.--Stage-discharge relation defined by current-meter measurements.

Maxima --January-February 1963: Discharge, 85 cfs 0100 hours Feb. 10 (gage height, $2.20 \mathrm{ft})$.

1907-41 (prior to regulation by M1llerton Lake): Discharge, 77,200 cf's

Dec. 11, 1937 (gage helght, $23.8 \mathrm{ft}$, site and datum then in use).

1942 to December 1962 (regulated by Millerton Lake): Discharge, $11,200 \mathrm{cfs}$ Jan. $-23,1943$.

Remarks.--Flow regulated by M1llerton Lake (see station 11-2501) beginning in 1944 and by other reservoirs described in Remarks for San Joaquin River below Kerckhoff powerhouse. Uncontrolled pondage in Millerton Lake began in September 1961. 
11-2571. Miam1 Creek near Oakhurst, Cal1f.

Location. - Lat $37^{\circ} 23137^{\prime \prime}$, long $119^{\circ} 39^{\prime} 12^{\prime \prime}$, in $\mathrm{NE} \frac{1}{4} \mathrm{SE} \frac{1}{4}$ sec.22, T.6 S., R.21 E., on left bank $200 \mathrm{ft}$ downstream from county road and 4.6 miles north of 0akhurst.

Drainage area. $--10.6 \mathrm{sq} \mathrm{mi}$.

Gage-height record.--Water-stage recorder graph. Altitude of gage is 3,500 $\mathrm{ft}$ (from topographic map).

Discharge record.--Stage-discharge relation defined by current-meter measurements below $210 \mathrm{cf}$; affected by 1ce Jan. $6,7,12,13,25-28$.

Maxima.--January-February 1963: D1scharge, 1,140 cf's 0100 hours Feb. 1 (gage helght, $9.08 \mathrm{ft}$ )

1960 to December 1962: Discharge, 251 cfs Feb. 10, 1962 (gage height, $6.03 \mathrm{ft})$.

Remarks. --Records furnished by California Department of Water Resources and reviewed by Geological Survey.

Mean discharge, in cublc feet per second, 1963

\begin{tabular}{|c|c|c|c|c|c|c|c|c|}
\hline Day & January & February & Day & January & February & Day & January & February \\
\hline $\begin{array}{c}1 \ldots \ldots \\
2 \ldots \ldots \\
3 \ldots \ldots \\
5 \ldots \ldots \\
6 \ldots \ldots \\
7 \ldots \ldots \\
9 \ldots \ldots \\
10 \ldots \ldots\end{array}$ & $\begin{array}{l}1.4 \\
1.2 \\
1.3 \\
1.3 \\
1.3 \\
1.3 \\
1.3 \\
1.3 \\
1.3 \\
1.3\end{array}$ & $\begin{array}{r}391 \\
45 \\
20 \\
13 \\
10 \\
9.1 \\
8.1 \\
7.2 \\
8.6 \\
30\end{array}$ & $\begin{array}{l}11 \ldots \ldots \\
12 \ldots \ldots \\
13 \ldots \ldots \\
14 \ldots \ldots \\
15 \ldots \ldots \\
16 \ldots \ldots \\
17 \ldots \ldots \\
18 \ldots \ldots \\
19 \ldots \ldots \\
20 \ldots \ldots\end{array}$ & $\begin{array}{l}1.3 \\
1.2 \\
1.0 \\
1.4 \\
1.3 \\
1.3 \\
1.3 \\
1.2 \\
1.1 \\
1.1\end{array}$ & $\begin{array}{l}17 \\
12 \\
22 \\
18 \\
12 \\
10 \\
9.5 \\
8.6 \\
7.9 \\
7.5\end{array}$ & $\begin{array}{l}21 \ldots \ldots \\
22 \ldots \ldots \\
23 \ldots \ldots \\
24 \ldots \ldots \\
25 \ldots \ldots \\
26 \ldots \ldots \\
27 \ldots \ldots \\
28 \ldots \ldots \\
29 \ldots \ldots \\
30 \ldots \ldots \\
31 \ldots \ldots\end{array}$ & $\begin{array}{r}1.1 \\
1.2 \\
1.2 \\
1.2 \\
1.2 \\
1.1 \\
1.2 \\
1.3 \\
1.6 \\
95 \\
443\end{array}$ & $\begin{array}{r}7.6 \\
7.2 \\
6.7 \\
6.4 \\
6.1 \\
5.9 \\
5.9 \\
5.7 \\
--.--. \\
-.-1\end{array}$ \\
\hline \multicolumn{7}{|c|}{ 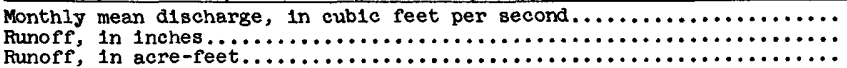 } & $\begin{array}{r}18.5 \\
2.01 \\
1,140 \\
\end{array}$ & $\begin{array}{r}25.6 \\
2.52 \\
1,420 \\
\end{array}$ \\
\hline
\end{tabular}

Gage height, in feet, and discharge, in cub1c feet per second, at indicated time, 1963

\begin{tabular}{|c|c|c|c|c|c|c|c|c|c|c|c|}
\hline Date & Hour & $\begin{array}{c}\text { Gage } \\
\text { helght }\end{array}$ & $\begin{array}{l}\text { D1s- } \\
\text { charge }\end{array}$ & Date & Hour & $\begin{array}{c}\text { Gage } \\
\text { height }\end{array}$ & $\begin{array}{c}\text { D1s- } \\
\text { charge }\end{array}$ & Date & Hour & $\begin{array}{c}\text { Gage } \\
\text { he1ght }\end{array}$ & $\begin{array}{c}\text { D1s- } \\
\text { charge }\end{array}$ \\
\hline $\begin{array}{r}\text { Jan. } 29 \\
30\end{array}$ & $\begin{array}{l}2400 \\
0200 \\
0400 \\
0900 \\
1300 \\
1400 \\
1500 \\
1800 \\
2000 \\
2100 \\
2300 \\
2400 \\
0100\end{array}$ & $\begin{array}{l}2.89 \\
3.03 \\
3.34 \\
3.75 \\
4.26 \\
4.34 \\
4.33 \\
4.90 \\
5.16 \\
5.45 \\
6.06 \\
6.04 \\
5.95\end{array}$ & $\begin{array}{c}4.8 \\
7.7 \\
17 \\
36 \\
70 \\
77 \\
76 \\
133 \\
169 \\
204 \\
303 \\
300 \\
\end{array}$ & Jan. 31 & $\begin{array}{l}0500 \\
0600 \\
0700 \\
0900 \\
1100 \\
1200 \\
1500 \\
1700 \\
1800 \\
1900 \\
2000 \\
2100 \\
2200 \\
2300 \\
2400\end{array}$ & $\begin{array}{l}5.87 \\
5.85 \\
5.64 \\
6.55 \\
7.01 \\
7.20 \\
8.38 \\
7.17 \\
6.90 \\
6.38 \\
6.26 \\
6.27 \\
6.16 \\
6.87 \\
8.10\end{array}$ & $\begin{array}{l}270 \\
267 \\
233 \\
399 \\
503 \\
549 \\
891 \\
542 \\
477 \\
364 \\
341 \\
343 \\
322 \\
470 \\
802\end{array}$ & Feb, 1 & $\begin{array}{l}0100 \\
0200 \\
0400 \\
0500 \\
0700 \\
0800 \\
1000 \\
1200 \\
1800 \\
2400 \\
0400 \\
1000 \\
1600 \\
2400\end{array}$ & $\begin{array}{l}9.08 \\
8.70 \\
8.16 \\
7.48 \\
6.84 \\
6.86 \\
6.54 \\
5.94 \\
4.88 \\
4.36 \\
4.10 \\
3.87 \\
3.71 \\
3.57\end{array}$ & $\begin{array}{r}1,140 \\
999 \\
820 \\
622 \\
463 \\
468 \\
397 \\
282 \\
130 \\
79 \\
58 \\
43 \\
33 \\
27\end{array}$ \\
\hline
\end{tabular}

11-2575. Fresno R1ver near Knowles, Cal1f.

Location.--Lat $37^{\circ} 14^{\prime} 15^{\prime \prime}$, long $119^{\circ} 46^{\prime} 25^{\prime \prime}$, in NW/1 sec.15, T.8 S., R.20 E., on left bank at Fresno Crossing, $0.1 \mathrm{mile}$ downstream from Bean Gulch and 6 miles northeast of Knowles.

Drainage area. $--133 \mathrm{sq} \mathrm{mi}$.

Gage-helght record --Water-stage recorder graph. Datum of gage is $1,086.4 \mathrm{ft}$ above mean sea leve1 (river-profile survey).

Discharge record.--Stage-discharge relation defined by current-meter measurements below $2,500 \mathrm{cfs}$ and by slope-area measurement at 13,300 cfs; affected by $1 \mathrm{ce}$
Jan. $13-19$.

Maxima --January-February 1963: Discharge, 5,180 cfs 0600 hours Feb. 1 (gage height, $7.36 \mathrm{ft}$ ).

1911-13, 1915 to December 1962: Discharge, 13,300 cfs Dec. 23, 1955 (gage height, $11.52 \mathrm{ft}$ ). 
Mean d1scharge, In cuble feet per second, 1963, of Fresno River near Knowles, Cal1f.

\begin{tabular}{|c|c|c|c|c|c|c|c|c|}
\hline Day & January & February & Day & January & February & Day & January & February \\
\hline $\begin{array}{c}1 \ldots \ldots \\
2 \ldots \ldots \\
4 \ldots \ldots \\
5 \ldots \ldots \\
6 \ldots \ldots \\
7 \ldots \ldots \\
9 \ldots \ldots \\
10 \ldots \ldots\end{array}$ & $\begin{array}{l}11 \\
11 \\
11 \\
11 \\
11 \\
11 \\
11 \\
11 \\
11 \\
11\end{array}$ & $\begin{array}{r}2,590 \\
437 \\
171 \\
115 \\
87 \\
95 \\
89 \\
81 \\
94 \\
422\end{array}$ & $\begin{array}{l}11 \ldots \ldots \\
12 \ldots \ldots \\
13 \ldots \ldots \\
14 \ldots \ldots \\
15 \ldots \ldots \\
16 \ldots \ldots \\
17 \ldots \ldots \\
18 \ldots \ldots \\
19 \ldots \ldots \\
20 \ldots \ldots\end{array}$ & $\begin{array}{r}11 \\
11 \\
9.0 \\
7.0 \\
9.0 \\
9.0 \\
9.0 \\
9.0 \\
9.0 \\
9.0\end{array}$ & $\begin{array}{r}200 \\
150 \\
223 \\
211 \\
143 \\
128 \\
112 \\
103 \\
95 \\
89\end{array}$ & $\begin{array}{l}21 \ldots \ldots \\
22 \ldots \ldots \\
23 \ldots \ldots \\
24 \ldots \ldots \\
25 \ldots \ldots \\
26 \ldots \ldots \\
27 \ldots \ldots \\
28 \ldots \ldots \\
29 \ldots \ldots \\
30 \ldots \ldots \\
31 \ldots \ldots\end{array}$ & $\begin{array}{c}9.0 \\
10 \\
11 \\
12 \\
11 \\
11 \\
10 \\
10 \\
11 \\
256 \\
2,140\end{array}$ & $\begin{array}{r}84 \\
81 \\
76 \\
74 \\
71 \\
68 \\
68 \\
66 \\
---- \\
----\end{array}$ \\
\hline noff, & $\begin{array}{l}\text { an dis } \\
\text { inche } \\
\text { acre }\end{array}$ & & & & & & $\begin{array}{r}86.9 \\
0.75 \\
5,340\end{array}$ & $\begin{array}{r}222 \\
1.74 \\
12,340 \\
\end{array}$ \\
\hline
\end{tabular}

Gage helght, in feet, and discharge, in cublc feet per second, at indicated time, 1963

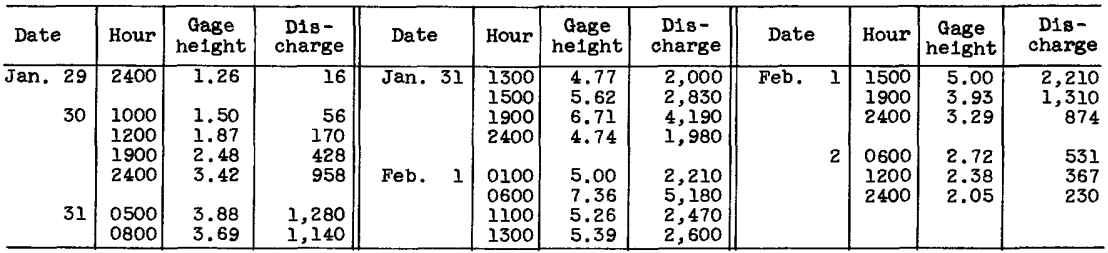

11-2577. P1cayune Creek near Coarsegold, Calif.

(Crest-stage station)

Location.--Lat $37^{\circ} 13^{\prime} 1^{\prime \prime}$, long $119^{\circ} 42^{\prime} 25^{\prime \prime}$, in NW $\frac{1}{4} S W \frac{1}{4}$ sec.20, T.8 S., R.21 E., on State Highway $41,3.0$ miles south of Coarsegold.

Drainage area. $--7.96 \mathrm{sq} \mathrm{mi}$.

Gage-helght record.--Crest stages only. Alt1tude of gage is $1,860 \mathrm{ft}$ (from topographic map).

Discharge record.--Stage-discharge relation defined by current-meter measurements below $67 \mathrm{cfs}$ and by computation of flow through culvert at $216 \mathrm{cfs}$.

Maxima.--January-February 1963: Discharge, $120 \mathrm{cfs}$ Feb. 1 (gage height, $3.88 \mathrm{ft}$ ). 1959 to December 1962: Discharge, 216 of's Feb. 10, 1962 (gage height,

$5.12 \mathrm{ft}$, from high-water profile).

11-2580. Fresno River near Daulton, Calif.

Location.--Lat $37^{\circ} 05^{\prime} 50^{\prime \prime}$, long $119^{\circ} 53120^{\prime \prime}$, in NW $\frac{1}{4}$ sec.3, T.10 S., R.19 E., on left bank 0.5 mile downstream from Willow Creek and 5.3 miles southeast of Daulton.

Drainage area. $--259 \mathrm{sq} \mathrm{ml}$.

Gage-helght record.--Water-stage recorder graph, except Jan. 1-8. Altitude of gage is $385 \mathrm{ft}$ (from topographic map). Gage datum used is that of Mar. 20, 1963 .

Discharge record.--Stage-discharge relation defined by current-meter measurements. Discharge for Jan. 1-8 estimated on basis of one discharge measurement and hydrographic comparison with Fresno River near Knowles.

Maxima.--January-February 1963: Discharge, 6,290 cfs 0900 hours Feb. 1 (gage helght, $8.23 \mathrm{ft}$, from recorder graph, $8.3 \mathrm{ft}$, from floodmarks).

1941 to December 1962: Discharge, 17,500 cfs Dec. 23, 1955 (gage height, $12.64 \mathrm{ft})$. 
Mean discharge, In cublc feet per second, 1963, of Fresno River near Daulton, Calif.

\begin{tabular}{|c|c|c|c|c|c|c|c|c|}
\hline Day & January & February & Day & Januery & February & Day & January & February \\
\hline $\begin{array}{c}1 \ldots \ldots \\
2 \ldots \ldots \\
3 \ldots \ldots \\
4 \ldots \ldots \\
5 \ldots \ldots \\
6 \ldots \ldots \\
8 \ldots \ldots \\
9 \ldots \ldots \\
10 \ldots \ldots\end{array}$ & $\begin{array}{l}10 \\
10 \\
10 \\
10 \\
10 \\
10 \\
10 \\
10 \\
11 \\
11\end{array}$ & $\begin{array}{r}3,540 \\
966 \\
323 \\
185 \\
123 \\
105 \\
100 \\
86 \\
86 \\
632\end{array}$ & $\begin{array}{l}11 \ldots \ldots \\
12 \ldots \ldots \\
13 \ldots \ldots \\
14 \ldots \ldots \\
15 \ldots \ldots \\
16 \ldots \ldots \\
17 \ldots \ldots \\
18 \ldots \ldots \\
19 \ldots \ldots \\
20 \ldots \ldots\end{array}$ & $\begin{array}{l}10 \\
10 \\
10 \\
8.0 \\
7.1 \\
8.8 \\
10 \\
10 \\
10 \\
10\end{array}$ & $\begin{array}{l}408 \\
248 \\
347 \\
405 \\
286 \\
226 \\
196 \\
174 \\
158 \\
147\end{array}$ & $\begin{array}{l}21 \ldots \ldots \\
22 \ldots \ldots \\
23 \ldots \ldots \\
24 \ldots \ldots \\
25 \ldots \ldots \\
26 \ldots \ldots \\
27 \ldots \ldots \\
28 \ldots \ldots \\
29 \ldots \ldots \\
30 \ldots \ldots \\
31 \ldots \ldots\end{array}$ & $\begin{array}{r}10 \\
10 \\
10 \\
11 \\
12 \\
12 \\
12 \\
12 \\
12 \\
48 \\
1,820\end{array}$ & 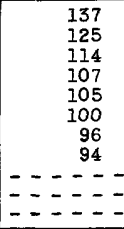 \\
\hline $\begin{array}{l}\text { Monthly } \\
\text { Runoff, } \\
\text { Runoff, }\end{array}$ & $\begin{array}{l}\text { an dis } \\
\text { Inche } \\
\text { acre- }\end{array}$ & & & & & & $\begin{array}{r}69.8 \\
0.31 \\
4,290\end{array}$ & $\begin{array}{r}344 \\
1.38 \\
19,080\end{array}$ \\
\hline
\end{tabular}

Gage height, in feet, and discharge, In cublc feet per second, at indicated time, 1963

\begin{tabular}{|c|c|c|c|c|c|c|c|c|c|c|c|}
\hline Date & Hour & $\begin{array}{c}\text { Gage } \\
\text { helght }\end{array}$ & $\begin{array}{l}\text { Dis- } \\
\text { charge }\end{array}$ & Date & Hour & $\begin{array}{c}\text { Gage } \\
\text { helght }\end{array}$ & $\begin{array}{c}\text { Dis- } \\
\text { charge }\end{array}$ & Date & Hour & $\begin{array}{c}\text { Gage } \\
\text { helght }\end{array}$ & $\begin{array}{l}\text { Dis - } \\
\text { charge }\end{array}$ \\
\hline $\begin{array}{r}\text { Jan. } 29 \\
30\end{array}$ & $\begin{array}{l}2400 \\
0800 \\
2000 \\
2100\end{array}$ & $\begin{array}{l}1.72 \\
1.73 \\
1.89 \\
2.33\end{array}$ & $\begin{array}{r}13 \\
14 \\
31 \\
131\end{array}$ & Jan. 31 & $\begin{array}{l}1200 \\
1800 \\
2300 \\
2400\end{array}$ & $\begin{array}{l}4.70 \\
5.80 \\
7.22 \\
6.85\end{array}$ & $\begin{array}{l}1,410 \\
2,400 \\
4,180 \\
3,610\end{array}$ & Feb. 1 & $\begin{array}{l}1600 \\
1700 \\
2100 \\
2400\end{array}$ & $\begin{array}{l}6.43 \\
6.50 \\
5.64 \\
5.00\end{array}$ & $\begin{array}{l}3,410 \\
3,500 \\
2,470 \\
1,830\end{array}$ \\
\hline 31 & $\begin{array}{l}2400 \\
0400 \\
1000\end{array}$ & $\begin{array}{r}2.92 \\
3.77 \\
4.82 \\
\end{array}$ & $\begin{array}{r}334 \\
772 \\
1,510 \\
\end{array}$ & Feb. I & $\begin{array}{l}0400 \\
0700 \\
0900 \\
1200\end{array}$ & $\begin{array}{l}5.99 \\
6.85 \\
8.23 \\
7.12\end{array}$ & $\begin{array}{l}2,590 \\
3,610 \\
6,290 \\
4,350\end{array}$ & 2 & $\begin{array}{l}0600 \\
1200 \\
1800 \\
2400\end{array}$ & $\begin{array}{l}4.28 \\
3.73 \\
3.34 \\
3.07\end{array}$ & $\begin{array}{r}1,230 \\
848 \\
625 \\
491 \\
\end{array}$ \\
\hline
\end{tabular}

\section{1-2588. East Fork Chowchilla River near Ahwahnee, Calif.}

Location.--Lat $37^{\circ} 20^{\prime} 10^{\prime \prime}$, long $119^{\circ} 48^{\prime} 55^{\prime \prime}$, In NW $\frac{1}{4} S W^{\frac{1}{4}}$ sec. 8 , T. 7 S., R. 20 E., on right bank 1.1 miles upstream from mouth and 5.5 miles west of Ahwahnee.

Dralnage area. $--57.8 \mathrm{sq} \mathrm{m}$.

Gage-he1ght record;--Water-stage recorder graph, except Feb. 15-18. Altitude of gage is $980 \mathrm{ft}$ (from topographic map).

Discharge record.--Stage-discharge relation defined by current-meter measurements below $1,900 \mathrm{c}$ fs. Discharge for Feb. 15-18 estimated on basis of one outside staff-gage reading, normal recession curve, and hydrographic comparison with nearby stations.

Maxima.--January-February 1963: Discharge, 3,710 cfs 1500 hours Jan. 31 (gage height, $\left.10.34 \mathrm{f}^{\prime} \mathrm{t}\right)$.

1957 to December 1962: Discharge, 3,290 cfs Apr. 3, 1958 (gage height, $9.88 \mathrm{ft}$ ).

Remarks. --Records furnished by Callfornia Department of Water Resources and reviewed by Geological Survey.

Mean discharge, in cublc feet per second, 1963

\begin{tabular}{|c|c|c|c|c|c|c|c|c|}
\hline Day & January & February & Day & January & February & Day & January & February \\
\hline $\begin{array}{c}1 \ldots \ldots \\
2 \ldots \ldots \\
3 \ldots \ldots \\
4 \ldots \ldots \\
5 \ldots \ldots \\
6 \ldots \ldots \\
8 \ldots \ldots \\
9 \ldots \ldots \\
10 \ldots \ldots\end{array}$ & $\begin{array}{l}2.2 \\
2.0 \\
1.9 \\
2.2 \\
2.4 \\
2.7 \\
2.8 \\
2.8 \\
2.8 \\
2.6\end{array}$ & $\begin{array}{r}1,370 \\
180 \\
115 \\
106 \\
103 \\
102 \\
101 \\
101 \\
106 \\
218\end{array}$ & $\begin{array}{l}11 \ldots \ldots \\
12 \ldots \ldots \\
13 \ldots \ldots \\
14 \ldots \ldots \\
15 \ldots \ldots \\
16 \ldots \ldots \\
17 \ldots \ldots \\
15 \ldots \ldots \\
19 \ldots \ldots \\
20 \ldots \ldots\end{array}$ & $\begin{array}{l}2.6 \\
2.8 \\
2.8 \\
2.6 \\
2.7 \\
2.7 \\
3.1 \\
3.0 \\
3.8 \\
3.5\end{array}$ & $\begin{array}{r}116 \\
109 \\
138 \\
125 \\
103 \\
85 \\
69 \\
51 \\
46 \\
41\end{array}$ & $\begin{array}{l}21 \ldots \ldots \\
22 \ldots \ldots \\
23 \ldots \ldots \\
24 \ldots \ldots \\
25 \ldots \ldots \\
26 \ldots \ldots \\
27 \ldots \ldots \\
25 \ldots \ldots \\
29 \ldots \ldots \\
30 \ldots \ldots \\
31 \ldots \ldots\end{array}$ & $\begin{array}{r}3.9 \\
3.9 \\
3.9 \\
4.3 \\
4.3 \\
4.7 \\
4.7 \\
4.7 \\
5.3 \\
365 \\
1,610\end{array}$ & $\begin{array}{r}37 \\
35 \\
32 \\
30 \\
28 \\
27 \\
26 \\
26 \\
---- \\
---2\end{array}$ \\
\hline \multicolumn{7}{|c|}{ 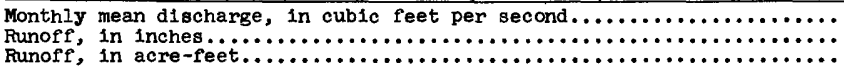 } & $\begin{array}{r}66.7 \\
1.33 \\
4,100\end{array}$ & $\begin{array}{r}130 \\
2.34 \\
7,190 \\
\end{array}$ \\
\hline
\end{tabular}


Gage height, in feet, and discharge, in cublc feet per second, at indicated time, 1963, of

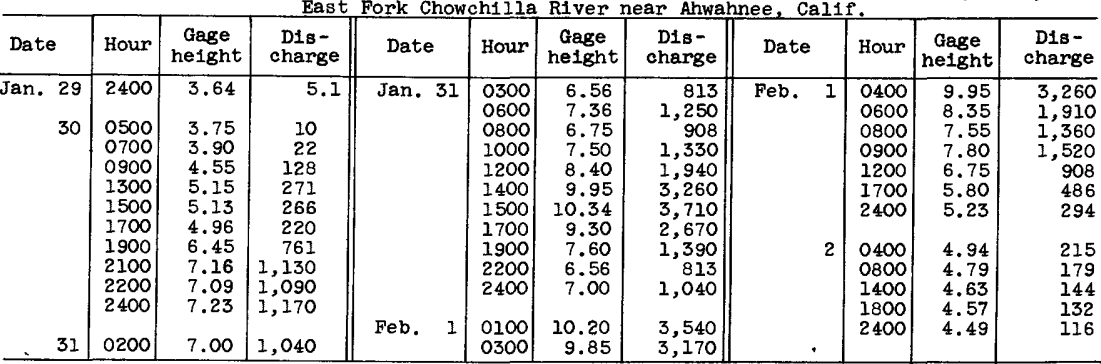

11-2589. West Fork Chowchilla River near Mariposa, Calif.

Location.--Lat $37^{\circ} 25^{\prime} 15^{\prime \prime}$, long $119^{\circ} 52^{1} 2^{\prime \prime}$, in SW $\frac{1}{4} S E_{\frac{1}{4}}^{\frac{1}{4}}$ sec.10, T.6 S., R.19 E., on left bank $15 \mathrm{f}^{\prime} t$ downstream from bridge on Indian Peak Road, $0.5 \mathrm{mile}$ downstream from Humbug Creek, and 6.7 miles southeast of Mariposa.

Drainage area. $--33.6 \mathrm{sq} \mathrm{mi}$.

Gage-height record.--Water-stage recorder graph. Altitude of gage is 1,680 $\mathrm{ft}$ (from topographic map).

Discharge record.--Stage-discharge relation defined by current-meter measurements below 1,900 cfs.

Maxima.--January-February 1963: Discharge, 3,520 cfs 1500 hours Jan. 31 (gage height, $8.63 \mathrm{ft}^{\prime} \mathrm{t}$.

1957 to December 1962: Discharge, 3,590 cfs Apr. 3, 1958 (gage height, $8.67 \mathrm{ft}$ ).

Remarks.--Records furnished by California Department of Water Resources and reviewed by Geological Survey.

Mean discharge, in cubic feet per second, 1963

\begin{tabular}{|c|c|c|c|c|c|c|c|c|}
\hline Day & January & February & Day & January & February & Day & January & February \\
\hline $\begin{array}{c}1 \ldots \ldots \\
2 \ldots \ldots \\
3 \ldots \ldots \\
5 \ldots \ldots \\
6 \ldots \ldots \\
8 \ldots \ldots \\
9 \ldots \ldots \\
10 \ldots \ldots\end{array}$ & $\begin{array}{r}0.4 \\
.5 \\
.4 \\
.4 \\
.3 \\
.3 \\
.3 \\
.3 \\
.3 \\
.3\end{array}$ & $\begin{array}{c}916 \\
74 \\
34 \\
20 \\
13 \\
10 \\
9.0 \\
7.9 \\
17 \\
162\end{array}$ & $\begin{array}{l}11 \ldots \ldots \\
12 \ldots \ldots \\
13 \ldots \ldots \\
14 \ldots \ldots \\
15 \ldots \ldots \\
16 \ldots \ldots \\
17 \ldots \ldots \\
18 \ldots \ldots \\
19 \ldots \ldots \\
20 \ldots \ldots\end{array}$ & $\begin{array}{l}0.3 \\
.3 \\
.3 \\
.3 \\
.3 \\
.3 \\
.3 \\
.4 \\
.4 \\
.3\end{array}$ & $\begin{array}{l}35 \\
27 \\
92 \\
69 \\
36 \\
27 \\
21 \\
17 \\
15 \\
13\end{array}$ & $\begin{array}{l}21 \ldots \ldots \\
22 \ldots \ldots \\
23 \ldots \ldots \\
24 \ldots \ldots \\
25 \ldots \ldots \\
26 \ldots \ldots \\
27 \ldots \ldots \\
28 \ldots \ldots \\
29 \ldots \ldots \\
30 \ldots \ldots \\
31 \ldots \ldots\end{array}$ & $\begin{array}{r}0.3 \\
.4 \\
.4 \\
.4 \\
.4 \\
.4 \\
.4 \\
.4 \\
.5 \\
233.0 \\
1,400\end{array}$ & $\begin{array}{r}12 \\
11 \\
10 \\
9.6 \\
8.9 \\
8.4 \\
7.9 \\
7.5 \\
----- \\
---.--\end{array}$ \\
\hline $\begin{array}{l}\text { nthly } \\
\text { anoff, } \\
\text { anoff, }\end{array}$ & $\begin{array}{l}\text { inche } \\
\text { acre }\end{array}$ & & & & & & $\begin{array}{r}53.0 \\
1.82 \\
3,260\end{array}$ & $\begin{array}{r}60.4 \\
1.87 \\
3,350 \\
\end{array}$ \\
\hline
\end{tabular}

Gage height, in feet, and discharge, in cublc feet per second, at indicated time, 1963

\begin{tabular}{|c|c|c|c|c|c|c|c|c|c|c|c|}
\hline Date & Hour & $\begin{array}{c}\text { Gage } \\
\text { helght }\end{array}$ & $\begin{array}{l}\text { DIs- } \\
\text { charge }\end{array}$ & Date & Hour & $\begin{array}{c}\text { Gage } \\
\text { helght }\end{array}$ & $\begin{array}{l}\text { D1s- } \\
\text { charge }\end{array}$ & Date & Hour & $\begin{array}{c}\text { Gage } \\
\text { helght }\end{array}$ & $\begin{array}{c}\text { Dis- } \\
\text { charge }\end{array}$ \\
\hline $\begin{array}{r}\text { an. } 29 \\
30\end{array}$ & $\begin{array}{l}2400 \\
0400 \\
0800 \\
1000 \\
1300 \\
1400 \\
1500 \\
1700 \\
1900 \\
2100 \\
2200 \\
2400 \\
\\
0200 \\
0300 \\
0600\end{array}$ & $\begin{array}{l}2.63 \\
2.88 \\
3.28 \\
3.90 \\
4.37 \\
4.47 \\
4.40 \\
4.59 \\
5.69 \\
6.34 \\
6.59 \\
6.33 \\
5.89 \\
5.95 \\
6.35\end{array}$ & $\begin{array}{c}1.7 \\
4.9 \\
17 \\
61 \\
125 \\
143 \\
130 \\
167 \\
529 \\
898 \\
1,080 \\
891 \\
\\
628 \\
661 \\
905\end{array}$ & Jan. 31 & $\begin{array}{l}0700 \\
0800 \\
0900 \\
1100 \\
1400 \\
1500 \\
1600 \\
1700 \\
1800 \\
1900 \\
2000 \\
2200 \\
2300 \\
2400 \\
0100 \\
0300\end{array}$ & $\begin{array}{l}6.16 \\
6.16 \\
6.28 \\
6.80 \\
8.04 \\
8.63 \\
8.36 \\
7.40 \\
6.89 \\
6.68 \\
6.16 \\
5.85 \\
6.64 \\
8.05 \\
8.53 \\
7.93\end{array}$ & $\begin{array}{r}782 \\
782 \\
858 \\
1,250 \\
2,640 \\
3,520 \\
3,120 \\
1,830 \\
1,320 \\
1,150 \\
782 \\
608 \\
1,120 \\
2,650 \\
3,400 \\
2,480\end{array}$ & Feb. & $\begin{array}{l}0400 \\
0600 \\
0700 \\
0900 \\
1100 \\
1300 \\
1500 \\
1800 \\
2100 \\
2400 \\
0400 \\
1000 \\
1400 \\
1800 \\
2400\end{array}$ & $\begin{array}{l}7.73 \\
6.63 \\
6.25 \\
6.30 \\
5.79 \\
5.36 \\
5.09 \\
4.80 \\
4.64 \\
4.43 \\
4.25 \\
4.07 \\
3.95 \\
3.87 \\
3.76\end{array}$ & $\begin{array}{r}2,220 \\
1,110 \\
839 \\
871 \\
577 \\
390 \\
297 \\
215 \\
178 \\
136 \\
105 \\
80 \\
66 \\
58 \\
47\end{array}$ \\
\hline
\end{tabular}


11-2589.2. Middle Fork Chowchilla River near Nipinnawassee, Calif.

Location.--Lat $37^{\circ} 23^{1} 00^{\prime \prime}$, long $119^{\circ} 50^{\prime} 12^{\prime \prime}$, in SW $\frac{1}{4} \mathrm{NE} \frac{1}{4}$ sec.25, T.6 S., R.19 E., on right bank 3.4 miles upstream from West Fork and 6 miles west of Nipinnawassee.

Drainage area. $--12.3 \mathrm{sq} \mathrm{ml}$.

Gage-height record:--Water-stage recorder graph. Altitude of gage is $1,520 \mathrm{ft}$ (from topographic map).

Discharge record.--Stage-discharge relation defined by current-meter measurements.

Maxima --January-February 1963: Discharge, 1,280 cfs 0200 hours Feb. I (gage height, $10.10 \mathrm{ft}$ ).

1958 to December 1962: Discharge, $925 \mathrm{cfs}$ Feb. 9, 1962 (gage height, $8.15 \mathrm{ft}$ ).

Remarks.--Records furmished by California Department of Water Resources and reviewed by Geological Survey.

Mean discharge, in cubic feet per second, 1963

\begin{tabular}{|c|c|c|c|c|c|c|c|c|}
\hline Day & January & February & Day & January & February & Day & January & February \\
\hline $\begin{array}{c}1 \ldots \ldots \\
2 \ldots \ldots \\
3 \ldots \ldots \\
5 \ldots \ldots \\
6 \ldots \ldots \\
7 \ldots \ldots \\
3 \ldots \ldots \\
9 \ldots \ldots \\
10 \ldots \ldots\end{array}$ & $\begin{array}{r}0.3 \\
.4 \\
.4 \\
.3 \\
.3 \\
.3 \\
.3 \\
.3 \\
.4 \\
.4\end{array}$ & $\begin{array}{r}473 \\
39 \\
17 \\
12 \\
5.9 \\
7.3 \\
6.1 \\
5.2 \\
8.2 \\
71\end{array}$ & $\begin{array}{l}11 \ldots \ldots \\
12 \ldots \ldots \\
13 \ldots \ldots \\
14 \ldots \ldots \\
15 . \ldots \ldots \\
16 \ldots \ldots \\
17 \ldots \ldots \\
15 \ldots \ldots \\
19 \ldots \ldots \\
20 \ldots \ldots\end{array}$ & $\begin{array}{l}0.4 \\
.3 \\
.3 \\
.3 \\
.3 \\
.3 \\
.3 \\
.3 \\
.4 \\
.4\end{array}$ & $\begin{array}{r}17 \\
14 \\
44 \\
36 \\
18 \\
14 \\
11 \\
9.7 \\
8.8 \\
7.8\end{array}$ & $\begin{array}{l}21 \ldots \ldots \\
22 \ldots \ldots \\
23 \ldots \ldots \\
24 \ldots \ldots \\
25 \ldots \ldots \\
26 \ldots \ldots \\
27 \ldots \ldots \\
25 \ldots \ldots \\
29 \ldots \ldots \\
30 \ldots \ldots \\
31 \ldots \ldots\end{array}$ & $\begin{array}{r}0.4 \\
.4 \\
.3 \\
.3 \\
.3 \\
.4 \\
.4 \\
.4 \\
134 \\
.6 \\
572\end{array}$ & $\begin{array}{r}6.4 \\
5.8 \\
5.3 \\
4.8 \\
4.5 \\
4.5 \\
4.5 \\
4.2 \\
----- \\
--.-- \\
-----\end{array}$ \\
\hline \multicolumn{7}{|c|}{ 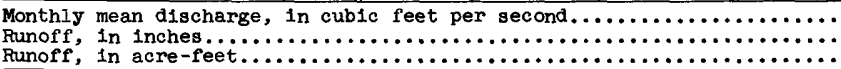 } & $\begin{array}{r}23.1 \\
2.17 \\
1,420\end{array}$ & $\begin{array}{r}31.0 \\
2.62 \\
1,720 \\
\end{array}$ \\
\hline
\end{tabular}

Gage height, in feet, and discharge, in cubic feet per second, at indicated time, 1963

\begin{tabular}{|c|c|c|c|c|c|c|c|c|c|c|c|}
\hline Date & Hour & $\begin{array}{c}\text { Gage } \\
\text { helght }\end{array}$ & $\begin{array}{c}\text { D1s- } \\
\text { charge }\end{array}$ & Date & Hour & $\begin{array}{c}\text { Gage } \\
\text { height }\end{array}$ & $\begin{array}{c}\text { Dis- } \\
\text { charge }\end{array}$ & Date & Hour & $\begin{array}{c}\text { Gage } \\
\text { helght }\end{array}$ & $\begin{array}{c}\text { Dis- } \\
\text { charge }\end{array}$ \\
\hline $\begin{array}{r} \\
\text { Jan. } \\
.30\end{array}$ & $\begin{array}{l}2400 \\
0600 \\
1400 \\
1600 \\
1900 \\
2200 \\
2300\end{array}$ & $\begin{array}{l}2.69 \\
3.05 \\
3.60 \\
3.63 \\
4.60 \\
5.27 \\
5.25\end{array}$ & $\begin{array}{c}1.4 \\
9.1 \\
50 \\
54 \\
316 \\
460 \\
457 \\
502\end{array}$ & Jan. 31 & $\begin{array}{l}1300 \\
1400 \\
1600 \\
1800 \\
1900 \\
2200 \\
2300 \\
2400\end{array}$ & $\begin{array}{l}7.75 \\
8.44 \\
7.70 \\
6.35 \\
5.40 \\
4.72 \\
5.00 \\
7.50\end{array}$ & $\begin{array}{l}\text { S72 } \\
990 \\
864 \\
637 \\
481 \\
373 \\
417 \\
\mathrm{~s} 30\end{array}$ & $F \in b . \quad I$ & $\begin{array}{l}0600 \\
0500 \\
0900 \\
1200 \\
1600 \\
2000 \\
2400\end{array}$ & $\begin{array}{l}6.35 \\
5.48 \\
6.19 \\
4.85 \\
4.32 \\
4.02 \\
3.83\end{array}$ & $\begin{array}{r}637 \\
494 \\
611 \\
392 \\
207 \\
123 \\
84\end{array}$ \\
\hline 31 & $\begin{array}{l}0600 \\
1000 \\
1100 \\
1200\end{array}$ & $\begin{array}{l}4.15 \\
4.15 \\
5.20 \\
5.95 \\
6.90\end{array}$ & $\begin{array}{l}502 \\
377 \\
449 \\
571 \\
729\end{array}$ & Feb. 1 & $\begin{array}{l}0100 \\
0200 \\
0300 \\
0400 \\
0500\end{array}$ & $\begin{array}{r}9.85 \\
10.10 \\
9.80 \\
8.90 \\
7.50\end{array}$ & $\begin{array}{r}1,230 \\
1,280 \\
1,220 \\
1,070 \\
830\end{array}$ & 2 & $\begin{array}{l}0600 \\
1200 \\
1800 \\
2400\end{array}$ & $\begin{array}{l}3.63 \\
3.51 \\
3.43 \\
3.36\end{array}$ & $\begin{array}{l}40 \\
32 \\
26\end{array}$ \\
\hline
\end{tabular}

11-2590. Chowchilla River at Buchanan damsite, near Raymond, Calif.

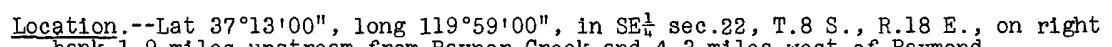
bank 1.9 miles upstream from Raynor Creek and 4.3 miles west of Raymond.

Drainage area. $--235 \mathrm{sq} \mathrm{mi}$.

Gage-he1ght record.--Water-stage recorder graph. Datum of gage is $407.30 \mathrm{ft}$ above mean sea level, adjustment of 1912 (levels by Merced Irrigation District).

Discharge record.--Stage-discharge relation defined by current-meter measurements below 6,000 cfs and by slope-area measurement at $22,500 \mathrm{cfs}$.

Maxima.--January-February 1963: Discharge, 9,740 cfs 0700 hours Feb. I (gage height, $11.68 \mathrm{ft}$, from recorder graph; $12.0 \mathrm{ft}$, from floodmarks).

$1921-23,1930$ to December 1962: Discharge, $30,000 \mathrm{cfs}$ Dec. 23, 1955 (gage height, $16.50 \mathrm{ft}$ ). 
Mean discharge, in cublc feet per second, 1963, of Chowchilla River at Buchanan damsite, near Raymond, Calif.

\begin{tabular}{|c|c|c|c|c|c|c|c|c|}
\hline Day & January & February & Day & January & Febmuary & Day & January & February \\
\hline $\begin{array}{r}1 \ldots \ldots \\
2 \ldots \ldots \\
3 \ldots \ldots \\
5 \ldots \ldots \\
6 \ldots \ldots \\
7 \ldots \ldots \\
8 \ldots \ldots \\
10 \ldots \ldots\end{array}$ & $\begin{array}{l}4.6 \\
4.6 \\
4.6 \\
4.6 \\
4.6 \\
4.4 \\
4.4 \\
4.4 \\
4.4 \\
4.4\end{array}$ & $\begin{array}{r}4,190 \\
641 \\
229 \\
146 \\
107 \\
85 \\
71 \\
61 \\
62 \\
649\end{array}$ & $\begin{array}{l}11 \ldots \ldots \\
12 \ldots \ldots \\
13 \ldots \ldots \\
14 \ldots \ldots \\
15 \ldots \ldots \\
16 \ldots \ldots \\
17 \ldots \ldots \\
18 \ldots \ldots \\
19 \ldots \ldots \\
20 \ldots \ldots\end{array}$ & $\begin{array}{l}4.4 \\
4.4 \\
4.2 \\
4.0 \\
4.2 \\
4.2 \\
4.4 \\
4.6 \\
4.6 \\
4.4\end{array}$ & $\begin{array}{r}282 \\
147 \\
354 \\
358 \\
197 \\
147 \\
120 \\
102 \\
89 \\
81\end{array}$ & $\begin{array}{l}21 \ldots \ldots \\
22 \ldots \ldots \\
23 \ldots \ldots \\
24 \ldots \ldots \\
25 \ldots \ldots \\
26 \ldots \ldots \\
27 \ldots \ldots \\
28 \ldots \ldots \\
29 \ldots \ldots \\
30 \ldots \ldots \\
31 \ldots \ldots\end{array}$ & $\begin{array}{r}4.4 \\
4.6 \\
4.6 \\
4.6 \\
4.6 \\
4.6 \\
4.6 \\
4.6 \\
5.0 \\
45 \\
3,970\end{array}$ & $\begin{array}{r}73 \\
66 \\
62 \\
57 \\
54 \\
51 \\
49 \\
48 \\
-\ldots-.-\end{array}$ \\
\hline $\begin{array}{l}\text { Monthly } \\
\text { Runoff, } \\
\text { Runoff, } \\
\end{array}$ & $\begin{array}{l}\text { mean discl } \\
\text { in inches } \\
\text { in acre-f }\end{array}$ & e, in & feet & & & & $\begin{array}{r}134 \\
0.66 \\
8,220 \\
\end{array}$ & $\begin{array}{r}306 \\
1.36 \\
17,010 \\
\end{array}$ \\
\hline
\end{tabular}

Gage height, in feet, and discharge, in cubic feet per second, at indicated time, 1983

\begin{tabular}{|c|c|c|c|c|c|c|c|c|c|c|c|}
\hline Date & Hour & $\begin{array}{c}\text { Gage } \\
\text { height }\end{array}$ & $\begin{array}{c}\text { Dis- } \\
\text { charge }\end{array}$ & Date & Hour & $\begin{array}{c}\text { Gage } \\
\text { helght }\end{array}$ & $\begin{array}{l}\text { Dis- } \\
\text { charge }\end{array}$ & Date & Hour & $\begin{array}{c}\text { Gage } \\
\text { helght }\end{array}$ & $\begin{array}{c}\text { Dis- } \\
\text { charge }\end{array}$ \\
\hline $\begin{array}{r}\text { Jan. } 29 \\
30\end{array}$ & $\begin{array}{l}2400 \\
1800 \\
2000 \\
2200 \\
2400\end{array}$ & $\begin{array}{l}1.77 \\
2.07 \\
2.16 \\
3.66\end{array}$ & $\begin{array}{c}6.2 \\
18 \\
24 \\
221\end{array}$ & Jan. 31 & $\begin{array}{l}1100 \\
1300 \\
1700 \\
2000 \\
2400\end{array}$ & $\begin{array}{r}8.00 \\
7.75 \\
10.00 \\
11.23 \\
8.90\end{array}$ & $\begin{array}{l}2,790 \\
2,530 \\
5,840 \\
8,580 \\
3,960\end{array}$ & Feb. I & $\begin{array}{l}1400 \\
1700 \\
2000 \\
2400\end{array}$ & $\begin{array}{l}9.03 \\
8.15 \\
7.08 \\
6.24\end{array}$ & $\begin{array}{l}4,170 \\
2,960 \\
1,960 \\
1,340\end{array}$ \\
\hline 31 & $\begin{array}{l}2400 \\
0100 \\
0200 \\
0500 \\
0900\end{array}$ & $\begin{array}{l}4.20 \\
5.00 \\
6.70 \\
8.49 \\
7.81\end{array}$ & $\begin{array}{r}364 \\
672 \\
1,660 \\
3,390 \\
2,590\end{array}$ & Feb. $\quad 1$ & $\begin{array}{l}0400 \\
0500 \\
0700 \\
1000 \\
1300\end{array}$ & $\begin{array}{r}7.63 \\
10.00 \\
11.68 \\
10.22 \\
8.89\end{array}$ & $\begin{array}{l}2,420 \\
5,840 \\
9,740 \\
6,280 \\
3,950\end{array}$ & 2 & $\begin{array}{l}0600 \\
1200 \\
1800 \\
2400\end{array}$ & $\begin{array}{l}5.28 \\
4.67 \\
4.31 \\
4.05\end{array}$ & $\begin{array}{l}801 \\
534 \\
400 \\
318\end{array}$ \\
\hline
\end{tabular}

11-2602. Bear Creek near Catheys Valley, Callf.

Location.--Lat $37^{\circ} 28^{1} 40^{\prime \prime}$, long $120^{\circ} 06^{1} 45^{\prime \prime}$, in SE $\frac{1}{4} \mathrm{SW} \frac{1}{4}$ sec.21, T.5 S., R.17 E., on downstream side of bridge, 0.9 mile upstream from Raster Gulch, and $3.7 \mathrm{miles}$ north of Catheys Valley School.

Drainage area. $--24.6 \mathrm{sq} \mathrm{mi}$.

D1scharge record.--Stage-discharge relation defined by current-meter measurements below 1,200 cis.

Maxima --January-February 1963: D1scharge, 3,850 cfs 0200 hours Feb. 1 (gage hel ght, $10.07 \mathrm{ft}$ ).

1958 to December 1962: Discharge, 2,570 cfs Apr. 3, 1958 (gage height, $9.36 \mathrm{ft}$ ).

Remarks.--Records furnished by California Department of Water Resources and reviewed by Geological Survey.

Mean discharge, in cubic feet per second, 1963

\begin{tabular}{|c|c|c|c|c|c|c|c|c|}
\hline Day & January & February & Day & January & February & Day & January & February \\
\hline $\begin{array}{c}1 \ldots \ldots \\
2 \ldots \ldots \\
3 \ldots \ldots \\
4 \ldots \ldots \\
5 \ldots \ldots \\
7 \ldots \ldots \\
8 \ldots \ldots \\
9 \ldots \ldots \\
10 \ldots \ldots\end{array}$ & $\begin{array}{r}0.6 \\
.6 \\
.6 \\
.5 \\
.5 \\
.5 \\
.5 \\
.4 \\
.5 \\
.4\end{array}$ & $\begin{array}{c}1,060 \\
95 \\
40 \\
24 \\
15 \\
11 \\
8.0 \\
5.7 \\
40 \\
290\end{array}$ & $\begin{array}{l}11 \ldots \ldots \\
12 \ldots \ldots \\
13 \ldots \ldots \\
14 \ldots \ldots \\
15 \ldots \ldots \\
16 \ldots \ldots \\
17 \ldots \ldots \\
18 \ldots \ldots \\
19 \ldots \ldots \\
20 \ldots \ldots\end{array}$ & $\begin{array}{l}0.3 \\
.3 \\
.3 \\
.3 \\
.3 \\
.3 \\
.3 \\
.3 \\
.3 \\
.2\end{array}$ & $\begin{array}{r}61 \\
41 \\
374 \\
154 \\
58 \\
33 \\
22 \\
17 \\
13 \\
11\end{array}$ & $\begin{array}{l}21 \ldots \ldots \\
22 \ldots \ldots \\
23 \ldots \ldots \\
24 \ldots \ldots \\
25 \ldots \ldots \\
26 \ldots \ldots \\
27 \ldots \ldots \\
28 \ldots \ldots \\
29 \ldots \ldots \\
30 \ldots \ldots \\
31 \ldots \ldots\end{array}$ & $\begin{array}{r}0.3 \\
.3 \\
.2 \\
.2 \\
.2 \\
.2 \\
.2 \\
.2 \\
.2 \\
128 \\
937\end{array}$ & $\begin{array}{r}8.0 \\
6.4 \\
5.4 \\
4.5 \\
3.5 \\
3.1 \\
2.7 \\
2.3 \\
----- \\
-----. \\
----.\end{array}$ \\
\hline \multicolumn{7}{|c|}{ 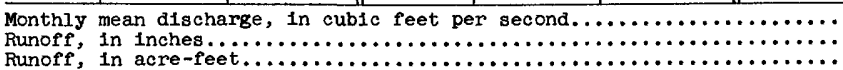 } & $\begin{array}{r}34.7 \\
1.62 \\
2,130\end{array}$ & $\begin{array}{r}86.0 \\
3.64 \\
4,780 \\
\end{array}$ \\
\hline
\end{tabular}


Gage height, in feet, and discharge, in cublc feet per second, at indicated time, 1963, of Bear Creek near Catheys Valley, Calif.

\begin{tabular}{|c|c|c|c|c|c|c|c|c|c|c|c|}
\hline Date & Hour & $\begin{array}{c}\text { Gage } \\
\text { he1ght }\end{array}$ & $\begin{array}{l}\text { D1s- } \\
\text { charge }\end{array}$ & Date & Hour & $\begin{array}{c}\text { Gage } \\
\text { helght }\end{array}$ & $\begin{array}{l}\text { D1s- } \\
\text { charge }\end{array}$ & Date & Hour & $\begin{array}{c}\text { Gage } \\
\text { helght }\end{array}$ & $\begin{array}{c}\text { D1s- } \\
\text { charge }\end{array}$ \\
\hline $\begin{array}{r}\text { Jan. } \\
30\end{array}$ & $\begin{array}{l}2400 \\
0300 \\
0600 \\
1000 \\
1400 \\
1600 \\
1600 \\
1900 \\
2000 \\
2200 \\
2300 \\
2400\end{array}$ & $\begin{array}{l}2.90 \\
2.93 \\
3.02 \\
3.13 \\
3.11 \\
3.15 \\
4.13 \\
4.10 \\
5.20 \\
6.22 \\
6.77 \\
6.57\end{array}$ & $\begin{array}{r}0.2 \\
.4 \\
3.0 \\
2.2 \\
1.9 \\
2.4 \\
41 \\
38 \\
209 \\
557 \\
842 \\
730\end{array}$ & Jan. 31 & $\begin{array}{l}0600 \\
0800 \\
0900 \\
1000 \\
1100 \\
1200 \\
1300 \\
1400 \\
1500 \\
1700 \\
1800 \\
2000 \\
2200\end{array}$ & $\begin{array}{l}6.43 \\
5.82 \\
5.71 \\
5.67 \\
5.74 \\
6.50 \\
7.07 \\
8.17 \\
8.54 \\
7.38 \\
7.31 \\
6.52 \\
5.97\end{array}$ & $\begin{array}{r}657 \\
395 \\
356 \\
343 \\
366 \\
693 \\
1,030 \\
1,940 \\
2,340 \\
1,250 \\
1,200 \\
703 \\
451\end{array}$ & Feb. 1 & $\begin{array}{l}0200 \\
0300 \\
0400 \\
0500 \\
0700 \\
1000 \\
1100 \\
1300 \\
1600 \\
2000 \\
2200 \\
2400\end{array}$ & $\begin{array}{r}10.07 \\
9.57 \\
8.23 \\
7.31 \\
6.41 \\
6.23 \\
6.50 \\
5.92 \\
5.42 \\
4.97 \\
4.79 \\
4.66\end{array}$ & $\begin{array}{r}3,850 \\
3,220 \\
1,880 \\
1,200 \\
705 \\
625 \\
747 \\
501 \\
336 \\
220 \\
182 \\
157\end{array}$ \\
\hline 31 & $\begin{array}{l}0200 \\
0300 \\
0400\end{array}$ & $\begin{array}{l}6.22 \\
6.22 \\
6.12\end{array}$ & $\begin{array}{l}557 \\
557 \\
513 \\
\end{array}$ & Feb. 1 & $\begin{array}{l}2300 \\
2400 \\
0100\end{array}$ & $\begin{array}{l}5.91 \\
7.97 \\
9.45\end{array}$ & $\begin{array}{r}428 \\
1,750 \\
3,080\end{array}$ & 2 & $\begin{array}{l}0300 \\
0900 \\
1600 \\
2400\end{array}$ & $\begin{array}{l}4.47 \\
4.22 \\
4.02 \\
3.82\end{array}$ & $\begin{array}{r}125 \\
89 \\
66 \\
47\end{array}$ \\
\hline
\end{tabular}

11-2602.1. Bear Creek tributary near Cathey8 Valley, Calif.

(Crest-stage station)

Location.--Lat $37^{\circ} 26^{\prime} 45^{\prime \prime}$, long $120^{\circ} 06^{\prime} 05^{\prime \prime}$, in NW $\frac{1}{4} N W \frac{1}{4}$ sec.3, T.6 S., R.17 E., 1 mile north of Catheys Valley.

Drainage area. $--1.16 \mathrm{sq} \mathrm{mi}$.

Gage-height record.--Crest stages only. Altitude of gage $181,320 \mathrm{ft}$ (from topographic map).

Discharge record.--Stage-discharge relation defined by current-meter measurements below $38 \mathrm{cf}$ 's and by computation of flow through culvert at $61 \mathrm{cfs}$.

Maxima.--January-February 1963: Discharge, $44 \mathrm{cfs}$ Feb. 1 (gage height, $22.17 \mathrm{ft}$ ). 1959 to December 1962: Discharge, 63 cfs Feb. 5, 1962 (gage height, $22.64 \mathrm{ft}$ ).

11-2604.8. Mariposa Creek near Catheys Valley, Calif.

Location. --Lat $37^{\circ} 23^{\prime} 5^{\prime \prime}$, long $120^{\circ} 00^{\prime} 10^{\prime \prime}$, in SW $\frac{1}{4} \mathrm{NE} \frac{1}{4}$ sec.21, T.6 S., R.18 E., on downstream side of bridge on White Rock Road, 0.3 mile downstream from China Gulch and 5.6 miles east of Catheys Valley School.

Drainage area. $--66.0 \mathrm{sq} \mathrm{mi}$.

Gage-height record.--Water-stage recorder graph. Altitude of gage is $1,230 \mathrm{ft}$ (from topographic map).

Discharge record.--Stage-discharge relation defined by current-meter measurements.

Maxima.--January-February 1963: Discharge, 5,290 cfs 0200 hours Feb. 1 (gage helght, $10.69 \mathrm{ft}$ ).

1958 to December 1962: Discharge, 7,180 cfs Apr. 3, 1958 (gage height, $11.62 \mathrm{ft})$.

Remarks.--Records furmished by California Department of Water Resources and reviewed by Geological Survey.

Mean discharge, in cuble feet per second, 1963

\begin{tabular}{|c|c|c|c|c|c|c|c|c|}
\hline Day & January & February & Day & January & February & Day & January & February \\
\hline $\begin{array}{c}1 \ldots \ldots \\
2 \ldots \ldots \\
3 \ldots \ldots \\
4 \ldots \ldots \\
5 \ldots \ldots \\
6 \ldots \ldots \\
8 \ldots \ldots \\
9 \ldots \ldots \\
10 \ldots \ldots\end{array}$ & $\begin{array}{l}3.5 \\
1.6 \\
1.6 \\
1.5 \\
1.4 \\
1.4 \\
1.4 \\
1.4 \\
1.4 \\
1.3\end{array}$ & $\begin{array}{c}1,700 \\
153 \\
62 \\
35 \\
21 \\
15 \\
11 \\
9.2 \\
66 \\
647\end{array}$ & $\begin{array}{l}11 \ldots \ldots \\
12 \ldots \ldots \\
13 \ldots \ldots \\
14 \ldots \ldots \\
15 \ldots \ldots \\
16 \ldots \ldots \\
17 \ldots \ldots \\
15 \ldots \ldots \\
19 \ldots \ldots \\
20 \ldots \ldots\end{array}$ & $\begin{array}{l}1.3 \\
1.2 \\
1.1 \\
1.1 \\
1.2 \\
1.2 \\
1.2 \\
1.3 \\
1.2 \\
1.2\end{array}$ & $\begin{array}{r}120 \\
79 \\
529 \\
332 \\
125 \\
79 \\
55 \\
41 \\
33 \\
26\end{array}$ & $\begin{array}{l}21 \ldots \ldots \\
22 \ldots \ldots \\
23 \ldots \ldots \\
24 \ldots \ldots \\
25 \ldots \ldots \\
26 \ldots \ldots \\
27 \ldots \ldots \\
25 \ldots \ldots \\
29 \ldots \ldots \\
30 \ldots \ldots \\
31 \ldots \ldots\end{array}$ & $\begin{array}{r}1.2 \\
1.2 \\
1.2 \\
1.2 \\
1.2 \\
1.3 \\
1.2 \\
1.2 \\
1.3 \\
453 \\
2,490 \\
\end{array}$ & $\begin{array}{r}20 \\
15 \\
16 \\
14 \\
13 \\
12 \\
11 \\
11 \\
-\ldots- \\
-\ldots-1\end{array}$ \\
\hline \multicolumn{7}{|l|}{$\begin{array}{l}\text { Monthly } \\
\text { Runoff, } \\
\text { Runoff, }\end{array}$} & $\begin{array}{r}96 \\
1.68 \\
5,910 \\
\end{array}$ & $\begin{array}{r}152 \\
2.40 \\
\mathrm{~s}, 440 \\
\end{array}$ \\
\hline
\end{tabular}


Gage height, in feet, and discharge, in cublc feet per second, at indicated time, 1963, of

\begin{tabular}{|c|c|c|c|c|c|c|c|c|c|c|c|}
\hline Date & Hour & $\begin{array}{l}\text { Gage } \\
\text { he1ght }\end{array}$ & $\begin{array}{l}\text { Dis- } \\
\text { charge }\end{array}$ & Date & Hour & $\begin{array}{c}\text { Gage } \\
\text { he1ght }\end{array}$ & $\begin{array}{c}\text { D1s- } \\
\text { charge }\end{array}$ & Date & Hour & $\underset{\text { helght }}{\text { Gage }}$ & $\begin{array}{l}\text { D1B- } \\
\text { charge }\end{array}$ \\
\hline $\begin{array}{r}\operatorname{Jan} .29 \\
30\end{array}$ & $\begin{array}{l}2400 \\
0300 \\
0600 \\
0700 \\
0900 \\
1000 \\
1100 \\
1200 \\
1300 \\
1700 \\
1800 \\
1900 \\
2000 \\
2200 \\
2300 \\
\end{array}$ & $\begin{array}{l}2.69 \\
2.75 \\
2.86 \\
2.94 \\
3.28 \\
4.11 \\
4.69 \\
5.74 \\
6.51 \\
5.79 \\
6.22 \\
7.68 \\
7.76 \\
8.41 \\
8.38 \\
\end{array}$ & $\begin{array}{c}2.4 \\
2.2 \\
3.8 \\
5.4 \\
15 \\
69 \\
137 \\
331 \\
547 \\
343 \\
454 \\
1,120 \\
1,170 \\
1,630 \\
1,610 \\
\end{array}$ & $\begin{array}{r}\text { Jan. } 30 \\
31\end{array}$ & $\begin{array}{l}2400 \\
0400 \\
0600 \\
0800 \\
0900 \\
1000 \\
1200 \\
1500 \\
1700 \\
1900 \\
2100 \\
2300 \\
2400 \\
0100 \\
\end{array}$ & $\begin{array}{r}8.53 \\
8.01 \\
8.42 \\
7.56 \\
7.88 \\
8.27 \\
9.16 \\
10.63 \\
9.44 \\
8.51 \\
7.52 \\
6.99 \\
8.54 \\
10.44 \\
\end{array}$ & $\begin{array}{l}1,730 \\
1,800 \\
2,170 \\
1,450 \\
1,700 \\
2,030 \\
2,940 \\
4,980 \\
3,280 \\
2,250 \\
1,420 \\
1,080 \\
2,280 \\
4,710 \\
\end{array}$ & Feb. 1 & $\begin{array}{l}0200 \\
0400 \\
0600 \\
0800 \\
1000 \\
1200 \\
1400 \\
1700 \\
2000 \\
2400 \\
0400 \\
1000 \\
1500 \\
2000 \\
2400 \\
\end{array}$ & $\begin{array}{r}10.69 \\
10.12 \\
8.67 \\
7.85 \\
7.97 \\
7.45 \\
6.79 \\
6.16 \\
5.64 \\
5.17 \\
4.85 \\
4.54 \\
4.33 \\
4.16 \\
4.07 \\
\end{array}$ & $\begin{array}{r}5,290 \\
4,160 \\
2,180 \\
1,400 \\
1,500 \\
1,100 \\
779 \\
549 \\
391 \\
271 \\
\\
203 \\
147 \\
114 \\
90 \\
79 \\
\end{array}$ \\
\hline
\end{tabular}

11-2610. Salt Slough near Los Banos, Cal1f.

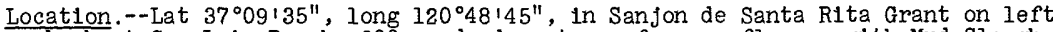
bank at San Luls Ranch, 600 yards downstream from confluence with Mud Slough and 7.0 miles north of Los Banos, Merced County.

Gage-helght record.--Water-stage recorder graph. Datum of gage is $70.60 \mathrm{ft}$ above mean sea level (levels by Bureau of Reclamation).

Discharge record. --Stage-discharge relation defined by current-meter measurements.

Maxima.--January-February 1963: Discharge, 244 cfs 1800 to 2100 hours Feb. 14 (gage helght, $4.55 \mathrm{ft}$ ).

1940 to December 1962: Dally mean discharge, 2,420 cfs Mar. 9, 1941.

11-2615. San Joaquin River at Fremont Ford Bridge, Calif.

Location. --Lat $37^{\circ} 18^{\prime} 35^{\prime \prime}$, long $120^{\circ} 55^{\prime} 45^{\prime \prime}$, In Orestimba Grant, on left bank $30 \mathrm{ft}$ downstream from Fremont Ford Brldge, Merced County, 2.1 miles downstream from Salt Slough, 4.5 miles west of Stevinson, and 6.7 miles upstream from Merced River.

Drainage area. $--8,090 \mathrm{sq} \mathrm{ml}$, approximately.

Gage-helght record.--Water-stage recorder graph, except Jan. 1-30. Datum of gage is mean sea level.

Discharge record.--Stage-discharge relation defined by current-meter measurements. Discharge Jan. 1-30 estimated on basis of recorded range in stage and records for San Joaquin Rlver near Newman and Merced River near Stevinson.

Maxima.--January-February 1963: Discharge, 2,160 cfs 0900 hours Feb. 16 (gage hel ght, $62.04 \mathrm{ft}$ ).

1937 to December 1962: Discharge, 5,910 cfs Apr. 6, 1958 (gage helght, $67.37 \mathrm{ft}$ ).

Remarks.--Floodflow affected by storage reservolrs and flow bypassing this station through Mud Slough.

\begin{tabular}{|c|c|c|c|c|c|c|c|c|}
\hline Day & January & February & Day & January & February & Day & $J$ anuary & February \\
\hline $\begin{array}{r}1 \ldots \ldots . \\
2 \ldots \ldots \\
3 \ldots \ldots \\
4 \ldots \ldots \\
5 \ldots \ldots \\
7 \ldots \ldots \\
8 \ldots \ldots \\
9 \ldots \ldots \\
10 \ldots . .\end{array}$ & $\begin{array}{l}100 \\
110 \\
115 \\
115 \\
120 \\
130 \\
150 \\
190 \\
230 \\
270\end{array}$ & $\begin{array}{r}429 \\
681 \\
1,330 \\
2,040 \\
1,970 \\
1,440 \\
1,030 \\
766 \\
610 \\
778\end{array}$ & 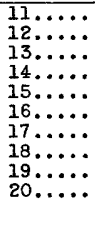 & $\begin{array}{l}270 \\
260 \\
250 \\
240 \\
235 \\
225 \\
215 \\
210 \\
205 \\
200\end{array}$ & $\begin{array}{l}1,060 \\
1,320 \\
1,540 \\
1,720 \\
2,020 \\
2,140 \\
1,910 \\
1,540 \\
1,230 \\
1,020\end{array}$ & $\begin{array}{l}21 \ldots \ldots \\
22, \ldots \ldots \\
23 \ldots \ldots \\
24 \ldots \ldots \\
25, \ldots \ldots \\
26 \ldots \ldots \\
27 \ldots \ldots \\
28 \ldots \ldots \\
29 \ldots \ldots \\
30 \ldots \ldots \\
31 \ldots \ldots\end{array}$ & $\begin{array}{l}190 \\
185 \\
175 \\
170 \\
165 \\
160 \\
155 \\
150 \\
145 \\
140 \\
201\end{array}$ & $\begin{array}{r}883 \\
797 \\
684 \\
592 \\
549 \\
503 \\
464 \\
429 \\
--0 \\
-0\end{array}$ \\
\hline nthl & & & & & & & $\begin{array}{r}183 \\
11,260\end{array}$ & $\begin{array}{r}1,124 \\
62,430\end{array}$ \\
\hline
\end{tabular}


11-2628. Los Banos Creek near Los Banos, Cal1f.

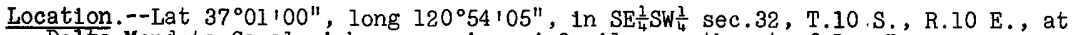
Delta-Mendota Canal siphon crossing, 4.3 miles southwest of Los Banos.

Drainage area. $-159 \mathrm{sq} \mathrm{ml}$.

Gage-helght record.--Water-stage recorder graph. Altitude of gage is $175 \mathrm{ft}$ (from topographic map)

Discharge record.--Stage-discharge relation defined by current-meter measurements below $1,300 \mathrm{c}$.

Maxima.--January-February 1963: Discharge, 2,640 cfs 0500 hours Feb. 1 (gage helght, $4.80 \mathrm{ft}$ ).

1955 to December 1962: Discharge, 11,400 cfs Dec. 23, 1955 (gage helght, $12.07 \mathrm{ft}$, from floodmark in well, $14.05 \mathrm{ft}$ outslde, proflie of floodmarks?.

Mean discharge, in cubic feet per second, 1963

\begin{tabular}{|c|c|c|c|c|c|c|c|c|}
\hline Day & January & February & Day & January & February & Day & January & Febmuary \\
\hline $\begin{array}{c}1 \ldots \ldots \\
2 \ldots \ldots \\
3 \ldots \ldots \\
4 \ldots \ldots \\
5 \ldots \ldots \\
6 \ldots \ldots \\
8 \ldots \ldots \\
9 \ldots \ldots \\
10 \ldots \ldots\end{array}$ & $\begin{array}{l}0 \\
0 \\
0 \\
0 \\
0 \\
0 \\
0 \\
0 \\
0 \\
0\end{array}$ & $\begin{array}{c}883 \\
103 \\
33 \\
15 \\
7.4 \\
2.9 \\
.5 \\
0 \\
0 \\
7.3\end{array}$ & $\begin{array}{l}11 \ldots \ldots \\
12 \ldots \ldots \\
13 \ldots \ldots \\
14 \ldots \ldots \\
15 \ldots \ldots \\
16 \ldots \ldots \\
17 \ldots \ldots \\
18 \ldots \ldots \\
19 \ldots \ldots \\
20 \ldots \ldots\end{array}$ & $\begin{array}{l}0 \\
0 \\
0 \\
0 \\
0 \\
0 \\
0 \\
0 \\
0 \\
0\end{array}$ & $\begin{array}{r}23 \\
14 \\
270 \\
129 \\
50 \\
31 \\
22 \\
16 \\
12 \\
9.7\end{array}$ & $\begin{array}{l}21 \ldots \ldots \\
22 \ldots \ldots \\
23 \ldots \ldots \\
24 \ldots \ldots \\
25 \ldots \ldots \\
26 \ldots \ldots \\
27 \ldots \ldots \\
28 \ldots \ldots \\
29 \ldots \ldots \\
30 \ldots \ldots \\
31 \ldots \ldots\end{array}$ & $\begin{array}{l}0 \\
0 \\
0 \\
0 \\
0 \\
0 \\
0 \\
0 \\
0 \\
0 \\
61\end{array}$ & $\begin{array}{r}8.2 \\
6.6 \\
5.0 \\
3.8 \\
2.9 \\
1.8 \\
1.0 \\
.1 \\
-\ldots--. \\
--.-1\end{array}$ \\
\hline \multicolumn{7}{|c|}{ 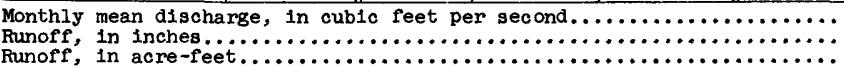 } & $\begin{array}{r}1.97 \\
0.01 \\
121\end{array}$ & $\begin{array}{r}59.2 \\
0.39 \\
3,290\end{array}$ \\
\hline
\end{tabular}

Gage height, in feet, and discharge, in cubic feet per second, at indicated time, 1963

\begin{tabular}{|c|c|c|c|c|c|c|c|c|c|c|c|}
\hline Date & Hour & $\begin{array}{c}\text { Gage } \\
\text { heIght }\end{array}$ & $\begin{array}{l}\text { D1s- } \\
\text { charge }\end{array}$ & Date & Hour & $\begin{array}{c}\text { Gage } \\
\text { helght }\end{array}$ & $\begin{array}{l}\text { Dis- } \\
\text { charge }\end{array}$ & Date & Hour & $\begin{array}{c}\text { Gage } \\
\text { helght }\end{array}$ & $\begin{array}{l}\text { Dis- } \\
\text { charge }\end{array}$ \\
\hline & 2400 & & & Feb. 1 & $\begin{array}{l}0400 \\
0500\end{array}$ & $\begin{array}{l}4.00 \\
4.80\end{array}$ & $\begin{array}{l}1,760 \\
2,640\end{array}$ & Feb. 1 & 2400 & 2.05 & 212 \\
\hline Feb. 1 & $\begin{array}{l}2000 \\
2100 \\
2400 \\
0300\end{array}$ & $\begin{array}{c}- \\
2.66 \\
2.31 \\
2.02\end{array}$ & $\begin{array}{r}0 \\
496 \\
314 \\
\\
202\end{array}$ & & $\begin{array}{l}0700 \\
1200 \\
1400 \\
1800 \\
2100\end{array}$ & $\begin{array}{l}4.12 \\
2.97 \\
3.17 \\
2.60 \\
2.27\end{array}$ & $\begin{array}{r}1,890 \\
716 \\
883 \\
460 \\
298\end{array}$ & 2 & $\begin{array}{l}0600 \\
1200 \\
1500 \\
2400\end{array}$ & $\begin{array}{l}1.75 \\
1.56 \\
1.42 \\
1.32\end{array}$ & $\begin{array}{r}128 \\
88 \\
64 \\
50\end{array}$ \\
\hline
\end{tabular}

11-2629.5. Wolf Creek near Volta, Callf.

(Crest-stage station)

Location.--Lat $37^{\circ} 04^{105^{\prime \prime}}$, long $121^{\circ} 09140^{\prime \prime}$, In San Luls Gonzaga Grant, on State Highway 152,13 miles west of Volta.

Drainage area. $--2.82 \mathrm{sq} \mathrm{ml}$.

Gage-helght record.--Crest stages only. Altitude of gage is 420 ft (from topo- . graphic map).

Discharge record.--Stage-discharge relation defined by current-meter measurements below $12 \mathrm{cfs}$ and by slope-area measurement at $207 \mathrm{cfs}$.

Maxima --January-February 1963: Discharge, 207 cfs Feb. 1 (gage helght, 5.70 ft). 1958 to December 1962: Discharge, $56 \mathrm{cfs}$ Feb. 18, 1962 (gage helght, 
11-2630. San Lu1s Creek near Los Banos, Calif.

Location.--Lat $37^{\circ} 03^{\prime} 55^{\prime \prime}$, long $121^{\circ} 04^{\prime} 15^{\prime \prime}$, In San Lu1s Gonzaga Grant, on left bank $300 \mathrm{ft}$ downstream from Cottonwood Creek and 11.5 miles west of Los Banos, Merced County.

Drainage area. $--84.6 \mathrm{sq} \mathrm{ml}$.

Gage-helght record;--Water-stage recorder graph. Altitude of gage 1s 231 ft (from topographic map).

Discharge record.--Stage-discharge relation defined by current-meter measurements below $230 \mathrm{cf}$ 's and by slope-area measurements at 2,640 and $3,420 \mathrm{cfs}$.

Maxima.--January-February 1963: Discharge, 2,930 cfs 0300 hours Feb. I (gage helght, $7.41 \mathrm{ft}$ ).

1949-53, 1958 to December 1962: Discharge, 3,420 cfs Apr. 2, 1958 (gage height, $7.99 \mathrm{ft}$ ).

Mean d1scharge, in cubic feet per second, 1963

\begin{tabular}{|c|c|c|c|c|c|c|c|c|}
\hline Dey & January & February & Day & January & February & Day & January & February \\
\hline $\begin{array}{r}1 \ldots \ldots \\
3 \ldots \ldots \\
4 \ldots \ldots \\
5 \ldots \ldots \\
6 \ldots \ldots \\
7 \ldots \ldots \\
9 \ldots \ldots \\
10 \ldots \ldots\end{array}$ & $\begin{array}{l}0 \\
0 \\
0 \\
0 \\
0 \\
0 \\
0 \\
0 \\
0 \\
0\end{array}$ & $\begin{array}{c}848 \\
71 \\
17 \\
4.4 \\
2.2 \\
1.7 \\
1.6 \\
1.2 \\
1.1 \\
22\end{array}$ & $\begin{array}{l}11 \ldots \ldots \\
12 \ldots \ldots \\
13 \ldots \ldots \\
14 \ldots \ldots \\
15 \ldots \ldots \\
16 \ldots \ldots \\
17 \ldots \ldots \\
18 \ldots \ldots \\
19 \ldots \ldots \\
20 \ldots \ldots\end{array}$ & $\begin{array}{l}0 \\
0 \\
0 \\
0 \\
0 \\
0 \\
0 \\
0 \\
0 \\
0\end{array}$ & $\begin{array}{c}10 \\
3.1 \\
132 \\
66 \\
24 \\
9.8 \\
4.4 \\
1.9 \\
1.5 \\
1.3\end{array}$ & $\begin{array}{l}21 \ldots \ldots \\
22 \ldots \ldots \\
23 \ldots \ldots \\
24 \ldots \ldots \\
25 \ldots \ldots \\
26 \ldots \ldots \\
27 \ldots \ldots \\
28 \ldots \ldots \\
29 \ldots \ldots \\
30 \ldots \ldots \\
31 \ldots \ldots\end{array}$ & 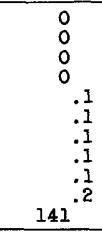 & $\begin{array}{r}1.2 \\
1.1 \\
1.1 \\
1.1 \\
1.1 \\
1.0 \\
1.0 \\
1.0 \\
--1-2 \\
\end{array}$ \\
\hline $\begin{array}{l}\text { inoff, } \\
\text { unoff, }\end{array}$ & $\begin{array}{l}\text { In Inche } \\
\text { in acre-1 }\end{array}$ & & & & & & $\begin{array}{r}4.57 \\
0.06 \\
281\end{array}$ & $\begin{array}{r}44.0 \\
0.54 \\
2,450 \\
\end{array}$ \\
\hline
\end{tabular}

Gage helght, in feet, and discharge, in cublc feet per second, at indicated time, 1963

\begin{tabular}{|c|c|c|c|c|c|c|c|c|c|c|c|}
\hline Date & Hour & $\begin{array}{c}\text { Gage } \\
\text { height }\end{array}$ & $\begin{array}{c}\text { Dis- } \\
\text { charge }\end{array}$ & Date & Hour & $\begin{array}{c}\text { Gage } \\
\text { helght }\end{array}$ & $\begin{array}{c}\text { D1B- } \\
\text { charge }\end{array}$ & Date & Hour & $\begin{array}{c}\text { Gage } \\
\text { helght }\end{array}$ & $\begin{array}{c}\text { D1s - } \\
\text { charge }\end{array}$ \\
\hline $\begin{array}{r}\text { Jan. } 30 \\
31\end{array}$ & $\begin{array}{l}2400 \\
1200 \\
1300 \\
1800 \\
1900 \\
2100 \\
2400\end{array}$ & $\begin{array}{l}1.82 \\
1.85 \\
1.98 \\
2.20 \\
5.11 \\
4.70 \\
4.07\end{array}$ & $\begin{array}{r}0.4 \\
2.6 \\
2.6 \\
12 \\
826 \\
620 \\
371\end{array}$ & Feb. 1 & $\begin{array}{l}0100 \\
0200 \\
0300 \\
0500 \\
0800 \\
1000 \\
1200 \\
1600\end{array}$ & $\begin{array}{l}5.60 \\
6.34 \\
7.41 \\
6.49 \\
5.13 \\
4.87 \\
4.82 \\
3.95\end{array}$ & $\begin{array}{r}1,130 \\
1,700 \\
2,930 \\
1,870 \\
878 \\
735 \\
710 \\
360\end{array}$ & Feb. 1 & $\begin{array}{l}1800 \\
2100 \\
2400 \\
\\
0600 \\
1200 \\
1800 \\
2400\end{array}$ & $\begin{array}{l}3.58 \\
3.26 \\
3.02 \\
2.68 \\
2.47 \\
2.25 \\
2.16\end{array}$ & $\begin{array}{r}255 \\
182 \\
138 \\
\\
91 \\
64 \\
44 \\
31\end{array}$ \\
\hline
\end{tabular}

11-2630.5. Garzas Creek near Gustine, Calif.

(Crest-stage station)

Location.--Lat $37^{\circ} 14^{\prime} 00^{\prime \prime}$, long $121^{\circ} 08^{100^{\prime \prime}}$, In SW $\frac{1}{4}$ sec.18, T.8 S., R.8 E., above diversion weir, 7.7 miles west of Gustine.

Drainage area. $--51.2 \mathrm{sq} \mathrm{mi}$.

Gage-he1ght record.--Crest stages only. Altitude of gage is $285 \mathrm{ft}$ (from topographic map).

Discharge record.--Stage-discharge relation defined by current-meter measurements below $20 \mathrm{cf}$ 's, by computation of flow over we1r at $161 \mathrm{cf}$, $370 \mathrm{cf}$, and 1,100 cf's and by slope-area measurement at $1,770 \mathrm{cfs}$.

Maxima.--January-February 1963: D1scharge, 1,770 cfs Feb. 1 (gage he1ght, $6.22 \mathrm{ft}$, from high-water profile).

1959 to December 1962: D1scharge, 1,100 cfs Feb. 21, 1959 (gage he1ght, $5.84 \mathrm{ft})$. 
11-2645. Merced River at Happy Isles Bridge, near Yosemite, Calif.

Location.--Lat $37^{\circ} 43^{\prime} 54^{\prime \prime}$, long $119^{\circ} 33^{\prime} 28^{\prime \prime}$, on right bank $10 \mathrm{ft}$ downstream from Happy Isles Bridge, 0.4 mile downstream from Illilouette Creek, and $2.0 \mathrm{miles}$ southeast of Yosemite National Park Headquarters, Mariposa County.

Drainage area. - - $181 \mathrm{sq} \mathrm{mi}$.

Gage-he1ght record. - Water-stage recorder graph. Datum of gage is $4,016.58 \mathrm{ft}$ above mean sea level, datum of 1929 .

Discharge record.--Stage-discharge relation defined by current-meter measurements below $4,000 \mathrm{cfs}$ and by contracted-opening measurements at 8,400 and $9,260 \mathrm{cfs}$.

Maxima.--January-February 1963: Discharge, 5,200 cfs 0800 hours Feb. 1, 1963 (gage helght, $8.29 \mathrm{ft}$ ).

1915 to December 1962: D1scharge, 9,860 cfs Dec. 23, 1955 (gage height, $12.73 \mathrm{ft})$.

Mean discharge, in cubio feet per secono, 1963

\begin{tabular}{|c|c|c|c|c|c|c|c|c|}
\hline Day & January & February & Day & January & February & Day & January & February \\
\hline $\begin{array}{r}1 \ldots \ldots \\
2 \ldots \ldots \\
3 \ldots \ldots \\
4 \ldots \ldots \\
6 \ldots \ldots \\
7 \ldots \ldots \\
5 \ldots \ldots \\
10 \ldots \ldots\end{array}$ & $\begin{array}{r}10 \\
9.6 \\
9.6 \\
9.3 \\
9.3 \\
8.9 \\
5.9 \\
8.9 \\
8.6 \\
8.2\end{array}$ & $\begin{array}{r}3,690 \\
1,060 \\
564 \\
461 \\
405 \\
352 \\
317 \\
302 \\
270 \\
260\end{array}$ & $\begin{array}{l}11 \ldots \ldots \\
12 \ldots \ldots \\
13 \ldots \ldots \\
14 \ldots \ldots \\
15 \ldots \ldots \\
16 \ldots \ldots \\
17 \ldots \ldots \\
15 \ldots \ldots \\
19 . \ldots \ldots \\
20 \ldots \ldots\end{array}$ & $\begin{array}{l}7.5 \\
5.6 \\
5.9 \\
5.9 \\
5.6 \\
5.6 \\
5.4 \\
5.6 \\
5.6 \\
5.1\end{array}$ & $\begin{array}{l}232 \\
202 \\
222 \\
208 \\
178 \\
172 \\
157 \\
152 \\
148 \\
152\end{array}$ & $\begin{array}{l}21 \ldots \ldots \\
22 \ldots \ldots \\
23 \ldots \ldots \\
24 \ldots \ldots \\
25 \ldots \ldots \\
26 \ldots \ldots \\
27 \ldots \ldots \\
25 \ldots \ldots \\
29 \ldots \ldots \\
30 \ldots \ldots \\
31 \ldots \ldots\end{array}$ & $\begin{array}{r}4.8 \\
4.6 \\
4.6 \\
4.6 \\
4.3 \\
4.3 \\
4.3 \\
4.1 \\
5.1 \\
61 \\
1,350\end{array}$ & 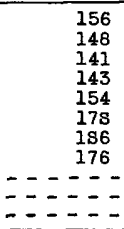 \\
\hline \multicolumn{7}{|l|}{$\begin{array}{l}\text { Monthly } \\
\text { Runoff, } \\
\text { Runoff, }\end{array}$} & $\begin{array}{r}51,6 \\
0.33 \\
3,180\end{array}$ & $\begin{array}{r}355 \\
2.22 \\
21,390\end{array}$ \\
\hline
\end{tabular}

Gage helght, in feet, and discharge, in cublc feet per second, at indicated time, 1963

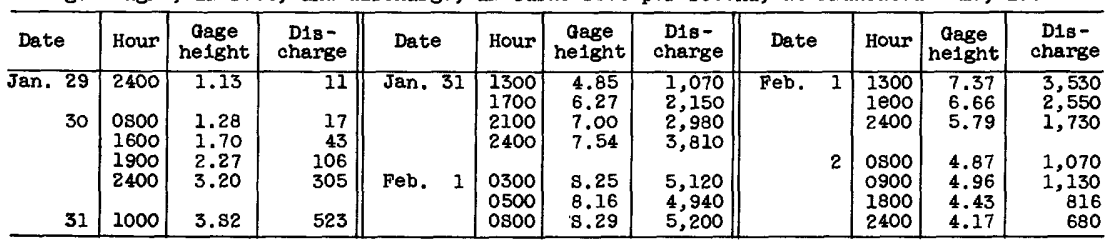

11-2665. Merced River at Pohono Bridge, near Yosemite, Callf.

Location.--Lat $37^{\circ} 43^{\prime} 01^{\prime \prime}$, long $119^{\circ} 39^{\prime} 55^{\prime \prime}$, on left bank $150 \mathrm{ft}$ upstream from Pohono Bridge, $0.4 \mathrm{mile}$ upstream from Artist Creek, and $4.8 \mathrm{miles}$ southwest of Yosemite National Park Headquarters, Mariposa County.

Drainage area. -321 sq $\mathrm{mi}$.

Gage-he1ght record.--Water-stage recorder graph. Datum of gage is $3,861.66 \mathrm{ft}$ above mean sea level, datum of 1929.

Discharge record.--Stage-discharge relation defined by current-meter measurements below $8,700 \mathrm{c}$ 's and by computation of flow over diversion dam for Yosemite powerhouse, 1 mile downstream, at 22,000 and $23,500 \mathrm{cfs}$.

Maxima.--January-February 1963: Discharge, 13,200 cfs 0900 hours Feb. I (gage helght, $14.25 \mathrm{ft}^{\mathrm{t}}$ ).

1916 to December 1962: D1scharge, 23,400 cf's Dec. 23, 1955 (gage height, $21.52 \mathrm{ft}$, from floodmark in well). 
Mean discharge, in cubic feet per second, 1963, of Merced River at Pohono Br1dge,

\begin{tabular}{|c|c|c|c|c|c|c|c|c|}
\hline Day & January & February & Day & January & February & Day & January & Febmuary \\
\hline $\begin{array}{c}1 \ldots \ldots \\
2 \ldots \ldots \\
4 \ldots \ldots \\
5 \ldots \ldots \\
6 \ldots \ldots \\
7 \ldots \ldots \\
9 \ldots \ldots \\
10 \ldots \ldots\end{array}$ & $\begin{array}{l}26 \\
26 \\
26 \\
25 \\
25 \\
24 \\
24 \\
24 \\
24 \\
23\end{array}$ & $\begin{array}{r}9,900 \\
2,670 \\
1,700 \\
1,290 \\
1,030 \\
876 \\
795 \\
750 \\
673 \\
650\end{array}$ & $\begin{array}{l}11 \ldots \ldots \\
12 \ldots \ldots \\
13 \ldots \ldots \\
14 \ldots \ldots \\
15 \ldots \ldots \\
16 \ldots \ldots \\
17 \ldots \ldots \\
18 \ldots \ldots \\
19 \ldots \ldots \\
20 \ldots \ldots\end{array}$ & $\begin{array}{l}23 \\
22 \\
21 \\
20 \\
20 \\
19 \\
19 \\
19 \\
19 \\
18\end{array}$ & $\begin{array}{l}566 \\
506 \\
530 \\
514 \\
444 \\
424 \\
388 \\
370 \\
367 \\
373\end{array}$ & $\begin{array}{l}21 \ldots \ldots \\
22 \ldots \ldots \\
23 \ldots \ldots \\
24 \ldots \ldots \\
25 \ldots \ldots \\
26 \ldots \ldots \\
27 \ldots \ldots \\
28 \ldots \ldots \\
29 \ldots \ldots \\
30 \ldots \ldots \\
31 \ldots \ldots\end{array}$ & $\begin{array}{r}17 \\
17 \\
17 \\
17 \\
17 \\
17 \\
17 \\
17 \\
19 \\
160 \\
3,170\end{array}$ & $\begin{array}{r}382 \\
367 \\
349 \\
358 \\
379 \\
452 \\
476 \\
444 \\
----- \\
-----\end{array}$ \\
\hline $\begin{array}{l}\text { onthly } \\
\text { anoff, } \\
\text { anoff, }\end{array}$ & $\begin{array}{l}\text { an dis } \\
\text { inche } \\
\text { acre }\end{array}$ & & & & & & $\begin{array}{r}127 \\
0.46 \\
7,800\end{array}$ & $\begin{array}{r}1,001 \\
3.25 \\
55,580 \\
\end{array}$ \\
\hline
\end{tabular}

Gage height, in feet, and discharge, in cubic feet per second, at ind1cated time, 1963

\begin{tabular}{|c|c|c|c|c|c|c|c|c|c|c|c|}
\hline Date & Hour & $\begin{array}{c}\text { Gage } \\
\text { helght }\end{array}$ & $\begin{array}{l}\text { Dis- } \\
\text { charge }\end{array}$ & Date & Hour & $\begin{array}{c}\text { Gage } \\
\text { helght }\end{array}$ & $\begin{array}{c}\text { D1s- } \\
\text { charge }\end{array}$ & Date & Hour & $\begin{array}{c}\text { Gage } \\
\text { helght }\end{array}$ & $\begin{array}{c}\text { D1s- } \\
\text { charge }\end{array}$ \\
\hline $\begin{array}{r}\operatorname{Jan} .29 \\
30\end{array}$ & $\begin{array}{l}2400 \\
0600 \\
0900 \\
1200 \\
1300 \\
1500 \\
1800 \\
2000 \\
2200 \\
2400 \\
0200 \\
0400 \\
\end{array}$ & $\begin{array}{l}1.50 \\
1.77 \\
1.97 \\
2.37 \\
2.30 \\
2.59 \\
2.85 \\
3.14 \\
3.84 \\
4.26 \\
4.59 \\
4.76\end{array}$ & $\begin{array}{r}28 \\
47 \\
63 \\
113 \\
102 \\
150 \\
203 \\
270 \\
464 \\
632 \\
800 \\
893 \\
\end{array}$ & Feb. 1 & $\begin{array}{l}0600 \\
0800 \\
1000 \\
1200 \\
1400 \\
1600 \\
1800 \\
2200 \\
2400 \\
0200 \\
0400 \\
0600 \\
0900\end{array}$ & $\begin{array}{r}4.80 \\
5.16 \\
5.62 \\
6.33 \\
7.44 \\
8.76 \\
9.51 \\
10.69 \\
11.65 \\
12.61 \\
13.34 \\
13.89 \\
14.25\end{array}$ & $\begin{array}{r}915 \\
1,130 \\
1,430 \\
2,020 \\
3,080 \\
4,500 \\
5,430 \\
7,060 \\
8,530 \\
10,100 \\
11,400 \\
12,500 \\
13,200\end{array}$ & Feb. 1 & $\begin{array}{l}1200 \\
1500 \\
1800 \\
2100 \\
2400 \\
\\
0200 \\
0400 \\
0600 \\
0900 \\
1200 \\
1500 \\
1800 \\
2400 \\
\end{array}$ & $\begin{array}{r}13.72 \\
12.41 \\
11.21 \\
10.13 \\
9.04 \\
8.33 \\
7.75 \\
7.36 \\
6.88 \\
6.64 \\
6.42 \\
6.30 \\
6.10 \\
\end{array}$ & $\begin{array}{r}12,100 \\
9,780 \\
7,840 \\
6,280 \\
4,880 \\
4,050 \\
3,430 \\
3,040 \\
2,590 \\
2,380 \\
2,190 \\
2,090 \\
1,930 \\
\end{array}$ \\
\hline
\end{tabular}

11-2673. South Fork Merced River at Wawona, Calif.

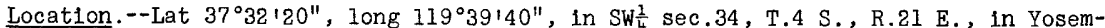
1te National Park, Mariposa County, 1,000 ft downstream from highway bridge at Wawona and $1,200 \mathrm{ft}$ upstream from Big Creek.

Drainage area. $--100 \mathrm{sq} \mathrm{ml}$.

Gage-helght record.--Water-stage recorder graph. Altitude of gage is 4,030 ft (from topographic map).

Discharge record.--Stage-discharge relation defined by current-meter measurements below $6,000 \mathrm{cfs}$; affected by ice Jan. 5-23.

Maxima.--January-February 1963: Discharge, 8,590 cfs 0100 hours Feb. I (gage he1ght, $9.56 \mathrm{ft}$ ).

1955 to December 1962: Discharge, about 15,000 cfs Dec. 23, 1955 (gage height, about $12 \mathrm{ft}$, from floodmarksi.

Mean discharge, in cublc feet per second, 1963

\begin{tabular}{|c|c|c|c|c|c|c|c|c|}
\hline Day & January & February & Day & January & February & Day & J anuary & February \\
\hline $\begin{array}{c}\ldots \ldots \\
2 \ldots \ldots \\
3 \ldots \ldots \\
4 \ldots \ldots \\
6 \ldots \ldots \\
7 \ldots \ldots \\
8 \ldots \ldots \\
10 \ldots \ldots\end{array}$ & $\begin{array}{l}5.8 \\
5.0 \\
5.0 \\
5.0 \\
5.0 \\
4.5 \\
4.5 \\
4.5 \\
4.5 \\
4.5\end{array}$ & $\begin{array}{r}5,380 \\
1,120 \\
575 \\
420 \\
332 \\
287 \\
263 \\
254 \\
251 \\
263\end{array}$ & $\begin{array}{l}11 \ldots \ldots \\
12 \ldots \ldots \\
13 \ldots \ldots \\
14 \ldots \ldots \\
15 . \ldots \ldots \\
16 \ldots \ldots \\
17 \ldots \ldots \\
18 \ldots \ldots \\
19 \ldots \ldots \\
20 \ldots \ldots\end{array}$ & $\begin{array}{l}4.0 \\
4.0 \\
4.0 \\
4.0 \\
4.0 \\
4.5 \\
4.5 \\
4.5 \\
4.5 \\
4.5\end{array}$ & $\begin{array}{l}203 \\
193 \\
219 \\
190 \\
160 \\
155 \\
140 \\
134 \\
132 \\
138\end{array}$ & $\begin{array}{l}21 \ldots \ldots \\
22 \ldots \ldots \\
23 \ldots \ldots \\
24 \ldots \ldots \\
25 \ldots \ldots \\
26 \ldots \ldots \\
27 \ldots \ldots \\
28 \ldots \ldots \\
29 \ldots \ldots \\
30 \ldots \ldots \\
31 \ldots \ldots\end{array}$ & $\begin{array}{r}5.0 \\
5.5 \\
6.0 \\
7.0 \\
5.8 \\
5.0 \\
5.0 \\
5.2 \\
5.6 \\
351 \\
3,080\end{array}$ & $\begin{array}{r}140 \\
134 \\
126 \\
130 \\
140 \\
173 \\
183 \\
173 \\
-\ldots- \\
-\ldots-1\end{array}$ \\
\hline $\begin{array}{l}\text { anoff, } \\
\text { anoff', }\end{array}$ & $\begin{array}{l}\text { Inche } \\
\text { acre- }\end{array}$ & & & & & & $\begin{array}{r}115 \\
1.33 \\
7,080\end{array}$ & $\begin{array}{r}429 \\
4.47 \\
23,820\end{array}$ \\
\hline
\end{tabular}


Gage height, In feet, and discharge, In cubic feet per second, at indicated time, 1963, of South Fork Merced River at Wawona, Calif.

\begin{tabular}{|c|c|c|c|c|c|c|c|c|c|c|c|}
\hline Date & Hour & $\begin{array}{l}\text { Gage } \\
\text { he1ght }\end{array}$ & $\begin{array}{l}\text { Dis- } \\
\text { charge }\end{array}$ & Date & Hour & $\begin{array}{c}\text { Gage } \\
\text { helght }\end{array}$ & $\begin{array}{c}\text { Dis- } \\
\text { charge }\end{array}$ & Date & Hour & $\begin{array}{c}\text { Gage } \\
\text { helght }\end{array}$ & $\begin{array}{c}\text { Dis- } \\
\text { charge }\end{array}$ \\
\hline $\begin{array}{r}\overline{\operatorname{Jan}} \cdot \overline{29} \\
30\end{array}$ & $\begin{array}{l}2400 \\
0400 \\
0700 \\
1000 \\
1300 \\
1500 \\
1800 \\
1900 \\
2200 \\
2300 \\
\end{array}$ & $\begin{array}{l}1.38 \\
1.59 \\
1.86 \\
2.32 \\
2.67 \\
3.30 \\
3.74 \\
3.68 \\
4.24 \\
4.30 \\
\end{array}$ & $\begin{array}{r}22 \\
38 \\
68 \\
142 \\
222 \\
445 \\
650 \\
620 \\
968 \\
1,010 \\
\end{array}$ & $\begin{array}{r}\text { Jan. } \\
31 \\
31\end{array}$ & $\begin{array}{l}2400 \\
0200 \\
0600 \\
1100 \\
1400 \\
1700 \\
2000 \\
2200 \\
2400\end{array}$ & $\begin{array}{l}4.20 \\
3.87 \\
4.70 \\
5.36 \\
6.98 \\
7.53 \\
7.08 \\
8.51 \\
9.25\end{array}$ & $\begin{array}{r}940 \\
722 \\
1,330 \\
1,960 \\
3,930 \\
4,750 \\
4,070 \\
6,440 \\
7,910\end{array}$ & Feb. & $\begin{array}{l}0100 \\
0600 \\
0800 \\
1100 \\
1800 \\
2400 \\
\\
0600 \\
1200 \\
1800 \\
2400 \\
\end{array}$ & $\begin{array}{l}9.56 \\
8.92 \\
8.11 \\
8.31 \\
6.35 \\
5.39 \\
\\
4.81 \\
4.40 \\
4.20 \\
3.97 \\
\end{array}$ & $\begin{array}{r}8,590 \\
7,240 \\
7,620 \\
6,060 \\
2,940 \\
1,850 \\
\\
1,320 \\
1,010 \\
875 \\
732 \\
\end{array}$ \\
\hline
\end{tabular}

11-2677. Strawberry Creek near Wawona, Cal1f.

(Crest-stage station)

Location.--Lat $37^{\circ} 38^{\prime} 10^{\prime \prime}$, long $119^{\circ} 40^{\prime} 55^{\prime \prime}$, in NW $\frac{1}{4}$ sec.33, T.3 S., R.21 E., on State Highway $41,7.0$ miles north of Wawona.

Drainage area. $--1.05 \mathrm{sq} \mathrm{ml}$.

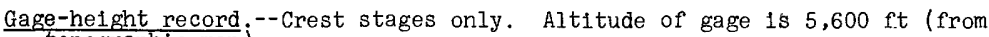
topographic map).

Discharge record.--Stage-discharge relation defined by current-meter measurements below $12 \mathrm{cfs}$ and by computation of flow through culvert at $34 \mathrm{cfs}$.

Maxima --January-February 1963: Discharge, $34 \mathrm{cfs}$ Feb. 1 (gage height, $22.57 \mathrm{ft}$ ). July to December 1962: No significant floodflow.

11-2680. South Fork Merced River near El Portal, Calif'.

Location. - Lat $37^{\circ} 39^{\prime} 05^{\prime \prime}$, long $119^{\circ} 53^{\prime} 05^{\prime \prime}$, in NW $\frac{1}{4} \mathrm{NE} \frac{1}{4}$ sec. 29 , T.3 S., R. 19 E., on right bank $1,400 \mathrm{ft}$ upstream from mouth and 6.2 miles west of El Portal.

Drainage area. $--241 \mathrm{sq} \mathrm{ml}$.

Gage-he1ght record.--Water-stage recorder graph. Altitude of gage is $1,400 \mathrm{ft}$ (from topographic map).

Discharge record.--Stage-discharge relation defined by current-meter measurements below $2,700 \mathrm{c}$ 's and by slope-area measurement at $37,600 \mathrm{cfs}$.

Maxima --January-February 1963: Discharge, 21,600 cfs 0400 hours Feb. 1 (gage height, $15.2 \mathrm{et}$ ).

1950 to December 1968: Discharge, 46,500 cfs Dec. 23, 1955 (gage height, $18.70 \mathrm{ftl}$.

Mean discharge, in cubic feet per second, 1963

\begin{tabular}{|c|c|c|c|c|c|c|c|c|}
\hline Day & January & February & Day & January & February & Day & January & February \\
\hline $\begin{array}{r}1 \ldots \ldots \\
2 \ldots \ldots \\
3 \ldots \ldots \\
4 \ldots \ldots \\
6 \ldots \ldots \\
7 \ldots \ldots \\
8 \ldots \ldots \\
9 \ldots \ldots \\
10 \ldots \ldots\end{array}$ & $\begin{array}{l}19 \\
19 \\
19 \\
19 \\
19 \\
19 \\
18 \\
18 \\
18 \\
19\end{array}$ & $\begin{array}{r}11,900 \\
2,110 \\
992 \\
724 \\
568 \\
464 \\
412 \\
392 \\
376 \\
605\end{array}$ & $\begin{array}{l}11 \ldots \ldots \\
12 \ldots \ldots \\
13 \ldots \ldots \\
14 \ldots \ldots \\
15 \ldots \ldots \\
16 \ldots \ldots \\
17 \ldots \ldots \\
18 \ldots \ldots \\
19 \ldots \ldots \\
20 \ldots \ldots\end{array}$ & $\begin{array}{l}18 \\
19 \\
17 \\
10 \\
16 \\
18 \\
18 \\
18 \\
18 \\
16\end{array}$ & $\begin{array}{l}436 \\
388 \\
554 \\
582 \\
432 \\
380 \\
322 \\
294 \\
277 \\
266\end{array}$ & $\begin{array}{l}21 \ldots \ldots \\
22 \ldots \ldots \\
23 \ldots \ldots \\
24 \ldots \ldots \\
25 \ldots \ldots \\
26 \ldots \ldots \\
27 \ldots \ldots \\
28 \ldots \ldots \\
29 \ldots \ldots \\
30 \ldots \ldots \\
31 \ldots \ldots\end{array}$ & $\begin{array}{r}17 \\
18 \\
18 \\
19 \\
19 \\
18 \\
18 \\
17 \\
18 \\
985 \\
6,880\end{array}$ & $\begin{array}{r}260 \\
246 \\
232 \\
229 \\
232 \\
256 \\
277 \\
263 \\
-.--- \\
-\ldots---\end{array}$ \\
\hline \multicolumn{7}{|l|}{$\begin{array}{l}\text { Monthly } \\
\text { Runoff, } \\
\text { Runoff, }\end{array}$} & $\begin{array}{r}270 \\
1.29 \\
16,630 \\
\end{array}$ & $\begin{array}{r}874 \\
3.78 \\
48,530 \\
\end{array}$ \\
\hline
\end{tabular}


Gage height, in feet, and discharge, in cub1c feet per second, at indlcated time, 1963, of South Fork Merced River near El Portal, Calif.

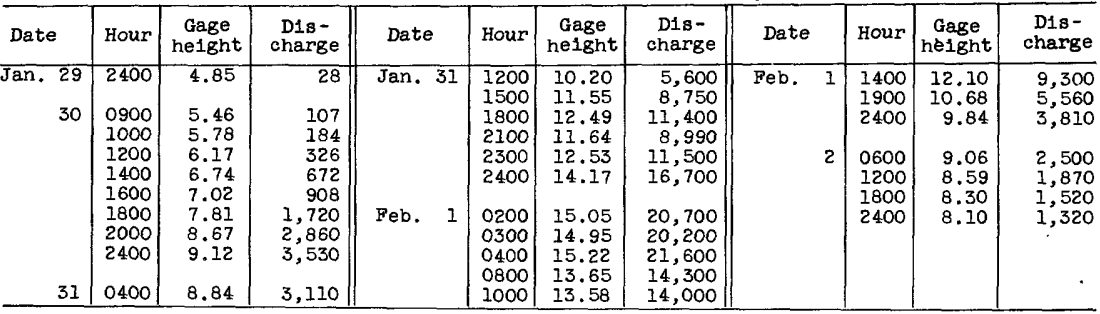

\section{1-2685. Merced River at Bagby, Calif.}

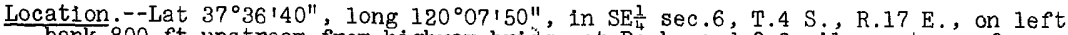
bank 800 ft upstream from highway bridge at Bagby and 0.3 mile upstream from Flyaway Gulch.

Drainage area. $--911 \mathrm{sq} \mathrm{mi}$.

Gage-height record.--Water-stage recorder graph, except Jan. 1 to Jan. 23. Datum of gage is $779.52 \mathrm{ft}$ above mean sea level, datum of 1929 .

Discharge record.--Stage-discharge relation defined by current-meter measurements below 25,000 cfs and by computed peak inflow to Lake Mcclure at 83,000 cfs and $92,500 \mathrm{cfs}$ for floods of November 1950 and December 1955. Discharge for period of no gage-height record estimated on basis of recorded range in stage, weather records, and records for Merced River at Pohono Bridge and South Fork Merced River near E1 Portal.

Maxima.--January-February 1963: D1scharge, 51,600 cfs 0400 hours Feb. 1 (gage he1ght, $19.17 \mathrm{ft}$ )

1922 to December 1962: Discharge, 92,500 cfs Dec. 23, 1955 (gage height, $26.80 \mathrm{ft}$ ).

Mean discharge, in cublc feet per second, 1963

\begin{tabular}{|c|c|c|c|c|c|c|c|c|}
\hline Day & January & February & Day & January & February & Day & January & February \\
\hline $\begin{array}{c}1 \ldots \ldots \\
3 \ldots \ldots \\
4 \ldots \ldots \\
5 \ldots \ldots \\
7 \ldots \ldots \\
8 \ldots \ldots \\
9 \ldots \ldots \\
10 \ldots \ldots\end{array}$ & $\begin{array}{l}78 \\
77 \\
75 \\
74 \\
74 \\
72 \\
72 \\
70 \\
69 \\
67\end{array}$ & $\begin{array}{r}32,500 \\
8,430 \\
3,900 \\
2,750 \\
2,140 \\
1,770 \\
1,520 \\
1,430 \\
1,350 \\
2,280\end{array}$ & $\begin{array}{l}11 \ldots \ldots \\
12 \ldots \ldots \\
13 \ldots \ldots \\
14 \ldots \ldots \\
15 \ldots \ldots \\
16 \ldots \ldots \\
17 \ldots \ldots \\
18 \ldots \ldots \\
19 \ldots \ldots \\
20 \ldots \ldots\end{array}$ & $\begin{array}{l}66 \\
63 \\
61 \\
59 \\
58 \\
58 \\
57 \\
56 \\
54 \\
52\end{array}$ & $\begin{array}{r}1,520 \\
1,260 \\
1,930 \\
2,190 \\
1,510 \\
1,280 \\
1,100 \\
978 \\
912 \\
872\end{array}$ & $\begin{array}{l}21 \ldots \ldots \\
22 \ldots \ldots \\
23 \ldots \ldots \\
24 \ldots \ldots \\
25 \ldots \ldots \\
26 \ldots \ldots \\
27 \ldots \ldots \\
28 \ldots \ldots \\
29 \ldots \ldots \\
30 \ldots \ldots \\
31 \ldots \ldots\end{array}$ & $\begin{array}{r}51 \\
51 \\
51 \\
52 \\
52 \\
52 \\
50 \\
52 \\
52 \\
1,540 \\
16,100\end{array}$ & $\begin{array}{r}856 \\
824 \\
776 \\
760 \\
760 \\
816 \\
896 \\
872 \\
----- \\
--.-2\end{array}$ \\
\hline unoff, & acre & & & & & & $\begin{array}{r}626 \\
0.79 \\
38,510\end{array}$ & $\begin{array}{r}2,792 \\
3,19 \\
155,100 \\
\end{array}$ \\
\hline
\end{tabular}

Gage helght, in feet, and discharge, in cublc feet per second, at ind1cated t1me, 1963

\begin{tabular}{|c|c|c|c|c|c|c|c|c|c|c|c|}
\hline Date & Hour & $\begin{array}{c}\text { Gage } \\
\text { he1ght }\end{array}$ & $\begin{array}{l}\text { Dis- } \\
\text { charge }\end{array}$ & Date & Hour & $\begin{array}{c}\text { Gage } \\
\text { helght }\end{array}$ & $\begin{array}{l}\text { D1s- } \\
\text { charge }\end{array}$ & Date & Hour & $\begin{array}{c}\text { Gage } \\
\text { height }\end{array}$ & $\begin{array}{c}\text { Dis- } \\
\text { charge }\end{array}$ \\
\hline $\begin{array}{r}\text { Jan. } 29 \\
30\end{array}$ & $\begin{array}{l}2400 \\
0800 \\
0900 \\
1000 \\
1100 \\
1600 \\
2000 \\
2200 \\
2400\end{array}$ & $\begin{array}{l}0.83 \\
1.04 \\
1.20 \\
2.00 \\
2.70 \\
3.23 \\
4.23 \\
5.26 \\
6.74\end{array}$ & $\begin{array}{r}53 \\
102 \\
148 \\
510 \\
1,050 \\
1,560 \\
2,850 \\
4,610 \\
7,760\end{array}$ & Feb. 1 & $\begin{array}{l}0600 \\
0700 \\
1400 \\
1600 \\
1900 \\
2200 \\
2400 \\
\\
0400 \\
1000 \\
1800 \\
\end{array}$ & $\begin{array}{r}7.00 \\
6.92 \\
10.00 \\
11.90 \\
12.92 \\
12.42 \\
13.70 \\
19.17 \\
15.81 \\
11.79\end{array}$ & $\begin{array}{r}8,380 \\
8,190 \\
16,600 \\
22,700 \\
26,300 \\
24,500 \\
29,100 \\
51,600 \\
37,400 \\
22,300 \\
\end{array}$ & Feb. & $\begin{array}{l}2400 \\
0600 \\
1200 \\
1800 \\
2400 \\
\\
0600 \\
1200 \\
1800 \\
2400 \\
\end{array}$ & $\begin{array}{l}9.63 \\
7.83 \\
6.53 \\
5.83 \\
5.41 \\
\\
5.07 \\
4.84 \\
4.60 \\
4.44 \\
\end{array}$ & $\begin{array}{r}15,500 \\
10,500 \\
7,270 \\
5,740 \\
5,000 \\
4,270 \\
3,850 \\
3,440 \\
3,180 \\
\end{array}$ \\
\hline
\end{tabular}


11-2693. Maxwell Creek at Coulterville, Cal1f.

Location.--Lat $37^{\circ} 42^{\prime} 58^{\prime \prime}$, long $120^{\circ} 11^{\prime} 20^{\prime \prime}$, in SE $\frac{1}{4}$ sec.34, T.2 S., R.16 E., on Dogtown road bridge, $0.40 \mathrm{mlle}$ downstream from Cuneo Creek and $0.5 \mathrm{mlle}$ northeast of town of Coulterville.

Drainage area. $--17.0 \mathrm{sq} \mathrm{ml}$.

Gage-height record:--Water-stage recorder graph. Altitude of gage is $1,740 \mathrm{ft}$ (from topographic map).

Discharge record.--Stage-discharge relation defined by current-meter measurements below $700 \mathrm{cfs}$.

Maxima.--January-February 1963: D1scharge, 1,300 cfs 2330 hours Jan. 31 (gage helght, $5.47 \mathrm{ft}$ ).

1959 to December 1962: Discharge, 1,720 cfs (revised) Feb. 8, 1960 (gage height, $5.73 \mathrm{ft}$ ).

Remarks.--Records furnished by California Department of Water Resources and reviewed by Geological Survey.

Mean discharge, in cubic feet per second, 1963

\begin{tabular}{|c|c|c|c|c|c|c|c|c|}
\hline Day & January & February & Day & January & Pebruary & Day & January & February \\
\hline $\begin{array}{c}1 \ldots \ldots \\
2 \ldots \ldots \\
3 \ldots \ldots \\
5 \ldots \ldots \\
6 \ldots \ldots \\
7 \ldots \ldots \\
8 \ldots \ldots \\
9 \ldots \ldots \\
10 \ldots \ldots\end{array}$ & $\begin{array}{r}0.2 \\
.2 \\
.2 \\
.2 \\
.2 \\
.2 \\
.3 \\
.3 \\
.3 \\
.2\end{array}$ & $\begin{array}{r}323 \\
15 \\
5.0 \\
3.0 \\
2.3 \\
1.8 \\
1.5 \\
1.4 \\
5.0 \\
49\end{array}$ & $\begin{array}{l}11 \ldots \ldots \\
12 \ldots \ldots \\
13 \ldots \ldots \\
14 \ldots \ldots \\
15 \ldots \ldots \\
16 \ldots \ldots \\
17 \ldots \ldots \\
18 \ldots \ldots \\
19 \ldots \ldots \\
20 \ldots \ldots\end{array}$ & $\begin{array}{r}0.2 \\
.2 \\
.2 \\
.2 \\
.2 \\
.2 \\
.2 \\
.2 \\
.2 \\
.2\end{array}$ & $\begin{array}{l}7.9 \\
5.5 \\
97 \\
38 \\
11 \\
6.2 \\
4.6 \\
3.4 \\
2.9 \\
2.6\end{array}$ & $\begin{array}{l}21 \ldots \ldots \\
22 \ldots \ldots \\
23 \ldots \ldots \\
24 \ldots \ldots \\
25 \ldots \ldots \\
26 \ldots \ldots \\
27 \ldots \ldots \\
28 \ldots \ldots \\
29 \ldots \ldots \\
30 \ldots \ldots \\
31 \ldots \ldots\end{array}$ & $\begin{array}{r}0.2 \\
.2 \\
.2 \\
.3 \\
.2 \\
.3 \\
.3 \\
.3 \\
.3 \\
56 \\
368\end{array}$ & $\begin{array}{r}2.2 \\
1.9 \\
1.9 \\
1.8 \\
1.6 \\
1.6 \\
1.6 \\
1.5 \\
----- \\
-------\end{array}$ \\
\hline \multicolumn{7}{|c|}{ 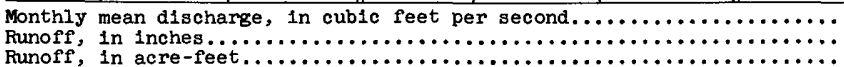 } & $\begin{array}{r}13.9 \\
0.94 \\
854\end{array}$ & $\begin{array}{r}21.4 \\
1.31 \\
1,190\end{array}$ \\
\hline
\end{tabular}

Gage height, in feet, and discharge, in cubic feet per second, at indicated time, I963

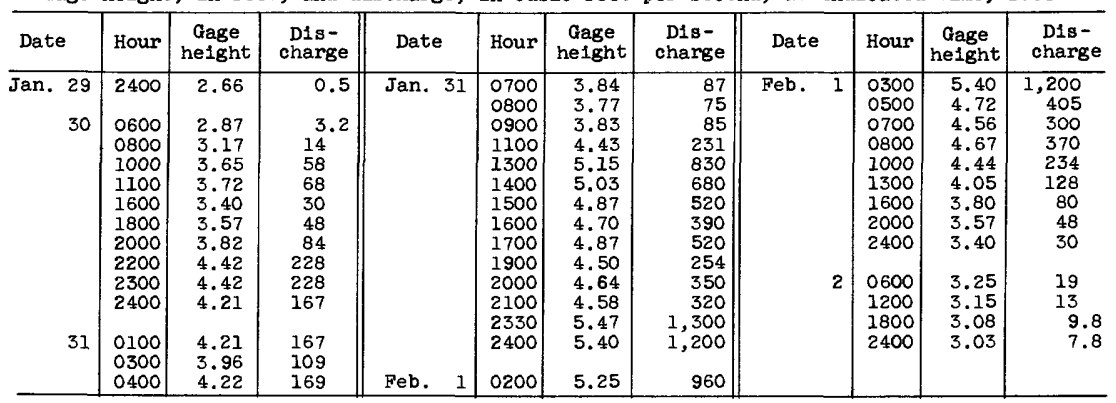

11-2693.5. North Fork Blacks Creek near Coulterville, Calif.

(Crest-stage station)

Location.--Lat $37^{\circ} 44^{\prime} 10^{\prime \prime}$, 1ong $120^{\circ} 13^{\prime} 30^{\prime \prime}$, in $\mathrm{NE} \frac{1}{4}$ sec.29, T.2 S., R.16 E., on State Highway $49,2.4$ miles northwest of Coultervilie.

Dralnage area. $--2.20 \mathrm{sq} \mathrm{mi}$.

Gage-helght record.--Crest stages only. Altitude of gage is $1,740 \mathrm{ft}$ (from topographic map).

Discharge record.--Stage-discharge relation defined by current-meter measurements below $19 \mathrm{cfs}$ and by computation of flow through culvert and over embankment at $472 \mathrm{cfs}$.

Maxima.--January-February 1963: Discharge, $472 \mathrm{cfs}$ Jan. 31 (gage height, $6.85 \mathrm{ft}$, from high-water profile). Ju1y to December 1962: No significant floodflow. 
11-2695. Lake McClure at Exchequer, Calif.

Location.--Lat $37^{\circ} 35^{\prime} 10^{\prime \prime}$, long $120^{\circ} 16^{\prime} 0^{\prime \prime}$, near center of sec.13, T.4 S., R.15 E., at center of upstream face of Exchequer Dam on Merced River, I mile east of Exchequer, and 5.5 miles northeast of Merced Falls.

Drainage area. $--1,020 \mathrm{sq} \mathrm{mi}$, approximately.

Gage-height record.--Indicator in powerhouse at foot of dam actuated by float in reservoir and selsyn motor circuit; indicator read every half hour when powerhouse is operating, once daliy, at midnight, when not. Datum of gage is at mean sea level (levels by Merced Irrigation District).

Contents record.--Contents computed from capacity table dated Jan. 11, 1939.

Maxima.--January-February 1963: Contents, 203,800 acre-ft Feb. 15 (elevation, $674.8 \mathrm{ft})$.

1926 to December 1962: Contents, 290,800 acre-f't Dec. 4, 1950 (elevation, $710.5 \mathrm{ft})$.

Remarks.--Reservolr is formed by concrete gravity-type dam completed in 1926 ; storage began in April 1926. Usable capacity, 280,900 acre-ft between elevations $442.6 \mathrm{ft}$ (bottom of sluice valve) and $707.0 \mathrm{ft}$ (top of spillway gates). Dead storage, 400 acre-ft or less. Figures given herein represent total contents. Gage-height record furnished by Merced Irrigation District.

Elevation, in feet, and contents, in acre-feet, at 2400 hours, 1963

\begin{tabular}{|c|c|c|c|c|c|c|c|c|c|}
\hline \multirow{2}{*}{ Day } & \multicolumn{2}{|c|}{ January } & \multicolumn{2}{|c|}{ February } & \multirow{2}{*}{ Day } & \multicolumn{2}{|c|}{ January } & \multicolumn{2}{|c|}{ February } \\
\hline & Elevation & Contents & Elevation & Contents & & Elevation & Contents & Elevation & Contents \\
\hline $\begin{array}{r}1 \\
2 \\
3 \\
4 \\
5 \\
6 \\
7 \\
8 \\
9 \\
10 \\
11 \\
12 \\
13 \\
14\end{array}$ & $\begin{array}{l}566.7 \\
566.8 \\
566.9 \\
566.9 \\
567.0 \\
567.0 \\
567.1 \\
567.2 \\
567.2 \\
567.2 \\
567.2 \\
567.3 \\
567.4 \\
567.3 \\
567.4\end{array}$ & $\begin{array}{l}44,300 \\
44,400 \\
44,500 \\
44,500 \\
44,600 \\
44,600 \\
44,700 \\
44,800 \\
44,500 \\
44,800 \\
44,800 \\
44,900 \\
45,000 \\
44,900 \\
45,000\end{array}$ & $\begin{array}{l}652.4 \\
661.5 \\
665.4 \\
668.1 \\
670.1 \\
670.6 \\
671.6 \\
671.4 \\
671.3 \\
673.0 \\
672.8 \\
672.6 \\
673.8 \\
674.7 \\
674.8\end{array}$ & $\begin{array}{l}159,300 \\
176,500 \\
184,300 \\
189,700 \\
193,900 \\
195,000 \\
197,100 \\
196,600 \\
196,400 \\
200,000 \\
199,600 \\
199,200 \\
201,700 \\
203,600 \\
203,800\end{array}$ & $\begin{array}{l}16 \\
17 \\
18 \\
19 \\
20 \\
21 \\
22 \\
23 \\
24 \\
25 \\
26 \\
27 \\
28 \\
29 \\
30 \\
31\end{array}$ & $\begin{array}{l}567.4 \\
567.4 \\
567.4 \\
567.4 \\
567.4 \\
567.5 \\
567.5 \\
567.5 \\
567.5 \\
567.5 \\
567.5 \\
567.4 \\
567.4 \\
567.6 \\
570.3 \\
602.7\end{array}$ & $\begin{array}{l}45,000 \\
45,000 \\
45,000 \\
45,000 \\
45,000 \\
45,000 \\
45,000 \\
45,000 \\
45,000 \\
45,000 \\
45,000 \\
45,000 \\
45,000 \\
45,100 \\
47,600 \\
83,300\end{array}$ & $\begin{array}{c}674.6 \\
675.3 \\
673.7 \\
673.2 \\
672.6 \\
672.0 \\
671.3 \\
670.6 \\
669.9 \\
669.2 \\
668.5 \\
667.8 \\
667.3 \\
- \\
- \\
-\end{array}$ & $\begin{array}{c}203,400 \\
202,700 \\
201,500 \\
200,400 \\
199,200 \\
197,900 \\
196,400 \\
195,000 \\
193,500 \\
192,000 \\
190,600 \\
189,100 \\
188,100 \\
- \\
- \\
-\end{array}$ \\
\hline & in cont & $\mathrm{s}$, in a & 1 Cou & & $\cdots$ & - & $+39,000$ & - & $+104, \mathrm{~s} 00$ \\
\hline
\end{tabular}

11-2700. Merced River at Exchequer, Calif.

Location.--Lat $37^{\circ} 34^{\prime} 5^{\prime \prime}$, long $120^{\circ} 16^{\prime} 45^{\prime \prime}$, in SE $\frac{1}{4} \mathrm{SE} \frac{1}{4}$ sec.14, T.4 S., R.15 E., on right bank at Exchequer, $0.65 \mathrm{mlle}$ downstream from Lake Mcclure, and 5 miles northeast of Merced Falls.

Drainage area. $--1,038 \mathrm{sq} \mathrm{m}$.

Gage-helght record ;-Water-stage recorder graph. Altitude of gage is 400 ft (from topographic map $;$.

Discharge record.--Stage-discharge relation defined by current-meter measurements below $10,000 \mathrm{cf}$ 's and by computation of flow over dam at $46,200 \mathrm{cfs}$.

Maxima.--January-February 1963: Discharge, 1,560 cf's 0500 hours Feb. 6 (gage helght, $3.84 \mathrm{ft}$ ).

$1901-13,1915$ to December 1962: Discharge observed, 47,700 cfs Jan. 31, 1911

(gage height, $23.3 \mathrm{ft}$, site and datum then in use).

Remarks.--Flow regulated by Exchequer powerplant and Lake Mcclure (see station $11-2695)$. 
Mean discharge, in cublc feet per second, 1963, of Merced River at Exchequer, Calif.

\begin{tabular}{|c|c|c|c|c|c|c|c|c|}
\hline Day & January & February & Day & January & February & Day & January & February \\
\hline $\begin{array}{c}\ldots \ldots \\
2 \ldots \ldots \\
3 \ldots \ldots \\
4 \ldots \ldots \\
5 \ldots \ldots \\
6 \ldots \ldots \\
7 \ldots \ldots \\
9 \ldots \ldots \\
10 \ldots \ldots\end{array}$ & $\begin{array}{l}43 \\
43 \\
43 \\
43 \\
43 \\
43 \\
43 \\
43 \\
43 \\
43\end{array}$ & $\begin{array}{r}38 \\
36 \\
37 \\
41 \\
64 \\
1,200 \\
665 \\
1,520 \\
1,520 \\
1,530\end{array}$ & $\begin{array}{l}11 \ldots \ldots \\
12 \ldots \ldots \\
13 \ldots \ldots \\
14 \ldots \ldots \\
15 \ldots \ldots \\
16 \ldots \ldots \\
17 \ldots \ldots \\
18 \ldots \ldots \\
19 \ldots \ldots \\
20 \ldots \ldots\end{array}$ & $\begin{array}{l}43 \\
43 \\
43 \\
43 \\
43 \\
43 \\
42 \\
44 \\
44 \\
44\end{array}$ & $\begin{array}{l}1,530 \\
1,540 \\
1,540 \\
1,540 \\
1,540 \\
1,540 \\
1,540 \\
1,540 \\
1,540 \\
1,540\end{array}$ & $\begin{array}{l}21 \ldots \ldots \\
22 \ldots \ldots \\
23 \ldots \ldots \\
24 \ldots \ldots \\
25 \ldots \ldots \\
26 \ldots \ldots \\
27 \ldots \ldots \\
28 \ldots \ldots \\
29 \ldots \ldots \\
30 \ldots \ldots \\
31 \ldots \ldots\end{array}$ & $\begin{array}{l}44 \\
45 \\
45 \\
46 \\
46 \\
46 \\
46 \\
46 \\
46 \\
46 \\
43\end{array}$ & $\begin{array}{r}1,540 \\
1,530 \\
1,530 \\
1,530 \\
1,530 \\
1,520 \\
1,520 \\
1,520 \\
--.-- \\
--.--- \\
-.--.\end{array}$ \\
\hline $\begin{array}{l}\text { nthly } \\
\text { noff, }\end{array}$ & - & & & & & & $\begin{array}{r}43.9 \\
2,700 \\
\end{array}$ & $\begin{array}{r}1,224 \\
67,960 \\
\end{array}$ \\
\hline
\end{tabular}

11-2713. Hayward Creek near La Grange, Cal1f.

(Crest-stage station)

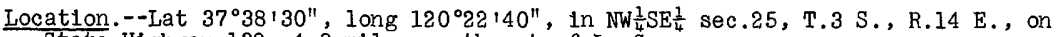
State Highway $132,4.9$ miles southeast of La Grange.

Dra1nage area. $--3.96 \mathrm{sq} \mathrm{ml}$.

Gage-height record.--Crest stages only. Alt1tude of gage is $570 \mathrm{ft}$ (from topographic map).

Discharge record.--Stage-discharge relation defined by current-meter measurements below $39 \mathrm{cfs}$ and by computation of flow through culvert at $140 \mathrm{cfs}$ and computation of flow through culvert and over embankment at 377 and $502 \mathrm{cfs}$.

Maxima --January-February 1963: Discharge, 520 cfs Feb. 1 (gage helght, $15.00 \mathrm{ft}$ ). 1959 to December 1962: Discharge, 502 cfs Mar. 5, 1962 (gage height,
$14.95 \mathrm{ft})$.

11-2725. Merced River near Stevinson, Calif.

Location.--Lat $37^{\circ} 22^{\prime} 15^{\prime \prime}$, long $120^{\circ} 55^{\prime} 45^{\prime \prime}$, In SW $\frac{1}{4} \mathrm{NE} \frac{1}{4}$ sec.36, T.6 S., R.9 E., on right bank 5 miles upstream from mouth and 6 miles northwest of Stevinson.

Drainage area. $--1,274 \mathrm{sq} \mathrm{ml}$.

Gage-he1ght record.--Water-stage recorder graph. Datum of gage is at mean sea level (levels by topographic division).

Discharge record.--Stage-discharge relation defined by current-meter measurements.

Max1ma.--January-February 1963: D1scharge, 2,950 cfs 1500 hours Feb. 14 (elevation, $64.84 \mathrm{ft}$ )

1940 to December 1962: Discharge, $13,600 \mathrm{cfs}$ Dec. 5, 1950 (elevation, $73.79 \mathrm{ft})$.

Remarks.--Flow regulated by Lake McClure.

Mean discharge, in cub1c feet per second, 1963

\begin{tabular}{|c|c|c|c|c|c|c|c|c|}
\hline Day & January & February & Day & January & February & Day & January & February \\
\hline $\begin{array}{c}1 \ldots \ldots \\
2 \ldots \ldots \\
3 \ldots \ldots \\
5 \ldots \ldots \\
6 \ldots \ldots \\
5 \ldots \ldots \\
9 \ldots \ldots \\
10 \ldots \ldots\end{array}$ & $\begin{array}{l}133 \\
132 \\
132 \\
131 \\
131 \\
131 \\
132 \\
132 \\
133 \\
132\end{array}$ & $\begin{array}{r}172 \\
418 \\
415 \\
306 \\
253 \\
237 \\
276 \\
717 \\
952 \\
1,570\end{array}$ & $\begin{array}{l}11 \ldots \ldots \\
12 \ldots \ldots \\
13 \ldots \ldots \\
14 \ldots \ldots \\
15 \ldots \ldots \\
16 \ldots \ldots \\
17 \ldots \ldots \\
18 \ldots \ldots \\
19 \ldots \ldots \\
20 \ldots \ldots\end{array}$ & $\begin{array}{l}134 \\
138 \\
134 \\
133 \\
134 \\
133 \\
133 \\
133 \\
134 \\
134\end{array}$ & $\begin{array}{l}2,150 \\
1,670 \\
1,760 \\
2,680 \\
2,060 \\
1,790 \\
1,720 \\
1,680 \\
1,650 \\
1,620\end{array}$ & $\begin{array}{l}21 \ldots \ldots \\
22 \ldots \ldots \\
23 \ldots \ldots \\
24 \ldots \ldots \\
25 \ldots \ldots \\
26 \ldots \ldots \\
27 \ldots \ldots \\
28 \ldots \ldots \\
29 \ldots \ldots \\
30 \ldots \ldots \\
31 \ldots \ldots\end{array}$ & $\begin{array}{l}135 \\
134 \\
134 \\
134 \\
133 \\
132 \\
133 \\
133 \\
130 \\
138 \\
146\end{array}$ & $\begin{array}{r}1,610 \\
1,600 \\
1,600 \\
1,590 \\
1,590 \\
1,590 \\
1,580 \\
1,570 \\
-.--- \\
--.-- \\
-.--\end{array}$ \\
\hline $\begin{array}{l}\text { onthly } \\
\text { anoff, }\end{array}$ & $\begin{array}{l}\text { an disc } \\
\text { acre-f }\end{array}$ & , & feet & & & & $\begin{array}{r}134 \\
8,210\end{array}$ & $\begin{array}{r}1,316 \\
73,100\end{array}$ \\
\hline
\end{tabular}


11-2730. Merced River Slough near' Newman, Cal1f.

Location.--Lat $37^{\circ} 21^{\prime} 35^{\prime \prime}$, long $120^{\circ} 57^{\prime} 40^{\prime \prime}$, in NE $\frac{1}{4} \mathrm{NE} \frac{1}{4}$ sec.3, T.7 S., R.9 E., on left bank $0.1 \mathrm{mile}$ downstream from bridge, $0.2 \mathrm{mile}$ downstream from head of slough between Merced and San Joaquin Rivers, and 4.5 miles northeast of Newman.

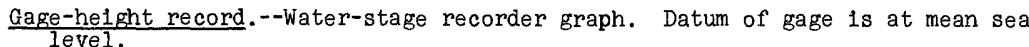

Discharge record.--Stage-discharge relation defined by current-meter measurements.

Maxima.--January-February 1963: No flow.

1941 to December 1962: Da1ly discharge, 7,770 ofs Apr. 6, 1958.

Remarks.--Slough flows from Merced River to San Joaquin River, bypassing gaging station on San Joaquin River near Newman.

11-2740. San Joaquin River near Newman, Calif.

Locat1on.--Lat $37^{\circ} 21^{102^{\prime \prime}}$, long $120^{\circ} 58^{13} 34^{\prime \prime}$, in SW $\frac{1}{4}$ sec.3, T.7 S., R.9 E., on left bank $300 \mathrm{ft}$ downstream from new bridge on H1lis Ferry road, $500 \mathrm{ft}$ downstream from Merced River, and 3.5 miles northeast of Newman.

Drainage area. $--9,524 \mathrm{sq} \mathrm{ml}$.

Gage-helght record.--Water-stage recorder graph. Datum of gage is at mean sea level. Discharge record.--Stage-discharge relation defined by current-meter measurements.

Maxima --January-February 1963: D1scharge, 4,870 cfs 2100 hours Feb. 14 (elevation, $57.17 \mathrm{ft}$ ).

1912 to December 1962: Discharge, 33,000 cfs Mar. 7, 1938 (elevation, 65.81 ft), Including flow in Merced River Slough.

Remarks.--Flow affected by upstream reservoirs and by part of flow bypassing through Merced River Slough.

Mean discharge, in cubic feet per second, 1963

\begin{tabular}{|c|c|c|c|c|c|c|c|c|}
\hline Day & January & February & Day & January & February & Day & January & February \\
\hline $\begin{array}{r}1 \ldots \ldots \\
3 \ldots \ldots \\
4 \ldots \ldots \\
5 \ldots \ldots \\
6 \ldots \ldots \\
7 \ldots \ldots \\
8 \ldots \ldots \\
10 \ldots \ldots\end{array}$ & $\begin{array}{l}355 \\
355 \\
360 \\
355 \\
350 \\
350 \\
400 \\
493 \\
565 \\
577\end{array}$ & $\begin{array}{r}756 \\
1,220 \\
1,820 \\
2,420 \\
2,620 \\
2,260 \\
1,790 \\
1,840 \\
1,800 \\
2,500\end{array}$ & $\begin{array}{l}11 \ldots \ldots \\
12 \ldots \ldots \\
13 \ldots \ldots \\
14 \ldots \ldots \\
15 \ldots \ldots \\
16 \ldots \ldots \\
17 \ldots \ldots \\
18 \ldots \ldots \\
19 \ldots \ldots \\
20 \ldots \ldots\end{array}$ & $\begin{array}{l}571 \\
547 \\
511 \\
505 \\
496 \\
472 \\
445 \\
418 \\
398 \\
388\end{array}$ & $\begin{array}{l}3,460 \\
3,480 \\
3,790 \\
4,540 \\
4,680 \\
4,580 \\
4,420 \\
3,980 \\
3,540 \\
3,200\end{array}$ & $\begin{array}{l}21 \ldots \ldots \\
22 \ldots \ldots \\
23 \ldots \ldots \\
24 \ldots \ldots \\
25 \ldots \ldots \\
26 \ldots \ldots \\
27 \ldots \ldots \\
28 \ldots \ldots \\
29 \ldots \ldots \\
30 \ldots \ldots \\
31 \ldots \ldots\end{array}$ & $\begin{array}{l}382 \\
380 \\
368 \\
360 \\
352 \\
350 \\
342 \\
352 \\
360 \\
382 \\
475\end{array}$ & $\begin{array}{r}2,970 \\
2,810 \\
2,640 \\
2,500 \\
2,420 \\
2,340 \\
2,270 \\
2,210 \\
---.-- \\
------ \\
-----\end{array}$ \\
\hline $\begin{array}{l}\text { onthly } \\
\text { anoff, }\end{array}$ & d1 & 1 & 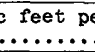 & & & & $\begin{array}{r}420 \\
25,810\end{array}$ & $\begin{array}{r}2,816 \\
156,400 \\
\end{array}$ \\
\hline
\end{tabular}

11-2745. Orestimba Creek near Newman, Calif.

Location.--Lat $37^{\circ} 19^{\prime} 09^{\prime \prime}$, long $121^{\circ} 07^{\prime} 12^{\prime \prime}$, on line between secs. 17 and $20, \mathrm{~T} .7 \mathrm{~S}$. , R.8 E., at left bank pier of county road bridge, 3 miles downstream from Oso Creek, and 5 miles west of Newman.

Drainage area. $-134 \mathrm{sq} \mathrm{m} 1$.

Gage-height record.--Water-stage recorder graph. Datum of gage is $188.86 \mathrm{ft}$ above mean sea level, adjustment of 1929 .

Discharge record.--Stage-discharge relation defined by current-meter measurements below 5,000 cis. Maxima -- -January-February 1963: D1scharge, 8,300 cfs 0100 hours Feb. 1 (gage helght,

1932 to December 1962: Discharge, 10,200 cfs Apr. 2, 1958 (gage height,

$6.57 \mathrm{ft}$, at site $120 \mathrm{ft}$ downstream at datum $3.00 \mathrm{ft}$ higher). 
Mean discharge, in cub1c feet per second, 1963, of Orest1mba Creek near Newman, Cal1f.

\begin{tabular}{|c|c|c|c|c|c|c|c|c|}
\hline Day & January & February & Day & January & February & Day & January & February \\
\hline $\begin{array}{c}1 \ldots \ldots \\
2 \ldots \ldots \\
3 \ldots \ldots \\
4 \ldots \ldots \\
6 \ldots \ldots \\
7 \ldots \ldots \\
8 \ldots \ldots \\
9 \ldots \ldots \\
10 \ldots \ldots\end{array}$ & $\begin{array}{l}0 \\
0 \\
0 \\
0 \\
0 \\
0 \\
0 \\
0 \\
0 \\
0\end{array}$ & $\begin{array}{c}2,090 \\
255 \\
95 \\
50 \\
28 \\
16 \\
8.0 \\
3.2 \\
19 \\
129\end{array}$ & $\begin{array}{l}11 \ldots \ldots \\
12 \ldots \ldots \\
13 \ldots \ldots \\
14 \ldots \ldots \\
15 \ldots \ldots \\
16 \ldots \ldots \\
17 \ldots \ldots \\
18 \ldots \ldots \\
19 \ldots \ldots \\
20 \ldots \ldots\end{array}$ & $\begin{array}{l}0 \\
0 \\
0 \\
0 \\
0 \\
0 \\
0 \\
0 \\
0 \\
0\end{array}$ & $\begin{array}{r}52 \\
42 \\
563 \\
296 \\
132 \\
83 \\
52 \\
40 \\
30 \\
24\end{array}$ & $\begin{array}{l}21 \ldots \ldots \\
22 \ldots \ldots \\
23 \ldots \ldots \\
24 \ldots \ldots \\
25 \ldots \ldots \\
26 \ldots \ldots \\
27 \ldots \ldots \\
28 \ldots \ldots \\
29 \ldots \ldots \\
30 \ldots \ldots \\
31 \ldots \ldots\end{array}$ & $\begin{array}{r}0 \\
0 \\
0 \\
0 \\
0 \\
0 \\
0 \\
0 \\
0 \\
0 \\
0 \\
1,330\end{array}$ & $\begin{array}{r}20 \\
16 \\
12 \\
11 \\
9.5 \\
9.0 \\
8.7 \\
8.7 \\
-\ldots-- \\
-\ldots-.-\end{array}$ \\
\hline $\begin{array}{l}\text { onthly } \\
\text { inoff, } \\
\text { inoff, }\end{array}$ & $\begin{array}{l}\text { mean disch } \\
\text { in inches. } \\
\text { in acre-fe }\end{array}$ & e, & feet & & & & $\begin{array}{r}42.9 \\
0.37 \\
2,640 \\
\end{array}$ & $\begin{array}{r}147 \\
1.14 \\
8,140 \\
\end{array}$ \\
\hline
\end{tabular}

Gage height, in feet, and discharge, in cublc feet per second, at indicated time, 1963

\begin{tabular}{|c|c|c|c|c|c|c|c|c|c|c|c|}
\hline Date & Hour & $\begin{array}{c}\text { Gage } \\
\text { he1ght }\end{array}$ & $\begin{array}{l}\text { D1s- } \\
\text { charge }\end{array}$ & Date & Hour & $\begin{array}{c}\text { Gage } \\
\text { helght }\end{array}$ & $\begin{array}{l}\text { D1s- } \\
\text { charge }\end{array}$ & Date & Hour & $\begin{array}{c}\text { Gage } \\
\text { he1ght }\end{array}$ & $\begin{array}{c}\text { D1s- } \\
\text { charge }\end{array}$ \\
\hline $\begin{array}{r}\text { Jan. } 30 \\
31\end{array}$ & $\begin{array}{l}2400 \\
0400 \\
0500 \\
0600 \\
0900 \\
1200 \\
1400 \\
1500 \\
\end{array}$ & $\begin{array}{c}- \\
- \\
5.00 \\
5.58 \\
6.06 \\
6.06 \\
6.58 \\
7.02\end{array}$ & $\begin{array}{r}0 \\
0 \\
0 \\
26 \\
173 \\
448 \\
448 \\
976 \\
1,570\end{array}$ & $\begin{array}{l}\text { Jan. } 31 \\
\text { Feb. } 1\end{array}$ & $\begin{array}{l}1700 \\
2000 \\
2200 \\
2400 \\
0100 \\
0300 \\
0600 \\
0900\end{array}$ & $\begin{array}{l}7.94 \\
7.17 \\
8.10 \\
9.00 \\
9.72 \\
8.70 \\
7.52 \\
6.89\end{array}$ & $\begin{array}{l}3,180 \\
1,790 \\
3,520 \\
5,820 \\
8,300 \\
4,960 \\
2,400 \\
1,460\end{array}$ & Feb. 1 & $\begin{array}{l}1500 \\
2000 \\
2400 \\
\\
0900 \\
1800 \\
2400\end{array}$ & $\begin{array}{l}6.41 \\
6.06 \\
5.86 \\
\\
5.54 \\
5.33 \\
5.24\end{array}$ & $\begin{array}{l}910 \\
598 \\
452 \\
\\
265 \\
172 \\
139\end{array}$ \\
\hline
\end{tabular}

11-2746. Del Puerto Creek tributary No. 1 near Patterson, Calif.

\section{(Crest-stage station)}

Location.--Lat $37^{\circ} 24^{\prime} 15^{\prime \prime}$, long $121^{\circ} 26^{\prime} 10^{\prime \prime}$, in NE $\frac{1}{4} \mathrm{NW} \frac{1}{4} \sec .21$, T.6 S., R.5 E., 17.5 miles southwest of Patterson.

Drainage area. $-0.71 \mathrm{sq} \mathrm{ml}$.

Gage-helght record.--Crest stages only. Altitude of gage is 1,760 ft (from topographic map).

Discharge record.--Stage-discharge relation defined by current-meter measurements below $6 \mathrm{cfs}$ and by computation of flow through culvert at $17 \mathrm{cfs}$.

Maxima.--January-February 1963: Discharge, $20 \mathrm{cfs} F e b .1$ (gage height, $93.73 \mathrm{ft}$ ). 1958 to December 1962: Discharge, $17 \mathrm{cfs}$ Feb. 16, 1959, and Mar. 7, 1962 (gage height, $93.57 \mathrm{ft}$ ).

11-2746.1. Del Puerto Creek tributary No. 2 near Patterson, Calif.

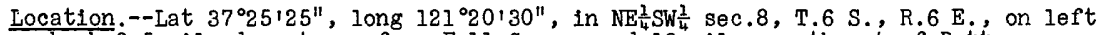
bank $0.5 \mathrm{mile}$ downstream from Fall Canyon and $12 \mathrm{mlles}$ southwest of Patterson.

Drainage area. $-0.024 \mathrm{sq} \mathrm{ml}$.

Gage-height record.--Water-stage recorder graph and crest-stage gage. Altitude of gage is $1,020 \mathrm{ft}$ (from topographic map).

Discharge record.--Stage-discharge relation defined by point of zero flow and computation of fiow through culvert at $0.5 \mathrm{cfs}$.

Maxima.--January-February 1963: No flow.

1958 to December 1962: Discharge, $0.5 \mathrm{cfs} F e b .16,1959$ (gage helght, $5.73 \mathrm{ft}$, from crest-stage gage). 
11-2746.2. Windmill Canyon Creek near Patterson, Calif.

(Crest-stage station)

Location.--Lat $37^{\circ} 27^{\prime} 15^{\prime \prime}$, long $121^{\circ} 16^{\prime} 10^{\prime \prime}$, in SE $\frac{1}{4}$ sec.35, T.5 S., R.6 E., 7.5 miles west of Patterson.

Drainage area. $--0.99 \mathrm{sq} \mathrm{ml}$. $\frac{\text { Gage-height record. }}{\text { graphic map). }}$-Crest stages only. Altitude of gage is $585 \mathrm{ft}$ (from topo-

Discharge record.--Maximum discharge by computation of flow thiough culvert.

Maxima.--January-February 1963: No flow.

1958 to December 1962: Discharge, 8 cfs (estimated) Nov. 13, 1960 (gage height, $3.70 \mathrm{ft}$ ).

11-2746.3. Del Puerto Creek near Patterson, Calif.

(Crest-stage station)

Location.--Lat $37^{\circ} 29^{\prime} 38^{\prime \prime}$, long $121^{\circ} 11^{\prime} 37^{\prime \prime}$, in SW $\frac{1}{4}$ SW $\frac{1}{4}$ sec.15, T.5 S., R.7 E., at Delta-Mendota Canal Crossing, 3.9 miles northwest of Patterson.

Drainage area. $-73.1 \mathrm{sq} \mathrm{mi}$.

Gage-helght record.--Crest stages only. Altitude of gage is $180 \mathrm{ft}$ (from topographic mapl.

D1scharge record.--Stage-discharge record defined by current-meter measurements below $700 \mathrm{cfs}$.

Maxima.--January-February 1963: Discharge, $490 \mathrm{cfs} F e b .1$ (gage height, $12.40 \mathrm{ft}$ ). 1959 to December 1962: Discharge, 1,800 cfs Feb. 16, 1959 (gage height, $14.68 \mathrm{ft})$.

11-2747.3. Budd Creek near Tuolumne Meadows, Callf.

(Crest-stage station)

Location. --Lat $37^{\circ} 52^{\prime} 25^{\prime \prime}$, long $119^{\circ} 22^{\prime} 5^{\prime \prime}$, in NW $\frac{1}{4}$ sec.7, T.1 S., R.24 E., on State Highway $120,3.0$ miles west of Tuolumne Meadows High Slerra Camp.

Drainage area. $--2.94 \mathrm{sq} \mathrm{mi}$.

Gage-helght record.--Crest stages only. Altitude of gage is $8,560 \mathrm{ft}$ (from topographic map).

Discharge record.--Stage-discharge relation defined by current-meter measurements below $19 \mathrm{cfs}$ and by computation of flow through culvert at 91 and $134 \mathrm{cfs}$.

Maxima.--January-February 1963: Discharge, $89 \mathrm{cfs}$ Feb. 1 (gage height, $5.46 \mathrm{ft}$ ). July to December 1962: No significant floodflow.

11-2750. Falls Creek near Hetch Hetchy, Calif.

Location.--Lat $37^{\circ} 58^{\prime} 15^{\prime \prime}$, long $119^{\circ} 45^{\prime 4} 5^{\prime \prime}$, in SE $\frac{1}{4}$ sec.3, T.1 N., R.20 E., on right bank in Yosemite National Park, 0.2 mile upstream from Wampana Falls, 0.6 mile upstream from mouth, and 2 miles northeast of Hetch Hetchy.

Drainage area. $--45.2 \mathrm{sq} \mathrm{mi}$.

Gage-height record.--Water-stage recorder graph. Altitude of gage is $5,350 \mathrm{ft}$ (from topographic map).

Discharge record.--Stage-discharge relation defined by current-meter measurements below $2,500 \mathrm{c}$ 's and extended above on basis of velocity-area studies.

Maxima --January-February 1963: Discharge, 5,560 cfs 0500 hours Feb. 1 (gage helght, $8.68 \mathrm{ft}$ ).

1915 to December 1962: Discharge, 6,660 cfs Nov. 19, 1950, Dec. 23, 1955 (gage height, $9.0 \mathrm{ft}$, from floodmarks). 
Mean discharge, in cublc feet per second, 1963, of Falls Creek near Hetch Hetchy, Calif.

\begin{tabular}{|c|c|c|c|c|c|c|c|c|}
\hline Day & January & February & Day & January & February & Day & January & February \\
\hline $\begin{array}{c}1 \ldots \ldots \\
2 \ldots \ldots \\
3 \ldots \ldots \\
4 \ldots \ldots \\
5 \ldots \ldots \\
6 \ldots \ldots \\
7 \ldots \ldots \\
8 \ldots \ldots \\
9 \ldots \ldots \\
10 \ldots \ldots\end{array}$ & $\begin{array}{l}6.0 \\
5.6 \\
5.2 \\
5.0 \\
4.8 \\
4.6 \\
4.4 \\
4.4 \\
4.2 \\
4.0\end{array}$ & $\begin{array}{r}3,870 \\
1,000 \\
502 \\
328 \\
243 \\
190 \\
159 \\
148 \\
122 \\
112\end{array}$ & $\begin{array}{l}11 \ldots \ldots \\
12 \ldots \ldots \\
13 \ldots \ldots \\
14 \ldots \ldots \\
15 \ldots \ldots \\
16 \ldots \ldots \\
17 \ldots \ldots \\
18 \ldots \ldots \\
19 \ldots \ldots \\
20 \ldots \ldots\end{array}$ & $\begin{array}{l}3.9 \\
3.5 \\
3.2 \\
2.9 \\
2.6 \\
2.5 \\
2.5 \\
2.5 \\
2.4 \\
2.4\end{array}$ & $\begin{array}{r}93 \\
80 \\
139 \\
112 \\
84 \\
75 \\
66 \\
59 \\
59 \\
60\end{array}$ & $\begin{array}{l}21 \ldots \ldots \\
22 \ldots \ldots \\
23 \ldots \ldots \\
24 \ldots \ldots \\
25 \ldots \ldots \\
26 \ldots \ldots \\
27 \ldots \ldots \\
28 \ldots \ldots \\
29 \ldots \ldots \\
30 \ldots \ldots \\
31 \ldots \ldots\end{array}$ & $\begin{array}{r}2.4 \\
2.3 \\
2.2 \\
2.2 \\
2.3 \\
2.3 \\
2.4 \\
2.4 \\
2.6 \\
203 \\
1,740\end{array}$ & $\begin{array}{r}62 \\
59 \\
50 \\
54 \\
56 \\
69 \\
80 \\
75 \\
----- \\
-----\end{array}$ \\
\hline \multicolumn{7}{|l|}{$\begin{array}{l}\text { Monthly } \\
\text { Runoff, } \\
\text { Runoff, }\end{array}$} & $\begin{array}{r}65.8 \\
1.68 \\
4,050 \\
\end{array}$ & $\begin{array}{r}286 \\
6.59 \\
15,880 \\
\end{array}$ \\
\hline
\end{tabular}

Gage height, in feet, and discharge, in cubic feet per second, at indicated time, 1963

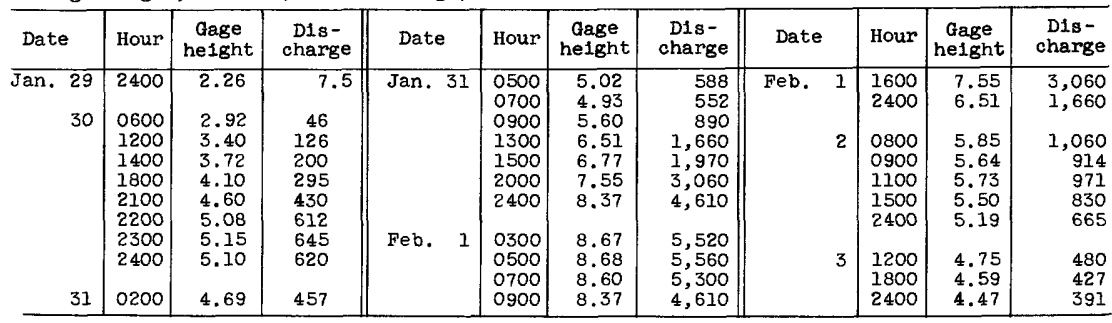

11-2755. Hetch Hetchy Reservoir at Hetch Hetchy, Calif.

Location.--Lat $37^{\circ} 56^{\prime} 55^{\prime \prime}$, long $119^{\circ} 47^{\prime} 10^{\prime \prime}$, in NW $\frac{1}{4}$ sec.16, T.1 N., R.20 E., near center of 0 'Shaughnessy Dam on Tuolumne River at Hetch Hetchy in Yosemite

National Park, 1.5 miles downstream from Falls Creek.

Drainage area. $--460 \mathrm{sq} \mathrm{mi}$.

Gage-height record.--Water-stage recorder graph. Datum of gage is at mean sea level (levels by city and county of San Francisco).

Contents record.--Contents computed from capacity table dated December 1934.

Maxima.--January-February 1963: Content's, 166,000 acre-ft 0730 hours Feb. 8 to 0700 hours Feb. 10 (elevation, 3,693.9 $\mathrm{ft}$ )

1923 to December 1962: Contents, 369,100 acre-ft Dec. 3, 1950 (elevation, $3,810.4 \mathrm{ft})$.

Remarks.--Reservoir is formed by concrete gravity-type dam, completed to crest elevation $3,726.5 \mathrm{ft}$ in 1923 and raised to $3,812.0 \mathrm{ft}$ in 1937; storage began Apr. 6 , 1923. Ten-foot drum gates were installed on spillway in 1949. Usable capacity, 360,400 acre-ft between elevations, 3,512.0 (somewhat above bottom outlet) and $3,806.0$ f't (top of drum-type spillway gates) above mean sea level. Water-stage recorder graph furnished by city and county of San Francisco.

Elevation, in feet, and contents, in acre-feet, at 2400 hours, 1963

\begin{tabular}{|c|c|c|c|c|c|c|c|c|c|}
\hline \multirow{2}{*}{ Day } & \multicolumn{2}{|c|}{ January } & \multicolumn{2}{|c|}{ February } & \multirow{2}{*}{ Day } & \multicolumn{2}{|c|}{ January } & \multicolumn{2}{|c|}{ February } \\
\hline & Elevation & Contents & Elevation & Contents & & Elevation & Contents & Elevation & Contents \\
\hline $\begin{array}{r}1 \\
2 \\
3 \\
4 \\
5 \\
6 \\
7 \\
8 \\
9 \\
10 \\
11 \\
12 \\
13 \\
14 \\
15\end{array}$ & $\begin{array}{l}3,684.6 \\
3,683.7 \\
3,682.7 \\
3,681.7 \\
3,680.8 \\
3,679.7 \\
3,678.7 \\
3,677.7 \\
3,676.7 \\
3,675.6 \\
3,674.4 \\
3,673.4 \\
3,672.4 \\
3,671.3 \\
3,670.3\end{array}$ & $\begin{array}{l}152,600 \\
151,400 \\
150,000 \\
148,600 \\
147,300 \\
145,800 \\
144,400 \\
143,100 \\
141,700 \\
140,300 \\
138,600 \\
137,300 \\
135,900 \\
134,500 \\
133,100\end{array}$ & $\begin{array}{l}3,687.0 \\
3,690.4 \\
3,691.9 \\
3,692.9 \\
3,693.4 \\
3,693.7 \\
3,693.8 \\
3,693.9 \\
3,693.9 \\
3,693.8 \\
3,693.6 \\
3,693.3 \\
3,693.3 \\
3,693.2 \\
3,692.8\end{array}$ & $\begin{array}{l}156,000 \\
160,800 \\
163,000 \\
164,500 \\
165,200 \\
165,700 \\
165,800 \\
166,000 \\
166,000 \\
165,800 \\
165,500 \\
165,100 \\
165,100 \\
164,900 \\
164,300\end{array}$ & $\begin{array}{l}16 \\
17 \\
18 \\
19 \\
20 \\
21 \\
22 \\
23 \\
24 \\
25 \\
26 \\
27 \\
28 \\
29 \\
30 \\
31\end{array}$ & $\begin{array}{l}3,669.3 \\
3,668.3 \\
3,667.2 \\
3,665.9 \\
3,665.0 \\
3,663.9 \\
3,663.0 \\
3,661.8 \\
3,660.8 \\
3,659.6 \\
3,658.6 \\
3,657.4 \\
3,656.5 \\
3,655.2 \\
3,655.7 \\
3,666.9\end{array}$ & $\begin{array}{l}131,800 \\
130,500 \\
129,100 \\
127,500 \\
126,300 \\
124,900 \\
123,700 \\
122,900 \\
120,900 \\
119,400 \\
118,300 \\
116,900 \\
115,800 \\
114,300 \\
114,900 \\
128,700\end{array}$ & $\begin{array}{c}3,692.5 \\
3,692.1 \\
3,691.7 \\
3,691.2 \\
3,690.8 \\
3,690.4 \\
3,689.9 \\
3,689.5 \\
3,689.0 \\
3,688.6 \\
3,688.3 \\
3,688.2 \\
3,687.7 \\
- \\
- \\
-\end{array}$ & $\begin{array}{c}163,900 \\
163,300 \\
164,200 \\
162,700 \\
161,400 \\
160,800 \\
160,100 \\
159,500 \\
158,800 \\
158,200 \\
157,800 \\
157,700 \\
157,000 \\
- \\
- \\
-\end{array}$ \\
\hline & 11 & & & & & - & $-25,500$ & $=$ & $+28,300$ \\
\hline
\end{tabular}


11-2765. Tuolumne River near Hetch Hetchy, Calif.

Location.--Lat $37^{\circ} 56^{\prime} 15^{\prime \prime}$, long $119^{\circ} 47^{\prime} 50^{\prime \prime}$, in SW $\frac{1}{4} \mathrm{SE} \frac{1}{4}$ sec.17, T.1 N., R.20 E., in Yosemite National Park, on left bank 1 mile downstream from O'Shaughnessy Dam at Hetch Hetchy and 2.5 miles downstream from Falls Creek.

Drainage area. $--462 \mathrm{sq} \mathrm{mi}$.

Gage-height record:- Water-stage recorder graph. Altitude of gage is $3,430 \mathrm{ft}$ (from topographic map).

Discharge record.--Stage-discharge relation defined by current-meter measurements.

Maxima.--January-February 1963: Discharge, 926 cfs 0830 hours Feb. 1 (gage height, $6.59 \mathrm{ft})$.

1910 to December 1962: Discharge, 12,900 cfs June 1, 1943 (gage height, $13.90 \mathrm{ft}$ ).

Remarks.--Flow regulated by Hetch Hetchy Reservoir since 1923 (see station 11-2755). Water-stage recorder graph and discharge measurements furntshed by city and county of San Francisco.

Mean discharge, in cublc feet per second, 1963

\begin{tabular}{|c|c|c|c|c|c|c|c|c|}
\hline Day & January & February & Day & January & February & Day & January & February \\
\hline $\begin{array}{r}1 \ldots \ldots \\
2 \ldots \ldots \\
3 \ldots \ldots \\
4 \ldots \ldots \\
5 \ldots \ldots \\
6 \ldots \ldots \\
7 \ldots \ldots \\
8 \ldots \ldots \\
9 \ldots \ldots \\
10 \ldots \ldots\end{array}$ & $\begin{array}{l}745 \\
739 \\
739 \\
739 \\
733 \\
739 \\
736 \\
736 \\
745 \\
748\end{array}$ & $\begin{array}{l}860 \\
825 \\
784 \\
748 \\
742 \\
742 \\
742 \\
745 \\
745 \\
745\end{array}$ & $\begin{array}{l}11 \ldots \ldots \\
12 \ldots \ldots \\
13 \ldots \ldots \\
14 \ldots \ldots \\
15 \ldots \ldots \\
16 \ldots \ldots \\
17 \ldots \ldots \\
18 \ldots \ldots \\
19 \ldots \ldots \\
20 \ldots \ldots\end{array}$ & $\begin{array}{l}745 \\
742 \\
739 \\
739 \\
736 \\
733 \\
730 \\
730 \\
742 \\
745\end{array}$ & $\begin{array}{l}745 \\
742 \\
745 \\
745 \\
742 \\
724 \\
718 \\
715 \\
712 \\
709\end{array}$ & $\begin{array}{l}21 \ldots \ldots \\
22 \ldots \ldots \\
23 \ldots \ldots \\
24 \ldots \ldots \\
25 \ldots \ldots \\
26 \ldots \ldots \\
27 \ldots \ldots \\
28 \ldots \ldots \\
29 \ldots \ldots \\
30 \ldots \ldots \\
31 \ldots \ldots\end{array}$ & $\begin{array}{l}742 \\
739 \\
736 \\
733 \\
730 \\
727 \\
724 \\
739 \\
742 \\
754 \\
814\end{array}$ & $\begin{array}{r}709 \\
706 \\
703 \\
715 \\
721 \\
718 \\
615 \\
739 \\
-.-2 \\
---.-1\end{array}$ \\
\hline \multicolumn{7}{|c|}{ Monthly mean discharge, in cubic feet per second................ } & $\begin{array}{r}741 \\
45,540\end{array}$ & $\begin{array}{r}736 \\
40,860\end{array}$ \\
\hline
\end{tabular}

11-2772. Cherry Lake near Hetch Hetchy, Calif.

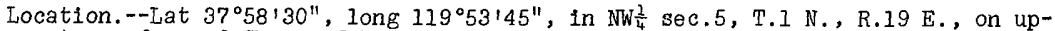
stream face of Cherry Valley Dam on Cherry Creek, 4.2 miles upstream from Eleanor Creek, 7 miles north of Early Intake, and 7.3 miles northwest of Hetch Hetchy.

Drainage area. $--117 \mathrm{sq} \mathrm{ml}$.

Gage-height record.--Staff gage read once daily. Datum of gage is at mean sea level (levels by city and county of San Francisco).

Contents record.--Contents computed from capacity table dated March 1956.

Maxima --January-February 1963: Contents, 151,700 acre-ft Feb. 27, 28 (elevation, $4,627.8 \mathrm{ft}$ ).

1956 to December 1962: Contents, 269,300 acre-ft July 1-3, 1957 (elevation, $4,700.6 \mathrm{ft})$.

Remarks.--Reservoir is formed by a rockfill dam completed in 1956; storage began in December 1955. Usable capacity, $268,180 \mathrm{acre}-\mathrm{ft}$ between elevations $4,430 \mathrm{ft}$ (bottom of sluice gates) and 4,700 ft (top of spillway gates) above mean sea level. Record of gage heights furnished by city and county of San Francisco. 
Elevation, in feet, and contents, in acre-feet, at 0800 hours, 1963, of Cherry Lake

\begin{tabular}{|c|c|c|c|c|c|c|c|c|c|}
\hline \multirow{2}{*}{ Day } & \multicolumn{2}{|c|}{ January } & \multicolumn{2}{|c|}{ February } & \multirow{2}{*}{ Day } & \multicolumn{2}{|c|}{ January } & \multicolumn{2}{|c|}{ February } \\
\hline & Elevation & Contents & Elevation & Contents & & Elevation & Contents & Elevation & Contents \\
\hline $\begin{array}{r}1 \\
2 \\
3 \\
4 \\
5 \\
6 \\
7 \\
8 \\
9 \\
10 \\
11 \\
12 \\
13 \\
14 \\
15\end{array}$ & $\begin{array}{c}- \\
4,595.7 \\
4,594.8 \\
4,594.0 \\
4,593.1 \\
4,592.5 \\
4,592.0 \\
4,591.2 \\
4,590.3 \\
4,589.4 \\
4,588.5 \\
4,587.6 \\
4,586.9 \\
4,586.5 \\
4,585.6\end{array}$ & $\begin{array}{c}- \\
106,500 \\
105,300 \\
104,300 \\
103,100 \\
102,200 \\
101,600 \\
100,500 \\
99,300 \\
98,100 \\
97,000 \\
95,800 \\
94,900 \\
94,400 \\
93,200\end{array}$ & $\begin{array}{l}4,597.7 \\
4,606.8 \\
4,609.4 \\
4,611.7 \\
4,613.2 \\
4,614.4 \\
4,615.5 \\
4,616.4 \\
4,617.3 \\
4,618.3 \\
4,619.4 \\
4,621.0 \\
4,622.1 \\
4,622.8\end{array}$ & $\begin{array}{c}109,200 \\
121,700 \\
125,300 \\
128,500 \\
130,600 \\
132,300 \\
133,900 \\
135,200 \\
136,500 \\
137,900 \\
139,400 \\
141,800 \\
143,400 \\
144,400\end{array}$ & $\begin{array}{l}16 \\
17 \\
18 \\
19 \\
20 \\
21 \\
22 \\
23 \\
24 \\
25 \\
26 \\
27 \\
28 \\
29 \\
30 \\
31 \\
\end{array}$ & $\begin{array}{l}4,584.6 \\
4,583.7 \\
4,582.8 \\
4,581.8 \\
4,581.1 \\
4,580.7 \\
4,579.7 \\
4,578.8 \\
4,577.7 \\
4,576.6 \\
4,575.4 \\
4,574.6 \\
4,573.7 \\
4,572.6 \\
4,571 \cdot 7 \\
4,575.3\end{array}$ & $\begin{array}{l}91,900 \\
90,800 \\
89,600 \\
88,300 \\
87,400 \\
86,900 \\
85,600 \\
84,500 \\
83,100 \\
81,800 \\
80,300 \\
79,300 \\
78,200 \\
76,800 \\
75,700 \\
80,200\end{array}$ & $\begin{array}{c}- \\
4,624.2 \\
4,625.1 \\
4,625.5 \\
4,625.9 \\
4,626.3 \\
4,626.5 \\
4,627.0 \\
4,627.1 \\
4,627.4 \\
4,627.5 \\
4,627.8 \\
4,627.8 \\
- \\
- \\
-\end{array}$ & $\begin{array}{c}- \\
146,400 \\
147,700 \\
148,300 \\
148,900 \\
149,500 \\
149,800 \\
150,500 \\
150,700 \\
151,100 \\
151,200 \\
151,700 \\
151,700 \\
- \\
- \\
-\end{array}$ \\
\hline & in conte & $s$, in a & & & & - & $-28,200$ & - & $+71,500$ \\
\hline
\end{tabular}

11-2773. Cherry Creek below Cherry Valley Dam, near Hetch Hetchy, Calif.

Location.--Lat $37^{\circ} 58^{\prime} 04^{\prime \prime}$, long 119 $54^{\prime} 59^{\prime \prime}$, in SW $\frac{1}{4}$ sec.5, T.1 N., R.19 E., on right bank 0.7 mile downstream from Cherry Valley Dam, 3.5 miles upstream from

Eleanor Creek, 6.7 miles north of Early Intake, and 7.2 miles west of Hetch Hetchy.

Drainage area. $--118 \mathrm{sq} \mathrm{mi}$.

Gage-height record.--Water-stage-recorder graph. Datum of gage is $4,337.08 \mathrm{ft}$ above mean sea level (levels by city and county of San Francisco).

Discharge record.--Stage-discharge relation defined by current-meter measurements.

Maxima.--January-February 1963: Discharge, 109 cfs 2300 hours Jan. 31 (gage height, $4.09 \mathrm{ft})$.

1956 to December 1962: Discharge, 3,830 cfs Apr. 25, 1958 (gage height, $9.95 \mathrm{ft}$ ).

Remarks. --Flow regulated by Cherry Lake (see station 11-2772). Water-stage recorder

graph and discharge measurements furnished by city and county of San Francisco.

Mean discharge, in cubic feet per second, 1963

\begin{tabular}{|c|c|c|c|c|c|c|c|c|}
\hline Day & January & February & Day & January & February & Day & January & February \\
\hline $\begin{array}{r}1 \ldots \ldots \\
2 \ldots \ldots \\
3 \ldots \ldots \\
4 \ldots \ldots \\
5 \ldots \ldots \\
7 \ldots \ldots \\
8 \ldots \ldots \\
9 \ldots \ldots \\
10 \ldots \ldots\end{array}$ & $\begin{array}{l}6.2 \\
6.2 \\
6.0 \\
6.0 \\
6.0 \\
6.0 \\
6.0 \\
6.0 \\
6.0 \\
6.0\end{array}$ & $\begin{array}{l}40 \\
13 \\
11 \\
10 \\
9.5 \\
9.2 \\
9.2 \\
8.9 \\
8.9 \\
8.9\end{array}$ & $\begin{array}{l}11 \ldots \ldots \\
12 \ldots \ldots \\
13 \ldots \ldots \\
14 \ldots \ldots \\
15 \ldots \ldots \\
16 \ldots \ldots \\
17 \ldots \ldots \\
18 \ldots \ldots \\
19 \ldots \ldots \\
20 \ldots \ldots\end{array}$ & $\begin{array}{l}6.0 \\
6.0 \\
6.2 \\
6.2 \\
6.2 \\
6.2 \\
6.0 \\
6.0 \\
6.0 \\
6.0\end{array}$ & $\begin{array}{r}8.6 \\
8.9 \\
10 \\
9.5 \\
9.2 \\
8.9 \\
8.9 \\
8.6 \\
8.3 \\
8.3\end{array}$ & $\begin{array}{l}21 \ldots \ldots \\
22 \ldots \ldots \\
23 \ldots \ldots \\
24 \ldots \ldots \\
25 \ldots \ldots \\
26 \ldots \ldots \\
27 \ldots \ldots \\
28 \ldots \ldots \\
29 \ldots \ldots \\
30 \ldots \ldots \\
31 \ldots \ldots\end{array}$ & $\begin{array}{l}6.0 \\
6.0 \\
6.0 \\
6.0 \\
6.0 \\
6.0 \\
6.0 \\
6.0 \\
6.2 \\
18 \\
49\end{array}$ & $\begin{array}{r}8.3 \\
8.3 \\
8.0 \\
8.0 \\
8.0 \\
8.0 \\
8.0 \\
8.0 \\
----- \\
-.-1- \\
-.-1\end{array}$ \\
\hline $\begin{array}{l}\text { onthly } \\
\text { unoff, }\end{array}$ & $\begin{array}{l}\text { an dis } \\
\text { acre- }\end{array}$ & e, & feet & & & & $\begin{array}{r}7.82 \\
481\end{array}$ & $\begin{array}{r}10.1 \\
560\end{array}$ \\
\hline
\end{tabular}

Gage height, in feet, and discharge, in cublc feet per second, at indicated time, 1963

\begin{tabular}{|c|c|c|c|c|c|c|c|c|c|c|c|}
\hline Date & Hour & $\begin{array}{c}\text { Gage } \\
\text { helght }\end{array}$ & $\begin{array}{c}\text { Dis- } \\
\text { charge }\end{array}$ & Date & Hour & $\begin{array}{c}\text { Gage } \\
\text { height }\end{array}$ & $\begin{array}{l}\text { Dis - } \\
\text { charge }\end{array}$ & Date & Hour & $\begin{array}{c}\text { Gage } \\
\text { helght }\end{array}$ & $\begin{array}{c}\text { Dis- } \\
\text { charge }\end{array}$ \\
\hline $\begin{array}{r}\text { Jan. } 29 \\
30\end{array}$ & $\begin{array}{l}2400 \\
0200 \\
0500 \\
0600 \\
0800 \\
1000 \\
1200 \\
1400 \\
1700 \\
1800 \\
2100\end{array}$ & $\begin{array}{l}2.88 \\
2.91 \\
3.06 \\
3.08 \\
3.07 \\
3.07 \\
3.22 \\
3.14 \\
3.22 \\
3.19 \\
3.38\end{array}$ & $\begin{array}{l}7.5 \\
8.3 \\
13 \\
14 \\
14 \\
14 \\
21 \\
17 \\
21 \\
20 \\
32\end{array}$ & $\begin{array}{r}\operatorname{Jan} .30 \\
31\end{array}$ & $\begin{array}{l}2400 \\
0200 \\
0300 \\
0500 \\
1000 \\
1100 \\
1200 \\
1400 \\
1500 \\
1600 \\
1700\end{array}$ & $\begin{array}{l}3.22 \\
3.17 \\
3.23 \\
3.17 \\
3.46 \\
3.52 \\
3.76 \\
3.71 \\
3.53 \\
3.64 \\
3.55\end{array}$ & $\begin{array}{l}21 \\
18 \\
22 \\
18 \\
38 \\
43 \\
67 \\
61 \\
44 \\
54 \\
40\end{array}$ & $\begin{array}{l}\text { Jan. } 31 \\
\text { Feb. } 1\end{array}$ & $\begin{array}{l}1900 \\
2300 \\
2400 \\
\\
0200 \\
0400 \\
0500 \\
1200 \\
1600 \\
2400\end{array}$ & $\begin{array}{l}3.80 \\
4.09 \\
4.01 \\
3.96 \\
3.73 \\
3.75 \\
3.34 \\
3.22 \\
3.10\end{array}$ & $\begin{array}{r}71 \\
109 \\
97 \\
91 \\
63 \\
66 \\
29 \\
21 \\
15\end{array}$ \\
\hline
\end{tabular}

$793-2850-66-17$ 
11-2775. Lake Eleanor near Hetch Hetchy, Calif.

Location. --Lat $37^{\circ} 58^{1} 30^{\prime \prime}$, long $119^{\circ} 52^{\prime} 45^{\prime \prime}$, in NW $\frac{1}{4}$ sec.3, T.I N., R.19 E., on downstream side of dam on Eleanor Creek, $720 \mathrm{ft}$ from left bank, 1.7 miles upstream from Miguel Creek, and 5.5 miles northwest of Hetch Hetchy.

Drainage area. $--78.1 \mathrm{sq} \mathrm{mi}$.

Gage-height record.--Water-stage recorder graph. Datum of gage is at mean sea level (levels by city and county of San Francisco).

Contents record.--Contents computed from capacity table dated May 1941.

Maxima.--January-February 1963: Contents, 29,400 acre-ft 0800 hours Feb. 1 (gage height, 4,663.3 ft).

1918 to December 1962: Contents, 31,000 acre-ft Dec. 11, 1937, from capacity table then in use (elevation, 4,663.4 ft).

Remarks.--Reservoir is formed by multiple-arch dam completed in 1918; storage began June 23, 1918. Usable capacity, 26,100 acre-ft between elevation $4,620.9$ $f t$ (natural outlet of old lake) and 4,660.0 ft (top of 5-foot flashboards) above mean sea level. Figures given herein represent usable contents. Waterstage recorder graph furnished by city and county of San Francisco.

Elevation, in feet, and contents, in acre-feet, at 2400 hours, 1963

\begin{tabular}{|c|c|c|c|c|c|c|c|c|c|}
\hline \multirow{2}{*}{ Day } & \multicolumn{2}{|c|}{ January } & \multicolumn{2}{|c|}{ February } & \multirow{2}{*}{ Day } & \multicolumn{2}{|c|}{ January } & \multicolumn{2}{|c|}{ February } \\
\hline & Elevation & Contents & Elevation & Contents & & Elevation & Contents & Elevation & Contents \\
\hline $\begin{array}{r}1 \\
2 \\
3 \\
4 \\
5 \\
6 \\
7 \\
8 \\
9 \\
10 \\
11 \\
12 \\
13 \\
14 \\
15\end{array}$ & $\begin{array}{l}4,638.7 \\
4,638.6 \\
4,638.5 \\
4,638 \cdot 5 \\
4,635 \cdot 4 \\
4,638.4 \\
4,635.3 \\
4,638.3 \\
4,638.2 \\
4,638.2 \\
4,638.2 \\
4,638.1 \\
4,638.1 \\
4,638.1 \\
4,638.0\end{array}$ & $\begin{array}{l}7,810 \\
7,740 \\
7,680 \\
7,680 \\
7,610 \\
7,610 \\
7,540 \\
7,540 \\
7,470 \\
7,470 \\
7,470 \\
7,400 \\
7,400 \\
7,400 \\
7,330\end{array}$ & $\begin{array}{l}4,661 \cdot 9 \\
4,661.0 \\
4,660.3 \\
4,659.1 \\
4,658.0 \\
4,656.7 \\
4,655.6 \\
4,654.3 \\
4,653.1 \\
4,651.9 \\
4,650.7 \\
4,649.5 \\
4,648.8 \\
4,647.9 \\
4,646.9\end{array}$ & $\begin{array}{l}28,000 \\
27,100 \\
26,400 \\
25,300 \\
24,300 \\
23,100 \\
22,100 \\
20,900 \\
19,800 \\
18,700 \\
17,600 \\
16,600 \\
16,000 \\
15,200 \\
14,300\end{array}$ & $\begin{array}{l}16 \\
17 \\
18 \\
19 \\
20 \\
21 \\
22 \\
23 \\
24 \\
25 \\
26 \\
27 \\
28 \\
29 \\
30 \\
31\end{array}$ & $\begin{array}{l}4,638.0 \\
4,638.0 \\
4,638.0 \\
4,637.9 \\
4,637.9 \\
4,637.9 \\
4,637.9 \\
4,637.9 \\
4,637.8 \\
4,637.8 \\
4,637.8 \\
4,637.8 \\
4,637.8 \\
4,637.9 \\
4,640.7 \\
4,656.7\end{array}$ & $\begin{array}{r}7,330 \\
7,330 \\
7,330 \\
7,260 \\
7,260 \\
7,260 \\
7,260 \\
7,260 \\
7,190 \\
7,190 \\
7,190 \\
7,190 \\
7,190 \\
7,260 \\
9,260 \\
23,100\end{array}$ & $\begin{array}{c}4,645.9 \\
4,644.9 \\
4,643.9 \\
4,642.9 \\
4,642.2 \\
4,641.7 \\
4,641.3 \\
4,641.0 \\
3,640.8 \\
3,640.6 \\
3,640.5 \\
3,640.5 \\
3,640.4 \\
- \\
- \\
-\end{array}$ & $\begin{array}{r}13,500 \\
12,600 \\
11,800 \\
11,000 \\
10,500 \\
10,100 \\
9,740 \\
9,500 \\
9,340 \\
9,100 \\
9,100 \\
9,100 \\
9,020 \\
- \\
- \\
-\end{array}$ \\
\hline W & in $c$ & $t s$, in $a$ & & & & $\overline{-}$ & $+15,290$ & - & $-14,080$ \\
\hline
\end{tabular}

11-2780. Eleanor Creek near Hetch Hetchy, Calif.

Location.--Lat $37^{\circ} 58^{\prime} 10^{\prime \prime}$, long $119^{\circ} 52^{1} 50^{\prime \prime}$, in SW $\frac{1}{4}$ sec.3, T.1 N., R.19 E., In Yosemite National Park, on right bank 0.5 mile downstream from Lake Eleanor Dam, 1.1 miles upstream from Miguel Creek, and 5.5 miles northwest of Hetch Hetchy.

Drainage area. $--80 \mathrm{sq} \mathrm{mi}$, approximately.

Gage-height record. - Water-stage recorder graph. Altitude of gage is 4,500 ft (from topographic map).

Discharge record.--Stage-discharge relation defined by current-meter measurements below 1,600 cf's and by slope-area measurement at 10,400 cfs.

Maxima.--January-February 1963: Discharge, 10,400 efs 0900 hours Feb. 1 (gage height, $12.24 \mathrm{ft}$ ).

1909 to December 1962: Discharge, 11,700 cfs Nov. 19, 1950 (gage height, $14.95 \mathrm{ft}$ ), from rating curve extended above 2,000 $\mathrm{cfs}$ on basis of velocity-area studies.

Remarks.--Flow regulated by Lake Eleanor since 1918 (see station 11-2775). 
Mean discharge, in cubic feet per second, 1963, of Eleanor Creek near Hetch Hetchy, Calif.

\begin{tabular}{|c|c|c|c|c|c|c|c|c|}
\hline Day & January & Febmuary & Day & January & February & Day & January & February \\
\hline $\begin{array}{c}1 \ldots \ldots \\
2 \ldots \ldots \\
3 \ldots \ldots \\
5 \ldots \ldots \\
6 \ldots \ldots \\
7 \ldots \ldots \\
8 \ldots \ldots \\
9 \ldots \ldots \\
10 \ldots \ldots\end{array}$ & $\begin{array}{l}5.1 \\
5.1 \\
5.1 \\
5.1 \\
5.1 \\
5.1 \\
4.8 \\
4.8 \\
4.8 \\
4.8\end{array}$ & $\begin{array}{r}5,310 \\
1,070 \\
220 \\
162 \\
106 \\
56 \\
21 \\
7.1 \\
7.1 \\
8.3\end{array}$ & $\begin{array}{l}11 \ldots \ldots \\
12 \ldots \ldots \\
13 \ldots \ldots \\
14 \ldots \ldots \\
15 \ldots \ldots \\
16 \ldots \ldots \\
17 \ldots \ldots \\
18 \ldots \ldots \\
19 \ldots \ldots \\
20 \ldots \ldots\end{array}$ & $\begin{array}{l}4.8 \\
4.8 \\
4.8 \\
4.8 \\
4.8 \\
4.8 \\
4.6 \\
4.6 \\
4.3 \\
4.3\end{array}$ & $\begin{array}{r}7.9 \\
8.3 \\
10 \\
7.5 \\
7.1 \\
7.1 \\
7.1 \\
7.5 \\
7.5 \\
7.5\end{array}$ & $\begin{array}{l}21 \ldots \ldots \\
22 \ldots \ldots \\
23 \ldots \ldots \\
24 \ldots \ldots \\
25 \ldots \ldots \\
26 \ldots \ldots \\
27 \ldots \ldots \\
28 \ldots \ldots \\
29 \ldots \ldots \\
30 \ldots \ldots \\
31 \ldots \ldots\end{array}$ & $\begin{array}{l}4.3 \\
4.3 \\
4.3 \\
4.3 \\
4.3 \\
4.3 \\
4.3 \\
4.3 \\
4.6 \\
17 \\
41\end{array}$ & $\begin{array}{r}7.5 \\
7.5 \\
7.1 \\
6.7 \\
6.7 \\
6.7 \\
6.3 \\
5.9 \\
-.--0 \\
-1-.-1\end{array}$ \\
\hline $\begin{array}{l}\text { onthly } \\
\text { anoff, }\end{array}$ & & & & & & & $\begin{array}{r}6.24 \\
384 \\
\end{array}$ & $\begin{array}{r}254 \\
14,080 \\
\end{array}$ \\
\hline
\end{tabular}

Gage height, in feet, and discharge, in cubic feet per second, at indicated time, 1963

\begin{tabular}{|c|c|c|c|c|c|c|c|c|c|c|c|}
\hline Date & Hour & $\begin{array}{c}\text { Gage } \\
\text { helght }\end{array}$ & $\begin{array}{c}\text { Dis- } \\
\text { charge }\end{array}$ & Date & Hour & $\begin{array}{c}\text { Gage } \\
\text { height }\end{array}$ & $\begin{array}{l}\text { Dis- } \\
\text { charge }\end{array}$ & Date & Hour & $\begin{array}{c}\text { Gage } \\
\text { height }\end{array}$ & $\begin{array}{l}\text { Dis - } \\
\text { charge }\end{array}$ \\
\hline Jan. 31 & 2400 & & 50 & Feb. 1 & $\begin{array}{l}0800 \\
0900\end{array}$ & $\begin{array}{l}12.16 \\
12.24\end{array}$ & $\begin{array}{l}10,300 \\
10,400\end{array}$ & Feb. I & 2400 & 6.70 & 2,700 \\
\hline Feb. 1 & $\begin{array}{l}0100 \\
0200 \\
0400 \\
0500 \\
0600 \\
0700\end{array}$ & $\begin{array}{r}2.47 \\
2.94 \\
3.43 \\
7.84 \\
10.50 \\
11.77\end{array}$ & $\begin{array}{r}81 \\
168 \\
289 \\
4,010 \\
7,700 \\
9,630\end{array}$ & & $\begin{array}{l}1200 \\
1300 \\
1400 \\
1500 \\
1700 \\
2000\end{array}$ & $\begin{array}{r}11.04 \\
10.50 \\
10.30 \\
9.65 \\
8.72 \\
7.80\end{array}$ & $\begin{array}{l}8,460 \\
7,700 \\
7,420 \\
6,510 \\
5,210 \\
3,960\end{array}$ & 2 & $\begin{array}{l}0400 \\
0600 \\
0900 \\
1500 \\
2000 \\
2400\end{array}$ & $\begin{array}{l}5.84 \\
5.50 \\
4.95 \\
4.24 \\
3.72 \\
3.41\end{array}$ & $\begin{array}{r}1,860 \\
1,550 \\
1,100 \\
624 \\
392 \\
288\end{array}$ \\
\hline
\end{tabular}

11-2783. Cherry Creek near Early Intake, Cal1f.

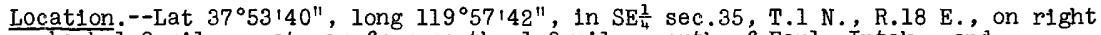
bank 1.2 miles upstream from mouth, 1.3 miles north of Early Intake, and

10.3 miles southwest of Hetch Hetchy.

Drainage area.--226 sq $\mathrm{ml}$.

Gage-helght record.--Water-stage recorder graph. Datum of gage is $2,272.00 \mathrm{ft}$ above mean sea level (levels by city and county of San Francisco). .

Discharge record.--Stage-discharge relation defined by current-meter measurements below 4,600 cfs.

Maxima.--January-February 1963: Discharge, 16,500 cfs 0900 hours Feb. 1 (gage helght, $14.50 \mathrm{ft})$.

1956 to December 1962: Discharge, 4,940 cfs May 6, 1958 (gage helght, $10.46 \mathrm{ft})$.

Remarks.--Flow regulated by Cherry Lake (see station 11-2772) and Lake Eleanor (see station 11-2775). Cherry Creek Canal diverts about 1.0 mile upstream from station. Diversion from Cherry Lake to Cherry powerhouse bypasses station since August 1960 .

Mean d1scharge, in cubic feet per second, 1963

\begin{tabular}{|c|c|c|c|c|c|c|c|c|}
\hline Day & January & February & Day & January & February & Day & January & February \\
\hline $\begin{array}{c}1 \ldots \ldots \\
2 \ldots \ldots \\
3 \ldots \ldots \\
4 \ldots \ldots \\
5 \ldots \ldots \\
7 \ldots \ldots \\
8 \ldots \ldots \\
9 \ldots \ldots \\
10 \ldots \ldots\end{array}$ & $\begin{array}{l}5.8 \\
5.8 \\
5.8 \\
5.8 \\
5.7 \\
5.7 \\
5.8 \\
5.7 \\
5.7 \\
5.7\end{array}$ & $\begin{array}{r}7,700 \\
1,400 \\
341 \\
248 \\
168 \\
112 \\
66 \\
42 \\
34 \\
34\end{array}$ & $\begin{array}{l}11 \ldots \ldots \\
12 \ldots \ldots \\
13 \ldots \ldots \\
14 \ldots \ldots \\
15 \ldots \ldots \\
16 \ldots \ldots \\
17 \ldots \ldots \\
18 \ldots \ldots \\
19 \ldots \ldots \\
20 \ldots \ldots\end{array}$ & $\begin{array}{l}5.7 \\
5.6 \\
4.4 \\
5.1 \\
5.7 \\
5.6 \\
5.6 \\
5.1 \\
4.6 \\
5.0\end{array}$ & $\begin{array}{l}29 \\
25 \\
60 \\
65 \\
43 \\
21 \\
1.5 \\
1.2 \\
5.1 \\
9.9\end{array}$ & $\begin{array}{l}21 \ldots \ldots \\
22 \ldots \ldots \\
23 \ldots \ldots \\
24 \ldots \ldots \\
25 \ldots \ldots \\
26 \ldots \ldots \\
27 \ldots \ldots \\
28 \ldots \ldots \\
29 \ldots \ldots \\
30 \ldots \ldots \\
31 \ldots \ldots\end{array}$ & $\begin{array}{r}5.0 \\
4.8 \\
4.7 \\
4.7 \\
4.7 \\
4.7 \\
4.7 \\
4.7 \cdot \\
5.0 \\
77 \\
478\end{array}$ & $\begin{array}{r}8.0 \\
1.8 \\
8.3 \\
22 \\
21 \\
20 \\
20 \\
19 \\
---.- \\
--.-- \\
--.--\end{array}$ \\
\hline $\begin{array}{l}\text { onthly } \\
\text { unoff, }\end{array}$ & $\begin{array}{l}\text { n disc } \\
\text { acre- }\end{array}$ &, 1 & fout & & & & $\begin{array}{r}22.8 \\
1,400 \\
\end{array}$ & $\begin{array}{r}376 \\
20,880 \\
\end{array}$ \\
\hline
\end{tabular}


Gage helght, In feet, and discharge, in cubic feet per second, at indicated time, 1963, of Cherry Creek near Early Intake, Calif.

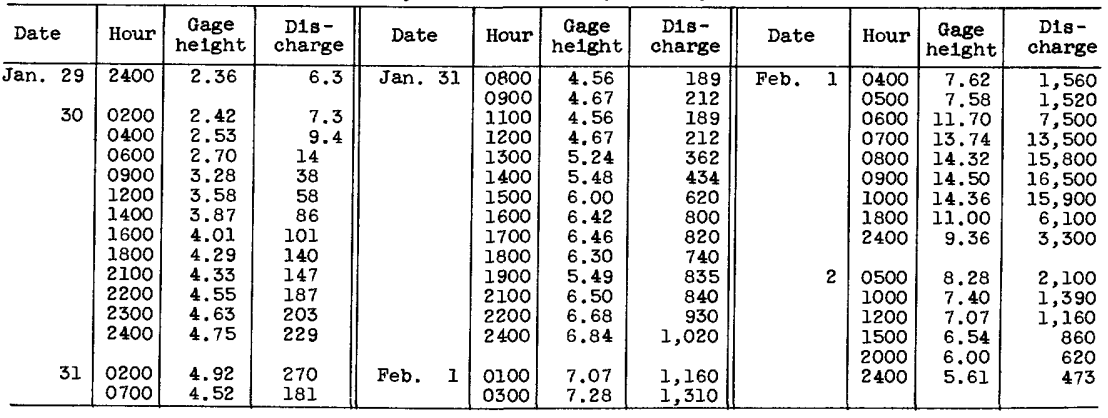

11-2793. Smoky Jack Creek near Yosemite Village, Calif.

(Crest-stage station)

Location.--Lat $37^{\circ} 49^{1} 10^{\prime \prime}$, long $119^{\circ} 42^{\prime} 45^{\prime \prime}$, in NW $\frac{1}{4} \mathrm{NW} \frac{1}{4}$ sec. 31 , T.1 S., R.21 E., on State Highway $120,8.5$ miles northwest of Yosemite Village.

Drainage area. $--0.70 \mathrm{sq} \mathrm{mi}$.

Gage-height record.--Crest stages only. Altitude of gage is 7,160 ft (from topographic map).

Discharge record.--Stage-discharge relation defined by current-meter measurements below $2.7 \mathrm{cfs}$ and by computation of flow through culvert at 97 and $118 \mathrm{cfs}$.

Maxima.--January-February 1963: Discharge, $101 \mathrm{cfs}$ Feb. 1 (gage height, 9.03 ft). July to December 1962: Discharge, 2.2 cfs Oct. 13, 1962 gage height, $4.69 \mathrm{ft}$ ).

11-2810. South Fork Tuolumne River near Oakland Recreation Camp, Calif.

Location.--Lat $37^{\circ} 49^{\prime} 16^{\prime \prime}$, long $120^{\circ} 00^{\prime} 48^{\prime \prime}$, in SE $\frac{1}{4}$ sec.29, T.1 S., R.18 E., on right bank $75 \mathrm{ft}$ downstream from highway bridge on Big Oak Flat Road, 0.5 mile southwest of Oakland Recreation Camp, and 0.6 mile upstream from Middle Tuolumne River.

Drainage area. $--87.6 \mathrm{sq} \mathrm{mi}$.

Gage-helght record.--Water-stage recorder graph. Altitude of gage is $2,800 \mathrm{ft}^{\mathrm{t}}$ (from topographic map).

Discharge record.--Stage-discharge relation defined by current-meter measurements below $1,300 \mathrm{cfs}$ and by slope-area measurements at 3,560 and $11,900 \mathrm{cfs}$; affected by 1ce Jan. 11-26.

Maxima.--January-February 1963: Discharge, 8,000 cfs 0300 hours Feb. 1 (gage helght, $9.60 \mathrm{ft}$ ).

1923 to December 1962: Discharge, 11,900 cfs Dec. 23, 1955 (gage height, $10.9 \mathrm{f} t$, from floodmarks).

Mean discharge, in cub1c feet per second, 1963

\begin{tabular}{|c|c|c|c|c|c|c|c|c|}
\hline Day & Janụary & February & Day & January & February & Day & January & February \\
\hline $\begin{array}{c}1 \ldots \ldots \\
2 \ldots \ldots \\
3 \ldots \ldots \\
5 \ldots \ldots \\
6 \ldots \ldots \\
7 \ldots \ldots \\
8 \ldots \ldots \\
9 \ldots \ldots \\
10 \ldots \ldots\end{array}$ & $\begin{array}{l}10 \\
9.6 \\
10 \\
10 \\
9.3 \\
9.1 \\
9.1 \\
9.0 \\
9.1 \\
9.0\end{array}$ & $\begin{array}{r}4,060 \\
655 \\
308 \\
205 \\
166 \\
137 \\
120 \\
111 \\
107 \\
162\end{array}$ & $\begin{array}{l}11 \ldots \ldots \\
12 \ldots \ldots \\
13 \ldots \ldots \\
14 \ldots \ldots \\
15 \ldots \ldots \\
16 \ldots \ldots \\
17 \ldots \ldots \\
18 \ldots \ldots \\
19 \ldots \ldots \\
20 \ldots \ldots\end{array}$ & $\begin{array}{l}8.0 \\
7.0 \\
6.0 \\
7.0 \\
7.0 \\
7.0 \\
7.0 \\
7.0 \\
7.0 \\
7.0\end{array}$ & $\begin{array}{r}119 \\
103 \\
172 \\
182 \\
129 \\
112 \\
99 \\
92 \\
86 \\
80\end{array}$ & $\begin{array}{l}21 \ldots \ldots \\
22 \ldots \ldots \\
23 \ldots \ldots \\
24 \ldots \ldots \\
25 \ldots \ldots \\
26 \ldots \ldots \\
27 \ldots \ldots \\
28 \ldots \ldots \\
29 \ldots \ldots \\
30 \ldots \ldots \\
31 \ldots \ldots\end{array}$ & $\begin{array}{r}7.5 \\
7.5 \\
7.5 \\
8.0 \\
8.0 \\
8.5 \\
9.0 \\
9.4 \\
1.1 \\
440 \\
2,570 \\
\end{array}$ & $\begin{array}{r}76 \\
73 \\
69 \\
68 \\
67 \\
69 \\
70 \\
66 \\
---- \\
--.- \\
\end{array}$ \\
\hline $\begin{array}{l}\text { onthiy } \\
\text { unoff, } \\
\text { unoff, }\end{array}$ & acre- & & & & & & $\begin{array}{r}105 \\
1.35 \\
6,450 \\
\end{array}$ & $\begin{array}{r}277 \\
3.30 \\
15,400 \\
\end{array}$ \\
\hline
\end{tabular}


Gage height, in feet, and discharge, in cubic feet per second, at indicated time, 1963, of South Fork Tuolumne R1ver near Oakland Recreation Camp, Cal1f

\begin{tabular}{|c|c|c|c|c|c|c|c|c|c|c|c|}
\hline Date & Hour & $\begin{array}{c}\text { Gage } \\
\text { height }\end{array}$ & $\begin{array}{c}\text { D1s- } \\
\text { charge }\end{array}$ & Date & Hour & $\begin{array}{c}\text { Gage } \\
\text { he1ght }\end{array}$ & $\begin{array}{c}\text { Dis- } \\
\text { charge }\end{array}$ & Date & Hour & $\begin{array}{c}\text { Gage } \\
\text { height }\end{array}$ & $\begin{array}{c}\text { Dis- } \\
\text { charge }\end{array}$ \\
\hline $\begin{array}{r}\overline{J a n} \cdot 29 \\
30\end{array}$ & $\begin{array}{l}2400 \\
0300 \\
0500 \\
0700 \\
1000 \\
1100 \\
1200 \\
1300 \\
1600 \\
1800 \\
1900 \\
2300 \\
2400\end{array}$ & $\begin{array}{l}1.53 \\
1.70 \\
2.00 \\
2.40 \\
2.90 \\
2.91 \\
3.17 \\
3.47 \\
3.94 \\
4.55 \\
4.94 \\
5.67 \\
5.55\end{array}$ & $\begin{array}{r}20 \\
26 \\
42 \\
76 \\
142 \\
144 \\
194 \\
268 \\
431 \\
718 \\
944 \\
1,520 \\
1,420\end{array}$ & Feb. 1 & $\begin{array}{l}0200 \\
0300 \\
0400 \\
0600 \\
0900 \\
1300 \\
1500 \\
1900 \\
2200 \\
2400 \\
0100 \\
0300 \\
0600\end{array}$ & $\begin{array}{l}5.31 \\
5.10 \\
5.13 \\
5.52 \\
5.57 \\
6.41 \\
7.19 \\
7.26 \\
8.10 \\
9.22 \\
9.53 \\
9.60 \\
8.34\end{array}$ & $\begin{array}{l}1,210 \\
1,050 \\
1,070 \\
1,390 \\
1,430 \\
2,280 \\
3,270 \\
3,360 \\
4,700 \\
7,050 \\
7,830 \\
8,000 \\
5,140\end{array}$ & Feb. I & $\begin{array}{l}0800 \\
1000 \\
1200 \\
1500 \\
1600 \\
1900 \\
2400 \\
\\
0300 \\
0500 \\
1100 \\
1600 \\
2400\end{array}$ & $\begin{array}{l}7.95 \\
8.58 \\
7.82 \\
6.60 \\
6.24 \\
5.80 \\
5.21 \\
4.95 \\
4.73 \\
4.38 \\
4.73 \\
3.86\end{array}$ & $\begin{array}{r}4,430 \\
5,620 \\
4,210 \\
2,510 \\
2,090 \\
1,650 \\
1,130 \\
\\
950 \\
818 \\
630 \\
509 \\
399\end{array}$ \\
\hline
\end{tabular}

11-2820. Middle Tuolumne River at Oakland Recreation Camp, Calif.

Location, --Lat $37^{\circ} 49^{1} 40^{\prime \prime}$, long $120^{\circ} 00^{\prime} 40^{\prime \prime}$, in Nw $\frac{1}{4}$ sec.28, T.1 S., R.18 E., on left bank $1,000 \mathrm{ft}$ downstream from 0akland Recreation Camp, 0.5 mile upstream from South Fork Tuolumne River, and 4 miles east of Buck Meadows Post office.

Drainage area. $--71.0 \mathrm{sq} \mathrm{ml}$.

Gage-height record:--Water-stage recorder graph. Altitude of gage is $2,800 \mathrm{ft}$ (from topographic map).

Discharge pecord.--Stage-discharge relation defined by current-meter measurements.

Maxima.--January-February 1963: Discharge, 2,290 cfs 1100 hours Feb. 1 (gage height, $8.56 \mathrm{ft}$ ).

1916 to December 1962: Discharge, 4,920 cfs Dec. 23, 1955 (gage height, $11.75 \mathrm{ft}$, from flood profile; $11.05 \mathrm{ft}$, from floodmarks inside gage well), from rating curve extended above $1,400 \mathrm{cfs}$ on basis of slope-area measurement of peak flow.

Mean discharge, in cubic feet per second, 1963

\begin{tabular}{|c|c|c|c|c|c|c|c|c|}
\hline Day & January & February & Day & January & February & Day & January & February \\
\hline $\begin{array}{r}1 \ldots \ldots \\
2 \ldots \ldots \\
3 \ldots \ldots \\
4 \ldots \ldots \\
5 \ldots \ldots \\
6 \ldots \ldots \\
8 \ldots \ldots \\
9 \ldots \ldots \\
10 \ldots \ldots\end{array}$ & $\begin{array}{l}2.9 \\
2.9 \\
3.1 \\
3.2 \\
3.0 \\
3.0 \\
2.9 \\
2.9 \\
3.0 \\
2.7\end{array}$ & $\begin{array}{r}1,590 \\
319 \\
159 \\
123 \\
102 \\
90 \\
80 \\
76 \\
76 \\
89\end{array}$ & $\begin{array}{l}11 \ldots \ldots \\
12 \ldots \ldots \\
13 \ldots \ldots \\
14 \ldots \ldots \\
15 \ldots \ldots \\
16 \ldots \ldots \\
17 \ldots \ldots \\
18 \ldots \ldots \\
19 \ldots \ldots \\
20 \ldots \ldots\end{array}$ & $\begin{array}{l}2.6 \\
2.5 \\
1.9 \\
2.3 \\
2.1 \\
2.2 \\
2.2 \\
2.2 \\
2.1 \\
2.3\end{array}$ & $\begin{array}{r}70 \\
67 \\
102 \\
95 \\
71 \\
66 \\
61 \\
55 \\
53 \\
52\end{array}$ & $\begin{array}{l}21 \ldots \ldots \\
22 \ldots \ldots \\
23 \ldots \ldots \\
24 \ldots \ldots \\
25 \ldots \ldots \\
26 \ldots \ldots \\
27 \ldots \ldots \\
28 \ldots \ldots \\
29 \ldots \ldots \\
30 \ldots \ldots \\
31 \ldots \ldots\end{array}$ & $\begin{array}{r}2.3 \\
2.1 \\
2.2 \\
2.3 \\
2.2 \\
2.3 \\
2.3 \\
2.5 \\
3.1 \\
276 \\
983\end{array}$ & $\begin{array}{r}50 \\
47 \\
46 \\
45 \\
45 \\
47 \\
50 \\
48 \\
----- \\
----- \\
----\end{array}$ \\
\hline \multicolumn{7}{|l|}{$\begin{array}{l}\text { Monthly } \\
\text { Runoff, } \\
\text { Runoff, }\end{array}$} & $\begin{array}{r}43.0 \\
0.70 \\
2,640 \\
\end{array}$ & $\begin{array}{r}135 \\
1.98 \\
7,490 \\
\end{array}$ \\
\hline
\end{tabular}

Gage height, in feet, and discharge, in cubic feet per second, at indicated time, 1963

\begin{tabular}{|c|c|c|c|c|c|c|c|c|c|c|c|}
\hline Date & Hour & $\begin{array}{c}\text { Gage } \\
\text { helght }\end{array}$ & $\begin{array}{c}\text { D1s- } \\
\text { charge }\end{array}$ & Date & Hour & $\begin{array}{c}\text { Gage } \\
\text { height }\end{array}$ & $\begin{array}{l}\text { D1s- } \\
\text { charge }\end{array}$ & Date & Hour & $\begin{array}{c}\text { Gage } \\
\text { height }\end{array}$ & $\begin{array}{c}\text { D1s- } \\
\text { charge }\end{array}$ \\
\hline $\begin{array}{r}\overline{\operatorname{Jan} .} 29 \\
30\end{array}$ & $\begin{array}{l}2400 \\
0300 \\
0500 \\
0800 \\
1000 \\
1200 \\
1300 \\
1500 \\
1700 \\
1800 \\
2000 \\
2200 \\
2400\end{array}$ & $\begin{array}{l}1.10 \\
1.31 \\
1.66 \\
6.09 \\
2.25 \\
2.66 \\
2.50 \\
2.91 \\
4.01 \\
3.95 \\
4.58 \\
4.93 \\
4.50\end{array}$ & $\begin{array}{r}7.0 \\
11 \\
21 \\
986 \\
55 \\
96 \\
78 \\
125 \\
302 \\
309 \\
464 \\
569 \\
440\end{array}$ & Jan. 31 & $\begin{array}{l}0500 \\
0700 \\
0800 \\
0900 \\
1000 \\
1300 \\
1400 \\
1500 \\
1600 \\
1800 \\
2000 \\
2200 \\
2300 \\
2400\end{array}$ & $\begin{array}{l}4.39 \\
5.00 \\
5.26 \\
5.08 \\
5.12 \\
6.30 \\
6.42 \\
6.24 \\
6.52 \\
6.34 \\
7.40 \\
8.02 \\
8.43 \\
e .40\end{array}$ & $\begin{array}{r}413 \\
590 \\
668 \\
614 \\
626 \\
1,070 \\
1,120 \\
1,050 \\
1,160 \\
1,090 \\
1,600 \\
1,960 \\
2,210 \\
2,190\end{array}$ & Feb. 1 & $\begin{array}{l}0600 \\
0800 \\
0900 \\
1000 \\
1100 \\
1300 \\
1500 \\
1700 \\
2400 \\
\\
0400 \\
0800 \\
1300 \\
1800 \\
2400\end{array}$ & $\begin{array}{l}7.59 \\
8.15 \\
8.51 \\
8.43 \\
8.56 \\
8.10 \\
7.02 \\
6.40 \\
5.10 \\
4.45 \\
4.05 \\
3.76 \\
3.57 \\
3.42\end{array}$ & $\begin{array}{r}1,700 \\
2,040 \\
2,260 \\
2,210 \\
2,290 \\
2,010 \\
1,410 \\
1,110 \\
620 \\
428 \\
331 \\
269 \\
230 \\
203\end{array}$ \\
\hline 31. & $\begin{array}{l}0200 \\
0400\end{array}$ & $\begin{array}{l}4.19 \\
4.63\end{array}$ & $\begin{array}{l}363 \\
479\end{array}$ & Feb. 1 & $\begin{array}{l}0100 \\
0400\end{array}$ & $\begin{array}{r}8.19 \\
.7 .81\end{array}$ & $\begin{array}{l}2,060 \\
1,840\end{array}$ & & & & \\
\hline
\end{tabular}


11-2835. Clavey River near Buck Meadows, Callf.

Location.--Lat $37^{\circ} 54^{1} 00^{\prime \prime}$, long $120^{\circ} 04^{\prime} 15^{\prime \prime}$, in SE $\frac{1}{4} N E \frac{1}{4} \sec .35$, T.1 N., R.17 E., on right bank $300 \mathrm{ft}$ upstream from Forest Service road bridge, 1.7 miles downstream from Quilty Creek, and 6 miles north of Buck Meadows Post Office.

Dra 1nage area. $--144 \mathrm{sq} \mathrm{ml}$.

Gage-height record.--Water-stage recorder graph. Datum of gage is $2,374.08 \mathrm{ft}$ above mean sea level.

Discharge record.--Stage-discharge relation defined by current-meter measurements below 1,200 cfs and by slope-area measurement at 19,200 cfs.

Maxima.--January-February 1963: Discharge, 19,200 cfs 0100 hours Feb. 1 (gage height, $21.40 \mathrm{ft}$, from recorder graph, $23.0 \mathrm{ft}$, from high-water profile . 1959 to December 1962: Discharge, 4,340 cfs Feb. 9, 1962 (gage he1ght, $13.32 \mathrm{ft})$.

Mean discharge, in cubic feet per second, 1963

\begin{tabular}{|c|c|c|c|c|c|c|c|c|}
\hline Day & January & February & Day & January & February & Day & January & February \\
\hline $\begin{array}{r}1 \ldots \ldots \\
2 \ldots \ldots \\
4 \ldots \ldots \\
5 \ldots \ldots \\
6 \ldots \ldots \\
8 \ldots \ldots \\
9 \ldots \ldots \\
10 \ldots \ldots\end{array}$ & $\begin{array}{l}20 \\
20 \\
20 \\
20 \\
18 \\
19 \\
18 \\
18 \\
19 \\
18\end{array}$ & $\begin{array}{r}9,980 \\
1,880 \\
852 \\
647 \\
495 \\
402 \\
350 \\
322 \\
288 \\
372\end{array}$ & $\begin{array}{l}11 \ldots \ldots \\
12 \ldots \ldots \\
13 \ldots \ldots \\
14 \ldots \ldots \\
15 \ldots \ldots \\
16 \ldots \ldots \\
17 \ldots \ldots \\
18 \ldots \ldots \\
19 \ldots \ldots \\
20 \ldots \ldots\end{array}$ & $\begin{array}{l}16 \\
13 \\
13 \\
17 \\
17 \\
17 \\
16 \\
16 \\
15 \\
16\end{array}$ & $\begin{array}{l}304 \\
267 \\
427 \\
471 \\
356 \\
317 \\
282 \\
255 \\
245 \\
235\end{array}$ & $\begin{array}{l}21 \ldots \ldots \\
22 \ldots \ldots \\
23 \ldots \ldots \\
24 \ldots \ldots \\
25 \ldots \ldots \\
26 \ldots \ldots \\
27 \ldots \ldots \\
28 \ldots \ldots \\
29 \ldots \ldots \\
30 \ldots \ldots \\
31 \ldots \ldots\end{array}$ & $\begin{array}{r}16 \\
17 \\
17 \\
17 \\
16 \\
16 \\
16 \\
16 \\
18 \\
676 \\
6,410\end{array}$ & $\begin{array}{r}225 \\
208 \\
190 \\
183 \\
179 \\
186 \\
188 \\
168 \\
-\ldots-\end{array}$ \\
\hline \multicolumn{7}{|l|}{$\begin{array}{l}\text { Monthly } \\
\text { Runoff, } \\
\text { Runoff, }\end{array}$} & $\begin{array}{r}245 \\
1.96 \\
15,040\end{array}$ & $\begin{array}{r}724 \\
5.24 \\
40,210 \\
\end{array}$ \\
\hline
\end{tabular}

Gage height, in feet, and discharge, in cubic feet per second, at 1na1cated t1me, 1963

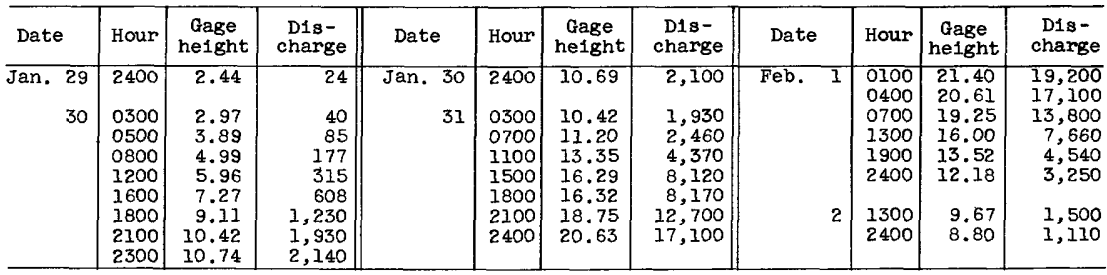

11-2845. B1g Creek near Groveland, Calif.

Location.--Lat $37^{\circ} 51^{1} 2^{\prime \prime}$, long $120^{\circ} 12^{\prime} 02^{\prime \prime}$, In NE $\frac{1}{4}$ sec.15, T.1 S., R.16 E., on right bank $0.5 \mathrm{mile}$ downstream from unnamed tributary and $2.0 \mathrm{miles}$ northeast of Groveland.

Drainage area. $--24.7 \mathrm{sq} \mathrm{mi}$.

Gage-height record.--Water-stage recorder graph, except 0100 hours Feb. 1 to 1100 hours $\mathrm{Feb} .10$. Altitude of gage is $2,450 \mathrm{ft}$ (from topographic map).

Discharge record.--Stage-discharge relation defined by current-meter measurements below 1,300 cfs and by slope-area measurement at 4,530 cfs. D1scharge for period of no gage-helght record estimated on basis of one discharge measurement, recorded range in stage, and records for North Fork Tuolumne River above Dyer Creek, near Tuolumne.

Max1ma.--January-February 1963: Discharge, 4,530 cfs about 0200 hours Feb. 1 (gage helght, $7.71 \mathrm{ft}$, from floodmark in gage well; $8.6 \mathrm{ft}$ outside, from floodmarks). 1931-33, 1959 to December 1962: Discharge, 3,000 cfs Feb. 6, 1932 (gage height, $6.70 \mathrm{ft}$ ).

Flood of December 1955 reached a stage of $7.6 \mathrm{ft}$, from floodmarks (discharge, about $4,300 \mathrm{cfs}$ ). 
Mean discharge, in cublc feet per second, 1963, of B1g Creek near Groveland, Cal1f.

\begin{tabular}{|c|c|c|c|c|c|c|c|c|}
\hline Day & January & February & Day & January & February & Day & $J$ anuary & February \\
\hline $\begin{array}{c}1 \ldots \ldots \\
2 \ldots \ldots \\
3 \ldots \ldots \\
4 \ldots \ldots \\
6 \ldots \ldots \\
7 \ldots \ldots \\
8 \ldots \ldots \\
9 \ldots \ldots \\
10 \ldots\end{array}$ & $\begin{array}{r}0.1 \\
.1 \\
.1 \\
.1 \\
.1 \\
.1 \\
.1 \\
.1 \\
.1 \\
.1\end{array}$ & $\begin{array}{c}1,200 \\
60 \\
30 \\
20 \\
10 \\
9.0 \\
8.0 \\
7.0 \\
6.0 \\
34\end{array}$ & $\begin{array}{l}11 \ldots \ldots \\
12 \ldots \ldots \\
13 \ldots \ldots \\
14 \ldots \ldots \\
15 \ldots \ldots \\
16 \ldots \ldots \\
17 \ldots \ldots \\
18 \ldots \ldots \\
19 \ldots \ldots \\
20 \ldots \ldots\end{array}$ & $\begin{array}{r}0.1 \\
.1 \\
.1 \\
.1 \\
.1 \\
.1 \\
.1 \\
.1 \\
.1 \\
.1\end{array}$ & $\begin{array}{c}12 \\
12 \\
72 \\
57 \\
23 \\
15 \\
12 \\
9.3 \\
7.7 \\
6.9\end{array}$ & $\begin{array}{l}21 \ldots \ldots \\
22 \ldots \ldots \\
23 \ldots \ldots \\
24 \ldots \ldots \\
25 \ldots \ldots \\
26 \ldots \ldots \\
27 \ldots \ldots \\
28 \ldots \ldots \\
29 \ldots \ldots \\
30 \ldots \ldots \\
31 \ldots \ldots\end{array}$ & $\begin{array}{r}0.1 \\
.1 \\
.1 \\
.1 \\
.1 \\
.1 \\
.1 \\
.1 \\
.2 \\
127^{.2} \\
1,000\end{array}$ & $\begin{array}{r}5.7 \\
5.3 \\
4.5 \\
4.1 \\
3.7 \\
3.3 \\
3.0 \\
3.0 \\
---- \\
---0 \\
---.-\end{array}$ \\
\hline $\begin{array}{l}\text { nthiy } \\
\text { noff, } \\
\text { anof'f, }\end{array}$ & $\begin{array}{l}\text { Inche } \\
\text { acre- }\end{array}$ & & & & & & $\begin{array}{r}36.5 \\
1.70 \\
2,240 \\
\end{array}$ & $\begin{array}{r}58.7 \\
2.47 \\
3,260 \\
\end{array}$ \\
\hline
\end{tabular}

Gage helght, in feet, and discharge, In cublc feet per second, at indlcated time, 1963

\begin{tabular}{|c|c|c|c|c|c|c|c|c|c|c|c|}
\hline Date & Hour & $\begin{array}{c}\text { Gage } \\
\text { height }\end{array}$ & $\begin{array}{l}\text { Dis- } \\
\text { charge }\end{array}$ & Date & Hour & $\begin{array}{c}\text { Gage } \\
\text { hetght }\end{array}$ & $\begin{array}{l}\text { D1s- } \\
\text { charge }\end{array}$ & Date & Hour & $\begin{array}{c}\text { Gage } \\
\text { helght }\end{array}$ & $\begin{array}{l}\text { Dis } \\
\text { charge }\end{array}$ \\
\hline an: $\begin{array}{r}29 \\
30\end{array}$ & $\begin{array}{l}2400 \\
0200 \\
0400 \\
0500 \\
0600 \\
0900 \\
1200 \\
1600 \\
\end{array}$ & $\begin{array}{l}1.76 \\
1.81 \\
1.87 \\
1.93 \\
2.16 \\
2.33 \\
2.54 \\
2.63\end{array}$ & $\begin{array}{l}0.7 \\
1.3 \\
2.2 \\
3.7 \\
14 \\
27 \\
50 \\
63\end{array}$ & Jan. 30 & $\begin{array}{l}1800 \\
2000 \\
2100 \\
2200 \\
2300 \\
2400 \\
0300 \\
0500\end{array}$ & $\begin{array}{l}2.88 \\
3.25 \\
3.59 \\
3.95 \\
4.42 \\
4.15 \\
3.71 \\
3.88\end{array}$ & $\begin{array}{l}111 \\
216 \\
350 \\
538 \\
812 \\
650 \\
\\
410 \\
499\end{array}$ & Jan. 31 & $\begin{array}{l}0800 \\
1000 \\
1300 \\
1500 \\
1900 \\
2200 \\
2400\end{array}$ & $\begin{array}{l}3.70 \\
3.85 \\
4.75 \\
5.52 \\
4.51 \\
5.70 \\
7.00\end{array}$ & $\begin{array}{r}405 \\
482 \\
1,040 \\
1,660 \\
867 \\
1,830 \\
3,390\end{array}$ \\
\hline
\end{tabular}

11-2847. North Fork Tholumne River near Long Barm, Calif.

Location.--Lat $120^{\circ} 06^{\prime} 00^{\prime \prime}$, long $38^{\circ} 05^{\prime} 55^{\prime \prime}$, in NW $\frac{1}{4}$ SW $\frac{1}{4}$ sec. 22 , T.3 N., R.17 E., $0.6 \mathrm{mile}$ upstream from smali tributary, 3.8 miles upstream from Wrights Creek, and 1.5 miles east of town of Long Barn.

Drainage area.--23.1 sq mi.

Gage-height record.--Water-stage recorder graph, except 0600 hours Jan. 30 to 1530 hours Jan. 31 , for which graph was reconstructed on basis of recorded trace for North Fork Tuolumne River above Dyer Creek near Tuolumne. Altitude of gage is $4,650 \mathrm{ft}$ (from topographic map).

Discharge record.--Stage-discharge relation defined by current-meter measurements below $530 \mathrm{cf}$ 's and by slope-area measurement at $2,560 \mathrm{cfs}$; affected by $1 \mathrm{ce}$ Jan. 1 to 13 .

Maxima.--January-February 1963: Discharge, 1,570 cfs 0300 hours Feb. 1 (gage height, $7.23 \mathrm{ft}$, from recorder graph; $8.2 \mathrm{ft}$, from floodmarks).

1955 to December 1962: Discharge, 2,560 cfs Dec. 23, 1955 (gage height,

$9.8 \mathrm{ft}$, from floodmarks).

Mean discharge, in cubic feet per second, 1963

\begin{tabular}{|c|c|c|c|c|c|c|c|c|}
\hline Day & January & February & Day & January & February & Day & January & February \\
\hline $\begin{array}{c}\ldots \ldots \\
2 \ldots \ldots \\
3 \ldots \ldots \\
4 \ldots \ldots \\
5 \ldots \ldots \\
6 \ldots \ldots \\
7 \ldots \ldots \\
9 \ldots \ldots \\
10 \ldots \ldots\end{array}$ & $\begin{array}{l}2.5 \\
2.0 \\
2.0\end{array}$ & $\begin{array}{r}819 \\
156 \\
81 \\
57 \\
44 \\
36 \\
30 \\
26 \\
27 \\
34\end{array}$ & $\begin{array}{l}11 \ldots \ldots \\
12 \ldots \ldots \\
13 \ldots \ldots \\
14 \ldots \ldots \\
15 \ldots \ldots \\
16 \ldots \ldots \\
17 \ldots \ldots \\
18 \ldots \ldots \\
19 \ldots \ldots \\
20 \ldots \ldots\end{array}$ & $\begin{array}{l}1.8 \\
2.0 \\
2.5 \\
3.7 \\
3.1 \\
2.5 \\
2.0 \\
1.8 \\
1.4 \\
1.0\end{array}$ & $\begin{array}{l}27 \\
26 \\
49 \\
49 \\
40 \\
35 \\
31 \\
28 \\
26 \\
24\end{array}$ & $\begin{array}{l}21 \ldots \ldots \\
22 \ldots \ldots \\
23 \ldots \ldots \\
24 \ldots \ldots \\
25 \ldots \ldots \\
26 \ldots \ldots \\
27 \ldots \ldots \\
28 \ldots \ldots \\
29 \ldots \ldots \\
30 \ldots \ldots \\
31 \ldots \ldots\end{array}$ & $\begin{array}{r}0.9 \\
.9 \\
.8 \\
.7 \\
.7 \\
.5 \\
.4 \\
.4 \\
142 \\
618\end{array}$ & $\begin{array}{r}22 \\
22 \\
20 \\
19 \\
17 \\
16 \\
15 \\
14 \\
----- \\
-----\end{array}$ \\
\hline $\begin{array}{l}\text { onthly } \\
\text { unoff, } \\
\text { unoff, }\end{array}$ & $\begin{array}{l}\text { In inche } \\
\text { in acre- }\end{array}$ & & & & & & $\begin{array}{r}26.2 \\
1.31 \\
1,610\end{array}$ & $\begin{array}{r}63.9 \\
2.88 \\
3,550\end{array}$ \\
\hline
\end{tabular}

Gage height, in feet, and discharge, in cubic feet per second, at indicated time, 1963

\begin{tabular}{|c|c|c|c|c|c|c|c|c|c|c|c|}
\hline Date & Hour & $\begin{array}{c}\text { Gage } \\
\text { height }\end{array}$ & $\begin{array}{l}\text { Dis- } \\
\text { charge }\end{array}$ & Date & Hour & $\begin{array}{c}\text { Gage } \\
\text { helght }\end{array}$ & $\begin{array}{c}\text { Dis- } \\
\text { charge }\end{array}$ & Date & Hour & $\begin{array}{c}\text { Geage } \\
\text { helght }\end{array}$ & $\begin{array}{l}\text { Dis- } \\
\text { charge }\end{array}$ \\
\hline $\begin{array}{r}\operatorname{Jan} . \\
30\end{array}$ & $\begin{array}{l}2400 \\
0600 \\
1200 \\
1800 \\
2400\end{array}$ & $\begin{array}{l}2.61 \\
2.77 \\
3.70 \\
4.78 \\
4.75\end{array}$ & $\begin{array}{c}0.8 \\
4.6 \\
80^{4} \\
324 \\
315\end{array}$ & Jan. 31 & $\begin{array}{l}1600 \\
1700 \\
1900 \\
2100 \\
2300 \\
2400\end{array}$ & $\begin{array}{l}5.80 \\
5.68 \\
6.16 \\
6.80 \\
7.13 \\
7.10\end{array}$ & $\begin{array}{r}740 \\
681 \\
928 \\
1,310 \\
1,510 \\
1,490\end{array}$ & Feb. & $\begin{array}{l}0700 \\
1000 \\
1200 \\
1500 \\
1700 \\
1900 \\
2400\end{array}$ & $\begin{array}{l}6.95 \\
6.06 \\
5.55 \\
5.05 \\
4.88 \\
4.87 \\
4.50\end{array}$ & $\begin{array}{r}1,400 \\
873 \\
622 \\
418 \\
358 \\
354 \\
240\end{array}$ \\
\hline 31 & $\begin{array}{l}0600 \\
1200 \\
1500\end{array}$ & $\begin{array}{l}4.27 \\
4.90 \\
5.75\end{array}$ & $\begin{array}{l}183 \\
365 \\
715\end{array}$ & Feb. 1 & $\begin{array}{l}0100 \\
0300 \\
0600\end{array}$ & $\begin{array}{l}7.01 \\
7.23 \\
6.87\end{array}$ & $\begin{array}{l}1,440 \\
1,570 \\
1,350\end{array}$ & 2 & $\begin{array}{l}0600 \\
1200 \\
2400\end{array}$ & $\begin{array}{l}4.25 \\
4.10 \\
3.88\end{array}$ & $\begin{array}{l}178 \\
146 \\
107\end{array}$ \\
\hline
\end{tabular}


11-2848. Sugarpine Creek near Long Barn, Calif.

(Crest-stage station)

Location.--Lat $38^{\circ} 06^{\prime} 10^{\prime \prime}$, long $120^{\circ} 07^{\prime} 18^{\prime \prime}$, in $\mathrm{SE} \frac{1}{4} \mathrm{NE} \frac{1}{4} \sec .20$, T.3 N., R.17 E., 1.1 miles northeast of Long Barn.

Drainage area. $--1.13 \mathrm{sq} \mathrm{m} 1$.

Gage-height record.--Crest stages only. Altitude of gage is 5,010 ft (from topographic map).

Discharge record.--Stage-discharge relation defined by current-meter measurements below $33 \mathrm{cfs}$ and by computation of flow through culvert at $95 \mathrm{cfs}$.

Maxima --January-February 1963: Discharge, $95 \mathrm{cfs} F e b .1$ (gage he1ght, $6.43 \mathrm{ft}$ ). $2.98 \mathrm{ft}$ ).

11-2850. North Fork Tuolumne River above Dyer Creek, near Tholumne, Calif.

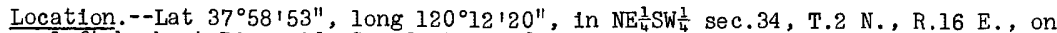
left bank at Riverside Guard Station, 0.2 mile upstream from Dyer Creek and 2.2 miles northeast of Tuolumne.

Drainage area. $--69.2 \mathrm{sq} \mathrm{mi}$.

Gage-height record:--Water-stage recorder graph. Altitude of gage is $2,200 \mathrm{ft}$ (from topographic map).

Discharge record.--Stage-discharge relation defined by current-meter measurements below 1,400 cfs.

Maxima.--January-February 1963: Discharge, 4,130 cfs 2400 hours Jan. 31 (gage helght, $5.79 \mathrm{ft}$ ).

1955 to December 1962: Flood of December 1955 reached a stage of $10.7 \mathrm{ft}$, from floodmarks.

Mean d1scharge, In cub1c feet per second, 1963

\begin{tabular}{|c|c|c|c|c|c|c|c|c|}
\hline Day & January & February & Day & January & February & Day & January & February \\
\hline $\begin{array}{c}\ldots \ldots \\
2 \ldots \ldots \\
3 \ldots \ldots \\
4 \ldots \ldots \\
5 \ldots \ldots \\
7 \ldots \ldots \\
8 \ldots \ldots \\
9 \ldots \ldots \\
10 \ldots \ldots\end{array}$ & $\begin{array}{l}7.7 \\
7.7 \\
8.4 \\
5.4 \\
7.7 \\
7.7 \\
7.7 \\
7.1 \\
7.1 \\
7.1\end{array}$ & $\begin{array}{r}2,020 \\
537 \\
283 \\
179 \\
134 \\
105 \\
86 \\
74 \\
72 \\
120\end{array}$ & $\begin{array}{l}11 \ldots \ldots \\
12 \ldots \ldots \\
13 \ldots \ldots \\
14 \ldots \ldots \\
15 \ldots \ldots \\
16 \ldots \ldots \\
17 \ldots \ldots \\
18 \ldots \ldots \\
19 \ldots \ldots \\
20 \ldots \ldots\end{array}$ & $\begin{array}{l}6.5 \\
5.0 \\
5.0 \\
7.1 \\
7.7 \\
7.1 \\
7.1 \\
7.1 \\
5.9 \\
6.5\end{array}$ & $\begin{array}{r}84 \\
76 \\
194 \\
194 \\
147 \\
125 \\
110 \\
98 \\
89 \\
78\end{array}$ & $\begin{array}{l}21 \ldots \ldots \\
22 \ldots \ldots \\
23 \ldots \ldots \\
24 \ldots \ldots \\
25 \ldots \ldots \\
26 \ldots \ldots \\
27 \ldots \ldots \\
28 \ldots \ldots \\
29 \ldots \ldots \\
30 \ldots \ldots \\
31 \ldots \ldots\end{array}$ & $\begin{array}{r}6.5 \\
7.1 \\
6.5 \\
7.1 \\
6.5 \\
6.5 \\
6.5 \\
6.5 \\
8.4 \\
412 \\
1,660\end{array}$ & $\begin{array}{r}72 \\
65 \\
62 \\
58 \\
54 \\
50 \\
47 \\
45 \\
-\ldots--- \\
--.---\end{array}$ \\
\hline $\begin{array}{l}\text { nthly } \\
\text { inoff, } \\
\text { noff, }\end{array}$ & acre & & & & & & $\begin{array}{r}73.4 \\
1.22 \\
4,510 \\
\end{array}$ & $\begin{array}{r}188 \\
2.83 \\
10,430 \\
\end{array}$ \\
\hline
\end{tabular}

Gage height, in feet, and discharge, In cubic feet per second, at indicated time, 1963

\begin{tabular}{|c|c|c|c|c|c|c|c|c|c|c|c|}
\hline Date & Hour & $\begin{array}{c}\text { Gage } \\
\text { height }\end{array}$ & $\begin{array}{l}\text { Dis- } \\
\text { charge }\end{array}$ & Date & Hour & $\begin{array}{c}\text { Gage } \\
\text { helght }\end{array}$ & $\begin{array}{c}\text { D1s- } \\
\text { charge }\end{array}$ & Date & Hour & $\begin{array}{c}\text { Gage } \\
\text { he1ght }\end{array}$ & $\begin{array}{c}\text { Dis- } \\
\text { charge }\end{array}$ \\
\hline $\begin{array}{r}29 \\
30\end{array}$ & $\begin{array}{l}2400 \\
0400 \\
0700 \\
1200 \\
1500 \\
2000 \\
2400 \\
\\
0400\end{array}$ & $\begin{array}{l}1.38 \\
1.54 \\
1.98 \\
2.45 \\
2.85 \\
3.59 \\
3.45 \\
3.16\end{array}$ & $\begin{array}{r}12 \\
28 \\
107 \\
270 \\
470 \\
1,020 \\
900 \\
672\end{array}$ & Feb. 1 & $\begin{array}{l}0800 \\
1000 \\
1400 \\
1700 \\
2000 \\
2400 \\
\\
0100 \\
0200 \\
0500\end{array}$ & $\begin{array}{l}3.24 \\
3.69 \\
4.57 \\
4.07 \\
5.00 \\
5.79 \\
5.32 \\
5.66 \\
5.00\end{array}$ & $\begin{array}{r}732 \\
1,710 \\
2,710 \\
1,510 \\
2,730 \\
4,130 \\
3,250 \\
3,870 \\
2,730\end{array}$ & Feb. & $\begin{array}{l}0600 \\
0900 \\
1200 \\
1500 \\
2400 \\
\\
0600 \\
1200 \\
1800 \\
2400 \\
\end{array}$ & $\begin{array}{l}5.20 \\
5.00 \\
4.20 \\
3.72 \\
3.38 \\
3.09 \\
2.90 \\
2.76 \\
2.65\end{array}$ & $\begin{array}{r}3,050 \\
2,730 \\
1,650 \\
1,140 \\
844 \\
\\
623 \\
500 \\
420 \\
365 \\
\end{array}$ \\
\hline
\end{tabular}


11-2863. Curtis Creek tributary near Standard, Calif.

\section{(Crest-stage station)}

Location. - -Lat $37^{\circ} 59^{\prime} 05^{\prime \prime}$, long $120^{\circ} 18^{\prime} 06^{\prime \prime}$, in SW $\frac{1}{4} N W \frac{1}{4}$ sec.35, T.2 N., R.15 E., on State Highway $108,1.3$ miles northeast of Standard.

Drainage area. $--0.26 \mathrm{sq} \mathrm{ml}$.

Gage-helght record.--Crest stages only. Altitude of piage is $2,570 \mathrm{ft}$ (from topographic map).

D1.scharge record.--Stage-discharge relation defined by current-meter measurements below $25 \mathrm{cfs}$ and by computation of flow through culvert at $36 \mathrm{cfs}$.

Maxima.--January-February 1963: Discharge, 36 cf's Feb. 1 (gage helght, $17.51 \mathrm{ft}$ ). July to December 1962: No signiflcant floodflow.

\section{1-2865. Woods Creek near Jacksonville, Calif.}

Location.--Lat $37^{\circ} 51^{\prime} 30^{\prime \prime}$, long $120^{\circ} 23^{\prime} 45^{\prime \prime}$, in SE $\frac{1}{4}$ sec.11, T.1 S., R.14 E., on right bank $200 \mathrm{ft}$ downstream from Blue Gulch, 1.5 miles upstream from mouth, and 1.5 miles northwest of Jacksonville.

Drainage area. $--97.2 \mathrm{sq} \mathrm{mi}$.

Gage-height record.--Water-stage recorder graph except Jan. 1 to 1400 hours Feb. 5 and 1700 hours Feb. 9 to 1500 hours Feb. 12. Datum of gage is $653.65 \mathrm{ft}$ above mean sea level.

Discharge record.--Stage-discharge relation defined by current-meter measurements below 3,900 cfs and by slope-area measurement at 14,400 cfs. Discharge for perlods of no gage-height record estimated on basis of recorded ranges in stage, weather records, and record for Big Creek near Groveland.

Maxima.--January-February 1963: Discharge, 11,300 cfs time unknown Jan. 31 (gage helght, $13.50 \mathrm{ft}$, from floodmark in weli).

1925 to December 1962: Discharge, 14,400 cfs Dec. 23, 1955 (gage height, $14.66 \mathrm{ftl}$.

Mean discharge, in cub1c feet per second, 1963

\begin{tabular}{|c|c|c|c|c|c|c|c|c|}
\hline Day & January & February & Day & January & February & Day & January & February \\
\hline $\begin{array}{r}1 \ldots . . \\
2 \ldots . \\
3 \ldots \ldots \\
4 \ldots \ldots \\
5 \ldots \ldots \\
6 \ldots \ldots \\
7 \ldots \ldots \\
8 \ldots \ldots \\
9 \ldots \ldots \\
10 \ldots .\end{array}$ & $\begin{array}{l}9.0 \\
8.6\end{array}$ & $\begin{array}{r}5,500 \\
600 \\
300 \\
100 \\
58 \\
52 \\
47 \\
40 \\
40 \\
300\end{array}$ & 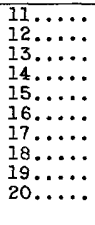 & 9.0 & $\begin{array}{r}100 \\
70 \\
656 \\
326 \\
128 \\
96 \\
83 \\
69 \\
64 \\
59\end{array}$ & $\begin{array}{l}21 \ldots \ldots \\
22 \ldots \ldots \\
23 \ldots \ldots \\
24 \ldots \ldots \\
25 \ldots \\
26 \ldots \\
27 \ldots \ldots \\
28 \ldots \\
29 \ldots \\
30 \ldots \\
31 \ldots \ldots\end{array}$ & $\begin{array}{l}9.0 \\
1,000 \\
4,000\end{array}$ & 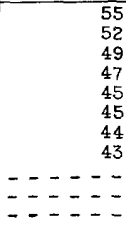 \\
\hline & & & & & & & $\begin{array}{r}170 \\
2.01 \\
10,430\end{array}$ & $\begin{array}{r}324 \\
3.47 \\
17,990\end{array}$ \\
\hline
\end{tabular}


11-2875. Don Pedro Reservoir near La Grange, Calif.

Location. --Lat $37^{\circ} 42148^{\prime \prime}$, long $120^{\circ} 24^{1} 14^{\prime \prime}$, In SW $\frac{1}{4}$ sec.35, T.2 S., R.14 E., $300 \mathrm{ft}$ from left bank on upstream face of Don Pedro Dam on Tuolumne River, 1 mile downstream from Rogers Creek, and $5.5 \mathrm{miles}$ upstream from La Grange.

Drainage area. $--1,539 \mathrm{sq} \mathrm{ml}$.

Gage-helght record.--Water-stage recorder graph. Datum of gage is at mean sea level (levels by Turlock Irrigation District).

Contents record.--Contents computed from capacity table dated Oct. 1, 1931 .

Maxima.--January-February 1963: Contents, 221,700 acre-ft 1400-1800 hours Feb. 2 (elevation, $582.9 \mathrm{ft}$ ).

1924 to December 1962: Contents, 292,100 acre-ft June 13, 1937 (elevation, $606.1 \mathrm{ft}$ ).

Remarks. --Reservolr is formed by concrete gravity-type dam, completed about Jan. I, 1923; storage began Nov. 14, 1922. Total capacity, 290,400 acre-ft at elevation $605.55 \mathrm{ft}$ (top of drum type spillway gates), of which 30,000 acre-ft below elevation, $476 \mathrm{ft}$ (mutually agreed-upon minimum) is not available for release. Figures given herein represent total contents. Water-stage-recorder graph furnished by Turlock and Modesto Irrigation Districts.

Elevation, in feet, and contents, in acre-feet, at 2400 hours, 1963

\begin{tabular}{|c|c|c|c|c|c|c|c|c|c|}
\hline \multirow{2}{*}{ Day } & \multicolumn{2}{|c|}{ January } & \multicolumn{2}{|c|}{ February } & \multirow{2}{*}{ Day } & \multicolumn{2}{|c|}{ January } & \multicolumn{2}{|c|}{ February } \\
\hline & Elevation & Contents & Elevation & Contents & & Elevation & Contents & Elevation & Contents \\
\hline $\begin{array}{r}1 \\
2 \\
3 \\
4 \\
5 \\
6 \\
7 \\
8 \\
9 \\
10 \\
11 \\
12 \\
13 \\
14 \\
15\end{array}$ & $\begin{array}{l}516.4 \\
516.0 \\
516.1 \\
516.7 \\
517.6 \\
518.5 \\
518.5 \\
518.9 \\
519.6 \\
520.0 \\
520.4 \\
521.1 \\
522.0 \\
522.4 \\
523.2\end{array}$ & $\begin{array}{l}72,900 \\
72,400 \\
72,500 \\
73,400 \\
74,600 \\
76,000 \\
76,000 \\
76,500 \\
77,600 \\
78,100 \\
78,700 \\
79,800 \\
81,100 \\
81,700 \\
82,900\end{array}$ & $\begin{array}{l}581.3 \\
582.7 \\
580.8 \\
578.4 \\
575.6 \\
573.6 \\
573.5 \\
572.6 \\
571.8 \\
571.7 \\
571.9 \\
572.2 \\
572.4 \\
572.2 \\
572.5\end{array}$ & $\begin{array}{l}217,100 \\
221,100 \\
215,600 \\
208,800 \\
201,000 \\
195,400 \\
195,200 \\
192,700 \\
190,500 \\
190,200 \\
190,800 \\
191,600 \\
192,100 \\
191,600 \\
192,400\end{array}$ & $\begin{array}{l}16 \\
17 \\
18 \\
19 \\
20 \\
21 \\
22 \\
23 \\
24 \\
25 \\
26 \\
27 \\
28 \\
29 \\
30 \\
31 \\
\end{array}$ & $\begin{array}{l}524.0 \\
524.8 \\
525.5 \\
526.3 \\
527.2 \\
527.7 \\
528.6 \\
529.5 \\
530.4 \\
530.9 \\
531.8 \\
532.7 \\
533.7 \\
533.8 \\
536.4 \\
554.3\end{array}$ & $\begin{array}{r}84,200 \\
85,400 \\
86,500 \\
87,800 \\
89,300 \\
90,200 \\
91,700 \\
93,300 \\
94,800 \\
95,700 \\
97,400 \\
98,900 \\
99,800 \\
101,100 \\
106,100 \\
146,000\end{array}$ & $\begin{array}{c}572.8 \\
572.8 \\
571.8 \\
571.5 \\
571.5 \\
571.2 \\
571.0 \\
571.1 \\
571.4 \\
571.4 \\
571.2 \\
571.2 \\
571.5 \\
- \\
- \\
-\end{array}$ & $\begin{array}{c}193,200 \\
193,200 \\
190,500 \\
189,700 \\
189,700 \\
188,900 \\
188,300 \\
188,600 \\
189,400 \\
189,400 \\
188,900 \\
188,900 \\
189,700 \\
- \\
- \\
-\end{array}$ \\
\hline Chan & in cont & $s$, in a & $-f$ & & & - & $+74,500$ & - & $+43,700$ \\
\hline
\end{tabular}

11-2880. Tuolumne River above La Grange Dam, near La Grange, Calif.

Location.--Lat $37^{\circ} 42^{\prime} 35^{\prime \prime}$, long $120^{\circ} 24145^{\prime \prime}$, in NE $\frac{1}{4}$ sec.3, T.3 S., R.14 E., on left bank 0.5 mile downstream from Don Pedro Dam, 3.5 miles upstream from La Grange Dam, and 5 miles upstream from La Grange.

Drainage area. $--1,534 \mathrm{sq} \mathrm{mi}$.

Gage-height record.--Digital recorder tape punched at 15-minute intervals. Altitude of gage is $330 \mathrm{ft}$ (from topographic map).

Discharge record.--Stage-discharge relation defined by current-meter measurements.

Maxima.--January-February 1963: Discharge, 7,130 cfs 1615 hours Feb. 2 (gage helght, $13.02 \mathrm{ft}$ ).

1895 to December 1962: Discharge, 61,000 cfs Dec. 8, 1950 (gage helght, $\left.43.8 \mathrm{f}^{\prime} \mathrm{t}\right)$.

Remarks. - Flow regulated by Don Pedro powerplant, Don Pedro Reservo1r (see station 11-2875), Hetch Hetchy Reservoir (see station 11-2755), Cherry Lake (see station 11-2772 and Lake Eleanor (see station 11-2775). Water-stage recorder graph furnished by city and county of San Francisco. 
Mean discharge, in cublc feet per second, 1963, of Tuolumne River above La Grange Dam, near La Grange, Calif.

\begin{tabular}{|c|c|c|c|c|c|c|c|c|}
\hline Day & January & February & Day & January & February & Day & January & February \\
\hline $\begin{array}{c}1 \ldots \ldots \\
2 \ldots \ldots \\
3 \ldots \ldots \\
4 \ldots \ldots \\
5 \ldots \ldots \\
7 \ldots \ldots \\
8 \ldots \ldots \\
9 \ldots \ldots \\
10 \ldots \ldots\end{array}$ & $\begin{array}{r}719 \\
1,530 \\
1,300 \\
928 \\
720 \\
540 \\
1,150 \\
1,040 \\
852 \\
1,080\end{array}$ & $\begin{array}{l}3,260 \\
7,000 \\
6,970 \\
6,920 \\
6,920 \\
5,570 \\
2,550 \\
3,420 \\
3,670 \\
3,420\end{array}$ & $\begin{array}{l}11 \ldots \ldots \\
12 \ldots \ldots \\
13 \ldots \ldots \\
14 \ldots \ldots \\
15 \ldots \ldots \\
16 \ldots \ldots \\
17 \ldots \ldots \\
18 \ldots \ldots \\
19 \ldots \ldots \\
20 \ldots \ldots\end{array}$ & $\begin{array}{r}, 120 \\
739 \\
454 \\
863 \\
765 \\
684 \\
749 \\
817 \\
594 \\
448\end{array}$ & $\begin{array}{l}2,210 \\
1,780 \\
4,310 \\
4,190 \\
2,170 \\
1,940 \\
1,900 \\
3,370 \\
2,120 \\
1,910\end{array}$ & $\begin{array}{l}21 \ldots \ldots \\
22 \ldots \ldots \\
23 \ldots \ldots \\
24 \ldots \ldots \\
25 \ldots \ldots \\
26 \ldots \ldots \\
27 \ldots \ldots \\
28 \ldots \ldots \\
29 \ldots \ldots \\
30 \ldots \ldots \\
31 \ldots \ldots\end{array}$ & $\begin{array}{l}727 \\
576 \\
624 \\
701 \\
833 \\
541 \\
364 \\
943 \\
778 \\
574 \\
668 \\
\end{array}$ & $\begin{array}{r}2,060 \\
1,880 \\
1,360 \\
1,060 \\
1,350 \\
1,670 \\
1,460 \\
1,020 \\
--1-- \\
------ \\
\end{array}$ \\
\hline \multicolumn{7}{|c|}{ 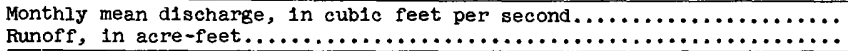 } & $\begin{array}{r}788 \\
48,440 \\
\end{array}$ & $\begin{array}{r}3,124 \\
173,500 \\
\end{array}$ \\
\hline
\end{tabular}

Gage helght, in feet, and discharge, in cublc feet per second, at ind1cated time, 1963

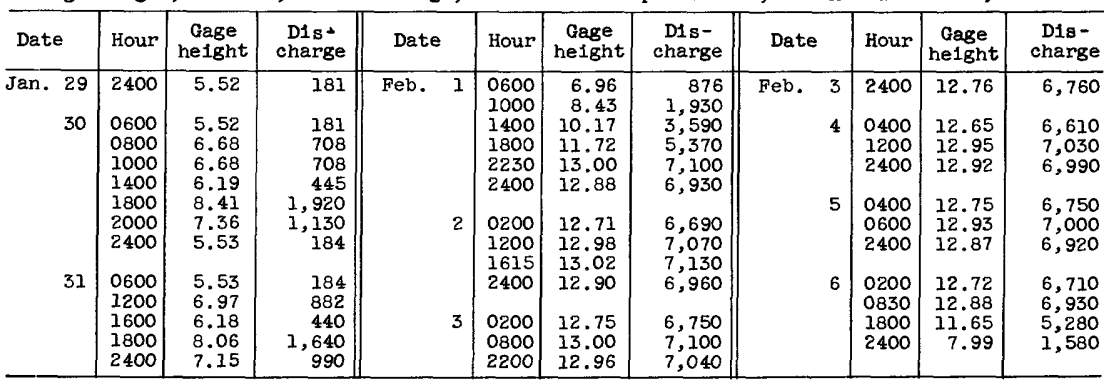

11-2900. Tholumne River at Modesto, Calif.

Location.--Lat $37^{\circ} 37^{\prime} 38^{\prime \prime}$, long $120^{\circ} 59120^{\prime \prime}$, in SW $\frac{1}{4}$ Sec.33, T.3 S., R.9 E., on left bank at bridge on U.S. Highway 99 in Modesto and 0.2 mile downstream from Dry Creek.

Drainage area. $--1,883 \mathrm{sq} \mathrm{ml}$.

Gage-helght record.--Water-stage recorder graph. Datum of gage is mean sea level, unadjusted (levels by Modesto Irrigation District).

Discharge record.--Stage-discharge relation defined by current-meter measurements.

Maxima.--January-February 1963: D1scharge, 7,340 cfs 1800 hours Feb. 14 (elevation, $51.21 \mathrm{ft})$

1895-96, 1940-63: Discharge observed, 57,000 cfs Dec. 9, 1950 (elevation, $69.19 \mathrm{ft})$.

Remarks.--Flow regulated by reservolrs and powerplants above station.

Mean discharge, in cub1c feet per second, 1963

\begin{tabular}{|c|c|c|c|c|c|c|c|c|}
\hline Day & January & February & Day & January & February & Day & January & February \\
\hline $\begin{array}{r}1 \ldots \ldots \\
2 \ldots \ldots \\
3 \ldots \ldots \\
4 \ldots \ldots \\
5 \ldots \ldots \\
7 \ldots \ldots \\
8 \ldots \ldots \\
9 \ldots \ldots \\
10 \ldots \ldots\end{array}$ & $\begin{array}{r}1,040 \\
859 \\
1,480 \\
1,440 \\
1,090 \\
903 \\
794 \\
1,080 \\
1,140 \\
982\end{array}$ & $\begin{array}{l}7,080 \\
4,930 \\
6,860 \\
6,890 \\
6,880 \\
6,900 \\
5,080 \\
3,160 \\
3,490 \\
3,910\end{array}$ & $\begin{array}{l}11 \ldots \ldots \\
12 \ldots \ldots \\
13 \ldots \ldots \\
14 \ldots \ldots \\
15 \ldots \ldots \\
16 \ldots \ldots \\
17 \ldots \ldots \\
18 \ldots \ldots \\
19 \ldots \ldots \\
20 \ldots \ldots\end{array}$ & $\begin{array}{r}1,110 \\
1,770 \\
903 \\
731 \\
690 \\
710 \\
762 \\
762 \\
773 \\
752\end{array}$ & $\begin{array}{l}4,200 \\
2,640 \\
2,450 \\
6,120 \\
4,440 \\
2,590 \\
2,250 \\
2,140 \\
3,300 \\
2,450\end{array}$ & $\begin{array}{l}21 \ldots \ldots \\
22 \ldots \ldots \\
23 \ldots \ldots \\
24 \ldots \ldots \\
25 \ldots \ldots \\
26 \ldots \ldots \\
27 \ldots \ldots \\
28 \ldots \ldots \\
29 \ldots \ldots \\
30 \ldots \ldots \\
31 \ldots \ldots\end{array}$ & $\begin{array}{l}660 \\
680 \\
752 \\
680 \\
762 \\
762 \\
742 \\
544 \\
640 \\
784 \\
773\end{array}$ & $\begin{array}{r}2,190 \\
2,290 \\
2,050 \\
1,510 \\
1,260 \\
1,620 \\
1,730 \\
1,590 \\
----- \\
---.-- \\
-----\end{array}$ \\
\hline $\begin{array}{l}\text { onthly } \\
\text { anoff, }\end{array}$ & $\begin{array}{l}\text { an di } \\
\text { acre }\end{array}$ & & & & & & $\begin{array}{r}869 \\
53,450 \\
\end{array}$ & $\begin{array}{r}3,429 \\
190,400 \\
\end{array}$ \\
\hline
\end{tabular}


11-2920. M1ddle Fork Stanislaus River at Kennedy Meadows, near Dardanelle, Callf.

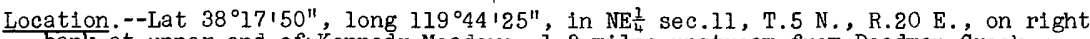
bank at upper end of Kennedy Meadows, 1.3 miles upstream from Deadman Creek, 1.6 miles downstream from Rellef Reservolr, and 6.0 miles west of Sonora Pass.

Drainage area. $--47.5 \mathrm{sq} \mathrm{ml}$.

Gage-he1ght record:--Water-stage recorder graph. Datum of gage is 6,320.1 ft above mean sea level (river-profile survey).

Discharge record.--Stage-discharge relation defined by current-meter measurements; affected by 1 ce Jan. 1, 2, 4-14, 19, 20.

Maxima.--January-February 1963: Discharge, 980 cfs 0300 hours Feb. 1 (gage height, $5.56 \mathrm{ft}$ )

1938 to December 1962: Discharge, 1,700 cfs Nov. 20, 1950 (gage height,

$6.66 \mathrm{ft}$ ).

Remarks.--Flow regulated by Rellef Reservolr (usable capacity, 15,600 acre-ft).

Mean discharge, in cubic feet per second, 1963

\begin{tabular}{|c|c|c|c|c|c|c|c|c|}
\hline Day & January & February & Day & January & February & Day & January & February \\
\hline $\begin{array}{c}1 \ldots \ldots \\
3 \ldots \ldots \\
4 \ldots \ldots \\
5 \ldots \ldots \\
6 \ldots \ldots \\
7 \ldots \ldots \\
9 \ldots \ldots \\
10 \ldots \ldots\end{array}$ & $\begin{array}{l}12 \\
12 \\
12 \\
12 \\
11 \\
11 \\
12 \\
12 \\
12 \\
12\end{array}$ & $\begin{array}{r}663 \\
171 \\
110 \\
95 \\
87 \\
76 \\
71 \\
66 \\
58 \\
53\end{array}$ & $\begin{array}{l}11 \ldots \ldots \\
12 \ldots \ldots \\
13 \ldots \ldots \\
14 \ldots \ldots \\
15 \ldots \ldots \\
16 \ldots \ldots \\
17 \ldots \ldots \\
18 \ldots \ldots \\
19 \ldots \ldots \\
20 \ldots \ldots\end{array}$ & $\begin{array}{l}10 \\
10 \\
10 \\
10 \\
12 \\
12 \\
11 \\
11 \\
10 \\
10\end{array}$ & $\begin{array}{l}49 \\
46 \\
46 \\
44 \\
47 \\
40 \\
38 \\
37 \\
37 \\
38\end{array}$ & $\begin{array}{l}21 \ldots \ldots \\
22 \ldots \ldots \\
23 \ldots \ldots \\
24 \ldots \ldots \\
25 \ldots \ldots \\
26 \ldots \ldots \\
27 \ldots \ldots \\
28 \ldots \ldots \\
29 \ldots \ldots \\
30 \ldots \ldots \\
31 \ldots \ldots\end{array}$ & $\begin{array}{l}10 \\
10 \\
10 \\
10 \\
10 \\
10 \\
10 \\
10 \\
11 \\
31 \\
329\end{array}$ & $\begin{array}{r}38 \\
37 \\
35 \\
37 \\
40 \\
43 \\
42 \\
42 \\
-\ldots--\end{array}$ \\
\hline $\begin{array}{l}\text { Monthly } \\
\text { Runoff, }\end{array}$ & $\begin{array}{l}\text { n disc } \\
\text { acre-f }\end{array}$ & 013 & 8 & & & & $\begin{array}{r}21.8 \\
1,340\end{array}$ & $\begin{array}{r}77.9 \\
4,320\end{array}$ \\
\hline
\end{tabular}

Gage height, in feet, and discharge, in cub1c feet per second, at indicated time, 1963

\begin{tabular}{|c|c|c|c|c|c|c|c|c|c|c|c|}
\hline Date & Hour & $\begin{array}{c}\text { Gage } \\
\text { helght }\end{array}$ & $\begin{array}{c}\text { Dis- } \\
\text { charge }\end{array}$ & Date & Hour & $\begin{array}{c}\text { Gage } \\
\text { height }\end{array}$ & $\begin{array}{l}\text { Dis- } \\
\text { charge }\end{array}$ & Date & Hour & $\begin{array}{c}\text { Gage } \\
\text { height }\end{array}$ & $\begin{array}{l}\text { Dis- } \\
\text { charge }\end{array}$ \\
\hline $\begin{array}{r}\text { Jan. } \\
30\end{array}$ & $\begin{array}{l}2400 \\
0300 \\
0900 \\
1500 \\
1900 \\
2300 \\
2400 \\
\end{array}$ & $\begin{array}{l}1.14 \\
1.11 \\
1.20 \\
1.56 \\
2.00 \\
2.56 \\
2.55 \\
2.32\end{array}$ & $\begin{array}{l}12 \\
\\
11 \\
14 \\
27 \\
48 \\
86 \\
85 \\
\end{array}$ & Feb. 1 & $\begin{array}{l}0600 \\
0700 \\
1400 \\
1700 \\
1500 \\
2100 \\
2400 \\
0300\end{array}$ & $\begin{array}{l}2.50 \\
2.50 \\
3.86 \\
4.65 \\
4.50 \\
4.90 \\
5.52 \\
5.56\end{array}$ & $\begin{array}{r}81 \\
81 \\
305 \\
560 \\
505 \\
660 \\
960 \\
980\end{array}$ & Feb. 1 & $\begin{array}{l}0800 \\
1100 \\
1700 \\
2400 \\
0500 \\
1100 \\
1800 \\
2400\end{array}$ & $\begin{array}{l}5.50 \\
5.00 \\
4.26 \\
3.66 \\
3.42 \\
3.20 \\
3.06 \\
2.91\end{array}$ & $\begin{array}{l}950 \\
700 \\
423 \\
256 \\
\\
205 \\
163 \\
141 \\
121\end{array}$ \\
\hline
\end{tabular}

11-2925. Clark Fork Stan1slaus River near Dardanelle, Calif.

Location.--Lat $38^{\circ} 21^{\prime} 50^{\prime \prime}$, long $119^{\circ} 52^{\prime} 30^{\prime \prime}$, in SE $\frac{1}{4}$ sec.15, T.6 N., R.19 E., on right bank $0.3 \mathrm{mlle}$ upstream from mouth and $3 \mathrm{mlles}$ northwest of Dardanelle.

Drainage area. $--65.7 \mathrm{sq} \mathrm{ml}$.

Gage-he1ght record --Water-stage recorder graph. Datum of gage $1 \mathrm{~s} 5,507.3 \mathrm{ft}$ above mean sea level (river-proflle survey).

Discharge record.--Stage-discharge relation defined by current-meter measurements below $1,100 \mathrm{cfs}$ and by slope-area measurement at $4,350 \mathrm{cfs}$; affected by lce Jan. $1-29$

Maxima.--January-February 1963: Discharge, 2,300 cfs 0400 hours Feb. 1 (gage helght, $9.00 \mathrm{ft}$ ).

1950 to December 1962: Discharge, 4,350 cfs Nov. 20, 1950 (gage helght, $11.88 \mathrm{ft})$. 
Mean d1scharge, In cub1c feet per second, 1963, of Clark Fork Stan1slaus R1ver near

\begin{tabular}{|c|c|c|c|c|c|c|c|c|}
\hline Day & January & February & Day & January & February & Day & January & February \\
\hline $\begin{array}{l}1 \ldots \ldots \\
2 \ldots \ldots \\
3 \ldots \ldots \\
4 \ldots \ldots \\
5 \ldots \ldots \\
6 \ldots \ldots \\
7 \ldots \ldots \\
9 \ldots \ldots \\
10 \ldots \ldots\end{array}$ & 25 & $\begin{array}{r}1,400 \\
381 \\
275 \\
246 \\
224 \\
198 \\
190 \\
180 \\
160 \\
151\end{array}$ & $\begin{array}{l}11 \ldots \ldots \\
12 \ldots \ldots \\
13 \ldots \ldots \\
14 \ldots \ldots \\
15 \ldots \ldots \\
16 \ldots \ldots \\
17 \ldots \ldots \\
18 \ldots \ldots \\
19 \ldots \ldots \\
20 \ldots \ldots\end{array}$ & $\begin{array}{l}18 \\
20 \\
18\end{array}$ & $\begin{array}{r}133 \\
124 \\
126 \\
116 \\
110 \\
107 \\
102 \\
99 \\
99 \\
99\end{array}$ & $\begin{array}{l}21 \ldots \ldots \\
22 \ldots \ldots \\
23 \ldots \ldots \\
24 \ldots \ldots \\
25 \ldots \ldots \\
26 \ldots \ldots \\
27 \ldots \ldots \\
28 \ldots \ldots \\
29 \ldots \ldots \\
30 \ldots \ldots \\
31 \ldots \ldots\end{array}$ & $\begin{array}{r}18 \\
\\
20 \\
25 \\
82 \\
650\end{array}$ & $\begin{array}{r}99 \\
99 \\
96 \\
97 \\
99 \\
110 \\
110 \\
109 \\
-\ldots- \\
-\ldots---1\end{array}$ \\
\hline $\begin{array}{l}\text { Monthly } \\
\text { Runoff, } \\
\text { Runoff, }\end{array}$ & $\begin{array}{l}\text { an dis } \\
\text { Inche } \\
\text { acre- }\end{array}$ & & & & & & $\begin{array}{r}43.6 \\
0.76 \\
2,680 \\
\end{array}$ & $\begin{array}{r}191 \\
3.02 \\
10,590 \\
\end{array}$ \\
\hline
\end{tabular}

Gage helght, in feet, and discharge, In cublc feet per second, at 1ndicated t1me, 1963

\begin{tabular}{|c|c|c|c|c|c|c|c|c|c|c|c|}
\hline Date & Hour & $\begin{array}{c}\text { Gage } \\
\text { he1ght }\end{array}$ & $\begin{array}{l}\text { Dis- } \\
\text { charge }\end{array}$ & Date & Hour & $\begin{array}{c}\text { Gage } \\
\text { helght }\end{array}$ & $\begin{array}{c}\text { Dis- } \\
\text { charge }\end{array}$ & Date & Hour & $\begin{array}{c}\text { Gage } \\
\text { he1ght }\end{array}$ & $\begin{array}{c}\text { D1s- } \\
\text { charge }\end{array}$ \\
\hline $\begin{array}{r}\text { Jan. } 29 \\
30\end{array}$ & $\begin{array}{l}2400 \\
0400 \\
0800 \\
1200 \\
1500 \\
1700 \\
1900 \\
2100 \\
2400\end{array}$ & $\begin{array}{l}2.51 \\
2.39 \\
2.37 \\
2.52 \\
2.82 \\
3.20 \\
3.44 \\
3.61 \\
3.67\end{array}$ & $\begin{array}{r}38 \\
27 \\
25 \\
39 \\
73 \\
125 \\
164 \\
194 \\
205\end{array}$ & Jan. 31 & $\begin{array}{l}0600 \\
0800 \\
0900 \\
1000 \\
1200 \\
1600 \\
1800 \\
2100 \\
2400\end{array}$ & $\begin{array}{l}3.81 \\
4.24 \\
4.07 \\
4.30 \\
4.85 \\
5.67 \\
6.15 \\
7.40 \\
8.30\end{array}$ & $\begin{array}{r}230 \\
319 \\
282 \\
332 \\
465 \\
720 \\
888 \\
1,400 \\
1,880\end{array}$ & Feb. I & $\begin{array}{l}0400 \\
0800 \\
1200 \\
1800 \\
2400 \\
\\
0600 \\
1200 \\
1800 \\
2400\end{array}$ & $\begin{array}{l}9.00 \\
8.44 \\
7.06 \\
5.85 \\
5.04 \\
4.60 \\
4.34 \\
4.18 \\
4.06\end{array}$ & $\begin{array}{r}2,300 \\
1,960 \\
1,260 \\
798 \\
542 \\
\\
425 \\
360 \\
322 \\
295\end{array}$ \\
\hline
\end{tabular}

11-2926. Donne11 Lake near Dardanelle, Calif.

(Formerly published as Donnelis Reservoir near Dardanelle)

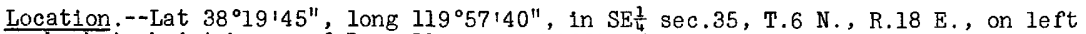
bank in hoist house of Donnell Dam on Middle Fork Stanislaus River, $1.2 \mathrm{miles}$ downstream from Niagara Creek, and 7.2 miles west of Dardanelle.

Drainage area. $--230 \mathrm{sq} \mathrm{mi}$.

Gage-helght record.--Water-stage recorder graph, except Feb, 4-17. Datum of gage is $4.84 \mathrm{ft}$ above mean sea level (levels by Oakdale and South San Joaquin Irrigation Districts).

Contents record.--Contents computed from capacity table dated oct. 1, 1956, furnished by Pacific Gas and Electric Co., except for period Feb. 4-17 when contents were interpolated.

Maxima.--January-February 1963: Computed bihourly inflow, 14,500 cfs 2400 hours Jan. 31 to 0200 hours Feb. 1; contents, 54,600 acre-ft Feb. 4 (gage height, $4,891.8 \mathrm{ft}$, estimated)

1957 to December 1962: Contents, 64,800 acre-ft June 1, 1959, July 2, 1962 (gage helght, 4,917.1 ft).

Remarks.--Lake is formed by concrete arch-type dam completed in 1957. Capacity, 62,590 acre-ft between gage heights 4,720 (minimum operating head) and 4,917.0 ft (top of spillway gates). Records represent total contents, of which 2,150 acre-ft is below minimum operating head. Inflow data furnished by Corps of Engineers. 
Elevation, in feet, and contents, In acre-feet, at 2400 hours, 1963, of Donnell Lake near

\begin{tabular}{|c|c|c|c|c|c|c|c|c|}
\hline \multicolumn{2}{|c|}{ January } & \multicolumn{2}{|c|}{ February } & \multirow{2}{*}{ Day } & \multicolumn{2}{|c|}{ January } & \multicolumn{2}{|c|}{ February } \\
\hline Elevation & Contents & Elevation & Contents & & Elevation & Contents & Elevation & Contents \\
\hline $\begin{array}{l}4,807.6 \\
4,807.7 \\
4,808.0 \\
4,808.3 \\
4,808.5 \\
4,808.8 \\
4,808.9 \\
4,808.7 \\
4,808.9 \\
4,809.2 \\
4,809.3 \\
4,809.3 \\
4,809.5 \\
4,809.7 \\
4,809.9\end{array}$ & $\begin{array}{l}24,400 \\
24,500 \\
24,600 \\
24,700 \\
24,700 \\
24,800 \\
24,900 \\
24,800 \\
24,900 \\
25,000 \\
25,000 \\
25,000 \\
25,100 \\
25,100 \\
25,200\end{array}$ & $\begin{array}{c}4,885.0 \\
4,889.9 \\
4,891.6 \\
= \\
= \\
= \\
= \\
= \\
= \\
= \\
= \\
-\end{array}$ & $\begin{array}{c}51,700 \\
53,700 \\
54,300 \\
= \\
= \\
= \\
= \\
- \\
- \\
= \\
= \\
- \\
-\end{array}$ & $\begin{array}{l}16 \\
17 \\
18 \\
19 \\
20 \\
21 \\
22 \\
23 \\
24 \\
25 \\
26 \\
27 \\
28 \\
29 \\
30 \\
31\end{array}$ & $\begin{array}{l}4,810.2 \\
4,810.4 \\
4,810.7 \\
4,810.8 \\
4,811.1 \\
4,811.3 \\
4,811.5 \\
4,811.7 \\
4,811.9 \\
4,812.1 \\
4,812.3 \\
4,812.5 \\
4,811.7 \\
4,811.6 \\
4,813.2 \\
4,845.4\end{array}$ & $\begin{array}{l}25,300 \\
25,300 \\
25,400 \\
25,500 \\
25,600 \\
25,600 \\
25,700 \\
25,800 \\
25,800 \\
25,900 \\
25,900 \\
26,000 \\
25,800 \\
25,700 \\
26,200 \\
37,100\end{array}$ & $\begin{array}{c}- \\
- \\
4,876.8 \\
4,874.7 \\
4,873.5 \\
4,872.6 \\
4,871.8 \\
4,870.9 \\
4,869.8 \\
4,869.1 \\
4,868.8 \\
4,868.8 \\
4,869.2 \\
- \\
- \\
-\end{array}$ & $\begin{array}{c}- \\
- \\
48,600 \\
47,800 \\
47,300 \\
47,000 \\
46,700 \\
46,300 \\
45,900 \\
45,700 \\
45,600 \\
45,600 \\
45,700 \\
- \\
- \\
-\end{array}$ \\
\hline & & & & & - & $+12,700$ & - & $+8,600$ \\
\hline
\end{tabular}

Average inflow, in cubic feet per second, for bihourly periods ending at indicated time, 1963

\begin{tabular}{|c|c|c|c|c|c|c|c|c|}
\hline Date & Hour & Inflow & Date & Hour & Inflow & Date & Hour & Inflow \\
\hline Jan. 31 & $\begin{array}{l}0200 \\
0400 \\
0600 \\
0800 \\
1000 \\
1200 \\
1400 \\
1600 \\
1800\end{array}$ & $\begin{array}{r}1,100 \\
910 \\
1,790 \\
2,000 \\
2,420 \\
4,040 \\
4,880 \\
6,730 \\
6,790\end{array}$ & $\begin{array}{l}\text { Jan. } 31 \\
\text { Feb. } 1\end{array}$ & $\begin{array}{l}2000 \\
2200 \\
2400 \\
\\
0200 \\
0400 \\
0600 \\
0800 \\
1000\end{array}$ & $\begin{array}{r}10,300 \\
13,500 \\
13,000 \\
14,500 \\
14,400 \\
11,500 \\
12,800 \\
7,410\end{array}$ & Feb. 1 & $\begin{array}{l}1200 \\
1400 \\
1600 \\
1800 \\
2000 \\
2200 \\
2400\end{array}$ & $\begin{array}{l}6,490 \\
6,290 \\
4,230 \\
4,010 \\
3,550 \\
2,390 \\
2,390\end{array}$ \\
\hline
\end{tabular}

11-2926.8. Cascade Creek near Pinecrest, Calif.

Location.--Lat $38^{\circ} 16^{\prime} 45^{\prime \prime}$, long $119^{\circ} 58^{\prime} 10^{\prime \prime}$, in SW $\frac{1}{4} \mathrm{SW} \frac{1}{4} \sec .14, \mathrm{~T} .5 \mathrm{~N} ., \mathrm{R} .18 \mathrm{E}$. , on State Highway $108,6.4$ miles northeast of town of Pinecrest.

Drainage area. $--4.97 \mathrm{sq} \mathrm{ml}$.

Gage-helght record.-Water-stage recorder graph and crest-stage gage. Altitude of gage is $6,020 . \mathrm{ft}$ (from topographic map).

Discharge record.--Stage-discharge relation defined by current-meter measurements below $220 \mathrm{cfs}$ and by computation of flow through culvert.

Maxima,--January-February 1963: Discharge, 532 cfs 0230 hours Feb. I (gage height, $10.35 \mathrm{ft}$ in gage wel1; $10.5 \mathrm{ft}$, from floodmarks). October-December 1962: Discharge, 4.4 cfs Dec. 16, 1962 (gage height, $3.38 \mathrm{ft}$ ).

Mean discharge, in cubic feet per second, 1963

\begin{tabular}{|c|c|c|c|c|c|c|c|c|}
\hline Day & Januery & February & Day & January & February & Day & January & February \\
\hline $\begin{array}{c}1 \ldots \ldots \\
2 \ldots \ldots \\
3 \ldots \ldots \\
5 \ldots \ldots \\
6 \ldots \ldots \\
8 \ldots \ldots \\
9 \ldots \ldots \\
10 \ldots \ldots\end{array}$ & 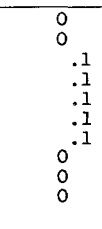 & $\begin{array}{r}260 \\
43 \\
23 \\
17 \\
13 \\
12 \\
12 \\
12 \\
11 \\
11\end{array}$ & $\begin{array}{l}11 \ldots \ldots \\
12 \ldots \ldots \\
13 \ldots \ldots \\
14 \ldots \ldots \\
15 \ldots \ldots \\
16 \ldots \ldots \\
17 \ldots \ldots \\
18 \ldots \ldots \\
19 \ldots \ldots \\
20 \ldots \ldots\end{array}$ & $\begin{array}{l}0 \\
0 \\
0 \\
0 \\
0 \\
0 \\
0 \\
0 \\
0 \\
0\end{array}$ & $\begin{array}{l}9.6 \\
8.8 \\
9.6 \\
7.8 \\
7.0 \\
6.7 \\
6.3 \\
6.2 \\
6.2 \\
6.2\end{array}$ & $\begin{array}{l}21 \ldots \ldots \\
22 \ldots \ldots \\
23 \ldots \ldots \\
24 \ldots \ldots \\
25 \ldots \ldots \\
26 \ldots \ldots \\
27 \ldots \ldots \\
28 \ldots \ldots \\
29 \ldots \ldots \\
30 \ldots \ldots \\
31 \ldots \ldots\end{array}$ & $\begin{array}{c}0 \\
0 \\
0 \\
0 \\
0 \\
0 \\
0 \\
0 \\
0 \\
5.7 \\
154\end{array}$ & $\begin{array}{r}6.0 \\
5.7 \\
5.2 \\
5.2 \\
5.2 \\
5.2 \\
5.1 \\
4.8 \\
---- \\
--.-\end{array}$ \\
\hline $\begin{array}{l}\text { Zunoff, } \\
\text { iunoff, }\end{array}$ & $\begin{array}{l}\text { inche } \\
\text { acre- }\end{array}$ & & & & & & $\begin{array}{r}5.17 \\
1.20 \\
318 \\
\end{array}$ & $\begin{array}{r}19.0 \\
3.96 \\
1,050 \\
\end{array}$ \\
\hline
\end{tabular}


Gage height, in feet, and discharge, in cublc feet per second, at indicated time, 1963, of Cascade creek near Pinecrest, Calif.

\begin{tabular}{|c|c|c|c|c|c|c|c|c|c|c|c|}
\hline Date & Hour & $\begin{array}{c}\text { Gage } \\
\text { helght }\end{array}$ & $\begin{array}{l}\text { D1s- } \\
\text { charge }\end{array}$ & Date & Hour & $\begin{array}{c}\text { Gage } \\
\text { helght }\end{array}$ & $\begin{array}{c}\text { DIs - } \\
\text { charge }\end{array}$ & Date & Hour & $\begin{array}{c}\text { Gage } \\
\text { helght }\end{array}$ & $\begin{array}{l}\text { D1s- } \\
\text { charge }\end{array}$ \\
\hline $\begin{array}{r}\text { Jan. } 30 \\
31\end{array}$ & $\begin{array}{l}2400 \\
0400 \\
0600 \\
0900 \\
1200 \\
1400 \\
1500 \\
1600 \\
1700 \\
1800 \\
2000 \\
2100 \\
2200\end{array}$ & $\begin{array}{l}3.64 \\
3.76 \\
3.73 \\
4.38 \\
5.97 \\
6.75 \\
6.55 \\
6.51 \\
7.12 \\
7.22 \\
7.90 \\
8.47 \\
8.27\end{array}$ & $\begin{array}{l}8.6 \\
11 \\
10 \\
37 \\
163 \\
225 \\
209 \\
206 \\
255 \\
263 \\
317 \\
363 \\
347\end{array}$ & Feb. 1 & $\begin{array}{l}2230 \\
2330 \\
2345 \\
2400 \\
\\
0030 \\
0130 \\
0230 \\
0300 \\
0500 \\
0715 \\
0800 \\
1000 \\
1300\end{array}$ & $\begin{array}{r}8.54 \\
8.57 \\
8.72 \\
8.50 \\
8.41 \\
9.45 \\
10.35 \\
9.95 \\
9.02 \\
8.30 \\
8.60 \\
7.23 \\
6.06\end{array}$ & $\begin{array}{l}369 \\
371 \\
385 \\
365 \\
358 \\
450 \\
532 \\
496 \\
412 \\
349 \\
374 \\
263 \\
170\end{array}$ & Feb. 1 & $\begin{array}{l}1600 \\
1700 \\
1900 \\
2000 \\
2200 \\
2400 \\
\\
0600 \\
1000 \\
1200 \\
1800 \\
2200 \\
2400\end{array}$ & $\begin{array}{l}5.82 \\
5.87 \\
5.41 \\
5.40 \\
5.06 \\
4.90 \\
4.57 \\
4.43 \\
4.42 \\
4.35 \\
4.25 \\
4.23\end{array}$ & $\begin{array}{r}151 \\
155 \\
118 \\
117 \\
90 \\
77\end{array}$ \\
\hline
\end{tabular}

11-2927. Middle Fork Stantslaus River at Hells Half Acre Bridge, Calif.

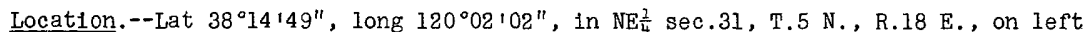
bank $200 \mathrm{ft}$ upstream from Donnells powerhouse, $800 \mathrm{ft}$ downstream from Hells Half Acre Bridge, 1.1 miles upstream from Cow Creek, and 3.7 miles northwest of Strawberry.

Drainage area. $--287 \mathrm{sq} \mathrm{mi}$.

Gage-he1ght record.--Water-stage recorder graph. Datum of gage is $3,410.94 \mathrm{ft}$ above mean sea level.

Discharge record.--Stage-discharge relation defined by current-meter measurements below 2,100 cfs and by computation of peak inflow to Beardsley Lake at $8,240 \mathrm{cfs}$.

Maxima.--January-February 1963: Discharge, 7,600 cfs 2400 hours Jan. 31 (gage height, $12.20 \mathrm{ft}$ ).

1905 to December 1962: Discharge, 26,600 cfs Dec. 23, 1955 (gage height, $17.72 \mathrm{ft}$ site and datum then in use, about $23 \mathrm{ft}$ present datum, from floodmarks).

Remarks.--Floodflow affected by Relief Reservolr since 1909 (capacity, 15,600 acre$f^{\prime} t$ ) and Donnell Lake (see station 11-2926) since 1957.

Mean discharge, in cuble feet per spcond, 1963

\begin{tabular}{|c|c|c|c|c|c|c|c|c|}
\hline Day & January & February & Day & January & February & Day & January & February \\
\hline $\begin{array}{r}\ldots \ldots \\
2 \ldots \ldots \\
3 \ldots \ldots \\
5 \ldots \ldots \\
6 \ldots \ldots \\
7 \ldots \ldots \\
8 \ldots \ldots \\
10 \ldots \ldots\end{array}$ & $\begin{array}{l}14 \\
14 \\
15 \\
15 \\
15 \\
15 \\
15 \\
15 \\
15 \\
15\end{array}$ & $\begin{array}{r}3,660 \\
711 \\
435 \\
345 \\
290 \\
240 \\
213 \\
191 \\
176 \\
176\end{array}$ & $\begin{array}{l}11 \ldots \ldots \\
12 \ldots \ldots \\
13 \ldots \ldots \\
14 \ldots \ldots \\
15 \ldots \ldots \\
16 \ldots \ldots \\
17 \ldots \ldots \\
15 \ldots \ldots \\
19 \ldots \ldots \\
20 \ldots \ldots\end{array}$ & $\begin{array}{l}14 \\
14 \\
14 \\
14 \\
14 \\
14 \\
14 \\
14 \\
14 \\
14\end{array}$ & $\begin{array}{l}160 \\
148 \\
222 \\
236 \\
184 \\
166 \\
152 \\
141 \\
135 \\
132\end{array}$ & $\begin{array}{l}21 \ldots \ldots \\
22 \ldots \ldots \\
23 \ldots \ldots \\
24 \ldots \ldots \\
25 \ldots \ldots \\
26 \ldots \ldots \\
27 \ldots \ldots \\
28 \ldots \ldots \\
29 \ldots \ldots \\
30 \ldots \ldots \\
31 \ldots \ldots\end{array}$ & $\begin{array}{r}14 \\
14 \\
15 \\
15 \\
15 \\
15 \\
15 \\
15 \\
16 \\
161 \\
3,200 \\
\end{array}$ & $\begin{array}{r}127 \\
116 \\
106 \\
102 \\
98 \\
98 \\
95 \\
85 \\
--- \\
-\ldots \\
-\end{array}$ \\
\hline \multicolumn{7}{|c|}{ 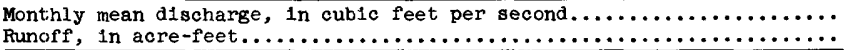 } & $\begin{array}{r}122 \\
7,500 \\
\end{array}$ & $\begin{array}{r}319 \\
17,730 \\
\end{array}$ \\
\hline
\end{tabular}

Gage he1ght, in feet, and discharge, in cub1c feet per second, at indicated time, 1963

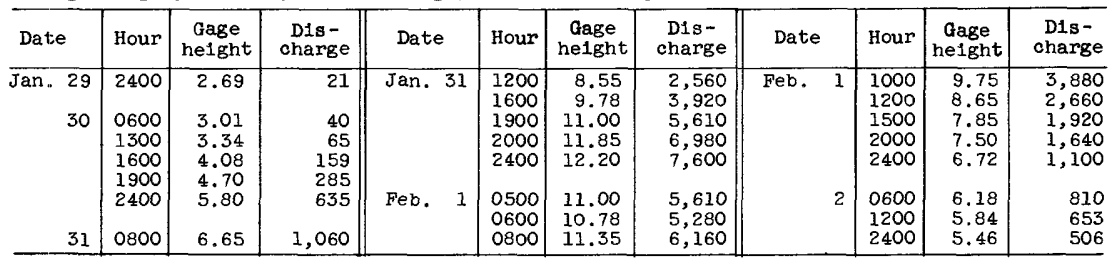


11-2928. Beardsley Lake near Strawberry, Calif.

Location.--Lat $38^{\circ} 12^{\prime} 17^{\prime \prime}$, long $120^{\circ} 04^{\prime} 31^{\prime \prime}$, in NW $\frac{1}{4}$ sec.14, T.4 N., R.17 E., in hoist house of Beardsley Dam on Middle Fork Stanislaus River, 2.4 miles upstream from Spring Gap powerhouse, 3.9 miles west of Strawberry, and 4.7 miles west of Pinecrest.

Drainage area. $--309 \mathrm{sq} \mathrm{mi}$.

Gage-height record. - Water-stage recorder graph. Datum of gage is $7.84 \mathrm{ft}$ above mean sea level (levels by Oakdale and South San Joaquin Irrigation District).

Contents record.--Contents computed from capacity table dated oct. 3, 1956 .

Maxima.--January-February 1963: Computed bihourly inflow, $8,240 \mathrm{cfs} 2200$ to 2400 hours Jan. 31. Contents, 78,400 acre-ft 0800 to 1600 hours Feb. 4 (gage height, $3,368.8 \mathrm{ft}$ ).

1957 to December 1962: Contents, 98,700 acre-ft June 27, 1957 (gage height, $3,398.2 \mathrm{ft}$ ).

Remarks.--Reservoir is formed by rockfill, earth-core dam completed in 1957. Capacity, 98,300 acre-ft between gage heights $3,145.0 \mathrm{ft}$ (tunnel invert) and $3,398.0 \mathrm{ft}$ (top of spillway gates). No dead storage. Records represent total contents.

Elevation, in feet, and contents, in acre-feet, at 2400 hours, 1963

\begin{tabular}{|c|c|c|c|c|c|c|c|c|c|}
\hline \multirow{2}{*}{ Day } & \multicolumn{2}{|c|}{ January } & \multicolumn{2}{|c|}{ February } & \multirow{2}{*}{ Day } & \multicolumn{2}{|c|}{ January } & \multicolumn{2}{|c|}{ February } \\
\hline & Elevation & Contents & Elevation & Contents & & Elevation & Contents & Elevation & Contents \\
\hline $\begin{array}{r}1 \\
2 \\
3 \\
4 \\
5 \\
6 \\
7 \\
8 \\
9 \\
10 \\
11 \\
12 \\
13 \\
14 \\
15\end{array}$ & $\begin{array}{l}3,347.4 \\
3,347.1 \\
3,346.9 \\
3,346.5 \\
3,346.3 \\
3,346.1 \\
3,345.8 \\
3,345.6 \\
3,345.6 \\
3,345.5 \\
3,344.9 \\
3,344.6 \\
3,344.4 \\
3,344.0 \\
3,343.8\end{array}$ & $\begin{array}{l}64,800 \\
64,600 \\
64,500 \\
64,200 \\
64,100 \\
64,000 \\
63,800 \\
63,700 \\
63,700 \\
63,600 \\
63,200 \\
63,100 \\
62,900 \\
62,700 \\
62,600\end{array}$ & $\begin{array}{l}3,365.4 \\
3,367.6 \\
3,368.7 \\
3,368.7 \\
3,368.7 \\
3,368.6 \\
3,368.6 \\
3,368.5 \\
3,368.5 \\
3,368.5 \\
3,368.4 \\
3,368.4 \\
3,368.6 \\
3,368.6 \\
3,368.5\end{array}$ & $\begin{array}{l}76,100 \\
77,600 \\
78,300 \\
78,300 \\
78,300 \\
78,200 \\
78,200 \\
78,200 \\
78,200 \\
78,200 \\
78,100 \\
78,100 \\
78,200 \\
78,200 \\
78,200\end{array}$ & $\begin{array}{l}16 \\
17 \\
18 \\
19 \\
20 \\
21 \\
22 \\
23 \\
24 \\
25 \\
26 \\
27 \\
28 \\
29 \\
30 \\
31\end{array}$ & $\begin{array}{l}3,343 \cdot 6 \\
3,343 \cdot 3 \\
3,343 \cdot 0 \\
3,342 \cdot 7 \\
3,342 \cdot 5 \\
3,342 \cdot 2 \\
3,342 \cdot 1 \\
3,341.8 \\
3,341.6 \\
3,341 \cdot 3 \\
3,341 \cdot 0 \\
3,340.8 \\
3,341 \cdot 1 \\
3,341 \cdot 1 \\
3,341 \cdot 7 \\
3,352 \cdot 5\end{array}$ & $\begin{array}{l}62,500 \\
62,300 \\
62,100 \\
61,900 \\
61,800 \\
61,600 \\
61,600 \\
61,400 \\
61,300 \\
61,100 \\
60,900 \\
60,800 \\
61,000 \\
61,000 \\
61,300 \\
67,900\end{array}$ & $\begin{array}{c}3,368.5 \\
3,368.5 \\
3,368.4 \\
3,368.4 \\
3,368.2 \\
3,368.0 \\
3,367.7 \\
3,367.5 \\
3,367.2 \\
3,366.8 \\
3,366.5 \\
3,366.1 \\
3,365.8 \\
- \\
- \\
-\end{array}$ & $\begin{array}{c}78,200 \\
78,200 \\
78,100 \\
78,100 \\
78,000 \\
77,800 \\
77,600 \\
77,500 \\
77,300 \\
77,100 \\
76,900 \\
76,600 \\
76,400 \\
- \\
- \\
-\end{array}$ \\
\hline & $111 \mathrm{con}$ & 3,211 & sect. & & & 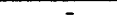 & $+3,100$ & - & $+8,500$ \\
\hline
\end{tabular}

11-2929. Middle Fork Stanislaus River below Beardsley Dam, Callf.

Location.--Lat $38^{\circ} 11^{\prime} 36^{\prime \prime}$, long $120^{\circ} 05^{\prime} 53^{\prime \prime}$, in NW $\frac{1}{4}$ sec.22, T.4 N., R.17 E., on right bank $0.5 \mathrm{mile}$ downstream from Beardsley powerhouse afterbay dam, $1.5 \mathrm{miles}$ downstream from Beardsley Dam, and 5.7 miles west of town of Pinecrest.

Drainage area. $--316 \mathrm{sq} \mathrm{m} 1$.

Gage-height record:--Water-stage recorder graph. Datum of gage is $3,044.7 \mathrm{ft}$ above mean sea level (river-profile survey).

Discharge record.--Stage-discharge relation defined by current-meter measurements below 4,000 cfs.

Maxima.--January-February 1963: Discharge, 1,020 cfs 1000 to 2300 hours Feb. 4 (gage helght, $6.15 \mathrm{ft}$ ).

1956 to Décember 1962: Discharge, 5,860 ofs May 23, 1958 (gage height, $10.48 \mathrm{ft})$.

Remarks.--Flow regulated by Relief Reservoir (capacity, 15,600 acre-ft), Donnell Lake (see station 11-2926) since April 1957, and by Beardsley Lake (see station 11-2928) since January 1957. 
Mean discharge, in cubic feet per second, 1963, of Middle Fork Stanislaus River below Beardsley Dam, Calif.

\begin{tabular}{|c|c|c|c|c|c|c|c|c|}
\hline Day & January & February & Day & January & February & Day & January & February \\
\hline $\begin{array}{r}\ldots \ldots \\
2 \ldots \ldots \\
3 \ldots \ldots \\
5 \ldots \ldots \\
6 \ldots \ldots \\
7 \ldots \ldots \\
9 \ldots \ldots \\
10 \ldots \ldots\end{array}$ & $\begin{array}{l}103 \\
106 \\
103 \\
114 \\
108 \\
112 \\
108 \\
112 \\
101 \\
103\end{array}$ & $\begin{array}{r}474 \\
615 \\
695 \\
1,010 \\
996 \\
942 \\
900 \\
876 \\
859 \\
859\end{array}$ & $\begin{array}{l}11 \ldots \ldots \\
12 \ldots \ldots \\
13 \ldots \ldots \\
14 \ldots \ldots \\
15 \ldots \ldots \\
16 \ldots \ldots \\
17 \ldots \ldots \\
18 \ldots \ldots \\
19 \ldots \ldots \\
20 \ldots \ldots\end{array}$ & $\begin{array}{l}101 \\
109 \\
113 \\
115 \\
103 \\
103 \\
101 \\
106 \\
103 \\
100\end{array}$ & $\begin{array}{l}842 \\
832 \\
888 \\
942 \\
888 \\
854 \\
837 \\
832 \\
820 \\
771\end{array}$ & $\begin{array}{l}21 \ldots \ldots \\
22 \ldots \ldots \\
23 \ldots \ldots \\
24 \ldots \ldots \\
25 \ldots \ldots \\
26 \ldots \ldots \\
27 \ldots \ldots \\
28 \ldots \ldots \\
29 \ldots \ldots \\
30 \ldots \ldots \\
31 \ldots \ldots\end{array}$ & $\begin{array}{r}100 \\
100 \\
101 \\
99 \\
100 \\
98 \\
97 \\
97 \\
97 \\
99 \\
117\end{array}$ & $\begin{array}{r}670 \\
646 \\
638 \\
638 \\
638 \\
633 \\
458 \\
369 \\
--.-- \\
-\ldots--\end{array}$ \\
\hline \multicolumn{7}{|c|}{ 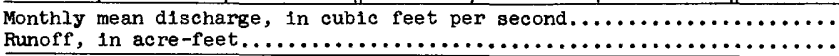 } & $\begin{array}{r}104 \\
6,400 \\
\end{array}$ & $\begin{array}{r}765 \\
42,490\end{array}$ \\
\hline
\end{tabular}

11-2930. Middle Fork Stanislaus River at Sand Bar Flat, near Avery, Calif.

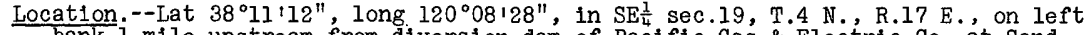
bank 1 mile upstream from diversion dam of Pacific Gas \& Electric Co. at Sand Bar Flat, 6.5 miles north of Long Barn, and 13 miles southeast of Avery.

Drainage area. $--325 \mathrm{sq} \mathrm{mi}$.

Gage-height record --Water-stage recorder graph. Datum of gage is 2,755 ft above mean sea level (river-profile survey).

Discharge record.--Stage-discharge relation defined by current-meter measurements.

Maxima.--January-February 1963: Discharge, 1,130 cfs 1000 hours Feb. 5 (gage height, $6.48 \mathrm{ft}$ ).

1905-57 (prior to regulation by Beardsley Lake and Donnells Reservo1r): Discharge, 26,000 cfs Dec. 23, 1955 gage height, $20.2 \mathrm{ft}$, from floodmarks), from rating curve extended above 6,000 cfs on basis of computation of peak flow over dam.

1957 to December 1962: Discharge, 6,030 cfs May 23, 1958 (gage height, $11.60 \mathrm{ft})$.

Remarks.--Flow regulated by Relief Reservoir since 1909 (capacity, 15,600 acre-ft), Donnells Reservoir since April 1957 (see station 11-2926), and Beardsley Lake since January 1957 (see station 11-2928).

Mean discharge, in cublc feet per second, 1963

\begin{tabular}{|c|c|c|c|c|c|c|c|c|}
\hline Day & January & February & Day & January & February & Day & January & February \\
\hline $\begin{array}{c}\ldots \ldots \\
2 \ldots \ldots \\
3 \ldots \ldots \\
4 \ldots \ldots \\
6 \ldots \ldots \\
7 \ldots \ldots \\
8 \ldots \ldots \\
9 \ldots \ldots \\
10 \ldots \ldots\end{array}$ & $\begin{array}{l}108 \\
112 \\
114 \\
118 \\
106 \\
112 \\
108 \\
114 \\
107 \\
107\end{array}$ & $\begin{array}{r}654 \\
734 \\
794 \\
1,080 \\
1,080 \\
1,020 \\
975 \\
950 \\
931 \\
931\end{array}$ & $\begin{array}{l}11 \ldots \ldots \\
12 \ldots \ldots \\
13 \ldots \ldots \\
14 \ldots \ldots \\
15 \ldots \ldots \\
16 \ldots \ldots \\
17 \ldots \ldots \\
18 \ldots \ldots \\
19 \ldots \ldots \\
20 \ldots \ldots\end{array}$ & $\begin{array}{l}110 \\
119 \\
128 \\
130 \\
118 \\
118 \\
117 \\
121 \\
118 \\
114\end{array}$ & $\begin{array}{r}918 \\
908 \\
965 \\
1,020 \\
970 \\
940 \\
922 \\
913 \\
904 \\
859\end{array}$ & $\begin{array}{l}21 \ldots \ldots \\
22 \ldots \ldots \\
23 \ldots \ldots \\
24 \ldots \ldots \\
25 \ldots \ldots \\
26 \ldots \ldots \\
27 \ldots \ldots \\
28 \ldots \ldots \\
29 \ldots \ldots \\
30 \ldots \ldots \\
31 \ldots \ldots\end{array}$ & $\begin{array}{l}112 \\
117 \\
111 \\
108 \\
104 \\
102 \\
102 \\
102 \\
102 \\
131 \\
233\end{array}$ & $\begin{array}{r}762 \\
746 \\
738 \\
734 \\
730 \\
730 \\
568 \\
444 \\
---- \\
---- \\
---\end{array}$ \\
\hline \multicolumn{7}{|c|}{ 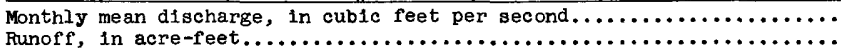 } & $\begin{array}{r}117 \\
7,190\end{array}$ & $\begin{array}{r}854 \\
47,440\end{array}$ \\
\hline
\end{tabular}

11-2933. North Fork Stanislaus River tributary near Lake Alpine, Calif.

(Crest-stage station)

Location.--Lat $38^{\circ} 30^{\prime} 20^{\prime \prime}$, long $119^{\circ} 56150^{\prime \prime}$, in $\mathrm{SE} \frac{1}{4} \mathrm{NW} \frac{1}{4} \sec .36, \mathrm{~T} .8 \mathrm{~N} ., \mathrm{R} .18 \mathrm{E}$. , on State Highway $4,3.2$ miles northeast of Lake Alpine.

Drainage area. $--0.28 \mathrm{sq} \mathrm{mi}$.

Gage-helght record.--Crest stages only. Altitude of gage is 7,930 ft (from topograph1c map).

D1scharge record.--Maximum discharge by computation of flow through culvert.

Maxima.--January-February 1963: Discharge, 23 cfs Feb. 1 (gage height, $13.04 \mathrm{ft}$, from high-water profile).

July to December 1962: No significant floodflow. 
11-2935. North Fork Stanislaus River below Silver Creek, Calif.

Location.--Lat $38^{\circ} 26^{\prime} 22^{\prime \prime}$, long $120^{\circ} 00^{\prime} 53^{\prime \prime}$, in SE $\frac{1}{4}$ sec.20, T.7 N., R.18 E., on right bank 100 ft downstream from Silver Creek and 5.6 miles northeast of Big Meadow.

Drainage area. $--27.8 \mathrm{sq} \mathrm{mi}$.

Gage-height record - -Water-stage recorder graph. Datum of gage is $6,677.3 \mathrm{ft}$ above mean sea level (river-profile survey).

Discharge record.--Stage-discharge relation defined by current-meter measurements; affected by 1ce Jan. 1, 11-13, Feb. 4-11, 13, 14 .

Maxima.--January-February 1963: Discharge, 970 cf's 2100 hours Jan. 31 (gage height, $8.75 \mathrm{ft})$.

1952 to December 1962: Discharge, 1,370 cfs Dec. 23, 1955 (gage height,

$9.17 \mathrm{ft}$ ), from rating curve extended above $500 \mathrm{cfs}$.

Flood of Nov. 20, 1950, reached a stage of $11.17 \mathrm{ft}$, from Pacific Gas \& Electric Co. recorder chart (discharge, 2,790 cf's).

Remarks.--Flow slightly affected by storage in Lake Alpine, Union, and Utica Reservoirs (combined capacity, 9,600 acre-ft).

Mean discharge, In cub1c feet per second, 1963

\begin{tabular}{|c|c|c|c|c|c|c|c|c|}
\hline Day & January & February & Day & January & February & Day & January & February \\
\hline $\begin{array}{c}1 \ldots \ldots \\
2 \ldots \ldots \\
3 \ldots \ldots \\
4 \ldots \ldots \\
6 \ldots \ldots \\
7 \ldots \ldots \\
5 \ldots \ldots \\
9 \ldots \ldots \\
10 \ldots \ldots\end{array}$ & $\begin{array}{l}5.6 \\
5.6 \\
5.3 \\
5.3 \\
5.2 \\
5.2 \\
5.0 \\
4.9 \\
4.9 \\
4.9\end{array}$ & $\begin{array}{l}636 \\
326 \\
224 \\
190 \\
170 \\
150 \\
130 \\
120 \\
100 \\
90\end{array}$ & $\begin{array}{l}11 \ldots \ldots \\
12 \ldots \ldots \\
13 \ldots \ldots \\
14 \ldots \ldots \\
15 \ldots \ldots \\
16 \ldots \ldots \\
17 \ldots \ldots \\
18 \ldots \ldots \\
19 \ldots \ldots \\
20 \ldots \ldots\end{array}$ & $\begin{array}{l}4.9 \\
4.8 \\
4.7 \\
4.7 \\
4.5 \\
4.5 \\
4.5 \\
4.3 \\
5.4 \\
9.6\end{array}$ & $\begin{array}{l}80 \\
72 \\
83 \\
80 \\
75 \\
70 \\
64 \\
60 \\
58 \\
58\end{array}$ & $\begin{array}{l}21 \ldots \ldots \\
22 \ldots \ldots \\
23 \ldots \ldots \\
24 \ldots \ldots \\
25 \ldots \ldots \\
26 \ldots \ldots \\
27 \ldots \ldots \\
28 \ldots \ldots \\
29 \ldots \ldots \\
30 \ldots \ldots \\
31 \ldots \ldots\end{array}$ & $\begin{array}{r}20 \\
17 \\
5.8 \\
5.0 \\
5.0 \\
4.9 \\
4.7 \\
4.7 \\
4.9 \\
11 \\
441\end{array}$ & $\begin{array}{r}60 \\
57 \\
53 \\
51 \\
49 \\
54 \\
71 \\
67 \\
----\end{array}$ \\
\hline \multicolumn{7}{|c|}{ 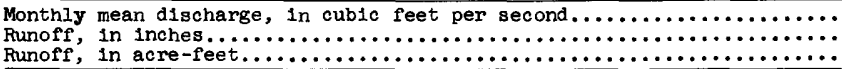 } & $\begin{array}{r}20.3 \\
0.84 \\
1,250\end{array}$ & $\begin{array}{r}11 a \\
4.41 \\
6,540 \\
\end{array}$ \\
\hline
\end{tabular}

Gage helght, in feet, and discharge, in cublc feet per second, at indicated time, 1963

\begin{tabular}{|c|c|c|c|c|c|c|c|c|c|c|c|}
\hline Date & Hour & $\begin{array}{c}\text { Cage } \\
\text { helght }\end{array}$ & $\begin{array}{l}\text { Dis- } \\
\text { charge }\end{array}$ & Date & Hour & $\begin{array}{c}\text { Gage } \\
\text { he1ght }\end{array}$ & $\begin{array}{c}\text { Dis- } \\
\text { charge }\end{array}$ & Date & Hour & $\begin{array}{c}\text { Gage } \\
\text { height }\end{array}$ & $\begin{array}{l}\text { D18- } \\
\text { charge }\end{array}$ \\
\hline $\begin{array}{r}\text { Jan. } \\
30 \\
30\end{array}$ & $\begin{array}{l}2400 \\
0500 \\
0600 \\
1500 \\
1700 \\
1900 \\
2100 \\
2400 \\
\\
0300 \\
0700\end{array}$ & $\begin{array}{l}2.02 \\
2.04 \\
2.12 \\
2.11 \\
2.27 \\
2.51 \\
2.88 \\
3.50 \\
4.00 \\
5.20\end{array}$ & $\begin{array}{c}5.6 \\
5.9 \\
7.1 \\
7.0 \\
9.8 \\
14 \\
22 \\
40 \\
61 \\
150\end{array}$ & Feb. 1 & $\begin{array}{l}0900 \\
1100 \\
1200 \\
1600 \\
1900 \\
2100 \\
2400 \\
\\
0100 \\
0300 \\
0500 \\
1100\end{array}$ & $\begin{array}{l}5.93 \\
6.75 \\
6.85 \\
7.84 \\
8.10 \\
8.75 \\
8.60 \\
\\
8.58 \\
8.64 \\
7.83 \\
6.96\end{array}$ & $\begin{array}{l}240 \\
371 \\
390 \\
642 \\
725 \\
970 \\
910 \\
\\
902 \\
926 \\
639 \\
412\end{array}$ & Feb. 1 & $\begin{array}{l}1300 \\
1400 \\
1600 \\
1500 \\
2100 \\
2400 \\
\\
0200 \\
0700 \\
1100 \\
1700 \\
2400\end{array}$ & $\begin{array}{l}6.64 \\
6.64 \\
7.76 \\
8.05 \\
7.74 \\
7.32 \\
7.10 \\
6.67 \\
6.43 \\
6.22 \\
6.03\end{array}$ & $\begin{array}{l}350 \\
350 \\
618 \\
708 \\
612 \\
495 \\
\\
440 \\
355 \\
311 \\
274 \\
243\end{array}$ \\
\hline
\end{tabular}


11-2940. Highland Creek below Spicer Meadows Reservolr, Calif.

Location.--Lat $38^{\circ} 23^{\prime} 50^{\prime \prime}$, long $119^{\circ} 59^{\prime} 30^{\prime \prime}$, in SW $\frac{1}{4}$ sec.3, T.6 N., R.18 E., on right bank just downstream from Spicer Meadows Reservolr dam, 5.5 miles upstream from mouth and 7 miles east of Big Meadow.

Drainage area. $--42.4 \mathrm{sq} \mathrm{ml}$.

Gage-helght record.--Water-stage recorder graph. Datum of gage is 6,374.8 ft above mean sea level (river-profile survey).

Discharge record.--Stage-discharge relation defined by current-meter measurements below 1,200 cfs; affected by 1ce Jan. 1, 3, 4, 13-28, Feb. 22, 27.

Maxima --January-February 1963: Discharge, 9,860 cfs 2400 hours Jan. 31 (gage hel ght, $11.88 \mathrm{ft}$ ).

1952 to December 1962: Discharge, 8,800 cfs Dec. 23, 1955 (gage height, $11.50 \mathrm{ft}$ ).

Flood of Nov. 20, 1950, reached a stage of $11.50 \mathrm{ft}$, from Paclfic Gas \& Electric Co. recorder chart (discharge, $8,800 \mathrm{cfs}$ ).

Remarks.--Flow slightly regulated by Spicer Meadows Reservoir (capac1ty, 4,060 acre-ft).

Mean discharge, in cub1c feet per second, 1963

\begin{tabular}{|c|c|c|c|c|c|c|c|c|}
\hline Day & January & February & Day & January & February & Day & January & February \\
\hline $\begin{array}{c}1 \ldots \ldots \\
2 \ldots \ldots \\
3 \ldots \ldots \\
4 \ldots \ldots \\
5 \ldots \ldots \\
6 \ldots \ldots \\
7 \ldots \ldots \\
8 \ldots \ldots \\
9 \ldots \ldots \\
10 \ldots \ldots\end{array}$ & $\begin{array}{l}10 \\
10 \\
10 \\
10 \\
10 \\
9.7 \\
9.3 \\
9.2 \\
9.4 \\
9.0\end{array}$ & $\begin{array}{r}4,130 \\
554 \\
355 \\
326 \\
285 \\
232 \\
211 \\
199 \\
166 \\
143\end{array}$ & $\begin{array}{l}11 \ldots \ldots \\
12 \ldots \ldots \\
13 \ldots \ldots \\
14 \ldots \ldots \\
15 \ldots \ldots \\
16 \ldots \ldots \\
17 \ldots \ldots \\
18 \ldots \ldots \\
19 \ldots \ldots \\
20 \ldots \ldots\end{array}$ & $\begin{array}{l}7.0 \\
5.2 \\
5.0 \\
5.0 \\
5.0 \\
5.0 \\
5.0 \\
5.0 \\
5.0 \\
4.7\end{array}$ & $\begin{array}{r}135 \\
115 \\
136 \\
128 \\
112 \\
108 \\
98 \\
93 \\
93 \\
94\end{array}$ & $\begin{array}{l}21 \ldots \ldots \\
22 \ldots \ldots \\
23 \ldots \ldots \\
24 \ldots \ldots \\
25 \ldots \ldots \\
26 \ldots \ldots \\
27 \ldots \ldots \\
28 \ldots \ldots \\
29 \ldots \ldots \\
30 \ldots \ldots \\
31 \ldots \ldots\end{array}$ & $\begin{array}{r}4.5 \\
4.5 \\
4.3 \\
4.1 \\
4.0 \\
4.0 \\
3.9 \\
4.5 \\
6.0 \\
20 \\
1,800\end{array}$ & $\begin{array}{r}95 \\
88 \\
81 \\
82 \\
84 \\
97 \\
103 \\
93 \\
----- \\
-\ldots---\end{array}$ \\
\hline
\end{tabular}

Gage he1ght, in feet, and discharge, In cub1c feet per second, at indicated time, 1963

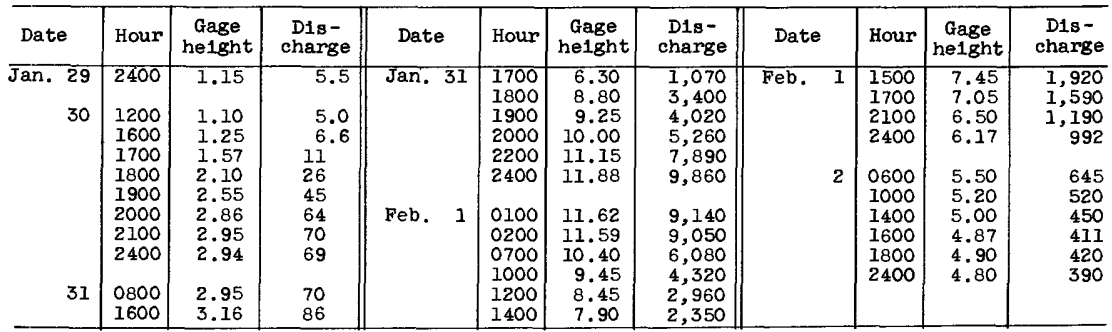


11-2943. North Fork Stanislaus River below Ganns damsite, Calif.

Location. --Lat $38^{\circ} 24^{\prime} 0^{\prime \prime}$, long $120^{\circ} 06^{1} 40^{\prime \prime}$, In SW $\frac{1}{4}$ sec.4, T.6 N., R.17 E., on left bank 0.25 mile upstream from Big Meadow Creek and 0.9 mile south of Big Meadow.

Drainage area. --111 sq $\mathrm{ml}$.

Gage-height record.--Water-stage recorder graph. Datum of gage is $5,405 \mathrm{ft}$ above mean sea level (from river-profile survey).

Discharge record.--Stage-discharge relation defined by current-meter measurements below $1,800 \mathrm{cfs}$ and by slope-area measurement at $21,000 \mathrm{cfs}$; affected by $1 \mathrm{ce}$ Jan. $3,4,10-14$.

Maxima.--January-February 1963: Discharge, 21,000 cfs 2400 hours Jan. 31 (gage helght, $16.12 \mathrm{ft}$, from recorder graph; $16.4 \mathrm{ft}$, from high-water profile). 1960 to December 1962: Discharge, 2,930 cfs May 5, 1962 (gage height, $9.14 \mathrm{ft}$ ).

Flood of December 1955 reached a stage of $17.0 \mathrm{ft}$, from floodmarks on right bank; flood of Jan. 31 , 1963, reached a stage of $18.8 \mathrm{ft}$ at same location.

Mean discharge, In cub1c feet per second, 1963

\begin{tabular}{|c|c|c|c|c|c|c|c|c|}
\hline Day & January & February & Day & January & February & Day & January & February \\
\hline $\begin{array}{r}1 \ldots \ldots \\
3 \ldots \ldots \\
4 \ldots \ldots \\
5 \ldots \ldots \\
6 \ldots \ldots \\
7 \ldots \ldots \\
5 \ldots \ldots \\
9 \ldots \ldots \\
10 \ldots \ldots\end{array}$ & $\begin{array}{l}24 \\
24 \\
23 \\
23 \\
23 \\
23 \\
22 \\
22 \\
22 \\
21\end{array}$ & $\begin{array}{r}9,430 \\
1,820 \\
1,030 \\
930 \\
794 \\
610 \\
548 \\
513 \\
429 \\
352\end{array}$ & $\begin{array}{l}11 \ldots \ldots \\
12 \ldots \ldots \\
13 \ldots \ldots \\
14 \ldots \ldots \\
15 \ldots \ldots \\
16 \ldots \ldots \\
17 \ldots \ldots \\
18 \ldots \ldots \\
19 \ldots \ldots \\
20 \ldots \ldots\end{array}$ & $\begin{array}{l}15 \\
17 \\
18 \\
19 \\
18 \\
18 \\
17 \\
18 \\
17 \\
17\end{array}$ & $\begin{array}{l}320 \\
250 \\
377 \\
364 \\
298 \\
283 \\
254 \\
237 \\
239 \\
245\end{array}$ & $\begin{array}{l}21 \ldots \ldots \\
22 \ldots \ldots \\
23 \ldots \ldots \\
24 \ldots \ldots \\
25 \ldots \ldots \\
26 \ldots \ldots \\
27 \ldots \ldots \\
28 \ldots \ldots \\
29 \ldots \ldots \\
30 \ldots \ldots \\
31 \ldots \ldots\end{array}$ & $\begin{array}{r}47 \\
73 \\
23 \\
18 \\
18 \\
19 \\
19 \\
15 \\
18 \\
567 \\
7,910 \\
\end{array}$ & $\begin{array}{r}243 \\
221 \\
199 \\
196 \\
197 \\
225 \\
248 \\
217 \\
----- \\
--.-- \\
\end{array}$ \\
\hline \multicolumn{7}{|l|}{$\begin{array}{l}\text { Monthly } \\
\text { Runoff, } \\
\text { Runoff, }\end{array}$} & $\begin{array}{r}295 \\
3.06 \\
18,110 \\
\end{array}$ & $\begin{array}{r}755 \\
7.08 \\
41,910 \\
\end{array}$ \\
\hline
\end{tabular}

Gage height, In feet, and discharge, in cublc feet per second, at 1nd1cated t1me, 1963

\begin{tabular}{|c|c|c|c|c|c|c|c|c|c|c|c|}
\hline Date & Hour & $\begin{array}{c}\text { Gage } \\
\text { heIght }\end{array}$ & $\begin{array}{l}\text { D1s- } \\
\text { charge }\end{array}$ & Date & Hour & $\begin{array}{c}\text { Gage } \\
\text { he1ght }\end{array}$ & $\begin{array}{c}\text { D1s- } \\
\text { charge }\end{array}$ & Date & Hour & $\begin{array}{c}\text { Gage } \\
\text { he1ght }\end{array}$ & $\begin{array}{c}\text { D1s- } \\
\text { charge }\end{array}$ \\
\hline $\begin{array}{r}\text { Jan. } 29 \\
30\end{array}$ & $\begin{array}{l}2400 \\
0900 \\
1200 \\
1300 \\
1400 \\
1500 \\
1600 \\
1900 \\
2000 \\
\end{array}$ & $\begin{array}{l}1.70 \\
1.71 \\
2.12 \\
2.60 \\
3.27 \\
3.86 \\
5.00 \\
6.34 \\
6.80 \\
\end{array}$ & $\begin{array}{r}19 \\
19 \\
34 \\
56 \\
100 \\
165 \\
402 \\
900 \\
1,150 \\
\end{array}$ & Jan. 30 & $\begin{array}{l}2100 \\
2200 \\
2400 \\
\\
0500 \\
0600 \\
1000 \\
1600 \\
1900 \\
2400\end{array}$ & $\begin{array}{r}8.37 \\
8.51 \\
8.68 \\
9.59 \\
8.54 \\
10.22 \\
12.05 \\
14.17 \\
16.12 \\
\end{array}$ & $\begin{array}{r}2,370 \\
2,810 \\
2,650 \\
3,690 \\
2,540 \\
4,550 \\
7,990 \\
13,600 \\
21,000 \\
\end{array}$ & Feb. & $\begin{array}{l}0700 \\
1100 \\
1500 \\
2400 \\
\\
0600 \\
1200 \\
1800 \\
2400\end{array}$ & $\begin{array}{r}14.12 \\
11.95 \\
10.55 \\
9.12 \\
8.12 \\
7.45 \\
7.11 \\
6.85\end{array}$ & $\begin{array}{r}13,500 \\
7,840 \\
5,080 \\
3,140 \\
2,150 \\
1,610 \\
1,350 \\
1,180\end{array}$ \\
\hline
\end{tabular}


11-2945. North Fork Stanislaus River near Avery, Calif.

Location.--Lat $38^{\circ} 14145^{\prime \prime}$, long $120^{\circ} 17120^{\prime \prime}$, in NE $\frac{1}{4}$ sec.35, T.5 N., R.15 E., on right bank $700 \mathrm{ft}$ upstream from intake of Utica Canal, 3.3 miles upstream from Beaver Creek and 5.1 miles northeast of Avery.

Drainage area. $--163 \mathrm{sq} \mathrm{mi}$.

Gage-height record.--Water-stage recorder graph, except 2100 hours Jan. 31 to 0600 hours Feb. 1 for which graph was reconstructed on basis of high-water mark in gage house and outside high-water marks. Datum of gage is $3,388.3 \mathrm{ft}$ above sea level (river-profile survey).

Discharge record.--Stage-discharge relation defined by current-meter measurements below 13,300 cfs and by slope-area measurement at $29,000 \mathrm{cfs}$.

Maxima.--Janua'ry-February 1963: Díscharge, 36,000 cfs 2400 hours Jan. 31 (gage height, $15.00 \mathrm{ft}$ in gage house and from floodmarks)

1914-22, 1928 to December 1962: Discharge, 32,000 cfs Dec. 23, 1955 (gage height, $14.23 \mathrm{ft}$, from floodmarks).

Remarks.--Flow slightly affected by Lake Alpine, Spicer Meadows, Union and Utica Reservoirs (combined capac1ty, 13,600 acre-ft).

Mean discharge, in cublc feet per second, 1963

\begin{tabular}{|c|c|c|c|c|c|c|c|c|}
\hline Day & January & February & Day & January & February & Day & January & February \\
\hline $\begin{array}{c}1 \ldots \ldots \\
2 \ldots \ldots \\
3 \ldots \ldots \\
4 \ldots \ldots \\
5 \ldots \ldots \\
7 \ldots \ldots \\
5 \ldots \ldots \\
9 \ldots \ldots \\
1.0 \ldots \ldots\end{array}$ & $\begin{array}{l}46 \\
42 \\
43 \\
42 \\
42 \\
39 \\
38 \\
36 \\
35 \\
35\end{array}$ & $\begin{array}{r}16,500 \\
2,550 \\
1,390 \\
1,220 \\
1,060 \\
857 \\
780 \\
725 \\
630 \\
590\end{array}$ & $\begin{array}{l}11 \ldots \ldots \\
12 \ldots \ldots \\
13 \ldots \ldots \\
14 \ldots \ldots \\
15 \ldots \ldots \\
16 \ldots \ldots \\
17 \ldots \ldots \\
18 \ldots \ldots \\
19 \ldots \ldots \\
20 \ldots \ldots\end{array}$ & $\begin{array}{l}30 \\
18 \\
25 \\
30 \\
31 \\
30 \\
29 \\
26 \\
24 \\
25\end{array}$ & $\begin{array}{l}510 \\
455 \\
666 \\
634 \\
513 \\
485 \\
440 \\
407 \\
401 \\
395\end{array}$ & $\begin{array}{l}21 \ldots \ldots \\
22 \ldots \ldots \\
23 \ldots \ldots \\
24 \ldots \ldots \\
25 \ldots \ldots \\
26 \ldots \ldots \\
27 \ldots \ldots \\
28 \ldots \ldots \\
29 \ldots \ldots \\
30 \ldots \ldots \\
31 \ldots \ldots\end{array}$ & $\begin{array}{r}26 \\
36 \\
42 \\
29 \\
26 \\
26 \\
25 \\
24 \\
29 \\
507 \\
11,000\end{array}$ & $\begin{array}{r}395 \\
365 \\
329 \\
319 \\
319 \\
335 \\
368 \\
340 \\
----- \\
----- \\
---\end{array}$ \\
\hline \multicolumn{7}{|c|}{ 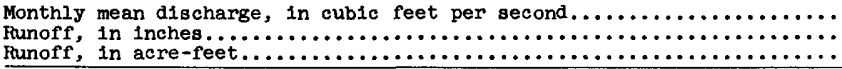 } & $\begin{array}{r}401 \\
2.84 \\
24,670 \\
\end{array}$ & $\begin{array}{r}1,215 \\
7,76 \\
67,450 \\
\end{array}$ \\
\hline
\end{tabular}

Gage height, in feet, and discharge, in cublc feet per second, at indicated time, 1963

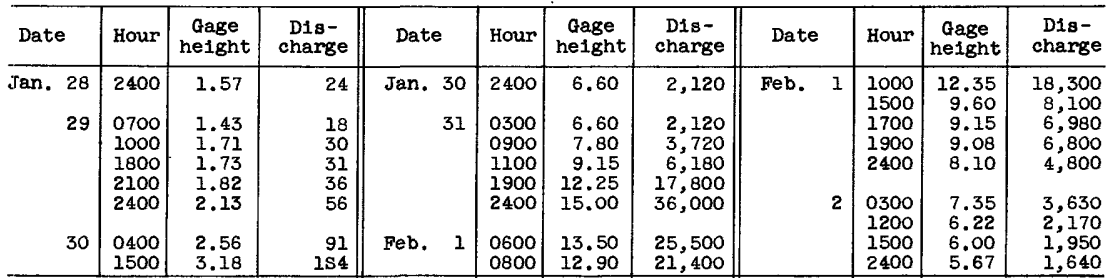


11-2965. South Fork Stanislaus River at Strawberry, Calif.

Location.--Lat $38^{\circ} 11^{1} 51^{\prime \prime}$, long $120^{\circ} 00^{\prime 2} 27^{\prime \prime}$, in SW $\frac{1}{4}$ sec.16, T.4 N., R.18 E., on right bank $0.3 \mathrm{mile}$ downstream from bridge on State Highway 108 at Strawberry, $0.6 \mathrm{~m} 11 \mathrm{e}$ downstream from Herring Creek, and 1.2 miles downstream from Pinecrest Lake.

Drainage area. $--44.8 \mathrm{sq} \mathrm{mi}$.

Gage-height record.--Water-stage recorder graph, except Jan. 7-11. Datum of gage is $5,235.1$ ft above mean sea level (river-proflle survey).

D1scharge record.--Stage-discharge relation defined by current-meter measurements. Discharge for Jan. 7-11 estimated on basis of one discharge measurement, recorded range in stage, and unpublished record for station near Strawberry.

Maxima.--January-February 1963: Discharge, 1,810 cfs 0500 hours Feb. 1 (gage height, $6.52 \mathrm{ft}$ ).

1911-17, 1938 to December 1962: Discharge, 3,900 cfs Nov. 21, 1950 (gage

helght, $9.25 \mathrm{ft}$ ), from rating curve extended above $1,100 \mathrm{cf}$ s on basis of

contracted-opening measurement of peak flow at bridge 0.3 mile below station.

Remarks.--Flow regulated by Pinecrest Lake since 1916 (capacity, 18,300 acre-ft).

Mean discharge, in cubic feet per second, 1963

\begin{tabular}{|c|c|c|c|c|c|c|c|c|}
\hline Day & January & February & Day & January & February & Day & January & February \\
\hline $\begin{array}{c}1 \ldots \ldots \\
2 \ldots \ldots \\
4 \ldots \ldots \\
5 \ldots \ldots \\
6 \ldots \ldots \\
7 \ldots \ldots \\
9 \ldots \ldots \\
10 \ldots \ldots\end{array}$ & $\begin{array}{l}25 \\
25 \\
25 \\
25 \\
25 \\
25 \\
25 \\
27 \\
26 \\
25\end{array}$ & $\begin{array}{r}1,090 \\
219 \\
136 \\
114 \\
93 \\
82 \\
75 \\
70 \\
63 \\
58\end{array}$ & $\begin{array}{l}11 \ldots \ldots \\
12 \ldots \ldots \\
13 \ldots \ldots \\
14 \ldots \ldots \\
15 \ldots \ldots \\
16 \ldots \ldots \\
17 \ldots \ldots \\
18 \ldots \ldots \\
19 \ldots \ldots \\
20 \ldots \ldots\end{array}$ & $\begin{array}{l}25 \\
25 \\
25 \\
25 \\
25 \\
24 \\
24 \\
24 \\
25 \\
25\end{array}$ & $\begin{array}{l}57 \\
58 \\
64 \\
60 \\
63 \\
64 \\
61 \\
59 \\
58 \\
58\end{array}$ & $\begin{array}{l}21 \ldots \ldots \\
22 \ldots \ldots \\
23 \ldots \ldots \\
24 \ldots \ldots \\
25 \ldots \ldots \\
26 \ldots \ldots \\
27 \ldots \ldots \\
28 \ldots \ldots \\
29 \ldots \ldots \\
30 \ldots \ldots \\
31 \ldots \ldots\end{array}$ & $\begin{array}{l}25 \\
25 \\
25 \\
25 \\
25 \\
25 \\
25 \\
25 \\
25 \\
35 \\
397 \\
\end{array}$ & $\begin{array}{r}59 \\
58 \\
57 \\
57 \\
59 \\
63 \\
64 \\
63 \\
--- \\
--.- \\
\end{array}$ \\
\hline $\begin{array}{l}\text { nthly } \\
\text { anoff, }\end{array}$ & $\begin{array}{l}\text { an disc } \\
\text { acre-f }\end{array}$ & $\begin{array}{l}0,1 n \\
\ldots \ldots\end{array}$ & feet & gecond & & & $\begin{array}{r}37.3 \\
2,290 \\
\end{array}$ & $\begin{array}{r}110 \\
6,110 \\
\end{array}$ \\
\hline
\end{tabular}

Gage height, in feet, and discharge, in cublc feet per second, at indicated time, 1963

\begin{tabular}{|c|c|c|c|c|c|c|c|c|c|c|c|}
\hline Date & Hour & $\begin{array}{c}\text { Gage } \\
\text { helght }\end{array}$ & $\begin{array}{c}\text { Dis- } \\
\text { charge }\end{array}$ & Date & Hour & $\begin{array}{c}\text { Gage } \\
\text { height }\end{array}$ & $\begin{array}{l}\text { Dis- } \\
\text { charge }\end{array}$ & Date & Hour & $\begin{array}{c}\text { Gage } \\
\text { helght }\end{array}$ & $\begin{array}{l}\text { Dis- } \\
\text { charge }\end{array}$ \\
\hline $\begin{array}{r}\text { Jan. } 30 \\
31\end{array}$ & $\begin{array}{l}2400 \\
0600 \\
1000 \\
1600 \\
1800 \\
2400\end{array}$ & $\begin{array}{l}1.94 \\
2.00 \\
2.35 \\
3.55 \\
4.65 \\
5.75\end{array}$ & $\begin{array}{r}48 \\
55 \\
102 \\
360 \\
778 \\
1,350\end{array}$ & Feb. 1 & $\begin{array}{l}0200 \\
0500 \\
0700 \\
1000 \\
1200 \\
2000\end{array}$ & $\begin{array}{l}6.30 \\
6.52 \\
6.40 \\
5.75 \\
5.06 \\
3.90\end{array}$ & $\begin{array}{r}1,680 \\
1,810 \\
1,740 \\
1,350 \\
980 \\
470\end{array}$ & Feb. I & $\begin{array}{l}2400 \\
0600 \\
1000 \\
1300 \\
2400\end{array}$ & $\begin{array}{l}3.50 \\
3.09 \\
2.92 \\
2.85 \\
2.65\end{array}$ & $\begin{array}{l}346 \\
248 \\
210 \\
196 \\
157\end{array}$ \\
\hline
\end{tabular}

11-2980. South Fork Stanislaus River near Long Barn, Calif.

Location.--Lat $38^{\circ} 05^{\prime} 33^{\prime \prime}$, long $120^{\circ} 10^{\prime} 02^{\prime \prime}$, in SW $\frac{1}{4}$ sec. 24 , T.3 N., R.16 E., on left bank $600 \mathrm{ft}$ downstream from Lyons Dam, 2 miles west of Long Barn, and $15 \mathrm{miles}$ northeast of Sonora.

Dra1nage area. $--66.9 \mathrm{sq} \mathrm{mi}$.

Gage-helght record.--Water-stage recorder graph. Datum of gage is 4,073.4 ft above mean sea level (river-profile survey).

Discharge record.--Stage-discharge relation defined by current-meter measurements.

Maxima.--January-February 1963: D1scharge, 1,570 cfs 1200 hours Feb. 1 (gage height, $6.23 \mathrm{ft}$ ).

1937 to December 1962: Discharge, 4,900 cfs Nov. 21, 1950 (gage he1ght, $9.3 \mathrm{ft}$ ), from rating curve extended above $1,100 \mathrm{cfs}$ on basis of computation of peak flow over Lyons Dam.

Remarks.--Flow regulated by Lyons Reservoir (capacity, 5,400 acre-ft) and Pinecrest Lake (capac1ty, 18,300 acre-ft). Diversion by Tuolumne Canal at Lyons Dam; Philadelphia Canal diverts 12 miles above station into basin of Middle Fork Stanislaus River. 
Mean discharge, in cublc feet per second, 1963, of South Fork Stanislaus River near Long Barn, Calif.

\begin{tabular}{|c|c|c|c|c|c|c|c|c|}
\hline Day & January & February & Day & January & February & Day & January & February \\
\hline $\begin{array}{c}\ldots \ldots \\
3 \ldots \ldots \\
3 \ldots \ldots \\
5 \ldots \ldots \\
7 \ldots \ldots \\
8 \ldots \ldots \\
9 \ldots \ldots \\
10 \ldots \ldots\end{array}$ & $\begin{array}{l}1.6 \\
2.1 \\
2.3 \\
2.3 \\
2.3 \\
2.3 \\
2.3 \\
2.3 \\
2.1 \\
2.1\end{array}$ & $\begin{array}{c}758 \\
419 \\
1.61 \\
102 \\
62 \\
41 \\
28 \\
18 \\
7.2 \\
13\end{array}$ & $\begin{array}{l}11 \ldots \ldots \\
12 \ldots \ldots \\
13 \ldots \ldots \\
14 \ldots \ldots \\
15 \ldots \ldots \\
16 \ldots \ldots \\
17 \ldots \ldots \\
18 \ldots \ldots \\
19 \ldots \ldots \\
20 \ldots \ldots\end{array}$ & $\begin{array}{l}2.1 \\
2.1 \\
2.1 \\
2.1 \\
2.1 \\
2.1 \\
2.1 \\
2.1 \\
2.1 \\
2.1\end{array}$ & $\begin{array}{l}5.1 \\
2.6 \\
24 \\
38 \\
19 \\
11 \\
7.6 \\
3.6 \\
1.8 \\
2.1\end{array}$ & $\begin{array}{l}21 \ldots \ldots \\
22 \ldots \ldots \\
23 \ldots \ldots \\
24 \ldots \ldots \\
25 \ldots \ldots \\
26 \ldots \ldots \\
27 \ldots \ldots \\
28 \ldots \ldots \\
29 \ldots \ldots \\
30 \ldots \ldots \\
31 \ldots \ldots\end{array}$ & $\begin{array}{l}2.1 \\
2.1 \\
2.1 \\
2.1 \\
2.1 \\
2.1 \\
1.8 \\
1.8 \\
1.8 \\
3.1 \\
4.5\end{array}$ & $\begin{array}{r}2.1 \\
2.1 \\
1.8 \\
1.8 \\
1.8 \\
1.8 \\
1.8 \\
1.8 \\
----- \\
--1--\end{array}$ \\
\hline $\begin{array}{l}\text { Monthly } \\
\text { Runoff, }\end{array}$ & $\begin{array}{l}\text { discl } \\
\text { cre }-f\end{array}$ &, 1 & reet & & & & $\begin{array}{r}2.20 \\
135\end{array}$ & $\begin{array}{r}62,1 \\
3,450 \\
\end{array}$ \\
\hline
\end{tabular}

Gage helght, in feet, and discharge, in cublc feet per second, at ind1cated time, 1963

\begin{tabular}{|c|c|c|c|c|c|c|c|c|c|c|c|}
\hline Date & Hour & $\begin{array}{c}\text { Gage } \\
\text { height }\end{array}$ & $\begin{array}{l}\text { DIs- } \\
\text { charge }\end{array}$ & Date & Hour & $\begin{array}{c}\text { Gage } \\
\text { height }\end{array}$ & $\begin{array}{c}\text { Dis- } \\
\text { charge }\end{array}$ & Date & Hour & $\begin{array}{c}\text { Gage } \\
\text { helght }\end{array}$ & $\begin{array}{c}\text { Dls - } \\
\text { charge }\end{array}$ \\
\hline $\begin{array}{l}\text { Jan. } 31 \\
\text { Feb. } 1\end{array}$ & $\begin{array}{l}2400 \\
0800 \\
0900 \\
\end{array}$ & $\begin{array}{r}0.95 \\
.93 \\
4.58 \\
\end{array}$ & $\begin{array}{r}5.4 \\
692^{4.8}\end{array}$ & Feb. 1 & $\begin{array}{l}1100 \\
1200 \\
2400\end{array}$ & $\begin{array}{l}6.03 \\
6.23 \\
4.82\end{array}$ & $\begin{array}{r}1,440 \\
1,570 \\
790\end{array}$ & Feb. 2 & $\begin{array}{l}0600 \\
1200 \\
1800 \\
2400 \\
\end{array}$ & $\begin{array}{l}4.12 \\
3.60 \\
3.18 \\
2.92\end{array}$ & $\begin{array}{l}517 \\
375 \\
277 \\
224 \\
\end{array}$ \\
\hline
\end{tabular}

11-2990. Melones Reservoir at Melones Dam, Calif.

Location.--Lat $37^{\circ} 57^{\prime} 15^{\prime \prime}$, long $120^{\circ} 30^{\prime} 45^{\prime \prime}$, near center of sec.11, T.1 N., R.13 E., at gate tower near left bank at Melones Dam on Stanislaus River, 0.1 mile downstream from Bear Creek and 7.5 miles southwest of Sonora.

Drainage area. --904 sq $\mathrm{mi}$.

Gage-height record.--Water-stage recorder graph. Datum of gage is at mean sea level (levels by Paclfic Gas \& Electric Co.).

Contents record.--Contents computed from capacity table dated June 1927 furnished by Pacific Gas \& Electric Co.

Maxima.--January-February 1963: Computed average bihourly inflow, 52,800 cfs 0200 hours Feb. 1; contents, 105,600 acre-ft 2400 hours Feb. 28 (elevation, $731.2 \mathrm{ft}$ ).

1927 to December 1962: Contents observed, 115,800 acre-ft May 27, 1959 (elevation, $736.7 \mathrm{ft}$ ).

Remarks.--Reservoir is formed by concrete overflow dam; storage began Aug. 21, 1926; dam completed in December 1926. Capacity for power development 1 mile below dam is 106,100 acre-ft between elevations 628.0 (minimum operating level) and 735.0 ft (top of drum-type splliway gates) above mean sea level; usable capacity for 1rrigation, 110,000 acre-ft between elevations 610.0 (floor of outlet tunnel) and $735.0 \mathrm{ft}$ above mean sea level. Flgures glven herein represent total contents, of which 2,630 acre-ft is not avaliable for release. Record of elevations furnished by Oakdale Irrigation District. Record of inflow furnished by Corps of Engineers.

Elevation, in feet, and contents, in acre-feet, at 2400 hours, 1963

\begin{tabular}{|c|c|c|c|c|c|c|c|c|c|}
\hline \multirow{2}{*}{ Day } & \multicolumn{2}{|c|}{ January } & \multicolumn{2}{|c|}{ February } & \multirow{2}{*}{ Day } & \multicolumn{2}{|c|}{ January } & \multicolumn{2}{|c|}{ February } \\
\hline & Elevation & Contents & Elevation & Contents & & Elevation & Contents & Elevation & Contents \\
\hline $\begin{array}{r}1 \\
2 \\
3 \\
4 \\
5 \\
6 \\
7 \\
8 \\
9 \\
10 \\
11 \\
12 \\
13 \\
14 \\
15\end{array}$ & $\begin{array}{l}664.0 \\
664.6 \\
665.1 \\
665.6 \\
666.1 \\
666.6 \\
667.0 \\
667.4 \\
667.8 \\
668.3 \\
668.7 \\
669.1 \\
669.5 \\
669.3 \\
668.8\end{array}$ & $\begin{array}{l}24,300 \\
24,700 \\
25,100 \\
25,500 \\
25,800 \\
26,200 \\
26,500 \\
26,800 \\
27,100 \\
27,500 \\
27,900 \\
28,200 \\
28,500 \\
28,300 \\
27,900\end{array}$ & $\begin{array}{l}729.2 \\
726.4 \\
725.2 \\
725.0 \\
725.4 \\
725.5 \\
725.3 \\
724.9 \\
724.8 \\
724.9 \\
724.7 \\
724.4 \\
725.6 \\
725.7 \\
725.2\end{array}$ & $\begin{array}{r}102,100 \\
97,300 \\
95,300 \\
95,000 \\
95,700 \\
95,800 \\
95,500 \\
95,000 \\
94,600 \\
94,800 \\
94,500 \\
94,000 \\
96,000 \\
96,200 \\
95,300\end{array}$ & $\begin{array}{l}16 \\
17 \\
18 \\
19 \\
20 \\
21 \\
22 \\
23 \\
24 \\
25 \\
26 \\
27 \\
28 \\
29 \\
30 \\
31\end{array}$ & $\begin{array}{l}668.1 \\
667.3 \\
666.5 \\
666.3 \\
666.7 \\
667.2 \\
667.6 \\
668.0 \\
668.5 \\
668.8 \\
669.2 \\
669.3 \\
669.3 \\
669.8 \\
672.0 \\
703.0\end{array}$ & $\begin{array}{l}27,400 \\
26,800 \\
26,100 \\
26,000 \\
26,300 \\
26,700 \\
27,000 \\
27,300 \\
27,700 \\
27,900 \\
28,300 \\
28,300 \\
28,300 \\
28,700 \\
30,600 \\
62,800\end{array}$ & $\begin{array}{c}724.7 \\
724.3 \\
724.2 \\
724.1 \\
724.5 \\
725.2 \\
725.7 \\
726.1 \\
726.6 \\
727.5 \\
728.8 \\
730.2 \\
731.2 \\
- \\
-\end{array}$ & $\begin{array}{c}94,500 \\
93,800 \\
93,600 \\
93,500 \\
94,100 \\
95,300 \\
96,200 \\
96,800 \\
97,700 \\
99,200 \\
101,400 \\
103,800 \\
105,600 \\
- \\
- \\
-\end{array}$ \\
\hline han & in & , & & & & - & $+39,100$ & - & $+42,800$ \\
\hline
\end{tabular}


Average inflow in cubic feet per second, for bihourly periods ending at Indicated time, 1963, of Melones Reservoir at Melones Dam, Calif.

\begin{tabular}{|c|c|c|c|c|c|c|c|c|c|c|c|}
\hline Date & Hour & $\begin{array}{l}\text { Ele- } \\
\text { vation }\end{array}$ & Inflow & Date & Hour & $\begin{array}{c}\text { Ele- } \\
\text { vation }\end{array}$ & Inflow & Date & Hour & $\begin{array}{c}\text { Ele- } \\
\text { vation }\end{array}$ & Inflow \\
\hline $\begin{array}{r}\operatorname{Jan} .30 \\
31\end{array}$ & $\begin{array}{l}2400 \\
0200 \\
0400 \\
0600 \\
0800 \\
1000 \\
1200 \\
1400 \\
1600 \\
1800 \\
2000\end{array}$ & $\begin{array}{l}672.0 \\
672.8 \\
673.8 \\
674.9 \\
675.9 \\
677.1 \\
678.8 \\
681.0 \\
683.9 \\
687.1 \\
690.7\end{array}$ & $\begin{array}{r}1,020 \\
4,090 \\
5,100 \\
6,150 \\
5,240 \\
6,460 \\
9,880 \\
13,600 \\
18,800 \\
19,900 \\
24,900\end{array}$ & $\begin{array}{l}\text { Jan. } 31 \\
\text { Feb. } 1\end{array}$ & $\begin{array}{l}2200 \\
2400 \\
0200 \\
0400 \\
0600 \\
0800 \\
1000 \\
1200 \\
1400 \\
1600 \\
1800\end{array}$ & $\begin{array}{l}695.8 \\
702.5 \\
709.0 \\
714.7 \\
719.3 \\
723.0 \\
725.9 \\
728.2 \\
729.3 \\
729.8 \\
729.7\end{array}$ & $\begin{array}{l}38,900 \\
51,500 \\
52,800 \\
47,800 \\
38,100 \\
34,800 \\
31,400 \\
29,100 \\
22,200 \\
17,900 \\
11,800\end{array}$ & Feb. I & $\begin{array}{l}2000 \\
2200 \\
2400 \\
\\
0200 \\
0400 \\
0600 \\
0800 \\
1000 \\
1200 \\
1400 \\
1600\end{array}$ & $\begin{array}{l}729.5 \\
729.3 \\
729.1 \\
728.8 \\
728.5 \\
728.3 \\
728.1 \\
727.8 \\
727.6 \\
727.3 \\
727.1\end{array}$ & $\begin{array}{r}11,200 \\
10,700 \\
10,100 \\
7,420 \\
6,620 \\
7,990 \\
7,500 \\
4,800 \\
6,240 \\
3,670 \\
5,100\end{array}$ \\
\hline
\end{tabular}

11-2995. Stanislaus River below Melones powerhouse, near Sonora, Calif.

Locat1on.--Lat $37^{\circ} 56^{\prime} 50^{\prime \prime}$, long $120^{\circ} 31^{\prime} 45^{\prime \prime}$, near line between secs.10 and 15, T.1 N., R.13 E. , on right bank $300 \mathrm{ft}$ downstream from powerhouse, $0.5 \mathrm{mlle}$ upstream from Bean Gulch, 1 mile downstream from Melones Dam, and 8.4 miles southwest of Sonora.

Drainage area. $--905 \mathrm{sq} \mathrm{ml}$.

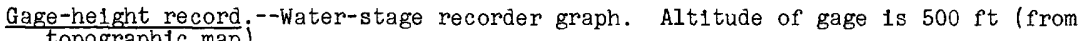
topographic mapi.

Discharge record.--Stage-discharge relation defined by current-meter measurements; affected by backwater from Tulloch Reservolr Jan. 31 to Feb. 28.

Maxima.--January-February 1963: Discharge, about 17,700 ofs 1700-1800 hours Feb. I (gage helght, $15.70 \mathrm{ft}$ ).

1931 to December 1962: Discharge, 62,800 ofs Dec. 23, 1955 (gage height, $29.0 \mathrm{ft}$, from floodmarks), from rating curve extended above $14,000 \mathrm{cf}$ on basis of computed flow over Melones Dam.

Remarks.--Flow regulated by Melones powerhouse, Melones Reservolr (see station 11-2990), Pinecrest Lake, Beardsley Lake, Lyons, Rellef, and Donnells Reservoirs (combined capacity, 312,300 acre-ft).

Mean discharge, in cubic feet per second, 1963

\begin{tabular}{|c|c|c|c|c|c|c|c|c|}
\hline Day & January & February & Day & January & February & Day & January & February \\
\hline $\begin{array}{r}1 \ldots \ldots \\
2 \ldots \ldots \\
3 \ldots \ldots \\
4 \ldots \ldots \\
5 \ldots \ldots \\
6 \ldots \ldots \\
7 \ldots \ldots \\
8 \ldots \ldots \\
10 \ldots \ldots\end{array}$ & $\begin{array}{l}6.0 \\
5.4 \\
5.7 \\
5.7 \\
5.7 \\
5.7 \\
5.7 \\
5.7 \\
4.5 \\
1.8\end{array}$ & $\begin{array}{r}8,260 \\
10,900 \\
4,880 \\
3,440 \\
2,500 \\
2,920 \\
2,830 \\
2,160 \\
2,290 \\
2,390\end{array}$ & $\begin{array}{l}11 \ldots . . \\
12 \ldots . . \\
13 \ldots . . \\
14 \ldots . \\
15 \ldots . \\
17 \ldots \ldots \\
18 \ldots . . \\
19 . \ldots . \\
20 . \ldots .\end{array}$ & $\begin{array}{c}1.4 \\
1.4 \\
1.4 \\
265 \\
354 \\
487 \\
492 \\
482 \\
270 \\
1.4\end{array}$ & $\begin{array}{l}2,270 \\
2,020 \\
2,460 \\
4,190 \\
3,240 \\
2,540 \\
2,180 \\
1,750 \\
1,660 \\
1,160\end{array}$ & $\begin{array}{l}21 \ldots \ldots \\
22 \ldots \ldots \\
23 \ldots \ldots \\
24 \ldots \ldots \\
25 \ldots \ldots \\
26 \ldots \ldots \\
27 \ldots \ldots \\
28 \ldots \ldots \\
29 \ldots \ldots \\
31 \ldots \ldots \\
31 \ldots \ldots\end{array}$ & $\begin{array}{c}1.2 \\
1.2 \\
11 \\
1.4 \\
1.2 \\
1.2 \\
1.2 \\
117 \\
2.5 \\
4.5 \\
15\end{array}$ & $\begin{array}{r}850 \\
810 \\
755 \\
622 \\
65 \\
65 \\
55 \\
55 \\
--0 .- \\
-0 .-0\end{array}$ \\
\hline thly & & & & & & & $\begin{array}{r}82,7 \\
5,090 \\
\end{array}$ & $\begin{array}{r}2,476 \\
137,500 \\
\end{array}$ \\
\hline
\end{tabular}




\section{1-2999.95. Tulloch Reservolr near Knights Ferry, Callf.}

Location.--Lat $37^{\circ} 52^{\prime} 30^{\prime \prime}$, long $120^{\circ} 36^{\prime} 15^{\prime \prime}$, In SW $\frac{1}{4}$ sec.1, T.1 S., R.12 E., in center of dam 1.6 miles upstream from Goodwin Dam, and 5.3 miles northeast of Knights Ferry.

Drainage area. $--980 \mathrm{sq} \mathrm{ml}$.

Elevation record. - Water-stage recorder graph. Datum of gage is at mean sea level (levels by Oakdale and South San Joaquin Irrigation Districts).

Contents record.--Contents computed from capacity table dated October 1956.

Maxima.--January-February 1963: Contents, 68,000 acre-ft Feb. 7, 8 (elevation, $510.8 \mathrm{ft}$ ). 1957 to December 1962: Contents, 68,300 acre-ft June 26, 1962 (elevation, $511.1 \mathrm{ft})$.

Remarks.--Reservolr is formed by gravity-type concrete dam completed in 0ctober 1957. Usable capacity, 56,840 acre-ft between elevations $431.0 \mathrm{ft}$ (normal

minimum water surface) and $511.0 \mathrm{ft}$ (top of radial gates) above mean sea level.

Dead storage, 11,560 acre-ft. Figures given herein represent total contents.

Elevation, in feet, and contents, in acre-feet, at 2400 hours, 1963

\begin{tabular}{|c|c|c|c|c|c|c|c|c|c|}
\hline \multirow{2}{*}{ Day } & \multicolumn{2}{|c|}{ January } & \multicolumn{2}{|c|}{ February } & \multirow{2}{*}{ Day } & \multicolumn{2}{|c|}{ January } & \multicolumn{2}{|c|}{ February } \\
\hline & Elevation & Contents & Elevation & Contents & & Elevation & Contents & Elevation & Contents \\
\hline $\begin{array}{r}1 \\
2 \\
3 \\
4 \\
5 \\
6 \\
7 \\
8 \\
9 \\
10 \\
11 \\
12 \\
13 \\
14 \\
15\end{array}$ & $\begin{array}{l}495.9 \\
495.8 \\
495.6 \\
495.4 \\
495.2 \\
495.0 \\
494.8 \\
494.6 \\
494.4 \\
494.4 \\
494.0 \\
493.8 \\
493.7 \\
494.1 \\
494.6\end{array}$ & $\begin{array}{l}51,000 \\
50,900 \\
50,700 \\
50,500 \\
50,300 \\
50,100 \\
49,900 \\
49,700 \\
49,500 \\
49,500 \\
49,100 \\
48,900 \\
48,800 \\
49,200 \\
49,700\end{array}$ & $\begin{array}{l}508.0 \\
509.8 \\
510.7 \\
510.5 \\
509.9 \\
510.5 \\
510.8 \\
510.8 \\
510.5 \\
508.3 \\
505.8 \\
504.3 \\
505.5 \\
506.5 \\
506.9\end{array}$ & $\begin{array}{l}64,500 \\
66,700 \\
67,800 \\
67,600 \\
66,800 \\
67,600 \\
68,000 \\
68,000 \\
67,600 \\
64,900 \\
61,800 \\
60,100 \\
61,500 \\
62,700 \\
63,200\end{array}$ & $\begin{array}{l}16 \\
17 \\
18 \\
19 \\
20 \\
21 \\
22 \\
23 \\
24 \\
25 \\
26 \\
27 \\
28 \\
29 \\
30 \\
31\end{array}$ & $\begin{array}{l}495.5 \\
496.3 \\
497.1 \\
497.5 \\
497.5 \\
497.4 \\
497.3 \\
497.3 \\
497.3 \\
497.2 \\
497.2 \\
497.2 \\
497.5 \\
497.5 \\
497.6 \\
501.4\end{array}$ & $\begin{array}{l}50,600 \\
51,400 \\
52,300 \\
52,700 \\
52,700 \\
52,600 \\
52,500 \\
52,500 \\
52,500 \\
52,400 \\
52,400 \\
52,400 \\
52,700 \\
52,700 \\
52,800 \\
56,800\end{array}$ & $\begin{array}{c}506.6 \\
506.1 \\
505.9 \\
506.0 \\
506.0 \\
506.0 \\
506.0 \\
505.9 \\
505.9 \\
505.9 \\
506.0 \\
506.0 \\
506.1 \\
- \\
- \\
-\end{array}$ & $\begin{array}{c}62,800 \\
62,200 \\
62,000 \\
62,100 \\
62,100 \\
62,100 \\
62,100 \\
62,000 \\
62,000 \\
62,000 \\
62,100 \\
62,100 \\
62,200 \\
- \\
- \\
-\end{array}$ \\
\hline Char & e In conte & $\mathrm{ts}$, in ac & -feet. & $\ldots \ldots$ & . & - & $+5,500$ & - & $+5,400$ \\
\hline
\end{tabular}

11-3020. Stanislaus River below Goodwin Dam, near Knights Ferry, Calif.

Location.--Lat $37^{\circ} 51^{\prime} 00^{\prime \prime}$, long $120^{\circ} 38^{\prime} 15^{\prime \prime}$, in $N \frac{1}{2}$ sec.15, T.1 S., R.12 E., on right bank 0.1 mile downstream from Owl Creek, 1.0 mile downstream from Goodwin Dam, and 3 miles northeast of Knights Ferry.

Drainage area. $--987 \mathrm{sq} \mathrm{ml}$.

Gage-helght record.--Water-stage recorder graph. Datum of gage is 252.83 ft above mean sea level.

Discharge record.--Stage-discharge relation defined by current-meter measurements.

Maxima.--January-February 1963: D1scharge, 11,800 cf's 0700 hours Feb. 2 (gage he1 ght, $17.18 \mathrm{ft}$ ).

1955 to December 1962: Discharge, 62,900 cf's Dec. 23, 1955 (gage height, unknown), by computation of flow over Goodwin Dam.

Remarks.--Flow affected by upstream reservolrs (combined capacity, 402,000 acre-ft).

Mean discharge, in cublc feet per second, 1963

\begin{tabular}{|c|c|c|c|c|c|c|c|c|}
\hline Day & January & February & Day & January & February & Day & January & February \\
\hline $\begin{array}{c}1 \ldots \ldots \\
2 \ldots \ldots \\
3 \ldots \ldots \\
5 \ldots \ldots \\
6 \ldots \ldots \\
8 \ldots \ldots \\
9 \ldots \ldots \\
10 \ldots \ldots\end{array}$ & $\begin{array}{l}84 \\
86 \\
82 \\
86 \\
86 \\
84 \\
84 \\
86 \\
90 \\
88\end{array}$ & $\begin{array}{l}5,800 \\
8,750 \\
4,030 \\
3,080 \\
2,500 \\
1,560 \\
1,670 \\
1,730 \\
2,010 \\
3,540\end{array}$ & $\begin{array}{l}11 \ldots \ldots \\
12 \ldots \ldots \\
13 \ldots \ldots \\
14 \ldots \ldots \\
15 \ldots \ldots \\
16 \ldots \ldots \\
17 \ldots \ldots \\
18 \ldots \ldots \\
19 \ldots \ldots \\
20 \ldots \ldots\end{array}$ & $\begin{array}{l}84 \\
75 \\
70 \\
60 \\
47 \\
48 \\
48 \\
50 \\
45 \\
35\end{array}$ & $\begin{array}{l}3,290 \\
2,890 \\
2,260 \\
2,420 \\
2,410 \\
2,400 \\
2,320 \\
1,840 \\
1,500 \\
1,080\end{array}$ & $\begin{array}{l}21 \ldots \ldots \\
22 \ldots \ldots \\
23 \ldots \ldots \\
24 \ldots \ldots \\
25 \ldots \ldots \\
26 \ldots \ldots \\
27 \ldots \ldots \\
28 \ldots \ldots \\
29 \ldots \ldots \\
30 \ldots \ldots \\
31 \ldots \ldots\end{array}$ & $\begin{array}{l}30 \\
23 \\
15 \\
15 \\
15 \\
14 \\
14 \\
14 \\
15 \\
18\end{array}$ & 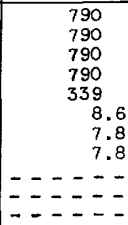 \\
\hline $\begin{array}{l}\text { onthly } \\
\text { unoff, }\end{array}$ & disc & , 1 & $8=$ & & & & $\begin{array}{r}51.8 \\
3,180 \\
\end{array}$ & $\begin{array}{r}2,164 \\
120,200 \\
\end{array}$ \\
\hline
\end{tabular}


Gage helght, in feet, and discharge, in cublc feet per second, at indicated time, 1963, of Stanislaus River below Goodwin Dam, near Knights Ferry, Calif.

\begin{tabular}{|c|c|c|c|c|c|c|c|c|c|c|c|}
\hline Date & Hour & $\underset{\text { he1ght }}{\text { Gage }}$ & $\begin{array}{c}\text { Dis- } \\
\text { charge }\end{array}$ & Date & Hour & $\begin{array}{c}\text { Gage } \\
\text { helght }\end{array}$ & $\begin{array}{c}\text { Dis- } \\
\text { charge }\end{array}$ & Date & Hour & $\begin{array}{c}\text { Gage } \\
\text { helght }\end{array}$ & $\begin{array}{l}\text { Dis- } \\
\text { charge }\end{array}$ \\
\hline Jan. 31 & 2400 & 6.81 & 17 & Feb, 2 & $\begin{array}{l}0700 \\
0800\end{array}$ & $\begin{array}{l}17.18 \\
16.80\end{array}$ & $\begin{array}{l}11,800 \\
11,000\end{array}$ & Feb. 2 & 2400 & 13.67 & 5,520 \\
\hline Feb. 1 & $\begin{array}{l}1000 \\
1000 \\
1100 \\
1200 \\
1300 \\
1400 \\
2400\end{array}$ & $\begin{array}{r}6.76 \\
12.00 \\
13.23 \\
13.91 \\
15.30 \\
16.80 \\
17.10\end{array}$ & $\begin{array}{r}13 \\
3,270 \\
4,900 \\
5,850 \\
8,140 \\
11,000 \\
11,600\end{array}$ & & $\begin{array}{l}0900 \\
1300 \\
1500 \\
1600 \\
1700 \\
2100 \\
2200\end{array}$ & $\begin{array}{l}15.93 \\
15.82 \\
14.57 \\
14.54 \\
13.98 \\
13.95 \\
13.70\end{array}$ & $\begin{array}{l}9,270 \\
9,080 \\
6,890 \\
6,840 \\
5,950 \\
5,910 \\
5,560\end{array}$ & 3 & $\begin{array}{l}0800 \\
0900 \\
1000 \\
1200 \\
1400 \\
2400\end{array}$ & $\begin{array}{l}13.65 \\
12.70 \\
12.30 \\
12.30 \\
11.75 \\
11.80\end{array}$ & $\begin{array}{l}5,490 \\
4,160 \\
3,640 \\
3,640 \\
2,970 \\
3,030\end{array}$ \\
\hline
\end{tabular}

11-3030. Stanislaus River at Ripon, Calif.

Location.--Lat $37^{\circ} 43^{1} 50^{\prime \prime}$, long $121^{\circ} 06^{1} 35^{\prime \prime}$, in SE $\frac{1}{4}$ sec.29, T.2 S., R.8 E., on left bank is ft downstream from railroad bridge, 1 mile southeast of Ripon, and 15 miles upstream from mouth.

Gage-height record.--Water-stage recorder graph. Datum of gage is $0.72 \mathrm{ft}$ above mean sea level, datum of 1929, adjustment of 1959 .

Discharge record.--Stage-discharge relation defined by current-meter measurements.

Maxima.--January-February 1963: Discharge, 7,340 cfs 1000 hours Feb. 3 (gage height, $55.33 \mathrm{ft}$ ).

1940 to December 1962: Discharge, 62,500 cf's Dec. 24, 1955 (gage height, $63.25 \mathrm{ft}^{\mathrm{t}}$ ).

Flood of Feb. 12, 1938, reached a stage of $64.4 \mathrm{ft}$, from floodmarks.

Remarks.--Flow affected by five major reservoirs (combined capacity, about 350,000 acre- $\left.f^{\prime} t\right)$.

Mean discharge, in cubic feet per second, 1963

\begin{tabular}{|c|c|c|c|c|c|c|c|c|}
\hline Day & January & February & Day & January & February & Day & January & February \\
\hline $\begin{array}{c}1 \ldots \ldots \\
2 \ldots \ldots \\
3 \ldots \ldots \\
4 \ldots \ldots \\
6 \ldots \ldots \\
7 \ldots \ldots \\
8 \ldots \ldots \\
10 \ldots \ldots\end{array}$ & $\begin{array}{l}546 \\
312 \\
237 \\
213 \\
201 \\
200 \\
198 \\
197 \\
195 \\
200\end{array}$ & $\begin{array}{r}203 \\
3,330 \\
6,880 \\
4,910 \\
3,420 \\
2,770 \\
2,050 \\
2,070 \\
2,090 \\
2,610\end{array}$ & $\begin{array}{l}11 \ldots \ldots \\
12 \ldots \ldots \\
13 \ldots \ldots \\
14 \ldots \ldots \\
15 \ldots \ldots \\
16 \ldots \ldots \\
17 \ldots \ldots \\
15 \ldots \ldots \\
19 \ldots \ldots \\
20 \ldots \ldots\end{array}$ & $\begin{array}{l}202 \\
200 \\
197 \\
190 \\
186 \\
177 \\
165 \\
160 \\
156 \\
155\end{array}$ & $\begin{array}{l}3,630 \\
3,450 \\
3,100 \\
3,230 \\
2,920 \\
2,790 \\
2,740 \\
2,650 \\
2,260 \\
1,950\end{array}$ & $\begin{array}{l}21 \ldots \ldots \\
22 \ldots \ldots \\
23 \ldots \ldots \\
24 \ldots \ldots \\
25 \ldots \ldots \\
26 \ldots \ldots \\
27 \ldots \ldots \\
28 \ldots \ldots \\
29 \ldots \ldots \\
30 \ldots \ldots \\
31 \ldots \ldots\end{array}$ & $\begin{array}{l}153 \\
145 \\
141 \\
136 \\
131 \\
128 \\
125 \\
123 \\
122 \\
125 \\
131\end{array}$ & $\begin{array}{r}1,600 \\
1,270 \\
1,220 \\
1,190 \\
1,170 \\
913 \\
513 \\
399 \\
----- \\
---1--\end{array}$ \\
\hline \multicolumn{7}{|c|}{ 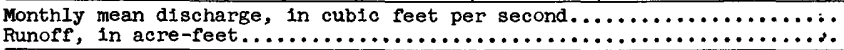 } & 11,400 & $\begin{array}{r}2,405 \\
133,500\end{array}$ \\
\hline
\end{tabular}

11-3035. San Joaquin River near Vermalis, Calif.

Location.--Lat $37^{\circ} 40^{\prime} 34^{\prime \prime}$, long $121^{\circ} 15^{\prime} 51^{\prime \prime}$, on left bank $30 \mathrm{ft}$ upstream from Durham Ferry highway bridge, 3 miles downstream from Stanislaus River, and 3.4 miles northeast of Vernalis, San Joaquin County.

Drainage area $,-13,540 \mathrm{sq} \mathrm{mi}$.

Gage-he1ght record.--Water-stage recorder graph, except 0200 hours Jan. 7 to 2300 hours Jan. 8, 2000 hours Jan. 15 to 1400 hours Feb. 1, and 1900 hours Feb. 8 to 1100 hours Feb. 15. Datum of gage is at mean sea level.

D1scharge record.--Stage-discharge relation defined by current-meter measurements. Discharge for periods of no gage-height record estimated on basis of recorded range in stage and once-daily wire-weight-gage readings for San Joaquin River at Maze Road. Maxima.--January-February 1963: Discharge, 12,400 ef's 2000 hours Feb. 4 (elevation,

1922 to December 1962: Discharge, about 79,000 cfs Dec. 9, 1950 (elevation,

$32.81 \mathrm{ft})$, including flow through breaks in levee.

Remarks.--Flow affected by upstream reservolrs. 
Mean discharge, in cubic feet per second, 1963, of San Joaquin River near Vernalis, Calif.

\begin{tabular}{|c|c|c|c|c|c|c|c|c|}
\hline Day & January & February & Day & January & Pebruary & Day & January & February \\
\hline $\begin{array}{l}1 \ldots \ldots \\
2 \ldots \ldots \\
3 \ldots \ldots \\
4 \ldots \ldots \\
5 \ldots \ldots \\
6 \ldots \ldots \\
7 \ldots \ldots \\
9 \ldots \ldots \\
10 \ldots \ldots\end{array}$ & $\begin{array}{l}2,190 \\
2,180 \\
1,940 \\
2,270 \\
2,270 \\
2,000 \\
1,720 \\
1,670 \\
1,960 \\
2,090\end{array}$ & $\begin{array}{r}1,920 \\
3,830 \\
9,220 \\
12,100 \\
12,000 \\
11,700 \\
11,000 \\
8,700 \\
7,500 \\
7,700\end{array}$ & 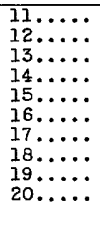 & $\begin{array}{l}2,000 \\
2,090 \\
2,130 \\
1,910 \\
1,690 \\
1,630 \\
1,630 \\
1,640 \\
1,590 \\
1,590\end{array}$ & $\begin{array}{r}9,100 \\
9,700 \\
8,700 \\
9,700 \\
11,900 \\
11,200 \\
9,970 \\
9,280 \\
8,660 \\
8,650\end{array}$ & $\begin{array}{l}21 \ldots \ldots \\
22 \ldots \ldots \\
23 \ldots \ldots \\
24 \ldots \ldots \\
25 \ldots \ldots \\
26 \ldots \\
27 \ldots \ldots \\
28 \ldots \ldots \\
29 \ldots \\
30 \ldots \\
31 \ldots \ldots\end{array}$ & $\begin{array}{l}1,530 \\
1,470 \\
1,470 \\
1,500 \\
1,470 \\
1,500 \\
1,500 \\
1,410 \\
1,300 \\
1,440 \\
1,590\end{array}$ & $\begin{array}{r}7,550 \\
6,690 \\
6,350 \\
5,950 \\
5,420 \\
5,100 \\
4,930 \\
4,670 \\
----- \\
-----\end{array}$ \\
\hline & & & & & & & $\begin{array}{r}1,754 \\
107,800\end{array}$ & $\begin{array}{r}8,185 \\
454,600\end{array}$ \\
\hline
\end{tabular}

11-3040. Corral Hollow Creek near Tracy, Calif.

Location.--Lat $37^{\circ} 39^{\prime} 24^{\prime \prime}$, long $121^{\circ} 28^{\prime} 40^{\prime \prime}$, in SE $\frac{1}{4} \mathrm{NE} \frac{1}{4}$ sec.24, T.3 S., R.4 E., on lef't bank just upstream from highway bridge, 0.8 mile downstream from Eik Ravine, and 6.3 miles southwest of Tracy.

Drainage area. $--61.6 \mathrm{sq} \mathrm{mi}$.

Gage-helght record ${ }^{--W a t e r-s t a g e ~ r e c o r d e r ~ g r a p h . ~ D a t u m ~ o f ~ g a g e ~ i s ~} 330 \mathrm{ft}$ (from topographic map)

Discharge record.--Stage-discharge relation defined by current-meter measurements. Maxima ${ }^{--J a n u a r y-F e b r u a r y ~ 1963: ~ D i s c h a r g e, ~} 56 \mathrm{cfs} 0700$ hours Feb. 1 (gage height,

1958 to December 1962: Discharge, 145 cfs Mar. 6, 1962 (gage height, $2.54 \mathrm{ft}$ ).

Mean discharge, in cubic feet per second, 1963

\begin{tabular}{|c|c|c|c|c|c|c|c|c|}
\hline Day & January & February & Day & January & February & Day & January & February \\
\hline $\begin{array}{c}1 \ldots \ldots \\
2 \ldots \ldots \\
3 \ldots \ldots \\
4 \ldots \ldots \\
5 \ldots \ldots \\
7 \ldots \ldots \\
8 \ldots \ldots \\
9 \ldots \ldots \\
10 \ldots \ldots\end{array}$ & $\begin{array}{r}0.2 \\
.2 \\
.2 \\
.2 \\
.2 \\
.2 \\
.2 \\
.2 \\
.2 \\
.2\end{array}$ & $\begin{array}{r}19 \\
2.7 \\
.5 \\
.4 \\
.4 \\
.4 \\
.4 \\
.4 \\
.5 \\
.6\end{array}$ & $\begin{array}{l}11 \ldots \ldots \\
12 \ldots \ldots \\
13 \ldots \ldots \\
14 \ldots \ldots \\
15 \ldots \ldots \\
16 \ldots \ldots \\
17 \ldots \ldots \\
18 \ldots \ldots \\
19 \ldots \ldots \\
20 \ldots \ldots\end{array}$ & $\begin{array}{l}0.2 \\
.2 \\
.2 \\
.2 \\
.2 \\
.2 \\
.2 \\
.2 \\
.2 \\
.2\end{array}$ & $\begin{array}{r}0.5 \\
.7 \\
2.4 \\
4.8 \\
.6 \\
.3 \\
.3 \\
.3 \\
.3 \\
.3\end{array}$ & $\begin{array}{l}21 \ldots \ldots \\
22 \ldots \ldots \\
23 \ldots \ldots \\
24 \ldots \ldots \\
25 \ldots \ldots \\
26 \ldots \ldots \\
27 \ldots \ldots \\
28 \ldots \ldots \\
29 \ldots \ldots \\
30 \ldots \ldots \\
31 \ldots \ldots\end{array}$ & $\begin{array}{r}0.2 \\
.2 \\
.2 \\
.2 \\
.2 \\
.2 \\
.2 \\
.2 \\
.2 \\
.4 \\
.4\end{array}$ & $\begin{array}{r}0.3 \\
.3 \\
.3 \\
.3 \\
.3 \\
.3 \\
.3 \\
.3 \\
----- \\
-----\end{array}$ \\
\hline \multicolumn{7}{|l|}{$\begin{array}{l}\text { Monthly } \\
\text { Runoff, } \\
\text { Runoff, }\end{array}$} & $\begin{array}{r}0.21 \\
0.004 \\
13\end{array}$ & $\begin{array}{r}1.36 \\
0.02 \\
76\end{array}$ \\
\hline
\end{tabular}

11-3050. San Domingo Creek near San Andreas, Calif.

(Crest-stage station)

Location.--Lat $38^{\circ} 06^{\prime} 55^{\prime \prime}$, long $120^{\circ} 37^{\prime} 00^{\prime \prime}$, in NE $\frac{1}{4}$ sec.14, T.3 N., R.12 E., on right bank 2.5 miles upstream from mouth, 3.2 miles downstream from French Gulch, and $6.5 \mathrm{miles}$ southeast of San Andreas.

Drainage area. $--26.2 \mathrm{sq} \mathrm{mi}$.

Gage-helght record.--Crest stages only. Altitude of gage is 1,060 ft (from topographic map).

Discharge record.--Stage-discharge relation defined by current-meter measurements below $125 \mathrm{cfs}$ and by slope-area measurement at $2,830 \mathrm{cfs}$. Max1ma.--January-February 1963: D1scharge, 1,380 cfs Jan. 31 (gage he1ght, $6.5 \mathrm{ft}$,

1950 to December 1962: Discharge, 2,830 cfs Dec. 23, 1955 (gage height, $8.24 \mathrm{ft})$. 
11-3055. San Antonio Creek near San Andreas, Calif.

\section{(Crest-stage station)}

Location.--Lat $38^{\circ} 07^{\prime} 50^{\prime \prime}$, Iong $120^{\circ} 38^{\prime} 10^{\prime \prime}$, in NE $\frac{1}{4}$ sec.10, T.3 N., R.12 E., $800 \mathrm{ft}$ below highway bridge, 1.9 miles upstream from mouth, 5 miles southeast of San Andreas.

Drainage area. $--48.1 \mathrm{sq} \mathrm{mi}$.

Gage-helght record.--Crest stages only. Altitude of gage is $940 \mathrm{ft}$ (from topographic mapl.

Discharge record.--Stage-discharge relation defined by current-meter measurements below $250 \mathrm{cfs}$ and by slope-area measurement at $2,500 \mathrm{cfs}$.

Maxima --January-February 1963: Discharge, 1,730 efs Jan. 31 (gage height, $4.77 \mathrm{ft}$ ). 1950 to December 1962: Discharge, 2,500 cfs Dec. 23, 1955 gage he1ght, $5.66 \mathrm{ft}$ ).

\section{1-3060. South Fork Calaveras River near San Andreas, Calif.}

Location -- Lat $38^{\circ} 08^{\prime} 40^{\prime \prime}$, long $120^{\circ} 39^{\prime} 50^{\prime \prime}$, in NW $\frac{1}{4}$ sec.4, T.3 N., R.12 E., on right bank 0.1 mile downstream from San Antonio Creek, 1.6 miles south of the Calaveras Cement Plant, and 3.7 miles south of San Andreas.

Drainage area. $-118 \mathrm{sq} \mathrm{mi}$.

Gage-height record ;-Water-stage recorder graph. Altitude of gage is $860 \mathrm{ft}$ (from topographic map ).

Discharge record.--Stage-discharge relation defined by current-meter measurements below 3,200 cfs and by slope-area measurement at 17,600 cfs.

Maxima.--January-February 1963: Discharge, 12,600 cfs 2100 hours Jan. 31 (gage height, $9.20 \mathrm{ft}$ ).

1950 to December 1962: Discharge, 17,600 cfs Dec. 23, 1955 (gage height, $10.29 \mathrm{ft}$.

Mean discharge, in cubic feet per second, 1963

\begin{tabular}{|c|c|c|c|c|c|c|c|c|}
\hline Day & January & February & Day & J anuary & February & Day & January & February \\
\hline $\begin{array}{c}1 \ldots \ldots \\
2 \ldots \ldots \\
4 \ldots \ldots \\
5 \ldots \ldots \\
6 \ldots \ldots \\
8 \ldots \ldots \\
9 \ldots \ldots \\
10 \ldots \ldots\end{array}$ & $\begin{array}{l}5.2 \\
5.2 \\
5.2 \\
5.2 \\
5.2 \\
5.2 \\
5.4 \\
5.7 \\
5.7 \\
5.7\end{array}$ & $\begin{array}{r}3,110 \\
519 \\
217 \\
138 \\
96 \\
77 \\
63 \\
65 \\
62 \\
283\end{array}$ & $\begin{array}{l}11 \ldots \ldots \\
12 \ldots \ldots \\
13 \ldots \ldots \\
14 \ldots \ldots \\
15 \ldots \ldots \\
16 \ldots \ldots \\
17 \ldots \ldots \\
15 \ldots \ldots \\
19 \ldots \ldots \\
20 \ldots \ldots\end{array}$ & $\begin{array}{l}5.7 \\
5.4 \\
4.4 \\
4.0 \\
4.9 \\
5.2 \\
5.2 \\
5.2 \\
5.2 \\
5.2\end{array}$ & $\begin{array}{r}118 \\
92 \\
651 \\
386 \\
175 \\
125 \\
98 \\
77 \\
66 \\
59\end{array}$ & $\begin{array}{l}21 \ldots \ldots \\
22 \ldots \ldots \\
23 \ldots \ldots \\
24 \ldots \ldots \\
25 \ldots \ldots \\
26 \ldots \ldots \\
27 \ldots \ldots \\
25 \ldots \ldots \\
29 \ldots \ldots \\
30 \ldots \ldots \\
31 \ldots \ldots\end{array}$ & $\begin{array}{r}4.9 \\
5.2 \\
4.9 \\
4.9 \\
4.4 \\
4.4 \\
4.4 \\
4.4 \\
4.7 \\
212 \\
3,280\end{array}$ & $\begin{array}{r}52 \\
49 \\
44 \\
41 \\
39 \\
36 \\
34 \\
33 \\
----\end{array}$ \\
\hline $\begin{array}{l}\text { nthly } \\
\text { dnoff, } \\
\text { dnoff, }\end{array}$ & $\begin{array}{l}\text { ean dis } \\
\text { n inche } \\
\text { acre }\end{array}$ & & & & & & $\begin{array}{r}117 \\
1.15 \\
7,220\end{array}$ & $\begin{array}{r}243 \\
2.14 \\
13,500\end{array}$ \\
\hline
\end{tabular}

Gage height, in feet, and discharge, in cublc feet per second, at indicated time, 1963

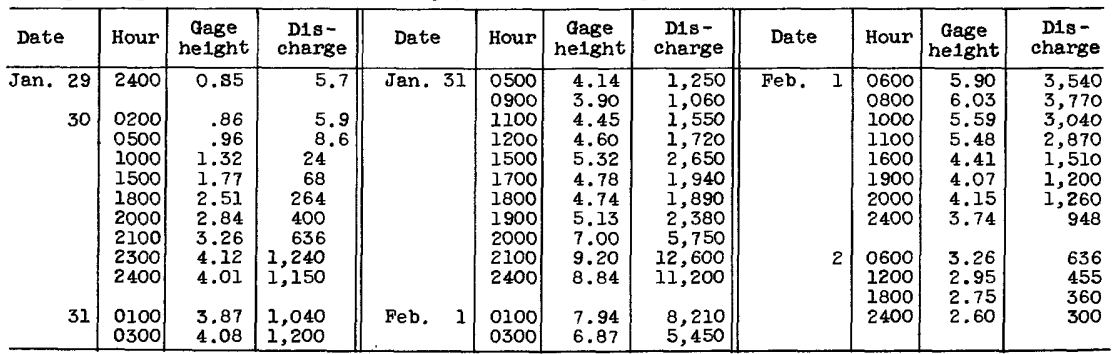


11-3065. Calaveritas Creek near San Andreas, Cal1f.

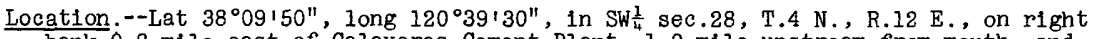
bank 0.8 mfle east of Calaveras Cement Plant, 1.0 mile upstream from mouth, and 2.6 miles southeast of San Andreas.

Drainage area. $--53.0 \mathrm{sq} \mathrm{mi}$.

Gage-height record :-Water-stage recorder graph. Alt1tude of gage is $865 \mathrm{f}^{\prime}$ (from topographic map).

Discharge record.--Stage-discharge relation defined by current-meter measurements.

Maxima.--January-February 1963: Discharge, 3,870 cfs 0100 hours Feb. 1 (gage helght, $6.35 \mathrm{ft}$ ).

1950 to December 1962: Discharge, 4,410 cfs Apr. 2, 1958 (gage height, $6.65 \mathrm{ft}$ ).

Mean d1scharge, In cub1c feet per second, 1963

\begin{tabular}{|c|c|c|c|c|c|c|c|c|}
\hline Day & January & February & Day & January & February & Day & January & February \\
\hline $\begin{array}{r}1 \ldots \ldots \\
2 \ldots \ldots \\
3 \ldots \ldots \\
4 \ldots \ldots \\
5 \ldots \ldots \\
6 \ldots \ldots \\
8 \ldots \ldots \\
9 \ldots \ldots \\
10 \ldots \ldots\end{array}$ & $\begin{array}{l}3.8 \\
3.6 \\
3.6 \\
3.6 \\
3.6 \\
3.2 \\
3.0 \\
3.0 \\
3.0 \\
3.0\end{array}$ & $\begin{array}{r}1,510 \\
234 \\
101 \\
56 \\
34 \\
25 \\
19 \\
16 \\
17 \\
43\end{array}$ & $\begin{array}{l}11 \ldots \ldots \\
12 \ldots \ldots \\
13 \ldots \ldots \\
14 \ldots \ldots \\
15 \ldots \ldots \\
16 \ldots \ldots \\
17 \ldots \ldots \\
18 \ldots \ldots \\
19 \ldots \ldots \\
20 \ldots \ldots\end{array}$ & $\begin{array}{l}3.2 \\
3.0 \\
3.0 \\
3.0 \\
3.0 \\
3.0 \\
2.8 \\
3.0 \\
3.2 \\
3.0\end{array}$ & $\begin{array}{r}43 \\
33 \\
93 \\
153 \\
96 \\
59 \\
39 \\
31 \\
25 \\
22\end{array}$ & $\begin{array}{l}21 \ldots \ldots \\
22 \ldots \ldots \\
23 \ldots \ldots \\
24 \ldots \ldots \\
25 \ldots \ldots \\
26 \ldots \ldots \\
27 \ldots \ldots \\
28 \ldots \ldots \\
29 \ldots \ldots \\
30 \ldots \ldots \\
31 \ldots \ldots\end{array}$ & $\begin{array}{r}3.0 \\
3.2 \\
3.2 \\
3.0 \\
3.0 \\
3.0 \\
3.0 \\
3.0 \\
3.2 \\
38 \\
721\end{array}$ & 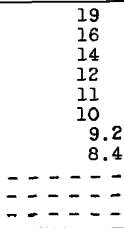 \\
\hline \multicolumn{7}{|l|}{$\begin{array}{l}\text { Monthly } \\
\text { Runoff, } \\
\text { Runoff, }\end{array}$} & $\begin{array}{r}27.4 \\
0.59 \\
1,690 \\
\end{array}$ & $\begin{array}{r}98.2 \\
1.92 \\
5,450 \\
\end{array}$ \\
\hline
\end{tabular}

Gage he1ght, in feet, and discharge, in cublc feet per second, at ind1cated t1me, 1963

\begin{tabular}{|c|c|c|c|c|c|c|c|c|c|c|c|}
\hline Date & Hour & $\begin{array}{c}\text { Gage } \\
\text { height }\end{array}$ & $\begin{array}{c}\text { Dis- } \\
\text { charge }\end{array}$ & Date & Hour & $\begin{array}{c}\text { Gage } \\
\text { helght }\end{array}$ & $\begin{array}{l}\text { D1s- } \\
\text { charge }\end{array}$ & Date & Hour & $\begin{array}{c}\text { Gage } \\
\text { he1ght }\end{array}$ & $\begin{array}{c}\text { D1s- } \\
\text { charge }\end{array}$ \\
\hline $\begin{array}{r}29 \\
30\end{array}$ & $\begin{array}{l}2400 \\
0200 \\
0600 \\
1000 \\
1300 \\
1600 \\
1900 \\
2100 \\
2400 \\
0100\end{array}$ & $\begin{array}{r}0.84 \\
.85 \\
1.00 \\
1.25 \\
1.67 \\
1.59 \\
1.85 \\
2.24 \\
1.87 \\
1.84\end{array}$ & $\begin{array}{c}3.4 \\
3.6 \\
7.0 \\
16 \\
43 \\
37 \\
63 \\
125 \\
65 \\
62\end{array}$ & Feb. 1 & $\begin{array}{l}0500 \\
0800 \\
1100 \\
1200 \\
1600 \\
1800 \\
2000 \\
2100 \\
2200 \\
2400 \\
0100\end{array}$ & $\begin{array}{l}2.26 \\
2.55 \\
2.39 \\
3.39 \\
3.34 \\
3.88 \\
5.00 \\
5.23 \\
5.13 \\
6.14 \\
6.35\end{array}$ & $\begin{array}{r}129 \\
196 \\
297 \\
505 \\
450 \\
788 \\
1,800 \\
2,080 \\
1,960 \\
3,490 \\
3,870\end{array}$ & Feb. J & $\begin{array}{l}0500 \\
0700 \\
0900 \\
1200 \\
1500 \\
1800 \\
2400 \\
\\
0700 \\
1200 \\
1800 \\
2400\end{array}$ & $\begin{array}{l}5.56 \\
5.00 \\
4.67 \\
4.75 \\
4.14 \\
3.65 \\
3.26 \\
\\
2.89 \\
2.68 \\
2.51 \\
2.37\end{array}$ & $\begin{array}{r}2,450 \\
1,700 \\
1,310 \\
1,400 \\
888 \\
585 \\
404 \\
\\
272 \\
210 \\
168 \\
139\end{array}$ \\
\hline
\end{tabular}

11-3070. Esperanza Creek near Mokelumne Hill, Cal1f.

(Crest-stage station)

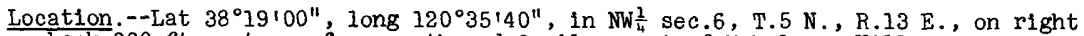
bank 600 ft upstream from mouth and 6 miles east of Mokelumne Hill.

Drainage area. $--16.6 \mathrm{sq} \mathrm{mi}$.

Gage-helght record.--Crest 8 tages only. Altitude of gage is 1,470 ft (from topographic map).

Discharge record.--Stage-discharge relation defined by current-meter measurements below $1,100 \mathrm{c}$ 's and by slope-area measurement at 3,060 $\mathrm{cf} 8$.

Maxima.--January-February 1963: Discharge, 2,550 cfs Jan. 31 (gage height, $6.27 \mathrm{ft}$, in gage well; $7.3 \mathrm{ft}$ outside, from floodmarks).

1951 to December 1962: Discharge, 3,060 cfs Dec. 23, 1955 (gage height,

$6.78 \mathrm{ft}$, in gage wel1; $7.7 \mathrm{ft}$ outside, from floodmarks): 
11-3075. Jesus Mar1a Creek near Mokelumne Hill, Calif.

(Crest-stage station)

Location.--Lat $38^{\circ} 17^{\prime} 00^{\prime \prime}$, long $120^{\circ} 39^{\prime} 00^{\prime \prime}$, in SE $\frac{1}{4}$ sec.16, T.5 N., R.12 E., on right bank 0.6 mile upstream from mouth, $1.0 \mathrm{mlle}$ downstream from Wet Gulch, and 3.2 miles southeast of Mokelumne H1ll.

Drainage area. $--34.6 \mathrm{sq} \mathrm{ml}$.

Gage-height record.--Crest stages only. Altitude of gage is $980 \mathrm{ft}$ (from topographic map).

Discharge record.--Stage-discharge relation defined by current-meter measurements below $1,300 \mathrm{cf}$ 's and by slope-area measurement at 5,490 cf's.

Maxima --January-February 1963: Discharge, 3,080 efs Jan. 31 (gage height, $6.88 \mathrm{ft}$ ). 1950 to December 1962: Discharge, 5,490 cfs Dec. 23, 1955 (gage helght, $7.63 \mathrm{ft})$.

11-3080. North Fork Calaveras River near San Andreas, Calif.

Location.--Lat $38^{\circ} 13^{\prime} 05^{\prime \prime}$, long $120^{\circ} 41^{\prime} 55^{\prime \prime}$, in NW $\frac{1}{4}$ sec.7, T.4 N., R.12 E., on right bank 0.5 mile upstream from Chile Gulch and 1.8 miles northwest of San Andreas.

Drainage area. $--85.6 \mathrm{sq} \mathrm{mi}$.

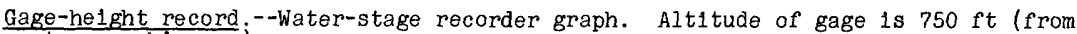
topographic map).

D1scharge record.--Stage-discharge relation defined by current-meter measurements below 3,900 cfs.

Maxima, --January-February 1963: D1scharge, 5,620 cfs 0100 hours Feb. 1 (gage helght, $11.72 \mathrm{ft})$.

1950 to December 1962: Discharge, 6,200 cfs Dec. 23, 1955 (gage height, $12.52 \mathrm{ft}$ ).

Mean discharge, In cubic feet per second, 1963

\begin{tabular}{|c|c|c|c|c|c|c|c|c|}
\hline Day & January & February & Day & January & February & Day & January & February \\
\hline $\begin{array}{c}1 \ldots \ldots \\
3 \ldots \ldots \\
4 \ldots \ldots \\
5 \ldots \ldots \\
7 \ldots \ldots \\
8 \ldots \ldots \\
9 \ldots \ldots \\
10 \ldots\end{array}$ & $\begin{array}{l}7.9 \\
7.4 \\
7.1 \\
6.8 \\
6.8 \\
7.1 \\
7.4 \\
6.8 \\
6.8 \\
7.1\end{array}$ & $\begin{array}{r}2,630 \\
449 \\
138 \\
75 \\
52 \\
39 \\
34 \\
30 \\
31 \\
88\end{array}$ & $\begin{array}{l}11 \ldots \ldots \\
12 \ldots \ldots \\
13 \ldots \ldots \\
14 \ldots \ldots \\
15 \ldots \ldots \\
16 \ldots \ldots \\
17 \ldots \ldots \\
18 \ldots \ldots \\
19 \ldots \ldots \\
20 \ldots \ldots\end{array}$ & $\begin{array}{l}6.8 \\
7.1 \\
5.8 \\
5.6 \\
5.6 \\
5.8 \\
5.8 \\
5.6 \\
5.6 \\
5.4\end{array}$ & $\begin{array}{r}57 \\
38 \\
177 \\
184 \\
91 \\
58 \\
43 \\
36 \\
33 \\
32\end{array}$ & $\begin{array}{l}21 \ldots \ldots \\
22 \ldots \ldots \\
23 \ldots \ldots \\
24 \ldots \ldots \\
25 \ldots \ldots \\
26 \ldots \ldots \\
27 \ldots \ldots \\
28 \ldots \ldots \\
20 \ldots \ldots \\
30 \ldots \ldots \\
31 \ldots \ldots\end{array}$ & $\begin{array}{r}5.4 \\
5.4 \\
5.6 \\
5.6 \\
5.8 \\
5.8 \\
6.0 \\
6.0 \\
6.3 \\
181.0 \\
1,590\end{array}$ & $\begin{array}{r}27 \\
25 \\
23 \\
20 \\
19 \\
19 \\
18 \\
17 \\
-\ldots---\end{array}$ \\
\hline \multicolumn{7}{|l|}{$\begin{array}{l}\text { Monthiy } \\
\text { Runoff, } \\
\text { Runoff, }\end{array}$} & $\begin{array}{r}63.0 \\
0.85 \\
3,880 \\
\end{array}$ & $\begin{array}{r}160 \\
1.95 \\
8,900 \\
\end{array}$ \\
\hline
\end{tabular}

Gage height, in feet, and discharge, in cubic feet per second, at indicated time, 1963

\begin{tabular}{|c|c|c|c|c|c|c|c|c|c|c|c|}
\hline Date & Hour & $\begin{array}{c}\text { Gage } \\
\text { he1ght }\end{array}$ & $\begin{array}{l}\text { D1s- } \\
\text { charge }\end{array}$ & Date & Hour & $\begin{array}{c}\text { Gage } \\
\text { helght }\end{array}$ & $\begin{array}{l}\text { Dis- } \\
\text { charge }\end{array}$ & Date & Hour & $\begin{array}{c}\text { Gage } \\
\text { height }\end{array}$ & $\begin{array}{l}\text { D1s- } \\
\text { charge }\end{array}$ \\
\hline $\begin{array}{r}29 \\
30\end{array}$ & $\begin{array}{l}2400 \\
0300 \\
0700 \\
1300 \\
1500 \\
1600 \\
1700 \\
1900 \\
2000 \\
2200 \\
2400\end{array}$ & $\begin{array}{l}1.11 \\
1.13 \\
1.19 \\
1.37 \\
1.64 \\
1.92 \\
3.18 \\
4.33 \\
4.46 \\
5.03 \\
5.57\end{array}$ & $\begin{array}{c}7.1 \\
7.6 \\
9.4 \\
16 \\
28 \\
44 \\
201 \\
474 \\
513 \\
699 \\
924\end{array}$ & Jan. 31 & $\begin{array}{l}0900 \\
1200 \\
1400 \\
1600 \\
1700 \\
1800 \\
1900 \\
2000 \\
2100 \\
2200 \\
2300 \\
2400\end{array}$ & $\begin{array}{r}5.47 \\
5.11 \\
6.41 \\
8.39 \\
8.53 \\
8.39 \\
7.76 \\
7.44 \\
7.33 \\
8.04 \\
10.50 \\
11.43\end{array}$ & $\begin{array}{r}878 \\
727 \\
1,340 \\
2,600 \\
2,700 \\
2,600 \\
2,160 \\
1,930 \\
1,850 \\
2,360 \\
4,340 \\
5,330\end{array}$ & Feb. 1 & $\begin{array}{l}0800 \\
0900 \\
1000 \\
1100 \\
1300 \\
1600 \\
1700 \\
1900 \\
2000 \\
2100 \\
2400\end{array}$ & $\begin{array}{l}7.94 \\
8.11 \\
8.50 \\
8.72 \\
7.66 \\
6.55 \\
6.35 \\
5.97 \\
5.95 \\
6.01 \\
5.55\end{array}$ & $\begin{array}{r}2,440 \\
2,560 \\
2,830 \\
3,000 \\
2,240 \\
1,520 \\
1,400 \\
1,180 \\
1,180 \\
1,200 \\
965\end{array}$ \\
\hline 31 & $\begin{array}{l}0200 \\
0400 \\
0600 \\
0800 \\
\end{array}$ & $\begin{array}{l}5.93 \\
5.55 \\
5.00 \\
5.23 \\
\end{array}$ & $\begin{array}{r}1,100 \\
914 \\
685 \\
776 \\
\end{array}$ & Feb. 1 & $\begin{array}{l}0100 \\
0200 \\
0300 \\
0600\end{array}$ & $\begin{array}{r}11.72 \\
11.66 \\
11.29 \\
8.84 \\
\end{array}$ & $\begin{array}{l}5,620 \\
5,560 \\
5,190 \\
3,090\end{array}$ & & $\begin{array}{l}1000 \\
1300 \\
1800 \\
2400\end{array}$ & $\begin{array}{l}4.92 \\
4.27 \\
4.02 \\
3.67 \\
3.38\end{array}$ & $\begin{array}{l}672 \\
435 \\
358 \\
269 \\
209\end{array}$ \\
\hline
\end{tabular}


11-3083. Eldorado Creek at Mountain Ranch, Calif.

(Crest-stage station)

Location.--Lat $38^{\circ} 13^{\prime} 38^{\prime \prime}$, long $120^{\circ} 32^{\prime} 37^{\prime \prime}$, in SE $\frac{1}{4}$ sec.4, T.4 N., R.13 E., 0.2 mile southwest of Mountain Ranch.

Drainage area. $--1.91 \mathrm{sq} \mathrm{ml}$.

Gage-helght record.--Crest stages only. Altitude of gage is 2,090 ft (from topographic map).

Discharge record.--Stage-discharge relation defined by current-meter measurements below $11 \mathrm{cfs}$ and by slope-area measurements at $130 \mathrm{cfs}$.

Maxima.--January-February 1963: Discharge, $130 \mathrm{cfs} F \mathrm{Feb} .1$ (gage he1ght, unknown; culvert partiy plugged).

July to December 1962: No slgniflcant floodflow.

11-3085. Murray Creek near San Andreas, Calif.

(Crest-stage station)

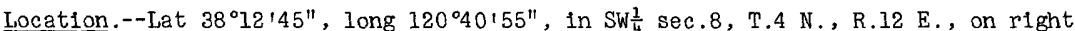
bank 600 ft upstream from bridge on State Highway $49,0.9$ mile downstream from North Fork Murray Creek, 1.1 miles north of San Andreas, and 1.5 mlles upstream from mouth.

Drainage area. $--23.4 \mathrm{sq} \mathrm{ml}$.

Gage-helght record.--Crest stages only. Alt1tude of gage is $830 \mathrm{ft}$ (from topographic mapl.

Discharge record. - -Stage-discharge relation defined by current-meter measurements below $850 \mathrm{cfs}$ and by slope-area measurement at 1,700 cfs.

Maxima.--January-February 1963: Discharge, 1,730 cf's Jan. 31 (gage helght, $6.70 \mathrm{ft}$ ). 1950 to December 1962: Discharge, 1,700 cfs Dec. 23, 1955 (gage height, $6.62 \mathrm{ft}$ ).

11-3089. Calaveras River below Hogan Dam, Calif.

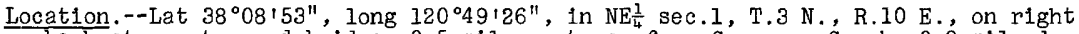
bank at county road bridge, $0.5 \mathrm{mile}$ upstream from Cosgrove Creek, $0.8 \mathrm{mile}$ downstream from Hogan Dam, and 3.0 miles south of Valley Springs.

Drainage area. $--363 \mathrm{sq} \mathrm{mi}$.

Gage-he1ght record.--Water-stage recorder graph, except Jan. 1-26. One staff-gage reading avallabie on Jan. 21. Datum of gage is $519.8 \mathrm{ft}$ above mean sea level (levels by Corps of Engineers).

Discharge record.--Stage-discharge relation defined by current-meter measurements. Discharge for perlods of no gage-height record estimated on basis of records for Calaveras River at Jenny Lind and Cosgrove Creek near Valley Springs.

Maxima.--January-February 1963: Discharge, 7,020 cfs 1330 hours Feb. 1 (gage helght, $6.76 \mathrm{ft}$ ).

1961 to December 1962: Dally discharge, 5,300 cfs Feb. 16, 1962.

Remarks.--Flow regulated by Hogan Reservolr at Stockton flood-control dam (usable capacity, 75,000 acre- $\mathrm{f}^{t}$ ) and by Bingham Reservolr (capacity, 775 acre-ft) on North Fork Calaveras River.

Mean discharge, in cubic feet per second, 1963

\begin{tabular}{|c|c|c|c|c|c|c|c|c|}
\hline Day & January & February & Day & January & February & Day & January & February \\
\hline $\begin{array}{r}1 \\
1 \ldots \ldots . \\
2 \ldots \ldots \\
3 \ldots \ldots \\
4 \ldots \ldots \\
5 \ldots \ldots \\
6 \ldots \ldots \\
7 \ldots \ldots \\
9 \ldots \ldots \\
10 \ldots . .\end{array}$ & 2 & $\begin{array}{r}6,430 \\
5,440 \\
3,500 \\
1,960 \\
472 \\
226 \\
162 \\
140 \\
120 \\
415\end{array}$ & $\begin{array}{l}11 \ldots \ldots \\
12 \ldots \ldots \\
13 \ldots \ldots \\
14 \ldots \ldots \\
15 \ldots \ldots \\
16 \ldots \\
17 \ldots \ldots \\
19 \ldots \ldots \\
20 \ldots \ldots\end{array}$ & 2 & $\begin{array}{r}415 \\
238 \\
699 \\
1,170 \\
387 \\
10 \\
9.6 \\
9.6 \\
9.6 \\
9.6\end{array}$ & $\begin{array}{l}21 \ldots \ldots \\
22 \ldots \ldots \\
23 \ldots \ldots \\
24 \ldots \\
25 \ldots \ldots \\
26 \ldots \ldots \\
27 \ldots \ldots \\
28 \ldots \ldots \\
29 \ldots \ldots \\
30 \ldots \ldots \\
31 \ldots \ldots\end{array}$ & $\begin{array}{r}2.4 \\
2 \\
\\
94 \\
84 \\
84 \\
129 \\
98 \\
1,700\end{array}$ & $\begin{array}{r}9.6 \\
9.6 \\
9.6 \\
9.6 \\
9.0 \\
9.0 \\
8.5 \\
8.5 \\
-0.0 \\
-0 .-0.0\end{array}$ \\
\hline $\begin{array}{l}\text { nthly } \\
\text { norf, }\end{array}$ & $\begin{array}{l}\text { an disc } \\
\text { acre-f }\end{array}$ & , & Peet & & & & $\begin{array}{r}69.6 \\
4,280\end{array}$ & $\begin{array}{r}782 \\
6,430\end{array}$ \\
\hline
\end{tabular}


Gage helght, in feet, and discharge, in cublc feet per second, at indicated time, 1963 , of Calaveras River below Hogan Dam, Calif

\begin{tabular}{|c|c|c|c|c|c|c|c|c|c|c|c|}
\hline Date & Hour & $\begin{array}{c}\text { Gage } \\
\text { helght }\end{array}$ & $\begin{array}{l}\text { Dis- } \\
\text { charge }\end{array}$ & Date & Hour & $\begin{array}{c}\text { Gage } \\
\text { he1ght }\end{array}$ & $\begin{array}{c}\text { D1s- } \\
\text { charge }\end{array}$ & Date & Hour & $\begin{array}{c}\text { Gage } \\
\text { helght }\end{array}$ & $\begin{array}{c}\text { Dis- } \\
\text { charge }\end{array}$ \\
\hline Jan. 30 & 2400 & 1.35 & 110 & Feb. & 0600 & 6.41 & 6,340 & Feb. 3 & 2400 & 4.37 & 2,920 \\
\hline 31 & $\begin{array}{l}0200 \\
0400 \\
0700 \\
1600 \\
1800\end{array}$ & $\begin{array}{l}1.75 \\
2.50 \\
3.02 \\
3.70 \\
4.06\end{array}$ & $\begin{array}{r}242 \\
690 \\
1,150 \\
1,990 \\
2,480\end{array}$ & & $\begin{array}{l}1330 \\
1600 \\
1900 \\
2400\end{array}$ & $\begin{array}{l}6.76 \\
6.75 \\
6.67 \\
6.59\end{array}$ & $\begin{array}{l}7,020 \\
7,000 \\
6,840 \\
6,680\end{array}$ & 4 & $\begin{array}{l}0600 \\
1200 \\
1900 \\
2400\end{array}$ & $\begin{array}{l}4.12 \\
3.76 \\
3.08 \\
2.66\end{array}$ & $\begin{array}{r}2,570 \\
2,070 \\
1,220 \\
818\end{array}$ \\
\hline & $\begin{array}{l}2100 \\
2400\end{array}$ & $\begin{array}{l}4.38 \\
4.92\end{array}$ & $\begin{array}{l}2,930 \\
3,750\end{array}$ & 2 & $\begin{array}{l}1200 \\
2400\end{array}$ & $\begin{array}{l}5.93 \\
5.15\end{array}$ & $\begin{array}{l}5,470 \\
4,120\end{array}$ & 5 & $\begin{array}{l}1200 \\
2400\end{array}$ & $\begin{array}{l}2.07 \\
1.82\end{array}$ & $\begin{array}{l}398 \\
272\end{array}$ \\
\hline Feb. 1 & 0300 & 5.93 & 5,470 & 3 & 1200 & 4.75 & 3,480 & & & & \\
\hline
\end{tabular}

\section{1-3090. Cosgrove Creek near Valley Springs, Calif.}

Location.--Lat $38^{\circ} 08^{\prime} 10^{\prime \prime}$, long $120^{\circ} 50^{\prime} 05^{\prime \prime}$, in SE $\frac{1}{4}$ sec. 35 , T.4 N., R.10 E., on right bank 0.4 mile upstream from mouth and 2.7 miles south of Valiey Springs.

Drainage area. $--21.1 \mathrm{sq} \mathrm{ml}$.

Gage-helght record.--Water-stage recorder graph, except Jan. 1-21. Datum of gage is $547.8 \mathrm{f}^{\prime} \mathrm{t}$ above mean sea level.

Discharge record.--Stage-discharge relation defined by current-meter measurements below $900 \mathrm{cfs}$ and by slope-area measurement at $3,240 \mathrm{cfs}$. Discharge for

Jan. 1-21 estimated on basis of weather records and hydrographic comparison with records for Bear Creek near Lockeford.

Maxima - - January-February 1963: D1scharge, 987 cfs 0100 hours Feb. I (gage helght, $5.74 \mathrm{ft})$.

1929 to December 1962: Discharge, 3,240 cfs Dec. 23, 1955 (gage helght, $8.96 \mathrm{ft})$.

Mean discharge, in cublc feet per second, 1963

\begin{tabular}{|c|c|c|c|c|c|c|c|c|}
\hline Day & January & February & Day & January & February & Day & $J$ anuary & February \\
\hline $\begin{array}{c}1 \ldots \ldots \\
2 \ldots \ldots \\
3 \ldots \ldots \\
4 \ldots \ldots \\
6 \ldots \ldots \\
7 \ldots \ldots \\
5 \ldots \ldots \\
9 \ldots \ldots \\
10 \ldots \ldots\end{array}$ & 2 & $\begin{array}{r}360 \\
49 \\
22 \\
14 \\
9.5 \\
6.5 \\
5.2 \\
4.0 \\
5.0 \\
32\end{array}$ & $\begin{array}{l}11 \ldots \ldots \\
12 \ldots \ldots \\
13 \ldots \ldots \\
14 \ldots \ldots \\
15 \ldots \ldots \\
16 \ldots \ldots \\
17 \ldots \ldots \\
18 \ldots \ldots \\
19 \ldots \ldots \\
20 \ldots \ldots\end{array}$ & 2 & $\begin{array}{c}12 \\
15 \\
161 \\
42 \\
20 \\
14 \\
10 \\
7.5 \\
6 \\
5.2\end{array}$ & $\begin{array}{l}21 \ldots \ldots \\
22 \ldots \ldots \\
23 \ldots \ldots \\
24 \ldots \ldots \\
25 \ldots \ldots \\
26 \ldots \ldots \\
27 \ldots \ldots \\
28 \ldots \ldots \\
29 \ldots \ldots \\
30 \ldots \ldots \\
31 \ldots \ldots\end{array}$ & $\begin{array}{r}0.2 \\
.2 \\
.2 \\
.2 \\
.2 \\
.2 \\
.2 \\
.2 \\
.3 \\
1.3 \\
145\end{array}$ & $\begin{array}{r}4.8 \\
3.8 \\
3.2 \\
2.8 \\
2.8 \\
2.4 \\
2.2 \\
1.8 \\
----- \\
------\end{array}$ \\
\hline \multicolumn{7}{|l|}{$\begin{array}{l}\text { Monthly } \\
\text { Runoff, } \\
\text { Runoff, }\end{array}$} & $\begin{array}{r}4.91 \\
0.27 \\
302\end{array}$ & $\begin{array}{r}29.4 \\
2.45 \\
1,630\end{array}$ \\
\hline
\end{tabular}

Gage helght, in feet, and discharge, in cublc feet per second, at indicated time, 1963

\begin{tabular}{|c|c|c|c|c|c|c|c|c|c|c|c|}
\hline Date & Hour & $\begin{array}{c}\text { Gage } \\
\text { height }\end{array}$ & $\begin{array}{c}\text { D1s- } \\
\text { charge }\end{array}$ & Date & Hour & $\begin{array}{c}\text { Gage } \\
\text { height }\end{array}$ & $\begin{array}{c}\text { Dis- } \\
\text { charge }\end{array}$ & Date & Hour & $\begin{array}{c}\text { Gage } \\
\text { helght }\end{array}$ & $\begin{array}{l}\text { D18- } \\
\text { charge }\end{array}$ \\
\hline $\begin{array}{r}\text { Jan. } 29 \\
30 \\
31\end{array}$ & $\begin{array}{l}2400 \\
1500 \\
2400 \\
0830 \\
1200 \\
1200 \\
1430 \\
1600 \\
1800 \\
1930\end{array}$ & $\begin{array}{l}2.10 \\
2.20 \\
2.38 \\
2.42 \\
2.62 \\
2.66 \\
3.00 \\
3.49 \\
3.47 \\
4.00\end{array}$ & $\begin{array}{c}0.3 \\
1.0 \\
4.0 \\
5.0 \\
13 \\
15 \\
38 \\
106 \\
103 \\
225\end{array}$ & Feb. 1 & $\begin{array}{l}2100 \\
2300 \\
2400 \\
0100 \\
0200 \\
0400 \\
0500 \\
0600 \\
0700 \\
0800\end{array}$ & $\begin{array}{l}5.05 \\
5.25 \\
5.50 \\
5.74 \\
5.50 \\
4.50 \\
4.14 \\
4.27 \\
5.05 \\
5.50\end{array}$ & $\begin{array}{l}625 \\
725 \\
855 \\
987 \\
855 \\
390 \\
267 \\
310 \\
625 \\
855\end{array}$ & Feb. 1 & $\begin{array}{l}1100 \\
1300 \\
1700 \\
1800 \\
1900 \\
2200 \\
2400 \\
\\
0600 \\
1200 \\
2400\end{array}$ & $\begin{array}{l}4.20 \\
3.83 \\
3.51 \\
3.79 \\
3.81 \\
3.53 \\
3.40 \\
3.17 \\
3.05 \\
2.88\end{array}$ & $\begin{array}{r}285 \\
182 \\
110 \\
172 \\
178 \\
114 \\
90 \\
56 \\
43 \\
29\end{array}$ \\
\hline
\end{tabular}


11-3095. Calaveras River at Jenny Lind, Calif.

Location.--Lat $38^{\circ} 05^{\prime} 20^{\prime \prime}$, long $120^{\circ} 51^{\prime} 53^{\prime \prime}$, in NW/ sec.27, T.3 N., R.10 E., on right bank 70 ft downstream from bridge on Milton road, 0.2 mile south of Jenny Lind, and 6.5 miles downstream from Cosgrove Creek.

Drainage area. $--393 \mathrm{sq} \mathrm{mi}$.

Gage-he1ght record.--Water-stage recorder graph, except 1200 hours Feb. 3 to 1100 hours Feb. 4, 0300 hours to 1400 hours Feb. 5, for which graph was reconstructed on basis of partial record for each day and record for station below Hogan Dam. Datum of gage is 207.1 ft above mean sea level.

Discharge record.--Stage-discharge relation defined by current-meter measurements.

Maxima.--January-February 1963: Discharge, 6,910 ofs 0900 hours Feb. I (gage height, $11.11 \mathrm{ft}$ ).

1907 to December 1962: Discharge, 50,000 cf's Jan. 31, 1911 (gage height, $21.0 \mathrm{ft}$ ).

Remarks.--Flow regulated by Hogan Reservoir at Stockton flood control dam (usable capacity, 75,000 acre-ft), and by Bingham Reservoir (capacity, 775 acre-ft) on North Fork Calaveras River.

Mean discharge, In cubic feet per second, 1963

\begin{tabular}{|c|c|c|c|c|c|c|c|c|}
\hline Day & January & February & Day & January & February & Day & January & February \\
\hline $\begin{array}{c}1 \ldots \ldots \\
2 \ldots \ldots \\
3 \ldots \ldots \\
4 \ldots \ldots \\
5 \ldots \ldots \\
6 \ldots \ldots \\
7 \ldots \ldots \\
8 \ldots \ldots \\
9 \ldots \ldots \\
10 \ldots \ldots\end{array}$ & $\begin{array}{r}1.5 \\
1.2 \\
.8 \\
.8 \\
.5 \\
.5 \\
.4 \\
.4 \\
.3 \\
.2\end{array}$ & $\begin{array}{r}6,250 \\
5,240 \\
3,390 \\
2,110 \\
576 \\
252 \\
179 \\
148 \\
123 \\
437\end{array}$ & $\begin{array}{l}11 \ldots \ldots \\
12 \ldots \ldots \\
13 \ldots \ldots \\
14 \ldots \ldots \\
15 \ldots \ldots \\
16 \ldots \ldots \\
17 \ldots \ldots \\
18 \ldots \ldots \\
19 \ldots \ldots \\
20 \ldots \ldots\end{array}$ & $\begin{array}{r}0.8 \\
1.1 \\
.7 \\
.5 \\
.5 \\
.4 \\
.3 \\
.3 \\
.5 \\
.5\end{array}$ & $\begin{array}{r}485 \\
277 \\
925 \\
1,370 \\
610 \\
23 \\
17 \\
14 \\
12 \\
11\end{array}$ & $\begin{array}{l}21 \ldots \ldots \\
22 \ldots \ldots \\
23 \ldots \ldots \\
24 \ldots \ldots \\
25 \ldots \ldots \\
26 \ldots \ldots \\
27 \ldots \ldots \\
28 \ldots \ldots \\
29 \ldots \ldots \\
30 \ldots \ldots \\
31 \ldots \ldots\end{array}$ & $\begin{array}{r}0.5 \\
.5 \\
.5 \\
1.0 \\
1.2 \\
47 \\
47 \\
60 \\
98 \\
88 \\
1,620\end{array}$ & $\begin{array}{r}11 \\
11 \\
10 \\
10 \\
9.9 \\
9.4 \\
9.4 \\
8.9 \\
----- \\
------ \\
-0\end{array}$ \\
\hline \multicolumn{7}{|c|}{ 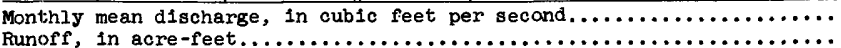 } & $\begin{array}{r}62,2 \\
3,830 \\
\end{array}$ & $\begin{array}{r}805 \\
44,680 \\
\end{array}$ \\
\hline
\end{tabular}

Gage height, in feet, and discharge, in cublc feet per second, at indicated time, 1963

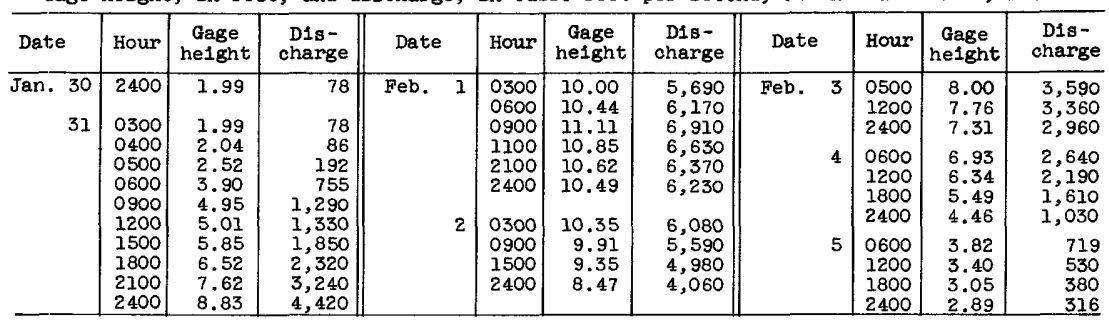

11-3114. Bear Creek tributary near Valley springs, Calif.

(Crest-stage station)

Location.--Lat $38^{\circ} 11^{\prime} 10^{\prime \prime}$, long $120^{\circ} 50145^{\prime \prime}$, in $\mathrm{SE} \frac{1}{4} \mathrm{NW} \frac{1}{4}$ sec.23, T.4 N., R.10 E., on State Highway $12,1.3$ miles southwest of Valley Springs.

Drainage area. $--0.15 \mathrm{sq} \mathrm{mi}$.

Gage-helght record.--Crest stages only. Altitude of gage is 590 ft (from topographic map).

Discharge record. --Maximum discharge by computation of flow through culvert.

Maxima --January-February 1963: Discharge, $34 \mathrm{cfs} F e b .1$ (gage height, $22.20 \mathrm{ft}$ ). 1959 to December 1962: Discharge, 12 cfs Mar..17, 1960 (gage height, $21.22 \mathrm{ft}$ ). 
11-3120. Bear Creek near Lockeford, Cal1f.

Location.--Lat $38^{\circ} 09^{\prime} 15^{\prime \prime}$, long $121^{\circ} 08^{\prime} 15^{\prime \prime}$, in $\mathrm{NW} \frac{1}{4} \mathrm{SE} \frac{1}{4} \sec .31$, T.4 N., R. 8 E., on right bank $15 \mathrm{ft}$ downstream from county road bridge and 0.8 mile' southeast of Lockeford.

Drainage area $--47.6 \mathrm{sq} \mathrm{ml}$.

Gage-height record --Water-stage recorder graph; Datum of gage is $80.3 \mathrm{ft}$ above mean sea level (levels by Corps of Engineers).

D1scharge record.--Stage-discharge relation defined by current-meter measurements. Maxima,--January-February 1963: D1scharge, 1,480 ofs 0300 hours Feb. 1 (gage
helght, 12.55 ft).

1930 to December 1962: Discharge, 2,930 cfs Apr. 3, 1958 (gage height, $15.13 \mathrm{ft}$ ).

Mean discharge, in cublc feet per second, 1963

\begin{tabular}{|c|c|c|c|c|c|c|c|c|}
\hline Day & January & February & Day & January & February & Day & January & February \\
\hline $\begin{array}{c}1 \ldots \ldots \\
2 \ldots \ldots \\
3 \ldots \ldots \\
4 \ldots \ldots \\
6 \ldots \ldots \\
7 \ldots \ldots \\
5 \ldots \ldots \\
9 \ldots \ldots \\
10 \ldots \ldots\end{array}$ & $\begin{array}{l}0 \\
0 \\
0 \\
0 \\
0 \\
0 \\
0 \\
0 \\
0 \\
0\end{array}$ & $\begin{array}{r}817 \\
68 \\
19 \\
10 \\
6.5 \\
4.8 \\
3.4 \\
2.5 \\
2.7 \\
42\end{array}$ & $\begin{array}{l}11 \ldots \ldots \\
12 \ldots \ldots \\
13 . \ldots \ldots \\
14 \ldots \ldots \\
15 \ldots \ldots \\
16 \ldots \ldots \\
17 \ldots \ldots \\
18 \ldots \ldots \\
19 \ldots \ldots \\
20 \ldots \ldots\end{array}$ & $\begin{array}{l}0 \\
0 \\
0 \\
0 \\
0 \\
0 \\
0 \\
0 \\
0 \\
0\end{array}$ & $\begin{array}{r}14 \\
21 \\
329 \\
138 \\
31 \\
16 \\
10 \\
7.4 \\
5.5 \\
5.0\end{array}$ & $\begin{array}{l}21 \ldots \ldots \\
22 \ldots \ldots \\
23 \ldots \ldots \\
24 \ldots \ldots \\
25 \ldots \ldots \\
26 \ldots \ldots \\
27 \ldots \ldots \\
28 \ldots \ldots \\
29 \ldots \ldots \\
30 \ldots \ldots \\
31 \ldots \ldots\end{array}$ & $\begin{array}{r}0 \\
0 \\
0 \\
0 \\
0 \\
0 \\
0 \\
0 \\
0 \\
0 \\
108 \\
\end{array}$ & 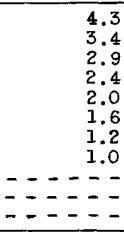 \\
\hline \multicolumn{7}{|l|}{$\begin{array}{l}\text { Monthly } \\
\text { Runoff, } \\
\text { Runoff, }\end{array}$} & $\begin{array}{r}3.48 \\
0.08 \\
214 \\
\end{array}$ & $\begin{array}{r}56.1 \\
1.23 \\
3,120 \\
\end{array}$ \\
\hline
\end{tabular}

Gage he1ght, in feet, and discharge, in cub1c feet per second, at indicated time, 1963

\begin{tabular}{|c|c|c|c|c|c|c|c|c|c|c|c|}
\hline Date & Hour & $\begin{array}{c}\text { aage } \\
\text { helght }\end{array}$ & $\begin{array}{c}\text { D1s- } \\
\text { charge }\end{array}$ & Date & Hour & $\begin{array}{c}\text { Gage } \\
\text { helght }\end{array}$ & $\begin{array}{c}\text { Dis- } \\
\text { charge }\end{array}$ & Date & Hour & $\begin{array}{c}\text { Gage } \\
\text { helght }\end{array}$ & $\begin{array}{c}\text { D1s- } \\
\text { charge }\end{array}$ \\
\hline $\begin{array}{r}30 \\
31\end{array}$ & $\begin{array}{l}2400 \\
0900 \\
1400 \\
1700 \\
1900 \\
2000 \\
2100 \\
2200\end{array}$ & $\begin{array}{l}3.39 \\
3.42 \\
3.79 \\
3.81 \\
4.27 \\
6.03 \\
7.70 \\
8.94\end{array}$ & $\begin{array}{r}0.3 \\
.7 \\
8.5 \\
9.2 \\
36 \\
191 \\
384 \\
573\end{array}$ & $\begin{array}{l}\text { Jan. } 31 \\
\text { Feb. } 1\end{array}$ & $\begin{array}{l}2300 \\
2400 \\
0100 \\
0300 \\
0600 \\
1000 \\
1400 \\
1600\end{array}$ & $\begin{array}{r}10.15 \\
11.12 \\
11.77 \\
12.55 \\
12.10 \\
11.18 \\
9.25 \\
8.30\end{array}$ & $\begin{array}{r}810 \\
1,040 \\
1,220 \\
1,480 \\
1,320 \\
1,050 \\
630 \\
468\end{array}$ & Feb. 1 & $\begin{array}{l}1800 \\
2100 \\
2400 \\
\\
0400 \\
1200 \\
2400\end{array}$ & $\begin{array}{l}7.80 \\
6.38 \\
5.65 \\
5.05 \\
4.54 \\
1.21\end{array}$ & $\begin{array}{r}398 \\
226 \\
153 \\
98 \\
55 \\
31\end{array}$ \\
\hline
\end{tabular}

11-3129.25. Mountain House Creek tributary near Altamont, Cal1f.

(Crest-stage station)

Location.--Lat $37^{\circ} 44^{\prime} 42^{\prime \prime}$, long $121^{\circ} 37^{\prime} 50^{\prime \prime}$, In SW $\frac{1}{4} \mathrm{NE} \frac{1}{4}$ sec.22, T.2 S., R.3 E., on old U.S. Highway $50,1.8$ miles east of Altamont.

Drainage area. $-0.27 \mathrm{sq} \mathrm{mi}$.

Gage-helght record.--Crest stages only. Altitude of gage 1 s $510 \mathrm{ft}$ (from topographic map).

D1scharge record.--Stage-discharge relation defined by current-meter measurements below 0.34 cfs.

Maxima --January-February 1963: D1scharge, 0.5 cfs Feb. 1 (gage helght, $6.25 \mathrm{ft}$ ). 1958 to December 1962: Discharge, $2 \mathrm{cfs} \mathrm{Feb} .1$, i960 (gage height, $6.10 \mathrm{ft}$ ). 
11-3129.5. Mountain House Creek near Midway, Calif.

(Crest-stage station)

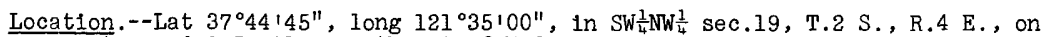
county road, 2.5 miles northwest of Midway.

Drainage area. $--11.7 \mathrm{sq} \mathrm{ml}$.

Gage-helght record.--Crest stages only. Altitude of gage 1 s $265 \mathrm{ft}$ (from topog,raphic map).

Discharge record.--Stage-discharge relation defined by current-meter measurements below 6 cfs and by computation of flow through culvert above.

Maxima.--January-February 1963: Discharge, $19 \mathrm{cfs}$ Feb. 1 (gage helght, $2.65 \mathrm{ft}$ ). 1958 to December 1962: Discharge, $60 \mathrm{cfs} \mathrm{Feb} .8,1960$ (gage helght, $4.12 \mathrm{ft}$ ).

\section{1-3131. Kellogg Creek tributary near Byron, Calif.}

(Crest-stage station)

Location. --Lat $37^{\circ} 50145^{\prime \prime}$, long $121^{\circ} 43^{\prime} 05^{\prime \prime}$, in SE $\frac{1}{4}$ sec.14, T.1 S., R.2 E., at culvert on county road, 4.5 miles southwest of Byron.

Drainage area. $-1.09 \mathrm{sq} \mathrm{ml}$.

Gage-height record.--Crest stages only. Altitude of gage is $250 \mathrm{ft}$ (from topographic map).

Discharge record.--Maximum discharge by computation of flow through culvert.

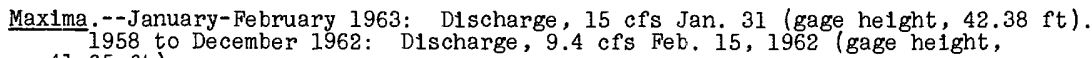
$41.65 \mathrm{ft})$.

11-3135. Salt Springs Reservolr near West Point, Cal1f.

Location.--Lat $38^{\circ} 30^{\prime} 0^{\prime \prime}$, long $120^{\circ} 12^{\prime} 5^{\prime \prime}$, In $\mathrm{SE}_{\frac{1}{4}} \mathrm{sec} .33$, T.8 N., R.16 E. , at right end of Salt Springs Dam on North Fork Mokelumne River, 2 miles upstream from Cole Creek and 18 miles northeast of West Point.

Drainage area.--169 sq $\mathrm{ml}$.

Gage-helght record.--Staff gage read once dally. Datum of gage is at mean sea level (levels by Pacific Gas \& Electric Co.).

Contents record.--Contents computed from capacity table dated March 1931.

Maxima.--January-February 1963: Contents observed, 96,100 acre-ft 1700 hours $\mathrm{Feb}$. 28 (elevation, 3,908.9 ft).

1931 to December 1962: Contents observed, 140,000 acre-ft for several days in June or July each year 1948-54, 1956-58, 1960, 1962 .

Remarks.--Reservolr is formed by concrete-faced, rockf1l1 dam, completed in 1931; storage began in March 1931; Usable capac1ty, 139,000 acre-ft between elevations $3,707.25$ (powerhouse Intake) and $3,957.0 \mathrm{ft}$ (upper operating 11mit, $1 \mathrm{ft}$ below top of radial gates) above mean sea level. Additional storage of 1,860 acre-ft is avallable for release to river through outlet drain at elevation $3,667.75 \mathrm{ft}$. Figures given herein represent contents avallable for use through powerhouse.

Records furnished by Paclfic Gas \& Electric Co. 
Elevation, in feet, and contents, in acre-feet, at 1700 hours, 1963, of Salt Springs Reservoir near West Point, Calif.

\begin{tabular}{|c|c|c|c|c|c|c|c|c|c|}
\hline \multirow{2}{*}{ Day } & \multicolumn{2}{|c|}{ January } & \multicolumn{2}{|c|}{ February } & \multirow{2}{*}{ Day } & \multicolumn{2}{|c|}{ January } & \multicolumn{2}{|c|}{ February } \\
\hline & Elevation & Contents & Elevation & Contents & & Elevation & Contents & Elevation & Contents \\
\hline $\begin{array}{r}1 \\
2 \\
3 \\
4 \\
5 \\
6 \\
7 \\
8 \\
9 \\
10 \\
11 \\
12 \\
13 \\
14 \\
15\end{array}$ & $\begin{array}{l}3,818.0 \\
3,816.8 \\
3,815.7 \\
3,814.6 \\
3,813.0 \\
3,811.3 \\
3,810.3 \\
3,809.1 \\
3,808.3 \\
3,808.0 \\
3,806.8 \\
3,805.2 \\
3,803.5 \\
3,801.8 \\
3,800.5\end{array}$ & $\begin{array}{l}34,800 \\
34,200 \\
33,600 \\
33,100 \\
32,300 \\
31,400 \\
31,000 \\
30,400 \\
30,000 \\
29,800 \\
29,300 \\
28,500 \\
27,700 \\
26,900 \\
26,400\end{array}$ & $\begin{array}{l}3,860.5 \\
3,871.3 \\
3,876.5 \\
3,881.4 \\
3,885.2 \\
3,887.8 \\
3,890.0 \\
3,891.8 \\
3,894.0 \\
3,895.0 \\
3,895.6 \\
3,896.4 \\
3,897.4 \\
3,898.8 \\
3,899.5\end{array}$ & $\begin{array}{l}59,800 \\
67,300 \\
71,000 \\
74,600 \\
77,400 \\
79,400 \\
81,100 \\
82,500 \\
84,200 \\
85,000 \\
85,400 \\
86,000 \\
86,800 \\
87,900 \\
88,500\end{array}$ & $\begin{array}{l}16 \\
17 \\
18 \\
19 \\
20 \\
21 \\
22 \\
23 \\
24 \\
25 \\
26 \\
27 \\
28 \\
29 \\
30 \\
31\end{array}$ & $\begin{array}{l}3,799.4 \\
3,798.1 \\
3,797.0 \\
3,796.2 \\
3,795.4 \\
3,793.8 \\
3,792.4 \\
3,791.0 \\
3,789.7 \\
3,788.3 \\
3,786.5 \\
3,784.6 \\
3,783.0 \\
3,782.3 \\
3,782.8 \\
3,802.0\end{array}$ & $\begin{array}{l}25,800 \\
25,300 \\
24,800 \\
24,400 \\
24,100 \\
23,400 \\
22,800 \\
22,200 \\
21,600 \\
21,000 \\
20,300 \\
19,500 \\
18,900 \\
18,600 \\
18,800 \\
27,000\end{array}$ & $\begin{array}{c}3,900.5 \\
3,901.4 \\
3,902.2 \\
3,902.8 \\
3,903.6 \\
3,904.3 \\
3,905.0 \\
3,905.7 \\
3,906.4 \\
3,906.8 \\
3,907.6 \\
3,908.2 \\
3,908.9 \\
- \\
- \\
-\end{array}$ & $\begin{array}{c}89,300 \\
90,000 \\
90,600 \\
91,100 \\
91,800 \\
92,300 \\
92,900 \\
93,500 \\
94,000 \\
94,400 \\
95,000 \\
95,500 \\
96,100 \\
= \\
= \\
-\end{array}$ \\
\hline \multicolumn{6}{|c|}{ 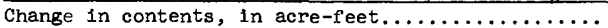 } & - & $-8,500$ & - & $+69,100$ \\
\hline
\end{tabular}

11-3145. North Fork Mokelumne River below Salt Springs Dam, Calif.

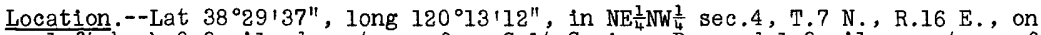
left bank 0.3 mile downstream from Salt Springs Dam and 1.3 miles upstream from Cole Creek.

Drainage area. $--170 \mathrm{sq} \mathrm{mi}$.

Gage-height record.--Water-stage recorder graph. Altitude of gage is $3,590 \mathrm{ft}$ (from topographic map).

Discharge record.--Stage-discharge relation defined by current-meter measurements. Maxima.--January-February 1963: - Discharge, 590 cfs 1130 hours Feb. 1 (gage height, $4.27 \mathrm{ft}$ ).

1926 to December 1962: Discharge, 16,000 cfs Nov. 21, 1950 (gage height,

$17.20 \mathrm{ft}$ ), from rating curve extended above $3,900 \mathrm{cf}$ s on basis of computations of flow over dam and discharge through powerhouse.

Remarks.--Flow regulated by Salt Springs Reservoir since 1931 (see station 11-3135).

Mean discharge, in cubic feet per second, 1963

\begin{tabular}{|c|c|c|c|c|c|c|c|c|}
\hline Day & January & February & Day & January & February & Day & January & February \\
\hline $\begin{array}{c}1 \ldots \ldots \\
2 \ldots \ldots \\
3 \ldots \ldots \\
4 \ldots \ldots \\
5 \ldots \ldots \\
6 \ldots \ldots \\
7 \ldots \ldots \\
9 \ldots \ldots \\
10 \ldots \ldots\end{array}$ & $\begin{array}{l}5.4 \\
6.1 \\
6.1 \\
6.4 \\
6.4 \\
6.4 \\
6.4 \\
6.4 \\
6.1 \\
6.1\end{array}$ & $\begin{array}{r}268 \\
216 \\
11 \\
9.7 \\
9.2 \\
9.2 \\
8.8 \\
8.5 \\
11 \\
8.5\end{array}$ & $\begin{array}{l}11 \ldots \ldots \\
12 \ldots \ldots \\
13 \ldots \ldots \\
14 \ldots \ldots \\
15 \ldots \ldots \\
16 \ldots \ldots \\
17 \ldots \ldots \\
18 \ldots \ldots \\
19 \ldots \ldots \\
20 \ldots \ldots\end{array}$ & $\begin{array}{l}6.1 \\
6.1 \\
6.1 \\
6.1 \\
6.4 \\
6.4 \\
6.4 \\
5.7 \\
6.4 \\
6.8\end{array}$ & $\begin{array}{l}8.5 \\
8.5 \\
8.8 \\
8.5 \\
8.1 \\
8.1 \\
7.8 \\
7.8 \\
8.1 \\
8.5\end{array}$ & $\begin{array}{l}21 \ldots \ldots \\
22 \ldots \ldots \\
23 \ldots \ldots \\
24 \ldots \ldots \\
25 \ldots \ldots \\
26 \ldots \ldots \\
27 \ldots \ldots \\
28 \ldots \ldots \\
29 \ldots \ldots \\
30 \ldots \ldots \\
31 \ldots \ldots\end{array}$ & $\begin{array}{l}6.8 \\
6.8 \\
6.4 \\
6.4 \\
6.4 \\
6.4 \\
6.4 \\
6.4 \\
6.4 \\
11 \\
35\end{array}$ & $\begin{array}{r}8.5 \\
8.1 \\
7.8 \\
7.8 \\
7.8 \\
7.8 \\
7.8 \\
7.4 \\
-.-- \\
-.-1 \\
-.-1\end{array}$ \\
\hline \multicolumn{7}{|c|}{ 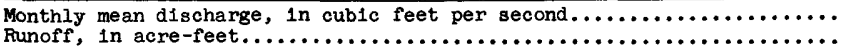 } & $\begin{array}{r}7.38 \\
454 \\
\end{array}$ & $\begin{array}{r}25.2 \\
1,400 \\
\end{array}$ \\
\hline
\end{tabular}


11-3150. Cole Creek near Salt Springs Dam, Calif.

Location.--Lat $38^{\circ} 31^{\prime} 26^{\prime \prime}$, long $120^{\circ} 12^{\prime} 28^{\prime \prime}$, in $\mathrm{SE} \frac{1}{4}$ sec.21, T.8 N., R.16 E., on right bank 1.8 miles north of Salt Springs Dam, 3.4 miles upstream from mouth, and 6.3 miles southwest of Mokelumne Peak.

Drainage area. $--20.4 \mathrm{sq} \mathrm{mi}$.

Gage-height record ; --Water-stage recorder graph. Altitude of gage is $5,970 \mathrm{ft}$ (from topograph1c map).

Discharge record.--Stage-discharge relation defined by current-meter measurements below $900 \mathrm{cfs}$ and by slope-area measurement at $5,500 \mathrm{cfs}$; affected by 1ce Jan. $8-10,14-30$.

Maxima.--January-February 1963: Discharge, 5,730 cfs 0200 hours Feb. 1 (gage height, $9.88 \mathrm{ft})$.

1927 to December 1962: Discharge, 5,500 cfs Nov. 18, 1950 (gage helght, $9.69 \mathrm{ft})$.

Mean discharge, in cub1c feet per second, 1963

\begin{tabular}{|c|c|c|c|c|c|c|c|c|}
\hline Day & January & February & Day & January & February & Day & January & February \\
\hline $\begin{array}{c}1 \ldots \ldots \\
2 \ldots \ldots \\
3 \ldots \ldots \\
4 \ldots \ldots \\
5 \ldots \ldots \\
7 \ldots \ldots \\
8 \ldots \ldots \\
9 \ldots \ldots \\
10 \ldots \ldots\end{array}$ & $\begin{array}{l}10 \\
9.7 \\
9.7 \\
9.7 \\
9.4 \\
8.7 \\
8.4 \\
8.2 \\
8.0 \\
7.8\end{array}$ & $\begin{array}{r}, 690 \\
352 \\
200 \\
165 \\
150 \\
130 \\
115 \\
100 \\
90 \\
80\end{array}$ & $\begin{array}{l}11 \ldots \ldots \\
12 \ldots \ldots \\
13 \ldots \ldots \\
14 \ldots \ldots \\
15 \ldots \ldots \\
16 \ldots \ldots \\
17 \ldots \ldots \\
18 \ldots \ldots \\
19 \ldots \ldots \\
20 \ldots \ldots\end{array}$ & $\begin{array}{l}7.6 \\
6.2 \\
5.1 \\
4.0 \\
3.0 \\
2.3 \\
2.2 \\
2.2 \\
2.1 \\
2.1\end{array}$ & $\begin{array}{l}72 \\
69 \\
91 \\
71 \\
59 \\
58 \\
50 \\
49 \\
52 \\
55\end{array}$ & $\begin{array}{l}21 \ldots \ldots \\
22 \ldots \ldots \\
23 \ldots \ldots \\
24 \ldots \ldots \\
25 \ldots \ldots \\
26 \ldots \ldots \\
27 \ldots \ldots \\
28 \ldots \ldots \\
29 \ldots \ldots \\
30 \ldots \ldots \\
31 \ldots \ldots\end{array}$ & $\begin{array}{r}2.0 \\
2.0 \\
2.0 \\
1.9 \\
1.8 \\
1.5 \\
1.8 \\
1.6 \\
1.6 \\
75 \\
1,910\end{array}$ & $\begin{array}{r}54 \\
45 \\
39 \\
41 \\
46 \\
59 \\
57 \\
46 \\
---\end{array}$ \\
\hline $\begin{array}{l}\text { Monthly } \\
\text { Runoff, } \\
\text { Runoff, }\end{array}$ & $\begin{array}{l}\text { mean disc } \\
\text { in inches } \\
\text { in acre-f }\end{array}$ & e, in & feet & cond & & & $\begin{array}{r}68.6 \\
3.88 \\
4,220 \\
\end{array}$ & $\begin{array}{r}182 \\
9.27 \\
10,090 \\
\end{array}$ \\
\hline
\end{tabular}

Gage height, in feet, and discharge, in cublc feet per second, at indicated time, 1963

\begin{tabular}{|c|c|c|c|c|c|c|c|c|c|c|c|}
\hline Date & Hour & $\begin{array}{l}\text { Gage } \\
\text { he1ght }\end{array}$ & $\begin{array}{l}\text { D1s- } \\
\text { charge }\end{array}$ & Date & Hour & $\begin{array}{c}\text { Gage } \\
\text { height }\end{array}$ & $\begin{array}{l}\text { Dis - } \\
\text { charge }\end{array}$ & Date & Hour & $\begin{array}{c}\text { Gage } \\
\text { helght }\end{array}$ & $\begin{array}{l}\text { Dis- } \\
\text { charge }\end{array}$ \\
\hline Jan. 30 & $\begin{array}{l}2100 \\
2200 \\
2400\end{array}$ & $\begin{array}{l}2.88 \\
3.26 \\
3.58\end{array}$ & $\begin{array}{l}203 \\
290 \\
379\end{array}$ & Jan. 31 & $\begin{array}{l}1500 \\
1900 \\
2400\end{array}$ & $\begin{array}{l}6.92 \\
7.97 \\
9.47\end{array}$ & $\begin{array}{l}2,370 \\
3,470 \\
5,230\end{array}$ & Feb. 1 & $\begin{array}{l}2100 \\
2400\end{array}$ & $\begin{array}{l}4.80 \\
4.30\end{array}$ & $\begin{array}{l}875 \\
635\end{array}$ \\
\hline 31 & $\begin{array}{l}0100 \\
0400 \\
0600 \\
0900 \\
1100 \\
\end{array}$ & $\begin{array}{l}3.69 \\
3.68 \\
3.84 \\
4.35 \\
5.00\end{array}$ & $\begin{array}{l}412 \\
409 \\
464 \\
658 \\
975\end{array}$ & Feb. 1 & $\begin{array}{l}0200 \\
0300 \\
0800 \\
1200 \\
1500\end{array}$ & $\begin{array}{l}9.88 \\
9.80 \\
8.20 \\
6.26 \\
5.61\end{array}$ & $\begin{array}{l}5,730 \\
5,630 \\
3,720 \\
1,790 \\
1,330\end{array}$ & 2 & $\begin{array}{l}0700 \\
1200 \\
1800 \\
2400\end{array}$ & $\begin{array}{l}3.63 \\
3.36 \\
3.12 \\
2.95\end{array}$ & $\begin{array}{l}394 \\
313 \\
250 \\
210\end{array}$ \\
\hline
\end{tabular}


11-3160. Bear River near Salt Springs Dam, Cal1f.

Location.--Lat $38^{\circ} 29^{\prime} 37^{\prime \prime}$, long $120^{\circ} 17^{\prime} 18^{\prime \prime}$, in NW $\frac{1}{4}$ sec.2, T.7 N., R.15 E., on right bank 200 ft upstream from diversion to Tiger Creek powerhouse conduit and highway bridge, 1.5 miles upstream from mouth, and 4 miles west of Salt Springs Dam.

Drainage area. $--48.0 \mathrm{sq} \mathrm{m} 1$.

Gage-he1ght record.--Water-stage recorder graph. Altitude of gage is $3,710 \mathrm{ft}$ (from topographic map).

D1scharge record.--Stage-discharge relation defined by current-meter measurements below $560 \mathrm{cfs}$; affected by 1ce Jan. 11-25.

Maxima.--January-February 1963: D1scharge, 1,400 cf's 0400 hours Feb. 1 (gage he1ght, $4.00 \mathrm{ft}$ ).

1951 to December 1962: Discharge, 3,060 cfs May 18, 1957 (gage helght, $5.35 \mathrm{ft}$ ).

Flood in November 1950 reached a stage of $11.2 \mathrm{ft}$, from floodmarks (discharge unknown).

Remarks.--Flow regulated by Bear River and Lower Bear River Reservoirs (combined capacity, 55,860 acre-ft\}.

Mean discharge, in cub1c feet per second, 1963

\begin{tabular}{|c|c|c|c|c|c|c|c|c|}
\hline Day & January & Pebruary & Day & January & February & Day & January & February \\
\hline $\begin{array}{c}1 \ldots \ldots \\
2 \ldots \ldots \\
4 \ldots \ldots \\
5 \ldots \ldots \\
6 \ldots \ldots \\
7 \ldots \ldots \\
8 \ldots \ldots \\
9 \ldots \ldots \\
10 \ldots \ldots\end{array}$ & $\begin{array}{l}4.6 \\
4.6 \\
4.4 \\
4.4 \\
4.4 \\
4.4 \\
4.2 \\
4.1 \\
4.2 \\
4.2\end{array}$ & $\begin{array}{r}575 \\
143 \\
85 \\
56 \\
40 \\
36 \\
28 \\
24 \\
23 \\
23\end{array}$ & $\begin{array}{l}11 \ldots \ldots \\
12 \ldots \ldots \\
13 \ldots \ldots \\
14 \ldots \ldots \\
15 \ldots \ldots \\
16 \ldots \ldots \\
17 \ldots \ldots \\
15 \ldots \ldots \\
19 \ldots \ldots \\
20 \ldots \ldots\end{array}$ & $\begin{array}{l}3.5 \\
2.7 \\
3.1 \\
3.1 \\
3.1 \\
3.0 \\
2.9 \\
2.9 \\
2.8 \\
2.9\end{array}$ & $\begin{array}{l}21 \\
22 \\
54 \\
36 \\
28 \\
24 \\
23 \\
21 \\
20 \\
15\end{array}$ & $\begin{array}{l}21 \ldots \ldots \\
22 \ldots \ldots \\
23 \ldots \ldots \\
24 \ldots \ldots \\
25 \ldots \ldots \\
26 \ldots \ldots \\
27 \ldots \ldots \\
28 \ldots \ldots \\
29 \ldots \ldots \\
30 \ldots \ldots \\
31 \ldots \ldots\end{array}$ & $\begin{array}{r}3.1 \\
3.6 \\
3.7 \\
3.8 \\
4.1 \\
4.1 \\
4.2 \\
4.6 \\
\text { s.1 } \\
\text { S7 } \\
714\end{array}$ & $\begin{array}{r}17 \\
17 \\
15 \\
15 \\
14 \\
13 \\
13 \\
12 \\
-\ldots--1\end{array}$ \\
\hline $\begin{array}{l}\text { onthly } \\
\text { unoff, }\end{array}$ & $\begin{array}{l}\text { an } \mathrm{dlsc} \\
\text { acre- }\end{array}$ & $\ldots \ldots$ & 8 & & & & $\begin{array}{r}29.5 \\
1,810 \\
\end{array}$ & $\begin{array}{r}50.6 \\
2,810 \\
\end{array}$ \\
\hline
\end{tabular}

Gage height, in feet, and discharge, in cublc feet per second, at ind1cated t1me, 1963

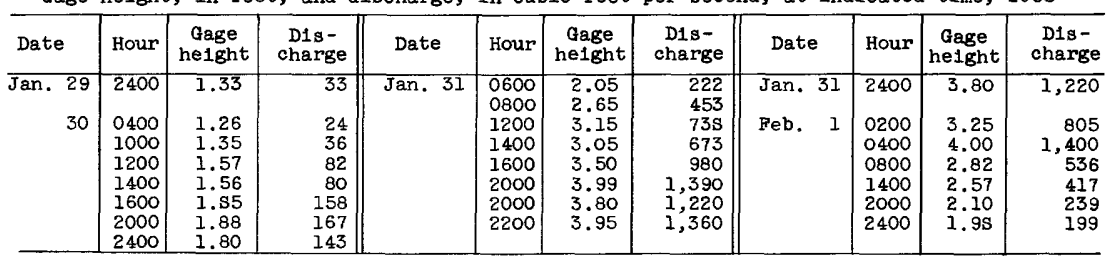

11-3166.5. Antelope Creek near West Point, Cal1f.

(Crest-stage station)

Location.--Lat $38^{\circ} 29^{1} 29^{\prime \prime}$, long $120^{\circ} 30^{\prime} 09^{\prime \prime}$, in NE $\frac{1}{4} \mathrm{sec} .2, \mathrm{~T} .7 \mathrm{~N} ., \mathrm{R} .13 \mathrm{E} ., 5.7 \mathrm{~m} 11 \mathrm{es}$ northeast of West Point.

Drainage area. $--1.48 \mathrm{sq} \mathrm{ml}$.

Gage-height record.--Crest stages only. Alt1tude of gage is 3,640 ft (from topographic map).

Discharge record.--Stage-discharge relation defined by current-meter measurements below $9.2 \mathrm{cfs}$ and by computation of flow through culvert and at 17 and $78 \mathrm{cfs}$.

Maxima:--January-February 1963: Discharge, 78 cfs Feb. 1 (gage helght, $5.10 \mathrm{ft}$ ). July to December 1962: Discharge, 11 cfs Dct. 13,1962 (gage helght,
$3.04 \mathrm{ft}$ ). 
11-3168. Forest Creek near W1lseyville, Calif.

Location.--Lat $38^{\circ} 24^{\prime} 10^{\prime \prime}$, long $120^{\circ} 26^{\prime} 45^{\prime \prime}$, in SW $\frac{1}{4} \mathrm{NW} \frac{1}{4}$ sec.4, T.6 N., R.14 E., on left bank $1.0 \mathrm{mile}$ downstream from Lion Creek, 1.8 miles upstream from mouth, and 4 miles northeast of Wilseyville.

Drainage area. $--20.8 \mathrm{sq} \mathrm{mi}$.

Gage-helght record.--Water-stage recorder graph, except Jan. 1 to 1445 hours Jan 22, Altitude of gage is $2,950 \mathrm{ft}$ (from topographic map).

Discharge record.--Stage-discharge relation defined by current-meter measurements below $200 \mathrm{cfs}$ and by slope-area measurement at $1,580 \mathrm{cfs}$; affected by ice Jan. 22-28. Discharge for Jan. 1-22 was estimated on basis of records for South Fork Mokelumne River near West Point and weather records.

Maxima.--January-February 1963: Discharge, 1,580 cfs 0100 hours Feb. I (gage helght, $7.41 \mathrm{ft}$, from recorder graph; $7.5 \mathrm{ft}$, from high-water profile . 1960 to December 1962: Discharge, $260 \mathrm{cfs}$ Feb. 15, 1962 (gage height, $4.60 \mathrm{ft}$ ).

Mean discharge, in cubic feet per second, 1963

\begin{tabular}{|c|c|c|c|c|c|c|c|c|}
\hline Day & January & February & Day & January & February & Day & January & February \\
\hline $\begin{array}{c}1 \ldots \ldots \\
2 \ldots \ldots \\
4 \ldots \ldots \\
5 \ldots \ldots \\
6 \ldots \ldots \\
7 \ldots \ldots \\
9 \ldots \ldots \\
10 \ldots \ldots\end{array}$ & $\begin{array}{l}5.2 \\
5.2 \\
5.2 \\
5.2 \\
5.0 \\
5.0 \\
5.0 \\
4.6 \\
4.6 \\
4.6\end{array}$ & $\begin{array}{r}764 \\
167 \\
100 \\
70 \\
56 \\
45 \\
38 \\
33 \\
31 \\
34\end{array}$ & $\begin{array}{l}11 \ldots \ldots \\
12 \ldots \ldots \\
13 \ldots \ldots \\
14 \ldots \ldots \\
15 \ldots \ldots \\
16 \ldots \ldots \\
17 \ldots \ldots \\
18 \ldots \ldots \\
19 \ldots \ldots \\
20 \ldots \ldots\end{array}$ & $\begin{array}{l}4.6 \\
4.6 \\
4.6 \\
4.6 \\
4.6 \\
4.6 \\
4.6 \\
4.6 \\
4.6 \\
4.6\end{array}$ & $\begin{array}{l}31 \\
28 \\
52 \\
50 \\
41 \\
37 \\
34 \\
31 \\
30 \\
28\end{array}$ & $\begin{array}{l}21 \ldots \ldots \\
22 \ldots \ldots \\
23 \ldots \ldots \\
24 \ldots \ldots \\
25 \ldots \ldots \\
26 \ldots \ldots \\
27 \ldots \ldots \\
28 \ldots \ldots \\
29 \ldots \ldots \\
30 \ldots \ldots \\
31 \ldots \ldots\end{array}$ & $\begin{array}{r}4.5 \\
4.5 \\
4.5 \\
4.3 \\
4.2 \\
4.2 \\
4.2 \\
4.2 \\
5.0 \\
87 \\
452\end{array}$ & $\begin{array}{r}27 \\
25 \\
24 \\
23 \\
22 \\
22 \\
22 \\
21 \\
-\ldots---\end{array}$ \\
\hline $\begin{array}{l}\text { onthly } \\
\text { anoff, } \\
\text { anoff, }\end{array}$ & $\begin{array}{l}\text { inche } \\
\text { n acre- }\end{array}$ & & & & & & $\begin{array}{r}21.7 \\
1.21 \\
1,340\end{array}$ & $\begin{array}{r}67.4 \\
3.37 \\
3,740 \\
\end{array}$ \\
\hline
\end{tabular}

Gage height, in feet, and discharge, in cublc feet per second, at indicated time, 1963

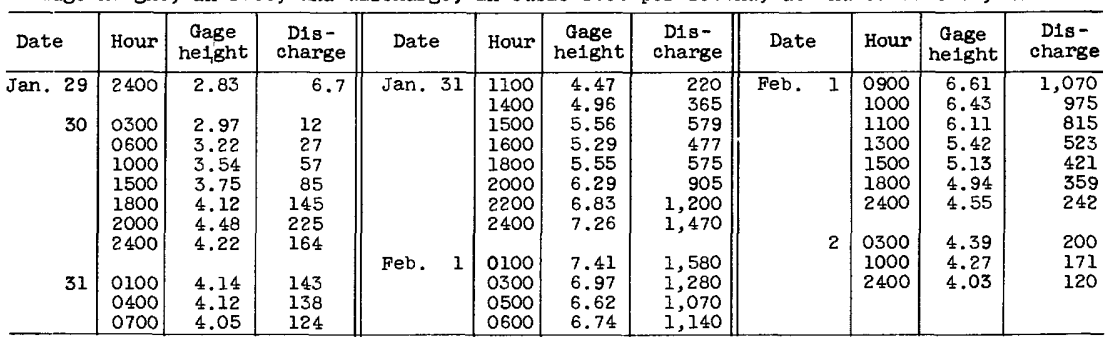

11-3170. Middle Fork Mokelumne River at West Point, Calif.

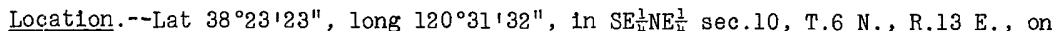
right bank $200 \mathrm{ft}$ downstream from highway bridge, $0.6 \mathrm{mile}$ south of West Point, and 4.5 miles upstream from South Fork.

Drainage area. $--68.4 \mathrm{sq} \mathrm{mi}$.

Gage-he1ght record.--Water-stage recorder graph, except Jan. 1-21. Alt1tude of gage is $2,450 \mathrm{ft}$ (from topographic map).

Discharge record.--Stage-discharge relation defined by current-meter measurements Discharge for period Jan. 1-21 estimated by hydrographic comparison with South Fork Mokelumne River near West Point.

Maxima.--January-February 1963: Discharge, 3,400 cfs 2400 hours Jan. 31 (gage helght, $8.22 \mathrm{ft})$

1911 to December 1962: Discharge, 4,320 ofs Dec. 23, 1955 (gage height, $8.98 \mathrm{ft})$. 
Mean discharge, In cuble feet per second, 1963, of M1ddle Fork Mokelumne River at West Polnt, Calif.

\begin{tabular}{|c|c|c|c|c|c|c|c|c|}
\hline Day & January & February & Day & January & February & Day & January & Febmuary \\
\hline $\begin{array}{c}1 \ldots \ldots \\
2 \ldots \ldots \\
3 \ldots \ldots \\
5 \ldots \ldots \\
6 \ldots \ldots \\
7 \ldots \ldots \\
8 \ldots \ldots \\
9 \ldots \ldots \\
10 \ldots \ldots\end{array}$ & $\begin{array}{l}19 \\
19 \\
19 \\
18 \\
17 \\
17 \\
16 \\
15 \\
15 \\
15\end{array}$ & $\begin{array}{r}2,000 \\
568 \\
294 \\
212 \\
168 \\
137 \\
119 \\
104 \\
98 \\
114\end{array}$ & $\begin{array}{l}11 \ldots \ldots \\
12 \ldots \ldots \\
13 \ldots \ldots \\
14 \ldots \ldots \\
15 \ldots \ldots \\
16 \ldots \ldots \\
17 \ldots \ldots \\
18 \ldots \ldots \\
19 \ldots \ldots \\
20 \ldots \ldots\end{array}$ & $\begin{array}{l}15 \\
15 \\
14 \\
14 \\
14 \\
13 \\
13 \\
13 \\
13 \\
12\end{array}$ & $\begin{array}{r}101 \\
92 \\
172 \\
166 \\
125 \\
110 \\
102 \\
93 \\
88 \\
82\end{array}$ & $\begin{array}{l}21 \ldots \ldots \\
22 \ldots \ldots \\
23 \ldots \ldots \\
24 \ldots \ldots \\
25 \ldots \ldots \\
26 \ldots \ldots \\
27 \ldots \ldots \\
28 \ldots \ldots \\
29 \ldots \ldots \\
30 \ldots \ldots \\
31 \ldots \ldots\end{array}$ & $\begin{array}{l}12 \\
11 \\
11 \\
11 \\
11 \\
11 \\
11 \\
10 \\
12 \\
190 \\
957\end{array}$ & $\begin{array}{r}78 \\
73 \\
68 \\
65 \\
62 \\
61 \\
59 \\
57 \\
-\ldots--\end{array}$ \\
\hline \multicolumn{7}{|l|}{$\begin{array}{l}\text { Monthly } \\
\text { Runoff, } \\
\text { Runoff, }\end{array}$} & $\begin{array}{r}50.1 \\
0.84 \\
3,080\end{array}$ & $\begin{array}{r}195 \\
2.97 \\
10,850\end{array}$ \\
\hline
\end{tabular}

Gage he1ght, in feet, and discharge, in cuble feet per second, at indicated t1me, 1963

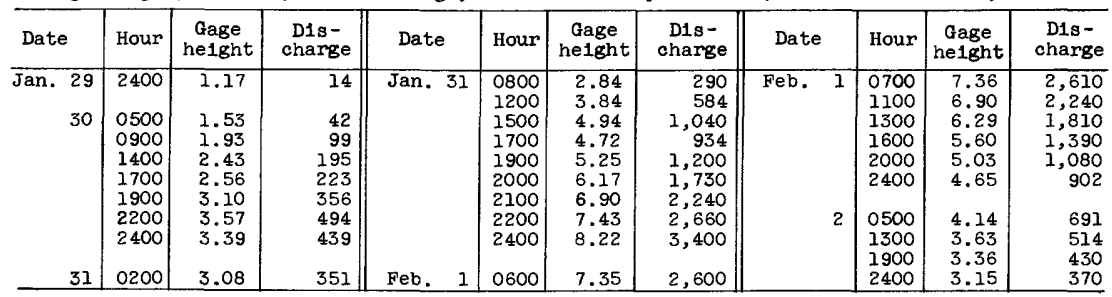

11-3185. South Fork Mokelumne River near West Point, Calif.

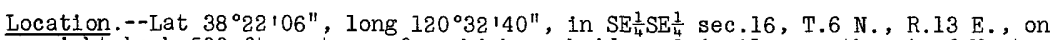
right bank $500 \mathrm{ft}$ upstream from highway bridge, 2.4 miles southwest of West Point, and 2.5 miles upstream from mouth.

Drainage area. $--75.1 \mathrm{sq} \mathrm{ml}$.

Gage-helght record.--Water-stage recorder graph. Altitude of gage is $1,950 \mathrm{ft}$ (from topographic map).

Discharge record.--Stage-discharge relation defined by current-meter measurements below $1,800 \mathrm{c}$ 's and slope-area measurement at $6,920 \mathrm{cfs}$; affected by ice Jan. $12-23$.

Maxima.--January-February 1963: Discharge, 5,690 cf's 2400 hours Jan. 31 (gage he1ght, $10.78 \mathrm{ft}$ )

1933 to December 1962: Discharge, 6,920 cfs Dec. 23, 1955 (gage height, $14.8 \mathrm{ft}$, from floodmarks, site and datum then in use).

Mean discharge, in cublc feet per second, 1963

\begin{tabular}{|c|c|c|c|c|c|c|c|c|}
\hline Day & January & February & Day & January & February & Day & January & February \\
\hline $\begin{array}{c}1 \ldots \ldots \\
2 \ldots \ldots \\
3 \ldots \ldots \\
4 \ldots \ldots \\
5 \ldots \ldots \\
7 \ldots \ldots \\
8 \ldots \ldots \\
9 \ldots \ldots \\
10 \ldots \ldots\end{array}$ & $\begin{array}{l}17 \\
17 \\
17 \\
17 \\
16 \\
16 \\
16 \\
15 \\
15 \\
15\end{array}$ & $\begin{array}{r}2,490 \\
609 \\
324 \\
225 \\
173 \\
142 \\
121 \\
108 \\
102 \\
128\end{array}$ & $\begin{array}{l}11 \ldots \ldots \\
12 \ldots \ldots \\
13 \ldots \ldots \\
14 \ldots \ldots \\
15 \ldots \ldots \\
16 \ldots \ldots \\
17 \ldots \ldots \\
18 \ldots \ldots \\
19 \ldots \ldots \\
20 \ldots \ldots\end{array}$ & $\begin{array}{l}15 \\
15 \\
15 \\
15 \\
15 \\
15 \\
15 \\
15 \\
15 \\
15\end{array}$ & $\begin{array}{r}101 \\
94 \\
203 \\
194 \\
149 \\
130 \\
117 \\
105 \\
97 \\
89\end{array}$ & $\begin{array}{l}21 \ldots \ldots \\
22 \ldots \ldots \\
23 \ldots \ldots \\
24 \ldots \ldots \\
25 \ldots \ldots \\
26 \ldots \ldots \\
27 \ldots \ldots \\
28 \ldots \ldots \\
29 \ldots \ldots \\
30 \ldots \ldots \\
31 \ldots \ldots\end{array}$ & $\begin{array}{r}16 \\
17 \\
18 \\
19 \\
17 \\
17 \\
15 \\
14 \\
15 \\
318 \\
1,940\end{array}$ & $\begin{array}{r}84 \\
78 \\
73 \\
70 \\
66 \\
64 \\
62 \\
58 \\
---- \\
---- \\
--\end{array}$ \\
\hline \multicolumn{7}{|l|}{$\begin{array}{l}\text { Monthly } \\
\text { Runoff, } \\
\text { Runoff, }\end{array}$} & $\begin{array}{r}87.6 \\
1.35 \\
5,390\end{array}$ & $\begin{array}{r}223 \\
3.10 \\
12,410 \\
\end{array}$ \\
\hline
\end{tabular}


Gage height, in feet, and discharge, in cubic feet per second, at indicated time, 1963, of South Fork Mokelumne River near West Polnt, Calif.

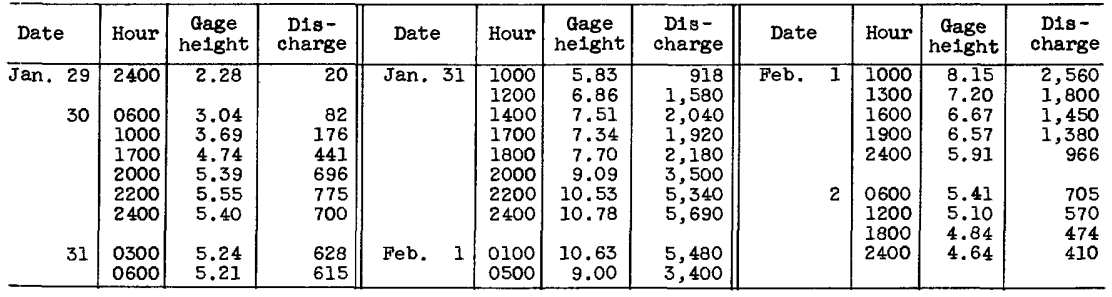

11-3195. Mokelumne River near Mokelumne Hill, Calif.

Location.--Lat $38^{\circ} 18^{14} 46^{\prime \prime}$, long $120^{\circ} 43^{\prime} 09^{\prime \prime}$, in SW $\frac{1}{4}$ SW $\frac{1}{4}$ sec.1, T.5 N., R.11 E., on downstream side of bridge, 1.2 miles northwest of Mokelumne H1li and 8 miles downstream from confluence of North and South Forks.

Drainage area. $--538 \mathrm{sq} \mathrm{m} 1$.

Gage-he1ght record.--Water-stage recorder graph, except Feb. 8-21. Datum of gage is $589.88 \mathrm{ft}^{\prime}$ above mean sea level (levels by Cal1fornia Division of H1ghways).

D1scharge record.--Stage-discharge relation defined by current-meter measurements. Discharge for Feb. 8-21 estimated on the basis of computed inflow to Pardee Reservoir.

Max1ma.--January-February 1963: D1scharge, 25,900 cf's 0300 hours Feb. 1 (gage helght, $16.15 \mathrm{ft}$ ).

$1901,1903-4$, 1927 to December 1962: D1scharge, 33,700 cf's Dec. 3, 1950

(gage he1ght, $18.5 \mathrm{ft}$ ).

Remarks.--Flow regulated by Salt Springs Reservolr beginning in 1931 (see station

11-3135), several smaller reservolrs, and four powerplants.

Mean discharge, in cubic feet per second, 1963

\begin{tabular}{|c|c|c|c|c|c|c|c|c|}
\hline Day & January & February & Day & January & February & Day & January & February \\
\hline $\begin{array}{r}1 \ldots \ldots . \\
2 \ldots \ldots \\
3 \ldots \ldots \\
4 \ldots \ldots \\
5 \ldots \ldots \\
6 \ldots \ldots \\
7 \ldots \ldots \\
9 \ldots \ldots \\
10 . \ldots .\end{array}$ & $\begin{array}{l}576 \\
470 \\
682 \\
470 \\
630 \\
490 \\
522 \\
496 \\
403 \\
449\end{array}$ & $\begin{array}{r}17,000 \\
3,940 \\
1,710 \\
1,450 \\
1,090 \\
1,030 \\
1,050 \\
981 \\
868 \\
848\end{array}$ & 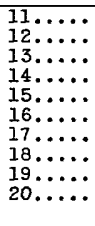 & $\begin{array}{l}628 \\
598 \\
572 \\
500 \\
738 \\
448 \\
435 \\
876 \\
516 \\
102\end{array}$ & $\begin{array}{r}844 \\
769 \\
981 \\
1,420 \\
1,130 \\
899 \\
717 \\
474 \\
496 \\
531\end{array}$ & $\begin{array}{l}21 \ldots \ldots \\
22 \ldots \ldots \\
23 \ldots \ldots \\
24 \ldots \\
25 \ldots \\
26 \ldots \\
27 \ldots \ldots \\
28 \ldots \\
29 \ldots \\
30 \ldots \\
31 \ldots \ldots\end{array}$ & $\begin{array}{r}338 \\
454 \\
610 \\
589 \\
632 \\
523 \\
692 \\
614 \\
478 \\
814 \\
6,670\end{array}$ & $\begin{array}{r}541 \\
369 \\
323 \\
292 \\
361 \\
508 \\
468 \\
410 \\
-0-0 \\
-0 .-0\end{array}$ \\
\hline athl & & & & & & & $\begin{array}{r}742 \\
45,650\end{array}$ & $\begin{array}{r}1,482 \\
82,310\end{array}$ \\
\hline
\end{tabular}

Gage height, in feet, and discharge, in cublc feet per second, at indicated time, 1963

\begin{tabular}{|c|c|c|c|c|c|c|c|c|c|c|c|}
\hline Date & Hour & $\begin{array}{c}\text { Gage } \\
\text { height }\end{array}$ & $\begin{array}{l}\text { D1s- } \\
\text { charge }\end{array}$ & Date & Hour & $\begin{array}{c}\text { Gage } \\
\text { height }\end{array}$ & $\begin{array}{c}\text { Dis- } \\
\text { charge }\end{array}$ & Date & Hour & $\begin{array}{c}\text { Gage } \\
\text { height }\end{array}$ & $\begin{array}{l}\text { Dia- } \\
\text { charge }\end{array}$ \\
\hline $\begin{array}{r}\text { Jan. } 30 \\
31\end{array}$ & \begin{tabular}{l|}
2400 \\
0200 \\
0600 \\
1000 \\
1200 \\
1500 \\
1700 \\
1800 \\
1900 \\
2000 \\
2030 \\
2200
\end{tabular} & $\begin{array}{r}5.35 \\
5.45 \\
5.20 \\
5.20 \\
5.53 \\
7.20 \\
9.43 \\
11.75 \\
11.40 \\
10.40 \\
12.35 \\
14.20\end{array}$ & $\begin{array}{r}2,180 \\
2,280 \\
2,020 \\
2,020 \\
2,370 \\
4,500 \\
8,070 \\
13,000 \\
12,200 \\
10,000 \\
14,500 \\
19,800\end{array}$ & $\begin{array}{l}\text { Jan. } 31 \\
\text { Feb. } 1\end{array}$ & $\begin{array}{l}2300 \\
2400 \\
0300 \\
0400 \\
0930 \\
1030 \\
1200 \\
1400 \\
1600 \\
1630 \\
1700 \\
2400\end{array}$ & $\begin{array}{r}15.40 \\
15.70 \\
16.15 \\
15.68 \\
14.57 \\
14.61 \\
13.88 \\
11.96 \\
10.92 \\
9.98 \\
10.70 \\
8.64\end{array}$ & $\begin{array}{r}23,500 \\
24,400 \\
25,900 \\
24,400 \\
21,000 \\
21,100 \\
19,000 \\
13,700 \\
11,300 \\
9,400 \\
10,900 \\
6,940\end{array}$ & Feb. 2 & $\begin{array}{l}0300 \\
0600 \\
1000 \\
1200 \\
1300 \\
1400 \\
1700 \\
1900 \\
2100 \\
2300 \\
2400\end{array}$ & $\begin{array}{l}7.62 \\
7.05 \\
6.60 \\
6.51 \\
6.02 \\
6.30 \\
6.29 \\
5.43 \\
5.69 \\
5.70 \\
5.36\end{array}$ & $\begin{array}{l}5,360 \\
4,540 \\
3,910 \\
3,800 \\
3,160 \\
3,520 \\
3,510 \\
2,460 \\
2,760 \\
2,780 \\
2,380\end{array}$ \\
\hline
\end{tabular}


11-3200. Pardee Reservoir near Valley Springs, Calif.

Location.--Lat $38^{\circ} 15^{\prime} 30^{\prime \prime}$, long $120^{\circ} 51^{\prime} 00^{\prime \prime}$, in $\mathrm{N} \frac{1}{2} \mathrm{SW} \frac{1}{4} \sec .26$, T.5 N., R.10 E., at Pardee Dam on the Mokelumne River, 4.5 miles north of Valley Springs.

Drainage area. $--578 \mathrm{sq} \mathrm{mi}$.

Gage-height record.--Water-stage recorder graph. Datum of gage is at mean sea level (levels by East Bay Municipal Utility District).

Contents record.--Contents computed from capacity table dated June 1930.

Maxima.--January-February 1963: Computed bihourly inflow, 26,000 cfs 0400 to 0600 hours Feb. 1. Contents, 209,600 acre-ft 2400 hours Feb. 1 (elevation, $567.5 \mathrm{ft}$ ). 1929 to December 1962: Contents, 219,300 acre-ft Dec. 23, 1955 (elevation, $571.72 \mathrm{ft}$ ).

Remarks.--Reservolr is formed by a curved concrete gravity dam, completed in 1929; storage began Mar. 9, 1929. Usable capacity, 194,100 acre-ft between elevations 393.50 (diversion tunnel invert) and $567.65 \mathrm{ft}$ (spillway crest) above mean sea level. Dead storage, 15,800 acre-ft. Figures glven herein represent total contents. Records furnished by East Bay Municipal Utility District.

Contents, in acre-feet, at 2400 hours, 1963

\begin{tabular}{|c|c|c|c|c|c|c|c|c|}
\hline Day & January & February & Day & January & February & Day & January & February \\
\hline $\begin{array}{c}1 \ldots \ldots \\
2 \ldots \ldots \\
4 \ldots \ldots \\
5 \ldots \ldots \\
6 \ldots \ldots \\
7 \ldots \ldots \\
9 \ldots \ldots \\
10 \ldots \ldots\end{array}$ & $\begin{array}{l}182,900 \\
182,700 \\
182,600 \\
182,000 \\
181,700 \\
181,200 \\
180,700 \\
180,100 \\
179,300 \\
178,800\end{array}$ & $\begin{array}{l}209,600 \\
207,500 \\
200,700 \\
194,500 \\
191,300 \\
191,400 \\
191,600 \\
191,500 \\
191,500 \\
191,400\end{array}$ & $\begin{array}{l}11 \ldots \ldots \\
12 \ldots \ldots \\
13 \ldots \ldots \\
14 \ldots \ldots \\
15 \ldots \ldots \\
16 \ldots \ldots \\
17 \ldots \ldots \\
18 \ldots \ldots \\
19 \ldots \ldots \\
20 \ldots \ldots\end{array}$ & $\begin{array}{l}178,600 \\
178,200 \\
177,800 \\
177,200 \\
177,100 \\
176,400 \\
175,800 \\
175,900 \\
175,400 \\
174,100\end{array}$ & $\begin{array}{l}191,000 \\
190,900 \\
191,800 \\
192,300 \\
192,500 \\
192,100 \\
191,400 \\
190,500 \\
189,700 \\
189,000\end{array}$ & $\begin{array}{l}21 \ldots \ldots \\
22 \ldots \ldots \\
23 \ldots \ldots \\
24 \ldots \ldots \\
25 \ldots \ldots \\
26 \ldots \ldots \\
27 \ldots \ldots \\
28 \ldots \ldots \\
29 \ldots \ldots \\
30 \ldots \ldots \\
31 \ldots \ldots\end{array}$ & $\begin{array}{l}173,200 \\
172,600 \\
172,200 \\
171,900 \\
171,600 \\
171,100 \\
171,000 \\
171,100 \\
171,200 \\
172,100 \\
184,600\end{array}$ & $\begin{array}{r}188,100 \\
186,900 \\
185,700 \\
184,300 \\
183,200 \\
182,200 \\
181,100 \\
179,900 \\
------ \\
------ \\
-\end{array}$ \\
\hline \multicolumn{7}{|c|}{ 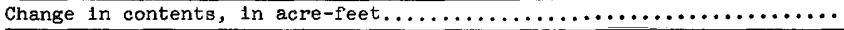 } & $+1,900$ & $-4,700$ \\
\hline
\end{tabular}

Average inflow, in cubic feet per second, for bihourly periods ending at indicated

\begin{tabular}{|c|c|c|c|c|c|c|c|c|}
\hline Date & Hour & Inflow & Date & Hour & Inflow & Date & Hour & Inflow \\
\hline Jan. 30 & $\begin{array}{l}0200 \\
0400 \\
0600 \\
0800 \\
1000 \\
1200 \\
1400 \\
1600 \\
1800 \\
2000 \\
2200 \\
2400 \\
0200 \\
0400 \\
0600 \\
0800\end{array}$ & $\begin{array}{r}441 \\
441 \\
320 \\
441 \\
562 \\
1,030 \\
913 \\
792 \\
1,510 \\
1,150 \\
1,390 \\
2,090 \\
2,440 \\
2,560 \\
2,100 \\
2,220\end{array}$ & $\operatorname{Jan} .31$ & $\begin{array}{l}1000 \\
1200 \\
1400 \\
1600 \\
1800 \\
2000 \\
2200 \\
2400 \\
\\
0200 \\
0400 \\
0600 \\
0800 \\
1000 \\
1200 \\
1400 \\
1600\end{array}$ & $\begin{array}{r}2,220 \\
2,220 \\
3,290 \\
5,220 \\
9,200 \\
11,300 \\
15,900 \\
23,600 \\
24,800 \\
24,200 \\
26,000 \\
21,800 \\
20,700 \\
20,600 \\
13,800 \\
11,400\end{array}$ & Feb. 1 & $\begin{array}{l}1800 \\
2000 \\
2200 \\
2400 \\
\\
0200 \\
0400 \\
0600 \\
0800 \\
1000 \\
1200 \\
1400 \\
1600 \\
1800 \\
2000 \\
2200 \\
2400\end{array}$ & $\begin{array}{l}9,480 \\
8,830 \\
7,760 \\
1,940 \\
5,750 \\
5,780 \\
4,950 \\
4,530 \\
4,540 \\
3,990 \\
3,850 \\
3,720 \\
3,720 \\
2,910 \\
2,910 \\
2,920\end{array}$ \\
\hline
\end{tabular}


11-3210. Mokelumne River at Lancha Plana, Calif.

Location,--Lat $38^{\circ} 13^{1} 2^{\prime \prime}$, long $120^{\circ} 53^{1} 20^{\prime \prime}$, in SW $\frac{1}{4}$ sec.4, T.4 N., R.10 E., on left bank 1 mile east of Lancha Plana, 3 miles downstream from Pardee Dam, and 5 miles upstream from Camanche Creek.

Drainage area. $--587 \mathrm{sq} \mathrm{mi}$.

Gage-height record.--Water-stage recorder graph. Datum of gage is $158.95 \mathrm{ft}$ above mean sea level (levels by East Bay Municipal utility District).

Discharge record.--Stage-discharge relation defined by current-meter measurements.

Maxima.--January-February 1963: Discharge, 4,930 cfs 1600 hours Feb. 1 (gage height, $8.28 \mathrm{ft}$. 1926 to December 1962: Discharge, 26,700 cfs Nov. 21, 1950 (gage he1ght, $20.1 \mathrm{ft}$ ).

Remarks.--Flow regulated by Pardee Reservoir (see station 11-3200), Salt Springs Reservolr (see station 11-3135), several smaller reservolrs, and four powerplants. Diversions above station were 8,330 acre-ft in January and 7,700 acre-ft in February.

Mean discharge, in cubic feet per second, 1963

\begin{tabular}{|c|c|c|c|c|c|c|c|c|}
\hline Day & January & February & Day & January & February & Day & January & February \\
\hline $\begin{array}{c}\ldots \ldots \\
2 \ldots \ldots \\
3 \ldots \ldots \\
4 \ldots \ldots \\
6 \ldots \ldots \\
7 \ldots \ldots \\
9 \ldots \ldots \\
10 \ldots \ldots\end{array}$ & $\begin{array}{l}290 \\
387 \\
560 \\
620 \\
620 \\
620 \\
625 \\
625 \\
625 \\
560\end{array}$ & $\begin{array}{r}3,520 \\
4,840 \\
4,820 \\
4,200 \\
2,510 \\
728 \\
733 \\
728 \\
733 \\
733\end{array}$ & $\begin{array}{l}11 \ldots \ldots \\
12 \ldots \ldots \\
13 \ldots \ldots \\
14 \ldots \ldots \\
15 \ldots \ldots \\
16 \ldots \ldots \\
17 \ldots \ldots \\
18 \ldots \ldots \\
19 \ldots \ldots \\
20 \ldots \ldots\end{array}$ & $\begin{array}{l}568 \\
620 \\
620 \\
615 \\
610 \\
610 \\
610 \\
610 \\
610 \\
615\end{array}$ & $\begin{array}{l}728 \\
733 \\
810 \\
755 \\
733 \\
728 \\
722 \\
722 \\
733 \\
744\end{array}$ & $\begin{array}{l}21 \ldots \ldots \\
22 \ldots \ldots \\
23 \ldots \ldots \\
24 \ldots \ldots \\
25 \ldots \ldots \\
26 \ldots \ldots \\
27 \ldots \ldots \\
28 \ldots \ldots \\
29 \ldots \ldots \\
30 \ldots \ldots \\
31 \ldots \ldots\end{array}$ & $\begin{array}{l}615 \\
625 \\
630 \\
630 \\
625 \\
625 \\
625 \\
420 \\
297 \\
296 \\
430\end{array}$ & $\begin{array}{r}760 \\
760 \\
760 \\
760 \\
777 \\
782 \\
799 \\
794 \\
-.--\end{array}$ \\
\hline $\begin{array}{l}\text { onthly } \\
\text { unoff, }\end{array}$ & n dis & , & & & & & $\begin{array}{r}563 \\
34,590 \\
\end{array}$ & $\begin{array}{r}1,327 \\
73,680 \\
\end{array}$ \\
\hline
\end{tabular}

11-3235. Mokelumne River below Camanche Dam, Calif.

Location.--Lat $38^{\circ} 13^{\prime} 1^{\prime \prime}$, long $121^{\circ} 02^{\prime} 20^{\prime \prime}$, in NW $\frac{1}{4} N W \frac{1}{4} \sec .7$, T. 4 N., R.9 E., on left bank 0.7 mile downstream from Murphy Creek and 3.4 miles northeast of Clements.

Drainage area. $--627 \mathrm{sq} \mathrm{mi}$.

Gage-height record.--Water-stage recorder graph, except 1100 hours Jan. 21 to 1300 hours Jan. 30 , and 1000 to 1400 hours on Feb. 1. Datum of gage is $82.91 \mathrm{ft}$ above mean sea level (levels by East Bay Municipal Utility District).

Discharge record.--Stage-discharge relation defined by current-meter measurements. Discharge for periods of no gage-height record estimated on basis of range in stage and records for Mokelumne River at Lancha Plana.

Maxima.--January-February 1963: Discharge, 5,920 of's 1830 hours Feb. 2, 1963 (gage helght, $10.87 \mathrm{ft}^{\mathrm{t}}$.

1904 to December 1962: Discharge, 28,800 cf's Nov. 21, 1950 (gage helght, $24.40 \mathrm{ft}$, site and datum then in use).

Remarks.--Flow affected by Pardee Reservoir (see station 11-3200) since 1929, by Salt Springs Reservoir (see station 11-3135) since 1931, and by several smaller reservoirs. 
Mean discharge, in cublc feet per second, 1963, of Mokelumne River below Camanche Dam, Calif.

\begin{tabular}{|c|c|c|c|c|c|c|c|c|}
\hline Day & January & Febmuary & Day & January & February & Day & January & February \\
\hline $\begin{array}{c}1 \ldots \ldots \\
2 \ldots \ldots \\
3 \ldots \ldots \\
4 \ldots \ldots \\
5 \ldots \ldots \\
6 \ldots \ldots \\
7 \ldots \ldots \\
8 \ldots \ldots \\
9 \ldots \ldots \\
10 \ldots \ldots\end{array}$ & $\begin{array}{l}375 \\
354 \\
560 \\
626 \\
626 \\
626 \\
632 \\
638 \\
632 \\
570\end{array}$ & $\begin{array}{r}3,230 \\
5,200 \\
5,090 \\
4,580 \\
3,060 \\
846 \\
840 \\
840 \\
840 \\
846\end{array}$ & $\begin{array}{l}11 \ldots \ldots \\
12 \ldots \ldots \\
13 \ldots \ldots \\
14 \ldots \ldots \\
15 \ldots \ldots \\
16 \ldots \ldots \\
17 \ldots \ldots \\
18 \ldots \ldots \\
19 \ldots \ldots \\
20 \ldots \ldots\end{array}$ & $\begin{array}{l}575 \\
632 \\
632 \\
638 \\
626 \\
632 \\
626 \\
632 \\
632 \\
638\end{array}$ & $\begin{array}{r}834 \\
852 \\
1,120 \\
914 \\
852 \\
840 \\
834 \\
828 \\
828 \\
840\end{array}$ & $\begin{array}{l}21 \ldots \ldots \\
22 \ldots \ldots \\
23 \ldots \ldots \\
24 \ldots \ldots \\
25 \ldots \ldots \\
26 \ldots \ldots \\
27 \ldots \ldots \\
28 \ldots \ldots \\
29 \ldots \ldots \\
30 \ldots \ldots \\
31 \ldots \ldots\end{array}$ & $\begin{array}{l}630 \\
630 \\
630 \\
630 \\
625 \\
625 \\
625 \\
450 \\
300 \\
300 \\
425\end{array}$ & $\begin{array}{r}864 \\
864 \\
864 \\
864 \\
870 \\
882 \\
900 \\
894 \\
---2 \\
----\end{array}$ \\
\hline \multicolumn{7}{|c|}{$\begin{array}{l}\text { Monthly mean discharge, in cubic feet per second } \ldots \ldots \ldots \ldots \ldots \ldots \ldots \ldots \ldots \ldots \ldots \\
\text { Runoff, in acre-feet } \ldots \ldots \ldots \ldots \ldots \ldots \ldots \ldots \ldots \ldots \ldots \ldots \ldots \ldots \ldots \ldots\end{array}$} & $\begin{array}{r}573 \\
35,250\end{array}$ & $\begin{array}{r}1,468 \\
81,550\end{array}$ \\
\hline
\end{tabular}

11-3255. Mokelumne River at Woodbridge, Calif.

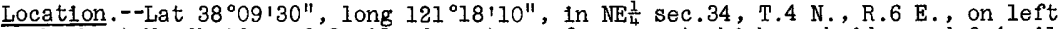
bank at Woodbridge, 0.3 mile downstream from county highway bridge and $0.4 \mathrm{mile}$ downstream from dam and canal intake of Woodbridge Irrigation District.

Drainage area. $--660 \mathrm{sq} \mathrm{ml}$.

Gage-helght record.--Water-stage recorder graph. Datum of gage is $14.9 \mathrm{ft}$ above mean sea level (levels by East Bay Municipal Utility District).

Discharge record.--Stage-discharge relation defined by current-meter measurements below 6,200 cfs and by contracted-opening measurement at 27,000 cfs.

Maxima.--January-February 1963: Discharge, 5,340 cfs 2100 hours Feb. 4 (gage he1 ght, $22.56 \mathrm{ft}$ )

1924 to December 1962: Discharge, 27,000 cfs Nov. 22, 1950 (gage helght, $29.58 \mathrm{ft}$ ).

Remarks.--Flow regulated by Pardee Reservolr (see station 11-3200), Salt Springs Reservolr (see station 11-3135), several smaller reservolrs, and four powerplants.

Mean discharge, in cubic feet per second, 1963

\begin{tabular}{|c|c|c|c|c|c|c|c|c|}
\hline Day & January & February & Day & January & February & Day & January & February \\
\hline $\begin{array}{c}1 \ldots \ldots \\
2 \ldots \ldots \\
3 \ldots \ldots \\
4 \ldots \ldots \\
6 \ldots \ldots \\
7 \ldots \ldots \\
8 \ldots \ldots \\
9 \ldots \ldots \\
10 \ldots \ldots\end{array}$ & $\begin{array}{l}511 \\
303 \\
348 \\
468 \\
567 \\
569 \\
569 \\
574 \\
579 \\
576\end{array}$ & $\begin{array}{r}1,360 \\
3,260 \\
4,770 \\
5,230 \\
4,940 \\
2,820 \\
1,030 \\
933 \\
896 \\
890\end{array}$ & $\begin{array}{l}11 \ldots \ldots \\
12 \ldots \ldots \\
13 \ldots \ldots \\
14 \ldots \ldots \\
15 \ldots \ldots \\
16 \ldots \ldots \\
17 \ldots \ldots \\
18 \ldots \ldots \\
19 \ldots \ldots \\
20 \ldots \ldots\end{array}$ & $\begin{array}{l}524 \\
528 \\
572 \\
574 \\
583 \\
571 \\
576 \\
576 \\
576 \\
576\end{array}$ & $\begin{array}{r}858 \\
846 \\
946 \\
1,070 \\
880 \\
850 \\
824 \\
808 \\
800 \\
794\end{array}$ & $\begin{array}{l}21 \ldots \ldots \\
22 \ldots \ldots \\
23 \ldots \ldots \\
24 \ldots \ldots \\
25 \ldots \ldots \\
26 \ldots \ldots \\
27 \ldots \ldots \\
28 \ldots \ldots \\
29 \ldots \ldots \\
30 \ldots \ldots \\
31 \ldots \ldots\end{array}$ & $\begin{array}{l}578 \\
578 \\
581 \\
583 \\
584 \\
581 \\
579 \\
578 \\
406 \\
332 \\
351 \\
\end{array}$ & 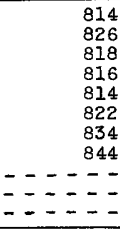 \\
\hline nthly & 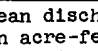 & & & & & & $\begin{array}{r}531 \\
32,630 \\
\end{array}$ & $\begin{array}{r}1,479 \\
82,110\end{array}$ \\
\hline
\end{tabular}

11-3263. Dry Creek above Sutter Creek, near Ione, Calif.

Location.--Lat $38^{\circ} 24^{\prime} 54^{\prime \prime}$, long $120^{\circ} 54^{\prime} 18^{\prime \prime}$, in SW $\frac{1}{4}$ SW $\frac{1}{4}$ sec.32, T. 7 N., R.10 E., on right bank 1,000 ft downstream from bridge on State Highway 104 and 4.6 miles northeast of Ione.

Drainage area. $--70.8 \mathrm{sq} \mathrm{m} 1$.

Gage-helght record --Water-stage recorder graph. Alt1tude of gage is $500 \mathrm{ft}$ (from topographic map).

D1scharge record.--Stage-discharge relation defined by current-meter measurements below $1,300 \mathrm{c}$ s

Maxima.--January-February 1963: Discharge, 4,560 cfs 0730 hours Feb. 1 (gage helght, 10.22 ).

1960 to December 1962: Discharge, 1,450 cfs Feb. 15, 1962 (gage he1ght, $7.40 \mathrm{ft})$.

Remarks.--Records furnished by California Department of Water Resources and reviewed by Geological Survey. 
Mean discharge, in cubic feet per second, 1963, of Dry Creek above Sutter Creek,

\begin{tabular}{|c|c|c|c|c|c|c|c|c|}
\hline Day & January & February & Day & January & February & Day & January & February \\
\hline $\begin{array}{r}1 \ldots . . \\
2 \ldots \ldots \\
3 \ldots \ldots \\
4 \ldots \ldots \\
5 \ldots \ldots \\
6 \ldots \ldots \\
8 \ldots \ldots \\
9 \ldots \ldots \\
10 \ldots .\end{array}$ & $\begin{array}{l}9.8 \\
9.4 \\
9.2 \\
9.0 \\
8.4 \\
8.2 \\
8.0 \\
7.8 \\
7.8 \\
7.4\end{array}$ & $\begin{array}{r}2,090 \\
336 \\
149 \\
91 \\
66 \\
53 \\
43 \\
38 \\
38 \\
54\end{array}$ & $\begin{array}{l}11 \ldots \ldots \\
12 \ldots \ldots \\
13 \ldots \ldots \\
14 \ldots \\
15 \ldots \\
16 \ldots \\
17 \ldots \\
18 \ldots \\
19 \ldots \\
20 \ldots \\
\end{array}$ & $\begin{array}{l}7.2 \\
6.6 \\
6.1 \\
6.4 \\
6.7 \\
6.5 \\
6.3 \\
6.3 \\
5.8 \\
6.0\end{array}$ & $\begin{array}{r}40 \\
38 \\
339 \\
236 \\
125 \\
89 \\
71 \\
58 \\
50 \\
44\end{array}$ & $\begin{array}{l}21 \ldots \ldots \\
22 \ldots \ldots \\
23 \ldots \ldots \\
24 \ldots \ldots \\
25 \ldots \ldots \\
26 \ldots \ldots \\
27 \ldots \ldots \\
28 \ldots \ldots \\
29 . \ldots \ldots \\
30 \ldots \ldots \\
31 \ldots \ldots\end{array}$ & $\begin{array}{r}5.8 \\
5.8 \\
5.6 \\
5.6 \\
5.6 \\
5.8 \\
5.8 \\
5.5 \\
5.9 \\
32 \\
795\end{array}$ & $\begin{array}{r}39 \\
36 \\
32 \\
29 \\
27 \\
25 \\
23 \\
22 \\
--.-- \\
-.-0\end{array}$ \\
\hline
\end{tabular}

Gage he1ght, In feet, and discharge, in cuble feet per second, at 1ndicated t1me, 1963

\begin{tabular}{|c|c|c|c|c|c|c|c|c|c|c|c|}
\hline Date & Hour & $\begin{array}{c}\text { Gage } \\
\text { he1ght }\end{array}$ & $\begin{array}{c}\text { Dis- } \\
\text { charge }\end{array}$ & Date & Hour & $\begin{array}{c}\text { Gage } \\
\text { he1ght }\end{array}$ & $\begin{array}{c}\text { D1s- } \\
\text { charge }\end{array}$ & Date & Hour & $\begin{array}{c}\text { Gage } \\
\text { helght }\end{array}$ & $\begin{array}{l}\text { Dis- } \\
\text { charge }\end{array}$ \\
\hline $\begin{array}{r}\operatorname{Jan} .29 \\
30\end{array}$ & $\begin{array}{l}2400 \\
0600 \\
1200 \\
1800 \\
2000 \\
2400\end{array}$ & $\begin{array}{l}3.34 \\
3.39 \\
3.53 \\
3.85 \\
4.13 \\
4.15\end{array}$ & $\begin{array}{c}7.6 \\
9.6 \\
17 \\
42 \\
76 \\
79\end{array}$ & Jan. 31 & $\begin{array}{l}1600 \\
1800 \\
2000 \\
2200 \\
2400\end{array}$ & $\begin{array}{l}5.80 \\
5.97 \\
7.05 \\
9.50 \\
9.65\end{array}$ & $\begin{array}{r}556 \\
632 \\
1,260 \\
3,630 \\
3,830\end{array}$ & Feb. 1 & $\begin{array}{l}0800 \\
1000 \\
1300 \\
1600 \\
2000 \\
2400\end{array}$ & $\begin{array}{r}10.05 \\
8.67 \\
7.50 \\
6.85 \\
6.35 \\
5.86\end{array}$ & $\begin{array}{r}4,310 \\
2,6610 \\
1,540 \\
1,090 \\
802 \\
569\end{array}$ \\
\hline 31 & $\begin{array}{l}0100 \\
0200 \\
0400 \\
0700 \\
1200 \\
\end{array}$ & $\begin{array}{l}4.18 \\
4.30 \\
4.60 \\
4.62 \\
4.84 \\
\end{array}$ & $\begin{array}{r}88 \\
108 \\
166 \\
171 \\
224 \\
\end{array}$ & Ned. & $\begin{array}{l}0200 \\
0300 \\
0500 \\
0600 \\
0700 \\
0730\end{array}$ & $\begin{array}{r}9.95 \\
9.15 \\
8.32 \\
8.90 \\
10.00 \\
10.22\end{array}$ & $\begin{array}{l}4,170 \\
3,140 \\
2,260 \\
2,860 \\
4,240 \\
4,560\end{array}$ & 2 & $\begin{array}{l}0600 \\
1200 \\
1800 \\
2400\end{array}$ & $\begin{array}{l}5.43 \\
5.13 \\
4.88 \\
4.68\end{array}$ & $\begin{array}{l}406 \\
309 \\
240 \\
192\end{array}$ \\
\hline
\end{tabular}

11-3270. Sutter Creek near Sutter Creek, Cal1f.

Location.--Lat $38^{\circ} 23^{14} 5^{\prime \prime}$, long $120^{\circ} 46^{\prime} 50^{\prime \prime}$, in $\mathrm{SE}_{\frac{1}{4}}$ sec.5, T.6 N., R.11 E., on left bank 1.3 miles east of town of Sutter Creek.

Drainage area. $--48.1 \mathrm{sq} \mathrm{ml}$.

Gage-height record:--Water-stage recorder graph. Altitude of gage is $1,220 \mathrm{ft}$ (from topographic map). $\frac{\text { Discharge record. }}{\text { below } 500 \mathrm{cfs} \text {. }}$-Stage-discharge relation defined by current-meter measurements

Maxima.--January-Febmuary 1963: D1scharge, 5,770 cfs 2400 hours Jan. 31 (gage he1ght, $6.27 \mathrm{ft}$ ).

1935-41, 1960 to December 1962: D1scharge, 3,900 cfs Feb. 22, 1936 (gage he1ght, $8.0 \mathrm{ft}$ ).

Remarks. --Records furnished by Californla Department of Water Resources and reviewed by the Geological Survey.

Mean discharge, in cub1c feet per second, 1963

\begin{tabular}{|c|c|c|c|c|c|c|c|c|}
\hline Day & January & February & Day & January & February & Day & January & February \\
\hline $\begin{array}{c}\overline{1} \ldots \ldots \\
2 \ldots \ldots \\
3 \ldots \ldots \\
5 \ldots \ldots \\
6 \ldots \ldots \\
7 \ldots \ldots \\
9 \ldots \ldots \\
10 \ldots \ldots\end{array}$ & $\begin{array}{l}5.9 \\
5.7 \\
5.7 \\
5.5 \\
5.5 \\
5.2 \\
5.0 \\
5.0 \\
5.0 \\
5.0\end{array}$ & $\begin{array}{r}2,260 \\
279 \\
136 \\
95 \\
75 \\
61 \\
49 \\
43 \\
41 \\
53\end{array}$ & $\begin{array}{l}11 \ldots \ldots \\
12 \ldots \ldots \\
13 \ldots \ldots \\
14 \ldots \ldots \\
15 \ldots \ldots \\
16 \ldots \ldots \\
17 \ldots \ldots \\
18 \ldots \ldots \\
19 \ldots \ldots \\
20 \ldots \ldots\end{array}$ & $\begin{array}{l}4.8 \\
4.2 \\
4.0 \\
4.2 \\
4.2 \\
4.4 \\
4.4 \\
4.7 \\
4.7 \\
4.4\end{array}$ & $\begin{array}{r}39 \\
34 \\
99 \\
102 \\
69 \\
55 \\
45 \\
38 \\
33 \\
32\end{array}$ & $\begin{array}{l}21 \ldots \ldots \\
22 \ldots \ldots \\
23 \ldots \ldots \\
24 \ldots \ldots \\
25 \ldots \ldots \\
26 \ldots \ldots \\
27 \ldots \ldots \\
28 \ldots \ldots \\
29 \ldots \ldots \\
30 \ldots \ldots \\
31 \ldots \ldots\end{array}$ & $\begin{array}{r}4.4 \\
4.4 \\
4.4 \\
4.4 \\
4.4 \\
4.4 \\
4.4 \\
4.4 \\
4.4 \\
97 \\
1,060\end{array}$ & $\begin{array}{r}29 \\
26 \\
23 \\
21 \\
19 \\
18 \\
17 \\
16 \\
-\ldots-\ldots \\
-\ldots-\ldots\end{array}$ \\
\hline \multicolumn{9}{|c|}{ 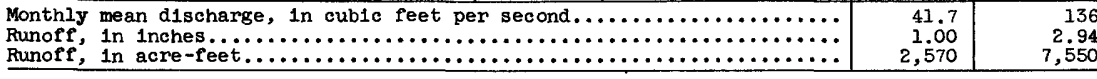 } \\
\hline
\end{tabular}


Gage helght, in feet, and discharge, in cublc feet per second, at indicated time, 1963, of Sutter Creek near Sutter Creek, Calif.

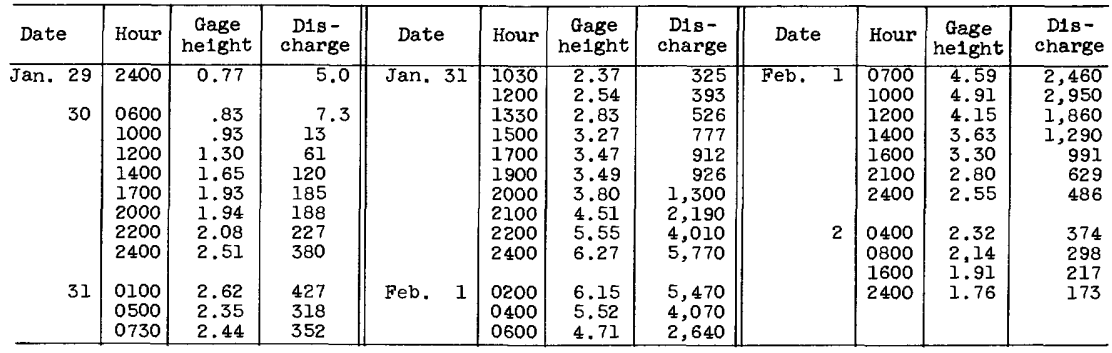

11-3278. Clay Creek near Ione, Callf.

(Crest-stage station)

Location.--Lat $38^{\circ} 19^{\prime} 05^{\prime \prime}$, long $120^{\circ} 56^{\prime} 20^{\prime \prime}$, In Arroyo Seco Land Grant, on State H1ghway $88,2.3$ miles south of Ione.

Drainage area. $--3.54 \mathrm{sq} \mathrm{ml}$.

Gage-helght record.--Crest stages only. Altitude of gage is $300 \mathrm{ft}$ (from topographic map).

Discharge record.--Stage-discharge relation defined by current-meter measurements below 6 cfs and by computation of flow through culvert at $75 \mathrm{cfs}$.

Maxima.--January-February 1963: Discharge, $75 \mathrm{cfs} F e b .1$ (gage helght, $22.68 \mathrm{ft}$ ). 1959 to December 1962: Discharge, $69 \mathrm{cfs}$ Feb. 15, 1962 (gage he1ght, $22.55 \mathrm{ft}$ ).

11-3295. Dry Creek near Galt, Calif.

Location.--Lat $38^{\circ} 14^{\prime} 48^{\prime \prime}$, long $121^{\circ} 13^{\prime} 03^{\prime \prime}$, in NE $\frac{1}{4}$ sec.32, T.5 N., R.7 E., on right bank of main channel just downstream from county road bridge, 2 miles downstream from Coyote Creek and 4 miles east of Galt.

Drainage area. $--329 \mathrm{sq} \mathrm{m} 1$.

Gage-helght record - Water-atage recorder graph. Datum of gage is $52.83 \mathrm{ft}$ above mean sea level (levels by East Bay Municlpal Utility District).

Discharge record.--Stage-discharge relation defined by current-meter measurements.

Maxima.--January-February 1963: Discharge, 9,320 cfs 1600 hours Feb. I (gage he1ght, $13.96 \mathrm{ft})$

1926-33, 1944 to December 1962: Discharge, 24,000 cf's Apr. 3, 1958 (gage he1ght, $15.28 \mathrm{ft}$ ).

Mean discharge, in cubic feet per second, 1963

\begin{tabular}{|c|c|c|c|c|c|c|c|c|}
\hline Day & January & February & Day & January & February & Day & January & February \\
\hline $\begin{array}{c}1 \ldots \ldots \\
2 \ldots \ldots \\
3 \ldots \ldots \\
4 \ldots \ldots \\
5 \ldots \ldots \\
7 \ldots \ldots \\
8 \ldots \ldots \\
9 \ldots \ldots \\
10 \ldots \ldots\end{array}$ & $\begin{array}{l}0.9 \\
.1 \\
0 \\
0 \\
0 \\
0 \\
0 \\
0 \\
0 \\
0\end{array}$ & $\begin{array}{r}6,960 \\
2,740 \\
774 \\
445 \\
309 \\
240 \\
189 \\
159 \\
144 \\
219\end{array}$ & $\begin{array}{l}11 \ldots \ldots \\
12 \ldots \ldots \\
13 \ldots \ldots \\
14 \ldots \ldots \\
15 \ldots \ldots \\
16 \ldots \ldots \\
17 \ldots \ldots \\
18 \ldots \ldots \\
19 \ldots \ldots \\
20 \ldots \ldots\end{array}$ & $\begin{array}{l}0 \\
0 \\
0 \\
0 \\
0 \\
0 \\
0 \\
0 \\
0 \\
0\end{array}$ & $\begin{array}{r}195 \\
152 \\
1,100 \\
1,290 \\
473 \\
312 \\
247 \\
198 \\
168 \\
150\end{array}$ & $\begin{array}{l}21 \ldots \ldots \\
22 \ldots \ldots \\
23 \ldots \ldots \\
24 \ldots \ldots \\
25 \ldots \ldots \\
26 \ldots \ldots \\
27 \ldots \ldots \\
22 \ldots \ldots \\
29 \ldots \ldots \\
30 \ldots \ldots \\
31 \ldots \ldots\end{array}$ & $\begin{array}{r}0 \\
0 \\
0 \\
0 \\
0 \\
0 \\
0 \\
0 \\
0 \\
0 \\
422\end{array}$ & $\begin{array}{r}128 \\
109 \\
100 \\
91 \\
84 \\
76 \\
70 \\
64 \\
-.--\end{array}$ \\
\hline \multicolumn{7}{|l|}{$\begin{array}{l}\text { Monthly } \\
\text { Runoff, } \\
\text { Runoff, }\end{array}$} & $\begin{array}{r}13.6 \\
0.05 \\
839 \\
\end{array}$ & $\begin{array}{r}614 \\
1.94 \\
34,090 \\
\end{array}$ \\
\hline
\end{tabular}


Clage height, in feet, and discharge, in cubic feet per second, at indicated time, I963, of Dry Creek near Galt, Calif.

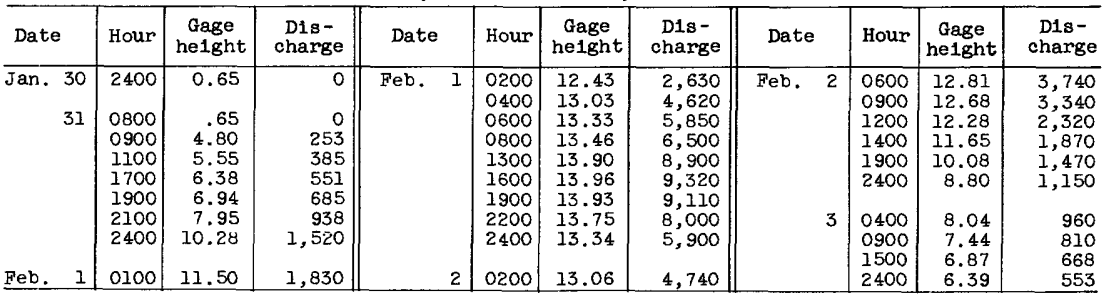

11-3330. Camp Creek near Somerset, Calif.

Location.--Lat $38^{\circ} 39126^{\prime \prime}$, long $120^{\circ} 39146^{\prime \prime}$, In SW $\frac{1}{4}$ sec.4, T.9 N., R.12 E., on right bank 0.2 mile upstream from mouth, 1.3 miles northeast of Somerset, and 5.6 miles south of Camino.

Drainage area. $--62.6 \mathrm{sq} \mathrm{ml}$.

Gage-height record.--Water-stage recorder graph. Altitude of gage is $1,820 \mathrm{ft}$ (from topographic map).

Discharge record.--Stage-discharge relation defined by current-meter measurements below 5,100 c fs.

Maxima.--January-February 1963: Discharge, 5,740 cfs 0200 hours Feb. 1 (gage helght, $12.25 \mathrm{ft}$, from recorder graph; $14.55 \mathrm{ft}$, from floodmark).

1954 to December 1962: Discharge, 6,020 cfs Dec. 23, 1955 (gage helght, $12.48 \mathrm{ftl}$.

Remarks.--Flow partly regulated since 1955 by Jenkinson Lake (usable capacity, 40,570 acre-ft).

Mean discharge, in cubic feet per second, 1963

\begin{tabular}{|c|c|c|c|c|c|c|c|c|}
\hline Day & January & February & Day & January & February & Day & January & February \\
\hline $\begin{array}{c}1 \ldots \ldots \\
3 \ldots \ldots \\
4 \ldots \ldots \\
5 \ldots \ldots \\
6 \ldots \ldots \\
8 \ldots \ldots \\
9 \ldots \ldots \\
10 \ldots \ldots\end{array}$ & $\begin{array}{l}5.8 \\
5.3 \\
5.3 \\
5.6 \\
5.8 \\
5.6 \\
5.6 \\
5.6 \\
5.3 \\
5.3\end{array}$ & $\begin{array}{r}3,050 \\
570 \\
86 \\
33 \\
22 \\
17 \\
15 \\
13 \\
12 \\
12\end{array}$ & $\begin{array}{l}11 \ldots \ldots \\
12 \ldots \ldots \\
13 \ldots \ldots \\
14 \ldots \ldots \\
15 \ldots \ldots \\
16 \ldots \ldots \\
17 \ldots \ldots \\
18 \ldots \ldots \\
19 \ldots \ldots \\
20 \ldots \ldots\end{array}$ & $\begin{array}{l}5.1 \\
3.5 \\
5.3 \\
5.6 \\
5.6 \\
5.6 \\
5.6 \\
5.6 \\
4.8 \\
5.6\end{array}$ & $\begin{array}{l}11 \\
11 \\
29 \\
24 \\
19 \\
16 \\
14 \\
13 \\
12 \\
11\end{array}$ & $\begin{array}{l}21 \ldots \ldots \\
22 \ldots \ldots \\
23 \ldots \ldots \\
24 \ldots \ldots \\
25 \ldots \ldots \\
26 \ldots \ldots \\
27 \ldots \ldots \\
28 \ldots \ldots \\
29 \ldots \ldots \\
30 \ldots \ldots \\
31 \ldots \ldots\end{array}$ & $\begin{array}{r}5.6 \\
5.6 \\
5.6 \\
5.6 \\
5.6 \\
5.3 \\
5.3 \\
5.6 \\
6.3 \\
33 \\
1,130\end{array}$ & $\begin{array}{r}11 \\
10 \\
10 \\
9.8 \\
9.5 \\
9.5 \\
9.2 \\
8.6 \\
---- \\
-----\end{array}$ \\
\hline \multicolumn{7}{|c|}{ 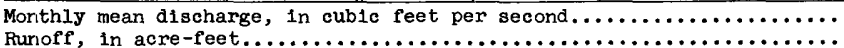 } & $\begin{array}{r}42.6 \\
2,620\end{array}$ & $\begin{array}{r}145 \\
8,070\end{array}$ \\
\hline
\end{tabular}

Gage he1ght, in feet, and discharge, in cub1c feet per second, at indicated t1me, 1963

\begin{tabular}{|c|c|c|c|c|c|c|c|c|c|c|c|}
\hline Date & Hour & $\begin{array}{c}\text { Gage } \\
\text { he1ght }\end{array}$ & $\begin{array}{l}\text { Dis - } \\
\text { charge }\end{array}$ & Date & \multirow{3}{*}{$\begin{array}{l}\text { Hour } \\
1700 \\
1800 \\
2100 \\
2300 \\
2400\end{array}$} & \multirow{3}{*}{$\begin{array}{r}\begin{array}{c}\text { Gage } \\
\text { he1ght }\end{array} \\
7.74 \\
7.83 \\
9.45 \\
11.20 \\
11.42\end{array}$} & \multirow{3}{*}{$\begin{array}{c}\begin{array}{c}\text { D1s- } \\
\text { charge }\end{array} \\
1,630 \\
1,690 \\
2,860 \\
4,520 \\
4,760\end{array}$} & Date & $\boldsymbol{u r}$ & $\begin{array}{c}\text { Gage } \\
\text { helght }\end{array}$ & $\begin{array}{c}\text { D1s- } \\
\text { charge }\end{array}$ \\
\hline Jan. 29 & 2400 & 1.75 & 7.1 & Jan. 31 & & & & Feb, 2 & 0300 & 6.26 & 904 \\
\hline 30 & $\begin{array}{l}0200 \\
0500 \\
0900 \\
1300 \\
1900 \\
2400\end{array}$ & $\begin{array}{l}1.78 \\
1.91 \\
2.28 \\
2.50 \\
2.57 \\
2.54\end{array}$ & $\begin{array}{l}7.8 \\
12 \\
29 \\
44 \\
50 \\
47\end{array}$ & Feb. 1 & & & & & $\begin{array}{l}0600 \\
0900 \\
1400 \\
1900 \\
2100 \\
2200 \\
2300\end{array}$ & $\begin{array}{l}5.94 \\
5.71 \\
5.43 \\
3.52 \\
3.63 \\
3.63 \\
3.45\end{array}$ & $\begin{array}{l}776 \\
694 \\
609 \\
153 \\
170 \\
170 \\
143\end{array}$ \\
\hline 31 & $\begin{array}{l}0200 \\
0300 \\
0600 \\
0900 \\
1100 \\
1200 \\
1500\end{array}$ & $\begin{array}{l}2.54 \\
3.81 \\
3.61 \\
3.55 \\
3.78 \\
4.03 \\
6.70\end{array}$ & $\begin{array}{r}47 \\
202 \\
167 \\
158 \\
196 \\
246 \\
1,090\end{array}$ & & $\begin{array}{l}0800 \\
1200 \\
1400 \\
1700 \\
1800 \\
2100 \\
2400\end{array}$ & $\begin{array}{r}11.15 \\
8.76 \\
8.08 \\
7.70 \\
7.81 \\
7.17 \\
6.73\end{array}$ & $\begin{array}{l}4,470 \\
2,320 \\
1,850 \\
1,610 \\
1,680 \\
1,310 \\
1,100\end{array}$ & 3 & $\begin{array}{l}2400 \\
0600 \\
1200 \\
1800 \\
2400\end{array}$ & $\begin{array}{l}3.43 \\
3.21 \\
3.00 \\
2.77 \\
2.63\end{array}$ & $\begin{array}{r}105 \\
83 \\
62 \\
50\end{array}$ \\
\hline
\end{tabular}


11-3335. North Fork Cosumnes River near El Dorado, Calif.

Location.--Lat $38^{\circ} 35^{\prime} 20^{\prime \prime}$, long $120^{\circ} 50^{\prime} 38^{\prime \prime}$, in SW $\frac{1}{4}$ sec.35, T.9 N., R.10 E., on downstream side of left abutment of county road bridge, 0.8 mile north of Nashville, 2.6 miles upstream from mouth, and 6 miles south of Ei Dorado.

Drainage area. $--205 \mathrm{sq} \mathrm{m} 1$.

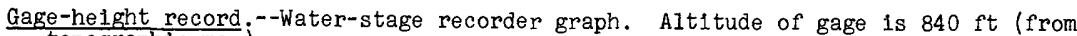
topographic map).

Discharge record.--Stage-discharge relation defined by current-meter measurements below $3,600 \mathrm{cfs}$ and by slope-area measurement at $15,800 \mathrm{cfs}$.

Maxima.--January-February 1963: Discharge, 12,800 ofs 0500 hours Feb. 1 (gage he1ght, $13.45 \mathrm{ft}$ ).

1911-41, 1948 to December 1962: Discharge, 15,800 cfs Dec. 23, 1955 (gage height, $14.8 \mathrm{ft}$ ).

Remarks.--Flow partly regulated since January 1955 by Jenkinson Lake (usable capacity, 40,570 acre-ft).

Mean discharge, in cublc feet per second, 1963

\begin{tabular}{|c|c|c|c|c|c|c|c|c|}
\hline Day & January & February & Day & January & February & Day & January & February \\
\hline $\begin{array}{c}1 \ldots \ldots \\
2 \ldots \ldots \\
3 \ldots \ldots \\
5 \ldots \ldots \\
6 \ldots \ldots \\
7 \ldots \ldots \\
9 \ldots \ldots \\
10 \ldots \ldots\end{array}$ & $\begin{array}{l}38 \\
34 \\
34 \\
34 \\
34 \\
32 \\
32 \\
31 \\
30 \\
30\end{array}$ & $\begin{array}{r}8,520 \\
2,170 \\
983 \\
638 \\
483 \\
364 \\
304 \\
260 \\
236 \\
224\end{array}$ & $\begin{array}{l}11 \ldots \ldots \\
12 \ldots \ldots \\
13 \ldots \ldots \\
14 \ldots \ldots \\
15 \ldots \ldots \\
16 \ldots \ldots \\
17 \ldots \ldots \\
18 \ldots \ldots \\
19 \ldots \ldots \\
20 \ldots \ldots\end{array}$ & $\begin{array}{l}29 \\
25 \\
17 \\
23 \\
27 \\
29 \\
27 \\
27 \\
26 \\
26\end{array}$ & $\begin{array}{l}209 \\
182 \\
388 \\
385 \\
280 \\
248 \\
226 \\
202 \\
180 \\
168\end{array}$ & $\begin{array}{l}21 \ldots \ldots \\
22 \ldots \ldots \\
23 \ldots \ldots \\
24 \ldots \ldots \\
25 \ldots \ldots \\
26 \ldots \ldots \\
27 \ldots \ldots \\
28 \ldots \ldots \\
29 \ldots \ldots \\
30 \ldots \ldots \\
31 \ldots \ldots\end{array}$ & $\begin{array}{r}25 \\
26 \\
25 \\
25 \\
25 \\
25 \\
24 \\
25 \\
25 \\
168 \\
2,770\end{array}$ & $\begin{array}{r}155 \\
144 \\
131 \\
123 \\
115 \\
110 \\
105 \\
99 \\
---.-\end{array}$ \\
\hline nthly & 40 & & & & & & $\begin{array}{r}121 \\
7,430 \\
\end{array}$ & $\begin{array}{r}630 \\
34,970 \\
\end{array}$ \\
\hline
\end{tabular}

Gage height, In feet, and discharge, In cublc feet per second, at indicated time, 1963

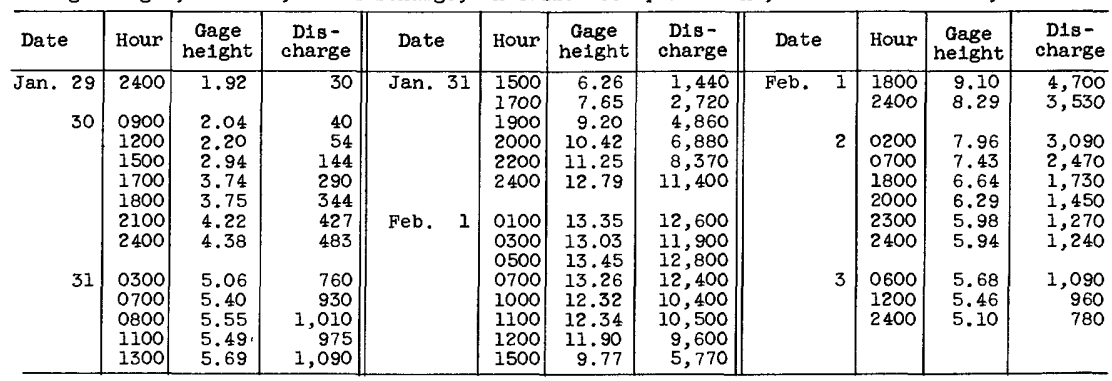


11-3342. Middle Fork Cosumnes River near Somerset, Calif'.

Location.--Lat $38^{\circ} 37^{\prime} 29^{\prime \prime}$, long $120^{\circ} 42^{1} 02^{\prime \prime}$, in NW $\frac{1}{4} N W \frac{1}{4}$ sec.19, T.9 N., R.12 E., on left bank 1,000 ft downstream from county road bridge, 0.2 mile downstream from Perry Creek, and 1.8 miles southwest of Somerset.

Drainage area. $--107 \mathrm{sq} \mathrm{ml}$.

Gage-height record.--Water-stage recorder graph, except Jan. 12-15. Datum of gage is $1,647.95 \mathrm{ft}$ above mean sea level (datum of 1929).

Discharge record.--Stage-discharge relation defined by current-meter measurements below 2,500 cfs and by computation of flow over dam at 11,800 cfs; affected by ice Jan. 6-11, 16-22. Discharge for Jan. 12-15 estimated on basis of hydrographic comparison with Cosumnes River at Michigan Bar and North Fork Cosumnes River near El Dorado.

Maxima --January-February 1963: Discharge, 11,800 cfs 0230 hours Feb. 1 (gage height, $16.20 \mathrm{ft}$, from recorder graph; $17.4 \mathrm{ft}$, from floodmarks).

1955 to December 1962: Discharge, about 13,500 cfs Dec. 23, i955 (gage height, $18.1 \mathrm{ft}$, from floodmarks).

Mean discharge, in cubic feet per second, 1963

\begin{tabular}{|c|c|c|c|c|c|c|c|c|}
\hline Day & January & February & Day & January & February & Day & January & February \\
\hline $\begin{array}{r}1 \ldots \ldots \\
3 \ldots \ldots \\
4 \ldots \ldots \\
5 \ldots \ldots \\
6 \ldots \ldots \\
8 \ldots \ldots \\
9 \ldots \ldots \\
10 \ldots \ldots\end{array}$ & $\begin{array}{l}34 \\
31 \\
32 \\
32 \\
29 \\
29 \\
29 \\
28 \\
27 \\
26\end{array}$ & $\begin{array}{r}7,580 \\
2,290 \\
1,180 \\
776 \\
554 \\
463 \\
380 \\
330 \\
298 \\
300\end{array}$ & $\begin{array}{l}11 \ldots \ldots \\
12 \ldots \ldots \\
13 \ldots \ldots \\
14 \ldots \ldots \\
15 \ldots \ldots \\
16 \ldots \ldots \\
17 \ldots \ldots \\
18 \ldots \ldots \\
19 \ldots \ldots \\
20 \ldots \ldots\end{array}$ & $\begin{array}{l}23 \\
19 \\
15 \\
18 \\
23 \\
25 \\
24 \\
24 \\
23 \\
22\end{array}$ & $\begin{array}{l}269 \\
242 \\
368 \\
352 \\
298 \\
278 \\
254 \\
236 \\
216 \\
204\end{array}$ & $\begin{array}{l}21 \ldots \ldots \\
22 \ldots \ldots \\
23 \ldots \ldots \\
24 \ldots \ldots \\
25 \ldots \ldots \\
26 \ldots \ldots \\
27 \ldots \ldots \\
28 \ldots \ldots \\
29 \ldots \ldots \\
30 \ldots \ldots \\
31 \ldots \ldots\end{array}$ & $\begin{array}{r}23 \\
23 \\
23 \\
23 \\
22 \\
22 \\
22 \\
22 \\
25 \\
285 \\
3,320\end{array}$ & $\begin{array}{r}192 \\
179 \\
163 \\
153 \\
146 \\
144 \\
146 \\
135 \\
----- \\
---1-\end{array}$ \\
\hline \multicolumn{7}{|l|}{$\begin{array}{l}\text { Monthiy } \\
\text { Runoff, } \\
\text { Runoff, }\end{array}$} & $\begin{array}{r}139 \\
1.50 \\
8,570\end{array}$ & $\begin{array}{r}647 \\
6.30 \\
35,950\end{array}$ \\
\hline
\end{tabular}

Gage height, in feet, and discharge, in cubic feet per second, at indicated time, 1963

\begin{tabular}{|c|c|c|c|c|c|c|c|c|c|c|c|}
\hline Date & Hour & $\begin{array}{c}\text { Gage } \\
\text { helght }\end{array}$ & $\begin{array}{l}\text { Dis- } \\
\text { charge }\end{array}$ & Date & Hour & $\begin{array}{c}\text { Gage } \\
\text { he1ght }\end{array}$ & $\begin{array}{l}\text { Dis- } \\
\text { charge }\end{array}$ & Date & Hour & $\begin{array}{c}\text { Gage } \\
\text { helght }\end{array}$ & $\begin{array}{c}\text { Dis- } \\
\text { charge }\end{array}$ \\
\hline $\begin{array}{r}\text { Jan. } 29 \\
30\end{array}$ & $\begin{array}{l}2400 \\
0400 \\
0600 \\
1100 \\
1700 \\
1900 \\
2100 \\
2400 \\
0100 \\
0200 \\
0700\end{array}$ & $\begin{array}{l}3.52 \\
3.70 \\
3.90 \\
4.82 \\
5.58 \\
5.98 \\
7.28 \\
8.16 \\
8.43 \\
8.54 \\
8.25\end{array}$ & $\begin{array}{r}28 \\
36 \\
47 \\
141 \\
276 \\
370 \\
812 \\
1,240 \\
1,400 \\
1,470 \\
1,290\end{array}$ & Feb. 1 & $\begin{array}{l}1200 \\
1600 \\
2000 \\
2300 \\
2400 \\
\\
0230 \\
0500 \\
0700 \\
0900 \\
1000 \\
1300 \\
1600\end{array}$ & $\begin{array}{r}9.11 \\
11.28 \\
12.50 \\
15.00 \\
15.42 \\
16.20 \\
16.05 \\
15.48 \\
15.19 \\
15.20 \\
12.85 \\
11.88\end{array}$ & $\begin{array}{r}1,870 \\
3,860 \\
5,400 \\
9,500 \\
10,300 \\
11,800 \\
11,500 \\
10,400 \\
9,840 \\
9,860 \\
5,890 \\
4,580\end{array}$ & Feb. & $\begin{array}{l}1800 \\
1900 \\
2400 \\
\\
0100 \\
1000 \\
2400 \\
\\
0800 \\
1600 \\
2400\end{array}$ & $\begin{array}{r}11.70 \\
11.90 \\
10.90 \\
10.63 \\
9.63 \\
8.68 \\
8.14 \\
7.80 \\
7.59\end{array}$ & $\begin{array}{r}4,360 \\
4,600 \\
3,460 \\
3,190 \\
2,280 \\
1,570 \\
1,220 \\
1,050 \\
945\end{array}$ \\
\hline
\end{tabular}

11-3343. South Fork Cosumnes River near River Pines, Calif.

Location.--Lat $38^{\circ} 33^{\prime} 25^{\prime \prime}$, long $120^{\circ} 47^{\prime} 32^{\prime \prime}$, in SE $\frac{1}{4} \mathrm{SW} \frac{1}{4} \sec .8$, T. $8 \mathrm{~N} ., \mathrm{R} .11 \mathrm{E}$., on left bank 2.4 miles upstream from mouth and 2.7 miles west of River Pines.

Drainage area. $--64.3 \mathrm{sq} \mathrm{ml}$.

Gage-height record -Water-stage recorder graph. Altitude of gage is $1,220 \mathrm{ft}$ (from topographic map).

Discharge record.--Stage-discharge relation defined by current-meter measurements below $1,900 \mathrm{cfs}$ and by slope-area measurement at $4,740 \mathrm{cfs}$.

Maxima.--January-February 1963: Discharge, 5,540 cfs 0700 hours Feb. I (gage height, $10.90 \mathrm{ft}$ ).

1957 to December 1962: Discharge, 4,740 cf's Apr. 3, 1958 (gage height, $9.90 \mathrm{ft}$ ). 
Mean discharge, In cub1c feet per second, 1963, of South Fork Cosumnes R1ver near R1ver P1nes, Calif.

\begin{tabular}{|c|c|c|c|c|c|c|c|c|}
\hline Day & January & February & Day & January & February & Day & January & February \\
\hline $\begin{array}{r}1 \ldots \ldots \\
2 \ldots \ldots \\
3 \ldots \ldots \\
4 \ldots \ldots \\
5 \ldots \ldots \\
6 \ldots \ldots \\
8 \ldots \ldots \\
9 \ldots \ldots \\
10 \ldots \ldots\end{array}$ & $\begin{array}{l}8.9 \\
8.3 \\
8.3 \\
8.3 \\
8.0 \\
7.7 \\
7.7 \\
7.1 \\
7.4 \\
7.1\end{array}$ & $\begin{array}{r}2,430 \\
447 \\
220 \\
144 \\
104 \\
78 \\
64 \\
56 \\
52 \\
56\end{array}$ & $\begin{array}{l}11 \ldots \ldots \\
12 \ldots \ldots \\
13 \ldots \ldots \\
14 \ldots \ldots \\
15 \ldots \ldots \\
16 \ldots \ldots \\
17 \ldots \ldots \\
18 \ldots \ldots \\
19 \ldots \ldots \\
20 \ldots \ldots\end{array}$ & $\begin{array}{l}6.8 \\
5.3 \\
5.1 \\
6.1 \\
5.9 \\
5.9 \\
5.9 \\
5.5 \\
6.1 \\
5.5\end{array}$ & $\begin{array}{r}50 \\
46 \\
175 \\
136 \\
90 \\
72 \\
63 \\
55 \\
50 \\
47\end{array}$ & $\begin{array}{l}21 \ldots \ldots \\
22 \ldots \ldots \\
23 \ldots \ldots \\
24 \ldots \ldots \\
25 \ldots \ldots \\
26 \ldots \ldots \\
27 \ldots \ldots \\
28 \ldots \ldots \\
29 \ldots \ldots \\
30 \ldots \ldots \\
31 \ldots \ldots\end{array}$ & $\begin{array}{r}5.5 \\
5.5 \\
5.9 \\
5.9 \\
5.9 \\
5.7 \\
5.9 \\
5.9 \\
6.4 \\
108 \\
1,180\end{array}$ & $\begin{array}{r}43 \\
41 \\
37 \\
35 \\
34 \\
32 \\
30 \\
29 \\
-\ldots--\end{array}$ \\
\hline \multicolumn{7}{|c|}{ 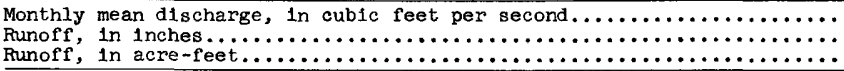 } & $\begin{array}{r}47.7 \\
0.85 \\
2,930\end{array}$ & $\begin{array}{r}168 \\
2.73 \\
9,350\end{array}$ \\
\hline
\end{tabular}

Gage he1ght, in feet, and discharge, in cubic feet per second, at 1nd1cated t1me, 1963

\begin{tabular}{|c|c|c|c|c|c|c|c|c|c|c|c|}
\hline Date & Hour & $\begin{array}{c}\text { Gage } \\
\text { he1ght }\end{array}$ & $\begin{array}{l}\text { D1s- } \\
\text { charge }\end{array}$ & Date & Hour & $\begin{array}{c}\text { Gage } \\
\text { he1ght }\end{array}$ & $\begin{array}{c}\text { D1s- } \\
\text { charge }\end{array}$ & Date & Hour & $\begin{array}{c}\text { Gage } \\
\text { he1ght }\end{array}$ & $\begin{array}{l}\text { D1B- } \\
\text { charge }\end{array}$ \\
\hline $\begin{array}{r}\text { Jan. } 29 \\
30\end{array}$ & $\begin{array}{l}2400 \\
0600 \\
0900 \\
1200 \\
1500 \\
1900 \\
2100 \\
2400 \\
0900 \\
1500 \\
\end{array}$ & $\begin{array}{r}0.79 \\
\\
.88 \\
1.01 \\
1.37 \\
2.02 \\
2.36 \\
2.47 \\
3.22 \\
3.22 \\
4.40 \\
\end{array}$ & $\begin{array}{r}6.8 \\
9.6 \\
16 \\
40 \\
126 \\
202 \\
230 \\
489 \\
\\
489 \\
I, 180 \\
\end{array}$ & Feb. I & $\begin{array}{l}1600 \\
1800 \\
2000 \\
2100 \\
2400 \\
\\
0100 \\
0300 \\
0400 \\
0500 \\
0600 \\
0700\end{array}$ & $\begin{array}{r}4.17 \\
4.38 \\
5.96 \\
7.05 \\
8.56 \\
8.86 \\
7.53 \\
7.10 \\
7.46 \\
9.68 \\
10.90 \\
\end{array}$ & $\begin{array}{l}1,030 \\
1,170 \\
2,130 \\
2,790 \\
3,790 \\
4,000 \\
3,100 \\
2,820 \\
3,050 \\
4,580 \\
5,540\end{array}$ & Feb. 1 & $\begin{array}{l}0800 \\
1000 \\
1300 \\
1500 \\
1600 \\
1900 \\
2400 \\
\\
0900 \\
1600 \\
2400\end{array}$ & $\begin{array}{l}9.24 \\
7.05 \\
5.38 \\
5.00 \\
4.93 \\
4.33 \\
3.68 \\
\\
3.14 \\
2.89 \\
2.67\end{array}$ & $\begin{array}{r}4,270 \\
2,790 \\
1,840 \\
1,600 \\
1,550 \\
1,130 \\
728 \\
\\
456 \\
356 \\
286\end{array}$ \\
\hline
\end{tabular}

11-3350. Cosumnes River at Michigan Bar, Calif.

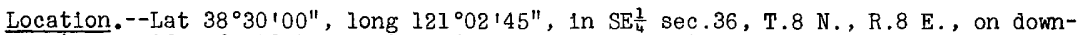
stream side of midstream pier of highway bridge at Michigan Bar, 5.5 miles southwest of Latrobe and 12 miles downstream from confluence of North and Middle Forks.

Drainage area. $-537 \mathrm{sq} \mathrm{ml}$.

Gage-height record.--Water-stage recorder graph. Datum of gage is $168.09 \mathrm{ft}$ above mean sea level, datum of 1929.

Discharge record.--Stage-discharge relation defined by current-meter measurements.

Maxima.--January-February 1963: Discharge, 39,400 cfs 0900 hours Feb. 1 (gage helght, $14.11 \mathrm{ft}$ ).

1907 to December 1962: Discharge, $42,000 \mathrm{cfs}$ Dec. 23, 1955 (gage height, $14.59 \mathrm{ft}$ ); maximum gage height, $16.3 \mathrm{ft}$ in March 1907.

Remarks.--Flow partly regulated by Jenkinson Lake (usable capacity, 40,570 acre-ft).

Mean d1scharge, in cublc feet per second, 1963

\begin{tabular}{|c|c|c|c|c|c|c|c|c|}
\hline Day & January & February & Day & January & February & Day & January & February \\
\hline $\begin{array}{c}1 \ldots \ldots \\
2 \ldots \ldots \\
3 \ldots \ldots \\
5 \ldots \ldots \\
6 \ldots \ldots \\
7 \ldots \ldots \\
8 \ldots \ldots \\
9 \ldots \ldots \\
10 \ldots \ldots\end{array}$ & $\begin{array}{l}94 \\
89 \\
87 \\
87 \\
85 \\
80 \\
78 \\
78 \\
76 \\
73\end{array}$ & $\begin{array}{r}26,700 \\
7,380 \\
3,140 \\
2,140 \\
1,710 \\
1,360 \\
1,120 \\
950 \\
820 \\
830\end{array}$ & $\begin{array}{l}11 \ldots \ldots \\
12 \ldots \ldots \\
13 \ldots \ldots \\
14 \ldots \ldots \\
15 \ldots \ldots \\
16 \ldots \ldots \\
17 \ldots \ldots \\
18 \ldots \ldots \\
19 \ldots \ldots \\
20 \ldots \ldots\end{array}$ & $\begin{array}{l}71 \\
68 \\
47 \\
45 \\
59 \\
70 \\
70 \\
66 \\
63 \\
62\end{array}$ & $\begin{array}{r}746 \\
643 \\
1,820 \\
1,630 \\
1,110 \\
940 \\
830 \\
714 \\
622 \\
573\end{array}$ & $\begin{array}{l}21 \ldots \ldots \\
22 \ldots \ldots \\
23 \ldots \ldots \\
24 \ldots \ldots \\
25 \ldots \ldots \\
26 \ldots \ldots \\
27 \ldots \ldots \\
28 \ldots \ldots \\
29 \ldots \ldots \\
30 \ldots \ldots \\
31 \ldots \ldots\end{array}$ & $\begin{array}{r}62 \\
62 \\
60 \\
59 \\
59 \\
59 \\
57 \\
57 \\
59 \\
187 \\
6,540\end{array}$ & $\begin{array}{r}504 \\
468 \\
390 \\
390 \\
360 \\
338 \\
322 \\
302 \\
----- \\
-----\end{array}$ \\
\hline noff, & acre- & & & & & & $\begin{array}{r}281 \\
0.60 \\
17,270 \\
\end{array}$ & $\begin{array}{r}2,102 \\
4.08 \\
116,700 \\
\end{array}$ \\
\hline
\end{tabular}


Gage helght, in feet, and discharge, in cuble feet per second, at indicated time, 1963, of Cosumnes River at Michigan Bar, Calif.

\begin{tabular}{|c|c|c|c|c|c|c|c|c|c|c|c|c|}
\hline Date & Hour & $\begin{array}{c}\text { Gage } \\
\text { helght }\end{array}$ & $\begin{array}{c}\text { Dis- } \\
\text { charge }\end{array}$ & Date & Hour & $\begin{array}{c}\text { Gage } \\
\text { height }\end{array}$ & $\begin{array}{c}\text { D1s- } \\
\text { charge }\end{array}$ & \multicolumn{2}{|l|}{ Date } & Hour & $\begin{array}{c}\text { Qage } \\
\text { height }\end{array}$ & $\begin{array}{l}\text { D1s- } \\
\text { charge }\end{array}$ \\
\hline Jan. 29 & 2400 & 2.63 & 65 & Jan. 31 & 1600 & 6.74 & 5,460 & Feb. & 1 & 2400 & 8.60 & 12,800 \\
\hline 30 & $\begin{array}{l}0700 \\
1200 \\
1500 \\
1800 \\
2100\end{array}$ & $\begin{array}{l}2.68 \\
2.78 \\
2.87 \\
3.09 \\
3.53\end{array}$ & $\begin{array}{r}73 \\
90 \\
109 \\
164 \\
322\end{array}$ & & $\begin{array}{l}1000 \\
2100 \\
2300 \\
2400\end{array}$ & $\begin{array}{r}8.62 \\
9.29 \\
10.83 \\
11.61\end{array}$ & $\begin{array}{l}12,900 \\
15,700 \\
22,600 \\
26,400\end{array}$ & & 2 & $\begin{array}{l}0600 \\
1200 \\
1800 \\
2100 \\
2400\end{array}$ & $\begin{array}{l}7.68 \\
7.13 \\
6.74 \\
6.58 \\
6.34\end{array}$ & $\begin{array}{l}8,690 \\
6,830 \\
5,460 \\
4,940 \\
4,200\end{array}$ \\
\hline & $\begin{array}{l}2200 \\
2300 \\
2400\end{array}$ & $\begin{array}{l}4.00 \\
4.38 \\
4.53\end{array}$ & $\begin{array}{r}580 \\
890 \\
1,040\end{array}$ & Feb. 1 & $\begin{array}{l}0200 \\
0400 \\
0700\end{array}$ & $\begin{array}{l}12.70 \\
12.96 \\
13.88\end{array}$ & $\begin{array}{l}31,900 \\
33,200 \\
38,100\end{array}$ & & 3 & $\begin{array}{l}0200 \\
0800\end{array}$ & $\begin{array}{l}6.22 \\
6.01\end{array}$ & $\begin{array}{l}3,860 \\
3,320\end{array}$ \\
\hline 31 & $\begin{array}{l}0200 \\
0600\end{array}$ & $\begin{array}{l}4.74 \\
5.73\end{array}$ & $\begin{array}{l}1,280 \\
2,740\end{array}$ & & $\begin{array}{l}0900 \\
1100\end{array}$ & $\begin{array}{l}14.11 \\
12.99\end{array}$ & $\begin{array}{l}39,400 \\
33,400\end{array}$ & & & 2400 & 5.59 & 2,480 \\
\hline & $\begin{array}{l}0800 \\
1100 \\
1200 \\
1400\end{array}$ & $\begin{array}{l}5.89 \\
6.00 \\
6.10 \\
6.22\end{array}$ & $\begin{array}{l}3,060 \\
3,300 \\
3,540 \\
3,860\end{array}$ & & $\begin{array}{l}1300 \\
1600 \\
1800 \\
2100\end{array}$ & $\begin{array}{r}12.14 \\
10.32 \\
9.58 \\
8.99\end{array}$ & $\begin{array}{l}29,100 \\
20,300 \\
17,000 \\
14,400\end{array}$ & & 4 & $\begin{array}{l}0600 \\
1200 \\
1800 \\
2400\end{array}$ & $\begin{array}{l}5.46 \\
5.36 \\
5.27 \\
5.17\end{array}$ & $\begin{array}{l}2,280 \\
2,130 \\
2,000 \\
1,860\end{array}$ \\
\hline
\end{tabular}

11-3356.5. Deer Creek near Shingle Springs, Calif'.

(Crest-stage station)

Location.--Lat $38^{\circ} 39^{\prime} 30^{\prime \prime}$, long $120^{\circ} 59^{\prime} 25^{\prime \prime}$, in $\mathrm{SW} \frac{1}{4} \mathrm{SE} \frac{1}{4} \sec .4$, T.9 N., R.9 E., $3.5 \mathrm{~m} i l e s$ west of Shingle Springs.

Drainage area. $--6.62 \mathrm{sq} \mathrm{ml}$.

Gage-helght record.--Crest stages only. Alt1tude of gage is 1,070 ft (from topographic map).

D1scharge record.--Stage-discharge relation defined by computation of flow through culvert at 857 and $1,320 \mathrm{cfs}$.

Maxima.--January-February 1963: Discharge, $857 \mathrm{cfs}$ Feb. 1 (gage height, $9.20 \mathrm{ft}$ ). August to December 1962: Discharge, 1,320 cfs Oct. 13, 1962 (gage he1ght, $11.59 \mathrm{ft}$ from crest-stage gage; $11.67 \mathrm{ft}$, from high-water proflle).

11-3357. Deer Creek near Sloughhouse, Calif.

Location.--Lat $38^{\circ} 33^{\prime} 06^{\prime \prime}$, long $121^{\circ} 06^{\prime} 30^{\prime \prime}$, in NW $\frac{1}{4} N \frac{1}{4}^{\frac{1}{4}}$ sec.16, T.8 N., R.8 E., on right bank 0.2 mile upstream from bridge on Scott Road, 0.4 mile upstream from Little Deer Creek, and 5.9 miles northeast of Sloughhouse.

Drainage area $--46.0 \mathrm{sq} \mathrm{ml}$.

Gage-he1ght record ;- Water-stage recorder graph. Alt1tude of gage is 160 ft (from topographic map).

Discharge record.--Stage-discharge relation defined by current-meter measurements below $2,200 \mathrm{c}$ fs.

Maxima.--January-February 1963: Discharge, 3,550 cfs 2130 hours Jan. 31 (gage hel ght, $11.01 \mathrm{ft}$ ).

1959 to December 1962: D1scharge, 6,560 cfs 0ct. 13, 1962 (gage helght, $12.86 \mathrm{ft}$, from floodmarks).

Remarks.--Records furnished by California Department of Water Resources and reviewed by Geological Survey. 
Mean discharge, in cubic feet per second, 1963, of Deer Creek near Sloughhouse, Calff.

\begin{tabular}{|c|c|c|c|c|c|c|c|c|}
\hline Day & January & February & Day & January & February & Day & January & February \\
\hline $\begin{array}{c}1 \ldots \ldots \\
2 \ldots \ldots \\
3 \ldots \ldots \\
4 \ldots \ldots \\
6 \ldots \ldots \\
7 \ldots \ldots \\
8 \ldots \ldots \\
9 \ldots \ldots \\
10 \ldots \ldots\end{array}$ & $\begin{array}{l}5.0 \\
5.0 \\
4.8 \\
5.0 \\
4.8 \\
4.4 \\
4.4 \\
4.7 \\
3.9 \\
4.1\end{array}$ & $\begin{array}{r}1,150 \\
170 \\
72 \\
47 \\
35 \\
26 \\
23 \\
19 \\
18 \\
33\end{array}$ & $\begin{array}{l}11 \ldots \ldots \\
12 \ldots \ldots \\
13 \ldots \ldots \\
14 \ldots \ldots \\
15 \ldots \ldots \\
16 \ldots \ldots \\
17 \ldots \ldots \\
18 \ldots \ldots \\
19 \ldots \ldots \\
20 \ldots \ldots\end{array}$ & $\begin{array}{l}4.5 \\
3.9 \\
3.8 \\
4.0 \\
4.3 \\
4.4 \\
4.6 \\
4.3 \\
4.0 \\
4.3\end{array}$ & $\begin{array}{r}22 \\
21 \\
227 \\
88 \\
47 \\
33 \\
28 \\
25 \\
21 \\
18\end{array}$ & $\begin{array}{l}21 \ldots \ldots \\
22 \ldots \ldots \\
23 \ldots \ldots \\
24 \ldots \ldots \\
25 \ldots \ldots \\
26 \ldots \ldots \\
27 \ldots \ldots \\
28 \ldots \ldots \\
29 \ldots \ldots \\
30 \ldots \ldots \\
31 \ldots \ldots\end{array}$ & $\begin{array}{r}6.5 \\
7.8 \\
8.1 \\
7.1 \\
6.1 \\
5.6 \\
5.6 \\
6.3 \\
6.4 \\
64 \\
1,200 \\
\end{array}$ & 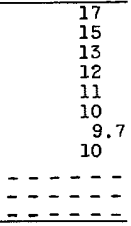 \\
\hline \multicolumn{7}{|c|}{ 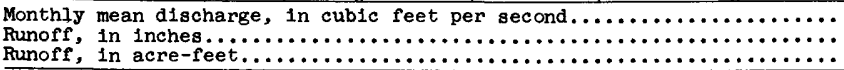 } & $\begin{array}{r}45.5 \\
1.14 \\
2,800 \\
\end{array}$ & $\begin{array}{r}79.3 \\
1.80 \\
4,400 \\
\end{array}$ \\
\hline
\end{tabular}

Gage helght, in feet, and discharge, in cublc feet per second, at indicated time, 1963

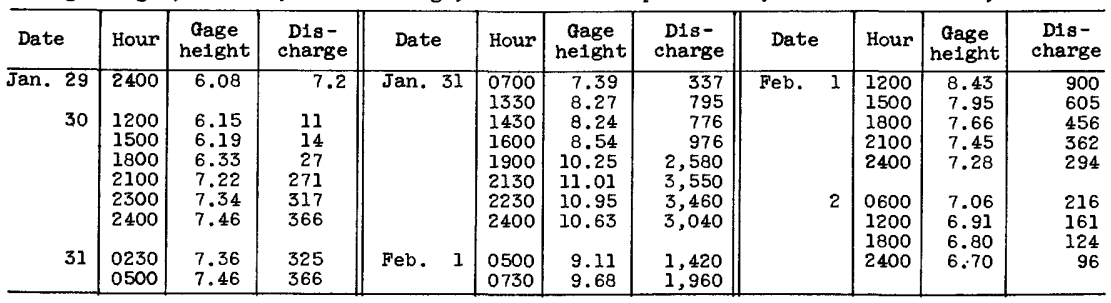

11-3360. Cosumnes River at McConnel1, Cal1f.

Location.--Lat $38^{\circ} 21^{\prime} 29^{\prime \prime}$, long $121^{\circ} 20^{\prime} 34^{\prime \prime}$, in sec.20, T.6 N., R.6 E., on downstream side of bridge on U.S. Highway $99,0.2$ mile south of McConneil, i mile downstream from Deer Creek, and 7 miles north of Galt.

Drainage area. $--724 \mathrm{sq} \mathrm{ml}$. $\frac{\text { Gage-helght record.--Water-stage recorder graph. Gage is set to datum of corps of }}{\text { Englneers. }}$

D1scharge record.--Stage-discharge relation def'lned by current-meter measurements.

Maxima.--January-February 1963: Discharge, 26,200 cfs 2200 hours Feb. I (gage helght, $45.52 \mathrm{ft}$ ).

1943 to December 1962: Discharge, 54,000 cfs Dec. 23, 1955 (gage helght, $46.26 \mathrm{ft}$ ).

Mean discharge, in cubic feet per second, 1963

\begin{tabular}{|c|c|c|c|c|c|c|c|c|}
\hline Day & January & February & Day & January & February & Day & J anuary & February \\
\hline $\begin{array}{r}1 \ldots . . \\
2 \ldots . . \\
3 \ldots \ldots \\
4 \ldots \ldots \\
5 \ldots \ldots \\
6 \ldots \ldots \\
7 \ldots \ldots \\
8 \ldots \ldots \\
9 \ldots \ldots \\
10 \ldots .\end{array}$ & $\begin{array}{l}70 \\
69 \\
64 \\
61 \\
59 \\
61 \\
59 \\
58 \\
58 \\
53\end{array}$ & $\begin{array}{r}14,600 \\
17,300 \\
5,030 \\
2,420 \\
1,740 \\
1,330 \\
1,080 \\
912 \\
795 \\
795\end{array}$ & 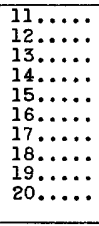 & $\begin{array}{l}53 \\
52 \\
49 \\
45 \\
37 \\
41 \\
52 \\
49 \\
46 \\
44\end{array}$ & $\begin{array}{r}783 \\
691 \\
1,470 \\
2,260 \\
1,290 \\
970 \\
835 \\
743 \\
644 \\
598\end{array}$ & $\begin{array}{l}21 \ldots \ldots \\
22, \ldots \ldots \\
23 \ldots \ldots \\
24 \ldots \ldots \\
25 \ldots \ldots \\
26 \ldots \ldots \\
27 \ldots \ldots \\
28 \ldots \ldots \\
30 \ldots \ldots \\
31 \ldots \ldots\end{array}$ & $\begin{array}{r}41 \\
43 \\
43 \\
44 \\
44 \\
44 \\
44 \\
43 \\
43 \\
51 \\
1,900 \\
\end{array}$ & $\begin{array}{r}549 \\
507 \\
473 \\
437 \\
407 \\
380 \\
353 \\
335 \\
---0 \\
-\end{array}$ \\
\hline no & & & & & & & $\begin{array}{r}110 \\
0.18 \\
6,780 \\
\end{array}$ & $\begin{array}{r}2,133 \\
3.07 \\
118,500 \\
\end{array}$ \\
\hline
\end{tabular}

Gage height, in feet, and discharge, in cubic feet per second, at indicated time, 1963

\begin{tabular}{|c|c|c|c|c|c|c|c|c|c|c|c|}
\hline Date & Hour & $\begin{array}{c}\text { Gage } \\
\text { height }\end{array}$ & $\begin{array}{c}\text { Dis- } \\
\text { charge }\end{array}$ & Date & Hour & $\begin{array}{c}\text { Gage } \\
\text { height }\end{array}$ & $\begin{array}{l}\text { Dis- } \\
\text { charge }\end{array}$ & Date & Hour & $\begin{array}{c}\text { Gage } \\
\text { helght }\end{array}$ & $\begin{array}{c}\text { Dis- } \\
\text { charge }\end{array}$ \\
\hline $\begin{array}{r}30 \\
31\end{array}$ & $\begin{array}{l}2400 \\
0400 \\
0600 \\
0700 \\
1000 \\
1300 \\
1700 \\
2100 \\
2400\end{array}$ & $\begin{array}{l}30.31 \\
30.45 \\
30.62 \\
30.86 \\
33.26 \\
35.19 \\
36.70 \\
38.00 \\
39.28\end{array}$ & $\begin{array}{r}56 \\
79 \\
107 \\
157 \\
924 \\
1,880 \\
3,000 \\
4,220 \\
5,760\end{array}$ & Feb. 1 & $\begin{array}{l}0300 \\
0400 \\
1000 \\
1200 \\
1400 \\
1700 \\
1830 \\
2200 \\
2400\end{array}$ & $\begin{array}{l}40.32 \\
40.30 \\
41.27 \\
42.50 \\
43.70 \\
44.58 \\
45.47 \\
45.52 \\
45.43\end{array}$ & $\begin{array}{r}7,150 \\
7,120 \\
8,740 \\
11,400 \\
15,400 \\
19,600 \\
25,900 \\
26,200 \\
25,600\end{array}$ & Feb. 2 & $\begin{array}{l}0600 \\
1200 \\
1800 \\
2400 \\
0900 \\
1500 \\
2100 \\
2400\end{array}$ & $\begin{array}{l}44.75 \\
43.99 \\
42.74 \\
41.30 \\
38.51 \\
37.70 \\
36.85 \\
36.56\end{array}$ & $\begin{array}{r}21,400 \\
17,600 \\
12,500 \\
8,650 \\
5,110 \\
4,000 \\
3,280 \\
3,070\end{array}$ \\
\hline
\end{tabular}


11-3365.80. Morrison Creek near Sacramento, Calif.

Location.--Lat $38^{\circ} 29^{\prime} 57^{\prime \prime}$, long $121^{\circ} 27^{\prime} 04^{\prime \prime}$, in NW $\frac{1}{4} \mathrm{SE}_{\frac{1}{4}}^{\frac{1}{2}}$ sec.32, T.8 N., R.5 E., on right bank $1,100 \mathrm{ft}$ upstream from Florin Road, 1.7 miles upstream from Elder Creek, and 2 miles south of Sacramento city limits.

Drainage area. $--48.6 \mathrm{sq} \mathrm{ml}$.

Gage-height record.--Water-stage recorder graph. Datum of gage is $19.93 \mathrm{ft}$ above mean sea level, datum of 1929 .

Discharge record.--Stage-discharge relation defined by current-meter measurements below 850 cfs

Maxima.--January-February 1963: Discharge, 1,010 cfs 0500 hours Feb. 1 (gage helght, $6.06 \mathrm{ft}$ )

1959 to December 1962: Discharge, 1,320 cfs Oct. 14, 1962 (gage height, $7.09 \mathrm{ft})$.

Mean discharge, in cublc feet per second, 1963

\begin{tabular}{|c|c|c|c|c|c|c|c|c|}
\hline Day & January & February & Day & January & February & Day & January & February \\
\hline $\begin{array}{c}1 \ldots \ldots \\
2 \ldots \ldots \\
3 \ldots \ldots \\
5 \ldots \ldots \\
6 \ldots \ldots \\
7 \ldots \ldots \\
9 \ldots \ldots \\
10 \ldots \ldots\end{array}$ & $\begin{array}{l}3.2 \\
4.3 \\
5.0 \\
5.0 \\
5.0 \\
6.7 \\
6.2 \\
5.8 \\
5.4 \\
5.4\end{array}$ & $\begin{array}{r}691 \\
157 \\
67 \\
44 \\
33 \\
26 \\
21 \\
22 \\
37 \\
70\end{array}$ & $\begin{array}{l}11 \ldots \ldots \\
12 \ldots \ldots \\
13 \ldots \ldots \\
14 \ldots \ldots \\
15 \ldots \ldots \\
16 \ldots \ldots \\
17 \ldots \ldots \\
18 \ldots \ldots \\
19 \ldots \ldots \\
20 \ldots \ldots\end{array}$ & $\begin{array}{l}4.7 \\
5.0 \\
5.8 \\
6.2 \\
6.7 \\
5.4 \\
5.4 \\
5.4 \\
5.4 \\
5.4\end{array}$ & $\begin{array}{r}39 \\
57 \\
232 \\
136 \\
53 \\
34 \\
26 \\
20 \\
16 \\
14\end{array}$ & $\begin{array}{l}21 \ldots \ldots \\
22 \ldots \ldots \\
23 \ldots \ldots \\
24 \ldots \ldots \\
25 \ldots \ldots \\
26 \ldots \ldots \\
27 \ldots \ldots \\
25 \ldots \ldots \\
29 \ldots \ldots \\
30 \ldots \ldots \\
31 \ldots \ldots\end{array}$ & $\begin{array}{r}5.0 \\
5.0 \\
5.4 \\
5.8 \\
5.8 \\
5.4 \\
5.8 \\
5.4 \\
13 \\
114 \\
462\end{array}$ & $\begin{array}{r}13 \\
11 \\
10 \\
8.6 \\
7.6 \\
6.7 \\
6.2 \\
6.2 \\
-\ldots--- \\
-\ldots-.-\end{array}$ \\
\hline \multicolumn{7}{|c|}{ 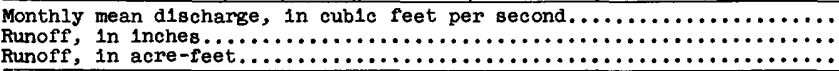 } & $\begin{array}{r}23.9 \\
0.57 \\
1,470\end{array}$ & $\begin{array}{r}66.6 \\
1.43 \\
3,700\end{array}$ \\
\hline
\end{tabular}

Gage he1ght, in feet, and discharge, in cub1c feet per second, at 1nd1cated t1me, 1963

\begin{tabular}{|c|c|c|c|c|c|c|c|c|c|c|c|}
\hline Date & Hour & $\begin{array}{c}\text { Gage } \\
\text { helght }\end{array}$ & $\begin{array}{c}\text { D1s- } \\
\text { charge }\end{array}$ & Date & Hour & $\begin{array}{c}\text { Gage } \\
\text { helght }\end{array}$ & $\begin{array}{c}\text { D1s - } \\
\text { charge }\end{array}$ & Date & Hour & $\begin{array}{c}\text { Gage } \\
\text { he1ght }\end{array}$ & $\begin{array}{c}\text { Dis- } \\
\text { charge }\end{array}$ \\
\hline $\begin{array}{r}\text { Jan. } 29 \\
30\end{array}$ & $\begin{array}{l}2400 \\
0200 \\
0400 \\
0500 \\
0900 \\
1400 \\
1500 \\
1700 \\
1900 \\
2000 \\
2200 \\
2400\end{array}$ & $\begin{array}{l}2.01 \\
1.96 \\
2.00 \\
1.97 \\
2.21 \\
2.59 \\
2.59 \\
3.02 \\
3.18 \\
3.11 \\
3.09 \\
2.82\end{array}$ & $\begin{array}{r}32 \\
27 \\
31 \\
28 \\
55 \\
120 \\
120 \\
210 \\
246 \\
230 \\
226 \\
166\end{array}$ & Feb. 1 & $\begin{array}{l}0300 \\
0500 \\
0700 \\
1000 \\
1400 \\
1500 \\
1700 \\
1800 \\
2100 \\
2400 \\
\\
0100 \\
0300\end{array}$ & $\begin{array}{l}3.15 \\
2.99 \\
3.02 \\
3.37 \\
4.15 \\
4.68 \\
5.34 \\
5.37 \\
5.24 \\
5.21 \\
5.35 \\
5.85\end{array}$ & $\begin{array}{l}239 \\
204 \\
210 \\
287 \\
471 \\
609 \\
793 \\
802 \\
765 \\
757 \\
796 \\
945\end{array}$ & Feb. 1 & $\begin{array}{l}0500 \\
0600 \\
1000 \\
1300 \\
1900 \\
2400 \\
\\
0300 \\
0700 \\
1600 \\
2400\end{array}$ & $\begin{array}{l}6.06 \\
6.03 \\
5.46 \\
4.92 \\
4.03 \\
3.40 \\
3.08 \\
2.86 \\
2.60 \\
2.44\end{array}$ & $\begin{array}{r}1,010 \\
999 \\
528 \\
676 \\
441 \\
294 \\
\\
224 \\
175 \\
122 \\
91\end{array}$ \\
\hline
\end{tabular}

11-3375. Marsh Creek near Byron, Calif.

Location.--Lat $37^{\circ} 52^{\prime} 25^{\prime \prime}$, long 121 $43^{\prime} 35^{\prime \prime}$, in Los Meganos Grant, on right bank $40 \mathrm{ft}$ downstream from highway bridge on Marsh Creek Road, 1.2 miles upstream from Marsh Creek Dam, and 5.0 miles west of Byron, Contra Costa County.

Drainage area. $--42.6 \mathrm{sq} \mathrm{mi}$.

Gage-height record.--Water-stage recorder graph. Datum of gage is $177.87 \mathrm{ft}$ above mean sea level, datum of 1929.

Discharge record.--Stage-discharge relation defined by current-meter measurements below $880 \mathrm{cf}$ 's and by slope-area measurement at 3,380 cfs. Backwater from Marsh Creek Reservoir 0900 hours Feb. I to 0600 hours Feb. 3.

Maxima.--January-February 1963: Discharge, 3,880 cfs 2230 hours Jan. 31 (gage height, $11.62 \mathrm{ft}$.

1953 to December 1962: Discharge, 3,800 cfs Dec. 23, 1955 (gage height, $12.98 \mathrm{ft}$ ), from rating curve extended above $320 \mathrm{cfs}$ on basis of slope-area measurement of peak flow. 
Mean discharge, In cub1c feet per second, 1963, of Marsh Creek near Byron, Cal1f.

\begin{tabular}{|c|c|c|c|c|c|c|c|c|}
\hline Day & January & February & Day & January & February & Day & January & February \\
\hline $\begin{array}{c}1 \ldots \ldots \\
2 \ldots \ldots \\
3 \ldots \ldots \\
4 \ldots \ldots \\
5 \ldots \ldots \\
7 \ldots \ldots \\
8 \ldots \ldots \\
9 \ldots \ldots \\
10 \ldots \ldots\end{array}$ & $\begin{array}{r}1.1 \\
1.1 \\
1.1 \\
1.0 \\
.9 \\
.8 \\
.6 \\
.6 \\
.6 \\
.6\end{array}$ & $\begin{array}{r}1,370 \\
232 \\
110 \\
60 \\
36 \\
28 \\
23 \\
20 \\
21 \\
35\end{array}$ & $\begin{array}{l}11 \ldots \ldots \\
12 \ldots \ldots \\
13 \ldots \ldots \\
14 \ldots \ldots \\
15 \ldots \ldots \\
16 \ldots \ldots \\
17 \ldots \ldots \\
18 \ldots \ldots \\
19 \ldots \ldots \\
20 \ldots \ldots\end{array}$ & $\begin{array}{l}0.5 \\
.3 \\
.4 \\
.2 \\
.2 \\
.2 \\
.2 \\
.4 \\
.3 \\
.2\end{array}$ & $\begin{array}{r}19 \\
40 \\
127 \\
52 \\
36 \\
31 \\
27 \\
22 \\
19 \\
17\end{array}$ & $\begin{array}{l}21 \ldots \ldots \\
22 \ldots \ldots \\
23 \ldots \ldots \\
24 \ldots \ldots \\
25 \ldots \ldots \\
26 \ldots \ldots \\
27 \ldots \ldots \\
28 \ldots \ldots \\
29 \ldots \ldots \\
30 \ldots \ldots \\
31 \ldots \ldots\end{array}$ & $\begin{array}{r}0.2 \\
.2 \\
.2 \\
.3 \\
.2 \\
.3 \\
.3 \\
.3 \\
20.4 \\
977\end{array}$ & $\begin{array}{c}16 \\
14 \\
13 \\
12 \\
12 \\
10 \\
10 \\
9.6 \\
---- \\
-\ldots--\end{array}$ \\
\hline $\begin{array}{l}\text { nethly } \\
\text { anoff, } \\
\text { anoff, }\end{array}$ & \multicolumn{6}{|c|}{ 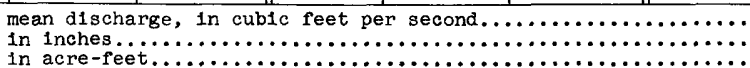 } & $\begin{array}{r}32.6 \\
0.88 \\
2,000\end{array}$ & $\begin{array}{r}86.5 \\
2.11 \\
4,800 \\
\end{array}$ \\
\hline
\end{tabular}

Gage he1ght, in feet, and discharge, in cublc feet per second, at indicated time, 1963

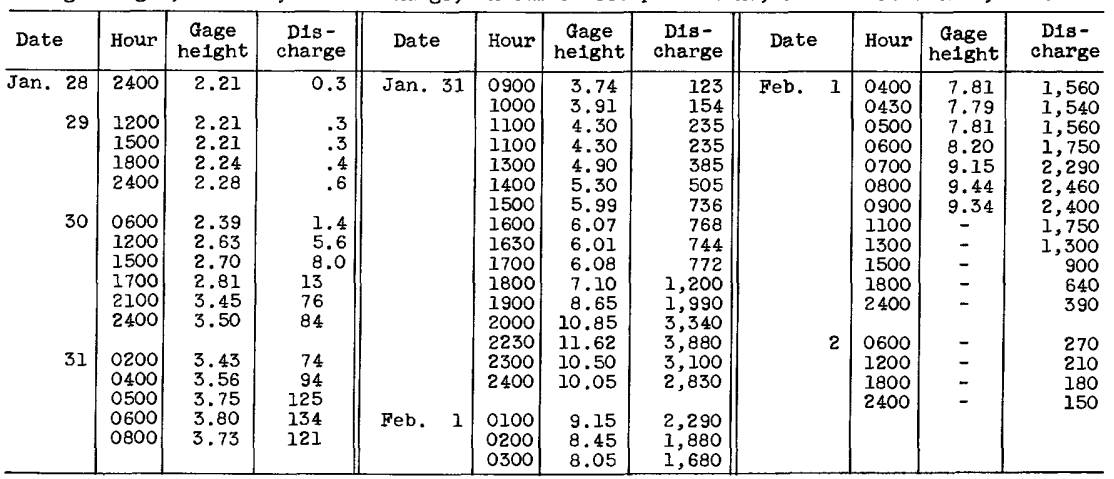

\section{SACRAMENTO VALIEYY}

\section{SACRAMENTO RIVER BASIN}

11-3415.5 Boulder Creek near La Molne, Calif.

\section{(Crest-stage station)}

Location.--Lat $41^{\circ} 01^{\prime} 00^{\prime \prime}$, long $122^{\circ} 24^{\prime} 15^{\prime \prime}$, in SW $\frac{1}{4} \mathrm{SE} \frac{1}{4} \sec .35$, T.37 N., R.5 W., on U.S. Highway $99,3.1$ miles northeast of La Moine.

Dra1nage area. $--6.57 \mathrm{sq} \mathrm{mi}$.

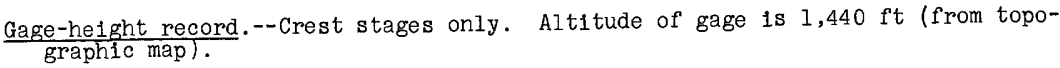

D1scharge record.--Stage-discharge relation defined by current-meter measurements below $443 \mathrm{cfs}$ and by computation of flow through culvert at 666 and $2,080 \mathrm{cfs}$.

Maxima.--January-February 1963: Discharge, $666 \mathrm{cfs}$ Jan. 31 (gage height, $32.59 \mathrm{ft}$ ). i960 to December 1962: Discharge, 2,080 of's oct. 12, 1962 (gage height,

$39.78 \mathrm{ft}$ ). 
11-3420. Sacramento River at Delta, Calif.

Location.--Lat $40^{\circ} 56^{1} 20^{\prime \prime}$, long $122^{\circ} 24^{\prime} 55^{\prime \prime}$, in NW $\frac{1}{4}$ sec.35, T.36 N., R.5 W., on left bank 0.2 mlle downstream from Dog Creek, 0.6 mile southeast of Delta, and 2.8 miles south of LaMolne.

Drainage area. $--425 \mathrm{sq} \mathrm{ml}$.

Gage helght record --Water-stage recorder graph. Datum of gage is $1,075.00 \mathrm{ft}$ above mean sea level (levels by Bureau of Reclamation).

Discharge record.--Stage-discharge relation defined by current-meter measurements below $19,000 \mathrm{cfs}$ and by slope-area measurement at $37,000 \mathrm{cfs}$.

Maxima.--January-February 1963: Discharge, 14,800 efs 1700 hours Jan. 31 (gage height $12.55 \mathrm{ft}$ ).

1944 to Decenber 1962: Discharge, 37,000 cfs Dec. 22, 1955 (gage height, $19.50 \mathrm{ft})$.

Mean discharge, In cub1c feet per second, 1963

\begin{tabular}{|c|c|c|c|c|c|c|c|c|}
\hline Day & January & February & Day & January & February & Day & January & February \\
\hline $\begin{array}{r}1 \ldots \ldots \\
2 \ldots \ldots \\
3 \ldots \ldots \\
4 \ldots \ldots \\
5 \ldots \ldots \\
6 \ldots \ldots \\
7 \ldots \ldots \\
8 \ldots \ldots \\
10 \ldots \ldots\end{array}$ & $\begin{array}{l}722 \\
700 \\
700 \\
672 \\
645 \\
625 \\
610 \\
590 \\
585 \\
570\end{array}$ & $\begin{array}{r}8,280 \\
5,370 \\
10,300 \\
7,400 \\
5,800 \\
4,550 \\
3,640 \\
3,340 \\
2,930 \\
2,730\end{array}$ & $\begin{array}{l}11 \ldots \ldots \\
12 \ldots \ldots \\
13 \ldots \ldots \\
14 \ldots \ldots \\
15 \ldots \ldots \\
16 \ldots \ldots \\
17 \ldots \ldots \\
18 \ldots \ldots \\
19 \ldots \ldots \\
20 \ldots \ldots\end{array}$ & $\begin{array}{l}528 \\
487 \\
505 \\
523 \\
514 \\
510 \\
496 \\
487 \\
474 \\
464\end{array}$ & $\begin{array}{l}2,370 \\
2,550 \\
4,600 \\
3,330 \\
2,710 \\
2,410 \\
2,130 \\
1,910 \\
1,760 \\
1,650\end{array}$ & $\begin{array}{l}21 \ldots \ldots \\
22 \ldots \ldots \\
23 \ldots \ldots \\
24 \ldots \ldots \\
25 \ldots \ldots \\
26 \ldots \ldots \\
27 \ldots \ldots \\
28 \ldots \ldots \\
29 \ldots \ldots \\
30 \ldots \ldots \\
31 \ldots \ldots\end{array}$ & $\begin{array}{r}469 \\
464 \\
456 \\
452 \\
448 \\
440 \\
436 \\
432 \\
444 \\
707 \\
7,560\end{array}$ & $\begin{array}{r}1,510 \\
1,400 \\
1,300 \\
1,240 \\
1,160 \\
1,120 \\
1,050 \\
999 \\
----- \\
--1--- \\
--.--\end{array}$ \\
\hline \multicolumn{7}{|c|}{ 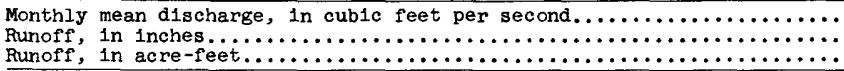 } & $\begin{array}{r}765 \\
2.07 \\
47,040\end{array}$ & $\begin{array}{r}3,198 \\
7.80 \\
177,600\end{array}$ \\
\hline
\end{tabular}

Gage height, in feet, and discharge, in cubic feet per second, at Indicated time, 1963

\begin{tabular}{|c|c|c|c|c|c|c|c|c|c|c|c|}
\hline Date & Hour & $\begin{array}{c}\text { Gage } \\
\text { he1ght }\end{array}$ & $\begin{array}{l}\text { Dis- } \\
\text { charge }\end{array}$ & Date & Hour & $\begin{array}{c}\text { Gage } \\
\text { height }\end{array}$ & $\begin{array}{c}\text { Dis- } \\
\text { charge }\end{array}$ & Date & Hour & $\begin{array}{c}\text { Gage } \\
\text { height }\end{array}$ & $\begin{array}{c}\text { Dis- } \\
\text { charge }\end{array}$ \\
\hline $\begin{array}{r}\text { Jan. } 30 \\
31\end{array}$ & $\begin{array}{l}2400 \\
0100 \\
0300 \\
0500 \\
0700 \\
1000 \\
1300 \\
1600 \\
1700 \\
1800 \\
2100 \\
2400\end{array}$ & $\begin{array}{r}5.62 \\
5.65 \\
5.91 \\
6.30 \\
6.91 \\
8.18 \\
10.22 \\
12.25 \\
12.55 \\
12.46 \\
12.00 \\
11.46\end{array}$ & $\begin{array}{r}1,200 \\
1,220 \\
1,450 \\
1,830 \\
2,490 \\
4,330 \\
8,410 \\
13,800 \\
14,800 \\
14,500 \\
13,100 \\
11,600\end{array}$ & Feb. & $\begin{array}{l}1400 \\
1600 \\
1800 \\
2100 \\
2400 \\
0600 \\
1000 \\
1300 \\
1600 \\
1900 \\
2200 \\
2400\end{array}$ & $\begin{array}{l}9.85 \\
9.86 \\
9.82 \\
9.51 \\
9.21 \\
8.68 \\
8.46 \\
8.42 \\
8.46 \\
8.71 \\
9.30 \\
9.68\end{array}$ & $\begin{array}{l}7,570 \\
7,590 \\
7,500 \\
6,820 \\
6,220 \\
5,190 \\
4,800 \\
4,730 \\
4,800 \\
5,250 \\
6,400 \\
7,200\end{array}$ & Feb. 3 & $\begin{array}{l}1400 \\
1900 \\
2400 \\
\\
0600 \\
1000 \\
1300 \\
1500 \\
1600 \\
1900 \\
2100 \\
2200 \\
2400\end{array}$ & $\begin{array}{r}11.47 \\
10.85 \\
10.28 \\
9.72 \\
9.41 \\
9.28 \\
9.36 \\
9.42 \\
10.35 \\
10.11 \\
10.06 \\
9.80\end{array}$ & $\begin{array}{r}11,600 \\
9,970 \\
8,550 \\
7,280 \\
6,620 \\
6,360 \\
6,520 \\
6,640 \\
8,720 \\
8,140 \\
8,030 \\
7,460\end{array}$ \\
\hline Feb. 1 & $\begin{array}{l}0100 \\
0300 \\
0700 \\
1200\end{array}$ & $\begin{array}{r}11.38 \\
11.11 \\
10.38 \\
9.73\end{array}$ & $\begin{array}{r}11,400 \\
10,600 \\
8,790 \\
7,310\end{array}$ & 3 & $\begin{array}{l}0500 \\
0600 \\
1000 \\
1200\end{array}$ & $\begin{array}{l}11.06 \\
11.12 \\
11.56 \\
11.61\end{array}$ & $\begin{array}{l}10,500 \\
10,700 \\
11,900 \\
12,000\end{array}$ & 5 & $\begin{array}{l}0400 \\
1000 \\
1600 \\
2400\end{array}$ & $\begin{array}{l}9.42 \\
9.03 \\
8.72 \\
8.44\end{array}$ & $\begin{array}{l}6,640 \\
5,860 \\
5,270 \\
4,770\end{array}$ \\
\hline
\end{tabular}

11-3645.5. W1110w Creek near Round Mountaln, Cal1f.

(Crest-stage station)

Location.--Lat $40^{\circ} 48^{\prime} 55^{\prime \prime}$, long $121^{\circ} 56^{\prime} 15^{\prime \prime}$, in $\mathrm{NW} \frac{1}{4} \mathrm{SE} \frac{1}{4} \sec .11$, T. $34 \mathrm{~N} ., \mathrm{R} .1 \mathrm{~W}$. , on U.S. Highway $299 \mathrm{E}, 1.4 \mathrm{mlles}$ north of Round Mountain.

Drainage area. $--2.61 \mathrm{sq} \mathrm{mi}$.

Gage-helght record.--Crest stages only. Altitude of gage is $2,080 \mathrm{ft}$ (from topographic mapl.

Discharge record.--Stage-discharge relation defined by current-meter measurements below $92 \mathrm{cf}$ s and by computation of flow through culvert at $784 \mathrm{cfs}$.

Maxima --January-February 1963: Discharge, $784 \mathrm{cfs} J a n .31$ (gage height, $18.72 \mathrm{ft}$ ). 1960 to December 1962: Discharge, $780 \mathrm{cfs}$ 0ct. 13, 1962 (gage helght,

$19.26 \mathrm{ft}$; backwater caused by debris). 
11-3650. Pit River near Montgomery Creek, Calif.

Location. - - Lat $40^{\circ} 51^{\prime} 10^{\prime \prime}$, long $121^{\circ} 58^{\prime} 30^{\prime \prime}$, in SW $\frac{1}{4} \mathrm{SE}_{\frac{1}{4}} \mathrm{sec} .28$, T.35 N., R.I W., on left bank 0.7 mile downstream from Hogback Creek and 3.0 miles west of town of Montgomery Creek. Prior to Feb. 17, 1963, at site 0.8 mile downstream.

Drainage area. $--5,170 \mathrm{sq} \mathrm{mi}$, approximately, excluding Goose Lake basin.

Gage-height record.--Water-stage recorder graph, except Jan. 1 to Feb. 16.

Discharge record.--Stage-discharge relation defined by current-meter measurements. Discharge for Jan. 1 to Feb. 16 estimated on basis of records of Pit No. 5 powerhouse.

Maxima.--January-February 1963: Daily discharge, 15,000 cfs Feb. 3.

14.1944 to December 1962: Discharge, 37,100 cfs Dec. 23, 1955 (gage he Ight,

Remarks:--Flow affected by many small reservolrs and several powerplants above station.

Mean discharge, in cuble feet per second, 1963

\begin{tabular}{|c|c|c|c|c|c|c|c|c|}
\hline Day & January & February & Day & January & February & Day & January & February \\
\hline $\begin{array}{r}1 \ldots \ldots \\
2 \ldots \ldots \\
3 \ldots \ldots \\
5 \ldots \ldots \\
6 \ldots \ldots \\
7 \ldots \ldots \\
9 \ldots \ldots \\
10 \ldots \ldots\end{array}$ & $\begin{array}{l}3,500 \\
4,500 \\
4,000 \\
3,800 \\
3,300 \\
2,700 \\
3,200 \\
3,300 \\
3,400 \\
3,400\end{array}$ & $\begin{array}{r}10,500 \\
13,000 \\
15,000 \\
14,000 \\
12,000 \\
10,000 \\
5,500 \\
7,500 \\
7,000 \\
6,500\end{array}$ & $\begin{array}{l}11 \ldots \ldots \\
12 \ldots \ldots \\
13 \ldots \ldots \\
14 \ldots \ldots \\
15 \ldots \ldots \\
16 \ldots \ldots \\
17 \ldots \ldots \\
18 \ldots \ldots \\
19 \ldots \ldots \\
20 \ldots \ldots\end{array}$ & $\begin{array}{l}3,400 \\
3,200 \\
1,600 \\
3,400 \\
3,300 \\
3,200 \\
3,000 \\
3,100 \\
2,500 \\
1,400\end{array}$ & $\begin{array}{l}6,000 \\
5,500 \\
5,600 \\
5,200 \\
5,000 \\
5,000 \\
5,310 \\
4,860 \\
4,830 \\
5,010\end{array}$ & $\begin{array}{l}21 \ldots \ldots \\
22 \ldots \ldots \\
23 \ldots \ldots \\
24 \ldots \ldots \\
25 \ldots \ldots \\
26 \ldots \ldots \\
27 \ldots \ldots \\
28 \ldots \ldots \\
29 \ldots \ldots \\
30 \ldots \ldots \\
31 \ldots \ldots\end{array}$ & $\begin{array}{l}3,000 \\
3,100 \\
3,300 \\
3,500 \\
3,300 \\
2,400 \\
2,200 \\
3,000 \\
3,600 \\
4,000 \\
6,000\end{array}$ & $\begin{array}{r}4,770 \\
4,710 \\
4,900 \\
4,930 \\
4,930 \\
4,500 \\
4,710 \\
4,580 \\
--.-- \\
---.-\end{array}$ \\
\hline $\begin{array}{l}\text { onthly } \\
\text { anoff, }\end{array}$ & dis &, 1 & feet $p$ & & & & $\begin{array}{r}3,245 \\
199,500 \\
\end{array}$ & $\begin{array}{r}6,941 \\
385,500 \\
\end{array}$ \\
\hline
\end{tabular}

11-3655. Squaw Creek above Shasta Lake, Cal1f.

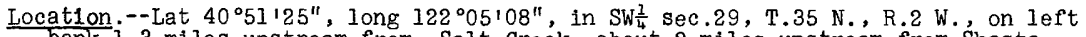
bank 1.3 miles upstream from Salt Creek, about 2 miles upstream from Shasta Lake, and 10 miles west of town of Montgomery Creek.

Drainage area. $--65.3 \mathrm{sq} \mathrm{mi}$.

Gage-height record.--Water-stage recorder graph, except Feb. 2-28. Alt1tude of gage is $1,170 \mathrm{ft}$ (from topographic map).

Discharge record.--Stage-discharge relation defined by current-meter measurements below 4,200 cfs and by slope-area measurement at $11,200 \mathrm{cfs}$. Discharge Feb. $2-28$ estimated on basis of records for Sacramento River at Delta.

Maxima.--January-February 1963: Discharge, 5,890 cfs 2000 hours Jan. 31 (gage height, $15.60 \mathrm{ft}$ ).

1944 to December 1962: Discharge, 17,800 cfs Dec. 21, 1955 (gage height, $21.90 \mathrm{ft})$.

Mean discharge, in cubic feet per second, 1963

\begin{tabular}{|c|c|c|c|c|c|c|c|c|}
\hline Day & January & February & Day & January & February & Day & January & February \\
\hline $\begin{array}{c}1 \ldots \ldots \\
2 \ldots \ldots \\
3 \ldots \ldots \\
4 \ldots \ldots \\
5 \ldots \ldots \\
6 \ldots \ldots \\
7 \ldots \ldots \\
8 \ldots \ldots \\
9 \ldots \ldots \\
10 \ldots \ldots\end{array}$ & $\begin{array}{r}115 \\
109 \\
104 \\
100 \\
97 \\
93 \\
91 \\
57 \\
85 \\
83\end{array}$ & $\begin{array}{r}2,800 \\
1,700 \\
1,800 \\
1,100 \\
850 \\
700 \\
600 \\
550 \\
480 \\
430\end{array}$ & $\begin{array}{l}11 \ldots \ldots \\
12 \ldots \ldots \\
13 \ldots \ldots \\
14 \ldots \ldots \\
15 \ldots \ldots \\
16 \ldots \ldots \\
17 \ldots \ldots \\
15 \ldots \ldots \\
19 \ldots \ldots \\
20 \ldots \ldots\end{array}$ & $\begin{array}{l}80 \\
76 \\
76 \\
74 \\
73 \\
72 \\
70 \\
68 \\
66 \\
65\end{array}$ & $\begin{array}{l}400 \\
350 \\
500 \\
640 \\
480 \\
400 \\
380 \\
330 \\
300 \\
280\end{array}$ & $\begin{array}{l}21 \ldots \ldots \\
22 \ldots \ldots \\
23 \ldots \ldots \\
24 \ldots \ldots \\
25, \ldots \ldots \\
26 \ldots \ldots \\
27 \ldots \ldots \\
28 \ldots \ldots \\
29 \ldots \ldots \\
30 \ldots \ldots \\
31 \ldots \ldots \\
\end{array}$ & $\begin{array}{r}64 \\
63 \\
61 \\
60 \\
59 \\
58 \\
57 \\
56 \\
59 \\
145 \\
2,840 \\
\end{array}$ & $\begin{array}{r}250 \\
230 \\
210 \\
200 \\
190 \\
180 \\
170 \\
170 \\
--1- \\
--1 \\
\end{array}$ \\
\hline $\begin{array}{l}\text { Monthly } \\
\text { Runoff, } \\
\text { Runoff, }\end{array}$ & $\begin{array}{l}\text { ean dis } \\
\text { inche } \\
\text { acre- }\end{array}$ & & & & & & $\begin{array}{r}168 \\
2.96 \\
10,330 \\
\end{array}$ & $\begin{array}{r}595 \\
9.49 \\
33,060 \\
\end{array}$ \\
\hline
\end{tabular}


Gage helght, in feet, and discharge, in cublc feet per second, at 1nd1cated time, 1963, of Squaw Creek above Shasta Lake, Callf.

\begin{tabular}{|c|c|c|c|c|c|c|c|c|c|c|c|}
\hline Date & Hour & $\begin{array}{c}\text { Gage } \\
\text { he1ght }\end{array}$ & $\begin{array}{l}\text { Dis- } \\
\text { charge }\end{array}$ & Date & Hour & $\begin{array}{c}\text { Gage } \\
\text { helght }\end{array}$ & $\begin{array}{l}\text { D1s- } \\
\text { charge }\end{array}$ & Date & Hour & $\begin{array}{c}\text { Gage } \\
\text { height }\end{array}$ & $\begin{array}{c}\text { Dis - } \\
\text { charge }\end{array}$ \\
\hline $\begin{array}{r}\operatorname{Jan} .29 \\
30\end{array}$ & $\begin{array}{l}2400 \\
0600 \\
1200 \\
1500 \\
1800 \\
2100 \\
2200 \\
2400\end{array}$ & $\begin{array}{l}6.78 \\
6.84 \\
6.98 \\
7.26 \\
7.80 \\
8.36 \\
8.42 \\
8.45\end{array}$ & $\begin{array}{r}68 \\
74 \\
87 \\
117 \\
200 \\
324 \\
341 \\
350\end{array}$ & Jan. 31 & $\begin{array}{l}0400 \\
0600 \\
0800 \\
1000 \\
1200 \\
1400 \\
1600 \\
1700 \\
1800 \\
2000\end{array}$ & $\begin{array}{r}8.49 \\
8.66 \\
9.15 \\
10.00 \\
11.70 \\
13.85 \\
15.10 \\
15.25 \\
15.20 \\
15.60\end{array}$ & $\begin{array}{r}362 \\
413 \\
600 \\
1,000 \\
2,220 \\
4,060 \\
5,310 \\
5,480 \\
5,420 \\
5,890\end{array}$ & $\begin{array}{l}\text { Jan. } 31 \\
\text { Feb. } 1\end{array}$ & $\begin{array}{l}2200 \\
2400 \\
\\
0200 \\
0500 \\
1100 \\
1200 \\
1600 \\
2000 \\
2400\end{array}$ & $\begin{array}{l}15.38 \\
14.90 \\
14.33 \\
13.50 \\
12.08 \\
12.08 \\
11.60 \\
11.16 \\
10.86\end{array}$ & $\begin{array}{l}5,630 \\
5,100 \\
\\
4,530 \\
3,750 \\
2,520 \\
2,520 \\
2,140 \\
1,790 \\
1,560\end{array}$ \\
\hline
\end{tabular}

11-3680. McCloud River above Shasta Lake, Cal1f.

Location.--Lat $40^{\circ} 57^{\prime} 30^{\prime \prime}$, long $122^{\circ} 13^{\prime} 05^{\prime \prime}$, In $N W^{\frac{1}{4}}$ sec. 28 , T. 36 N., R.3 W., on right bank just upstream from Shasta Lake, 0.2 mlle downstream from B1g Bollibokka Creek and 11.3 miles east of La Moine.

Drainage area. $--606 \mathrm{sq} \mathrm{mi}$.

Gage-he1ght record.--Water-stage recorder graph. Datum of gage 1s 1,100.00 ft above mean sea level (levels by Bureau of Reclamation).

Discharge record.--Stage-discharge relation defined by current-meter measurements below $6,400 \mathrm{c}$ 's and by slope-area measurement at 45,200 cfs.

Maxima.--January-February 1963: Discharge, 9,700 cfs 2400 hours Jan. 31 (gage he1ght, 18.00).

1945 to December 1962:' Discharge, 45,200 cfs Dec. 22, 1955 (gage he1ght, $28.20 \mathrm{ft})$.

Mean discharge, in cubic feet per second, 1963

\begin{tabular}{|c|c|c|c|c|c|c|c|c|}
\hline Day & January & February & Day & January & February & Day & January & February \\
\hline $\begin{array}{c}\ldots \ldots \\
2 \ldots \ldots \\
3 \ldots \ldots \\
4 \ldots \ldots \\
5 \ldots \ldots \\
6 \ldots \ldots \\
8 \ldots \ldots \\
9 \ldots \ldots \\
10 \ldots \ldots\end{array}$ & $\begin{array}{l}1,390 \\
1,370 \\
1,360 \\
1,340 \\
1,310 \\
1,280 \\
1,270 \\
1,250 \\
1,240 \\
1,220\end{array}$ & $\begin{array}{l}\mathbf{7}, 500 \\
4,780 \\
6,320 \\
5,830 \\
4,970 \\
3,970 \\
3,350 \\
3,110 \\
2,900 \\
2,720\end{array}$ & $\begin{array}{l}11 \ldots \ldots \\
12 \ldots \ldots \\
13 \ldots \ldots \\
14 \ldots \ldots \\
15 \ldots \ldots \\
16 \ldots \ldots \\
17 \ldots \ldots \\
18 \ldots \ldots \\
19 \ldots \ldots \\
20 \ldots \ldots\end{array}$ & $\begin{array}{l}1,190 \\
1,160 \\
1,170 \\
1,190 \\
1,170 \\
1,170 \\
1,160 \\
1,150 \\
1,140 \\
1,130\end{array}$ & $\begin{array}{l}2,410 \\
2,450 \\
3,240 \\
3,090 \\
2,840 \\
2,610 \\
2,470 \\
2,300 \\
2,180 \\
2,100\end{array}$ & $\begin{array}{l}21 \ldots \ldots \\
22 \ldots \ldots \\
23 \ldots \ldots \\
24 \ldots \ldots \\
25 \ldots \ldots \\
26 \ldots \ldots \\
27 \ldots \ldots \\
28 \ldots \ldots \\
29 \ldots \ldots \\
30 \ldots \ldots \\
31 \ldots \ldots\end{array}$ & $\begin{array}{l}1,120 \\
1,120 \\
1,120 \\
1,110 \\
1,110 \\
1,100 \\
1,100 \\
1,100 \\
1,120 \\
1,300 \\
4,970\end{array}$ & $\begin{array}{r}2,010 \\
1,930 \\
1,870 \\
1,800 \\
1,760 \\
1,710 \\
1,660 \\
1,630 \\
-.--- \\
-\ldots-.--.\end{array}$ \\
\hline $\begin{array}{l}\text { Monthly } \\
\text { Runoff, } \\
\text { liunoff, }\end{array}$ & \multicolumn{6}{|c|}{ 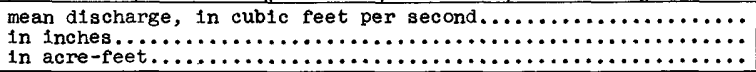 } & $\begin{array}{r}1,320 \\
2.51 \\
81,180 \\
\end{array}$ & $\begin{array}{r}3,054 \\
5.25 \\
169,600 \\
\end{array}$ \\
\hline
\end{tabular}

Gage helght, in feet, and discharge, in cublc feet per second, at indicated time, 1963

\begin{tabular}{|c|c|c|c|c|c|c|c|c|c|c|c|}
\hline Date & Hour & $\begin{array}{c}\text { Gage } \\
\text { helght }\end{array}$ & $\begin{array}{l}\text { D1s- } \\
\text { charge }\end{array}$ & Date & Hour & $\begin{array}{c}\text { Gage } \\
\text { he1ght }\end{array}$ & $\begin{array}{c}\text { Dis- } \\
\text { charge }\end{array}$ & Date & Hour & $\begin{array}{c}\text { Gage } \\
\text { he1ght }\end{array}$ & $\begin{array}{c}\text { D1s - } \\
\text { charge }\end{array}$ \\
\hline $\begin{array}{r}\operatorname{Tan} .29 \\
30\end{array}$ & $\begin{array}{l}2400 \\
0600 \\
0900 \\
1200 \\
1900 \\
2400 \\
\\
0400 \\
0700 \\
1000 \\
1200 \\
1400 \\
1600\end{array}$ & $\begin{array}{l}11.37 \\
11.36 \\
11.37 \\
11.43 \\
11.85 \\
11.92 \\
12.07 \\
12.35 \\
13.19 \\
14.18 \\
15.40 \\
16.65 \\
\end{array}$ & $\begin{array}{l}1,160 \\
1,150 \\
1,160 \\
1,200 \\
1,530 \\
1,590 \\
1,720 \\
1,980 \\
2,790 \\
3,880 \\
5,420 \\
7,260 \\
\end{array}$ & Jan. 18 & $\begin{array}{l}1800 \\
2100 \\
2400 \\
0200 \\
0400 \\
0800 \\
1100 \\
1400 \\
1800 \\
2400 \\
0300 \\
0600\end{array}$ & $\begin{array}{l}17.43 \\
17.81 \\
18.00 \\
17.86 \\
17.65 \\
17.00 \\
16.71 \\
16.62 \\
16.21 \\
15.55 \\
15.30 \\
15.12\end{array}$ & $\begin{array}{l}8,590 \\
9,320 \\
9,700 \\
9,420 \\
9,000 \\
7,820 \\
7,360 \\
7,210 \\
6,580 \\
5,630 \\
5,280 \\
5,050\end{array}$ & $\mathrm{Feb}, 2$ & $\begin{array}{l}0900 \\
1200 \\
1500 \\
1800 \\
2100 \\
2400 \\
\\
0600 \\
1100 \\
1400 \\
1600 \\
2200 \\
2400\end{array}$ & $\begin{array}{l}14.87 \\
14.75 \\
14.67 \\
14.64 \\
14.75 \\
14.94 \\
15.72 \\
16.22 \\
16.42 \\
16.45 \\
16.32 \\
16.22\end{array}$ & $\begin{array}{l}4,720 \\
4,560 \\
4,460 \\
4,430 \\
4,560 \\
4,810 \\
5,870 \\
6,600 \\
6,900 \\
6,940 \\
6,750 \\
6,600\end{array}$ \\
\hline
\end{tabular}


11-3700. Shasta Lake near Redding, Cal1f.

Location.--Lat $40^{\circ} 43^{\prime} 10^{\prime \prime}$, long $122^{\circ} 25^{\prime} 10^{\prime \prime}$, in NW $\frac{1}{4}$ sec.15, T 33 N., R. 5 W., in Shasta Dam on Sacramento River near right bank, 2 miles downstream from Squaw Creek and 9.5 miles north of Redding.

Drainage area. $--6,665 \mathrm{sq} \mathrm{m} 1$, excluding Goose Lake basin.

Gage-helght record.--Water stage recorder graph. Datum of gage is at mean sea level (levels by Bureau of Reclamation).

Maxima.--January-February 1963: Computed bihourly inflow, 72,200 cfs 1600 to 1800 hours Jan. 31 . Contents, 3,509,800 acre-ft 0800 hours Feb. 15 (elevation,

1942 to December 1962: Contents, 4,528,900 acre-ft May 18, 1957 elevation, 1,066.22 ft).

Remarks.--Reservolr is formed by concrete gravity-type dam completed in 1949; regulation began Dec. 30, 1943. Usable capac1ty, 4,377,000 acre-ft between elevations 737.75 (bottom of lowest set of river outlets) and 1,065.0 ft (top of drum-type spiliway gates)above mean sea level. Dead storage, 115,700 acre-ft. All water passes down Sacramento River, some first passing through powerplant at dam. Figures given herein represent total contents. Records furmished by Bureau of Reclamation.

Elevation, in feet, and contents, in acre-feet, at 2400 hours, 1963

\begin{tabular}{|c|c|c|c|c|c|c|c|c|c|}
\hline \multirow{2}{*}{ Day } & \multicolumn{2}{|c|}{ January } & \multicolumn{2}{|c|}{ February } & \multirow{2}{*}{ Day } & \multicolumn{2}{|c|}{ January } & \multicolumn{2}{|c|}{ February } \\
\hline & Elevation & Contents & Elevation & Contents & & Elevation & Contents & Elevation & Contents \\
\hline $\begin{array}{r}1 \\
2 \\
3 \\
4 \\
5 \\
6 \\
7 \\
8 \\
9 \\
10 \\
11 \\
12 \\
13 \\
14 \\
15\end{array}$ & $\begin{array}{l}1,018.59 \\
1,018.23 \\
1,017.01 \\
1,017.54 \\
1,017.17 \\
1,016.73 \\
1,016.38 \\
1,016.06 \\
1,015.79 \\
1,015.55 \\
1,015.32 \\
1,015.12 \\
1,014.81 \\
1,014.67 \\
1,014.52\end{array}$ & $\begin{array}{l}3,253,000 \\
3,244,400 \\
3,236,800 \\
3,228,000 \\
3,219,100 \\
3,208,700 \\
3,200,400 \\
3,192,800 \\
3,186,400 \\
3,180,800 \\
3,175,400 \\
3,170,700 \\
3,163,400 \\
3,160,100 \\
3,156,600\end{array}$ & $\begin{array}{l}1,018.68 \\
1,020.30 \\
1,022.90 \\
1,024.90 \\
1,026.41 \\
1,027.34 \\
1,027.86 \\
1,028.21 \\
1,028.34 \\
1,028.38 \\
1,028.30 \\
1,028.42 \\
1,028.88 \\
1,029.02 \\
1,029.05\end{array}$ & $\begin{array}{l}3,255,200 \\
3,294,200 \\
3,357,200 \\
3,406,200 \\
3,443,600 \\
3,466,700 \\
3,479,700 \\
3,488,400 \\
3,491,700 \\
3,492,700 \\
3,490,700 \\
3,493,700 \\
3,505,300 \\
3,508,800 \\
3,509,500\end{array}$ & $\begin{array}{l}16 \\
17 \\
18 \\
19 \\
20 \\
21 \\
22 \\
23 \\
24 \\
25 \\
26 \\
27 \\
28 \\
29 \\
30 \\
31\end{array}$ & $\begin{array}{l}1,014.40 \\
1,014.25 \\
1,014.09 \\
1,013.07 \\
1,013.64 \\
1,013.50 \\
1,013.38 \\
1,013.25 \\
1,013.15 \\
1,013.05 \\
1,012.88 \\
1,012.66 \\
1,012.52 \\
1,012.52 \\
1,012.78 \\
1,016.01\end{array}$ & $\begin{array}{l}3,153,700 \\
3,150,200 \\
3,146,500 \\
3,141,300 \\
3,136,000 \\
3,132,700 \\
3,129,900 \\
3,126,900 \\
3,124,500 \\
3,122,200 \\
3,118,200 \\
3,113,100 \\
3,109,900 \\
3,109,900 \\
3,115,900 \\
3,191,600\end{array}$ & $\begin{array}{c}1,028.99 \\
1,028.85 \\
1,028.66 \\
1,028.54 \\
1,028.54 \\
1,028.51 \\
1,028.22 \\
1,027.92 \\
1,027.63 \\
1,027.30 \\
1,026.93 \\
1,026.57 \\
1,026.17 \\
- \\
- \\
-\end{array}$ & $\begin{array}{c}3,508,000 \\
3,504,500 \\
3,499,700 \\
3,496,700 \\
3,496,700 \\
3,496,000 \\
3,488,700 \\
3,481,200 \\
3,473,900 \\
3,465,700 \\
3,456,500 \\
3,447,500 \\
3,437,600 \\
- \\
-\end{array}$ \\
\hline sine & in cont & (1) & 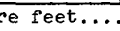 & & & - & $-71,300$ & - & $+246,000$ \\
\hline
\end{tabular}

Average inflow, in cublc feet per second, for bihourly periods ending at indicated time, 1963

\begin{tabular}{|c|c|c|c|c|c|c|c|c|}
\hline Date & Hour & Inflow & Date & Hour & Inflow & Date & Hour & Inflow \\
\hline Jan. 30 & $\begin{array}{l}0200 \\
0400 \\
0600 \\
0800 \\
1000 \\
1200 \\
1400 \\
1600 \\
1800 \\
2000 \\
2200 \\
2400\end{array}$ & $\begin{array}{r}6,850 \\
5,750 \\
5,740 \\
6,460 \\
7,980 \\
9,630 \\
9,390 \\
9,430 \\
12,200 \\
12,800 \\
10,400 \\
11,400\end{array}$ & Feb. 1 & $\begin{array}{l}0200 \\
0400 \\
0600 \\
0800 \\
1000 \\
1200 \\
1400 \\
1600 \\
1800 \\
2000 \\
2200 \\
2400\end{array}$ & $\begin{array}{l}61,100 \\
55,400 \\
47,500 \\
43,000 \\
41,100 \\
40,100 \\
42,800 \\
36,200 \\
33,100 \\
33,000 \\
32,100 \\
28,600\end{array}$ & Feb. 3 & $\begin{array}{l}0200 \\
0400 \\
0600 \\
0800 \\
1000 \\
1200 \\
1400 \\
1600 \\
1800 \\
2000 \\
2200 \\
2400\end{array}$ & $\begin{array}{l}40,800 \\
35,500 \\
39,100 \\
45,000 \\
37,800 \\
43,400 \\
42,800 \\
41,800 \\
41,900 \\
41,400 \\
39,200 \\
41,300\end{array}$ \\
\hline 31 & $\begin{array}{l}0200 \\
0400 \\
0600 \\
0800 \\
1000 \\
1200 \\
1400 \\
1600 \\
1800 \\
2000 \\
2200 \\
2400\end{array}$ & $\begin{array}{l}12,100 \\
12,800 \\
18,400 \\
22,200 \\
32,100 \\
45,100 \\
60,700 \\
62,600 \\
72,200 \\
68,600 \\
65,100 \\
59,800\end{array}$ & 2 & $\begin{array}{l}0200 \\
0400 \\
0600 \\
0800 \\
1000 \\
1200 \\
1400 \\
1600 \\
1800 \\
2000 \\
2200 \\
2400\end{array}$ & $\begin{array}{l}28,500 \\
27,100 \\
26,500 \\
29,500 \\
24,900 \\
28,700 \\
27,300 \\
31,000 \\
28,500 \\
30,800 \\
28,300 \\
33,300\end{array}$ & 4 & $\begin{array}{l}0200 \\
0400 \\
0600 \\
0800 \\
1000 \\
1200 \\
1400 \\
1600 \\
1800 \\
2000 \\
2200 \\
2400 \\
\end{array}$ & $\begin{array}{l}36,400 \\
36,000 \\
33,200 \\
35,600 \\
36,700 \\
31,700 \\
32,200 \\
31,700 \\
33,500 \\
34,800 \\
34,500 \\
31,600\end{array}$ \\
\hline
\end{tabular}


11-3705. Sacramento River at Keswick, Calif.

Location.--Lat $40^{\circ} 36^{\prime} 0^{\prime \prime}$, long $122^{\circ} 26^{\prime} 3^{\prime \prime}$, in SW $\frac{1}{4} \mathrm{NW} \frac{1}{4}$ sec.28, T.32 N., R.5 W., on right bank 0.4 mile upstream from Middle Creek, 0.8 mile downstream from Keswick Dam, 1.6 miles downstream from Keswick, and 10 miles downstream from Shasta Dam.

Drainage area. $--6,468 \mathrm{sq} \mathrm{mi}$, excluding Goose Lake basin.

Gage-height record.--Water-stage recorder graph. Datum of gage is $479.81 \mathrm{ft}$ above mean sea level, datum of 1929 .

Discharge record.--Stage-discharge relation defined by current-meter measurements.

Maxima.--January-February 1963: Discharge, 13,600 cf's 1900 hours Feb. 11 (gage height, $15.63 \mathrm{ft}$ ).

$1938-43$ (prior to regulation by Shasta Lake): Discharge, 186,000 cfs Feb. 23, 1940 (gage helght, $47.2 \mathrm{ft}$, site and datum then in use), from rating curve extended above $75,000 \mathrm{cfs}$ on basis of peak discharge at Kennett plus $4,000 \mathrm{cf}$ 's estimated inflow.

1944 to December 1962: Discharge, 78,800 cfs Feb. 21, 1958 (gage height, $31.55 \mathrm{ft}$ ).

Remarks.--Floodflow regulated by Shasta Lake (see station 11-3700) since Dec. 30 , 1943. Diumal fluctuations from Shasta powerplant re-regulated by Keswick Reservo1r (capacity, 4,170 acre-f't between normal operation elevations 579.0 and $586.0 \mathrm{ft}$ ) and powerplant.

Mean discharge, in cublc feet per second, 1963

\begin{tabular}{|c|c|c|c|c|c|c|c|c|}
\hline Day & January & February & Day & January & February & Day & January & February \\
\hline $\begin{array}{c}1 \ldots \ldots \\
2 \ldots \ldots \\
3 \ldots \ldots \\
4 \ldots \ldots \\
5 \ldots \ldots \\
6 \ldots \ldots \\
8 \ldots \ldots \\
9 \ldots \ldots \\
10 \ldots \ldots\end{array}$ & $\begin{array}{r}11,400 \\
11,400 \\
11,000 \\
10,700 \\
10,400 \\
10,400 \\
10,200 \\
9,710 \\
9,220 \\
8,720\end{array}$ & $\begin{array}{r}9,700 \\
9,630 \\
9,640 \\
9,710 \\
9,950 \\
11,000 \\
11,700 \\
12,500 \\
13,400 \\
13,500\end{array}$ & $\begin{array}{l}11 \ldots \ldots \\
12 \ldots \ldots \\
13 \ldots \ldots \\
14 \ldots \ldots \\
15 \ldots \ldots \\
16 \ldots \ldots \\
17 \ldots \ldots \\
18 \ldots \ldots \\
19 \ldots \ldots \\
20 \ldots \ldots\end{array}$ & $\begin{array}{l}8,210 \\
7,690 \\
7,460 \\
7,440 \\
7,210 \\
6,950 \\
6,940 \\
6,920 \\
6,730 \\
6,580\end{array}$ & $\begin{array}{l}13,500 \\
12,600 \\
12,900 \\
13,600 \\
13,500 \\
13,500 \\
13,600 \\
13,300 \\
11,800 \\
10,300\end{array}$ & $\begin{array}{l}21 \ldots \ldots \\
22 \ldots \ldots \\
23 \ldots \ldots \\
24 \ldots \ldots \\
25 \ldots \ldots \\
26 \ldots \ldots \\
27 \ldots \ldots \\
25 \ldots \ldots \\
29 \ldots \ldots \\
30 \ldots \ldots \\
31 \ldots \ldots\end{array}$ & $\begin{array}{l}6, \\
6, \\
6, \\
6, \\
6, \\
6,6 \\
6,6 \\
6, \\
6,6 \\
6,6 \\
8,\end{array}$ & $\begin{array}{r}10,200 \\
12,600 \\
12,700 \\
12,700 \\
12,700 \\
12,800 \\
12,800 \\
12,800 \\
------ \\
------ \\
-----\end{array}$ \\
\hline \multicolumn{7}{|c|}{ 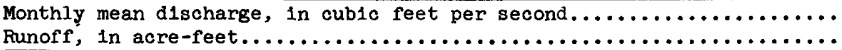 } & $\begin{array}{r}8,075 \\
496,500 \\
\end{array}$ & $\begin{array}{r}12,090 \\
671,700 \\
\end{array}$ \\
\hline
\end{tabular}

11-3710. Clear Creek at French Gulch, Cal1f.

Location.--Lat $40^{\circ} 41^{1} 40^{\prime \prime}$, long $122^{\circ} 38^{\prime} 10^{\prime \prime}$, in NE $\frac{1}{4} \sec .27$, T. 33 N., R.7 W., on right bank 1,200 ft downstream from Right Fork, 0.3 mile south of French Gulch, and 15 miles northwest of Redding.

Drainage area. - - $115 \mathrm{sq} \mathrm{ml}$.

Gage-height record.--Water-stage recorder graph. Datum of gage is 1,320.60 ft above above mean sea level, datum of 1929 , supplementary adjustment of 1956.

Discharge record.--Stage discharge relation defined by current-meter measurements below 4,600 cfs and by slope-area measurement at 7,050 cfs.

Maxima.--January-February 1963: Discharge, 2,400 cfs 1900 hours Jan. 31 (gage helght, $8.64 \mathrm{ft}$ ).

1950 to December 1962: D1scharge, 7,050 cf's Dec. 22, 1955 (gage height, $13.49 \mathrm{ft})$. 
Mean d1scharge, in cuble feet per second, 1963, of Clear Creek at French Gulch, Calif.

\begin{tabular}{|c|c|c|c|c|c|c|c|c|}
\hline Day & January & February & Day & January & February & Day & January & February \\
\hline $\begin{array}{c}1 \ldots \ldots \\
2 \ldots \ldots \\
3 \ldots \ldots \\
4 \ldots \ldots \\
5 \ldots \ldots \\
6 \ldots \ldots \\
7 \ldots \ldots \\
8 \ldots \ldots \\
9 \ldots \ldots \\
10 \ldots \ldots\end{array}$ & $\begin{array}{l}80 \\
78 \\
75 \\
71 \\
68 \\
66 \\
65 \\
63 \\
63 \\
61\end{array}$ & $\begin{array}{r}1,520 \\
1,010 \\
1,030 \\
875 \\
705 \\
580 \\
476 \\
413 \\
392 \\
504\end{array}$ & $\begin{array}{l}11 \ldots \ldots \\
12 \ldots \ldots \\
13 \ldots \ldots \\
14 \ldots \ldots \\
15 \ldots \ldots \\
16 \ldots \ldots \\
17 \ldots \ldots \\
18 \ldots \ldots \\
19 \ldots \ldots \\
20 \ldots \ldots\end{array}$ & $\begin{array}{l}58 \\
55 \\
61 \\
60 \\
57 \\
55 \\
54 \\
52 \\
51 \\
51\end{array}$ & $\begin{array}{l}528 \\
568 \\
865 \\
755 \\
616 \\
536 \\
460 \\
402 \\
360 \\
329\end{array}$ & $\begin{array}{l}21 \ldots \ldots \\
22 \ldots \ldots \\
23 \ldots \ldots \\
24 \ldots \ldots \\
25 \ldots \ldots \\
26 \ldots \ldots \\
27 \ldots \ldots \\
28 \ldots \ldots \\
29 \ldots \ldots \\
30 \ldots \ldots \\
31 \ldots \ldots\end{array}$ & $\begin{array}{r}51 \\
49 \\
48 \\
48 \\
47 \\
47 \\
45 \\
47 \\
51 \\
94 \\
1,130\end{array}$ & $\begin{array}{r}299 \\
273 \\
254 \\
236 \\
224 \\
210 \\
199 \\
188 \\
--.-- \\
---.--\end{array}$ \\
\hline $\begin{array}{l}\text { thly } \\
\text { loff, } \\
\text { loff, }\end{array}$ & acre & & & & & & $\begin{array}{r}93.6 \\
0.94 \\
5,750 \\
\end{array}$ & $\begin{array}{r}529 \\
4.79 \\
29,370 \\
\end{array}$ \\
\hline
\end{tabular}

Gage he1ght, in feet, and discharge, in cublc feet per second, at 1ndicated t1me, 1963

\begin{tabular}{|c|c|c|c|c|c|c|c|c|c|c|c|}
\hline Date & Hour & $\begin{array}{c}\text { Gage } \\
\text { helght }\end{array}$ & $\begin{array}{l}\text { Dis- } \\
\text { charge }\end{array}$ & Date & Hour & $\begin{array}{c}\text { Gage } \\
\text { helght }\end{array}$ & $\begin{array}{l}\text { D1s- } \\
\text { charge }\end{array}$ & Date & Hour & $\begin{array}{c}\text { Gage } \\
\text { helght }\end{array}$ & $\begin{array}{c}\text { Dis- } \\
\text { charge }\end{array}$ \\
\hline Jan. 29 & 2400 & & 58 & Jan. 31 & $\begin{array}{l}1400 \\
1800\end{array}$ & $\begin{array}{l}7.16 \\
8.58\end{array}$ & $\begin{array}{l}1,360 \\
2,360\end{array}$ & Feb. I & $\begin{array}{l}1900 \\
2400\end{array}$ & $\begin{array}{l}7.10 \\
6.88\end{array}$ & $\begin{array}{l}1,340 \\
1,210\end{array}$ \\
\hline 30 & $\begin{array}{l}1200 \\
2000 \\
2400\end{array}$ & $\begin{array}{l}3.96 \\
4.41 \\
4.42\end{array}$ & $\begin{array}{r}65 \\
158 \\
160\end{array}$ & & $\begin{array}{l}1900 \\
2000 \\
2400\end{array}$ & $\begin{array}{l}8.64 \\
8.61 \\
8.20\end{array}$ & $\begin{array}{l}2,400 \\
2,380 \\
2,090\end{array}$ & 2 & $\begin{array}{l}0600 \\
1200\end{array}$ & $\begin{array}{l}6.64 \\
6.45 \\
6.33\end{array}$ & $\begin{array}{r}1,070 \\
975 \\
915\end{array}$ \\
\hline 31 & $\begin{array}{l}0600 \\
0800 \\
1000\end{array}$ & $\begin{array}{l}4.61 \\
4.83 \\
5.31\end{array}$ & $\begin{array}{l}211 \\
273 \\
424\end{array}$ & Feb. 1 & $\begin{array}{l}1000 \\
1200 \\
1500\end{array}$ & $\begin{array}{l}7.28 \\
7.17 \\
7.21\end{array}$ & $\begin{array}{l}1,450 \\
1,380 \\
1,410\end{array}$ & & $\begin{array}{l}2100 \\
2400\end{array}$ & $\begin{array}{l}6.34 \\
6.42\end{array}$ & $\begin{array}{l}920 \\
960\end{array}$ \\
\hline
\end{tabular}

11-3720. Clear Creek near Igo, Calif.

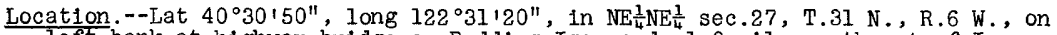
left bank at highway bridge on Redding-Igo road, 1.0 mile northeast of Igo, 8 miles southwest of Redding, and 11.1 miles upstream from mouth.

Drainage area. $--228 \mathrm{sq} \mathrm{ml}$.

Gage-helght record.--Digital-recorder tape punched at 15-minute intervals. Datum of gage is $675 \mathrm{ft}$ (from river-profile map).

Discharge record.--Stage-discharge relation defined by current-meter measurements.

Maxima.--January-February 1963: Discharge, 6,030 cfs 1445 hours Jan. 31 (gage helght, $7.72 \mathrm{ft}$ ).

1940 to December 1962: Discharge, 24,500 cfs Dec. 21, 1955 (gage height, $13.75 \mathrm{ft}$ ).

Remarks.--Minor regulation by Whiskeytown Dam in 1963.

Mean d1scharge, in cub1c feet per second, 1963

\begin{tabular}{|c|c|c|c|c|c|c|c|c|}
\hline Day & January & February & Day & January & February & Day & January & February \\
\hline $\begin{array}{c}1 \ldots \ldots \\
2 \ldots \ldots \\
3 \ldots \ldots \\
4 \ldots \ldots \\
5 \ldots \ldots \\
6 \ldots \ldots \\
7 \ldots \ldots \\
8 \ldots \ldots \\
9 \ldots \ldots \\
10 \ldots \ldots\end{array}$ & $\begin{array}{l}169 \\
163 \\
160 \\
153 \\
146 \\
142 \\
141 \\
140 \\
135 \\
132\end{array}$ & $\begin{array}{r}2,590 \\
1,600 \\
1,680 \\
1,370 \\
1,070 \\
851 \\
705 \\
659 \\
646 \\
984\end{array}$ & $\begin{array}{l}11 \ldots \ldots \\
12 \ldots \ldots \\
13 \ldots \ldots \\
14 \ldots \ldots \\
15 \ldots \ldots \\
16 \ldots \ldots \\
17 \ldots \ldots \\
18 \ldots \ldots \\
19 \ldots \ldots \\
20 \ldots \ldots\end{array}$ & $\begin{array}{l}126 \\
113 \\
121 \\
125 \\
122 \\
119 \\
116 \\
114 \\
111 \\
109\end{array}$ & $\begin{array}{r}946 \\
1,400 \\
2,100 \\
1,450 \\
1,120 \\
976 \\
836 \\
720 \\
641 \\
589\end{array}$ & $\begin{array}{l}21 \ldots \ldots \\
22 \ldots \ldots \\
23 \ldots \ldots \\
24 \ldots \ldots \\
25 \ldots \ldots \\
26 \ldots \ldots \\
27 \ldots \ldots \\
28 \ldots \ldots \\
29 \ldots \ldots \\
30 \ldots \ldots \\
31 \ldots \ldots\end{array}$ & $\begin{array}{l}108 \\
108 \\
106 \\
104 \\
103 \\
101 \\
100 \\
100 \\
112 \\
304 \\
3,120 \\
\end{array}$ & $\begin{array}{r}530 \\
484 \\
446 \\
418 \\
392 \\
371 \\
350 \\
335 \\
----- \\
---.-\end{array}$ \\
\hline noff, & acre- & & & & & & $\begin{array}{r}227 \\
1.15 \\
13,930 \\
\end{array}$ & $\begin{array}{r}938 \\
4.28 \\
52,080 \\
\end{array}$ \\
\hline
\end{tabular}


Gage helght, In feet, and discharge, In cublc feet per second, at 1ndicated t1me, 1963, of Clear Creek near Igo, Callf.

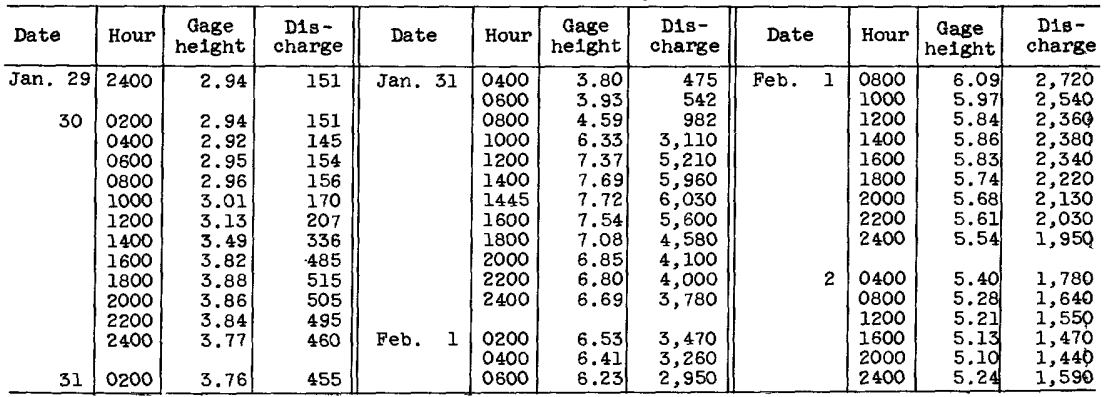

11-3720.5. Churn Creek near Redding, Calif.

Location.--Lat $40^{\circ} 38^{\prime} 35^{\prime \prime}$, long $122^{\circ} 22^{\prime} 05^{\prime \prime}$, in NE $\frac{1}{4} \mathrm{SW}_{\frac{1}{4}} \mathrm{sec} .7, \mathrm{~T} .32 \mathrm{~N} ., \mathrm{R} .4 \mathrm{~W}$. , on right bank 0.3 mile upstream from Newtown Creek, 0.35 mile upstream from Oasis Road bridge, and 4 miles north of Redding.

Drainage area. $--9.34 \mathrm{sq} \mathrm{ml}$.

Gage-he1ght record ${ }^{--W a t e r-s t a g e ~ r e c o r d e r ~ g r a p h . ~ A l t i t u d e ~ o f ~ g a g e ~ i s ~} 640 \mathrm{ft}$ (from topographic mapi.

Discharge record.--Stage-discharge relation defined by current-meter measurements below 1,200 cfs and by slope-area measurement at 4,860 cfs.

Maxima.--January-February 1963: Discharge, 1,230 cfs 1400 hours Jan. 31 (gage helght, $6.61 \mathrm{ft}$ ).

1959 to December 1962: Discharge, 4,860 cfs Sept. 18, 1959 (gage height, $9.8 \mathrm{ft}$, from floodmarks).

Mean discharge, in cublc feet per second, 1963

\begin{tabular}{|c|c|c|c|c|c|c|c|c|}
\hline Day & anuary & ebruary & Day & January & Rebruary & Day & January & February \\
\hline $\begin{array}{r} \\
1 \\
2 \ldots \ldots . \\
-3 \ldots \ldots \\
4 \ldots \ldots \\
5 \ldots \ldots \\
6 \ldots \ldots \\
7 \ldots \ldots \\
8 \ldots \ldots \\
90 . \ldots .\end{array}$ & $\begin{array}{l}3.5 \\
3.4 \\
3.4 \\
3.1 \\
2.7 \\
2.6 \\
2.4 \\
2.4 \\
2.4 \\
2.3\end{array}$ & $\begin{array}{r}148 \\
72 \\
95 \\
62 \\
42 \\
32 \\
26 \\
23 \\
21 \\
26\end{array}$ & 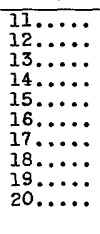 & $\begin{array}{l}2.5 \\
1.8 \\
1.8 \\
1.8 \\
1.8 \\
1.8 \\
1.8 \\
1.6\end{array}$ & $\begin{array}{l}70 \\
46 \\
34 \\
32 \\
27 \\
22 \\
19 \\
17\end{array}$ & $\begin{array}{l}a \ldots \ldots \\
3 \ldots \ldots \\
4 \ldots \ldots \\
5 \ldots \ldots \\
6 \ldots \ldots \\
7 \ldots \ldots \\
9 \ldots \ldots \\
1 \ldots \ldots \\
\ldots\end{array}$ & $\begin{array}{r}1.6 \\
1.6 \\
1.6 \\
1.6 \\
1.6 \\
1.6 \\
1.6 \\
1.6 \\
3.4 \\
32 \\
436\end{array}$ & $\begin{array}{r}14 \\
12 \\
11 \\
9.8 \\
9.0 \\
8.2 \\
7.0 \\
6.6 \\
-0.0 \\
-0.0\end{array}$ \\
\hline \multicolumn{9}{|c|}{ 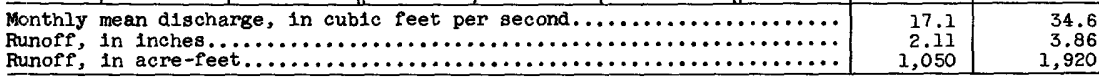 } \\
\hline
\end{tabular}

Gage helght, in feet, and discharge, in cubic feet per second, at indicated time, 1963

\begin{tabular}{|c|c|c|c|c|c|c|c|c|c|c|c|}
\hline Date & Hour & $\begin{array}{c}\text { Gage } \\
\text { helght }\end{array}$ & $\begin{array}{l}\text { Dis- } \\
\text { charge }\end{array}$ & Date & Hour & $\underset{\text { helght }}{\text { Gage }}$ & $\begin{array}{c}\text { D1s - } \\
\text { charge }\end{array}$ & Date & Hour & $\begin{array}{c}\text { Gage } \\
\text { helght }\end{array}$ & $\begin{array}{c}\text { Dis - } \\
\text { charge }\end{array}$ \\
\hline Jan. 29 & 2400 & 1.98 & 14 & Jan. 31 & 0200 & 2.50 & 7 & Jan. 31 & 2400 & 4.13 & 281 \\
\hline 30 & $\begin{array}{l}0100 \\
0700 \\
0900 \\
1100 \\
1300 \\
1600 \\
2100 \\
2400\end{array}$ & $\begin{array}{l}2.02 \\
1.90 \\
1.90 \\
1.97 \\
2.19 \\
2.78 \\
2.53 \\
2.50\end{array}$ & $\begin{array}{l}16 \\
10 \\
10 \\
14 \\
26 \\
72 \\
49 \\
47\end{array}$ & & $\begin{array}{l}0800 \\
0900 \\
1000 \\
1200 \\
1400 \\
1600 \\
1800 \\
2000\end{array}$ & $\begin{array}{l}3.20 \\
3.80 \\
4.55 \\
6.00 \\
6.61 \\
5.98 \\
5.13 \\
4.63\end{array}$ & $\begin{array}{r}120 \\
222 \\
410 \\
930 \\
1,230 \\
912 \\
567 \\
410 \\
\end{array}$ & Feb. 1 & $\begin{array}{l}0400 \\
1200 \\
1400 \\
2000 \\
2400\end{array}$ & $\begin{array}{l}3.66 \\
3.20 \\
3.32 \\
3.04 \\
2.88\end{array}$ & $\begin{array}{r}192 \\
122 \\
139 \\
102 \\
84\end{array}$ \\
\hline
\end{tabular}


11-3722. South Cow Creek near Millville, Calif.

Location.--Lat $40^{\circ} 32^{\prime} 5^{\prime \prime}$, long $122^{\circ} 05^{\prime} 30^{\prime \prime}$, In NW $\frac{1}{4} \mathrm{NE} \frac{1}{4}$ sec.16, T.31 N., R.2 W., on left bank 2.5 miles upstream from 0ld Cow Creek and 4.4 miles east of Miliville.

Drainage area. $--77.3 \mathrm{sq} \mathrm{ml}$.

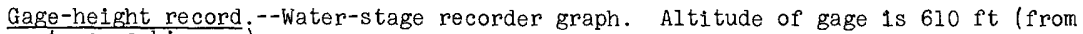
topographic map)

Discharge record.--Stage-discharge relation defined by current-meter measurements below 3,300 cfs.

Maxima.--January-February 1963: Discharge, 3,630 ofs 1600 hours Feb. I (gage helght, $7.35 \mathrm{ft}$ ).

1956 to December 1962: Discharge, 5,720 cfs May 18, 1957 (gage height, $9.23 \mathrm{ft}$, site and datum then in use).

Mean discharge, in cubic feet per second, 1963

\begin{tabular}{|c|c|c|c|c|c|c|c|c|}
\hline Day & January & February & Day & January & February & Day & January & Febmuary \\
\hline $\begin{array}{c}1 \ldots \ldots \\
2 \ldots \ldots \\
3 \ldots \ldots \\
4 \ldots \ldots \\
5 \ldots \ldots \\
7 \ldots \ldots \\
8 \ldots \ldots \\
9 \ldots \ldots \\
10 \ldots \ldots\end{array}$ & $\begin{array}{l}60 \\
57 \\
57 \\
55 \\
52 \\
50 \\
48 \\
47 \\
46 \\
44\end{array}$ & $\begin{array}{r}1,300 \\
654 \\
532 \\
376 \\
295 \\
252 \\
218 \\
204 \\
182 \\
189\end{array}$ & $\begin{array}{l}11 \ldots \ldots \\
12 \ldots \ldots \\
13 \ldots \ldots \\
14 \ldots \ldots \\
15 \ldots \ldots \\
16 \ldots \ldots \\
17 \ldots \ldots \\
18 \ldots \ldots \\
19 \ldots \ldots \\
20 . \ldots \ldots\end{array}$ & $\begin{array}{l}40 \\
36 \\
43 \\
40 \\
37 \\
37 \\
36 \\
36 \\
35 \\
34\end{array}$ & $\begin{array}{l}178 \\
204 \\
286 \\
185 \\
160 \\
152 \\
180 \\
150 \\
138 \\
140\end{array}$ & $\begin{array}{l}21 \ldots \ldots \\
22 \ldots \ldots \\
23 \ldots \ldots \\
24 \ldots \ldots \\
25 \ldots \ldots \\
26 \ldots \ldots \\
27 \ldots \ldots \\
28 \ldots \ldots \\
29 \ldots \ldots \\
30 \ldots \ldots \\
31 \ldots \ldots\end{array}$ & $\begin{array}{r}34 \\
35 \\
34 \\
34 \\
34 \\
33 \\
32 \\
32 \\
36 \\
1,090 \\
1,460 \\
\end{array}$ & $\begin{array}{r}130 \\
120 \\
113 \\
107 \\
102 \\
98 \\
94 \\
90 \\
-\ldots---\end{array}$ \\
\hline \multicolumn{7}{|l|}{$\begin{array}{l}\text { Monthly } \\
\text { Runoff, } \\
\text { Runoff, }\end{array}$} & $\begin{array}{r}121 \\
1.66 \\
7,430 \\
\end{array}$ & $\begin{array}{r}244 \\
3.29 \\
13,550 \\
\end{array}$ \\
\hline
\end{tabular}

Gage height, in feet, and discharge, in cublc feet per second, at indicated time, 1963

\begin{tabular}{|c|c|c|c|c|c|c|c|c|c|c|c|}
\hline Date & Hour & $\begin{array}{c}\text { Gage } \\
\text { helght }\end{array}$ & $\begin{array}{l}\text { Dis- } \\
\text { charge }\end{array}$ & Date & Hour & $\begin{array}{c}\text { Gage } \\
\text { height }\end{array}$ & $\begin{array}{c}\text { Dis- } \\
\text { charge }\end{array}$ & Date & Hour & $\begin{array}{c}\text { Gage } \\
\text { he1ght }\end{array}$ & $\begin{array}{l}\text { Dis- } \\
\text { charge }\end{array}$ \\
\hline $\begin{array}{r}\operatorname{Jan} .29 \\
30\end{array}$ & $\begin{array}{l}2400 \\
0400 \\
0800 \\
1000 \\
1300 \\
1500 \\
1700 \\
2000 \\
2400 \\
0300\end{array}$ & $\begin{array}{l}1.30 \\
1.92 \\
2.39 \\
3.38 \\
5.20 \\
5.95 \\
5.42 \\
5.19 \\
3.77 \\
3.26\end{array}$ & $\begin{array}{r}50 \\
145 \\
267 \\
700 \\
1,870 \\
2,400 \\
2,020 \\
1,860 \\
922 \\
640\end{array}$ & Feb. 1 & $\begin{array}{l}0400 \\
0600 \\
0800 \\
1000 \\
1200 \\
1300 \\
1600 \\
2000 \\
2100 \\
2400 \\
0400\end{array}$ & $\begin{array}{l}3.25 \\
4.18 \\
5.05 \\
4.77 \\
5.55 \\
5.58 \\
5.15 \\
4.65 \\
4.71 \\
4.28 \\
4.07\end{array}$ & $\begin{array}{r}635 \\
1,170 \\
1,760 \\
1,570 \\
2,120 \\
2,140 \\
1,840 \\
1,480 \\
1,530 \\
1,230 \\
1,100\end{array}$ & Feb. I & $\begin{array}{l}1300 \\
1500 \\
1600 \\
1800 \\
2000 \\
2400 \\
\\
1000 \\
1300 \\
1900 \\
2200 \\
2400\end{array}$ & $\begin{array}{l}3.34 \\
5.30 \\
7.35 \\
5.60 \\
4.70 \\
4.05 \\
\\
3.55 \\
3.64 \\
3.42 \\
3.48 \\
3.42\end{array}$ & $\begin{array}{r}680 \\
1,940 \\
3,630 \\
1,980 \\
1,290 \\
870 \\
\\
628 \\
668 \\
569 \\
596 \\
562\end{array}$ \\
\hline
\end{tabular}

11-3732. Oak Run Cresk near Oak Run, Cal1f.

Location.--Lat $40^{\circ} 41^{\prime} 25^{\prime \prime}$, long $122^{\circ} 02^{\prime} 35^{\prime \prime}$, in SE $\frac{1}{4} N W \frac{1}{4} \sec .25$, T. 33 N., R.2 W., on left bank $800 \mathrm{ft}$ downstream from road bridge, 1.1 miles northwest of town of oak Run, 3.2 miles upstream from Tracy Creek, and 12.2 miles northeast of Millville.

Drainage area. $--11.0 \mathrm{sq} \mathrm{mi}$.

Gage-helght record.--Water-stage recorder graph. Alt1tude of gage is $1,400 \mathrm{ft}$ (from topographic map).

Discharge record.--Stage-discharge relation defined by current-meter measurements below $240 \mathrm{cf}$ 's and by slope-area measurement at $930 \mathrm{cfs}$.

Maxima.--January-February 1963: Discharge, 380 cfs 1100 hours Jan. 31 (gage height, $5.00 \mathrm{ftl}$

1957 to December 1962: Discharge, 1,440 cfs 0ct. 11, 1962 (gage height, $6.53 \mathrm{ft}$ ). 
Mean discharge, in cubic feet per second, 1963, of Oak Run Creek near Oak Run, Calif.

\begin{tabular}{|c|c|c|c|c|c|c|c|c|}
\hline Day & January & February & Day & January & February & Day & January & Febmuary \\
\hline $\begin{array}{c}\ldots \ldots \\
2 \ldots \ldots \\
3 \ldots \ldots \\
4 \ldots \ldots \\
5 \ldots \ldots \\
6 \ldots \ldots \\
7 \ldots \ldots \\
8 \ldots \ldots \\
9 \ldots \ldots \\
10 \ldots \ldots\end{array}$ & $\begin{array}{l}10 \\
9.5 \\
9.5 \\
9.0 \\
8.3 \\
8.0 \\
7.8 \\
7.6 \\
7.6 \\
7.5\end{array}$ & $\begin{array}{r}1 \overline{28} \\
70 \\
58 \\
42 \\
33 \\
28 \\
23 \\
24 \\
21 \\
24\end{array}$ & $\begin{array}{l}11 \ldots \ldots \\
12 \ldots \ldots \\
13 \ldots \ldots \\
14 \ldots \ldots \\
15 \ldots \ldots \\
16 \ldots \ldots \\
17 \ldots \ldots \\
18 \ldots \ldots \\
19 \ldots \ldots \\
20 \ldots \ldots\end{array}$ & $\begin{array}{l}6.4 \\
7.6 \\
6.7 \\
6.8 \\
6.7 \\
6.5 \\
6.4 \\
6.2 \\
5.8 \\
5.9\end{array}$ & $\begin{array}{l}20 \\
34 \\
40 \\
36 \\
26 \\
28 \\
26 \\
21 \\
19 \\
20\end{array}$ & $\begin{array}{l}21 \ldots \ldots \\
22 \ldots \ldots \\
23 \ldots \ldots \\
24 \ldots \ldots \\
25 \ldots \ldots \\
26 \ldots \ldots \\
27 \ldots \ldots \\
28 \ldots \ldots \\
29 \ldots \ldots \\
30 \ldots \ldots \\
31 \ldots \ldots\end{array}$ & $\begin{array}{r}6.0 \\
6.0 \\
5.9 \\
5.8 \\
5.9 \\
5.8 \\
5.6 \\
5.8 \\
8.5 \\
143 \\
228\end{array}$ & $\begin{array}{r}17 \\
16 \\
15 \\
14 \\
14 \\
13 \\
12 \\
12 \\
-\ldots-.-1\end{array}$ \\
\hline 101 & $\begin{array}{l}\text { inches } \\
\text { acre-f }\end{array}$ & & & & & & $\begin{array}{r}18.6 \\
1.95 \\
1,140 \\
\end{array}$ & $\begin{array}{r}29.8 \\
2.82 \\
1,650 \\
\end{array}$ \\
\hline
\end{tabular}

Gage he1ght, in feet, and discharge, in cubic feet per second, at ind1cated time, 1963

\begin{tabular}{|c|c|c|c|c|c|c|c|c|c|c|c|}
\hline Date & Hour & $\begin{array}{c}\text { Gage } \\
\text { height }\end{array}$ & $\begin{array}{l}\text { Dis- } \\
\text { charge }\end{array}$ & Date & Hour & $\begin{array}{c}\text { Gage } \\
\text { helght }\end{array}$ & $\begin{array}{l}\text { Dis- } \\
\text { charge }\end{array}$ & Date & Hour & $\begin{array}{c}\text { Gage } \\
\text { helght }\end{array}$ & $\begin{array}{l}\text { D1s- } \\
\text { charge }\end{array}$ \\
\hline $\begin{array}{r}\operatorname{Jan} .29 \\
30\end{array}$ & $\begin{array}{l}2400 \\
0300 \\
0700 \\
0900 \\
1100 \\
1300 \\
1500 \\
1700 \\
1900 \\
2200 \\
2400\end{array}$ & $\begin{array}{l}2.28 \\
2.57 \\
2.69 \\
3.10 \\
3.76 \\
4.21 \\
4.62 \\
4.39 \\
4.76 \\
4.29 \\
3.88\end{array}$ & $\begin{array}{r}21 \\
33 \\
38 \\
65 \\
127 \\
192 \\
272 \\
223 \\
307 \\
205 \\
142\end{array}$ & $\operatorname{Jan} .31$ & $\begin{array}{l}0400 \\
0500 \\
0700 \\
0900 \\
1100 \\
1200 \\
1400 \\
1600 \\
1700 \\
1900 \\
2200 \\
2400\end{array}$ & $\begin{array}{l}3.54 \\
4.07 \\
4.80 \\
4.63 \\
5.00 \\
4.74 \\
4.66 \\
4.45 \\
4.54 \\
4.18 \\
3.87 \\
4.50\end{array}$ & $\begin{array}{l}103 \\
170 \\
371 \\
274 \\
380 \\
301 \\
281 \\
235 \\
254 \\
187 \\
141 \\
245\end{array}$ & Feb. I & $\begin{array}{l}0300 \\
1000 \\
1200 \\
1300 \\
1400 \\
1700 \\
2000 \\
2400 \\
\\
0800 \\
1300 \\
1900 \\
2400\end{array}$ & $\begin{array}{l}3.83 \\
3.35 \\
3.27 \\
3.82 \\
4.41 \\
3.88 \\
3.50 \\
3.27 \\
3.07 \\
3.29 \\
3.08 \\
3.17\end{array}$ & $\begin{array}{r}136 \\
86 \\
79 \\
135 \\
227 \\
142 \\
99 \\
79 \\
\\
63 \\
80 \\
64 \\
71\end{array}$ \\
\hline
\end{tabular}

11-3733. Little Cow Creek near Ingot, Calif.

Location.--Lat $40^{\circ} 44^{1} 45^{\prime \prime}$, long $122^{\circ} 03^{\prime} 40^{\prime \prime}$, in $\mathrm{SE}_{\frac{1}{4}} \mathrm{NW} \frac{1}{4} \sec .2, \mathrm{~T} .33 \mathrm{~N} ., \mathrm{R} .2 \mathrm{~W}$., on right bank 1.8 miles northeast of Ingot and 7 miles southwest of Round Mountain.

Drainage area. $--60.6 \mathrm{sq} \mathrm{m}$.

Gage-height record.--Water-stage recorder graph. Altitude of gage is $1,140 \mathrm{ft}$ (from topographic map).

Discharge record.--Stage-discharge relation defined by current-meter measurements below 3,300 cfs.

Naxima.--January-February 1963: Discharge, 4,790 cf's 0100 hours Feb. I (gage hei ght, $14.57 \mathrm{ft}$ ).

1957 to December 1962: Discharge, 8,200 cfs Nov. 13, 1957 (gage height, $16.64 \mathrm{ft}$ ).

Fiemarks.--Records furnished by California Department of water Resources and reviewed by Geological Survey.

Mean discharge, in cublc feet per second, 1963

\begin{tabular}{|c|c|c|c|c|c|c|c|c|}
\hline Day & January & February & Day & January & February & Day & January & February \\
\hline $\begin{array}{c}1 \ldots \ldots \\
2 \ldots \ldots \\
3 \ldots \ldots \\
4 \ldots \ldots \\
5 \ldots \ldots \\
6 \ldots \ldots \\
8 \ldots \ldots \\
9 \ldots \ldots \\
10 \ldots \ldots\end{array}$ & $\begin{array}{l}87 \\
85 \\
85 \\
78 \\
75 \\
70 \\
68 \\
65 \\
61 \\
57\end{array}$ & $\begin{array}{r}1,780 \\
719 \\
635 \\
439 \\
335 \\
272 \\
229 \\
213 \\
186 \\
196\end{array}$ & $\begin{array}{l}11 \ldots \ldots \\
12 \ldots \ldots \\
13 \ldots \ldots \\
14 \ldots \ldots \\
15 \ldots \ldots \\
16 \ldots \ldots \\
17 \ldots \ldots \\
18 \ldots \ldots \\
19 \ldots \ldots \\
20 \ldots \ldots\end{array}$ & $\begin{array}{l}50 \\
61 \\
52 \\
52 \\
51 \\
50 \\
50 \\
48 \\
44 \\
45\end{array}$ & $\begin{array}{l}172 \\
213 \\
413 \\
309 \\
238 \\
227 \\
240 \\
186 \\
167 \\
172\end{array}$ & $\begin{array}{l}21 \ldots \ldots \\
22 \ldots \ldots \\
23 \ldots \ldots \\
24 \ldots \ldots \\
25 \ldots \ldots \\
26 \ldots \ldots \\
27 \ldots \ldots \\
28 \ldots \ldots \\
29 \ldots \ldots \\
30 \ldots \ldots \\
31 \ldots \ldots\end{array}$ & $\begin{array}{r}45 \\
44 \\
43 \\
43 \\
42 \\
40 \\
39 \\
40 \\
44 \\
828 \\
2,700 \\
\end{array}$ & $\begin{array}{r}152 \\
137 \\
129 \\
123 \\
118 \\
114 \\
107 \\
103 \\
----- \\
---- \\
--1\end{array}$ \\
\hline \multicolumn{7}{|l|}{$\begin{array}{l}\text { Monthly } \\
\text { Runoff, } \\
\text { Runoff, }\end{array}$} & $\begin{array}{r}166 \\
3.16 \\
10,200\end{array}$ & $\begin{array}{r}297 \\
5,11 \\
16,510 \\
\end{array}$ \\
\hline
\end{tabular}


Gage height, in feet, and discharge, In cub1c feet per second, at indicated time, 1963, of ittle Cow creek near Ingot, Calif.

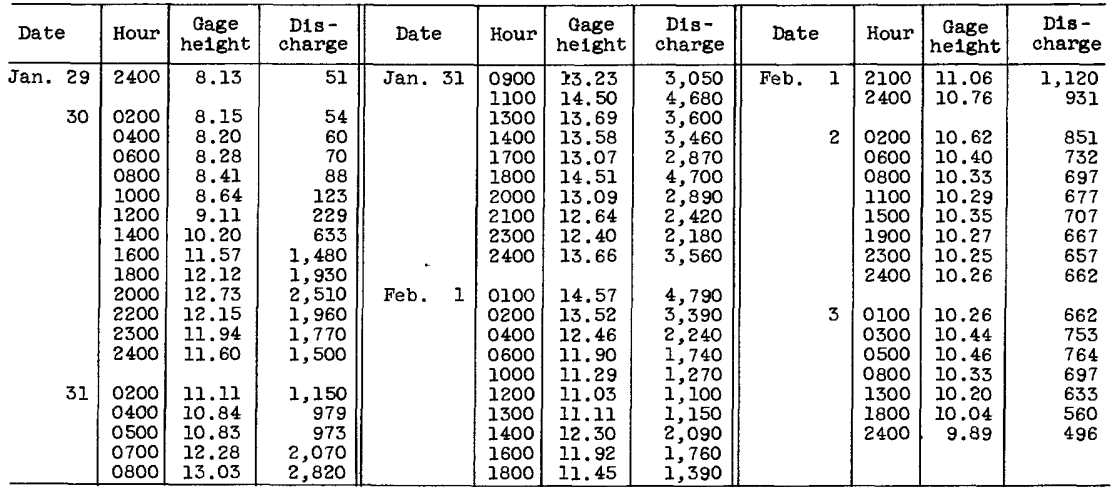

\section{1-3740. Cow Creek near Millville, Calif.}

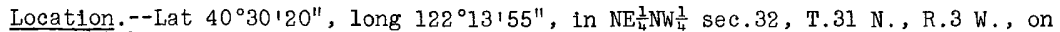
right bank 4.2 miles southwest of Millville and 4.3 miles downstream from Little Cow Creek.

Drainage area $--425 \mathrm{sq} \mathrm{mi}$.

Gage-height record ;-Water-stage recorder graph. Altitude of gage is $400 \mathrm{ft}$ (from topographic map).

Discharge record.--Stage-discharge relation defined by current-meter measurements. Maxima.--January-February 1963: Discharge, 17,000 cf's 1500 hours Jan. 31 (gage helght, $13.91 \mathrm{ft}$ ).

1949 to December 1962: Discharge, 45,200 cf's Dec. 27, 1951 (gage height, $21.55 \mathrm{ft}$ ).

Mean d1scharge, in cub1c feet per second, 1963

\begin{tabular}{|c|c|c|c|c|c|c|c|c|}
\hline Day & Tanuary & February & Day & January & Febmuary & Day & January & February \\
\hline $\begin{array}{r}1 \ldots \ldots \\
2 \ldots \ldots \\
3 \ldots \ldots \\
4 \ldots \ldots \\
5 \ldots \ldots \\
6 \ldots \ldots \\
7 \ldots \ldots \\
8 \ldots \ldots \\
10 \ldots \ldots\end{array}$ & $\begin{array}{l}325 \\
311 \\
305 \\
298 \\
279 \\
267 \\
258 \\
255 \\
249 \\
241\end{array}$ & $\begin{array}{r}7,390 \\
3,810 \\
3,160 \\
2,040 \\
1,580 \\
1,250 \\
1,050 \\
958 \\
874 \\
895\end{array}$ & 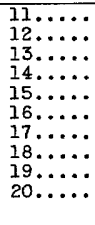 & $\begin{array}{l}216 \\
214 \\
212 \\
206 \\
204 \\
194 \\
192\end{array}$ & $\begin{array}{r}860 \\
1,040 \\
1,930 \\
1,590 \\
1,070 \\
944 \\
1,190 \\
839 \\
739 \\
714\end{array}$ & $\begin{array}{l}21 \ldots \ldots \\
22 \ldots \ldots \\
23 \ldots \ldots \\
24 \ldots \ldots \\
25 \ldots \ldots \\
26 \ldots \ldots \\
27 \ldots \ldots \\
28 \ldots \\
29 \ldots \ldots \\
30 \ldots \ldots \\
31 \ldots \ldots\end{array}$ & $\begin{array}{r}194 \\
194 \\
194 \\
189 \\
189 \\
185 \\
182 \\
182 \\
199 \\
4,980 \\
11,000\end{array}$ & $\begin{array}{r}660 \\
584 \\
539 \\
500 \\
476 \\
448 \\
422 \\
404 \\
--.--\end{array}$ \\
\hline \multicolumn{7}{|c|}{ 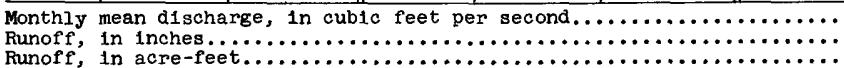 } & $\begin{array}{r}727 \\
1.96 \\
44,710 \\
\end{array}$ & $\begin{array}{r}1,356 \\
3.31 \\
75,280\end{array}$ \\
\hline
\end{tabular}

Gage height, in feet, and discharge, in cubic feet per second, at indicated time, 1963

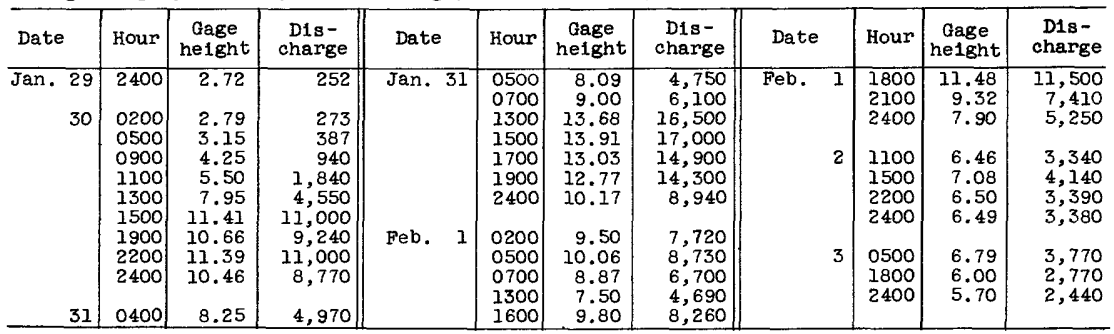


11-3740.6. Shingle Creek near Shingletown, Calif.

(Crest-stage station)

Location.--Lat $40^{\circ} 30^{1} 00^{\prime \prime}$, long $121^{\circ} 58120^{\prime \prime}$, in NW $\frac{1}{4} \mathrm{SW} \frac{1}{4} \sec .34, \mathrm{~T} .31 \mathrm{~N} ., \mathrm{R} .1 \mathrm{~W}$. , on State Highway $44,4.5$ miles west of Shíngletown.

Drainage area. $--3.25 \mathrm{sq} \mathrm{mi}$.

Gage-height record.--Crest stages only. Altitude of gage is $2,140 \mathrm{ft}$ (from topographic map).

Discharge record.--Stage-discharge relation defined by current-meter measurements below $90 \mathrm{cfs}$ and by computation of flow through culvert at $156 \mathrm{cfs}$ and $167 \mathrm{cfs}$.

Maxima --January-February 1963: Discharge, 108 cf's Jan. 31 (gage height, $3.06 \mathrm{ft}$ ). 1960 to December 1962: Discharge, $167 \mathrm{cfs}$ Dec. 1, 1961 (gage height, $3.62 \mathrm{ft}$ ).

11-3741. Bear Creek near Miliville, Calif.

Location. - - Lat $40^{\circ} 31^{\prime} 50^{\prime \prime}$, long $122^{\circ} 06^{\prime} 30^{\prime \prime}$, in $\mathrm{SE} \frac{1}{4} \mathrm{NE} \frac{1}{4} \sec .20$, T.31 N., R.2 W., on right bank $10 \mathrm{ft}$ downstream from bridge on State Highway 44 and 3.8 miles southeast of town of Millville.

Drainage area,$-75.6 \mathrm{sq} \mathrm{mi}$.

Gage-height record ${ }^{--W a t e r-s t a g e ~ r e c o r d e r ~ g r a p h . ~ A l t i t u d e ~ o f ~ g a g e ~ i s ~} 720 \mathrm{ft}$ (from topographic mapj.

Discharge record.--Stage-discharge relation defined by current-meter measurements below $1,100 \mathrm{cfs}$.

Maxima --January-February 1963: Discharge, 1,870 cfs 1500 hours Jan. 31 (gage helght, $8.96 \mathrm{ft}$ ).

1959 to December 1962: Discharge, 3,140 cfs Dec. 1, 1961 (gage height, $10.44 \mathrm{ft}^{\mathrm{t}}$ ).

Remarks.--Records furnished by California Department of Water Resources and reviewed by Geological Survey.

Mean discharge, in cub1c feet per second, 1963

\begin{tabular}{|c|c|c|c|c|c|c|c|c|}
\hline Day & January & February & Day & January & February & Day & January & February \\
\hline $\begin{array}{c}1 \ldots \ldots \\
2 \ldots \ldots \\
3 \ldots \ldots \\
4 \ldots \ldots \\
5 \ldots \ldots \\
7 \ldots \ldots \\
8 \ldots \ldots \\
9 \ldots \ldots \\
10 \ldots \ldots\end{array}$ & $\begin{array}{l}73 \\
70 \\
70 \\
67 \\
62 \\
59 \\
57 \\
55 \\
55 \\
63\end{array}$ & $\begin{array}{l}826 \\
505 \\
418 \\
315 \\
251 \\
213 \\
187 \\
186 \\
166 \\
173\end{array}$ & $\begin{array}{l}11 \ldots \ldots \\
12 \ldots \ldots \\
13 \ldots \ldots \\
14 \ldots \ldots \\
15 \ldots \ldots \\
16 \ldots \ldots \\
17 \ldots \ldots \\
18 \ldots \ldots \\
19 \ldots \ldots \\
20 \ldots \ldots\end{array}$ & $\begin{array}{l}50 \\
45 \\
52 \\
51 \\
46 \\
45 \\
44 \\
44 \\
42 \\
41\end{array}$ & $\begin{array}{l}172 \\
175 \\
244 \\
167 \\
143 \\
134 \\
162 \\
131 \\
116 \\
119\end{array}$ & $\begin{array}{l}21 \ldots \ldots \\
22 \ldots \ldots \\
23 \ldots \ldots \\
24 \ldots \ldots \\
25 \ldots \ldots \\
26 \ldots \ldots \\
27 \ldots \ldots \\
28 \ldots \ldots \\
29 \ldots \ldots \\
30 \ldots \ldots \\
31 \ldots \ldots\end{array}$ & $\begin{array}{r}41 \\
41 \\
40 \\
40 \\
40 \\
38 \\
37 \\
37 \\
42 \\
524 \\
1,190\end{array}$ & $\begin{array}{r}109 \\
100 \\
93 \\
87 \\
83 \\
80 \\
77 \\
73 \\
-\ldots--\end{array}$ \\
\hline \multicolumn{7}{|l|}{$\begin{array}{l}\text { Monthly } \\
\text { Runoff, } \\
\text { Runoff, }\end{array}$} & $\begin{array}{r}102 \\
1.55 \\
6,250 \\
\end{array}$ & $\begin{array}{r}197 \\
2.71 \\
10,920 \\
\end{array}$ \\
\hline
\end{tabular}

Gage he1ght, In feet, and discharge, in cublc feet per second, at 1ndicated time, 1963

\begin{tabular}{|c|c|c|c|c|c|c|c|c|c|c|c|}
\hline Date & Hour & $\begin{array}{c}\text { Gage } \\
\text { he1ght }\end{array}$ & $\begin{array}{c}\text { D1s- } \\
\text { charge }\end{array}$ & Date & Hour & $\begin{array}{c}\text { Gage } \\
\text { he1ght }\end{array}$ & $\begin{array}{l}\text { D1s- } \\
\text { charge }\end{array}$ & Date & Hour & $\begin{array}{c}\text { Gage } \\
\text { he1ght }\end{array}$ & $\begin{array}{l}\text { D1s- } \\
\text { charge }\end{array}$ \\
\hline $\begin{array}{r}\text { Jan. } 29 \\
30\end{array}$ & $\begin{array}{l}2400 \\
0500 \\
0900 \\
1300 \\
1400 \\
1600 \\
1730 \\
2000 \\
2100 \\
2400 \\
0300 \\
0400 \\
0600 \\
0700\end{array}$ & $\begin{array}{l}4.13 \\
4.23 \\
4.74 \\
6.38 \\
7.00 \\
7.86 \\
8.06 \\
8.83 \\
8.86 \\
6.89 \\
6.54 \\
6.65 \\
7.00 \\
7.59\end{array}$ & $\begin{array}{r}54 \\
63 \\
123 \\
509 \\
745 \\
1,160 \\
1,280 \\
1,780 \\
1,800 \\
699 \\
565 \\
605 \\
745 \\
1,020\end{array}$ & Feb. 1 & $\begin{array}{l}0800 \\
1000 \\
1300 \\
1500 \\
1700 \\
1800 \\
2100 \\
2400 \\
0300 \\
0700 \\
1400 \\
1500 \\
1630 \\
1700 \\
1730\end{array}$ & $\begin{array}{l}8.07 \\
8.30 \\
8.91 \\
8.96 \\
8.50 \\
8.36 \\
7.77 \\
7.37 \\
7.37 \\
6.86 \\
6.42 \\
6.45 \\
7.07 \\
7.74 \\
8.68\end{array}$ & $\begin{array}{r}1,280 \\
1,300 \\
1,840 \\
1,870 \\
1,550 \\
1,460 \\
1,120 \\
912 \\
912 \\
687 \\
523 \\
533 \\
775 \\
1,100 \\
1,670\end{array}$ & Feb. I & $\begin{array}{l}1800 \\
1900 \\
2100 \\
2400 \\
\\
0600 \\
1000 \\
1300 \\
1800 \\
2400 \\
\\
0400 \\
0700 \\
0900 \\
1200 \\
2400\end{array}$ & $\begin{array}{l}8.44 \\
7.77 \\
7.24 \\
6.93 \\
6.46 \\
6.30 \\
6.30 \\
6.14 \\
6.10 \\
6.09 \\
6.25 \\
6.19 \\
6.18 \\
5.86\end{array}$ & $\begin{array}{r}1,510 \\
1,120 \\
851 \\
715 \\
\\
537 \\
483 \\
483 \\
432 \\
420 \\
417 \\
467 \\
448 \\
445 \\
352 \\
\end{array}$ \\
\hline
\end{tabular}

793-285 $0-66-21$ 
11-3744. Middle Fork Cottonwood Creek near Ono, Calif.

Location. --Lat $40^{\circ} 23^{\prime} 25^{\prime \prime}$, long $122^{\circ} 31^{\prime} 15^{\prime \prime}$, in SE $\frac{1}{4} \mathrm{SE} \frac{1}{4}$ sec.3, T.29 N., R.6 W., on left bank 0.4 mile upstream from North Fork and 7.8 miles southeast of Ono.

Drainage area. $--249 \mathrm{sq} \mathrm{mi}$.

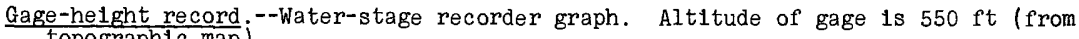
topographic map).

Discharge record.--Stage-discharge relation defined by current-meter measurements. Maxima.--January-February 1963: Discharge, 5,230 cfs 2100 hours Jan. 31 (gage
helght, 11.71 ft).

1956 to December 1962: Discharge, 9,090 cfs Feb. 18, 1958 (gage height, $14.74 \mathrm{ft})$.

Mean discharge, in cub1c feet per second, 1963

\begin{tabular}{|c|c|c|c|c|c|c|c|c|}
\hline Day & January & February & Day & January & February & Day & January & February \\
\hline $\begin{array}{c}1 \ldots \ldots \\
2 \ldots \ldots \\
3 \ldots \ldots \\
4 \ldots \ldots \\
5 \ldots \ldots \\
7 \ldots \ldots \\
8 \ldots \ldots \\
9 \ldots \ldots \\
10 \ldots \ldots\end{array}$ & $\begin{array}{l}85 \\
82 \\
79 \\
77 \\
74 \\
72 \\
70 \\
68 \\
66 \\
65\end{array}$ & $\begin{array}{r}3,340 \\
1,520 \\
1,210 \\
800 \\
615 \\
505 \\
442 \\
420 \\
846 \\
2,910\end{array}$ & $\begin{array}{l}11 \ldots \ldots \\
12 \ldots \ldots \\
13 . \ldots \\
14 \ldots \ldots \\
15 \ldots \ldots \\
16 \ldots \ldots \\
17 \ldots \ldots \\
18 \ldots \ldots \\
19 \ldots \ldots \\
20 \ldots \ldots\end{array}$ & $\begin{array}{l}63 \\
53 \\
58 \\
63 \\
63 \\
62 \\
53 \\
56 \\
52 \\
52\end{array}$ & $\begin{array}{r}1,580 \\
1,440 \\
1,750 \\
1,080 \\
752 \\
668 \\
561 \\
482 \\
420 \\
378\end{array}$ & $\begin{array}{l}21 \ldots \ldots \\
22 \ldots \ldots \\
23 \ldots \ldots \\
24 \ldots \ldots \\
25 \ldots \ldots \\
26 \ldots \ldots \\
27 \ldots \ldots \\
28 \ldots \\
29 \ldots \ldots \\
30 \ldots \ldots \\
31 \ldots \ldots\end{array}$ & $\begin{array}{r}54 \\
54 \\
52 \\
51 \\
50 \\
49 \\
49 \\
49 \\
51 \\
179 \\
2,550\end{array}$ & $\begin{array}{r}336 \\
302 \\
285 \\
273 \\
256 \\
242 \\
225 \\
212 \\
----- \\
----- \\
----\end{array}$ \\
\hline \multicolumn{7}{|c|}{ 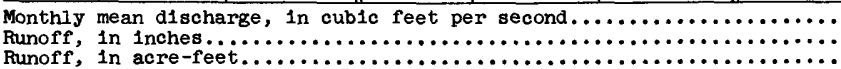 } & $\begin{array}{r}145 \\
0.67 \\
8,930\end{array}$ & $\begin{array}{r}852 \\
3.56 \\
47,310\end{array}$ \\
\hline
\end{tabular}

Gage he1ght, In feet, and discharge, in cub1c feet per second, at 1nd1cated time, 1963

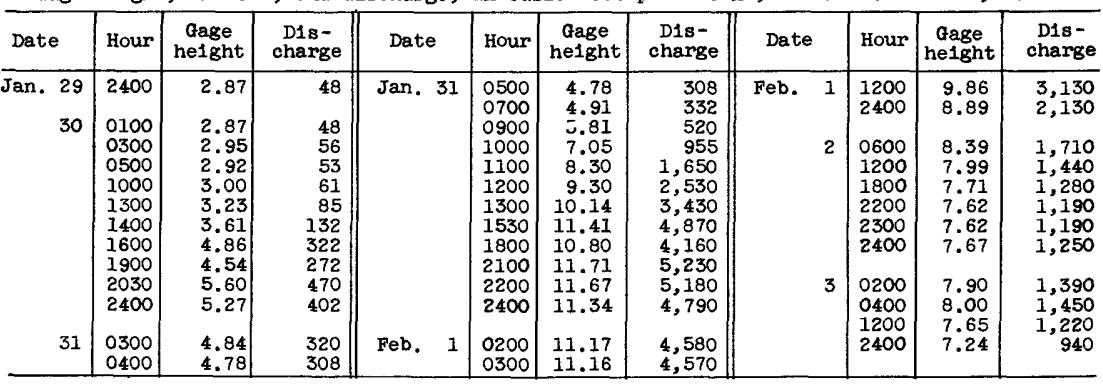

11-3756. Hulling Creek tributary at Ono, Callf.

(Crest-stage station)

Location :-Lat $40^{\circ} 28^{1} 40^{\prime \prime}$, long $122^{\circ} 36^{\prime} 10^{\prime \prime}$, in $\operatorname{SW}_{\frac{1}{4}} \mathrm{SE} \frac{1}{4} \sec .1$, T. 30 N., R.7 W. , $0.9 \mathrm{mile}$ east of Ono.

Drainage area $--0.067 \mathrm{sq} \mathrm{ml}$.

Gage-helght record.--Crest stages only. Altitude of gage is 925 ft (from topographic map).

Discharge record.--Stage-discharge relation defined by current-meter measurements below $2.3 \mathrm{cfs}$ and by computation of flow through culvert at $5.1 \mathrm{cfs}$ and $8.5 \mathrm{cfs}$.

Maxima --January-February 1963: Discharge, 4 cfs Jan. 31 (gage he1ght, $3.44 \mathrm{ft}$ ). 1960 to December 1962: Discharge. I1 cfs Oct. i2, 1962 (gage helght, $4.14 \mathrm{ft}$ ). 
11-3757. North Fork Cottonwood Creek near Igo, Calif.

Location.--Lat $40^{\circ} 26^{\prime} 32^{\prime \prime}$, Iong $122^{\circ} 32^{\prime} 57^{\prime \prime}$, in SE $\frac{1}{4} \mathrm{NW} \frac{1}{4} \sec .21$, T.30 N., R. 6 W., near right bank on downstream side of bridge on Gas Point Road, 1.2 miles downstream from Huling Creek, $4.4 \mathrm{mIles}$ south of Igo, and $4.5 \mathrm{mlles}$ upstream from Middle
Fork.

Drainage area. $--88.7 \mathrm{sq} \mathrm{ml}$. $\frac{\text { Gage-height record }}{\text { topographic map). }}$.-Water-stage recorder graph. Altitude of gage is $630 \mathrm{ft}$ (from

Discharge record.--Stage-discharge relation defined by current-meter measurements below 6,400 cf's.

Maxima.--January-February 1963: Discharge, 7,810 cfs 1400 hours Jan. 31 (gage he1ght, $35.92 \mathrm{ft}^{\prime} \mathrm{l}$.

1955 to December 1962: Discharge, $12,100 \mathrm{cfs}$ Dec. 21, 1955, by slope-area measurement at site 1.2 miles upstream (above Huling Creek).

Remarks.--Flow affected by Rainbow Lake (capacity, 4,800 acre-ft). Records furnished by the Califormia Department of Water Resources and reviewed by Geological Survey.

Mean discharge, in cublc feet per second, 1963

\begin{tabular}{|c|c|c|c|c|c|c|c|c|}
\hline Day & January & February & Day & January & February & Day & January & February \\
\hline $\begin{array}{r}1 \ldots \ldots \\
2 \ldots \ldots \\
4 \ldots \ldots \\
5 \ldots \ldots \\
6 \ldots \ldots \\
8 \ldots \ldots \\
9 \ldots \ldots \\
10 \ldots \ldots\end{array}$ & $\begin{array}{l}67 \\
67 \\
67 \\
65 \\
62 \\
59 \\
58 \\
56 \\
56 \\
56\end{array}$ & $\begin{array}{l}706 \\
456 \\
477 \\
252 \\
195 \\
172 \\
160 \\
156 \\
241 \\
830\end{array}$ & $\begin{array}{l}11 \ldots \ldots \\
12 \ldots \ldots \\
13 \ldots \ldots \\
14 \ldots \ldots \\
15 \ldots \ldots \\
16 \ldots \ldots \\
17 \ldots \ldots \\
18 \ldots \ldots \\
19 \ldots \ldots \\
20 \ldots \ldots\end{array}$ & $\begin{array}{l}58 \\
58 \\
58 \\
56 \\
54 \\
51 \\
51 \\
53 \\
49 \\
49\end{array}$ & $\begin{array}{l}462 \\
705 \\
816 \\
488 \\
362 \\
344 \\
276 \\
219 \\
192 \\
182\end{array}$ & $\begin{array}{l}21 \ldots \ldots \\
22 \ldots \ldots \\
23 \ldots \ldots \\
24 \ldots \ldots \\
25 \ldots \ldots \\
26 \ldots \ldots \\
27 \ldots \ldots \\
28 \ldots \ldots \\
29 \ldots \ldots \\
30 \ldots \ldots \\
31 \ldots \ldots\end{array}$ & $\begin{array}{r}48 \\
47 \\
46 \\
46 \\
46 \\
46 \\
45 \\
43 \\
49 \\
218 \\
2,240\end{array}$ & $\begin{array}{r}172 \\
156 \\
149 \\
143 \\
136 \\
130 \\
126 \\
121 \\
-.-1 \\
-1-2\end{array}$ \\
\hline off & acre- & & & & & & $\begin{array}{r}130 \\
1.69 \\
7,980\end{array}$ & $\begin{array}{r}315 \\
3.70 \\
17,500 \\
\end{array}$ \\
\hline
\end{tabular}

Gage height, In feet, and discharge, in cublc feet per second, at indicated t1me, 1963

\begin{tabular}{|c|c|c|c|c|c|c|c|c|c|c|c|}
\hline Date & Hour & $\begin{array}{c}\text { Qage } \\
\text { helght }\end{array}$ & $\begin{array}{l}\text { D1s- } \\
\text { charge }\end{array}$ & Date & Hour & $\begin{array}{c}\text { Gage } \\
\text { helght }\end{array}$ & $\begin{array}{l}\text { Dls- } \\
\text { charge }\end{array}$ & Date & Hour & $\begin{array}{c}\text { Gage } \\
\text { helght }\end{array}$ & $\begin{array}{l}\text { D1s- } \\
\text { charge }\end{array}$ \\
\hline $\begin{array}{r}\text { Jan. } 29 \\
30\end{array}$ & $\begin{array}{l}2400 \\
0200 \\
0400 \\
0800 \\
1100 \\
1200 \\
1300 \\
1500 \\
1700 \\
1900 \\
2200\end{array}$ & $\begin{array}{l}30.59 \\
30.65 \\
30.67 \\
30.65 \\
30.65 \\
30.68 \\
30.78 \\
31.48 \\
31.81 \\
31.43 \\
31.18\end{array}$ & $\begin{array}{r}80 \\
\\
95 \\
100 \\
95 \\
95 \\
103 \\
133 \\
405 \\
586 \\
381 \\
272\end{array}$ & $\begin{array}{r}\text { Jan. } 30 \\
31\end{array}$ & $\begin{array}{l}2400 \\
0200 \\
0600 \\
0700 \\
0800 \\
1000 \\
1100 \\
1200 \\
1400 \\
1500 \\
1700\end{array}$ & $\begin{array}{l}31.05 \\
30.97 \\
30.90 \\
30.90 \\
30.98 \\
31.73 \\
32.49 \\
34.87 \\
35.92 \\
35.85 \\
34.77\end{array}$ & $\begin{array}{r}223 \\
195 \\
172 \\
172 \\
198 \\
539 \\
1,070 \\
5,200 \\
7,810 \\
7,620 \\
4,980\end{array}$ & Jan. 31 & $\begin{array}{l}2000 \\
2400 \\
0400 \\
0800 \\
1300 \\
1400 \\
1600 \\
1700 \\
2000 \\
2400\end{array}$ & $\begin{array}{l}32.78 \\
32.46 \\
32.16 \\
31.97 \\
31.79 \\
31.83 \\
32.11 \\
32.13 \\
31.86 \\
31.65\end{array}$ & $\begin{array}{r}1,320 \\
1,040 \\
816 \\
686 \\
574 \\
598 \\
780 \\
794 \\
616 \\
494\end{array}$ \\
\hline
\end{tabular}

11-3758.2. South Fork Cottonwood Creek near Cottonwood, Cal1f.

Location.--Lat $40^{\circ} 18^{\prime} 58^{\prime \prime}$, long $122^{\circ} 26^{\prime} 52^{\prime \prime}$, in $\mathrm{NE}_{\frac{1}{4}} \mathrm{sec} .5, \mathrm{~T} .28 \mathrm{~N} ., \mathrm{R} .5 \mathrm{~W}$, , on right bank $70 \mathrm{ft}$ upstream from highway bridge, $0.7 \mathrm{mile}$ upstream from Dry Fork, and 10.3 miles southwest of Cottonwood.

Drainage area. $--218 \mathrm{sq} \mathrm{mi}$.

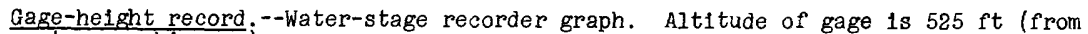
topographic map).

Discharge record.--Stage-discharge relation defined by current-meter measurements below 1,300 cfs.

Maximum.--January-February 1963: Discharge, 6,230 cfs 2100 hours Jan. 31 (gage height, $7.84 \mathrm{ft}$ ).

Remarks.--Records furnished by Cal1fornia Department of Water Resources and reviewed by Geological Survey. 
Mean discharge, in cublc feet per second, 1963, of South Fork Cottonwood Creek near Cottonwood, Calif.

\begin{tabular}{|c|c|c|c|c|c|c|c|c|}
\hline Day & January & February & Day & January & February & Day & January & February \\
\hline $\begin{array}{c}I \ldots \ldots \\
2 \ldots \ldots \\
3 \ldots \ldots \\
4 \ldots \ldots \\
6 \ldots \ldots \\
7 \ldots \ldots \\
8 \ldots \ldots \\
9 \ldots \ldots \\
10 \ldots \ldots\end{array}$ & $\begin{array}{l}59 \\
59 \\
58 \\
57 \\
57 \\
55 \\
54 \\
55 \\
56 \\
55\end{array}$ & $\begin{array}{r}4,130 \\
1,980 \\
1,450 \\
1,100 \\
924 \\
739 \\
632 \\
565 \\
846 \\
1,980\end{array}$ & $\begin{array}{l}11 \ldots \ldots \\
12 \ldots \ldots \\
13 \ldots \ldots \\
14 \ldots \ldots \\
15 \ldots \ldots \\
16 \ldots \ldots \\
17 \ldots \ldots \\
18 \ldots \ldots \\
19 \ldots \ldots \\
20 \ldots \ldots\end{array}$ & $\begin{array}{l}53 \\
48 \\
36 \\
43 \\
53 \\
50 \\
46 \\
43 \\
42 \\
38\end{array}$ & $\begin{array}{r}1,060 \\
837 \\
932 \\
728 \\
620 \\
550 \\
523 \\
447 \\
403 \\
369\end{array}$ & $\begin{array}{l}21 \ldots \ldots \\
22 \ldots \ldots \\
23 \ldots \ldots \\
24 \ldots \ldots \\
25 \ldots \ldots \\
26 \ldots \ldots \\
27 \ldots \ldots \\
28 \ldots \ldots \\
29 \ldots \ldots \\
30 \ldots \ldots \\
31 \ldots \ldots\end{array}$ & $\begin{array}{r}39 \\
40 \\
37 \\
36 \\
35 \\
35 \\
32 \\
32 \\
32 \\
59 \\
2,630 \\
\end{array}$ & $\begin{array}{r}342 \\
310 \\
288 \\
258 \\
233 \\
216 \\
194 \\
179 \\
---- \\
--.-- \\
\end{array}$ \\
\hline \multicolumn{7}{|l|}{$\begin{array}{l}\text { Monthly } \\
\text { Runoff, } \\
\text { Runoff, }\end{array}$} & $\begin{array}{r}130 \\
0.69 \\
7,980 \\
\end{array}$ & $\begin{array}{r}816 \\
3.90 \\
45,290 \\
\end{array}$ \\
\hline
\end{tabular}

Gage height, in feet, and discharge, in cublc feet per second, at indicated time, 1963

\begin{tabular}{|c|c|c|c|c|c|c|c|c|c|c|c|}
\hline Date & Hour & $\begin{array}{c}\text { Gage } \\
\text { helght }\end{array}$ & $\begin{array}{c}\text { Dis- } \\
\text { charge }\end{array}$ & Date & Hour & $\begin{array}{c}\text { Gage } \\
\text { height }\end{array}$ & $\begin{array}{c}\text { Dis- } \\
\text { charge }\end{array}$ & Date & Hour & $\begin{array}{c}\text { Gage } \\
\text { height }\end{array}$ & $\begin{array}{c}\text { Dis- } \\
\text { charge }\end{array}$ \\
\hline $\begin{array}{r}\text { Jan. } 29 \\
30\end{array}$ & $\begin{array}{l}2400 \\
0300 \\
1000 \\
1600 \\
1800 \\
2100 \\
2400 \\
\\
0400 \\
0500 \\
0600\end{array}$ & $\begin{array}{l}1.66 \\
1.69 \\
1.67 \\
1.80 \\
1.83 \\
2.05 \\
2.28 \\
\\
2.59 \\
3.43 \\
3.64\end{array}$ & $\begin{array}{r}38 \\
41 \\
39 \\
56 \\
61 \\
100 \\
153 \\
\\
245 \\
622 \\
747\end{array}$ & Feb. 1 & $\begin{array}{l}0800 \\
1100 \\
1300 \\
1600 \\
1800 \\
2000 \\
2100 \\
2200 \\
2300 \\
2400 \\
0100\end{array}$ & $\begin{array}{l}3.91 \\
5.00 \\
5.86 \\
6.13 \\
6.84 \\
7.57 \\
7.84 \\
7.73 \\
7.75 \\
7.61 \\
7.42\end{array}$ & $\begin{array}{r}926 \\
1,880 \\
2,900 \\
3,270 \\
4,370 \\
5,690 \\
6,230 \\
6,000 \\
6,040 \\
5,770 \\
5,380\end{array}$ & Feb. $\quad 1$ & $\begin{array}{l}0600 \\
0800 \\
1100 \\
1600 \\
1900 \\
2400 \\
\\
0400 \\
0600 \\
1300 \\
1800 \\
2400\end{array}$ & $\begin{array}{l}7.52 \\
7.26 \\
6.73 \\
6.14 \\
5.94 \\
5.70 \\
5.49 \\
5.33 \\
5.00 \\
4.81 \\
4.66\end{array}$ & $\begin{array}{l}5,570 \\
5,090 \\
4,170 \\
3,270 \\
2,990 \\
2,680 \\
2,420 \\
2,230 \\
1,870 \\
1,680 \\
1,530\end{array}$ \\
\hline
\end{tabular}

11-3758.3. Budden Canyon near Beegum, Cal1f.

(Crest-stage station)

Location.-Lat $40^{\circ} 19^{\prime} 00^{\prime \prime}$, long $122^{\circ} 46^{\prime} 35^{\prime \prime}$, in $\operatorname{SE} \frac{1}{4} \operatorname{SW} \frac{1}{4} \sec .33$, T.29 N., R.8 W., on State Highway $36,4.7$ miles southeast of Beegum.

Drainage area, $--1.09 \mathrm{sq} \mathrm{m} 1$.

Gage-helght record.--Crest stages only. Altitude of gage is $1,450 \mathrm{ft}$ (from topographic map).

Discharge record.--Stage-discharge relation defined by current-meter measurements below $4.6 \mathrm{cf}$ 's and by computation of flow through culvert at 28,63 , and $66 \mathrm{cfs}$.

Maxima.--January-February 1963: Discharge, $66 \mathrm{cfs}$ Feb. 1 (gage height, $8.73 \mathrm{ft}$ ). 1960 to December 1962: Discharge, $63 \mathrm{cfs}$ Feb. 10, 1961 (gage height, $8.72^{\circ} \mathrm{ft}$ ).

11-3759.5. Cottonwood Creek tributary near Cottonwood, Calif.

(Crest-stage station)

Location.--Lat $40^{\circ} 19120^{\prime \prime}$, long $122^{\circ} 16125^{\prime \prime}$, in NW $\frac{1}{4} \mathrm{SE} \frac{1}{4}$ sec.35, T.29 N., R.4 W., on U.S. Highway $99,4.4$ miles south of Cottonwood.

Drainage area. $--0.44 \mathrm{sq} \mathrm{ml}$.

Gage-helght record.--Crest stages only. Altltude of gage is $600 \mathrm{ft}$ (from topographic map).

Discharge record.--Stage-discharge relation defined by current-meter measurements below $15 \mathrm{cf}$ s and by computation of flow through culvert at 22 and $27 \mathrm{cfs}$.

Maxima.--January-February 1963: Discharge, $8.7 \mathrm{cfs}$ Jan. 31 (gage height, $3.34 \mathrm{ft}$ ). 1960 to December 1962: Discharge, $27 \mathrm{cfs}$ 0ct. 12, 1962 (gage height, $5.16 \mathrm{ft}$, from high-water profile). 
11-3760. Cottonwood Creek near Cottonwood, Calif.

Location.--Lat $40^{\circ} 23^{\prime} 10^{\prime \prime}$, long $122^{\circ} 14^{\prime} 15^{\prime \prime}$, in $\mathrm{NE} \frac{1}{4}$ sec.7, T.29 N., R.3 W., on right bank 2 miles east of cottonwood and 2.4 miles upstream from mouth.

Drainage area. $--922 \mathrm{sq} \mathrm{mi}$.

Gage-height record.--Water-stage recorder graph, except Feb. 23-28. Altitude of gage is $370 \mathrm{ft}$ (from river-profile map).

Discharge record.--Stage-discharge relation defined by current-meter measurements. Discharge Feb. 23-28 estimated on basis of recorded range in stage, weather records, and hydrographic comparison with Middle Fork Cottonwood Creek near Ono.

Maxima.--January-February 1963: Discharge, 23,100 cfs 2030 hours Jan. 31 (gage height, $12.28 \mathrm{ft}$ ).

1940 to December 1962: Discharge, 52,300 cfs Mar. 1, 1941 (gage height, $15.4 \mathrm{ft}$ ).

Mean discharge, in cublc feet per second, 1963

\begin{tabular}{|c|c|c|c|c|c|c|c|c|}
\hline Day & January & February & Day & January & February & Day & January & February \\
\hline $\begin{array}{c}1 \ldots \ldots \\
2 \ldots \ldots \\
3 \ldots \ldots \\
4 \ldots \ldots \\
6 \ldots \ldots \\
7 \ldots \ldots \\
8 \ldots \ldots \\
9 \ldots \ldots \\
10 \ldots \ldots\end{array}$ & $\begin{array}{l}280 \\
274 \\
268 \\
256 \\
250 \\
241 \\
232 \\
226 \\
223 \\
217\end{array}$ & $\begin{array}{r}12,600 \\
5,340 \\
4,070 \\
2,990 \\
2,410 \\
1,960 \\
1,700 \\
1,520 \\
2,060 \\
7,730\end{array}$ & $\begin{array}{l}11 \ldots \ldots \\
12 \ldots \ldots \\
13 \ldots \ldots \\
14 \ldots \ldots \\
15 \ldots \ldots \\
16 \ldots \ldots \\
17 \ldots \ldots \\
18 \ldots \ldots \\
19 \ldots \ldots \\
20 \ldots \ldots\end{array}$ & $\begin{array}{l}208 \\
188 \\
172 \\
180 \\
208 \\
205 \\
193 \\
190 \\
182 \\
178\end{array}$ & $\begin{array}{l}4,430 \\
3,750 \\
4,860 \\
3,270 \\
2,550 \\
2,160 \\
2,170 \\
1,610 \\
1,330 \\
1,150\end{array}$ & $\begin{array}{l}21 \ldots \ldots \\
22 \ldots \ldots \\
23 \ldots \ldots \\
24 \ldots \ldots \\
25 \ldots \ldots \\
26 \ldots \ldots \\
27 \ldots \ldots \\
28 \ldots \ldots \\
29 \ldots \ldots \\
30 \ldots \ldots \\
31 \ldots \ldots\end{array}$ & $\begin{array}{r}178 \\
180 \\
178 \\
178 \\
172 \\
172 \\
170 \\
170 \\
180 \\
625 \\
10,100 \\
\end{array}$ & $\begin{array}{r}994 \\
868 \\
800 \\
740 \\
690 \\
650 \\
620 \\
590 \\
----- \\
---- \\
\end{array}$ \\
\hline \multicolumn{7}{|c|}{ 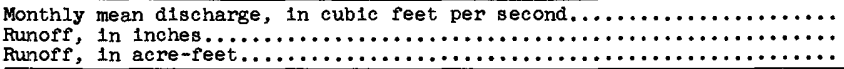 } & $\begin{array}{r}538 \\
0.67 \\
33,070 \\
\end{array}$ & $\begin{array}{r}2,700 \\
3.05 \\
150,000 \\
\end{array}$ \\
\hline
\end{tabular}

Gage he1ght, In feet, and discharge, In cublc feet per second, at indicated time, 1963

\begin{tabular}{|c|c|c|c|c|c|c|c|c|c|c|c|}
\hline Date & Hour & $\begin{array}{c}\text { Gage } \\
\text { helght }\end{array}$ & $\begin{array}{l}\text { D1s- } \\
\text { charge }\end{array}$ & Date & Hour & $\begin{array}{c}\text { Gage } \\
\text { height }\end{array}$ & $\begin{array}{c}\text { D1s- } \\
\text { charge }\end{array}$ & Date & Hour & $\begin{array}{c}\text { Gage } \\
\text { helght }\end{array}$ & $\begin{array}{c}\text { D1s- } \\
\text { charge }\end{array}$ \\
\hline $\begin{array}{r}\text { Jan. } 29 \\
30\end{array}$ & $\begin{array}{l}2400 \\
0700 \\
1400 \\
1600 \\
1900 \\
2000 \\
2100 \\
2400\end{array}$ & $\begin{array}{l}1.26 \\
1.27 \\
1.75 \\
2.82 \\
3.15 \\
4.25 \\
4.65 \\
4.20\end{array}$ & $\begin{array}{r}205 \\
205 \\
332 \\
709 \\
870 \\
1,820 \\
2,280 \\
1,760\end{array}$ & Jan. 31 & $\begin{array}{l}0100 \\
0300 \\
0500 \\
0900 \\
1200 \\
1400 \\
1600 \\
2030 \\
2400\end{array}$ & $\begin{array}{r}4.13 \\
4.35 \\
4.30 \\
5.39 \\
7.28 \\
9.49 \\
11.01 \\
12.28 \\
11.70\end{array}$ & $\begin{array}{r}1,680 \\
1,920 \\
1,870 \\
3,250 \\
7,050 \\
12,900 \\
17,300 \\
23,100 \\
20,200\end{array}$ & Feb. 1 & $\begin{array}{l}0600 \\
1200 \\
1800 \\
2400 \\
\\
0600 \\
1200 \\
1800 \\
2400 \\
\end{array}$ & $\begin{array}{r}10.66 \\
9.68 \\
8.66 \\
8.11 \\
7.48 \\
6.96 \\
6.66 \\
6.38 \\
\end{array}$ & $\begin{array}{r}15,800 \\
12,300 \\
9,000 \\
7,680 \\
6,270 \\
5,260 \\
4,700 \\
4,190\end{array}$ \\
\hline
\end{tabular}

\section{1-3762. Summit Creek near Mineral, Calif.}

(Crest-stage station)

Location.--Lat $40^{\circ} 22^{1} 05^{\prime \prime}$, long $121^{\circ} 32^{\prime} 20^{\prime \prime}$, In $\mathrm{SW}_{\frac{1}{4}} \mathrm{SE} \frac{1}{4}$ sec.16, T.29 N., R.4 E., on State Highway $36,3.3$ miles northeast of Mineral.

Drainage area. $--1.80 \mathrm{sq} \mathrm{m}$.

Gage-height record.--Crest stages only. Altitude of gage 1s 5,600 ft (from topographic map).

D1.scharge record.--Stage-discharge relation defined by current-meter measurements below $26 \mathrm{cfs}$ and by computation of flow through culvert at 88 and $100 \mathrm{cfs}$.

Maxima.--January-February 1963: Discharge, $100 \mathrm{cfs} F \mathrm{Feb}, 1$ (gage height, $8.25 \mathrm{ft}$ ). 1960 to December 1962: D1scharge, $88 \mathrm{cfs}$ 0ct. 13, 1962 (gage helght, $7.92 \mathrm{ft}$, from high-water profile). 
11-3765.5. Battle Creek below Coleman Fish Hatchery, near Cottonwood, Calif.

Location.--Lat $40^{\circ} 23^{\prime} 55^{\prime \prime}$, long $122^{\circ} 08^{\prime} 45^{\prime \prime}$, in SW $\frac{1}{4} \mathrm{NE} \frac{1}{4} \sec .1$, T.29 N., R.3 W., on right bank 3.7 miles downstream from Spring Branch, $5.7 \mathrm{miles}$ upatream from mouth, and 7.0 miles east of Cottonwood.

Drainage area. $--358 \mathrm{sq} \mathrm{mi}$.

Gage-height record;--Water-stage recorder graph. Altitude of gage is $415 \mathrm{ft}$ (from topographic map).

Discharge record.--Stage-discharge relation defined by current-meter measurements.

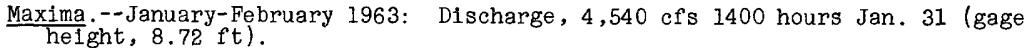

1937 to December 1962: Discharge, 35,000 efs Dec. 11, 1937 (gage height,

$15.8 \mathrm{ft}$, from floodmarks at former site and datum), from slope-area measurement of peak flow.

Mean discharge, in cub1c feet per second, 1963

\begin{tabular}{|c|c|c|c|c|c|c|c|c|}
\hline Day & January & February & Day & January & February & Day & January & February \\
\hline $\begin{array}{c}1 \ldots \ldots \\
2 \ldots \ldots \\
3 \ldots \ldots \\
5 \ldots \ldots \\
6 \ldots \ldots \\
7 \ldots \ldots \\
8 \ldots \ldots \\
9 \ldots \ldots \\
10 \ldots \ldots\end{array}$ & $\begin{array}{l}376 \\
372 \\
368 \\
368 \\
358 \\
354 \\
350 \\
354 \\
345 \\
345\end{array}$ & $\begin{array}{r}2,540 \\
1,280 \\
1,380 \\
1,120 \\
1,010 \\
849 \\
752 \\
722 \\
698 \\
674\end{array}$ & $\begin{array}{l}11 \ldots \ldots \\
12 \ldots \ldots \\
13 \ldots \ldots \\
14 \ldots \ldots \\
15 \ldots \ldots \\
16 \ldots \ldots \\
17 \ldots \ldots \\
18 \ldots \ldots \\
19 \ldots \ldots \\
20 \ldots \ldots\end{array}$ & $\begin{array}{l}327 \\
314 \\
309 \\
322 \\
332 \\
327 \\
322 \\
318 \\
318 \\
314\end{array}$ & $\begin{array}{l}644 \\
656 \\
776 \\
626 \\
566 \\
560 \\
614 \\
544 \\
522 \\
510\end{array}$ & $\begin{array}{l}21 \ldots \ldots \\
22 \ldots \ldots \\
23 \ldots \ldots \\
24 \ldots \ldots \\
25 \ldots \ldots \\
26 \ldots \ldots \\
27 \ldots \ldots \\
28 \ldots \ldots \\
29 \ldots \ldots \\
30 \ldots \ldots \\
31 \ldots \ldots\end{array}$ & $\begin{array}{r}318 \\
318 \\
317 \\
318 \\
314 \\
314 \\
309 \\
309 \\
327 \\
1,800 \\
3,080\end{array}$ & $\begin{array}{r}505 \\
472 \\
450 \\
440 \\
425 \\
415 \\
400 \\
390 \\
-\div--- \\
-----\end{array}$ \\
\hline \multicolumn{7}{|c|}{ 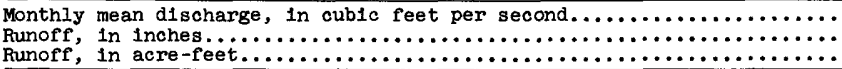 } & $\begin{array}{r}468 \\
1.51 \\
28,790\end{array}$ & $\begin{array}{r}734 \\
2.13 \\
40,740 \\
\end{array}$ \\
\hline
\end{tabular}

Gage height, in feet, and discharge, in cublo feet per second, at indicated time, 1963

\begin{tabular}{|c|c|c|c|c|c|c|c|c|c|c|c|}
\hline Date & Hour & $\begin{array}{c}\text { Gage } \\
\text { helght }\end{array}$ & $\begin{array}{l}\text { D1s- } \\
\text { charge }\end{array}$ & Date & Hour & $\begin{array}{c}\text { Gage } \\
\text { helght }\end{array}$ & $\begin{array}{c}\text { Dis- } \\
\text { charge }\end{array}$ & Date & Hour & $\begin{array}{c}\text { Gage } \\
\text { helght }\end{array}$ & $\begin{array}{l}\text { Dis- } \\
\text { charge }\end{array}$ \\
\hline $\begin{array}{r}\text { Jan. } 29 \\
30\end{array}$ & $\begin{array}{l}2400 \\
0600 \\
0900 \\
1100 \\
1300 \\
1600 \\
1700 \\
2100 \\
2400\end{array}$ & $\begin{array}{l}4.22 \\
4.35 \\
4.67 \\
5.42 \\
6.63 \\
8.30 \\
8.40 \\
7.35 \\
6.29\end{array}$ & $\begin{array}{r}355 \\
412 \\
556 \\
1,010 \\
2,150 \\
4,040 \\
4,160 \\
2,940 \\
1,790\end{array}$ & Jan. 31 & $\begin{array}{l}0200 \\
0300 \\
0500 \\
0700 \\
1100 \\
1400 \\
1900 \\
2100 \\
2200 \\
2400\end{array}$ & $\begin{array}{l}5.30 \\
5.99 \\
6.08 \\
6.75 \\
7.61 \\
8.72 \\
7.86 \\
8.28 \\
8.34 \\
8.10\end{array}$ & $\begin{array}{l}1,320 \\
1,490 \\
1,580 \\
2,280 \\
3,230 \\
4,540 \\
3,540 \\
4,030 \\
4,100 \\
3,820\end{array}$ & Feb. 1 & $\begin{array}{l}0030 \\
0130 \\
0500 \\
0600 \\
0800 \\
1000 \\
1200 \\
1500 \\
1800 \\
2100 \\
2400\end{array}$ & $\begin{array}{l}7.98 \\
8.38 \\
7.77 \\
7.66 \\
7.30 \\
7.00 \\
6.69 \\
6.39 \\
6.16 \\
6.09 \\
5.97\end{array}$ & $\begin{array}{l}3,680 \\
4,150 \\
3,430 \\
3,320 \\
2,930 \\
2,600 \\
2,270 \\
1,960 \\
1,730 \\
1,660 \\
1,540\end{array}$ \\
\hline
\end{tabular}

11-3775. Paynes Creek near Red Bluff, Calif.

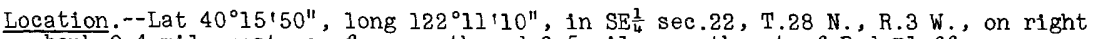
bank 0.4 mile upstream from mouth and 6.5 miles northeast of Red Bluff.'

Drainage area. $--92.7 \mathrm{sq} \mathrm{mi}$.

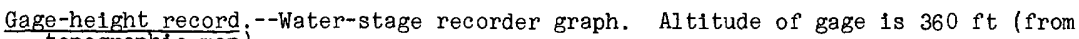
topographic mapj.

D1scharge record.--Stage-discharge relation defined by current-meter measurements.

Maxima.--January-February 1963: Discharge, 3,300 cfs 1700 hours Jan. 30 (gage helght, $7.65 \mathrm{ft}$ ).

1949 to December 1962: Discharge, 10,600 cfs Dec. 1, 1961 (gage height, $11.33 \mathrm{ftl}$. 
Mean discharge, in cublc feet per second, 1963, of Paynes Creek near Red Bluff, Callf.

\begin{tabular}{|c|c|c|c|c|c|c|c|c|}
\hline Day & January & February & Day & January & February & Day & January & February \\
\hline $\begin{array}{r}1 \ldots \ldots \\
2 \ldots \ldots \\
3 \ldots \ldots \\
4 \ldots \ldots \\
5 \ldots \ldots \\
7 \ldots \ldots \\
8 \ldots \ldots \\
9 \ldots \ldots \\
10 \ldots \ldots \\
\end{array}$ & $\begin{array}{l}22 \\
21 \\
21 \\
20 \\
19 \\
19 \\
18 \\
18 \\
18 \\
18\end{array}$ & $\begin{array}{r}631 \\
344 \\
355 \\
241 \\
182 \\
136 \\
109 \\
104 \\
100 \\
93 \\
.\end{array}$ & $\begin{array}{l}11 \ldots \ldots \\
12 \ldots \ldots \\
13 \ldots \ldots \\
14 \ldots \ldots \\
15 \ldots \ldots \\
16 \ldots \ldots \\
17 \ldots \ldots \\
18 \ldots \ldots \\
19 \ldots \ldots \\
20 \ldots \ldots\end{array}$ & $\begin{array}{l}18 \\
18 \\
18 \\
18 \\
18 \\
18 \\
18 \\
17 \\
16 \\
16\end{array}$ & \begin{tabular}{r|}
82 \\
154 \\
278 \\
144 \\
102 \\
96 \\
150 \\
87 \\
72 \\
64
\end{tabular} & $\begin{array}{l}21 \ldots \ldots \\
22 \ldots \ldots \\
23 \ldots \ldots \\
24 \ldots \ldots \\
25 \ldots \ldots \\
26 \ldots \ldots \\
27 \ldots \ldots \\
28 \ldots \ldots \\
29 \ldots \ldots \\
30 \ldots \ldots \\
31 \ldots \ldots\end{array}$ & $\begin{array}{r}16 \\
16 \\
16 \\
16 \\
15 \\
15 \\
15 \\
15 \\
17 \\
1,270 \\
1,740\end{array}$ & $\begin{array}{r}56 \\
47 \\
41 \\
36 \\
34 \\
32 \\
29 \\
28 \\
-\ldots-.-- \\
-\ldots-.--\end{array}$ \\
\hline inoff & acre- & & & & & & $\begin{array}{r}114 \\
1.41 \\
6,980\end{array}$ & $\begin{array}{r}137 \\
1.54 \\
7,590 \\
\end{array}$ \\
\hline
\end{tabular}

Gage height, in feet, and discharge, in cub1c feet per second, at indicated time, 1963

\begin{tabular}{|c|c|c|c|c|c|c|c|c|c|c|c|}
\hline Date & Hour & $\begin{array}{c}\text { Gage } \\
\text { helght }\end{array}$ & $\begin{array}{l}\text { Dis- } \\
\text { charge }\end{array}$ & Date & Hour & $\begin{array}{c}\text { Gage } \\
\text { height }\end{array}$ & $\begin{array}{c}\text { Dis- } \\
\text { charge }\end{array}$ & Date & Hour & $\begin{array}{c}\text { Gage } \\
\text { helght }\end{array}$ & $\begin{array}{l}\text { Dis - } \\
\text { charge }\end{array}$ \\
\hline $\begin{array}{r}\text { Jan. } \\
30\end{array}$ & $\begin{array}{l}2400 \\
0700 \\
0900 \\
1100 \\
1200 \\
1400 \\
1600 \\
1700 \\
1900\end{array}$ & $\begin{array}{l}2.65 \\
2.91 \\
3.28 \\
4.32 \\
4.91 \\
6.45 \\
7.55 \\
7.65 \\
7.48\end{array}$ & $\begin{array}{r}24 \\
57 \\
134 \\
482 \\
762 \\
1,920 \\
3,160 \\
3,300 \\
3,040\end{array}$ & Jan. 30 & $\begin{array}{l}2200 \\
2400 \\
0400 \\
0600 \\
0700 \\
0900 \\
1400 \\
1800 \\
2400\end{array}$ & $\begin{array}{l}6.65 \\
6.00 \\
5.22 \\
5.35 \\
6.00 \\
6.76 \\
7.25 \\
6.28 \\
5.28\end{array}$ & $\begin{array}{r}2,120 \\
1,510 \\
\\
942 \\
1,020 \\
1,510 \\
2,230 \\
2,790 \\
1,760 \\
978\end{array}$ & Feb. 1 & $\begin{array}{l}0500 \\
1500 \\
2400 \\
1000 \\
1500 \\
2200 \\
2400\end{array}$ & $\begin{array}{l}4.93 \\
4.45 \\
4.18 \\
3.96 \\
3.95 \\
3.87 \\
3.89\end{array}$ & $\begin{array}{l}768 \\
530 \\
422 \\
\\
341 \\
338 \\
310 \\
316\end{array}$ \\
\hline
\end{tabular}

11-3780. Sacramento River near Red Bluff, Calif.

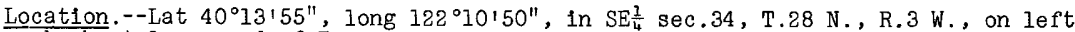
bank at lower end of Iron Canyon, 0.5 mile downstream from Sevenmile Creek and 4.6 miles northeast of Red Bluff.

Drainage area.--9,022 sq $\mathrm{mi}$, excluding Goose Lake basin.

Gage-he1ght record.--Water-stage recorder graph. Datum of gage is $253.18 \mathrm{ft}$ above mean sea level, datum of 1929 (levels by Corps of Engineers).

Discharge record.--Stage-discharge relation defined by current-meter measurements.

Maxima.--January-February 1963: Discharge, 76,700 cfs 0200 hours Feb. 1 (gage helght, $17.16 \mathrm{ft}$ ).

1878-88, 1892 to December 1962: D1scharge, 291,000 cfs Feb. 28, 1940 (gage

height, $38.9 \mathrm{ft}$ ), from rating curve extended above $170,000 \mathrm{cfs}$ on bas $1 \mathrm{~s}$ of veloc1ty-area studies.

Remarks.--Floodflow affected by Shasta Lake (see station 11-3700).

Mean discharge, in cubic feet per second, 1963

\begin{tabular}{|c|c|c|c|c|c|c|c|c|}
\hline Day & January & February & Day & January & February & Day & January & February \\
\hline $\begin{array}{c}1 \ldots \ldots \\
3 \ldots \ldots \\
4 \ldots \ldots \\
5 \ldots \ldots \\
6 \ldots \ldots \\
7 \ldots \ldots \\
9 \ldots \ldots \\
10 \ldots \ldots\end{array}$ & $\begin{array}{r}12,700 \\
12,500 \\
12,200 \\
11,900 \\
11,400 \\
11,300 \\
11,200 \\
10,700 \\
10,200 \\
9,690\end{array}$ & $\begin{array}{l}52,300 \\
27,300 \\
23,300 \\
19,900 \\
18,000 \\
16,600 \\
17,400 \\
17,300 \\
18,000 \\
24,800\end{array}$ & $\begin{array}{l}11 \ldots \ldots \\
12 \ldots \ldots \\
13 \ldots \ldots \\
14 \ldots \ldots \\
15 \ldots \ldots \\
16 \ldots \ldots \\
17 \ldots \ldots \\
18 \ldots \ldots \\
19 \ldots \ldots \\
20 \ldots \ldots\end{array}$ & $\begin{array}{l}9,150 \\
8,540 \\
8,130 \\
8,130 \\
8,130 \\
7,700 \\
7,670 \\
7,590 \\
7,560 \\
7,210\end{array}$ & $\begin{array}{l}22,300 \\
19,800 \\
26,000 \\
22,300 \\
20,200 \\
19,200 \\
20,000 \\
18,600 \\
17,000 \\
15,000\end{array}$ & $\begin{array}{l}21 \ldots \ldots \\
22 \ldots \ldots \\
23 \ldots \ldots \\
24 \ldots \ldots \\
25 \ldots \ldots \\
26 \ldots \ldots \\
27 \ldots \ldots \\
28 \ldots \ldots \\
29 \ldots \ldots \\
30 \ldots \ldots \\
31 \ldots \ldots\end{array}$ & $\begin{array}{r}7,240 \\
7,240 \\
7,240 \\
7,240 \\
7,290 \\
7,240 \\
7,240 \\
7,240 \\
7,320 \\
15,100 \\
38,600\end{array}$ & $\begin{array}{r}13,800 \\
15,300 \\
15,900 \\
15,600 \\
15,500 \\
15,400 \\
15,200 \\
15,100 \\
--1--- \\
--1---\end{array}$ \\
\hline \multicolumn{7}{|c|}{ 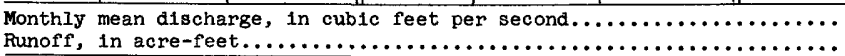 } & $\begin{array}{r}10,080 \\
620,000\end{array}$ & $\begin{array}{r}19,900 \\
1,105,000\end{array}$ \\
\hline
\end{tabular}


Gage helght, in feet, and discharge, in cub1c feet per second, at indicated t1me, 1963, of

\begin{tabular}{|c|c|c|c|c|c|c|c|c|c|c|c|}
\hline Date & Hour & $\begin{array}{c}\text { Gage } \\
\text { he1ght }\end{array}$ & $\begin{array}{l}\text { Dis- } \\
\text { charge }\end{array}$ & Date & Hour & $\begin{array}{c}\text { Gage } \\
\text { height }\end{array}$ & $\begin{array}{l}\text { Dis- } \\
\text { charge }\end{array}$ & Date & Hour & $\begin{array}{c}\text { Gage } \\
\text { height }\end{array}$ & $\begin{array}{l}\text { D1s- } \\
\text { charge }\end{array}$ \\
\hline $\begin{array}{r}\text { Jan. } 29 \\
30\end{array}$ & $\begin{array}{l}2400 \\
0900 \\
1100 \\
1300 \\
1900 \\
2100 \\
2300 \\
2400 \\
\\
0300 \\
0700 \\
0900 \\
1100\end{array}$ & $\begin{array}{l}2.45 \\
2.66 \\
2.90 \\
3.64 \\
7.64 \\
8.68 \\
9.13 \\
9.13 \\
8.88 \\
8.17 \\
8.00 \\
8.17\end{array}$ & $\begin{array}{r}7,640 \\
8,210 \\
8,870 \\
11,000 \\
25,000 \\
29,500 \\
31,600 \\
31,600 \\
30,400 \\
27,200 \\
26,500 \\
27,200 \\
\end{array}$ & Feb. I & $\begin{array}{l}1300 \\
1500 \\
1700 \\
2000 \\
2200 \\
2400 \\
0100 \\
0200 \\
0400 \\
0900 \\
1300 \\
1900 \\
2000\end{array}$ & $\begin{array}{r}8.92 \\
10.00 \\
11.00 \\
13.86 \\
15.69 \\
16.81 \\
17.10 \\
17.16 \\
16.60 \\
13.83 \\
12.18 \\
10.00 \\
9.83\end{array}$ & $\begin{array}{l}30,600 \\
35,800 \\
40,800 \\
56,000 \\
67,100 \\
74,300 \\
76,300 \\
76,700 \\
73,000 \\
55,800 \\
46,800 \\
35,800 \\
35,000\end{array}$ & Feb. 1 & $\begin{array}{l}2100 \\
2200 \\
2400 \\
\\
0300 \\
0600 \\
1200 \\
1400 \\
1600 \\
1800 \\
2100 \\
2400\end{array}$ & $\begin{array}{r}9.86 \\
10.00 \\
10.33 \\
9.76 \\
8.58 \\
7.62 \\
7.52 \\
7.40 \\
7.40 \\
7.46 \\
7.31\end{array}$ & $\begin{array}{l}35,100 \\
35,800 \\
37,400 \\
\\
34,600 \\
29,100 \\
24,900 \\
24,500 \\
24,000 \\
24,000 \\
24,200 \\
23,600 .\end{array}$ \\
\hline
\end{tabular}

11-3787. Vale Gulch tributary near Red Bank, Calif.

(Crest-stage station)

Location.--Lat $40^{\circ} 04^{\prime} 00^{\prime \prime}$, long $122^{\circ} 29^{\prime} 12^{\prime \prime}$, in SW $\frac{1}{4} N E \frac{1}{4} \sec .36$, T.26 N., R.6 W., $3.2 \mathrm{miles}$ southwest of Red Bank.

Drainage area. $-0.19 \mathrm{sq} \mathrm{mi}$.

Gage-helght record.--Crest stages only. Alt1tude of gage is $670 \mathrm{ft}$ (from topographic map T.

Discharge record.--Maximum discharge by computation of flow through culvert.

Maxima.--January-February 1963: Discharge, $27 \mathrm{cfs}$ Feb. 1 (gage height, $4.41 \mathrm{ft}$ ). 1960 to December 1962: Discharge, $53 \mathrm{cfs}$ Dec. 1, 1961 (gage helght, $5.97 \mathrm{ft}$ ).

11-3788. Red Bank Creek near Red Bluff, Calif.

Location.--Lat $40^{\circ} 05^{\prime} 25^{\prime \prime}$, long $122^{\circ} 24145^{\prime \prime}$, in SE $\frac{1}{4} \sec .22$, T.26 N., R.5 W., on road bridge near left bank, 0.1 mile downstream from unnamed tributary, 1.8 miles southeast of town of Red Bank, and about 13 miles west of Red Bluff.

Drainage area. $--93.5 \mathrm{sq} \mathrm{mi}$.

Gage-height record.--Water-stage recorder graph, except Jan. 6-29. Altitude of gage is $470 \mathrm{ft}^{2}$ (from topographic map).

Discharge record.--Stage-discharge relation defined by current-meter measurements . Discharge for period Jan. 6-29 estimated on one discharge measurement and records for Elder Creek near Paskenta.

Maxima.--January-February 1963: Discharge, 5,770 cfs 1300 hours Jan. 31 (gage height, $8.67 \mathrm{ft}$ ).

1959 to December 1962: Discharge, 2,980 cfs Feb. 13, 1962 (gage height, $8.30 \mathrm{ft}$ ).

Remarks.--Records furnished by California Department of Water Resources and reviewed by Geologlcal Survey.

Mean discharge, in cubic feet per second, 1963

\begin{tabular}{|c|c|c|c|c|c|c|c|c|}
\hline Day & January & February & Day & January & February & Day & January & February \\
\hline $\begin{array}{c}\ldots \ldots \\
2 \ldots \ldots \\
3 \ldots \ldots \\
4 \ldots \ldots \\
5 \ldots \ldots \\
6 \ldots \ldots \\
7 \ldots \ldots \\
8 \ldots \ldots \\
9 \ldots \ldots \\
10 \ldots \ldots\end{array}$ & $\begin{array}{l}5.9 \\
5.4 \\
5.4 \\
4.4 \\
4 \\
3 \\
\\
2\end{array}$ & $\begin{array}{l}648 \\
290 \\
228 \\
197 \\
167 \\
145 \\
126 \\
127 \\
693 \\
953\end{array}$ & $\begin{array}{l}11 \ldots \ldots \\
12 \ldots \ldots \\
13 \ldots \ldots \\
14 \ldots \ldots \\
15 \ldots \ldots \\
16 \ldots \ldots \\
17 \ldots \ldots \\
18 \ldots \ldots \\
19 \ldots \ldots \\
20 \ldots \ldots\end{array}$ & 1 & $\begin{array}{r}229 \\
414 \\
321 \\
151 \\
108 \\
112 \\
130 \\
84 \\
67 \\
57\end{array}$ & $\begin{array}{l}21 \ldots \ldots \\
22 \ldots \ldots \\
23 \ldots \ldots \\
24 \ldots \ldots \\
25 \ldots \ldots \\
26 \ldots \ldots \\
27 \ldots \ldots \\
28 \ldots \ldots \\
29 \ldots \ldots \\
30 \ldots \ldots \\
31 \ldots \ldots\end{array}$ & $\begin{array}{r}318 \\
2,350\end{array}$ & $\begin{array}{r}47 \\
36 \\
31 \\
26 \\
23 \\
19 \\
18 \\
16 \\
---.-\end{array}$ \\
\hline \multicolumn{7}{|l|}{$\begin{array}{l}\text { Monthly } \\
\text { Runoff, } \\
\text { Runoff, }\end{array}$} & $\begin{array}{r}88.0 \\
1.08 \\
5,410 \\
\end{array}$ & $\begin{array}{r}195 \\
2.17 \\
10,840 \\
\end{array}$ \\
\hline
\end{tabular}


Gage helght, in feet, and discharge, in cublc feet per second, at indicated time, 1963, of Red Bank Creek near Red Bluff, Calif.

\begin{tabular}{|c|c|c|c|c|c|c|c|c|c|c|c|}
\hline Date & Hour & $\begin{array}{c}\text { Gage } \\
\text { he1ght }\end{array}$ & $\begin{array}{l}\text { Dis- } \\
\text { charge }\end{array}$ & Date & Hour & $\begin{array}{c}\text { Gage } \\
\text { helght }\end{array}$ & $\begin{array}{c}\text { Dis- } \\
\text { charge }\end{array}$ & Date & Hour & $\begin{array}{c}\text { Gage } \\
\text { helght }\end{array}$ & $\begin{array}{c}\text { D1s- } \\
\text { charge }\end{array}$ \\
\hline $\begin{array}{r}\overline{\operatorname{Jan}} .29 \\
30\end{array}$ & $\begin{array}{l}2400 \\
1000 \\
1100 \\
1200 \\
1300 \\
1400 \\
1500 \\
1600 \\
1800 \\
2100 \\
2400\end{array}$ & $\begin{array}{l}4.43 \\
4.49 \\
4.56 \\
4.80 \\
5.50 \\
6.30 \\
6.58 \\
6.51 \\
6.17 \\
5.86 \\
5.60\end{array}$ & $\begin{array}{c}3.6 \\
5.9 \\
10 \\
37 \\
257 \\
860 \\
1,180 \\
1,190 \\
732 \\
476 \\
310\end{array}$ & Jan. 31 & $\begin{array}{l}0300 \\
0400 \\
0500 \\
0700 \\
0800 \\
0900 \\
1000 \\
1100 \\
1200 \\
1300 \\
1400 \\
1600\end{array}$ & $\begin{array}{l}5.47 \\
5.46 \\
5.60 \\
5.92 \\
6.30 \\
6.82 \\
7.75 \\
8.40 \\
8.60 \\
8.67 \\
8.55 \\
8.15\end{array}$ & $\begin{array}{r}242 \\
237 \\
310 \\
520 \\
860 \\
1,500 \\
3,230 \\
4,930 \\
5,550 \\
5,770 \\
5,390 \\
4,230\end{array}$ & Jan. 31 & $\begin{array}{l}1800 \\
2100 \\
2400 \\
\\
0300 \\
0900 \\
1500 \\
2400 \\
\\
0600 \\
1200 \\
1800 \\
2400\end{array}$ & $\begin{array}{l}7.66 \\
6.95 \\
6.64 \\
6.48 \\
6.09 \\
5.88 \\
5.70 \\
5.62 \\
5.57 \\
5.52 \\
5.48\end{array}$ & $\begin{array}{r}3,030 \\
1,700 \\
1,260 \\
1,050 \\
651 \\
483 \\
362 \\
\\
315 \\
288 \\
262 \\
242\end{array}$ \\
\hline
\end{tabular}

11-3790. Antelope Creek near Red Bluff, Calif.

Location.--Lat $40^{\circ} 12^{\prime} 10^{\prime \prime}$, long $122^{\circ} 07^{\prime} 05^{\prime \prime}$, in R10 De Los Berrendos Grant, on right bank 1.8 miles upstream from diversion dam of Los Molinos Mutual Water Co.,

6.5 miles east of Red Bluff, Tehama County, and 9.7 miles upstream from mouth.

Drainage area. $--123 \mathrm{sq} \mathrm{ml}$.

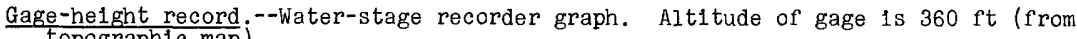
topographic map) .

Discharge record.--Stage-discharge relation defined by current-meter measurements below $3,100 \mathrm{cf}$ 's and by slope-area measurement at $11,100 \mathrm{cfs}$.

Maxima --January-February 1963: D1scharge, 3,740 cfs 1400 hours Jan. 31 (gage height, $9.67 \mathrm{ft}$ ).

1940 to December 1962: Discharge, 11,500 cfs Feb. 22, 1956 (gage height, $12.43 \mathrm{ft}$ ).

Flood of December 1937 reached a stage of about $22 \mathrm{ft}$, from floodmarks, at former site and datum.

Mean discharge, in cubic feet per second, 1963

\begin{tabular}{|c|c|c|c|c|c|c|c|c|}
\hline Day & January & February & Day & January & Febmuary & Day & January & February \\
\hline $\begin{array}{c}\ldots \ldots \\
2 \ldots \ldots \\
3 \ldots \ldots \\
4 \ldots \ldots \\
5 \ldots \ldots \\
7 \ldots \ldots \\
8 \ldots \ldots \\
9 \ldots \ldots \\
10 \ldots \ldots\end{array}$ & $\begin{array}{l}74 \\
70 \\
68 \\
67 \\
64 \\
62 \\
61 \\
59 \\
57 \\
56\end{array}$ & $\begin{array}{r}1,380 \\
668 \\
696 \\
493 \\
391 \\
308 \\
261 \\
251 \\
227 \\
209\end{array}$ & $\begin{array}{l}11 \ldots \ldots \\
12 \ldots \ldots \\
13 \ldots \ldots \\
14 \ldots \ldots \\
15 \ldots \ldots \\
16 \ldots \ldots \\
17 \ldots \ldots \\
18 \ldots \ldots \\
19 \ldots \ldots \\
20 \ldots \ldots\end{array}$ & $\begin{array}{l}53 \\
48 \\
49 \\
53 \\
51 \\
50 \\
50 \\
48 \\
48 \\
48\end{array}$ & $\begin{array}{l}193 \\
199 \\
292 \\
225 \\
195 \\
177 \\
185 \\
159 \\
143 \\
137\end{array}$ & $\begin{array}{l}21 \ldots \ldots \\
22 \ldots \ldots \\
23 \ldots \ldots \\
24 \ldots \ldots \\
25 \ldots \ldots \\
26 \ldots \ldots \\
27 \ldots \ldots \\
28 \ldots \ldots \\
29 \ldots \ldots \\
30 \ldots \ldots \\
31 \ldots \ldots\end{array}$ & $\begin{array}{r}48 \\
48 \\
48 \\
48 \\
47 \\
46 \\
46 \\
46 \\
51 \\
1,130 \\
2,230\end{array}$ & $\begin{array}{r}128 \\
116 \\
108 \\
103 \\
97 \\
94 \\
88 \\
83 \\
-\ldots--\end{array}$ \\
\hline 10 & acre-f & & & & & & $\begin{array}{r}159 \\
1.49 \\
9,770 \\
\end{array}$ & $\begin{array}{r}272 \\
2.30 \\
15,090 \\
\end{array}$ \\
\hline
\end{tabular}

Gage height, in feet, and discharge, in cublc feet per second, at indicated time, 1963

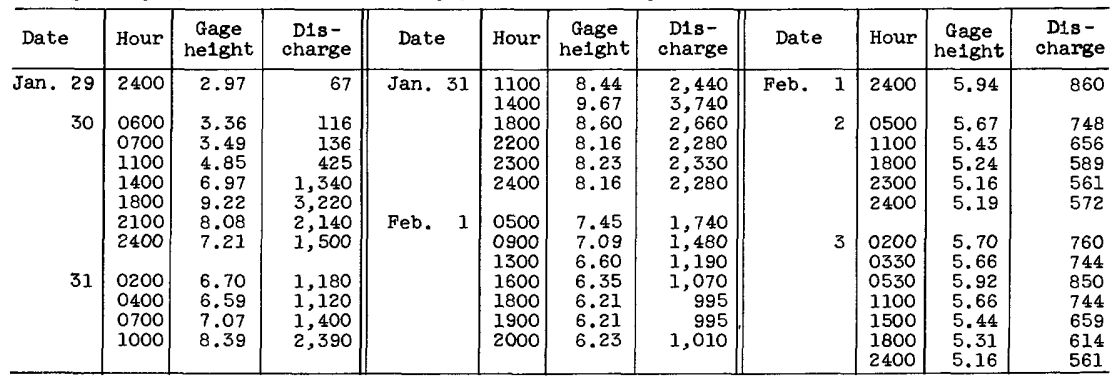


11-3795. Elder Creek near Paskenta, Calif.

Location. --Lat $40^{\circ} 01^{\prime} 30^{\prime \prime}$, long $122^{\circ} 30^{\prime} 30^{\prime \prime}$, in NW/ sec.14, T.25 N., R.6 W., on right bank 2.5 miles downstream from South Fork, 8 miles northeast of Fioumoy, and 11 miles north of Paskenta.

Drainage area. $--95.8 \mathrm{sq} \mathrm{m} 1$.

Gage-height record.--Water-stage recorder graph. No gage-height record Jan. 1. Altitude of gage is $720 \mathrm{ft}$ (from topographic map).

Discharge record. - -Stage-discharge relation defined by current-meter measurements below $3,500 \mathrm{c}$ fs and by slope-area measurements at 7,160 and $10,700 \mathrm{cfs}$. Discharge for Jan. 1 estimated on basis of ad jacent records.

Maxima.--January-February 1963: Discharge, 4,890 efs 1400 hours Jan. 31 (gage helght, $10.29 \mathrm{ft}$ ).

1948 to December 1962: Discharge, 11,700 cfs Feb. 24, 1958 (gage height, $13.90 \mathrm{ft}$ ).

Mean discharge, in cublc feet per second, 1963

\begin{tabular}{|c|c|c|c|c|c|c|c|c|}
\hline Day & January & February & Day & January & February & Day & January & February \\
\hline $\begin{array}{c}1 \ldots \ldots \\
2 \ldots \ldots \\
3 \ldots \ldots \\
4 \ldots \ldots \\
5 \ldots \ldots \\
6 \ldots \ldots \\
8 \ldots \ldots \\
9 \ldots \ldots \\
10 \ldots \ldots\end{array}$ & $\begin{array}{l}24 \\
24 \\
22 \\
22 \\
21 \\
19 \\
19 \\
18 \\
18 \\
18\end{array}$ & $\begin{array}{r}1,440 \\
541 \\
405 \\
306 \\
235 \\
195 \\
156 \\
146 \\
1,130 \\
1,860\end{array}$ & $\begin{array}{l}11 \ldots \ldots \\
12 \ldots \ldots \\
13 \ldots \ldots \\
14 \ldots \ldots \\
15 \ldots \ldots \\
16 \ldots \ldots \\
17 \ldots \ldots \\
18 \ldots \ldots \\
19 \ldots \ldots \\
20 \ldots \ldots\end{array}$ & $\begin{array}{l}16 \\
17 \\
20 \\
20 \\
16 \\
15 \\
15 \\
14 \\
14 \\
13\end{array}$ & $\begin{array}{l}661 \\
690 \\
595 \\
420 \\
342 \\
334 \\
301 \\
228 \\
211 \\
195\end{array}$ & $\begin{array}{l}21 \ldots \ldots \\
22 \ldots \ldots \\
23 \ldots \ldots \\
24 \ldots \ldots \\
25 \ldots \ldots \\
26 \ldots \ldots \\
27 \ldots \ldots \\
28 \ldots \ldots \\
29 \ldots \ldots \\
30 \ldots \ldots \\
31 \ldots \ldots\end{array}$ & $\begin{array}{r}14 \\
13 \\
13 \\
13 \\
12 \\
12 \\
12 \\
12 \\
15 \\
250 \\
2,600\end{array}$ & 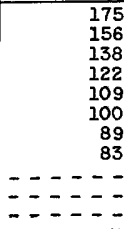 \\
\hline \multicolumn{7}{|c|}{ 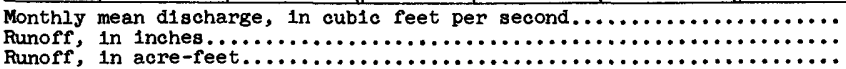 } & $\begin{array}{r}107 \\
1.29 \\
6,610\end{array}$ & 22,540 \\
\hline
\end{tabular}

Gage height, in feet, and discharge, in cublc feet per second, at indicated time, 1963

\begin{tabular}{|c|c|c|c|c|c|c|c|c|c|c|c|}
\hline Date & Hour & $\begin{array}{c}\text { Gage } \\
\text { he1ght }\end{array}$ & $\begin{array}{l}\text { D1B- } \\
\text { charge }\end{array}$ & Date & Hour & $\begin{array}{c}\text { Gage } \\
\text { helght }\end{array}$ & $\begin{array}{l}\text { D1s- } \\
\text { charge }\end{array}$ & Date & Hour & $\begin{array}{c}\text { Gage } \\
\text { helght }\end{array}$ & $\begin{array}{l}\text { D1s - } \\
\text { charge }\end{array}$ \\
\hline $\begin{array}{r}\text { Jan. } 29 \\
30\end{array}$ & $\begin{array}{l}2400 \\
0200 \\
0400 \\
0600 \\
0900 \\
1000 \\
1200 \\
1300 \\
1400 \\
1500 \\
1700\end{array}$ & $\begin{array}{l}3.13 \\
3.23 \\
3.64 \\
3.77 \\
3.65 \\
3.65 \\
3.99 \\
4.57 \\
5.54 \\
6.06 \\
5.40\end{array}$ & $\begin{array}{r}25 \\
32 \\
69 \\
86 \\
70 \\
70 \\
120 \\
238 \\
556 \\
780 \\
500\end{array}$ & Jan. 30 & $\begin{array}{l}1900 \\
2200 \\
2400 \\
\\
0300 \\
0400 \\
0700 \\
0900 \\
1000 \\
1200 \\
1300 \\
1400\end{array}$ & $\begin{array}{r}5.08 \\
4.98 \\
4.92 \\
4.85 \\
4.89 \\
5.78 \\
7.38 \\
8.72 \\
10.13 \\
10.27 \\
10.29\end{array}$ & $\begin{array}{r}383 \\
349 \\
331 \\
310 \\
322 \\
652 \\
1,610 \\
2,910 \\
4,660 \\
4,860 \\
4,890\end{array}$ & Jan. 31 & $\begin{array}{l}1500 \\
1700 \\
2100 \\
2400 \\
0300 \\
0600 \\
1100 \\
1800 \\
2400\end{array}$ & $\begin{array}{r}10.27 \\
9.88 \\
8.83 \\
8.87 \\
8.48 \\
7.62 \\
6.72 \\
6.18 \\
5.98\end{array}$ & $\begin{array}{r}4,860 \\
4,310 \\
3,030 \\
3,080 \\
2,650 \\
1,820 \\
1,150 \\
855 \\
756\end{array}$ \\
\hline
\end{tabular}

\section{1-3805. Elder Creek at Gerber, Calif.}

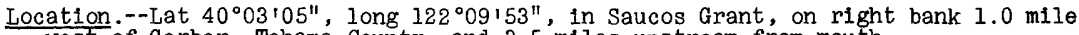
west of Gerber, Tehama County, and 3.5 miles upstream from mouth.

Drainage area. $--136 \mathrm{sq} \mathrm{ml}$.

Gage-height record.--Water-stage recorder graph. Datum of gage is $232.14 \mathrm{ft}$ above mean sea level (from Bureau of Reclamation bench mark).

Discharge record.--Stage-discharge relation defined by current-meter measurements.

Maxima.--January-February 1963: Discharge, 6,200 cfs 1600 hours Jan. 31 (gage hel ght, $10.60 \mathrm{ft})$.

1949 to December 1962: Discharge, $11,000 \mathrm{cfs}$ Feb. 19, 1958 (gage height,

$14.40 \mathrm{ft}$, at site $150 \mathrm{ft}$ upstream and at datum $4.32 \mathrm{ft}$ higher). 
Mean discharge, in cublc feet per second, 1963, of Elder Creek at Gerber, Calif.

\begin{tabular}{|c|c|c|c|c|c|c|c|c|}
\hline Day & January & February & Day & January & February & Day & January & February \\
\hline $\begin{array}{l}1 \ldots \ldots \\
2 \ldots \ldots \\
3 \ldots \ldots \\
4 \ldots \ldots \\
5 \ldots \ldots \\
6 \ldots \ldots \\
7 \ldots \ldots \\
8 \ldots \ldots \\
9 \ldots \ldots \\
10 \ldots \ldots\end{array}$ & $\begin{array}{l}18 \\
16 \\
15 \\
15 \\
14 \\
13 \\
12 \\
12 \\
11 \\
10\end{array}$ & $\begin{array}{r}1,910 \\
707 \\
430 \\
308 \\
238 \\
190 \\
159 \\
152 \\
611 \\
2,540\end{array}$ & $\begin{array}{l}11 \ldots \ldots \\
12 \ldots \ldots \\
13 \ldots \ldots \\
14 \ldots \ldots \\
15 \ldots \ldots \\
16 \ldots \ldots \\
17 \ldots \ldots \\
18 \ldots \ldots \\
19 \ldots \ldots \\
20 \ldots \ldots\end{array}$ & $\begin{array}{l}7.8 \\
9.8 \\
6.3 \\
7.3 \\
9.8 \\
9.8 \\
8.3 \\
8.3 \\
7.3 \\
7.3\end{array}$ & $\begin{array}{l}870 \\
802 \\
836 \\
440 \\
326 \\
264 \\
295 \\
198 \\
170 \\
152\end{array}$ & $\begin{array}{l}21 \ldots \ldots \\
22 \ldots \ldots \\
23 \ldots \ldots \\
24 \ldots \ldots \\
25 \ldots \ldots \\
26 \ldots \ldots \\
27 \ldots \ldots \\
28 \ldots \ldots \\
29 \ldots \ldots \\
30 \ldots \ldots \\
31 \ldots \ldots\end{array}$ & $\begin{array}{r}7.3 \\
7.3 \\
7.3 \\
7.3 \\
7.3 \\
7.3 \\
7.3 \\
7.3 \\
9.3 \\
252 \\
2,510 \\
\end{array}$ & $\begin{array}{r}134 \\
122 \\
109 \\
100 \\
95 \\
90 \\
82 \\
75 \\
--- \\
---- \\
--1\end{array}$ \\
\hline & & & & & & & $\begin{array}{r}98.3 \\
0.83 \\
6,050 \\
\end{array}$ & $\begin{array}{r}443 \\
3.39 \\
24,600 \\
\end{array}$ \\
\hline
\end{tabular}

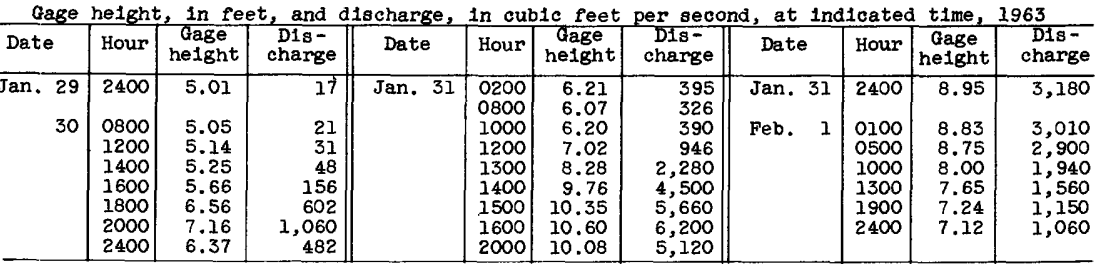

11-3815. Mill Creek near Los Molinos, Calif.

Location.--Lat $40^{\circ} 03^{\prime} 17^{\prime \prime}$, long $122^{\circ} 01^{\prime} 23^{\prime \prime}$, in NE $\frac{1}{4} \mathrm{NW} \frac{1}{4}$ sec.6, T.25 N., R.1 W., on right bank $4 \frac{1}{2}$ miles northeast of Los Molinos and 5.5 miles upstream from mouth.

Drainage area. - -131 sq $\mathrm{mi}$.

Gage-height record $j^{--W a t e r-s t a g e ~ r e c o r d e r ~ g r a p h . ~ A l t i t u d e ~ o f ~ g a g e ~ i s ~} 380 \mathrm{ft}$ (from topographic map).

Discharge record. --Stage-discharge relation defined by current-meter measurements below 5,200 cfs and by slope-area measurement at $23,000 \mathrm{cfs}$.

Maxima.--January-February 1963: Discharge, 8,600 cfs 2000 hours Jan. 31 (gage helght, $11.19 \mathrm{ft}^{\prime}$ ).

1928 to December 1962: Discharge, about 23,000 cfs Dec. 11, 1937 (gage height $23.4 \mathrm{ft}$, from floodmarks).

Mean discharge, in cuble feet per second, 1963

\begin{tabular}{|c|c|c|c|c|c|c|c|c|}
\hline Da.y & January & February & Day & Januaxy & February & Day & January & February \\
\hline $\begin{array}{c}1 \ldots \ldots \\
2 \ldots \ldots \\
3 \ldots \ldots \\
4 \ldots \ldots \\
6 \ldots \ldots \\
7 \ldots \ldots \\
8 \ldots \ldots \\
10 \ldots \ldots\end{array}$ & $\begin{array}{l}206 \\
197 \\
197 \\
190 \\
180 \\
176 \\
174 \\
172 \\
170 \\
166\end{array}$ & $\begin{array}{r}3,890 \\
1,480 \\
1,640 \\
1,190 \\
982 \\
766 \\
638 \\
610 \\
564 \\
502\end{array}$ & $\begin{array}{l}11 \ldots \ldots \\
12 \ldots \ldots \\
13 \ldots \ldots \\
14 \ldots \ldots \\
15 \ldots \ldots \\
16 \ldots \ldots \\
17 \ldots \ldots \\
18 \ldots \ldots \\
19 \ldots \ldots \\
20 \ldots \ldots\end{array}$ & $\begin{array}{l}154 \\
142 \\
146 \\
150 \\
150 \\
150 \\
146 \\
146 \\
140 \\
138\end{array}$ & $\begin{array}{l}449 \\
467 \\
575 \\
458 \\
410 \\
386 \\
383 \\
353 \\
340 \\
342\end{array}$ & $\begin{array}{l}21 \ldots \ldots \\
22 \ldots \ldots \\
23 \ldots \ldots \\
24 \ldots \ldots \\
25 \ldots \ldots \\
26 \ldots \ldots \\
27 \ldots \ldots \\
28 \ldots \ldots \\
29 \ldots \ldots \\
30 \ldots \ldots \\
31 \ldots \ldots\end{array}$ & $\begin{array}{l}140 \\
140 \\
140 \\
740 \\
738 \\
136 \\
736 \\
136 \\
150 \\
1,290 \\
4,740\end{array}$ & $\begin{array}{r}324 \\
300 \\
285 \\
273 \\
266 \\
264 \\
252 \\
242 \\
--- \\
--2 \\
--2\end{array}$ \\
\hline $\begin{array}{l}\text { nthly } \\
\text { anoff, } \\
\text { anoff, }\end{array}$ & $\begin{array}{l}\text { mean dis } \\
\text { In Inche } \\
\text { In acre }\end{array}$ & & & 2 & & $\begin{array}{c}\ldots \ldots \\
\ldots \ldots \ldots \\
\cdots\end{array}$ & $\begin{array}{r}341 \\
3.00 \\
20,980 \\
\end{array}$ & $\begin{array}{r}665 \\
5.29 \\
36,950 \\
\end{array}$ \\
\hline
\end{tabular}

Gage helght, in feet, and discharge, In cuble feet per second, at indicated time, I963

\begin{tabular}{|c|c|c|c|c|c|c|c|c|c|c|c|}
\hline Date & Hour & $\begin{array}{c}\text { Cage } \\
\text { helght }\end{array}$ & $\begin{array}{c}\text { Dis- } \\
\text { charge }\end{array}$ & Date & Hour & $\begin{array}{c}\text { Gage } \\
\text { helght }\end{array}$ & $\begin{array}{c}\text { Dis- } \\
\text { charge }\end{array}$ & Date & Hour & $\begin{array}{c}\text { Gage } \\
\text { helght }\end{array}$ & $\begin{array}{c}\text { Dis- } \\
\text { charge }\end{array}$ \\
\hline 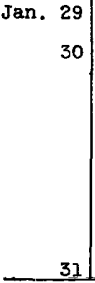 & $\begin{array}{l}2400 \\
0100 \\
0400 \\
0800 \\
1000 \\
1200 \\
1500 \\
1600 \\
1900 \\
2200 \\
2400 \\
0200\end{array}$ & $\begin{array}{l}1.80 \\
1.86 \\
2.24 \\
3.07 \\
3.85 \\
5.00 \\
6.71 \\
6.80 \\
5.70 \\
5.02 \\
5.00 \\
4.87\end{array}$ & $\begin{array}{r}186 \\
199 \\
288 \\
530 \\
838 \\
1,430 \\
2,910 \\
3,010 \\
1,940 \\
1,440 \\
1,430 \\
1,350\end{array}$ & Jan. 31 & $\begin{array}{l}0700 \\
0900 \\
1300 \\
1400 \\
2000 \\
2200 \\
2400 \\
\\
0500 \\
0600 \\
1000 \\
1500 \\
2400\end{array}$ & $\begin{array}{r}6.11 \\
6.50 \\
8.90 \\
8.80 \\
11.19 \\
10.96 \\
10.20 \\
-8.94 \\
8.80 \\
7.50 \\
6.48 \\
5.63\end{array}$ & $\begin{array}{l}2,300 \\
2,680 \\
5,620 \\
5,490 \\
8,600 \\
8,300 \\
7,310 \\
5,670 \\
5,490 \\
3,850 \\
2,660 \\
1,880\end{array}$ & Feb. Z & $\begin{array}{l}0400 \\
1000 \\
1400 \\
1900 \\
2300 \\
2400 \\
\\
0100 \\
0200 \\
0600 \\
1000 \\
1100 \\
1600 \\
2400 \\
\end{array}$ & $\begin{array}{l}5.34 \\
5.06 \\
4.88 \\
4.78 \\
4.87 \\
5.00 \\
5.05 \\
5.05 \\
5.48 \\
5.68 \\
5.68 \\
5.27 \\
4.90\end{array}$ & $\begin{array}{l}1,660 \\
1,470 \\
1,360 \\
1,300 \\
1,350 \\
1,430 \\
1,460 \\
1,460 \\
1,760 \\
1,920 \\
1,920 \\
1,610 \\
1,370\end{array}$ \\
\hline
\end{tabular}


11-3819.9. Thomes Creek tributary at Paskenta, Calif.

(Crest-stage station)

Location.--Lat $39^{\circ} 52^{\prime} 5^{\prime \prime}$, long $122^{\circ} 33^{\prime} 20^{\prime \prime}$, in NW $\frac{1}{4} \mathrm{NE} \frac{1}{4} \sec .8$, T.23 N., R.6 W. , $1.2 \mathrm{miles}$ southwest of Paskenta.

Drainage area. $--0.64 \mathrm{sq} \mathrm{ml}$.

Gage-helght record.--Crest stages only. Altitude of gage is 825 ft (from topograph1c map).

Discharge record.--Stage-discharge relation defined by current-meter measurements below $20 \mathrm{cfs}$ and by computation of flow through culvert at 47 and $53 \mathrm{cfs}$.

Maxima.--January-February 1963: Discharge, 51 cfs Jan, 31 (gage height, 5.57 ft). 1960 to December 1962: Discharge, $53 \mathrm{cfs}$ Mar. 5, 1962 (gage height, 5.60 ft).

11-3820. Thomes Creek at Paskenta, Cal1f.

Location.--Lat $39^{\circ} 52^{\prime} 55^{\prime \prime}$, long $122^{\circ} 33^{\prime} 05^{\prime \prime}$, in NW $\frac{1}{4}$ sec.4, T.23 N., R.6 W., on left bank 0.25 mile upstream from Digger Creek and 0.3 mile upstream from highway bridge at Paskenta.

Drainage area. $--194 \mathrm{sq} \mathrm{ml}$.

Gage-helght record --Water-stage recorder graph. Altitude of gage is $750 \mathrm{ft}$ (from topographic map).

Discharge record.--Stage-discharge relation defined by current-meter measurements; affected by 1 ce Jan. 12-14, 19-21.

Maxima.--January-February 1963: Discharge, 19,200 efs 1730 hours Jan. 31 (gage helght, $12.63 \mathrm{ft}$, from recorder graph; $13.1 \mathrm{ft}$, from floodmarks).

1921 to December 1962: Discharge, 23,500 cfs Dec. 12, 1955 (gage helght, $13.89 \mathrm{ft}$ ).

Mean discharge, in cubic feet per second, 1963

\begin{tabular}{|c|c|c|c|c|c|c|c|c|}
\hline Day & January & February & Day & January & February & Day & January & February \\
\hline $\begin{array}{r}1 \ldots \ldots \\
2 \ldots \ldots \\
3 \ldots \ldots \\
4 \ldots \ldots \\
6 \ldots \ldots \\
7 \ldots \ldots \\
8 \ldots \ldots \\
9 \ldots \ldots \\
10 \ldots \ldots\end{array}$ & $\begin{array}{r}107 \\
99 \\
94 \\
89 \\
80 \\
76 \\
71 \\
67 \\
63 \\
61\end{array}$ & $\begin{array}{r}7,420 \\
2,830 \\
2,240 \\
1,500 \\
1,100 \\
896 \\
737 \\
674 \\
1,630 \\
3,570\end{array}$ & $\begin{array}{l}11 \ldots \ldots \\
12 \ldots \ldots \\
13 \ldots \ldots \\
14 \ldots \ldots \\
15 \ldots \ldots \\
16 \ldots \ldots \\
17 \ldots \ldots \\
18 \ldots \ldots \\
19 \ldots \ldots \\
20 \ldots \ldots\end{array}$ & $\begin{array}{l}55 \\
44 \\
51 \\
59 \\
57 \\
51 \\
48 \\
44 \\
39 \\
37\end{array}$ & $\begin{array}{r}1,690 \\
1,490 \\
1,330 \\
1,020 \\
824 \\
723 \\
642 \\
558 \\
498 \\
458\end{array}$ & $\begin{array}{l}21 \ldots \ldots \\
22 \ldots \ldots \\
23 \ldots \ldots \\
24 \ldots \ldots \\
25 \ldots \ldots \\
26 \ldots \ldots \\
27 \ldots \ldots \\
28 \ldots \ldots \\
29 \ldots \ldots \\
30 \ldots \ldots \\
31 \ldots \ldots\end{array}$ & $\begin{array}{r}39 \\
39 \\
37 \\
36 \\
36 \\
34 \\
33 \\
33 \\
41 \\
279 \\
8,210 \\
\end{array}$ & $\begin{array}{r}420 \\
376 \\
335 \\
305 \\
275 \\
261 \\
243 \\
221 \\
----- \\
---.- \\
\end{array}$ \\
\hline \multicolumn{7}{|l|}{$\begin{array}{l}\text { Monthly } \\
\text { Runoff, } \\
\text { Runoff, }\end{array}$} & $\begin{array}{r}326 \\
1.94 \\
20,050 \\
\end{array}$ & $\begin{array}{r}1,224 \\
6.57 \\
67,970 \\
\end{array}$ \\
\hline
\end{tabular}

Gage helght, in feet, and discharge, in cubic feet per second, at indicated time, 1963

\begin{tabular}{|c|c|c|c|c|c|c|c|c|c|c|c|}
\hline Date & Hour & $\begin{array}{c}\text { Gage } \\
\text { he1ght }\end{array}$ & $\begin{array}{c}\text { Dis - } \\
\text { charge }\end{array}$ & Date & Hour & $\begin{array}{c}\text { Gage } \\
\text { helght }\end{array}$ & $\begin{array}{c}\text { Dis- } \\
\text { charge }\end{array}$ & Date & Hour & $\begin{array}{c}\text { Gage } \\
\text { helght }\end{array}$ & $\begin{array}{c}\text { Dis - } \\
\text { charge }\end{array}$ \\
\hline $\begin{array}{r}\text { Jan. } 29 \\
30\end{array}$ & $\begin{array}{l}2400 \\
0400 \\
0900 \\
1100 \\
1300 \\
1500 \\
1800 \\
2130 \\
2200 \\
2300 \\
2400\end{array}$ & $\begin{array}{l}3.70 \\
3.77 \\
3.69 \\
3.78 \\
4.28 \\
4.74 \\
4.45 \\
4.22 \\
5.00 \\
5.53 \\
5.97\end{array}$ & $\begin{array}{r}76 \\
92 \\
73 \\
94 \\
270 \\
516 \\
355 \\
243 \\
648 \\
1,010 \\
1,440\end{array}$ & Jan. 31 & $\begin{array}{l}0130 \\
0630 \\
0900 \\
1100 \\
1200 \\
1300 \\
1400 \\
1500 \\
1730 \\
2100 \\
2200 \\
2400\end{array}$ & $\begin{array}{r}6.09 \\
5.79 \\
6.21 \\
7.10 \\
8.20 \\
9.75 \\
11.05 \\
11.55 \\
12.63 \\
11.48 \\
11.40 \\
11.60\end{array}$ & $\begin{array}{r}1,590 \\
1,250 \\
1,730 \\
2,960 \\
4,960 \\
8,820 \\
12,800 \\
14,600 \\
19,200 \\
14,300 \\
14,000 \\
14,800\end{array}$ & Feb. 1 & $\begin{array}{l}0200 \\
0400 \\
0700 \\
1000 \\
1400 \\
1500 \\
1730 \\
1900 \\
2200 \\
2400\end{array}$ & $\begin{array}{r}11.18 \\
10.46 \\
9.50 \\
8.94 \\
8.40 \\
8.40 \\
8.56 \\
8.38 \\
8.00 \\
7.80\end{array}$ & $\begin{array}{r}13,200 \\
10,900 \\
8,120 \\
6,660 \\
5,400 \\
5,400 \\
5,750 \\
5,360 \\
4,560 \\
4,160\end{array}$ \\
\hline
\end{tabular}


11-3825.5. Deer Creek below Slate Creek, near Deer Creek Meadows, Calif.

Location. --Lat $40^{\circ} 14^{\prime} 00^{\prime \prime}$, long $121^{\circ} 27^{\prime} 50^{\prime \prime}$, In NE $\frac{1}{4} \mathrm{NE} \frac{1}{4}$ sec.1, T.27 N., R.4 E., on right bank 0.4 mile downstream from Slate Creek and 15 miles southwest of Chester.

Drainage area. $--69.4 \mathrm{sq} \mathrm{ml}$.

Gage-helght record.--Water-stage recorder graph. Altitude of gage is 4,300 $\mathrm{ft}$ (from topographic map).

Discharge record.--Stage-discharge relation defined by current-meter measurements below $910 \mathrm{cfs}$ and by slope-area measurement at 4,970 cfs; affected by 1ce Jan. 11,12 .

Maxima.--January-February 1963: Discharge, 4,970 cfs 1800 hours Jan. 31 (gage helght, $9.06 \mathrm{ft}$, from recorder graph; $9.85 \mathrm{ft}$, from floodmarks).

1961 to December 1962: D1scharge, 3,660 cfs Oct. 13, 1962 (gage he1ght, $8.11 \mathrm{ft}$ ).

Mean discharge, in cublc feet per second, 1963

\begin{tabular}{|c|c|c|c|c|c|c|c|c|}
\hline Day & January & February & Day & January & February & Day & January & February \\
\hline $\begin{array}{r}1 \ldots \ldots \\
2 \ldots \ldots \\
3 \ldots \ldots \\
4 \ldots \ldots \\
5 \ldots \ldots \\
6 \ldots \ldots \\
7 \ldots \ldots \\
8 \ldots \ldots \\
9 \ldots \ldots \\
10 \ldots \ldots\end{array}$ & $\begin{array}{l}97 \\
94 \\
99 \\
94 \\
91 \\
88 \\
83 \\
83 \\
82 \\
79\end{array}$ & $\begin{array}{r}1,800 \\
732 \\
691 \\
517 \\
414 \\
336 \\
292 \\
282 \\
252 \\
238\end{array}$ & $\begin{array}{l}11 \ldots \ldots \\
12 \ldots \ldots \\
13 \ldots \ldots \\
14 \ldots \ldots \\
15 \ldots \ldots \\
16 \ldots \ldots \\
17 \ldots \ldots \\
18 \ldots \ldots \\
19 \ldots \ldots \\
20 \ldots \ldots\end{array}$ & $\begin{array}{l}70 \\
65 \\
67 \\
70 \\
70 \\
71 \\
70 \\
68 \\
68 \\
67\end{array}$ & $\begin{array}{l}216 \\
216 \\
246 \\
201 \\
188 \\
181 \\
181 \\
170 \\
163 \\
172\end{array}$ & $\begin{array}{l}21 \ldots \ldots \\
22 \ldots \ldots \\
23 \ldots \ldots \\
24 \ldots \ldots \\
25 \ldots \ldots \\
26 \ldots \ldots \\
27 \ldots \ldots \\
28 \ldots \ldots \\
29 \ldots \ldots \\
30 \ldots \ldots \\
31 \ldots \ldots\end{array}$ & $\begin{array}{r}67 \\
68 \\
68 \\
68 \\
67 \\
67 \\
66 \\
66 \\
67 \\
91 \\
2,140 \\
\end{array}$ & $\begin{array}{r}154 \\
148 \\
142 \\
138 \\
134 \\
130 \\
124 \\
123 \\
---- \\
-1--1 \\
\end{array}$ \\
\hline \multicolumn{7}{|l|}{$\begin{array}{l}\text { Monthly } \\
\text { Rumoff, } \\
\text { Rusoff, }\end{array}$} & $\begin{array}{r}142 \\
2.36 \\
8,740 \\
\end{array}$ & $\begin{array}{r}306 \\
4.60 \\
17,020 \\
\end{array}$ \\
\hline
\end{tabular}

Gage height, in feet, and discharge, in cublc feet per second, at indlcated time, 1963

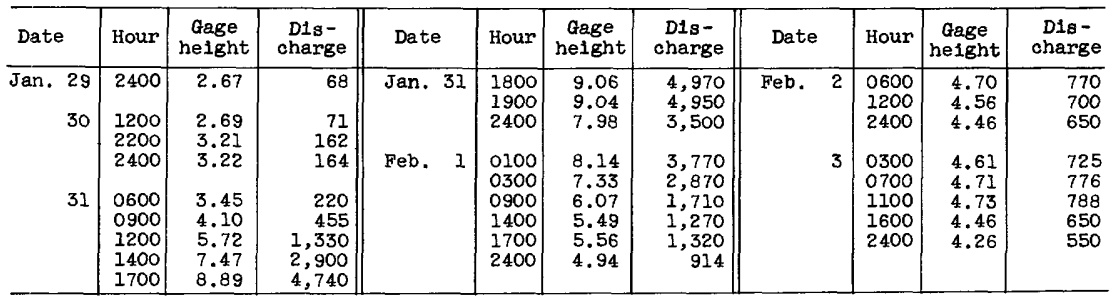

11-3835. Deer Creek near Vina, Cal1f.

Location. --Lat $40^{\circ} 00^{\prime} 50^{\prime \prime}$, long $121^{\circ} 56^{\prime} 50^{\prime \prime}$, In $\mathrm{NW}_{4} \mathrm{NE} \frac{1}{4}$ sec. 23 , T. $25 \mathrm{~N} ., \mathrm{R} .1 \mathrm{~W}$., on left bank $0.5 \mathrm{mlle}$ upstream from concrete diversion dam and 7.9 miles northeast of Vina.

Drainage area. $--208 \mathrm{sq} \mathrm{ml}$.

Gage-he1ght record - Water-stage recorder graph. Datum of gage is $479.5 \mathrm{ft}$ above mean sea level (river-proflle survey).

D1scharge record.--Stage-discharge relation defined by current-meter measurements below $9,200 \mathrm{c}$ s

Maxima.--January-February 1963: D1scharge, 9,470 cfs 2200 hours Jan, 31 (gage helght, $11.03 \mathrm{ft}$ ).

1911-15, 1920-37, 1939 to December 1962: D1scharge, 23,800 cfs Dec. 10, 1937 (gage height, $19.2 \mathrm{ft}$, from floodmarks). 
Mean discharge, in cubic feet per second, 1963, of Deer Creek near V1na, Calif.

\begin{tabular}{|c|c|c|c|c|c|c|c|c|}
\hline Day & January & February & Day & January & February & Day & January & February \\
\hline $\begin{array}{c}\ldots \ldots \\
2 \ldots \ldots \\
3 \ldots \ldots \\
4 \ldots \ldots \\
5 \ldots \ldots \\
6 \ldots \ldots \\
7 \ldots \ldots \\
8 \ldots \ldots \\
9 \ldots \ldots \\
10 \ldots \ldots\end{array}$ & $\begin{array}{l}217 \\
204 \\
202 \\
197 \\
187 \\
179 \\
177 \\
172 \\
167 \\
167\end{array}$ & $\begin{array}{r}4,620 \\
1,950 \\
1,470 \\
1,120 \\
953 \\
760 \\
660 \\
620 \\
588 \\
543\end{array}$ & $\begin{array}{l}11 \ldots \ldots \\
12 \ldots \ldots \\
13 \ldots \ldots \\
14 \ldots \ldots \\
15 \ldots \ldots \\
16 \ldots \ldots \\
17 \ldots \ldots \\
18 \ldots \ldots \\
19 \ldots \ldots \\
20 \ldots \ldots\end{array}$ & $\begin{array}{l}156 \\
131 \\
133 \\
151 \\
151 \\
149 \\
147 \\
142 \\
138 \\
133\end{array}$ & $\begin{array}{l}492 \\
488 \\
601 \\
504 \\
452 \\
436 \\
432 \\
397 \\
369 \\
365\end{array}$ & $\begin{array}{l}21 \ldots \ldots \\
22 \ldots \ldots \\
23 \ldots \ldots \\
24 \ldots \ldots \\
25 \ldots \ldots \\
26 \ldots \ldots \\
27 \ldots \ldots \\
28 \ldots \ldots \\
29 \ldots \ldots \\
30 \ldots \ldots \\
31 \ldots \ldots\end{array}$ & $\begin{array}{r}135 \\
138 \\
138 \\
135 \\
133 \\
133 \\
129 \\
129 \\
138 \\
1,110 \\
4,610\end{array}$ & $\begin{array}{r}344 \\
320 \\
304 \\
292 \\
279 \\
264 \\
255 \\
243 \\
--.-- \\
--.--\end{array}$ \\
\hline \multicolumn{7}{|c|}{ 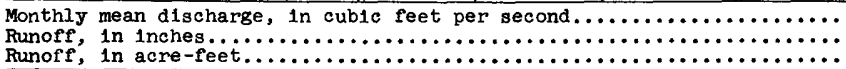 } & $\begin{array}{r}330 \\
1.83 \\
20,290 \\
\end{array}$ & $\begin{array}{r}719 \\
3.60 \\
39,910 \\
\end{array}$ \\
\hline
\end{tabular}

Gage helght, In feet, and discharge, in cublc feet per second, at indicated t1me, 1963

\begin{tabular}{|c|c|c|c|c|c|c|c|c|c|c|c|}
\hline Date & Hour & $\begin{array}{c}\text { Gage } \\
\text { he1ght }\end{array}$ & $\begin{array}{c}\text { D1s- } \\
\text { charge }\end{array}$ & Date & Hour & $\begin{array}{c}\text { Gage } \\
\text { height }\end{array}$ & $\begin{array}{c}\text { D1s- } \\
\text { charge }\end{array}$ & Date & Hour & $\begin{array}{c}\text { Gage } \\
\text { helght }\end{array}$ & $\begin{array}{c}\text { Dis- } \\
\text { charge }\end{array}$ \\
\hline $\begin{array}{r}\text { Jan. } \\
30\end{array}$ & $\begin{array}{l}2400 \\
0300 \\
0600 \\
0900 \\
1200 \\
1400 \\
1700 \\
2000 \\
2400 \\
0100\end{array}$ & $\begin{array}{l}2.38 \\
3.02 \\
3.35 \\
3.79 \\
4.54 \\
5.53 \\
6.34 \\
6.16 \\
5.63 \\
5.47\end{array}$ & $\begin{array}{r}172 \\
209 \\
301 \\
468 \\
866 \\
1,560 \\
2,270 \\
2,110 \\
1,650 \\
1,520\end{array}$ & Feb. 1 & $\begin{array}{l}0400 \\
0700 \\
1000 \\
1300 \\
1600 \\
1800 \\
2000 \\
2200 \\
2400 \\
\\
0400 \\
0600\end{array}$ & $\begin{array}{r}5.55 \\
6.34 \\
7.26 \\
8.16 \\
8.80 \\
9.75 \\
10.55 \\
11.03 \\
10.75 \\
9.77 \\
9.58\end{array}$ & $\begin{array}{l}1,580 \\
2,270 \\
3,270 \\
4,420 \\
5,360 \\
6,950 \\
8,480 \\
9,470 \\
8,880 \\
6,820 \\
6,440\end{array}$ & Feb. 1 & $\begin{array}{l}0900 \\
1200 \\
1600 \\
1800 \\
2000 \\
2400 \\
\\
0200 \\
0700 \\
1300 \\
1800 \\
2400\end{array}$ & $\begin{array}{l}8.68 \\
7.97 \\
7.33 \\
7.12 \\
7.01 \\
6.86 \\
\\
6.75 \\
6.36 \\
6.03 \\
5.79 \\
5.69\end{array}$ & $\begin{array}{l}4,910 \\
4,880 \\
3,080 \\
3,850 \\
2,740 \\
2,590 \\
2,480 \\
2,120 \\
1,840 \\
1,650 \\
1,570\end{array}$ \\
\hline
\end{tabular}

11-3840. Big Chico Creek near Chico, Calif.

Location.--Lat $39^{\circ} 46^{\prime} 35^{\prime \prime}$, long $121^{\circ} 45^{\prime} 10^{\prime \prime}$, in Arroyo Chico Grant, on right bank $1.8 \mathrm{miles} u p s t r e a m$ from golf clubhouse in Bidwell Park, 2.6 miles upstream from Lindo Channel, and 7 miles northeast of Chico, Butte county.

Drainage area. $--72.5 \mathrm{sq} \mathrm{ml}$.

Gage-height record.--Digital-recorder tape punched at 15-minute intervals, except Jan. 1-8, Jan. 30 to Feb. 1, Feb. 10-16, 28. Altitude of gage is $300 \mathrm{ft}$ (from topographic map).

Discharge record.--Stage-discharge relation defined by current-meter measurements. Discharge for periods of no gage-height record estimated on basis of floodmarks and hydrographic comparison with Butte Creek near Chico.

Maxima.--January-February 1963: Discharge, 5,140 cfs, time unknown, probably Jan. 31 (gage height, $12.21 \mathrm{ft}$, from floodmark in well).

1930 to December 1962: Discharge, 8,260 cfs Dec. 10, 1937 (gage height, $16.6 \mathrm{ft}$, site and datum then in use).

Mean discharge, in cuble feet per second, 1963

\begin{tabular}{|c|c|c|c|c|c|c|c|c|}
\hline Day & January & February & Day & January & February & Day & J anuary & February \\
\hline $\begin{array}{r}1 \ldots \ldots \\
2 \ldots \ldots \\
4 \ldots \ldots \\
5 \ldots \ldots \\
6 \ldots \ldots \\
7 \ldots \ldots \\
9 \ldots \ldots \\
10 \ldots \ldots\end{array}$ & $\begin{array}{l}95 \\
90 \\
85 \\
80 \\
75 \\
70 \\
65 \\
60 \\
56 \\
55\end{array}$ & $\begin{array}{r}2,350 \\
1,080 \\
699 \\
528 \\
398 \\
318 \\
273 \\
258 \\
240 \\
230\end{array}$ & $\begin{array}{l}11 \ldots \ldots \\
12 \ldots \ldots \\
13 \ldots \ldots \\
14 \ldots \ldots \\
15 \ldots \ldots \\
16 \ldots \ldots \\
17 \ldots \ldots \\
18 \ldots \ldots \\
19 \ldots \ldots \\
20 \ldots \ldots\end{array}$ & $\begin{array}{l}54 \\
50 \\
50 \\
52 \\
50 \\
49 \\
48 \\
48 \\
47 \\
46\end{array}$ & $\begin{array}{l}220 \\
230 \\
270 \\
260 \\
250 \\
240 \\
230 \\
200 \\
182 \\
167\end{array}$ & $\begin{array}{l}21 \ldots \ldots \\
22 \ldots \ldots \\
23 \ldots \ldots \\
24 \ldots \ldots \\
25 \ldots \ldots \\
26 \ldots \ldots \\
27 \ldots \ldots \\
28 \ldots \ldots \\
29 \ldots \ldots \\
30 \ldots \ldots \\
31 \ldots \ldots\end{array}$ & $\begin{array}{r}46 \\
46 \\
45 \\
45 \\
45 \\
44 \\
42 \\
44 \\
48 \\
600 \\
2,920\end{array}$ & $\begin{array}{r}154 \\
140 \\
130 \\
122 \\
115 \\
108 \\
102 \\
100 \\
----- \\
-2--1\end{array}$ \\
\hline $\begin{array}{l}\text { onthly } \\
\text { unoff, } \\
\text { unoff, }\end{array}$ & $\begin{array}{l}\text { an discl } \\
\text { Inches } \\
\text { acre-f }\end{array}$ & e, 1 & fopt & & & & $\begin{array}{r}366 \\
2.64 \\
10,210 \\
\end{array}$ & $\begin{array}{r}343 \\
4.92 \\
19,030 \\
\end{array}$ \\
\hline
\end{tabular}


Gage height, in feet, and discharge, in cublc feet per second, at indicated t1me, 1963, of Big Chico Creek near Chico, Calif.

\begin{tabular}{|c|c|c|c|c|c|c|c|c|c|c|c|}
\hline Date & Hour & $\begin{array}{c}\text { Gage } \\
\text { helght }\end{array}$ & $\begin{array}{l}\text { D1s- } \\
\text { charge }\end{array}$ & Date & Hour & $\begin{array}{c}\text { Gage } \\
\text { helght }\end{array}$ & $\begin{array}{c}\text { Dis- } \\
\text { charge }\end{array}$ & Date & Hour & $\begin{array}{c}\text { Gage } \\
\text { height }\end{array}$ & $\begin{array}{l}\text { D1s- } \\
\text { charge }\end{array}$ \\
\hline $\begin{array}{r}\operatorname{Jan} .29 \\
30\end{array}$ & $\begin{array}{l}2400 \\
0200 \\
0400 \\
0600 \\
0800 \\
1000 \\
1200 \\
1400 \\
1600 \\
1800 \\
2000 \\
2200 \\
2400 \\
0200 \\
0400 \\
0600\end{array}$ & $\begin{array}{l}- \\
2.84 \\
2.99 \\
3.20 \\
3.45 \\
3.79 \\
4.32 \\
4.90 \\
5.25 \\
- \\
- \\
- \\
- \\
- \\
- \\
-\end{array}$ & $\begin{array}{r}70 \\
82 \\
109 \\
160 \\
228 \\
338 \\
552 \\
830 \\
1,000 \\
1,100 \\
1,150 \\
1,100 \\
1,000 \\
1,000 \\
1,000 \\
1,200\end{array}$ & Feb. 1 & $\begin{array}{l}0800 \\
1000 \\
1200 \\
1400 \\
1600 \\
1800 \\
2000 \\
2200 \\
2400 \\
0200 \\
0400 \\
0600 \\
0800 \\
1000 \\
1200 \\
1400 \\
1600\end{array}$ & $\begin{array}{c}- \\
- \\
- \\
- \\
12.21 \\
- \\
- \\
- \\
- \\
- \\
- \\
- \\
7.50 \\
7.15 \\
6.86 \\
6.64\end{array}$ & $\begin{array}{l}1,500 \\
2,200 \\
3,100 \\
4,000 \\
4,700 \\
5,140 \\
4,700 \\
4,200 \\
3,700 \\
3,500 \\
3,200 \\
2,900 \\
2,600 \\
2,400 \\
2,200 \\
2,010 \\
1,900\end{array}$ & Feb. 1 & $\begin{array}{l}1800 \\
2000 \\
2200 \\
2400 \\
0200 \\
0400 \\
0600 \\
0800 \\
1000 \\
1200 \\
1400 \\
1600 \\
1800 \\
2000 \\
2200 \\
2400\end{array}$ & $\begin{array}{l}6.43 \\
6.28 \\
6.04 \\
5.88 \\
5.74 \\
5.60 \\
5.50 \\
5.43 \\
5.33 \\
5.25 \\
5.15 \\
5.07 \\
4.98 \\
4.91 \\
4.85 \\
4.80\end{array}$ & $\begin{array}{r}1,750 \\
1,670 \\
1,510 \\
1,420 \\
1,340 \\
1,270 \\
1,220 \\
1,180 \\
1,120 \\
1,080 \\
1,020 \\
970 \\
920 \\
880 \\
845 \\
810\end{array}$ \\
\hline
\end{tabular}

11-3847. Gilmore Creek near Lodoga, Calif.

(Crest-stage station)

Location --Lat $39^{\circ} 18^{\prime} 40^{\prime \prime}$, long $122^{\circ} 31140^{\prime \prime}$, in $\mathrm{NE} \frac{1}{4} \mathrm{SE} \frac{1}{4} \operatorname{sec.21}, \mathrm{T} .17$ N., R.6 W., $2.3 \mathrm{miles}$ northwest of Lodoga.

Drainage area. $--0.49 \mathrm{sq} \mathrm{m} 1$.

Gage-helght record.--Crest stages only. Alt1tude of gage is 1 ,250 ft (from topographic map).

Discharge record.--Stage-discharge relation defined by current-meter measurements below $30 \mathrm{cfs}$ and by computation of flow through culvert at $43 \mathrm{cfs}$.

Maxima.--January-February 1963: Discharge, 53 cf's Jan. 31 (gage he1ght, $23.12 \mathrm{ft}$ ). 1959 to December 1962: Discharge, 43 cfs Feb. 14, 1962 lgage he1ght, $22.74 \mathrm{ft}$ ).

11-3864. Grindstone Creek tributary near Elk Creek, Calif.

(Crest-stage station)

Location :-Lat $39^{\circ} 39^{\prime} 25^{\prime \prime}$, long $122^{\circ} 35^{\prime} 40^{\prime \prime}$, in $\mathrm{SE} \frac{1}{4} \sec .24$, T.21 N., R.7 W. , 4.6 miles northwest of Elk Creek.

Drainage area. $--0.80 \mathrm{sq} \mathrm{mi}$.

Gage-helght record.--Crest stages only. Alt1tude of gage is 1,050 ft (from topographic map).

D1scharge record.--Stage-discharge relation defined by current-meter measurements below $9.7 \mathrm{cfs}$ and by computation of flow through culvert at 23 and $85 \mathrm{cfs}$.

Maxima --January-February 1963: Discharge, $14 \mathrm{cfs}$ Feb. 1 (gage he1ght, $16.92 \mathrm{ft}$ ) 1959 to December 1962: Discharge, $85 \mathrm{cfs}$ Sept. i6, 1961 (gage he1ght, 21.75

ft, from high-water profile). 
11-3870. Stony Creek near Fruto, Calif.

Location.--Lat $39^{\circ} 40115^{\prime \prime}$, long $122^{\circ} 31^{\prime} 05^{\prime \prime}$, In SW $\frac{1}{4} \mathrm{SE} \frac{1}{4} \sec .15$, T.21 N., R.6 W., on right bank 0.3 mile downstream from Grindstone Creek and 6.5 miles northwest of Fruto.

Drainage area. $-599 \mathrm{sq} \mathrm{ml}$.

Gage-he1ght record.--Water-stage recorder graph, except Jan. 1-15. Once-daily telemark-gage readings Jan. 2-4, 7-11, 14, 15. Altitude of gage is $600 \mathrm{ft}$ (from topographic map).

Discharge record.--Stage-discharge relation defined by current-meter measurements below 13,000 cfs. Discharge for periods of no gage-height record interpolated.

Maxima.--January-February 1963: Discharge, 16,000 cfs 2100 hours Jan. 31 (gage helght, $11.64 \mathrm{ft}$ ).

1901-12, 1960 to December 1962: Discharge, 36,000 cfs Feb. 2, 1909 (gage height, $16.3 \mathrm{ft}$, site and datum then in use).

Remarks.--Flow regulated by East Park Reservoir beginning in 1910 (usable capacity, 50,600 acre- $f t$ ) and by Stony Gorge Reservoir beginning in 1928 (usable capacity, 50,100 acre-ft).

Mean discharge, in cublc feet per second, 1963

\begin{tabular}{|c|c|c|c|c|c|c|c|c|}
\hline Day & January & February & Day & January & February & Day & January & February \\
\hline $\begin{array}{c}1 \ldots \ldots \\
3 \ldots \ldots \\
4 \ldots \ldots \\
5 \ldots \ldots \\
7 \ldots \ldots \\
8 \ldots \ldots \\
9 \ldots \ldots \\
10 \ldots \ldots\end{array}$ & $\begin{array}{l}75 \\
72 \\
70 \\
66 \\
65 \\
60 \\
58 \\
58 \\
52 \\
52\end{array}$ & $\begin{array}{r}9,600 \\
5,170 \\
2,800 \\
1,440 \\
894 \\
1,020 \\
713 \\
430 \\
2,530 \\
6,700\end{array}$ & $\begin{array}{l}11 \ldots \ldots \\
12 \ldots \ldots \\
13 \ldots \ldots \\
14 \ldots \ldots \\
15 \ldots \ldots \\
16 \ldots \ldots \\
17 \ldots \ldots \\
18 \ldots \ldots \\
19 \ldots \ldots \\
20 \ldots \ldots\end{array}$ & $\begin{array}{l}50 \\
45 \\
40 \\
40 \\
44 \\
42 \\
42 \\
40 \\
38 \\
37\end{array}$ & $\begin{array}{l}4,450 \\
4,740 \\
5,390 \\
3,200 \\
1,670 \\
1,360 \\
1,550 \\
1,460 \\
1,210 \\
1,090\end{array}$ & $\begin{array}{l}21 \ldots \ldots \\
22 \ldots \ldots \\
23 \ldots \ldots \\
24 \ldots \ldots \\
25 \ldots \ldots \\
26 \ldots \ldots \\
27 \ldots \ldots \\
28 \ldots \ldots \\
29 \ldots \ldots \\
30 \ldots \ldots \\
31 \ldots \ldots\end{array}$ & $\begin{array}{r}35 \\
38 \\
38 \\
37 \\
37 \\
35 \\
35 \\
34 \\
41 \\
900 \\
7,970\end{array}$ & $\begin{array}{r}781 \\
614 \\
669 \\
662 \\
634 \\
608 \\
590 \\
380 \\
--.-1 \\
--\ldots-\end{array}$ \\
\hline \multicolumn{7}{|c|}{ 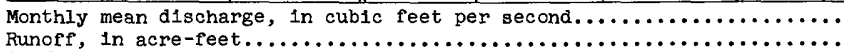 } & 20,330 & $\begin{array}{r}2,227 \\
123,700\end{array}$ \\
\hline
\end{tabular}

Gage helght, In feet, and discharge, in cubic feet per second, at indicated time, 1963

\begin{tabular}{|c|c|c|c|c|c|c|c|c|c|c|c|}
\hline Date & Hour & $\begin{array}{c}\text { Gage } \\
\text { helght }\end{array}$ & $\begin{array}{l}\text { D1s- } \\
\text { charge }\end{array}$ & Date & Hour & $\begin{array}{c}\text { Gage } \\
\text { helght }\end{array}$ & $\begin{array}{c}\text { D1s- } \\
\text { charge }\end{array}$ & Date & Hour & $\begin{array}{c}\text { Gage } \\
\text { height }\end{array}$ & $\begin{array}{c}\text { Dis- } \\
\text { charge }\end{array}$ \\
\hline $\begin{array}{r}\operatorname{Jan} .29 \\
30\end{array}$ & $\begin{array}{l}2400 \\
0200 \\
1100 \\
1300 \\
1500 \\
1700 \\
1900 \\
2400 \\
0500\end{array}$ & $\begin{array}{l}2.77 \\
2.80 \\
3.30 \\
4.10 \\
5.55 \\
6.00 \\
5.82 \\
5.04 \\
4.61\end{array}$ & $\begin{array}{r}66 \\
80 \\
255 \\
660 \\
1,740 \\
2,200 \\
2,030 \\
1,350 \\
1,040\end{array}$ & $\operatorname{Jan} .31$ & $\begin{array}{l}0600 \\
0800 \\
0900 \\
1000 \\
1100 \\
1200 \\
1300 \\
1400 \\
1500 \\
1700 \\
1900\end{array}$ & $\begin{array}{r}4.63 \\
5.29 \\
6.29 \\
7.26 \\
8.08 \\
9.05 \\
9.77 \\
10.81 \\
11.38 \\
11.12 \\
11.27\end{array}$ & $\begin{array}{r}1,050 \\
1,550 \\
2,490 \\
3,550 \\
4,900 \\
7,080 \\
9,000 \\
12,400 \\
14,800 \\
13,700 \\
14,300\end{array}$ & Feb. 1 & $\begin{array}{l}2000 \\
2100 \\
2400 \\
\\
0100 \\
0300 \\
1000 \\
1100 \\
1700 \\
2000 \\
2400\end{array}$ & $\begin{array}{r}11.62 \\
11.64 \\
11.37 \\
11.11 \\
11.00 \\
9.70 \\
8.55 \\
8.50 \\
8.61 \\
8.22\end{array}$ & $\begin{array}{r}15,900 \\
16,000 \\
15,000 \\
14,200 \\
13,800 \\
10,600 \\
7,330 \\
7,200 \\
7,490 \\
6,500\end{array}$ \\
\hline
\end{tabular}

11-3879. Masterson Hollow Creek near Newville, Calif.

(Crest-stage station)

Location; -Lat $39^{\circ} 47^{\prime} 5^{\prime \prime}$, long $122^{\circ} 25^{\prime} 50^{\prime \prime}$, in NE $\frac{1}{4} N W \frac{1}{4} \sec .4$, T.22 N., R.5 W. , $5.1 \mathrm{miles}$ east of Newville.

Drainage area. $--0.93 \mathrm{sq} \mathrm{ml}$.

Gage-height record.--Crest stages only. Altitude of gage is $515 \mathrm{ft}$ (from topographic map).

Discharge record.--Stage-discharge relation defined by current-meter measurements below $8.7 \mathrm{cfs}$ and by computation of flow through culvert at $30 \mathrm{cfs}$.

Maxima.--January-February 1963: Discharge, $22 \mathrm{cfs}$ Feb. 9 (gage height, $12.35 \mathrm{ft}$ ). 1959 to December 1962: Discharge, $30 \mathrm{cfs}$ Feb. 2, 1961 (gage height, $12.84 \mathrm{ft}$ ). 
11-3880. Stony Creek below Black Butte Dam, near 0rland, Calif.

(Formerly published as Stony Creek at Black Butte damsite, near Oriand)

Location.--Lat $39^{\circ} 49^{1} 00^{\prime \prime}$, long $122^{\circ} 19^{\prime} 25^{\prime \prime}$, in SW $\frac{1}{4}$ sec.28, T.23 N., R.4 W., on downstream side of road bridge, 0.6 mile downstream from Black Butte Dam and

8.1 miles northwest of 0rland.

Drainage area. $--740 \mathrm{sq} \mathrm{mi}$.

Gage-helght record.--W1re-weight gage read once da1ly, except Jan. 1, 5, 6, 12, 13, $19,20,26,27$, Feb. 9, 10, 16, 17, 22-24. Jan. 31 to Feb. 3 based on graph of numerous gage readings. Alt1tude of gage is $360 \mathrm{ft}$ (from topographic map).

Discharge record.--Stage-discharge relation defined by current-meter measurements. Discharge for periods of no gage-height record estimated on basis of hydrographic comparison with Stony Creek near Fruto.

Maxima.--January-February 1963: D1scharge, 10,700 cfs 1200 hours Feb. I (gage helght, $13.37 \mathrm{ft}^{\prime}$ ).

1955 to December 1962: Discharge, 36,300 cfs Feb. 24, 1958 (gage helght, $11.82 \mathrm{ft}$, site and datum then in usej.

Remarks.--Flow affected by East Park Reservolr, Stony Gorge Reservolr (combined capacity, 100,700 acre-ft), and minor detention storage Jan. 31 to Feb. 3 by cofferdam at Black Butte Dam (under construction in 1963).

Mean discharge, in cublc feet per second, 1963

\begin{tabular}{|c|c|c|c|c|c|c|c|c|}
\hline Day & January & February & Day & January & February & Day & January & February \\
\hline $\begin{array}{c}1 \ldots \ldots \\
2 \ldots \ldots \\
3 \ldots \ldots \\
4 \ldots \ldots \\
6 \ldots \ldots \\
7 \ldots \ldots \\
9 \ldots \ldots \\
10 \ldots \ldots\end{array}$ & $\begin{array}{l}60 \\
54 \\
56 \\
50 \\
50 \\
45 \\
43 \\
40 \\
38 \\
36\end{array}$ & $\begin{array}{r}9,900 \\
8,100 \\
4,010 \\
1,840 \\
1,090 \\
1,060 \\
1,030 \\
605 \\
1,000 \\
6,800\end{array}$ & $\begin{array}{l}11 \ldots \ldots \\
12 \ldots \ldots \\
13 \ldots \ldots \\
14 \ldots \ldots \\
15 \ldots \ldots \\
16 \ldots \ldots \\
17 \ldots \ldots \\
18 \ldots \ldots \\
19 \ldots \ldots \\
20 \ldots \ldots\end{array}$ & $\begin{array}{l}32 \\
28 \\
25 \\
22 \\
32 \\
32 \\
33 \\
28 \\
27 \\
26\end{array}$ & $\begin{array}{l}5,250 \\
2,930 \\
5,400 \\
3,620 \\
2,090 \\
1,500 \\
1,600 \\
1,330 \\
1,230 \\
1,110\end{array}$ & $\begin{array}{l}21 \ldots \ldots \\
22 \ldots \ldots \\
23 \ldots \ldots \\
24 \ldots \ldots \\
25 \ldots \ldots \\
26 \ldots \ldots \\
27 \ldots \ldots \\
28 \ldots \ldots \\
29 \ldots \ldots \\
30 \ldots \ldots \\
31 \ldots \ldots\end{array}$ & $\begin{array}{r}25 \\
26 \\
24 \\
24 \\
24 \\
24 \\
24 \\
23 \\
22 \\
106 \\
3,010 \\
\end{array}$ & $\begin{array}{r}1,030 \\
700 \\
650 \\
700 \\
620 \\
585 \\
585 \\
494 \\
----- \\
----- \\
-\end{array}$ \\
\hline $\begin{array}{l}\text { onthly } \\
\text { anoff, }\end{array}$ & $\begin{array}{l}\text { an disc } \\
\text { acre- }\end{array}$ & $\Rightarrow$ & Cont & & & & $\begin{array}{r}132 \\
8,110\end{array}$ & $\begin{array}{r}2,388 \\
132,600\end{array}$ \\
\hline
\end{tabular}

Gage helght, in feet, and discharge, in cubic feet per second, at indicated time, 1963

\begin{tabular}{|c|c|c|c|c|c|c|c|c|c|c|c|}
\hline I)ate & Hour & $\begin{array}{c}\text { Gage } \\
\text { height }\end{array}$ & $\begin{array}{l}\text { Dis- } \\
\text { charge }\end{array}$ & Date & Hour & $\begin{array}{c}\text { Gage } \\
\text { height }\end{array}$ & $\begin{array}{l}\text { D1s- } \\
\text { charge }\end{array}$ & Date & Hour & $\begin{array}{c}\text { Gage } \\
\text { height }\end{array}$ & $\begin{array}{l}\text { Dis- } \\
\text { charge }\end{array}$ \\
\hline $\begin{array}{r}\text { Jan. } 29 \\
30\end{array}$ & $\begin{array}{l}2400 \\
0800 \\
1500 \\
1900\end{array}$ & $\begin{array}{l}6.23 \\
6.36 \\
6.80 \\
7.40\end{array}$ & $\begin{array}{r}26 \\
34 \\
76 \\
170\end{array}$ & $\operatorname{Jan} .31$ & $\begin{array}{l}1500 \\
1900 \\
2300 \\
2400\end{array}$ & $\begin{array}{l}11.00 \\
11.98 \\
12.30 \\
12.60\end{array}$ & $\begin{array}{l}3,250 \\
5,940 \\
6,950 \\
8,000\end{array}$ & Feb. 2 & $\begin{array}{l}0300 \\
1300 \\
1800 \\
2400\end{array}$ & $\begin{array}{l}12.90 \\
12.74 \\
12.43 \\
12.10\end{array}$ & $\begin{array}{l}9,050 \\
8,490 \\
8,100 \\
6,300\end{array}$ \\
\hline 31 & $\begin{array}{l}2400 \\
0400 \\
0800 \\
1200 \\
\end{array}$ & $\begin{array}{r}8.27 \\
9.00 \\
9.68 \\
10.41 \\
\end{array}$ & $\begin{array}{r}404 \\
750 \\
1,310 \\
2,190 \\
\end{array}$ & Feb. 1 & $\begin{array}{l}0700 \\
1100 \\
1200 \\
1700 \\
2400\end{array}$ & $\begin{array}{l}13.15 \\
13.27 \\
13.37 \\
13.35 \\
13.07\end{array}$ & $\begin{array}{r}9,890 \\
10,300 \\
10,700 \\
10,600 \\
9,640\end{array}$ & 3 & $\begin{array}{l}0600 \\
1200 \\
1800 \\
2400\end{array}$ & $\begin{array}{l}11.75 \\
11.20 \\
10.75 \\
10.50\end{array}$ & $\begin{array}{l}5,250 \\
3,700 \\
2,760 \\
2,330\end{array}$ \\
\hline
\end{tabular}

11-3885. Stony Creek near Hamilton City, Calif.

Location.--Iat $39^{\circ} 43^{\prime} 25^{\prime \prime}$, long $122^{\circ} 02^{\prime} 47^{\prime \prime}$, in Capay Grant, on right bank 2.3 miles southwest of Hamilton C1ty, 6 miles upstream from mouth, and 8 miles east of Orland, Glenn County.

Drainage area. $--777 \mathrm{sq} \mathrm{m} 1$.

Gage-height record :- Water-stage recorder graph. Altitude of gage is $150 \mathrm{ft}$ (from topographic map).

Discharge record.--Stage-discharge relation defined by current-meter measurements. Maxima - --January-February 1963: Discharge, 9,300 cfs 2000 hours Feb. I (gage height,

1940 to December 1962: Discharge, 39,900 cf's Feb. 23, 1958 (gage height,

$18.31 \mathrm{ft}^{\prime}$, at site and datum then in use).

Remarks.--Flow regulated by East Park Reservoir (usable capacity, 50,600 acre-ft), Stony Gorge Reservoir (usable capacity, 50,100 acre-ft), and by temporary de-

tention in Black Butte Reservolr (under construction in 1963). 
Mean discharge, in cubic feet per second, 1963, of Stony Creek near Hamilton City. Calif.

\begin{tabular}{|c|c|c|c|c|c|c|c|c|}
\hline Day & January & February & Day & January & February & Day & January & February \\
\hline $\begin{array}{r}1 \ldots \ldots \\
2 \ldots \ldots \\
3 \ldots \ldots \\
4 \ldots \ldots \\
6 \ldots \ldots \\
7 \ldots \ldots \\
8 \ldots \ldots \\
10 \ldots \ldots \\
10 \ldots \\
\end{array}$ & $\begin{array}{l}26 \\
24 \\
22 \\
19 \\
15 \\
12 \\
11 \\
10 \\
9.0 \\
8.6\end{array}$ & $\begin{array}{r}7,360 \\
8,030 \\
5,040 \\
2,240 \\
1,270 \\
940 \\
863 \\
545 \\
559 \\
5,510\end{array}$ & $\begin{array}{l}11 \ldots \ldots \\
12 \ldots \ldots \\
13 \ldots \ldots \\
14 \ldots \ldots \\
15 \ldots \ldots \\
16 \ldots \ldots \\
17 \ldots \ldots \\
18 \ldots \ldots \\
19 \ldots \ldots \\
20 \ldots \ldots\end{array}$ & $\begin{array}{l}7.8 \\
2.9 \\
3 \\
0 \\
0 \\
0 \\
0 \\
0 \\
0 \\
0\end{array}$ & $\begin{array}{l}5,720 \\
3,480 \\
5,080 \\
4,150 \\
2,510 \\
1,550 \\
1,520 \\
1,470 \\
1,330 \\
1,190\end{array}$ & $\begin{array}{l}21 \ldots \ldots \\
22 \ldots \ldots \\
23 \ldots \ldots \\
24 \ldots \ldots \\
25 \ldots \ldots \\
26 \ldots \ldots \\
27 \ldots \ldots \\
28 \ldots \ldots \\
29 \ldots \ldots \\
30 \ldots \ldots \\
31 \ldots \ldots\end{array}$ & $\begin{array}{r}0 \\
0 \\
0 \\
0 \\
0 \\
0 \\
0 \\
0 \\
0 \\
0 \\
1,230\end{array}$ & $\begin{array}{r}1,070 \\
682 \\
610 \\
622 \\
604 \\
577 \\
560 \\
525 \\
-.---. \\
-.-1-\end{array}$ \\
\hline $\begin{array}{l}\text { onthly } \\
\text { anoff, }\end{array}$ & $\mathrm{d}$ dis & , & 0 & & & & $\begin{array}{r}45.1 \\
2,770\end{array}$ & $\begin{array}{r}2,343 \\
130,100\end{array}$ \\
\hline
\end{tabular}

Gage height, in feet, and discharge, In cublc feet per second, at indicated t1me, I963

\begin{tabular}{|c|c|c|c|c|c|c|c|c|c|c|c|}
\hline Date & Hour & $\begin{array}{c}\text { Gage } \\
\text { helght }\end{array}$ & $\begin{array}{l}\text { Dis- } \\
\text { charge }\end{array}$ & Date & Iour & $\begin{array}{c}\text { Gage } \\
\text { height }\end{array}$ & $\begin{array}{c}\text { Dis- } \\
\text { charge }\end{array}$ & Date & Hour & $\begin{array}{c}\text { Gage } \\
\text { helght }\end{array}$ & $\begin{array}{c}\text { Dis - } \\
\text { charge }\end{array}$ \\
\hline $\begin{array}{r}\text { Jan. } 30 \\
31\end{array}$ & $\begin{array}{l}2400 \\
0330 \\
0400 \\
0600 \\
0700 \\
0900 \\
1200 \\
1500 \\
1600 \\
1700 \\
2000\end{array}$ & $\begin{array}{l}- \\
- \\
6.15 \\
7.22 \\
7.34 \\
7.46 \\
7.44 \\
7.39 \\
7.39 \\
7.50 \\
8.42\end{array}$ & $\begin{array}{r}0 \\
0 \\
410 \\
962 \\
1,040 \\
1,120 \\
1,110 \\
1,070 \\
1,070 \\
1,150 \\
1,950\end{array}$ & $\begin{array}{l}\text { Jan. } 31 \\
\text { Feb. } 1\end{array}$ & $\begin{array}{l}2200 \\
2400 \\
0200 \\
0400 \\
0700 \\
1000 \\
1400 \\
1600 \\
1800 \\
2000 \\
2200\end{array}$ & $\begin{array}{r}9.22 \\
9.89 \\
10.38 \\
10.58 \\
11.27 \\
11.62 \\
12.00 \\
12.18 \\
12.27 \\
12.32 \\
12.30\end{array}$ & $\begin{array}{l}2,870 \\
3,810 \\
4,610 \\
4,970 \\
6,360 \\
7,180 \\
8,250 \\
8,830 \\
9,130 \\
9,300 \\
9,230\end{array}$ & Feb. & \begin{tabular}{|l|}
2400 \\
\\
0600 \\
1000 \\
1400 \\
1800 \\
2100 \\
2400 \\
\\
0800 \\
1800 \\
2100 \\
2400 \\
\end{tabular} & $\begin{array}{r}12.28 \\
12.13 \\
12.00 \\
11.85 \\
11.69 \\
11.58 \\
11.40 \\
10.75 \\
9.86 \\
9.48 \\
9.00\end{array}$ & $\begin{array}{l}9,160 \\
8,670 \\
8,250 \\
7,810 \\
7,420 \\
7,180 \\
6,790 \\
5,610 \\
4,230 \\
3,720 \\
3,140\end{array}$ \\
\hline
\end{tabular}

11-3890. Sacramento River at Butte C1ty, Calif.

Location.--Lat $39^{\circ} 27^{\prime} 35^{\prime \prime}$, long $121^{\circ} 59^{\prime} 35^{\prime \prime}$, in $\mathrm{NE} \frac{1}{4}$ sec.32, T.19 N., R.1 W., on left bank $0.5 \mathrm{mile}$ south of Butte City.

Drainage area.--12,096 sq $\mathrm{ml}$, excluding Goose Lake basin.

Gage-he1ght record.--Water-stage recorder graph, except Jan. 6-15, Jan. 31 to Feb. 2. Datum of gage set to datum of Corps of Engineers.

Discharge record.--Stage-discharge relation defined by current-meter measurements . Discharge for perlods of no gage-helght record estimated on basis of records for station at Colusa.

Maxima --January-February 1963: Discharge, 100,000 about 0200 hours Feb. 2 (gage helght, $91.3 \mathrm{ft}$, from floodmark).

1940 to December 1962: Discharge, 170,000 cfs Feb. 7, 1942 (gage height, $96.87 \mathrm{ft}$ )

Remarks. --Flow affected by storage reservolrs.

Mean discharge, in cublc feet per second, 1963

\begin{tabular}{|c|c|c|c|c|c|c|c|c|}
\hline Day & January & February & Day & January & February & Day & January & February \\
\hline $\begin{array}{c}1 \ldots \ldots \\
2 \ldots \ldots \\
4 \ldots \ldots \\
5 \ldots \ldots \\
6 \ldots \ldots \\
7 \ldots \ldots \\
9 \ldots \ldots \\
10 \ldots \ldots\end{array}$ & $\begin{array}{l}14,200 \\
13,900 \\
13,300 \\
13,000 \\
12,800 \\
12,500 \\
12,200 \\
11,700 \\
11,200 \\
10,700\end{array}$ & $\begin{array}{l}81,100 \\
88,700 \\
54,600 \\
38,400 \\
30,400 \\
25,800 \\
23,400 \\
23,100 \\
22,800 \\
30,700\end{array}$ & $\begin{array}{l}11 \ldots \ldots \\
12 \ldots \ldots \\
13 \ldots \ldots \\
14 \ldots \ldots \\
15 \ldots \ldots \\
16 \ldots \ldots \\
17 \ldots \ldots \\
18 \ldots \ldots \\
19 \ldots \ldots \\
20 \ldots \ldots\end{array}$ & $\begin{array}{r}10,200 \\
9,600 \\
9,100 \\
8,800 \\
8,600 \\
8,600 \\
8,360 \\
8,120 \\
8,120 \\
7,880\end{array}$ & $\begin{array}{l}41,600 \\
33,800 \\
36,300 \\
39,400 \\
32,400 \\
27,900 \\
26,800 \\
26,500 \\
24,300 \\
22,200\end{array}$ & $\begin{array}{l}21 \ldots \ldots \\
22 \ldots \ldots \\
23 \ldots \ldots \\
24 \ldots \ldots \\
25 \ldots \ldots \\
26 \ldots \ldots \\
27 \ldots \ldots \\
28 \ldots \ldots \\
29 \ldots \ldots \\
30 \ldots \ldots \\
31 \ldots \ldots\end{array}$ & $\begin{array}{r}7,6 \\
7,6 \\
7,6 \\
7,6 \\
7,6 \\
7,6 \\
7,4 \\
7,4 \\
7,4 \\
9,6 \\
32,1\end{array}$ & $\begin{array}{r}20,100 \\
18,600 \\
19,500 \\
19,500 \\
19,200 \\
18,900 \\
18,600 \\
18,300 \\
------ \\
-----\end{array}$ \\
\hline \multicolumn{7}{|c|}{ 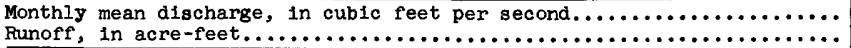 } & $\begin{array}{r}10,410 \\
640,000 \\
\end{array}$ & $\begin{array}{r}31,530 \\
1,751,000 \\
\end{array}$ \\
\hline
\end{tabular}


11-3895. Sacramento River at Colusa, Calif.

Location. --Lat $39^{\circ} 12^{\prime} 50^{\prime \prime}$, long $121^{\circ} 59^{\prime} 55^{\prime \prime}$, at north end of Jimeno Grant, on right bank just downstream from highway bridge at Colusa, Colusa County, at mile 89.4 upstream from Sacramento.

Drainage area.--12,110 sq $\mathrm{ml}$, excluding Goose Lake basin.

Gage-height record.--Water-stage recorder graph. Datum of gage is set to datum of Corps of Engineers.

Dlscharge record.--Stage-discharge relation defined by current-meter measurements.

Maxima.--January-February 1963: D1scharge, 38,100 cfs 1800 hours Feb. 2 (gage helght, $64.68 \mathrm{ft}$ ).

1940 to December 1962: Discharge, 49,000 cfs Feb. 8, 1942 (gage height, $69.20 \mathrm{ft}$ ).

Remarks.--Flows affected by storage reservoirs and bypassing for flood control.

Mean discharge, in cublc feet per second, 1963

\begin{tabular}{r|r|r||r|r|r||r|r|r}
\hline Day & January & February & Day & January & February & Day & January & February \\
\hline $1 \ldots \ldots$ & 14,000 & 32,800 & $11 \ldots \ldots$ & 11,300 & 31,100 & $21 \ldots \ldots$ & 8,860 & 19,800 \\
$2 \ldots \ldots$ & 13,800 & 37,400 & $12 \ldots \ldots$ & 10,700 & 30,700 & $22 \ldots \ldots$ & 8,750 & 18,100 \\
$3 \ldots \ldots$ & 13,700 & 35,800 & $13 \ldots \ldots$ & 10,200 & 29,800 & $23 \ldots \ldots$ & 8,640 & 17,400 \\
$4 \ldots \ldots$ & 13,400 & 32,200 & $14 \ldots \ldots$ & 9,800 & 31,600 & $24 \ldots \ldots$ & 8,640 & 17,900 \\
$5 \ldots \ldots$ & 13,100 & 29,600 & $15 \ldots \ldots$ & 9,680 & 30,200 & $25 \ldots \ldots$ & 8,530 & 17,600 \\
$6 \ldots \ldots$ & 12,700 & 26,400 & $16 \ldots \ldots$ & 9,580 & 27,800 & $26 \ldots \ldots$ & 8,530 & 17,400 \\
$7 \ldots \ldots$ & 12,500 & 23,200 & $17 \ldots \ldots$ & 9,360 & 25,600 & $27 \ldots \ldots$ & 8,530 & 17,100 \\
$8 \ldots \ldots$ & 12,300 & 22,100 & $18 \ldots \ldots$ & 9,300 & 25,600 & $28 \ldots \ldots$ & 8,420 & 16,900 \\
$9 \ldots \ldots$ & 12,000 & 21,400 & $19 \ldots \ldots$ & 9,080 & 23,900 & $29 \ldots \ldots$ & 8,420 & $-\ldots--\ldots-$ \\
$10 \ldots \ldots$ & 11,700 & 23,500 & $20 \ldots \ldots$ & 8,970 & 22,100 & $30 \ldots \ldots$ & 8,860 & $-\ldots-\ldots$ \\
\end{tabular}

11-3897. Butte Creek at Butte Meadows, Calif.

Location.--Lat $40^{\circ} 04^{\prime} 05^{\prime \prime}$, long $121^{\circ} 34^{\prime} 25^{\prime \prime}$, on right bank in NW $\frac{1}{4}$ sec. $31, T .26$ N. , $\overline{\mathrm{R} .4 \mathrm{E}}$., $1.0 \mathrm{mile}$ downstream from small tributary, $1.5 \mathrm{miles}$ southwest of Butte Meadows, and 15 miles northeast of Forest Ranch.

Drainage area. $--44.4 \mathrm{sq} \mathrm{ml}$.

Gage-height record --Water-stage recorder graph. Altitude of gage is $4,260 \mathrm{ft}$ (from topographic map).

D1scharge record.--Stage-discharge relation defined by current-meter measurements below $1,900 \mathrm{cfs}$.

Maxima.--January-February 1963: Discharge, 3,220 cfs 1800 hours Jan. 31 (gage hel ght, $7.03 \mathrm{ft}$ ).

1960 to December 1962: Discharge, 2,770 cfs 0ct. 13, 1962 (gage height, $6.66 \mathrm{ft})$.

Mean discharge, in cublc feet per second, 1963

\begin{tabular}{|c|c|c|c|c|c|c|c|c|}
\hline Day & January & February & Day & January & February & Day & January & February \\
\hline $\begin{array}{c}1 \ldots \ldots \\
2 \ldots \ldots \\
3 \ldots \ldots \\
5 \ldots \ldots \\
6 \ldots \ldots \\
7 \ldots \ldots \\
8 \ldots \ldots \\
9 \ldots \ldots \\
10 \ldots \ldots\end{array}$ & $\begin{array}{r}116 \\
115 \\
115 \\
113 \\
107 \\
107 \\
104 \\
106 \\
99 \\
97\end{array}$ & $\begin{array}{r}1,210 \\
648 \\
568 \\
496 \\
428 \\
352 \\
309 \\
302 \\
270 \\
258\end{array}$ & $\begin{array}{l}11 \ldots \ldots \\
12 \ldots \ldots \\
13 \ldots \ldots \\
14 \ldots \ldots \\
15 \ldots \ldots \\
16 \ldots \ldots \\
17 \ldots \ldots \\
18 \ldots \ldots \\
19 \ldots \ldots \\
20 \ldots \ldots\end{array}$ & $\begin{array}{r}89 \\
91 \\
102 \\
91 \\
91 \\
88 \\
86 \\
86 \\
82 \\
82\end{array}$ & $\begin{array}{l}231 \\
222 \\
249 \\
210 \\
198 \\
190 \\
188 \\
173 \\
168 \\
168\end{array}$ & $\begin{array}{l}21 \ldots \ldots \\
22 \ldots \ldots \\
23 \ldots \ldots \\
24 \ldots \ldots \\
25 \ldots \ldots \\
26 \ldots \ldots \\
27 \ldots \ldots \\
28 \ldots \ldots \\
29 \ldots \ldots \\
30 \ldots \ldots \\
31 \ldots \ldots\end{array}$ & $\begin{array}{r}83 \\
83 \\
82 \\
80 \\
80 \\
79 \\
79 \\
79 \\
80 \\
224 \\
1,650\end{array}$ & $\begin{array}{r}158 \\
150 \\
146 \\
142 \\
138 \\
134 \\
130 \\
126 \\
---- \\
-----\end{array}$ \\
\hline \multicolumn{7}{|c|}{ 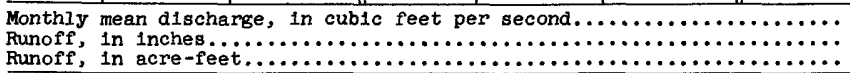 } & $\begin{array}{r}148 \\
3.83 \\
9,080\end{array}$ & $\begin{array}{r}284 \\
6.67 \\
15,790 \\
\end{array}$ \\
\hline
\end{tabular}


Gage helght, in feet, and discharge, in cublc feet per second at ind1cated time, 1963 , of

\begin{tabular}{|c|c|c|c|c|c|c|c|c|c|c|c|}
\hline Date & Hour & $\begin{array}{c}\text { Gage } \\
\text { height }\end{array}$ & $\begin{array}{c}\text { Dis- } \\
\text { charge }\end{array}$ & Date & Hour & $\begin{array}{c}\text { Gage } \\
\text { height }\end{array}$ & $\begin{array}{c}\text { Dis- } \\
\text { charge }\end{array}$ & Date & Hour & $\begin{array}{c}\text { Gage } \\
\text { helght }\end{array}$ & $\begin{array}{c}\text { D1s- } \\
\text { charge }\end{array}$ \\
\hline $\begin{array}{r}\operatorname{Jan} .29 \\
30\end{array}$ & $\begin{array}{l}2400 \\
0300 \\
1300 \\
1600 \\
1900 \\
2100 \\
2300 \\
2400\end{array}$ & $\begin{array}{l}2.10 \\
2.14 \\
2.48 \\
2.89 \\
3.27 \\
3.46 \\
3.37 \\
3.40\end{array}$ & $\begin{array}{r}86 \\
92 \\
92 \\
156 \\
267 \\
408 \\
484 \\
448 \\
460\end{array}$ & Jan. 31 & $\begin{array}{l}0400 \\
0600 \\
0900 \\
1100 \\
1300 \\
1500 \\
1600 \\
1800 \\
2000\end{array}$ & $\begin{array}{l}3.45 \\
3.61 \\
4.35 \\
5.13 \\
6.09 \\
6.76 \\
6.58 \\
7.03 \\
6.33\end{array}$ & $\begin{array}{r}480 \\
544 \\
885 \\
1,340 \\
2,150 \\
2,890 \\
2,680 \\
3,220 \\
2,500\end{array}$ & $\begin{array}{l}\text { Jan. } 31 \\
\text { Feb. } 1\end{array}$ & $\begin{array}{l}2100 \\
2400 \\
\\
0200 \\
0600 \\
0700 \\
0900 \\
1200 \\
1800 \\
2400\end{array}$ & $\begin{array}{l}6.55 \\
5.69 \\
5.80 \\
5.08 \\
5.03 \\
4.48 \\
4.26 \\
4.27 \\
4.03 \\
\end{array}$ & $\begin{array}{r}2,720 \\
1,940 \\
\\
2,040 \\
1,440 \\
1,420 \\
1,080 \\
950 \\
955 \\
825 \\
\end{array}$ \\
\hline
\end{tabular}

11-3900. Butte Creek near Chico, Cal1f.

Location.--Lat $39^{\circ} 43^{\prime} 34^{\prime \prime}$, long $121^{\circ} 42^{\prime} 28^{\prime \prime}$, in NW $\frac{1}{4} N W \frac{1}{4}$ sec. 36 , T.22 N., R.2 E., on right bank $0.7 \mathrm{mlle}$ downstream from Little Butte Creek and $7.5 \mathrm{miles}$ east of Chico.

Drainage area. $--147 \mathrm{sq} \mathrm{ml}$.

Gage-height record ${ }^{--W a t e r-s t a g e ~ r e c o r d e r ~ g r a p h . ~ A l t i t u d e ~ o f ~ g a g e ~ i s ~} 320$ ft (from topographic mapi.

Discharge record.--Stage-discharge relation defined by current-meter measurements below 6,900 cfs and by slope-area measurement at 18,700 cfs.

Maxima.--January-February 1963: Discharge, 14,200 cf's 1900 hours Jan. 31 (gage helght, $11.67 \mathrm{ft}$, from recorder graph; $12.0 \mathrm{ft}$, from floodmarks).

1930 to December 1962: Discharge, $18,700 \mathrm{cfs}$ Dec. 22, 1955 (gage height, $13.35 \mathrm{ft}$ ).

Mean discharge, in cubic feet per second, 1963

\begin{tabular}{|c|c|c|c|c|c|c|c|c|}
\hline Day & January & February & Day & January & February & Day & January & February \\
\hline $\begin{array}{c}1 \ldots \ldots \\
3 \ldots \ldots \\
4 \ldots \ldots \\
5 \ldots \ldots \\
6 \ldots \ldots \\
8 \ldots \ldots \\
9 \ldots \ldots \\
10 \ldots \ldots\end{array}$ & $\begin{array}{l}360 \\
360 \\
360 \\
342 \\
355 \\
338 \\
326 \\
326 \\
326 \\
318\end{array}$ & $\begin{array}{r}5,010 \\
2,160 \\
1,640 \\
1,370 \\
1,210 \\
998 \\
896 \\
882 \\
840 \\
805\end{array}$ & $\begin{array}{l}11 \ldots \ldots \\
12 \ldots \ldots \\
13 \ldots \ldots \\
14 \ldots \ldots \\
15 \ldots \ldots \\
16 \ldots \ldots \\
17 \ldots \ldots \\
18 \ldots \ldots \\
19 \ldots \ldots \\
20 \ldots \ldots\end{array}$ & $\begin{array}{l}306 \\
278 \\
294 \\
298 \\
274 \\
278 \\
290 \\
323 \\
230 \\
270\end{array}$ & $\begin{array}{l}735 \\
721 \\
926 \\
934 \\
798 \\
735 \\
686 \\
637 \\
602 \\
595\end{array}$ & $\begin{array}{l}21 \ldots \ldots \\
22 \ldots \ldots \\
23 \ldots \ldots \\
24 \ldots \ldots \\
25 \ldots \ldots \\
26 \ldots \ldots \\
27 \ldots \ldots \\
28 \ldots \ldots \\
29 \ldots \ldots \\
30 \ldots \ldots \\
31 \ldots \ldots\end{array}$ & $\begin{array}{r}270 \\
266 \\
262 \\
262 \\
254 \\
254 \\
250 \\
250 \\
270 \\
1,230 \\
7,710\end{array}$ & $\begin{array}{r}525 \\
511 \\
484 \\
460 \\
442 \\
430 \\
430 \\
418 \\
-----\end{array}$ \\
\hline \multicolumn{7}{|l|}{$\begin{array}{l}\text { Monthly } \\
\text { Runoff, } \\
\text { Runoff, }\end{array}$} & $\begin{array}{r}565 \\
4.40 \\
34,770 \\
\end{array}$ & $\begin{array}{r}960 \\
6.75 \\
53,320 \\
\end{array}$ \\
\hline
\end{tabular}

Gage height, in feet, and discharge, In cublc feet per second, at indicated time, 1963

\begin{tabular}{|c|c|c|c|c|c|c|c|c|c|c|c|}
\hline Date & Hour & $\begin{array}{c}\text { Gage } \\
\text { helght }\end{array}$ & $\begin{array}{c}\text { D1s- } \\
\text { charge }\end{array}$ & Date & Hour & $\begin{array}{c}\text { Gage } \\
\text { helght }\end{array}$ & $\begin{array}{c}\text { Dis- } \\
\text { charge }\end{array}$ & Date & Hour & $\begin{array}{c}\text { Gage } \\
\text { helght }\end{array}$ & $\begin{array}{c}\text { Dis- } \\
\text { charge }\end{array}$ \\
\hline$\overline{\operatorname{Jan} .29}$ & 2400 & 2.69 & 306 & Jan. 30 & 2400 & 5.82 & 2,960 & Jan. 31 & $\begin{array}{l}2100 \\
2400\end{array}$ & $\begin{array}{l}11.14 \\
10.04\end{array}$ & $\begin{array}{l}12,900 \\
10,200\end{array}$ \\
\hline 30 & $\begin{array}{l}0200 \\
0500 \\
0900 \\
1500 \\
1700 \\
1800 \\
2100 \\
2300 \\
\end{array}$ & $\begin{array}{l}2.76 \\
2.98 \\
3.40 \\
4.40 \\
4.52 \\
4.63 \\
5.51 \\
5.80 \\
\end{array}$ & $\begin{array}{r}334 \\
435 \\
669 \\
1,420 \\
1,520 \\
1,630 \\
2,590 \\
2,940 \\
\end{array}$ & 31 & $\begin{array}{l}0200 \\
0300 \\
0400 \\
0600 \\
1200 \\
1600 \\
1800 \\
1900 \\
\end{array}$ & $\begin{array}{r}5.52 \\
5.55 \\
5.58 \\
6.00 \\
8.52 \\
10.86 \\
11.55 \\
11.67 \\
\end{array}$ & $\begin{array}{r}2,600 \\
2,640 \\
2,680 \\
3,180 \\
7,060 \\
12,200 \\
13,900 \\
14,200 \\
\end{array}$ & Feb. 1 & $\begin{array}{l}0400 \\
0600 \\
1200 \\
1600 \\
1700 \\
2000 \\
2400 \\
\end{array}$ & $\begin{array}{l}8.65 \\
8.24 \\
6.57 \\
6.00 \\
5.87 \\
5.67 \\
5.52 \\
\end{array}$ & $\begin{array}{l}7,320 \\
6,590 \\
4,080 \\
3,380 \\
3,240 \\
3,020 \\
2,850 \\
\end{array}$ \\
\hline
\end{tabular}


11-3900.45. Little Chico Creek tributary near Forest Ranch, Calif.

(Crest-stage station)

Location.--Lat $39^{\circ} 52^{\prime} 40^{\prime \prime}$, long $121^{\circ} 40125^{\prime \prime}$, In SE $\frac{1}{4}$ sec.6, T.23 N., R.3 E., on state Highway $32,0.2$ mile south of Forest Ranch.

Drainage area. $--0.65 \mathrm{sq} \mathrm{ml}$.

Gage-helght record.--Crest stages only. Altitude of gage is 2,300 ft (from topographic map).

Discharge record.--Stage-discharge relation defined by current-meter measurements below $24 \mathrm{cfs}$ and by computation of flow through culvert at $34 \mathrm{cfs}$.

Maxima.--January-February 1963: Discharge, $14 \mathrm{cfs} F \mathrm{Feb} .1$ (gage he1ght, $4.04 \mathrm{ft}$ ). July to December 1962: Discharge, 34 cfs 0ct. 13, 1962 (gage height, $4.32 \mathrm{ft})$

11-3902. Gold Run tributary near Nelson, Cal1f.

(Crest-stage station)

Location.--Lat $39^{\circ} 35^{\prime} 21^{\prime \prime}$, long $121^{\circ} 41^{\prime} 1^{\prime \prime}$, on west line sec.18, T.20 N., R.3 E., on U.S. Highway $99 \mathrm{E}, 4.8$ miles northeast of Nelson.

Drainage area. $--1.31 \mathrm{sq} \mathrm{mi}$.

Gage-helght record.--Crest stages only. Altitude of gage is $160 \mathrm{ft}$ (from topographic map ?.

D1scharge record.--Stage-discharge relation defined by current-meter measurements below I70 cfs and by computation of flow through culvert at $205 \mathrm{cfs}$.

Maxima --January-February 1963: Discharge, 205 cfs Feb. 13 (gage helght, $5.79 \mathrm{ft}$ ). i959 to December 1962: Discharge, $194 \mathrm{cfs} 0 \mathrm{ct}$. 13, 1962 ?gage height, $5.56 \mathrm{ft})$.

11-3905. Sacramento River below Wilkins Slough, Calif.

Location.--Lat $39^{\circ} 00^{1} 35^{\prime \prime}$, long $121^{\circ} 49125^{\prime \prime}$, in J1meno Grant, on right bank 1,500 ft downstream from Wilkins Slough, Colusa County, 6 miles southeast of Grimes, and at mile 62.9 upstream from Sacramento.

Drainage area. $--12,940 \mathrm{sq} \mathrm{m1}$, excluding Goose Lake basin.

Gage-he1ght record.--Water-stage recorder graph, except Feb. 1-3. Gage is set to datum of Corps of EngIneers.

Discharge record.--Stage-discharge relation defined by current-meter measurements. Discharge for Feb. 1-3 estimated on basis of record for station at Colusa.

Maxima.--January-February 1963: Discharge, 25,500 cfs about 0200 hours Feb. 3 (gage helght, $48.79 \mathrm{ft}$, from floodmark in gage well).

1938 to December 1962: Discharge, 28,900 cfs Feb. 27, 1958 (gage height, $51.41 \mathrm{ft}$ ).

Remarks.--Flow affected by storage reservolrs and bypassing for flood control.

Mean discharge, in cub1c feet per second, 1963

\begin{tabular}{|c|c|c|c|c|c|c|c|c|}
\hline Day & January & February & Day & January & February & Day & January & February \\
\hline $\begin{array}{r}1 \ldots \ldots \\
2 \ldots \ldots \\
3 \ldots \ldots \\
4 \ldots \ldots \\
5 \ldots \ldots \\
6 \ldots \ldots \\
8 \ldots \ldots \\
9 \ldots \ldots \\
10 \ldots \ldots\end{array}$ & $\begin{array}{l}14,400 \\
14,100 \\
13,900 \\
13,600 \\
13,300 \\
12,900 \\
12,600 \\
12,500 \\
12,300 \\
12,000\end{array}$ & $\begin{array}{l}23,600 \\
24,800 \\
25,000 \\
24,400 \\
24,000 \\
23,500 \\
22,500 \\
22,000 \\
21,600 \\
22,300\end{array}$ & $\begin{array}{l}11 \ldots \ldots \\
12 \ldots \ldots \\
13 \ldots \ldots \\
14 \ldots \ldots \\
15 \ldots \ldots \\
16 \ldots \ldots \\
17 \ldots \ldots \\
18 \ldots \ldots \\
19 \ldots \ldots \\
20 \ldots \ldots\end{array}$ & $\begin{array}{r}11,500 \\
11,000 \\
10,400 \\
9,920 \\
9,650 \\
9,470 \\
9,380 \\
9,200 \\
9,020 \\
8,840\end{array}$ & $\begin{array}{l}25, \\
24, \\
24, \\
24, \\
24, \\
23, \\
23, \\
23,\end{array}$ & $\begin{array}{l}21 \ldots \ldots \\
22 \ldots \ldots \\
23 \ldots \ldots \\
24 \ldots \ldots \\
25 \ldots \ldots \\
26 \ldots \ldots \\
27 \ldots \ldots \\
28 \ldots \ldots \\
29 \ldots \ldots \\
30 \ldots \ldots \\
31 \ldots \ldots\end{array}$ & $\begin{array}{r}8,7 \\
8,5 \\
8,4 \\
8,4 \\
8,3 \\
8,3 \\
8,3 \\
8,2 \\
8,2 \\
8,5 \\
13,8\end{array}$ & $\begin{array}{r}21,300 \\
19,400 \\
18,300 \\
19,100 \\
19,100 \\
18,800 \\
18,500 \\
18,200 \\
----- \\
------\end{array}$ \\
\hline \multicolumn{7}{|c|}{ 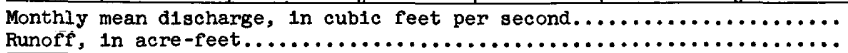 } & $\begin{array}{r}10,580 \\
650,800\end{array}$ & $\begin{array}{r}22,440 \\
1,246,000 \\
\end{array}$ \\
\hline
\end{tabular}


11-3906.72. Stone Corral Creek near Sites, Calif'.

Location.--Lat $39^{\circ} 17^{\prime} 18^{\prime \prime}$, long $122^{\circ} 18^{\prime} 00^{\prime \prime}$, in $\mathrm{NE} \frac{1}{4} \mathrm{NW} \frac{1}{4} \sec .34, \mathrm{~T} .17 \mathrm{~N} ., \mathrm{R} .4 \mathrm{~W}$, on lef't bank at road bridge 2.4 miles southeast of Sites.

Drainage area. $--38.5 \mathrm{sq} \mathrm{mi}$.

Gage-height record ${ }^{--W a t e r-s t a g e ~ r e c o r d e r ~ g r a p h . ~ A l t i t u d e ~ o f ~ g a g e ~ i s ~} 180 \mathrm{ft}^{\prime} \mathrm{\text {(f'rom }}$ topographic map).

Discharge record.--Stage-discharge relation defined by current-meter measurements below $1,200 \mathrm{c}$ s.

Maxima.--January-February 1963: Discharge, 880 cf's 2100 hours Feb. 12 (gage height, $\left.10.36 \mathrm{f}^{\prime} \mathrm{t}\right)$

1958 to December 1962: Discharge, 2,500 cf's Apr. 2, 1958 (gage helght, $\left.14.93 \mathrm{f}^{\prime} \mathrm{t}\right)$.

Remarks.--Records furnished by Calif'ornia Department of Water Resources and reviewed by the Geological Survey.

Mean discharge, in cublc feet per second, 1963

\begin{tabular}{|c|c|c|c|c|c|c|c|c|}
\hline Day & January & February & Day & January & February & Day & January & February \\
\hline $\begin{array}{c}1 \ldots \ldots \\
2 \ldots \ldots \\
3 \ldots \ldots \\
4 \ldots \ldots \\
5 \ldots \ldots \\
6 \ldots \ldots \\
8 \ldots \ldots \\
9 \ldots \ldots \\
10 \ldots \ldots\end{array}$ & $\begin{array}{l}0 \\
0 \\
0 \\
0 \\
0 \\
0 \\
0 \\
0 \\
0 \\
0\end{array}$ & $\begin{array}{r}42 \\
5.7 \\
2.3 \\
1.1 \\
.6 \\
.4 \\
.3 \\
31.2 \\
316\end{array}$ & $\begin{array}{l}11 \ldots \ldots \\
12 \ldots \ldots \\
13 \ldots \ldots \\
14 \ldots \ldots \\
15, \ldots \ldots \\
16 \ldots \ldots \\
17 \ldots \ldots \\
15 \ldots \ldots \\
19 \ldots \ldots \\
20 \ldots \ldots\end{array}$ & $\begin{array}{l}0 \\
0 \\
0 \\
0 \\
0 \\
0 \\
0 \\
0 \\
0 \\
0\end{array}$ & $\begin{array}{r}12 \\
152 \\
75 \\
16 \\
9.2 \\
6.5 \\
5.3 \\
3.7 \\
2.9 \\
2.5\end{array}$ & $\begin{array}{l}21 \ldots \ldots \\
22 \ldots \ldots \\
23 \ldots \ldots \\
24 \ldots \ldots \\
25 \ldots \ldots \\
26 \ldots \ldots \\
27 \ldots \ldots \\
28 \ldots \ldots \\
29 \ldots \ldots \\
30 \ldots \ldots \\
31 \ldots \ldots\end{array}$ & $\begin{array}{r}0 \\
0 \\
0 \\
0 \\
0 \\
0 \\
0 \\
0 \\
0 \\
17 \\
219\end{array}$ & $\begin{array}{r}2.2 \\
1.9 \\
1.5 \\
1.4 \\
1.4 \\
1.3 \\
1.1 \\
1.0 \\
-----\end{array}$ \\
\hline $\begin{array}{l}\text { inoff', } \\
\text { inoff, }\end{array}$ & $\begin{array}{l}\text { inches } \\
\text { acre- }\end{array}$ & & & & & & $\begin{array}{r}7.61 \\
0.23 \\
468\end{array}$ & $\begin{array}{r}17.7 \\
0.45 \\
955\end{array}$ \\
\hline
\end{tabular}

11-3906.8. Salt Creek near Williams, Callf'.

(Crest-stage station)

Location.--Lat $39^{\circ} 06^{1} 30^{\prime \prime}$, long $122^{\circ} 18^{1} 20^{\prime \prime}$, in NW $\frac{1}{4} S E \frac{1}{4}$ sec.33, T.15 N., R.4 W. on State Highway $20,9.2$ miles southwest of Williams.

Drainage area. $--12.9 \mathrm{sq} \mathrm{mi}$.

Gage-he1ght record.--Crest stages only. Alt1tude of gage is 325 ft (f'rom topographic map).

Discharge record.--Stage-discharge relation defined by current-meter measurements below $233 \mathrm{cfs}$ and by computation of flow through culvert at $499 \mathrm{cf}$.

Maxima --January-February 1963: Discharge, 308 cf's Jan. 31 (gage height, 22.75 f't). 1959 to December 1962: Discharge, $427 \mathrm{cfs}$ Feb. 14, 1962 qgage height, $\left.23.88 \mathrm{f}^{\prime} \mathrm{t}\right)$

11-3910. Sacramento River at Knights Landing, Calif.

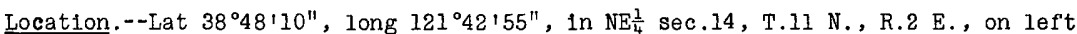
bank just upstream from Southern Pacific Railroad bridge at Knights Landing, 13.1 miles upstream from Feather River and at mile 34.0 upstream from Sacramento.

Drainage area. - -14,550 sq mi, excluding Goose Lake basin.

Gage-height record.--Water-stage recorder graph. Auxiliary water-stage recorder at site 6.0 miles downstream from base gage. Gages at datum of Corps of Engineers.

Discharge record.--Computed from stage-discharge relation def'ined by current-meter measurements and using f'all as a factor.

Maxima.--January-February 1963: Discharge, 27,600 cfs 2000 hours Feb. 2; gage height, $39.90 \mathrm{ft} 0900$ hours Feb. 2 (backwater f'rom Feather River and Sutter bypass).

1940 to December 1962: Discharge, 30,000 cf's Dec. 3, 1960; gage helght, 41.83 f't Feb. 8, 1942 (backwater f'rom Feather River and Sutter bypass).

Remarks.--Flow affected by storage reservolrs and bypassing for f'lood control. 
Mean discharge, in cubic feet per second, 1963, of Sacramento River at Knights Landing, Cal1f.

\begin{tabular}{r|r|r||r|r|r||r|r|r}
\hline Day & January & February & Day & January & February & Day & January & February \\
\hline $1 \ldots \ldots$ & 15,000 & 18,600 & $11 \ldots \ldots$ & 12,600 & 24,100 & $21 \ldots \ldots$ & 9,610 & 22,800 \\
$\ldots \ldots \ldots$ & 15,000 & 26,300 & $12 \ldots \ldots$ & 11,600 & 23,900 & $22 \ldots \ldots$ & 9,360 & 20,900 \\
$3 \ldots \ldots$ & 14,900 & 26,600 & $13 \ldots \ldots$ & 11,500 & 23,600 & $23 \ldots \ldots$ & 9,230 & 19,400 \\
$4 \ldots \ldots$ & 14,500 & 24,800 & $14 \ldots \ldots$ & 11,000 & 24,300 & $24 \ldots \ldots$ & 9,150 & 19,400 \\
$5 \ldots \ldots$ & 14,200 & 25,400 & $15 \ldots \ldots$ & 10,600 & 24,200 & $25 \ldots \ldots$ & 9,110 & 19,200 \\
$6 \ldots \ldots$ & 14,000 & 24,000 & $16 \ldots \ldots$ & 10,400 & 23,800 & $26 \ldots \ldots$ & 9,230 & 19,200 \\
$7 \ldots \ldots$ & 13,700 & 23,800 & $17 \ldots \ldots$ & 10,300 & 23,900 & $27 \ldots \ldots$ & 9,120 & 18,900 \\
$8 \ldots \ldots$ & 13,500 & 23,500 & $18 \ldots \ldots$ & 10,100 & 24,500 & $28 \ldots \ldots$ & 9,010 & 18,600 \\
$9 \ldots \ldots$ & 13,400 & 22,900 & $19 \ldots \ldots$ & 9,890 & 24,100 & $29 \ldots \ldots$ & 9,070 & $-\ldots-\ldots$ \\
$10 \ldots \ldots$ & 13,100 & 23,100 & $20 \ldots \ldots$ & 9,680 & 24,100 & $30 \ldots \ldots$ & 9,230 & $-\ldots-\ldots$ \\
\end{tabular}

11-3914. Little Last Chance Creek near Chilcott, Callf.

Location.--Lat $39^{\circ} 52^{\prime} 00^{\prime \prime}$, long $120^{\circ} 10^{\prime} 05^{\prime \prime}$, in $N \frac{1}{2} N E \frac{1}{4}$ sec.10, T.23 N., R.16 E., on left bank $500 \mathrm{ft}$ downstream from highway bridge, 0.9 mile downstream from unnamed tributary, 4.5 miles north of Vinton, and 5.0 miles north of chilcott.

Drainage area. $--84.2 \mathrm{sq} \mathrm{mi}$.

Gage-helght record.--Water-stage recorder graph, except Jan. 5 to Feb. 28. Altitude of gage 1s $5,140 \mathrm{ft}$ (from topographic map).

Discharge record.--Stage-discharge relation defined by current-meter measurements below $140 \mathrm{cfs}$; affected by backwater from ice Jan. 1-5. Discharge for Jan. 5 to Feb. 28 estimated on basis of release from Frenchman Dam, two discharge measurements and runoff per square mile for the intervening area between the dam and the station.

Maxima.--January-February 1963: Daily discharge, 40 cfs Feb. 1.

1958 to December 1962: Discharge, $784 \mathrm{cfs} \mathrm{Feb.} \mathrm{8,} 1960$ (gage helght, $5.56 \mathrm{ft}$ ).

Remarks.--Flow regulated by Frenchman Reservoir beginning Nov. 7, 1961. Records furmished by Calfornia Department of Water Resources and reviewed by Geological Survey.

Mean discharge, in cubic feet per second, 1963

\begin{tabular}{|c|c|c|c|c|c|c|c|c|}
\hline Day & January & February & Day & January & February & Day & January & February \\
\hline $\begin{array}{c}1 \ldots \ldots \\
2 \ldots \ldots \\
4 \ldots \ldots \\
5 \ldots \ldots \\
6 \ldots \ldots \\
7 \ldots \ldots \\
8 \ldots \ldots \\
10 \ldots \ldots\end{array}$ & $\begin{array}{l}1.9 \\
1.9 \\
2.1 \\
2.5 \\
2.0 \\
1.9 \\
1.9 \\
1.9 \\
1.9 \\
1.9\end{array}$ & $\begin{array}{r}40 \\
20 \\
12 \\
8.0 \\
7.0 \\
6.0 \\
5.5 \\
5.0 \\
4.5 \\
6.0\end{array}$ & $\begin{array}{l}11 \ldots \ldots \\
12 \ldots \ldots \\
13 \ldots \ldots \\
14 \ldots \ldots \\
15 \ldots \ldots \\
16 \ldots \ldots \\
17 \ldots \ldots \\
18 \ldots \ldots \\
19 \ldots \ldots \\
20 \ldots \ldots\end{array}$ & $\begin{array}{l}1.9 \\
1.9 \\
1.9 \\
1.9 \\
1.9 \\
1.9 \\
1.9 \\
1.9 \\
1.9 \\
1.9\end{array}$ & $\begin{array}{l}5.0 \\
4.0 \\
4.5 \\
3.5 \\
3.0 \\
2.8 \\
2.7 \\
2.6 \\
2.6 \\
2.6\end{array}$ & $\begin{array}{l}21 \ldots \ldots \\
22 \ldots \ldots \\
23 \ldots \ldots \\
24 \ldots \ldots \\
25 \ldots \ldots \\
26 \ldots \ldots \\
27 \ldots \ldots \\
28 \ldots \ldots \\
29 \ldots \ldots \\
30 \ldots \ldots \\
31 \ldots \ldots\end{array}$ & $\begin{array}{l}1.9 \\
1.9 \\
1.9 \\
1.9 \\
1.9 \\
1.9 \\
1.9 \\
1.9 \\
1.9 \\
6.4 \\
30\end{array}$ & $\begin{array}{r}2.5 \\
2.5 \\
2.5 \\
2.5 \\
2.5 \\
2.5 \\
2.5 \\
2.5 \\
--.-- \\
-2-2 \\
-2-1-\end{array}$ \\
\hline $\begin{array}{l}\text { onthiy } \\
\text { inoff, }\end{array}$ & 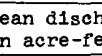 & 3 & & & & & $\begin{array}{r}2.98 \\
183 \\
\end{array}$ & $\begin{array}{r}5.98 \\
332 \\
\end{array}$ \\
\hline
\end{tabular}

11-3915. Big Grizzly Creek near Portola, Cal1f.

Location.--Lat $39^{\circ} 52^{\prime} 00^{\prime \prime}$, long $120^{\circ} 27_{1} 20^{\prime \prime}$, in NW $\frac{1}{4} N W \frac{1}{4}$ sec.7, T.23 N., R.14 E., on left bank $500 \mathrm{ft}$ upstream from small tributary, 4.3 miles upstream from mouth, and 4.5 miles north of Portola.

Drainage area. $--45.5 \mathrm{sq} \mathrm{ml}$.

Gage-height record.--Water-stage recorder graph. Altitude of gage is $5,320 \mathrm{ft}$ (from topographic map).

Discharge record.--Stage-discharge relation defined by current-meter measurements below $600 \mathrm{cfs}$ and by slope-area measurement at $4,080 \mathrm{cfs}$; affected by ice Jan. $1-13,19,20,24-28$.

Maxima.--January-February 1963: Discharge, 4,080 cf's 0100 hours Feb. 1 (gage height, $8.03 \mathrm{ft}$ ).

1925-32, 1950-53, 1954 to December 1962: Discharge, 3,090 cfs 0ct. 13, 1962 (gage height, $7.48 \mathrm{ft}$ ). 
Mean discharge, in cubic feet per second, 1963, of Big Grizzly Creek near Portola, Calif.

\begin{tabular}{|c|c|c|c|c|c|c|c|c|}
\hline Day & January & February & Day & January & February & Day & January & February \\
\hline $\begin{array}{c}1 \ldots \ldots \\
2 \ldots \ldots \\
3 \ldots \ldots \\
4 \ldots \ldots \\
5 \ldots \ldots \\
6 \ldots \ldots \\
7 \ldots \ldots \\
8 \ldots \ldots \\
10 \ldots \ldots\end{array}$ & $\begin{array}{r}9.7 \\
9.0 \\
12 \\
14 \\
9.0 \\
6.8 \\
5.3 \\
4.4 \\
5.1 \\
4.1\end{array}$ & $\begin{array}{r}1,710 \\
363 \\
250 \\
228 \\
192 \\
136 \\
115 \\
107 \\
96 \\
119\end{array}$ & $\begin{array}{l}11 \ldots \ldots \\
12 \ldots \ldots \\
13 \ldots \ldots \\
14 \ldots \ldots \\
15 \ldots \ldots \\
16 \ldots \ldots \\
17 \ldots \ldots \\
18 \ldots \ldots \\
19 \ldots \ldots \\
20 \ldots \ldots\end{array}$ & $\begin{array}{l}2.0 \\
1.9 \\
2.7 \\
4.0 \\
4.7 \\
4.9 \\
4.7 \\
4.7 \\
3.4 \\
3.0\end{array}$ & $\begin{array}{r}98 \\
82 \\
167 \\
96 \\
75 \\
72 \\
67 \\
59 \\
56 \\
63\end{array}$ & $\begin{array}{l}21 \ldots \ldots \\
22 \ldots \ldots \\
23 \ldots \ldots \\
24 \ldots \ldots \\
25 \ldots \ldots \\
26 \ldots \ldots \\
27 \ldots \ldots \\
28 \ldots \ldots \\
29 \ldots \ldots \\
30 \ldots \ldots \\
31 \ldots \ldots\end{array}$ & $\begin{array}{r}4.1 \\
5.7 \\
5.7 \\
5.6 \\
4.1 \\
2.0 \\
1.9 \\
3.0 \\
4.0 \\
146 \\
2,220\end{array}$ & $\begin{array}{r}56 \\
47 \\
41 \\
41 \\
39 \\
39 \\
31 \\
30 \\
-\ldots-- \\
--.--\end{array}$ \\
\hline noff, & acr & & & & & & $\begin{array}{r}81.2 \\
2.06 \\
4,990\end{array}$ & $\begin{array}{r}160 \\
3.66 \\
8,880 \\
\end{array}$ \\
\hline
\end{tabular}

Gage he1ght, In feet, and discharge, in cubic feet per second, at Indicated time, 1963

\begin{tabular}{|c|c|c|c|c|c|c|c|c|c|c|c|}
\hline Date & Hour & $\begin{array}{c}\text { Gage } \\
\text { heIght }\end{array}$ & $\begin{array}{l}\text { Dis- } \\
\text { charge }\end{array}$ & Date & Hour & $\begin{array}{c}\text { Gage } \\
\text { he1ght }\end{array}$ & $\begin{array}{c}\text { D18- } \\
\text { charge }\end{array}$ & Date & Hour & $\begin{array}{c}\text { Gage } \\
\text { helght }\end{array}$ & $\begin{array}{l}\text { Dis- } \\
\text { charge }\end{array}$ \\
\hline $\begin{array}{r}\text { Jan. } 29 \\
30\end{array}$ & $\begin{array}{l}2400 \\
0600 \\
0900 \\
1200 \\
1600 \\
1700 \\
1800 \\
1900 \\
2000 \\
2100 \\
2300 \\
2400\end{array}$ & $\begin{array}{l}1.58 \\
1.68 \\
1.72 \\
1.82 \\
2.08 \\
2.91 \\
3.41 \\
3.90 \\
4.35 \\
4.85 \\
5.05 \\
4.98\end{array}$ & $\begin{array}{r}3.8 \\
6.3 \\
7.4 \\
11 \\
21 \\
97 \\
175 \\
290 \\
420 \\
625 \\
730 \\
690\end{array}$ & $\operatorname{Jan} .31$ & $\begin{array}{l}0300 \\
0500 \\
0600 \\
0800 \\
1300 \\
2400 \\
\\
0100 \\
0800 \\
1400 \\
1500 \\
1800 \\
2400\end{array}$ & $\begin{array}{l}4.66 \\
4.97 \\
5.50 \\
6.13 \\
7.30 \\
7.87 \\
8.03 \\
6.57 \\
5.13 \\
5.07 \\
5.44 \\
4.98\end{array}$ & $\begin{array}{r}534 \\
685 \\
1,000 \\
1,460 \\
2,800 \\
3,770 \\
\\
4,080 \\
1,870 \\
778 \\
742 \\
964 \\
690\end{array}$ & Feb. 2 & $\begin{array}{l}1200 \\
2400 \\
0300 \\
0600 \\
1200 \\
2400 \\
\\
0900 \\
1500 \\
1800 \\
2100 \\
2400\end{array}$ & $\begin{array}{l}3.89 \\
3.67 \\
3.61 \\
3.72 \\
3.64 \\
3.39 \\
3.12 \\
3.19 \\
3.86 \\
4.06 \\
3.87\end{array}$ & $\begin{array}{l}308 \\
264 \\
\\
252 \\
274 \\
258 \\
214 \\
\\
\\
173 \\
184 \\
302 \\
342 \\
304\end{array}$ \\
\hline 31 & 0300 & 4.83 & 615 & 2 & 0600 & 4.22 & 381 & & & & \\
\hline
\end{tabular}

11-3923. Willow Creek tributary near Blairsden, Calif.

(Crest-stage station)

Location.--Lat $39^{\circ} 47^{\prime} 00^{\prime \prime}$, long $120^{\circ} 33^{\prime} 15^{\prime \prime}$, in SE $\frac{1}{4}$ sec.7, T.22 N., R.13 E., on U.S. Highway Alternate $40,3.3$ miles east of Blairsden.

Drainage area. $--1.08 \mathrm{sq} \mathrm{ml}$.

Gage-height record.--Crest stages only. Altitude of gage is 4,850 ft (from topographic map).

Discharge record.--Stage-discharge relation defined by current-meter measurements below $32 \mathrm{cf}$ 's and by computation of flow through culvert at $77 \mathrm{cfs}$.

Maxima.--January-February 1963: Discharge, $77 \mathrm{cfs} F e b .1$ (gage height, $7.18 \mathrm{ft}$ ). August to December 1962: Discharge, 64 cfs oct. 13 (gage height, $6.73 \mathrm{ft}$ ).

11-3925. Middle Fork Feather River near Clio, Calif.

Location.--Lat $39^{\circ} 45^{1} 10^{\prime \prime}$, long $120^{\circ} 35^{14} 0^{\prime \prime}$, in SE $\frac{1}{4} \sec .23$, T.22 N., R.12 E., on left bank 0.6 mile upstream from Frazier Creek, 1.0 mile northwest of Clio, and 2.2 miles southeast of Blairsden.

Drainage area. $--686 \mathrm{sq} \mathrm{mi}$.

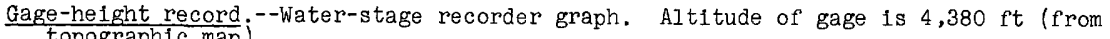
topographic mapj).

Discharge record.--Stage-discharge relation defined by current-meter measurements; affected by 1 ce Jan. 1 to Jan. 13, Jan. 18-28.

Maxima.--January-February 1963: Discharge, 14,500 cfs 0100 hours Feb. 1 (gage height, $16.19 \mathrm{ft}$ ).

1925 to December 1962: Discharge, 14,400 cfs Dec. 23, 1955 (gage height, $15.77 \mathrm{ft}$. 
Mean discharge, in cub1c feet per second, 1963, of M1ddle Fork Feather R1ver near Cl1o, Cal1 $\mathrm{f}$.

\begin{tabular}{|c|c|c|c|c|c|c|c|c|}
\hline Day & January & February & Day & January & February & Day & January & February \\
\hline $\begin{array}{c}1 \ldots \ldots \\
2 \ldots \ldots \\
3 \ldots \ldots \\
4 \ldots \ldots \\
5 \ldots \ldots \\
7 \ldots \ldots \\
8 \ldots \ldots \\
9 \ldots \ldots \\
10 \ldots \ldots\end{array}$ & $\begin{array}{r}140 \\
140 \\
135 \\
130 \\
125 \\
120 \\
110 \\
105 \\
100 \\
90\end{array}$ & $\begin{array}{r}12,900 \\
11,000 \\
6,620 \\
3,390 \\
2,300 \\
1,700 \\
1,400 \\
1,140 \\
997 \\
934\end{array}$ & $\begin{array}{l}11 \ldots \ldots \\
12 \ldots \ldots \\
13 \ldots \ldots \\
14 \ldots \ldots \\
15 \ldots \ldots \\
16 \ldots \ldots \\
17 \ldots \ldots \\
18 \ldots \ldots \\
19 \ldots \ldots \\
20 \ldots \ldots\end{array}$ & $\begin{array}{l}70 \\
55 \\
60 \\
63 \\
62 \\
64 \\
64 \\
65 \\
60 \\
60\end{array}$ & $\begin{array}{l}975 \\
975 \\
961 \\
860 \\
812 \\
708 \\
603 \\
530 \\
484 \\
458\end{array}$ & $\begin{array}{l}21 \ldots \ldots \\
22 \ldots \ldots \\
23 \ldots \ldots \\
24 \ldots \ldots \\
25 \ldots \ldots \\
26 \ldots \ldots \\
27 \ldots \ldots \\
28 \ldots \ldots \\
29 \ldots \ldots \\
30 \ldots \ldots \\
31 \ldots \ldots\end{array}$ & $\begin{array}{r}60 \\
60 \\
60 \\
60 \\
60 \\
60 \\
65 \\
80 \\
89 \\
844 \\
6,840\end{array}$ & $\begin{array}{r}430 \\
394 \\
364 \\
346 \\
324 \\
294 \\
274 \\
259 \\
----\end{array}$ \\
\hline & & & & & & & $\begin{array}{r}326 \\
0.55 \\
20,030 \\
\end{array}$ & $\begin{array}{r}1,873 \\
2.84 \\
104,000\end{array}$ \\
\hline
\end{tabular}

Gage helght, In feet, and discharge, in cublc feet per second, at ind1cated time, 1963

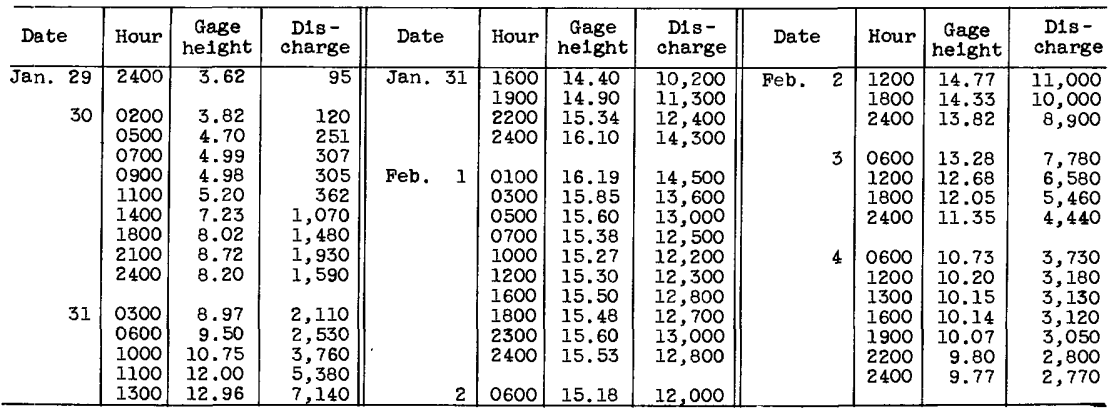

11-3945. Middle Fork Feather River near Merrimac, Calif.

Location.--Lat $39^{\circ} 42^{\prime} 30^{\prime \prime}$, long $121^{\circ} 16^{\prime} 15^{\prime \prime}$, in NE $\frac{1}{4}$ sec.2, T.21 N., R.6 E., on right bank $400 \mathrm{ft}$ downstream from bridge on M1lsap Bar Road, $500 \mathrm{ft}$ downstream from Little North Fork, 4.5 miles southeast of Merrimac, and 20 miles northeast of Orovilie.

Drainage area $--1,068 \mathrm{sq} \mathrm{mi}$.

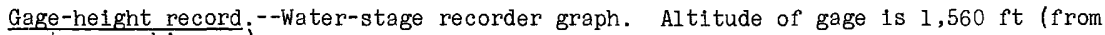
topographic map).

D1scharge record.--Stage-discharge relation defined by current-meter measurements below 19,000 cf's and by comparison of upstream and downstream peak discharges and study of runoff per square mile for intervening areas for flood of December 1955.

Maxima.--January-February 1963: Discharge, 65,400 cfs 0230 hours Feb. 1 (gage height, $21.65 \mathrm{ft}$, from recorder graph; $22.0 \mathrm{ft}$, from floodmarks).

1951 to December 1962: Discharge, 62,000 cf's Dec. 23, 1955 (gage height, $21.2 \mathrm{ft}$ ).

Mean discharge, in cuble feet per second, 1963

\begin{tabular}{|c|c|c|c|c|c|c|c|c|}
\hline Day & January & February & Day & January & February & Day & January & February \\
\hline $\begin{array}{c}1 \ldots \ldots \\
2 \ldots \ldots \\
3 \ldots \ldots \\
4 \ldots \ldots \\
5 \ldots \ldots \\
7 \ldots \ldots \\
8 \ldots \ldots \\
9 \ldots \ldots \\
10 \ldots \ldots\end{array}$ & $\begin{array}{l}880 \\
838 \\
826 \\
850 \\
802 \\
766 \\
745 \\
725 \\
710 \\
695\end{array}$ & $\begin{array}{r}39,200 \\
20,700 \\
13,400 \\
8,130 \\
6,240 \\
4,930 \\
4,230 \\
3,650 \\
3,270 \\
2,950\end{array}$ & $\begin{array}{l}11 \ldots \ldots \\
12 \ldots \ldots \\
13 \ldots \ldots \\
14 \ldots \ldots \\
15 \ldots \ldots \\
16 \ldots \ldots \\
17 \ldots \ldots \\
18 \ldots \ldots \\
19 \ldots \ldots \\
20 \ldots \ldots\end{array}$ & $\begin{array}{l}635 \\
490 \\
535 \\
590 \\
575 \\
555 \\
535 \\
525 \\
510 \\
494\end{array}$ & $\begin{array}{l}2,850 \\
2,670 \\
3,310 \\
2,920 \\
2,620 \\
2,430 \\
2,180 \\
1,990 \\
1,860 \\
1,760\end{array}$ & $\begin{array}{l}21 \ldots \ldots \\
22 \ldots \ldots \\
23 \ldots \ldots \\
24 \ldots \ldots \\
25 \ldots \ldots \\
26 \ldots \ldots \\
27 \ldots \ldots \\
28 \ldots \ldots \\
29 \ldots \ldots \\
30 \ldots \ldots \\
31 \ldots \ldots\end{array}$ & $\begin{array}{r}506 \\
510 \\
498 \\
498 \\
498 \\
494 \\
486 \\
482 \\
516 \\
2,500 \\
31,200 \\
\end{array}$ & $\begin{array}{r}1,670 \\
1,640 \\
1,470 \\
1,400 \\
1,320 \\
1,260 \\
1,200 \\
1,150 \\
--.--- \\
--.---\end{array}$ \\
\hline \multicolumn{7}{|c|}{ 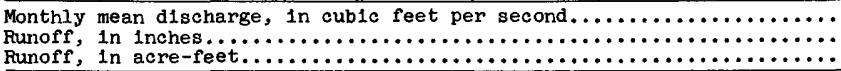 } & $\begin{array}{r}1,660 \\
102,79 \\
102,100\end{array}$ & $\begin{array}{r}5,086 \\
4.96 \\
282,400 \\
\end{array}$ \\
\hline
\end{tabular}


Gage height, in feet, and discharge, in cubic feet per second, at indicated time, 1963, of Middle Fork Feather River near Merrimac, Calif.

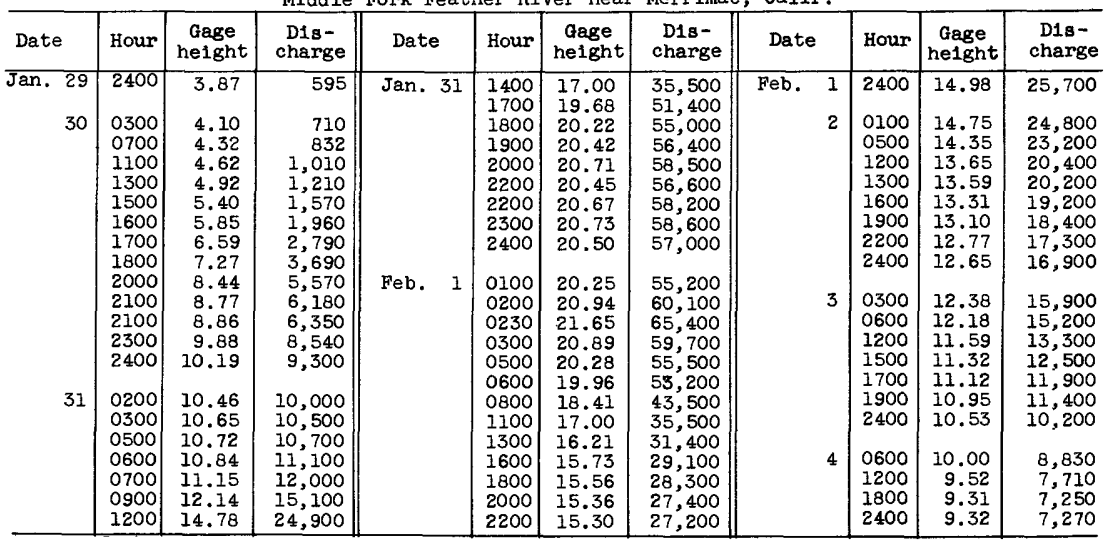

11-3948. South Fork Feather River above Little Grass Valley Reservolr, Calif'.

Location.--Lat $39^{\circ} 45^{\prime} 07^{\prime \prime}$, long $120^{\circ} 57^{\prime} 26^{\prime \prime}$, In NW $\frac{1}{4} \mathrm{SE} \frac{1}{4} \sec .22$, T.22 N., R.9 E., on right bank about 0.6 mile upstream from maximum pool elevation of Little Grass Valley Reservolr, $0.5 \mathrm{mlle}$ downstream from unnamed tributary, and $5 \mathrm{miles}$ north of LaPorte.

Drainage area. $--8.09 \mathrm{sq} \mathrm{mi}$.

Gage-he1ght record.--Water-stage recorder graph, except Jan. 1-2 and Jan. 25 to Feb. 6. Alt1tude of gage 5,080 f't (from topographic map).

Discharge record.--Stage-discharge relation defined by current-meter measurements below $110 \mathrm{cfs}$ and by slope-area measurement at 1,640 cfs; affected by 1ce Jan. 11-13, 17-23. Discharge for perlods of no gage-helght record estimated on basis of records for Lost Creek above Sly Creek Reservolr.

Maxima.--January-February 1963: Discharge, 4,160 cfs, time unknown, Jan. 31 (gage helght, $7.12 \mathrm{ft}$, from floodmarks in well: $7.35 \mathrm{ft}$, from floodmarks)

1960 to December 1962: D1scharge, 1,640 cfs Oct. 13, 1962 (gage helght, $5.47 \mathrm{ft})$.

Mean discharge, in cublc feet per second, 1963

\begin{tabular}{|c|c|c|c|c|c|c|c|c|}
\hline Day & January & February & Day & Jamuary & February & Day & January & February \\
\hline $\begin{array}{r}1 \ldots \ldots \\
2 \ldots \ldots \\
4 \ldots \ldots \\
5 \ldots \ldots \\
6 \ldots \ldots \\
7 \ldots \ldots \\
9 \ldots \ldots \\
10 \ldots \ldots\end{array}$ & $\begin{array}{l}16 \\
15 \\
14 \\
14 \\
13 \\
13 \\
12 \\
11 \\
11 \\
10\end{array}$ & $\begin{array}{r}1,050 \\
260 \\
190 \\
150 \\
110 \\
80 \\
66 \\
63 \\
55 \\
53\end{array}$ & $\begin{array}{l}11 \ldots \ldots \\
12 \ldots \ldots \\
13 \ldots \ldots \\
14 \ldots \ldots \\
15 \ldots \ldots \\
16 \ldots \ldots \\
17 \ldots \ldots \\
18 \ldots \ldots \\
19 \ldots \ldots \\
20 \ldots \ldots\end{array}$ & $\begin{array}{l}9.5 \\
9.0 \\
9.0 \\
8.5 \\
7.8 \\
7.5 \\
7.5 \\
7.5 \\
7.5 \\
7.0\end{array}$ & $\begin{array}{l}45 \\
44 \\
71 \\
52 \\
47 \\
45 \\
41 \\
36 \\
34 \\
34\end{array}$ & $\begin{array}{l}21 \ldots \ldots \\
22 \ldots \ldots \\
23 \ldots \ldots \\
24 \ldots \ldots \\
25 \ldots \ldots \\
26 \ldots \ldots \\
27 \ldots \ldots \\
28 \ldots \ldots \\
29 \ldots \ldots \\
30 \ldots \ldots \\
31 \ldots \ldots\end{array}$ & $\begin{array}{r}6.0 \\
5.5 \\
5.5 \\
5.0 \\
5 \\
5 \\
5 \\
5 \\
5 \\
150 \\
1,250 \\
\end{array}$ & $\begin{array}{r}31 \\
29 \\
26 \\
25 \\
23 \\
22 \\
20 \\
18 \\
-\ldots-- \\
-\ldots- \\
\end{array}$ \\
\hline \multicolumn{7}{|l|}{$\begin{array}{l}\text { Monthly } \\
\text { Runoff, } \\
\text { Runoff, }\end{array}$} & $\begin{array}{r}53.4 \\
7.62 \\
3,290 \\
\end{array}$ & $\begin{array}{r}97.1 \\
12.50 \\
5,400 \\
\end{array}$ \\
\hline
\end{tabular}


11-3950.2. Little Grass Valley Reservoir near LaPorte, Calif.

Location.--Lat $39^{\circ} 43^{\prime} 25^{\prime \prime}$, long $121^{\circ} 01^{\prime} 10^{\prime \prime}$, in W $\frac{1}{2}$ sec.31, T.22 N., R.9 E., on right bank $300 \mathrm{ft}$ upstream from dam on South Fork Feather River and 3.3 miles northwest of LaPorte.

Drainage area. $--25.5 \mathrm{sq} \mathrm{mi}$.

Gage-height record:--Water-stage recorder graph. Datum of gage is at mean sea level (levels by Oroville-Wyandotte Irrigation District).

Contents record.--Contents computed from capacity table dated Dec. 17, 1962 , furnished by Oroville-Wyandotte Irrigation District.

Maxima.--January-February 1963: Computed bihourly inflow, 9,020 cfs 1600 to 1800 hours Jan. 31. Contents, 83,600 acre-ft 0300 hours Feb. 1 (elevation, $5,040.05 \mathrm{ft})$.

1961 to December 1962: Contents, 76,800 acre-ft Dec. 16, 1962 (elevat1on, $5,035.4 \mathrm{ft}$ ).

Remarks.--Reservoir is formed by rockfill dam. Storage began in October 1961. Capacity, 94,600 acre-ft between elevations $4,876 \mathrm{ft}$ (invert of release valve) and $5,047 \mathrm{ft}$ (top of spillway gates), all of which is usable.

Elevation, in feet, and contents, in acre-feet, at 2400 hours, 1963

\begin{tabular}{|c|c|c|c|c|c|c|c|c|c|}
\hline \multirow{2}{*}{ Day } & \multicolumn{2}{|c|}{ January } & \multicolumn{2}{|c|}{ February } & \multirow{2}{*}{ Day } & \multicolumn{2}{|c|}{ January } & \multicolumn{2}{|c|}{ February } \\
\hline & Elevation & Contents & Elevation & Contents & & Elevation & Contents & Elevation & Contents \\
\hline $\begin{array}{r}1 \\
2 \\
3 \\
4 \\
5 \\
6 \\
7 \\
8 \\
9 \\
10 \\
11 \\
12 \\
13 \\
14 \\
15\end{array}$ & $\begin{array}{l}5,034.4 \\
5,034.4 \\
5,034.4 \\
5,034.3 \\
5,034.3 \\
5,034.3 \\
5,034.3 \\
5,034.3 \\
5,034.2 \\
5,034.2 \\
5,034.2 \\
5,034.2 \\
5,034.2 \\
5,034.2 \\
5,034.2\end{array}$ & $\begin{array}{l}75,300 \\
75,300 \\
75,300 \\
75,200 \\
75,200 \\
75,200 \\
75,200 \\
75,200 \\
75,000 \\
75,000 \\
75,000 \\
75,000 \\
75,000 \\
75,000 \\
75,000\end{array}$ & $\begin{array}{l}5,038.5 \\
5,037.1 \\
5,036.4 \\
5,035.9 \\
5,035.6 \\
5,035.4 \\
5,035.2 \\
5,035.1 \\
5,035.0 \\
5,034.9 \\
5,034.8 \\
5,034.9 \\
5,035.0 \\
5,034.9 \\
5,034.8\end{array}$ & $\begin{array}{l}81,300 \\
79,200 \\
78,200 \\
77,500 \\
77,100 \\
76,800 \\
76,500 \\
76,300 \\
76,200 \\
76,000 \\
75,900 \\
76,000 \\
76,200 \\
76,000 \\
75,900\end{array}$ & $\begin{array}{l}16 \\
17 \\
18 \\
19 \\
20 \\
21 \\
22 \\
23 \\
24 \\
25 \\
26 \\
27 \\
28 \\
29 \\
30 \\
31\end{array}$ & $\begin{array}{l}5,034.2 \\
5,034.2 \\
5,034.2 \\
5,034.2 \\
5,034.2 \\
5,034.2 \\
5,034.2 \\
5,034.2 \\
5,034.2 \\
5,034.1 \\
5,034.1 \\
5,034.1 \\
5,034.1 \\
5,034.3 \\
5,035.0 \\
5,039.7\end{array}$ & $\begin{array}{l}75,000 \\
75,000 \\
75,000 \\
75,000 \\
75,000 \\
75,000 \\
75,000 \\
75,000 \\
75,000 \\
74,900 \\
74,900 \\
74,900 \\
74,900 \\
75,200 \\
76,200 \\
83,000\end{array}$ & $\begin{array}{c}5,034.8 \\
5,034.8 \\
5,034.7 \\
5,034.7 \\
5,034.7 \\
5,034.6 \\
5,034.6 \\
5,034.6 \\
5,034.5 \\
5,034.5 \\
5,034.5 \\
5,034.5 \\
5,034.5 \\
- \\
- \\
-\end{array}$ & $\begin{array}{c}75,900 \\
75,900 \\
75,700 \\
75,700 \\
75,700 \\
75,600 \\
75,600 \\
75,600 \\
75,500 \\
75,500 \\
75,500 \\
75,500 \\
75,500 \\
- \\
- \\
-\end{array}$ \\
\hline 20 & $\overline{\ln c}$ & $s$, In & e-feet. & & & - & $+7,700$ & - & $-7,500$ \\
\hline
\end{tabular}

Average inflow in cublic feet per second, for bihourly periods ending at indicated time

\begin{tabular}{|c|c|c|c|c|c|c|c|c|}
\hline Date & Hour & Inflow & Date & Hour & Inflow & Date & Hour & Inflow \\
\hline Jan. 31 & $\begin{array}{l}0200 \\
0400 \\
0600 \\
0800 \\
1000 \\
1200 \\
1400 \\
1600 \\
1800 \\
2000 \\
2200 \\
2400\end{array}$ & $\begin{array}{r}888 \\
1,100 \\
1,140 \\
2,170 \\
3,320 \\
4,790 \\
5,870 \\
7,060 \\
9,020 \\
8,030 \\
7,970 \\
7,230\end{array}$ & Feb. 1 & $\begin{array}{l}0200 \\
0400 \\
0600 \\
0800 \\
1000 \\
1200 \\
1400 \\
1600 \\
1800 \\
2000 \\
2200 \\
2400\end{array}$ & $\begin{array}{l}6,260 \\
4,220 \\
3,720 \\
2,070 \\
2,290 \\
1,830 \\
1,860 \\
2,080 \\
2,190 \\
2,000 \\
1,520 \\
1,400\end{array}$ & Feb. 2 & $\begin{array}{l}0200 \\
0400 \\
0600 \\
0800 \\
1000 \\
1200 \\
1400 \\
1600 \\
1800 \\
2000 \\
2200 \\
2400\end{array}$ & $\begin{array}{r}2,200 \\
1,010 \\
1,290 \\
874 \\
1,130 \\
1,020 \\
987 \\
787 \\
949 \\
747 \\
859 \\
547\end{array}$ \\
\hline
\end{tabular}


11-3950.3. South Fork Feather River below Little Grass Valley Dam, Calif'.

Location. - -Lat $39^{\circ} 43^{\prime} 26^{\prime \prime}$, long $121^{\circ} 01^{\prime} 10^{\prime \prime}$, in SW $\frac{1}{4} \mathrm{NW} \frac{1}{4}$ sec.31, T.22 N., R.9 E., on outlet works at base of Little Grass Valley Dam, 0.6 mile downstream from Ice Creek and 3.5 miles northwest of LaPorte.

Drainage area. $--25.9 \mathrm{sq} \mathrm{mi}$.

Gage-height record.--No gage-height record available. Datum of gage is $4,850.00 \mathrm{ft}$ above mean sea level.

Discharge record.--Discharge estimated on basis of observer's notations of settings of the release valve, fishwater valve, reservoir elevation, computed discharge over spillway, and two discharge measurements.

Maxima.--January-February 1963: Discharge, 4,240 cfs 0300 hours Feb. 1. 1927-33, 1960-63: Discharge, 2,600 cfs Mar. 26, 1988 (gage height, 7.00 ft, site and datum then in use).

Remarks.--Flow regulated by Little Grass Valley Reservoir (see station 11-3950.2) beginning in october 1961 .

Mean discharge, in cublc feet per second, 1963

\begin{tabular}{|c|c|c|c|c|c|c|c|c|}
\hline Day & January & February & Day & January & February & Day & January & February \\
\hline $\begin{array}{r}1 \ldots \ldots \\
2 \ldots \ldots \\
3 \ldots \ldots \\
5 \ldots \ldots \\
6 \ldots \ldots \\
7 \ldots \ldots \\
8 \ldots \ldots \\
9 \ldots \ldots \\
10 \ldots \ldots\end{array}$ & $\begin{array}{l}73 \\
71 \\
59 \\
55 \\
48 \\
44 \\
44 \\
41 \\
39 \\
35\end{array}$ & $\begin{array}{r}3,530 \\
1,970 \\
1,210 \\
808 \\
606 \\
456 \\
372 \\
318 \\
265 \\
234\end{array}$ & $\begin{array}{l}11 \ldots \ldots \\
12 \ldots \ldots \\
13 \ldots \ldots \\
14 \ldots \ldots \\
15 \ldots \ldots \\
16 \ldots \ldots \\
17 \ldots \ldots \\
18 \ldots \ldots \\
19 \ldots \ldots \\
20 \ldots \ldots\end{array}$ & $\begin{array}{l}29 \\
24 \\
24 \\
26 \\
26 \\
26 \\
26 \\
26 \\
24 \\
23\end{array}$ & $\begin{array}{l}206 \\
189 \\
245 \\
226 \\
211 \\
186 \\
175 \\
159 \\
149 \\
143\end{array}$ & $\begin{array}{l}21 \ldots \ldots \\
22 \ldots \ldots \\
23 \ldots \ldots \\
24 \ldots \ldots \\
25 \ldots \ldots \\
26 \ldots \ldots \\
27 \ldots \ldots \\
28 \ldots \ldots \\
29 \ldots \ldots \\
30 \ldots \ldots \\
31 \ldots \ldots\end{array}$ & $\begin{array}{r}21 \\
21 \\
21 \\
21 \\
20 \\
20 \\
18 \\
17 \\
24 \\
112 \\
1,400 \\
\end{array}$ & 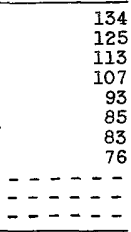 \\
\hline $\begin{array}{l}\text { onthiy } \\
\text { inoff, }\end{array}$ & $\mathrm{n}$ dis & ; & foot $n$ & & & & $\begin{array}{r}79.3 \\
4,880\end{array}$ & $\begin{array}{r}446 \\
24,740\end{array}$ \\
\hline
\end{tabular}

Gage helght, in feet, and discharge, In cublc feet per second, at indicated time, 1963

\begin{tabular}{|c|c|c|c|c|c|c|c|c|c|c|c|}
\hline Date & Hour & $\begin{array}{c}\text { Gage } \\
\text { helght }\end{array}$ & $\begin{array}{c}\text { Dis- } \\
\text { charge }\end{array}$ & Date & Hour & $\begin{array}{c}\text { Gage } \\
\text { helght }\end{array}$ & $\begin{array}{c}\text { D1s- } \\
\text { charge }\end{array}$ & Date & Hour & $\begin{array}{c}\text { Gage } \\
\text { he1ght }\end{array}$ & $\begin{array}{l}\text { D1s- } \\
\text { charge }\end{array}$ \\
\hline $\begin{array}{r}\operatorname{Jan} .30 \\
31\end{array}$ & $\begin{array}{l}2400 \\
0200 \\
0400 \\
0600 \\
0800 \\
1000 \\
1200 \\
1400 \\
1600 \\
1800 \\
2000 \\
\end{array}$ & $\begin{array}{l}- \\
\overline{-} \\
\overline{-} \\
\overline{-} \\
\overline{-} \\
\overline{-} \\
\end{array}$ & $\begin{array}{r}268 \\
312 \\
350 \\
420 \\
535 \\
735 \\
1,030 \\
1,490 \\
2,060 \\
2,640 \\
3,250 \\
\end{array}$ & $\begin{array}{l}\text { Jan. } 31 \\
\text { Feb. I }\end{array}$ & $\begin{array}{l}2200 \\
2400 \\
0200 \\
0300 \\
0400 \\
0600 \\
0800 \\
1000 \\
1200 \\
1400 \\
1600 \\
\end{array}$ & $\begin{array}{l}- \\
- \\
- \\
z \\
- \\
- \\
- \\
-\end{array}$ & $\begin{array}{l}3,720 \\
3,900 \\
4,160 \\
4,240 \\
4,140 \\
3,940 \\
3,800 \\
3,580 \\
3,370 \\
3,230 \\
3,150 \\
\end{array}$ & Feb. 1 & $\begin{array}{l}1800 \\
2000 \\
2200 \\
2400 \\
\\
0400 \\
0800 \\
1200 \\
1600 \\
2000 \\
2400\end{array}$ & $\begin{array}{l}\overline{-} \\
\overline{-} \\
\overline{-} \\
\overline{-} \\
\overline{-} \\
-\end{array}$ & $\begin{array}{l}3,020 \\
2,850 \\
2,730 \\
2,660 \\
2,310 \\
2,090 \\
1,890 \\
1,730 \\
1,580 \\
1,470\end{array}$ \\
\hline
\end{tabular}


11-3952. South Fork Feather River below diversion dam, near Strawberry Valley, Calif.

Location.--Lat $39^{\circ} 38^{\prime} 51^{\prime \prime}$, long $121^{\circ} 07^{\prime} 04^{\prime \prime}$, in $\mathrm{NE}_{\frac{1}{4}} \mathrm{SE} \frac{3}{4} \sec .30$, T.21 N., R.8 E., on right bank 0.1 mile downstream from diversion dam, 3.1 miles upstream from Rock Creek, and 5.8 miles north of Strawberry Valley.

Drainage area. $--37.7 \mathrm{sq} \mathrm{mi}$.

Gage-height record.--Water-stage recorder graph. Datum of gage is 3,535.02 $\mathrm{ft}$ above mean sea level (levels by Oroville-Wyandotte Irrigation District).

Discharge record.--Stage-discharge relation defined by current-meter measurements below $500 \mathrm{cfs}$ and by computation of flow over diversion dam at $6,330 \mathrm{cfs}$.

Maxima (river only).--January-February 1963: Discharge, 6,330 cfs 2400 hours Jan. 31 (gage height, $13.21 \mathrm{ft}$ ).

1960 to December 1962: Discharge observed, 1,380 cfs Feb. 9, 1961 (gage height, $4.10 \mathrm{ft}$ ).

Maxima (river plus diversion).--January-February 1963: Discharge, 6,370 cfs 2400 hours Jan. 31 .

1960 to December 1962: Discharge, 1,860 cfs 0ct. 13, 1962.

Remarks.--Flow regulated by IIttle Grass Valley Reservoir (usable capacity, 94,700 acre- $f^{\prime}$ ) beginning 0ctober 1961. South Fork diversion tunnel (maximum capacity, about $600^{\circ} \mathrm{cfs}$ ) diverts $500 \mathrm{ft}$ upstream to Sly Creek Reservoir. All discharge figures in the tables below are the combined flow of South Fork Feather River below diversion dam and South Fork diversion tunnel.

Mean d1scharge, in cub1c feet per second, 1963

\begin{tabular}{|c|c|c|c|c|c|c|c|c|}
\hline Day & January & February & Day & January & February & Day & January & February \\
\hline 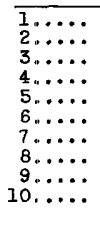 & $\begin{array}{l}91 \\
85 \\
82 \\
83 \\
75 \\
70 \\
66 \\
62 \\
58 \\
54\end{array}$ & $\begin{array}{r}5,020 \\
2,570 \\
1,700 \\
1,100 \\
851 \\
676 \\
507 \\
467 \\
401 \\
331\end{array}$ & 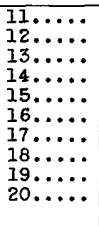 & $\begin{array}{l}52 \\
42 \\
39 \\
38 \\
36 \\
36 \\
36 \\
35 \\
35 \\
33\end{array}$ & $\begin{array}{l}260 \\
221 \\
401 \\
361 \\
301 \\
261 \\
241 \\
220 \\
200 \\
180\end{array}$ & $\begin{array}{l}21 \ldots \ldots \\
22 \ldots \ldots \\
23 \ldots \ldots \\
24 \ldots \ldots \\
25 \ldots \ldots \\
26 \ldots \ldots \\
27 \ldots \ldots \\
25 \ldots \ldots \\
29 \ldots \ldots \\
30 \ldots \ldots \\
31 \ldots \ldots\end{array}$ & $\begin{array}{r}33 \\
31 \\
31 \\
31 \\
31 \\
30 \\
29 \\
28 \\
31 \\
232 \\
3,590\end{array}$ & $\begin{array}{r}160 \\
150 \\
140 \\
130 \\
110 \\
57 \\
81 \\
77 \\
-0 .-0 \\
-0 .-0\end{array}$ \\
\hline $\begin{array}{l}\text { onthly } \\
\text { unoff, }\end{array}$ & $\begin{array}{l}\text { an disc } \\
\text { acre }\end{array}$ & ... & eet & & & ... & $\begin{array}{r}168 \\
10,330\end{array}$ & $\begin{array}{r}625 \\
34,720 \\
\end{array}$ \\
\hline
\end{tabular}

Gage he1ght, in feet, and discharge, in cub1c feet per second, at 1nd1cated t1me, 1963

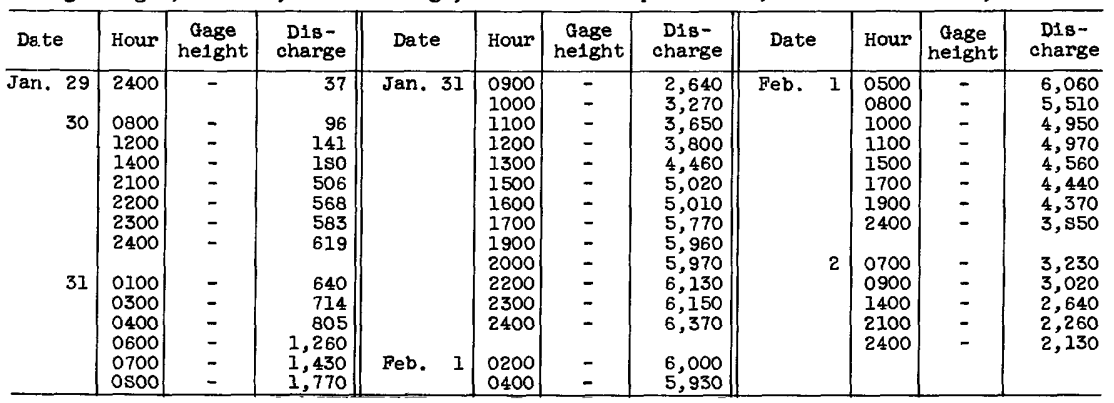


11-3953. Lost Creek above Sly Creek Reservoir, Calif.

Location.--Lat $39^{\circ} 37^{\prime} 05^{\prime \prime}$, long $121^{\circ} 05^{\prime} 19^{\prime \prime}$, in $\mathrm{NE} \frac{2}{4} \operatorname{SW} \frac{1}{4} \sec .4$, T.20 N., R.8 E., on left bank 0.4 mile upstream from French Creek and 3.8 miles north of Strawberry Valley.

Drainage area. $--14.1 \mathrm{sq} \mathrm{mi}$.

Gage-height record:--Water-stage recorder graph. Altitude of gage is $3,570 \mathrm{ft}$ (from topographic map).

Discharge record.--Stage-discharge relation defined by current-meter measurements below $300 \mathrm{cfs}$ and by slope-area measurements at 2,110 and $4,350 \mathrm{cfs}$. Affected by Ice Jan. 12,13 . Maxima.--January-February 1963: Discharge, 4,570 efs 1900 hours Jan. 31 (gage

1960 to December 1962: Discharge, 1,900 cfs oct. 13, 1962 (gage height, $5.97 \mathrm{ft}$ ).

Mean discharge, in cubic feet per second, 1963

\begin{tabular}{|c|c|c|c|c|c|c|c|c|}
\hline Day & January & February & Day & January & February & Day & January & Pebruary \\
\hline $\begin{array}{c}1 \ldots \ldots \\
2 \ldots \ldots \\
3 \ldots \ldots \\
4 \ldots \ldots \\
6 \ldots \ldots \\
7 \ldots \ldots \\
8 \ldots \ldots \\
9 \ldots \ldots \\
10 \ldots \ldots\end{array}$ & $\begin{array}{l}31 \\
30 \\
30 \\
28 \\
28 \\
28 \\
26 \\
25 \\
25 \\
24\end{array}$ & $\begin{array}{r}1,520 \\
505 \\
316 \\
235 \\
180 \\
144 \\
122 \\
310 \\
97 \\
89\end{array}$ & $\begin{array}{l}11 \ldots \ldots \\
12 \ldots \ldots \\
13 \ldots \ldots \\
14 \ldots \ldots \\
15 \ldots \ldots \\
16 \ldots \ldots \\
17 \ldots \ldots \\
18 \ldots \ldots \\
19 . \ldots \ldots \\
20 \ldots \ldots\end{array}$ & $\begin{array}{l}23 \\
23 \\
22 \\
22 \\
21 \\
20 \\
20 \\
20 \\
20 \\
19\end{array}$ & $\begin{array}{r}79 \\
79 \\
131 \\
99 \\
86 \\
79 \\
72 \\
66 \\
60 \\
58\end{array}$ & $\begin{array}{l}21 \ldots \ldots \\
22 \ldots \ldots \\
23 \ldots \ldots \\
24 \ldots \ldots \\
25 \ldots \ldots \\
26 \ldots \ldots \\
27 \ldots \ldots \\
28 \ldots \ldots \\
29 \ldots \ldots \\
30 \ldots \ldots \\
31 \ldots \ldots\end{array}$ & $\begin{array}{r}19 \\
19 \\
18 \\
18 \\
17 \\
17 \\
17 \\
17 \\
17 \\
179 \\
1,930 \\
\end{array}$ & $\begin{array}{r}56 \\
53 \\
49 \\
48 \\
46 \\
45 \\
42 \\
40 \\
--- \\
---- \\
--. \\
\end{array}$ \\
\hline $\begin{array}{l}\text { nthly } \\
\text { anoff, } \\
\text { anoff, }\end{array}$ & \multicolumn{6}{|c|}{ 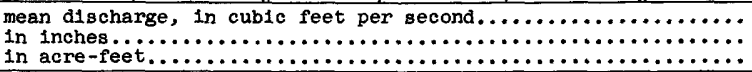 } & $\begin{array}{r}88.8 \\
7.26 \\
5,460\end{array}$ & $\begin{array}{r}161 \\
11.89 \\
8,940 \\
\end{array}$ \\
\hline
\end{tabular}

Gage height, in feet, and discharge, in cublc feet per second, at indicated time, 1963

\begin{tabular}{|c|c|c|c|c|c|c|c|c|c|c|c|}
\hline Date & Hour & $\begin{array}{c}\text { Gage } \\
\text { height }\end{array}$ & $\begin{array}{c}\text { D1s- } \\
\text { charge }\end{array}$ & Date & Hour & $\begin{array}{c}\text { Gage } \\
\text { helght }\end{array}$ & $\begin{array}{c}\text { DIs- } \\
\text { charge }\end{array}$ & Date & Hour & $\begin{array}{c}\text { Gage } \\
\text { helght }\end{array}$ & $\begin{array}{l}\text { Dis - } \\
\text { charge }\end{array}$ \\
\hline $\begin{array}{r}\text { Jan. } 29 \\
30\end{array}$ & $\begin{array}{l}2400 \\
0400 \\
0900 \\
1200 \\
1400 \\
1600 \\
1800 \\
2300 \\
2400\end{array}$ & $\begin{array}{l}1.97 \\
2.13 \\
2.43 \\
2.70 \\
3.09 \\
3.60 \\
4.05 \\
4.28 \\
4.20\end{array}$ & $\begin{array}{r}22 \\
33 \\
60 \\
92 \\
149 \\
250 \\
365 \\
452 \\
420\end{array}$ & Jan. 31 & $\begin{array}{l}0400 \\
0600 \\
0800 \\
1000 \\
1300 \\
1600 \\
1900 \\
2100 \\
2200 \\
2400\end{array}$ & $\begin{array}{l}4.11 \\
4.28 \\
4.80 \\
5.26 \\
6.12 \\
6.48 \\
7.87 \\
7.27 \\
7.44 \\
6.97\end{array}$ & $\begin{array}{r}384 \\
452 \\
730 \\
1,100 \\
2,100 \\
2,540 \\
4,570 \\
3,620 \\
3,880 \\
3,200\end{array}$ & Feb. 1 & $\begin{array}{l}0200 \\
0400 \\
0700 \\
1200 \\
1500 \\
2000 \\
2400 \\
\\
0600 \\
1400 \\
2400\end{array}$ & $\begin{array}{l}7.09 \\
6.28 \\
5.77 \\
5.18 \\
5.00 \\
4.69 \\
4.45 \\
\\
4.23 \\
3.97 \\
3.75\end{array}$ & $\begin{array}{r}3,370 \\
2,300 \\
1,730 \\
1,210 \\
1,070 \\
554 \\
710 \\
\\
585 \\
455 \\
360\end{array}$ \\
\hline 31 & 0200 & 4.10 & 380 & Feb. & 0100 & 6.97 & 3,200 & & & & \\
\hline
\end{tabular}

11-3954. Sly Creek Reservolr near Strawberry Valley, Calif.

Location.--Lat $39^{\circ} 35^{\prime} 00^{\prime \prime}$, long $121^{\circ} 06^{\prime} 45^{\prime \prime}$, in NW $\frac{1}{4} N W \frac{1}{4} \sec .20$, T.20 N., R. 8 E., in valve chamber Inside dam, 1.4 miles northwest of Strawberry Valley.

Drainage area. $--24.1 \mathrm{sq} \mathrm{mi}$.

Gage-height record.--Water-stage recorder graph. Datum of gage is at mean sea level (levels by Oroville-Wyandotte Irrigation District).

Contents record. -- Computed from capacity table dated Apr. 23, 1963, furnished by Oroville-Wyandotte Irrigation District.

Maxima.--January-February 1963: Contents, 56,500 acre-ft 1500 to 2000 hours Feb. 15 (elevation, $3,515.5 \mathrm{ft}$ ).

1961 to December 1962: Contents, 65,500 acre-ft June 2-5, 11, 12, 1962 (elevation, $3,531.5 \mathrm{ft}$ ).

Remarks. --Reservoir is formed by earthfill dam. Storage began in November 1961.

Capacity, 65,200 acre-ft between elevations 3,285 ft (invert of outlet) and 3,531

ft (top splilway gate). Water is diverted into reservolr from South Fork

Feather River through South Fork diversion tunnel and from North Yuba River

basin through Slate Creek tunnel. 
Elevation, In feet, and contents, In acre-feet, at 2400 hours, 1963, of Sly Creek Reservo1r

\begin{tabular}{|c|c|c|c|c|c|c|c|c|c|}
\hline \multirow{2}{*}{ Day } & \multicolumn{2}{|c|}{ January } & \multicolumn{2}{|c|}{ February } & \multirow{2}{*}{ Day } & \multicolumn{2}{|c|}{ January } & \multicolumn{2}{|c|}{ February } \\
\hline & Elevation & Contents & Elevation & Contents & & Elevation & Contents & Elevation & Contents \\
\hline $\begin{array}{r}1 \\
2 \\
3 \\
4 \\
5 \\
6 \\
7 \\
8 \\
9 \\
10 \\
11 \\
12 \\
13 \\
14 \\
15\end{array}$ & $\begin{array}{l}3,510.5 \\
3,510.5 \\
3,510.6 \\
3,510.0 \\
3,508.5 \\
3,508.0 \\
3,507.5 \\
3,506.0 \\
3,506.0 \\
3,505.0 \\
3,504.0 \\
3,502.5 \\
3,501.5 \\
3,500.5 \\
3,499.0\end{array}$ & $\begin{array}{l}53,700 \\
53,700 \\
53,800 \\
53,400 \\
52,700 \\
52,400 \\
52,100 \\
51,300 \\
51,300 \\
50,800 \\
50,300 \\
49,500 \\
48,900 \\
48,400 \\
47,700\end{array}$ & $\begin{array}{l}3,501.0 \\
3,506.0 \\
3,508.0 \\
3,510.5 \\
3,512.0 \\
3,513.0 \\
3,513.0 \\
3,513.5 \\
3,513.5 \\
3,513.5 \\
3,513.5 \\
3,514.0 \\
3,514.5 \\
3,514.5 \\
3,515.0\end{array}$ & $\begin{array}{l}48,700 \\
51,300 \\
52,400 \\
53,700 \\
54,600 \\
55,100 \\
55,100 \\
55,400 \\
55,400 \\
55,400 \\
55,400 \\
55,700 \\
56,000 \\
56,000 \\
56,300\end{array}$ & $\begin{array}{l}16 \\
17 \\
18 \\
19 \\
20 \\
21 \\
22 \\
23 \\
24 \\
25 \\
26 \\
27 \\
28 \\
29 \\
30 \\
31\end{array}$ & $\begin{array}{l}3,498.5 \\
3,497.0 \\
3,496.5 \\
3,495.0 \\
3,492.5 \\
3,492.0 \\
3,491.5 \\
3,489.0 \\
3,488.0 \\
3,486.0 \\
3,483.0 \\
3,482.0 \\
3,480.5 \\
3,479.0 \\
3,480.0 \\
3,487.4\end{array}$ & $\begin{array}{l}47,400 \\
46,700 \\
46,400 \\
45,700 \\
44,400 \\
44,200 \\
43,900 \\
42,700 \\
42,200 \\
41,300 \\
39,900 \\
39,400 \\
38,700 \\
38,100 \\
38,500 \\
42,000\end{array}$ & $\begin{array}{c}3,514.0 \\
3,514.0 \\
3,513.5 \\
3,513.0 \\
3,513.0 \\
3,512.0 \\
3,511.5 \\
3,510.0 \\
3,509.0 \\
3,508.0 \\
3,507.5 \\
3,507.0 \\
3,507.1 \\
- \\
= \\
-\end{array}$ & $\begin{array}{c}55,700 \\
55,700 \\
55,400 \\
55,100 \\
55,100 \\
54,600 \\
54,300 \\
53,400 \\
52,900 \\
52,400 \\
52,100 \\
51,900 \\
51,900 \\
- \\
- \\
-\end{array}$ \\
\hline Chas & e In conte & $\mathrm{ts}$, in a & & & $\ldots$ & - & $-12,000$ & - & $+9,900$ \\
\hline
\end{tabular}

11-3960. Lost Creek near Clipper Mills, Calif.

Location.--Lal $39^{\circ} 34^{1} 25^{\prime \prime}$, long $121^{\circ} 08^{\prime} 25^{\prime \prime}$, in SW $\frac{1}{4} \sec .24$, T.20 N., R.7 E., on left bank 0.3 mile downstream from Lost Creek Reservoir, $0.3 \mathrm{mile}$ downstream from. Pinkard Creek, and 2.8 miles north of Clipper Mills.

Drainage area. $--30.0 \mathrm{sq} \mathrm{mi}$.

Gage-height record.--Water-stage recorder graph. Altitude of gage is $3,170 \mathrm{ft}$ (from topographic map).

Discharge record.--Stage-discharge relation defined by current-meter measurements.

Naxima --January-February 1963: Discharge, 555 cfs 2000 hours Jan. 31 (gage height, $3.22 \mathrm{ft}$ ).

1927-41, 1948 to December 1962: Discharge, 5,000 cf's Dec. 22, 1955 (gage height, $6.90 \mathrm{ft}$ ).

Remarks.--Flow regulated by Sly Creek Reservoir (see station 11-3954) and Lost Creek Reservoir. Water is diverted into SIy Creek Reservoir through South Fork diversion tunnel from South Fork Feather River and through Slate Creek tunnel from North Yuba River basin. Woodleaf tunnel diverts from Lost Creek Reservoir to Woodleaf powerhouse. Oroville-Wyandotte Canal diverts from Woodleaf penstock for 1 rrigation and domestic use. Records below represent release or spill from Lost Creek Dam to Lost Creek.

Mean discharge, in cublc feet per second, 1963

\begin{tabular}{|c|c|c|c|c|c|c|c|c|}
\hline Day & January & February & Day & January & February & Day & January & February \\
\hline $\begin{array}{c}\overline{1} \ldots \ldots \\
2 \ldots \ldots \\
4 \ldots \ldots \\
5 \ldots \ldots \\
6 \ldots \ldots \\
7 \ldots \ldots \\
9 \ldots \ldots \\
10 \ldots \ldots\end{array}$ & $\begin{array}{l}1.7 \\
1.7 \\
1.7 \\
1.6 \\
1.6 \\
1.6 \\
1.6 \\
1.7 \\
1.7 \\
1.7\end{array}$ & $\begin{array}{r}216 \\
5.1 \\
3.3 \\
2.9 \\
2.5 \\
2.3 \\
2.1 \\
2.1 \\
1.9 \\
1.9\end{array}$ & $\begin{array}{l}11 \ldots \ldots \\
12 \ldots \ldots \\
13 \ldots \ldots \\
14 \ldots \ldots \\
15 \ldots \ldots \\
16 \ldots \ldots \\
17 \ldots \ldots \\
18 \ldots \ldots \\
19 \ldots \ldots \\
20 \ldots \ldots\end{array}$ & $\begin{array}{l}1.6 \\
1.6 \\
1.6 \\
1.6 \\
1.7 \\
1.6 \\
1.6 \\
1.6 \\
1.6 \\
1.6\end{array}$ & $\begin{array}{l}1.7 \\
2.1 \\
2.1 \\
2.1 \\
1.9 \\
1.9 \\
1.7 \\
1.7 \\
1.7 \\
1.7\end{array}$ & $\begin{array}{l}21 \ldots \ldots \\
22 \ldots \ldots \\
23 \ldots \ldots \\
24 \ldots \ldots \\
25 \ldots \ldots \\
26 \ldots \ldots \\
27 \ldots \ldots \\
28 \ldots \ldots \\
29 \ldots \ldots \\
30 \ldots \ldots \\
31 \ldots \ldots\end{array}$ & $\begin{array}{l}1.6 \\
1.4 \\
1.4 \\
1.4 \\
1.4 \\
1.4 \\
1.4 \\
1.4 \\
1.6 \\
4.7 \\
150\end{array}$ & $\begin{array}{r}1.7 \\
1.7 \\
1.6 \\
1.6 \\
1.4 \\
1.4 \\
1.4 \\
1.4 \\
--.-- \\
--.--\end{array}$ \\
\hline \multicolumn{7}{|c|}{ Monthly mean discharge, in cuble feet per second.................. } & 6.46 & 9.68 \\
\hline \multicolumn{7}{|c|}{ 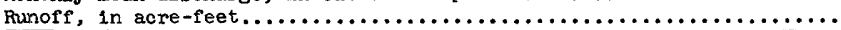 } & 397 & 537 \\
\hline
\end{tabular}

Gage helght, in feet, and discharge, In cublc feet per second, at indicated t1me, I963

\begin{tabular}{|c|c|c|c|c|c|c|c|c|c|c|c|}
\hline Date & Hour & $\begin{array}{c}\text { Gage } \\
\text { he1ght }\end{array}$ & $\begin{array}{l}\text { Dis- } \\
\text { charge }\end{array}$ & Date & Hour & $\begin{array}{c}\text { Gage } \\
\text { helght }\end{array}$ & $\begin{array}{c}\text { Dis- } \\
\text { charge }\end{array}$ & Date & Hour & $\begin{array}{c}\text { Gage } \\
\text { helght }\end{array}$ & $\begin{array}{c}\text { D1s- } \\
\text { charge }\end{array}$ \\
\hline $\begin{array}{r}\operatorname{Jan} .29 \\
30\end{array}$ & $\begin{array}{l}2400 \\
0600 \\
1000 \\
1400 \\
1700 \\
2200 \\
2400\end{array}$ & $\begin{array}{r}0.82 \\
.86 \\
.90 \\
.98 \\
1.02 \\
1.00 \\
.99\end{array}$ & $\begin{array}{l}1.9 \\
2.7 \\
3.5 \\
5.9 \\
7.4 \\
6.5 \\
6.2\end{array}$ & Jan. 31 & $\begin{array}{l}1200 \\
1400 \\
1600 \\
1700 \\
1800 \\
1900 \\
2000 \\
2200 \\
2400\end{array}$ & $\begin{array}{l}1.12 \\
1.18 \\
1.20 \\
2.45 \\
2.90 \\
3.05 \\
3.22 \\
3.08 \\
2.90\end{array}$ & $\begin{array}{r}12 \\
16 \\
17 \\
258 \\
430 \\
505 \\
555 \\
490 \\
410\end{array}$ & Feb. 1 & $\begin{array}{l}0800 \\
1200 \\
1400 \\
1500 \\
1600 \\
1700 \\
1900 \\
2000 \\
2400\end{array}$ & $\begin{array}{l}2.45 \\
2.26 \\
2.23 \\
2.23 \\
2.01 \\
1.98 \\
2.04 \\
1.98 \\
1.22\end{array}$ & $\begin{array}{r}250 \\
198 \\
189 \\
189 \\
132 \\
126 \\
140 \\
126 \\
19\end{array}$ \\
\hline 31 & $\begin{array}{l}0300 \\
1000 \\
\end{array}$ & $\begin{array}{r}.98 \\
1.11 \\
\end{array}$ & 12.9 & $\mathrm{Feb}, \quad 1$ & $\begin{array}{l}6400 \\
0100\end{array}$ & $\begin{array}{l}2.90 \\
2.91 \\
\end{array}$ & 414 & & & & \\
\hline
\end{tabular}


11-3962. South Fork Feather River below Forbestown Dam, Calif.

Location.--Lat $39^{\circ} 33^{\prime} 05^{\prime \prime}$, long $121^{\circ} 12^{1} 30^{\prime \prime}$, in NE $\frac{1}{4}$ sec.32, T.20 N., R.7 E., $500 \mathrm{ft}^{\prime}$ downstream from Forbestown Dam, 0.4 mile upstream from Oroleve Creek, and 4.0 miles northeast of Forbestown.

Drainage area. $--87.5 \mathrm{sq} \mathrm{mi}$.

Gage-height record.--Water-stage recorder graph. Altitude of gage is $1,690 \mathrm{ft}$ (from topographic map).

Discharge record.--Stage-discharge relation defined by current-meter measurements.

Maxima.--January-February 1963: Discharge, 7,510 cfs 2230 hours Jan. 31 (gage height, $13.85 \mathrm{ft}$, from recorder graph; $15.3 \mathrm{ft}$, from floodmarks).

July to December 1962: Discharge, 6,490 cfs 0ct. 13, 1962 (gage height, $13.27 \mathrm{ft}$ )

Remarks.--Flow regulated by Little Grass Valley Reservoir (see 11-3950.2), Sly Creek Reservoir (see 11-3954) and smaller reservoirs.

Mean discharge, in cub1c feet per second, 1963

\begin{tabular}{|c|c|c|c|c|c|c|c|c|}
\hline Day & January & February & Day & January & February & Day & January & February \\
\hline $\begin{array}{c}1 \ldots \ldots \\
2 \ldots \ldots \\
3 \ldots \ldots \\
5 \ldots \ldots \\
6 \ldots \ldots \\
8 \ldots \ldots \\
9 \ldots \ldots \\
10 \ldots \ldots\end{array}$ & $\begin{array}{r}7.0 \\
7.0 \\
6.6 \\
6.2 \\
6.2 \\
24 \\
6.4 \\
18 \\
6.6 \\
6.8\end{array}$ & $\begin{array}{r}5,250 \\
2,430 \\
1,650 \\
908 \\
682 \\
508 \\
379 \\
229 \\
81 \\
72\end{array}$ & $\begin{array}{l}11 \ldots \ldots \\
12 \ldots \ldots \\
13 \ldots \ldots \\
14 \ldots \ldots \\
15 \ldots \ldots \\
16 \ldots \ldots \\
17 \ldots \ldots \\
18 \ldots \ldots \\
19 \ldots \ldots \\
20 \ldots \ldots\end{array}$ & $\begin{array}{r}7.7 \\
7.5 \\
7.0 \\
7.0 \\
7.0 \\
60 \\
6.4 \\
6.4 \\
6.4 \\
6.6\end{array}$ & $\begin{array}{l}36 \\
60 \\
47 \\
82 \\
72 \\
67 \\
64 \\
59 \\
58 \\
58\end{array}$ & $\begin{array}{l}21 \ldots \ldots \\
22 \ldots \ldots \\
23 \ldots \ldots \\
24 \ldots \ldots \\
25 \ldots \ldots \\
26 \ldots \ldots \\
27 \ldots \ldots \\
28 \ldots \ldots \\
29 \ldots \ldots \\
30 \ldots \ldots \\
31 \ldots \ldots\end{array}$ & $\begin{array}{r}27 \\
49 \\
55 \\
55 \\
55 \\
55 \\
55 \\
55 \\
64 \\
157 \\
2,990\end{array}$ & $\begin{array}{r}76 \\
85 \\
82 \\
82 \\
78 \\
81 \\
50 \\
70 \\
-\ldots--\end{array}$ \\
\hline $\begin{array}{l}\text { Monthly } \\
\text { Runoff, }\end{array}$ & acre & 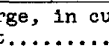 & & & & & $\begin{array}{r}124 \\
7,600\end{array}$ & $\begin{array}{r}478 \\
26,570\end{array}$ \\
\hline
\end{tabular}

Gage height, in feet, and discharge, in cubic feet per second, at indicated time, 1963

\begin{tabular}{|c|c|c|c|c|c|c|c|c|c|c|c|}
\hline Date & Hour & $\begin{array}{c}\text { Gage } \\
\text { helght }\end{array}$ & $\begin{array}{c}\text { Dis- } \\
\text { charge }\end{array}$ & Date & Hour & $\begin{array}{c}\text { Gage } \\
\text { height }\end{array}$ & $\begin{array}{c}\text { Dis- } \\
\text { charge }\end{array}$ & Date & Hour & $\begin{array}{c}\text { Gage } \\
\text { height }\end{array}$ & $\begin{array}{c}\text { Dis- } \\
\text { charge }\end{array}$ \\
\hline $\begin{array}{r}\operatorname{Jan} .30 \\
31\end{array}$ & $\begin{array}{l}2400 \\
0600 \\
0700 \\
0800 \\
0900 \\
1000 \\
1200 \\
1400 \\
1700 \\
1900 \\
2000 \\
2100 \\
\end{array}$ & $\begin{array}{r}5.63 \\
5.63 \\
5.88 \\
7.00 \\
7.24 \\
8.06 \\
10.20 \\
11.00 \\
12.00 \\
13.40 \\
13.04 \\
13.66 \\
\end{array}$ & $\begin{array}{r}286 \\
286 \\
336 \\
650 \\
734 \\
1,090 \\
2,600 \\
3,400 \\
4,620 \\
6,700 \\
6,120 \\
7,170 \\
\end{array}$ & $\begin{array}{l}\text { Jan. } 31 \\
\text { Feb. } 1\end{array}$ & $\begin{array}{l}2230 \\
2400 \\
0100 \\
0200 \\
0500 \\
0600 \\
1400 \\
1500 \\
1600 \\
1700 \\
1800 \\
1900\end{array}$ & $\begin{array}{l}13.85 \\
13.35 \\
13.27 \\
13.38 \\
13.07 \\
13.18 \\
12.00 \\
12.15 \\
12.00 \\
11.50 \\
11.45 \\
11.78\end{array}$ & $\begin{array}{l}7,510 \\
6,620 \\
6,490 \\
6,670 \\
6,170 \\
6,350 \\
4,620 \\
4,830 \\
4,620 \\
4,000 \\
3,940 \\
4,340\end{array}$ & Feb. 1 & $\begin{array}{l}2100 \\
2200 \\
2400 \\
\\
0100 \\
0700 \\
0800 \\
1000 \\
1100 \\
2100 \\
2200 \\
2400\end{array}$ & $\begin{array}{r}11.76 \\
11.35 \\
11.04 \\
10.55 \\
10.13 \\
10.42 \\
10.28 \\
9.94 \\
9.39 \\
9.78 \\
9.70\end{array}$ & $\begin{array}{l}4,310 \\
4,820 \\
3,450 \\
2,950 \\
2,530 \\
2,820 \\
2,680 \\
2,370 \\
1,930 \\
2,240 \\
2,180\end{array}$ \\
\hline
\end{tabular}


11-3963.5. South Fork Feather River below Ponderosa Dam, Calif.

Location. --Lat $39^{\circ} 33^{\prime} 05^{\prime \prime}$, long $121^{\circ} 18^{\prime} 30^{\prime \prime}$, in NW $\frac{1}{4}$ sec.33, T.20 N., R.6 E., on left bank I,000 ft upstream from Sucker Run, I,800 ft downstream from Ponderosa Dam, and 2.8 miles northwest of Forbestown.

Drainage area. $--108 \mathrm{sq} \mathrm{mi.}$

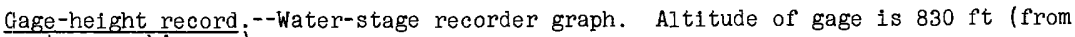
topographic map).

Discharge record.--Stage-discharge relation defined by current-meter measurements.

Maxima (river onIy).--January-February 1963: Discharge, 8,570 cfs 2030 hours Jan. 31 (gage height, $11.24 \mathrm{ft}$ ).

July to December 1962: Discharge, 8,320 cfs 0ct. 13, 1962 (gage height, $11.10 \mathrm{ft}$ ).

Maxima (river plus diversion).--January-February 1963: Discharge, 8,750 cfs 2030 hours Jan. 31 .

July-December 1962: Discharge, 8,320 cfs 0ct. 13, 1962.

Femarks.--Flow regulated by several reservoirs and diversions above station (see Remarks for station 11-3962). All discharge flgures in the tables below are the combined flow of South Fork Feather River and Miners Ranch Canal.

Mean discharge, in cublc feet per second, 1963

\begin{tabular}{|c|c|c|c|c|c|c|c|c|}
\hline Day & January & February & Day & $J_{\text {anuary }}{ }^{\circ}$ & February & Day & January & February \\
\hline $\begin{array}{c}1 \ldots \ldots \\
2 \ldots \ldots \\
3 \ldots \ldots \\
4 \ldots \ldots \\
6 \ldots \ldots \\
7 \ldots \ldots \\
8 \ldots \ldots \\
9 \ldots \ldots \\
10 \ldots \ldots\end{array}$ & $\begin{array}{l}366 \\
361 \\
463 \\
482 \\
478 \\
345 \\
464 \\
478 \\
490 \\
464\end{array}$ & $\begin{array}{r}6,190 \\
3,530 \\
2,480 \\
1,870 \\
1,480 \\
1,270 \\
1,090 \\
895 \\
639 \\
602\end{array}$ & $\begin{array}{l}11 \ldots \ldots \\
12 \ldots \ldots \\
13 \ldots \ldots \\
14 \ldots \ldots \\
15 \ldots \ldots \\
16 \ldots \ldots \\
17 \ldots \ldots \\
18 \ldots \ldots \\
19 \ldots \ldots \\
20 \ldots \ldots\end{array}$ & $\begin{array}{l}460 \\
425 \\
472 \\
474 \\
455 \\
411 \\
319 \\
370 \\
476 \\
484\end{array}$ & $\begin{array}{l}523 \\
553 \\
526 \\
601 \\
611 \\
585 \\
575 \\
565 \\
561 \\
558\end{array}$ & $\begin{array}{l}21 \ldots \ldots \\
22 \ldots \ldots \\
23 \ldots \ldots \\
24 \ldots \ldots \\
25 \ldots \ldots \\
26 \ldots \ldots \\
27 \ldots \ldots \\
28 \ldots \ldots \\
29 \ldots \ldots \\
30 \ldots \ldots \\
31 \ldots \ldots\end{array}$ & $\begin{array}{r}488 \\
524 \\
530 \\
514 \\
530 \\
509 \\
522 \\
519 \\
529 \\
821 \\
3,980 \\
\end{array}$ & $\begin{array}{r}572 \\
599 \\
590 \\
575 \\
570 \\
513 \\
508 \\
497 \\
----0- \\
---.-- \\
\end{array}$ \\
\hline \multicolumn{7}{|c|}{ 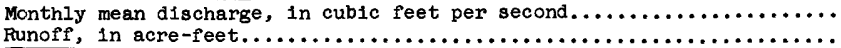 } & $\begin{array}{r}587 \\
36,100 \\
\end{array}$ & $\begin{array}{r}1,076 \\
59,760 \\
\end{array}$ \\
\hline
\end{tabular}

Gage height, in feet, and discharge, in cublc feet per second, at indicated time, 1963

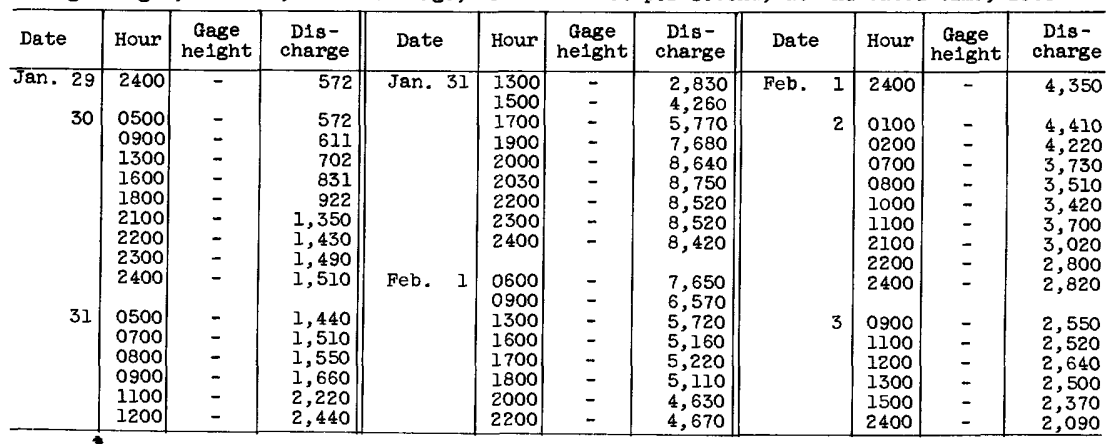


11-3970. South Fork Feather River at Enterprise, Calif.

Location.--Iat $39^{\circ} 32^{\prime} 15^{\prime \prime}$, long $121^{\circ} 20145^{\prime \prime}$, in NW $\frac{1}{4}$ sec.6, T.19 N., R.6 E., on left bank 0.5 mile upstream from McCabe Creek, 1 mile upstream from highway bridge at Enterprise, and 11 miles east of Oroville.

Drainage area. $--132 \mathrm{sq} \mathrm{mi}$.

Gage-height record.--Stage-discharge relation defined by current-meter measurements below $5,700 \mathrm{cfs}$ and by computed flow over diversion dam at 19,200 cfs.

Maxima.--January-February 1963: Discharge, 10,500 efs 2100 hours Jan. 31 (gage height, $16.60 \mathrm{ft}$ ).

1911 to December 1962: Discharge, 19,200 cfs Dec. 22, 1955 (gage height, $21.60 \mathrm{ft})$.

Remarks.--Flow regulated by several reservolrs and diversions above station (see Remarks for station 11-3963.5).

Mean discharge, in cubic feet per second, 1963

\begin{tabular}{|c|c|c|c|c|c|c|c|c|}
\hline Day & January & February & Day & January & February & Day & January & February \\
\hline $\begin{array}{c}1 \ldots \ldots \\
2 \ldots \ldots \\
3 \ldots \ldots \\
4 \ldots \ldots \\
6 \ldots \ldots \\
7 \ldots \ldots \\
8 \ldots \ldots \\
9 \ldots \ldots \\
10 \ldots \ldots\end{array}$ & $\begin{array}{l}182 \\
178 \\
285 \\
291 \\
287 \\
149 \\
253 \\
259 \\
472 \\
249\end{array}$ & $\begin{array}{r}7,010 \\
3,590 \\
2,360 \\
1,740 \\
1,320 \\
1,050 \\
860 \\
726 \\
482 \\
437\end{array}$ & $\begin{array}{l}11 \ldots \ldots \\
12 \ldots \ldots \\
13 \ldots \ldots \\
14 \ldots \ldots \\
15 \ldots \ldots \\
16 \ldots \ldots \\
17 \ldots \ldots \\
18 \ldots \ldots \\
19 \ldots \ldots \\
20 \ldots \ldots\end{array}$ & $\begin{array}{l}253 \\
259 \\
307 \\
307 \\
305 \\
286 \\
120 \\
176 \\
285 \\
294\end{array}$ & $\begin{array}{l}338 \\
368 \\
370 \\
421 \\
413 \\
400 \\
398 \\
385 \\
376 \\
373\end{array}$ & $\begin{array}{l}21 \ldots \ldots \\
22 \ldots \ldots \\
23 \ldots \ldots \\
24 \ldots \ldots \\
25 \ldots \ldots \\
26 \ldots \ldots \\
27 \ldots \ldots \\
28 \ldots \ldots \\
29 \ldots \ldots \\
30 \ldots \ldots \\
31 \ldots \ldots\end{array}$ & $\begin{array}{r}300 \\
338 \\
333 \\
340 \\
344 \\
302 \\
309 \\
322 \\
338 \\
698 \\
4,600 \\
\end{array}$ & $\begin{array}{r}380 \\
406 \\
378 \\
361 \\
359 \\
308 \\
287 \\
276 \\
----- \\
----- \\
\end{array}$ \\
\hline \multicolumn{7}{|c|}{ 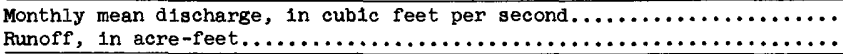 } & $\begin{array}{r}433 \\
26,620\end{array}$ & $\begin{array}{r}935 \\
51,910\end{array}$ \\
\hline
\end{tabular}

Gage height, in feet, and discharge, in cublc feet per second, at indicated t1me, 1963

\begin{tabular}{|c|c|c|c|c|c|c|c|c|c|c|c|}
\hline Date & Hour & $\begin{array}{c}\text { Gage } \\
\text { height }\end{array}$ & $\begin{array}{c}\text { Dis- } \\
\text { charge }\end{array}$ & Date & Hour & $\begin{array}{c}\text { Gage } \\
\text { helght }\end{array}$ & $\begin{array}{c}\text { Dis- } \\
\text { charge }\end{array}$ & Date & Jour & $\begin{array}{c}\text { Gage } \\
\text { height }\end{array}$ & $\begin{array}{c}\text { Dis- } \\
\text { charge }\end{array}$ \\
\hline $\begin{array}{r}\text { Jan. } 29 \\
30\end{array}$ & $\begin{array}{l}2400 \\
0600 \\
1500 \\
1700 \\
1800 \\
2000 \\
2300 \\
2400 \\
\\
0500 \\
0700 \\
0900 \\
1100 \\
\end{array}$ & $\begin{array}{l}4.78 \\
4.86 \\
5.52 \\
6.00 \\
6.65 \\
7.18 \\
7.92 \\
8.00 \\
7.83 \\
8.00 \\
8.50 \\
9.35 \\
\end{array}$ & $\begin{array}{r}361 \\
395 \\
575 \\
734 \\
980 \\
1,220 \\
1,610 \\
1,660 \\
1,560 \\
1,660 \\
1,960 \\
2,500 \\
\end{array}$ & Feb. 1 & $\begin{array}{l}1300 \\
1400 \\
1500 \\
1600 \\
1700 \\
1900 \\
2100 \\
2400 \\
\\
0500 \\
1100 \\
1500 \\
1700 \\
1800\end{array}$ & $\begin{array}{l}10.20 \\
11.10 \\
12.15 \\
13.00 \\
13.90 \\
15.50 \\
16.60 \\
16.35 \\
15.60 \\
14.20 \\
13.10 \\
12.80 \\
12.80\end{array}$ & $\begin{array}{r}3,160 \\
3,880 \\
4,850 \\
5,700 \\
6,740 \\
8,920 \\
10,500 \\
10,100 \\
9,060 \\
7,100 \\
5,810 \\
5,500 \\
5,500 \\
\end{array}$ & Feb. 1 & $\begin{array}{l}2000 \\
2400 \\
\\
0200 \\
0400 \\
0700 \\
0900 \\
1000 \\
1100 \\
1600 \\
2200 \\
2300 \\
2400\end{array}$ & $\begin{array}{r}12.17 \\
11.88 \\
11.75 \\
11.40 \\
11.10 \\
10.80 \\
10.92 \\
10.95 \\
10.35 \\
9.80 \\
9.58 \\
9.62\end{array}$ & $\begin{array}{l}4,870 \\
4,580 \\
4,460 \\
4,150 \\
3,880 \\
3,640 \\
3,740 \\
3,760 \\
3,280 \\
2,840 \\
2,670 \\
2,690\end{array}$ \\
\hline
\end{tabular}

11-3975. Feather River at Bidwell Bar, Calif.

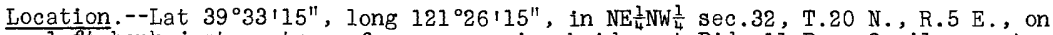
left bank just upstream from suspension bridge at Bidwell Bar, 2 miles upstream from North Fork and 7 miles northeast of Oroville.

Drainage area. $--1,347 \mathrm{sq} \mathrm{ml}$.

Gege-height record.--Water-stage recorder graph, except 2000 hours Jan. 31 to 0400 hours Feb. 1, for which graph was reconstructed on basis of high-water mark in gage well. Altitude of gage is $290 \mathrm{ft}$ (from topographic map).

Discharge record.--Stage-discharge relation defined by current-meter measurements below 28,000 cfs and by studies of upstream and downstream peaks of December 1955.

Maxima.--January-February 1963: Discharge, 93,600 cfs 2400 hours Jan. 31 (gage helght, $24.30 \mathrm{ft}$, from high-water mark in gage well).

1911 to December 1962: Discharge, 104,000 cfs Dec. 23, 1955 (gage height,

$25.5 \mathrm{ft}$ ); gage height, $31.2 \mathrm{ft}$ in January 1862 .

Remarks.--Flow partly regulated by reservoirs and powerplants. 
Mean discharge, in cublc feet per second, 1963, of Feather River at Bldwell Bar, Cal1f.

\begin{tabular}{|c|c|c|c|c|c|c|c|c|}
\hline Day & January & February & Day & January & February & Day & January & February \\
\hline $\begin{array}{c}1 \ldots \ldots \\
3 \ldots \ldots \\
4 \ldots \ldots \\
5 \ldots \ldots \\
6 \ldots \ldots \\
8 \ldots \ldots \\
9 \ldots \ldots \\
10 \ldots \ldots\end{array}$ & $\begin{array}{l}1,240 \\
1,200 \\
1,260 \\
1,290 \\
1,250 \\
1,100 \\
1,100 \\
1,100 \\
1,100 \\
1,060\end{array}$ & $\begin{array}{r}61,500 \\
29,200 \\
19,500 \\
12,500 \\
9,450 \\
7,300 \\
6,110 \\
5,200 \\
4,450 \\
4,010\end{array}$ & $\begin{array}{l}11 \ldots \ldots \\
12 \ldots \ldots \\
13 \ldots \ldots \\
14 \ldots \ldots \\
15 \ldots \ldots \\
16 \ldots \ldots \\
17 \ldots \ldots \\
18 \ldots \ldots \\
19 \ldots \ldots \\
20 \ldots \ldots\end{array}$ & $\begin{array}{r}1,030 \\
865 \\
936 \\
1,010 \\
990 \\
1,000 \\
745 \\
810 \\
876 \\
876\end{array}$ & $\begin{array}{l}3,740 \\
3,590 \\
4,790 \\
4,360 \\
3,810 \\
3,550 \\
3,300 \\
2,990 \\
2,820 \\
2,650\end{array}$ & $\begin{array}{l}21 \ldots \ldots \\
22 \ldots \ldots \\
23 \ldots \ldots \\
24 \ldots \ldots \\
25 \ldots \ldots \\
26 \ldots \ldots \\
27 \ldots \ldots \\
28 \ldots \ldots \\
29 \ldots \ldots \\
30 \ldots \ldots \\
31 \ldots \ldots\end{array}$ & $\begin{array}{r}882 \\
924 \\
918 \\
912 \\
930 \\
865 \\
860 \\
865 \\
930 \\
3,480 \\
40,600 \\
\end{array}$ & $\begin{array}{r}2,570 \\
2,460 \\
2,320 \\
2,190 \\
2,100 \\
1,960 \\
1,870 \\
1,760 \\
--.-- \\
--.-- \\
-\end{array}$ \\
\hline & acr & & & & & & $\begin{array}{r}2,355 \\
2.02 \\
144,800 \\
\end{array}$ & $\begin{array}{r}2,573 \\
5.85 \\
420,600 \\
\end{array}$ \\
\hline
\end{tabular}

Gage he1ght, in feet, and discharge, In cublc feet per second, at indicated time, 1963

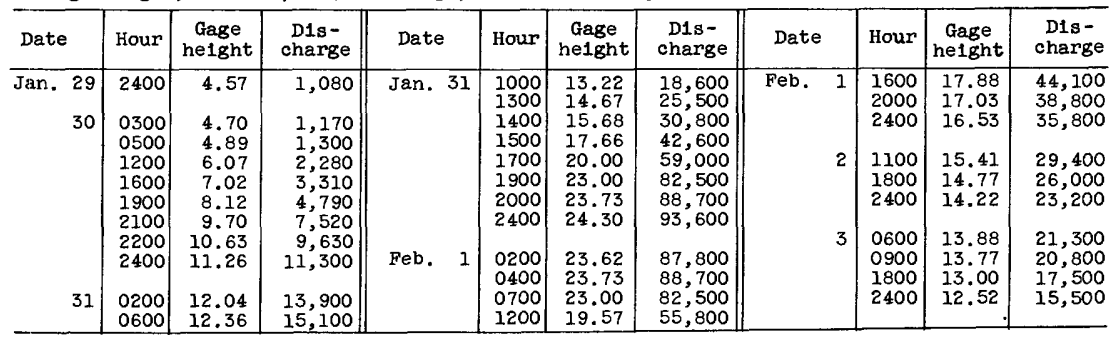

11-3979.7. Lake Almanor tributary near Almanor, Calif.

(Crest-stage station)

Location.--Lat $40^{\circ} 12^{\prime} 01^{\prime \prime}$, long $121^{\circ} 08^{\prime} 47^{\prime \prime}$, in $\mathrm{SE}_{\frac{1}{4}} \mathrm{NW} \frac{1}{4} \mathrm{sec} .13$, T.27 N., R.7 E., on State Highway $89,1.8$ miles southeast of Almanor.

Drainage area. $--1.66 \mathrm{sq} \mathrm{mi}$.

Gage-helght record.--Crest stages only. Altitude of gage is 4,580 ft (from topographic map).

Discharge record.--Stage-discharge relation defined by computation of flow through culvert and by slope-area measurement at 111 cfs.

Maxima --January-February 1963: Discharge, 52 cfs Feb. 1 (gage height, $6.66 \mathrm{ft}$ ).

July to December 1962: Discharge, $111 \mathrm{cfs}$ Oct. 13 (gage height, $8.85 \mathrm{ft}$, backwater from debris in culvert).

11-3990. Lake Almanor near Prattville, Calif.

Location.--Lat $40^{\circ} 10^{\prime} 33^{\prime \prime}$, long $121^{\circ} 05^{\prime} 17^{\prime \prime}$, in $\mathrm{NE} \frac{1}{4} \mathrm{NW} \frac{1}{4}$ sec.28, T.27 N., R. 8 E., at outlet tower at dam on North Fork Feather River, 1.0 mile west of Canyondam, and 4.4 miles southeast of Prattville.

Drainage area. $--491 \mathrm{sq} \mathrm{mi}$.

Gage-height record.--Staff gage read once daily. Datum of gage is at mean sea level.

Contents record.--Contents computed by Pacific Gas \& Electric Co. from capacity table based on surveys of 1924-26 by Great Western Power Co.

Maxima.--January-February 1963: Contents observed, 422,900 acre-ft 2400 hours Feb. 28 (elevation, $4,462.65 \mathrm{ft}$ ).

1913 to December 1962: Contents observed, 798,900 acre-ft June 9, 1928 (elevation, $4,480.5 \mathrm{ft}$ ).

Remarks.--Lake is formed by earthfill dam; storage began in July 1913; dam raised to elevation $4,455 \mathrm{ft}$ above mean sea level in 1917 and to $4,515 \mathrm{ft}$ above mean sea level in 1927. Usable capacity, 641,600 acre- $\mathrm{ft}$ between elevations $4,422 \mathrm{ft}$ (bottom of outlet to river) and $4,474 \mathrm{ft}$ (present upper storage limit). Figures given herein represent total contents at 2400 hours interpolated from readings made at 1700 hours. Records furnished by Pacific Gas \& Electric Co. 
Elevation, in feet, and contents, in acre-feet, at 2400 hours, 1963, of Lake Almanor near

\begin{tabular}{|c|c|c|c|c|c|c|c|c|}
\hline \multicolumn{2}{|c|}{ January } & \multicolumn{2}{|c|}{ February } & \multirow{2}{*}{ Day } & \multicolumn{2}{|c|}{ January } & \multicolumn{2}{|c|}{ February } \\
\hline Elevation & Contents & Elevation & Contents & & Elevation & Contents & Elevation & Contents \\
\hline $\begin{array}{l}4,453.95 \\
4,454.06 \\
4,454.17 \\
4,454.27 \\
4,454.37 \\
4,454.46 \\
4,454.56 \\
4,454.66 \\
4,454.75 \\
4,454.83 \\
4,454.93 \\
4,455.02 \\
4,455.07 \\
4,455.08 \\
4,455.12\end{array}$ & $\begin{array}{l}277,600 \\
279,300 \\
281,000 \\
282,500 \\
284,000 \\
285,400 \\
287,000 \\
288,500 \\
289,900 \\
291,200 \\
292,700 \\
294,100 \\
294,900 \\
295,100 \\
295,700\end{array}$ & $\begin{array}{l}4,457.69 \\
4,458.20 \\
4,458.71 \\
4,459.18 \\
4,459.47 \\
4,459.75 \\
4,459.95 \\
4,460.74 \\
4,460.33 \\
4,460.54 \\
4,460.72 \\
4,460.89 \\
4,461.06 \\
4,461.18 \\
4,461.29\end{array}$ & $\begin{array}{l}336,900 \\
345,400 \\
353,900 \\
361,900 \\
366,800 \\
371,600 \\
375,100 \\
378,400 \\
381,700 \\
385,400 \\
388,500 \\
391,500 \\
394,600 \\
396,500 \\
398,500\end{array}$ & $\begin{array}{l}16 \\
17 \\
18 \\
19 \\
20 \\
21 \\
22 \\
23 \\
24 \\
25 \\
26 \\
27 \\
28 \\
29 \\
30 \\
31 \\
\end{array}$ & $\begin{array}{l}4,455.20 \\
4,455.29 \\
4,455.35 \\
4,455.44 \\
4,455.50 \\
4,455.58 \\
4,455.61 \\
4,455.68 \\
4,455.77 \\
4,455.85 \\
4,455.93 \\
4,456.01 \\
4,456.06 \\
4,456.15 \\
4,456.39 \\
4,456.77\end{array}$ & $\begin{array}{l}296,900 \\
298,400 \\
299,300 \\
300,700 \\
301,700 \\
303,000 \\
303,400 \\
304,500 \\
306,000 \\
307,200 \\
308,500 \\
309,800 \\
310,500 \\
312,000 \\
315,800 \\
321,900\end{array}$ & $\begin{array}{c}4,461.41 \\
4,461.52 \\
4,461.63 \\
4,461.75 \\
4,461.87 \\
4,461.97 \\
4,462.08 \\
4,462.18 \\
4,462.28 \\
4,462.38 \\
4,462.48 \\
4,462.57 \\
4,462.65 \\
- \\
- \\
-\end{array}$ & $\begin{array}{c}400,600 \\
402,600 \\
404,500 \\
406,700 \\
408,800 \\
410,600 \\
412,600 \\
414,400 \\
416,200 \\
418,000 \\
419,800 \\
421,500 \\
422,900 \\
- \\
- \\
-\end{array}$ \\
\hline In $c$ & & & & & - & $+46,100$ & - & $+101,000$ \\
\hline
\end{tabular}

11-3995. North Fork Feather River near Prattville, Calif.

Location. --Lat $40^{\circ} 10^{1} 10^{\prime \prime}$, long $121^{\circ} 05129^{\prime \prime}$, in $\mathrm{NE} \frac{1}{4} \mathrm{SW} \frac{1}{4} \sec .28$, T.27 N., R.8 E., on left bank 0.5 mile downstream from Almanor Dam, 4.5 miles southeast of Prattville, and 9 miles upstream from Butt Creek.

Drainage area. $-493 \mathrm{sq} \mathrm{mi}$.

Gage-helght record:--Water-stage recorder graph. Altitude of gage is 4,380 ft (from topographic map).

Discharge record.--Stage-discharge relation defined by current-meter measurements.

Maxima --January-February 1963: Discharge, 19 ofs 1600 hours Jan. 31 (gage height, $2.07 \mathrm{ft})$.

1905 to December 1962: Discharge, 10,000 of's Mar. 19, 1907, before con-

struction of dam (gage height, $16.2 \mathrm{ft}$, at former site), from rating curve extended above $3,700 \mathrm{cfs}$.

Remarks.--Flow regulated by Lake Almanor since 1913 (see station 11-3990).

Mean discharge, in cubic feet per second, 1963

\begin{tabular}{|c|c|c|c|c|c|c|c|c|}
\hline Day & January & February & Day & January & February & Day & January & February \\
\hline $\begin{array}{c}1 \ldots \ldots \\
2 \ldots \ldots \\
3 \ldots \ldots \\
5 \ldots \ldots \\
6 \ldots \ldots \\
7 \ldots \ldots \\
9 \ldots \ldots \\
10 \ldots \ldots\end{array}$ & $\begin{array}{l}9.5 \\
9.5 \\
9.5 \\
9.5 \\
9.5 \\
9.5 \\
9.5 \\
9.5 \\
9.5 \\
9.5\end{array}$ & $\begin{array}{l}12 \\
11 \\
11 \\
11 \\
9.8 \\
10 \\
10 \\
10 \\
10 \\
11\end{array}$ & $\begin{array}{l}11 \ldots \ldots \\
12 \ldots \ldots \\
13 \ldots \ldots \\
14 \ldots \ldots \\
15 \ldots \ldots \\
16 \ldots \ldots \\
17 \ldots \ldots \\
18 \ldots \ldots \\
19 \ldots \ldots \\
20 \ldots \ldots\end{array}$ & $\begin{array}{l}9.2 \\
9.5 \\
8.6 \\
9.5 \\
9.5 \\
9.5 \\
9.2 \\
9.2 \\
9.5 \\
9.5\end{array}$ & $\begin{array}{l}10 \\
10 \\
10 \\
9.8 \\
9.8 \\
10 \\
10 \\
10 \\
10 \\
10\end{array}$ & $\begin{array}{l}21 \ldots \ldots \\
22 \ldots \ldots \\
23 \ldots \ldots \\
24 \ldots \ldots \\
25 \ldots \ldots \\
26 \ldots \ldots \\
27 \ldots \ldots \\
28 \ldots \ldots \\
29 \ldots \ldots \\
30 \ldots \ldots \\
31 \ldots \ldots\end{array}$ & $\begin{array}{l}9.5 \\
9.5 \\
9.2 \\
9.2 \\
9.2 \\
9.2 \\
9.2 \\
9.2 \\
9.2 \\
9.2 \\
14\end{array}$ & $\begin{array}{r}10 \\
10 \\
10 \\
10 \\
10 \\
10 \\
10 \\
10 \\
-\ldots--\end{array}$ \\
\hline \multicolumn{7}{|c|}{ 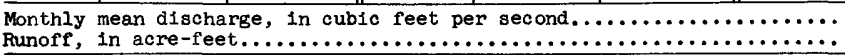 } & $\begin{array}{r}9.51 \\
585 \\
\end{array}$ & $\begin{array}{r}10.2 \\
566 \\
\end{array}$ \\
\hline
\end{tabular}


11-4000. Butt Creek above Almanor-Butt Creek tunnel, near Prattville, Calif.

Location.--Lat $40^{\circ} 11^{\prime} 23^{\prime \prime}$, long $121^{\circ} 11^{\prime} 23^{\prime \prime}$, in NWt sec.22, T.27 N., R.7 E., on left bank 0.2 mile upstream from outlet of old tunnel from Lake Almanor to Butt Creek and 2.2 miles southwest of Prattville.

Drainage area. $--68.6 \mathrm{sq} \mathrm{ml}$.

Gage-height record:--Water-stage recorder graph. Altitude of gage is $4,400 \mathrm{ft}$ (from topographic map).

Discharge record.--Stage-discharge relation defined by current-meter measurements below $380 \mathrm{cfs}$.

Naxima.--January-February 1963: Discharge, 1,320 cfs 2200 hours Jan. 31 (gage height, $3.47 \mathrm{ft}$ ).

1936 to December 1962: Discharge, 2,320 cfs Dec. 11, 1937 (gage height, $6.48 \mathrm{ft}$, site and datum then in use), from rating curve extended above 170 ' cfs on basis of shape of later ratings.

Mean discharge, in cubıc feet per second, 1963

\begin{tabular}{|c|c|c|c|c|c|c|c|c|}
\hline Day & January & February & Day & January & February & Day & January & February \\
\hline $\begin{array}{c}1 \ldots \ldots \\
2 \ldots \ldots \\
3 \ldots \ldots \\
4 \ldots \ldots \\
6 \ldots \ldots \\
7 \ldots \ldots \\
8 \ldots \ldots \\
10 \ldots \ldots\end{array}$ & $\begin{array}{l}61 \\
58 \\
58 \\
58 \\
54 \\
53 \\
52 \\
51 \\
50 \\
49\end{array}$ & $\begin{array}{l}835 \\
399 \\
352 \\
300 \\
272 \\
212 \\
184 \\
177 \\
161 \\
156\end{array}$ & $\begin{array}{l}11 \ldots \ldots \\
12 \ldots \ldots \\
13 \ldots \ldots \\
14 \ldots \ldots \\
15 \ldots \ldots \\
16 \ldots \ldots \\
17 \ldots \ldots \\
18 \ldots \ldots \\
19 \ldots \ldots \\
20 \ldots \ldots\end{array}$ & $\begin{array}{l}37 \\
33 \\
41 \\
45 \\
46 \\
45 \\
43 \\
44 \\
38 \\
39\end{array}$ & $\begin{array}{r}138 \\
132 \\
152 \\
123 \\
115 \\
110 \\
108 \\
104 \\
96 \\
99\end{array}$ & $\begin{array}{l}21 \ldots \ldots \\
22 \ldots \ldots \\
23 \ldots \ldots \\
24 \ldots \ldots \\
25 \ldots \ldots \\
26 \ldots \ldots \\
27 \ldots \ldots \\
28 \ldots \ldots \\
29 \ldots \ldots \\
30 \ldots \ldots \\
31 \ldots \ldots\end{array}$ & $\begin{array}{r}43 \\
43 \\
43 \\
44 \\
43 \\
42 \\
42 \\
41 \\
43 \\
50 \\
525\end{array}$ & $\begin{array}{r}93 \\
86 \\
83 \\
80 \\
76 \\
75 \\
70 \\
70 \\
---- \\
----\end{array}$ \\
\hline $\begin{array}{l}\text { nthly } \\
\text { noff, } \\
\text { noff, }\end{array}$ & $\begin{array}{l}\text { Inc } \\
\text { acr }\end{array}$ & & & & & & $\begin{array}{r}61.7 \\
1.04 \\
3,800\end{array}$ & $\begin{array}{r}174 \\
2.63 \\
9,640\end{array}$ \\
\hline
\end{tabular}

Gage height, in feet, and discharge, in cubic feet per second, at indicated time, 1963

\begin{tabular}{|c|c|c|c|c|c|c|c|c|c|c|c|}
\hline Date & Hour & $\begin{array}{c}\text { Gage } \\
\text { he1ght }\end{array}$ & $\begin{array}{c}\text { Dis- } \\
\text { charge }\end{array}$ & Date & Hour & $\begin{array}{c}\text { Gage } \\
\text { helght }\end{array}$ & $\begin{array}{c}\text { D1s - } \\
\text { charge }\end{array}$ & Date & Hour & $\begin{array}{c}\text { Gage } \\
\text { helght }\end{array}$ & $\begin{array}{c}\text { Dis- } \\
\text { charge }\end{array}$ \\
\hline Jan. 30 & 2400 & 0.43 & 73 & Jan. 31 & 2400 & & 1,250 & Feb. 1 & $\begin{array}{l}2000 \\
2400\end{array}$ & $\begin{array}{l}2.15 \\
1.86\end{array}$ & $\begin{array}{l}613 \\
494\end{array}$ \\
\hline 31 & $\begin{array}{l}0700 \\
1000 \\
1300 \\
1800 \\
1900 \\
2200 \\
2300\end{array}$ & $\begin{array}{l}.65 \\
1.13 \\
1.65 \\
2.96 \\
2.89 \\
3.47 \\
3.30\end{array}$ & $\begin{array}{r}108 \\
224 \\
410 \\
1,020 \\
975 \\
1,320 \\
1,220\end{array}$ & Feb. I & $\begin{array}{l}0100 \\
0200 \\
0400 \\
0500 \\
0600 \\
1200 \\
1800\end{array}$ & $\begin{array}{l}3.40 \\
3.30 \\
3.13 \\
3.17 \\
3.12 \\
2.38 \\
2.15\end{array}$ & $\begin{array}{r}1,280 \\
1,220 \\
1,120 \\
1,140 \\
1,110 \\
720 \\
613\end{array}$ & 2 & $\begin{array}{l}0600 \\
1200 \\
1800 \\
2400\end{array}$ & $\begin{array}{l}1.66 \\
1.57 \\
1.57 \\
1.51\end{array}$ & $\begin{array}{l}414 \\
378 \\
378 \\
354\end{array}$ \\
\hline
\end{tabular}

11-4011.5. Red Clover Creek near Genesee, Calif.

Location. --Lat $40^{\circ} 03^{\prime} 00^{\prime \prime}$, long $120^{\circ} 39^{\prime} 50^{\prime \prime}$, in NW $\frac{1}{4} \mathrm{SW} \frac{1}{4}$ sec. 5, T.25 N., R.12 E., $0.3 \mathrm{mile}$ downstream from Rock Creek, 4.5 miles east of Genesee, and $9.5 \mathrm{miles}$ east of Taylorsville.

Drainage area. $-122 \mathrm{sq} \mathrm{mi}$.

Gage-height record.--Water-stage recorder graph, except Jan. 1-31. Altitude of gage is $3,830 \mathrm{ft}$ (from topographic map).

Discharge record.--Stage-discharge relation defined by current-meter measurements below 2,100 cfs. Discharge for period Jan. 1-29 established from records for nearby stations. Discharge for period from 2400 hours Jan. 29 to 1300 hours Jan. 31 estimated from reconstructed gage-height graph.

Maxima.--January-February 1963: Discharge, 7,870 cfs 0130 hours Feb. 1 (gage height, $9.49 \mathrm{f}^{\prime} \mathrm{t}$ ).

1958 to December 1962: Discharge, 4,720 cfs 0ct. 13, 1962 (gage height, $8.50 \mathrm{ft})$.

Remarks.--Records furnished by California Department of Water Resources and reviewed by Geological Survey. 
Mean discharge, in cub1c feet per second, 1963, of Red Clover Creek near Genesee, Cal1f.

\begin{tabular}{|c|c|c|c|c|c|c|c|c|}
\hline Day & January & February & Day & January & February & Day & January & February \\
\hline $\begin{array}{c}1 \ldots \ldots \\
2 \ldots \ldots \\
3 \ldots \ldots \\
4 \ldots \ldots \\
6 \ldots \ldots \\
7 \ldots \ldots \\
8 \ldots \ldots \\
9 \ldots \ldots \\
10 \ldots \ldots\end{array}$ & $\begin{array}{l}45 \\
45 \\
55 \\
62 \\
52 \\
50 \\
46 \\
45 \\
45 \\
40\end{array}$ & $\begin{array}{r}4,360 \\
1,590 \\
976 \\
749 \\
657 \\
469 \\
377 \\
322 \\
282 \\
318\end{array}$ & $\begin{array}{l}11 \ldots \ldots \\
12 \ldots \ldots \\
13 \ldots \ldots \\
14 \ldots \ldots \\
15 \ldots \ldots \\
16 \ldots \ldots \\
17 \ldots \ldots \\
18 \ldots \ldots \\
19 \ldots \ldots \\
20 \ldots \ldots\end{array}$ & $\begin{array}{l}30 \\
22 \\
23 \\
25 \\
25 \\
25 \\
23 \\
22 \\
20 \\
20\end{array}$ & $\begin{array}{l}278 \\
213 \\
334 \\
230 \\
194 \\
182 \\
175 \\
157 \\
146 \\
146\end{array}$ & $\begin{array}{l}21 \ldots \ldots \\
22 \ldots \ldots \\
23 \ldots \ldots \\
24 \ldots \ldots \\
25 \ldots \ldots \\
26 \ldots \ldots \\
27 \ldots \ldots \\
28 \ldots \ldots \\
29 \ldots \ldots \\
30 \ldots \ldots \\
31 \ldots \ldots\end{array}$ & $\begin{array}{r}21 \\
23 \\
24 \\
25 \\
25 \\
24 \\
23 \\
20 \\
24 \\
58 \\
2,840 \\
\end{array}$ & $\begin{array}{r}137 \\
124 \\
112 \\
109 \\
102 \\
99 \\
88 \\
84 \\
----- \\
--.-- \\
\end{array}$ \\
\hline $\begin{array}{l}\text { onthly } \\
\text { anoff, } \\
\text { anoff, }\end{array}$ & $\begin{array}{l}\text { inches } \\
\text { acre- }\end{array}$ & & & & & & $\begin{array}{r}124 \\
1.17 \\
7,590 \\
\end{array}$ & $\begin{array}{r}465 \\
3.97 \\
25,810 \\
\end{array}$ \\
\hline
\end{tabular}

Gage height, In feet, and discharge, in cublc feet per second, at 1ndicated time, 1963

\begin{tabular}{|c|c|c|c|c|c|c|c|c|c|c|c|}
\hline Date & Hour & $\begin{array}{c}\text { Gage } \\
\text { helght }\end{array}$ & $\begin{array}{l}\text { D18- } \\
\text { charge }\end{array}$ & Date & Hour & $\begin{array}{c}\text { Gage } \\
\text { helght }\end{array}$ & $\begin{array}{l}\text { Dis- } \\
\text { charge }\end{array}$ & Date & Hour & $\begin{array}{c}\text { Gage } \\
\text { he1ght }\end{array}$ & $\begin{array}{l}\text { D1s- } \\
\text { charge }\end{array}$ \\
\hline $\begin{array}{r}\overline{\operatorname{Jan}} \cdot \overline{\mathbf{9}} \\
30\end{array}$ & $\begin{array}{l}2400 \\
1300 \\
1800 \\
2400 \\
\\
0800 \\
1200\end{array}$ & $\begin{array}{l}- \\
- \\
- \\
- \\
-\end{array}$ & $\begin{array}{r}37 \\
37 \\
48 \\
114 \\
1,230 \\
2,210\end{array}$ & Jan. 31 & $\begin{array}{l}1300 \\
1800 \\
1900 \\
2100 \\
2200 \\
2300 \\
2400\end{array}$ & $\begin{array}{l}6.85 \\
8.30 \\
8.06 \\
9.06 \\
9.09 \\
9.47 \\
9.26\end{array}$ & $\begin{array}{l}2,340 \\
4,380 \\
4,660 \\
6,790 \\
6,860 \\
7,820 \\
7,280\end{array}$ & Feb. 1 & $\begin{array}{l}0130 \\
0300 \\
0500 \\
1000 \\
1300 \\
1800 \\
2200 \\
2400 \\
\end{array}$ & $\begin{array}{l}9.49 \\
9.15 \\
8.53 \\
7.77 \\
7.22 \\
6.82 \\
6.70 \\
6.59\end{array}$ & $\begin{array}{l}7,870 \\
7,010 \\
5,600 . \\
4,140 \\
3,260 \\
2,700 \\
2,540 \\
2,410\end{array}$ \\
\hline
\end{tabular}

11-4012. Indian Creek near Taylorsville, Calif.

Location.--Lat $40^{\circ} 03^{\prime} 3^{\prime \prime}$, long $120^{\circ} 49^{\prime} 15^{\prime \prime}$, in SW $\frac{1}{4} \mathrm{NW} \frac{1}{4} \sec .1$, T.25 N., R.10 E., on right bank 0.7 mile downstream from Montgomery Creek and 1.5 miles southeast of Taylorsville.

Drainage area. $--533 \mathrm{sq} \mathrm{mi}$.

Gage-height record --Water-stage recorder graph, except Jan. 10-30. Altitude of gage is $3,560 \mathrm{f} i$ (from topographic map).

Discharge record.--Stage-discharge relation defined by current-meter measurements below 1,000 cf's and by slope-area measurements at 17,300 and 30,200 cfs. Discharge for Jan. 10-30 estimated on basis of summation of records for Indian Creek near Boulder Creek Guard Station and Red Clover Creek near Genesee.

Maxima.--January-February 1963: Discharge, 30,200 cfs 0700 hours Feb. 1 (gage helght, $10.65 \mathrm{ft}$ from recorder graph; $10.7 \mathrm{ft}$, from floodmarks).

1957 to December 1962; Discharge, 17,300 cfs oct. 12, 1962 (gage height, $10.3 \mathrm{ft}$, from floodmarks).

Flood of Dec. 23, 1955, reached a stage of $11.5 \mathrm{ft}$.

Remarks.--Records furnished by California Department of Water Resources and reviewed by Geological Survey.

Mean discharge, in cublc feet per second, 1963

\begin{tabular}{|c|c|c|c|c|c|c|c|c|}
\hline Day & January & February & Day & January & February & Day & January & February \\
\hline $\begin{array}{c}1 \ldots \ldots \\
2 \ldots \ldots \\
3 \ldots \ldots \\
4 \ldots \ldots \\
5 \ldots \ldots \\
7 \ldots \ldots \\
8 \ldots \ldots \\
9 \ldots \ldots \\
10 \ldots \ldots\end{array}$ & $\begin{array}{l}162 \\
158 \\
176 \\
190 \\
163 \\
166 \\
161 \\
150 \\
147 \\
130\end{array}$ & $\begin{array}{r}23,000 \\
9,340 \\
5,470 \\
3,840 \\
3,380 \\
2,450 \\
1,970 \\
1,700 \\
1,490 \\
1,520\end{array}$ & $\begin{array}{l}11 \ldots \ldots \\
12 \ldots \ldots \\
13 \ldots \ldots \\
14 \ldots \ldots \\
15 \ldots \ldots \\
16 \ldots \ldots \\
17 \ldots \ldots \\
18 \ldots \ldots \\
19 \ldots \ldots \\
20 \ldots \ldots\end{array}$ & $\begin{array}{r}100 \\
80 \\
85 \\
90 \\
100 \\
100 \\
90 \\
80 \\
70 \\
70\end{array}$ & $\begin{array}{r}1,480 \\
1,130 \\
1,540 \\
1,250 \\
1,050 \\
987 \\
939 \\
834 \\
768 \\
745\end{array}$ & $\begin{array}{l}21 \ldots \ldots \\
22 \ldots \ldots \\
23 \ldots \ldots \\
24 \ldots \ldots \\
25 \ldots \ldots \\
26 \ldots \ldots \\
27 \ldots \ldots \\
28 \ldots \ldots \\
29 \ldots \ldots \\
30 \ldots \ldots \\
31 \ldots \ldots\end{array}$ & $\begin{array}{r}78 \\
85 \\
92 \\
100 \\
100 \\
95 \\
85 \\
75 \\
200 \\
800 \\
8,700\end{array}$ & $\begin{array}{r}713 \\
618 \\
551 \\
543 \\
503 \\
478 \\
422 \\
396 \\
---- \\
-----\end{array}$ \\
\hline \multicolumn{7}{|c|}{ 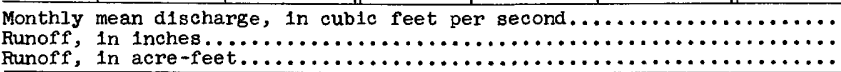 } & $\begin{array}{r}415 \\
0.90 \\
25,540\end{array}$ & $\begin{array}{r}2,468 \\
4.82 \\
137,100\end{array}$ \\
\hline
\end{tabular}


Gage helght, in feet, and discharge, in cublc feet per second, at indlcated time, 1963, of Indian Creek near Taylorsville, Callf.

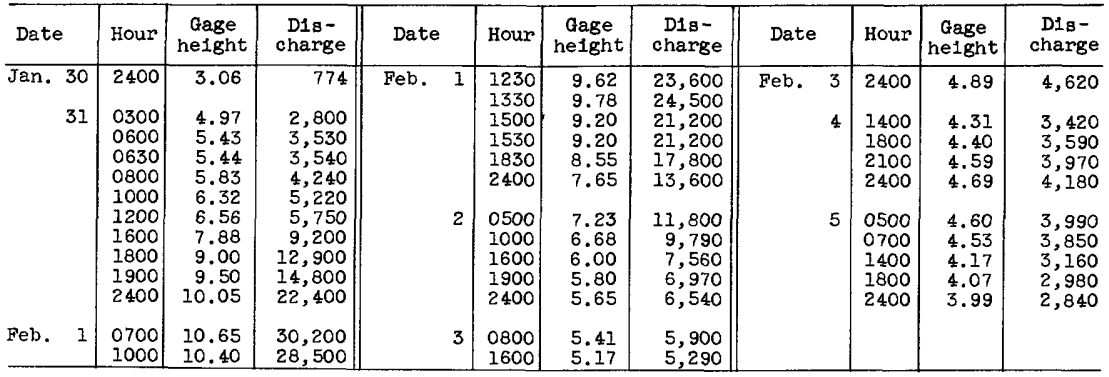

11-4015. Indian Creek near Crescent Mills, Calif.

Location.--Lat $40^{\circ} 04^{1} 20^{\prime \prime}$, long $120^{\circ} 55^{\prime} 35^{\prime \prime}$, in SW $\frac{1}{4} \mathrm{SW} \frac{1}{4} \sec .25$, T.26 N., R.9 E., on left bank 0.8 mile upstream from Dixie creek and 1.5 miles south of town of Crescent Milis.

Drainage area. $--739 \mathrm{sq} \mathrm{m}$.

Gage-height record.--Water-stage recorder graph. Altitude of gage is 3,500 ft (from topographic map).

Discharge record.--Stage-discharge relation defined by current-meter measurements below 16,000 efs.

Maxima.--January-February 1963; Discharge, 24,900 cfs 1300 hours Feb. 1 (gage height, $18.35 \mathrm{ft}$ )

1906-9, 1911-18, 1930 to December 1962: Discharge, 25,000 cfs Mar. 19, 1907 (gage height, $20.2 \mathrm{ft}$, site and datum then in use).

Mean d1scharge, in cub1c feet per second, 1963

\begin{tabular}{|c|c|c|c|c|c|c|c|c|}
\hline Day & January & February & Day & January & February & Day & January & February \\
\hline $\begin{array}{c}1 \ldots \ldots \\
2 \ldots \ldots \\
3 \ldots \ldots \\
4 \ldots \ldots \\
5 \ldots \ldots \\
7 \ldots \ldots \\
8 \ldots \ldots \\
9 \ldots \ldots \\
10 \ldots \ldots\end{array}$ & $\begin{array}{l}308 \\
280 \\
295 \\
310 \\
283 \\
270 \\
260 \\
244 \\
234 \\
170\end{array}$ & $\begin{array}{r}21,700 \\
13,700 \\
6,710 \\
4,730 \\
3,830 \\
3,070 \\
2,360 \\
1,950 \\
1,720 \\
1,630 \\
.\end{array}$ & $\begin{array}{l}11 \ldots \ldots \\
12 \ldots \ldots \\
13 \ldots \ldots \\
14 \ldots \ldots \\
15 \ldots \ldots \\
16 \ldots \ldots \\
17 \ldots \ldots \\
18 \ldots \ldots \\
19 \ldots \ldots \\
20 \ldots \ldots\end{array}$ & $\begin{array}{l}140 \\
105 \\
115 \\
130 \\
140 \\
140 \\
130 \\
115 \\
110 \\
115\end{array}$ & $\begin{array}{r}1,650 \\
1,330 \\
1,580 \\
1,440 \\
1,250 \\
1,180 \\
1,120 \\
1,040 \\
980 \\
955\end{array}$ & $\begin{array}{l}21 \ldots \ldots \\
22 \ldots \ldots \\
23 \ldots \ldots \\
24 \ldots \ldots \\
25 \ldots \ldots \\
26 \ldots \ldots \\
27 \ldots \ldots \\
28 \ldots \ldots \\
29 \ldots \ldots \\
30 \ldots \ldots \\
31 \ldots \ldots\end{array}$ & $\begin{array}{l}120 \\
125 \\
130 \\
135 \\
140 \\
140 \\
150 \\
156 \\
164 \\
426 \\
4,100 \\
\end{array}$ & $\begin{array}{r}920 \\
826 \\
767 \\
745 \\
700 \\
675 \\
631 \\
587 \\
---- \\
--.-- \\
\end{array}$ \\
\hline \multicolumn{7}{|l|}{$\begin{array}{l}\text { Monthly } \\
\text { Runoff, } \\
\text { Runoff, }\end{array}$} & $\begin{array}{r}312 \\
0.49 \\
19,200 \\
\end{array}$ & $\begin{array}{r}2,849 \\
4.01 \\
158,200 \\
\end{array}$ \\
\hline
\end{tabular}

Gage he1ght, in feet, and discharge, in cublc feet per second, at indicated t1me, 1963

\begin{tabular}{|c|c|c|c|c|c|c|c|c|c|c|c|}
\hline Date & Hour & $\begin{array}{c}\text { Gage } \\
\text { helght }\end{array}$ & $\begin{array}{l}\text { D1s- } \\
\text { charge }\end{array}$ & Date & Hour & $\begin{array}{c}\text { Gage } \\
\text { helght }\end{array}$ & $\begin{array}{l}\text { Dis - } \\
\text { charge }\end{array}$ & Date & Hour & $\begin{array}{c}\text { Gage } \\
\text { helght }\end{array}$ & $\begin{array}{l}\text { D1s- } \\
\text { charge }\end{array}$ \\
\hline $\begin{array}{r}\text { Jan. } 29 \\
30\end{array}$ & $\begin{array}{l}2400 \\
0400 \\
1200 \\
1300 \\
1400 \\
1500 \\
1600 \\
1800 \\
2100 \\
2300 \\
2400 \\
0100 \\
0300 \\
0300 \\
0500\end{array}$ & $\begin{array}{l}2.75 \\
2.78 \\
2.93 \\
2.96 \\
3.04 \\
3.15 \\
3.31 \\
3.89 \\
5.37 \\
6.18 \\
6.45 \\
6.47 \\
6.47 \\
6.65 \\
7.28\end{array}$ & $\begin{array}{r}173 \\
177 \\
206 \\
212 \\
228 \\
250 \\
288 \\
442 \\
1,040 \\
1,490 \\
1,670 \\
1,680 \\
1,680 \\
1,810 \\
2,260\end{array}$ & Feb. 1 & $\begin{array}{l}0700 \\
1200 \\
1500 \\
2000 \\
2200 \\
2400 \\
\\
0400 \\
0500 \\
0800 \\
1200 \\
1300 \\
2000 \\
2300 \\
2400 \\
0500\end{array}$ & $\begin{array}{r}7.78 \\
8.71 \\
9.20 \\
10.75 \\
11.80 \\
12.96 \\
16.75 \\
17.21 \\
17.93 \\
18.34 \\
18.35 \\
17.70 \\
17.26 \\
17.08 \\
16.06\end{array}$ & $\begin{array}{r}2,660 \\
3,530 \\
4,060 \\
6,160 \\
7,880 \\
10,000 \\
19,500 \\
20,900 \\
23,500 \\
24,900 \\
24,900 \\
22,700 \\
21,100 \\
20,500 \\
17,300\end{array}$ & Feb. 2 & $\begin{array}{l}1000 \\
1200 \\
1400 \\
1800 \\
2100 \\
2200 \\
2400 \\
0400 \\
0700 \\
1100 \\
1500 \\
1600 \\
1600 \\
2200 \\
2400\end{array}$ & $\begin{array}{r}14.93 \\
14.48 \\
13.85 \\
12.83 \\
12.14 \\
11.93 \\
11.61 \\
11.16 \\
10.87 \\
10.54 \\
10.30 \\
10.25 \\
10.26 \\
9.90 \\
9.83\end{array}$ & $\begin{array}{r}14,500 \\
13,600 \\
12,300 \\
10,500 \\
9,250 \\
8,890 \\
8,380 \\
7,660 \\
7,190 \\
6,660 \\
6,280 \\
6,200 \\
6,220 \\
5,660 \\
5,560\end{array}$ \\
\hline
\end{tabular}




\section{1-4019. Spanish Creek near Quincy, Calif.}

Location.--Lat $39^{\circ} 56^{\prime} 45^{\prime \prime}$, long $121^{\circ} 00120^{\prime \prime}$, in SW $\frac{1}{4} N W \frac{1}{4} \sec .17$, T.24 N., R.9 E., on right bank $0.9 \mathrm{mile}$ downstream from Slate Creek and 3.2 miles west of Quincy.

Drainage area. $--69.1 \mathrm{sq} \mathrm{mi}$.

Gage-height record.--Water-stage recorder graph, except Jan. 12-28, Feb. 9-28. Altitude of gage is $3,470 \mathrm{ft}$ (from topographic map).

Discharge record.--Stage-discharge relation defined by current-meter measurements below 1,100 ffs. Discharge for period of no gage-height record estimated on basis of records for station above Blackhawk Creek at Keddie.

Maxima.--January-February 1963: Discharge, 11,200 cfs 1630 hours Jan. 31 (gage height, $10.90 \mathrm{ft}$ ).

1958 to December 1962: Discharge, 7,450 cfs 0ct. 13, 1962 (gage height, $9.82 \mathrm{ft}$ ).

Remarks.--Flow affected by four small lakes. Records furnished by California Department of Water Resources and reviewed by Geological Survey.

Mean discharge, in cublc feet per second, 1963

\begin{tabular}{|c|c|c|c|c|c|c|c|c|}
\hline Day & January & February & Day & January & February & Day & January & February \\
\hline $\begin{array}{c}1 \ldots \ldots \\
2 \ldots \ldots \\
4 \ldots \ldots \\
5 \ldots \ldots \\
6 \ldots \ldots \\
8 \ldots \ldots \\
9 \ldots \ldots \\
10 \ldots \ldots\end{array}$ & $\begin{array}{l}85 \\
80 \\
79 \\
77 \\
70 \\
68 \\
66 \\
65 \\
62 \\
63\end{array}$ & $\begin{array}{r}, 040 \\
1,510 \\
830 \\
591 \\
464 \\
344 \\
293 \\
277 \\
250 \\
220\end{array}$ & $\begin{array}{l}11 \ldots \ldots \\
12 \ldots \ldots \\
13 \ldots \ldots \\
14 \ldots \ldots \\
15 \ldots \ldots \\
16 \ldots \ldots \\
17 \ldots \ldots \\
18 \ldots \ldots \\
19 \ldots \ldots \\
20 \ldots \ldots\end{array}$ & $\begin{array}{l}54 \\
50 \\
45 \\
42 \\
42 \\
42 \\
42 \\
42 \\
42 \\
42\end{array}$ & $\begin{array}{l}210 \\
200 \\
279 \\
261 \\
210 \\
190 \\
170 \\
150 \\
140 \\
135\end{array}$ & $\begin{array}{l}21 \ldots \ldots \\
22 \ldots \ldots \\
23 \ldots \ldots \\
24 \ldots \ldots \\
25 \ldots \ldots \\
26 \ldots \ldots \\
27 \ldots \ldots \\
28 \ldots \ldots \\
29 \ldots \ldots \\
30 \ldots \ldots \\
31 \ldots \ldots\end{array}$ & $\begin{array}{r}42 \\
42 \\
42 \\
41 \\
40 \\
39 \\
38 \\
37 \\
37 \\
632 \\
6,050\end{array}$ & $\begin{array}{r}125 \\
118 \\
110 \\
105 \\
100 \\
95 \\
90 \\
85 \\
----\end{array}$ \\
\hline \multicolumn{7}{|c|}{ 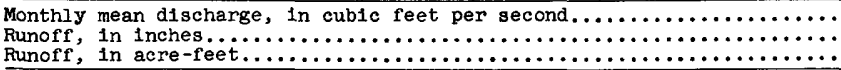 } & $\begin{array}{r}265 \\
4.41 \\
16,260 \\
\end{array}$ & $\begin{array}{r}450 \\
6.78 \\
24,980 \\
\end{array}$ \\
\hline
\end{tabular}

Gage height, in feet, and discharge, in cublc feet per second, at indicated time, 1963

\begin{tabular}{|c|c|c|c|c|c|c|c|c|c|c|c|}
\hline Date & Hour & $\begin{array}{c}\text { Gage } \\
\text { height }\end{array}$ & $\begin{array}{l}\text { D1s- } \\
\text { charge }\end{array}$ & Date & Hour & $\begin{array}{c}\text { Gage } \\
\text { helght }\end{array}$ & $\begin{array}{l}\text { Dis- } \\
\text { charge }\end{array}$ & Date & Hour & $\begin{array}{c}\text { Gage } \\
\text { height }\end{array}$ & $\begin{array}{l}\text { Dis- } \\
\text { charge }\end{array}$ \\
\hline $\begin{array}{r}\text { Jan. } 29 \\
30\end{array}$ & $\begin{array}{l}2400 \\
0400 \\
0800 \\
1200 \\
1700 \\
1830 \\
1900 \\
2000 \\
2230 \\
2400\end{array}$ & $\begin{array}{l}3.04 \\
3.31 \\
3.50 \\
3.90 \\
5.27 \\
5.85 \\
5.75 \\
5.82 \\
5.64 \\
5.65\end{array}$ & $\begin{array}{r}48 \\
100 \\
149 \\
284 \\
1,090 \\
1,600 \\
1,500 \\
1,570 \\
1,400 \\
1,410\end{array}$ & Jan. 31 & $\begin{array}{l}0300 \\
0600 \\
0800 \\
1630 \\
1830 \\
1900 \\
2000 \\
2030 \\
2200 \\
2230 \\
2400\end{array}$ & $\begin{array}{r}5.71 \\
6.00 \\
7.04 \\
10.90 \\
10.43 \\
10.75 \\
10.40 \\
10.58 \\
10.44 \\
10.84 \\
10.53\end{array}$ & $\begin{array}{r}1,470 \\
1,760 \\
3,070 \\
11,200 \\
8,960 \\
9,730 \\
8,890 \\
9,320 \\
8,980 \\
9,950 \\
9,200\end{array}$ & Feb. & $\begin{array}{l}0130 \\
0800 \\
1330 \\
1500 \\
1600 \\
1700 \\
2000 \\
2400 \\
\\
0600 \\
1200 \\
2400\end{array}$ & $\begin{array}{r}10.71 \\
8.05 \\
7.15 \\
7.17 \\
7.13 \\
7.02 \\
6.62 \\
6.31 \\
5.70 \\
5.25 \\
4.70 \\
\end{array}$ & $\begin{array}{r}10,800 \\
5,020 \\
3,590 \\
3,620 \\
3,560 \\
3,400 \\
2,860 \\
2,470 \\
1,800 \\
1,370 \\
925\end{array}$ \\
\hline
\end{tabular}

11-4019.4. Mill Creek near Quincy, Calif.

(Crest-stage station)

Location.--Lat $39^{\circ} 56^{\prime} 03^{\prime \prime}$, long $120^{\circ} 54^{\prime} 18^{\prime \prime}$, in $\mathrm{NE} \frac{1}{4} \mathrm{NW} \frac{1}{4} \sec .19$, T.24 N., R.10 E., on State Highways 24 and $89,2.2$ miles east of Quincy.

Drainage area $--6.72 \mathrm{sq} \mathrm{mi}$.

Gage-height record.--Crest stages only. Altitude of gage is $3,500 \mathrm{ft}$ (from topographic map).

Discharge record.--Stage-discharge relation defined by current-meter measurements below 221 cf's and by computation of flow through culvert above.

Maxima.--January-February 1963: Discharge, $447 \mathrm{cfs}$ Jan. 31 (gage height, $5.53 \mathrm{f} t$ ). July to December 1962: Discharge, $338 \mathrm{cf}$ 's Oct. 13, 1962 (gage height, $4.73 \mathrm{ft}$ ). 
11-4020. Spanish Creek above Blackhawk Creek, at Keddie, Calif.

Location.--Lat $40^{\circ} 00^{\prime} 05^{\prime \prime}$, long $120^{\circ} 57^{\prime} 20^{\prime \prime}$, in NE $\frac{1}{4} \sec .27$, T.25 N., R.9 E., on right bank $200 \mathrm{ft}$ upstream from Blackhawk Creek and 0.9 mile southeast of Keddie.

Drainage area. $--184 \mathrm{sq} \mathrm{mi}$.

Gage-height record.--Digital-recorder tape punched at 15-minute intervals, except Jan. 1-4. Altitude of gage is 3,250 ft (from topographic map)

Discharge record.--Stage-discharge relation defined by current-meter measurements below $4,400 \mathrm{cf}$ s and by slope-area measurement at $13,100 \mathrm{cfs}$. Discharge for Jan. 1-4 estimated on basis of records for Indian Creek near Crescent Mills; affected by ice Jan. 5-26.

Maxima.--January-February 1963: Discharge, 15,000 cf's 0100 hours Feb. 1 (gage height, $13.37 \mathrm{ft}$, in gage well; $14.5 \mathrm{ft}$, from floodmarks).

1933 to December 1962: Discharge, 13,200 cfs Oct. 13, 1962 (gage height, $12.50 \mathrm{ft})$.

Mean discharge, in cublc feet per second, 1963

\begin{tabular}{|c|c|c|c|c|c|c|c|c|}
\hline Day & January & February & Day & January & February & Day & January & February \\
\hline $\begin{array}{c}\ldots \ldots \\
2 \ldots \ldots \\
3 \ldots \ldots \\
4 \ldots \ldots \\
5 \ldots \ldots \\
7 \ldots \ldots \\
8 \ldots \ldots \\
9 \ldots \ldots \\
10 \ldots \ldots\end{array}$ & $\begin{array}{l}160 \\
170 \\
150 \\
140 \\
135 \\
121 \\
114 \\
108 \\
101 \\
95\end{array}$ & $\begin{array}{r}8,970 \\
2,840 \\
1,600 \\
1,215 \\
1,040 \\
774 \\
638 \\
575 \\
515 \\
495\end{array}$ & $\begin{array}{l}11 \ldots \ldots \\
12 \ldots \ldots \\
13 \ldots \ldots \\
14 \ldots \ldots \\
15 \ldots \ldots \\
16 \ldots \ldots \\
17 \ldots \ldots \\
18 \ldots \ldots \\
19 \ldots \ldots \\
20 \ldots \ldots\end{array}$ & $\begin{array}{l}92 \\
90 \\
89 \\
89 \\
89 \\
89 \\
89 \\
89 \\
90 \\
90\end{array}$ & $\begin{array}{l}428 \\
388 \\
545 \\
470 \\
410 \\
374 \\
345 \\
313 \\
293 \\
282\end{array}$ & $\begin{array}{l}21 \ldots \ldots \\
22 \ldots \ldots \\
23 \ldots \ldots \\
24 \ldots \ldots \\
25 \ldots \ldots \\
26 \ldots \ldots \\
27 \ldots \ldots \\
28 \ldots \ldots \\
29 \ldots \ldots \\
30 \ldots \ldots \\
31 \ldots \ldots\end{array}$ & $\begin{array}{r}90 \\
90 \\
90 \\
90 \\
90 \\
90 \\
89 \\
91 \\
96 \\
786 \\
7,000 \\
\end{array}$ & $\begin{array}{r}268 \\
247 \\
229 \\
218 \\
208 \\
200 \\
191 \\
186 \\
-\ldots-.- \\
-\ldots-.- \\
-.-1\end{array}$ \\
\hline \multicolumn{7}{|l|}{$\begin{array}{l}\text { Monthly } \\
\text { Runoff, } \\
\text { Runoff, } 1\end{array}$} & $\begin{array}{r}348 \\
2.18 \\
21,410\end{array}$ & $\begin{array}{r}866 \\
4,90 \\
48,110 \\
\end{array}$ \\
\hline
\end{tabular}

Gage height, in feet, and discharge, in cublc feet per second, at 1ndicated time, 1963

\begin{tabular}{|c|c|c|c|c|c|c|c|c|c|c|c|}
\hline Date & Hour & $\begin{array}{c}\text { Gage } \\
\text { helght }\end{array}$ & $\begin{array}{l}\text { D1s- } \\
\text { charge }\end{array}$ & Date & Hour & $\begin{array}{c}\text { Gage } \\
\text { he1ght }\end{array}$ & $\begin{array}{l}\text { D1s- } \\
\text { charge }\end{array}$ & Date & Hour & $\begin{array}{c}\text { Gage } \\
\text { he1ght }\end{array}$ & $\begin{array}{l}\text { Dis- } \\
\text { charge }\end{array}$ \\
\hline $\begin{array}{r}\text { Jan. } 29 \\
30\end{array}$ & $\begin{array}{l}2400 \\
0200 \\
0400 \\
0600 \\
0800 \\
1000 \\
1200 \\
1400 \\
1600 \\
1800 \\
2000 \\
2200 \\
2400 \\
0200 \\
0400 \\
0600\end{array}$ & $\begin{array}{l}2.25 \\
2.28 \\
2.33 \\
2.43 \\
2.59 \\
2.78 \\
2.94 \\
3.21 \\
3.91 \\
4.82 \\
5.68 \\
5.98 \\
5.78 \\
5.63 \\
5.59 \\
5.69\end{array}$ & $\begin{array}{r}109 \\
113 \\
121 \\
139 \\
173 \\
220 \\
267 \\
359 \\
696 \\
1,350 \\
2,220 \\
2,550 \\
2,330 \\
2,160 \\
2,120 \\
2,230\end{array}$ & Feb. 1 & $\begin{array}{l}0800 \\
1000 \\
1200 \\
1400 \\
1600 \\
1800 \\
2000 \\
2200 \\
2400 \\
0100 \\
0200 \\
0400 \\
0600 \\
0800 \\
1000 \\
1200 \\
1400\end{array}$ & $\begin{array}{r}6.05 \\
7.01 \\
7.94 \\
9.42 \\
10.89 \\
11.98 \\
12.81 \\
12.92 \\
13.23 \\
13.37 \\
13.32 \\
13.21 \\
12.74 \\
11.60 \\
10.35 \\
9.41 \\
8.76\end{array}$ & $\begin{array}{r}2,630 \\
3,820 \\
5,100 \\
7,450 \\
10,100 \\
12,100 \\
13,800 \\
14,000 \\
14,700 \\
15,000 \\
14,900 \\
14,700 \\
13,600 \\
11,400 \\
8,900 \\
7,130 \\
5,990\end{array}$ & Feb. I & $\begin{array}{l}1600 \\
1800 \\
2000 \\
2200 \\
2400 \\
\\
0200 \\
0400 \\
0600 \\
0800 \\
1000 \\
1200 \\
1400 \\
1600 \\
1800 \\
2000 \\
2200 \\
2400\end{array}$ & $\begin{array}{l}8.81 \\
8.38 \\
8.23 \\
7.99 \\
7.73 \\
7.52 \\
7.31 \\
6.90 \\
6.75 \\
6.50 \\
6.32 \\
6.15 \\
6.02 \\
5.75 \\
5.64 \\
5.59 \\
5.47\end{array}$ & $\begin{array}{l}6,080 \\
5,380 \\
5,140 \\
4,780 \\
4,410 \\
4,120 \\
3,840 \\
3,330 \\
3,150 \\
2,870 \\
2,670 \\
2,500 \\
2,370 \\
2,120 \\
2,020 \\
1,970 \\
1,860\end{array}$ \\
\hline
\end{tabular}

11-4027. Kingsbury Creek near Twain, Calif.

(Crest-stage station)

Location.--Lat $40^{\circ} 01^{\prime} 15^{\prime \prime}$, long $121^{\circ} 04^{\prime} 15^{\prime \prime}$, in NW $\frac{1}{4} \mathrm{NE} \frac{1}{4} \sec .22$, T. 25 N., R. 8 E., on U.S. Highway Alternate 40 , Plumas National Forest, 2 miles west of Twain.

Drainage area. $--1.36 \mathrm{sq} \mathrm{mi}$.

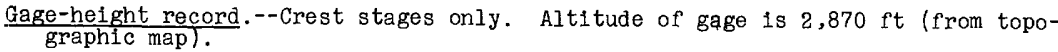

Discharge record.--Stage-discharge relation defined by current-meter measurements below 53 cf's and by computation of flow through culvert above.

Maxima.--January-February 1963: Discharge, $107 \mathrm{cfs} F \mathrm{Feb}$. 1 (gage height, $4.64 \mathrm{ft}$ ). July to December 1962: Discharge, $114 \mathrm{cfs}$ Oct. 13 (gage height, $4.75 \mathrm{ft}$, from crest-stage gage; $4.91 \mathrm{ft}$, from floodmarks). 
11-4033.4. Granite Creek near Tobin, Cal1f.

(Crest-stage station)

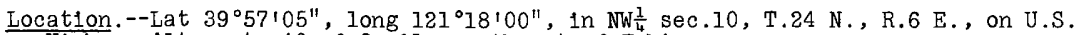
H1ghway Alternate $40,0.9$ mile northeast of Tobin.

Drainage area. $-0.79 \mathrm{sq} \mathrm{ml}$.

Gage-height record.--Crest stages only. Alt1tude of gage is 2,020 ft (from topographic map).

Discharge record.--Stage-discharge relation defined by current-meter measurements below $25 \mathrm{cfs}$ and by computation of flow through culvert at 62 and $72 \mathrm{cfs}$.

Maxima.--January-February 1963: D1scharge, 62 cfs Jan. 31 (gage height, $8.74 \mathrm{ft}$ ). July to December 1962: Discharge, 72 cfs Oct. 13, 1962 (gage he1ght, $9.01 \mathrm{ft})$.

11-4035. Bucks Lake near Bucks Lodge, Cal1f.

Location.--Lat $39^{\circ} 53^{\prime} 45^{\prime \prime}$, long $121^{\circ} 12^{\prime} 10^{\prime \prime}$, in NW $\frac{1}{4}$ sec.33, T.24 N., R.7 E., in intake tower No. 2 upstream from dam on Bucks Creek, 2 miles northwest of Bucks Lodge and 15 miles west of Quincy.

Drainage area. $--28.6 \mathrm{sq} \cdot \mathrm{mi}$.

Gage-helght record.--Water-stage recorder graph. Datum of gage is at mean sea level (levels by Feather River Power Co.).

Contents record.--Contents computed from capac1ty table F-574 (Feather River Power Co.).

Maxima.--January-February 1963: Contents, 93,900 acre-ft 2400 hours Feb. 14 to 1200 hours Feb. 15 (elevation, 5,150.5 ft)

1928 to December 1962: Contents, 105,800 acre-ft June 23, 1938 (elevation, $5,157.1 \mathrm{ft})$.

Remarks.--Reservoir is formed by concrete-faced, rockfill dam completed in 1928; storage began in May 1927. Capacity, 101,400 acre-ft between elevations $5,064.75 \mathrm{ft}$ (s111 of outlet gate) and $5,154.85 \mathrm{ft}$ (spillway crest) above mean sea level. Figures given herein represent total contents, of which 274 acre-ft is not ava1lable for release. Records furnished by Pacific Gas \& Electric Co.

Elevation, in feet, and contents, in acre-feet, at 2400 hours, 1963

\begin{tabular}{|c|c|c|c|c|c|c|c|c|c|}
\hline \multirow{2}{*}{ Day } & \multicolumn{2}{|c|}{ January } & \multicolumn{2}{|c|}{ February } & \multirow{2}{*}{ Day } & \multicolumn{2}{|c|}{ January } & \multicolumn{2}{|c|}{ February } \\
\hline & Elevation & Contents & Elevation & Contents & & Elevation & Contents & Elevation & Contents \\
\hline $\begin{array}{r}1 \\
2 \\
3 \\
4 \\
5 \\
6 \\
7 \\
8 \\
9 \\
10 \\
11 \\
12 \\
13 \\
14 \\
15\end{array}$ & $\begin{array}{l}5,144.8 \\
5,144.7 \\
5,144.5 \\
5,144.3 \\
5,144.0 \\
5,143.8 \\
5,143.6 \\
5,143.4 \\
5,143.1 \\
5,143.1 \\
5,142.8 \\
5,142.5 \\
5,142.3 \\
5,142.0 \\
5,141.8\end{array}$ & $\begin{array}{l}83,900 \\
83,700 \\
83,400 \\
83,100 \\
82,600 \\
82,300 \\
81,900 \\
81,500 \\
81,100 \\
81,100 \\
80,600 \\
80,000 \\
79,700 \\
79,200 \\
78,900\end{array}$ & $\begin{array}{l}5,146.3 \\
5,147.1 \\
5,147.7 \\
5,148.1 \\
5,148.5 \\
5,148.8 \\
5,149.0 \\
5,149.4 \\
5,149.6 \\
5,149.9 \\
5,150.0 \\
5,150.2 \\
5,150.4 \\
5,150.5 \\
5,150.5\end{array}$ & $\begin{array}{l}86,500 \\
87,800 \\
88,800 \\
89,700 \\
90,300 \\
90,800 \\
91,200 \\
91,800 \\
92,300 \\
92,800 \\
93,000 \\
93,300 \\
93,700 \\
93,900 \\
93,800\end{array}$ & $\begin{array}{l}16 \\
17 \\
18 \\
19 \\
20 \\
21 \\
22 \\
23 \\
24 \\
25 \\
26 \\
27 \\
28 \\
29 \\
30 \\
31\end{array}$ & $\begin{array}{l}5,141.5 \\
5,141.3 \\
5,141.0 \\
5,140.8 \\
5,140.5 \\
5,140.3 \\
5,140.0 \\
5,139.8 \\
5,139.5 \\
5,139.2 \\
5,139.0 \\
5,138.8 \\
5,138.5 \\
5,138.5 \\
5,139.4 \\
5,144.7\end{array}$ & $\begin{array}{l}78,400 \\
78,000 \\
77,600 \\
77,200 \\
76,800 \\
76,400 \\
75,900 \\
75,500 \\
75,100 \\
74,700 \\
74,200 \\
73,900 \\
73,400 \\
73,400 \\
74,900 \\
83,800\end{array}$ & $\begin{array}{c}5,150.4 \\
5,150.3 \\
5,150.1 \\
5,150.0 \\
5,149.9 \\
5,149.9 \\
5,149.8 \\
5,149.6 \\
5,148.9 \\
5,148.7 \\
5,148.5 \\
5,148.3 \\
5,148.2 \\
- \\
- \\
-\end{array}$ & $\begin{array}{c}93,600 \\
93,400 \\
93,200 \\
93,000 \\
92,700 \\
91,800 \\
91,600 \\
91,300 \\
91,000 \\
90,700 \\
90,400 \\
90,000 \\
89,800 \\
- \\
- \\
-\end{array}$ \\
\hline \multicolumn{6}{|c|}{ 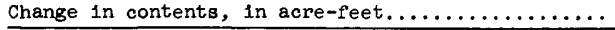 } & - & -300 & - & $+6,000$ \\
\hline
\end{tabular}


11-4045. North Fork Feather River at Pulga, Calif.

Location.--Lat $39^{\circ} 47^{\prime} 40^{\prime \prime}$, long $121^{\circ} 27^{\prime} 00^{\prime \prime}$, in NE⿺ sec.6, T.22 N., R.5 E., on left bank between rallroad and highway bridges, 0.5 mile downstream from flea Valley Creek and Pulga and 1.5 miles downstream from Poe Dam.

Drainage area. $--1,953 \mathrm{sq} \mathrm{ml}$.

Gage-height record.--Water-stage recorder graph. Altitude of gage is $1,320 \mathrm{ft}^{\prime} \mathrm{t}$ (from topographic map).

Discharge record.--Stage-discharge relation defined by current-meter measurements.

Maxima --January-February 1963: Discharge, 54,900 cfs 1730 hours Jan. 31 (gage height, $31.72 \mathrm{ft}$ ).

1910-57 (prior to diversion to Poe powerhouse): Discharge, 72,400 cfs Dec. 23 , 1955 (gage height, $35.60 \mathrm{ft}$ ), from rating curve extended above $34,000 \mathrm{cf}$.

1958 to December 1962: Discharge, 34,300 cfs Feb. 8, 1960 (gage height, $25.10 \mathrm{ft})$.

Remarks:--Flow regulated. by Lake Almanor (see station 11-3990), Bucks Lake (see station 11-4035), Butt Valley Reservoir, and Cresta, Rock Creek, and Poe powerplants.

Mean discharge, in cubic feet per second, 1963

\begin{tabular}{|c|c|c|c|c|c|c|c|c|}
\hline Day & January & February & Day & January & February & Day & January & February \\
\hline $\begin{array}{r}1 \ldots \ldots \\
2 \ldots \ldots \\
3 \ldots \ldots \\
4 \ldots \ldots \\
5 \ldots \ldots \\
7 \ldots \ldots \\
8 \ldots \ldots \\
9 \ldots \ldots \\
10 \ldots \ldots\end{array}$ & $\begin{array}{l}74 \\
73 \\
71 \\
67 \\
64 \\
63 \\
65 \\
73 \\
62 \\
63\end{array}$ & $\begin{array}{r}42,600 \\
25,200 \\
14,700 \\
11,200 \\
9,550 \\
8,180 \\
7,030 \\
6,510 \\
5,350 \\
5,270\end{array}$ & $\begin{array}{l}11 \ldots \ldots \\
12 \ldots \ldots \\
13 \ldots \ldots \\
14 \ldots \ldots \\
15 \ldots \ldots \\
16 \ldots \ldots \\
17 \ldots \ldots \\
18 \ldots \ldots \\
19 \ldots \ldots \\
20 \ldots \ldots\end{array}$ & $\begin{array}{l}61 \\
56 \\
58 \\
58 \\
57 \\
56 \\
56 \\
54 \\
53 \\
56\end{array}$ & $\begin{array}{r}5,530 \\
5,710 \\
5,350 \\
2,930 \\
171 \\
126 \\
114 \\
103 \\
100 \\
94\end{array}$ & $\begin{array}{l}21 \ldots \ldots \\
22 \ldots \ldots \\
23 \ldots \ldots \\
24 \ldots \ldots \\
25 \ldots \ldots \\
26 \ldots \ldots \\
27 \ldots \ldots \\
28 \ldots \ldots \\
29 \ldots \ldots \\
30 \ldots \ldots \\
31 \ldots \ldots\end{array}$ & $\begin{array}{r}56 \\
57 \\
57 \\
57 \\
66 \\
298 \\
812 \\
253 \\
58 \\
2,110 \\
30,100\end{array}$ & $\begin{array}{r}90 \\
87 \\
83 \\
82 \\
78 \\
77 \\
72 \\
70 \\
-\ldots--\end{array}$ \\
\hline \multicolumn{7}{|c|}{ Monthly mean discharge, in cuble feet per second.................. } & $\begin{array}{r}1,134 \\
69,750\end{array}$ & $\begin{array}{r}5,588 \\
310,300\end{array}$ \\
\hline
\end{tabular}

Gage he1ght, in feet, and discharge, in cub1c feet per second, at ind1cated time, 1963

\begin{tabular}{|c|c|c|c|c|c|c|c|c|c|c|c|}
\hline Date & Hour & $\begin{array}{c}\text { Gage } \\
\text { he1ght }\end{array}$ & $\begin{array}{l}\text { D1s- } \\
\text { charge }\end{array}$ & Date & Hour & $\begin{array}{c}\text { Gage } \\
\text { helght }\end{array}$ & $\begin{array}{l}\text { Dis - } \\
\text { charge }\end{array}$ & Date & Hour & $\begin{array}{c}\text { Gage } \\
\text { helght }\end{array}$ & $\begin{array}{c}\text { D1s- } \\
\text { charge }\end{array}$ \\
\hline $\begin{array}{r}\operatorname{Jan}, 29 \\
30\end{array}$ & $\begin{array}{l}2400 \\
0300 \\
0600 \\
1200 \\
1300 \\
1400 \\
1600 \\
1700 \\
1800 \\
1900 \\
1900 \\
2000 \\
2000 \\
2100 \\
2100 \\
2200 \\
2300 \\
2400 \\
0200 \\
0300\end{array}$ & $\begin{array}{r}3.78 \\
4.08 \\
4.19 \\
4.62 \\
7.17 \\
7.35 \\
8.19 \\
9.30 \\
11.04 \\
10.04 \\
15.41 \\
10.82 \\
13.86 \\
14.88 \\
12.65 \\
14.12 \\
14.07 \\
14.04 \\
13.91 \\
13.91\end{array}$ & $\begin{array}{r}79 \\
114 \\
129 \\
193 \\
955 \\
1,050 \\
1,510 \\
2,210 \\
3,840 \\
2,840 \\
9,700 \\
3,620 \\
7,300 \\
8,810 \\
5,650 \\
7,670 \\
7,600 \\
7,560 \\
7,370 \\
7,370\end{array}$ & Feb. 1 & $\begin{array}{l}0500 \\
0600 \\
0800 \\
1000 \\
1100 \\
1200 \\
1300 \\
1500 \\
1700 \\
1730 \\
1800 \\
2100 \\
2200 \\
2400 \\
\\
0300 \\
0400 \\
0500 \\
0600 \\
0700 \\
0800 \\
1000\end{array}$ & $\begin{array}{l}14.07 \\
16.60 \\
18.50 \\
20.90 \\
22.90 \\
24.10 \\
26.60 \\
29.10 \\
31.00 \\
31.72 \\
31.60 \\
30.20 \\
30.40 \\
28.70 \\
29.30 \\
29.00 \\
29.20 \\
29.20 \\
28.00 \\
28.90 \\
28.70\end{array}$ & $\begin{array}{r}7,600 \\
11,800 \\
15,500 \\
20,800 \\
25,800 \\
29,300 \\
36,800 \\
44,400 \\
52,000 \\
54,900 \\
54,400 \\
48,800 \\
49,600 \\
43,100 \\
46,900 \\
46,000 \\
46,600 \\
46,600 \\
43,000 \\
45,700 \\
45,100\end{array}$ & Feb. 1 & $\begin{array}{l}1600 \\
1700 \\
1800 \\
1900 \\
2400 \\
\\
0700 \\
1000 \\
1300 \\
1400 \\
1500 \\
1600 \\
1600 \\
1700 \\
1800 \\
1900 \\
2000 \\
2100 \\
2200 \\
2300 \\
2400\end{array}$ & $\begin{array}{l}27.20 \\
26.90 \\
27.00 \\
27.00 \\
25.50 \\
23.51 \\
22.88 \\
21.80 \\
17.39 \\
20.96 \\
18.85 \\
20.12 \\
18.27 \\
20.30 \\
20.15 \\
20.15 \\
20.30 \\
19.45 \\
18.95 \\
18.95\end{array}$ & $\begin{array}{l}40,600 \\
39,700 \\
40,000 \\
40,000 \\
35,500 \\
29,500 \\
27,700 \\
24,800 \\
14,400 \\
22,600 \\
17,400 \\
20,400 \\
16,100 \\
20,900 \\
20,500 \\
20,500 \\
20,900 \\
18,800 \\
17,600 \\
17,600\end{array}$ \\
\hline
\end{tabular}


11-4053. West Branch Feather River near Paradise, Calif.

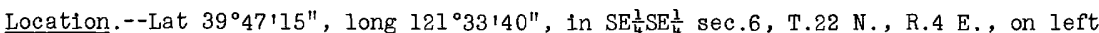

bank $0.6 \mathrm{mile}$ upstream from Griffin Gulch and 4.0 miles northeast of Paradise.

Drainage area. $--113 \mathrm{sq} \mathrm{m} 1$.

Gage-height record:--Water-stage recorder graph. Altitude of gage is $1,370 \mathrm{ft}$ (from topographic map).

Discharge record.--Stage-discharge relation def'ined by current-meter measurements.

Maxima.--January-February 1963: Discharge, 21,200 cfs 1700 hours Jan. 31 (gage height, $23.35 \mathrm{ft}$ ).

1957 to December 1962: Discharge, 14,000 cf's Feb. 8, 1960 (gage height, $18.55 \mathrm{ft}$ ).

Remarks. - Flow regulated by Round Valley Reservoir and Philbrook Reservoir (combined capacity, 6,290 acre-ft).

Mean discharge, In cublc feet per second, 1963

\begin{tabular}{|c|c|c|c|c|c|c|c|c|}
\hline Day & January & February & Day & January & Pebruary & Day & January & February \\
\hline $\begin{array}{c}1 \ldots \ldots \\
2 \ldots \ldots \\
3 \ldots \ldots \\
4 \ldots \ldots \\
5 \ldots \ldots \\
6 \ldots \ldots \\
8 \ldots \ldots \\
9 \ldots \ldots \\
10 \ldots \ldots\end{array}$ & $\begin{array}{r}145 \\
132 \\
124 \\
119 \\
96 \\
80 \\
74 \\
68 \\
57 \\
55\end{array}$ & $\begin{array}{r}6,360 \\
2,830 \\
2,030 \\
1,500 \\
1,220 \\
930 \\
745 \\
730 \\
670 \\
634\end{array}$ & $\begin{array}{l}11 \ldots \ldots \\
12 \ldots \ldots \\
13 \ldots \ldots \\
14 \ldots \ldots \\
15 \ldots \ldots \\
16 \ldots \ldots \\
17 \ldots \ldots \\
18 \ldots \ldots \\
19 \ldots \ldots \\
20 \ldots \ldots\end{array}$ & $\begin{array}{l}48 \\
38 \\
42 \\
47 \\
43 \\
42 \\
39 \\
39 \\
37 \\
36\end{array}$ & $\begin{array}{l}518 \\
491 \\
881 \\
630 \\
514 \\
445 \\
413 \\
378 \\
345 \\
328\end{array}$ & $\begin{array}{l}21 \ldots \ldots \\
22 \ldots \ldots \\
23 \ldots \ldots \\
24 \ldots \ldots \\
25 \ldots \ldots \\
26 \ldots \ldots \\
27 \ldots \ldots \\
28 \ldots \ldots \\
29 \ldots \ldots \\
30 \ldots \ldots \\
31 \ldots \ldots\end{array}$ & $\begin{array}{r}35 \\
34 \\
33 \\
32 \\
31 \\
30 \\
28 \\
28 \\
37 \\
1,260 \\
11,900\end{array}$ & $\begin{array}{r}308 \\
283 \\
260 \\
245 \\
230 \\
214 \\
178 \\
167 \\
--.-- \\
---.-\end{array}$ \\
\hline I, & acre & & & & & & $\begin{array}{r}478 \\
4.87 \\
29,370 \\
\end{array}$ & $\begin{array}{r}874 \\
8.06 \\
48,550 \\
\end{array}$ \\
\hline
\end{tabular}

Gage height, in feet, and discharge, in cublo feet per second, at indicated time, 1963

\begin{tabular}{|c|c|c|c|c|c|c|c|c|c|c|c|}
\hline Date & Hour & $\begin{array}{c}\text { Gage } \\
\text { height }\end{array}$ & $\begin{array}{c}\text { Dis- } \\
\text { charge }\end{array}$ & Date & Hour & $\underset{\text { hage }}{\text { Gaght }}$ & $\begin{array}{c}\text { Dis- } \\
\text { charge }\end{array}$ & Date & Hour & $\begin{array}{c}\text { Gage } \\
\text { helght }\end{array}$ & $\begin{array}{c}\text { D1s- } \\
\text { charge }\end{array}$ \\
\hline n. $\begin{array}{r}29 \\
30\end{array}$ & $\begin{array}{l}2400 \\
0300 \\
0600 \\
0900 \\
1200 \\
1400 \\
1600 \\
1800 \\
2000 \\
2100 \\
2300 \\
2400 \\
0200 \\
0400 \\
0600 \\
\end{array}$ & $\begin{array}{r}3.53 \\
4.08 \\
4.73 \\
5.34 \\
5.92 \\
6.62 \\
7.36 \\
8.52 \\
10.24 \\
10.50 \\
10.70 \\
10.59 \\
10.31 \\
10.54 \\
11.54 \\
\end{array}$ & $\begin{array}{r}73 \\
143 \\
256 \\
402 \\
588 \\
890 \\
1,270 \\
1,970 \\
3,360 \\
3,590 \\
3,770 \\
3,670 \\
3,420 \\
3,630 \\
4,560 \\
\end{array}$ & Jan. 31 & $\begin{array}{l}0800 \\
1000 \\
1200 \\
1400 \\
1600 \\
1700 \\
1800 \\
2000 \\
2200 \\
2400 \\
\\
0100 \\
0200 \\
0300 \\
0500 \\
0700 \\
1000 \\
\end{array}$ & $\begin{array}{l}13.45 \\
15.65 \\
18.50 \\
21.20 \\
22.90 \\
23.35 \\
23.05 \\
21.40 \\
19.90 \\
17.95 \\
16.50 \\
16.65 \\
16.93 \\
15.35 \\
14.05 \\
12.31\end{array}$ & $\begin{array}{r}6,700 \\
9,590 \\
13,600 \\
17,800 \\
20,500 \\
21,200 \\
20,800 \\
18,100 \\
15,700 \\
12,800 \\
10,800 \\
11,000 \\
11,400 \\
9,170 \\
7,460 \\
5,510 \\
\end{array}$ & Feb. 1 & $\begin{array}{l}1300 \\
1600 \\
1700 \\
1800 \\
2000 \\
2100 \\
2400 \\
\\
0400 \\
0500 \\
1100 \\
1200 \\
1200 \\
1300 \\
1600 \\
2400\end{array}$ & $\begin{array}{r}11.35 \\
10.80 \\
10.72 \\
10.81 \\
11.29 \\
11.23 \\
10.71 \\
10.05 \\
9.89 \\
9.34 \\
9.22 \\
9.31 \\
9.15 \\
8.87 \\
8.48\end{array}$ & $\begin{array}{l}4,580 \\
4,080 \\
4,010 \\
4,090 \\
4,520 \\
4,470 \\
4,000 \\
3,410 \\
3,260 \\
2,810 \\
2,720 \\
2,790 \\
2,660 \\
2,440 \\
2,140\end{array}$ \\
\hline
\end{tabular}

11-4065. West Branch Feather River near Yankee Hill, Calif.

Location.--Lat $39^{\circ} 41^{\prime} 55^{\prime \prime}$, long $121^{\circ} 33^{\prime} 38^{\prime \prime}$, in SE $\frac{1}{4} \mathrm{SE} \frac{1}{4}$ sec.6, T.21 N., R.4 E., on right bank $800 \mathrm{ft}$ upstream from highway bridge, 1.7 miles downstream from Concow Creek, 2.1 miles west of Yankee Hill, and 4.9 miles southeast of Paradise.

Drainage area. --149 sq $\mathrm{mi}$.

Gage-height record --Water-stage recorder graph. Altitude of gage is $650 \mathrm{ft}$ (from topographic map).

Discharge record.--Stage-discharge relation defined by current-meter measurements.

Maxima.--January-February 1963: Discharge, 21,300 cf's 1800 hours Jan. 31 (gage height, $30.15 \mathrm{ft}$, from recorder graph; $30.45 \mathrm{ft}$, from floodmarks).

1930 to December 1962: Discharge, 21,400 cf's Dec. 11, 1937 (gage height, $30.3 \mathrm{ft}^{\mathrm{t}}$ ).

Remarks.--Flow regulated by Round Valley Reservoir, Philbrook Reservoir, and Lake Wilenor (combined capacity, 19,100 acre-ft). 
Mean discharge, in cubic feet per second, 1963, of West Branch Feather R1ver near

\begin{tabular}{|c|c|c|c|c|c|c|c|c|}
\hline Day & January & February & Day & January & February & Day & January & February \\
\hline $\begin{array}{c}1 \ldots \ldots \\
2 \ldots \ldots \\
4 \ldots \ldots \\
5 \ldots \ldots \\
6 \ldots \ldots \\
8 \ldots \ldots \\
9 \ldots \ldots \\
10 \ldots \ldots\end{array}$ & $\begin{array}{r}161 \\
148 \\
140 \\
137 \\
116 \\
101 \\
91 \\
87 \\
76 \\
72\end{array}$ & $\begin{array}{r}7,430 \\
3,060 \\
2,110 \\
1,500 \\
1,240 \\
952 \\
768 \\
741 \\
696 \\
654\end{array}$ & $\begin{array}{l}11 \ldots \ldots \\
12 \ldots \ldots \\
13 \ldots \ldots \\
14 \ldots \ldots \\
15 \ldots \ldots \\
16 \ldots \ldots \\
17 \ldots \ldots \\
18 \ldots \ldots \\
19 \ldots \ldots \\
20 \ldots \ldots\end{array}$ & $\begin{array}{l}66 \\
52 \\
55 \\
60 \\
58 \\
55 \\
53 \\
51 \\
47 \\
44\end{array}$ & $\begin{array}{l}565 \\
538 \\
940 \\
840 \\
660 \\
558 \\
518 \\
458 \\
408 \\
378 .\end{array}$ & $\begin{array}{l}21 \ldots \ldots \\
22 \ldots \ldots \\
23 \ldots \ldots \\
24 \ldots \ldots \\
25 \ldots \ldots \\
26 \ldots \ldots \\
27 \ldots \ldots \\
28 \ldots \ldots \\
29 \ldots \ldots \\
30 \ldots \ldots \\
31 \ldots \ldots\end{array}$ & $\begin{array}{r}46 \\
44 \\
43 \\
41 \\
40 \\
39 \\
38 \\
37 \\
43 \\
1,210 \\
11,900\end{array}$ & $\begin{array}{r}353 \\
312 \\
288 \\
270 \\
252 \\
240 \\
202 \\
174 \\
---- \\
-----\end{array}$ \\
\hline \multicolumn{7}{|l|}{$\begin{array}{l}\text { Monthly } \\
\text { Runoff, } \\
\text { Runoff, }\end{array}$} & $\begin{array}{r}489 \\
3.78 \\
30,050 \\
\end{array}$ & $\begin{array}{r}968 \\
6.77 \\
53,760 \\
\end{array}$ \\
\hline
\end{tabular}

Gage he1ght, in feet, and discharge, in cublc feet per second, at indicated time, 1963

\begin{tabular}{|c|c|c|c|c|c|c|c|c|c|c|c|}
\hline Date & Hour & $\begin{array}{c}\text { Gage } \\
\text { helght }\end{array}$ & $\begin{array}{c}\text { D1s- } \\
\text { charge }\end{array}$ & Date & Hour & $\begin{array}{c}\text { Gage } \\
\text { helght }\end{array}$ & $\begin{array}{l}\text { Dis- } \\
\text { charge }\end{array}$ & Date & Hour & $\begin{array}{c}\text { Gage } \\
\text { helght }\end{array}$ & $\begin{array}{c}\text { Dis - } \\
\text { charge }\end{array}$ \\
\hline $\begin{array}{r}\text { Jan. } 29 \\
30\end{array}$ & $\begin{array}{l}2400 \\
0300 \\
0500 \\
0900 \\
1400 \\
1700 \\
1800 \\
1900 \\
2100 \\
2200 \\
2300 \\
2400 \\
0100 \\
\end{array}$ & $\begin{array}{r}3.20 \\
3.65 \\
4.15 \\
5.56 \\
7.19 \\
8.52 \\
8.72 \\
9.20 \\
11.25 \\
12.00 \\
12.30 \\
12.35 \\
12.52 \\
\end{array}$ & $\begin{array}{r}68 \\
120 \\
205 \\
500 \\
1,010 \\
1,540 \\
1,640 \\
1,880 \\
3,140 \\
3,660 \\
3,880 \\
3,920 \\
4,060\end{array}$ & Feb. 1 & $\begin{array}{l}0300 \\
0400 \\
0600 \\
0800 \\
1000 \\
1200 \\
1400 \\
1600 \\
1800 \\
2000 \\
2200 \\
2400 \\
0300 \\
0400\end{array}$ & $\begin{array}{l}12.23 \\
12.22 \\
12.85 \\
14.75 \\
17.80 \\
20.95 \\
25.50 \\
28.40 \\
30.15 \\
29.05 \\
26.70 \\
24.60 \\
21.07 \\
21.30\end{array}$ & $\begin{array}{r}3,820 \\
3,820 \\
4,320 \\
5,980 \\
8,720 \\
11,800 \\
16,300 \\
19,300 \\
21,300 \\
20,100 \\
17,500 \\
15,400 \\
11,900 \\
12,100\end{array}$ & Feb. & $\begin{array}{l}0600 \\
0800 \\
1100 \\
1300 \\
1500 \\
1800 \\
1900 \\
2200 \\
2400 \\
\\
0500 \\
0800 \\
1500 \\
2000 \\
2400 \\
\end{array}$ & $\begin{array}{r}18.95 \\
17.55 \\
15.15 \\
14.15 \\
13.57 \\
12.85 \\
12.80 \\
13.40 \\
12.99 \\
11.96 \\
11.44 \\
10.60 \\
10.17 \\
9.89 \\
\end{array}$ & $\begin{array}{l}9,760 \\
8,500 \\
6,340 \\
5,440 \\
4,910 \\
4,320 \\
4,280 \\
4,760 \\
4,430 \\
3,630 \\
3,270 \\
2,690 \\
2,430 \\
2,260 \\
\end{array}$ \\
\hline
\end{tabular}

11-4070. Feather River at .Oroville, Calif.

Location.--Lat $39^{\circ} 31^{\prime} 06^{\prime \prime}$, long $121^{\circ} 32^{\prime} 57^{\prime \prime}$, in SW $\frac{1}{4}$ sec.8, T.19 N., R.4 E., on right bank $200 \mathrm{ft}$ downstream from bridge on Oroville-Chico highway and $0.4 \mathrm{mile}$ northeast of Oroville business district.

Drainage area. $--3,632 \mathrm{sq} \mathrm{ml}$.

Gage-height record.--Water-stage recorder graph, except Feb. 14-28. Datum of gage is at mean sea level, datum of 1929 .

Discharge record.--Stage-discharge relation defined by current-meter measurements below 85,000 cf's and extended above on basis of floodmarks at $166.4 \mathrm{ft}$ gage height (present gage site) for flood of Dec. 23, 1955, and well-defined peak discharge of $203,000 \mathrm{cf}$ 's for that flood. Discharge for Feb. 14-28 was estimeted on basis of record for discontinued station "near 0roville."

Naxima.--January-Febmuary 1963: Discharge, 191,000 cfs 2100 hours Jan. 31 (gage height, $165.37 \mathrm{ft}^{\mathrm{t}}$ ).

1901 to December 1962: Discharge, 230,000 cfs Mar. 19, 1907 (gage height, $167.5 \mathrm{ft}$, reading from U.S. Weather Bureau staff gage at bridge; probably had been higher during night).

Remarks.--Flow partly regulated by powerplants and reservolrs above station.

Wean discharge, in cublc feet per second, 1963

\begin{tabular}{|c|c|c|c|c|c|c|c|c|}
\hline Day & January & February & Day & January & February & Day & January & February \\
\hline $\begin{array}{r}1 \ldots \ldots \\
2 \ldots \ldots \\
3 \ldots \ldots \\
4 \ldots \ldots \\
5 \ldots \ldots \\
6 \ldots \ldots \\
8 \ldots \ldots \\
9 \ldots \ldots \\
10 \ldots \ldots\end{array}$ & $\begin{array}{l}3,560 \\
3,580 \\
3,530 \\
3,630 \\
3,730 \\
3,180 \\
3,060 \\
3,180 \\
2,840 \\
2,900\end{array}$ & $\begin{array}{r}125,000 \\
61,900 \\
36,600 \\
24,900 \\
20,400 \\
16,800 \\
14,500 \\
13,200 \\
12,000 \\
10,900\end{array}$ & $\begin{array}{l}11 \ldots \ldots \\
12 \ldots \ldots \\
13 \ldots \ldots \\
14 \ldots \ldots \\
15 \ldots \ldots \\
16 \ldots \ldots \\
17 \ldots \ldots \\
18 \ldots \ldots \\
19 \ldots \ldots \\
20 \ldots \ldots\end{array}$ & $\begin{array}{l}3,260 \\
2,190 \\
2,160 \\
2,780 \\
2,710 \\
2,590 \\
2,370 \\
2,420 \\
2,360 \\
2,300\end{array}$ & $\begin{array}{r}10,300 \\
10,000 \\
11,700 \\
11,600 \\
10,400 \\
9,800 \\
9,200 \\
8,400 \\
8,100 \\
7,800\end{array}$ & $\begin{array}{l}21 \ldots \ldots \\
22 \ldots \ldots \\
23 \ldots \ldots \\
24 \ldots \ldots \\
25 \ldots \ldots \\
26 \ldots \ldots \\
27 \ldots \ldots \\
28 \ldots \ldots \\
29 \ldots \ldots \\
30 \ldots \ldots \\
31 \ldots \ldots\end{array}$ & $\begin{array}{r}2,460 \\
2,610 \\
2,670 \\
2,370 \\
2,600 \\
2,330 \\
2,470 \\
2,530 \\
2,760 \\
7,310 \\
84,700\end{array}$ & $\begin{array}{r}7,800 \\
7,000 \\
6,800 \\
6,600 \\
6,100 \\
5,700 \\
6,000 \\
5,400 \\
----- \\
----- \\
\end{array}$ \\
\hline \multicolumn{7}{|c|}{$\begin{array}{l}\text { Monthly } \\
\text { Runoff, } \\
\text { Runoff, }\end{array}$} & $\begin{array}{r}5,585 \\
1.77 \\
343,400 \\
\end{array}$ & $\begin{array}{r}17,320 \\
4.97 \\
961,800 \\
\end{array}$ \\
\hline
\end{tabular}


Gage height, in feet, and discharge, in cubic feet per second, at indicated time, 1963, of

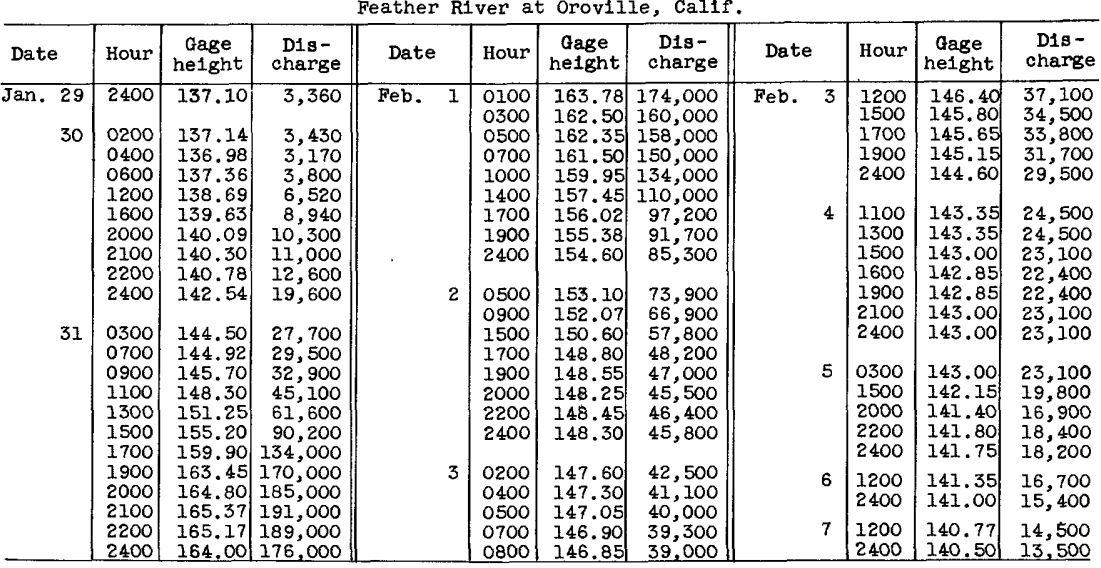

11-4074. Wyman Ravine tributary near Palermo, Calif.

(Crest-stage station)

Location.--Lat $39^{\circ} 22^{\prime} 57^{\prime \prime}$, long $121^{\circ} 34143^{\prime \prime}$, in $\mathrm{SE}_{\frac{1}{4}}$ sec.25, T.18 N., R.3 E., on county road 4.1 miles southwest of Palermo.

Drainage area. $--1.72 \mathrm{sq} \mathrm{mi}$.

Gage-height record.--Crest stages only. Altitude of gage is $99 \mathrm{ft}$ (from topographic map).

Discharge record.--Stage-discharge relation defined by current-meter measurements below $45 \mathrm{cf}$ 's and by computation of flow through culverts above, including computation of flow over road at stages above $13.19 \mathrm{ft}$.

Maxima.--January-February 1963: Discharge, $43 \mathrm{cfs}$ Feb. 1 (gage height, $11.17 \mathrm{ft}$ ). 1959 to December 1962: Discharge, $260 \mathrm{cfs}$ 0ct. 13, 1962 (gage height, $13.70 \mathrm{ft})$.

11-4075. South Honcut Creek near Bangor, Calif.

Location.--Lat $39^{\circ} 22^{\prime} 05^{\prime \prime}$, long $121^{\circ} 22^{\prime} 1^{\prime \prime}$, in SE $\frac{1}{4}$ sec.35, T.18 N., R.5 E., on right bank 2.3 miles southeast of Bangor and 3.3 miles upstream from Tennessee Creek.

Drainage area. $--30.5 \mathrm{sq} \mathrm{mi}$.

Gage-height record :-Water-stage recorder graph. Altitude of gage is $620 \mathrm{ft}$ (from topographic map).

Discharge record.--Stage-discharge relation defined by current-meter measurements below 2,200 cf's and by slope-area measurement at 6,340 cfs.

Maxima.--January-February 1963: Discharge, 2,100 cfs 2200 hours Jan. 30 (gage height, $7.85 \mathrm{ft}$ ).

1950 to December 1962: Discharge, 8,280 cfs 0ct. 13, 1962 (gage height, $12.40 \mathrm{ft}$ ). 
Mean discharge, in cublc feet per second, 1963, of South Honcut Creek near Bangor, Calif.

\begin{tabular}{|c|c|c|c|c|c|c|c|c|}
\hline Day & January & February & Day & January & Pebruary & Day & January & February \\
\hline $\begin{array}{c}1 \ldots \ldots \\
2 \ldots \ldots \\
3 \ldots \ldots \\
4 \ldots \ldots \\
5 \ldots \ldots \\
7 \ldots \ldots \\
8 \ldots \ldots \\
9 \ldots \ldots \\
10 \ldots \ldots\end{array}$ & $\begin{array}{l}10 \\
10 \\
9.7 \\
9.4 \\
8.8 \\
8.4 \\
7.8 \\
7.8 \\
7.5 \\
7.5\end{array}$ & $\begin{array}{r}350 \\
156 \\
109 \\
81 \\
66 \\
53 \\
45 \\
49 \\
44 \\
43\end{array}$ & $\begin{array}{l}11 \ldots \ldots \\
12 \ldots \ldots \\
13 \ldots \ldots \\
14 \ldots \ldots \\
15 \ldots \ldots \\
16 \ldots \ldots \\
17 \ldots \ldots \\
18 \ldots \ldots \\
19 \ldots \ldots \\
20 \ldots \ldots\end{array}$ & $\begin{array}{l}7.0 \\
6.8 \\
6.5 \\
6.5 \\
6.5 \\
6.5 \\
6.5 \\
6.5 \\
6.2 \\
6.2\end{array}$ & $\begin{array}{r}35 \\
55 \\
190 \\
96 \\
69 \\
57 \\
54 \\
44 \\
37 \\
34\end{array}$ & $\begin{array}{l}21 \ldots \ldots \\
22 \ldots \ldots \\
23 \ldots \ldots \\
24 \ldots \ldots \\
25 \ldots \ldots \\
26 \ldots \ldots \\
27 \ldots \ldots \\
28 \ldots \ldots \\
29 \ldots \ldots \\
30 \ldots \ldots \\
31 \ldots \ldots\end{array}$ & $\begin{array}{r}6.2 \\
6.2 \\
6.8 \\
7.3 \\
7.0 \\
7.0 \\
7.0 \\
7.3 \\
9.4 \\
609 \\
1,400\end{array}$ & $\begin{array}{r}31 \\
28 \\
26 \\
25 \\
23 \\
22 \\
20 \\
18 \\
-\ldots--\end{array}$ \\
\hline $\begin{array}{l}\text { onthly } \\
\text { unoff, } \\
\text { unoff, }\end{array}$ & \multicolumn{6}{|c|}{ 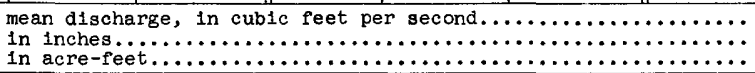 } & $\begin{array}{r}71.8 \\
2.71 \\
4,410\end{array}$ & $\begin{array}{r}66.4 \\
2.27 \\
3,690\end{array}$ \\
\hline
\end{tabular}

Gage height, in feet, and discharge, in cublc feet per second, at Indicated time, 1963

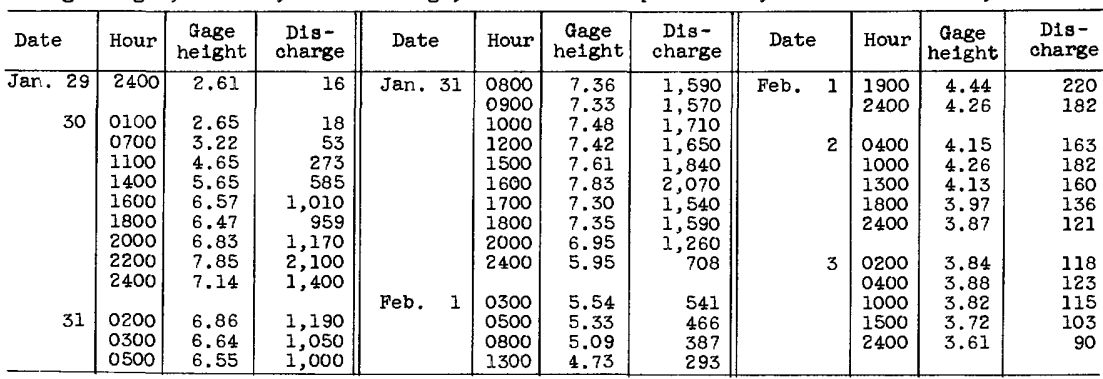

11-4085. Middle Yuba River at Milton, Calif.

Location.--Lat $39^{\circ} 31^{1} 22^{\prime \prime}$, long $120^{\circ} 35^{\prime} 01^{\prime \prime}$, in SW $\frac{1}{4}$ sec.12, T.19 N., R.12 E., on right bank at diversion dam of Nevada Irrigation District, at old townsite of Milton, 4 miles southeast of Sierra City, and 8 miles upstream from South Fork of Middle Yuba River.

Drainage area. $--39.8 \mathrm{sq} \mathrm{mi}$.

Gage-height record. - Water-stage recorder graph, except 1700 hours Feb. 3 to 1400 hours Feb. 6. Datum of gage is $5,689.97 \mathrm{ft}$ above mean sea level (datum of 1929).

Discharge record.--Stage-discharge relation defined by current-meter measurements below 1,500 cf's. Discharge for period Feb. 3-6 estimated on bas is of fragmentary gage-height record, recorded range in stage, and records for Haypress Creek near Sierra city. Maxima.--January-February 1963: Discharge, 10,200 cfs 1900 hours Jan. 31 (gage

1925 to December 1962: Discharge, 6,800 cfs Dec. 11, 1937 (gage height, $4.18 \mathrm{ft}$ ).

Remarks.--Milton-Bowman tunnel diverts practically all of low and medium flow into Bowman Lake above station.

Mean discharge, in cublc feet per second, 1963

\begin{tabular}{|c|c|c|c|c|c|c|c|c|}
\hline Day & January & February & Day & January & February & Day & J anuary & February \\
\hline $\begin{array}{c}1 \ldots \ldots \\
2 \ldots \ldots \\
3 \ldots \ldots \\
4 \ldots \ldots \\
5 \ldots \ldots \\
6 \ldots \ldots \\
7 \ldots \ldots \\
8 \ldots \ldots \\
9 \ldots \ldots \\
10 \ldots \ldots\end{array}$ & $\begin{array}{l}0 \\
0 \\
0 \\
0 \\
0 \\
0 \\
0 \\
0 \\
0 \\
0\end{array}$ & $\begin{array}{r}2,760 \\
804 \\
610 \\
520 \\
420 \\
250 \\
0 \\
0 \\
0 \\
0\end{array}$ & $\begin{array}{l}11 \ldots \ldots \\
12 \ldots \ldots \\
13 \ldots \ldots \\
14 \ldots \ldots \\
15 \ldots \ldots \\
16 \ldots \ldots \\
17 \ldots \ldots \\
18 \ldots \ldots \\
19 \ldots \ldots \\
20 \ldots \ldots\end{array}$ & $\begin{array}{l}0 \\
0 \\
0 \\
0 \\
0 \\
0 \\
0 \\
0 \\
0 \\
0\end{array}$ & $\begin{array}{l}0 \\
0 \\
0 \\
0 \\
0 \\
0 \\
0 \\
0 \\
0 \\
0\end{array}$ & $\begin{array}{l}21 \ldots \ldots \\
22 \ldots \ldots \\
23 \ldots \ldots \\
24 \ldots \ldots \\
25 \ldots \ldots \\
26 \ldots \ldots \\
27 \ldots \ldots \\
28 \ldots \ldots \\
29 \ldots \ldots \\
30 \ldots \ldots \\
31 \ldots \ldots\end{array}$ & $\begin{array}{r}0 \\
0 \\
0 \\
0 \\
0 \\
0 \\
0 \\
0 \\
0 \\
315 \\
5,660\end{array}$ & $\begin{array}{r}0 \\
0 \\
0 \\
0 \\
0 \\
0 \\
0 \\
0 \\
------ \\
---1\end{array}$ \\
\hline \multicolumn{7}{|c|}{$\begin{array}{l}\text { Monthly mear } \\
\text { Runoff, in } \\
\text { Runoff, in }\end{array}$} & $\begin{array}{r}193 \\
5.58 \\
11,850 \\
\end{array}$ & $\begin{array}{r}192 \\
5.01 \\
10,640 \\
\end{array}$ \\
\hline
\end{tabular}


Gage helght, in feet, and discharge, in cub1c feet per second, at indicated time, 1963, of Middle Yuba River at Milton, Cal1f.

\begin{tabular}{|c|c|c|c|c|c|c|c|c|c|c|c|}
\hline Date & Hour & $\begin{array}{c}\text { Gage } \\
\text { helght }\end{array}$ & $\begin{array}{c}\text { D1s- } \\
\text { charge }\end{array}$ & Date & Hour & $\begin{array}{c}\text { Gage } \\
\text { he1ght }\end{array}$ & $\begin{array}{l}\text { Dis- } \\
\text { charge }\end{array}$ & Date & Hour & $\begin{array}{c}\text { Gage } \\
\text { helght }\end{array}$ & $\begin{array}{c}\text { Dis- } \\
\text { charge }\end{array}$ \\
\hline $\begin{array}{r}\text { Jan. } 29 \\
30\end{array}$ & $\begin{array}{l}2400 \\
1200 \\
1400 \\
1600 \\
2000 \\
2100 \\
2400 \\
\end{array}$ & $\begin{array}{r}0.76 \\
.76 \\
.19 \\
.71 \\
1.31 \\
1.40 \\
1.30 \\
\end{array}$ & $\begin{array}{r}0 \\
0 \\
0 \\
386 \\
1,030 \\
1,150 \\
1,020\end{array}$ & Jan. 31 & $\begin{array}{l}0200 \\
0600 \\
0800 \\
1200 \\
1900 \\
2400 \\
\\
0600\end{array}$ & $\begin{array}{l}1.35 \\
1.80 \\
2.43 \\
4.08 \\
5.25 \\
4.53 \\
\\
2.52\end{array}$ & $\begin{array}{r}1,080 \\
1,730 \\
2,840 \\
6,680 \\
10,200 \\
7,960 \\
3,010\end{array}$ & Feb. & $\begin{array}{l}0800 \\
1100 \\
1700 \\
2400 \\
1200 \\
2400\end{array}$ & $\begin{array}{l}2.12 \\
1.86 \\
1.92 \\
1.36 \\
1.04 \\
1.02\end{array}$ & $\begin{array}{r}2,270 \\
1,830 \\
1,920 \\
1,100 \\
714 \\
692\end{array}$ \\
\hline
\end{tabular}

11-4087. Midale Yuba River near Alleghany, Calif.

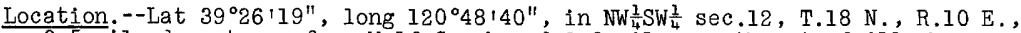
$0.5 \mathrm{mile}$ downstream from Wolf Creek and $2.8 \mathrm{miles}$ southeast of Alieghany.

Drainage area. $--96.3 \mathrm{sq} \mathrm{mi}$.

Gage-height record.--Water-stage recorder graph. Altitude of gage is $2,960 \mathrm{ft}$ (from topographic map).

Discharge record.--Stage-discharge relation defined by current-meter measurements below 2,100 cfs and by slope-area measurements at 6,300 and $23,700 \mathrm{cf}$.

Maxima.--January-February 1963: Dishcarge, 23,700 cfs 2200 hours Jan. 31 (gage height, $18.95 \mathrm{ft}$, from recorder graph; $19.3 \mathrm{ft}$, from floodmarks).

1957 to December 1962: Discharge, 9,870 cfs 0ct. 13, 1962 (gage he1ght, $12.68 \mathrm{ft}$ ).

Remarks.--Flow slightly affected by Milton-Bowman tunnel diversion to Bowman Lake.

Mean discharge, in cublc feet per second, 1963

\begin{tabular}{|c|c|c|c|c|c|c|c|c|}
\hline Day & January & February & Day & January & February & Day & January & February \\
\hline $\begin{array}{c}1 \ldots \ldots \\
2 \ldots \ldots \\
3 \ldots \ldots \\
4 \ldots \ldots \\
5 \ldots \ldots \\
6 \ldots \ldots \\
7 \ldots \ldots \\
9 \ldots \ldots \\
10 \ldots \ldots\end{array}$ & $\begin{array}{r}101 \\
96 \\
93 \\
91 \\
87 \\
84 \\
81 \\
79 \\
78 \\
76\end{array}$ & $\begin{array}{r}9,850 \\
3,200 \\
1,920 \\
1,420 \\
1,160 \\
816 \\
438 \\
366 \\
320 \\
299\end{array}$ & $\begin{array}{l}11 \ldots \ldots \\
12 \ldots \ldots \\
13 \ldots \ldots \\
14 \ldots \ldots \\
15 \ldots \ldots \\
16 \ldots \ldots \\
17 \ldots \ldots \\
18 \ldots \ldots \\
19 \ldots \ldots \\
20 \ldots \ldots\end{array}$ & $\begin{array}{l}66 \\
62 \\
70 \\
69 \\
65 \\
66 \\
64 \\
63 \\
60 \\
60\end{array}$ & $\begin{array}{l}258 \\
240 \\
366 \\
296 \\
255 \\
235 \\
220 \\
200 \\
186 \\
177\end{array}$ & $\begin{array}{l}21 \ldots \ldots \\
22 \ldots \ldots \\
23 \ldots \ldots \\
24 \ldots \ldots \\
25 \ldots \ldots \\
26 \ldots \ldots \\
27 \ldots \ldots \\
28 \ldots \ldots \\
29 \ldots \ldots \\
30 \ldots \ldots \\
31 \ldots \ldots\end{array}$ & $\begin{array}{r}59 \\
58 \\
57 \\
57 \\
56 \\
55 \\
54 \\
54 \\
59 \\
829 \\
11,800\end{array}$ & $\begin{array}{r}168 \\
154 \\
140 \\
131 \\
124 \\
120 \\
113 \\
107 \\
----- \\
---.--\end{array}$ \\
\hline \multicolumn{7}{|c|}{ 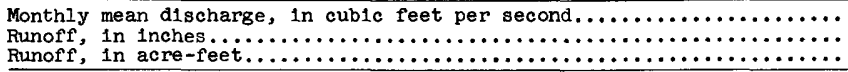 } & $\begin{array}{r}473 \\
5.66 \\
29,060 \\
\end{array}$ & $\begin{array}{r}831 \\
8.99 \\
46,170 \\
\end{array}$ \\
\hline
\end{tabular}

Gage height, In feet, and discharge, In cublc feet per second, at Indicated time, 1963

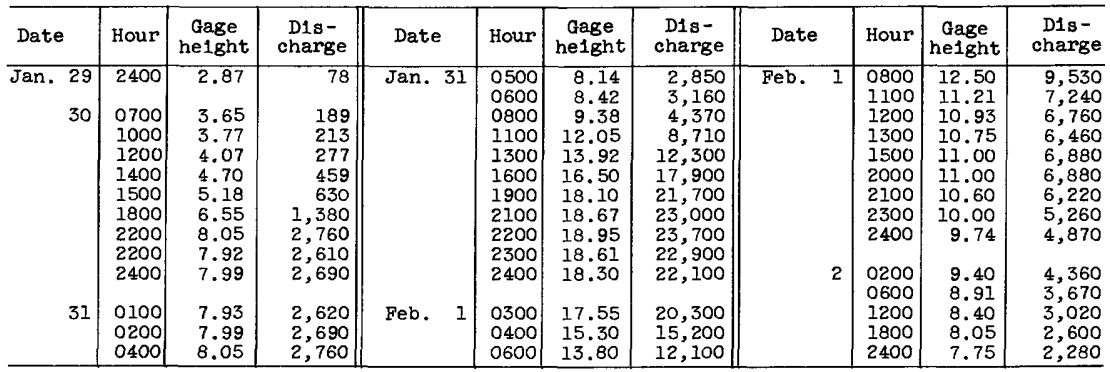


11-4090. M1ddle Yuba River above Oregon Creek, Calif.

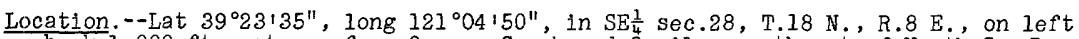
bank $1,000 \mathrm{ft}$ upstream from Oregon Creek and 2 miles northeast of North San Juan.

Dipainage area. $--162 \mathrm{sq} \mathrm{m} 1$.

Gage-helght record.--Water-stage recorder graph, except 2400 hours on Jan. 31 which was obtained from floodmark in well. Altitude of gage is 1,440 ft (from topographic map).

Discharge record. --Stage-discharge relation defined by current-meter measurements below 8,200 cf's and by slope-area measurement at 19,500 cfs.

Maxima --January-February 1963: Discharge, 31,600 of's 2400 hours Jan. 31 (gage helght, $18.55 \mathrm{ft}$, from floodmark in weli).

1910 to December 1962: Discharge, 26,400 efs Dec. 22, 1955 (gage height, $17.25 \mathrm{ft}$ ).

Remarks.--Flow slightly affected by Milton-Bowman tunnel diversion to Bowman Lake.

Mean discharge, in cubic feet per second, 1963

\begin{tabular}{|c|c|c|c|c|c|c|c|c|}
\hline Day & January & February & Day & January & February & Day & January & February \\
\hline $\begin{array}{c}1 \ldots \ldots \\
2 \ldots \ldots \\
3 \ldots \ldots \\
4 \ldots \ldots \\
5 \ldots \ldots \\
7 \ldots \ldots \\
8 \ldots \ldots \\
9 \ldots \ldots \\
10 \ldots \ldots\end{array}$ & $\begin{array}{l}144 \\
136 \\
130 \\
128 \\
123 \\
119 \\
114 \\
110 \\
107 \\
105\end{array}$ & $\begin{array}{r}15,200 \\
4,850 \\
2,670 \\
1,900 \\
1,620 \\
1,160 \\
823 \\
705 \\
631 \\
582\end{array}$ & $\begin{array}{l}11 \ldots \ldots \\
12 \ldots \ldots \\
13 \ldots \ldots \\
14 \ldots \ldots \\
15 \ldots \ldots \\
16 \ldots \ldots \\
17 \ldots \ldots \\
18 \ldots \ldots \\
19 \ldots \ldots \\
20 \ldots \ldots\end{array}$ & $\begin{array}{r}100 \\
84 \\
104 \\
110 \\
104 \\
92 \\
91 \\
88 \\
84 \\
86\end{array}$ & $\begin{array}{l}523 \\
481 \\
823 \\
690 \\
572 \\
514 \\
489 \\
445 \\
418 \\
400\end{array}$ & $\begin{array}{l}21 \ldots \ldots \\
22 \ldots \ldots \\
23 \ldots \ldots \\
24 \ldots \ldots \\
25 \ldots \ldots \\
26 \ldots \ldots \\
27 \ldots \ldots \\
28 \ldots \ldots \\
29 \ldots \ldots \\
30 \ldots \ldots \\
31 \ldots \ldots\end{array}$ & $\begin{array}{r}84 \\
82 \\
80 \\
80 \\
79 \\
76 \\
75 \\
75 \\
84 \\
927 \\
12,800\end{array}$ & $\begin{array}{r}376 \\
362 \\
339 \\
320 \\
305 \\
296 \\
281 \\
266 \\
----- \\
-----\end{array}$ \\
\hline \multicolumn{7}{|l|}{$\begin{array}{l}\text { Monthly } \\
\text { Runoff, } \\
\text { Runoff, }\end{array}$} & $\begin{array}{r}536 \\
3.81 \\
32,930 \\
\end{array}$ & $\begin{array}{r}1,359 \\
8.73 \\
75,450 \\
\end{array}$ \\
\hline
\end{tabular}

Gage helght, in feet, and discharge, in cublc feet per second, at indicated time, 1963

\begin{tabular}{|c|c|c|c|c|c|c|c|c|c|c|c|}
\hline Date & Hour & $\begin{array}{c}\text { Gage } \\
\text { he1ght }\end{array}$ & $\begin{array}{c}\text { D1s- } \\
\text { charge }\end{array}$ & Date & Hour & $\begin{array}{c}\text { Gage } \\
\text { helght }\end{array}$ & $\begin{array}{c}\text { D1s- } \\
\text { charge }\end{array}$ & Date & Hour & $\begin{array}{c}\text { Gage } \\
\text { helght }\end{array}$ & $\begin{array}{c}\text { Dis - } \\
\text { charge }\end{array}$ \\
\hline $\begin{array}{rr}\text { Jan. } & 29 \\
30\end{array}$ & $\begin{array}{l}2400 \\
0500 \\
0800 \\
1200 \\
1500 \\
1600 \\
2300 \\
2400 \\
0100\end{array}$ & $\begin{array}{l}3.00 \\
3.17 \\
3.50 \\
4.47 \\
4.83 \\
5.00 \\
7.86 \\
8.10 \\
8.45\end{array}$ & $\begin{array}{r}102 \\
130 \\
195 \\
518 \\
675 \\
760 \\
3,210 \\
3,510 \\
3,970\end{array}$ & Jan. 31 & $\begin{array}{l}0200 \\
0600 \\
0800 \\
1200 \\
1800 \\
2400 \\
\\
0800 \\
1500 \\
1700 \\
2000\end{array}$ & $\begin{array}{r}8.25 \\
8.43 \\
8.63 \\
11.00 \\
16.00 \\
18.55 \\
14.00 \\
11.20 \\
11.05 \\
11.50\end{array}$ & $\begin{array}{r}3,700 \\
3,940 \\
4,220 \\
8,440 \\
21,900 \\
31,600 \\
16,100 \\
9,380 \\
9,060 \\
10,000\end{array}$ & Feb. 1 & $\begin{array}{l}2300 \\
2400 \\
\\
0400 \\
0700 \\
1300 \\
1400 \\
2100 \\
2400\end{array}$ & $\begin{array}{l}11.00 \\
10.70 \\
9.54 \\
9.00 \\
8.33 \\
8.31 \\
7.67 \\
7.55\end{array}$ & $\begin{array}{l}8,960 \\
8,350 \\
6,200 \\
5,310 \\
4,300 \\
4,270 \\
3,400 \\
3,240\end{array}$ \\
\hline
\end{tabular}

11-4095. Oregon Creek near North San Juan, Calif.

Location.--Lat $39^{\circ} 24^{\prime} 10^{\prime \prime}$, long $121^{\circ} 04^{\prime} 35^{\prime \prime}$, in NW $\frac{1}{4} N W \frac{1}{4}$ sec. 27, T.18 N., R. 8 E., on right bank 0.7 mile upstream from mouth and 2.7 miles northeast of North San Juan.

Drainage area. $--34.4 \mathrm{sq} \mathrm{mi}$.

Gage-helght record.--Digital-recorder tape punched at 15-minute intervals. Altitude of gage is $1,580 \mathrm{ft}$ (from topographic map).

Discharge record.--Stage-discharge relation defined by current-meter measurements.

Maxima.--January-February 1963: Discharge, 3,990 efs 2300 hours Jan. 31 (gage helght, $10.44 \mathrm{ft}$, from recorder tape; $11.9 \mathrm{ft}$, from floodmarks).

1911 to December 1962: Discharge, 5,390 cf's Dec. 22, 1955 (gage height, $11.90 \mathrm{ft})$. 
Mean discharge, in cuble feet per second, 1963, of Oregon Creek near North San Juan, Cal1f.

\begin{tabular}{|c|c|c|c|c|c|c|c|c|}
\hline Day & January & February & Day & January & February & Day & January & February \\
\hline $\begin{array}{c}1 \ldots \ldots \\
2 \ldots \ldots \\
3 \ldots \ldots \\
4 \ldots \ldots \\
5 \ldots \ldots \\
7 \ldots \ldots \\
8 \ldots \ldots \\
9 \ldots \ldots \\
10 \ldots \ldots \\
\end{array}$ & $\begin{array}{l}56 \\
53 \\
53 \\
50 \\
46 \\
44 \\
44 \\
42 \\
41 \\
41\end{array}$ & $\begin{array}{r}2,900 \\
1,360 \\
739 \\
499 \\
368 \\
288 \\
233 \\
200 \\
177 \\
160\end{array}$ & $\begin{array}{l}11 \ldots \ldots \\
12 \ldots \ldots \\
13 \ldots \ldots \\
14 \ldots \ldots \\
15 \ldots \ldots \\
16 \ldots \ldots \\
17 \ldots \ldots \\
18 \ldots \ldots \\
19 \ldots \ldots \\
20 \ldots \ldots\end{array}$ & $\begin{array}{l}35 \\
32 \\
34 \\
36 \\
32 \\
33 \\
30 \\
30 \\
29 \\
28\end{array}$ & $\begin{array}{l}142 \\
136 \\
340 \\
220 \\
180 \\
160 \\
147 \\
133 \\
122 \\
114\end{array}$ & $\begin{array}{l}21 \ldots \ldots \\
22 \ldots \ldots \\
23 \ldots \ldots \\
24 \ldots \ldots \\
25 \ldots \ldots \\
26 \ldots \ldots \\
27 \ldots \ldots \\
28 \ldots \ldots \\
29 \ldots \ldots \\
30 \ldots \ldots \\
31 \ldots \ldots\end{array}$ & $\begin{array}{r}29 \\
28 \\
26 \\
25 \\
26 \\
25 \\
25 \\
24 \\
30 \\
371 \\
2,200\end{array}$ & $\begin{array}{r}105 \\
98 \\
92 \\
87 \\
83 \\
76 \\
73 \\
72 \\
----\end{array}$ \\
\hline \multicolumn{7}{|c|}{ 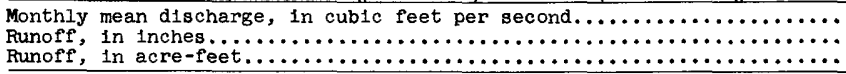 } & $\begin{array}{r}116 \\
3.88 \\
7,140\end{array}$ & $\begin{array}{r}332 \\
10.05 \\
18,450 \\
\end{array}$ \\
\hline
\end{tabular}

Gage helght, in feet, and discharge, in cubic feet per second, at indicated time, 1963

\begin{tabular}{|c|c|c|c|c|c|c|c|c|c|c|c|}
\hline Date & Hour & $\begin{array}{c}\text { Gage } \\
\text { helght }\end{array}$ & $\begin{array}{l}\text { Dis- } \\
\text { charge }\end{array}$ & Date & Hour & $\begin{array}{c}\text { Gage } \\
\text { helght }\end{array}$ & $\begin{array}{l}\text { Dis- } \\
\text { charge }\end{array}$ & Date & Hour & $\begin{array}{c}\text { Gage } \\
\text { height }\end{array}$ & $\begin{array}{l}\text { Dis- } \\
\text { charge }\end{array}$ \\
\hline $\begin{array}{r}\operatorname{Jan} .29 \\
30\end{array}$ & $\begin{array}{l}2400 \\
0200 \\
0400 \\
0600 \\
0800 \\
1000 \\
1200 \\
1400 \\
1600 \\
1800 \\
2000 \\
2200 \\
2400 \\
0200 \\
0400 \\
0600 \\
0800 \\
1000 \\
1200 \\
1400 \\
1600 \\
\end{array}$ & $\begin{array}{l}2.60 \\
2.70 \\
2.94 \\
3.25 \\
3.71 \\
4.23 \\
4.49 \\
4.75 \\
5.18 \\
5.99 \\
6.50 \\
6.64 \\
6.69 \\
6.49 \\
6.41 \\
6.47 \\
6.73 \\
7.64 \\
8.62 \\
9.28 \\
9.78 \\
\end{array}$ & $\begin{array}{r}41 \\
47 \\
63 \\
87 \\
130 \\
203 \\
248 \\
303 \\
407 \\
666 \\
870 \\
930 \\
955 \\
\\
866 \\
834 \\
858 \\
975 \\
1,500 \\
2,220 \\
2,770 \\
3,280 \\
\end{array}$ & Feb. 1 & $\begin{array}{l}1800 \\
2000 \\
2200 \\
2300 \\
2400 \\
0200 \\
0400 \\
0600 \\
0800 \\
1000 \\
1200 \\
1400 \\
1600 \\
1800 \\
2000 \\
2200 \\
2400 \\
0200 \\
0400 \\
0600 \\
0800\end{array}$ & $\begin{array}{r}9.96 \\
10.08 \\
10.10 \\
10.44 \\
10.16 \\
10.21 \\
10.06 \\
9.73 \\
9.26 \\
8.73 \\
8.43 \\
8.19 \\
8.80 \\
8.74 \\
8.62 \\
8.27 \\
7.97 \\
7.78 \\
7.53 \\
7.37 \\
7.24 \\
\end{array}$ & $\begin{array}{r}3,460 \\
3,570 \\
3,590 \\
3,990 \\
3,790 \\
3,820 \\
3,710 \\
3,470 \\
3,120 \\
2,700 \\
2,430 \\
2,230 \\
2,760 \\
2,710 \\
2,600 \\
2,300 \\
2,060 \\
1,910 \\
1,730 \\
1,620 \\
1,530\end{array}$ & Feb. 2 & $\begin{array}{l}1000 \\
1200 \\
1400 \\
1600 \\
1800 \\
2000 \\
2200 \\
2400 \\
\\
0200 \\
0400 \\
0600 \\
0800 \\
1000 \\
1200 \\
1400 \\
1600 \\
1800 \\
2000 \\
2200 \\
2400\end{array}$ & $\begin{array}{l}7.09 \\
6.92 \\
6.74 \\
6.54 \\
6.46 \\
6.38 \\
6.24 \\
6.15 \\
6.05 \\
6.03 \\
5.99 \\
5.96 \\
5.94 \\
5.87 \\
5.81 \\
5.72 \\
5.68 \\
5.62 \\
5.55 \\
5.49\end{array}$ & $\begin{array}{r}1,420 \\
1,320 \\
1,210 \\
1,100 \\
1,050 \\
1,010 \\
935 \\
890 \\
\\
840 \\
830 \\
810 \\
795 \\
785 \\
752 \\
724 \\
684 \\
666 \\
639 \\
610 \\
586\end{array}$ \\
\hline
\end{tabular}

11-4104. Haypress Creek near Sierra C1ty, Calif.

Location.--Lat $39^{\circ} 33^{\prime} 50^{\prime \prime}$, long $120^{\circ} 32^{\prime} 50^{\prime \prime}$, in NW $\frac{1}{4} \mathrm{NW} \frac{1}{4}$ 8ec.32, T.20 N., R.13 E., $0.4 \mathrm{mile}$ downstream from Dead Horse Canyon and 4.5 miles east of Sierra City.

Drainage area. $-18.2 \mathrm{sq} \mathrm{mi}$.

Gage-helght record.--Water-stage recorder graph. Altitude of gage is 5,840 ft (from topographic map).

Discharge record.--Stage-discharge relation defined by current-meter measurements below $180 \mathrm{cfs}$ and by computed flow over weir at 573 and $3,100 \mathrm{cfs}$; affected by 1ce Jan. 1 to Feb. 7, Feb. 13, 15-21, 26, 27 .

Maxima.--January-February 1963: Discharge, 3,100 cfs 2300 hours Jan. 31 (gage helght, $3.75 \mathrm{ft}$, from recorder graph; $5.2 \mathrm{ft}$, from floodmark 8 ).

1960 to December 1962: Discharge, 573 cfs oct. 13, 1962 (gage helght, $1.85 \mathrm{ft})$.

Mean discharge, in cubic feet per second, 1963

\begin{tabular}{|c|c|c|c|c|c|c|c|c|}
\hline Day & January & February & Day & January & February & Day & January & February \\
\hline $\begin{array}{c}1 \ldots \ldots \\
2 \ldots \ldots \\
3 \ldots \ldots \\
5 \ldots \ldots \\
6 \ldots \ldots \\
7 \ldots \ldots \\
8 \ldots \ldots \\
9 \ldots \ldots \\
10 \ldots \ldots\end{array}$ & $\begin{array}{l}28 \\
21 \\
21 \\
20 \\
18 \\
18 \\
17 \\
17 \\
16 \\
16\end{array}$ & $\begin{array}{r}754 \\
238 \\
199 \\
164 \\
133 \\
118 \\
106 \\
94 \\
90 \\
88\end{array}$ & $\begin{array}{l}11 \ldots \ldots \\
12 \ldots \ldots \\
13 \ldots \ldots \\
14 \ldots \ldots \\
15 \ldots \ldots \\
16 \ldots \ldots \\
17 \ldots \ldots \\
18 \ldots \ldots \\
19 \ldots \ldots \\
20 \ldots \ldots\end{array}$ & $\begin{array}{l}14 \\
12 \\
10 \\
12 \\
12 \\
12 \\
11 \\
11 \\
11 \\
11\end{array}$ & $\begin{array}{l}82 \\
75 \\
75 \\
69 \\
65 \\
63 \\
60 \\
58 \\
56 \\
56\end{array}$ & $\begin{array}{l}21 \ldots \ldots \\
22 \ldots \ldots \\
23 \ldots \ldots \\
24 \ldots \ldots \\
25 \ldots \ldots \\
26 \ldots \ldots \\
27 \ldots \ldots \\
28 \ldots \ldots \\
29 \ldots \ldots \\
30 \ldots \ldots \\
31 \ldots \ldots\end{array}$ & $\begin{array}{c}11 \\
11 \\
11 \\
11 \\
11 \\
10 \\
10 \\
9.2 \\
10 \\
92 \\
1,150\end{array}$ & $\begin{array}{r}54 \\
50 \\
48 \\
47 \\
47 \\
48 \\
45 \\
43 \\
---- \\
---- \\
---\end{array}$ \\
\hline $\begin{array}{l}\text { nthly } \\
\text { anoff, } \\
\text { anoff, }\end{array}$ & acre & & & & & & $\begin{array}{r}53.0 \\
3.36 \\
3,260 \\
\end{array}$ & $\begin{array}{r}108 \\
6.18 \\
6,000 \\
\end{array}$ \\
\hline
\end{tabular}


Gage helght, in feet, and discharge, In cublc feet per second, at indicated t1me, 1963, of Haypress Creek near Sierra C1ty, Callf.

\begin{tabular}{|c|c|c|c|c|c|c|c|c|c|c|c|}
\hline Date & Hour & $\begin{array}{c}\text { Gage } \\
\text { height }\end{array}$ & $\begin{array}{c}\text { Dis- } \\
\text { charge }\end{array}$ & Date & Hour & $\begin{array}{c}\text { Gage } \\
\text { helght }\end{array}$ & $\begin{array}{c}\text { Dis- } \\
\text { charge }\end{array}$ & Date & Hour & $\begin{array}{c}\text { Gage } \\
\text { helght }\end{array}$ & $\begin{array}{c}\text { Dis- } \\
\text { charge }\end{array}$ \\
\hline $\begin{array}{r}\operatorname{Jan} .29 \\
30\end{array}$ & $\begin{array}{l}2400 \\
1200 \\
1600 \\
1800 \\
1900 \\
2000 \\
2100 \\
2200 \\
2400\end{array}$ & $\begin{array}{r}0.23 \\
.25 \\
.49 \\
.69 \\
.95 \\
1.35 \\
1.41 \\
1.54 \\
1.56\end{array}$ & $\begin{array}{r}10 \\
12 \\
50 \\
90 \\
156 \\
300 \\
327 \\
391 \\
401\end{array}$ & Jan. 3I & $\begin{array}{l}0900 \\
1100 \\
1200 \\
1300 \\
1500 \\
1800 \\
2000 \\
2200 \\
2300 \\
2400\end{array}$ & $\begin{array}{l}1.24 \\
1.58 \\
2.00 \\
2.30 \\
2.70 \\
3.00 \\
3.45 \\
3.70 \\
3.75 \\
3.55\end{array}$ & $\begin{array}{r}254 \\
412 \\
675 \\
910 \\
1,310 \\
1,700 \\
2,470 \\
2,990 \\
3,100 \\
2,670\end{array}$ & Feb. & $\begin{array}{l}0500 \\
0700 \\
0800 \\
0900 \\
1000 \\
1400 \\
1630 \\
2100 \\
2400\end{array}$ & $\begin{array}{l}2.58 \\
2.18 \\
1.72 \\
1.72 \\
1.58 \\
1.45 \\
1.57 \\
1.50 \\
1.41\end{array}$ & $\begin{array}{r}1,180 \\
814 \\
490 \\
490 \\
412 \\
346 \\
406 \\
370 \\
327\end{array}$ \\
\hline 31 & $\begin{array}{l}0200 \\
0400 \\
0800\end{array}$ & $\begin{array}{l}1.48 \\
1.52 \\
1.45\end{array}$ & $\begin{array}{l}360 \\
380 \\
346\end{array}$ & Feb. 1 & $\begin{array}{l}0130 \\
0200 \\
0300\end{array}$ & $\begin{array}{l}2.95 \\
3.36 \\
3.08\end{array}$ & $\begin{array}{l}1,630 \\
2,300 \\
1,820\end{array}$ & 2 & $\begin{array}{l}1200 \\
2400\end{array}$ & $\begin{array}{l}1.18 \\
1.12\end{array}$ & $\begin{array}{l}231 \\
209\end{array}$ \\
\hline
\end{tabular}

Woodruff Creek at Goodyears Bar, Calif.

(Miscellaneous site)

Location.--Lat $39^{\circ} 32^{\prime} 10^{\prime \prime}$, long $120^{\circ} 53^{\prime} 05^{\prime \prime}$, in NW $\frac{1}{4}$ sec.8, T.19 N., R.10 E., 0.2 mile above mouth and 0.4 mile south of Goodyears Bar. Altitude is 2,780 ft (from topographic map).

Drainage area $--4.12 \mathrm{sq} \mathrm{mi}$.

Discharge record.--Maximum discharge determined by field estimate.

Maxima.--January-February 1963: Discharge, about 1,000 cfs Jan. 31. 1943 to December 1962: Discharge, 786 cfs Dec. 23, 1955.

\section{1-4120. Rock Creek at Goodyears Bar, Calif.}

(Gaging station, discontinued 1933)

Location.--Lat $39^{\circ} 32^{\prime} 15^{\prime \prime}$, long $120^{\circ} 53^{\prime} 05^{\prime \prime}$, in SW $\frac{1}{4}$ sec.5, T. 19 N., R.10 E. , at footbridge at Goodyears Bar, 350 ft downstream from Woodruff Creek and $600 \mathrm{ft}$ upstream from mouth. Altitude is $2,680 \mathrm{ft}$ (from topographic map).

Drainage area. $--8.98 \mathrm{sq} \mathrm{mi}$.

Discharge record.--Maximum discharge determined by summation of field estimate of peak flow on Woodruff Creek and Rock Creek above Woodruff Creek.

Maxima.--January-February 1963: Discharge, about 2,400 cfs Jan. 31.

1910-33. 1943 to December 1962: Discharge, 2,390 cfs Dec. 23, 1955.

11-4125. Goodyears Creek at Goodyears Bar, Calif.

(Gaging station, discontinued 1933)

Location.--Lat $39^{\circ} 32130^{\prime \prime}$, long $120^{\circ} 53^{1} 12^{\prime \prime}$, in NW $\frac{1}{4} \sec .5$, T. $19 \mathrm{~N} ., \mathrm{R} .10 \mathrm{E} ., 300 \mathrm{ft}$ upstream from mouth and $0.5 \mathrm{mile}$ north of Goodyears Bar. Altitude is $2,650 \mathrm{ft}$ (from topographic map).

Drainage area. $--12.9 \mathrm{sq} \mathrm{ml}$.

Discharge record,--Maximum discharge by slope-area measurement.

Maxima --January-February 1963: Discharge, 3,240 cfs Jan. 31.

1910-33: Discharge, about 1,800 cfs Mar. 25, 1928 (gage height, $9.5 \mathrm{ft}$, probably affected by backwater from North Yuba River). 
11-4127. North Yuba River tributary near Goodyears Bar, Calif.

(Crest-stage station)

Location. - Lat $39^{\circ} 32^{\prime} 31^{\prime \prime}$, long $120^{\circ} 53146^{\prime \prime}$, in $\mathrm{NE} \frac{1}{4}$ sec.6, T. 19 N., R.10 E., on State Highway 49, 0.7 mile west of Goodyears Bar.

Drainage area. $-0.24 \mathrm{sq} \mathrm{mi}$.

Gage-helght record.--Crest stages only. Altitude of gage is $2,720 \mathrm{ft}$ (from topographic map).

Discharge record.--Maximum discharge by computation of flow through culvert.

Maxima.--January-February 1963: Discharge, $75 \mathrm{cfs}$ Feb. 1 (gage height, $9.07 \mathrm{ft}$, from high-water profile)

October to December 1962: Discharge, $28 \mathrm{cfs} 0 \mathrm{ct} .13$ (gage he1ght, $6.77 \mathrm{ft}$, from high-water profile).

11-4130. North Yuba River below Goodyears Bar, Calif.

Location.--Lat $39^{\circ} 31^{\prime} 30^{\prime \prime}$, long $120^{\circ} 56^{\prime} 13^{\prime \prime}$, in SW $\frac{1}{4}$ sec.11, T.19 N., R.9 E., on right bank $200 \mathrm{ft}$ downstream from St. Catherine Creek, 3.1 miles southwest of Goodyears Bar, and 6.4 miles southwest of Downieville.

Drainage area.--250 sq mi.

Gage-height record.--Water-stage recorder graph, except 0100-0400 hours Feb. 1, Feb. 4-13. Record for 0100-0400 hours Feb. 1 computed from reconstructed gagehelght graph based on outside high-water profile. Datum of gage is $2,453 \mathrm{ft}$ above mean sea level (river-profile survey).

Discharge record.--Stage-discharge relation defined by current-meter measurements below 4,300 cfs, by float measurement at $17,900 \mathrm{cfs}$, and slope-area measurements at 26,200 and 40,000 cfs. Discharge for Feb. 4-13 estimated on basis of one discharge measurement and records for Middle Yuba River near Alleghany.

Maxima.--January-February 1963: Discharge, 40,000 cfs about 0200 hours Feb. 1 (gage height, $23.8 \mathrm{ft}$, from floodmarks).

1930 to December 1962: Discharge, 26,800 cfs Dec. 23, 1955 (gage height, $19.30 \mathrm{ft}$ ).

Mean discharge, in cubic feet per second, 1963

\begin{tabular}{|c|c|c|c|c|c|c|c|c|}
\hline Day & January & February & Day & January & February & Day & January & February \\
\hline $\begin{array}{c}1 \ldots \ldots \\
2 \ldots \ldots \\
3 \ldots \ldots \\
4 \ldots \ldots \\
5 \ldots \ldots \\
7 \ldots \ldots \\
8 \ldots \ldots \\
9 \ldots \ldots \\
10 \ldots \ldots\end{array}$ & $\begin{array}{l}474 \\
458 \\
452 \\
449 \\
421 \\
408 \\
396 \\
386 \\
381 \\
374\end{array}$ & $\begin{array}{r}18,900 \\
7,440 \\
4,910 \\
3,750 \\
2,920 \\
2,360 \\
1,990 \\
1,750 \\
1,580 \\
1,460\end{array}$ & $\begin{array}{l}11 \ldots \ldots \\
12 \ldots \ldots \\
13 \ldots \ldots \\
14 \ldots \ldots \\
15 \ldots \ldots \\
16 \ldots \ldots \\
17 \ldots \ldots \\
18 \ldots \ldots \\
19 \ldots \ldots \\
20 \ldots \ldots\end{array}$ & $\begin{array}{l}332 \\
294 \\
339 \\
343 \\
332 \\
326 \\
317 \\
315 \\
298 \\
298\end{array}$ & $\begin{array}{r}1,310 \\
1,180 \\
2,000 \\
1,360 \\
1,220 \\
1,140 \\
1,070 \\
1,010 \\
955 \\
930\end{array}$ & $\begin{array}{l}21 \ldots \ldots \\
22 \ldots \ldots \\
23 \ldots \ldots \\
24 \ldots \ldots \\
25 \ldots \ldots \\
26 \ldots \ldots \\
27 \ldots \ldots \\
28 \ldots \ldots \\
29 \ldots \ldots \\
30 \ldots \ldots \\
31 \ldots \ldots\end{array}$ & $\begin{array}{r}298 \\
298 \\
294 \\
290 \\
286 \\
280 \\
276 \\
273 \\
294 \\
1,980 \\
16,500\end{array}$ & $\begin{array}{r}890 \\
840 \\
795 \\
765 \\
740 \\
730 \\
694 \\
666 \\
---- \\
---- \\
---1\end{array}$ \\
\hline noff, & acre & & & & & & $\begin{array}{r}918 \\
4.23 \\
56,450\end{array}$ & $\begin{array}{r}2,334 \\
9.72 \\
129,600\end{array}$ \\
\hline
\end{tabular}

Gage height, in feet, and discharge, in cublc feet per second, at indicated time, 1963

\begin{tabular}{|c|c|c|c|c|c|c|c|c|c|c|c|}
\hline Date & Hour & $\begin{array}{c}\text { Gage } \\
\text { helght }\end{array}$ & $\begin{array}{c}\text { Dis- } \\
\text { charge }\end{array}$ & Date & Hour & $\begin{array}{c}\text { Gage } \\
\text { helght }\end{array}$ & $\begin{array}{c}\text { Dis- } \\
\text { charge }\end{array}$ & Dete & Hour & $\begin{array}{c}\text { Gage } \\
\text { helght }\end{array}$ & $\begin{array}{l}\text { Dis- } \\
\text { charge }\end{array}$ \\
\hline $\begin{array}{r}\text { Jan. } 29 \\
30\end{array}$ & $\begin{array}{l}2400 \\
0300 \\
0800 \\
1300 \\
1500 \\
1800 \\
2100 \\
2400 \\
\\
0400 \\
0700\end{array}$ & $\begin{array}{r}3.02 \\
3.40 \\
4.28 \\
5.10 \\
5.82 \\
7.80 \\
9.28 \\
10.27 \\
10.10 \\
11.00\end{array}$ & $\begin{array}{r}355 \\
452 \\
742 \\
1,100 \\
1,490 \\
3,200 \\
4,940 \\
6,280 \\
6,040 \\
7,360\end{array}$ & Feb. 1 & $\begin{array}{l}1000 \\
1200 \\
1500 \\
1800 \\
2400 \\
\\
0200 \\
0600 \\
1000 \\
1500 \\
1800 \\
2400\end{array}$ & $\begin{array}{l}13.20 \\
14.80 \\
17.00 \\
19.50 \\
20.50 \\
23.8 \\
18.00 \\
15.40 \\
13.65 \\
13.83 \\
12.80\end{array}$ & $\begin{array}{l}11,300 \\
14,900 \\
20,500 \\
27,400 \\
30,200 \\
40,000 \\
23,200 \\
16,400 \\
12,300 \\
12,700 \\
10,500\end{array}$ & Feb. 2 & $\begin{array}{l}0400 \\
0800 \\
1200 \\
2400 \\
0600 \\
0800 \\
1400 \\
1700 \\
2400\end{array}$ & $\begin{array}{r}12.00 \\
11.39 \\
10.80 \\
9.73 \\
9.47 \\
9.50 \\
9.10 \\
8.98 \\
8.87\end{array}$ & $\begin{array}{l}9,000 \\
7,980 \\
7,060 \\
5,530 \\
5,190 \\
5,230 \\
4,710 \\
4,560 \\
4,420\end{array}$ \\
\hline
\end{tabular}


11-4133. Slate Creek below diversion dam, near Strawberry Valley, Calif.

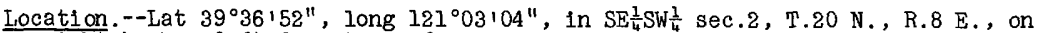
right bank $300 \mathrm{ft}$ downstream from diversion dam, 0.2 mile upstream from Feney Ravine, and 4.5 miles northeast of town of Strawberry Valley.

Drainage area. $--49.4 \mathrm{sq} \mathrm{mi}$.

Gage-height record.--Water-stage recorder graph. Altitude of gage is $3,5^{\prime} 70 \mathrm{f}^{\prime} \mathrm{t}$ (from topographic map).

Discharge record.--Stage-discharge relation defined by current-meter measurements below 5,500 cfs and by computation of filow over dam at 7,460 and 12,200 cfs.

Maxima (creek only) --January-February 1963: Discharge, 12,200 cf's 1900 hours Jan. 31 (gage height, $15.90 \mathrm{ft}$ ).

1960 to December 1962: Discharge, 7,460 cfs 0ct. 13, 1962 (gage height, $12.75 \mathrm{ft})$.

Maxima (creek plus diversion).--January-February 1963: Discharge, 12,600 cfs 1900 hours Jan. 31.

1960 to December 1962: D1scharge, 7,460 cfs Oct. 13, 1962.

Remarks. - Water is diverted through Slate Creek tunnel (maximum capacity about 900 cfs) to Sly Creek Reservoir at times.

Mean discharge, in cublc feet per second, 1963 (combined flow of Creek and Slate Creek tunneI)

\begin{tabular}{|c|c|c|c|c|c|c|c|c|}
\hline Day & January & February & Day & January & February & Day & January & February \\
\hline $\begin{array}{c}1 \ldots \ldots \\
2 \ldots \ldots \\
3 \ldots \ldots \\
5 \ldots \ldots \\
6 \ldots \ldots \\
7 \ldots \ldots \\
8 \ldots \ldots \\
9 \ldots \ldots \\
10 \ldots \ldots\end{array}$ & $\begin{array}{r}108 \\
101 \\
97 \\
94 \\
85 \\
82 \\
76 \\
73 \\
70 \\
69\end{array}$ & $\begin{array}{r}5,140 \\
1,500 \\
894 \\
674 \\
520 \\
398 \\
496 \\
590 \\
398 \\
324\end{array}$ & $\begin{array}{l}11 \ldots \ldots \\
12 \ldots \ldots \\
13 \ldots \ldots \\
14 \ldots \ldots \\
15 \ldots \ldots \\
16 \ldots \ldots \\
17 \ldots \ldots \\
18 \ldots \ldots \\
19 \ldots \ldots \\
20 \ldots \ldots\end{array}$ & $\begin{array}{l}48 \\
42 \\
59 \\
67 \\
62 \\
59 \\
55 \\
55 \\
50 \\
53\end{array}$ & $\begin{array}{l}268 \\
420 \\
882 \\
779 \\
493 \\
327 \\
275 \\
246 \\
228 \\
218\end{array}$ & $\begin{array}{l}21 \ldots \ldots \\
22 \ldots \ldots \\
23 \ldots \ldots \\
24 \ldots \ldots \\
25 \ldots \ldots \\
26 \ldots \ldots \\
27 \ldots \ldots \\
28 \ldots \ldots \\
29 \ldots \ldots \\
30 \ldots \ldots \\
31 \ldots \ldots\end{array}$ & $\begin{array}{r}52 \\
51 \\
49 \\
48 \\
45 \\
45 \\
44 \\
44 \\
47 \\
967 \\
7,000\end{array}$ & $\begin{array}{r}202 \\
182 \\
168 \\
154 \\
140 \\
142 \\
129 \\
122 \\
----- \\
------\end{array}$ \\
\hline $\begin{array}{l}\text { nthly } \\
\text { moff, } \\
\text { noff, }\end{array}$ & in acre-f & & & & & & $\begin{array}{r}316 \\
7.38 \\
19,430 \\
\end{array}$ & $\begin{array}{r}552 \\
12.28 \\
32,350 \\
\end{array}$ \\
\hline
\end{tabular}

Gage height, in feet, and discharge, in cublc feet per second, (combined flow), at indicated

\begin{tabular}{|c|c|c|c|c|c|c|c|c|c|c|c|}
\hline Date & Hour & $\begin{array}{c}\text { Gage } \\
\text { height }\end{array}$ & $\begin{array}{l}\text { Dis- } \\
\text { charge }\end{array}$ & Date & Hour & $\begin{array}{c}\text { Gage } \\
\text { nelght }\end{array}$ & $\begin{array}{l}\text { Dis- } \\
\text { charge }\end{array}$ & Date & Hour & $\begin{array}{c}\text { Gage } \\
\text { helght }\end{array}$ & $\begin{array}{c}\text { D1s- } \\
\text { charge }\end{array}$ \\
\hline $\begin{array}{r}\text { Jan. } 29 \\
30\end{array}$ & $\begin{array}{l}2400 \\
0400 \\
0800 \\
1000 \\
1100 \\
1300 \\
1400 \\
1500 \\
1600 \\
1700 \\
1800 \\
1900 \\
2100 \\
2300 \\
2400 \\
0300\end{array}$ & $\begin{array}{l}- \\
= \\
\overline{-} \\
= \\
= \\
= \\
= \\
= \\
= \\
= \\
-\end{array}$ & $\begin{array}{r}55 \\
77 \\
117 \\
147 \\
173 \\
260 \\
407 \\
1,130 \\
1,210 \\
1,650 \\
2,050 \\
2,400 \\
2,660 \\
3,110 \\
3,040 \\
2,540\end{array}$ & Feb. I & $\begin{array}{l}0400 \\
0500 \\
0600 \\
0800 \\
0900 \\
1100 \\
1300 \\
1400 \\
1700 \\
1500 \\
1900 \\
2100 \\
2300 \\
2400 \\
0100 \\
0200 \\
0500\end{array}$ & $\begin{array}{l}- \\
\overline{-} \\
\overline{-} \\
\overline{-} \\
- \\
\overline{-} \\
- \\
- \\
- \\
- \\
-\end{array}$ & $\begin{array}{r}2,450 \\
2,460 \\
2,620 \\
3,590 \\
4,350 \\
5,750 \\
8,120 \\
8,930 \\
10,500 \\
12,100 \\
12,600 \\
11,200 \\
10,700 \\
10,400 \\
10,100 \\
10,000 \\
7,970\end{array}$ & Feb. I & $\begin{array}{l}0800 \\
1000 \\
1300 \\
1500 \\
1700 \\
1800 \\
2100 \\
2400 \\
\\
0200 \\
0700 \\
1200 \\
1500 \\
1600 \\
2100 \\
2400\end{array}$ & $\begin{array}{l}- \\
- \\
- \\
- \\
- \\
- \\
- \\
- \\
- \\
- \\
-\end{array}$ & $\begin{array}{l}5,470 \\
4,520 \\
3,820 \\
3,580 \\
3,110 \\
3,050 \\
2,780 \\
2,250 \\
2,010 \\
2,080 \\
1,430 \\
1,290 \\
1,270 \\
1,110 \\
1,050\end{array}$ \\
\hline
\end{tabular}


11-4135. North Yuba River below Bullards Bar Dam, Calif.

Location.--Lat $39^{\circ} 24^{\prime} 1^{\prime \prime}$, long $121^{\circ} 08^{\prime} 30^{\prime \prime}$, in SW $\frac{1}{4}$ sec. 24 , T.18 N., R.7 E., on right bank 2,000 ft downstream from Bullards Bar Dam, 3 miles upstream from confluence with Middle Yuba River, and 3 miles northwest of North San Juan.

Drainage area. $--487 \mathrm{sq} \mathrm{mi}$.

Gage-height record.--Digital-recorder tape punched at 15-minute intervals, except Jan. 24 to Feb. 15. Water-stage recorder graph at site 1.5 miles downstream

Feb. 16-28. Altitude of gage is $1,390 \mathrm{ft}$ (from river-profile map).

Discharge record.--Stage-discharge relation defined by current-meter measurements below $32,000 \mathrm{cfs}$ and by computations of flow over dam at 42,300 and 83,000 cf's. Discharge for period of no gage-height record estimated on the basis of records of spill and release at Bullards Bar Dam, and diversion to Colgate tunnel, records for North Yuba River at Goodyears Bar, and weather records.

Maxima.--January-February 1963; Discharge, 83,000 cfs about 0300 hours Feb. 1 (gage height, $42.0 \mathrm{ft}$, from floodmark).

1940 to December 1962: Discharge, 70,000 cfs Dec. 23, 1955 (gage height, $39.0 \mathrm{ft}$, from floodmark).

Remarks.--Flow affected by Bullards Bar Reservoir (usable capacity, 13,050 acre-ft) and diversion out of the basin through Slate Creek tunnel into Lost Creek.

Mean discharge, in cubic feet per second, 1963

\begin{tabular}{|c|c|c|c|c|c|c|c|c|}
\hline Day & January & February & Day & January & February & Day & January & February \\
\hline $\begin{array}{c}1 \ldots \ldots \\
2 \ldots \ldots \\
3 \ldots \ldots \\
4 \ldots \ldots \\
5 \ldots \ldots \\
6 \ldots \ldots \\
8 \ldots \ldots \\
9 \ldots \ldots \\
10 \ldots \ldots\end{array}$ & $\begin{array}{l}848 \\
815 \\
788 \\
783 \\
757 \\
731 \\
712 \\
695 \\
680 \\
667\end{array}$ & $\begin{array}{r}42,000 \\
16,500 \\
11,000 \\
6,010 \\
4,160 \\
3,890 \\
3,580 \\
3,580 \\
3,140 \\
2,970\end{array}$ & $\begin{array}{l}11 \ldots \ldots \\
12 \ldots \ldots \\
13 \ldots \ldots \\
14 \ldots \ldots \\
15 \ldots \ldots \\
16 \ldots \ldots \\
17 \ldots \ldots \\
18 \ldots \ldots \\
19 \ldots \ldots \\
20 \ldots \ldots\end{array}$ & $\begin{array}{l}652 \\
631 \\
630 \\
630 \\
612 \\
627 \\
627 \\
627 \\
627 \\
627\end{array}$ & $\begin{array}{l}2,690 \\
2,560 \\
3,970 \\
3,510 \\
2,680 \\
2,350 \\
2,180 \\
2,040 \\
1,930 \\
1,840\end{array}$ & $\begin{array}{l}21 \ldots \ldots \\
22 \ldots \ldots \\
23 \ldots \ldots \\
24 \ldots \ldots \\
25 \ldots \ldots \\
26 \ldots \ldots \\
27 \ldots \ldots \\
28 \ldots \ldots \\
29 \ldots \ldots \\
30 \ldots \ldots \\
31 \ldots \ldots\end{array}$ & $\begin{array}{r}627 \\
627 \\
630 \\
630 \\
630 \\
620 \\
620 \\
620 \\
620 \\
630 \\
36,000\end{array}$ & $\begin{array}{r}1,730 \\
1,630 \\
1,510 \\
1,430 \\
1,360 \\
1,300 \\
1,120 \\
1,050 \\
-.--- \\
-.-1--\end{array}$ \\
\hline $\begin{array}{l}\text { lonthly } \\
\text { unoff, } \\
\text { unoff, }\end{array}$ & acre & & & & & & $\begin{array}{r}1,807 \\
4.28 \\
111,100\end{array}$ & $\begin{array}{r}4,775 \\
10.21 \\
265,200\end{array}$ \\
\hline
\end{tabular}

11-4136. Sweetland Creek near North San Juan, Calif.

(Crest-stage station)

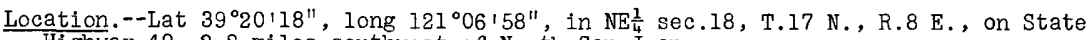
Highway $49,2.2$ miles southwest of North San Juan.

Drainage area. $--2.68 \mathrm{sq} \mathrm{mi}$.

Gage-height record.--Crest stages only. Altitude of gage is 1,860 ft (from topographic map).

Discharge record --Stage-discharge relation defined by computation of flow through culvert at 368 and $526 \mathrm{cfs}$.

Maxima.--January-February 1963: Discharge, 368 cfs Feb. 1 (gage height, 4.46 ft). August to December 1962: Discharge, 526 cfs oct. 13, 1962 (gage height, $6.17 \mathrm{ft}$ ). 
11-4139. Upper Castle Creek at Soda Springs, Calif.

Location. --Lat $39^{\circ} 19^{\prime} 30^{\prime \prime}$, long $120^{\circ} 22^{\prime} 05^{\prime \prime}$, in $\mathrm{SW} \frac{1}{4} \mathrm{NE} \frac{1}{4}$ sec.23, T.17 N., R.14 E., on left bank at Central Sierra Snow Laboratory, U.S. Forest Service, 0.25 mile upstream from mouth and 0.6 mile east of Soda Springs.

Drainage area. $--3.96 \mathrm{sq} \mathrm{mi}$.

Gage-height record.- Water-stage recorder graph, except 1530 hours Jan. 31 to 0900 hours Feb. 8 and $\mathrm{Feb} .27,28$. Altitude of gage is 6,850 ft (from topographic map)

Discharge record.--Stage-discharge relation defined by $\mathrm{V}$-notch weir rating or Parshall flume rating Jan. 1-31, and by current-meter measurements below 220 cfs Feb. 9-28; affected by ice Jan. 12, 13, Feb. 13-15. Peak discharge determined by computation of flow through culvert and adjustment for drainage area difference. Discharge for Jan. 31 to Feb. 8, Feb. 27, 28, estimated on basis of one culvert computation, weather records, recession curve, and records for nearby stations.

Maxima.--January-February 1963: Discharge, 1,300 cfs, time unknown, Jan. 31 (gage height, unknown).

1958 to December 1962: Discharge, 452 cfs 0ct. 13, 1962 (gage height, 4.10 ft).

Remarks.--Gage-height record furnished by the U.S. Forest Service.

Mean discharge, in cubic feet per second, 1963

\begin{tabular}{|c|c|c|c|c|c|c|c|c|}
\hline Day & January & February & Day & January & February & Day & January & February \\
\hline $\begin{array}{c}7 \ldots \ldots \\
3 \ldots \ldots \\
4 \ldots \ldots \\
5 \ldots \ldots \\
6 \ldots \ldots \\
8 \ldots \ldots \\
9 \ldots \ldots \\
10 \ldots \ldots\end{array}$ & $\begin{array}{l}4.20 \\
4.20 \\
4.20 \\
3.91 \\
3.77 \\
3.64 \\
3.38 \\
3.25 \\
3.25 \\
3.01\end{array}$ & $\begin{array}{l}400 \\
155 \\
85 \\
65 \\
55 \\
40 \\
30 \\
25 \\
19.0 \\
15.8\end{array}$ & $\begin{array}{l}11 \ldots \ldots \\
12 \ldots \ldots \\
13 \ldots \ldots \\
14 \ldots \ldots \\
15 \ldots \ldots \\
16 \ldots \ldots \\
17 \ldots \ldots \\
18 \ldots \ldots \\
19 \ldots \ldots \\
20 \ldots \ldots\end{array}$ & $\begin{array}{l}2.34 \\
2.30 \\
2.20 \\
2.14 \\
2.14 \\
2.14 \\
1.95 \\
1.95 \\
1.52 \\
1.52\end{array}$ & $\begin{array}{r}13.2 \\
11.3 \\
10.0 \\
9.0 \\
8.0 \\
7.6 \\
7.1 \\
7.1 \\
7.1 \\
7.1\end{array}$ & $\begin{array}{l}21 \ldots \ldots \\
22 \ldots \ldots \\
23 \ldots \ldots \\
24 \ldots \ldots \\
25 \ldots \ldots \\
26 \ldots \ldots \\
27 \ldots \ldots \\
28 \ldots \ldots \\
29 \ldots \ldots \\
30 \ldots \ldots \\
31 \ldots \ldots\end{array}$ & $\begin{array}{l}1.77 \\
1.95 \\
1.86 \\
1.77 \\
1.69 \\
1.52 \\
1.44 \\
1.37 \\
1.44 \\
2.00 \\
500\end{array}$ & 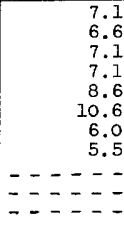 \\
\hline \multicolumn{7}{|c|}{ 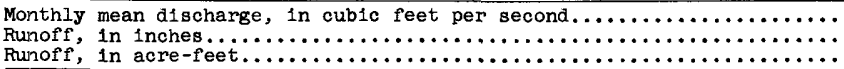 } & $\begin{array}{r}18.51 \\
5.39 \\
1,140\end{array}$ & $\begin{array}{r}37.0 \\
9.73 \\
2,050 \\
\end{array}$ \\
\hline
\end{tabular}

11-4139.5. South Yuba River tributary near Soda Springs, Calif.

(Crest-stage station)

Location.--Lat $39^{\circ} 18^{\prime} 56^{\prime \prime}$, long $120^{\circ} 27124^{\prime \prime}$, in $\mathrm{NE}_{\frac{1}{4}} \mathrm{NE} \frac{1}{4} \mathrm{sec} .25$, T.17 N., R.13 E., on old U.S. Highway $40,4.3$ miles west of Soda Springs.

Drainage area. $-0.90 \mathrm{sq} \mathrm{mi}$.

Gage-height record.--Crest stages only. Altitude of gage is 6,050 ft (from topographic map).

Discharge record. - - Stage-discharge relation defined by computation of flow through culvert at 274 and 489 ofs.

Maxima.--January-February 1963: Discharge, 489 cfs Feb. 1 (gage height, $21.84 \mathrm{ft}$, from high-water profile).

August to December 1962: Discharge, $274 \mathrm{cfs}$ 0ct. 13, 1962 (gage height, $18.96 \mathrm{ft}$, from high-water profile). 
11-4140. South Yuba River near Cisco, Calif.

Location.--Lat $39^{\circ} 19^{\prime} 12^{\prime \prime}$, long $120^{\circ} 33^{\prime} 38^{\prime \prime}$, in SW $\frac{1}{4}$ sec.19, T.17 N., R.13 E., on right bank 0.7 mile downstream from Rattlesnake Creek, 1.3 miles west of Cisco Grove, and 1.5 miles northwest of Cisco.

Drainage area. $--51.8 \mathrm{sq} \mathrm{mi}$.

Gage-height record:--Water-stage recorder graph, except 1800 hours Jan. 31 to 1000 hours Feb. 6. Altitude of gage is 5,520 ft (from river-profile map).

Discharge record.--Stage-discharge relation defined by current-meter measurements below 4,600 cf's and by slope-area measurement at $11,700 \mathrm{cfs}$; affected by ice Jan. 11-13, 19. Discharge for Jan. 31 to Feb. 6 estimated on basis of weather records and records for Middle Fork American River at French Meadows.

Maxima.--January-February 1963: Discharge, 18,400 cfs about 2400 hours Jan. 31 (gage height, $19.6 \mathrm{ft}$, from floodmark in gage house; $20.6 \mathrm{ft}$, from outside floodmarks).

1942 to December 1962: Discharge, $11,700 \mathrm{cfs}$ Nov. 20, 1950 (gage height, $15.82 \mathrm{ft}$ ).

Mean discharge, in cublc feet per second, 1963

\begin{tabular}{|c|c|c|c|c|c|c|c|c|}
\hline Day & January & February & Day & January & February & Day & January & February \\
\hline $\begin{array}{c}1 \ldots \ldots \\
2 \ldots \ldots \\
3 \ldots \ldots \\
4 \ldots \ldots \\
6 \ldots \ldots \\
7 \ldots \ldots \\
8 \ldots \ldots \\
10 \ldots \ldots\end{array}$ & $\begin{array}{l}79 \\
76 \\
79 \\
76 \\
73 \\
69 \\
67 \\
66 \\
65 \\
66\end{array}$ & $\begin{array}{r}6,500 \\
1,100 \\
760 \\
580 \\
500 \\
430 \\
380 \\
323 \\
266 \\
249\end{array}$ & $\begin{array}{l}11 \ldots \ldots \\
12 \ldots \ldots \\
13 \ldots \ldots \\
14 \ldots \ldots \\
15 \ldots \ldots \\
16 \ldots \ldots \\
17 \ldots \ldots \\
18 \ldots \ldots \\
19 \ldots \ldots \\
20 \ldots \ldots\end{array}$ & $\begin{array}{l}66 \\
65 \\
65 \\
64 \\
61 \\
60 \\
60 \\
60 \\
58 \\
56\end{array}$ & $\begin{array}{l}214 \\
184 \\
246 \\
210 \\
173 \\
167 \\
158 \\
154 \\
158 \\
160\end{array}$ & $\begin{array}{l}21 \ldots \ldots \\
22 \ldots \ldots \\
23 \ldots \ldots \\
24 \ldots \ldots \\
25 \ldots \ldots \\
26 \ldots \ldots \\
27 \ldots \ldots \\
28 \ldots \ldots \\
29 \ldots \ldots \\
30 \ldots \ldots \\
31 \ldots \ldots\end{array}$ & $\begin{array}{r}55 \\
55 \\
55 \\
55 \\
55 \\
55 \\
54 \\
53 \\
55 \\
480 \\
8,460\end{array}$ & $\begin{array}{r}154 \\
139 \\
127 \\
129 \\
134 \\
152 \\
139 \\
122 \\
----- \\
-----1 \\
-----\end{array}$ \\
\hline \multicolumn{7}{|c|}{ 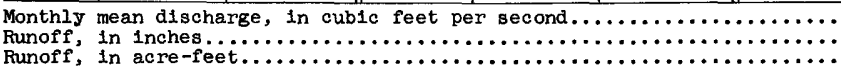 } & $\begin{array}{r}347 \\
7.77 \\
21,350\end{array}$ & $\begin{array}{r}500 \\
10.1 \\
27,780\end{array}$ \\
\hline
\end{tabular}

Gage he1ght, in feet, and discharge, in cubic feet per second, at 1ndicated t1me, 1963

\begin{tabular}{|c|c|c|c|c|c|c|c|c|c|c|c|}
\hline Date & Hour & $\begin{array}{c}\text { Gage } \\
\text { height }\end{array}$ & $\begin{array}{l}\text { D1s- } \\
\text { charge }\end{array}$ & Date & Hour & $\begin{array}{c}\text { Gage } \\
\text { height }\end{array}$ & $\begin{array}{c}\text { D1s- } \\
\text { charge }\end{array}$ & Date & Hour & $\begin{array}{c}\text { Gage } \\
\text { helght }\end{array}$ & $\begin{array}{l}\text { Dis - } \\
\text { charge }\end{array}$ \\
\hline $\begin{array}{r}\text { Jan. } 29 \\
30\end{array}$ & $\begin{array}{l}2400 \\
0500 \\
0700 \\
1000 \\
1200 \\
1500 \\
\end{array}$ & $\begin{array}{l}2.63 \\
2.79 \\
2.79 \\
2.73 \\
2.89 \\
3.75 \\
\end{array}$ & $\begin{array}{r}65 \\
87 \\
87 \\
79 \\
102 \\
310 \\
\end{array}$ & Jan. 30 & $\begin{array}{l}1900 \\
2200 \\
2400 \\
\\
0100 \\
0200 \\
0600 \\
\end{array}$ & $\begin{array}{l}5.35 \\
6.76 \\
7.03 \\
7.03 \\
7.12 \\
8.12 \\
\end{array}$ & $\begin{array}{r}932 \\
1,680 \\
1,840 \\
1,840 \\
1,890 \\
2,600 \\
\end{array}$ & $\operatorname{Jan} .31$ & $\begin{array}{l}0800 \\
1100 \\
1400 \\
1600 \\
1800 \\
2400\end{array}$ & $\begin{array}{r}9.15 \\
11.70 \\
15.30 \\
16.22 \\
17.00 \\
19.6\end{array}$ & $\begin{array}{r}3,440 \\
5,970 \\
10,800 \\
12,300 \\
13,600 \\
18,400\end{array}$ \\
\hline
\end{tabular}

11-4155. Bowman Lake near Graniteville, Cal1f.

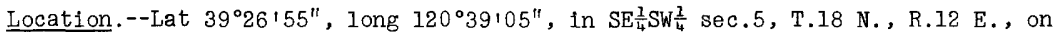
rockfill portion of Bowman Dam on Canyon Creek, 4.5 miles east of Graniteville and 8 miles south of Sierra City.

Drainage area. $--27.3 \mathrm{sq} \mathrm{mi}$.

Gage-he1ght record.--Once-da1ly staff-gage readings obtained between 1000 and 1500 hours furnished by Nevada Irrigation District. Datum of gage is at mean sea level (levels by Nevada Irrigation District).

Contents record.--Contents computed from capacity table dated Mar. 14, 1934 .

Maxima.--January-February 1963: Maximum contents observed, 66,200 acre-ft Feb. 20 (elevation, 5,560.5 $\mathrm{ft}$ ).

1926 to December 1962: Maximum contents observed, 70,500 acre-ft for one or more days in $1937,1943,1950-51,1953-54$ (elevation, $5,565.9 \mathrm{ft}$ ).

Remarks.--Lake is formed by one rockfill and one concrete-arch dam; completed and storage began in November 1926. Total capacity, 68,200 acre-ft between elevations 5,400 ft (bottom of outlet tunnel) and 5,563 ft (crest of concrete-arch dam) above mean sea level. Flashboards are occasionally added, increasing elevation to $5,565.8 \mathrm{ft}$ and capacity to 70,400 acre- $\mathrm{ft}^{\mathrm{t}}$, all of which is avaliable for release. Lake receives water from Middle Yuba River through Milton-Bowman tunnel and releases it through Bowman-Spaulding Canal which conveys it to reservoirs of Pacific Gas and Electric Co. 
Elevation, in feet, and contents, in acre-feet, at various hours, 1963, of Bowman Lake near Grantteville, Calif.

\begin{tabular}{|c|c|c|c|c|c|c|c|c|c|}
\hline \multirow{2}{*}{ Day } & \multicolumn{2}{|c|}{ January } & \multicolumn{2}{|c|}{ February } & \multirow{2}{*}{ Day } & \multicolumn{2}{|c|}{ January } & \multicolumn{2}{|c|}{ February } \\
\hline & Elevation & Contents & Elevation & Contents & & Elevation & Contents & Elevation & Contents \\
\hline $\begin{array}{r}1 \\
2 \\
3 \\
4 \\
5 \\
6 \\
7 \\
8 \\
9 \\
10 \\
11 \\
12 \\
13 \\
14 \\
15\end{array}$ & $\begin{array}{l}5,541.0 \\
5,540.7 \\
5,540.4 \\
5,540.1 \\
5,539.8 \\
5,539.5 \\
5,539.1 \\
5,538.7 \\
5,538.4 \\
5,537.9 \\
5,537.4 \\
5,537.0 \\
5,536.7 \\
5,536.3 \\
5,535.8\end{array}$ & $\begin{array}{l}50,600 \\
50,400 \\
50,100 \\
49,900 \\
49,700 \\
49,400 \\
49,200 \\
48,900 \\
48,700 \\
48,300 \\
48,000 \\
47,700 \\
47,500 \\
47,200 \\
46,900\end{array}$ & $\begin{array}{l}5,550.0 \\
5,552.5 \\
5,553.5 \\
5,554.3 \\
5,555.3 \\
5,556.1 \\
5,556.7 \\
5,557.4 \\
5,557.8 \\
5,558.3 \\
5,558.6 \\
5,558.8 \\
5,559.4 \\
5,560.0 \\
5,560.2\end{array}$ & $\begin{array}{l}57,800 \\
59,800 \\
60,600 \\
61,200 \\
62,000 \\
62,700 \\
63,200 \\
63,700 \\
64,000 \\
64,400 \\
64,700 \\
64,800 \\
65,300 \\
65,800 \\
66,000\end{array}$ & $\begin{array}{l}16 \\
17 \\
18 \\
19 \\
20 \\
21 \\
22 \\
23 \\
24 \\
25 \\
26 \\
27 \\
28 \\
29 \\
30 \\
31\end{array}$ & $\begin{array}{l}5,535.3 \\
5,534.9 \\
5,534.5 \\
5,534.1 \\
5,533.6 \\
5,533.1 \\
5,532.7 \\
5,532.2 \\
5,531.7 \\
5,531.2 \\
5,530.8 \\
5,530.3 \\
5,529.8 \\
5,529.3 \\
5,529.4 \\
5,535.6\end{array}$ & $\begin{array}{l}46,500 \\
46,200 \\
46,000 \\
45,700 \\
45,300 \\
45,000 \\
44,700 \\
44,300 \\
44,000 \\
43,600 \\
43,400 \\
43,000 \\
42,700 \\
42,300 \\
42,400 \\
46,700\end{array}$ & $\begin{array}{c}5,560.3 \\
5,560.3 \\
5,560.4 \\
5,560.4 \\
5,560.5 \\
5,560.4 \\
5,560.4 \\
5,560.2 \\
5,560.1 \\
5,560.0 \\
5,559.9 \\
5,559.7 \\
5,559.6 \\
- \\
- \\
-\end{array}$ & $\begin{array}{c}66,000 \\
66,000 \\
66,100 \\
66,100 \\
66,200 \\
66,100 \\
66,100 \\
66,000 \\
65,900 \\
65,800 \\
65,700 \\
65,600 \\
65,500 \\
- \\
- \\
-\end{array}$ \\
\hline (1) & $1 \pi \cos n$ & 8,100 & 1ter. & & . & - & $-4,100$ & - & $+18,800$ \\
\hline
\end{tabular}

11-4165. Canyon Creek below Bowman Lake, Cal1f.

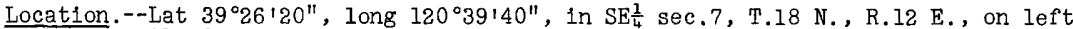
bank 1 mile downstream from Bowman Lake, 3 miles upstream from Texas Creek, and 9 miles south of Sierra City.

Drainage area. $--28.6 \mathrm{sq} \mathrm{mi}$.

Gage-he1ght record:--Water-stage recorder graph. Alt1tude of gage is $5,100 \mathrm{ft}$ (from topographic map).

Discharge record.--Stage-discharge relation defined by current-meter measurements.

Maxima.--January-February 1963: Discharge, 157 cfs 2300 hours Jan. 31 (gage helght, $3.05 \mathrm{ft}$ ).

1927 to December 1962: Discharge, 2,520 cfs Dec. 4, 1950 (gage height, $6.28 \mathrm{ft}$ ).

Remarks.--Flow regulated by French Lake Reservolr (usable capac1ty, 13,840 acre-ft), by Bowman Lake (see station 11-4155), and several smaller reservoirs.

Mean discharge, in cubic feet per second, 1963

\begin{tabular}{|c|c|c|c|c|c|c|c|c|}
\hline Day & January & February & Day & January & February & Day & January & Febmuary \\
\hline $\begin{array}{l}1 \ldots \ldots \\
2 \ldots \ldots \\
3 \ldots \ldots \\
4 \ldots \ldots \\
5 \ldots \ldots \\
6 \ldots \ldots \\
7 \ldots \ldots \\
8 \ldots \ldots \\
9 \ldots \ldots \\
10 \ldots \ldots\end{array}$ & $\begin{array}{l}0.7 \\
.6 \\
.6 \\
.6 \\
.6 \\
.5 \\
.5 \\
.5 \\
.5 \\
.5\end{array}$ & $\begin{array}{r}41 \\
5.6 \\
3.8 \\
13 \\
4.7 \\
2.1 \\
2.2 \\
2.1 \\
1.6 \\
1.8\end{array}$ & $\begin{array}{l}11 \ldots \ldots \\
12 \ldots \ldots \\
13 \ldots \ldots \\
14 \ldots \ldots \\
15 \ldots \ldots \\
16 \ldots \ldots \\
17 \ldots \ldots \\
18 \ldots \ldots \\
19 \ldots \ldots \\
20 \ldots \ldots\end{array}$ & $\begin{array}{l}0.4 \\
.5 \\
.5 \\
.5 \\
.4 \\
.4 \\
.4 \\
.4 \\
.8 \\
.4\end{array}$ & $\begin{array}{r}2.4 \\
2.1 \\
11 \\
3.0 \\
2.3 \\
2.3 \\
2.5 \\
2.4 \\
2.0 \\
1.7\end{array}$ & $\begin{array}{l}21 \ldots \ldots \\
22 \ldots \ldots \\
23 \ldots \ldots \\
24 \ldots \ldots \\
25 \ldots \ldots \\
26 \ldots \ldots \\
27 \ldots \ldots \\
28 \ldots \ldots \\
29 \ldots \ldots \\
30 \ldots \ldots \\
31 \ldots \ldots\end{array}$ & $\begin{array}{r}0.4 \\
.4 \\
.4 \\
.4 \\
.4 \\
.3 \\
.3 \\
.3 \\
.4 \\
31 \\
87 \\
\end{array}$ & $\begin{array}{r}1.6 \\
2.5 \\
5.6 \\
1.7 \\
1.3 \\
1.2 \\
1.6 \\
2.5 \\
-\ldots--- \\
-.-1\end{array}$ \\
\hline $\begin{array}{l}\text { nthly } \\
\text { noff, }\end{array}$ & 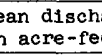 & 9 & & & & & $\begin{array}{r}4.25 \\
261 \\
\end{array}$ & $\begin{array}{r}4.56 \\
253 \\
\end{array}$ \\
\hline
\end{tabular}


11-4170. South Yuba River near Washington, Calif.

Location.--Lat $39^{\circ} 21^{\prime} 38^{\prime \prime}$, long $120^{\circ} 46^{\prime} 14^{\prime \prime}$, on line between secs. 5 and 8 , T.17 N., R.11 E., on left bank $800 \mathrm{ft}$ upstream from unnamed tributary and 1.5 miles east of Washington.

Drainage area. $--199 \mathrm{sq} \mathrm{mi}$.

Gage-height record.--Water-stage recorder graph. Altitude of gage is $2,735 \mathrm{ft}^{\mathrm{t}}$ (from river-profile map).

Discharge record.--Stage-discharge relation defined by current-meter measurements below 6,500 cf's and by slope-area measurement at 26,300 cfs.

Maxima.--January-February 1963: Discharge, 28,500 ofs 0300 hours Feb. I (gage helght, $17.16 \mathrm{ft}$, from recorder graph; $18.5 \mathrm{ft}$, from floodmarks ).

1942 to December 1962: Discharge, 26,300 cf's Dec. 23, 1955 (gage height, $17.8 \mathrm{ft}$, from floodmarks).

Remarks.--Flow affected by Lake Spaulding beginning in 1912 (capacity, 74,500 acre-ft), Bowman Lake (see station $11-4155$ ), Fordyce Lake beginning in 1926 (capacity, 46,700 acre-ft), and diversions into and out of basin for several powerhouses.

Mean discharge, in cub1c feet per second, 1963

\begin{tabular}{|c|c|c|c|c|c|c|c|c|}
\hline Day & January & February & Day & January & February & Day & January & February \\
\hline $\begin{array}{r}1 \ldots \ldots \\
2 \ldots \ldots \\
3 \ldots \ldots \\
4 \ldots \ldots \\
5 \ldots \ldots \\
6 \ldots \ldots \\
8 \ldots \ldots \\
9 \ldots \ldots \\
10 \ldots \ldots\end{array}$ & $\begin{array}{r}115 \\
112 \\
111 \\
109 \\
105 \\
102 \\
101 \\
100 \\
99 \\
98\end{array}$ & $\begin{array}{r}14,800 \\
3,600 \\
1,350 \\
1,290 \\
1,440 \\
854 \\
475 \\
264 \\
241 \\
230\end{array}$ & $\begin{array}{l}11 \ldots \ldots \\
12 \ldots \ldots \\
13 \ldots \ldots \\
14 \ldots \ldots \\
15 \ldots \ldots \\
16 \ldots \ldots \\
17 \ldots \ldots \\
18 \ldots \ldots \\
19 \ldots \ldots \\
20 \ldots \ldots\end{array}$ & $\begin{array}{l}94 \\
92 \\
95 \\
92 \\
88 \\
88 \\
88 \\
87 \\
83 \\
82\end{array}$ & $\begin{array}{l}218 \\
206 \\
451 \\
297 \\
241 \\
214 \\
210 \\
196 \\
184 \\
176\end{array}$ & $\begin{array}{l}21 \ldots \ldots \\
22 \ldots \ldots \\
23 \ldots \ldots \\
24 \ldots \ldots \\
25 \ldots \ldots \\
26 \ldots \ldots \\
27 \ldots \ldots \\
28 \ldots \ldots \\
29 \ldots \ldots \\
30 \ldots \ldots \\
31 \ldots \ldots\end{array}$ & $\begin{array}{r}82 \\
81 \\
80 \\
79 \\
41 \\
37 \\
36 \\
36 \\
41 \\
950 \\
6,190 \\
\end{array}$ & $\begin{array}{r}170 \\
162 \\
157 \\
149 \\
141 \\
92 \\
85 \\
84 \\
----- \\
--.---\end{array}$ \\
\hline $\begin{array}{l}\text { inthly } \\
\text { inoff, }\end{array}$ & disc & 2,1 & $t$ & & & & $\begin{array}{r}309 \\
19,030 \\
\end{array}$ & $\begin{array}{r}999 \\
55,490 \\
\end{array}$ \\
\hline
\end{tabular}

Gage helght, in feet, and discharge, In cublc feet per second, at indicated time, 1963

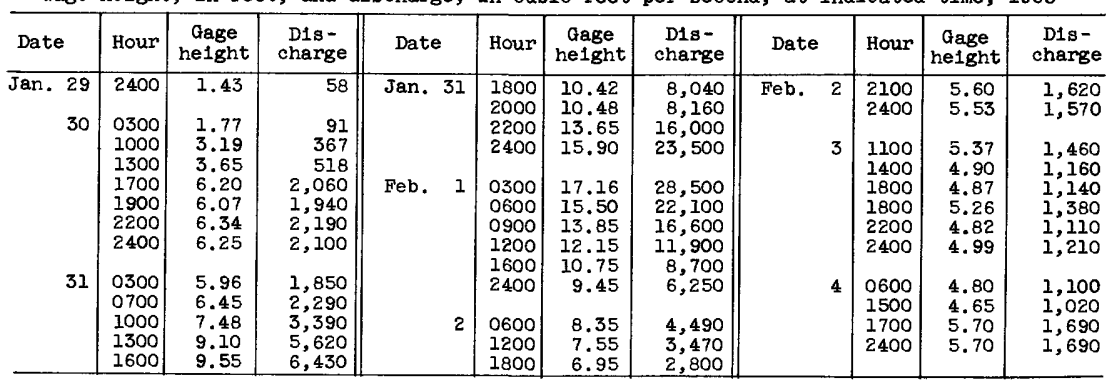


11-4171. Poorman Creek near Washington, Calif.

Location:--Lat $39^{\circ} 21^{\prime} 36^{\prime \prime}$, long $120^{\circ} 48^{\prime} 24^{\prime \prime}$, in SW $\frac{1}{4}$ sec.l, T.17 N., R.10 E., on left bank just downstream from U.S. Forest Service road bridge, 0.4 mile west of Washington and 1.4 miles downstream from Deadman Creek.

Drainage area. $--23.2 \mathrm{sq} \mathrm{mi}$.

Gage-helght record.--Digital-recorder tape punched at 15-minute intervals. Alt1tude of gage $1 \mathrm{~s} 2,600 \mathrm{ft}$ (from topographic map).

Discharge record.--Stage-discharge relation defined by current-meter measurements below $1,700 \mathrm{c}$ 's and by slope-area measurement at 4,320 cf's.

Maxima.--January-February 1963: Discharge, 4,320 efs 2200 hours Jan. 31 (gage height, $10.95 \mathrm{ft}$, from recorder graph; $12.1 \mathrm{ft}$, from floodmarks).

1961 to December 1962: Discharge, $2,380 \mathrm{cfs}$ 0ct. 13, 1962 (gage height, $8.85 \mathrm{ft}$ ).

Mean discharge, in cub1c feet per second, 1963

\begin{tabular}{|c|c|c|c|c|c|c|c|c|}
\hline Day & January & February & Day & January & February & Day & January & February \\
\hline $\begin{array}{c}1 \ldots \ldots \\
2 \ldots \ldots \\
4 \ldots \ldots \\
5 \ldots \ldots \\
6 \ldots \ldots \\
8 \ldots \ldots \\
9 \ldots \ldots \\
10 \ldots \ldots\end{array}$ & $\begin{array}{l}32 \\
30 \\
30 \\
30 \\
29 \\
28 \\
27 \\
26 \\
26 \\
26\end{array}$ & $\begin{array}{r}1,590 \\
478 \\
310 \\
236 \\
186 \\
149 \\
129 \\
112 \\
103 \\
99\end{array}$ & $\begin{array}{l}11 \ldots \ldots \\
12 \ldots \ldots \\
13 \ldots \ldots \\
14 \ldots \ldots \\
15 \ldots \ldots \\
16 \ldots \ldots \\
17 \ldots \ldots \\
18 \ldots \ldots \\
19 \ldots \ldots \\
20 \ldots \ldots\end{array}$ & $\begin{array}{l}24 \\
22 \\
24 \\
24 \\
24 \\
23 \\
22 \\
22 \\
22 \\
21\end{array}$ & $\begin{array}{r}89 \\
84 \\
162 \\
113 \\
95 \\
88 \\
84 \\
78 \\
72 \\
70\end{array}$ & $\begin{array}{l}21 \ldots \ldots \\
22 \ldots \ldots \\
23 \ldots \ldots \\
24 \ldots \ldots \\
25 \ldots \ldots \\
26 \ldots \ldots \\
27 \ldots \ldots \\
28 \ldots \ldots \\
29 \ldots \ldots \\
30 \ldots \ldots \\
31 \ldots \ldots\end{array}$ & $\begin{array}{r}22 \\
22 \\
21 \\
21 \\
20 \\
20 \\
20 \\
20 \\
22 \\
355 \\
2,120\end{array}$ & $\begin{array}{r}66 \\
63 \\
59 \\
57 \\
55 \\
53 \\
50 \\
49 \\
----- \\
-----\end{array}$ \\
\hline \multicolumn{7}{|c|}{ 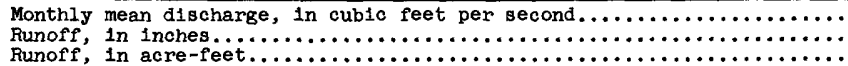 } & $\begin{array}{r}102 \\
5.09 \\
6,300 \\
\end{array}$ & $\begin{array}{r}171 \\
7.66 \\
9,480 \\
\end{array}$ \\
\hline
\end{tabular}

Gage height, in feet, and discharge, in cublc feet per second, at indicated t1me, 1963

\begin{tabular}{|c|c|c|c|c|c|c|c|c|c|c|c|}
\hline Date & Hour & $\begin{array}{c}\text { Gage } \\
\text { height }\end{array}$ & $\begin{array}{l}\text { D1s - } \\
\text { charge }\end{array}$ & Date & Hour & $\begin{array}{c}\text { Gage } \\
\text { helght }\end{array}$ & $\begin{array}{l}\text { D1s- } \\
\text { charge }\end{array}$ & Date & Hour & $\begin{array}{c}\text { Gage } \\
\text { he1ght }\end{array}$ & $\begin{array}{l}\text { Dis- } \\
\text { charge }\end{array}$ \\
\hline $\begin{array}{r}\text { Jan. } 29 \\
30\end{array}$ & $\begin{array}{l}2400 \\
0400 \\
0600 \\
0800 \\
0900 \\
1200 \\
1400 \\
1600 \\
1800 \\
2100 \\
2200 \\
2400\end{array}$ & $\begin{array}{l}2.81 \\
2.98 \\
3.14 \\
3.52 \\
3.77 \\
4.09 \\
4.68 \\
5.54 \\
5.91 \\
6.39 \\
6.37 \\
6.06\end{array}$ & \begin{tabular}{r|}
29 \\
38 \\
48 \\
79 \\
107 \\
160 \\
297 \\
569 \\
714 \\
926 \\
917 \\
777 \\
\end{tabular} & Feb. 1 & $\begin{array}{l}0200 \\
0400 \\
0700 \\
1100 \\
1500 \\
1600 \\
1800 \\
1900 \\
2000 \\
2200 \\
2400 \\
0300\end{array}$ & $\begin{array}{r}5.78 \\
5.78 \\
6.22 \\
7.95 \\
8.96 \\
9.08 \\
10.03 \\
10.35 \\
10.47 \\
10.95 \\
10.67 \\
10.17\end{array}$ & $\begin{array}{r}662 \\
662 \\
849 \\
1,740 \\
2,470 \\
2,560 \\
3,400 \\
3,720 \\
3,840 \\
4,320 \\
4,040 \\
3,540 \\
\end{array}$ & Feb, 1 & $\begin{array}{l}0600 \\
0800 \\
1100 \\
1400 \\
1900 \\
2000 \\
2200 \\
2400 \\
\\
0600 \\
1200 \\
1800 \\
2400\end{array}$ & $\begin{array}{l}8.40 \\
7.57 \\
6.80 \\
6.43 \\
6.22 \\
6.27 \\
6.00 \\
5.80 \\
5.54 \\
5.33 \\
5.17 \\
5.09\end{array}$ & $\begin{array}{r}2,040 \\
1,490 \\
1,080 \\
909 \\
814 \\
837 \\
720 \\
640 \\
\\
536 \\
461 \\
405 \\
379\end{array}$ \\
\hline
\end{tabular}


11-4175. South Yuba River at Jones Bar, Calif.

Location.--Lat $39^{\circ} 17^{\prime} 32^{\prime \prime}$, long $121^{\circ} 06^{\prime} 13^{\prime \prime}$, near center of sec.32, T.17 N., R. 8 E., on left bank $100 \mathrm{ft}$ upstream from Rush Creek, $0.9 \mathrm{mile}$ downstream from bridge on State Highway 49 , and 5 miles northwest of Grass Valley.

Drainage area. $--310 \mathrm{sq} \mathrm{mi}$.

Gage-helght record.--Water-stage recorder graph, except Feb. 1-28. Altitude of gage is $1,060 \mathrm{ft}$ (from river-profile map).

Discharge record.--Stage-discharge relation defined by current-meter measurements below 18,000 cfs and extended above on basis of comparison with peak for station near Washington and study of runoff per square mile for intervening area. Discharge for period of no gage-height record estimated on basis of three discharge measurements, trend of recorder chart, weather records, and comparison with station near washington.

Maxima.--January-February 1963: Discharge, about 40,000 cfs 2400 hours Jan. 31 (gage height, $21.5 \mathrm{ft}$, from floodmarks). 1940-48, 1959 to December 1962: Discharge, 20,700 cfs 0ct. 13, 1962 (gage height, $17.70 \mathrm{ft}$ )

Flood of Dec. 23, 1955, reached a stage of $28.7 \mathrm{ft}$.

Remarks.--Flow affected by Lake Spaulding (capacity, 74,500 acre-ft), Fordyce Lake (capacity, 46,700 acre ft), Bowman Lake (see station 11-4155), many smaller reservolis and diversion into and out of the basin for power generation and irrigation.

Mean discharge, in cublc feet per second, 1963

\begin{tabular}{|c|c|c|c|c|c|c|c|c|}
\hline Day & January & February & Day & January & February & Day & January & February \\
\hline $\begin{array}{c}1 \ldots \ldots \\
2 \ldots \ldots \\
3 \ldots \ldots \\
4 \ldots \ldots \\
5 \ldots \ldots \\
7 \ldots \ldots \\
8 \ldots \ldots \\
9 \ldots \ldots \\
10 \ldots \ldots\end{array}$ & $\begin{array}{l}217 \\
212 \\
209 \\
209 \\
200 \\
192 \\
187 \\
184 \\
180 \\
177\end{array}$ & $\begin{array}{r}18,000 \\
6,000 \\
2,500 \\
2,100 \\
2,300 \\
1,500 \\
1,000 \\
760 \\
690 \\
660\end{array}$ & $\begin{array}{l}11 \ldots \ldots \\
12 \ldots \ldots \\
13 \ldots \ldots \\
14 \ldots \ldots \\
15 \ldots \ldots \\
16 \ldots \ldots \\
17 \ldots \ldots \\
18 \ldots \ldots \\
19 \ldots \ldots \\
20 \ldots \ldots\end{array}$ & $\begin{array}{l}173 \\
158 \\
166 \\
165 \\
161 \\
159 \\
158 \\
157 \\
152 \\
148\end{array}$ & $\begin{array}{r}600 \\
560 \\
1,100 \\
840 \\
680 \\
600 \\
580 \\
540 \\
500 \\
480\end{array}$ & $\begin{array}{l}21 \ldots \ldots \\
22 \ldots \ldots \\
23 \ldots \ldots \\
24 \ldots \ldots \\
25 \ldots \ldots \\
26 \ldots \ldots \\
27 \ldots \ldots \\
28 \ldots \ldots \\
29 \ldots \ldots \\
30 \ldots \ldots \\
31 \ldots \ldots\end{array}$ & $\begin{array}{r}149 \\
150 \\
153 \\
150 \\
134 \\
101 \\
97 \\
97 \\
106 \\
1,540 \\
12,500\end{array}$ & $\begin{array}{r}450 \\
430 \\
410 \\
400 \\
380 \\
310 \\
270 \\
260 \\
---- \\
---.--\end{array}$ \\
\hline $\begin{array}{l}\text { onthly } \\
\text { inoff, }\end{array}$ & $\begin{array}{l}\text { an d1sc } \\
\text { acre-1 }\end{array}$ & 3 & $f e$ & & & & $\begin{array}{r}605 \\
37,170 \\
\end{array}$ & $\begin{array}{r}1,604 \\
89,060 \\
\end{array}$ \\
\hline
\end{tabular}

Gage he1ght, in feet, and discharge, in cublc feet per second, at indicated t1me, 1963

\begin{tabular}{|c|c|c|c|c|c|c|c|c|c|c|c|}
\hline Date & Hour & $\begin{array}{c}\text { Gage } \\
\text { height }\end{array}$ & $\begin{array}{l}\text { D1s- } \\
\text { charge }\end{array}$ & Date & Hour & $\begin{array}{c}\text { Gage } \\
\text { helght }\end{array}$ & $\begin{array}{c}\text { Dis- } \\
\text { charge }\end{array}$ & Date & Hour & $\begin{array}{c}\text { Gage } \\
\text { height }\end{array}$ & $\begin{array}{c}\text { Dis- } \\
\text { charge }\end{array}$ \\
\hline $\begin{array}{r}\text { Jan. } 29 \\
30\end{array}$ & $\begin{array}{l}2400 \\
0500 \\
0800 \\
1200 \\
1400 \\
\end{array}$ & $\begin{array}{l}4.78 \\
4.47 \\
4.84 \\
5.70 \\
6.75 \\
\end{array}$ & $\begin{array}{l}137 \\
\\
175 \\
233 \\
441 \\
828 \\
\end{array}$ & Jan. 30 & $\begin{array}{l}1600 \\
1800 \\
2100 \\
2200 \\
2400\end{array}$ & $\begin{array}{r}8.20 \\
9.45 \\
11.46 \\
11.37 \\
11.38\end{array}$ & $\begin{array}{l}1,640 \\
2,640 \\
5,030 \\
4,910 \\
4,920\end{array}$ & Jan. 31 & $\begin{array}{l}0500 \\
0600 \\
1200 \\
1500 \\
1800 \\
2400 \\
\end{array}$ & $\begin{array}{l}10.95 \\
10.96 \\
12.75 \\
14.70 \\
16.60 \\
21.50\end{array}$ & $\begin{array}{r}4,340 \\
4,350 \\
7,110 \\
11,200 \\
16,600 \\
40,000 \\
\end{array}$ \\
\hline
\end{tabular}


11-4180. Yuba River at Englebright Dam, Calif.

Location.--Lat $39^{\circ} 14^{\prime} 22^{\prime \prime}$, long $121^{\circ} 16^{\prime} 00^{\prime \prime}$, in SW $\frac{1}{4} \mathrm{SE} \frac{1}{4}$ sec.14, T.16 N., R.6 E., on left bank upstream from spillway of Englebright Dam, 1 mile upstream from Deer Creek and 2.5 miles northeast of Smartville.

Drainage area. $--1,104 \mathrm{sq} \mathrm{m} 1$.

Gage-height record.--Water-stage recorder graph, flowmeter in penstock and watt meter in powerhouse just below dam. Datum of gage is at mean sea level (levels by Corps of Engineers).

Discharge record.--Stage-discharge relation defined by current-meter measurements below 25,000 cfs, by computation of peak flow over spillway of dam at $147,000 \mathrm{cfs}$.

Maxima.--January-February 1963: Discharge, 150,000 cfs 0430 hours Feb. 1, including flow through powerhouse.

1941 to December 1962: Discharge, $148,000 \mathrm{cfs}$ Dec. 23, 1955, including flow through powerhouse.

Remarks.--Flow partly regulated by several reservoirs. Records show total flow over Englebright Dam spillway and through and past powerhouse. Records of flow through powerplant furnished by Pacific Gas and Electric Co.

Mean d1scharge, in cub1c feet per second, 1963

\begin{tabular}{|c|c|c|c|c|c|c|c|c|}
\hline Day & January & February & Day & January & February & Day & January & February \\
\hline $\begin{array}{r}1 \ldots \ldots \\
2, \ldots . \\
3 \ldots \ldots \\
4 \ldots \ldots \\
5 \ldots \ldots \\
6 \ldots \ldots \\
7 \ldots \ldots \\
8 \ldots \ldots \\
10 \ldots \ldots\end{array}$ & $\begin{array}{l}1,360 \\
1,330 \\
1,280 \\
1,260 \\
1,220 \\
1,170 \\
1,130 \\
1,100 \\
1,070 \\
1,060\end{array}$ & $\begin{array}{r}98,900 \\
31,100 \\
16,200 \\
11,200 \\
9,890 \\
7,530 \\
6,020 \\
5,560 \\
5,260 \\
4,840\end{array}$ & $\begin{array}{l}11 \ldots . . . \\
12 . \ldots . \\
13 . \ldots . \\
14 \ldots . \\
15 . \ldots \\
16, \ldots . \\
17 . \ldots . \\
19 . \ldots . \\
20 . \ldots\end{array}$ & $\begin{array}{l}997 \\
942 \\
931 \\
964 \\
991 \\
985 \\
963 \\
952 \\
925 \\
917\end{array}$ & $\begin{array}{l}4,500 \\
4,210 \\
6,380 \\
5,960 \\
4,680 \\
4,120 \\
3,820 \\
3,520 \\
3,000 \\
2,800\end{array}$ & $\begin{array}{l}21 \ldots \ldots \\
22 \ldots \ldots \\
23 \ldots \ldots \\
24 \ldots \ldots \\
25 \ldots \ldots \\
26 \ldots \ldots \\
27 \ldots \ldots \\
28 \ldots \ldots \\
29 \ldots \ldots \\
30 \ldots \ldots \\
31 \ldots \ldots\end{array}$ & $\begin{array}{r}936 \\
947 \\
926 \\
926 \\
916 \\
875 \\
850 \\
859 \\
883 \\
2,520 \\
57,600\end{array}$ & $\begin{array}{r}2,700 \\
2,550 \\
2,400 \\
2,300 \\
2,150 \\
2,100 \\
2,000 \\
1,900 \\
----- \\
-----\end{array}$ \\
\hline & & & & & & & $\begin{array}{r}2,896 \\
178,100 \\
\end{array}$ & $\begin{array}{r}9,200 \\
510,900 \\
\end{array}$ \\
\hline
\end{tabular}

Gage height, in feet, and discharge, in cubic feet per second, at 1ndicated time, 1963

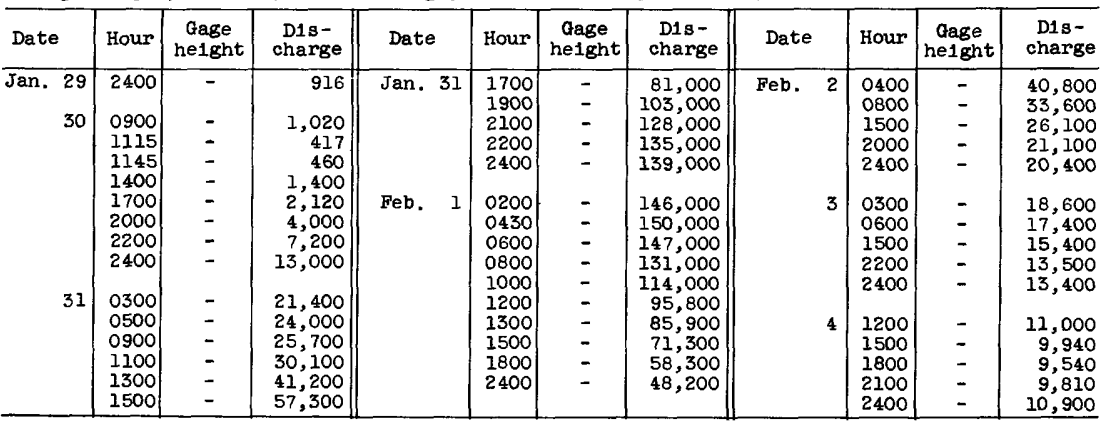


11-4185. Deer Creek near Smartv111e, Calif.

Location.--Lat $39^{\circ} 13^{\prime} 28^{\prime \prime}$, 1ong $121^{\circ} 16^{\prime} 03^{\prime \prime}$, in SW $\frac{1}{4} S E \frac{1}{4}$ sec. 23 , T.16 N., R.6 E., on left bank $400 \mathrm{ft}^{\prime} \mathrm{upstream}$ from county road bridge, 0.9 mile upstream from mouth, and 2 miles northeast of Smartville.

Dralnage area. $--84.6 \mathrm{sq} \mathrm{ml}$.

Gage-helght record.--Water-stage recorder graph. Altitude of gage is $630 \mathrm{ft}$ (from river-profile map).

Discharge record.--Stage-discharge relation defined by current-meter measurements below 5,200 cfs.

Maxima --January-February 1963: Discharge, 5,810 cf's 2000 hours Jan. 31 (gage he1ght, $10.10 \mathrm{ft}$ ).

1935 to December 1962: Discharge, 11,600 cfs Oct. 13, 1962 (gage helght, $13.77 \mathrm{ft})$.

Remarks.--Floodflow affected by Scotts Flat Reservolr (usable capac1ty, 49,000 acre-ft) and Deer Creek Reservolr (capac1ty, 1,400 acre-ft).

Mean discharge, in cubic feet per second, 1963

\begin{tabular}{|c|c|c|c|c|c|c|c|c|}
\hline Day & Jamuary & February & Day & Jamuary & February & Day & January & February \\
\hline $\begin{array}{r}1 \ldots \ldots \\
3 \ldots \ldots \\
4 \ldots \ldots \\
5 \ldots \ldots \\
6 \ldots \ldots \\
7 \ldots \ldots \\
8 \ldots \ldots \\
10 \ldots \ldots\end{array}$ & $\begin{array}{r}106 \\
105 \\
106 \\
102 \\
84 \\
87 \\
90 \\
92 \\
90 \\
93\end{array}$ & $\begin{array}{r}3,650 \\
1,580 \\
765 \\
536 \\
427 \\
318 \\
252 \\
216 \\
194 \\
181\end{array}$ & $\begin{array}{l}11 \ldots \ldots \\
12 \ldots \ldots \\
13 \ldots \ldots \\
14 \ldots \ldots \\
15 \ldots \ldots \\
16 \ldots \ldots \\
17 \ldots \ldots \\
18 \ldots \ldots \\
19 \ldots \ldots \\
20 \ldots \ldots\end{array}$ & $\begin{array}{r}94 \\
94 \\
94 \\
94 \\
94 \\
94 \\
96 \\
94 \\
115 \\
111\end{array}$ & $\begin{array}{l}153 \\
137 \\
500 \\
312 \\
248 \\
230 \\
222 \\
207 \\
199 \\
200\end{array}$ & $\begin{array}{l}21 \ldots \ldots \\
22 \ldots \ldots \\
23 \ldots \ldots \\
24 \ldots \ldots \\
25 \ldots \ldots \\
26 \ldots \ldots \\
27 \ldots \ldots \\
28 \ldots \ldots \\
29 \ldots \ldots \\
30 \ldots \ldots \\
31 \ldots \ldots\end{array}$ & $\begin{array}{r}99 \\
92 \\
86 \\
88 \\
81 \\
81 \\
86 \\
86 \\
89 \\
1,350 \\
4,080 \\
\end{array}$ & 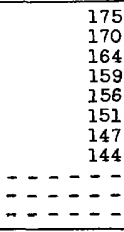 \\
\hline $\begin{array}{l}\text { onthly } \\
\text { anoff, }\end{array}$ & $\begin{array}{l}\text { in dis } \\
\text { acre - }\end{array}$ & , & feet & & & & $\begin{array}{r}263 \\
16,170 \\
\end{array}$ & $\begin{array}{r}421 \\
23,380 \\
\end{array}$ \\
\hline
\end{tabular}

Gage height, in feet, and discharge, in cubic feet per second, at indicated time, 1963

\begin{tabular}{|c|c|c|c|c|c|c|c|c|c|c|c|}
\hline Date & Hour & $\begin{array}{c}\text { Gage } \\
\text { height }\end{array}$ & $\begin{array}{c}\text { D1s- } \\
\text { charge }\end{array}$ & Date & Hour & $\begin{array}{c}\text { Gage } \\
\text { helght }\end{array}$ & $\begin{array}{c}\text { Dis - } \\
\text { charge }\end{array}$ & Date & Hour & $\begin{array}{c}\text { Gage } \\
\text { he1ght }\end{array}$ & $\begin{array}{l}\text { Dis- } \\
\text { charge }\end{array}$ \\
\hline $\begin{array}{r}\text { Jan. } \\
30\end{array}$ & $\begin{array}{l}2400 \\
0300 \\
0600 \\
0800 \\
1100 \\
1400 \\
1600 \\
1700 \\
1800 \\
2000 \\
2200 \\
2400 \\
0200 \\
\end{array}$ & $\begin{array}{l}2.50 \\
2.66 \\
2.75 \\
2.92 \\
3.45 \\
4.60 \\
5.80 \\
6.90 \\
7.75 \\
8.32 \\
9.12 \\
8.38 \\
7.75\end{array}$ & $\begin{array}{r}100 \\
120 \\
133 \\
157 \\
250 \\
590 \\
1,310 \\
2,210 \\
3,050 \\
3,650 \\
4,550 \\
3,720 \\
3,050\end{array}$ & Jan. 31 & $\begin{array}{l}0300 \\
0400 \\
0600 \\
0800 \\
0900 \\
1100 \\
1300 \\
1500 \\
1700 \\
1800 \\
2000 \\
2100 \\
2200 \\
2400\end{array}$ & $\begin{array}{r}7.67 \\
7.81 \\
7.84 \\
8.10 \\
8.08 \\
8.22 \\
8.10 \\
8.45 \\
9.60 \\
9.88 \\
10.10 \\
9.93 \\
9.89 \\
9.82\end{array}$ & $\begin{array}{l}2,970 \\
3,110 \\
3,140 \\
3,410 \\
3,390 \\
3,540 \\
3,410 \\
3,800 \\
5,130 \\
5,500 \\
5,810 \\
5,570 \\
5,520 \\
5,420\end{array}$ & Feb. & $\begin{array}{l}0400 \\
0500 \\
0600 \\
0800 \\
1200 \\
1700 \\
2100 \\
2300 \\
2400 \\
0200 \\
0900 \\
1600 \\
2200 \\
2400\end{array}$ & $\begin{array}{l}9.15 \\
9.21 \\
9.18 \\
8.91 \\
8.28 \\
7.56 \\
7.12 \\
6.95 \\
6.95 \\
6.87 \\
6.28 \\
5.81 \\
5.52 \\
5.43\end{array}$ & $\begin{array}{l}4,590 \\
4,660 \\
4,630 \\
4,300 \\
3,610 \\
2,860 \\
2,420 \\
2,260 \\
2,260 \\
2,180 \\
1,670 \\
1,320 \\
1,110 \\
1,050 \\
\end{array}$ \\
\hline
\end{tabular}

11-4203. W11low Glen Creek near Rackerby, Callf.

(Crest-stage station)

Location.--Lat $39^{\circ} 24^{\prime} 22^{\prime \prime}$, long $121^{\circ} 18^{\prime} 31^{\prime \prime}$, In NW $\frac{1}{4}$ sec.21, T.18 N., R.6 E., 2 miles southeast of Rackerby.

Drainage area. $--1.95 \mathrm{sq} \mathrm{ml}$.

Gage-height record.--Crest stages only. Alt1tude of gage 1s 1,890 ft (from topographic map).

D1scharge record.--Stage-discharge relation defined by current-meter measurements below $83 \mathrm{cf}$ 's and by computation of flow through culvert and flow over the road at 344 cf's.

Maxima --January-February 1963: Discharge, $108 \mathrm{cfs}$ Jan. 31 (gage he1ght, $6.64 \mathrm{ft}$ ). August to December 1962: Discharge, 344 cf's 0ct. 13, 1962 (gage helght, 10.75 $\mathrm{ft}$, from crest-stage gage; $10.90 \mathrm{ft}$, from h1gh-water profile). 
11-4210. Yuba River near Marysville, Calif.

Location.--Lat $39^{\circ} 10^{\prime} 35^{\prime \prime}$, long $121^{\circ} 31^{\prime} 25^{\prime \prime}$, on left bank in New Helvetia land grant, 4.2 miles northeast of Marysville, Yuba County, and 5 miles downstream from Dry Creek.

Drainage area. $-1,340 \mathrm{sq} \mathrm{mi}$.

Gage-height record.--Water-stage recorder graph, except 0200-1400 hours Feb. 1 and 1500 hours Feb. 5 to 1300 hours Feb. 8. The graph for Feb. 1 was reconstructed based on floodmarks, estimated time of peak and the shape of the trace for the station at Englebright Darl.

Discharge record.--Stage-discharge relation defined by current-meter measurements below 50,000 cfs and by Corps of Engineers flood-routing studies for 100,000, 146,000 , and $160,000 \mathrm{cfs}$. There was backwater from the Feather River about 1100 hours Feb. 1 to about 1200 hours Feb. 3. Discharge for Feb. 5-8 was estimated on basis of normal recession.

Maxima.--January-February 1963: Discharge, 146,000 ofs about 0700-0800 hours Feb. 1 (gage height, $88.9 \mathrm{ft}$, from floodmarks).

1943 to December 1962: Discharge, 160,000 cfs Dec. 23, 1955 (gage height, $88.85 \mathrm{ft}$, from floodmarks).

Remarks.--Flow affected by several reservoirs above station (see station 11-4180).

Mean d1scharge, in cubic feet per second, 1963

\begin{tabular}{|c|c|c|c|c|c|c|c|c|}
\hline Day & January & February & Day & January & February & Day & January & February \\
\hline $\begin{array}{c}\ldots \ldots \\
2 \ldots \ldots \\
3 \ldots \ldots \\
4 \ldots \ldots \\
5 \ldots \ldots \\
6 \ldots \ldots \\
7 \ldots \ldots \\
9 \ldots \ldots \\
10 \ldots \ldots\end{array}$ & $\begin{array}{l}1,320 \\
1,280 \\
1,260 \\
1,220 \\
1,180 \\
1,200 \\
1,270 \\
1,150 \\
1,130 \\
1,110\end{array}$ & $\begin{array}{r}101,000 \\
35,000 \\
19,100 \\
13,900 \\
11,600 \\
8,140 \\
6,820 \\
5,800 \\
5,080 \\
4,600\end{array}$ & $\begin{array}{l}11 \ldots \ldots \\
12 \ldots \ldots \\
13 \ldots \ldots \\
14 \ldots \ldots \\
15 \ldots \ldots \\
16 \ldots \ldots \\
17 \ldots \ldots \\
18 \ldots \ldots \\
19 \ldots \ldots \\
20 \ldots \ldots\end{array}$ & $\begin{array}{l}1,110 \\
1,060 \\
1,040 \\
1,060 \\
1,100 \\
1,110 \\
1,140 \\
1,060 \\
1,050 \\
1,140\end{array}$ & $\begin{array}{l}4,120 \\
3,580 \\
6,880 \\
6,970 \\
4,910 \\
3,990 \\
3,670 \\
3,340 \\
2,980 \\
2,820\end{array}$ & $\begin{array}{l}21 \ldots \ldots \\
22 \ldots \ldots \\
23 \ldots \ldots \\
24 \ldots \ldots \\
25 \ldots \ldots \\
26 \ldots \ldots \\
27 \ldots \ldots \\
28 \ldots \ldots \\
29 \ldots \ldots \\
30 \ldots \ldots \\
31 \ldots \ldots\end{array}$ & $\begin{array}{r}1,120 \\
1,100 \\
1,080 \\
1,080 \\
1,070 \\
1,020 \\
1,000 \\
1,000 \\
1,030 \\
3,050 \\
46,100\end{array}$ & $\begin{array}{r}2,660 \\
2,530 \\
2,350 \\
2,270 \\
2,180 \\
2,120 \\
1,950 \\
1,880 \\
---.-- \\
---.-- \\
--.--\end{array}$ \\
\hline \multicolumn{7}{|c|}{ 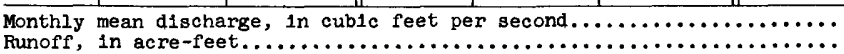 } & $\begin{array}{r}2,634 \\
161,900 \\
\end{array}$ & $\begin{array}{r}9,723 \\
540,000\end{array}$ \\
\hline
\end{tabular}

Gage he1ght, In feet, and discharge, in cublc feet per second, at ind1cated t1me, 1963

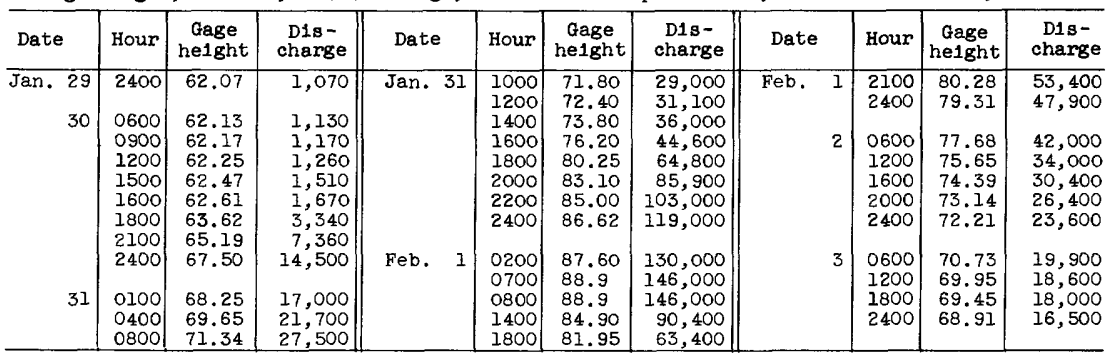


11-4230. Bear River near Auburn, Calif.

Location.--Lat $39^{\circ} 00^{\prime} 45^{\prime \prime}$, long $121^{\circ} 06^{\prime} 10^{\prime \prime}$, in $\mathrm{NE} \frac{1}{4}$ sec.5, T.13 N., R.8 E., on right bank $200 \mathrm{ft}$ upstream from bridge on State Highway $49,2.6$ miles upstream from Wolf Creek, and 8 miles north of Auburn.

Drainage area. $--139 \mathrm{sq} \mathrm{mi}$.

Gage-height record.--Water-stage recorder graph. Altitude of gage is $1,250 \mathrm{ft}$ (from topographic map).

Discharge record.--Stage-discharge relation defined by current-meter measurements below 9,500 cfs and by computation of flow over dam at 19,100 and 19,300 cfs.

Maxima.--January-February 1963: Discharge, 19,100 cfs 2400 hours Jan. 31 (gage height, $16.15 \mathrm{ft}$ ).

1940 to December 1962: Discharge, 19,700 cfs Dec. 22, 1955 (gage height, $16.56 \mathrm{ft}$ ).

Remarks.--Flow affected by Lake Combie (usable capacity, 7,840 acre-ft) and other reservoirs.

Mean discharge, in cubic feet per second, 1963

\begin{tabular}{|c|c|c|c|c|c|c|c|c|}
\hline Day & January & February & Day & Januery & February & Day & January & February \\
\hline $\begin{array}{r}1 \ldots \ldots \\
2 \ldots \ldots \\
3 \ldots \ldots \\
4 \ldots \ldots \\
5 \ldots \ldots \\
6 \ldots \ldots \\
7 \ldots \ldots \\
8 \ldots \ldots \\
9 \ldots \ldots \\
10 . \ldots .\end{array}$ & $\begin{array}{l}218 \\
228 \\
245 \\
220 \\
212 \\
197 \\
195 \\
188 \\
190 \\
190\end{array}$ & $\begin{array}{r}10,600 \\
3,120 \\
1,890 \\
1,390 \\
1,100 \\
919 \\
850 \\
710 \\
680 \\
655\end{array}$ & $\begin{array}{l}11 \ldots \ldots \\
12 \ldots \ldots \\
13 \ldots \ldots \\
14 \ldots \ldots \\
15 \ldots \ldots \\
16 \ldots \ldots \\
17 \ldots \ldots \\
19 \ldots \ldots \\
20 \ldots \ldots\end{array}$ & $\begin{array}{l}183 \\
170 \\
118 \\
146 \\
152 \\
127 \\
122 \\
125 \\
122 \\
120\end{array}$ & $\begin{array}{r}574 \\
556 \\
1,430 \\
1,030 \\
750 \\
632 \\
569 \\
524 \\
464 \\
460\end{array}$ & $\begin{array}{l}21 \ldots \ldots \\
22, \ldots \ldots \\
23 \ldots \ldots \\
24 \ldots \ldots \\
25 \ldots \ldots \\
26 \ldots \ldots \\
27 \ldots \ldots \\
28 \ldots \ldots \\
29 \ldots \ldots \\
30 \ldots \ldots \\
31 \ldots \ldots\end{array}$ & $\begin{array}{r}122 \\
116 \\
112 \\
113 \\
113 \\
65 \\
36 \\
40 \\
38 \\
1,180 \\
8,410\end{array}$ & $\begin{array}{r}428 \\
383 \\
365 \\
348 \\
324 \\
292 \\
247 \\
232 \\
---0 \\
-0 .-\end{array}$ \\
\hline & & & & & & & $\begin{array}{r}446 \\
3.70 \\
27,410\end{array}$ & $\begin{array}{r}1,126 \\
8.43 \\
62,520\end{array}$ \\
\hline
\end{tabular}

Qage height, in feet, and discharge, in cublc feet per second, at indicated t1me, 1963

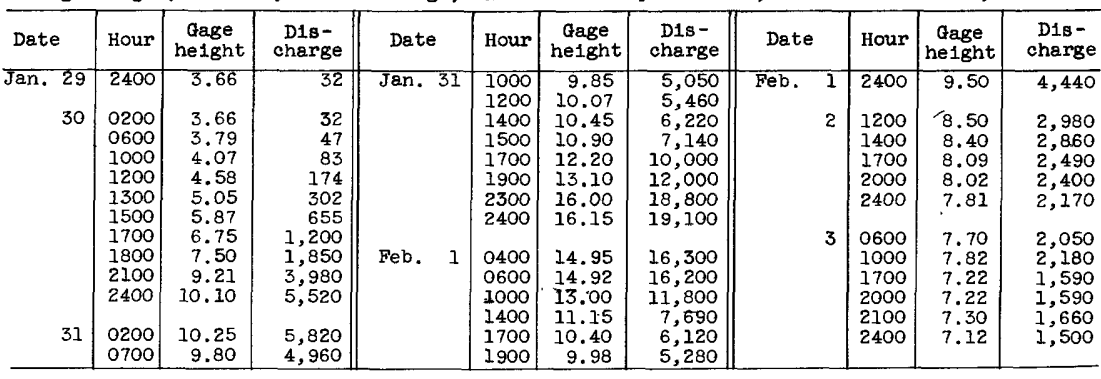

11-4230.5. Magnolia Creek near Auburn, Calif.

(Crest-stage station)

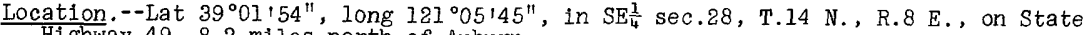
Highway $49,8.2$ miles north of Auburn.

Drainage area. $--5.65 \mathrm{sq} \mathrm{mi}$.

Gage-helght record.--Crest stages only. Altitude of gage is 1,385 ft (from topographic mapl.

Discharge record.--Stage-discharge relation defined by current-meter measurements. below $77 \mathrm{cfs}$ and by computation of flow through road culvert at 408 and $1,380 \mathrm{crs}$.

Maxima.--January-February 1963: Discharge, $408 \mathrm{cfs} F \mathrm{Feb} .1$ (gage height, $6.82 \mathrm{ft}$ ). August to December 1962: Discharge, 1,380 cfs 0ct. 13, 1962 (gage height. $12.01 \mathrm{ft}$ ). 
11-4240. Bear River near Wheatland, Calif.

Location.--Lat $39^{\circ} 00^{\prime} 01^{\prime \prime}$, long $121^{\circ} 24120^{\prime \prime}$, in sec.3, T.13 N., R.5 E., in midstream on downstream side of bridge on U.S. Highway $99 \mathrm{E}, 1$ mile southeast of wheatland and 6.5 miles downstream from Rock Creek.

Drainage area. $--292 \mathrm{sq} \mathrm{mi}$.

Gage-height record.--Water-stage recorder graph, except Feb. 12, 18-28. Altitude of gage is $78 . \overline{9} 2 \mathrm{ft}$ above mean sea level (levels by California Department of Water Resources).

Discharge record.--Stage-discharge relation defined by current-meter measurements. Discharge for periods of no gage-height record estimated on basis of records for station near Auburn.

Maxima.--January-February 1963: Discharge, 22,000 cf's 0500 hours Feb. 1 (gage height, $13.95 \mathrm{ft}$ ).

1928 to December 1962: Discharge, 33,000 cfs Dec. 22, 1955 (gage height, $19.30 \mathrm{ft})$; gage height, $20.83 \mathrm{ft}$ Nov. $21,1950$.

Remarks.--Flows affected by detention storage in partly-constructed Camp Far West Reservoir.

Mean d1scharge, in cublc feet per second, 1963

\begin{tabular}{|c|c|c|c|c|c|c|c|c|}
\hline Day & January & February & Day & January & February & Day & January & February \\
\hline $\begin{array}{c}1 \ldots \ldots \\
3 \ldots \ldots \\
4 \ldots \ldots \\
5 \ldots \ldots \\
6 \ldots \ldots \\
7 \ldots \ldots \\
9 \ldots \ldots \\
10 \ldots \ldots\end{array}$ & $\begin{array}{l}310 \\
305 \\
323 \\
310 \\
293 \\
289 \\
273 \\
269 \\
265 \\
273\end{array}$ & $\begin{array}{r}16,100 \\
5,340 \\
3,210 \\
2,030 \\
1,480 \\
1,160 \\
1,050 \\
843 \\
780 \\
822\end{array}$ & $\begin{array}{l}11 \ldots \ldots \\
12 \ldots \ldots \\
13 \ldots \ldots \\
14 \ldots \ldots \\
15 \ldots \ldots \\
16 \ldots \ldots \\
17 \ldots \ldots \\
18 \ldots \ldots \\
19 \ldots \ldots \\
20 \ldots \ldots\end{array}$ & $\begin{array}{l}261 \\
249 \\
222 \\
187 \\
222 \\
204 \\
179 \\
190 \\
197 \\
187\end{array}$ & $\begin{array}{r}660 \\
630 \\
2,660 \\
1,880 \\
1,100 \\
822 \\
714 \\
620 \\
560 \\
530\end{array}$ & $\begin{array}{l}21 \ldots \ldots \\
22 \ldots \ldots \\
23 \ldots \ldots \\
24 \ldots \ldots \\
25 \ldots \ldots \\
26 \ldots \ldots \\
27 \ldots \ldots \\
28 \ldots \ldots \\
29 \ldots \ldots \\
30 \ldots \ldots \\
31 \ldots \ldots\end{array}$ & $\begin{array}{r}187 \\
187 \\
178 \\
178 \\
175 \\
175 \\
112 \\
98 \\
112 \\
1,160 \\
9,020\end{array}$ & $\begin{array}{r}480 \\
430 \\
390 \\
350 \\
320 \\
300 \\
230 \\
100 \\
---- \\
----- \\
-\end{array}$ \\
\hline \multicolumn{7}{|l|}{$\begin{array}{l}\text { Monthly } \\
\text { Runoff, } \\
\text { Runoff, }\end{array}$} & $\begin{array}{r}535 \\
2.09 \\
32,910 \\
\end{array}$ & $\begin{array}{r}1,628 \\
5.75 \\
90,430 \\
\end{array}$ \\
\hline
\end{tabular}

Gage height, in feet, and discharge, in cublc feet per second, at indicated time, 1963

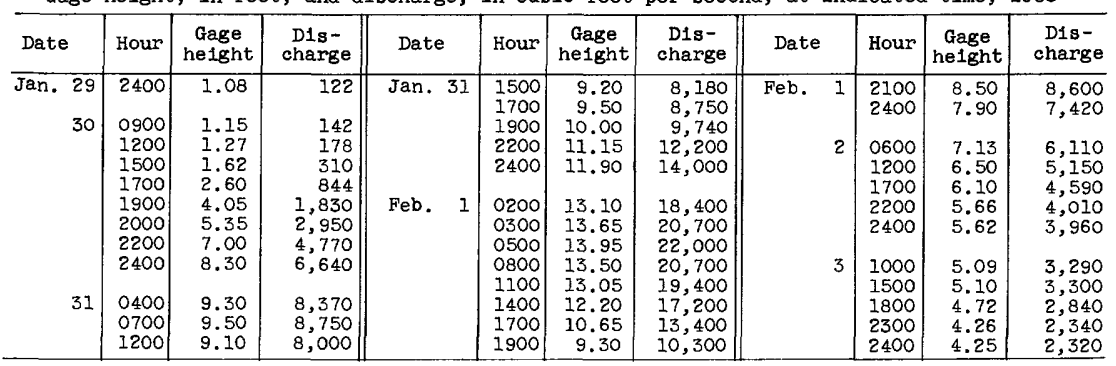

11-4246. Wellman Creek near Smartville, Calif.

(Crest-stage station)

Location.--Lat $39^{\circ} 11^{\prime} 37^{\prime \prime}$, long $121^{\circ} 20^{\prime} 23^{\prime \prime}$, in $\mathrm{SW}_{\frac{1}{4}} \mathrm{SE}_{\frac{1}{4}} \sec .31$, T.16 N., R.6 E., 2.3 miles southwest of Smartville.

Drainage area. $--0.59 \mathrm{sq} \mathrm{mi}$.

Gage-helght record.--Crest stages only. Altitude of gage is $495 \mathrm{ft}$ (from topographic map).

Discharge record.--Stage-discharge relation defined by current-meter measurements below $41 \mathrm{cfs}$ and by computation of flow through culverts above $41 \mathrm{cfs}$ including road overflow above $70 \mathrm{cfs}$.

Maxima --January-February 1963: Discharge, 57 cfs Jan. 31 (gage height, $12.56 \mathrm{ft}$ ). 1959 to December 1962: Discharge, 211 cfs Oct. 13, 1962 (gage height, 14.56 $\mathrm{ft}$, from crest-stage gage and high-water profiles).

$793-2850-66-25$ 
11-4250. Feather River at Nicolaus, Calif.

Location.--Lat $38^{\circ} 54^{\prime} 00^{\prime \prime}$, long $121^{\circ} 35^{\prime} 00^{\prime \prime}$, on left bank at Nicolaus, Sutter County, at highway briage 2.9 miles downstream from Bear River.

Drainage area. $--5,928 \mathrm{sq} \mathrm{mi}$.

Gage-he1ght record.--Water-stage recorder graph. Gage is set to datum of Corps of Engineers.

Discharge record.--Stage-discharge relation defined by current-meter measurements. Backwater from the Sacramento River Feb. 7-28.

Maxima.--January-February 1963: Discharge, 260,000 cfs 1600 hours Feb. I (gage height, $50.05 \mathrm{ft}$ ).

1943 to December 1962: Discharge, 357,000 cfs Dec. 23, 1955 (gage he1ght, $51.60 \mathrm{ft}$ ).

Remarks.--Flow partly regulated by reservolrs and powerplants.

Mean discharge, in cublc feet per second, 1963

\begin{tabular}{|c|c|c|c|c|c|c|c|c|}
\hline Day & January & February & Day & January & February & Day & January & February \\
\hline $\begin{array}{r}1 \ldots \ldots \\
2 \ldots \ldots \\
4 \ldots \ldots \\
5 \ldots \ldots \\
6 \ldots \ldots \\
7 \ldots \ldots \\
9 \ldots \ldots \\
10 \ldots \ldots\end{array}$ & $\begin{array}{l}6,190 \\
6,190 \\
6,050 \\
6,050 \\
6,050 \\
6,050 \\
5,630 \\
5,490 \\
5,490 \\
5,220\end{array}$ & $\begin{array}{r}200,000 \\
179,000 \\
101,000 \\
65,400 \\
49,000 \\
41,300 \\
31,400 \\
25,200 \\
22,200 \\
19,700\end{array}$ & $\begin{array}{l}11 \ldots \ldots \\
12 \ldots \ldots \\
13 \ldots \ldots \\
14 \ldots \ldots \\
15 \ldots \ldots \\
16 \ldots \ldots \\
17 \ldots \ldots \\
18 \ldots \ldots \\
19 \ldots \ldots \\
20 \ldots \ldots\end{array}$ & $\begin{array}{l}5,220 \\
5,220 \\
4,310 \\
4,190 \\
4,700 \\
4,700 \\
4,440 \\
4,310 \\
4,310 \\
4,190\end{array}$ & $\begin{array}{l}18,100 \\
17,000 \\
19,300 \\
25,200 \\
21,900 \\
19,000 \\
16,800 \\
15,200 \\
13,700 \\
12,700\end{array}$ & $\begin{array}{l}21 \ldots \ldots \\
22 \ldots \ldots \\
23 \ldots \ldots \\
24 \ldots \ldots \\
25 \ldots \ldots \\
26 \ldots \ldots \\
27 \ldots \ldots \\
28 \ldots \ldots \\
29 \ldots \ldots \\
30 \ldots \ldots \\
31 \ldots \ldots\end{array}$ & $\begin{array}{l}\text { 4, } \\
4, \\
4, \\
4, \\
4, \\
4, \\
3, \\
3, \\
4, \\
5, \\
34,\end{array}$ & $\begin{array}{r}11,300 \\
10,500 \\
9,460 \\
9,280 \\
9,120 \\
8,640 \\
8,160 \\
8,160 \\
----- \\
-.---\end{array}$ \\
\hline \multicolumn{7}{|c|}{$\begin{array}{l}\text { Ionthly mean discharge, in cubic feet per second } \ldots \ldots \ldots \ldots \ldots \ldots \ldots \ldots \ldots \ldots \ldots \\
\text { iunoff, in acre-feet. } \ldots \ldots \ldots \ldots \ldots \ldots \ldots \ldots \ldots \ldots \ldots \ldots \ldots \ldots \ldots \ldots \ldots \\
\end{array}$} & $\begin{array}{r}5,830 \\
358,500 \\
\end{array}$ & $\begin{array}{r}35,280 \\
1,959,000 \\
\end{array}$ \\
\hline
\end{tabular}

Gage helght, in feet, and discharge, in cubic feet per second, at ind1cated time, 1963

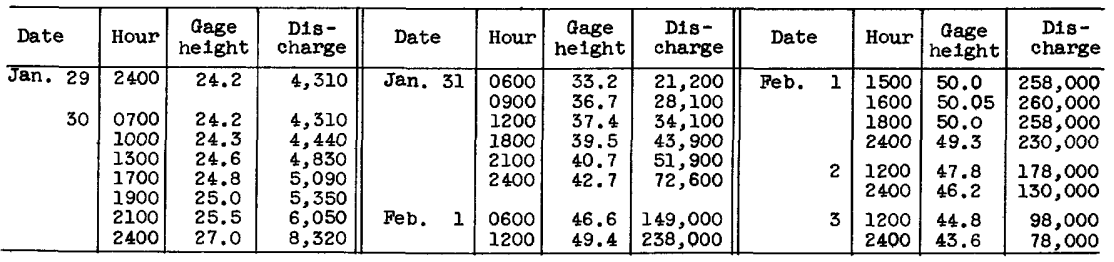

11-4255. Sacramento River at Verona, Calif.

Location.--Lat $38^{\circ} 46^{\prime} 50^{\prime \prime}$, long $121^{\circ} 36^{\prime} 10^{\prime \prime}$, in SE $\frac{1}{4}$ sec.23, T.11 N., R.3 E., on left bank 0.8 mile southeast of Verona, 1 mile downstream from Feather River,

6.2 miles east of Knights Landing, and at mile 19.6 upstream from Sacramento.

Gage-height record.--Water-stage recorder graph. Datum of gage is $0.06 \mathrm{ft}$ below datum of Corps of Engineers.

Discharge record.--Stage-discharge relation defined by current-meter measurements.

Maxima.--January-February 1963: Discharge, 69,400 cfs 2300 hours Feb. 1 (gage helght, $38.14 \mathrm{ft}$ ).

1926 to December 1962: Discharge, $79,200 \mathrm{cfs}$ Mar. 1, 1940 (gage height, $41.20 \mathrm{ft}$ ).

Remarks.--Flow regulated by Shasta Lake (see station 11-3700) beginning Dec. 30 , 1943 , and by several other reservoirs. When discharge exceeds about 55,000 cfs flow begins over Fremont weir into Yolo bypass (see station 11-4530). 
Mean discharge, In cuble feet per second, 1963, of Sacramento River at Verona, Calif.

\begin{tabular}{|c|c|c|c|c|c|c|c|c|}
\hline Day & January & February & Day & January & February & Day & January & February \\
\hline $\begin{array}{l}1 . \ldots \ldots \\
2 \ldots \ldots \\
4 \ldots \ldots \\
5 \ldots \ldots \\
6 \ldots \ldots \\
7 \ldots \ldots \\
9 \ldots \ldots \\
10 \ldots \ldots\end{array}$ & $\begin{array}{l}22,100 \\
21,700 \\
21,500 \\
20,800 \\
20,400 \\
20,200 \\
19,700 \\
19,100 \\
19,100 \\
18,400\end{array}$ & $\begin{array}{l}61,300 \\
68,500 \\
65,000 \\
62,300 \\
60,000 \\
58,100 \\
56,100 \\
54,400 \\
52,500 \\
51,400\end{array}$ & $\begin{array}{l}11 \ldots \ldots \\
12 \ldots \ldots \\
13 \ldots \ldots \\
14 \ldots \ldots \\
15 \ldots \ldots \\
16 \ldots \ldots \\
17 \ldots \ldots \\
18 \ldots \ldots \\
19 \ldots \ldots \\
20 \ldots \ldots\end{array}$ & $\begin{array}{l}18,000 \\
17,300 \\
16,000 \\
15,000 \\
14,600 \\
14,600 \\
14,400 \\
14,000 \\
13,800 \\
13,400\end{array}$ & $\begin{array}{l}50,60 C \\
50,600 \\
51,900 \\
54,400 \\
54,200 \\
53,000 \\
51,900 \\
50,000 \\
47,900 \\
45,500\end{array}$ & $\begin{array}{l}21 \ldots \ldots \\
22 \ldots \ldots \\
23 \ldots \ldots \\
24 \ldots \ldots \\
25 \ldots \ldots \\
26 \ldots \ldots \\
27 \ldots \ldots \\
28 \ldots \ldots \\
29 \ldots \ldots \\
30 \ldots \ldots \\
31 \ldots \ldots\end{array}$ & $\begin{array}{l}13,200 \\
13,000 \\
13,200 \\
13,200 \\
12,800 \\
13,000 \\
12,600 \\
12,600 \\
12,600 \\
13,800 \\
30,700\end{array}$ & $\begin{array}{r}42,600 \\
39,500 \\
35,800 \\
33,700 \\
32,600 \\
31,700 \\
30,500 \\
29,600 \\
------ \\
------\end{array}$ \\
\hline 312 & t & & & & & & $\begin{array}{r}16,610 \\
921,000\end{array}$ & $\begin{array}{r}49,130 \\
2,728,000\end{array}$ \\
\hline
\end{tabular}

Gage height, in feet, and discharge, in cuble feet per second, at indicated time, 1963

\begin{tabular}{|c|c|c|c|c|c|c|c|c|c|c|c|}
\hline Date & Hour & $\begin{array}{c}\text { Gage } \\
\text { he1ght }\end{array}$ & $\begin{array}{l}\text { D1s- } \\
\text { charge }\end{array}$ & Date & Hour & $\begin{array}{c}\text { Gage } \\
\text { helght }\end{array}$ & $\begin{array}{c}\text { DIs- } \\
\text { charge }\end{array}$ & Date & Hour & $\begin{array}{c}\text { Gage } \\
\text { helght }\end{array}$ & $\begin{array}{l}\text { DIs - } \\
\text { charge }\end{array}$ \\
\hline $\begin{array}{r}\operatorname{Jan} .29 \\
30\end{array}$ & $\begin{array}{l}2400 \\
0600 \\
0900 \\
1200 \\
1800 \\
2100 \\
2400\end{array}$ & $\begin{array}{l}15.4 \\
15.5 \\
15.6 \\
15.7 \\
16.0 \\
16.2 \\
16.6\end{array}$ & $\begin{array}{l}13,000 \\
13,200 \\
13,400 \\
13,600 \\
14,200 \\
14,600 \\
15,400\end{array}$ & Jan. 31 & $\begin{array}{l}0600 \\
1200 \\
1800 \\
2400 \\
\\
0600 \\
1200 \\
1800\end{array}$ & $\begin{array}{l}19.8 \\
23.8 \\
26.9 \\
29.2 \\
33.0 \\
36.4 \\
37.7 \\
\end{array}$ & $\begin{array}{l}22,400 \\
31,400 \\
38,800 \\
44,700 \\
55,000 \\
64,500 \\
68,200\end{array}$ & Feb. 1 & $\begin{array}{l}2100 \\
2300 \\
2400 \\
\\
0800 \\
1200 \\
1800 \\
2400 \\
\end{array}$ & $\begin{array}{l}38.1 \\
38.14 \\
38.1 \\
38.1 \\
37.9 \\
37.6 \\
37.2\end{array}$ & $\begin{array}{l}69,300 \\
69,400 \\
69,300 \\
69,300 \\
68,700 \\
67,900 \\
66,800\end{array}$ \\
\hline
\end{tabular}

11-4260. Sacramento weir spill to Yolo bypass near Sacramento, Calif'.

Location.--Lat $38^{\circ} 36^{\prime} 25^{\prime \prime}$, long $121^{\circ} 33^{\prime} 15^{\prime \prime}$, on right bank $100 \mathrm{ft}$ downstream from weir, 3.2 miles upstream f'rom American River, 4 miles northwest of Sacramento, and at mile 4.2 upstream f'rom Sacramento.

Gage-height record.- Water-stage recorder graph. Gage is set to datum of Corps of Engineers.

Discharge record.--Stage-discharge relation defined by weir formula and checked by current-meter measurements.

Maxima.--January-February 1963: Discharge, $82,600 \mathrm{cf}$ 's 0930 hours Feb. 2 (gage helght, $31.83 \mathrm{f}^{\prime} \mathrm{t}$ ).

1926 to December 1962: Discharge, 118,000 cf's Mar. 26, 1928; gage he1ght, 33.01 f't Dec. 23, 1955.

Remarks.--Crest of weir is at elevation $25.0 \mathrm{f}^{\prime} \mathrm{t}$ and top of movable gates at $31.0 \mathrm{f} t$. We1r consists of 48 gates, each 38.1 ft long. Flow over weir enters Yolo bypass by way of Sacramento bypass. Flows are regulated by weir gates. Records furnished by Califormia Department of Water Resources.

Mean discharge, in cubtc feet per second, 1963

\begin{tabular}{|c|c|c|c|c|c|c|c|c|}
\hline Day & January & February & Day & January & February & Day & January & February \\
\hline $\begin{array}{c}1 \ldots \ldots \\
2 \ldots \ldots \\
3 \ldots \ldots \\
4 \ldots \ldots \\
5 \ldots \ldots \\
6 \ldots \ldots \\
7 \ldots \ldots \\
8 \ldots \ldots \\
9 \ldots \ldots \\
10 \ldots \ldots\end{array}$ & $\begin{array}{l}0 \\
0 \\
0 \\
0 \\
0 \\
0 \\
0 \\
0 \\
0 \\
0\end{array}$ & $\begin{array}{r}6,790 \\
72,800 \\
32,900 \\
26,200 \\
8,650 \\
6,430 \\
637 \\
32 \\
0 \\
0\end{array}$ & $\begin{array}{l}11 \ldots \ldots \\
12 \ldots \ldots \\
13 \ldots \ldots \\
14 \ldots \ldots \\
15 \ldots \ldots \\
16 \ldots \ldots \\
17 \ldots \ldots \\
18 \ldots \ldots \\
19 \ldots \ldots \\
20 \ldots \ldots\end{array}$ & $\begin{array}{l}0 \\
0 \\
0 \\
0 \\
0 \\
0 \\
0 \\
0 \\
0 \\
0\end{array}$ & $\begin{array}{l}0 \\
0 \\
0 \\
0 \\
0 \\
0 \\
0 \\
0 \\
0 \\
0\end{array}$ & $\begin{array}{l}21 \ldots \ldots \\
22 \ldots \ldots \\
23 \ldots \ldots \\
24 \ldots \ldots \\
25 \ldots \ldots \\
26 \ldots \ldots \\
27 \ldots \ldots \\
28 \ldots \ldots \\
29 \ldots \ldots \\
30 \ldots \ldots \\
31 \ldots \ldots\end{array}$ & $\begin{array}{l}0 \\
0 \\
0 \\
0 \\
0 \\
0 \\
0 \\
0 \\
0 \\
0 \\
0\end{array}$ & 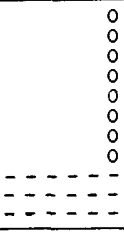 \\
\hline \multicolumn{7}{|c|}{ 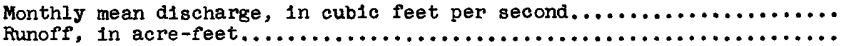 } & $\begin{array}{l}0 \\
0 \\
\end{array}$ & $\begin{array}{r}5,516 \\
306,300 \\
\end{array}$ \\
\hline
\end{tabular}


Gage height, in feet, and discharge, in cubic feet per second, at indicated time, 1963,

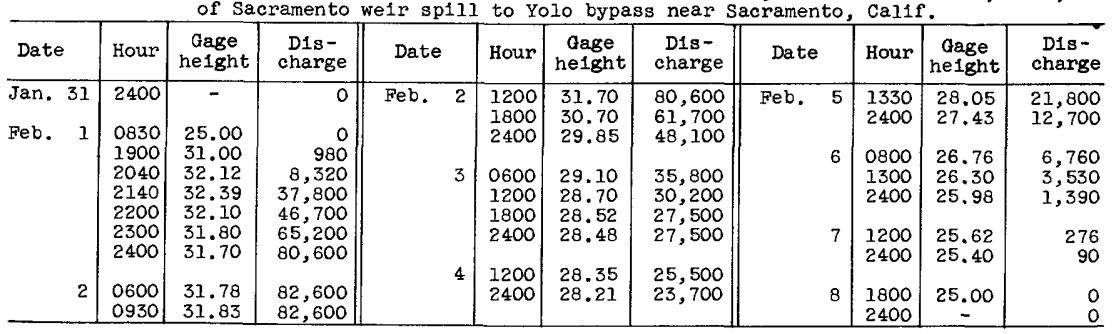

11-4261.1. Onion Creek tributary No. 3 near Soda Springs, Calif.

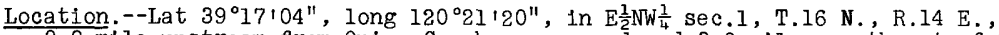
$0.8 \mathrm{mile}$ upstream from Onion Creek campground and 3.0 miles southeast of 'Soda Springs.

Drainage area $--0.65 \mathrm{sq} \mathrm{mi}$.

Gage-he1ght record.--Water-stage recorder graph, except Feb. 1-28.

Discharge record.--Stage-discharge relation defined by $120^{\circ}$ sharp-crested V-notch weir; affected by 1ce Jan. 11-13, 19. Discharge for Feb. 1-28 estimated from records for nearby streams.

Maxima.--January-February 1963: Discharge, $242 \mathrm{cfs} 0020$ hours Feb. 1 (gage helght, $5.00 \mathrm{ft}$ ).

October 1958 to December 1962: Discharge, 34.5 cfs Oct. 13, 1962 (gage helght, $2.29 \mathrm{ft}$ ).

Remarks.--Gage-height record furnished by U.S. Forest Service.

Mean discharge, in cublc feet per second, 1963

\begin{tabular}{|c|c|c|c|c|c|c|c|c|}
\hline Day & January & February & Day & January & February & Day & January & February \\
\hline $\begin{array}{c}1 \ldots \ldots \\
2 \ldots \ldots \\
3 \ldots \ldots \\
4 \ldots \ldots \\
5 \ldots \ldots \\
6 \ldots \ldots \\
8 \ldots \ldots \\
9 \ldots \ldots \\
10 \ldots \ldots\end{array}$ & $\begin{array}{r}0.98 \\
.98 \\
.94 \\
.90 \\
.88 \\
.84 \\
.81 \\
.78 \\
.75 \\
.71\end{array}$ & $\begin{array}{r}42.0 \\
16.0 \\
11.0 \\
9.10 \\
7.80 \\
5.85 \\
4.55 \\
4.22 \\
3.90 \\
3.77\end{array}$ & $\begin{array}{l}11 \ldots \ldots \\
12 \ldots \ldots \\
13 \ldots \ldots \\
14 \ldots \ldots \\
15 \ldots \ldots \\
16 \ldots \ldots \\
17 \ldots \ldots \\
18 \ldots \ldots \\
19 \ldots \ldots \\
20 \ldots \ldots\end{array}$ & $\begin{array}{l}0.53 \\
.61 \\
.60 \\
.60 \\
.59 \\
.56 \\
.54 \\
.52 \\
.50 \\
.49\end{array}$ & $\begin{array}{l}3.44 \\
3.25 \\
3.12 \\
3.06 \\
2.92 \\
2.86 \\
2.80 \\
2.73 \\
2.66 \\
2.54\end{array}$ & $\begin{array}{l}21 \ldots \ldots \\
22 \ldots \ldots \\
23 \ldots \ldots \\
24 \ldots \ldots \\
25 \ldots \ldots \\
26 \ldots \ldots \\
27 \ldots \ldots \\
28 \ldots \ldots \\
29 \ldots \ldots \\
30 \ldots \ldots \\
31 \ldots \ldots\end{array}$ & $\begin{array}{r}0.49 \\
.48 \\
.45 \\
.43 \\
.43 \\
.42 \\
.42 \\
.39 \\
.38 \\
2.27 \\
74.2 \\
\end{array}$ & $\begin{array}{r}2.34 \\
2.14 \\
2.02 \\
1.82 \\
1.76 \\
1.76 \\
1.62 \\
1.56 \\
--.--- \\
-.--.- \\
\end{array}$ \\
\hline $\begin{array}{l}\text { Monthly } \\
\text { Runoff, } \\
\text { Runoff, }\end{array}$ & $\begin{array}{l}\text { mean dis } \\
\text { in Inche } \\
\text { in acre- }\end{array}$ & $=$ & 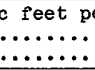 & & & & $\begin{array}{r}3.05 \\
5.40 \\
187 \\
\end{array}$ & $\begin{array}{r}5.45 \\
8.73 \\
303 \\
\end{array}$ \\
\hline
\end{tabular}

Gage helght, in feet, and discharge, in cubic feet per second, at indicated time, 1963

\begin{tabular}{|c|c|c|c|c|c|c|c|c|c|c|c|}
\hline Date & Hour & $\begin{array}{c}\text { Gage } \\
\text { helght }\end{array}$ & $\begin{array}{l}\text { Dis- } \\
\text { charge }\end{array}$ & Date & Hour & $\begin{array}{c}\text { Gage } \\
\text { he1ght }\end{array}$ & $\begin{array}{l}\text { D1s- } \\
\text { charge }\end{array}$ & Date & Hour & $\begin{array}{c}\text { Gage } \\
\text { helght }\end{array}$ & $\begin{array}{c}\text { Dis- } \\
\text { charge }\end{array}$ \\
\hline $\begin{array}{r}\text { Jan. } 29 \\
30\end{array}$ & $\begin{array}{l}2400 \\
0600 \\
1300 \\
1500 \\
1700 \\
1900 \\
2000\end{array}$ & $\begin{array}{r}0.38 \\
.33 \\
.39 \\
.54 \\
.65 \\
.95 \\
1.35\end{array}$ & $\begin{array}{r}0.40 \\
.28 \\
.42 \\
.95 \\
1.51 \\
3.87 \\
9.29\end{array}$ & $\begin{array}{r}\text { Jan. } 30 \\
31\end{array}$ & $\begin{array}{l}2400 \\
0100 \\
0400 \\
0600 \\
0800 \\
1000 \\
1200\end{array}$ & $\begin{array}{l}1.26 \\
1.24 \\
1.40 \\
1.55 \\
1.91 \\
2.31 \\
2.71 \\
\end{array}$ & $\begin{array}{r}7.82 \\
7.52 \\
10.2 \\
13.1 \\
22.0 \\
35.4 \\
52.7 \\
\end{array}$ & Feb. 1 & $\begin{array}{l}1500 \\
1800 \\
1900 \\
2200 \\
2400 \\
0020\end{array}$ & $\begin{array}{l}3.02 \\
4.23 \\
4.10 \\
4.28 \\
4.91 \\
5.00\end{array}$ & $\begin{array}{l}69.0 \\
160.0 \\
148 \\
164 \\
231 \\
242\end{array}$ \\
\hline
\end{tabular}


11-4261.2. Onion Creek tributary No. 5A near Soda Springs, Calif.

Location.--Lat $39^{\circ} 17^{\prime} 04^{\prime \prime}$, long $120^{\circ} 20^{\prime} 44^{\prime \prime}$, in $\mathrm{SE} \frac{1}{4} \mathrm{NE} \frac{1}{4} \sec .1$, T.16 N., R.14 E., 1.1 miles upstream from Onion Creek campground and 3.3 miles southeast of Soda Springs.

Drainage area. $--0.39 \mathrm{sq} \mathrm{m}$.

Gage-height record.--Water-stage recorder graph, except Feb. 1-15, 21-28.

Discharge record.--Stage-discharge relation defined by $120^{\circ}$ sharp-crested V-notch

weir. Discharge for Feb. 1-15, 21-28 estimated from records for nearby streams.

Maxima.--January-February 1963: Discharge, 135 cfs 2340 hours Jan. 31 (gage height, $3.96 \mathrm{ft})$.

October 1958 to December 1962: Discharge, 45.3 cfs Oct. 13, 1962 (gage helght, $2.55 \mathrm{ft}$, from floodmarks).

Remarks.--Gage-height record furnished by U.S. Forest Service.

Mean d1scharge, in cublc feet per second, 1963

\begin{tabular}{|c|c|c|c|c|c|c|c|c|}
\hline Day & January & Pebruary & Day & January & February & Day & January & February \\
\hline $\begin{array}{c}1 \ldots \ldots \\
2 \ldots \ldots \\
3 \ldots \ldots \\
4 \ldots \ldots \\
5 \ldots \ldots \\
6 \ldots \ldots \\
7 \ldots \ldots \\
9 \ldots \ldots \\
10 \ldots \ldots\end{array}$ & $\begin{array}{l}0.42 \\
.42 \\
.40 \\
.37 \\
.35 \\
.35 \\
.32 \\
.32 \\
.30 \\
.30\end{array}$ & $\begin{array}{r}31.0 \\
10.0 \\
6.20 \\
5.10 \\
4.30 \\
3.50 \\
2.70 \\
2.50 \\
2.20 \\
1.95\end{array}$ & $\begin{array}{l}11 \ldots \ldots \\
12 \ldots \ldots \\
13 \ldots \ldots \\
14 \ldots \ldots \\
15 \ldots \ldots \\
16 \ldots \ldots \\
17 \ldots \ldots \\
18 \ldots \ldots \\
19 \ldots \ldots \\
20 \ldots \ldots\end{array}$ & $\begin{array}{l}0.22 \\
.15 \\
.22 \\
.24 \\
.22 \\
.22 \\
.22 \\
.22 \\
.22 \\
.22\end{array}$ & $\begin{array}{l}1.87 \\
1.76 \\
1.68 \\
1.64 \\
1.56 \\
1.39 \\
1.39 \\
1.51 \\
1.39 \\
1.34\end{array}$ & $\begin{array}{l}21 \ldots \ldots \\
22 \ldots \ldots \\
23 \ldots \ldots \\
24 \ldots \ldots \\
25 \ldots \ldots \\
26 \ldots \ldots \\
27 \ldots \ldots \\
28 \ldots \ldots \\
29 \ldots \ldots \\
30 \ldots \ldots \\
31 \ldots \ldots\end{array}$ & $\begin{array}{r}0.22 \\
.22 \\
.20 \\
.20 \\
.17 \\
.15 \\
.15 \\
.15 \\
.15 \\
3.53 \\
56.0\end{array}$ & $\begin{array}{r}1.25 \\
1.21 \\
1.13 \\
1.09 \\
1.01 \\
.94 \\
.90 \\
.82 \\
-.-.- \\
-.-1-\end{array}$ \\
\hline \multicolumn{7}{|c|}{ 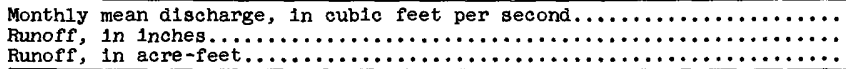 } & $\begin{array}{r}2.16 \\
6.37 \\
133 \\
\end{array}$ & $\begin{array}{r}3.33 \\
8.90 \\
185 \\
\end{array}$ \\
\hline
\end{tabular}

Gage helght, in feet, and discharge, in cublc feet per second, at indicated time, 1963

\begin{tabular}{|c|c|c|c|c|c|c|c|c|c|c|c|}
\hline Date & Hour & $\begin{array}{c}\text { Gage } \\
\text { helght }\end{array}$ & $\begin{array}{l}\text { D1s- } \\
\text { charge }\end{array}$ & Date & Hour & $\begin{array}{c}\text { Gage } \\
\text { helght }\end{array}$ & $\begin{array}{c}\text { D1s- } \\
\text { charge }\end{array}$ & Date & Hour & $\begin{array}{c}\text { Gage } \\
\text { helght }\end{array}$ & $\begin{array}{l}\text { D1s- } \\
\text { charge }\end{array}$ \\
\hline $\begin{array}{r}\text { Jan. } 29 \\
30\end{array}$ & $\begin{array}{l}2400 \\
1200 \\
1400 \\
1600 \\
1900 \\
1930 \\
2000 \\
2030 \\
2100 \\
2200 \\
2300 \\
\end{array}$ & $\begin{array}{r}0.26 \\
.26 \\
.28 \\
.39 \\
.48 \\
1.82 \\
1.47 \\
1.75 \\
1.71 \\
1.77 \\
1.74 \\
\end{array}$ & $\begin{array}{r}0.15 \\
.15 \\
.18 \\
.42 \\
.71 \\
19.5 \\
11.5 \\
17.7 \\
16.7 \\
18.2 \\
17.5 \\
\end{array}$ & $\begin{array}{r}\operatorname{Jan} .30 \\
31\end{array}$ & $\begin{array}{l}2400 \\
0230 \\
5000 \\
7000 \\
9000 \\
1030 \\
1200 \\
1300 \\
1330 \\
1400 \\
1500\end{array}$ & $\begin{array}{l}1.65 \\
1.57 \\
1.64 \\
1.82 \\
2.12 \\
2.35 \\
2.63 \\
2.84 \\
2.82 \\
2.90 \\
2.99\end{array}$ & $\begin{array}{l}15.3 \\
13.5 \\
15.1 \\
19.5 \\
28.6 \\
36.9 \\
48.9 \\
59.2 \\
58.2 \\
62.3 \\
67.3\end{array}$ & Jan. 31 & $\begin{array}{l}1600 \\
1630 \\
1700 \\
1800 \\
1900 \\
2000 \\
2100 \\
2220 \\
2300 \\
2340 \\
2400\end{array}$ & $\begin{array}{l}3.27 \\
3.24 \\
3.27 \\
3.41 \\
3.50 \\
3.69 \\
3.58 \\
3.45 \\
3.79 \\
3.96 \\
3.92\end{array}$ & $\begin{array}{c}84.1 \\
82.2 \\
84.1 \\
93.3 \\
99.6 \\
114 \\
105 \\
96.1 \\
121 \\
135 \\
132\end{array}$ \\
\hline
\end{tabular}

11-4261.3. Onion Creek tributary No. 2 near Soda Springs, Calif.

Location.--Lat $39^{\circ} 16^{\prime} 34^{\prime \prime}$, long $120^{\circ} 21^{1} 57^{\prime \prime}$, in SE $\frac{1}{4} S E \frac{1}{4}$ Sec.2, T.16 N., R.14 E., 0.25 mile above junction with Onion Creek and 3.4 miles southeast of Soda Springs.

Drainage area $--0.48 \mathrm{sq} \mathrm{mi}$.

Gage-height record.--Water-stage recorder graph, except Jan. I-4 and Feb. I-4, 18-28. Altitude of gage is $6,160 \mathrm{ft}$.

Discharge record. --Stage-discharge relation defined by $120^{\circ} \mathrm{V}$-notch weir; affected by 1ce Jan. 1 , 12. Discharge for Jan. 1-4 and Feb. $1-4,18-28$ estimated from records for nearby streams.

Maxima.--January-February 1963: Discharge, 116 cfs 2100 hours Jan. 31 (gage height, $3.72 \mathrm{ft}$, from recorder graph).

October 1957 to December 1962: Discharge, $44.8 \mathrm{cfs}$ oct. 13, 1962 (gage height, $2.54 \mathrm{ft}$ ).

Remarks.--Gage-height record furnished by U.S. Forest Service. 
Mean discharge, in cublc feet per second, 1963, of Onion Creek tributary No. 2

\begin{tabular}{|c|c|c|c|c|c|c|c|c|}
\hline Day & January & February & Day & January & February & Day & January & February \\
\hline $\begin{array}{l}\ldots \ldots \\
2 \ldots \ldots \\
3 \ldots \ldots \\
4 \ldots \ldots \\
5 \ldots \ldots \\
6 \ldots \ldots \\
7 \ldots \ldots \\
8 \ldots \ldots \\
9 \ldots \ldots \\
10 \ldots \ldots\end{array}$ & $\begin{array}{l}0.67 \\
.62 \\
.61 \\
.61 \\
.60 \\
.57 \\
.57 \\
.54 \\
.51 \\
.51\end{array}$ & $\begin{array}{r}38.0 \\
13.0 \\
8.20 \\
7.00 \\
6.10 \\
4.62 \\
3.77 \\
3.20 \\
2.85 \\
2.85\end{array}$ & $\begin{array}{l}11 \ldots \ldots \\
12 \ldots \ldots \\
13 \ldots \ldots \\
14 \ldots \ldots \\
15 \ldots \ldots \\
16 \ldots \ldots \\
17 \ldots \ldots \\
18 \ldots \ldots \\
19 \ldots \ldots \\
20 \ldots \ldots\end{array}$ & $\begin{array}{l}0.40 \\
.40 \\
.40 \\
.40 \\
.40 \\
.40 \\
.37 \\
.37 \\
.35 \\
.32\end{array}$ & $\begin{array}{l}2.60 \\
2.52 \\
2.52 \\
2.37 \\
2.52 \\
2.37 \\
2.30 \\
2.11 \\
2.11 \\
1.97\end{array}$ & $\begin{array}{l}21 \ldots \ldots \\
22 \ldots \ldots \\
23 \ldots \ldots \\
24 \ldots \ldots \\
25 \ldots \ldots \\
26 \ldots \ldots \\
27 \ldots \ldots \\
28 \ldots \ldots \\
29 \ldots \ldots \\
30 \ldots \ldots \\
31 \ldots \ldots\end{array}$ & $\begin{array}{r}0.32 \\
.32 \\
.30 \\
.30 \\
.28 \\
.28 \\
.26 \\
.26 \\
.26 \\
2.45 \\
57.1\end{array}$ & $\begin{array}{r}1.82 \\
1.68 \\
1.54 \\
1.39 \\
1.39 \\
1.34 \\
1.30 \\
1.20 \\
---.-- \\
-.-1 .-1\end{array}$ \\
\hline $10 \mathrm{ff}$, & acr & & & & & & $\begin{array}{r}2.31 \\
5.55 \\
142\end{array}$ & $\begin{array}{r}4.45 \\
9.65 \\
247 \\
\end{array}$ \\
\hline
\end{tabular}

Gage he1ght, In feet, and discharge, In cublc feet per second, at Indicated t1me, 1963

\begin{tabular}{|c|c|c|c|c|c|c|c|c|c|c|c|}
\hline Date & Hour & $\begin{array}{c}\text { Gage } \\
\text { he1ght }\end{array}$ & $\begin{array}{l}\text { Dis- } \\
\text { charge }\end{array}$ & Date & Hour & $\begin{array}{c}\text { Gage } \\
\text { helght }\end{array}$ & $\begin{array}{c}\text { DIs - } \\
\text { charge }\end{array}$ & Date & Hour & $\begin{array}{c}\text { Gage } \\
\text { he1ght }\end{array}$ & $\begin{array}{c}\text { Dis- } \\
\text { charge }\end{array}$ \\
\hline $\begin{array}{rr}\text { Jan. } & 29 \\
& 30\end{array}$ & $\begin{array}{l}2400 \\
0700 \\
1100 \\
1300 \\
1500 \\
1700 \\
1730 \\
1900 \\
2100 \\
2200 \\
2300 \\
\end{array}$ & $\begin{array}{r}0.32 \\
.29 \\
.31 \\
.38 \\
.66 \\
.74 \\
.97 \\
1.09 \\
1.23 \\
1.39 \\
1.38 \\
\end{array}$ & $\begin{array}{r}0.26 \\
.20 \\
.24 \\
.40 \\
1.56 \\
2.08 \\
4.08 \\
5.45 \\
7.37 \\
9.99 \\
9.81 \\
\end{array}$ & $\begin{array}{r}\text { Jan. } 30 \\
31\end{array}$ & $\begin{array}{l}2400 \\
0100 \\
0400 \\
0500 \\
0700 \\
0800 \\
0815 \\
0900 \\
0915 \\
1000 \\
1200\end{array}$ & $\begin{array}{l}1.39 \\
1.42 \\
1.62 \\
1.65 \\
1.97 \\
2.08 \\
2.60 \\
2.50 \\
2.21 \\
2.51 \\
2.88\end{array}$ & $\begin{array}{c}9.99 \\
10.5 \\
14.6 \\
15.3 \\
23.8 \\
27.3 \\
47.5 \\
43.1 \\
31.7 \\
43.5 \\
61.3 \\
\end{array}$ & Jan. 31 & $\begin{array}{l}1330 \\
1430 \\
1500 \\
1600 \\
1800 \\
1930 \\
2000 \\
2100 \\
2230 \\
2300 \\
2400\end{array}$ & $\begin{array}{l}3.00 \\
2.92 \\
3.06 \\
3.30 \\
3.49 \\
3.70 \\
3.67 \\
3.72 \\
3.18 \\
3.25 \\
3.15\end{array}$ & $\begin{array}{c}67.8 \\
63.4 \\
71.3 \\
86.0 \\
98.9 \\
114 \\
112 \\
116 \\
78.4 \\
82.8 \\
76.6\end{array}$ \\
\hline
\end{tabular}

11-4261.4. Onion Creek tributary No. 1 near Soda Springs, Calif.

Location.--Lat $39^{\circ} 16^{\prime} 30^{\prime \prime}$, long $120^{\circ} 21^{\prime} 58^{\prime \prime}$, in SE $\frac{1}{4}$ sec.2, T.16 N., R.14 E.,

0.25 mile west of Onion Creek campground and 3.4 miles southeast of Soda Springs.

Drainage area. $--0.19 \mathrm{sq} \mathrm{mi}$.

Gage-helght record.--Water-stage recorder graph, except Jan. 1-4, 12 and Feb. 1-4.

Discharge record.--Stage-discharge relation defined by $120^{\circ}$ sharp-crested V-notch weir; affected by ice Jan. 11. Discharge for Jan. 1-4, 12 and Feb. 1-4 estimated from records for nearby streams.

Maxima.--January-February 1963: Discharge, 54.6 cfs 2400 hours Jan. 31 (gage helght, $2.75 \mathrm{ft}$ ).

1957 to December 1962: Discharge, $16.3 \mathrm{cf}$ 's 0 ct. 13, 1962 (gage height, $1.69 \mathrm{ft})$.

Remarks.--Records of daily discharge furnished by U.S. Forest Service and reviewed by Geological Survey.

Mean discharge, in cublc feet per second, 1963

\begin{tabular}{|c|c|c|c|c|c|c|c|c|}
\hline Day & January & February & Day & January & February & Day & January & February \\
\hline $\begin{array}{c}1 \ldots \ldots \\
2 \ldots \ldots \\
3 \ldots \ldots \\
4 \ldots \ldots \\
5 \ldots \ldots \\
6 \ldots \ldots \\
8 \ldots \ldots \\
9 \ldots \ldots \\
10 \ldots \ldots\end{array}$ & $\begin{array}{r}0.21 \\
.20 \\
.20 \\
.20 \\
.19 \\
.18 \\
.17 \\
.17 \\
.16 \\
.16\end{array}$ & $\begin{array}{r}15.00 \\
4.80 \\
3.20 \\
2.65 \\
2.38 \\
1.79 \\
1.46 \\
1.29 \\
1.16 \\
1.15\end{array}$ & $\begin{array}{l}11 \ldots \ldots \\
12 \ldots \ldots \\
13 \ldots \ldots \\
14 \ldots \ldots \\
15 \ldots \ldots \\
16 \ldots \ldots \\
17 \ldots \ldots \\
18 \ldots \ldots \\
19 \ldots \ldots \\
20 \ldots \ldots\end{array}$ & $\begin{array}{l}0.10 \\
.10 \\
.11 \\
.12 \\
.12 \\
.12 \\
.12 \\
.11 \\
.10 \\
.11\end{array}$ & $\begin{array}{r}1.02 \\
.96 \\
.97 \\
.90 \\
.83 \\
.78 \\
.74 \\
.69 \\
.67 \\
.66\end{array}$ & $\begin{array}{l}21 \ldots \ldots \\
22 \ldots \ldots \\
23 \ldots \ldots \\
24 \ldots \ldots \\
25 \ldots \ldots \\
26 \ldots \ldots \\
27 \ldots \ldots \\
28 \ldots \ldots \\
29 \ldots \ldots \\
30 \ldots \ldots \\
31 \ldots \ldots\end{array}$ & $\begin{array}{r}0.11 \\
.11 \\
.10 \\
.10 \\
.10 \\
.09 \\
.09 \\
.09 \\
.09 \\
.81 \\
22.30 \\
\end{array}$ & $\begin{array}{r}0.64 \\
.61 \\
.55 \\
.54 \\
.53 \\
.52 \\
.48 \\
.46 \\
-.-.- \\
-.-.- \\
\end{array}$ \\
\hline \multicolumn{7}{|c|}{ 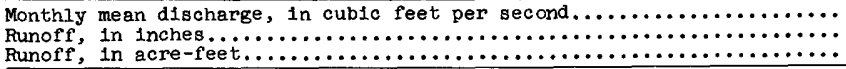 } & $\begin{array}{r}0.869 \\
5.27 \\
53.4 \\
\end{array}$ & $\begin{array}{l}1.69 \\
9.28 \\
94.1\end{array}$ \\
\hline
\end{tabular}


Gage height, in feet, and discharge, in cublc feet per second, at indicated time, 1963, of Onion Creek tributary No. I near Soda Springs, Calif.

\begin{tabular}{|c|c|c|c|c|c|c|c|c|c|c|c|}
\hline Date & Hour & $\begin{array}{c}\text { Gage } \\
\text { helght }\end{array}$ & $\begin{array}{c}\text { Dis- } \\
\text { charge }\end{array}$ & Date & Hour & $\begin{array}{c}\text { Gage } \\
\text { helght }\end{array}$ & $\begin{array}{c}\text { D1s- } \\
\text { charge }\end{array}$ & Date & Hour & $\begin{array}{c}\text { Gage } \\
\text { he1ght }\end{array}$ & $\begin{array}{l}\text { Dis- } \\
\text { charge }\end{array}$ \\
\hline $\begin{array}{r}\text { Jan. } 29 \\
30\end{array}$ & $\begin{array}{l}2400 \\
1100 \\
1300 \\
1600 \\
1830 \\
2100\end{array}$ & $\begin{array}{l}0.21 \\
.21 \\
.23 \\
.42 \\
.52 \\
.91\end{array}$ & $\begin{array}{r}0.09 \\
.09 \\
.11 \\
.51 \\
.86 \\
3.48\end{array}$ & $\begin{array}{r}\operatorname{Jan} . \\
31\end{array}$ & $\begin{array}{l}2400 \\
0230 \\
0630 \\
0840 \\
1200 \\
1500\end{array}$ & $\begin{array}{r}0.90 \\
\\
.98 \\
1.14 \\
1.35 \\
1.89 \\
2.20\end{array}$ & $\begin{array}{r}3.38 \\
4.18 \\
6.10 \\
9.29 \\
21.5 \\
31.3\end{array}$ & Jan. $31^{\circ}$ & $\begin{array}{l}1755 \\
1840 \\
1920 \\
2150 \\
2300 \\
2320 \\
2400\end{array}$ & $\begin{array}{l}2.29 \\
2.48 \\
2.39 \\
2.52 \\
2.59 \\
2.53 \\
2.75\end{array}$ & $\begin{array}{l}34.6 \\
42.2 \\
38.5 \\
43.9 \\
47.0 \\
44.4 \\
54.6\end{array}$ \\
\hline
\end{tabular}

1l-4261.5. Onion Creek near Soda Springs, Calif.

Location.--Lat $39^{\circ} 16^{\prime} 00^{\prime \prime}$, long $120^{\circ} 21^{\prime} 50^{\prime \prime}$, in SE $\frac{1}{4} \mathrm{NE} \frac{1}{4}$ sec.11, T.16 N., R.14 E., on right bank 0.3 mile upstream from unnamed tributary, i mile upstream from mouth, and 4.0 miles south of Soda Springs.

Drainage area. $--3.58 \mathrm{sq} \mathrm{mi}$.

Gage-helght record.--Water-stage recorder graph, except Jan. 14-29. Altitude of gage is 5,900 fit (from topographic map).

Discharge recurd. --Stage-discharge relation defined by current-meter measurements below $60 \mathrm{cfs}$ and by slope-area measurements at 218 and $960 \mathrm{cfs}$. Discharge for Jan. 14-29 estimated on basis of weather records and records for Onion Creek tributaries Nos. 1, 2, 3, 5A.

Maxima -January-February 1963: Discharge, 960 ofs 2000 hours Jan. 31 (gage height, $3.64 \mathrm{ft}$, from recorder graph; $4.5 \mathrm{ft}$, from floodmark).

1959 to December 1962: Discharge, 219 cfs Oct. 13, 1962 (gage height, $2.62 \mathrm{ft}$ ).

Mean discharge, in cub1c feet per second, 1963

\begin{tabular}{|c|c|c|c|c|c|c|c|c|}
\hline Day & January & February & Day & January & February & Day & January & February \\
\hline $\begin{array}{c}1 \ldots \ldots \\
2 \ldots \ldots \\
4 \ldots \ldots \\
5 \ldots \ldots \\
6 \ldots \ldots \\
8 \ldots \ldots \\
9 \ldots \ldots \\
10 \ldots \ldots\end{array}$ & $\begin{array}{l}3.3 \\
3.3 \\
3.0 \\
3.0 \\
2.8 \\
2.8 \\
2.5 \\
2.5 \\
2.5 \\
2.3\end{array}$ & $\begin{array}{r}292 \\
89 \\
79 \\
63 \\
54 \\
39 \\
27 \\
25 \\
22 \\
22\end{array}$ & $\begin{array}{l}11 \ldots \ldots \\
12 \ldots \ldots \\
13 \ldots \ldots \\
14 \ldots \ldots \\
15 \ldots \ldots \\
16 \ldots \ldots \\
17 \ldots \ldots \\
18 \ldots \ldots \\
19 \ldots \ldots \\
20 \ldots \ldots\end{array}$ & $\begin{array}{l}2.3 \\
2 \\
2 \\
2 \\
2 \\
2 \\
2 \\
1.5 \\
1.5 \\
1.5\end{array}$ & $\begin{array}{l}18 \\
17 \\
18 \\
17 \\
16 \\
16 \\
16 \\
15 \\
15 \\
14\end{array}$ & $\begin{array}{l}21 \ldots \ldots \\
22 \ldots \ldots \\
23 \ldots \ldots \\
24 \ldots \ldots \\
25 \ldots \ldots \\
26 \ldots \ldots \\
27 \ldots \ldots \\
28 \ldots \ldots \\
29 \ldots \ldots \\
30 \ldots \ldots \\
31 \ldots \ldots\end{array}$ & $\begin{array}{r}1.5 \\
1.5 \\
1.5 \\
1.3 \\
1.3 \\
1.3 \\
1.3 \\
1.3 \\
1.3 \\
19 \\
366 \\
\end{array}$ & $\begin{array}{r}13 \\
12 \\
10 \\
9.9 \\
9.9 \\
9.4 \\
8.2 \\
7.7 \\
--1 .- \\
-0\end{array}$ \\
\hline $\begin{array}{l}\text { onthly } \\
\text { anoff, } \\
\text { unoff, }\end{array}$ & $\begin{array}{l}\text { mean dis } \\
\text { in inche } \\
\text { in acre- }\end{array}$ & & & & & $\ldots \ldots \ldots$ & $\begin{array}{r}14.3 \\
4.61 \\
881 \\
\end{array}$ & $\begin{array}{r}34.1 \\
9.91 \\
1,890 \\
\end{array}$ \\
\hline
\end{tabular}

Gage height, in feet, and discharge, in cubic feet per second, at indlcated time, 1963

\begin{tabular}{|c|c|c|c|c|c|c|c|c|c|c|c|}
\hline Date & Hour & $\begin{array}{c}\text { Gage } \\
\text { height }\end{array}$ & $\begin{array}{c}\text { Dis- } \\
\text { charge }\end{array}$ & Date & Hour & $\begin{array}{c}\text { Gage } \\
\text { helght }\end{array}$ & $\begin{array}{l}\text { D1s- } \\
\text { charge }\end{array}$ & Date & Hour & $\begin{array}{c}\text { Gage } \\
\text { helght }\end{array}$ & $\begin{array}{c}\text { D1s- } \\
\text { charge }\end{array}$ \\
\hline $\begin{array}{r}29 \\
30\end{array}$ & $\begin{array}{l}2400 \\
1300 \\
1700 \\
1900 \\
2300 \\
2400 \\
0200\end{array}$ & $\begin{array}{l}1.62 \\
1.64 \\
1.72 \\
2.07 \\
2.11 \\
2.11 \\
2.13\end{array}$ & $\begin{array}{l}5.4 \\
6.3 \\
10 \\
54 \\
61 \\
61 \\
65\end{array}$ & Jan. 31 & $\begin{array}{l}0400 \\
0600 \\
1000 \\
1200 \\
1500 \\
1800 \\
1900 \\
2000 \\
2300 \\
2400\end{array}$ & $\begin{array}{l}2.25 \\
2.25 \\
2.50 \\
2.95 \\
3.02 \\
3.23 \\
3.15 \\
3.64 \\
3.30 \\
3.48\end{array}$ & $\begin{array}{r}92 \\
92 \\
170 \\
390 \\
434 \\
594 \\
530 \\
960 \\
650 \\
812\end{array}$ & Feb. 1 & $\begin{array}{l}0300 \\
0400 \\
0500 \\
0900 \\
1400 \\
1500 \\
2000 \\
2400\end{array}$ & $\begin{array}{l}3.12 \\
3.34 \\
3.14 \\
2.67 \\
2.41 \\
2.47 \\
2.40 \\
2.30\end{array}$ & $\begin{array}{l}506 \\
686 \\
522 \\
242 \\
138 \\
159 \\
134 \\
104\end{array}$ \\
\hline
\end{tabular}


11-4261.6. Onion Creek tributary No. 7 near Soda Springs, Calif.

Location.--Lat $39^{\circ} 15^{\prime} 58^{\prime \prime}$, long $120^{\circ} 21^{\prime} 19^{\prime \prime}$, in NE $\frac{1}{4} S W \frac{1}{4}$ sec.12, T.16 N., R.14 E. , 0.4 mile upstream from junction with Onion Creek, 0.6 mile southeast of onion Creek campground, and 4.1 miles southeast of Soda Springs.

Drainage area,$-0.80 \mathrm{sq} \mathrm{mi}$.

Gage-height record.--Water-stage recorder graph, except Feb. 1-28.

Discharge record.--Stage-discharge relation defined by $120^{\circ} \mathrm{V}$-notch weir; affected by 1ce Jan. 11-13, 19, 20, Discharge for Feb. 1-28 estimated from records for nearby streams.

Maxima.--January-February 1963: Discharge, $181 \mathrm{cfs} 2300$ hours Jan. 31 (gage he1ght, $4.45 \mathrm{ft}$ ); gage height, $5.3 \mathrm{ft}$ Feb. 1 (backwater from debris).

1958 to December 1962: Discharge, 55.1 cfs oct. 13, 1962 (gage height, $2.76 \mathrm{ft}$ ).

Remarks.--Gage-height record furnished by U.S Forest Service.

Mean d1scharge, in cub1c feet per second, 1963

\begin{tabular}{|c|c|c|c|c|c|c|c|c|}
\hline Day & January & February & Day & January & February & Day & January & February \\
\hline $\begin{array}{c}1 \ldots \ldots \\
2 \ldots \ldots \\
3 \ldots \ldots \\
4 \ldots \ldots \\
5 \ldots \ldots \\
6 \ldots \ldots \\
8 \ldots \ldots \\
9 \ldots \ldots \\
10 \ldots \ldots\end{array}$ & $\begin{array}{l}0.86 \\
.82 \\
.82 \\
.78 \\
.74 \\
.74 \\
.71 \\
.67 \\
.67 \\
.64\end{array}$ & $\begin{array}{c}58.0 \\
22.0 \\
14.0 \\
11.0 \\
8.60 \\
6.50 \\
5.00 \\
4.68 \\
4.32 \\
4.03\end{array}$ & $\begin{array}{l}11 \ldots \ldots \\
12 \ldots \ldots \\
13 \ldots \ldots \\
14 \ldots \ldots \\
15 \ldots \ldots \\
16 \ldots \ldots \\
17 \ldots \ldots \\
18 \ldots \ldots \\
19 \ldots \ldots \\
20 \ldots \ldots\end{array}$ & $\begin{array}{l}0.60 \\
.58 \\
.56 \\
.54 \\
.54 \\
.51 \\
.51 \\
.51 \\
.45 \\
.45\end{array}$ & $\begin{array}{l}3.89 \\
3.74 \\
3.46 \\
3.38 \\
3.24 \\
3.10 \\
3.02 \\
2.88 \\
2.81 \\
2.66\end{array}$ & $\begin{array}{l}21 \ldots \ldots \\
22 \ldots \ldots \\
23 \ldots \ldots \\
24 \ldots \ldots \\
25 \ldots \ldots \\
26 \ldots \ldots \\
27 \ldots \ldots \\
28 \ldots \ldots \\
29 \ldots \ldots \\
30 \ldots \ldots \\
31 \ldots \ldots\end{array}$ & $\begin{array}{r}0.45 \\
.45 \\
.42 \\
.42 \\
.42 \\
.40 \\
.40 \\
.40 \\
.40 \\
3.18 \\
80.0\end{array}$ & $\begin{array}{r}2.45 \\
2.30 \\
2.16 \\
2.02 \\
1.94 \\
1.87 \\
1.73 \\
1.66 \\
------ \\
--.---\end{array}$ \\
\hline $\begin{array}{l}\text { Monthly } \\
\text { Runoff, } \\
\text { Runoff, }\end{array}$ & $\begin{array}{l}\text { an disch } \\
\text { Inches. } \\
\text { acre-fe }\end{array}$ & $\ldots$ & $\cdots$ & $\square$ & - & $\ldots \ldots \ldots$ & $\begin{array}{r}3.21 \\
4.63 \\
198\end{array}$ & $\begin{array}{r}6.66 \\
8.67 \\
370\end{array}$ \\
\hline
\end{tabular}

Gage he1ght, in feet, and discharge, in cublc feet per second, at 1ndicated time, 1963

\begin{tabular}{|c|c|c|c|c|c|c|c|c|c|c|c|}
\hline Date & Hour & $\begin{array}{c}\text { Gage } \\
\text { helght }\end{array}$ & $\begin{array}{l}\text { Dis- } \\
\text { charge }\end{array}$ & Date & Hour & $\begin{array}{c}\text { Gage } \\
\text { height }\end{array}$ & $\begin{array}{l}\text { Dis - } \\
\text { charge }\end{array}$ & Date & Hour & $\begin{array}{c}\text { Gage } \\
\text { helght }\end{array}$ & $\begin{array}{l}\text { D18- } \\
\text { charge }\end{array}$ \\
\hline $\begin{array}{r}\operatorname{Jan} .29 \\
30\end{array}$ & $\begin{array}{l}2400 \\
1100 \\
1300 \\
1600 \\
1800 \\
1930 \\
2000 \\
2200 \\
\end{array}$ & $\begin{array}{r}0.38 \\
.38 \\
.40 \\
.60 \\
.69 \\
1.32 \\
1.49 \\
1.56 \\
\end{array}$ & $\begin{array}{r}0.40 \\
.40 \\
.45 \\
1.23 \\
1.75 \\
8.78 \\
11.9 \\
13.3 \\
\end{array}$ & $\begin{array}{r}\operatorname{Jan} .30 \\
31\end{array}$ & $\begin{array}{l}2400 \\
\\
0230 \\
0600 \\
1000 \\
1100 \\
1300 \\
1500 \\
1700\end{array}$ & $\begin{array}{l}1.59 \\
1.60 \\
1.81 \\
2.32 \\
2.51 \\
3.22 \\
3.51 \\
4.08\end{array}$ & $\begin{array}{r}14.0 \\
14.2 \\
19.3 \\
35.8 \\
43.5 \\
80.9 \\
100 \\
146\end{array}$ & Jan. 31 & $\begin{array}{l}1800 \\
1830 \\
1900 \\
2000 \\
2030 \\
2100 \\
2200 \\
2300 \\
2400\end{array}$ & $\begin{array}{l}4.21 \\
4.15 \\
4.21 \\
4.41 \\
3.89 \\
4.09 \\
4.38 \\
4.45 \\
4.35\end{array}$ & $\begin{array}{l}158 \\
152 \\
158 \\
177 \\
130 \\
147 \\
174 \\
181 \\
171\end{array}$ \\
\hline
\end{tabular}

11-4262. North Fork Forbes Creek near Dutch Flat, Calif.

Location.--Lat $39^{\circ} 08^{\prime} 37^{\prime \prime}$, long $120^{\circ} 45^{\prime} 30^{\prime \prime}$, in SE $\frac{1}{4}$ sec.17, T.15 N., R.11 E., on right bank 0.2 mile downstream from Big Reservolr and 6.0 miles southeast of Dutch Flat.

Drainage area. $--1.68 \mathrm{sq} \mathrm{mi}$.

Gage-height record.--Water-stage recorder graph, except from 2300 hours Jan. 31 to 0100 hours $\mathrm{Feb} .1$, for which graph was reconstructed on basis of adjacent trace. Altitude of gage is 3,980 ft (from topographic map).

Discharge record.--Stage-discharge relation defined by current-meter measurements below $160 \mathrm{cfs}$. Maxima ${ }^{--J a n u a r y-F e b r u a r y ~ 1963: ~ D i s c h a r g e, ~} 200 \mathrm{cfs} 0400$ hours Feb. 1 (gage height,

1956 to December 1962: Discharge, $91 \mathrm{cfs} \mathrm{Feb.} \mathrm{14,} 1962$ (gage height, $3.64 \mathrm{ft}$ ).

Maximum stage known, $6.40 \mathrm{ft}$ probably Dec. 23, 1955, from floodmarks (discharge unknown I.

Remarks.--Records furnished by Bureau of Reclamation. Flow affected by Big Reservoir (capacity, 2,200 acre-ft). 
Mean discharge, in cubic feet per second, 1963, of North Fork Forbes Creek near Dutch Flat, Cal1f.

\begin{tabular}{|c|c|c|c|c|c|c|c|c|}
\hline Day & January & February & Day & January & February & Day & January & February \\
\hline $\begin{array}{c}1 \ldots \ldots \\
2 \ldots \ldots \\
3 \ldots \ldots \\
4 \ldots \ldots \\
5 \ldots \ldots \\
7 \ldots \ldots \\
8 \ldots \ldots \\
9 \ldots \ldots \\
10 \ldots \ldots\end{array}$ & $\begin{array}{l}4.6 \\
4.4 \\
4.2 \\
4.2 \\
3.9 \\
3.8 \\
3.6 \\
3.5 \\
3.4 \\
3.3\end{array}$ & $\begin{array}{r}163 \\
86 \\
54 \\
39 \\
29 \\
25 \\
22 \\
19 \\
17 \\
16\end{array}$ & $\begin{array}{l}11 \ldots \ldots \\
12 \ldots \ldots \\
13 \ldots \ldots \\
14 \ldots \ldots \\
15 \ldots \ldots \\
16 \ldots \ldots \\
17 \ldots \ldots \\
18 \ldots \ldots \\
19 \ldots \ldots \\
20 \ldots \ldots\end{array}$ & $\begin{array}{l}3.1 \\
2.8 \\
2.7 \\
2.7 \\
2.7 \\
2.7 \\
2.6 \\
2.6 \\
2.5 \\
2.5\end{array}$ & $\begin{array}{l}15 \\
12 \\
14 \\
13 \\
12 \\
10 \\
9.3 \\
8.4 \\
7.8 \\
7.4\end{array}$ & $\begin{array}{l}21 \ldots \ldots \\
22 \ldots \ldots \\
23 \ldots \ldots \\
24 \ldots \ldots \\
25 \ldots \ldots \\
26 \ldots \ldots \\
27 \ldots \ldots \\
28 \ldots \ldots \\
29 \ldots \ldots \\
30 \ldots \ldots \\
31 \ldots \ldots\end{array}$ & $\begin{array}{l}2.4 \\
2.4 \\
2.3 \\
2.1 \\
1.9 \\
1.9 \\
1.8 \\
2.2 \\
2.9 \\
7.6 \\
59\end{array}$ & $\begin{array}{r}7.0 \\
7.5 \\
7.3 \\
6.4 \\
5.4 \\
5.1 \\
4.9 \\
4.7 \\
----1 \\
----- \\
-\end{array}$ \\
\hline of & acre- & & & & & & $\begin{array}{r}4.91 \\
3.37 \\
302 \\
\end{array}$ & $\begin{array}{r}22.4 \\
13.9 \\
1,240 \\
\end{array}$ \\
\hline
\end{tabular}

Gage height, in feet, and discharge, in cubic feet per second, at indicated t1me, 1963

\begin{tabular}{|c|c|c|c|c|c|c|c|c|c|c|c|c|}
\hline Date & Hour & $\begin{array}{c}\text { Gage } \\
\text { helght }\end{array}$ & $\begin{array}{c}\text { D1s- } \\
\text { charge }\end{array}$ & Date & Hour & $\begin{array}{c}\text { Gage } \\
\text { helght }\end{array}$ & $\begin{array}{c}\text { Dis- } \\
\text { charge }\end{array}$ & \multicolumn{2}{|l|}{ Date } & Hour & $\begin{array}{c}\text { Gage } \\
\text { helght }\end{array}$ & $\begin{array}{c}\text { Dis- } \\
\text { charge }\end{array}$ \\
\hline Jan. 29 & 2400 & 1.90 & 3.9 & $\operatorname{Jan} .31$ & 0700 & 2.57 & \multirow{4}{*}{$\begin{array}{r}20 \\
27 \\
29 \\
42 \\
48 \\
48 \\
109 \\
102 \\
135 \\
146 \\
153\end{array}$} & \multirow{4}{*}{ Feb. } & & \multirow[b]{2}{*}{$\begin{array}{l}0200 \\
0400 \\
0700 \\
1400 \\
1600 \\
2400\end{array}$} & \multirow[b]{2}{*}{$\begin{array}{l}3.99 \\
4.18 \\
4.05 \\
3.91 \\
3.95 \\
3.70\end{array}$} & \multirow[b]{2}{*}{$\begin{array}{l}162 \\
200 \\
174 \\
148 \\
155 \\
114\end{array}$} \\
\hline 30 & $\begin{array}{l}1000 \\
1100 \\
1400 \\
1500 \\
1800\end{array}$ & $\begin{array}{l}2.09 \\
2.07 \\
2.17 \\
2.05 \\
2.18 \\
2.29\end{array}$ & $\begin{array}{r}7.0 \\
6.6 \\
8.5 \\
6.2 \\
8.8\end{array}$ & & $\begin{array}{l}1000 \\
1200 \\
1300 \\
1500 \\
1600 \\
1900\end{array}$ & $\begin{array}{l}2.72 \\
2.77 \\
3.03 \\
3.12 \\
3.13 \\
3.66\end{array}$ & & & & & & \\
\hline & 2400 & 2.33 & $\begin{array}{l}11 \\
12\end{array}$ & & & & & & 2 & $\begin{array}{l}0600 \\
1300\end{array}$ & $\begin{array}{l}3.57 \\
3.45\end{array}$ & $\begin{array}{l}96 \\
81\end{array}$ \\
\hline 31 & $\begin{array}{l}0400 \\
0600\end{array}$ & $\begin{array}{l}2.44 \\
2.49 \\
\end{array}$ & $\begin{array}{l}16 \\
17\end{array}$ & & $\begin{array}{l}2300 \\
2400\end{array}$ & $\begin{array}{l}3.90 \\
3.94\end{array}$ & & & & $\begin{array}{l}1800 \\
2400\end{array}$ & $\begin{array}{l}3.41 \\
3.32\end{array}$ & $\begin{array}{l}76 \\
67\end{array}$ \\
\hline
\end{tabular}

11-4264. North Shirttail Creek near Dutch Flat, Calif.

Location,--Lat $39^{\circ} 07149^{\prime \prime}$, long $120^{\circ} 47144^{\prime \prime}$, in SE $\frac{1}{4}$ sec. 24 , T. 15 N., R.10 E., on right bank $200 \mathrm{f}^{\mathrm{t} t}$ downstream from Forbes Creek and 7.0 miles southeast of Dutch Flat.

Drainage area. $--9.10 \mathrm{sq} \mathrm{mi}$.

Gage-height record:--Water-stage recorder graph. Altitude of gage is $3,500 \mathrm{ft}$ (from topographic map).

Discharge record.--Stage-discharge relation defined by current-meter measurements below $590 \mathrm{cf}$ 's and by slope-area measurement at $1,250 \mathrm{cf}$.

Maxima.--January-February 1963: Discharge, 1,250 cf's 1930 hours Jan. 31 (gage height, $6.36 \mathrm{ft}$, from floodmark in well; $6.5 \mathrm{ft}$, from high-water profile).

1956 to December 1962: Discharge, 737 cfs 0ct. 13, 1962 (gage height, $4.97 \mathrm{ft}$ ) Maximum stage known, $7.30 \mathrm{ft}$ probably Dec. 23 , 1955, from floodmarks (dis-
charge, about $1,900 \mathrm{cfs}$ ). Remarks.--Records furnished by U.S. Bureau of Reclamation and reviewed by Geolog-
ical Survey.

\begin{tabular}{|c|c|c|c|c|c|c|c|c|}
\hline Day & January & February & Day & January & February & Day & January & Pebruary \\
\hline $\begin{array}{c}\ldots \ldots \\
3 \ldots \ldots \\
4 \ldots \ldots \\
5 \ldots \ldots \\
6 \ldots \ldots \\
8 \ldots \ldots \\
9 \ldots \ldots \\
10 \ldots \ldots\end{array}$ & $\begin{array}{l}18 \\
18 \\
17 \\
16 \\
16 \\
15 \\
15 \\
14 \\
14 \\
14\end{array}$ & $\begin{array}{r}704 \\
268 \\
170 \\
125 \\
104 \\
88 \\
77 \\
67 \\
59 \\
55\end{array}$ & $\begin{array}{l}11 \ldots \ldots \\
12 \ldots \ldots \\
13 \ldots \ldots \\
14 \ldots \ldots \\
15 \ldots \ldots \\
16 \ldots \ldots \\
17 \ldots \ldots \\
18 \ldots \ldots \\
19 \ldots \ldots \\
20 \ldots \ldots\end{array}$ & $\begin{array}{l}13 \\
12 \\
12 \\
12 \\
12 \\
12 \\
11 \\
11 \\
11 \\
10\end{array}$ & $\begin{array}{l}50 \\
46 \\
89 \\
65 \\
55 \\
49 \\
45 \\
40 \\
38 \\
35\end{array}$ & $\begin{array}{l}21 \ldots \ldots \\
22 \ldots \ldots \\
23 \ldots \ldots \\
24 \ldots \ldots \\
25 \ldots \ldots \\
26 \ldots \ldots \\
27 \ldots \ldots \\
28 \ldots \ldots \\
29 \ldots \ldots \\
30 \ldots \ldots \\
31 \ldots \ldots\end{array}$ & $\begin{array}{c}10 \\
10 \\
10 \\
9.8 \\
9.2 \\
8.9 \\
8.5 \\
8.7 \\
11 \\
91 \\
601\end{array}$ & $\begin{array}{r}32 \\
31 \\
29 \\
28 \\
26 \\
24 \\
23 \\
22 \\
-\ldots--\end{array}$ \\
\hline $\begin{array}{l}\text { onthly } \\
\text { anoff, } \\
\text { inoff, }\end{array}$ & $\begin{array}{l}\text { ean dis } \\
n \text { inche } \\
n \text { acre- }\end{array}$ & & & & & & $\begin{array}{r}33.9 \\
4.30 \\
2.080 \\
\end{array}$ & $\begin{array}{r}87.3 \\
9.99 \\
4,850 \\
\end{array}$ \\
\hline
\end{tabular}

Gage height, in feet, and discharge, in cublc feet per second, at indicated time, 1963

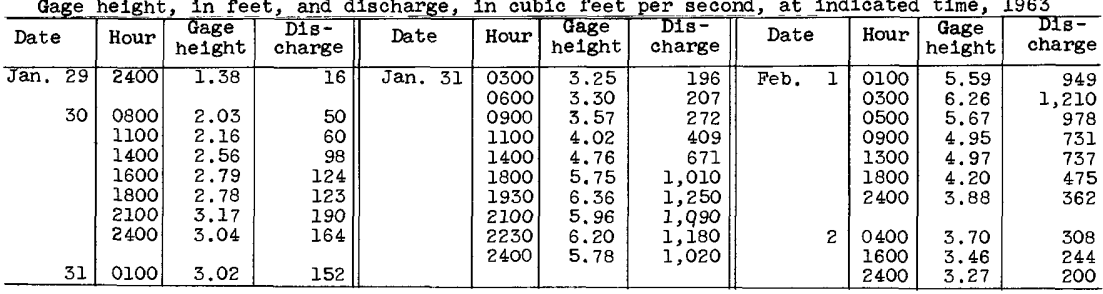


11-4270. North Fork American River at North Fork Dam, Calif.

Location.--Lat $38^{\circ} 56^{\prime} 15^{\prime \prime}$, long $121^{\circ} 01^{\prime} 25^{\prime \prime}$, in SW $\frac{1}{4} N W^{\frac{1}{4}}$ sec.31, T.13 N., R.9 E., on left bank $50 \mathrm{ft}$ upstream from spillway of North Fork Dam, 2 miles upstream from Middle Fork, and 4 miles northeast of Auburn.

Drainage area.--343 sq mi.

Gage-height record.--Water-stage recorder graph; Datum of gage is $715.0 \mathrm{ft}$ above mean sea leveI (levels by Corps of Engineers).

Discharge record.--Stage-discharge relation defined by current-meter measurements below $23,200 \mathrm{c}$ s and by computed flow over spillway of dam at 49,100 cfs.

Maxima.--January-February 1963: Discharge, 59,700 cf's at 2400 hours Jan. 31 (gage helght, $11.30 \mathrm{ft}$, from recorder graph; $11.36 \mathrm{ft}$, from floodmarks).

1941 to December 1962: Discharge, 49,100 cf's Dec. 23, 1955 (gage height, $10.22 \mathrm{ft}$ ).

Mean discharge, in cubic feet per second, 1963

\begin{tabular}{|c|c|c|c|c|c|c|c|c|}
\hline Day & January & February & Day & January & February & Day & January & February \\
\hline $\begin{array}{c}1 \ldots \ldots \\
3 \ldots \ldots \\
4 \ldots \ldots \\
5 \ldots \ldots \\
6 \ldots \ldots \\
8 \ldots \ldots \\
9 \ldots \ldots \\
10 \ldots \ldots\end{array}$ & $\begin{array}{l}362 \\
340 \\
332 \\
318 \\
304 \\
297 \\
284 \\
277 \\
263 \\
256\end{array}$ & $\begin{array}{r}33,300 \\
8,800 \\
4,930 \\
3,570 \\
3,050 \\
2,420 \\
1,980 \\
1,660 \\
1,500 \\
1,370\end{array}$ & $\begin{array}{l}11 \ldots \ldots \\
12 \ldots \ldots \\
13 \ldots \ldots \\
14 \ldots \ldots \\
15 \ldots \ldots \\
16 \ldots \ldots \\
17 \ldots \ldots \\
18 \ldots \ldots \\
19 \ldots \ldots \\
20 \ldots \ldots\end{array}$ & $\begin{array}{l}250 \\
219 \\
206 \\
213 \\
219 \\
213 \\
206 \\
200 \\
194 \\
182\end{array}$ & $\begin{array}{r}1,240 \\
1,070 \\
2,620 \\
2,340 \\
1,620 \\
1,380 \\
1,250 \\
1,100 \\
1,010 \\
959\end{array}$ & $\begin{array}{l}21 \ldots \ldots \\
22 \ldots \ldots \\
23 \ldots \ldots \\
24 \ldots \ldots \\
25 \ldots \ldots \\
26 \ldots \ldots \\
27 \ldots \ldots \\
28 \ldots \ldots \\
29 \ldots \ldots \\
30 \ldots \ldots \\
31 \ldots \ldots\end{array}$ & $\begin{array}{r}182 \\
182 \\
176 \\
176 \\
170 \\
170 \\
165 \\
165 \\
173 \\
1,780 \\
26,700\end{array}$ & $\begin{array}{r}904 \\
830 \\
760 \\
712 \\
665 \\
638 \\
620 \\
593 \\
-\ldots-- \\
-.--\end{array}$ \\
\hline $\begin{array}{l}\text { onthly } \\
\text { unoff, } \\
\text { unoff, }\end{array}$ & acre- & & & & & & $\begin{array}{r}1,135 \\
3,81 \\
69,770\end{array}$ & $\begin{array}{r}2,960 \\
8,99 \\
164,400\end{array}$ \\
\hline
\end{tabular}

Gage height, in feet, and discharge, in cubic feet per second, at indicated time, 1963

\begin{tabular}{|c|c|c|c|c|c|c|c|c|c|c|c|}
\hline Date & Hour & $\begin{array}{c}\text { Gage } \\
\text { helght }\end{array}$ & $\begin{array}{l}\text { Dis- } \\
\text { charge }\end{array}$ & Date & Hour & $\begin{array}{c}\text { Gage } \\
\text { helght }\end{array}$ & $\begin{array}{c}\text { D1s- } \\
\text { charge }\end{array}$ & Date & Hour & $\begin{array}{c}\text { Gage } \\
\text { he1ght }\end{array}$ & $\begin{array}{c}\text { Dis- } \\
\text { charge }\end{array}$ \\
\hline $\begin{array}{r}\operatorname{Jan} . \\
30\end{array}$ & $\begin{array}{l}2400 \\
0400 \\
0900 \\
1200 \\
1400 \\
1700 \\
1900 \\
2000 \\
2100 \\
2400 \\
0300 \\
0700 \\
0900\end{array}$ & $\begin{array}{r}0.61 \\
.65 \\
.79 \\
1.01 \\
1.22 \\
1.90 \\
2.61 \\
3.16 \\
3.87 \\
4.96 \\
5.41 \\
5.29 \\
5.45\end{array}$ & $\begin{array}{r}200 \\
225 \\
318 \\
494 \\
684 \\
1,440 \\
2,390 \\
3,430 \\
5,530 \\
10,200 \\
12,500 \\
11,900 \\
12,700\end{array}$ & Jan. 31 & $\begin{array}{l}1100 \\
1400 \\
1600 \\
1800 \\
2000 \\
2200 \\
2400 \\
\\
0400 \\
0700 \\
1100 \\
1500 \\
2000 \\
2400\end{array}$ & $\begin{array}{r}5.69 \\
7.10 \\
8.50 \\
9.50 \\
10.32 \\
11.15 \\
11.30 \\
11.20 \\
10.12 \\
8.00 \\
6.68 \\
6.00 \\
5.61\end{array}$ & $\begin{array}{l}14,000 \\
22,900 \\
33,600 \\
42,300 \\
50,000 \\
58,200 \\
59,700 \\
58,700 \\
48,100 \\
29,600 \\
20,000 \\
15,800 \\
13,600\end{array}$ & Feb. & $\begin{array}{l}1200 \\
2400 \\
1900 \\
2400 \\
1900 \\
2200 \\
2400 \\
0400 \\
1000 \\
1500 \\
1800 \\
2400\end{array}$ & $\begin{array}{l}4.47 \\
3.96 \\
3.51 \\
3.46 \\
3.04 \\
3.01 \\
3.03 \\
3.24 \\
3.04 \\
2.88 \\
2.90 \\
2.82\end{array}$ & $\begin{array}{l}7,870 \\
5,860 \\
4,350 \\
4,210 \\
3,160 \\
3,100 \\
3,140 \\
3,620 \\
3,160 \\
2,840 \\
2,740 \\
2,600\end{array}$ \\
\hline
\end{tabular}

11-4275. Middle Fork American River at French Meadows, Calif.

Location.--Lat $39^{\circ} 06^{\prime} 35^{\prime \prime}$, long $120^{\circ} 28^{\prime} 49^{\prime \prime}$, in W $\frac{1}{2} \mathrm{NW} \frac{1}{4} \sec .36$, T.15 N., R.13 E., on left' bंank $0.6 \mathrm{mile}$ downstream from French Meadows Dam, 4.1 miles upstream from Chipmunk Creek, and 14 miles south of Cisco.

Drainage area. $--47.9 \mathrm{sq} \mathrm{mi}$.

Gage-height record.--Water-stage recorder graph. Altitude of gage is 4,920 $\mathrm{ft}$ (from topographic map).

Discharge record.-Stage-discharge relation defined by current-meter measurements below $1,100 \mathrm{cf}$ 's and by peak flows at former site.

Maxima.--January-February 1963: Discharge, 21,500 cf's 2100 hours Jan. 31 (gage he1ght, $14.20 \mathrm{ft}$, from recorder graph; $17.6 \mathrm{ft}$, from floodmarks ).

1951 to December 1962: Discharge, 16,300 cf's Dec. 23, 1955 (gage helght, $14.95 \mathrm{ft}$, site and datum then in use . 
Mean discharge, in cub1c feet per second, 1963, of Middle Fork American River at French Meadows, Cálif.

\begin{tabular}{|c|c|c|c|c|c|c|c|c|}
\hline Day & January & February & Day & January & February & Day & January & February \\
\hline $\begin{array}{r}\ldots \ldots \\
2 \ldots \ldots \\
3 \ldots \ldots \\
4 \ldots \ldots \\
5 \ldots \ldots \\
6 \ldots \ldots \\
7 \ldots \ldots \\
8 \ldots \ldots \\
9 \ldots \ldots \\
10 \ldots \ldots\end{array}$ & $\begin{array}{l}60 \\
57 \\
56 \\
56 \\
52 \\
51 \\
49 \\
48 \\
46 \\
45\end{array}$ & $\begin{array}{r}7,750 \\
1,350 \\
858 \\
683 \\
581 \\
405 \\
326 \\
274 \\
244 \\
233\end{array}$ & $\begin{array}{l}11 \ldots \ldots \\
12 \ldots \ldots \\
13 \ldots \ldots \\
14 \ldots \ldots \\
15 \ldots \ldots \\
16 \ldots \ldots \\
17 \ldots \ldots \\
18 \ldots \ldots \\
19 \ldots \ldots \\
20 \ldots \ldots\end{array}$ & $\begin{array}{l}33 \\
30 \\
38 \\
39 \\
38 \\
37 \\
35 \\
34 \\
31 \\
32\end{array}$ & $\begin{array}{l}209 \\
192 \\
294 \\
252 \\
211 \\
198 \\
183 \\
172 \\
166 \\
160\end{array}$ & $\begin{array}{l}21 \ldots \ldots \\
22 \ldots \ldots \\
23 \ldots \ldots \\
24 \ldots \ldots \\
25 \ldots \ldots \\
26 \ldots \ldots \\
27 \ldots \ldots \\
28 \ldots \ldots \\
29 \ldots \ldots \\
30 \ldots \ldots \\
31 \ldots \ldots\end{array}$ & $\begin{array}{r}31 \\
31 \\
31 \\
30 \\
29 \\
29 \\
28 \\
28 \\
29 \\
390 \\
9,980 \\
\end{array}$ & $\begin{array}{r}151 \\
136 \\
125 \\
119 \\
112 \\
112 \\
106 \\
97 \\
---- \\
---- \\
-\end{array}$ \\
\hline \multicolumn{7}{|c|}{ 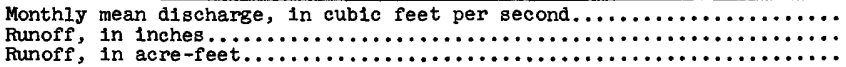 } & $\begin{array}{r}371 \\
8.93 \\
22,820\end{array}$ & $\begin{array}{r}561 \\
12.2 \\
31,140 \\
\end{array}$ \\
\hline
\end{tabular}

Gage height, in feet, and discharge, in cublc feet per second, at indicated time, 1963

\begin{tabular}{|c|c|c|c|c|c|c|c|c|c|c|c|}
\hline Date & Hour & $\begin{array}{c}\text { Gage } \\
\text { height }\end{array}$ & $\begin{array}{c}\text { Dis- } \\
\text { charge }\end{array}$ & Date & Hour & $\begin{array}{c}\text { Gage } \\
\text { helght }\end{array}$ & $\begin{array}{c}\text { Dis- } \\
\text { charge }\end{array}$ & Date & Hour & $\begin{array}{c}\text { Gage } \\
\text { hel ght }\end{array}$ & $\begin{array}{c}\text { D18- } \\
\text { charge }\end{array}$ \\
\hline $\begin{array}{r}29 \\
30\end{array}$ & $\begin{array}{l}2400 \\
0400 \\
0600 \\
0800 \\
1200 \\
1500 \\
1800 \\
2000 \\
2100 \\
2100 \\
2300 \\
2400 \\
0200 \\
\end{array}$ & $\begin{array}{l}3.49 \\
3.70 \\
3.67 \\
3.72 \\
4.02 \\
4.50 \\
5.30 \\
6.77 \\
8.00 \\
7.77 \\
8.07 \\
8.13 \\
8.20\end{array}$ & $\begin{array}{r}36 \\
52 \\
50 \\
54 \\
84 \\
154 \\
340 \\
915 \\
1,690 \\
1,520 \\
1,750 \\
1,790 \\
1,850 \\
\end{array}$ & Feb. 1 & $\begin{array}{l}0300 \\
0600 \\
0800 \\
1000 \\
1200 \\
1400 \\
1600 \\
1800 \\
1900 \\
2000 \\
2100 \\
2300 \\
2400 \\
0200\end{array}$ & $\begin{array}{r}8.28 \\
8.66 \\
9.17 \\
9.95 \\
11.00 \\
12.85 \\
13.33 \\
13.55 \\
14.00 \\
13.80 \\
14.20 \\
14.03 \\
14.13 \\
13.95\end{array}$ & $\begin{array}{r}1,920 \\
2,280 \\
2,900 \\
4,150 \\
6,500 \\
13,600 \\
16,200 \\
17,500 \\
20,200 \\
19,000 \\
21,500 \\
20,400 \\
21,000 \\
19,900\end{array}$ & Feb. 1 & $\begin{array}{l}0500 \\
0600 \\
0800 \\
1000 \\
1200 \\
1400 \\
1600 \\
1700 \\
1800 \\
2000 \\
2400 \\
0600 \\
1200 \\
2400\end{array}$ & $\begin{array}{r}13.10 \\
12.73 \\
11.08 \\
10.23 \\
9.78 \\
10.00 \\
9.95 \\
10.05 \\
10.03 \\
9.33 \\
8.82 \\
8.24 \\
7.84 \\
7.46\end{array}$ & $\begin{array}{r}14,900 \\
13,000 \\
6,490 \\
4,460 \\
3,580 \\
4,000 \\
3,900 \\
4,100 \\
4,060 \\
2,880 \\
2,140 \\
1,540 \\
1,210 \\
956\end{array}$ \\
\hline
\end{tabular}

11-4277. Duncan Creek near French Meadows, Calif.

Location.--Lat $39^{\circ} 08^{\prime} 10^{\prime \prime}$, long $122^{\circ} 28^{\prime} 39^{\prime \prime}$, in SW $\frac{1}{4} \mathrm{NW} \frac{1}{4}$ sec.24, T.15 N., R.13 E., on right bank 0.5 mile downstream from Little Duncan Creek, 2 miles northwest' of French Meadows, and 20 miles northeast of Foresthill.

Drainage area.- $-9.94 \mathrm{sq} \mathrm{mi}$.

Gage-height record.-Water-stage recorder graph. Altitude of gage is $5,280 \mathrm{ft}$ (from topographic mapj.

Discharge record.--Stage-discharge relation defined by current-meter measurements below $220 \mathrm{cf}$ 's and by slope-area measurement at $841 \mathrm{cfs}$ and maximum discharge for flood of Jan. 31 measured at site 2 miles downstream. Affected by ice Jan. 11-17. Stage-discharge relation indefintte from 1000 hours Jan. 31 to 0600 hours Feb. 1; discharge estimated on basis of rating curve extended to slope-area measurement at gage height $8.78 \mathrm{ft}$.

Maxima.--January-February 1963: Discharge, 4,610 cfs 1500 hours Jan. 31 (gage height, $8.78 \mathrm{ft}$, from recorder graph; $9.95 \mathrm{ft}$, from floodmarks).

1960 to December 1962: Discharge, 841 cfs 0ct. 13, 1962 (gage height, $6.34 \mathrm{ft}$, from recorder graph; $6.85 \mathrm{ft}$, from floodmarks). 
Mean discharge in cuble feet per second, 1963, of Duncan Creek near French Meadows, Cal1f.

\begin{tabular}{|c|c|c|c|c|c|c|c|c|}
\hline Day & January & February & Day & January & February & Day & January & February \\
\hline $\begin{array}{c}1 \ldots \ldots \\
2 \ldots \ldots \\
4 \ldots \ldots \\
5 \ldots \ldots \\
6 \ldots \ldots \\
8 \ldots \ldots \\
9 \ldots \ldots \\
10 \ldots \ldots\end{array}$ & $\begin{array}{l}13 \\
13 \\
13 \\
12 \\
12 \\
11 \\
10 \\
10 \\
9.7 \\
9.4\end{array}$ & $\begin{array}{r}1,040 \\
348 \\
217 \\
162 \\
123 \\
92 \\
74 \\
63 \\
55 \\
50\end{array}$ & $\begin{array}{l}11 \ldots \ldots \\
12 \ldots \ldots \\
13 \ldots \ldots \\
14 \ldots \ldots \\
15 \ldots \ldots \\
16 \ldots \ldots \\
17 \ldots \ldots \\
18 \ldots \ldots \\
19 \ldots \ldots \\
20 \ldots \ldots\end{array}$ & $\begin{array}{l}8.0 \\
7.0 \\
8.5 \\
8.5 \\
8.5 \\
8.0 \\
8.0 \\
7.7 \\
7.7 \\
7.5\end{array}$ & $\begin{array}{l}42 \\
58 \\
46 \\
42 \\
40 \\
38 \\
36 \\
34 \\
33\end{array}$ & $\begin{array}{l}21 \ldots \ldots \\
22 \ldots \ldots \\
23 \ldots \ldots \\
24 \ldots \ldots \\
25 \ldots \ldots \\
26 \ldots \ldots \\
27 \ldots \ldots \\
28 \ldots \ldots \\
29 \ldots \ldots \\
30 \ldots \ldots \\
31 \ldots \ldots\end{array}$ & $\begin{array}{r}7.0 \\
6.8 \\
6.4 \\
6.2 \\
6.1 \\
5.9 \\
5.7 \\
5.7 \\
6.1 \\
181 \\
I, 870\end{array}$ & $\begin{array}{r}31 \\
30 \\
28 \\
26 \\
25 \\
24 \\
22 \\
21 \\
-\ldots--- \\
-----\end{array}$ \\
\hline noff, & \multicolumn{6}{|c|}{ 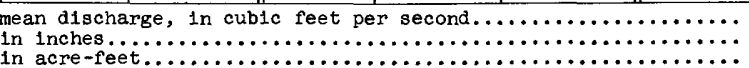 } & $\begin{array}{r}74.2 \\
8.60 \\
4,560\end{array}$ & $\begin{array}{r}102 \\
10.6 \\
5,640 \\
\end{array}$ \\
\hline
\end{tabular}

Gage helght, In feet, and discharge, in cublc feet per second, at Indicated time, 1963

\begin{tabular}{|c|c|c|c|c|c|c|c|c|c|c|c|}
\hline Date & Hour & $\begin{array}{c}\text { Gage } \\
\text { he1ght }\end{array}$ & $\begin{array}{l}\text { D1s- } \\
\text { charge }\end{array}$ & Date & Hour & $\begin{array}{c}\text { Gage } \\
\text { helght }\end{array}$ & $\begin{array}{l}\text { Dis- } \\
\text { charge }\end{array}$ & Date & Hour & $\begin{array}{c}\text { Gage } \\
\text { height }\end{array}$ & $\begin{array}{l}\text { Dis- } \\
\text { charge }\end{array}$ \\
\hline $\begin{array}{r}29 \\
30\end{array}$ & $\begin{array}{l}2400 \\
0400 \\
0500 \\
1100 \\
1400 \\
1700 \\
2000 \\
2200 \\
2400 \\
0300\end{array}$ & $\begin{array}{l}2.38 \\
3.30 \\
3.29 \\
2.98 \\
3.75 \\
4.78 \\
5.26 \\
5.21 \\
5.08 \\
5.23\end{array}$ & $\begin{array}{r}7.9 \\
65 \\
64 \\
37 \\
122 \\
325 \\
458 \\
443 \\
404 \\
449\end{array}$ & Jan. 31 & $\begin{array}{l}0600 \\
1000 \\
1200 \\
1500 \\
1600 \\
1700 \\
1800 \\
1900 \\
2100 \\
2300 \\
2400\end{array}$ & $\begin{array}{l}5.46 \\
6.50 \\
7.55 \\
8.78 \\
7.75 \\
8.50 \\
8.40 \\
7.90 \\
8.40 \\
6.75 \\
7.15\end{array}$ & $\begin{array}{r}518 \\
910 \\
1,650 \\
4,610 \\
2,560 \\
3,940 \\
3,700 \\
2,780 \\
3,700 \\
1,510 \\
1,860\end{array}$ & Feb. I & $\begin{array}{l}0100 \\
0400 \\
0600 \\
1200 \\
1800 \\
2400 \\
\\
0600 \\
1200 \\
1800 \\
2400\end{array}$ & $\begin{array}{l}6.75 \\
7.40 \\
6.45 \\
5.64 \\
5.42 \\
4.85 \\
4.55 \\
4.27 \\
4.12 \\
3.97\end{array}$ & $\begin{array}{r}1,510 \\
2,120 \\
1,280 \\
820 \\
719 \\
492 \\
\\
402 \\
328 \\
290 \\
256\end{array}$ \\
\hline
\end{tabular}

11-4280. Rubicon River at Rubicon Springs, near Meeks Bay, Calif.

Location.--Lat $39^{\circ} 01^{\prime} 10^{\prime \prime}$, long $120^{\circ} 14^{\prime} 46^{\prime \prime}$, in SW $\mathrm{NE}_{\frac{1}{4}}$ sec.31, T.14 N., R.16 E., on right bank $200 \mathrm{ft}$ downstream from Rubicon Springs, 0.7 mile upstream from Miller Creek, and 7 miles west of Meeks Bay.

Drainage are. $--31.4 \mathrm{sq} \mathrm{mi}$.

Gage-height record.-Water-stage recorder graph. Datum of gage is $6,052.97$ ft above mean sea level, datum of 1929 .

Discharge record.--Stage-discharge relation defined by current-meter measurements below I,200 cfs and by slope-conveyance computation of maximum flow.

Maxima.--January-February 1963: Discharge, 11,500 cfs 0200 hours Feb. 1 (gage helght, $14.28 \mathrm{ft}$ ).

1910-14, 1955 to December 1962: Discharge, 9,270 cfs Dec. 23, 1955 (gage height, $13.0 \mathrm{ft}$, from floodmarks).

Mean discharge, in cublc feet per second, 1963

\begin{tabular}{|c|c|c|c|c|c|c|c|c|}
\hline Day & January & February & Day & January & February & Day & January & February \\
\hline $\begin{array}{c}1 \ldots \ldots \\
2 \ldots \ldots \\
4 \ldots \ldots \\
5 \ldots \ldots \\
6 \ldots \ldots \\
7 \ldots \ldots \\
9 \ldots \ldots \\
10 \ldots \ldots\end{array}$ & $\begin{array}{l}18 \\
16 \\
16 \\
17 \\
16 \\
16 \\
16 \\
15 \\
14 \\
14\end{array}$ & $\begin{array}{r}5,330 \\
600 \\
578 \\
600 \\
529 \\
267 \\
211 \\
180 \\
138 \\
108\end{array}$ & $\begin{array}{l}11 \ldots \ldots \\
12 \ldots \ldots \\
13 \ldots \ldots \\
14 \ldots \ldots \\
15 \ldots \ldots \\
16 \ldots \ldots \\
17 \ldots \ldots \\
18 \ldots \ldots \\
19 \ldots \ldots \\
20 \ldots \ldots\end{array}$ & $\begin{array}{l}9.5 \\
9.1 \\
8.7 \\
8.7 \\
9.1 \\
9.1 \\
8.7 \\
8.3 \\
6.7 \\
7.0\end{array}$ & $\begin{array}{r}89 \\
75 \\
117 \\
89 \\
69 \\
67 \\
57 \\
53 \\
55 \\
57\end{array}$ & $\begin{array}{l}21 \ldots \ldots \\
22 \ldots \ldots \\
23 \ldots \ldots \\
24 \ldots \ldots \\
25 \ldots \ldots \\
26 \ldots \ldots \\
27 \ldots \ldots \\
28 \ldots \ldots \\
29 \ldots \ldots \\
30 \ldots \ldots \\
31 \ldots \ldots\end{array}$ & $\begin{array}{r}7.0 \\
7.6 \\
7.9 \\
7.9 \\
7.9 \\
7.9 \\
7.6 \\
7.3 \\
7.9 \\
458 \\
4,830\end{array}$ & $\begin{array}{r}56 \\
46 \\
40 \\
42 \\
45 \\
73 \\
73 \\
55 \\
--- \\
----\end{array}$ \\
\hline $\begin{array}{l}\text { Dnthly } \\
\text { inoff, } \\
\text { anoff, }\end{array}$ & inche &. & $\ldots$ & & & & $\begin{array}{r}181 \\
6.61 \\
11,110\end{array}$ & $\begin{array}{r}346 \\
11.4 \\
19,240 \\
\end{array}$ \\
\hline
\end{tabular}


Gage helght, in feet, and discharge, in cublc feet per second, at indicated time, 1963,

\begin{tabular}{|c|c|c|c|c|c|c|c|c|c|c|c|}
\hline Date & Hour & $\begin{array}{c}\text { Gage } \\
\text { helght }\end{array}$ & $\begin{array}{l}\text { Dis- } \\
\text { charge }\end{array}$ & Date & Hour & $\begin{array}{c}\text { Gage } \\
\text { helght }\end{array}$ & $\begin{array}{l}\text { Dis- } \\
\text { charge }\end{array}$ & Date & Hour & $\begin{array}{c}\text { Gage } \\
\text { helght }\end{array}$ & $\begin{array}{c}\text { D1s - } \\
\text { charge }\end{array}$ \\
\hline $\begin{array}{r}\text { Jan. } 29 \\
30\end{array}$ & $\begin{array}{l}2400 \\
0800 \\
1000 \\
1200 \\
1400 \\
1600 \\
2200 \\
2400 \\
0100 \\
0300 \\
0500\end{array}$ & $\begin{array}{l}1.88 \\
2.07 \\
2.22 \\
2.58 \\
3.72 \\
5.13 \\
6.57 \\
6.31 \\
6.11 \\
6.14 \\
6.50\end{array}$ & $\begin{array}{r}10 \\
19 \\
28 \\
56 \\
230 \\
688 \\
1,530 \\
1,350 \\
1,220 \\
1,230 \\
1,480\end{array}$ & Feb. 1 & $\begin{array}{l}0800 \\
1000 \\
1200 \\
1500 \\
1700 \\
2000 \\
2200 \\
2400 \\
\\
0200 \\
0400 \\
0600 \\
0800\end{array}$ & $\begin{array}{r}7.42 \\
8.10 \\
9.10 \\
11.14 \\
11.93 \\
12.60 \\
13.20 \\
13.85 \\
14.28 \\
14.00 \\
13.15 \\
11.70\end{array}$ & $\begin{array}{r}2,210 \\
2,830 \\
3,870 \\
6,430 \\
7,580 \\
8,620 \\
9,610 \\
10,700 \\
11,500 \\
11,000 \\
9,520 \\
7,230\end{array}$ & Feb. 1 & $\begin{array}{l}1000 \\
1200 \\
1400 \\
1800 \\
2400 \\
\\
0600 \\
1200 \\
1500 \\
1900 \\
2400\end{array}$ & $\begin{array}{r}10.10 \\
8.90 \\
8.10 \\
7.10 \\
5.85 \\
\\
5.10 \\
4.66 \\
4.59 \\
4.60 \\
4.54\end{array}$ & $\begin{array}{r}5,040 \\
3,650 \\
2,830 \\
1,940 \\
1,060 \\
\\
675 \\
498 \\
473 \\
476 \\
456\end{array}$ \\
\hline
\end{tabular}

11-4295. Gerle Creek below Loon Lake Dam, near Meeks Bay, Calif.

Location.--Lat $39^{\circ} 00^{\prime} 20^{\prime \prime}$, long $120^{\circ} 18^{\prime} 52^{\prime \prime}$, in NE $\frac{1}{4} \mathrm{sec} .5, \mathrm{~T} .13 \mathrm{~N} ., \mathrm{R} .15 \mathrm{E} ., 0.3 \mathrm{mile}$ downstream from Loon Lake Dam and 11 miles southwest of Meeks Bay.

Drainage area. $--8.01 \mathrm{sq} \mathrm{mi}$.

Gage-height record.--Water-stage recorder graph. Altitude of gage is $6,250 \mathrm{ft}$ (from topographic mapi.

Discharge record.--Stage-discharge relation defined by current-meter measurements below $320 \mathrm{cf}$ 's and by slope-area measurement at $3,240 \mathrm{cfs}$; affected by $1 \mathrm{ce} \mathrm{Jan} .12$.

Maxima.--January-February 1963: Discharge, 3,240 cfs 0200 hours Feb. 1 (gage he1ght, $12.65 \mathrm{ft}$, from floodmarks).

1910-14, August to December 1962: Discharge, 472 cfs 0ct. 27, 1962 (gage height, 6.44 ft).

Remarks.--Flow regulated, beginning 1884, by Loon Lake (former capacity, 8,000 acre-ft; present capac1ty, 76,000 acre-f't) except November 1962 to December 1963 when flow was regulated only by natural storage in the original lake.

Mean discharge, in cub1c feet per second, 1963

\begin{tabular}{|c|c|c|c|c|c|c|c|c|}
\hline Day & January & February & Day & January & February & Day & January & February \\
\hline $\begin{array}{c}1 \ldots \ldots \\
2 \ldots \ldots \\
4 \ldots \ldots \\
5 \ldots \ldots \\
6 \ldots \ldots \\
8 \ldots \ldots \\
9 \ldots \ldots \\
10 \ldots \ldots\end{array}$ & $\begin{array}{l}8.7 \\
8.5 \\
7.7 \\
7.4 \\
7.0 \\
6.7 \\
6.7 \\
6.5 \\
6.2 \\
6.0\end{array}$ & $\begin{array}{r}1,560 \\
237 \\
109 \\
74 \\
68 \\
49 \\
36 \\
27 \\
24 \\
23\end{array}$ & $\begin{array}{l}11 \ldots \ldots \\
12 \ldots \ldots \\
13 \ldots \ldots \\
14 \ldots \ldots \\
15 \ldots \ldots \\
16 \ldots \ldots \\
17 \ldots \ldots \\
18 \ldots \ldots \\
19 \ldots \ldots \\
20 \ldots \ldots\end{array}$ & $\begin{array}{l}5.6 \\
5.4 \\
5.4 \\
4.9 \\
4.5 \\
4.5 \\
4.3 \\
4.1 \\
3.8 \\
4.0\end{array}$ & $\begin{array}{l}21 \\
21 \\
40 \\
44 \\
40 \\
35 \\
32 \\
29 \\
28 \\
25\end{array}$ & $\begin{array}{l}21 \ldots \ldots \\
22 \ldots \ldots \\
23 \ldots \ldots \\
24 \ldots \ldots \\
25 \ldots \ldots \\
26 \ldots \ldots \\
27 \ldots \ldots \\
28 \ldots \ldots \\
29 \ldots \ldots \\
30 \ldots \ldots \\
31 \ldots \ldots\end{array}$ & $\begin{array}{r}4.1 \\
4.0 \\
4.0 \\
2.8 \\
4.0 \\
4.0 \\
4.0 \\
4.0 \\
4.5 \\
24 \\
1,650\end{array}$ & $\begin{array}{r}23 \\
20 \\
18 \\
17 \\
16 \\
16 \\
15 \\
14 \\
-\ldots--1\end{array}$ \\
\hline $\begin{array}{l}\text { onthly } \\
\text { anoff, } \\
\text { anoff, }\end{array}$ & $\begin{array}{l}\text { Inche } \\
\text { acre }\end{array}$ & 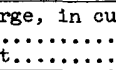 & & & & & $\begin{array}{r}58.9 \\
8.48 \\
3,620\end{array}$ & $\begin{array}{r}95.0 \\
12.3 \\
5,280\end{array}$ \\
\hline
\end{tabular}


Gage he1ght, in feet, and discharge, in cubic feet per second, at 1ndicated time, 1963, of Gerle Creek below Loon Lake near Meeks Bay, Cal1f.

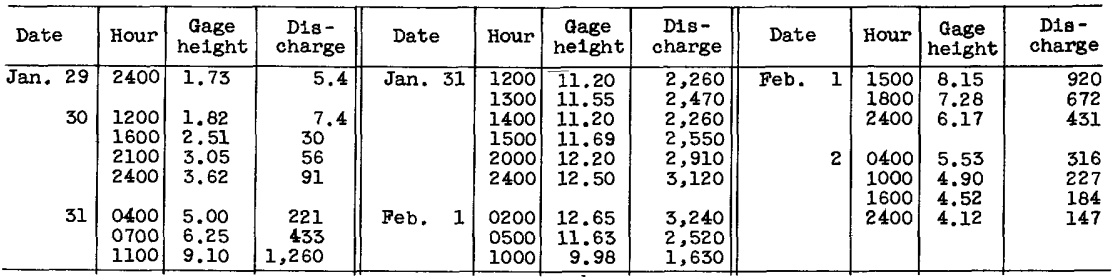

11-4300. South Fork Rubicon River below Gerle Creek, near Georgetown, Calif.

Location.--Lat $38^{\circ} 57^{\prime} 15^{\prime \prime}$, long $120^{\circ} 24^{\prime} 00^{\prime \prime}$, in SW $\frac{1}{4} S W^{\frac{1}{4}} \mathrm{sec} .22$, T.13 N., R.14 E., on left bank $600 \mathrm{ft}$ downstream from Gerle Creek and 18 miles east of Georgetown.

Drainage area. $--47.6 \mathrm{sq} \mathrm{ml}$.

Gage-height record.--Water-stage recorder graph. Altitude of gage 4,970 ft (from topographic mapi.

Discharge record.--Stage-discharge relation defined by current-meter measurements below $770 \mathrm{cfs}$ and by slope-area measurement at $11,500 \mathrm{cfs}$.

Maxima (river only).--January-February 1963: Discharge, 11,500 cf's 2300 hours Jan. 31 (gage height, $12.32 \mathrm{ft}$, from recorder graph; $13.8 \mathrm{ft}$, from floodmarks). 1910-14, 1961 to December 1962: Discharge, 2,650 cfs Oct. 13, 1962 (gage height, $7.88 \mathrm{ft}$ ).

Maxima (river plus diversion).--January-February 1963: Discharge, 12,800 cfs 2300

1910-14, 1961 to December 1962: Discharge, 3,040 cfs Oct. 13, 1962.

Remarks.--Flow regulated, beginning 1884, by Loon Lake on Gerle Creek (former capacity, 8,000 acre-ft; present capacity, 76,000 acre-ft) except November 1962 to December 1963 when flow was regulated only by natural storage in the original lake. Prior to Dec. 3, 1961, water was diverted out of the basin in Georgetown Divide ditch. Robbs Peak tunnel began diversion of up to $1,320 \mathrm{cfs}$ to Silver Creek basin 0ctober 1962. All discharge figures in the tables below are the combined flow of South Fork Rubicon River and Robbs Peak tunnel.

Mean discharge, in cublc feet per second, 1963 (comb1ned flow of river and diversion)

\begin{tabular}{|c|c|c|c|c|c|c|c|c|}
\hline Day & January & February & Day & January & Bebruary & Day & January & February \\
\hline $\begin{array}{c}1 \ldots \ldots \\
2 \ldots \ldots \\
3 \ldots \ldots \\
4 \ldots \ldots \\
5 \ldots \ldots \\
6 \ldots \ldots \\
7 \ldots \ldots \\
8 \ldots \ldots \\
9 \ldots \ldots \\
10 \ldots \ldots\end{array}$ & $\begin{array}{l}43 \\
41 \\
41 \\
40 \\
38 \\
36 \\
36 \\
34 \\
34 \\
32\end{array}$ & $\begin{array}{r}6,050 \\
1,210 \\
660 \\
488 \\
435 \\
313 \\
250 \\
216 \\
189 \\
179\end{array}$ & $\begin{array}{l}11 \ldots \ldots \\
12 \ldots \ldots \\
13 \ldots \ldots \\
14 \ldots \ldots \\
15 \ldots \ldots \\
16 \ldots \ldots \\
17 \ldots \ldots \\
18 \ldots \ldots \\
19 \ldots \ldots \\
20 \ldots \ldots\end{array}$ & $\begin{array}{l}27 \\
21 \\
22 \\
25 \\
26 \\
25 \\
24 \\
23 \\
22 \\
22\end{array}$ & $\begin{array}{l}155 \\
148 \\
307 \\
323 \\
235 \\
198 \\
179 \\
162 \\
150 \\
141\end{array}$ & $\begin{array}{l}21 \ldots \ldots \\
22 \ldots \ldots \\
23 \ldots \ldots \\
24 \ldots \ldots \\
25 \ldots \ldots \\
26 \ldots \ldots \\
27 \ldots \ldots \\
28 \ldots \ldots \\
29 \ldots \ldots \\
30 \ldots \ldots \\
31 \ldots \ldots\end{array}$ & $\begin{array}{r}22 \\
23 \\
23 \\
23 \\
22 \\
22 \\
22 \\
21 \\
23 \\
392 \\
6,720 \\
\end{array}$ & $\begin{array}{r}135 \\
120 \\
104 \\
98 \\
92 \\
92 \\
85 \\
76 \\
-.--- \\
-.---\end{array}$ \\
\hline off, & acre- & & & & & & $\begin{array}{r}256 \\
6.19 \\
15,720 \\
\end{array}$ & $\begin{array}{r}457 \\
10.00 \\
25,370 \\
\end{array}$ \\
\hline
\end{tabular}


Discharge, in cubic feet per second, at Indicated time, 1963, of South Fork Rubicon River below Gerle Creek near Georgetown plus Robbs Peak tunnel near Riverton, Calif.

\begin{tabular}{|c|c|c|c|c|c|c|c|c|c|c|c|}
\hline Date & Hour & $\begin{array}{c}\text { Gage } \\
\text { heIght }\end{array}$ & $\begin{array}{l}\text { Dis- } \\
\text { charge }\end{array}$ & Date & Hour & $\begin{array}{c}\text { Gage } \\
\text { heIght }\end{array}$ & $\begin{array}{c}\text { Dis- } \\
\text { charge }\end{array}$ & Date & Hour & $\begin{array}{c}\text { Gage } \\
\text { heIght }\end{array}$ & $\begin{array}{l}\text { Dis- } \\
\text { charge }\end{array}$ \\
\hline $\begin{array}{r}\operatorname{Jan} .29 \\
30\end{array}$ & $\begin{array}{l}2400 \\
0700 \\
1200 \\
1400 \\
1800 \\
2000 \\
2200 \\
2400 \\
0100 \\
0200 \\
0400\end{array}$ & $\begin{array}{l}- \\
- \\
- \\
- \\
\overline{-} \\
- \\
- \\
-\end{array}$ & $\begin{array}{r}30 \\
60 \\
132 \\
256 \\
672 \\
961 \\
1,230 \\
1,360 \\
1,580 \\
1,750 \\
2,210 \\
\end{array}$ & Feb. 1 & $\begin{array}{l}0600 \\
0900 \\
1200 \\
1600 \\
1900 \\
2100 \\
2300 \\
2400 \\
0100 \\
0500 \\
1000 \\
1300\end{array}$ & $\begin{array}{l}- \\
- \\
- \\
z \\
- \\
- \\
- \\
- \\
-\end{array}$ & $\begin{array}{r}2,700 \\
4,260 \\
6,390 \\
9,400 \\
11,400 \\
11,500 \\
12,800 \\
12,600 \\
12,500 \\
10,300 \\
5,720 \\
4,100\end{array}$ & Feb. 1 & $\begin{array}{l}1700 \\
1900 \\
2100 \\
2400 \\
\\
0300 \\
0500 \\
0700 \\
0900 \\
1300 \\
1900 \\
2400\end{array}$ & $\begin{array}{l}- \\
- \\
- \\
- \\
- \\
- \\
- \\
-\end{array}$ & $\begin{array}{r}3,080 \\
2,860 \\
2,490 \\
1,970 \\
1,650 \\
1,480 \\
1,390 \\
1,340 \\
1,100 \\
901 \\
808\end{array}$ \\
\hline
\end{tabular}

11-4310. Rubicon River near Georgetown, Calif.

Location.--Lat $38^{\circ} 57^{\prime} 30^{\prime \prime}$, long $120^{\circ} 29^{\prime} 0^{\prime \prime}$, in SE $\frac{1}{4}$ sec.23, T.13 N., R.13 E., on left bank I.3 miles downstream from South Fork and 20 miles east of Georgetown.

Drainage area.,--195 sq $\mathrm{mi}$.

Gage-helght record.--Water-stage recorder graph, except Jan. 18 to Feb. 28 . Altitude of gage is 3,350 ft (from topographic map).

Discharge record.--Stage-discharge relation defined by current-meter measurements below $11,000 \mathrm{c}$ ss and by slope-area measurements at $44,600 \mathrm{cfs}$ and $58,000 \mathrm{cfs}$. Discharge for Jan. 18 to Feb. 28 estimated on basis of one discharge measurement, weather records, and records for station at Rubicon Springs and Middle Fork American River near Foresthill.

Maxima.--January-February 1963: Discharge, 58,000 cfs about 0100 hours Feb. 1 (gage height, $25.8 \mathrm{ft}$, from floodmarks).

1909-14, 1943 to December 1962: Discharge, 51,000 cfs Dec. 23, 1955 (gage height, $18.76 \mathrm{ft}$ in gage we11, $21.5 \mathrm{ft}$ outside, from floodmarks).

Remarks.--Beginning oct. 1, 1962 , up to 1,320 cfs diverted through Robbs Peak tunne1 to Silver Creek basin.

Mean discharge, in cub1c feet per second, 1963

\begin{tabular}{|c|c|c|c|c|c|c|c|c|}
\hline Day & January & February & Day & January & February & Day & January & Bebruary \\
\hline $\begin{array}{c}1 \ldots \ldots \\
2 \ldots \ldots \\
3 \ldots \ldots \\
4 \ldots \ldots \\
5 \ldots \ldots \\
7 \ldots \ldots \\
8 \ldots \ldots \\
9 \ldots \ldots \\
10 \ldots \ldots\end{array}$ & $\begin{array}{r}126 \\
124 \\
120 \\
121 \\
115 \\
112 \\
108 \\
104 \\
101 \\
97\end{array}$ & $\begin{array}{r}30,000 \\
5,000 \\
3,000 \\
2,000 \\
1,500 \\
1,000 \\
850 \\
750 \\
650 \\
600\end{array}$ & $\begin{array}{l}11 \ldots \ldots \\
12 \ldots \ldots \\
13 \ldots \ldots \\
14 \ldots \ldots \\
15 \ldots \ldots \\
16 \ldots \ldots \\
17 \ldots \ldots \\
18 \ldots \ldots \\
19 \ldots \ldots \\
20 \ldots \ldots\end{array}$ & $\begin{array}{r}86 \\
54 \\
97 \\
100 \\
83 \\
79 \\
74 \\
70 \\
65 \\
65\end{array}$ & $\begin{array}{l}550 \\
500 \\
650 \\
600 \\
560 \\
540 \\
520 \\
500 \\
480 \\
460\end{array}$ & $\begin{array}{l}21 \ldots \ldots \\
22 \ldots \ldots \\
23 \ldots \ldots \\
24 \ldots \ldots \\
25 \ldots \ldots \\
26 \ldots \ldots \\
27 \ldots \ldots \\
28 \ldots \ldots \\
29 \ldots \ldots \\
30 \ldots \ldots \\
31 \ldots \ldots\end{array}$ & $\begin{array}{r}65 \\
65 \\
65 \\
60 \\
60 \\
60 \\
60 \\
60 \\
65 \\
1,000 \\
25,000 \\
\end{array}$ & $\begin{array}{r}440 \\
410 \\
390 \\
370 \\
350 \\
360 \\
380 \\
350 \\
----- \\
--.-- \\
\end{array}$ \\
\hline $\begin{array}{l}\text { onthly } \\
\text { snoff, }\end{array}$ & $\begin{array}{l}\text { in dis } \\
\text { acre }\end{array}$ & , & font & & & & $\begin{array}{r}918 \\
56,450 \\
\end{array}$ & $\begin{array}{r}1,920 \\
106,600 \\
\end{array}$ \\
\hline
\end{tabular}


11-4318. Pilot Creek above Stumpy Meadows Reservoir, Calif.

Location.--Lat $38^{\circ} 53^{\prime} 41^{\prime \prime}$, long $120^{\circ} 34^{\prime} 02^{\prime \prime}$, in NE $\frac{1}{4} N W \frac{1}{4}$ sec.18, T.12 N., R.13 E., on right bank 2.1 miles upstream from Stumpy Meadows Dam and 12.5 miles east of Georgetown.

Drainage area. $--11.7 \mathrm{sq} \mathrm{ml}$.

Gage-height record.--Water-stage recorder graph. Altitude of gage is $4,280 \mathrm{ft}$ (from topographic map).

Discharge record.--Stage-discharge relation defined by current-meter measurements below $170 \mathrm{cfs}$ and by field estimate of peak flow at 2,070 cfs.

Maxima.--January-February 1963: Discharge, 2,070 cfs 1900 hours Jan. 31 (gage height, $8.05 \mathrm{ft}$, from recorder graph; $8.95 \mathrm{ft}$, from floodmarks).

1960 to December 1962: Discharge, 455 ofs 0ct. 13, 1962 (gage helght, $4.76 \mathrm{ft}$ ).

Mean discharge, in cubic feet per second, 1963

\begin{tabular}{|c|c|c|c|c|c|c|c|c|}
\hline Day & January & February & Day & January & Febmuary & Day & January & February \\
\hline $\begin{array}{r}7 \ldots \ldots \\
2 \ldots \ldots \\
3 \ldots \ldots \\
4 \ldots \ldots \\
5 \ldots \ldots \\
6 \ldots \ldots \\
7 \ldots \ldots \\
8 \ldots \ldots \\
90 \ldots\end{array}$ & $\begin{array}{l}9.6 \\
9.3 \\
9.3 \\
9.3 \\
9.0 \\
8.7 \\
8.7 \\
8.4 \\
8.4 \\
8.4\end{array}$ & $\begin{array}{r}625 \\
279 \\
172 \\
125 \\
89 \\
70 \\
60 \\
52 \\
46 \\
41\end{array}$ & 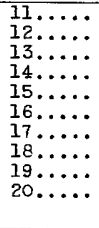 & $\begin{array}{l}8.4 \\
8.4 \\
8.4 \\
8.4 \\
8.4 \\
8.2 \\
8.2 \\
8.2 \\
8.2 \\
8.2\end{array}$ & $\begin{array}{l}38 \\
35 \\
52 \\
43 \\
37 \\
34 \\
33 \\
30 \\
29 \\
28\end{array}$ & $\begin{array}{l}21 \ldots \ldots \\
22, \ldots \ldots \\
23 \ldots \ldots \\
24 \ldots \ldots \\
25 \ldots \\
26 \ldots \\
27 \ldots \ldots \\
28 \ldots \\
29 \ldots \\
30 \ldots \ldots \\
31 \ldots \ldots\end{array}$ & $\begin{array}{r}7.9 \\
7.3 \\
7.3 \\
7.3 \\
7.3 \\
7.3 \\
7.3 \\
7.3 \\
7.9 \\
128 \\
882\end{array}$ & $\begin{array}{r}26 \\
25 \\
24 \\
23 \\
22 \\
21 \\
20 \\
19 \\
-0 .-\end{array}$ \\
\hline & & & & & & & $\begin{array}{r}40.3 \\
3.97 \\
2,480 \\
\end{array}$ & $\begin{array}{r}74.9 \\
6.67 \\
4,160 \\
\end{array}$ \\
\hline
\end{tabular}

- Gage height, in feet, and discharge, in cubic feet per second, at indicated time, 1963

\begin{tabular}{r|c|c|r||r|r|r|r||r|r|r|r}
\hline Date & Hour & $\begin{array}{c}\text { Gage } \\
\text { he1ght }\end{array}$ & $\begin{array}{c}\text { Dis- } \\
\text { charge }\end{array}$ & Date & Hour & $\begin{array}{c}\text { Gage } \\
\text { he1ght }\end{array}$ & $\begin{array}{c}\text { D18- } \\
\text { charge }\end{array}$ & Date & Hour & $\begin{array}{c}\text { Gage } \\
\text { he1ght }\end{array}$ & $\begin{array}{c}\text { Dis- } \\
\text { charge }\end{array}$ \\
\hline Jan. 29 & 2400 & 2.23 & 15 & Jan. 31 & 0600 & 4.18 & 289 & Feb. I & 0200 & 5.05 & 902 \\
& & & & & 0800 & 4.38 & 342 & & 0400 & 5.40 & 1,060 \\
& 0500 & 2.78 & 53 & & 1200 & 5.70 & 800 & & 0600 & 4.70 & 780 \\
& 1200 & 3.06 & 78 & & 1500 & 6.28 & 1,050 & & 1000 & 4.00 & 552 \\
& 1500 & 3.35 & 116 & & 1900 & 8.05 & 2,070 & & 1500 & 3.72 & 474 \\
& 1800 & 3.85 & 209 & & 2100 & 5.84 & 1,220 & & 1900 & 3.63 & 446 \\
& 2100 & 4.24 & 304 & & 2200 & 6.53 & 1,540 & & 2400 & 3.37 & 379 \\
& 2200 & 4.25 & 307 & & 2300 & 6.59 & 1,570 & & & \\
& 2400 & 4.18 & 289 & & 2400 & 5.52 & 1,110 & & 0900 & 3.02 & 289 \\
31 & 0300 & 4.11 & 271 & Feb. 1 & 0100 & 5.41 & 1,060 & & 1800 & 2.80 & 236 \\
\hline
\end{tabular}

11-4330.4. Pilot Creek below Mutton Canyon, near Georgetown, Calif.

Location.--Lat $38^{\circ} 55^{\prime} 25^{\prime \prime}$, long $120^{\circ} 38^{\prime} 27^{\prime \prime}$, in $\mathrm{NE}_{\frac{1}{4}} \mathrm{NW} \frac{1}{4} \mathrm{sec} .4$, T.12 N., R.12 E., $450 \mathrm{ft}$ downstream from Mutton Canyon, $500 \mathrm{ft}$ downstream from Georgetown Divide diversion dam, 2.5 miles downstream from Stumpy Meadows Dam, and 10 miles east of Georgetown.

Drainage area. $-21.1 \mathrm{sq} \mathrm{ml}$.

Gage-height record.--Water-stage recorder graph. Alt1tude of gage is 3,760 ft (from topographic mapt.

Discharge record.--Stage-discharge relation defined by current-meter measurements below $150 \mathrm{cfs}$ and by slope-area measurement at $690 \mathrm{cfs}$.

Maxima.--January-February 1963: Discharge,464 cfs 2200 hours Jan. 31 (gage height, $4.5 \mathrm{ft}$, from recorder graph; $5.11 \mathrm{ft}$, from floodmarks).

1961 to December 1962: Discharge, $160 \mathrm{cfs}$ 0ct. 14, 1962 (gage helght, $3.46 \mathrm{ft}$ ).

Remarks.--Flow regulated by Stumpy Meadows Reservoir (usable capacity, 20,000 acre-ft). 
Mean discharge, in cubic feet per second, 1963, of P1lot Creek below Mutton Canyon, near Georgetown, Cal1f.

\begin{tabular}{|c|c|c|c|c|c|c|c|c|}
\hline Day & January & February & Day & January & February & Day & January & February \\
\hline $\begin{array}{c}\ldots \ldots \\
2 \ldots \ldots \\
3 \ldots \ldots \\
4 \ldots \ldots \\
5 \ldots \ldots \\
6 \ldots \ldots \\
7 \ldots \ldots \\
9 \ldots \ldots \\
10 \ldots \ldots\end{array}$ & $\begin{array}{l}2.3 \\
2.2 \\
2.2 \\
2.2 \\
2.1 \\
2.1 \\
2.1 \\
2.0 \\
2.0 \\
1.9\end{array}$ & $\begin{array}{r}228 \\
115 \\
86 \\
68 \\
99 \\
127 \\
114 \\
104 \\
95 \\
91\end{array}$ & $\begin{array}{l}11 \ldots \ldots \\
12 \ldots \ldots \\
13 \ldots \ldots \\
14 \ldots \ldots \\
15 \ldots \ldots \\
16 \ldots \ldots \\
17 \ldots \ldots \\
18 \ldots \ldots \\
19 \ldots \ldots \\
20 \ldots \ldots\end{array}$ & $\begin{array}{l}1.8 \\
1.6 \\
1.4 \\
1.8 \\
2.8 \\
2.9 \\
2.8 \\
2.8 \\
2.6 \\
2.6\end{array}$ & $\begin{array}{l}81 \\
72 \\
99 \\
90 \\
75 \\
66 \\
60 \\
59 \\
56 \\
53\end{array}$ & $\begin{array}{l}21 \ldots \ldots \\
22 \ldots \ldots \\
23 \ldots \ldots \\
24 \ldots \ldots \\
25 \ldots \ldots \\
26 \ldots \ldots \\
27 \ldots \ldots \\
28 \ldots \ldots \\
29 \ldots \ldots \\
30 \ldots \ldots \\
31 \ldots \ldots\end{array}$ & $\begin{array}{r}2.6 \\
2.6 \\
2.6 \\
2.6 \\
2.6 \\
2.5 \\
2.5 \\
2.5 \\
3.3 \\
34 \\
162 \\
\end{array}$ & $\begin{array}{r}50 \\
46 \\
42 \\
40 \\
40 \\
40 \\
32 \\
23 \\
-\ldots--. \\
-\ldots-.-\end{array}$ \\
\hline $\begin{array}{l}\text { onthly } \\
\text { unoff, }\end{array}$ & $\begin{array}{l}\text { in dis } \\
\text { acre- }\end{array}$ & 2, 1 & feet & & & & $\begin{array}{r}8.52 \\
524 \\
\end{array}$ & $\begin{array}{r}76.8 \\
4,270 \\
\end{array}$ \\
\hline
\end{tabular}

Gage height, In feet, and discharge, in cublc feet per second, at indicated t1me, 1963

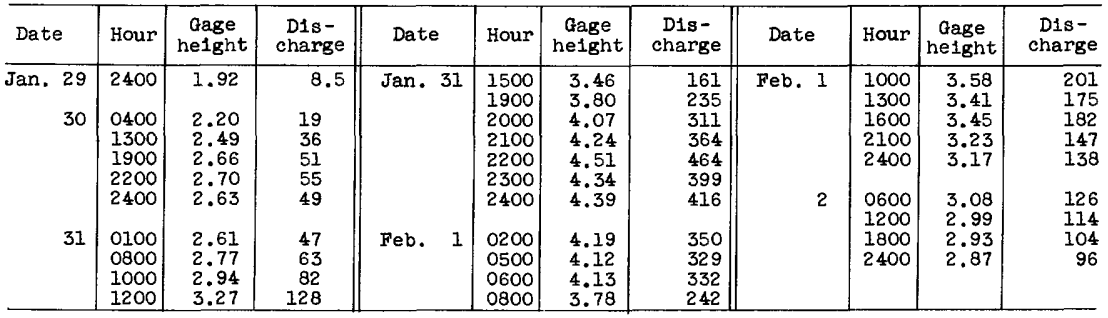

11-4331. Long Canyon Creek near French Meadows, Calif.

Location.--Lat $39^{\circ} 01^{\prime} 16^{\prime \prime}$, long $120^{\circ} 30^{\prime} 53^{\prime \prime}$, in $\mathrm{SE} \frac{1}{4} \mathrm{NW} \frac{1}{4}$ sec.34, T.14 N., R.13 E., on right bank $75 \mathrm{ft}$ downstream from North' Fork Long Canyon, $6 \frac{1}{2}$ miles south of 'French Meadows, and 18 miles east of Foresthill.

Drainage area. $--18.0 \mathrm{sq} \mathrm{mi}$.

Gage-height record.--Water-stage recorder graph. Altitude of gage is $4,100 \mathrm{ft}$ (from topographic map).

Discharge record.--Stage-discharge relation defined by current-meter measurements below $170 \mathrm{cfs}$ and by slope-area measurements at 672 and $3,540 \mathrm{cfs}$.

Maxima.--January-February 1963: Discharge, 3,540 cfs 0400 hours Feb. 1 (gage height, $10.27 \mathrm{ft}$, from recorder graph; $11.3 \mathrm{ft}$, from floodmarks).

1960 to December 1962: Discharge, $674 \mathrm{cfs}$ Oct. 13, 1962 (gage helght, $6.62 \mathrm{ft}$ )

Mean discharge, in cublc feet per second, 1963

\begin{tabular}{|c|c|c|c|c|c|c|c|c|}
\hline Day & January & February & Day & January & February & Day & $J$ anuary & February \\
\hline $\begin{array}{r}1 \ldots \ldots \\
2 \ldots \ldots \\
3 \ldots \ldots \\
4 \ldots \ldots \\
5 \ldots \ldots \\
6 \ldots \ldots \\
7 \ldots \ldots \\
8 \ldots \ldots \\
9 \ldots \ldots \\
10 \ldots \ldots\end{array}$ & $\begin{array}{l}15 \\
14 \\
14 \\
13 \\
13 \\
13 \\
12 \\
12 \\
11 \\
11\end{array}$ & $\begin{array}{r}1,780 \\
496 \\
298 \\
226 \\
185 \\
151 \\
126 \\
109 \\
99 \\
89\end{array}$ & $\begin{array}{l}11 \ldots \ldots \\
12 \ldots \ldots \\
13 \ldots \ldots \\
14 \ldots \ldots \\
15 \ldots \ldots \\
16 \ldots \ldots \\
17 \ldots \ldots \\
18 \ldots \ldots \\
19 \ldots \ldots \\
20 \ldots \ldots\end{array}$ & $\begin{array}{l}11 \\
9.6 \\
10 \\
11 \\
10 \\
10 \\
9.8 \\
9.6 \\
9.2 \\
9.1\end{array}$ & $\begin{array}{r}79 \\
74 \\
157 \\
122 \\
97 \\
86 \\
77 \\
70 \\
64 \\
59\end{array}$ & $\begin{array}{l}21 \ldots \ldots \\
22 \ldots \ldots \\
23 \ldots \ldots \\
24 \ldots \ldots \\
25 \ldots \ldots \\
26 \ldots \ldots \\
27 \ldots \ldots \\
28 \ldots \ldots \\
29 \ldots \ldots \\
30 \ldots \ldots \\
31 \ldots \ldots\end{array}$ & $\begin{array}{r}9.1 \\
8.9 \\
8.7 \\
8.5 \\
8.2 \\
8.1 \\
7.9 \\
7.7 \\
8.8 \\
168 \\
1,450 \\
\end{array}$ & $\begin{array}{r}52 \\
48 \\
45 \\
41 \\
38 \\
37 \\
35 \\
33 \\
-\ldots-.- \\
-\ldots-\end{array}$ \\
\hline $\begin{array}{l}\text { nthly } \\
\text { unoff, } \\
\text { anoff, }\end{array}$ & $\begin{array}{l}\text { Inche } \\
\text { acre- }\end{array}$ & & & & & & $\begin{array}{r}62.0 \\
3.97 \\
3,810 \\
\end{array}$ & $\begin{array}{r}170 \\
9.86 \\
9,470 \\
\end{array}$ \\
\hline
\end{tabular}


Gage height, in feet, and discharge, in cubic feet per second, at indicated time, 1963, of

\begin{tabular}{|c|c|c|c|c|c|c|c|c|c|c|c|}
\hline Date & Hour & $\begin{array}{c}\text { Gage } \\
\text { helght }\end{array}$ & $\begin{array}{l}\text { D1s- } \\
\text { charge }\end{array}$ & Date & Hour & $\begin{array}{c}\text { Gage } \\
\text { helght }\end{array}$ & $\begin{array}{c}\text { Dis- } \\
\text { charge }\end{array}$ & Date & Hour & $\begin{array}{c}\text { Gage } \\
\text { helght }\end{array}$ & $\begin{array}{l}\text { Dis- } \\
\text { charge }\end{array}$ \\
\hline $\begin{array}{r}\operatorname{Jan} .29 \\
30\end{array}$ & $\begin{array}{l}2400 \\
0500 \\
0900 \\
1200 \\
1500 \\
1800 \\
2100 \\
2400 \\
0100 \\
0600\end{array}$ & $\begin{array}{l}3.14 \\
3.59 \\
3.83 \\
4.13 \\
5.09 \\
5.75 \\
6.10 \\
5.73 \\
5.60 \\
6.00\end{array}$ & $\begin{array}{r}15 \\
31 \\
43 \\
65 \\
196 \\
346 \\
460 \\
340 \\
\\
306 \\
425\end{array}$ & $\begin{array}{l}\text { Jan. } 31 \\
\text { Feb. } 1\end{array}$ & $\begin{array}{l}1000 \\
1500 \\
1800 \\
1900 \\
2100 \\
2300 \\
2400 \\
\\
0100 \\
0200 \\
0300 \\
0400\end{array}$ & $\begin{array}{r}6.77 \\
9.00 \\
8.85 \\
9.25 \\
9.32 \\
9.90 \\
9.98 \\
10.10 \\
10.20 \\
10.09 \\
10.27\end{array}$ & $\begin{array}{r}745 \\
2,250 \\
2,120 \\
2,480 \\
2,540 \\
3,130 \\
3,220 \\
3,350 \\
3,460 \\
3,340 \\
3,540\end{array}$ & Feb. 1 & $\begin{array}{l}0700 \\
1200 \\
1500 \\
1700 \\
1900 \\
2400 \\
\\
0600 \\
1200 \\
1800 \\
2400\end{array}$ & $\begin{array}{l}8.75 \\
7.77 \\
7.47 \\
7.38 \\
7.47 \\
6.82 \\
6.44 \\
6.20 \\
6.04 \\
5.91\end{array}$ & $\begin{array}{r}2,030 \\
1,310 \\
1,110 \\
1,050 \\
1,110 \\
735 \\
\\
561 \\
465 \\
409 \\
364\end{array}$ \\
\hline
\end{tabular}

11-4332. Rubicon River near Foresthill, Calif.

Location.--Lat $38^{\circ} 59^{\prime} 23^{\prime \prime}$, long $120^{\circ} 41^{\prime} 15^{\prime \prime}$, in NW $\frac{1}{4} S W^{\frac{1}{4}}$ sec.7, T.13 N., R.12 E., on right bank $150 \mathrm{ft}$ downstream from Ralstion Bridge, 400 ft downstream from Long Canyon Creek, and 7.3 miles southeast of Foresthill.

Drainage area. $--311 \mathrm{sq} \mathrm{mi}$.

Gage-height record.--Water-stage recorder graph, except 0800 hours Jan. 17 to Feb. 28. Datum of gage is 1,362.20 ft above mean sea level, datum of 1929 .

Discharge record.--Stage-discharge relation defined by current-meter measurements below 5,000 cf's and extended above on basis of studies of peak discharges at upstream and downstream stations and runoff per square mile for intervening areas. Discharge for perlod of no gage-helght record estimated from weather records and records for station near Georgetown and Middle Fork American River near Foresthil1.

Maxima.--January-February 1963: Discharge, about 83,000 cfs, time unknown, Feb. 1 (gage height, $35.0 \mathrm{ft}$, from floodmarks).

1958 to December 1962: Discharge, about 13,000 cfs oct. 13, 1962 (gage helght, $16.49 \mathrm{ft}$, from floodmark in well).

Remarks.--Flow affected by Loon Lake (usable capacity, 8,000 acre-ft), Stumpy Meadows Reservoir (capacity, 20,000 acre-ft), and diversion of up to 1,320 cfs out of the basin in Robbs Peak tunnel.

Mean discharge, in cubic feet per second, 1963

\begin{tabular}{|c|c|c|c|c|c|c|c|c|}
\hline Day & January & February & Day & January & February & Day & January & February \\
\hline $\begin{array}{c}1 \ldots \ldots \\
2 \ldots \ldots \\
3 \ldots \ldots \\
4 \ldots \ldots \\
6 \ldots \ldots \\
7 \ldots \ldots \\
5 \ldots \ldots \\
9 \ldots \ldots \\
10 \ldots \ldots\end{array}$ & $\begin{array}{l}183 \\
176 \\
169 \\
167 \\
163 \\
156 \\
152 \\
148 \\
142 \\
140\end{array}$ & $\begin{array}{r}44,000 \\
7,000 \\
4,000 \\
3,000 \\
2,000 \\
1,500 \\
1,200 \\
1,000 \\
900 \\
850\end{array}$ & $\begin{array}{l}11 \ldots \ldots \\
12 \ldots \ldots \\
13 \ldots \ldots \\
14 \ldots \ldots \\
15 \ldots \ldots \\
16 \ldots \ldots \\
17 \ldots \ldots \\
18 \ldots \ldots \\
19 \ldots \ldots \\
20 \ldots \ldots\end{array}$ & $\begin{array}{r}136 \\
100 \\
95 \\
127 \\
124 \\
118 \\
115 \\
105 \\
95 \\
95\end{array}$ & $\begin{array}{l}800 \\
750 \\
950 \\
900 \\
850 \\
800 \\
760 \\
730 \\
700 \\
660\end{array}$ & $\begin{array}{l}21 \ldots \ldots \\
22 \ldots \ldots \\
23 \ldots \ldots \\
24 \ldots \ldots \\
25 \ldots \ldots \\
26 \ldots \ldots \\
27 \ldots \ldots \\
28 \ldots \ldots \\
29 \ldots \ldots \\
30 \ldots \ldots \\
31 \ldots \ldots\end{array}$ & $\begin{array}{r}95 \\
95 \\
95 \\
90 \\
90 \\
90 \\
90 \\
90 \\
100 \\
1,500 \\
35,000\end{array}$ & $\begin{array}{r}620 \\
580 \\
540 \\
500 \\
460 \\
490 \\
520 \\
460 \\
---.- \\
--.--\end{array}$ \\
\hline \multicolumn{7}{|c|}{ 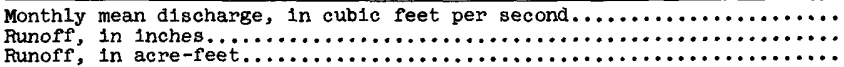 } & $\begin{array}{r}1,292 \\
4,79 \\
79,420 \\
\end{array}$ & $\begin{array}{r}2,769 \\
9.27 \\
153,800 \\
\end{array}$ \\
\hline
\end{tabular}


11-4333. Middle Fork American River near Foresthill, Calif.

Location.--Lat $38^{\circ} 59^{\prime} 58^{\prime \prime}$, long $120^{\circ} 47^{\prime} 27^{\prime \prime}$, near center sec.6, T.13 N., R.11 E., on right bank $800 \mathrm{ft}$ downstream from Josephine Canyon and 2 miles southeast of Fores thill.

Drainage area. $--534 \mathrm{sq} \mathrm{mi}$.

Gage-height record.--Water-stage recorder graph. Altitude of gage is $940 \mathrm{ft}$ (from topographic mapj.

Discharge record.--Stage-discharge relation defined by current-meter measurements below 5,600 cr's and by slope-area measurement at $113,000 \mathrm{cfs}$.

Maxima.--January-February 1963: Discharge, 113,000 cfs 0300 hours Feb. I (gage helght, $38.00 \mathrm{ft}$ ).

1958 to December 1962: Discharge, 29,800 cfs 0ct. 14, 1962 (gage height, $20.70 \mathrm{ft}$, from recorder graph; $22.6 \mathrm{ft}$, from floodmarks).

Mean'discharge, in cublc feet per second, 1963

\begin{tabular}{|c|c|c|c|c|c|c|c|c|}
\hline Day & January & February & Day & January & February & Day & January & February \\
\hline $\begin{array}{c}1 \ldots \ldots \\
2 \ldots \ldots \\
4 \ldots \ldots \\
5 \ldots \ldots \\
6 \ldots \ldots \\
7 \ldots \ldots \\
8 \ldots \ldots \\
10 \ldots \ldots\end{array}$ & $\begin{array}{l}429 \\
415 \\
404 \\
394 \\
380 \\
362 \\
348 \\
336 \\
330 \\
321\end{array}$ & $\begin{array}{r}60,700 \\
11,900 \\
7,400 \\
5,420 \\
4,930 \\
3,240 \\
2,600 \\
2,240 \\
2,000 \\
1,840\end{array}$ & $\begin{array}{l}11 \ldots \ldots \\
12 \ldots \ldots \\
13 \ldots \ldots \\
14 \ldots \ldots \\
15 \ldots \ldots \\
16 \ldots \ldots \\
17 \ldots \ldots \\
18 \ldots \ldots \\
19 \ldots \ldots \\
20 \ldots \ldots\end{array}$ & $\begin{array}{l}309 \\
242 \\
230 \\
285 \\
282 \\
270 \\
261 \\
252 \\
242 \\
230\end{array}$ & $\begin{array}{l}1,630 \\
1,540 \\
2,210 \\
2,180 \\
1,800 \\
1,640 \\
1,530 \\
1,440 \\
1,370 \\
1,330\end{array}$ & $\begin{array}{l}21 \ldots \ldots \\
22 \ldots \ldots \\
23 \ldots \ldots \\
24 \ldots \ldots \\
25 \ldots \ldots \\
26 \ldots \ldots \\
27 \ldots \ldots \\
28 \ldots \ldots \\
29 \ldots \ldots \\
30 \ldots \ldots \\
31 \ldots \ldots\end{array}$ & $\begin{array}{r}235 \\
232 \\
232 \\
228 \\
223 \\
218 \\
214 \\
209 \\
227 \\
3,170 \\
4 \mathrm{~S}, 400\end{array}$ & $\begin{array}{r}1,280 \\
1,220 \\
1,150 \\
1,090 \\
1,050 \\
1,020 \\
1,020 \\
944 \\
---1-- \\
--.---\end{array}$ \\
\hline \multicolumn{7}{|c|}{ 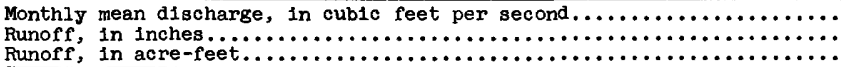 } & $\begin{array}{r}1,933 \\
4.17 \\
118,800 \\
\end{array}$ & $\begin{array}{r}4,563 \\
8.90 \\
253,400 \\
\end{array}$ \\
\hline
\end{tabular}

Gage height, in feet, and discharge, in cubic feet per second, at indicated time, 1963

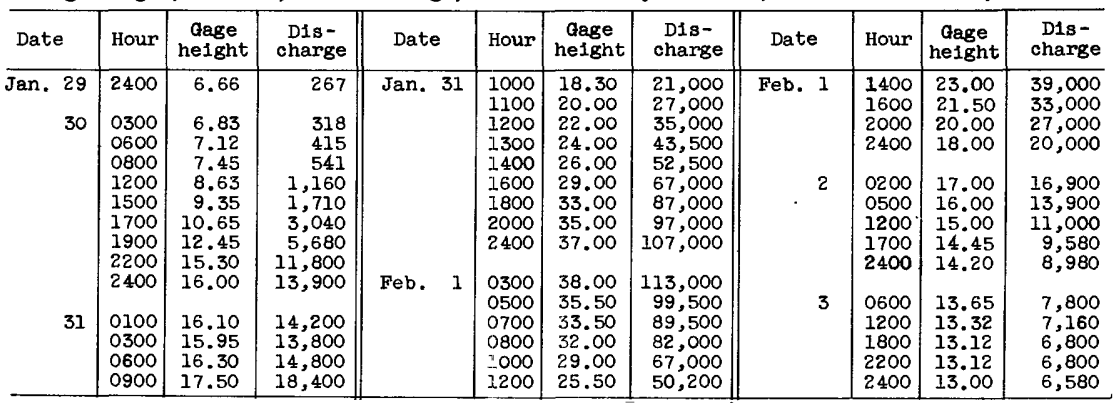


11-4335. Middle Fork American River near Auburn, Calif.

Location.--Lat $38^{\circ} 55^{\prime} 05^{\prime \prime}$, long $121^{\circ} 00^{\prime} 20^{\prime \prime}$, in SE $\frac{1}{4}$ sec.6, T.12 N., R.9 E., on left bank 0.5 mile upstream from Mountain Quarry Co. plant, $i .9$ miles upstream from mouth, and 3.5 miles northeast of Auburn.

Drainage area.--612 sq $\mathrm{ml}$.

Gage-height record.--Digital recorder tape punched at 15-minute intervals, except Jan. 26 to Feb. 28. Datum of gage is $568.5 \mathrm{ft}$ above mean sea level (riverprofile survey).

Discharge record.--Stage-discharge relation defined by current-meter measurements below $68,500 \mathrm{c}$ 's and extended above on basis of comparison with upstream stations and runoff per square mile for intervening areas. Discharge for period Jan. 26 to Feb. 28 estimated on basis of hydrographic comparison with Middle Fork
American River near Foresthill, Calif.

Maxima.--January-February 1963: Discharge, 121,000 cfs about 0400 hours Feb. I (gage helght, $43.1 \mathrm{ft}$, from floodmarks).

1911 to December 1962: Discharge, 79,000 cfs Dec. 23, 1955 (gage height,

Mean discharge, in cub1c feet per second, 1963

\begin{tabular}{|c|c|c|c|c|c|c|c|c|}
\hline Day & January & February & Day & January & February & Day & January & February \\
\hline $\begin{array}{c}1 \ldots \ldots \\
2 \ldots \ldots \\
3 \ldots \ldots \\
4 \ldots \ldots \\
5 \ldots \ldots \\
7 \ldots \ldots \\
8 \ldots \ldots \\
9 \ldots \ldots \\
10 \ldots \ldots\end{array}$ & $\begin{array}{l}477 \\
454 \\
441 \\
430 \\
420 \\
404 \\
389 \\
380 \\
370 \\
358\end{array}$ & $\begin{array}{r}68,000 \\
15,000 \\
9,000 \\
7,000 \\
6,000 \\
4,500 \\
3,500 \\
2,500 \\
2,200 \\
2,000\end{array}$ & $\begin{array}{l}11 \ldots \ldots \\
12 \ldots \ldots \\
13 \ldots \ldots \\
14 \ldots \ldots \\
15 \ldots \ldots \\
16 \ldots \ldots \\
17 \ldots \ldots \\
15 \ldots \ldots \\
19 \ldots \ldots \\
20 \ldots \ldots\end{array}$ & $\begin{array}{l}353 \\
313 \\
258 \\
304 \\
322 \\
311 \\
300 \\
292 \\
284 \\
268\end{array}$ & $\begin{array}{l}1,800 \\
1,700 \\
2,500 \\
2,400 \\
2,000 \\
1,800 \\
1,700 \\
1,600 \\
1,500 \\
1,400\end{array}$ & $\begin{array}{l}21 \ldots \ldots \\
22 \ldots \ldots \\
23 \ldots \ldots \\
24 \ldots \ldots \\
25 \ldots \ldots \\
26 \ldots \ldots \\
27 \ldots \ldots \\
28 \ldots \ldots \\
29 \ldots \ldots \\
30 \ldots \ldots \\
31 \ldots \ldots\end{array}$ & $\begin{array}{r}270 \\
272 \\
268 \\
266 \\
262 \\
255 \\
250 \\
250 \\
310 \\
4,000 \\
41,000\end{array}$ & $\begin{array}{r}1,400 \\
1,300 \\
1,300 \\
1,200 \\
1,100 \\
1,100 \\
1,100 \\
1,000 \\
---.-- \\
--.-1- \\
-.-1-.\end{array}$ \\
\hline \multicolumn{9}{|c|}{ 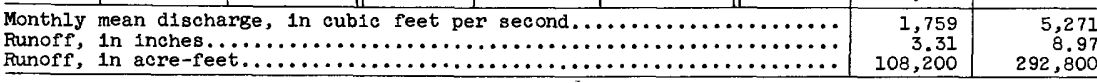 } \\
\hline
\end{tabular}

11-4360. Silver Lake Outlet near Kirkwood, Calif.

Location.--Lat $38^{\circ} 40^{\prime} 17^{\prime \prime}$, long $120^{\circ} 07^{\prime} 18^{\prime \prime}$, in SW $\frac{1}{4}$ sec.32, T.10 N., R.17 E., on right bank 1,000 ft downstream from Silver Lake Dam and 3.5 miles southwest of Kirkwood.

Drainage area.--15.2 sq $\mathrm{ml}$.

Gage-height record.--Water-stage recorder graph. Datum of gage is $7,199.5 \mathrm{ft}$ above mean sea level, unad justed.

Discharge record.--Stage-discharge relation defined by current-meter measurements below 200 cf's.

Maxima.--January-February 1963: Discharge, 424 cfs 1430 hours Feb. 1 (gage height, $4.60 \mathrm{ft}$ ).

1922 to December 1962: Discharge, 676 cfs Nov. 21, 1950 (gage height, $6.03 \mathrm{ft})$.

Remarks.-Flow regulated by Silver Lake since beginning of record (usable capacity, 8,590 acre-ft).

Mean discharge, in cubic feet per second, 1963

\begin{tabular}{|c|c|c|c|c|c|c|c|c|}
\hline Day & January & February & Day & January & February & Day & January & February \\
\hline $\begin{array}{c}1 \ldots \ldots \\
2 \ldots \ldots \\
3 \ldots \ldots \\
4 \ldots \ldots \\
6 \ldots \ldots \\
7 \ldots \ldots \\
9 \ldots \ldots \\
10 \ldots \ldots\end{array}$ & $\begin{array}{l}14 \\
14 \\
14 \\
13 \\
13 \\
13 \\
13 \\
13 \\
13 \\
13\end{array}$ & $\begin{array}{r}364 \\
345 \\
266 \\
215 \\
189 \\
153 \\
125 \\
106 \\
91 \\
77\end{array}$ & $\begin{array}{l}11 \ldots \ldots \\
12 \ldots \ldots \\
13 \ldots \ldots \\
14 \ldots \ldots \\
15 \ldots \ldots \\
16 \ldots \ldots \\
17 \ldots \ldots \\
18 \ldots \ldots \\
19 \ldots \ldots \\
20 \ldots \ldots\end{array}$ & $\begin{array}{l}13 \\
12 \\
12 \\
11 \\
11 \\
11 \\
11 \\
9.6 \\
6.7 \\
7.7\end{array}$ & $\begin{array}{l}63 \\
55 \\
52 \\
46 \\
40 \\
37 \\
34 \\
33 \\
33 \\
33\end{array}$ & $\begin{array}{l}21 \ldots \ldots \\
22 \ldots \ldots \\
23 \ldots \ldots \\
24 \ldots \ldots \\
25 \ldots \ldots \\
26 \ldots \ldots \\
27 \ldots \ldots \\
28 \ldots \ldots \\
29 \ldots \ldots \\
30 \ldots \ldots \\
31 \ldots \ldots\end{array}$ & $\begin{array}{l}7.2 \\
7.2 \\
11 \\
14 \\
13 \\
13 \\
14 \\
13 \\
12 \\
12 \\
25\end{array}$ & $\begin{array}{r}33 \\
33 \\
32 \\
32 \\
31 \\
31 \\
31 \\
31 \\
-\ldots--0 \\
-\ldots-\ldots\end{array}$ \\
\hline \multicolumn{7}{|c|}{ 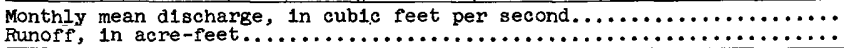 } & $\begin{array}{r}12.2 \\
753 \\
\end{array}$ & $\begin{array}{r}93.3 \\
5,180 \\
\end{array}$ \\
\hline
\end{tabular}


11-4375.6. Kirkwood Creek near S1lver Lake, Calıf.

(Crest-stage station)

Location.--Lat $38^{\circ} 42^{\prime} 10^{\prime \prime}$, long $120^{\circ} 04^{\prime} 10^{\prime \prime}$, in SW $\frac{1}{4} \mathrm{NE} \frac{1}{4}$ sec. 22 , T.10 N., R.17 E., on State Highway $88,3.7$ miles northeast of Silver Lake outlet.

Drainage area. $-3.62 \mathrm{sq} \mathrm{mi}$.

Gage-helght record.--Crest stages only. Altitude of gage is 7,760 ft (from topographic map).

Discharge record.--Stage-discharge relation defined by current-meter measurements below $43 \mathrm{cf}$ 's and by computation of flow through culvert at $385 \mathrm{cfs}$.

Maxima.--January-February 1963: Discharge, 385 cfs Feb. 1 (gage he1ght, 9.71 ft, from floodmarks).

July to December 1962: No significant floodflow.

11-4395. South Fork American River near Kyburz, Cal1f.

Location.--Lat $38^{\circ} 45^{\prime} 49^{\prime \prime}$, long $120^{\circ} 19^{\prime} 39^{\prime \prime}$, In SW $\frac{1}{4} \mathrm{SW} \frac{1}{4} \sec .29$, T.11 N., R.15 E., on right bank beside U.S. Highway $50,0.8$ mile downstream from Silver Fork of 'South Fork and 1.9 miles southwest of Kyburz.

Drainage area.--193 sq $\mathrm{ml}$.

Gage-helght record.--Water-stage recorder graph. Alt1tude of gage is $3,840 \mathrm{ft}$ (from topographic map).

Discharge record.--Stage-discharge relation defined by current-meter measurements below 6,500 cfs and by contracted-opening measurement at 14,500 cfs; affected by ice Jan. 13-15.

Maxima (river only).--January-February 1963: Discharge, 15,500 cfs 0600 hours Feb.1 (gage helght, $10.53 \mathrm{ft}$ ).

1907, 1923 to December 1962: Discharge, 14,500 cfs Nov. 21, 1950 (gage height, $10.40 \mathrm{ft}$ ).

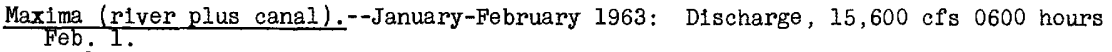

1907, 1923 to December 1962: Discharge, 14,500 cfs Nov. 21, 1950.

Remarks.--Flow partly regulated by four reservolrs since beginning of record (total usabie capacity, 37,100 acre-ft). El Dorado Canal diverts 0.5 mile above station. Mean discharge figures and tabulation of discharge at indicated times are the combined flow of South Fork American River and El Dorado Canal.

Mean discharge, in cublc feet per second, 1963

\begin{tabular}{|c|c|c|c|c|c|c|c|c|}
\hline Day & January & Febmuary & Day & January & February & Day & Jamuary & February \\
\hline $\begin{array}{c}1 \ldots \ldots \\
2 \ldots \ldots \\
3 \ldots \ldots \\
5 \ldots \ldots \\
6 \ldots \ldots \\
7 \ldots \ldots \\
9 \ldots \ldots \\
10 \ldots \ldots\end{array}$ & $\begin{array}{l}124 \\
124 \\
123 \\
122 \\
120 \\
119 \\
118 \\
104 \\
101 \\
104\end{array}$ & $\begin{array}{r}9,670 \\
2,720 \\
1,810 \\
1,530 \\
1,440 \\
1,040 \\
866 \\
742 \\
648 \\
576\end{array}$ & $\begin{array}{l}11 \ldots \ldots \\
12 \ldots \ldots \\
13 \ldots \ldots \\
14 \ldots \ldots \\
15 \ldots \ldots \\
16 \ldots \ldots \\
17 \ldots \ldots \\
18 \ldots \ldots \\
19 \ldots \ldots \\
20 \ldots \ldots\end{array}$ & $\begin{array}{r}91 \\
89 \\
94 \\
100 \\
107 \\
108 \\
110 \\
111 \\
110 \\
112\end{array}$ & $\begin{array}{l}510 \\
450 \\
559 \\
522 \\
435 \\
407 \\
372 \\
322 \\
337 \\
329\end{array}$ & $\begin{array}{l}21 \ldots \ldots \\
22 \ldots \ldots \\
23 \ldots \ldots \\
24 \ldots \ldots \\
25 \ldots \ldots \\
26 \ldots \ldots \\
27 \ldots \ldots \\
28 \ldots \ldots \\
29 \ldots \ldots \\
30 \ldots \ldots \\
31 \ldots \ldots\end{array}$ & $\begin{array}{r}115 \\
111 \\
111 \\
103 \\
91 \\
91 \\
89 \\
88 \\
92 \\
512 \\
6,410\end{array}$ & $\begin{array}{r}317 \\
291 \\
278 \\
283 \\
267 \\
280 \\
280 \\
258 \\
----- \\
----- \\
-----\end{array}$ \\
\hline \multicolumn{7}{|l|}{$\begin{array}{l}\text { Monthly } \\
\text { Runoff, } \\
\text { Runoff, }\end{array}$} & $\begin{array}{r}323 \\
1.93 \\
19,840 \\
\end{array}$ & $\begin{array}{r}984 \\
5.31 \\
54,620 \\
\end{array}$ \\
\hline
\end{tabular}


Gage height, in feet, and discharge, in cubic feet per second, at indicated t1me, 1963, of South Fork Amerlcan R1ver near Kyburz, Calif. (combined flow of $r i v e r$ and El Dorado Canal)

\begin{tabular}{|c|c|c|c|c|c|c|c|c|c|c|c|}
\hline Date & Hour & $\begin{array}{c}\text { Gage } \\
\text { he1ght }\end{array}$ & $\begin{array}{c}\text { Dis- } \\
\text { charge }\end{array}$ & Date & Hour & $\begin{array}{c}\text { Gage } \\
\text { helght }\end{array}$ & $\begin{array}{c}\text { D1s- } \\
\text { charge }\end{array}$ & Date & Hour & $\begin{array}{c}\text { Gage } \\
\text { helght }\end{array}$ & $\begin{array}{l}\text { D1s- } \\
\text { charge }\end{array}$ \\
\hline $\begin{array}{r}\text { Jan. } 29 \\
30\end{array}$ & $\begin{array}{l}2400 \\
0400 \\
0600 \\
0800 \\
1000 \\
1200 \\
1400 \\
1600 \\
1700 \\
1800 \\
1900 \\
2000\end{array}$ & $\begin{array}{c}- \\
= \\
= \\
= \\
= \\
= \\
= \\
5.16 \\
5.20\end{array}$ & $\begin{array}{r}102 \\
121 \\
127 \\
142 \\
160 \\
165 \\
209 \\
290 \\
360 \\
736 \\
I, 320 \\
I, 340\end{array}$ & Jan. 30 & $\begin{array}{l}2300 \\
2400 \\
\\
0300 \\
0700 \\
0900 \\
1000 \\
1200 \\
1600 \\
2100 \\
2200 \\
2300 \\
2330\end{array}$ & $\begin{array}{r}5.70 \\
5.70 \\
5.44 \\
6.05 \\
6.64 \\
7.12 \\
8.15 \\
9.08 \\
10.00 \\
10.26 \\
9.80 \\
10.33\end{array}$ & $\begin{array}{r}1,840 \\
1,840 \\
1,580 \\
2,220 \\
3,000 \\
3,810 \\
5,990 \\
8,790 \\
12,600 \\
13,900 \\
11,700 \\
14,300\end{array}$ & $\begin{array}{l}\text { Jan. } 31 \\
\text { Feb. } 1\end{array}$ & $\begin{array}{l}2400 \\
0200 \\
0300 \\
0500 \\
0600 \\
0900 \\
1200 \\
1700 \\
2400 \\
1100 \\
2400\end{array}$ & $\begin{array}{r}10.00 \\
10.50 \\
10.50 \\
10.38 \\
10.53 \\
9.50 \\
8.55 \\
8.20 \\
7.04 \\
6.02 \\
5.58\end{array}$ & $\begin{array}{r}13,100 \\
15,400 \\
15,400 \\
14,800 \\
15,600 \\
11,100 \\
7,770 \\
6,710 \\
4,090 \\
2,500 \\
2,010\end{array}$ \\
\hline
\end{tabular}

11-4400. Alder Creek near White Hall, Calif.

Location.--Lat $38^{\circ} 45^{\prime} 19^{\prime \prime}$, long $120^{\circ} 22^{\prime} 17^{\prime \prime}$, In $\mathrm{NE}_{\frac{1}{4}}^{\frac{1}{2}} \mathrm{SE}_{\frac{1}{4}}^{\frac{1}{3}} \sec .35$, T.11 N., R. 14 E., on right bank 0.9 mile upstream from mouth and 2.2 miles southeast of white Hail.

Drainage area.--22.1 sq $\mathrm{mi}$.

Gage-height record - -Water-stage recorder graph, except Jan. 12-29. Altitude of gage is 3,840 ft (from topographic map).

Discharge record.--Stage-discharge relation defined by current-meter measurements below 600 cfs and by slope-area measurement at $4,430 \mathrm{cf} s$. Discharge for Jan. 12-29 estimated on basis of fleld estimate of flow, weather records, and records for Cole Creek near Mokelumne Peak.

Maxima.--January-February 1963: Discharge, 4,430 cfs 2400 hours Jan. 31 (gage helght, $7.37 \mathrm{ft}$ ).

1922 to December 1962: Discharge, 5,500 cfs Dec. 23, 1955 (gage height,

$8.40 \mathrm{ft}$, from floodmarks), from rating curve extended above $500 \mathrm{cfs}$.

Mean discharge, in cub1c feet per second, 1963

\begin{tabular}{|c|c|c|c|c|c|c|c|c|}
\hline Day & January & February & Day & January & February & Day & January & February \\
\hline $\begin{array}{r}1 \ldots \ldots \\
2 \ldots . \\
3 \ldots \ldots \\
4 \ldots \ldots \\
5 \ldots \ldots \\
6 \ldots \ldots \\
7 \ldots \ldots \\
8 \ldots \ldots \\
9 \ldots \ldots\end{array}$ & $\begin{array}{l}7.0 \\
7.7 \\
7.2 \\
7.2 \\
7.6 \\
7.5 \\
7.4 \\
7.2 \\
7.0 \\
6.8\end{array}$ & $\begin{array}{r}1,790 \\
592 \\
362 \\
261 \\
205 \\
147 \\
106 \\
94 \\
81 \\
73\end{array}$ & 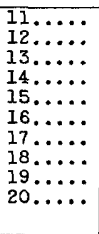 & $\begin{array}{l}4.0 \\
3.6 \\
4.5 \\
4.5 \\
4.5 \\
4.3 \\
4.7 \\
4.1 \\
4.7 \\
4.0\end{array}$ & $\begin{array}{l}64 \\
61 \\
82 \\
80 \\
71 \\
65 \\
61 \\
57 \\
52 \\
45\end{array}$ & $\begin{array}{l}21 \ldots \ldots \\
22 \ldots \ldots \\
23 \ldots \ldots \\
24 \ldots \\
25 \ldots \\
26 \ldots \\
27 \ldots \ldots \\
25 \ldots \\
29 \ldots \\
30 \ldots \\
31 \ldots \ldots \\
\end{array}$ & $\begin{array}{r}3.9 \\
3.5 \\
5.6 \\
5.6 \\
6.0 \\
6.5 \\
6.0 \\
5.5 \\
6.3 \\
212 \\
1,520\end{array}$ & $\begin{array}{r}46 \\
43 \\
42 \\
39 \\
36 \\
35 \\
33 \\
31 \\
-0-1 \\
\end{array}$ \\
\hline $\begin{array}{l}\text { onthly } \\
\text { anoff', } \\
\text { anoff, }\end{array}$ & acre- & & & & & & $\begin{array}{r}61.2 \\
3.19 \\
3,760 \\
\end{array}$ & $\begin{array}{r}166 \\
7.84 \\
9,240 \\
\end{array}$ \\
\hline
\end{tabular}

Gage height, in feet, and discharge, in cubic feet per second, at indicated time, 1963

\begin{tabular}{|c|c|c|c|c|c|c|c|c|c|c|c|}
\hline Date & Hour & $\begin{array}{c}\text { Gage } \\
\text { height }\end{array}$ & $\begin{array}{l}\text { Dis- } \\
\text { charge }\end{array}$ & Date & Hour & $\begin{array}{c}\text { Gage } \\
\text { height }\end{array}$ & $\begin{array}{c}\text { Dis- } \\
\text { charge }\end{array}$ & Date & Hour & $\begin{array}{c}\text { Gage } \\
\text { he1ght }\end{array}$ & $\begin{array}{l}\text { Dis- } \\
\text { charge }\end{array}$ \\
\hline $\begin{array}{r}\text { Jan. } 29 \\
30\end{array}$ & $\begin{array}{l}2400 \\
0600 \\
0900 \\
1200 \\
1200 \\
1500 \\
1900 \\
2100 \\
2300 \\
2400\end{array}$ & $\begin{array}{l}1.36 \\
1.50 \\
1.76 \\
2.12 \\
2.00 \\
2.51 \\
3.46 \\
3.71 \\
3.61 \\
3.47\end{array}$ & $\begin{array}{c}6.4 \\
17 \\
47 \\
97 \\
79 \\
171 \\
515 \\
646 \\
591 \\
520\end{array}$ & Jan. 31 & $\begin{array}{l}1000 \\
1100 \\
1300 \\
1300 \\
1400 \\
1500 \\
1600 \\
1800 \\
2000 \\
2100 \\
2300\end{array}$ & $\begin{array}{l}4.30 \\
4.20 \\
4.75 \\
4.40 \\
4.90 \\
5.70 \\
4.75 \\
5.85 \\
6.00 \\
6.80 \\
6.65 \\
7.37\end{array}$ & $\begin{array}{r}1,010 \\
945 \\
1,330 \\
1,080 \\
1,450 \\
2,250 \\
1,330 \\
2,420 \\
2,600 \\
3,600 \\
3,400 \\
4,430\end{array}$ & Feb. I & $\begin{array}{l}0700 \\
0800 \\
0900 \\
1300 \\
1400 \\
1600 \\
1700 \\
1900 \\
2100 \\
2400\end{array}$ & $\begin{array}{l}6.60 \\
5.00 \\
4.60 \\
4.48 \\
4.35 \\
4.55 \\
4.52 \\
4.02 \\
3.83 \\
3.81\end{array}$ & $\begin{array}{r}3,430 \\
1,710 \\
1,380 \\
1,290 \\
1,190 \\
1,340 \\
1,320 \\
944 \\
811 \\
797\end{array}$ \\
\hline 31 & $\begin{array}{l}0200 \\
0600\end{array}$ & $\begin{array}{l}3.27 \\
3.34\end{array}$ & $\begin{array}{l}427 \\
458\end{array}$ & Feb, I & & & & 2 & $\begin{array}{l}1400 \\
2400\end{array}$ & $\begin{array}{l}3.36 \\
3.16\end{array}$ & $\begin{array}{l}538 \\
436\end{array}$ \\
\hline
\end{tabular}




\section{1-4410.01. Union Valley Reservoir near Riverton, Calif.}

Location.--Lat $38^{\circ} 52^{\prime} 00^{\prime \prime}$, long $120^{\circ} 26^{\prime} 25^{\prime \prime}$, in SW $\frac{1}{4} S W^{\frac{1}{4}}$ sec.20, T.12 N., R.14 E., $0.6 \mathrm{mi} l e$ upstream from Little Silver Creek and 6.6 miles north of Riverton.

Drainage area. $--83.6 \mathrm{sq} \mathrm{mi}$.

Gage-height record.--Water-stage recorder graph. Datum of gage is at mean sea level (levels by Sacramento Municipal vtility District).

Contents record.--Contents computed from capacity table dated July 12, 1962, furnished by Sacramento Municipal Utility District.

Maxima.--January-February 1963: Computed bihourly inflow, 21,100 cf's 2400 hours Jan. 31 to 0200 hours Feb. 1 . Contents, 121,900 acre-ft 2400 hours Feb. 28 (elevation, 4,802.7 ft).

October to December 1962: Contents, 45,300 acre-ft Dec. 31, 1962 (elevation, $4,736.1 \mathrm{ft})$.

1924-60: Maximum discharge at former gaging station 0.7 mile upstream, 15,800 cfs Dec. 23,1955 .

Remarks.--Reservoir is formed by earthfill dam completed in December 1962. Storage began in May 1962. Usable capacity, 264,000 acre-ft between elevations 4,645.0 (minimum operating level) and $4,870.0 \mathrm{ft}$ (top of radial spillway gates) above mean sea level. Dead storage, 7,000 acre-ft. Figures given herein represent total contents.

Elevation, in feet, and contents, in acre-feet, at 2400 hours, 1963

\begin{tabular}{|c|c|c|c|c|c|c|c|c|c|}
\hline \multirow{2}{*}{ Day } & \multicolumn{2}{|c|}{ January } & \multicolumn{2}{|c|}{ February } & \multirow{2}{*}{ Day } & \multicolumn{2}{|c|}{ January } & \multicolumn{2}{|c|}{ February } \\
\hline & Elevation & Contents & Elevation & Contents & & Elevat1on & Contents & Elevation & Contents \\
\hline $\begin{array}{r}1 \\
2 \\
3 \\
4 \\
5 \\
6 \\
7 \\
8 \\
9 \\
10 \\
11 \\
12 \\
13 \\
14 \\
15\end{array}$ & $\begin{array}{l}4,736.3 \\
4,736.5 \\
4,736.8 \\
4,736.9 \\
4,737.2 \\
4,737.4 \\
4,737.5 \\
4,737.7 \\
4,737.9 \\
4,738.0 \\
4,738.2 \\
4,738.3 \\
4,738.4 \\
4,738.5 \\
4,738.6\end{array}$ & $\begin{array}{l}45,400 \\
45,600 \\
45,800 \\
45,800 \\
46,000 \\
46,200 \\
46,200 \\
46,400 \\
46,500 \\
46,600 \\
46,700 \\
46,800 \\
46,900 \\
47,000 \\
47,000\end{array}$ & $\begin{array}{l}4,780.8 \\
4,784.5 \\
4,786.8 \\
4,788.6 \\
4,790.2 \\
4,791.3 \\
4,792.2 \\
4,793.0 \\
4,793.6 \\
4,794.2 \\
4,794.8 \\
4,795.3 \\
4,796.4 \\
4,797.3 \\
4,797.9\end{array}$ & $\begin{array}{r}89,100 \\
94,300 \\
97,500 \\
100,000 \\
102,300 \\
104,000 \\
105,300 \\
106,500 \\
107,400 \\
108,300 \\
109,200 \\
110,000 \\
111,600 \\
113,000 \\
113,800\end{array}$ & $\begin{array}{l}16 \\
17 \\
18 \\
19 \\
20 \\
21 \\
22 \\
23 \\
24 \\
25 \\
26 \\
27 \\
28 \\
29 \\
30 \\
31\end{array}$ & $\begin{array}{l}4,738.8 \\
4,738.9 \\
4,739.0 \\
4,739.1 \\
4,739.2 \\
4,739.3 \\
4,739.4 \\
4,739.5 \\
4,739.6 \\
4,739.7 \\
4,739.8 \\
4,739.9 \\
4,740.1 \\
4,740.4 \\
4,743.4 \\
4,764.7\end{array}$ & $\begin{array}{l}47,200 \\
47,200 \\
47,300 \\
47,400 \\
47,400 \\
47,500 \\
47,600 \\
47,600 \\
47,700 \\
47,800 \\
47,900 \\
47,900 \\
48,100 \\
48,300 \\
50,700 \\
70,200\end{array}$ & $\begin{array}{c}4,798.5 \\
4,798.9 \\
4,799.4 \\
4,799.8 \\
4,800.1 \\
4,800 \cdot 5 \\
4,800 \cdot 9 \\
4,801.2 \\
4,801.5 \\
4,801.8 \\
4,802.2 \\
4,802.5 \\
4,802.7 \\
- \\
- \\
-\end{array}$ & $\begin{array}{c}114,800 \\
115,400 \\
116,100 \\
116,700 \\
117,200 \\
117,900 \\
115,600 \\
119,200 \\
119,700 \\
120,200 \\
121,000 \\
121,500 \\
121,900 \\
- \\
- \\
-\end{array}$ \\
\hline & $n$ & 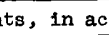 & & & & & $+24,900$ & - & $+51,700$ \\
\hline
\end{tabular}

Average inflow, in cubic feet per second, for bihourly periods ending at indicated time, 1963

\begin{tabular}{|c|c|c|c|c|c|c|c|c|}
\hline Date & Hour & Inflow & Date & Hour & Inflow & Date & Hour & Inflow \\
\hline Jan. 30 & $\begin{array}{l}0200 \\
0400 \\
0600 \\
0800 \\
1000 \\
1200 \\
1400 \\
1600 \\
1800 \\
2000 \\
2200 \\
2400 \\
0200 \\
0400 \\
0600 \\
0800\end{array}$ & $\begin{array}{r}281 \\
334 \\
268 \\
385 \\
372 \\
592 \\
1,020 \\
1,000 \\
1,230 \\
1,480 \\
1,850 \\
1,970 \\
2,330 \\
2,350 \\
2,810 \\
3,420\end{array}$ & Feb. 1 & $\begin{array}{l}1000 \\
1200 \\
1400 \\
1600 \\
1800 \\
2000 \\
2200 \\
2400 \\
\\
0200 \\
0400 \\
0600 \\
0800 \\
1000 \\
1200 \\
1400 \\
1600\end{array}$ & $\begin{array}{r}4,020 \\
6,420 \\
8,680 \\
11,200 \\
11,900 \\
13,300 \\
15,900 \\
19,200 \\
21,100 \\
17,600 \\
15,000 \\
11,500 \\
7,380 \\
5,520 \\
4,250 \\
3,940\end{array}$ & Feb. 1 & $\begin{array}{l}1800 \\
2000 \\
2200 \\
2400 \\
0200 \\
0400 \\
0600 \\
0800 \\
1000 \\
1200 \\
1400 \\
1600 \\
1800 \\
2000 \\
2200 \\
2400\end{array}$ & $\begin{array}{r}3,700 \\
3,390 \\
3,030 \\
2,850 \\
2,250 \\
2,300 \\
2,060 \\
1,700 \\
1,500 \\
1,360 \\
1,340 \\
1,240 \\
1,120 \\
1,180 \\
920 \\
897\end{array}$ \\
\hline
\end{tabular}


11-4411. Ice House Reservolr near Kyburz, Calif.

Location.--Lat $38^{\circ} 49^{\prime} 26^{\prime \prime}$, long $120^{\circ} 21^{\prime} 34^{\prime \prime}$, in SE $\frac{1}{4} \mathrm{SW}_{\frac{1}{4}}$ sec.1, T.11 N., R.14 E., on left bank at Ice House Dam on South Fork Silver Creek, 0.5 mile upstream from

Peavine Creek and 4.75 miles northwest of Kyburz.

Drainage area.--27.2 sq $\mathrm{mi}$.

Gage-helght record.--Water-stage recorder graph. Datum of gage is at mean sea level

(datum of Sacramento Municlpal Utility District).

Contents record.--Contents computed from capacity table dated Apr. 4, 1960.

Maxima.--January-February 1963: Computed bihourly Inflow, 5,640 cfs 2400 hours

Jan. 31 to 0200 hours Feb. i. Contents, 20,100 acre-ft 2400 hours Feb. 28

(elevation, 5,405.36 ft).

1959 to December 1962: Contents, 46,100 acre-ft, several days in May and

June 1961 (elevation, 5,450.24 ft, from high-water marks).

Remarks.--Reservoir is formed by earthfill dam. Storage began Dec. 15, 1959.

Usabie capacity, 45,800 acre-ft between elevations 5,327.5 ft (centerline of fish

water outlet) and 5,450.0 ft (top of spillway gates). Dead storage, 160 acre-ft.

Figures given herein represent total contents.

Elevation, in feet, and contents, in acre-feet, at 2400 hours, 1963

\begin{tabular}{|c|c|c|c|c|c|c|c|c|c|}
\hline \multirow{2}{*}{ Day } & \multicolumn{2}{|c|}{ January } & \multicolumn{2}{|c|}{ February } & \multirow{2}{*}{ Day } & \multicolumn{2}{|c|}{ January } & \multicolumn{2}{|c|}{ February } \\
\hline & Elevation & Contents & Elevation & Contents & & Elevation & Contents & Elevation & Contents \\
\hline $\begin{array}{r}1 \\
2 \\
3 \\
4 \\
5 \\
6 \\
7 \\
8 \\
9 \\
10 \\
11 \\
12 \\
13 \\
14 \\
15\end{array}$ & $\begin{array}{l}5,363.71 \\
5,363.79 \\
5,363.88 \\
5,363.97 \\
5,364.07 \\
5,364.13 \\
5,364.18 \\
5,364.24 \\
5,364.28 \\
5,364.29 \\
5,364.30 \\
5,364.30 \\
5,364.36 \\
5,364.41 \\
5,364.46\end{array}$ & $\begin{array}{l}4,730 \\
4,750 \\
4,770 \\
4,790 \\
4,820 \\
4,830 \\
4,840 \\
4,860 \\
4,870 \\
4,870 \\
4,870 \\
4,870 \\
4,890 \\
4,900 \\
4,910\end{array}$ & $\begin{array}{l}5,391.58 \\
5,393.70 \\
5,395.09 \\
5,396.36 \\
5,397.51 \\
5,398.31 \\
5,399.00 \\
5,399.56 \\
5,399.97 \\
5,400.29 \\
5,400.79 \\
5,401.10 \\
5,401.55 \\
5,401.89 \\
5,402.28\end{array}$ & $\begin{array}{l}13,100 \\
15,000 \\
15,500 \\
16,000 \\
16,500 \\
16,800 \\
17,200 \\
17,400 \\
17,600 \\
17,700 \\
18,000 \\
18,100 \\
18,300 \\
18,500 \\
18,600\end{array}$ & $\begin{array}{l}16 \\
17 \\
18 \\
19 \\
20 \\
21 \\
22 \\
23 \\
24 \\
25 \\
26 \\
27 \\
28 \\
29 \\
30 \\
31\end{array}$ & $\begin{array}{l}5,364.50 \\
5,364.51 \\
5,364.54 \\
5,364.56 \\
5,364.58 \\
5,364.63 \\
5,364.68 \\
5,364.71 \\
5,364.74 \\
5,364.75 \\
5,364.75 \\
5,364.73 \\
5,364.71 \\
5,364.83 \\
5,365.54 \\
5,376.16\end{array}$ & $\begin{array}{l}4,920 \\
4,920 \\
4,930 \\
4,930 \\
4,940 \\
4,950 \\
4,960 \\
4,970 \\
4,980 \\
4,980 \\
4,980 \\
4,980 \\
4,970 \\
5,000 \\
5,180 \\
8,260\end{array}$ & $\begin{array}{c}5,402.52 \\
5,402.81 \\
5,403.10 \\
5,403.33 \\
5,403.59 \\
5,403.81 \\
5,404.03 \\
5,404.25 \\
5,404.44 \\
5,404.71 \\
5,404.90 \\
5,405.14 \\
5,405.36 \\
- \\
- \\
-\end{array}$ & $\begin{array}{c}18,700 \\
18,900 \\
19,000 \\
19,100 \\
19,200 \\
19,300 \\
19,400 \\
19,500 \\
19,600 \\
19,800 \\
19,800 \\
20,000 \\
20,100 \\
- \\
- \\
-\end{array}$ \\
\hline & In & 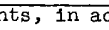 & & & & - & $+3,540$ & - & $+11,840$ \\
\hline
\end{tabular}

Average Inflow, in cuble feet per second, for bihourly periods ending at indicated time, 1963

\begin{tabular}{|c|c|c|c|c|c|c|c|c|}
\hline Date & Hour & Inflow & Date & Hour & Inflow & Date & Hour & Inflow \\
\hline $\operatorname{Jan} .30$ & $\begin{array}{l}0200 \\
0400 \\
0600 \\
0800 \\
1000 \\
1200 \\
1400 \\
1600 \\
1800 \\
2000 \\
2200 \\
2400 \\
\\
0200 \\
0400 \\
0600 \\
0800 \\
\end{array}$ & $\begin{array}{r}50 \\
38 \\
68 \\
81 \\
99 \\
117 \\
135 \\
196 \\
135 \\
117 \\
87 \\
68 \\
\\
153 \\
177 \\
202 \\
274 \\
\end{array}$ & $\begin{array}{l}\text { Jan. } 31 \\
\text { Feb. } 1\end{array}$ & $\begin{array}{l}1000 \\
1200 \\
1400 \\
1600 \\
1800 \\
2000 \\
2200 \\
2400 \\
0200 \\
0400 \\
0600 \\
0800 \\
1000 \\
1200 \\
1400 \\
1600 \\
\end{array}$ & $\begin{array}{r}565 \\
613 \\
976 \\
1,760 \\
2,910 \\
2,790 \\
3,580 \\
4,730 \\
5,640 \\
5,520 \\
4,850 \\
4,850 \\
3,030 \\
3,030 \\
1,900 \\
1,780 \\
\end{array}$ & Feb. 1 & $\begin{array}{l}1800 \\
2000 \\
2200 \\
2400 \\
0200 \\
0400 \\
0600 \\
0800 \\
1000 \\
1200 \\
1400 \\
1600 \\
1800 \\
2000 \\
2200 \\
2400 \\
\end{array}$ & $\begin{array}{r}1,750 \\
1,370 \\
1,050 \\
855 \\
\\
710 \\
613 \\
492 \\
468 \\
444 \\
444 \\
419 \\
371 \\
347 \\
347 \\
298 \\
298 \\
\end{array}$ \\
\hline
\end{tabular}


11-4415. South Fork Silver Creek near Ice House, Calif.

Location.--Lat $38^{\circ} 49^{\prime} 08^{\prime \prime}$, long $120^{\circ} 21^{\prime} 51^{\prime \prime}$, in NW $\frac{1}{4} N W \frac{1}{4}$ sec.12, T.11 N., R.14 E., on right bank $300 \mathrm{ft}$ upstream from Peavine Creek, 0.4 mile downstream from Ice

House Dam, and 4.8 miles northwest of town of Kyburz.

Drainage area. $--27.5 \mathrm{sq} \mathrm{ml}$.

Gage-height record.--Water-stage recorder graph. Altitude of gage is $5,290 \mathrm{ft}$ (from topographic map).

Discharge record.--Stage-discharge relation defined by current-meter measurements.

Maxima.--January-February 1963: Discharge, 54 cfs Feb. 1 (gage height, 3.15 ft). I924 to December 1962: Discharge, 3,940 cf's Dec. 23, 1955 (gage height,

$6.71 \mathrm{ft}$, site and datum then in use).

Remarks.--Flow regulated by Ice House Reservoir (see station 11-4411) since December 1959.

Mean discharge, in cublc feet per second, 1963

\begin{tabular}{|c|c|c|c|c|c|c|c|c|}
\hline Day & January & February & Day & January & February & Day & January & February \\
\hline $\begin{array}{c}\ldots \ldots \\
2 \ldots \ldots \\
3 \ldots \ldots \\
4 \ldots \ldots \\
5 \ldots \ldots \\
6 \ldots \ldots \\
8 \ldots \ldots \\
9 \ldots \ldots \\
10 \ldots \ldots\end{array}$ & $\begin{array}{l}4.6 \\
4.6 \\
4.6 \\
4.6 \\
4.6 \\
4.6 \\
4.6 \\
4.6 \\
4.6 \\
4.6\end{array}$ & $\begin{array}{l}20 \\
11 \\
10 \\
11 \\
11 \\
11 \\
11 \\
11 \\
11 \\
11\end{array}$ & $\begin{array}{l}11 \ldots \ldots \\
12 \ldots \ldots \\
13 \ldots \ldots \\
14 \ldots \ldots \\
15 \ldots \ldots \\
16 \ldots \ldots \\
17 \ldots \ldots \\
18 \ldots \ldots \\
19 \ldots \ldots \\
20 \ldots \ldots\end{array}$ & $\begin{array}{l}4.6 \\
4.6 \\
4.6 \\
4.6 \\
4.9 \\
4.9 \\
4.9 \\
4.9 \\
4.9 \\
4.9\end{array}$ & $\begin{array}{l}11 \\
11 \\
12 \\
11 \\
11 \\
10 \\
10 \\
10 \\
10 \\
10\end{array}$ & $\begin{array}{l}21 \ldots \ldots \\
22 \ldots \ldots \\
23 \ldots \ldots \\
24 \ldots \ldots \\
25 \ldots \ldots \\
26 \ldots \ldots \\
27 \ldots \ldots \\
28 \ldots \ldots \\
29 \ldots \ldots \\
30 \ldots \ldots \\
31 \ldots \ldots\end{array}$ & $\begin{array}{l}4.9 \\
4.9 \\
4.9 \\
4.9 \\
5.8 \\
8.0 \\
8.0 \\
8.0 \\
8.3 \\
12 \\
18\end{array}$ & $\begin{array}{r}10 \\
10 \\
10 \\
10 \\
10 \\
10 \\
9.3 \\
7.4 \\
-\ldots--. \\
-\ldots-.--\end{array}$ \\
\hline $\begin{array}{l}\text { Monthly } \\
\text { Runoff, }\end{array}$ & $\begin{array}{l}\text { n disc } \\
\text { acre- }\end{array}$ &, & fo & & & & $\begin{array}{r}5.85 \\
360\end{array}$ & $\begin{array}{r}10.7 \\
596\end{array}$ \\
\hline
\end{tabular}

11-4419. Silver Creek below Camino diversion dam, Calif.

Location.--Lat $38^{\circ} 49^{\prime} 26^{\prime \prime}$, long $120^{\circ} 32^{\prime} 18^{\prime \prime}$, on line between secs.4 and 5, T.1. N. , R.I3 E., on right bank $300 \mathrm{ft}$ downstream from Round Tent Canyon, 0.4 mile downstream from diversion dam, and 5 miles northeast of Pollock Pines.

Drainage area.--171 sq mi.

Gage-helght record.--Digital recorder tape punched at 15-minute intervals. Datum of gage is 2,754.06 ft above mean sea level (Bechtel Engineering Co. bench mark).

Discharge reocrd.--Stage-discharge relation defined by current-meter measurements below 1,300 cf's and by slope-area measurement at 19,300 cfs.

Maxima.--January-February 1963: Discharge, 19,300 cfs 1900 hours Jan. 31. (gage helght, $11.28 \mathrm{ft}$, from recorder tape; $11.9 \mathrm{ft}$, from high-water profile). 1960 to December 1962: Discharge, 2,740 cfs Apr. 15, 1962 (gage height, $7.05 \mathrm{ft}$.

Remarks.--Flow regulated by several. storage reservoirs (combined capacity 320,050 acre-ft), diversions and powerplants.

Mean discharge, in cublc feet per second, 1963

\begin{tabular}{|c|c|c|c|c|c|c|c|c|}
\hline Day & $J$ anuary & February & Day & January & February & Day & January & February \\
\hline $\begin{array}{c}1 \ldots \ldots \\
2 \ldots \ldots \\
3 \ldots \ldots \\
4 \ldots \ldots \\
6 \ldots \ldots \\
7 \ldots \ldots \\
8 \ldots \ldots \\
10 \ldots \ldots \\
\end{array}$ & $\begin{array}{l}34 \\
33 \\
33 \\
33 \\
33 \\
32 \\
32 \\
32 \\
31 \\
30\end{array}$ & $\begin{array}{r}5,860 \\
1,710 \\
366 \\
730 \\
242 \\
222 \\
453 \\
240 \\
303 \\
93\end{array}$ & $\begin{array}{l}11 \ldots \ldots \\
12 \ldots \ldots \\
13 \ldots \ldots \\
14 \ldots \ldots \\
15 \ldots \ldots \\
16 \ldots \ldots \\
17 \ldots \ldots \\
18 \ldots \ldots \\
19 \ldots \ldots \\
20 \ldots \ldots\end{array}$ & $\begin{array}{l}30 \\
28 \\
28 \\
30 \\
33 \\
33 \\
33 \\
32 \\
32 \\
32\end{array}$ & $\begin{array}{r}85 \\
188 \\
263 \\
248 \\
241 \\
172 \\
89 \\
190 \\
239 \\
168\end{array}$ & $\begin{array}{l}21 \ldots \ldots \\
22 \ldots \ldots \\
23 \ldots \ldots \\
24 \ldots \ldots \\
25 \ldots \ldots \\
26 \ldots \ldots \\
27 \ldots \ldots \\
28 \ldots \ldots \\
29 \ldots \ldots \\
30 \ldots \ldots \\
31 \ldots \ldots\end{array}$ & $\begin{array}{r}34 \\
36 \\
36 \\
34 \\
34 \\
33 \\
33 \\
32 \\
32 \\
611 \\
3,200\end{array}$ & $\begin{array}{r}137 \\
67 \\
63 \\
61 \\
58 \\
85 \\
55 \\
117 \\
-\ldots---\end{array}$ \\
\hline $\begin{array}{l}\text { onthly } \\
\text { anoff, }\end{array}$ & di & , & eet & & & & $\begin{array}{r}153 \\
9,420\end{array}$ & $\begin{array}{r}455 \\
25,280 \\
\end{array}$ \\
\hline
\end{tabular}


Gage he1ght, in feet, and discharge, in cublc feet per second, at indicated time, 1963, of Silver Creek below Camino diversion dam, Calif.

\begin{tabular}{|c|c|c|c|c|c|c|c|c|c|c|c|}
\hline Date & Hour & $\begin{array}{c}\text { Gage } \\
\text { he1ght }\end{array}$ & $\begin{array}{c}\text { Dis- } \\
\text { charge }\end{array}$ & Date & Hour & $\begin{array}{c}\text { Gage } \\
\text { height }\end{array}$ & $\begin{array}{l}\text { D1s- } \\
\text { charge }\end{array}$ & Date & Hour & $\begin{array}{c}\text { Gage } \\
\text { he1ght }\end{array}$ & $\begin{array}{l}\text { Dis- } \\
\text { charge }\end{array}$ \\
\hline n. $\begin{array}{r}29 \\
30\end{array}$ & $\begin{array}{l}2400 \\
0200 \\
0400 \\
0600 \\
0800 \\
1000 \\
1200 \\
1400 \\
1600 \\
1800 \\
1900 \\
2000 \\
2200 \\
2400 \\
0200 \\
0400 \\
0600\end{array}$ & $\begin{array}{l}2.68 \\
2.71 \\
2.75 \\
2.83 \\
2.91 \\
2.99 \\
3.11 \\
3.30 \\
3.37 \\
5.78 \\
7.56 \\
6.95 \\
6.40 \\
6.13 \\
4.54 \\
4.55 \\
4.65\end{array}$ & $\begin{array}{r}35 \\
37 \\
40 \\
46 \\
52 \\
59 \\
71 \\
97 \\
109 \\
1,230 \\
3,640 \\
2,580 \\
1,850 \\
1,560 \\
\\
478 \\
482 \\
528\end{array}$ & Feb. 1 & $\begin{array}{l}0800 \\
1000 \\
1200 \\
1400 \\
1600 \\
1800 \\
1900 \\
2000 \\
2200 \\
2400 \\
0100 \\
0200 \\
0400 \\
0600 \\
0800 \\
1000 \\
1200 \\
1400\end{array}$ & $\begin{array}{r}5.20 \\
6.36 \\
6.71 \\
7.05 \\
7.19 \\
7.65 \\
11.28 \\
9.35 \\
9.73 \\
10.16 \\
10.17 \\
10.04 \\
9.97 \\
9.67 \\
9.25 \\
8.65 \\
8.12 \\
7.69\end{array}$ & $\begin{array}{r}820 \\
1,810 \\
2,230 \\
2,740 \\
2,960 \\
3,820 \\
19,300 \\
8,800 \\
10,400 \\
12,400 \\
12,500 \\
11,800 \\
11,500 \\
10,100 \\
8,400 \\
6,320 \\
4,850 \\
3,900\end{array}$ & Feb. 1 & $\begin{array}{l}1600 \\
1800 \\
2000 \\
2200 \\
2400 \\
\\
0200 \\
0400 \\
0600 \\
0800 \\
1000 \\
1200 \\
1400 \\
1600 \\
1800 \\
2000 \\
2200 \\
2400\end{array}$ & $\begin{array}{l}7.48 \\
7.19 \\
6.99 \\
6.85 \\
6.74 \\
\\
6.66 \\
6.61 \\
6.57 \\
6.53 \\
6.50 \\
6.03 \\
5.99 \\
5.95 \\
6.37 \\
6.33 \\
6.30 \\
4.50\end{array}$ & $\begin{array}{r}3,480 \\
2,960 \\
2,640 \\
2,430 \\
2,280 \\
2,170 \\
2,100 \\
2,050 \\
2,010 \\
1,970 \\
1,460 \\
1,420 \\
1,380 \\
1,820 \\
1,770 \\
1,740 \\
460\end{array}$ \\
\hline
\end{tabular}

11-4435. South Fork Amer1can River near Camino, Calif.

Location.--Lat $38^{\circ} 46^{\prime} 20^{\prime \prime}$, long $120^{\circ} 42^{\prime} 05^{\prime \prime}$, in SE $\frac{1}{4} N W^{\frac{1}{4}} \sec .25$, T.11 N., R.11 E., on right bank $400 \mathrm{ft}$ upstream from Iowa Canyon Creek, 1 .i miles downstream from intake of American River flume, and 2.8 miles northwest of Camino.

Drainage area. $-493 \mathrm{sq} \mathrm{mi}$.

Gage-height record.--Water-stage recorder graph. Altitude of gage is $1,630 \mathrm{ft}$ (from topographic mapl.

Discharge record.--Stage-discharge relation defined by current-meter measurements.

Maxima.--January-February 1963: Discharge, 37,200 cfs 0200 hours Feb. 1 (gage helght, $26.56 \mathrm{ft}$ in gage well; $29.2 \mathrm{ft}$, from outside gage).

1922 to December 1962: Discharge, 49,800 cfs Dec. 23, 1955 (gage helght, $32.6 \mathrm{ft}$, from floodmarks $)$, from rating curve extended above $24,000 \mathrm{cfs}$ on basis of computation of peak flow over dam.

Remarks.--Flow regulated by seven reservoirs (total usable capacity, 350,200 acre-ft) Diversion above station by American River flume Jan. 1-31. All discharge figures are the combined flow of South Fork American River and American River flume, although diversion is insignificant during floodflow.

Mean discharge, in cubic feet per second, 1963

\begin{tabular}{|c|c|c|c|c|c|c|c|c|}
\hline Day & January & Febmuary & Day & January & Febmuary & Day & January & February \\
\hline $\begin{array}{c}1 \ldots \ldots \\
2 \ldots \ldots \\
3 \ldots \ldots \\
4 \ldots \ldots \\
5 \ldots \ldots \\
6 \ldots \ldots \\
8 \ldots \ldots \\
9 \ldots \ldots \\
10 \ldots \ldots\end{array}$ & $\begin{array}{l}184 \\
169 \\
182 \\
184 \\
180 \\
157 \\
169 \\
161 \\
154 \\
149\end{array}$ & $\begin{array}{r}22,300 \\
6,850 \\
3,210 \\
2,920 \\
2,310 \\
1,730 \\
1,700 \\
1,410 \\
1,260 \\
1,040\end{array}$ & $\begin{array}{l}11 \ldots \ldots \\
12 \ldots \ldots \\
13 \ldots \ldots \\
14 \ldots \ldots \\
15 \ldots \ldots \\
16 \ldots \ldots \\
17 \ldots \ldots \\
18 \ldots \ldots \\
19 \ldots \ldots \\
20 \ldots \ldots\end{array}$ & $\begin{array}{r}146 \\
93 \\
90 \\
132 \\
159 \\
171 \\
158 \\
121 \\
138 \\
129\end{array}$ & $\begin{array}{r}820 \\
805 \\
1,210 \\
1,140 \\
979 \\
925 \\
687 \\
712 \\
786 \\
717\end{array}$ & $\begin{array}{l}21 \ldots \ldots \\
22 \ldots \ldots \\
23 \ldots \ldots \\
24 \ldots \ldots \\
25 \ldots \ldots \\
26 \ldots \ldots \\
27 \ldots \ldots \\
28 \ldots \ldots \\
29 \ldots \ldots \\
30 \ldots \ldots \\
31 \ldots \ldots\end{array}$ & $\begin{array}{r}135 \\
165 \\
179 \\
155 \\
153 \\
137 \\
134 \\
148 \\
121 \\
1,450 \\
13,300\end{array}$ & $\begin{array}{r}643 \\
537 \\
494 \\
482 \\
473 \\
473 \\
470 \\
454 \\
----- \\
-----\end{array}$ \\
\hline $\begin{array}{l}\text { nthly } \\
\text { unofe, }\end{array}$ & $\begin{array}{l}\text { n d1sc } \\
\text { acre-f }\end{array}$ & 1 & feA & & & & $\begin{array}{r}616 \\
37,890\end{array}$ & $\begin{array}{r}2,055 \\
114,100\end{array}$ \\
\hline
\end{tabular}


Gage he1ght, in feet, and discharge, in cub1c feet per second, at 1ndicated t1me, 1963, of South Fork American River and American River flume near Camino, Calif.

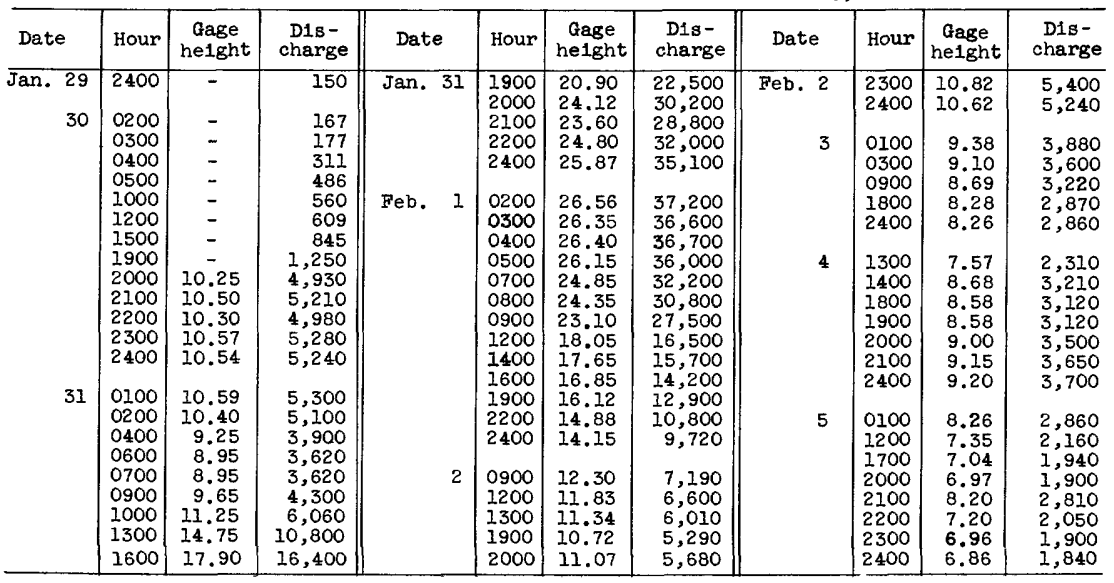

11-4455. South Fork American River near Lotus, Calif.

Location.--Lat $38^{\circ} 49^{\prime} 05^{\prime \prime}$, long $120^{\circ} 56^{\prime} 45^{\prime \prime}$, in SW $\frac{1}{4}$ sec.11, T.11 N., R.9 E., on left bank 0.4 mile downstream from Greenwood Creek, 2.4 miles northwest of Lotus, and 3.3 miles northwest of Coloma.

Drainage area.--673 sq $\mathrm{ml}$.

Gage-helght record.--Water-stage recorder graph. Altitude of gage is $635 \mathrm{ft}$ (from topographic mapi.

Discharge record.--Stage-discharge relation defined by current-meter measurements.

Maxima.--January-February 1963: Discharge, 60,400 cfs 0600 hours Feb. 1 (gage helght, $19.85 \mathrm{ft}$ ).

1862 to December 1962: Discharge, $71,800 \mathrm{cfs}$ Dec. 23, 1955 (gage height, $21.37 \mathrm{ft}^{\mathrm{t}}$ ).

Eemarks.--Flow partly regulated by seven reservoirs (total usable capacity, 350,200 acre-ft).

Mean d1scharge, in cublc feet per second, 1963

\begin{tabular}{|c|c|c|c|c|c|c|c|c|}
\hline Day & January & Febmuary & Day & January & February & Day & January & February \\
\hline $\begin{array}{c}1 \ldots \ldots \\
2 \ldots \ldots \\
3 \ldots \ldots \\
4 \ldots \ldots \\
5 \ldots \ldots \\
6 \ldots \ldots \\
7 \ldots \ldots \\
8 \ldots \ldots \\
9 \ldots \ldots \\
10 \ldots \ldots\end{array}$ & $\begin{array}{l}233 \\
245 \\
242 \\
242 \\
242 \\
221 \\
233 \\
230 \\
209 \\
206\end{array}$ & $\begin{array}{r}39,400 \\
8,790 \\
4,260 \\
3,210 \\
2,920 \\
2,080 \\
1,930 \\
1,720 \\
1,500 \\
1,380\end{array}$ & $\begin{array}{l}11 \ldots \ldots \\
12 \ldots \ldots \\
13 \ldots \ldots \\
14 \ldots \ldots \\
15 \ldots \ldots \\
16 \ldots \ldots \\
17 \ldots \ldots \\
18 \ldots \ldots \\
19 \ldots \ldots \\
20 \ldots \ldots\end{array}$ & $\begin{array}{l}203 \\
182 \\
145 \\
165 \\
200 \\
212 \\
215 \\
198 \\
188 \\
190\end{array}$ & $\begin{array}{r}1,040 \\
948 \\
1,630 \\
1,630 \\
1,290 \\
1,190 \\
996 \\
858 \\
924 \\
916\end{array}$ & $\begin{array}{l}21 \ldots \ldots \\
22 \ldots \ldots \\
23 \ldots \ldots \\
24 \ldots \ldots \\
25 \ldots \ldots \\
26 \ldots \ldots \\
27 \ldots \ldots \\
28 \ldots \ldots \\
29 \ldots \ldots \\
30 \ldots \ldots \\
31 \ldots \ldots\end{array}$ & $\begin{array}{r}185 \\
203 \\
218 \\
221 \\
206 \\
198 \\
190 \\
188 \\
202 \\
838 \\
14,200 \\
\end{array}$ & $\begin{array}{r}830 \\
753 \\
648 \\
612 \\
612 \\
582 \\
612 \\
552 \\
----- \\
--.--\end{array}$ \\
\hline $\begin{array}{l}\text { nthly } \\
\text { inoffe, }\end{array}$ & $\begin{array}{l}\text { n dis } \\
\text { acre }\end{array}$ &, 1 & e & & & & $\begin{array}{r}679 \\
41,750\end{array}$ & $\begin{array}{r}2,993 \\
166,200\end{array}$ \\
\hline
\end{tabular}


Gage helght, in feet, and discharge, in cubic feet per second, at indicated time, 1963 , of South Fork American River near Lotus, Calif.

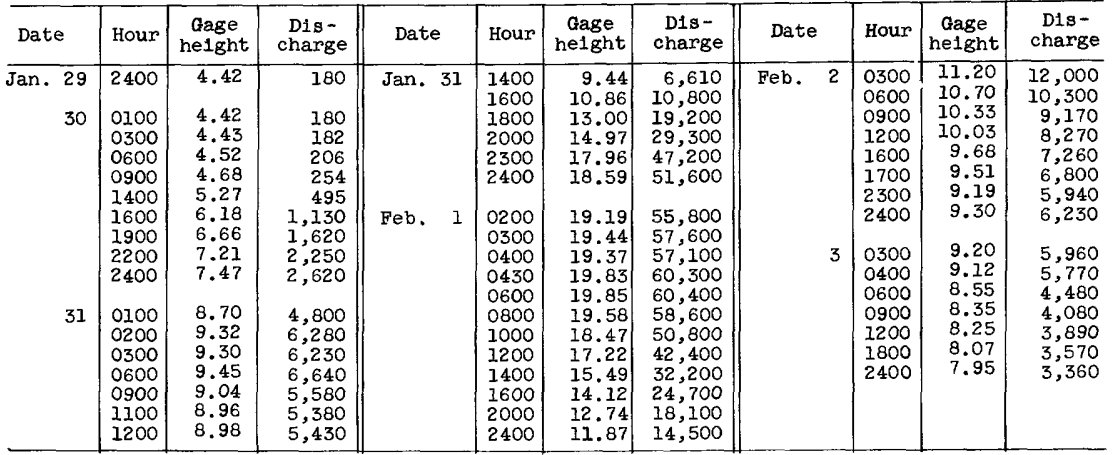

11-4462. Folsom Lake near Folsom, Calif.

Location.--Lat $38^{\circ} 42^{\prime} 29^{\prime \prime}$, long $121^{\circ} 09^{\prime} 22^{\prime \prime}$, in NW $\frac{1}{4} \mathrm{NE} \frac{1}{4}$ sec. 24, T.10 N., R.7 E., $0.7 \mathrm{mile}$ downstream from South Fork American River and 2.3 miles northeast of Folsom.

Drainage area.--1,863 $\mathrm{sq} \mathrm{mi}$.

Gage-height record.--Water-stage recorder graph. Datum of gage is at mean sea level (levels by Bureau of Reclamation).

Maxima.--January-February 1963: Computed bihourly inflow, 240,000 cfs 2400 hours Jan. 31 to 0200 hours Feb. 1 . Contents, 835,700 acre-ft 1600 hours Feb. I (elevation, $450.10 \mathrm{ft}$ ).

1955 to December 1962: Contents, 1,020,500 acre-ft June 3, 1960 (elevation, $466.89 \mathrm{ft}$ ).

Remarks.--Reservoir is formed by concrete gravity-type dam with rolled-earth wing dams, and dikes, completed May 14, 1956. Spillway gates installed July 31, 1955; control valves installed July 23, 1956. Capacity, 1,010,300 acre-ft between elevations $205.5 \mathrm{ft}$ (invert of lower tier of river outlets) and

$466.0 \mathrm{ft}$ (gross pool elevation) above mean sea level, all of which is avallable for release. Spillway design flood pool elevation is $475.4 \mathrm{ft}$ (capacity, $1,120,200$ acre-ft). Folsom Iake is one of the storage units in the central valley project. Records furnished by Bureau of Reclamation.

Elevation, in feet, and contents, in acre-feet, at 2400 hours, 1963

\begin{tabular}{|c|c|c|c|c|c|c|c|c|c|}
\hline \multirow{2}{*}{ Day } & \multicolumn{2}{|c|}{ January } & \multicolumn{2}{|c|}{ February } & \multirow{2}{*}{ Day } & \multicolumn{2}{|c|}{ January } & \multicolumn{2}{|c|}{ February } \\
\hline & Elevation & Contents & Elevation & Contents & & Elevation & Contents & Elevation & Contents \\
\hline $\begin{array}{r}7 \\
2 \\
3 \\
4 \\
5 \\
6 \\
7 \\
8 \\
9 \\
10 \\
11 \\
12 \\
13 \\
14 \\
15\end{array}$ & $\begin{array}{l}413.12 \\
412.85 \\
412.61 \\
412.33 \\
412.03 \\
411.72 \\
411.40 \\
411.06 \\
410.73 \\
410.38 \\
410.02 \\
409.68 \\
409.30 \\
408.93 \\
408.65\end{array}$ & $\begin{array}{l}491,400 \\
489,200 \\
487,300 \\
485,100 \\
482,700 \\
480,300 \\
477,800 \\
475,100 \\
472,500 \\
469,800 \\
467,000 \\
464,400 \\
461,400 \\
458,600 \\
456,400\end{array}$ & $\begin{array}{l}448.03 \\
439.78 \\
435.18 \\
429.30 \\
424.31 \\
423.71 \\
423.71 \\
423.48 \\
423.14 \\
422.66 \\
422.35 \\
422.25 \\
423.02 \\
423.72 \\
424.34\end{array}$ & $\begin{array}{l}814,100 \\
730,700 \\
686,000 \\
630,800 \\
585,800 \\
580,500 \\
580,500 \\
578,400 \\
575,400 \\
571,200 \\
568,500 \\
567,700 \\
574,400 \\
580,500 \\
586,000\end{array}$ & $\begin{array}{l}16 \\
17 \\
18 \\
19 \\
20 \\
21 \\
22 \\
23 \\
24 \\
25 \\
26 \\
27 \\
28 \\
29 \\
30 \\
31\end{array}$ & $\begin{array}{l}408.38 \\
408.15 \\
407.93 \\
407.85 \\
407.75 \\
407.65 \\
407.60 \\
407.52 \\
407.44 \\
407.33 \\
407.24 \\
407.12 \\
407.02 \\
406.94 \\
407.85 \\
427.25\end{array}$ & $\begin{array}{l}454,400 \\
452,600 \\
451,000 \\
450,400 \\
449,600 \\
448,800 \\
448,500 \\
447,900 \\
447,300 \\
446,400 \\
445,700 \\
444,800 \\
444,100 \\
443,500 \\
450,400 \\
612,100\end{array}$ & $\begin{array}{c}425.00 \\
425.60 \\
426.12 \\
426.57 \\
427.05 \\
427.49 \\
427.80 \\
426.06 \\
428.26 \\
428.45 \\
428.59 \\
428.70 \\
428.81 \\
- \\
- \\
-\end{array}$ & $\begin{array}{c}591,900 \\
597,300 \\
601,900 \\
606,000 \\
610,300 \\
614,300 \\
617,100 \\
619,500 \\
621,300 \\
623,000 \\
624,300 \\
625,300 \\
626,300 \\
- \\
-\end{array}$ \\
\hline \multicolumn{6}{|c|}{ Change in contents, in acre-feet.............. } & - & $+118,200$ & - & $+14,200$ \\
\hline
\end{tabular}


Average inflow, in cubic feet per second, for bihourly periods ending at indicated time, 1963, of Folsom Lake near Folsom, Calif.

\begin{tabular}{|c|c|c|c|c|c|c|c|c|}
\hline Date & Hour & Inflow & Date & Hour & Inflow & Date & Hour & Inflow \\
\hline Jan. 30 & $\begin{array}{l}0200 \\
0400 \\
0600 \\
0800 \\
1000 \\
1200 \\
1400 \\
1600 \\
1800 \\
2000 \\
2200 \\
2400\end{array}$ & $\begin{array}{r}931 \\
1,840 \\
1,400 \\
1,400 \\
1,780 \\
2,780 \\
1,400 \\
3,680 \\
7,030 \\
8,480 \\
10,100 \\
18,300\end{array}$ & Feb, 1 & $\begin{array}{l}200 \\
0400 \\
0600 \\
0800 \\
1000 \\
1200 \\
1400 \\
1600 \\
1800 \\
2000 \\
2200 \\
2400\end{array}$ & $\begin{array}{r}240,000 \\
234,000 \\
233,000 \\
228,000 \\
189,000 \\
165,000 \\
136,000 \\
108,000 \\
90,800 \\
77,300 \\
69,100 \\
66,700\end{array}$ & Feb. 3 & $\begin{array}{l}0200 \\
0400 \\
0600 \\
0800 \\
1000 \\
1200 \\
1400 \\
1600 \\
1800 \\
2000 \\
2200 \\
2400\end{array}$ & $\begin{array}{l}20,400 \\
21,600 \\
19,900 \\
20,400 \\
18,800 \\
17,200 \\
17,300 \\
16,100 \\
16,800 \\
15,700 \\
14,200 \\
13,200\end{array}$ \\
\hline 31 & $\begin{array}{l}0200 \\
0400 \\
0600 \\
0800 \\
1000 \\
1200 \\
1400 \\
1600 \\
1800 \\
2000 \\
2200 \\
2400\end{array}$ & $\begin{array}{r}27,700 \\
37,500 \\
41,600 \\
34,000 \\
41,600 \\
42,600 \\
49,800 \\
71,700 \\
113,000 \\
152,000 \\
188,000 \\
207,000\end{array}$ & 2 & $\begin{array}{l}0200 \\
0400 \\
0600 \\
0800 \\
1000 \\
1200 \\
1400 \\
1600 \\
1800 \\
2000 \\
2200 \\
2400\end{array}$ & $\begin{array}{l}61,300 \\
49,500 \\
42,500 \\
31,200 \\
39,800 \\
36,400 \\
33,100 \\
33,100 \\
28,900 \\
29,900 \\
26,800 \\
24,400\end{array}$ & 4 & $\begin{array}{l}0200 \\
0400 \\
0600 \\
0800 \\
1000 \\
1200 \\
1400 \\
1600 \\
1800 \\
2000 \\
2200 \\
2400\end{array}$ & $\begin{array}{r}13,900 \\
15,800 \\
14,100 \\
13,100 \\
12,600 \\
10,500 \\
13,600 \\
9,730 \\
10,400 \\
13,300 \\
12,300 \\
14,200\end{array}$ \\
\hline
\end{tabular}

11-4465. American River at Fair Oaks, Calif.

Location.--Lat $38^{\circ} 38^{\prime} 08^{\prime \prime}$, long $121^{\circ} 13^{\prime} 36^{\prime \prime}$, in SE $\frac{1}{4} \mathrm{NE} \frac{1}{4}$ sec.17, T.9 N., R.7 E., on right bank $2,100 \mathrm{ft}$ downs tream from Nimbus Dam, 2.4 miles east of Fair Oaks, 8.1 miles downstream from South Fork, and at mile 19.3.

Drainage area.--1,889 sq $\mathrm{ml}$.

Gage-height record.--Water-stage recorder graph. Datum of gage is $77.53 \mathrm{ft}$ above mean sea level.

Discharge record.--Stage-discharge relation defined by current-meter measurements .

Maxima.--January-February 1963: Discharge, 101,000 cfs 0600 hours Feb. 2 (gage helght, $21.44 \mathrm{ft}$ ).

1904-52 (prior to regulation by Folsom Lake): Discharge, 180,000 cfs Nov. 21, 1950 (gage helght, $31.85 \mathrm{ft}$, site and datum then in use).

1953 to December 1962: Discharge, 71,500 cfs (fully regulated) Dec. 24, 1955 (gage helght, $20.35 \mathrm{ft}$, site and datum then in use).

Remarks.--Floodflow regulated by Folsom Lake since Feb. 25, 1955 (see station $11-4462)$.

Mean discharge, in cubic feet per second, 1963

\begin{tabular}{|c|c|c|c|c|c|c|c|c|}
\hline Day & January & February & Day & January & February & Day & January & Febmuary \\
\hline $\begin{array}{c}1 \ldots \ldots \\
2 \ldots \ldots \\
3 \ldots \ldots \\
4 \ldots \ldots \\
5 \ldots \ldots \\
6 \ldots \ldots \\
8 \ldots \ldots \\
9 \ldots \ldots \\
10 \ldots \ldots\end{array}$ & $\begin{array}{l}2,520 \\
2,570 \\
2,520 \\
2,560 \\
2,520 \\
2,460 \\
2,420 \\
2,450 \\
2,450 \\
2,450\end{array}$ & $\begin{array}{r}42,400 \\
74,100 \\
40,400 \\
39,900 \\
33,700 \\
12,200 \\
7,790 \\
7,540 \\
7,600 \\
7,480\end{array}$ & $\begin{array}{l}11 \ldots \ldots \\
12 \ldots \ldots \\
13 \ldots \ldots \\
14 \ldots \ldots \\
15 \ldots \ldots \\
16 \ldots \ldots \\
17 \ldots \ldots \\
18 \ldots \ldots \\
19 \ldots \ldots \\
20 \ldots \ldots\end{array}$ & $\begin{array}{l}2,510 \\
2,500 \\
2,480 \\
2,450 \\
2,240 \\
2,070 \\
1,770 \\
1,560 \\
1,340 \\
1,390\end{array}$ & $\begin{array}{l}5,880 \\
5,410 \\
5,350 \\
4,510 \\
3,530 \\
2,310 \\
2,080 \\
1,690 \\
1,970 \\
2,000\end{array}$ & $\begin{array}{l}21 \ldots \ldots \\
22 \ldots \ldots \\
23 \ldots \ldots \\
24 \ldots \ldots \\
25 \ldots \ldots \\
26 \ldots \ldots \\
27 \ldots \ldots \\
28 \ldots \ldots \\
29 \ldots \ldots \\
30 \ldots \ldots \\
31 \ldots \ldots\end{array}$ & $\begin{array}{l}1,400 \\
1,480 \\
1,410 \\
1,430 \\
1,420 \\
1,420 \\
1,430 \\
1,440 \\
1,410 \\
1,400 \\
2,830\end{array}$ & $\begin{array}{r}1,980 \\
2,050 \\
2,050 \\
2,050 \\
2,040 \\
2,050 \\
2,040 \\
1,980 \\
----- \\
---.--\end{array}$ \\
\hline $\begin{array}{l}\text { nth } \\
\text { inoff }\end{array}$ & & & & & & & $\begin{array}{r}2,010 \\
123,600\end{array}$ & $\begin{array}{r}11,570 \\
642,800\end{array}$ \\
\hline
\end{tabular}

Gage height, in feet, and discharge, in cublc feet per second, at indicated time, 1963

\begin{tabular}{|c|c|c|c|c|c|c|c|c|c|c|c|}
\hline Date & Hour & $\begin{array}{c}\text { Gage } \\
\text { height }\end{array}$ & $\begin{array}{c}\text { D1s- } \\
\text { charge }\end{array}$ & Date & Hour & $\begin{array}{c}\text { Gage } \\
\text { height }\end{array}$ & $\begin{array}{c}\text { Dis- } \\
\text { charge }\end{array}$ & Date & Hour & $\begin{array}{c}\text { Gage } \\
\text { helght }\end{array}$ & $\begin{array}{l}\text { Dis- } \\
\text { charge }\end{array}$ \\
\hline $\begin{array}{l}\text { Jan. } 31 \\
\text { Feb. } 1\end{array}$ & $\begin{array}{l}2400 \\
0200 \\
0300 \\
0800 \\
1000 \\
1100 \\
1200 \\
1300\end{array}$ & $\begin{array}{r}4.98 \\
4.98 \\
5.18 \\
5.11 \\
6.18 \\
8.52 \\
11.15 \\
12.49\end{array}$ & $\begin{array}{r}7,710 \\
7,710 \\
8,340 \\
8,150 \\
11,000 \\
19,300 \\
31,000 \\
37,600\end{array}$ & Feb. 1 & $\begin{array}{l}1500 \\
1700 \\
2000 \\
2100 \\
2400 \\
\\
0300 \\
0600 \\
0800\end{array}$ & $\begin{array}{l}15.17 \\
18.90 \\
20.52 \\
20.32 \\
20.57 \\
20.50 \\
21.44 \\
20.05\end{array}$ & $\begin{array}{r}53,400 \\
80,700 \\
93,700 \\
92,100 \\
94,100 \\
93,500 \\
101,000 \\
89,900\end{array}$ & Feb. 2 & $\begin{array}{l}1000 \\
1400 \\
1600 \\
1700 \\
2000 \\
2100 \\
2200 \\
2400\end{array}$ & $\begin{array}{l}17.96 \\
16.66 \\
16.32 \\
15.22 \\
14.95 \\
13.97 \\
13.80 \\
13.76\end{array}$ & $\begin{array}{l}75,200 \\
66,800 \\
64,600 \\
57,800 \\
56,200 \\
50,300 \\
49,300 \\
49,100\end{array}$ \\
\hline
\end{tabular}


11-4473. Dry Creek tributary near Roseville, Calif.

\section{(Crest-stage station)}

Location.--Lat $38^{\circ} 43^{\prime} 44^{\prime \prime}$, long $121^{\circ} 21^{\prime} 08^{\prime \prime}$, in NW $\mathrm{NWW}^{\frac{1}{4}} \sec .17$, T.10 N., R.6 E., 3.7 miles southwest of Roseville.

Drainage area. $-0.39 \mathrm{sq} \mathrm{mi}$.

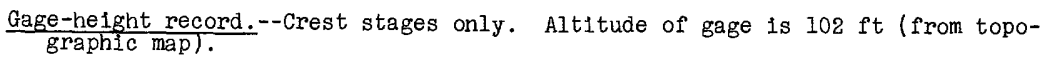

Discharge record.--Stage-discharge relation defined by current-meter measurements below 32 cf's and by computation of flow through culvert at 71 and 220 cfs (including flow over road).

Maxima.--January-February 1963: Discharge, $42 \mathrm{cfs}$ Feb. 1 (gage helght, $14.23 \mathrm{ft}$ ). 1959 to December 1962: Discharge, $220 \mathrm{cfs} \mathrm{Feb.} 9,1962$ (gage height,
$17.00 \mathrm{ft}$ ).

11-4475. Sacramento River at Sacramento, Calif.

Location.--Lat $38^{\circ} 35^{\prime} 20^{\prime \prime}$, long $121^{\circ} 30^{\prime} 15^{\prime \prime}$, on left bank $1,000 \mathrm{ft}$ upstream from I Street Bridge, in clty of Sacramento, and 0.5 mile downstream from American River.

Gage-helght record.-Water-stage recorder graph. Auxlliary water-stage recorder 10.8 miles downstream. Datum of gage is at mean sea level.

Discharge record.--Stage-discharge relation defined by current-meter measurements .

Maxima.--January-February 1963: Discharge, 98,100 cfs 2130 hours Feb. 1 (gage height, $28.52 \mathrm{ft}$ ).

1909 to December 1962: Discharge, 104,000 cfs Nov. 21, 1950 (gage height, $30.14 \mathrm{ft}$, site and datum then in use\}.

Remarks.--Flow affected by Shasta Lake (see station 11-3700), Folsom Lake (see station 11-4462) and several other reservoirs, and by bypassing for flood control. When discharge at Verona exceeds about $55,000 \mathrm{cfs}$, flow begins over Fremont weir (26 miles upstream) into Yolo bypass (see station 11-4530). When stage at Sacramento reaches $27.5 \mathrm{ft}$, gates are opened in Sacramento weir 4 miles upstream (see station $11-4260$ ) to reduce discharge at Sacramento.

Mean discharge, in cublc feet per second, 1963

\begin{tabular}{|c|c|c|c|c|c|c|c|c|}
\hline Day & January & February & Day & January & February & Day & January & February \\
\hline $\begin{array}{r}1 \ldots \ldots \\
2 \ldots \ldots \\
3, \ldots \ldots \\
4 \ldots \ldots \\
5 \ldots \ldots \\
6 \ldots \ldots \\
7 \ldots \ldots \\
9 \ldots \ldots \\
10 \ldots \ldots\end{array}$ & $\begin{array}{l}24,400 \\
24,100 \\
23,800 \\
23,300 \\
23,100 \\
22,800 \\
22,400 \\
21,800 \\
21,600 \\
21,200\end{array}$ & $\begin{array}{l}71,100 \\
94,400 \\
81,800 \\
78,800 \\
76,400 \\
68,600 \\
63,800 \\
62,100 \\
60,500 \\
59,100\end{array}$ & 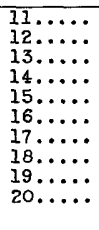 & $\begin{array}{l}20,900 \\
20,600 \\
19,700 \\
18,300 \\
18,200 \\
17,900 \\
17,300 \\
16,700 \\
16,400 \\
15,900\end{array}$ & $\begin{array}{l}57,200 \\
56,200 \\
57,800 \\
59,900 \\
59,200 \\
57,100 \\
55,300 \\
53,400 \\
51,500 \\
49,100\end{array}$ & $\begin{array}{l}21 \ldots \ldots \\
22 \ldots \ldots \\
23 \ldots \ldots \\
24 \ldots \ldots \\
25 \ldots \\
26 \ldots \ldots \\
27 \ldots \ldots \\
28, \ldots \ldots \\
29 . \ldots \\
30 \ldots \\
31 \ldots \ldots\end{array}$ & $\begin{array}{l}15,700 \\
15,400 \\
15,500 \\
15,100 \\
14,900 \\
15,000 \\
14,600 \\
14,400 \\
14,700 \\
19,000 \\
33,200\end{array}$ & $\begin{array}{r}46,300 \\
43,000 \\
39,200 \\
36,100 \\
35,100 \\
33,800 \\
32,300 \\
31,400 \\
- \\
---1-\end{array}$ \\
\hline onthly & 2 & .... & & & & & $\begin{array}{r}19,290 \\
1,186,000\end{array}$ & $\begin{array}{r}56,090 \\
3,115,000\end{array}$ \\
\hline
\end{tabular}

Gage height, in feet, and discharge, in cublc feet per second, at indicated time, 1963

\begin{tabular}{|c|c|c|c|c|c|c|c|c|c|c|c|c|}
\hline Date & Hour & $\begin{array}{c}\text { Gage } \\
\text { he1ght }\end{array}$ & $\begin{array}{l}\text { Dis- } \\
\text { charge }\end{array}$ & Date & & Hour & $\begin{array}{c}\text { Gage } \\
\text { he1ght }\end{array}$ & $\begin{array}{c}\text { D1s- } \\
\text { charge }\end{array}$ & Date & Hour & $\begin{array}{c}\text { Gage } \\
\text { helght }\end{array}$ & $\begin{array}{c}\text { D1s- } \\
\text { charge }\end{array}$ \\
\hline $\begin{array}{r}\text { Jan. } 30 \\
31\end{array}$ & $\begin{array}{l}2400 \\
0400 \\
0600 \\
0800 \\
1300 \\
1400 \\
1800 \\
2400 \\
\end{array}$ & $\begin{array}{r}7.25 \\
7.57 \\
7.82 \\
8.28 \\
11.06 \\
11.43 \\
13.28 \\
15.34 \\
\end{array}$ & $\begin{array}{l}23,100 \\
24,000 \\
24,800 \\
26,100 \\
34,300 \\
35,400 \\
40,900 \\
47,300 \\
\end{array}$ & Fei. & 1 & $\begin{array}{l}0600 \\
1200 \\
1830 \\
2130 \\
2400 \\
1000 \\
1200 \\
1800 \\
\end{array}$ & $\begin{array}{l}17.96 \\
21.49 \\
26.12 \\
28.52 \\
28.33 \\
28.43 \\
28.21 \\
27.14 \\
\end{array}$ & $\begin{array}{l}55,600 \\
67,200 \\
86,600 \\
98,100 \\
97,200 \\
97,700 \\
96,600 \\
91,200 \\
\end{array}$ & $\begin{array}{r}\text { Feb. } 2 \\
3\end{array}$ & $\begin{array}{l}2400 \\
0600 \\
0900 \\
1200 \\
1800 \\
2400\end{array}$ & $\begin{array}{l}26.14 \\
25.43 \\
25.06 \\
24.89 \\
24.73 \\
24.66\end{array}$ & $\begin{array}{l}86,600 \\
82,900 \\
81,700 \\
80,900 \\
80,200 \\
79,900\end{array}$ \\
\hline
\end{tabular}


11-4485. Adobe Creek near Kelseyville, Calif.

Location.--Lat $38^{\circ} 55^{\prime} 40^{\prime \prime}$, long $122^{\circ} 52^{\prime} 45^{\prime \prime}$, in $\mathrm{SE} \frac{1}{4}$ sec.5, T.12 N., R.9 W., on left bank 2.5 miles upstream from Highland Creek and 4.2 miles south of Keiseyville.

Drainage area. $--6.39 \mathrm{sq} \mathrm{mi}$.

Gage-height record.--Water-stage recorder graph. Datum of gage is $1,478.1 \mathrm{ft}$ above mean sea Ievel (levels by topographic division).

Discharge record.--Stage-discharge relation defined by current-meter measurements below $410 \mathrm{cfs}$ and by computation flow over dam at 1,250 cfs.

Maxima.--January-February 1963: Discharge, 1,450 cfs 1400 hours Jan. 31 (gage height, $9.22 \mathrm{ft}$ ).

1954 to December 1962: Discharge, 1,430 cfs 0ct. 12, 1962 (gage height,

Mean discharge, In cub1c feet per second, 1963

\begin{tabular}{|c|c|c|c|c|c|c|c|c|}
\hline Day & January & February & Day & January & February & Day & January & February \\
\hline $\begin{array}{c}1 \ldots \ldots \\
2 \ldots \ldots \\
3 \ldots \ldots \\
4 \ldots \ldots \\
5 \ldots \ldots \\
6 \ldots \ldots \\
7 \ldots \ldots \\
8 \ldots \ldots \\
10 \ldots \ldots\end{array}$ & $\begin{array}{l}3.1 \\
2.9 \\
2.9 \\
2.6 \\
2.1 \\
1.9 \\
1.9 \\
1.9 \\
1.6 \\
1.6\end{array}$ & $\begin{array}{r}246 \\
80 \\
48 \\
33 \\
25 \\
19 \\
15 \\
21 \\
39 \\
42\end{array}$ & 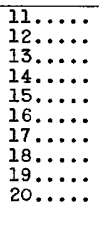 & $\begin{array}{l}1.4 \\
1.2 \\
1.2 \\
1.4 \\
1.4 \\
1.4 \\
1.4 \\
1.2 \\
1.2 \\
1.1\end{array}$ & $\begin{array}{l}31 \\
75 \\
62 \\
36 \\
26 \\
20 \\
16 \\
14 \\
12 \\
10\end{array}$ & $\begin{array}{l}21 \ldots \ldots \\
22 \ldots \ldots \\
23, \ldots \ldots \\
24 \ldots \ldots \\
25, \ldots \ldots \\
26 \ldots \ldots \\
27 \ldots \ldots \\
28 \ldots \ldots \\
30 \ldots \ldots \\
31 \ldots \ldots\end{array}$ & $\begin{array}{r}1.2 \\
1.2 \\
1.2 \\
1.2 \\
1.1 \\
1.1 \\
1.1 \\
1.1 \\
4.1 \\
294 \\
725\end{array}$ & 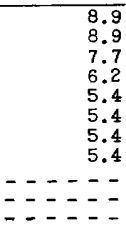 \\
\hline & & & & & & & $\begin{array}{r}34.4 \\
6.21 \\
2,120 \\
\end{array}$ & $\begin{array}{r}33.0 \\
5.37 \\
1,830 \\
\end{array}$ \\
\hline
\end{tabular}

Gage helght, In feet, and discharge, In cublc feet per second, at indicated time, 1963

\begin{tabular}{|c|c|c|c|c|c|c|c|c|c|c|c|}
\hline Date & Hour & $\begin{array}{c}\text { Gage } \\
\text { helght }\end{array}$ & $\begin{array}{c}\text { Dls- } \\
\text { charge }\end{array}$ & Date & Hour & $\begin{array}{c}\text { Gage } \\
\text { helght }\end{array}$ & $\begin{array}{c}\text { Dis- } \\
\text { charge }\end{array}$ & Date & Hour & $\begin{array}{c}\text { Gage } \\
\text { helght }\end{array}$ & $\begin{array}{c}\text { D1s- } \\
\text { charge }\end{array}$ \\
\hline $\begin{array}{r}\operatorname{Jan} .28 \\
29\end{array}$ & $\begin{array}{l}2400 \\
1200 \\
1600 \\
2000 \\
2200 \\
2400\end{array}$ & $\begin{array}{l}4.04 \\
4.04 \\
4.12 \\
4.25 \\
4.27 \\
4.52\end{array}$ & $\begin{array}{r}1.1 \\
1.1 \\
2.9 \\
7.7 \\
8.9 \\
31\end{array}$ & Jan. 30 & $\begin{array}{l}1000 \\
1100 \\
1300 \\
1500 \\
1700 \\
1900 \\
2000 \\
2400\end{array}$ & $\begin{array}{l}5.52 \\
5.58 \\
6.63 \\
7.30 \\
6.56 \\
6.05 \\
6.05 \\
5.60\end{array}$ & $\begin{array}{l}199 \\
213 \\
509 \\
730 \\
488 \\
335 \\
335 \\
218\end{array}$ & $\operatorname{Jan} .31$ & $\begin{array}{l}1300 \\
1400 \\
1500 \\
1700 \\
1900 \\
2000 \\
2300 \\
2400\end{array}$ & $\begin{array}{l}8.42 \\
9.22 \\
8.95 \\
8.35 \\
7.55 \\
7.41 \\
6.69 \\
6.72\end{array}$ & $\begin{array}{r}1,130 \\
1,450 \\
1,340 \\
1,100 \\
818 \\
769 \\
527 \\
536\end{array}$ \\
\hline 30 & $\begin{array}{l}0300 \\
0400 \\
0600 \\
0700 \\
0800 \\
0900\end{array}$ & $\begin{array}{l}4.88 \\
5.48 \\
5.38 \\
5.47 \\
5.45 \\
5.53\end{array}$ & $\begin{array}{r}77 \\
190 \\
168 \\
187 \\
183 \\
201\end{array}$ & 31 & $\begin{array}{l}0300 \\
0400 \\
0700 \\
1000 \\
1200\end{array}$ & $\begin{array}{l}5.41 \\
5.42 \\
6.40 \\
8.04 \\
8.42\end{array}$ & $\begin{array}{r}174 \\
176 \\
440 \\
989 \\
1,130\end{array}$ & Feb. 1 & $\begin{array}{l}0200 \\
0600 \\
1200 \\
1400 \\
2400\end{array}$ & $\begin{array}{l}6.48 \\
5.93 \\
5.50 \\
5.45 \\
5.12\end{array}$ & $\begin{array}{l}464 \\
302 \\
194 \\
183 \\
117\end{array}$ \\
\hline
\end{tabular}

11-4489. Highland Creek above Highland Creek Dam, Calif.

Location.--Lat $38^{\circ} 55^{\prime} 45^{\prime \prime}$, long $122^{\circ} 55^{\prime} 10^{\prime \prime}$, in $\mathrm{NW}_{4}^{\frac{1}{4} \mathrm{SE}} \frac{1}{4} \sec .36, \mathrm{~T} .13 \mathrm{~N} ., \mathrm{R} .10 \mathrm{~W}$. , on left bank $100 \mathrm{ft}$ downstream from Pipeline Creek, 1.7 miles upstream from Highland Creek Dam, and 5.7 miles southwest of Kelseyvilie.

Drainage area.--11.9 sq $\mathrm{mi}$.

Gage-height record.--Water-stage recorder graph. Altitude of gage is $1,500 \mathrm{ft}$ (from topographic mapi.

Discharge record.--Stage-discharge relation defined by current-meter measurements .

Maxima.--January-February 1963: Discharge, 1,720 cfs 1300 hours Jan. 31 (gage he1ght, $9.60 \mathrm{ft}$ ).

October to December 1962: Discharge, 2,320 cfs Oct. 12, 1962 (gage he1ght, $10.98 \mathrm{ft})$. 
Mean discharge, in cubic feet per second, 1963, of Highland Creek above Highland Creek Dam,

\begin{tabular}{|c|c|c|c|c|c|c|c|c|}
\hline Day & January & February & Day & January & February & Day & January & February \\
\hline $\begin{array}{c}1 \ldots \ldots \\
2 \ldots \ldots \\
3 \ldots \ldots \\
4 \ldots \ldots \\
6 \ldots \ldots \\
7 \ldots \ldots \\
8 \ldots \ldots \\
10 \ldots \ldots\end{array}$ & $\begin{array}{l}5.3 \\
4.9 \\
4.4 \\
3.8 \\
3.5 \\
3.5 \\
3.2 \\
3.2 \\
3.2 \\
3.0\end{array}$ & $\begin{array}{r}358 \\
131 \\
83 \\
65 \\
51 \\
43 \\
37 \\
49 \\
96 \\
79\end{array}$ & $\begin{array}{l}11 \ldots \ldots \\
12 \ldots \ldots \\
13 \ldots \ldots \\
14 \ldots \ldots \\
15 \ldots \ldots \\
16 \ldots \ldots \\
17 \ldots \ldots \\
18 \ldots \ldots \\
19 \ldots \ldots \\
20 \ldots \ldots\end{array}$ & $\begin{array}{l}2.8 \\
2.8 \\
2.8 \\
2.8 \\
2.8 \\
2.8 \\
2.6 \\
2.6 \\
2.6 \\
2.6\end{array}$ & $\begin{array}{r}52 \\
104 \\
82 \\
55 \\
43 \\
36 \\
27 \\
22 \\
19 \\
16\end{array}$ & $\begin{array}{l}21 \ldots \ldots \\
22 \ldots \ldots \\
23 \ldots \ldots \\
24 \ldots \ldots \\
25 \ldots \ldots \\
26 \ldots \ldots \\
27 \ldots \ldots \\
28 \ldots \ldots \\
29 \ldots \ldots \\
30 \ldots \ldots \\
31 \ldots \ldots\end{array}$ & $\begin{array}{r}2.6 \\
2.6 \\
2.6 \\
2.6 \\
2.6 \\
2.5 \\
2.5 \\
2.5 \\
11 \\
426 \\
936 \\
\end{array}$ & $\begin{array}{r}14 \\
12 \\
11 \\
9.4 \\
8.4 \\
7.9 \\
7.6 \\
6.8 \\
--.-- \\
-.-1 \\
\end{array}$ \\
\hline \multicolumn{7}{|l|}{$\begin{array}{l}\text { Monthly } \\
\text { Runoff, } \\
\text { Runoff, }\end{array}$} & $\begin{array}{r}47.1 \\
4.56 \\
2,890 \\
\end{array}$ & $\begin{array}{r}54.5 \\
4.77 \\
3,020 \\
\end{array}$ \\
\hline
\end{tabular}

Gage he1ght, in feet, and discharge, in cub1c feet per second, at indicated time, 1963

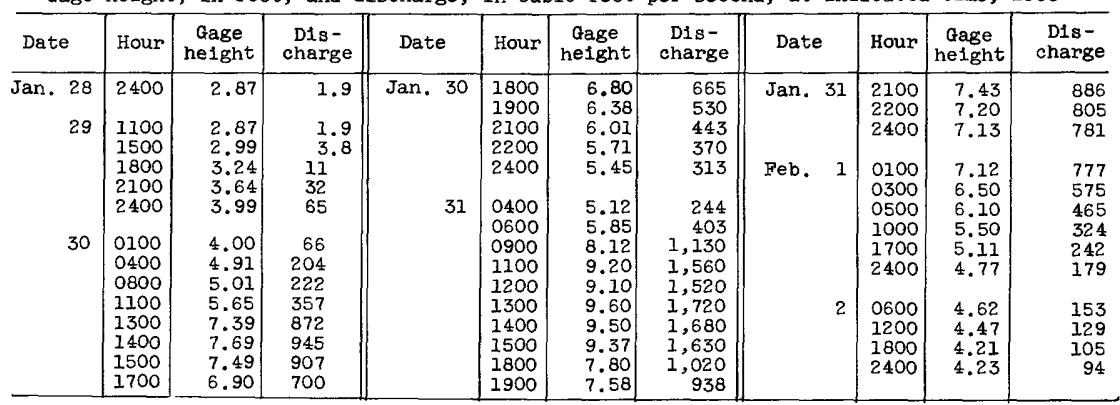

11-4490.6. Lyons Creek tributary near Lakeport, Calif.

(Crest-stage station)

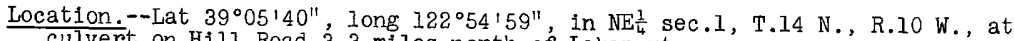
culvert on Hill Road 3.3 miles north of Lakeport.

Drainage area. $-0.16 \mathrm{sq} \mathrm{ml}$.

Gage-height record.--Crest stages only. Altitude of gage is 1,410 ft (from topographic map).

Discharge record.--Stage-discharge relation not defined. Maxima --January-February 1963: Discharge, not determined, occurred Jan. 31 (gage
he1ght, $12.08 \mathrm{ft}$ ).

September to December 1962: Discharge, $23 \mathrm{cfs}$ 0ct. 12, 1962 (gage height, $11.65 \mathrm{ft})$, by computation of flow through culvert. 
11-4491. Scotts Creek near Lakeport, Calif.

Location.--Iat $39^{\circ} 03^{\prime} 45^{\prime \prime}$, long $122^{\circ} 56^{\prime} 50^{\prime \prime}$, in SW $\frac{1}{4}$ sec.14, T.14 N., R.10 W., $100 \mathrm{ft}$ downstream from bridge on Hartley Cemetery Road and $0.8 \mathrm{mile}$ northwest of Lakeport.

Drainage area. $--52.3 \mathrm{sq} \mathrm{mi}$.

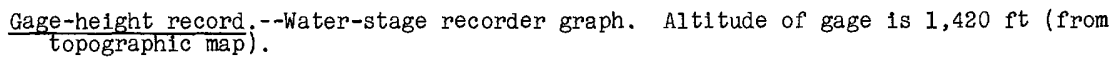

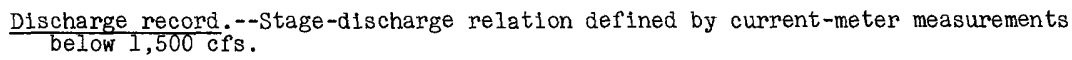

Maxima.--January-February 1963: Discharge, 6,500 cf's 1530 hours Jan. 31 (gage helght, $14.02 \mathrm{ft}$ ).

1960 to December 1962: Discharge, 3,910 cfs Feb. 14, 1962 (gage height, $10.98 \mathrm{ft})$.

Remarks. --Records furnished by Californla Department of Water Resources.

Mean discharge, in cubic feet per second, 1963

\begin{tabular}{|c|c|c|c|c|c|c|c|c|}
\hline Day & January & February & Day & January & February & Day & January & February \\
\hline $\begin{array}{c}1 \ldots \ldots \\
2 \ldots \ldots \\
3 \ldots \ldots \\
5 \ldots \ldots \\
6 \ldots \ldots \\
7 \ldots \ldots \\
9 \ldots \ldots \\
10 \ldots \ldots\end{array}$ & $\begin{array}{c}14 \\
13 \\
13 \\
12 \\
10 \\
9.9 \\
10 \\
9.6 \\
9.6 \\
9.1\end{array}$ & $\begin{array}{r}1,400 \\
446 \\
259 \\
171 \\
131 \\
105 \\
88 \\
96 \\
283 \\
406\end{array}$ & $\begin{array}{l}11 \ldots \ldots \\
12 \ldots \ldots \\
13 \ldots \ldots \\
14 \ldots \ldots \\
15 \ldots \ldots \\
16 \ldots \ldots \\
17 \ldots \ldots \\
18 \ldots \ldots \\
19 \ldots \ldots \\
20 \ldots \ldots\end{array}$ & $\begin{array}{l}8.3 \\
6.4 \\
6.9 \\
7.5 \\
7.0 \\
7.1 \\
6.7 \\
7.3 \\
6.1 \\
5.6\end{array}$ & $\begin{array}{r}252 \\
426 \\
490 \\
294 \\
187 \\
141 \\
110 \\
88 \\
75 \\
66\end{array}$ & $\begin{array}{l}21 \ldots \ldots \\
22 \ldots \ldots \\
23 \ldots \ldots \\
24 \ldots \ldots \\
25 \ldots \ldots \\
26 \ldots \ldots \\
27 \ldots \ldots \\
28 \ldots \ldots \\
29 \ldots \ldots \\
30 \ldots \ldots \\
31 \ldots \ldots\end{array}$ & $\begin{array}{r}6.6 \\
6.5 \\
6.0 \\
6.3 \\
6.1 \\
5.7 \\
5.6 \\
5.7 \\
18 \\
1,420 \\
3,240\end{array}$ & $\begin{array}{r}57 \\
51 \\
45 \\
41 \\
40 \\
36 \\
34 \\
32 \\
-\ldots--\end{array}$ \\
\hline \multicolumn{7}{|c|}{ 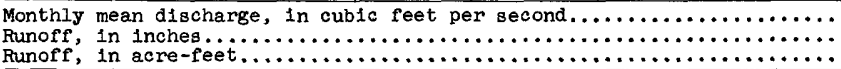 } & $\begin{array}{r}158 \\
3.49 \\
9,730\end{array}$ & $\begin{array}{r}209 \\
4.16 \\
11,600 \\
\end{array}$ \\
\hline
\end{tabular}

Gage helght, in feet, and discharge, in cubic feet per second, at indicated time, 1963

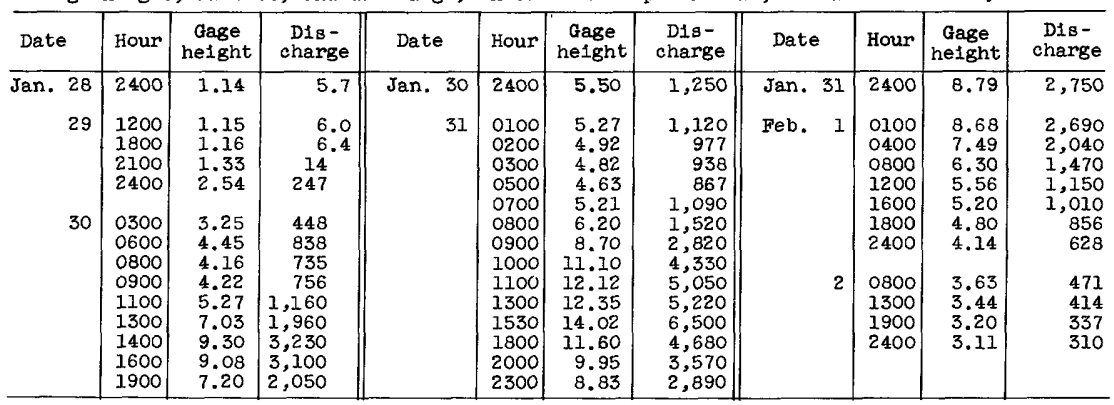

11-4493.5. Burns Valley Creek near Clearlake Highlands, Calif.

Location.--Iat $38^{\circ} 58^{\prime} 33^{\prime \prime}$, long $122^{\circ} 36^{\circ} 42^{\prime \prime}$, in SE $\frac{1}{4}$ sec.15, T.13 N., R.7 W., on right bank $500 \mathrm{ft}$ downstream from unnamed tributary and 2.7 miles northeast of

Clearlake Highlands.

Drainage area. $--4.38 \mathrm{sq} \mathrm{mi}$.

Gage-height record. - Water-stage recorder graph. Altitude of gage is 1,380 ft (from topographic map).

Discharge record.--Stage-discharge relation defined by current-meter measurements.

Maxima.--January-February 1963: D1scharge, 277 cf's 1300 hours Jan. 31 (gage helght, $4.38 \mathrm{ft}$. 
Mean discharge, in cublc feet per second, 1963, of Burns Valley Creek near clearlake H1ghlands, Calif.

\begin{tabular}{|c|c|c|c|c|c|c|c|c|}
\hline Day & January & February & Day & January & February & Day & January & February \\
\hline $\begin{array}{c}1 \ldots \ldots \\
2 \ldots \ldots \\
3 \ldots \ldots \\
5 \ldots \ldots \\
6 \ldots \ldots \\
7 \ldots \ldots \\
8 \ldots \ldots \\
9 \ldots \ldots\end{array}$ & $\begin{array}{l}0 \\
0 \\
0 \\
0 \\
0 \\
0 \\
0 \\
0 \\
0 \\
0\end{array}$ & $\begin{array}{r}18 \\
4.7 \\
2.8 \\
1.4 \\
.6 \\
.4 \\
.2 \\
.4 \\
3.5 \\
4.4\end{array}$ & $\begin{array}{l}11 \ldots \ldots \\
12 \ldots \ldots \\
13 \ldots \ldots \\
14 \ldots \ldots \\
15 \ldots \ldots \\
16 \ldots \ldots \\
17 \ldots \ldots \\
18 \ldots \ldots \\
19 \ldots \ldots \\
20 \ldots \ldots\end{array}$ & $\begin{array}{l}0 \\
0 \\
0 \\
0 \\
0 \\
0 \\
0 \\
0 \\
0 \\
0\end{array}$ & $\begin{array}{l}1.3 \\
25 \\
14 \\
4.7 \\
2.6 \\
1.8 \\
1.1 \\
.6 \\
.4 \\
.4\end{array}$ & $\begin{array}{l}21 \ldots \ldots \\
22 \ldots \ldots \\
23 \ldots \ldots \\
24 \ldots \ldots \\
25 \ldots \ldots \\
26 \ldots \ldots \\
27 \ldots \ldots \\
28 \ldots \ldots \\
29 \ldots \ldots \\
30 \ldots \ldots \\
31 \ldots \ldots\end{array}$ & $\begin{array}{l}0 \\
0 \\
0 \\
0 \\
0 \\
0 \\
0 \\
0 \\
0 \\
52 \\
92\end{array}$ & $\begin{array}{r}0.2 \\
.2 \\
.1 \\
.1 \\
.1 \\
.1 \\
.1 \\
.1 \\
--0 .--\end{array}$ \\
\hline $\begin{array}{l}\text { nthly } \\
\text { noff, } \\
\text { noff, }\end{array}$ & $\begin{array}{l}\text { Inche } \\
\text { acre- }\end{array}$ & & & & & & $\begin{array}{r}4.65 \\
1.22 \\
286\end{array}$ & $\begin{array}{r}3.19 \\
0.76 \\
177\end{array}$ \\
\hline
\end{tabular}

11-4495. Kelsey Creek near Kelseyville, Callf.

Location.--Lat $38^{\circ} 55^{\prime} 45^{\prime \prime}$, long $122^{\circ} 50^{\prime} 35^{\prime \prime}$, in SE $\frac{1}{4}$ sec.34, T.13 N., R.9 W., on left bank 1.6 miles downstream from W1dow Creek and 3.5 miles south Kelseyville.

Drainage area. $--37.2 \mathrm{sq} \mathrm{mi}$.

Gage-helght record --Water-stage recorder graph. Datum of gage is $1,475.1 \mathrm{ft}$ above mean sea level (levels by topographic division).

Discharge record.--Stage-discharge relation defined by current-meter measurements.

Maxima --January-February 1963: Discharge, 6,300 cfs 1400 hours Jan. 31 (gage helght, $12.80 \mathrm{ft}$ ).

1946 to December 1962: Discharge, 8,800 cfs Dec. 21, 1955 (gage height, $12.80 \mathrm{ft}$ ).

Mean discharge, In cublc feet per second, 1963

\begin{tabular}{|c|c|c|c|c|c|c|c|c|}
\hline Day & January & February & Day & January & February & Day & January & February \\
\hline $\begin{array}{c}1 \ldots \ldots \\
2 \ldots \ldots \\
3 \ldots \ldots \\
4 \ldots \ldots \\
5 \ldots \ldots \\
6 \ldots \ldots \\
7 \ldots \ldots \\
5 \ldots \ldots \\
9 \ldots \ldots \\
10 \ldots \ldots\end{array}$ & $\begin{array}{l}33 \\
31 \\
30 \\
28 \\
26 \\
26 \\
25 \\
24 \\
23 \\
22\end{array}$ & $\begin{array}{r}1,240 \\
470 \\
294 \\
217 \\
167 \\
141 \\
121 \\
144 \\
351 \\
302\end{array}$ & $\begin{array}{l}11 \ldots \ldots \\
12 \ldots \ldots \\
13 \ldots \ldots \\
14 \ldots \ldots \\
15 \ldots \ldots \\
16 \ldots \ldots \\
17 \ldots \ldots \\
18 \ldots \ldots \\
19 \ldots \ldots \\
20 \ldots \ldots\end{array}$ & $\begin{array}{l}21 \\
20 \\
20 \\
20 \\
20 \\
20 \\
19 \\
19 \\
19 \\
18\end{array}$ & $\begin{array}{r}198 \\
359 \\
313 \\
215 \\
167 \\
145 \\
124 \\
110 \\
98 \\
90\end{array}$ & $\begin{array}{l}21 \ldots \ldots \\
22 \ldots \ldots \\
23 \ldots \ldots \\
24 \ldots \ldots \\
25 \ldots \ldots \\
26 \ldots \ldots \\
27 \ldots \ldots \\
28 \ldots \ldots \\
29 \ldots \ldots \\
30 \ldots \ldots \\
31 \ldots \ldots\end{array}$ & $\begin{array}{r}17 \\
17 \\
17 \\
17 \\
17 \\
17 \\
16 \\
16 \\
46 \\
1,380 \\
3,430 \\
\end{array}$ & $\begin{array}{r}82 \\
75 \\
71 \\
67 \\
64 \\
59 \\
57 \\
54 \\
----- \\
-0 .--\end{array}$ \\
\hline nof & acre-1 & & & & & & $\begin{array}{r}176 \\
5.45 \\
10,820 \\
\end{array}$ & $\begin{array}{r}207 \\
5.79 \\
11,490 \\
\end{array}$ \\
\hline
\end{tabular}

Gage he1ght, in feet, and discharga, in cublc feet per second, at indicated time, 1963

\begin{tabular}{|c|c|c|c|c|c|c|c|c|c|c|c|}
\hline Date & Hour & $\begin{array}{c}\text { Gage } \\
\text { helght }\end{array}$ & $\begin{array}{l}\text { D1s- } \\
\text { charge }\end{array}$ & Date & Hour & $\begin{array}{c}\text { Gage } \\
\text { haight }\end{array}$ & $\begin{array}{l}\text { Dis- } \\
\text { charge }\end{array}$ & Date & Hour & $\begin{array}{c}\text { Gage } \\
\text { helght }\end{array}$ & $\begin{array}{c}\text { Dia- } \\
\text { charge }\end{array}$ \\
\hline $\begin{array}{r}\text { Jan. } 28 \\
29\end{array}$ & $\begin{array}{l}2400 \\
1000 \\
1800 \\
2000 \\
2100 \\
2200 \\
2300 \\
2400 \\
\\
0400 \\
0600 \\
0900 \\
1000 \\
1200\end{array}$ & $\begin{array}{l}3.25 \\
3.25 \\
3.38 \\
3.47 \\
5.00 \\
5.30 \\
5.28 \\
5.41 \\
7.00 \\
7.20 \\
6.90 \\
7.06 \\
8.38\end{array}$ & $\begin{array}{r}16 \\
16 \\
21 \\
25 \\
165 \\
228 \\
224 \\
254 \\
810 \\
904 \\
760 \\
835 \\
1,560\end{array}$ & $\begin{array}{c}\text { Jan. } 30 \\
.\end{array}$ & $\begin{array}{l}1500 \\
1800 \\
2100 \\
2400 \\
\\
0300 \\
0400 \\
0600 \\
0700 \\
0900 \\
1000 \\
1100 \\
1200 \\
1300 \\
1400\end{array}$ & $\begin{array}{r}10.28 \\
8.85 \\
8.05 \\
7.43 \\
7.12 \\
7.17 \\
8.22 \\
9.00 \\
10.95 \\
10.85 \\
11.20 \\
11.60 \\
12.35 \\
12.80\end{array}$ & $\begin{array}{r}3,270 \\
1,930 \\
1,340 \\
1,020 \\
866 \\
888 \\
1,450 \\
2,030 \\
3,970 \\
3,840 \\
4,280 \\
4,820 \\
5,980 \\
6,300\end{array}$ & $\operatorname{Jan} .31$ & $\begin{array}{l}1700 \\
1900 \\
2200 \\
2400 \\
0200 \\
0600 \\
0800 \\
1200 \\
1800 \\
2400 \\
0600 \\
1200 \\
1800 \\
2400\end{array}$ & $\begin{array}{r}12.65 \\
11.06 \\
9.83 \\
9.42 \\
9.30 \\
8.20 \\
7.92 \\
7.53 \\
7.12 \\
6.64 \\
6.27 \\
6.04 \\
5.80 \\
5.65\end{array}$ & $\begin{array}{r}6,140 \\
4,100 \\
2,800 \\
2,400 \\
\\
2,280 \\
1,440 \\
1,270 \\
1,070 \\
866 \\
646 \\
\\
529 \\
461 \\
391 \\
350\end{array}$ \\
\hline
\end{tabular}


1]-4500. Clear Lake at Lakeport, Cal1f.

Location.--Lat $39^{\circ} 02^{\prime} 40^{\prime \prime}$, long $122^{\circ} 54^{\prime} 45^{\prime \prime}$, in $\mathrm{SE} \frac{1}{4}$ sec.24, T.14 N., R.10 W., on private pler at foot of Fourth Street in Lakeport.

Drainage area. $--528 \mathrm{sq} \mathrm{mi}$.

Gage-he1ght record.--Water-stage recorder graph.

Maxima.--January-February 1963: Da1ly mean gage height, $7.42 \mathrm{ft} \mathrm{Feb.} \mathrm{27,} 28$. 1913 to December 1962: Gage helght observed, $11.12 \mathrm{ft} \mathrm{Jan} .28,1914$.

Remarks.--Th1s natural lake is regulated by a concrete overflow at outlet, completed in 1915 . Capacity between gage helghts 0.00 and $7.56 \mathrm{ft}$ (IImits stipulated by court decree of 1920), about 319,000 acre-ft. Record of daily gage helghts furnished by the Clear Lake Water Co.

Gage helght, in feet, 1963

\begin{tabular}{|c|c|c|c|c|c|c|c|c|}
\hline Day & January & February & Day & January & February & Day & January & February \\
\hline $\begin{array}{c}1 \ldots \ldots \\
2 \ldots \ldots \\
3 \ldots \ldots \\
4 \ldots \ldots \\
5 \ldots \ldots \\
7 \ldots \ldots \\
8 \ldots \ldots \\
9 \ldots \ldots \\
10 \ldots \ldots\end{array}$ & $\begin{array}{l}3.94 \\
3.95 \\
3.96 \\
3.96 \\
3.96 \\
3.96 \\
3.96 \\
3.96 \\
3.96 \\
3.96\end{array}$ & $\begin{array}{l}5.90 \\
6.10 \\
6.23 \\
6.35 \\
6.28 \\
6.32 \\
6.35 \\
6.41 \\
6.50 \\
6.63\end{array}$ & $\begin{array}{l}11 \ldots \ldots \\
12 \ldots \ldots \\
13 \ldots \ldots \\
14 \ldots \ldots \\
15 \ldots \ldots \\
16 \ldots \ldots \\
17 \ldots \ldots \\
18 \ldots \ldots \\
19 \ldots \ldots \\
20 \ldots \ldots\end{array}$ & $\begin{array}{l}3.96 \\
3.95 \\
3.95 \\
3.94 \\
3.94 \\
3.95 \\
3.95 \\
3.95 \\
3.96 \\
3.96\end{array}$ & $\begin{array}{l}6.71 \\
6.90 \\
7.04 \\
7.12 \\
7.19 \\
7.24 \\
7.25 \\
7.29 \\
7.31 \\
7.33\end{array}$ & $\begin{array}{l}21 \ldots \ldots \\
22 \ldots \ldots \\
23 \ldots \ldots \\
24 \ldots \ldots \\
25 \ldots \ldots \\
26 \ldots \ldots \\
27 \ldots \ldots \\
28 \ldots \ldots \\
29 \ldots \ldots \\
30 \ldots \ldots \\
31 \ldots \ldots\end{array}$ & $\begin{array}{l}3.96 \\
3.96 \\
3.97 \\
3.97 \\
3.97 \\
3.97 \\
3.98 \\
4.00 \\
4.13 \\
4.35 \\
5.00\end{array}$ & $\begin{array}{r}7.35 \\
7.37 \\
7.35 \\
7.39 \\
7.40 \\
7.41 \\
7.42 \\
7.42 \\
-.-1- \\
-.-1 .-\end{array}$ \\
\hline
\end{tabular}

11-4506. Copsey Creek near Lower Lake, Calif.

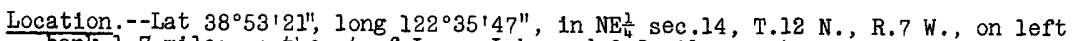
bank 1.7 miles southeast of Lower Lake and 2.5 miles upstream from mouth.

Drainage area. $-13.2 \mathrm{sq} \mathrm{ml}$.

Gage-height record - -Water-stage recorder graph. Altitude of gage is 1,400 ft (from topographic mapj.

Discharge record.--Stage-discharge relation defined by current-meter measurements below 790 cf's. Maxima.--January-February 1963: D1scharge, 2,340 cfs 1330 hours Jan. 30 (gage

1960 to December 1962: Discharge, 1,530 cfs Feb. 14, 1962 (gage height, $11.13 \mathrm{ft}$ ).

Remarks.--Records furnished by California Department of Water Resources.

Mean discharge, in cubic feet per second, 1963

\begin{tabular}{|c|c|c|c|c|c|c|c|c|}
\hline Day & Inuary & ebruary & Day & anuary & February & Day & January & February \\
\hline $\begin{array}{r}1 \ldots \ldots \\
2 \ldots \ldots \\
3 \ldots \ldots \\
4 \ldots \ldots \\
5 \ldots \ldots \\
6 \ldots \ldots \\
7 \ldots \ldots \\
9 \ldots \ldots \\
10 \ldots .\end{array}$ & $\begin{array}{l}2.0 \\
2.1 \\
1.9 \\
1.7 \\
1.7 \\
1.7 \\
1.6 \\
1.6\end{array}$ & $\begin{array}{r}246 \\
63 \\
37 \\
24 \\
17 \\
14 \\
13 \\
18 \\
91 \\
75\end{array}$ & $\begin{array}{l}1 \ldots \ldots \\
2 \ldots \ldots \\
4 \ldots \ldots \\
5 \ldots \ldots \\
6 \ldots \ldots \\
7 \ldots \ldots \\
9 \ldots \ldots \\
9 \ldots \ldots \\
0 \ldots\end{array}$ & $\begin{array}{l}1.3 \\
1.3 \\
1.4 \\
1.4 \\
1.4 \\
1.4 \\
1.4\end{array}$ & $\begin{array}{r}30 \\
224 \\
139 \\
45 \\
30 \\
23 \\
18 \\
16 \\
13 \\
12\end{array}$ & & $\begin{array}{r}1.4 \\
1.4 \\
1.3 \\
1.3 \\
1.3 \\
1.3 \\
1.3 \\
1.3 \\
20 \\
\text { s13 } \\
1,140\end{array}$ & $\begin{array}{r}10 \\
8.8 \\
8.7 \\
8.1 \\
7.3 \\
6.7 \\
6.2 \\
5.7 \\
- \\
-0 .--.-\end{array}$ \\
\hline \multicolumn{9}{|c|}{ 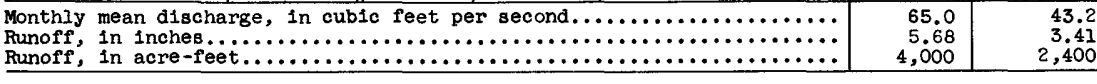 } \\
\hline
\end{tabular}


Gage height, in feet, and discharge, in cubic feet per second, at indicated time, I963, of Copsey Creek near Lower Lake, Calif.

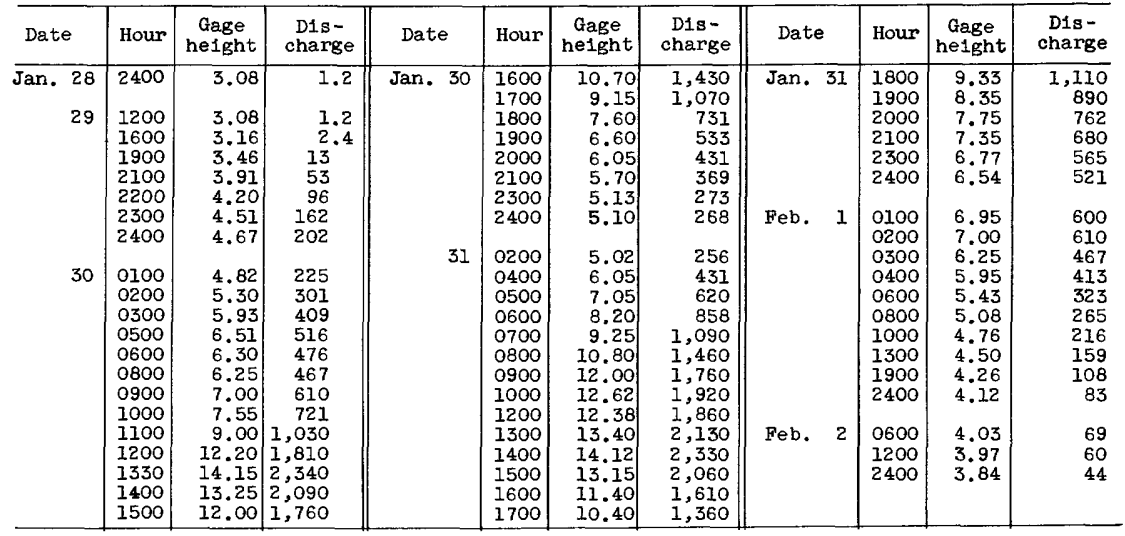

11-4510. Cache Creek near Lower Lake, Calif.

Location.--Lat $38^{\circ} 55^{\prime} 27^{\prime \prime}$, Iong $122^{\circ} 33^{\prime} 53^{\prime \prime}$, in sec.6, T.12 N., R.6 W., on left bank 500 ft downstream from Clear Lake Dam, 1.9 miles downstream from Copsey Creek, and 2.5 miles northeast of Lower Lake.

Drainage area. $--528 \mathrm{sq} \mathrm{m}$.

Gage-helght record --Water-stage recorder graph. Datum of gage is $1,280.3 \mathrm{ft}$ above mean sea leve1 (river-profile survey).

D1scharge record.--Stage-discharge relation defined by current-meter measurements .

Maxima.--January-February 1963: Discharge, 5,660 cfs 1000 hours Feb. 4 (gage height, $8.38 \mathrm{ft}$ ).

1944 to December 1962: D1scharge, 8,000 cfs Feb. 24, 1958 (gage he1ght, $9.40 \mathrm{ft}$ ).

Remarks.--Flow regulated by Clear Lake (see station 11-4500).

Mean discharge, in cubic feet per second, 1963

\begin{tabular}{|c|c|c|c|c|c|c|c|c|}
\hline Day & January & February & Day & January & Febmuary & Day & January & February \\
\hline $\begin{array}{c}1 \ldots \ldots \\
2 \ldots \ldots \\
3 \ldots \ldots \\
4 \ldots \ldots \\
5 \ldots \ldots \\
7 \ldots \ldots \\
8 \ldots \ldots \\
9 \ldots \ldots \\
10 \ldots \ldots\end{array}$ & $\begin{array}{l}2.5 \\
2.5 \\
2.5 \\
2.5 \\
2.5 \\
2.6 \\
2.6 \\
2.6 \\
2.6 \\
2.6\end{array}$ & $\begin{array}{r}1,640 \\
611 \\
579 \\
416 \\
525 \\
6.6 \\
6.6 \\
6.4 \\
6.4 \\
6.4\end{array}$ & $\begin{array}{l}11 \ldots \ldots \\
12 \ldots \ldots \\
13 \ldots \ldots \\
14 \ldots \ldots \\
15 \ldots \ldots \\
16 \ldots \ldots \\
17 \ldots \ldots \\
18 \ldots \ldots \\
19 \ldots \ldots\end{array}$ & $\begin{array}{l}2.5 \\
2.5 \\
2.4 \\
2.4 \\
2.4 \\
2.5 \\
2.5 \\
2.5 \\
2.4 \\
2.4\end{array}$ & $\begin{array}{l}6.4 \\
98 \\
16 \\
6.9 \\
6.6 \\
6.6 \\
6.6 \\
6.4 \\
6.6 \\
6.9\end{array}$ & $\begin{array}{l}21 \ldots \ldots \\
22 \ldots \ldots \\
23 \ldots \ldots \\
24 \ldots \ldots \\
25 \ldots \ldots \\
26 \ldots \ldots \\
27 \ldots \ldots \\
28 \ldots \ldots \\
29 \ldots \ldots \\
30 \ldots \ldots \\
31 \ldots \ldots\end{array}$ & $\begin{array}{r}2.4 \\
2.4 \\
2.4 \\
2.4 \\
2.4 \\
2.4 \\
2.4 \\
2.4 \\
2.5 \\
367 \\
1,490\end{array}$ & $\begin{array}{r}6.9 \\
6.9 \\
6.9 \\
6.9 \\
6.6 \\
6.6 \\
6.4 \\
6.1 \\
--.-1 \\
-.--.\end{array}$ \\
\hline $\begin{array}{l}\text { Ionthly } \\
\text { kunoff, }\end{array}$ & $\begin{array}{l}\text { an dis } \\
\text { acre-1 }\end{array}$ & e, & feet & & & & $\begin{array}{r}62.2 \\
3,830\end{array}$ & $\begin{array}{r}144 \\
7,980\end{array}$ \\
\hline
\end{tabular}


11-4515. North Fork Cache Creek near Lower Lake, Calif.

Location.--Lat $39^{\circ} 01^{\prime}$, long $122^{\circ} 33^{\prime}$, in $\mathrm{NE} \frac{1}{4}$ sec.31, T.14 N., R. 6 W. , on right bank 500 f't upstream from Sweet Hollow Creek, 5 miles upstream from mouth, and 7 miles northeast of Lower Lake.

Drainage area. $--198 \mathrm{sq} \mathrm{ml}$.

Gage-height record.--Water-stage recorder graph. Datum of gage is $1,035.60 \mathrm{ft}$ above mean sea level, preliminary adjustment of 1929 .

Discharge record.--Stage-discharge relation defined by current-meter measurements.

Maxima.--January-February 1963: Discharge, 13,400 cfs 1900 hours Jan. 31 (gage helght, $11.44 \mathrm{ft}$ ).

1930 to December 1962: Discharge, 20,300 cfs Dec. 11, 1937 (gage height, $13.98 \mathrm{ft}$, from floodmarks), from rating curve extended above $7,600 \mathrm{cfs}$ on basis of slope-area measurement at gage height $13.9 \mathrm{ft}$ for peak of Feb. 28,1940 .

Mean discharge, in cublc feet per second, 1963

\begin{tabular}{|c|c|c|c|c|c|c|c|c|}
\hline Day & January & Febmuary & Day & January & February & Day & January & February \\
\hline $\begin{array}{c}1 \ldots \ldots \\
2 \ldots \ldots \\
3 \ldots \ldots \\
4 \ldots \ldots \\
5 \ldots \ldots \\
7 \ldots \ldots \\
8 \ldots \ldots \\
9 \ldots \ldots \\
10 \ldots \ldots\end{array}$ & $\begin{array}{l}72 \\
66 \\
65 \\
60 \\
57 \\
54 \\
53 \\
52 \\
52 \\
51\end{array}$ & $\begin{array}{r}4,480 \\
1,330 \\
824 \\
658 \\
530 \\
453 \\
403 \\
385 \\
403 \\
707\end{array}$ & $\begin{array}{l}11 \ldots \ldots \\
12 \ldots \ldots \\
13 \ldots \ldots \\
14 \ldots \ldots \\
15 \ldots \ldots \\
16 \ldots \ldots \\
17 \ldots \ldots \\
18 \ldots \ldots \\
19 \ldots \ldots \\
20 \ldots \ldots\end{array}$ & $\begin{array}{l}48 \\
43 \\
44 \\
44 \\
43 \\
42 \\
41 \\
41 \\
40 \\
39\end{array}$ & $\begin{array}{l}540 \\
705 \\
777 \\
490 \\
394 \\
340 \\
296 \\
252 \\
223 \\
201\end{array}$ & $\begin{array}{l}21 \ldots \ldots \\
22 \ldots \ldots \\
23 \ldots \ldots \\
24 \ldots \ldots \\
25 \ldots \ldots \\
26 \ldots \ldots \\
27 \ldots \ldots \\
28 \ldots \ldots \\
29 \ldots \ldots \\
30 \ldots \ldots \\
31 \ldots \ldots\end{array}$ & $\begin{array}{r}39 \\
39 \\
38 \\
37 \\
37 \\
37 \\
36 \\
36 \\
41 \\
1,430 \\
6,420\end{array}$ & $\begin{array}{r}179 \\
166 \\
156 \\
148 \\
141 \\
137 \\
127 \\
123 \\
----- \\
---.-\end{array}$ \\
\hline \multicolumn{7}{|c|}{ 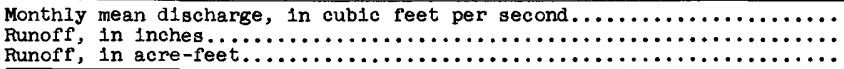 } & $\begin{array}{r}297 \\
18,243 \\
18,240\end{array}$ & $\begin{array}{r}556 \\
2.92 \\
30,880\end{array}$ \\
\hline
\end{tabular}

Gage height, in feet, and discharge, in cublc feet per second, at ind1cated time, 1963

\begin{tabular}{|c|c|c|c|c|c|c|c|c|c|c|c|}
\hline Date & Hour & $\begin{array}{c}\text { Gage } \\
\text { helght }\end{array}$ & $\begin{array}{c}\text { D1s- } \\
\text { charge }\end{array}$ & Date & Hour & $\begin{array}{c}\text { Gage } \\
\text { helght }\end{array}$ & $\begin{array}{l}\text { Dis- } \\
\text { charge }\end{array}$ & Date & Hour & $\begin{array}{c}\text { Gage } \\
\text { helght }\end{array}$ & $\begin{array}{c}\text { D1s- } \\
\text { charge }\end{array}$ \\
\hline $\begin{array}{r}\operatorname{Jan} .29 \\
30\end{array}$ & $\begin{array}{l}2400 \\
0400 \\
1000 \\
1400 \\
1600 \\
1700 \\
1900 \\
2000 \\
2200 \\
2400 \\
0400\end{array}$ & $\begin{array}{l}2.75 \\
2.95 \\
3.73 \\
5.03 \\
6.41 \\
7.48 \\
7.76 \\
7.57 \\
6.72 \\
6.14 \\
5.55\end{array}$ & $\begin{array}{r}63 \\
95 \\
315 \\
1,010 \\
2,290 \\
3,070 \\
4,370 \\
4,030 \\
2,690 \\
1,980 \\
1,420\end{array}$ & Feb. 1 & $\begin{array}{l}0700 \\
0900 \\
1000 \\
1200 \\
1400 \\
1600 \\
1900 \\
2100 \\
2200 \\
2400 \\
0400 \\
0800\end{array}$ & $\begin{array}{r}5.29 \\
5.75 \\
6.52 \\
8.83 \\
9.95 \\
10.90 \\
11.44 \\
10.65 \\
10.18 \\
9.60 \\
5.93 \\
8.07\end{array}$ & $\begin{array}{r}1,200 \\
1,600 \\
2,430 \\
6,670 \\
9,470 \\
11,900 \\
13,400 \\
11,300 \\
10,100 \\
8,590 \\
6,920 \\
4,980\end{array}$ & Feb. & $\begin{array}{l}1100 \\
1400 \\
1600 \\
1900 \\
2400 \\
0400 \\
0900 \\
1600 \\
1900 \\
2400\end{array}$ & $\begin{array}{l}7.55 \\
7.20 \\
7.09 \\
6.86 \\
6.21 \\
5.75 \\
5.49 \\
5.18 \\
5.16 \\
4.94\end{array}$ & $\begin{array}{r}3,990 \\
3,400 \\
3,230 \\
2,880 \\
2,060 \\
1,620 \\
1,360 \\
1,120 \\
1,100 \\
948\end{array}$ \\
\hline
\end{tabular}

11-4515.3. Phipps Creek near Lower Lake, Calif.

(Crest-stage station)

Location.--Lat $38^{\circ} 59^{\prime} 51^{\prime \prime}$, long $122^{\circ} 33^{\prime} 16^{\prime \prime}$, T.13 N., R.6 W. (unsurveyed), at culvert on State Highway $20,6.7$ miles northeast of Lower Lake.

Drainage area. $--3.05 \mathrm{sq} \mathrm{mi}$.

Gage-height record.--Crest stages only. Altitude of gage is 1,020 ft (from topographic map).

Discharge record.--Maximum discharge by computation of flow through culvert.

Maxima.--January-February 1963: Discharge, 99 cfs Jan. 31 (gage height, $12.95 \mathrm{ft}$ ). September to December 1962: Discharge, 63 cfs 0ct. 12, 1962 (gage height, $12.14 \mathrm{ft})$. 
11-4517. Bear Creek tributary near Wilbur Springs, Calif.

Location.--Lat $39^{\circ} 00^{\prime} 45^{\prime \prime}$, long $122^{\circ} 21^{\prime} 30^{\prime \prime}$, in SE $\frac{1}{4}$ sec.36, T.14 N., R.5 W., on State Highway $20,3.8$ miles southeast of Wilbur Springs.

Drainage area. $--4.50 \mathrm{sq} \mathrm{mi}$.

Gage-height record.--Water-stage recorder graph and crest-stage gage. Alt1tude of gage is I,050 ft (from topographic map).

Discharge record.--Stage-discharge relation defined by current-meter measurements below $240 \mathrm{cfs}$ and by computation of flow through culvert.

Maxima.--January-February 1963: Discharge, 357 cfs 1415 hours Jan. 30 (gage height, $27.54 \mathrm{ft}$, from recorder graph; $27.79 \mathrm{ft}$, from crest-stage gage).

1961 to December 1962: Discharge, 355 cfs (revised) Feb. 14, 1962 (gage helght, $27.92 \mathrm{f}^{\prime} \mathrm{t}$ ).

Mean discharge, In cublc feet per second, 1963

\begin{tabular}{|c|c|c|c|c|c|c|c|c|}
\hline Day & January & February & Day & January & February & Day & January & February \\
\hline $\begin{array}{c}1 \ldots \ldots \\
2 \ldots \ldots \\
4 \ldots \ldots \\
5 \ldots \ldots \\
6 \ldots \ldots \\
7 \ldots \ldots \\
9 \ldots \ldots \\
10 \ldots \ldots\end{array}$ & $\begin{array}{l}0 \\
0 \\
0 \\
0 \\
0 \\
0 \\
0 \\
0 \\
0 \\
0\end{array}$ & $\begin{array}{r}16 \\
2.7 \\
1.7 \\
1.1 \\
.8 \\
.7 \\
.6 \\
.6 \\
7.6 \\
6.7\end{array}$ & $\begin{array}{l}11 \ldots \ldots \\
12 \ldots \ldots \\
13 \ldots \ldots \\
14 \ldots \ldots \\
15 \ldots \ldots \\
16 \ldots \ldots \\
17 \ldots \ldots \\
18 \ldots \ldots \\
19 \ldots \ldots \\
20 \ldots \ldots\end{array}$ & $\begin{array}{l}0 \\
0 \\
0 \\
0 \\
0 \\
0 \\
0 \\
0 \\
0 \\
0\end{array}$ & $\begin{array}{r}1.6 \\
34 \\
9.2 \\
2.4 \\
1.7 \\
1.3 \\
1.1 \\
1.0 \\
.8 \\
.8\end{array}$ & $\begin{array}{l}21 \ldots \ldots \\
22 \ldots \ldots \\
23 \ldots \ldots \\
24 \ldots \ldots \\
25 \ldots \ldots \\
26 \ldots \ldots \\
27 \ldots \ldots \\
28 \ldots \ldots \\
29 \ldots \ldots \\
30 \ldots \ldots \\
31 \ldots \ldots\end{array}$ & $\begin{array}{l}0 \\
0 \\
0 \\
0 \\
0 \\
0 \\
0 \\
0 \\
70^{.4} \\
81\end{array}$ & $\begin{array}{r}.7 \\
.6 \\
.5 \\
.5 \\
.4 \\
.4 \\
.3 \\
.4 \\
--\ldots \\
--2-.-\end{array}$ \\
\hline \multicolumn{7}{|l|}{$\begin{array}{l}\text { Monthly } \\
\text { Runoff, } \\
\text { Runoff, }\end{array}$} & $\begin{array}{r}4.88 \\
1.25 \\
300\end{array}$ & $\begin{array}{r}3.44 \\
0.79 \\
191\end{array}$ \\
\hline
\end{tabular}

Gage helght, in feet, and discharge, In cuble feet per second, at Indicated t1me, 1963

\begin{tabular}{|c|c|c|c|c|c|c|c|c|c|c|c|}
\hline Date & Hour & $\begin{array}{c}\text { Gage } \\
\text { helght }\end{array}$ & $\begin{array}{l}\text { Dis - } \\
\text { charge }\end{array}$ & Date & Hour & $\begin{array}{c}\text { Gage } \\
\text { he1ght }\end{array}$ & $\begin{array}{l}\text { D1s- } \\
\text { charge }\end{array}$ & Date & Hour & $\begin{array}{c}\text { Gage } \\
\text { helght }\end{array}$ & $\begin{array}{c}\text { Dis- } \\
\text { charge }\end{array}$ \\
\hline $\begin{array}{r}29 \\
30\end{array}$ & $\begin{array}{l}2400 \\
0100 \\
0200 \\
0400 \\
0600 \\
0500 \\
0945 \\
1030 \\
1100 \\
1200 \\
1300 \\
1315 \\
1330 \\
1415 \\
1500 \\
1530 \\
1700\end{array}$ & $\begin{array}{l}20.18 \\
20.19 \\
20.23 \\
20.33 \\
20.34 \\
20.54 \\
20.96 \\
21.58 \\
22.29 \\
24.15 \\
27.40 \\
27.52 \\
27.53 \\
27.54 \\
26.60 \\
24.60 \\
22.70\end{array}$ & $\begin{array}{c}1.6 \\
1.7 \\
2.2 \\
3.8 \\
4.0 \\
7.8 \\
18 \\
37 \\
64 \\
175 \\
348 \\
356 \\
357 \\
357 \\
292 \\
166 \\
80\end{array}$ & Jan. 30 & $\begin{array}{l}1730 \\
1900 \\
2100 \\
2200 \\
2400 \\
0300 \\
0400 \\
0600 \\
0700 \\
0800 \\
0900 \\
0945 \\
1100 \\
1130 \\
1230 \\
1400 \\
1530\end{array}$ & $\begin{array}{l}22.25 \\
21.55 \\
21.05 \\
20.58 \\
20.69 \\
20.56 \\
20.56 \\
21.15 \\
22.45 \\
24.70 \\
25.57 \\
25.30 \\
24.24 \\
24.46 \\
24.10 \\
24.86 \\
23.20\end{array}$ & $\begin{array}{c}62 \\
36 \\
20 \\
16 \\
11 \\
8.2 \\
8.0 \\
24 \\
70 \\
187 \\
239 \\
223 \\
159 \\
173 \\
151 \\
197 \\
105\end{array}$ & Feb. 1 & $\begin{array}{l}1700 \\
1830 \\
2030 \\
2200 \\
2345 \\
2400 \\
\\
0100 \\
0215 \\
0230 \\
0330 \\
0430 \\
0600 \\
0900 \\
1230 \\
1730 \\
2100 \\
2400\end{array}$ & $\begin{array}{l}22.10 \\
21.95 \\
21.45 \\
21.15 \\
20.95 \\
20.96 \\
21.34 \\
22.58 \\
22.50 \\
21.16 \\
21.36 \\
21.02 \\
20.73 \\
20.57 \\
20.45 \\
20.38 \\
20.34\end{array}$ & $\begin{array}{l}56 \\
50 \\
32 \\
24 \\
18 \\
18 \\
\\
29 \\
75 \\
72 \\
43 \\
30 \\
20 \\
12 \\
8.4 \\
6.0 \\
4.7 \\
4.0\end{array}$ \\
\hline
\end{tabular}


11-4517.2. Bear Creek near Rumsey, Cal1f.

Location.--Lat $39^{\circ} 56^{\prime} 35^{\prime \prime}$, long $122^{\circ} 20^{\prime} 40^{\prime \prime}$, in $\mathrm{NE}_{\frac{1}{4}} \mathrm{SW} \frac{1}{4} \sec .30$, T.13 N., R.4 W., on left bank 0.3 mile downstream from Brophy Canyon, 1.4 miles upstream from mouth, and 7.3 miles northwest of Rumsey.

Drainage area. $--96.8 \mathrm{sq} \mathrm{mi}$.

Gage-height record. - Water-stage recorder graph, except from 0600 hours Feb. 1 to 1100 hours Feb. 4 , for which graph was reconstructed on basis of three staffgage readings. Altitude of gage is $750 \mathrm{ft}$ (from topographic map).

Discharge record.--Stage-discharge relation defined by current-meter measurements below 2,300 cfs.

Maxima.--January-February 1963: Discharge, 5,600 cfs 1500 hours Jan. 31 (gage helght, $9.95 \mathrm{ft}$ ).

1958 to December 1962: Discharge, 5,040 cfs (revised) Feb. 14, 1962 (gage height, $9.59 \mathrm{ft}$ ).

Faximum stage since 1955, I2.33 ft Feb. 24, 1958.

Remarks.--Records furnished by California Department of Water Resourses and reviewed by U.S. Geological Survey.

Mean discharge, in cublc feet per second, 1963

\begin{tabular}{|c|c|c|c|c|c|c|c|c|}
\hline Day & January & February & Day & January & February & Day & January & February \\
\hline $\begin{array}{c}1 \ldots \ldots \\
2 \ldots \ldots \\
3 \ldots \ldots \\
5 \ldots \ldots \\
6 \ldots \ldots \\
7 \ldots \ldots \\
8 \ldots \ldots \\
10 \ldots \ldots\end{array}$ & $\begin{array}{l}11 \\
10 \\
10 \\
9.9 \\
9.6 \\
9.3 \\
8.7 \\
8.7 \\
8.7 \\
8.7\end{array}$ & $\begin{array}{r}1,120 \\
196 \\
122 \\
88 \\
71 \\
59 \\
52 \\
50 \\
119 \\
401\end{array}$ & $\begin{array}{l}11 \ldots \ldots \\
12 \ldots \ldots \\
13 \ldots \ldots \\
14 \ldots \ldots \\
15 \ldots \ldots \\
16 \ldots \ldots \\
17 \ldots \ldots \\
18 \ldots \ldots \\
19 \ldots \ldots \\
20 \ldots \ldots\end{array}$ & $\begin{array}{l}8.2 \\
5.6 \\
7.2 \\
8.0 \\
7.5 \\
7.6 \\
7.6 \\
7.6 \\
7.2 \\
6.3\end{array}$ & $\begin{array}{r}117 \\
415 \\
531 \\
149 \\
108 \\
91 \\
83 \\
68 \\
61 \\
56\end{array}$ & $\begin{array}{l}21 \ldots \ldots \\
22 \ldots \ldots \\
23 \ldots \ldots \\
24 \ldots \ldots \\
25 \ldots \ldots \\
26 \ldots \ldots \\
27 \ldots \ldots \\
28 \ldots \ldots \\
29 \ldots \ldots \\
30 \ldots \ldots \\
31 \ldots \ldots\end{array}$ & $\begin{array}{r}6.2 \\
6.9 \\
6.6 \\
7.4 \\
6.9 \\
6.6 \\
6.6 \\
6.9 \\
10 \\
1,150 \\
2,940\end{array}$ & $\begin{array}{r}52 \\
47 \\
43 \\
40 \\
37 \\
36 \\
33 \\
31 \\
----- \\
-0---\end{array}$ \\
\hline $\begin{array}{l}\text { Monthly } \\
\text { Runoff, } \\
\text { Runoff, }\end{array}$ & \multicolumn{6}{|c|}{ 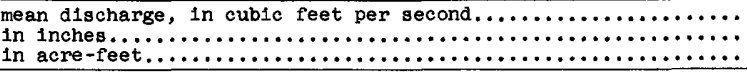 } & $\begin{array}{r}139 \\
1.66 \\
8,570 \\
\end{array}$ & $\begin{array}{r}153 \\
1.64 \\
8,480 \\
\end{array}$ \\
\hline
\end{tabular}

Gage height, in feet, and discharge, in cublc feet per second, at indicated t1me, 1963

\begin{tabular}{|c|c|c|c|c|c|c|c|c|c|c|c|}
\hline Date & Hour & $\begin{array}{c}\text { Gage } \\
\text { helght }\end{array}$ & $\begin{array}{l}\text { Dis- } \\
\text { charge }\end{array}$ & Date & Hour & $\begin{array}{c}\text { Gage } \\
\text { he1ght }\end{array}$ & $\begin{array}{l}\text { D1s- } \\
\text { charge }\end{array}$ & Date & Hour & $\begin{array}{c}\text { Gage } \\
\text { helght }\end{array}$ & $\begin{array}{c}\text { Dis- } \\
\text { charge }\end{array}$ \\
\hline $\begin{array}{r}\text { Jan. } \\
30\end{array}$ & $\begin{array}{l}2400 \\
0200 \\
0400 \\
0500 \\
0800 \\
1000 \\
1200 \\
1300 \\
1400 \\
1430 \\
1500 \\
1600 \\
1700 \\
1800 \\
1900 \\
2000 \\
2200 \\
2400\end{array}$ & $\begin{array}{l}1.67 \\
1.78 \\
2.13 \\
2.36 \\
2.68 \\
3.22 \\
5.00 \\
6.21 \\
7.62 \\
7.69 \\
7.69 \\
7.05 \\
7.34 \\
7.31 \\
7.48 \\
7.43 \\
6.39 \\
5.31\end{array}$ & $\begin{array}{r}20 \\
27 \\
57 \\
84 \\
132 \\
242 \\
896 \\
1,630 \\
2,810 \\
2,880 \\
2,880 \\
2,290 \\
2,540 \\
2,520 \\
2,670 \\
2,630 \\
1,760 \\
1,060\end{array}$ & Feb. 1 & $\begin{array}{l}0200 \\
0500 \\
0700 \\
0800 \\
0900 \\
1200 \\
1300 \\
1400 \\
1500 \\
1600 \\
1700 \\
1800 \\
2000 \\
2200 \\
2400 \\
0100 \\
0200 \\
0300 \\
0500\end{array}$ & $\begin{array}{l}4.71 \\
4.23 \\
5.00 \\
6.39 \\
6.83 \\
7.18 \\
9.16 \\
9.64 \\
9.95 \\
9.89 \\
9.86 \\
9.88 \\
9.60 \\
8.56 \\
7.41 \\
7.12 \\
7.07 \\
7.08 \\
6.90\end{array}$ & $\begin{array}{r}757 \\
555 \\
896 \\
1,760 \\
2,100 \\
2,400 \\
4,530 \\
5,160 \\
5,600 \\
5,510 \\
5,470 \\
5,500 \\
5,110 \\
3,800 \\
2,610 \\
2,350 \\
2,300 \\
2,310 \\
2,160\end{array}$ & Feb. 1 & $\begin{array}{l}0700 \\
1000 \\
1300 \\
1700 \\
2100 \\
2400 \\
0300 \\
0800 \\
1300 \\
1500 \\
1800 \\
2100 \\
2400 \\
\\
0400 \\
1000 \\
1300 \\
1800 \\
2400\end{array}$ & $\begin{array}{l}- \\
\overline{-} \\
\bar{z} \\
- \\
- \\
- \\
\overline{-} \\
- \\
- \\
- \\
- \\
- \\
-\end{array}$ & $\begin{array}{r}1,840 \\
1,180 \\
734 \\
474 \\
357 \\
301 \\
\\
257 \\
210 \\
178 \\
168 \\
159 \\
150 \\
144 \\
\\
136 \\
124 \\
121 \\
111 \\
88\end{array}$ \\
\hline
\end{tabular}


11-4520. Cache Creek near Capay, Calif.

Location.--Lat $38^{\circ} 43^{\prime} 40^{\prime \prime}$, long $122^{\circ} 06^{\prime} 15^{\prime \prime}$, in Canada de Capay Grant, in Yolo County, on right bank 1.8 miles upstream from Clear Lake Water Co.'s diversion dam, 3.2 miles northwest of Capay, and 5.4 miles northwest of Esparto.

Drainage area. $--1,052 \mathrm{sq} \mathrm{ml}$.

Gage-helght record.--Water-stage recorder graph. Altitude of gage is 225 ft (from river-profile map).

Discharge record.--Stage-discharge relation defined by current-meter measurements below 20,000 cfs.

Maxima.--January-February 1963: Discharge, 26,300 cfs 0200 hours Feb. I (gage helght, $16.35 \mathrm{ft}$ ).

1942 to.December 1962: Discharge, 51,600 cfs Feb. 24, 1958 (gage he1ght, $20.90 \mathrm{ft})$.

Remarks.--Flow regulated by Clear Lake (see station 11-4500).

Mean discharge, in cublc feet per second, 1963

\begin{tabular}{|c|c|c|c|c|c|c|c|c|}
\hline Day & January & February & Day & January & February & Day & January & February \\
\hline $\begin{array}{r}1 \ldots \ldots \\
2 \ldots \ldots \\
3 \ldots \ldots \\
4 \ldots \ldots \\
5 \ldots \ldots \\
7 \ldots \ldots \\
8 \ldots \ldots \\
9 \ldots \ldots \\
10 \ldots \ldots\end{array}$ & $\begin{array}{r}114 \\
109 \\
105 \\
101 \\
95 \\
90 \\
85 \\
83 \\
80 \\
79\end{array}$ & $\begin{array}{r}14,600 \\
4,530 \\
2,110 \\
1,980 \\
1,370 \\
961 \\
685 \\
600 \\
588 \\
1,340\end{array}$ & $\begin{array}{l}11 \ldots \ldots \\
12 \ldots \ldots \\
13 \ldots \ldots \\
14 \ldots \ldots \\
15 \ldots \ldots \\
16 \ldots \ldots \\
17 \ldots \ldots \\
18 \ldots \ldots \\
19 \ldots \ldots \\
20 \ldots \ldots\end{array}$ & $\begin{array}{l}77 \\
73 \\
70 \\
68 \\
68 \\
68 \\
67 \\
66 \\
64 \\
62\end{array}$ & $\begin{array}{r}946 \\
873 \\
2,700 \\
1,220 \\
952 \\
815 \\
710 \\
608 \\
536 \\
492\end{array}$ & $\begin{array}{l}21 \ldots \ldots \\
22 \ldots \ldots \\
23 \ldots \ldots \\
24 \ldots \ldots \\
25 \ldots \ldots \\
26 \ldots \ldots \\
27 \ldots \ldots \\
28 \ldots \ldots \\
29 \ldots \ldots \\
30 \ldots \ldots \\
31 \ldots \ldots\end{array}$ & $\begin{array}{r}61 \\
60 \\
60 \\
59 \\
58 \\
57 \\
56 \\
55 \\
59 \\
2,910 \\
11,600\end{array}$ & $\begin{array}{r}450 \\
412 \\
379 \\
358 \\
334 \\
315 \\
298 \\
282 \\
---- \\
-----\end{array}$ \\
\hline \multicolumn{7}{|c|}{ 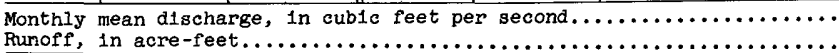 } & $\begin{array}{r}537 \\
33,040\end{array}$ & $\begin{array}{r}1,480 \\
82,200\end{array}$ \\
\hline
\end{tabular}

Gage he1ght, in feet, and discharge, in cublc feet per second, at Indicated time, 1963

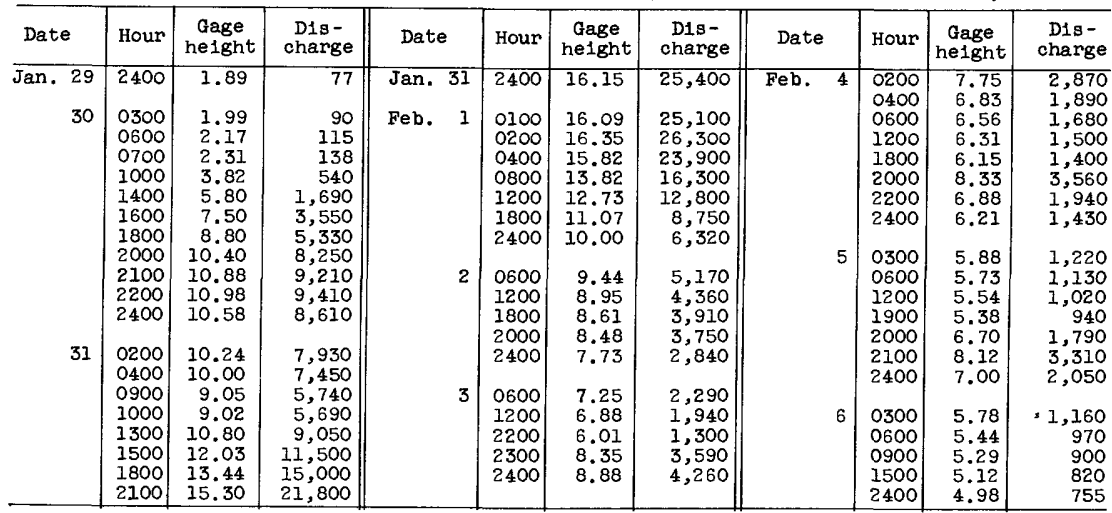


11-4525. Cache Creek at Yolo, Calif.

Location.--Lat $38^{\circ} 43^{1} 30^{\prime \prime}$, long $121^{\circ} 48^{\prime} 25^{\prime \prime}$, in Rio Jesus Maria Grant, on left bank $800 \mathrm{ft}$ upstream from highway bridge and $0.5 \mathrm{~m} 1 \mathrm{le}$ south of Yolo, Yolo County.

Drainage area $--1,137 \mathrm{sq} \mathrm{ml}$.

Gage-height record.--Water-stage recorder graph, except Jan. 1-10, 15-29. Record for Jan. 4 based on two staff-gage readings. Datum of gage is 52.27 ft above mean sea level, adjustment of 1929.

Discharge record.--Stage-discharge relation defined by current-meter measurements. Discharge for period of no gage-helght record estimated on bas is of hydrographer's and observer's notes, and trend in flow.

Max1ma.--January-February 1963: Discharge, 24,000 cfs 0700 hours Feb. I (gage height, $26.92 \mathrm{ft}$ ).

1903 to December 1962: Discharge, 41,400 cfs Feb. 25, 1958 (gage height, $33.11 \mathrm{ft}$ ); gage height observed, $34.2 \mathrm{ft}$ Mar. 10, 1904.

Remarks.--Flow regulated by Clear Lake beginning in 1915 (see station 11-4500).

Mean discharge, In cubic feet per second, 1963

\begin{tabular}{|c|c|c|c|c|c|c|c|c|}
\hline Day & January & February & Day & January & Febmuary & Day & January & Febmuary \\
\hline $\begin{array}{c}1 \ldots \ldots \\
2 \ldots \ldots \\
3 \ldots \ldots \\
4 \ldots \ldots \\
6 \ldots \ldots \\
7 \ldots \ldots \\
8 \ldots \ldots \\
10 \ldots \ldots\end{array}$ & $\begin{array}{l}50 \\
40 \\
35 \\
26 \\
20 \\
18 \\
18 \\
16 \\
16 \\
16\end{array}$ & $\begin{array}{r}18,200 \\
5,790 \\
2,460 \\
2,160 \\
1,510 \\
1,400 \\
707 \\
590 \\
574 \\
1,350\end{array}$ & $\begin{array}{l}11 \ldots \ldots \\
12 \ldots \ldots \\
13 \ldots \ldots \\
14 \ldots \ldots \\
15 \ldots \ldots \\
16 \ldots \ldots \\
17 \ldots \ldots \\
15 \ldots \ldots \\
19 \ldots \ldots \\
20 \ldots \ldots\end{array}$ & $\begin{array}{r}14 \\
29 \\
13 \\
10 \\
3 \\
2 \\
1 \\
.9 \\
.8 \\
.7\end{array}$ & $\begin{array}{r}1,200 \\
830 \\
3,420 \\
1,760 \\
1,150 \\
920 \\
774 \\
671 \\
586 \\
496\end{array}$ & $\begin{array}{l}21 \ldots \ldots \\
22 \ldots \ldots \\
23 \ldots \ldots \\
24 \ldots \ldots \\
25 \ldots \ldots \\
26 \ldots \ldots \\
27 \ldots \ldots \\
28 \ldots \ldots \\
29 \ldots \ldots \\
30 \ldots \ldots \\
31 \ldots \ldots\end{array}$ & $\begin{array}{r}0.6 \\
.5 \\
.4 \\
.3 \\
.2 \\
0^{.1} \\
0 \\
0 \\
0 \\
1,260 \\
11,100\end{array}$ & $\begin{array}{r}447 \\
413 \\
371 \\
338 \\
299 \\
299 \\
272 \\
248 \\
----- \\
-----\end{array}$ \\
\hline $\begin{array}{l}\text { onthly } \\
\text { unoff, }\end{array}$ & $\begin{array}{l}\text { an dis } \\
\text { acre- }\end{array}$ & $e, 1$ & te & & & & $\begin{array}{r}409 \\
25,170\end{array}$ & $\begin{array}{r}1,759 \\
97,720\end{array}$ \\
\hline
\end{tabular}

Gage helght, in feet, and discharge, In cublc feet per second, at indicated t1me, 1963

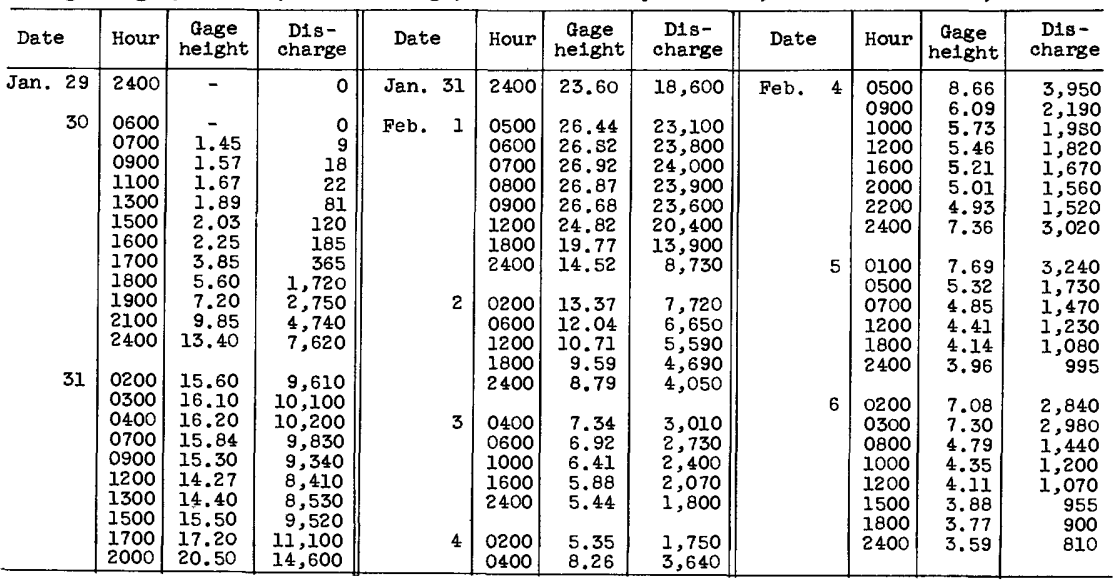


11-4530. Yolo bypass near Woodland, Calif.

Location.--Lat $38^{\circ} 40^{\prime} 40^{\prime \prime}$, long $121^{\circ} 38^{\prime} 35^{\prime \prime}$, on left bank just upstream from Sacramento and Woodland railroad bridge, 6 miles upstream from Sacramento bypass,

7 miles downstream from Fremont weir, and 7 miles east of Woodland, Yolo County.

Gage-height record.--Water-stage recorder graph. Datum of gage is set to Corps of Engineers datum.

Discharge record.--Stage-discharge relation defined by current-meter measurements.

Maxima.--January-February; 1963: Discharge, 163,000 cfs 0900 hours Feb. 2 (gage he1ght, $30.62 \mathrm{ft}$ ).

1939 to December 1962: Discharge, 272,000 cfs Feb. 8, 1942 (gage height, $32.00 \mathrm{ft}$ ).

Remarks.--Flow is from Cache Creek and Knights Landing Ridge Cut plus floodwater passing over Fremont weir.

Mean discharge, in cubic feet per second, 1963

\begin{tabular}{|c|c|c|c|c|c|c|c|c|}
\hline Day & January & February & Day & January & February & Day & January & February \\
\hline $\begin{array}{c}1 \ldots \ldots \\
2 \ldots \ldots \\
4 \ldots \ldots \\
5 \ldots \ldots \\
6 \ldots \ldots \\
7 \ldots \ldots \\
9 \ldots \ldots \\
10 \ldots \ldots\end{array}$ & $\begin{array}{r}211 \\
164 \\
142 \\
144 \\
134 \\
113 \\
100 \\
87 \\
92 \\
134\end{array}$ & $\begin{array}{r}65,700 \\
157,000 \\
114,000 \\
75,600 \\
50,700 \\
32,400 \\
20,200 \\
12,200 \\
6,180 \\
3,740\end{array}$ & $\begin{array}{l}11 \ldots \ldots \\
12 \ldots \ldots \\
13 \ldots \ldots \\
14 \ldots \ldots \\
15 \ldots \ldots \\
16 \ldots \ldots \\
17 \ldots \ldots \\
18 \ldots \ldots \\
19 \ldots \ldots \\
20 \ldots \ldots\end{array}$ & $\begin{array}{r}104 \\
69 \\
56 \\
52 \\
45 \\
39 \\
35 \\
34 \\
32 \\
27\end{array}$ & $\begin{array}{l}3,570 \\
3,390 \\
4,400 \\
7,920 \\
9,970 \\
7,800 \\
5,600 \\
4,020 \\
3,060 \\
2,570\end{array}$ & $\begin{array}{l}21 \ldots \ldots \\
22 \ldots \ldots \\
23 \ldots \ldots \\
24 \ldots \ldots \\
25 \ldots \ldots \\
26 \ldots \ldots \\
27 \ldots \ldots \\
28 \ldots \ldots \\
29 \ldots \ldots \\
30 \ldots \ldots \\
31 \ldots \ldots\end{array}$ & $\begin{array}{r}26 \\
26 \\
26 \\
25 \\
24 \\
22 \\
22 \\
22 \\
22 \\
86 \\
4,480\end{array}$ & $\begin{array}{r}1,930 \\
1,560 \\
1,290 \\
1,100 \\
948 \\
818 \\
764 \\
665 \\
----- \\
-----\end{array}$ \\
\hline $\begin{array}{l}\text { nthly } \\
\text { noff, }\end{array}$ & $\begin{array}{l}\text { in dis } \\
\text { acre- }\end{array}$ & 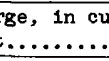 & for & & & & $\begin{array}{r}213 \\
13,080\end{array}$ & $\begin{array}{r}21,400 \\
1,188,000\end{array}$ \\
\hline
\end{tabular}

Gage helght, in feet, and discharge, In cublc feet per second, at indicated time, 1963

\begin{tabular}{|c|c|c|c|c|c|c|c|c|c|c|c|}
\hline Date & Hour & $\begin{array}{c}\text { Gage } \\
\text { helght }\end{array}$ & $\begin{array}{c}\text { Dis - } \\
\text { charge }\end{array}$ & Date & Hour & $\begin{array}{c}\text { Gage } \\
\text { helght }\end{array}$ & $\begin{array}{c}\text { Dis- } \\
\text { charge }\end{array}$ & Date & Hour & $\begin{array}{c}\text { Gage } \\
\text { height }\end{array}$ & $\begin{array}{l}\text { Dis- } \\
\text { charge }\end{array}$ \\
\hline \multirow[t]{5}{*}{$\begin{array}{r}\operatorname{Jan} .29 \\
30\end{array}$} & $\begin{array}{l}2400 \\
0800 \\
0900 \\
1100\end{array}$ & $\begin{array}{r}10.44 \\
10.51 \\
9.46 \\
9.61\end{array}$ & $\begin{array}{l}20 \\
27 \\
33 \\
42\end{array}$ & $\operatorname{Jan} .31$ & $\begin{array}{l}1300 \\
1800 \\
2100 \\
2400\end{array}$ & $\begin{array}{l}21.34 \\
22.10 \\
22.41 \\
22.96\end{array}$ & $\begin{array}{l}5,500 \\
7,030 \\
7,720 \\
9,430\end{array}$ & Feb. 2 & $\begin{array}{l}0900 \\
1200 \\
1800 \\
2400\end{array}$ & $\begin{array}{l}30.62 \\
30.61 \\
30.36 \\
29.99\end{array}$ & $\begin{array}{l}163,000 \\
163,000 \\
154,000 \\
141,000\end{array}$ \\
\hline & $\begin{array}{l}1500 \\
2000 \\
2400\end{array}$ & $\begin{array}{l}10.50 \\
11.34 \\
11.93\end{array}$ & $\begin{array}{l}103 \\
174 \\
223\end{array}$ & Feb. 1 & $\begin{array}{l}0600 \\
0800 \\
1000\end{array}$ & $\begin{array}{l}24.32 \\
24.73 \\
25.34\end{array}$ & $\begin{array}{l}15,100 \\
18,000 \\
24,100\end{array}$ & 3 & $\begin{array}{l}1200 \\
2400\end{array}$ & $\begin{array}{l}29.14 \\
28.36\end{array}$ & $\begin{array}{r}111,000 \\
91,100\end{array}$ \\
\hline & 0200 & $\begin{array}{l}12.20 \\
12.70\end{array}$ & $\begin{array}{l}253 \\
303\end{array}$ & & $\begin{array}{l}1300 \\
1600 \\
1800\end{array}$ & $\begin{array}{l}27.00 \\
28.78 \\
29.54\end{array}$ & $\begin{array}{r}56,000 \\
98,800 \\
125,000\end{array}$ & 4 & $\begin{array}{l}1200 \\
2400\end{array}$ & $\begin{array}{l}27.79 \\
27.20\end{array}$ & $\begin{array}{l}74,600 \\
62,000\end{array}$ \\
\hline & $\begin{array}{l}0400 \\
0600 \\
0800\end{array}$ & $\begin{array}{l}14.00 \\
16.70 \\
19.00\end{array}$ & $\begin{array}{r}516 \\
1,310 \\
2,630\end{array}$ & & $\begin{array}{l}2100 \\
2400\end{array}$ & $\begin{array}{l}30.09 \\
30.32\end{array}$ & $\begin{array}{l}145,000 \\
153,000\end{array}$ & 5 & $\begin{array}{l}1200 \\
2400\end{array}$ & $\begin{array}{l}26.70 \\
26.26\end{array}$ & $\begin{array}{l}50,500 \\
39,700\end{array}$ \\
\hline & & & & 2 & 0600 & 30.59 & 162,000 & & & & \\
\hline
\end{tabular}

11-4531.5. Putah Creek tributary near Whispering Pines, Calif.

(Crest-stage station)

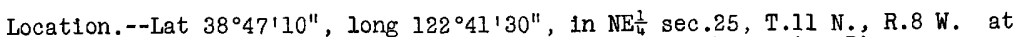
culvert on State Highway 29,2 miles southeast of Whispering Pines.

Drainage area. $-0.24 \mathrm{sq} \mathrm{ml}$.

Gage-height record.--Crest stages only. Altitude of gage is 1,600 ft (from topographic map).

Discharge record.--Maximum discharge by computation of flow through culvert.

Maxima.-January-February 1963: Discharge, $58 \mathrm{cfs}$ Feb. 1 (gage he1ght, $13.60 \mathrm{ft}$ ). 1958 to December 1962: Discharge, 40 cfs Feb. 13, 1962 (gage height, $12.41 \mathrm{ft})$. 
11-4532. Dry Creek near Middletown, Calif.

Location.--Lat $38^{\circ} 44^{\prime} 05^{\prime \prime}$, long $122^{\circ} 38^{\prime} 50^{\prime \prime}$, in NW $\frac{1}{4}$ sec.9, T.10 N., R.7 W., on right bank 0.3 mile downstream from Kroll Creek, 2.1 miles southwest of Middletown, and 2.7 miles upstream from mouth.

Dralnage area. $--8.41 \mathrm{sq} \mathrm{mi}$.

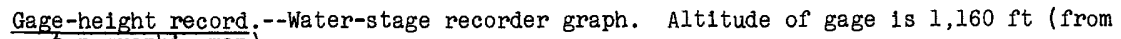
topographic map).

Discharge record.--Stage-discharge relation defined by current-meter measurements below $950 \mathrm{cfs}$.

Maxima.--January-February 1963: Discharge, 3,010 cfs 1000 hours Jan. 31 (gage height, $9.54 \mathrm{ft}$ ).

1959 to December 1962: Discharge, $3,470 \mathrm{cfs} F \mathrm{Feb} .8,1960$ (gage height, $9.90 \mathrm{ft})$.

Mean discharge, in cublc feet per second, 1963

\begin{tabular}{|c|c|c|c|c|c|c|c|c|}
\hline Day & January & February & Day & January & February & Day & January & February \\
\hline $\begin{array}{c}1 \ldots \ldots \\
2 \ldots \ldots \\
3 \ldots \ldots \\
4 \ldots \ldots \\
6 \ldots \ldots \\
7 \ldots \ldots \\
9 \ldots \ldots \\
10 \ldots \ldots\end{array}$ & $\begin{array}{l}9.4 \\
9.0 \\
8.5 \\
8.1 \\
7.6 \\
7.4 \\
7.0 \\
6.8 \\
6.6 \\
6.4\end{array}$ & $\begin{array}{r}421 \\
162 \\
95 \\
72 \\
57 \\
50 \\
42 \\
72 \\
91 \\
93\end{array}$ & $\begin{array}{l}11 \ldots \ldots \\
12 \ldots \ldots \\
13 \ldots \ldots \\
14 \ldots \ldots \\
15 \ldots \ldots \\
16 \ldots \ldots \\
17 \ldots \ldots \\
18 \ldots \ldots \\
19 \ldots \ldots \\
20 \ldots \ldots\end{array}$ & $\begin{array}{l}6.4 \\
6.0 \\
5.8 \\
5.8 \\
5.8 \\
5.6 \\
5.4 \\
5.8 \\
5.8 \\
4.8\end{array}$ & $\begin{array}{r}68 \\
173 \\
144 \\
51 \\
60 \\
50 \\
41 \\
33 \\
27 \\
24\end{array}$ & $\begin{array}{l}21 \ldots \ldots \\
22 \ldots \ldots \\
23 \ldots \ldots \\
24 \ldots \ldots \\
25 \ldots \ldots \\
26 \ldots \ldots \\
27 \ldots \ldots \\
28 \ldots \ldots \\
29 \ldots \ldots \\
30 \ldots \ldots \\
31 \ldots \ldots\end{array}$ & $\begin{array}{r}4.6 \\
4.6 \\
4.5 \\
4.5 \\
4.3 \\
4.3 \\
4.7 \\
4.7 \\
7.7 \\
573 \\
1,560\end{array}$ & $\begin{array}{r}22 \\
19 \\
17 \\
17 \\
15 \\
14 \\
14 \\
13 \\
--- \\
---1 \\
--1\end{array}$ \\
\hline \multicolumn{7}{|c|}{ 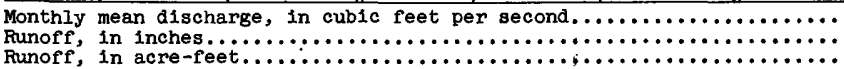 } & $\begin{array}{r}74.5 \\
10.21 \\
4,580\end{array}$ & $\begin{array}{r}71.0 \\
8.79 \\
3,940\end{array}$ \\
\hline
\end{tabular}

Gage height, in feet, and discharge, in cubic feet per second, at indicated time, 1963

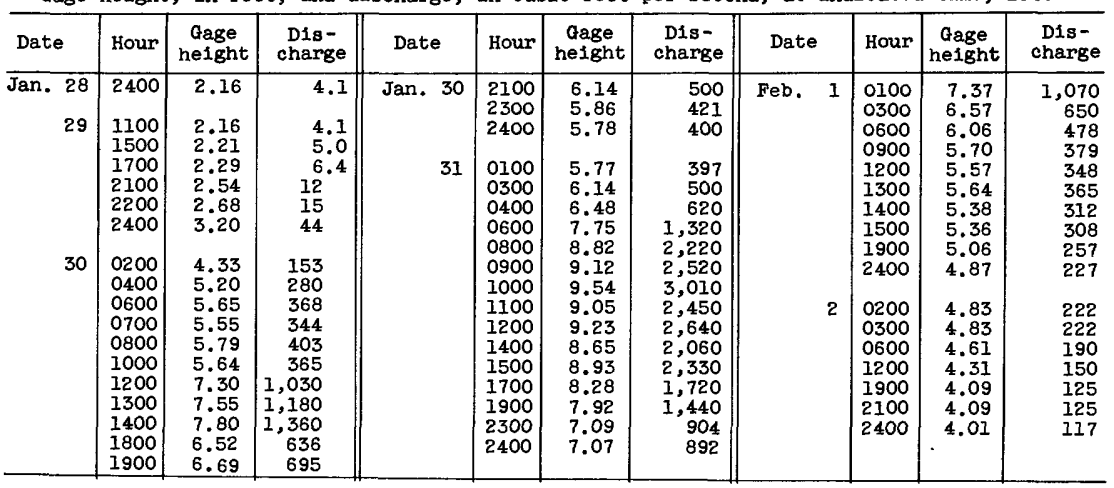


11-4535. Putah Creek near Guenoc, Calif.

Location.--Lat $38^{\circ} 46^{\prime} 45^{\prime \prime}$, long $122^{\circ} 31^{\prime} 00^{\prime \prime}$, in Guenoc land grant, on right bank just upstream from Coyote Valley damsite, 2.8 miles upstream from soda Creek 3.2 miles downstream from highway bridge at Guenoc, Lake County, and 5.6 miles northeast of Middletown.

Drainage area. $--112 \mathrm{sq} \mathrm{mi}$.

Gage-helght record.--Water-stage recorder graph. Datum of gage is 913.4 ft above mean sea level (river-profile survey).

Discharge record.--Stage-discharge relation defined by current-meter measurements below 13,000 cfs.

Maxima.--January-February 1963: Discharge, 26,500 cfs 1600 hours Jan. 31 (gage helght, $20.91 \mathrm{ft}$ ).

1904-6, 1930 to December 1962: Discharge, 32,000 cfs Dec. 11, 1937 (gage height, $22.7 \mathrm{ft}$ ), from rating curve extended above $7,200 \mathrm{cfs}$.

Mean discharge, in cubic feet per second, 1963

\begin{tabular}{|c|c|c|c|c|c|c|c|c|}
\hline Day & January & February & Day & January & February & Day & January & February \\
\hline $\begin{array}{c}1 \ldots \ldots \\
2 \ldots \ldots \\
3 \ldots \ldots \\
4 \ldots \ldots \\
5 \ldots \ldots \\
6 \ldots \ldots \\
7 \ldots \ldots \\
9 \ldots \ldots \\
10 \ldots \ldots\end{array}$ & $\begin{array}{l}93 \\
88 \\
83 \\
79 \\
75 \\
71 \\
68 \\
66 \\
64 \\
61\end{array}$ & $\begin{array}{r}5,070 \\
1,710 \\
1,060 \\
766 \\
586 \\
471 \\
391 \\
467 \\
790 \\
1,070\end{array}$ & $\begin{array}{l}11 \ldots \ldots \\
12 \ldots \ldots \\
13 \ldots \ldots \\
14 \ldots \ldots \\
15 \ldots \ldots \\
16 \ldots \ldots \\
17 \ldots \ldots \\
18 \ldots \ldots \\
19 \ldots \ldots \\
20 \ldots \ldots\end{array}$ & $\begin{array}{l}58 \\
55 \\
54 \\
53 \\
52 \\
51 \\
50 \\
49 \\
48 \\
47\end{array}$ & $\begin{array}{r}669 \\
1,650 \\
1,770 \\
923 \\
677 \\
550 \\
451 \\
382 \\
328 \\
291\end{array}$ & $\begin{array}{l}21 \ldots \ldots \\
22 \ldots \ldots \\
23 \ldots \ldots \\
24 \ldots \ldots \\
25 \ldots \ldots \\
26 \ldots \ldots \\
27 \ldots \ldots \\
28 \ldots \ldots \\
29 \ldots \ldots \\
30 \ldots \ldots \\
31 \ldots \ldots\end{array}$ & $\begin{array}{r}46 \\
45 \\
44 \\
43 \\
43 \\
42 \\
41 \\
41 \\
59 \\
5,270 \\
13,800\end{array}$ & $\begin{array}{r}260 \\
235 \\
212 \\
196 \\
180 \\
167 \\
157 \\
146 \\
----- \\
---.-\end{array}$ \\
\hline \multicolumn{9}{|c|}{ 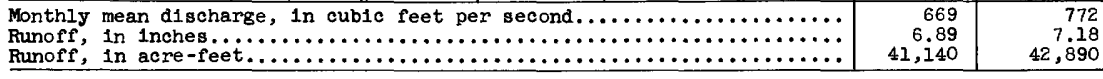 } \\
\hline
\end{tabular}

Gage helght, in feet, and discharge, in cublc feet per second, at indicated time, 1963

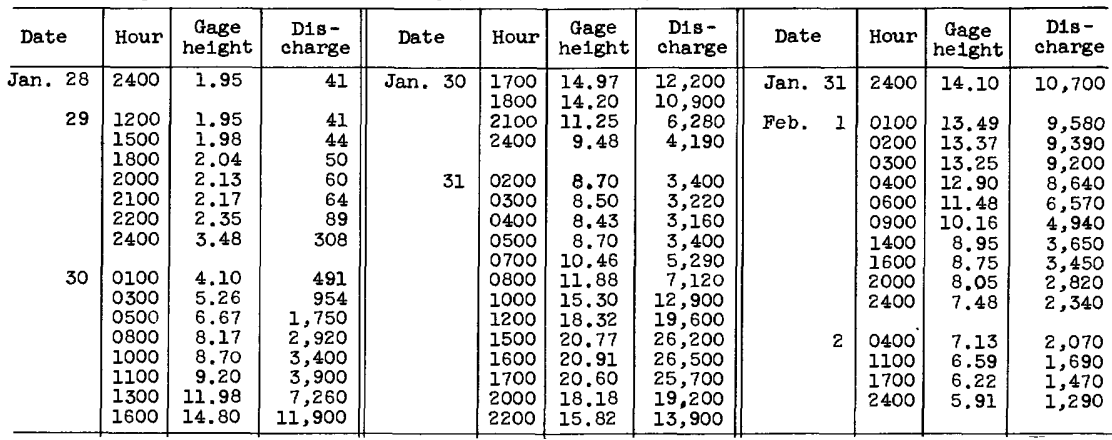


11-4536. Pope Creek near Pope Valley, Calif.

Location.--Lat $38^{\circ} 37^{\prime} 48^{\prime \prime}$, long $122^{\circ} 19^{\prime} 52^{\prime \prime}$, in SW $\frac{1}{4} \sec .17$, T.9 N., R.4 W., on left bank 0.2 mile upstream from Lake Berryessa, 0.7 mile downstream from Maxwell Creek, and 5.2 miles east of Pope Valiey.

Drainage area. $--78.3 \mathrm{sq} \mathrm{mi}$.

Gage-height record.--Water-stage recorder graph. Altitude of gage is $450 \mathrm{ft}$ (from topographic mapt.

Discharge record.--Stage-discharge relation defined by current-meter measurements below 7,700 cfs.

Maxima.--January-February 1963: Discharge, 18,000 cfs 1430 hours Jan. 31 (gage heIght, $19.79 \mathrm{ft}$ ).

1960 to December 1962: Discharge, 7,540 cfs Feb. 14, 1962 (gage height, $13.58 \mathrm{ft}$ ).

Remarks.--Records furnished by California. Department of Water Resources.

Mean discharge, in cubic feet per second, 1963

\begin{tabular}{|c|c|c|c|c|c|c|c|c|}
\hline Day & January & February & Day & January & February & Day & January & February \\
\hline $\begin{array}{c}1 \ldots \ldots \\
2 \ldots \ldots \\
3 \ldots \ldots \\
4 \ldots \ldots \\
5 \ldots \ldots \\
7 \ldots \ldots \\
8 \ldots \ldots \\
9 \ldots \ldots \\
10 \ldots \ldots\end{array}$ & $\begin{array}{l}28 \\
27 \\
26 \\
24 \\
22 \\
22 \\
20 \\
19 \\
19 \\
18\end{array}$ & $\begin{array}{r}2,350 \\
599 \\
365 \\
248 \\
195 \\
152 \\
129 \\
138 \\
345 \\
473\end{array}$ & $\begin{array}{l}12 \ldots \ldots \\
12 \ldots \ldots \\
13 \ldots \ldots \\
14 \ldots \ldots \\
15 \ldots \ldots \\
16 \ldots \ldots \\
17 \ldots \ldots \\
18 \ldots \ldots \\
19 \ldots \ldots \\
20 \ldots \ldots\end{array}$ & $\begin{array}{l}17 \\
15 \\
15 \\
15 \\
15 \\
15 \\
14 \\
14 \\
13 \\
13\end{array}$ & $\begin{array}{l}221 \\
662 \\
697 \\
330 \\
239 \\
194 \\
160 \\
134 \\
119 \\
104\end{array}$ & $\begin{array}{l}22 \ldots \ldots \\
22 \ldots \ldots \\
23 \ldots \ldots \\
24 \ldots \ldots \\
25 \ldots \ldots \\
26 \ldots \ldots \\
27 \ldots \ldots \\
28 \ldots \ldots \\
29 \ldots \ldots \\
30 \ldots \ldots \\
31 \ldots \ldots\end{array}$ & $\begin{array}{r}13 \\
13 \\
13 \\
13 \\
12 \\
12 \\
12 \\
12 \\
18 \\
3,010 \\
8,630\end{array}$ & $\begin{array}{r}95 \\
86 \\
77 \\
73 \\
68 \\
63 \\
59 \\
55 \\
----- \\
-----\end{array}$ \\
\hline \multicolumn{7}{|l|}{$\begin{array}{l}\text { Monthly } \\
\text { Runoff, } \\
\text { Runoff, }\end{array}$} & $\begin{array}{r}391 \\
5.76 \\
24,060 \\
\end{array}$ & $\begin{array}{r}301 \\
4.00 \\
16,720 \\
\end{array}$ \\
\hline
\end{tabular}

Gage height, in feet, and discharge, in cubic feet per second, at indicated time, 1963

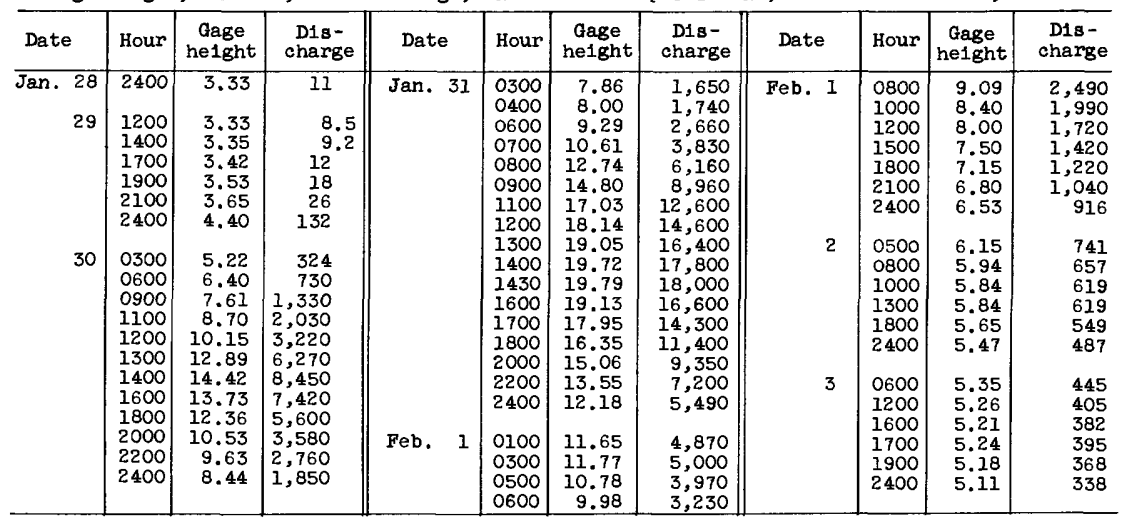


11-4537. Capell Creek tributary near Wooden Valley, Calif.

Location.--Lat $38^{\circ} 26^{\prime} 0^{\prime \prime}$, long $122^{\circ} 12^{\prime} 15^{\prime \prime}$, in SW $\frac{1}{4}$ sec.21, T.7 N., R.3 W., on State Highway 37,4 miles north of town of Wooden Valley.

Drainage area. $--0.87 \mathrm{sq} \mathrm{mi}$.

Gage-height record ${ }^{--W a t e r-s t a g e ~ r e c o r d e r ~ g r a p h . ~ A l t i t u d e ~ o f ~ g a g e ~ i s ~} 790 \mathrm{ft}$ (from topographic map).

Discharge record.--Stage-discharge relation defined by current-meter measurements below $95 \mathrm{cf}$ 's and by indirect measurement of peak flow through culvert at $376 \mathrm{cfs}$.

Maxima --January-February 1963: Discharge, 376 cfs 1245 hours Jan. 31 (gage helght, $7.29 \mathrm{ft}$ in gage well; $7.70 \mathrm{ft}$, from floodmarks).

1958 to December 1962: Discharge, $158 \mathrm{cfs}$ Feb. 8, 1960 (gage he1ght, $4.91 \mathrm{ft}$ ), by computation of maximum flow through culvert.

Mean discharge, in cubic feet per second, 1963

\begin{tabular}{|c|c|c|c|c|c|c|c|c|}
\hline Day & January & Bebruary & Day & Januarry & February & Day & January & February \\
\hline $\begin{array}{c}1 \ldots \ldots \\
2 \ldots \ldots \\
3 \ldots \ldots \\
4 \ldots \ldots \\
6 \ldots \ldots \\
7 \ldots \ldots \\
9 \ldots \ldots \\
10 \ldots \ldots\end{array}$ & $\begin{array}{r}0.2 \\
.2 \\
.2 \\
.2 \\
.2 \\
.2 \\
.2 \\
.2 \\
.2 \\
.2\end{array}$ & $\begin{array}{l}28 \\
6.9 \\
4.1 \\
3.2 \\
2.3 \\
1.4 \\
1.4 \\
1.3 \\
5.6 \\
6.6\end{array}$ & $\begin{array}{l}11 \ldots \ldots \\
12 \ldots \ldots \\
13 \ldots \ldots \\
14 \ldots \ldots \\
15 \ldots \ldots \\
16 \ldots \ldots \\
17 \ldots \ldots \\
18 \ldots \ldots \\
19 \ldots \ldots \\
20 \ldots \ldots\end{array}$ & $\begin{array}{r}0.2 \\
.2 \\
.2 \\
.2 \\
.2 \\
.2 \\
.2 \\
.2 \\
.2 \\
.2\end{array}$ & $\begin{array}{l}3.5 \\
6.6 \\
7.6 \\
4.4 \\
3.2 \\
2.6 \\
2.3 \\
2.0 \\
1.4 \\
1.4\end{array}$ & $\begin{array}{l}21 \ldots \ldots \\
22 \ldots \ldots \\
23 \ldots \ldots \\
24 \ldots \ldots \\
25 \ldots \ldots \\
26 \ldots \ldots \\
27 \ldots \ldots \\
25 \ldots \ldots \\
29 \ldots \ldots \\
30 \ldots \ldots \\
31 \ldots \ldots\end{array}$ & $\begin{array}{r}0.2 \\
.2 \\
.2 \\
.2 \\
.2 \\
.2 \\
.2 \\
.2 \\
1.7 \\
53 \\
159\end{array}$ & 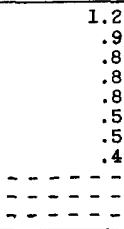 \\
\hline \multicolumn{7}{|c|}{$\begin{array}{l}\text { Monthly mea } \\
\text { Runoff, in } \\
\text { Runoff, in }\end{array}$} & $\begin{array}{r}7.07 \\
9.37 \\
435 \\
\end{array}$ & $\begin{array}{r}3.63 \\
4.35 \\
202 \\
\end{array}$ \\
\hline
\end{tabular}

Gage helght, in feet, and discharge, in cub1c feet per second, at indicated time, 1963

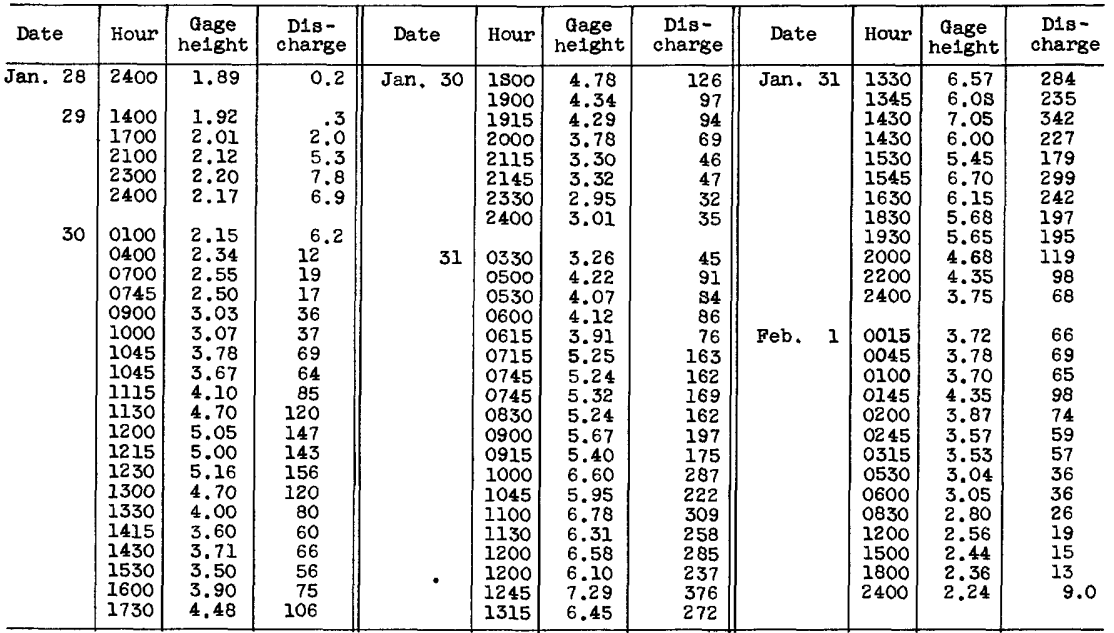


11-4539. Lake Berryessa near Winters, Calif.

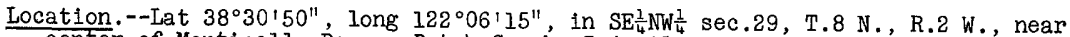
center of Monticello Dam on Putah Creek, 7.4 miles west of Winters.

Drainage area. $--577 \mathrm{sq} \mathrm{mi}$.

Gage-height record.--Water-stage recorder graph. Datum of gage is at mean sea level (levels by Bureau of Reclamation).

Contents record.--Contents computed from capacity table dated September 1956.

Maxima.--January-February 1963: Computed bihourly inflow, 84,200 cfs 1400 to 1600 hours Jan; 31 . Contents, 1,441,800 acre-ft 2400 hours Feb. 28 (elevation, $431.50 \mathrm{ft}$ ).

1957 to December 1962: Contents, 1,243,400 acre-ft Apr. 3-7, 1962 (elevation, $420.43 \mathrm{f}^{\prime} \mathrm{t}$ ).

Remarks.--Reservoir is formed concrete arch-gravity dam, completed November 1956 Usable capacity, 1,592,000 acre-ft between elevations 253.25 (invert of outlet valves) and $440 \mathrm{ft}$ (controlled spillway elevation) above mean sea level. Dead storage, 10,340 acre-ft. Records, including extremes, show total contents. Record of contents furnished by Bureau of Reclamation.

Contents, in acre-feet, at 2400 hours, 1963

\begin{tabular}{c|c|c||c|c|c||c|c|c}
\hline Day & January & Febmuary & Day & January & February & Day & January & February \\
\hline $1 \ldots \ldots$ & $1,202,600$ & $1,363,400$ & $11 \ldots \ldots$ & $1,203,100$ & $1,399,900$ & $21 \ldots \ldots$ & $1,201,900$ & $1,436,200$ \\
$2 \ldots \ldots$ & $1,202,600$ & $1,372,100$ & $12 \ldots \ldots$ & $1,203,200$ & $1,409,200$ & $22 \ldots \ldots$ & $1,201,900$ & $1,437,000$ \\
$3 \ldots \ldots$ & $1,202,700$ & $1,376,800$ & $13 \ldots \ldots$ & $1,202,100$ & $1,418,900$ & $23 \ldots \ldots$ & $1,201,900$ & $1,438,100$ \\
$4 \ldots \ldots$ & $1,202,900$ & $1,379,700$ & $14 \ldots \ldots$ & $1,202,200$ & $1,423,400$ & $24 \ldots \ldots$ & $1,201,700$ & $1,439,000$ \\
$5 \ldots \ldots$ & $1,202,900$ & $1,382,100$ & $15 \ldots \ldots$ & $1,202,400$ & $1,425,700$ & $25 \ldots \ldots$ & $1,201,500$ & $1,439,900$ \\
$6 \ldots \ldots$ & $1,202,900$ & $1,384,100$ & $16 \ldots \ldots$ & $1,202,400$ & $1,428,300$ & $26 \ldots \ldots$ & $1,201,400$ & $1,440,300$ \\
$7 \ldots \ldots$ & $1,202,900$ & $1,385,500$ & $17 \ldots \ldots$ & $1,202,100$ & $1,430,300$ & $27 \ldots \ldots$ & $1,201,000$ & $1,440,900$ \\
$8 \ldots \ldots$ & $1,203,100$ & $1,357,200$ & $18 \ldots \ldots$ & $1,201,900$ & $1,432,200$ & $25 \ldots \ldots$ & $1,201,000$ & $1,441,500$ \\
$9 \ldots \ldots$ & $1,203,100$ & $1,391,900$ & $19 \ldots \ldots$ & $1,201,900$ & $1,433,600$ & $29 \ldots \ldots$ & $1,202,400$ & $-\ldots-\ldots$ \\
$10 \ldots \ldots$ & $1,203,100$ & $1,397,400$ & $20 \ldots \ldots$ & $1,201,900$ & $1,435,100$ & $30 \ldots \ldots$ & $1,240,500$ & $-\ldots-\ldots$ \\
10
\end{tabular}

Average Inflow, in cublc feet per second, for bihourly periods ending at indicated t1me, 1963

\begin{tabular}{|c|c|c|c|c|c|c|c|c|}
\hline Date & Hour & Inflow & Date & Hour & Inflow & Date & Hour & Inflow \\
\hline Jan. 30 & $\begin{array}{l}0200 \\
0400 \\
0600 \\
0800 \\
1000 \\
1200 \\
1400 \\
1600 \\
1800 \\
2000 \\
2200 \\
2400 \\
\\
0200 \\
0400 \\
0600 \\
0800 \\
1000\end{array}$ & $\begin{array}{r}- \\
2,080 \\
3,120 \\
9,360 \\
8,310 \\
17,700 \\
31,100 \\
45,800 \\
36,600 \\
35,500 \\
23,000 \\
15,800 \\
15,800 \\
10,500 \\
12,600 \\
24,200 \\
38,000\end{array}$ & Feb. 1 & $\begin{array}{l}1200 \\
1400 \\
1600 \\
1800 \\
2000 \\
2200 \\
2400 \\
\\
0200 \\
0400 \\
0600 \\
0800 \\
1000 \\
1200 \\
1400 \\
1600 \\
1800\end{array}$ & $\begin{array}{r}64,500 \\
74,300 \\
84,200 \\
78,100 \\
76,300 \\
59,300 \\
35,700 \\
32,400 \\
31,500 \\
19,600 \\
18,500 \\
13,100 \\
10,900 \\
12,000 \\
5,440 \\
8,730\end{array}$ & Feb. 1 & $\begin{array}{l}2000 \\
2200 \\
2400 \\
\\
0200 \\
0400 \\
0600 \\
0800 \\
1000 \\
1200 \\
1400 \\
1600 \\
1800 \\
2000 \\
2200 \\
2400\end{array}$ & $\begin{array}{l}7,660 \\
8,760 \\
4,390 \\
6,570 \\
9,860 \\
1,100 \\
4,380 \\
4,380 \\
4,380 \\
3,290 \\
5,480 \\
1,100 \\
2,200 \\
6,570 \\
2,190\end{array}$ \\
\hline
\end{tabular}


11-4540. Putah Creek near Winters, Calif.

Location.--Lat $38^{\circ} 30^{\prime} 55^{\prime \prime}$, long $122^{\circ} 04^{\prime} 50^{\prime \prime}$, in $\mathrm{NE} \frac{1}{4} \mathrm{NE} \frac{1}{4} \sec .28$, T. 8 N., R.2 W., on left bank 1.3 miles downstream from Monticeilo Dam, 6 miles west of Winters, and 8 miles downstream from Capell Creek.

Drainage area. $--577 \mathrm{sq} \mathrm{ml}$.

Gage-height record.--Water-stage recorder. Datum of gage is $160.75 \mathrm{ft}$ above mean sea level (river-profile survey).

Discharge record.--Stage-discharge relation defined by current-meter measurements.

Maxima.--January-February, 1963: Discharge, 1,060 cfs 1300 hours Jan. 31 (gage height, $8.77 \mathrm{ft}$. $30.5 \mathrm{ft}$ ).

Remarks.--Flow regulated by Lake Berryessa (station 1l-4539) since Jan. 11, 1957.

Mean discharge, in cublc feet per second, 1963

\begin{tabular}{|c|c|c|c|c|c|c|c|c|}
\hline Day & January & February & Day & January & February & Day & January & February \\
\hline $\begin{array}{c}1 \ldots \ldots \\
2 \ldots \ldots \\
3 \ldots \ldots \\
4 \ldots \ldots \\
6 \ldots \ldots \\
7 \ldots \ldots \\
8 \ldots \ldots \\
9 \ldots \ldots \\
10 \ldots \ldots\end{array}$ & $\begin{array}{l}83 \\
77 \\
74 \\
76 \\
78 \\
78 \\
78 \\
78 \\
78 \\
77\end{array}$ & $\begin{array}{r}196 \\
54 \\
34 \\
26 \\
21 \\
41 \\
52 \\
41 \\
39 \\
43\end{array}$ & $\begin{array}{l}11 \ldots \ldots \\
12 \ldots \ldots \\
13 \ldots \ldots \\
14 \ldots \ldots \\
15 \ldots \ldots \\
16 \ldots \ldots \\
17 \ldots \ldots \\
18 \ldots \ldots \\
19 \ldots \ldots \\
20 \ldots \ldots\end{array}$ & $\begin{array}{l}74 \\
69 \\
69 \\
51 \\
36 \\
35 \\
42 \\
56 \\
56 \\
56\end{array}$ & $\begin{array}{l}29 \\
35 \\
58 \\
39 \\
34 \\
32 \\
28 \\
25 \\
24 \\
27\end{array}$ & $\begin{array}{l}21 \ldots \ldots \\
22 \ldots \ldots \\
23 \ldots \ldots \\
24 \ldots \ldots \\
25 \ldots \ldots \\
26 \ldots \ldots \\
27 \ldots \ldots \\
28 \ldots \ldots \\
29 \ldots \ldots \\
30 \ldots \ldots \\
31 \ldots \ldots\end{array}$ & $\begin{array}{r}58 \\
62 \\
65 \\
90 \\
141 \\
187 \\
145 \\
65 \\
58 \\
170 \\
621\end{array}$ & $\begin{array}{r}39 \\
43 \\
41 \\
41 \\
40 \\
40 \\
40 \\
39 \\
-\ldots---\end{array}$ \\
\hline $\begin{array}{l}\text { onthly } \\
\text { unoff, }\end{array}$ & \multicolumn{6}{|c|}{ 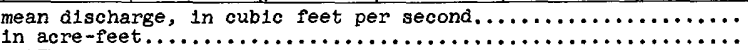 } & $\begin{array}{r}96.2 \\
5,920\end{array}$ & $\begin{array}{r}42.9 \\
2,380 \\
\end{array}$ \\
\hline
\end{tabular}

Gage helght, in feet, and discharge, in cublc feet per second, at indlcated time, 1963

\begin{tabular}{|c|c|c|c|c|c|c|c|c|c|c|c|}
\hline Date & Hour & $\begin{array}{c}\text { Gage } \\
\text { helght }\end{array}$ & $\begin{array}{l}\text { D1s- } \\
\text { charge }\end{array}$ & Date & Hour & $\begin{array}{c}\text { Gage } \\
\text { helght }\end{array}$ & $\begin{array}{c}\text { Dis- } \\
\text { charge }\end{array}$ & Date & Hour & $\begin{array}{c}\text { Gage } \\
\text { helght }\end{array}$ & $\begin{array}{c}\text { Dis- } \\
\text { charge }\end{array}$ \\
\hline $\operatorname{Jan} .29$ & 2400 & & & $\operatorname{Jan} .31$ & $\begin{array}{l}0300 \\
0500\end{array}$ & $\begin{array}{l}5.71 \\
5.88\end{array}$ & $\begin{array}{l}163 \\
189\end{array}$ & Jan. 31 & 2400 & 6.97 & 416 \\
\hline $\operatorname{Jan} .31$ & $\begin{array}{l}1100 \\
1300 \\
1500 \\
1800 \\
2100 \\
2400 \\
0300 \\
\end{array}$ & $\begin{array}{l}4.50 \\
5.60 \\
7.00 \\
6.38 \\
6.78 \\
6.00 \\
5.71\end{array}$ & $\begin{array}{r}39 \\
148 \\
424 \\
280 \\
369 \\
208 \\
\\
163 \\
\end{array}$ & & $\begin{array}{l}0700 \\
0800 \\
1000 \\
1300 \\
1400 \\
1600 \\
1800 \\
2100\end{array}$ & $\begin{array}{l}6.65 \\
7.10 \\
8.15 \\
8.77 \\
8.72 \\
8.72 \\
8.54 \\
7.73\end{array}$ & $\begin{array}{r}339 \\
450 \\
790 \\
i, 060 \\
1,030 \\
1,030 \\
953 \\
636\end{array}$ & Feb. 1 & $\begin{array}{l}0300 \\
0500 \\
1000 \\
1800 \\
2400\end{array}$ & $\begin{array}{l}6.52 \\
6.57 \\
5.85 \\
5.28 \\
5.00\end{array}$ & $\begin{array}{r}310 \\
321 \\
184 \\
108 \\
78\end{array}$ \\
\hline
\end{tabular}

11-4540.2. Putah Creek tributary No. 2 near Winters, Calif.

(Crest-stage station)

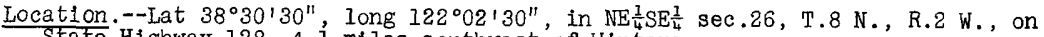
State Highway $128,4.1$ miles southwest' of Winters.

Drainage area. $--0.050 \mathrm{sq} \mathrm{mi}$.

Gage-height record.--Crest stages only. Altitude of gage is $170 \mathrm{ft}$ (from topographic map).

Discharge record.--Stage-discharge relation defined by current-meter measurements below $0.2 \mathrm{cf}$ 's and by computation of flow through culvert at $1.8 \mathrm{cfs}$ and $7.2 \mathrm{cfs}$.

Maxima.--January-February 1963: Discharge, $6.3 \mathrm{cfs}$ Feb. 1 (gage height, $21.49 \mathrm{ft}$ ).

1959 to December 1962: Discharge, 7.2 cfs Feb. 9, 1962 (gage height, $21.60 \mathrm{ft}$ ). 
11-4541. Pleasants Creek near Winters, Calif.

Location.--Lat $38^{\circ} 28^{\prime} 40^{\prime \prime}$, long $122^{\circ} 01^{\prime} 43^{\prime \prime}$, in $\mathrm{SW}_{\frac{1}{4}} \mathrm{SE} \frac{1}{4}$ sec.l, T.7 N., R.2 W., on left bank 0.2 mile upstream from unnamed tributary, 0.3 mile above bridge on Pleasants Valley road, 1.3 miles northeast of Pleasants Valley School, and 5 miles west of Winters.

Drainage area. $--15.9 \mathrm{sq} \mathrm{mi}$.

Gage-height record.--Water-stage recorder graph. Datum of gage is $150.33 \mathrm{ft}$ above mean sea level.

Discharge record.--Stage-discharge relation defined by current-meter measurements below $1,100 \mathrm{c}$ s.

Maxima.--January-February 1963: Discharge, 3,780 cfs 1730 hours Jan. 31 (gage height, $12.36 \mathrm{ft}^{\mathrm{t}}$ ).

1959 to December 1962: Discharge, 1,580 cfs Feb. 9, 1962 (gage height, $8.55 \mathrm{ft}$ ).

Remarks.--Records furnished by the California Department of Water Resources and reviewed by Geological Survey.

Mean d1scharge, in cub1c feet per second, 1963

\begin{tabular}{|c|c|c|c|c|c|c|c|c|}
\hline Day & January & February & Day & January & February & Day & January & February \\
\hline $\begin{array}{r}\ldots \ldots \\
2 \ldots \ldots \\
3 \ldots \ldots \\
4 \ldots \ldots \\
5 \ldots \ldots \\
6 \ldots \ldots \\
7 \ldots \ldots \\
9 \ldots \ldots \\
10 \ldots \ldots\end{array}$ & $\begin{array}{l}1.2 \\
1.2 \\
1.1 \\
1.2 \\
1.2 \\
1.2 \\
1.2 \\
1.2 \\
1.3 \\
1.2\end{array}$ & $\begin{array}{r}380 \\
78 \\
47 \\
33 \\
25 \\
20 \\
17 \\
15 \\
44 \\
58\end{array}$ & $\begin{array}{l}11 \ldots \ldots \\
12 \ldots \ldots \\
13 \ldots \ldots \\
14 \ldots \ldots \\
15 \ldots \ldots \\
16 \ldots \ldots \\
17 \ldots \ldots \\
18 \ldots \ldots \\
19 \ldots \ldots \\
20 \ldots \ldots\end{array}$ & $\begin{array}{r}1.0 \\
1.0 \\
1.1 \\
1.1 \\
1.0 \\
1.1 \\
1.0 \\
1.0 \\
1.0 \\
.9\end{array}$ & $\begin{array}{l}26 \\
62 \\
72 \\
37 \\
29 \\
25 \\
21 \\
18 \\
16 \\
15\end{array}$ & $\begin{array}{l}21 \ldots \ldots \\
22 \ldots \ldots \\
23 \ldots \ldots \\
24 \ldots \ldots \\
25 \ldots \ldots \\
26 \ldots \ldots \\
27 \ldots \ldots \\
28 \ldots \ldots \\
29 \ldots \ldots \\
30 \ldots \ldots \\
31 \ldots \ldots\end{array}$ & $\begin{array}{r}.9 \\
.9 \\
.9 \\
.9 \\
.9 \\
.9 \\
.9 \\
.9 \\
4.0 \\
605 \\
1,660\end{array}$ & $\begin{array}{r}13 \\
12 \\
11 \\
10 \\
10 \\
9.2 \\
8.8 \\
8.2 \\
----- \\
---.-\end{array}$ \\
\hline $\begin{array}{l}\text { lonthiy } \\
\text { unoff, } \\
\text { tunoff, }\end{array}$ & acre & & & & & & $\begin{array}{r}74.1 \\
5.37 \\
4.560 \\
\end{array}$ & $\begin{array}{r}40.0 \\
2.62 \\
2,220 \\
\end{array}$ \\
\hline
\end{tabular}

Gage height, in feet, and discharge, in cublc feet per second, at indicated time, 1963

\begin{tabular}{|c|c|c|c|c|c|c|c|c|c|c|c|}
\hline Date & Hour & $\begin{array}{c}\text { Gage } \\
\text { he1ght }\end{array}$ & $\underset{\text { charge }}{\text { Dis- }}$ & Date & Hour & $\begin{array}{c}\text { Gage } \\
\text { helght }\end{array}$ & $\begin{array}{c}\text { D1s- } \\
\text { charge }\end{array}$ & Date & Hour & $\begin{array}{c}\text { Gage } \\
\text { he1ght }\end{array}$ & $\begin{array}{c}\text { Dts- } \\
\text { charge }\end{array}$ \\
\hline $\begin{array}{r}\operatorname{Jan} .28 \\
29\end{array}$ & $\begin{array}{l}2400 \\
1400 \\
1700 \\
2200 \\
2300 \\
2400\end{array}$ & $\begin{array}{l}1.38 \\
1.38 \\
1.42 \\
1.61 \\
2.81 \\
2.74\end{array}$ & $\begin{array}{r}0.8 \\
.4 \\
.7 \\
3.1 \\
64 \\
58\end{array}$ & Jan. 30 & $\begin{array}{l}1500 \\
1.600 \\
1700 \\
2030 \\
2200 \\
2400\end{array}$ & $\begin{array}{l}9.00 \\
6.94 \\
6.24 \\
7.35 \\
5.96 \\
5.00\end{array}$ & $\begin{array}{r}1,790 \\
931 \\
705 \\
1,080 \\
623 \\
384\end{array}$ & Jan. 31 & $\begin{array}{l}1600 \\
1730 \\
1900 \\
2000 \\
2200 \\
2400\end{array}$ & $\begin{array}{r}9.79 \\
12.36 \\
11.04 \\
10.26 \\
8.84 \\
7.14\end{array}$ & $\begin{array}{r}2,160 \\
3,780 \\
2,890 \\
2,430 \\
1,680 \\
980\end{array}$ \\
\hline 30 & $\begin{array}{l}0200 \\
0400 \\
0600 \\
0800 \\
0900 \\
1100 \\
1200 \\
1300 \\
1400\end{array}$ & $\begin{array}{l}2.78 \\
2.58 \\
3.14 \\
3.52 \\
3.71 \\
4.73 \\
6.15 \\
8.55 \\
9.96\end{array}$ & $\begin{array}{r}56 \\
41 \\
88 \\
131 \\
156 \\
327 \\
678 \\
1,580 \\
2,290\end{array}$ & 31 & $\begin{array}{l}0100 \\
0300 \\
0500 \\
0600 \\
0700 \\
0900 \\
1000 \\
1200 \\
1300 \\
1500\end{array}$ & $\begin{array}{r}4.63 \\
5.40 \\
5.29 \\
5.64 \\
7.57 \\
8.15 \\
9.18 \\
10.30 \\
10.08 \\
9.54\end{array}$ & $\begin{array}{r}296 \\
462 \\
436 \\
521 \\
1,140 \\
1,370 \\
1,850 \\
2,450 \\
2,320 \\
2,030\end{array}$ & Feb. & $\begin{array}{l}0230 \\
0400 \\
0600 \\
0800 \\
1000 \\
1200 \\
1600 \\
2000 \\
2400\end{array}$ & $\begin{array}{l}6.04 \\
8.11 \\
6.58 \\
5.53 \\
4.99 \\
4.61 \\
4.08 \\
3.72 \\
3.47\end{array}$ & $\begin{array}{r}549 \\
1,180 \\
690 \\
432 \\
325 \\
257 \\
181 \\
135 \\
109\end{array}$ \\
\hline
\end{tabular}


NORTH-COASTAL CALIFORNIA

\section{NAPA RIVER BASIN}

11-4559.5. Sulphur Creek near St. Helena, Calif.

$$
\text { (Crest-stage station) }
$$

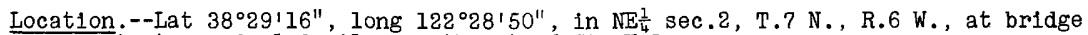
on private road, 1.3 miles southwest of St. Helena.

Drainage area. $--4.49 \mathrm{sq} \mathrm{mi}$.

Gage-height record.--Crest stages only. Altitude of gage is $300 \mathrm{ft}$ (from topographic map).

D1scharge record.--Stage-discharge relation defined by current-meter measurements below $170 \mathrm{cf}$ 's and by slope-area measurement at $924 \mathrm{cfs}$.

Maxima.--January-February 1963: D1scharge, 500 cfs Jan. 31 (gage he1ght, $11.71 \mathrm{ft}$ ). 1957 to December 1962: Discharge, $924 \mathrm{cfs} \mathrm{Feb} .24$, 1958 (gage helght, $13.53 \mathrm{ft}$ ).

Flood of Dec. 21, 1955, reached a stage of $15.80 \mathrm{ft}$, from floodmarks.

11-4560. Napa River near St. Helena, Cal1f.

Location.--Lat $38^{\circ} 29^{\prime} 40^{\prime \prime}$, long $122^{\circ} 25^{\prime} 50^{\prime \prime}$, in SE $\frac{1}{4}$ sec.32, T. 8 N., R.5 W., on right bank $0.2 \mathrm{mile}$ upstream from highway bridge, 1.3 miles northeast of $\mathrm{Zinfandel}$, and 2.5 miles east of St. Helena.

Drainage area. $--81.1 \mathrm{sq} \mathrm{mi}$.

Gage-he1ght record --Water-stage recorder graph, except Feb. 26-28. Altitude of gage is $200 \mathrm{ft}$ (from topographic map).

Discharge record.--Stage-discharge relation defined by current-meter measurements. Discharge Feb. 26-28 estimated on basis of interpolation and records for station near Napa.

Maxima.--January-February 1963: D1scharge, 12,300 cfs 1730 hours Jan. 31 (gage he1ght, $15.30 \mathrm{ft}$ ).

1929-32, 1939 to December 1962: D1scharge, 12,600 cfs Dec. 22, 1955 (gage height, $16.17 \mathrm{ft}$ ).

Mean discharge, in cublc feet per second, 1963

\begin{tabular}{|c|c|c|c|c|c|c|c|c|}
\hline Day & January & February & Day & January & February & Day & January & February \\
\hline $\begin{array}{c}1 \ldots \ldots \\
3 \ldots \ldots \\
4 \ldots \ldots \\
5 \ldots \ldots \\
6 \ldots \ldots \\
7 \ldots \ldots \\
9 \ldots \ldots \\
10 \ldots \ldots\end{array}$ & $\begin{array}{l}44 \\
42 \\
41 \\
38 \\
36 \\
34 \\
33 \\
32 \\
31 \\
30\end{array}$ & $\begin{array}{r}2,920 \\
967 \\
626 \\
341 \\
241 \\
201 \\
174 \\
183 \\
424 \\
674\end{array}$ & $\begin{array}{l}11 \ldots \ldots \\
12 \ldots \ldots \\
13 \ldots \ldots \\
14 \ldots \ldots \\
15 \ldots \ldots \\
16 \ldots \ldots \\
17 \ldots \ldots \\
18 \ldots \ldots \\
19 \ldots \ldots \\
20 \ldots \ldots\end{array}$ & $\begin{array}{l}28 \\
26 \\
25 \\
25 \\
24 \\
24 \\
24 \\
23 \\
21 \\
20\end{array}$ & $\begin{array}{l}310 \\
533 \\
962 \\
436 \\
334 \\
254 \\
215 \\
185 \\
150 \\
147\end{array}$ & $\begin{array}{l}21 \ldots \ldots \\
22 \ldots \ldots \\
23 \ldots \ldots \\
24 \ldots \ldots \\
25 \ldots \ldots \\
26 \ldots \ldots \\
27 \ldots \ldots \\
28 \ldots \ldots \\
29 \ldots \ldots \\
30 \ldots \ldots \\
31 \ldots \ldots\end{array}$ & $\begin{array}{r}21 \\
20 \\
20 \\
20 \\
19 \\
18 \\
18 \\
18 \\
27 \\
2,020 \\
7,160\end{array}$ & 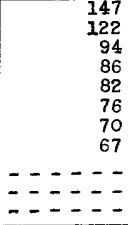 \\
\hline \multicolumn{7}{|c|}{ 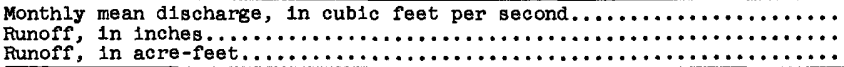 } & $\begin{array}{r}321 \\
4.57 \\
19,760 \\
\end{array}$ & $\begin{array}{r}394 \\
5.05 \\
21,860 \\
\end{array}$ \\
\hline
\end{tabular}

Gage helght, in feet, and discharge, in cublc feet per second, at indlcated time, 1963

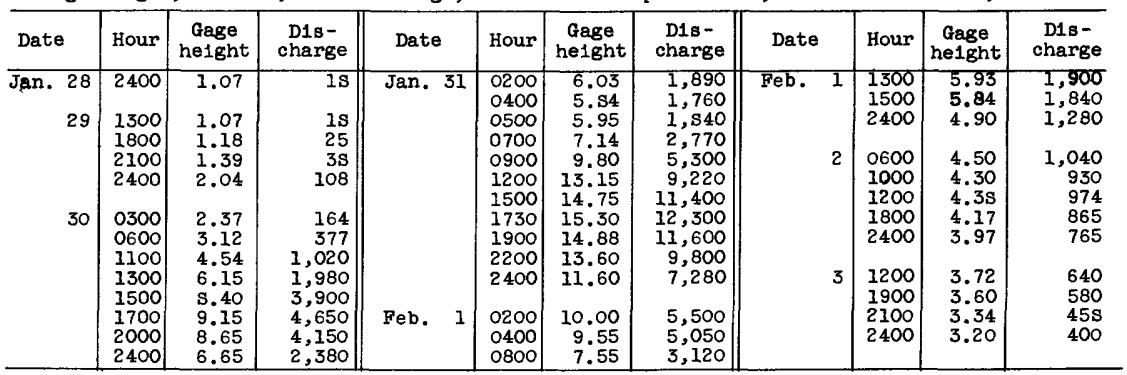


11-4564. Lake Hennessey tributary near Rutherford, Cal1f.

\section{(Crest-stage station)}

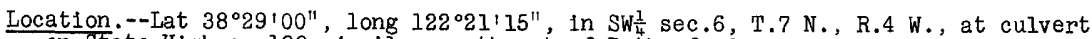
on State Highway 128,4 miles northeast of Rutherford.

Drainage area. $--1.04 \mathrm{sq} \mathrm{mi}$.

Gage-height record.--Crest stages only. Altitude of gage is $330 \mathrm{ft}$ (from topographlc map).

Discharge record.--Maximum discharge by computation of flow through culvert.

Maxima --January-February. 1963: Discharge, $149 \mathrm{cf}$ s Jan. 31 (gage he1ght, $7.71 \mathrm{ft}$ ). 1958 to December 1962: Discharge, $64 \mathrm{cfs}$ Feb. 14, 1962 (gage height, $5.69 \mathrm{ft}$ ).

\section{1-4570. Dry Creek near Napa, Calif.}

Location.--Lat $38^{\circ} 21^{\prime} 23^{\prime \prime}$, long $122^{\circ} 21^{\prime} 50^{\prime \prime}$, in Napa Grant, on right bank 3.7 miles upstream from mouth and 5.5 miles northwest of Napa, Napa County.

Drainage area. $--17.4 \mathrm{sq} \mathrm{mi}$.

Gage-height record ${ }^{--W a t e r-s t a g e ~ r e c o r d e r ~ g r a p h . ~ A l t i t u d e ~ o f ~ g a g e ~ i s ~} 190 \mathrm{ft}$ (from topographic map)

Discharge record. - Stage-discharge relation defined by current-meter measurements.. Maxima.--January-February 1963: Discharge, 2,230 cfs 1700 hours Jan. 31 (gage

1951 to December 1962: Discharge, 3,460 cfs Feb. 24, 1958 (gage height, $8.11 \mathrm{ft}$ ).

Mean discharge, in cubic feet per second, 1963

\begin{tabular}{|c|c|c|c|c|c|c|c|c|}
\hline Day & January & February & Day & January & February & Day & January & February \\
\hline $\begin{array}{c}1 \ldots \ldots \\
2 \ldots \ldots \\
4 \ldots \ldots \\
5 \ldots \ldots \\
6 \ldots \ldots \\
7 \ldots \ldots \\
8 \ldots \ldots \\
10 \ldots \ldots\end{array}$ & $\begin{array}{l}9.3 \\
9.0 \\
8.5 \\
8.0 \\
7.5 \\
7.1 \\
6.9 \\
6.7 \\
6.4 \\
6.2\end{array}$ & $\begin{array}{r}675 \\
236 \\
133 \\
90 \\
69 \\
57 \\
50 \\
49 \\
79 \\
97\end{array}$ & $\begin{array}{l}11 \ldots \ldots \\
12 \ldots \ldots \\
13 \ldots \ldots \\
14 \ldots \ldots \\
15 \ldots \ldots \\
16 \ldots \ldots \\
17 \ldots \ldots \\
18 \ldots \ldots \\
19 \ldots \ldots \\
20 \ldots \ldots\end{array}$ & $\begin{array}{l}6.0 \\
5.6 \\
5.5 \\
5.5 \\
5.6 \\
5.3 \\
5.3 \\
5.3 \\
5.1 \\
4.7\end{array}$ & $\begin{array}{r}66 \\
105 \\
142 \\
94 \\
76 \\
68 \\
57 \\
50 \\
44 \\
41\end{array}$ & $\begin{array}{l}21 \ldots \ldots \\
22 \ldots \ldots \\
23 \ldots \ldots \\
24 \ldots \ldots \\
25 \ldots \ldots \\
26 \ldots \ldots \\
27 \ldots \ldots \\
28 \ldots \ldots \\
29 \ldots \ldots \\
30 \ldots \ldots \\
31 \ldots \ldots\end{array}$ & $\begin{array}{r}4.7 \\
4.7 \\
4.7 \\
4.7 \\
4.7 \\
4.7 \\
4.7 \\
4.7 \\
5.8 \\
408 \\
1,340\end{array}$ & $\begin{array}{r}36 \\
32 \\
28 \\
26 \\
24 \\
21 \\
20 \\
18 \\
-\ldots--\end{array}$ \\
\hline \multicolumn{7}{|l|}{$\begin{array}{l}\text { Monthly } \\
\text { Runoff, } \\
\text { Runoff, }\end{array}$} & $\begin{array}{r}62.0 \\
4.11 \\
3,810\end{array}$ & $\begin{array}{r}88.7 \\
5.31 \\
4,920\end{array}$ \\
\hline
\end{tabular}

Gage height, in feet, and discharge, in cubic feet per second, at indicated time, 1963

\begin{tabular}{|c|c|c|c|c|c|c|c|c|c|c|c|}
\hline Date & Hour & $\begin{array}{c}\text { Gage } \\
\text { neight }\end{array}$ & $\begin{array}{c}\text { Dis- } \\
\text { charge }\end{array}$ & Date & Hour & $\begin{array}{c}\text { Gage } \\
\text { height }\end{array}$ & $\begin{array}{c}\text { Dis- } \\
\text { charge }\end{array}$ & Date & Hour & $\begin{array}{c}\text { Gage } \\
\text { height }\end{array}$ & $\begin{array}{l}\text { D1s- } \\
\text { charge }\end{array}$ \\
\hline $\begin{array}{r}\text { Jan. } 28 \\
29\end{array}$ & $\begin{array}{l}2400 \\
1600 \\
1800 \\
2000 \\
2200 \\
2300 \\
2400 \\
0500 \\
0700 \\
\end{array}$ & $\begin{array}{l}2.42 \\
2.42 \\
2.45 \\
2.53 \\
2.63 \\
2.80 \\
2.92 \\
3.54 \\
3.75\end{array}$ & $\begin{array}{c}4.6 \\
4.6 \\
5.1 \\
6.7 \\
9.0 \\
14 \\
19 \\
79 \\
125 \\
\end{array}$ & Jan. 30 & $\begin{array}{l}1100 \\
1400 \\
1600 \\
1800 \\
1900 \\
2000 \\
2400 \\
\\
0500 \\
0700 \\
0900\end{array}$ & $\begin{array}{l}3.88 \\
5.45 \\
4.94 \\
5.00 \\
4.93 \\
4.94 \\
4.60 \\
4.66 \\
5.15 \\
6.00\end{array}$ & $\begin{array}{r}162 \\
1,050 \\
696 \\
735 \\
690 \\
696 \\
485 \\
\\
521 \\
835 \\
1,450\end{array}$ & Jan. 31 & $\begin{array}{l}1000 \\
1500 \\
1700 \\
2000 \\
2200 \\
2400 \\
\\
0200 \\
0400 \\
1300 \\
2400\end{array}$ & $\begin{array}{l}6.43 \\
6.23 \\
6.88 \\
6.33 \\
6.06 \\
5.62 \\
\\
5.32 \\
5.48 \\
4.70 \\
4.30\end{array}$ & $\begin{array}{r}1,820 \\
1,640 \\
2,230 \\
1,730 \\
1,500 \\
1,160 \\
\\
954 \\
1,070 \\
545 \\
325\end{array}$ \\
\hline
\end{tabular}


11-4580. Napa River near Napa, Calif.

Location.--Lat $38^{\circ} 22^{\prime} 06^{\prime \prime}$, long $122^{\circ} 18^{\prime} 08^{\prime \prime}$, in Yajome Grant, on left bank at downstream side of Oak Knoll Avenue Bridge, 0.4 mile downstream from Dry Creek and 5 miles north of Napa, Napa County.

Drainage area. $--218 \mathrm{sq} \mathrm{ml}$.

Gage-height record --Water-stage recorder graph. Datum of gage is 24.72 ft above mean sea level (levels by Corps of Engineers).

Discharge record.--Stage-discharge relation defined by current-meter measurements.

Maxima --January-February 1963: D1scharge, 16,900 cfs 2230 hours Jan. 31 (gage height, $27.59 \mathrm{ft}$ ) 1929-32, 1959 to December 1962: D1scharge, 12,300 cfs Feb. 8, 1960 (gage he1ght, $23.10 \mathrm{ft}$ ). Remarks.--Flow slightly regulated by Lake Hennessey since December 1945 (capacity,
31,000 acre-ft).

Mean discharge, In cublc feet per second, 1963

\begin{tabular}{|c|c|c|c|c|c|c|c|c|}
\hline Day & January & February & Day & January & February & Day & January & February \\
\hline $\begin{array}{c}1 \ldots \ldots \\
3 \ldots \ldots \\
4 \ldots \ldots \\
5 \ldots \ldots \\
7 \ldots \ldots \\
8 \ldots \ldots \\
9 \ldots \ldots \\
10 \ldots \ldots\end{array}$ & $\begin{array}{l}90 \\
87 \\
85 \\
80 \\
76 \\
75 \\
73 \\
71 \\
65 \\
59\end{array}$ & $\begin{array}{r}9,820 \\
2,950 \\
1,600 \\
898 \\
690 \\
637 \\
462 \\
435 \\
788 \\
1,480\end{array}$ & $\begin{array}{l}11 \ldots \ldots \\
12 \ldots \ldots \\
13 \ldots \ldots \\
14 \ldots \ldots \\
15 \ldots \ldots \\
16 \ldots \ldots \\
17 \ldots \ldots \\
18 \ldots \ldots \\
19 \ldots \ldots \\
20 \ldots \ldots\end{array}$ & $\begin{array}{l}55 \\
52 \\
52 \\
52 \\
50 \\
50 \\
50 \\
50 \\
50 \\
50\end{array}$ & $\begin{array}{r}663 \\
838 \\
2,240 \\
1,260 \\
938 \\
740 \\
601 \\
487 \\
403 \\
362\end{array}$ & $\begin{array}{l}21 \ldots \ldots \\
22 \ldots \ldots \\
23 \ldots \ldots \\
24 \ldots \ldots \\
25 \ldots \ldots \\
26 \ldots \ldots \\
27 \ldots \ldots \\
28 \ldots \ldots \\
29 \ldots \ldots \\
30 \ldots \ldots \\
31 \ldots \ldots\end{array}$ & $\begin{array}{r}50 \\
50 \\
50 \\
50 \\
50 \\
50 \\
50 \\
50 \\
34 \\
3,000 \\
11,100\end{array}$ & $\begin{array}{r}336 \\
294 \\
248 \\
229 \\
212 \\
197 \\
186 \\
170 \\
----- \\
-----\end{array}$ \\
\hline $\begin{array}{l}\text { onthly } \\
\text { unoff, } \\
\text { unoff, }\end{array}$ & $\begin{array}{l}\text { Inches } \\
\text { acre-f }\end{array}$ & $\cdots$ & 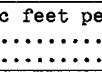 & & & & $\begin{array}{r}510 \\
2,70 \\
31,350 \\
\end{array}$ & $\begin{array}{r}1,077 \\
5,15 \\
59,830 \\
\end{array}$ \\
\hline
\end{tabular}

Gage helght, in feet, and discharge, in cublc feet per second, at indicated time, 1963

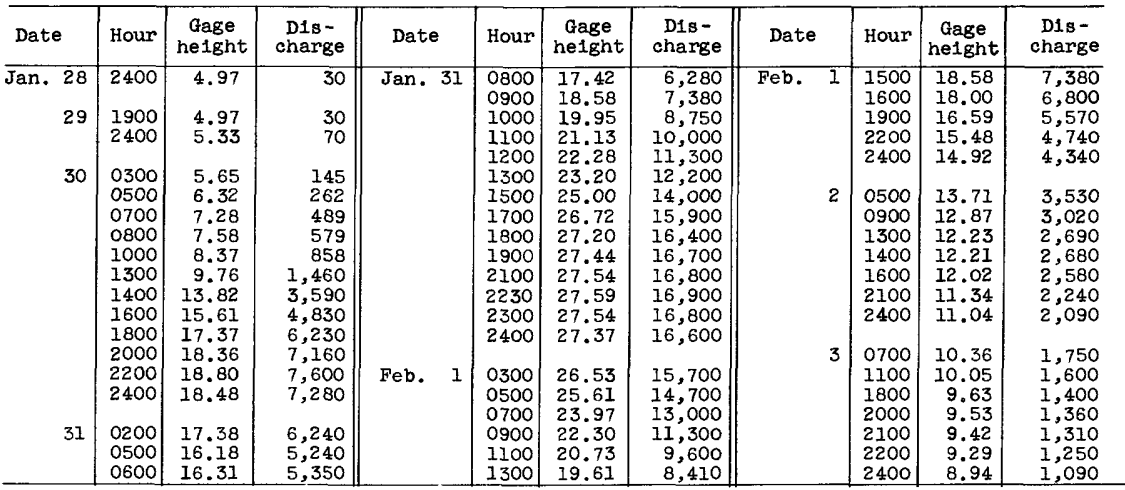


11-4582. Redwood Creek near Napa, Calif.

Location.--Lat $38^{\circ} 19^{\prime} 05^{\prime \prime}$, long $122^{\circ} 20^{\prime} 35^{\prime \prime}$, In Napa Grant, on right bank 2.9 miles upstream from confluence with Browns Válley Creek and 3.4 miles northwest of Napa, Napa County.

Drainage area. $--9.81 \mathrm{sq} \mathrm{ml}$.

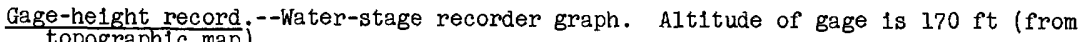
topographic map).

D1scharge record.--Stage-discharge relation defined by current-meter measurements below $270 \mathrm{cf's}$ and by slope-area measurement at $1,070 \mathrm{cfs}$.

Maxima.--January-February 1963: D1scharge, 1,330 cfs 1600 hours Jan. 31 (gage helght, $9.90 \mathrm{ft}$ ).

1958 to December 1962: Discharge, 1,120 cfs Feb. 13, 1962 (gage height, $8.83 \mathrm{ft}$ ).

Mean discharge, in cub1c feet per second, 1963

\begin{tabular}{|c|c|c|c|c|c|c|c|c|}
\hline Day & January & February & Day & January & February & Day & January & February \\
\hline $\begin{array}{c}1 \ldots \ldots \\
2 \ldots \ldots \\
3 \ldots \ldots \\
4 \ldots \ldots \\
5 \ldots \ldots \\
6 \ldots \ldots \\
7 \ldots \ldots \\
8 \ldots \ldots \\
9 \ldots \ldots \\
10 \ldots \ldots\end{array}$ & $\begin{array}{l}3.9 \\
3.3 \\
3.1 \\
3.0 \\
2.8 \\
2.7 \\
2.4 \\
2.4 \\
2.3 \\
2.3\end{array}$ & $\begin{array}{r}334 \\
115 \\
65 \\
46 \\
30 \\
22 \\
16 \\
16 \\
54 \\
51\end{array}$ & $\begin{array}{l}11 \ldots \ldots \\
12 \ldots \ldots \\
13 \ldots \ldots \\
14 \ldots \ldots \\
15 \ldots \ldots \\
16 \ldots \ldots \\
17 \ldots \ldots \\
18 \ldots \ldots \\
19 \ldots \ldots \\
20 \ldots \ldots\end{array}$ & $\begin{array}{l}2.2 \\
2.1 \\
2.1 \\
2.1 \\
2.1 \\
2.1 \\
2.1 \\
2.1 \\
2.0 \\
1.9\end{array}$ & $\begin{array}{l}30 \\
78 \\
84 \\
44 \\
33 \\
29 \\
26 \\
23 \\
20 \\
17\end{array}$ & $\begin{array}{l}21 \ldots \ldots \\
22 \ldots \ldots \\
23 \ldots \ldots \\
24 \ldots \ldots \\
25 \ldots \ldots \\
26 \ldots \ldots \\
27 \ldots \ldots \\
25 \ldots \ldots \\
29 \ldots \ldots \\
30 \ldots \ldots \\
31 \ldots \ldots\end{array}$ & $\begin{array}{r}1.9 \\
1.9 \\
1.9 \\
1.9 \\
1.9 \\
1.9 \\
1.8 \\
1.5 \\
2.5 \\
297 \\
775\end{array}$ & 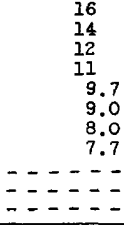 \\
\hline $\begin{array}{l}\text { onthly } \\
\text { unoff, } \\
\text { unoff, }\end{array}$ & $\begin{array}{l}\text { Inche } \\
\text { acre- }\end{array}$ & & & & & & $\begin{array}{r}36.7 \\
4.32 \\
2,260 \\
\end{array}$ & $\begin{array}{r}43.6 \\
4.63 \\
2,420 \\
\end{array}$ \\
\hline
\end{tabular}

Gage he1ght, In feet, and discharge, in cub1c feet per second, at Indicated time, 1953

\begin{tabular}{|c|c|c|c|c|c|c|c|c|c|c|c|}
\hline Date & Hour & $\begin{array}{c}\text { Gage } \\
\text { he1ght }\end{array}$ & $\begin{array}{c}\text { Dis- } \\
\text { charge }\end{array}$ & Date & Hour & $\begin{array}{c}\text { Gage } \\
\text { helght }\end{array}$ & $\begin{array}{l}\text { D1s- } \\
\text { charge }\end{array}$ & Date & Hour & $\begin{array}{c}\text { Gage } \\
\text { height }\end{array}$ & $\begin{array}{l}\text { D1s- } \\
\text { charge }\end{array}$ \\
\hline $\begin{array}{r}\operatorname{Jan} .2 \mathrm{~s} \\
29\end{array}$ & $\begin{array}{l}2400 \\
1500 \\
2100 \\
2300 \\
2400\end{array}$ & $\begin{array}{l}2.06 \\
2.07 \\
2.17 \\
2.39 \\
2.50\end{array}$ & $\begin{array}{r}1.8 \\
1.9 \\
2.9 \\
6.5 \\
10\end{array}$ & Jan. 30 & $\begin{array}{l}1500 \\
1700 \\
1500 \\
1900 \\
2100 \\
2200 \\
2400\end{array}$ & $\begin{array}{l}6.62 \\
4.85 \\
5.23 \\
5.85 \\
5.00 \\
4.62 \\
4.49\end{array}$ & $\begin{array}{l}674 \\
339 \\
410 \\
528 \\
366 \\
298 \\
274\end{array}$ & Jan. 31 & $\begin{array}{l}1500 \\
1600 \\
1700 \\
1800 \\
1900 \\
2200 \\
2400\end{array}$ & $\begin{array}{l}7.45 \\
9.90 \\
9.22 \\
8.55 \\
8.74 \\
7.04 \\
6.09\end{array}$ & $\begin{array}{r}540 \\
1,330 \\
1,190 \\
1,060 \\
1,100 \\
755 \\
573\end{array}$ \\
\hline 30 & $\begin{array}{l}0100 \\
0200 \\
0400 \\
0500 \\
0600 \\
0700 \\
0900 \\
1000 \\
1100 \\
1200 \\
1200 \\
1300 \\
1400 \\
1400\end{array}$ & $\begin{array}{l}2.68 \\
2.73 \\
2.88 \\
3.06 \\
3.62 \\
3.94 \\
3.90 \\
3.93 \\
4.02 \\
5.00 \\
6.00 \\
7.00 \\
7.59 \\
6.75\end{array}$ & $\begin{array}{r}18 \\
21 \\
28 \\
41 \\
115 \\
175 \\
168 \\
173 \\
190 \\
366 \\
556 \\
750 \\
868 \\
700\end{array}$ & 31 & $\begin{array}{l}0200 \\
0300 \\
0400 \\
0500 \\
0600 \\
0700 \\
0800 \\
0900 \\
1000 \\
1100 \\
1200 \\
1300 \\
1400\end{array}$ & $\begin{array}{l}4.74 \\
4.78 \\
5.00 \\
5.41 \\
5.99 \\
6.20 \\
7.01 \\
8.13 \\
7.91 \\
8.66 \\
8.10 \\
7.58 \\
7.75\end{array}$ & $\begin{array}{r}319 \\
326 \\
366 \\
\mathbf{4 4 4} \\
\mathbf{5 5 4} \\
\mathbf{5 9 4} \\
752 \\
976 \\
932 \\
1,080 \\
970 \\
866 \\
900\end{array}$ & Feb. $\quad 1$ & $\begin{array}{l}0200 \\
0300 \\
0500 \\
0800 \\
1200 \\
2000 \\
2400 \\
\\
0500 \\
1300 \\
2400\end{array}$ & $\begin{array}{l}5.61 \\
6.63 \\
5.63 \\
4.97 \\
4.54 \\
4.07 \\
3.88 \\
3.92 \\
3.75 \\
3.62\end{array}$ & $\begin{array}{r}482 \\
676 \\
486 \\
361 \\
283 \\
199 \\
164 \\
\\
136 \\
105 \\
83\end{array}$ \\
\hline
\end{tabular}




\section{SONOMA CREEK BASIN}

11-4584. Sonoma Creek near Kenwood, Calif.

\section{(Crest-stage station)}

Location. - Lat $38^{\circ} 26^{\prime} 32^{\prime \prime}$, long $122^{\circ} 32^{\prime} 15^{\prime \prime}$, in $\mathrm{NE} \frac{1}{4}$ sec. 20 , T.7 N. R.6 W., at bridge on private road, 2.0 miles north of Kenwood.

Drainage area. $--6.06 \mathrm{sq} \mathrm{mi}$.

Gage-helght record.--Crest stages only. Altitude of gage is $580 \mathrm{ft}$ (from topographic map).

Discharge record.--Stage-discharge relation defined by current-meter measurement at $878 \mathrm{cfs}$ and siope-area measurements at 642 and $934 \mathrm{cfs}$.

Maxima.--January-February 1963: Discharge, $910 \mathrm{cfs}$ Jan. 31 (gage height, $13.10 \mathrm{ft}$ ). 1957 to December 1962: Discharge, 1,510 cfs Feb. 24, 1958 (gage height, $13.25 \mathrm{ft}$ ), by slope-area measurement of maximum flow.

11-4585. Sonoma Creek at Boyes Hot Springs, Calif.

Location.--Lat $38^{\circ} 18^{\prime} 49^{\prime \prime}$, long $122^{\circ} 29^{\prime} 09^{\prime \prime}$, in Agua Caliente Grant, on left bank $10 \mathrm{ft}^{\mathrm{t}}$ downstream from county highway bridge at Boyes Hot Springs, Sonoma County, and 2.2 miles northwest of Sonoma.

Drainage area. $--62.2 \mathrm{sq} \mathrm{mi}$.

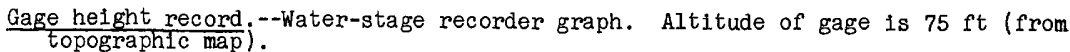

Discharge record.--Stage-discharge relation defined by current-meter measurements.

Maxima.--January-February 1963: Discharge, 4,710 cf's 1700 hours Jan. 31 (gage helght, $12.17 \mathrm{ft}^{\mathrm{t}}$ )

1955 to December 1962: Discharge, 8,880 cfs Dec. 22, 1955 (gage height, $17.10 \mathrm{ft}$ ), from rating curve extended above $4,100 \mathrm{cfs}$ on basis of slope-area measurement of peak flow.

Mean discharge, in cubic feet per second, 1963

\begin{tabular}{|c|c|c|c|c|c|c|c|c|}
\hline Day & January & February & Day & January & February & Day & January & February \\
\hline $\begin{array}{c}1 \ldots \ldots \\
2 \ldots \ldots \\
3 \ldots \ldots \\
5 \ldots \ldots \\
6 \ldots \ldots \\
8 \ldots \ldots \\
9 \ldots \ldots \\
10 \ldots \ldots\end{array}$ & $\begin{array}{l}26 \\
25 \\
25 \\
23 \\
21 \\
20 \\
18 \\
16 \\
15 \\
15\end{array}$ & $\begin{array}{r}1,510 \\
450 \\
295 \\
205 \\
158 \\
135 \\
122 \\
124 \\
218 \\
248\end{array}$ & $\begin{array}{l}11 \ldots \ldots \\
12 \ldots \ldots \\
13 \ldots \ldots \\
14 \ldots \ldots \\
15 \ldots \ldots \\
16 \ldots \ldots \\
17 \ldots \ldots \\
18 \ldots \ldots \\
19 \ldots \ldots \\
20 \ldots \ldots\end{array}$ & $\begin{array}{l}15 \\
13 \\
13 \\
13 \\
13 \\
13 \\
12 \\
12 \\
10 \\
10\end{array}$ & $\begin{array}{r}147 \\
439 \\
491 \\
250 \\
188 \\
168 \\
142 \\
118 \\
100 \\
92\end{array}$ & $\begin{array}{l}21 \ldots \ldots \\
22 \ldots \ldots \\
23 \ldots \ldots \\
24 \ldots \ldots \\
25 \ldots \ldots \\
26 \ldots \ldots \\
27 \ldots \ldots \\
28 \ldots \ldots \\
29 \ldots \ldots \\
30 \ldots \ldots \\
31 \ldots \ldots\end{array}$ & $\begin{array}{c}10 \\
11 \\
12 \\
10 \\
10 \\
10 \\
10 \\
9.5 \\
21 \\
1,650 \\
3,330\end{array}$ & $\begin{array}{r}79 \\
71 \\
64 \\
60 \\
54 \\
50 \\
48 \\
43 \\
-\ldots- \\
-----\end{array}$ \\
\hline $\begin{array}{l}\text { noff, } \\
\text { inoff, }\end{array}$ & acre - & & & & & & $\begin{array}{r}175 \\
3.24 \\
10,730\end{array}$ & $\begin{array}{r}218 \\
3.65 \\
12,100\end{array}$ \\
\hline
\end{tabular}

Gage helght, in feet, and discharge, in cublc feet per second, at indicated t1me, 1963

\begin{tabular}{|c|c|c|c|c|c|c|c|c|c|c|c|}
\hline Date & Hour & $\begin{array}{c}\text { Gage } \\
\text { helght }\end{array}$ & $\begin{array}{l}\text { Dis- } \\
\text { charge }\end{array}$ & Date & Hour & $\begin{array}{c}\text { Gage } \\
\text { he1ght }\end{array}$ & $\begin{array}{c}\text { Dis- } \\
\text { charge }\end{array}$ & Date & Hour & $\begin{array}{c}\text { Gage } \\
\text { helght }\end{array}$ & $\begin{array}{l}\text { Dis- } \\
\text { charge }\end{array}$ \\
\hline $\begin{array}{r}\operatorname{Jan} .28 \\
29\end{array}$ & $\begin{array}{l}2400 \\
1400 \\
1800 \\
2100 \\
2300 \\
2400\end{array}$ & $\begin{array}{l}2.29 \\
2.30 \\
2.37 \\
2.56 \\
2.89\end{array}$ & $\begin{array}{l}9.0 \\
9.5 \\
14 \\
31 \\
79 \\
203\end{array}$ & Jan. 30 & $\begin{array}{l}1200 \\
1300 \\
1500 \\
1600 \\
1900 \\
2000\end{array}$ & $\begin{array}{r}9.12 \\
11.23 \\
9.25 \\
8.74 \\
8.50 \\
8.28\end{array}$ & $\begin{array}{l}2,710 \\
4,050 \\
2,790 \\
2,480 \\
2,350 \\
2,220 \\
\end{array}$ & Jan. 31 & $\begin{array}{l}1400 \\
1500 \\
1700 \\
2000 \\
2400\end{array}$ & $\begin{array}{r}11.59 \\
11.26 \\
12.17 \\
11.93 \\
9.78\end{array}$ & $\begin{array}{l}4,290 \\
4,070 \\
4,710 \\
4,530 \\
3,110\end{array}$ \\
\hline 30 & $\begin{array}{l}0100 \\
0200 \\
0300 \\
0400 \\
0600 \\
0800 \\
0900 \\
1000 \\
\end{array}$ & $\begin{array}{l}3.64 \\
3.64 \\
4.18 \\
4.84 \\
5.61 \\
5.83 \\
5.90 \\
5.96\end{array}$ & $\begin{array}{r}250 \\
250 \\
409 \\
634 \\
904 \\
992 \\
1,020 \\
1,040 \\
\end{array}$ & 31 & $\begin{array}{l}0100 \\
0300 \\
0500 \\
0700 \\
0800 \\
1000 \\
1100 \\
1200\end{array}$ & $\begin{array}{r}6.14 \\
6.43 \\
7.17 \\
8.92 \\
9.95 \\
11.59 \\
11.26 \\
11.49\end{array}$ & $\begin{array}{l}1,120 \\
1,250 \\
1,620 \\
2,590 \\
3,220 \\
4,290 \\
4,070 \\
4,220\end{array}$ & & $\begin{array}{l}0200 \\
0300 \\
0400 \\
0500 \\
0700 \\
1000 \\
1900 \\
2400\end{array}$ & $\begin{array}{l}8.61 \\
9.14 \\
8.92 \\
8.61 \\
7.61 \\
6.76 \\
5.45 \\
4.99\end{array}$ & $\begin{array}{r}2,410 \\
2,720 \\
2,590 \\
2,410 \\
1,860 \\
1,410 \\
848 \\
687\end{array}$ \\
\hline
\end{tabular}




\section{PETALUMA RIVER BASIN}

11-4590. Petaluma River at Petaluma, Calif.

Location.--Lat $38^{\circ} 15^{\prime} 40^{\prime \prime}$, long $122^{\circ} 39^{\prime} 35^{\prime \prime}$, In Roblar de la Miseria Grant, on right bank $70 \mathrm{ft}$ downstream from county highway bridge in Petaluma, Sonoma County, and 1.3 miles downstream from Lichau Creek.

Drainage area. $--30.9 \mathrm{sq} \mathrm{mi}$.

Gage-height record ${ }_{\text {t }}$-Water-stage recorder graph. Altitude of gage is $20 \mathrm{ft}$ (from topographic map).

Discharge record.--Stage-discharge relation defined by current-meter measurements.

Maxima.--January-February 1963: Discharge, 1,320 cfs 1900 hours Jan. 31 (gage height, $10.76 \mathrm{ft}$ )

1948 to December 1962: Discharge, 1,860 efs Dec. 22, 26, 1955, Jan. 14, 1956; gage helght, $13.55 \mathrm{ft}$ Dec. 22,1955 .

Mean discharge, in cublc feet per second, 1963

\begin{tabular}{|c|c|c|c|c|c|c|c|c|}
\hline Day & January & February & Day & January & February & Day & $J$ anuary & February \\
\hline $\begin{array}{r}I \ldots \ldots \\
2 \ldots \ldots \\
3 \ldots \ldots \\
4 \ldots \ldots \\
5 \ldots \ldots \\
7 \ldots \ldots \\
8 \ldots \ldots \\
9 \ldots \ldots \\
10 \ldots \ldots\end{array}$ & $\begin{array}{r}2.0 \\
2.0 \\
2.0 \\
1.9 \\
1.7 \\
1.3 \\
.9 \\
.8 \\
.9 \\
.9\end{array}$ & $\begin{array}{r}490 \\
91 \\
49 \\
32 \\
22 \\
17 \\
15 \\
25 \\
100 \\
163\end{array}$ & $\begin{array}{l}11 \ldots \ldots \\
12 \ldots \ldots \\
13 \ldots \ldots \\
14 \ldots \ldots \\
15 \ldots \ldots \\
16 \ldots \ldots \\
17 \ldots \ldots \\
18 \ldots \ldots \\
19 \ldots \ldots \\
20 \ldots \ldots\end{array}$ & $\begin{array}{r}1.0 \\
.8 \\
.6 \\
.6 \\
.5 \\
.5 \\
.5 \\
.6 \\
.6 \\
.6\end{array}$ & $\begin{array}{r}52 \\
236 \\
383 \\
56 \\
28 \\
29 \\
36 \\
17 \\
13 \\
11\end{array}$ & $\begin{array}{l}21 \ldots \ldots \\
22 \ldots \ldots \\
23 \ldots \ldots \\
24 \ldots \ldots \\
25 \ldots \ldots \\
26 \ldots \ldots \\
27 \ldots \ldots \\
28 \ldots \ldots \\
29 \ldots \ldots \\
30 \ldots \ldots \\
31 \ldots \ldots\end{array}$ & $\begin{array}{r}0.5 \\
.4 \\
.4 \\
.5 \\
.6 \\
.6 \\
.7 \\
.6 \\
1.8 \\
668 \\
977\end{array}$ & $\begin{array}{r}8.4 \\
6.6 \\
5.3 \\
4.2 \\
4.0 \\
3.4 \\
2.8 \\
2.2 \\
---.- \\
--.--.-\end{array}$ \\
\hline $\begin{array}{l}\text { onthly } \\
\text { anoff, } \\
\text { anoff, }\end{array}$ & $\begin{array}{l}\text { an disch } \\
\text { Inches. } \\
\text { acre-fe }\end{array}$ & . & 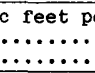 & & & & $\begin{array}{r}53.9 \\
2.01 \\
3,320 \\
\end{array}$ & $\begin{array}{r}67.9 \\
2.29 \\
3,770 \\
\end{array}$ \\
\hline
\end{tabular}

Gage height, in feet, and discharge, in cubic feet per second, at indicated time, 1963

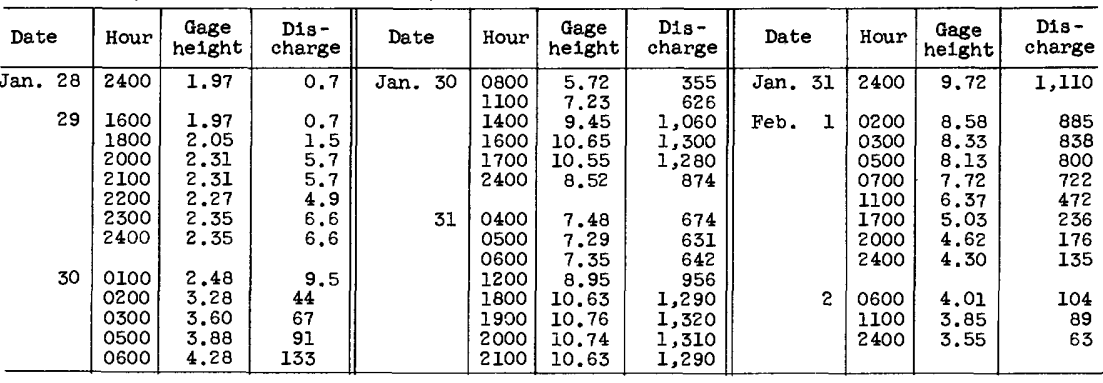

\section{NOVATO CREEK BASIN}

11-4595. Novato Creek near Novato, Calif.

Location.--Lat $38^{\circ} 06^{\prime} 45^{\prime \prime}$, long $122^{\circ} 35^{\prime} 05^{\prime \prime}$, in Novato Grant, on right bank $500 \mathrm{ft}$ downstream from highway bridge and 1 mile west of U.S. Highway 101 in Novato, Marin County.

Dra1nage area. $--17.5 \mathrm{sq} \mathrm{mi}$.

Gage-helght record --Water-stage recorder graph. Alt1tude of gage is $45 \mathrm{ft}$ (from topographic map).

D1scharge record.--Stage-discharge relation defined by current-meter measurements.

Maxima.--January-February 1963: Discharge, $733 \mathrm{cfs} 1230$ hours Jan. 30 (gage height, $5.77 \mathrm{ft})$.

1946 to December 1962: Discharge, 1,190 cfs Feb. 24, 1958 (gage height, $8.24 \mathrm{ft}$ ).

Remarks.--Flow partly regulated by Stafford Lake (capac1ty, 4,500 acre-ft). 
Mean discharge, in cublc feet per second, 1963, of Novato Creek near Novato, Cal1f.

\begin{tabular}{|c|c|c|c|c|c|c|c|c|}
\hline Day & January & February & Day & January & February & Day & January & February \\
\hline $\begin{array}{c}1 \ldots \ldots \\
2 \ldots \ldots \\
4 \ldots \ldots \\
5 \ldots \ldots \\
6 \ldots \ldots \\
7 \ldots \ldots \\
9 \ldots \ldots \\
10 \ldots \ldots\end{array}$ & $\begin{array}{l}1.6 \\
1.6 \\
1.5 \\
1.4 \\
1.3 \\
1.3 \\
1.3 \\
1.3 \\
1.4 \\
1.4\end{array}$ & $\begin{array}{r}216 \\
134 \\
82 \\
59 \\
45 \\
35 \\
28 \\
28 \\
79 \\
85\end{array}$ & $\begin{array}{l}11 \ldots \ldots \\
12 \ldots \ldots \\
13 \ldots \ldots \\
14 \ldots \ldots \\
15 \ldots \ldots \\
16 \ldots \ldots \\
17 \ldots \ldots \\
18 \ldots \ldots \\
19 \ldots \ldots \\
20 \ldots \ldots\end{array}$ & $\begin{array}{l}1.3 \\
1.3 \\
1.3 \\
1.3 \\
1.3 \\
1.3 \\
1.3 \\
1.2 \\
1.2 \\
1.2\end{array}$ & $\begin{array}{r}57 \\
94 \\
105 \\
67 \\
52 \\
43 \\
35 \\
29 \\
26 \\
21\end{array}$ & $\begin{array}{l}21 \ldots \ldots \\
22 \ldots \ldots \\
23 \ldots \ldots \\
24 \ldots \ldots \\
25 \ldots \ldots \\
26 \ldots \ldots \\
27 \ldots \ldots \\
28 \ldots \ldots \\
29 \ldots \ldots \\
30 \ldots \ldots \\
31 \ldots \ldots\end{array}$ & $\begin{array}{r}1.2 \\
1.2 \\
1.2 \\
1.2 \\
1.2 \\
1.2 \\
1.2 \\
1.1 \\
7.9 \\
241 \\
323\end{array}$ & $\begin{array}{r}18 \\
16 \\
14 \\
12 \\
11 \\
10 \\
9.5 \\
8.6 \\
--\ldots-\end{array}$ \\
\hline $\begin{array}{l}\text { unoff, } \\
\text { unoff, }\end{array}$ & $\begin{array}{l}n \text { inche } \\
n \text { acre- }\end{array}$ & & & & & & $\begin{array}{r}19.6 \\
1.29 \\
1,210\end{array}$ & $\begin{array}{r}50.7 \\
3.02 \\
2,810\end{array}$ \\
\hline
\end{tabular}

Gage height, in feet, and discharge, in cub1c feet per second, at 1ndicated time, 1963

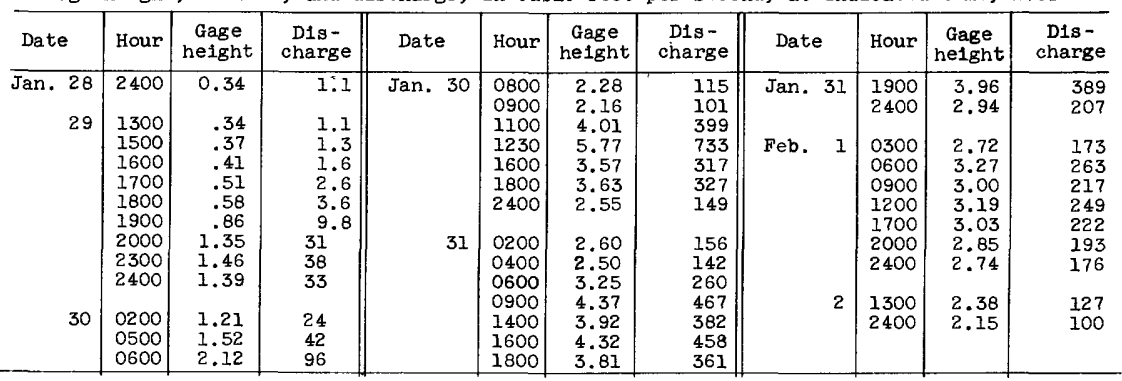

CORTE MADERA CREEK BASIN

11-4600. Corte Madera Creek at Ross, Calif.

Location.--Lat $37^{\circ} 57^{\prime} 45^{\prime \prime}$, long $122^{\circ} 33^{\prime} 20^{\prime \prime}$, In Punta de Quentin Grant, on left bank behind fire station at Ross, Marin County, 1.7 miles southwest of San Rafael and 4 miles upstream from mouth.

Drainage area. $--18.1 \mathrm{sq} \mathrm{mi}$.

Gage-helght record.-Water-stage recorder graph, except Feb. 2,3. Altitude of gage is $8 \mathrm{ft}$ (from topographic map).

Discharge record.--Stage-discharge relation defined by current-meter measurements. Discharge for Feb. 2,3 estimated on basis of normal recession, weather records, and records for nearby stations.

Maxima.--January-February 1963: Discharge, 2,460 cfs 1300 hours Jan. 30 (gage helght, $15.24 \mathrm{ft}^{\prime}$ ).

1951 to December 1962: Discharge, 3,620 cfs Dec. 22, 1955 (gage he1ght, $17.45 \mathrm{ft}$ ), from rating curve extended above $1,600 \mathrm{cfs}$.

Remarks.--Flow slightly regulated by Phoenix Lake (capacity, 612 acre-ft).

Mean discharge, in cuble feet per second, 1963

\begin{tabular}{|c|c|c|c|c|c|c|c|c|}
\hline Day & January & February & Day & January & February & Day & January & February \\
\hline $\begin{array}{c}1 \ldots \ldots \\
2 \ldots \ldots \\
3 \ldots \ldots \\
4 \ldots \ldots \\
5 \ldots \ldots \\
7 \ldots \ldots \\
8 \ldots \ldots \\
9 \ldots \ldots \\
10 \ldots \ldots\end{array}$ & $\begin{array}{r}6.2 \\
6.2 \\
5.8 \\
5.1 \\
4.7 \\
4.7 \\
4.7 \\
12 \\
8.5 \\
7.7\end{array}$ & $\begin{array}{r}651 \\
350 \\
150 \\
60 \\
40 \\
29 \\
23 \\
26 \\
171 \\
175\end{array}$ & $\begin{array}{l}11 \ldots \ldots \\
12 \ldots \ldots \\
13 \ldots \ldots \\
14 \ldots \ldots \\
15 \ldots \ldots \\
16 \ldots \ldots \\
17 \ldots \ldots \\
18 \ldots \ldots \\
19 \ldots \ldots \\
20 \ldots \ldots\end{array}$ & $\begin{array}{l}4.4 \\
4.0 \\
3.7 \\
3.7 \\
4.4 \\
3.7 \\
3.4 \\
3.4 \\
3.4 \\
3.1\end{array}$ & $\begin{array}{r}82 \\
143 \\
165 \\
85 \\
56 \\
45 \\
34 \\
26 \\
23 \\
19\end{array}$ & $\begin{array}{l}21 \ldots \ldots \\
22 \ldots \ldots \\
23 \ldots \ldots \\
24 \ldots \ldots \\
25 \ldots \ldots \\
26 \ldots \ldots \\
27 \ldots \ldots \\
28 \ldots \ldots \\
29 \ldots \ldots \\
30 \ldots \ldots \\
31 \ldots \ldots\end{array}$ & $\begin{array}{r}3.4 \\
3.1 \\
3.1 \\
3.1 \\
3.1 \\
3.1 \\
3.1 \\
2.9 \\
105.0 \\
1,380 \\
1,620\end{array}$ & $\begin{array}{c}17 \\
16 \\
13 \\
12 \\
11 \\
10 \\
10 \\
9.0 \\
\ldots-.-- \\
-\ldots-.-\end{array}$ \\
\hline $\begin{array}{l}\text { anthly } \\
\text { unoff, } \\
\text { גnoff, }\end{array}$ & $\begin{array}{l}\text { inche } \\
\text { acre- }\end{array}$ & , & & & & & $\begin{array}{r}104 \\
6.64 \\
6,410 \\
\end{array}$ & $\begin{array}{r}87.5 \\
5.04 \\
4,860 \\
\end{array}$ \\
\hline
\end{tabular}


Gage height, in feet, and discharge, in cubic feet per second, at indicated time, 1963, of Corte Madera Creek at Ross, Calif.

\begin{tabular}{|c|c|c|c|c|c|c|c|c|c|c|c|}
\hline Date & Hour & $\begin{array}{c}\text { Gage } \\
\text { height }\end{array}$ & $\begin{array}{l}\text { Dis - } \\
\text { charge }\end{array}$ & Date & Hour & $\begin{array}{c}\text { Gage } \\
\text { heIght }\end{array}$ & $\begin{array}{l}\text { Dis- } \\
\text { charge }\end{array}$ & Date & Hour & $\begin{array}{c}\text { Gage } \\
\text { helght }\end{array}$ & $\begin{array}{l}\text { D1s- } \\
\text { charge }\end{array}$ \\
\hline an. $\begin{array}{r}28 \\
29\end{array}$ & $\begin{array}{l}2400 \\
1100 \\
1200 \\
1300 \\
1400 \\
1600 \\
1700 \\
1900 \\
2000 \\
2100 \\
2400 \\
\\
0200 \\
0300 \\
0400 \\
0600 \\
0800 \\
1100 \\
1200\end{array}$ & $\begin{array}{r}4.49 \\
4.49 \\
4.71 \\
4.80 \\
5.14 \\
5.68 \\
6.13 \\
6.81 \\
6.71 \\
7.27 \\
6.39 \\
6.72 \\
7.18 \\
8.00 \\
9.15 \\
10.75 \\
13.00 \\
14.87\end{array}$ & \begin{tabular}{|c|}
2.9 \\
2.9 \\
13 \\
19 \\
56 \\
129 \\
195 \\
306 \\
289 \\
389 \\
235 \\
\\
290 \\
372 \\
534 \\
787 \\
1,190 \\
1,790 \\
2,350
\end{tabular} & Jan. 30 & $\begin{array}{l}1300 \\
1400 \\
1500 \\
1600 \\
1700 \\
1900 \\
2000 \\
2100 \\
2200 \\
2300 \\
2400 \\
0100 \\
0200 \\
0400 \\
0500 \\
0600 \\
0700 \\
0800 \\
1000\end{array}$ & $\begin{array}{l}15.24 \\
14.10 \\
13.03 \\
12.53 \\
13.13 \\
14.03 \\
13.55 \\
12.35 \\
11.67 \\
11.00 \\
10.90 \\
10.87 \\
10.42 \\
10.08 \\
10.96 \\
11.70 \\
13.43 \\
13.08 \\
13.93\end{array}$ & $\begin{array}{l}2,460 \\
2,120 \\
1,800 \\
1,660 \\
1,830 \\
2,100 \\
1,960 \\
1,610 \\
1,420 \\
1,250 \\
1,220 \\
1,220 \\
1,100 \\
1,010 \\
1,240 \\
1,430 \\
1,920 \\
1,810 \\
2,070\end{array}$ & Feb. 1 & $\begin{array}{l}1200 \\
1400 \\
1500 \\
1700 \\
1900 \\
2100 \\
2200 \\
2300 \\
2400 \\
0200 \\
0300 \\
0500 \\
0600 \\
0700 \\
0900 \\
1200 \\
1800 \\
2400\end{array}$ & $\begin{array}{r}12.58 \\
11.32 \\
12.15 \\
12.84 \\
14.70 \\
13.65 \\
12.62 \\
11.58 \\
10.81 \\
9.66 \\
9.78 \\
10.31 \\
9.64 \\
9.12 \\
8.56 \\
8.03 \\
7.62 \\
7.26\end{array}$ & $\begin{array}{r}1,670 \\
1,330 \\
1,550 \\
1,750 \\
2,300 \\
1,990 \\
1,680 \\
1,400 \\
1,200 \\
\\
908 \\
937 \\
1,070 \\
904 \\
780 \\
657 \\
541 \\
456 \\
387\end{array}$ \\
\hline
\end{tabular}

\section{REDWOOD CREEK BASIN}

11-4601.5. Redwood Creek near Tamalpais Valley, Calif.

(Crest-stage station)

Location.--Lat $37^{\circ} 52^{\prime} 30^{\prime \prime}$, long $122^{\circ} 34^{\prime} 55^{\prime \prime}$, in Mount Tamalpais game refuge, at culvert on Frank Valley road, 2.5 miles southwest of Mill valley and $3.0 \mathrm{miles}$ west of Tamalpais Valley.

Drainage area. $--6.38 \mathrm{sq} \mathrm{ml}$.

Gage-height record.--Crest stages only. Altitude of gage is $35 \mathrm{ft}$ (from topographic map).

D1scharge record.--Stage-discharge relation defined by current-meter measurements.

Maxima.--January-February 1963: Discharge, $710 \mathrm{cfs}$ Jan. 31 (gage height, $6.28 \mathrm{ft}$ ). i961 to December 1962: Discharge, $880 \mathrm{cfs}$ Feb. 13, 1962 (gage height, $6.67 \mathrm{ftl}$.

\section{LAGUNITAS CREEK BASIN}

11-4604.4. Nicasio Creek near Nicasio, Calif.

(Crest-stage station)

Location.--Lat $38^{\circ} 02^{\prime} 57^{\prime \prime}$, long $122^{\circ} 38^{\prime} 33^{\prime \prime}$, at culvert on Lucas Valley road, 3.1 miles southeast of Nicasio.

Drainage area. $--1.74 \mathrm{sq} \mathrm{ml}$.

Gage-he1ght record.--Crest stages only. Altitude of gage is $375 \mathrm{ft}$ (from topographic map).

Discharge record.--Stage-discharge relation defined by current-meter measurements below $55 \mathrm{cfs}$ and by computation of flow through culvert at $380 \mathrm{cfs}$.

Maxima.--January-February 1963: Discharge, $290 \mathrm{cfs}$ Jan. 31, 1963 (gage height, $11.38 \mathrm{ft})$.

1961 to December 1962: Discharge, $380 \mathrm{cfs} F e b .9,1962$ (gage height, $12.96 \mathrm{ft})$. 


\section{WALKER CREEK BASIN}

11-4608. Walker Creek near Tomales, Calif.

Location.--Lat $38^{\circ} 12^{\prime} 35^{\prime \prime}$, long $122^{\circ} 51^{\prime} 35^{\prime \prime}$, in Nicasio Grant, on left bank $1,300 \mathrm{ft}$ upstream from Chileno' Creek and 3.5 miles southeast of Tomales, Marin County.

Drainage area. $--37.1 \mathrm{sq} \mathrm{ml}$.

Gage-height record; --Water-stage recorder graph. Altitude of gage is $70 \mathrm{ft}$ (from topographic map).

D1scharge record.--Stage-discharge relation defined by current-meter measurements.

Maxima.--January-February 1963: Discharge, 3,210 cfs 2000 hours Jan. 31 gage height, $17.89 \mathrm{ft}$ ).

1959 to December 1962: Discharge, 3,430 cfs Jan. 31, 1961, Feb. 13, 1962 ; gage height, $18.18 \mathrm{ft}$ Jan. 31, 1961.

Flood of Feb. 24, 1958, reached a stage of $19.8 \mathrm{ft}$, from floodmarks.

Mean discharge, in cubic feet per second, 1963

\begin{tabular}{|c|c|c|c|c|c|c|c|c|}
\hline Day & January & February & Day & January & February & Day & January & February \\
\hline $\begin{array}{c}1 \ldots \ldots \\
2 \ldots \ldots \\
4 \ldots \ldots \\
5 \ldots \ldots \\
6 \ldots \ldots \\
7 \ldots \ldots \\
9 \ldots \ldots \\
10 \ldots \ldots\end{array}$ & $\begin{array}{l}15 \\
14 \\
14 \\
13 \\
12 \\
11 \\
13 \\
10 \\
10 \\
9.5\end{array}$ & $\begin{array}{r}1,100 \\
336 \\
183 \\
120 \\
87 \\
71 \\
63 \\
66 \\
141 \\
215\end{array}$ & $\begin{array}{l}11 \ldots \ldots \\
12 \ldots \ldots \\
13 \ldots \ldots \\
14 \ldots \ldots \\
15 \ldots \ldots \\
16 \ldots \ldots \\
17 \ldots \ldots \\
18 \ldots \ldots \\
19 \ldots \ldots \\
20 \ldots \ldots\end{array}$ & $\begin{array}{l}8.7 \\
8.3 \\
7.9 \\
7.9 \\
7.5 \\
7.5 \\
7.1 \\
6.7 \\
6.3 \\
5.5\end{array}$ & $\begin{array}{r}126 \\
318 \\
439 \\
217 \\
146 \\
117 \\
94 \\
71 \\
62 \\
56\end{array}$ & $\begin{array}{l}21 \ldots \ldots \\
22 \ldots \ldots \\
23 \ldots \ldots \\
24 \ldots \ldots \\
25 \ldots \ldots \\
26 \ldots \ldots \\
27 \ldots \ldots \\
28 \ldots \ldots \\
29 \ldots \ldots \\
30 \ldots \ldots \\
31 \ldots \ldots\end{array}$ & $\begin{array}{r}5.3 \\
5.3 \\
5.3 \\
5.0 \\
5.0 \\
5.0 \\
5.0 \\
4.8 \\
7.9 \\
1,200 \\
2,210\end{array}$ & $\begin{array}{r}49 \\
42 \\
38 \\
35 \\
31 \\
27 \\
24 \\
22 \\
-\ldots--- \\
-\ldots-\end{array}$ \\
\hline \multicolumn{7}{|l|}{$\begin{array}{l}\text { Monthly } \\
\text { Runoff, } \\
\text { Runoff, }\end{array}$} & $\begin{array}{r}118 \\
3,66 \\
7,250 \\
\end{array}$ & $\begin{array}{r}153 \\
4.31 \\
8,520 \\
\end{array}$ \\
\hline
\end{tabular}

Gage he1ght, In feet, and discharge, in cublc feet per second, at indicated t1me, 1963

\begin{tabular}{|c|c|c|c|c|c|c|c|c|c|c|c|}
\hline Date & Hour & $\begin{array}{c}\text { Gage } \\
\text { he1ght }\end{array}$ & $\begin{array}{c}\text { Dis- } \\
\text { charge }\end{array}$ & Date & Hour & $\begin{array}{c}\text { Gage } \\
\text { he1ght }\end{array}$ & $\begin{array}{l}\text { Dis- } \\
\text { charge }\end{array}$ & Date & Hour & $\begin{array}{c}\text { Gage } \\
\text { hetght }\end{array}$ & $\begin{array}{l}\text { Dis- } \\
\text { charge }\end{array}$ \\
\hline $\begin{array}{r}\text { Jan. } 29 \\
30\end{array}$ & $\begin{array}{l}2400 \\
0300 \\
0700 \\
1100 \\
1200 \\
1300 \\
1400 \\
1600 \\
1900 \\
2000 \\
2100\end{array}$ & $\begin{array}{r}5.31 \\
5.91 \\
7.30 \\
9.70 \\
12.25 \\
15.00 \\
15.73 \\
15.88 \\
13.58 \\
13.29 \\
13.39\end{array}$ & $\begin{array}{r}51 \\
132 \\
363 \\
826 \\
1,440 \\
2,250 \\
2,490 \\
2,530 \\
1,810 \\
1,730 \\
1,760\end{array}$ & $\begin{array}{r}30 \\
31\end{array}$ & $\begin{array}{l}2400 \\
0200 \\
0400 \\
0500 \\
0600 \\
0800 \\
1100 \\
1300 \\
1500 \\
1600 \\
1900\end{array}$ & $\begin{array}{l}12.21 \\
11.50 \\
11.22 \\
11.29 \\
11.85 \\
13.65 \\
15.82 \\
16.07 \\
15.70 \\
16.10 \\
17.79\end{array}$ & $\begin{array}{l}1,430 \\
1,250 \\
1,180 \\
1,190 \\
1,340 \\
1,840 \\
2,510 \\
2,590 \\
2,480 \\
2,600 \\
3,170\end{array}$ & Jan. 31 & $\begin{array}{l}2000 \\
2200 \\
2400 \\
0300 \\
0500 \\
0800 \\
1200 \\
1600 \\
2000 \\
2400\end{array}$ & $\begin{array}{r}17.89 \\
16.80 \\
15.20 \\
13.09 \\
12.35 \\
11.81 \\
10.36 \\
9.43 \\
8.67 \\
8.10\end{array}$ & $\begin{array}{r}3,210 \\
2,840 \\
2,320 \\
1,670 \\
1,470 \\
1,330 \\
971 \\
767 \\
614 \\
506\end{array}$ \\
\hline
\end{tabular}

\section{ROSCOE CREEK BASDN}

11-4609. Roscoe Creek near Bodega Bay, Calif.

(Crest-stage station)

Location.--Lat $38^{\circ} 20^{\prime} 25^{\prime \prime}$, long $123^{\circ} 02^{\prime} 44^{\prime \prime}$, at culvert on State Highway $1,0.5 \mathrm{mile}$ north of Bodega Bay.

Drainage area. $--0.25 \mathrm{sq} \mathrm{mi}$.

Gage-height record.--Crest stages only. Altitude of gage is $110 \mathrm{ft}$ (from topographic map).

Discharge record.--Maximum discharge by computation of flow through culvert.

Maxima.--January-February 1963: Discharge, 48 cfs Jan. 31 (gage he1ght, $8.59 \mathrm{ft}$ ). 1961 to December 1962: Discharge, $37 \mathrm{cfs} F \mathrm{Feb}$. 13, 1962 (gage height, $8.16 \mathrm{ft}$ ). 


\section{SALMON CREEK BASIN}

11-4609.2. Salmon Creek at Bodega, Cal1f.

Location.--Lat $38^{\circ} 20^{\prime} 54^{\prime \prime}$, long $122^{\circ} 58^{\prime} 45^{\prime \prime}$, in Estero Americano Grant, on left bank 100 ft upstream from private road bridge, 0.3 mile upstream from unnamed tributary, and $0.4 \mathrm{mile}$ northwest of Bodega, Sonoma County.

Dralnage area. $--15.7 \mathrm{sq} \mathrm{ml}$.

Gage-helght record:--Digital recorder tape punched at 15-minute intervals. Altitude of gage is $80 \mathrm{ft}$ (from topographic map).

Discharge record.--Stage-discharge relation defined by current-meter measurements below 800 cf's.

Maxima.--January-February 1963: Discharge, 1,430 cfs 1200 hours Jan. 31 (gage height, $15.56 \mathrm{ft}^{\prime}$ ).

July to December 1962: Discharge, $813 \mathrm{cfs}$ Dec. 15 (gage height, $11.52 \mathrm{ft}$ ).

Mean discharge, in cublc feet per second, 1963

\begin{tabular}{|c|c|c|c|c|c|c|c|c|}
\hline Day & January & February & Day & January & February & Day & January & February \\
\hline $\begin{array}{c}1 \ldots \ldots \\
2 \ldots \ldots \\
3 \ldots \ldots \\
4 \ldots \ldots \\
6 \ldots \ldots \\
7 \ldots \ldots \\
8 \ldots \ldots \\
10 \ldots \ldots\end{array}$ & $\begin{array}{l}6.4 \\
6.0 \\
5.7 \\
5.2 \\
4.7 \\
4.5 \\
4.3 \\
4.2 \\
4.1 \\
4.2\end{array}$ & $\begin{array}{r}226 \\
82 \\
54 \\
38 \\
29 \\
29 \\
23 \\
34 \\
74 \\
75\end{array}$ & $\begin{array}{l}11 \ldots \ldots \\
12 \ldots \ldots \\
13 \ldots \ldots \\
14 \ldots \ldots \\
15 \ldots \ldots \\
16 \ldots \ldots \\
17 \ldots \ldots \\
18 \ldots \ldots \\
19 \ldots \ldots \\
20 \ldots \ldots\end{array}$ & $\begin{array}{l}4.0 \\
3.9 \\
4.3 \\
3.7 \\
3.7 \\
3.7 \\
3.7 \\
3.6 \\
3.3 \\
2.8\end{array}$ & $\begin{array}{r}45 \\
280 \\
166 \\
66 \\
45 \\
43 \\
34 \\
24 \\
21 \\
18\end{array}$ & $\begin{array}{l}21 \ldots \ldots \\
22 \ldots \ldots \\
23 \ldots \ldots \\
24 \ldots \ldots \\
25 \ldots \ldots \\
26 \ldots \ldots \\
27 \ldots \ldots \\
28 \ldots \ldots \\
29 \ldots \ldots \\
30 \ldots \ldots \\
31 \ldots \ldots\end{array}$ & $\begin{array}{r}2.9 \\
2.9 \\
2.9 \\
3.0 \\
3.0 \\
3.1 \\
3.0 \\
2.9 \\
26 \\
567 \\
797\end{array}$ & 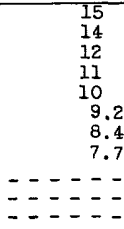 \\
\hline \multicolumn{7}{|l|}{$\begin{array}{l}\text { Monthly } \\
\text { Runoff, } \\
\text { Runoff, }\end{array}$} & $\begin{array}{r}48.4 \\
3.55 \\
2,970\end{array}$ & $\begin{array}{r}53.3 \\
3.54 \\
2,960\end{array}$ \\
\hline
\end{tabular}

Gage he1ght, in feet, and discharge, in cublc feet per second, at indicated time, 1963

\begin{tabular}{|c|c|c|c|c|c|c|c|c|c|c|c|}
\hline Date & Hour & $\begin{array}{c}\text { Gage } \\
\text { helght }\end{array}$ & $\begin{array}{c}\text { D1s - } \\
\text { charge }\end{array}$ & Date & Hour & $\begin{array}{c}\text { Gage } \\
\text { helght }\end{array}$ & $\begin{array}{c}\text { Dis- } \\
\text { charge }\end{array}$ & Date & Hour & $\begin{array}{c}\text { Gage } \\
\text { helght }\end{array}$ & $\begin{array}{c}\text { Dis- } \\
\text { charge }\end{array}$ \\
\hline $\begin{array}{r}\text { Jan. } 28 \\
29\end{array}$ & $\begin{array}{l}2400 \\
1200 \\
1800 \\
2000 \\
2200 \\
2400 \\
\\
0200 \\
0400 \\
0600 \\
1000\end{array}$ & $\begin{array}{r}4.18 \\
4.16 \\
4.44 \\
5.02 \\
6.38 \\
6.91 \\
7.04 \\
6.97 \\
8.38 \\
10.72\end{array}$ & $\begin{array}{c}2.9 \\
2.6 \\
7.9 \\
30 \\
142 \\
203 \\
\\
219 \\
210 \\
389 \\
701\end{array}$ & Jan. 30 & $\begin{array}{l}1200 \\
1400 \\
1600 \\
1800 \\
2000 \\
2400 \\
\\
0200 \\
0600 \\
0800 \\
1000 \\
1200\end{array}$ & $\begin{array}{r}13.86 \\
14.74 \\
11.73 \\
9.13 \\
8.02 \\
7.09 \\
6.99 \\
7.75 \\
11.69 \\
14.79 \\
15.56\end{array}$ & $\begin{array}{r}1,160 \\
1,300 \\
842 \\
487 \\
343 \\
225 \\
\\
213 \\
308 \\
837 \\
1,310 \\
1,430\end{array}$ & Jan. 31 & $\begin{array}{l}1400 \\
1600 \\
1800 \\
2000 \\
2200 \\
2400 \\
\\
0200 \\
0800 \\
1400 \\
2000 \\
2400\end{array}$ & $\begin{array}{r}13.80 \\
13.00 \\
13.18 \\
12.34 \\
10.80 \\
9.19 \\
8.36 \\
7.32 \\
6.61 \\
6.27 \\
6.09\end{array}$ & $\begin{array}{r}1,150 \\
1,030 \\
1,060 \\
931 \\
712 \\
495 \\
\\
387 \\
252 \\
167 \\
130 \\
111\end{array}$ \\
\hline
\end{tabular}

\section{RUSSIAN RIVER BASIN}

11-4610. Russian Rlver near Uklah, Cal1f.

Location.--Lat $39^{\circ} 12^{\prime} 07^{\prime \prime}$, long $123^{\circ} 11^{\prime} 5^{\prime \prime}$, in Yokayo Rancho Grant, on left bank $200 \mathrm{f}^{\prime} t$ downstream from York Creek, $0.7 \mathrm{mlle}$ upstream from East Fork, and 3.6 miles north of Ukiah, Mendocino County.

Dralnage area. $--99.6 \mathrm{sq} \mathrm{ml}$.

Gage-helght record.--Water-stage recorder graph, except Feb. 20-28. Datum of gage is $612.02 \mathrm{f}^{\prime} \mathrm{above}$ mean sea level (levels by Corps of Engineers).

Discharge record.--Stage-discharge relation defined by current-meter measurements. Discharge for period of no gage-helght record estimated on bas is of recorded range in stage and records for outlet Creek near Longvale.

Maxima.--January-February 1963: Discharge, 11,800 cfs 1700 hours Jan. 31 (gage height, $15.43 \mathrm{ft})$.

1911-13, 1952 to December 1962: Discharge, 18,900 cfs Dec. 21, 1955 (gage height, $21.0 \mathrm{ft}$ ), from rating curve extended above $13,000 \mathrm{cfs}$ on basis of slope-area measurement of peak flow. 
Mean discharge, in cublc feet per second, 1963, of Russian River near Ukiah, Cal1f.

\begin{tabular}{|c|c|c|c|c|c|c|c|c|}
\hline Day & January & February & Day & January & February & Day & January & February \\
\hline $\begin{array}{c}\ldots \ldots \\
2 \ldots \ldots \\
3 \ldots \ldots \\
5 \ldots \ldots \\
6 \ldots \ldots \\
7 \ldots \ldots \\
9 \ldots \ldots \\
10 \ldots \ldots\end{array}$ & $\begin{array}{l}51 \\
49 \\
47 \\
44 \\
43 \\
37 \\
35 \\
34 \\
33 \\
32\end{array}$ & $\begin{array}{r}2,690 \\
941 \\
537 \\
383 \\
320 \\
263 \\
223 \\
230 \\
298 \\
314\end{array}$ & $\begin{array}{l}11 \ldots \ldots \\
12 \ldots \ldots \\
13 \ldots \ldots \\
14 \ldots \ldots \\
15 \ldots \ldots \\
16 \ldots \ldots \\
17 \ldots \ldots \\
18 \ldots \ldots \\
19 \ldots \ldots \\
20 \ldots \ldots\end{array}$ & $\begin{array}{l}31 \\
31 \\
29 \\
29 \\
29 \\
29 \\
28 \\
28 \\
27 \\
27\end{array}$ & $\begin{array}{l}225 \\
359 \\
383 \\
266 \\
223 \\
204 \\
184 \\
157 \\
147 \\
138\end{array}$ & $\begin{array}{l}21 \ldots \ldots \\
22 \ldots \ldots \\
23 \ldots \ldots \\
24 \ldots \ldots \\
25 \ldots \ldots \\
26 \ldots \ldots \\
27 \ldots \ldots \\
28 \ldots \ldots \\
29 \ldots \ldots \\
30 \ldots \ldots \\
31 \ldots \ldots\end{array}$ & $\begin{array}{r}27 \\
27 \\
27 \\
27 \\
27 \\
27 \\
27 \\
27 \\
31 \\
I, 210 \\
4,790\end{array}$ & $\begin{array}{r}126 \\
110 \\
100 \\
90 \\
82 \\
76 \\
71 \\
67 \\
-\ldots \\
-\ldots-\ldots\end{array}$ \\
\hline \multicolumn{7}{|c|}{ 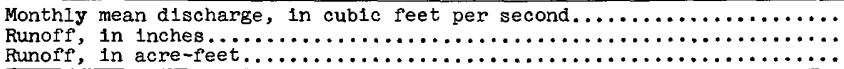 } & $\begin{array}{r}224 \\
2.59 \\
13,770\end{array}$ & $\begin{array}{r}329 \\
3.44 \\
18,260\end{array}$ \\
\hline
\end{tabular}

Gage height, in feet, and discharge, in cub1c feet per second, at 1ndicated time, 1963

\begin{tabular}{|c|c|c|c|c|c|c|c|c|c|c|c|}
\hline Date & Hour & $\begin{array}{c}\text { Gage } \\
\text { helght }\end{array}$ & $\begin{array}{c}\text { Dis- } \\
\text { charge }\end{array}$ & Date & Hour & $\begin{array}{c}\text { Gage } \\
\text { helght }\end{array}$ & $\begin{array}{l}\text { Dis- } \\
\text { charge }\end{array}$ & Date & Hour & $\begin{array}{c}\text { Gage } \\
\text { he1ght }\end{array}$ & $\begin{array}{l}\text { D1s- } \\
\text { charge }\end{array}$ \\
\hline $\begin{array}{r}\text { Jan. } \\
30\end{array}$ & $\begin{array}{l}2400 \\
0100 \\
0300 \\
0500 \\
0800 \\
0900 \\
1100 \\
1200 \\
1400 \\
1500 \\
1600 \\
1800 \\
1900 \\
2200 \\
2400\end{array}$ & $\begin{array}{l}1.36 \\
1.81 \\
2.46 \\
3.29 \\
4.20 \\
4.30 \\
4.86 \\
5.05 \\
6.33 \\
7.13 \\
7.26 \\
5.95 \\
5.63 \\
5.14 \\
4.69\end{array}$ & $\begin{array}{r}66 \\
\\
121 \\
246 \\
492 \\
860 \\
905 \\
I, 180 \\
I, 290 \\
2,090 \\
2,650 \\
2,760 \\
1,830 \\
I, 640 \\
I, 340 \\
I, 100 \\
\end{array}$ & Jan. $3 I$ & $\begin{array}{l}0500 \\
0600 \\
0700 \\
0800 \\
0900 \\
1000 \\
1100 \\
1200 \\
1300 \\
1400 \\
1500 \\
1600 \\
1700 \\
1800 \\
2000 \\
2200\end{array}$ & $\begin{array}{r}3.93 \\
3.88 \\
3.92 \\
4.54 \\
5.83 \\
7.60 \\
10.47 \\
11.56 \\
11.93 \\
11.97 \\
12.50 \\
14.40 \\
15.43 \\
14.40 \\
11.78 \\
10.38\end{array}$ & $\begin{array}{r}739 \\
717 \\
734 \\
1,020 \\
1,760 \\
3,030 \\
5,670 \\
6,820 \\
7,220 \\
7,270 \\
7,900 \\
10,400 \\
11,800 \\
10,400 \\
7,060 \\
5,580\end{array}$ & $\begin{array}{l}\text { Jan. } 3 I \\
\text { Feb. I }\end{array}$ & $\begin{array}{l}2300 \\
2400 \\
\\
0100 \\
0200 \\
0300 \\
0500 \\
0700 \\
0800 \\
1200 \\
1400 \\
1500 \\
1600 \\
1700 \\
2000 \\
2400 \\
\end{array}$ & $\begin{array}{r}9.71 \\
10.00 \\
10.64 \\
9.80 \\
9.25 \\
8.20 \\
7.45 \\
7.24 \\
6.48 \\
6.18 \\
6.14 \\
6.17 \\
6.19 \\
5.68 \\
5.21 \\
\end{array}$ & $\begin{array}{l}4,910 \\
5,200 \\
5,840 \\
5,000 \\
4,470 \\
3,520 \\
2,910 \\
2,740 \\
2,200 \\
1,990 \\
1,960 \\
1,980 \\
1,990 \\
1,670 \\
1,390\end{array}$ \\
\hline
\end{tabular}

11-4614. East Fork Russian River tributary near Potter Valley, Calif.

$$
\text { (Crest-stage station) }
$$

Location.--Lat $39^{\circ} 15^{\prime} 30^{\prime \prime}$, long $123^{\circ} 06^{\prime} 5^{\prime \prime}$, in $\mathrm{NE} \frac{1}{4}$ sec. 7, T.16 N., R.11 W., at culvert on Potter Valiey road, 4.4 miles south of Potter Valiey.

Drainage area. $--0.158 \mathrm{q} \mathrm{mi}$.

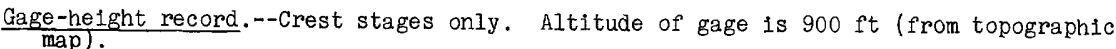

Discharge record.- - Stage-discharge relation defined by current-meter measurements below 8 cf's and by computation of flow through culvert at 19,65 , and 94 cfs.

Maxima --January-February 1963: Discharge, $20 \mathrm{cfs}$ Jan. 31 (gage height, $8.04 \mathrm{ft}$ ). 1958 to December 1962: Discharge, 94 cfs oct. 12, 1962 (gage height,
$11.72 \mathrm{ft}$ ). 
11-4615. East Fork Russian River near Calpella, Calif.

Location.--Lat $39^{\circ} 14^{\prime} 35^{\prime \prime}$, long $123^{\circ} 08^{\prime} 10^{\prime \prime}$, in NW $\frac{1}{4}$ sec.13, T.16 N., R.12 W., on left bank 0.5 mile downstream from Cold Creek and 3.6 miles east of Calpella.

Drainage area. $--93.0 \mathrm{sq} \mathrm{mi}$.

Gage-height record.--Water-stage recorder graph. Alt1tude of gage is $800 \mathrm{ft}$ (from topographic map):

Discharge record.--Stage-discharge relation defined by current-meter measurements below 3,200 efs . Maxima $---J a n u a r y-F e b r u a r y ~ 1963:$ Discharge, 7,940 efs 1600 hours Jan. 31 (gage

1941 to December 1962: Discharge, 13,300 cfs Dec. 21, 1955 (gage height, $15.06 \mathrm{ft}$, site and datum then in use), from rating curve extended above $8,600 \mathrm{cfs}$.

Remarks.-Flows affected by importation of average dally flow of 300 cfs diverted from Eel River through Potter Valley powerhouse.

Mean discharge, In cubic feet per second, 1963

\begin{tabular}{|c|c|c|c|c|c|c|c|c|}
\hline Day & January & February & Day & January & February & Day & $J$ anuary & February \\
\hline $\begin{array}{c}1 \ldots \ldots \\
2 \ldots \ldots \\
3 \ldots \ldots \\
4 \ldots \ldots \\
5 \ldots \ldots \\
7 \ldots \ldots \\
8 \ldots \ldots \\
9 \ldots \ldots \\
10 \ldots \ldots\end{array}$ & $\begin{array}{l}358 \\
349 \\
334 \\
334 \\
328 \\
325 \\
325 \\
322 \\
322 \\
245\end{array}$ & $\begin{array}{r}1,920 \\
869 \\
686 \\
562 \\
516 \\
474 \\
454 \\
471 \\
631 \\
646\end{array}$ & $\begin{array}{l}11 \ldots \ldots \\
12 \ldots \ldots \\
13 \ldots \ldots \\
14 \ldots \ldots \\
15 \ldots \ldots \\
16 \ldots \ldots \\
17 \ldots \ldots \\
18 \ldots \ldots \\
19 \ldots \ldots \\
20 \ldots \ldots\end{array}$ & $\begin{array}{l}307 \\
322 \\
322 \\
325 \\
322 \\
322 \\
325 \\
328 \\
325 \\
325\end{array}$ & $\begin{array}{l}495 \\
586 \\
574 \\
495 \\
460 \\
454 \\
445 \\
433 \\
424 \\
418\end{array}$ & $\begin{array}{l}21 \ldots \ldots \\
22 \ldots \ldots \\
23 \ldots \ldots \\
24 \ldots \ldots \\
25 \ldots \ldots \\
26 \ldots \ldots \\
27 \ldots \ldots \\
28 \ldots \ldots \\
29 \ldots \ldots \\
30 \ldots \ldots \\
31 \ldots \ldots\end{array}$ & $\begin{array}{r}325 \\
325 \\
325 \\
322 \\
322 \\
322 \\
322 \\
322 \\
334 \\
1,130 \\
3,960\end{array}$ & $\begin{array}{r}403 \\
394 \\
394 \\
394 \\
394 \\
391 \\
388 \\
382 \\
---- \\
-----\end{array}$ \\
\hline $\begin{array}{l}\text { onthly } \\
\text { unoff, }\end{array}$ & \multicolumn{6}{|c|}{ 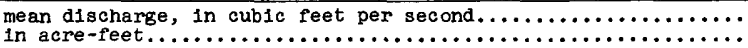 } & $\begin{array}{r}467 \\
28,710\end{array}$ & 30,060 \\
\hline
\end{tabular}

Gage height, in feet, and discharge, in cubic feet per second, at indicated time, 1963

\begin{tabular}{|c|c|c|c|c|c|c|c|c|c|c|c|}
\hline Date & Hour & $\begin{array}{c}\text { Gage } \\
\text { height }\end{array}$ & $\begin{array}{l}\text { Dis- } \\
\text { charge }\end{array}$ & Date & Hour & $\begin{array}{c}\text { Gage } \\
\text { height }\end{array}$ & $\begin{array}{c}\text { Dis- } \\
\text { charge }\end{array}$ & Date & Hour & $\begin{array}{c}\text { Gage } \\
\text { he1ght }\end{array}$ & $\begin{array}{c}\text { D18- } \\
\text { charge }\end{array}$ \\
\hline $\begin{array}{r}\text { Jan. } 29 \\
30\end{array}$ & $\begin{array}{l}2400 \\
0300 \\
0600 \\
0800 \\
1000 \\
1100 \\
1300 \\
1400 \\
1500 \\
1600 \\
1800 \\
2000 \\
2100 \\
2400\end{array}$ & $\begin{array}{l}2.61 \\
2.86 \\
3.56 \\
3.67 \\
3.95 \\
4.25 \\
5.38 \\
5.91 \\
6.21 \\
6.10 \\
5.35 \\
5.06 \\
4.78 \\
4.04\end{array}$ & $\begin{array}{r}373 \\
448 \\
414 \\
758 \\
878 \\
1,010 \\
1,630 \\
1,960 \\
2,170 \\
2,090 \\
1,610 \\
1,440 \\
1,270 \\
918\end{array}$ & Jan. 31 & $\begin{array}{l}0300 \\
0400 \\
0600 \\
0700 \\
0800 \\
0900 \\
1000 \\
1100 \\
1300 \\
1600 \\
1700 \\
1800 \\
2000 \\
2200 \\
2300\end{array}$ & $\begin{array}{r}3.72 \\
3.59 \\
3.60 \\
3.90 \\
4.87 \\
6.89 \\
9.00 \\
10.58 \\
11.02 \\
12.49 \\
12.29 \\
11.70 \\
9.56 \\
8.46 \\
8.64\end{array}$ & $\begin{array}{r}778 \\
726 \\
730 \\
855 \\
1,320 \\
2,640 \\
4,350 \\
5,880 \\
6,320 \\
7,940 \\
7,720 \\
7,070 \\
4,860 \\
3,870 \\
4,030\end{array}$ & $\begin{array}{l}\text { Jan. } 31 \\
\text { Feb. } 1\end{array}$ & $\begin{array}{l}2400 \\
0100 \\
0300 \\
0600 \\
1100 \\
1200 \\
1400 \\
1500 \\
1600 \\
1700 \\
1800 \\
2400\end{array}$ & $\begin{array}{l}9.28 \\
8.87 \\
7.30 \\
6.10 \\
5.18 \\
5.10 \\
5.23 \\
5.26 \\
5.21 \\
5.06 \\
5.00 \\
4.33\end{array}$ & $\begin{array}{l}4,600 \\
4,230 \\
2,940 \\
2,090 \\
1,510 \\
1,460 \\
1,540 \\
1,560 \\
1,530 \\
1,440 \\
1,400 \\
1,050\end{array}$ \\
\hline
\end{tabular}

11-4620. East Fork Russian River near Uk1ah, Calif.

Location.--Lat $39^{\circ} 11^{\prime} 45^{\prime \prime}$, long $123^{\circ} 11^{\prime} 30^{\prime \prime}$, in Yokayo Rancho Grant, on right bank of outlet channel, $500 \mathrm{ft}$ downstream from Coyote Dam, 1,300 ft upstream from mouth, and 3.2 miles northeast of Ukiah, Mendocino County.

Drainage. $--105 \mathrm{sq} \mathrm{mi}$.

Gage-height record.--Digital-recorder tape punched at 15-minute intervals, except Jan. 1, 2; Datum of gage is $614.43 \mathrm{ft}$ above mean sea level (levels by Corps of Engineers).

Discharge record.--Stage-discharge relation defined by current-meter measurements. Discharge for Jan. 1, 2 estimated on basis of one discharge measurement.

Maxima.--January-February 1963: Discharge, 4,150 cf's 1145 hours Feb. 2 (gage height, $8.92 \mathrm{ft})$.

1911-i3, 1951-56, 1957 to December 1962: Discharge, 13,300 efs Dec. 21, 1955 (gage height, 16.86 ft, site and datum then in use), from rating curve extended above $1,700 \mathrm{cfs}$ on basis of peak flow at station upstream which was defined to $8,600 \mathrm{efs}$.

Remarks.--Flow regulated by Lake Mendocino since 1958 (capacity, 122,500 acre-ft). 
Mean discharge, in cub1c feet per second, 1963, of East Fork Russian River near Ukiah, Cal1f.

\begin{tabular}{|c|c|c|c|c|c|c|c|c|}
\hline Day & January & February & Day & January & February & Day & January & February \\
\hline $\begin{array}{l}1 \ldots \ldots \\
2 \ldots \ldots \\
3 \ldots \ldots \\
4 \ldots \ldots \\
5 \ldots \ldots \\
6 \ldots \ldots \\
7 \ldots \ldots \\
8 \ldots \ldots \\
9 \ldots \ldots \\
0 \ldots \ldots\end{array}$ & $\begin{array}{r}16 \\
17 \\
17 \\
17 \\
17 \\
17 \\
1,880 \\
3,220 \\
1,060 \\
29\end{array}$ & $\begin{array}{r}507 \\
2,830 \\
3,920 \\
3,210 \\
3,360 \\
2,500 \\
332 \\
223 \\
222 \\
223\end{array}$ & $\begin{array}{l}11 \ldots \ldots \\
12 \ldots \ldots \\
13 \ldots \ldots \\
14 \ldots \ldots \\
15 \ldots \ldots \\
16 \ldots \ldots \\
17 \ldots \ldots \\
18 \ldots \ldots \\
19 \ldots \ldots \\
20 \ldots \ldots\end{array}$ & $\begin{array}{l}33 \\
48 \\
48 \\
48 \\
48 \\
48 \\
62 \\
73 \\
73 \\
73\end{array}$ & $\begin{array}{r}268 \\
309 \\
308 \\
308 \\
257 \\
220 \\
220 \\
940 \\
2,090 \\
488\end{array}$ & $\begin{array}{l}21 \ldots \ldots \\
22 \ldots \ldots \\
23 \ldots \ldots \\
24 \ldots \ldots \\
25 \ldots \ldots \\
26 \ldots \ldots \\
27 \ldots \ldots \\
28 \ldots \ldots \\
29 \ldots \ldots \\
30 \ldots \ldots \\
31 \ldots \ldots\end{array}$ & $\begin{array}{r}73 \\
73 \\
73 \\
73 \\
94 \\
106 \\
106 \\
106 \\
107 \\
68 \\
17\end{array}$ & $\begin{array}{r}26 \\
25 \\
24 \\
22 \\
22 \\
22 \\
22 \\
22 \\
-\ldots--- \\
-\ldots-\ldots\end{array}$ \\
\hline $\begin{array}{l}\text { hly } \\
\text { ff, }\end{array}$ & 10 & & & & & & $\begin{array}{r}250 \\
15,350 \\
\end{array}$ & $\begin{array}{r}819 \\
45,460 \\
\end{array}$ \\
\hline
\end{tabular}

11-4621.25. Slide Creek near Uk1ah, Calif.

(Crest-stage station)

Location. --Lat $39^{\circ} 04^{\prime} 15^{\prime \prime}$, long $123^{\circ} 12^{\prime} 35^{\prime \prime}$, in NW $\frac{1}{4}$ SW $\frac{1}{4}$ sec.17, T.14 N., R.12 W., at culvert on Boonville Road, 5.5 miles south of Ukiah.

Drainage area. $-0.57 \mathrm{sq} \mathrm{mi}$.

$\frac{\text { Gage-he1ght record.--Crest stages only. Altitude of gage is } 940 \mathrm{ft} \text { (from topographic }}{\text { map). }}$

Discharge record.--Stage-discharge relation defined by current-meter measurements below $25 \mathrm{cf}$ and by computation of flow through culvert at $65 \mathrm{cf} 8$.

Maxima, -January-February 1963: Discharge, 64 cfs Jan. 31 (gage height, $13.61 \mathrm{ft}$ ).

1958 to December 1962: Discharge, 65 cfs Feb. 21, 1959 (gage he1ght, $13.64 \mathrm{ft}$ ).

11-4625. Russian River near Hopland, Calif.

Location.--Lat $39^{\circ} 01^{\prime} 35^{\prime \prime}$, long $123^{\circ} 07^{\prime} 45^{\prime \prime}$, in Rancho de Sanel Grant, on right bank at abandoned highway bridge, 0.2 mile downstream from McNab Creek, 4 miles north of Hopland, Mendocino County, and 17 miles upstream from Sulphur Creek.

Drainage area. $-362 \mathrm{sq} \mathrm{ms}$.

Gage-he1ght record --Water-stage recorder graph Jan. 1 to Feb. 14. Digital-recorder tape punched at i5-minute intervals Feb. 15-28. Datum of gage is $497.43 \mathrm{ft}$ above mean sea level, datum of 1929.

Discharge record.--Stage-discharge relation defined by current-meter measurements.

Maxima.--January-February 1963: Discharge, 21,200 cf's 2200 hours Jan. 31 (gage helght, $19.24 \mathrm{ft}$ ).

1939 to December 1962: Discharge, 45,000 cfs Dec. 22, 1955 (gage height, $27.00 \mathrm{ft}$ ).

Flood in December 1937 reached a stage of $30.0 \mathrm{ft}$, from floodmarks.

Remarks.--Flow regulated by Lake Mendocino (capacity, 122,500 acre-ft).

Mean discharge, in cubic feet per second, 1963

\begin{tabular}{|c|c|c|c|c|c|c|c|c|}
\hline Day & January & February & Day & January & February & Day & January & February \\
\hline $\begin{array}{r}1 \ldots \ldots \\
2 \ldots . . \\
3 \ldots \ldots \\
4 \ldots \ldots \\
5 \ldots \ldots \\
6 \ldots \ldots \\
7 \ldots \ldots \\
9 \ldots \ldots \\
10 \ldots .\end{array}$ & $\begin{array}{l}137 \\
131 \\
128 \\
124 \\
122 \\
121 \\
1,070 \\
3,300 \\
1,650 \\
220\end{array}$ & $\begin{array}{l}8,780 \\
4,850 \\
5,260 \\
4,510 \\
3,770 \\
3,700 \\
1,310 \\
1,080 \\
1,250 \\
1,380\end{array}$ & 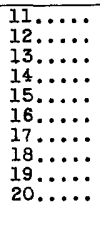 & $\begin{array}{l}140 \\
131 \\
126 \\
123 \\
121 \\
121 \\
121 \\
125 \\
125 \\
124\end{array}$ & $\begin{array}{r}1,110 \\
1,260 \\
1,430 \\
1,150 \\
978 \\
874 \\
805 \\
1,110 \\
2,380 \\
1,040\end{array}$ & $\begin{array}{l}21 \ldots \ldots \\
22 \ldots \ldots \\
23 \ldots \ldots \\
24 \ldots \ldots \\
25 \ldots \ldots \\
26 \ldots \ldots \\
27 \ldots \ldots \\
28 \ldots \ldots \\
29 \ldots \ldots \\
30 \ldots \ldots \\
31 \ldots \ldots\end{array}$ & $\begin{array}{r}124 \\
123 \\
122 \\
122 \\
125 \\
135 \\
135 \\
135 \\
150 \\
3,070 \\
10,500\end{array}$ & $\begin{array}{r}455 \\
383 \\
345 \\
318 \\
295 \\
277 \\
262 \\
250 \\
--0- \\
-0 .-\end{array}$ \\
\hline $\begin{array}{l}\text { nthly } \\
\text { nof }\end{array}$ & $e-1$ & & & & & $\ldots$ & $\begin{array}{r}742 \\
45,620 \\
\end{array}$ & $\begin{array}{r}1,808 \\
100,400 \\
\end{array}$ \\
\hline
\end{tabular}


Gage height, in feet, and discharge, in cublc feet per second, at indicated time, 1963, of

\begin{tabular}{|c|c|c|c|c|c|c|c|c|c|c|c|}
\hline Date & Hour & $\begin{array}{c}\text { Gage } \\
\text { helght }\end{array}$ & $\begin{array}{c}\text { D1s- } \\
\text { charge }\end{array}$ & Date & Hour & $\begin{array}{c}\text { Gage } \\
\text { helght }\end{array}$ & $\begin{array}{l}\text { D1s- } \\
\text { charge }\end{array}$ & Date & Hour & $\begin{array}{c}\text { Gage } \\
\text { he1ght }\end{array}$ & $\begin{array}{l}\text { Dis- } \\
\text { charge }\end{array}$ \\
\hline $\begin{array}{r}\text { Jan. } 29 \\
30\end{array}$ & $\begin{array}{l}2400 \\
0200 \\
0400 \\
0800 \\
1200 \\
1500 \\
1700 \\
1800 \\
1900 \\
2100 \\
2300 \\
2400\end{array}$ & $\begin{array}{r}5.38 \\
5.64 \\
6.26 \\
7.88 \\
9.16 \\
11.19 \\
12.22 \\
12.42 \\
12.24 \\
11.08 \\
10.06 \\
9.75\end{array}$ & $\begin{array}{r}241 \\
321 \\
576 \\
1,500 \\
2,620 \\
5,040 \\
6,510 \\
6,830 \\
6,540 \\
4,890 \\
3,610 \\
3,250\end{array}$ & $\operatorname{Jan} .31$ & $\begin{array}{l}0300 \\
0500 \\
0600 \\
0800 \\
1000 \\
1200 \\
1400 \\
1600 \\
1800 \\
1900 \\
2000 \\
2200 \\
2400\end{array}$ & $\begin{array}{r}9.00 \\
8.64 \\
8.62 \\
9.20 \\
10.95 \\
14.00 \\
16.50 \\
17.90 \\
18.40 \\
18.35 \\
18.66 \\
19.24 \\
18.62\end{array}$ & $\begin{array}{r}2,460 \\
2,120 \\
2,100 \\
2,660 \\
4,720 \\
9,450 \\
14,200 \\
17,500 \\
18,800 \\
18,700 \\
19,500 \\
21,200 \\
19,400\end{array}$ & Feb. 1 & $\begin{array}{l}0300 \\
0600 \\
0900 \\
1200 \\
1500 \\
1700 \\
1800 \\
2000 \\
2400\end{array}$ & $\begin{array}{l}16.97 \\
15.15 \\
13.25 \\
12.30 \\
11.60 \\
11.94 \\
11.95 \\
11.67 \\
11.06\end{array}$ & $\begin{array}{r}15,200 \\
11,500 \\
8,080 \\
6,510 \\
5,460 \\
5,960 \\
5,980 \\
5,560 \\
4,770\end{array}$ \\
\hline
\end{tabular}

11-4627. Fellz Creek near Hopland, Calif.

Location.--Lat $38^{\circ} 58^{\prime} 20^{\prime \prime}$, long $123^{\circ} 08^{\prime} 30^{\prime \prime}$, In Rancho de Sanel Grant, on left bank just upstream from county road bridge, 0.1 mile upstream from Johnson Creek and 1.4 miles west of Hopland, Mendocino County.

Drainage area. $--31.1 \mathrm{sq} \mathrm{m}$.

Gage-height record.--Water-stage recorder graph. Alt1tude of gage is $500 \mathrm{ft}$ (from topographic map).

D1scharge record.--Stage-discharge relation defined by current-meter measurements.

Maxima.--January-February 1963: Discharge, 2,910 cfs 1300 hours Jan. 31 (gage helght, $13.43 \mathrm{ft}$ ).

1958 to December 1962: Discharge, 2,880 cfs Feb. 13, 1962 (gage height, $13.35 \mathrm{f}^{\prime} \mathrm{t}$ ).

Flood of Dec. 23, 1955, reached a stage of $13.60 \mathrm{ft}$, from floodmarks (discharge, $2,710 \mathrm{cfs}$ on basis of slope-area measurement of peak flow).

Mean discharge, in cublc feet per second, 1963

\begin{tabular}{|c|c|c|c|c|c|c|c|c|}
\hline Day & January & February & Day & Jenuary & February & Day & January & February \\
\hline $\begin{array}{c}1 \ldots \ldots \\
2 \ldots \ldots \\
4 \ldots \ldots \\
5 \ldots \ldots \\
6 \ldots \ldots \\
7 \ldots \ldots \\
8 \ldots \ldots \\
9 \ldots \ldots\end{array}$ & $\begin{array}{l}11 \\
10 \\
9.5 \\
9.0 \\
8.5 \\
8.0 \\
7.5 \\
7.5 \\
7.5 \\
7.0\end{array}$ & $\begin{array}{r}723 \\
288 \\
163 \\
109 \\
83 \\
71 \\
60 \\
96 \\
268 \\
215\end{array}$ & $\begin{array}{l}11 \ldots \ldots \\
12 \ldots \ldots \\
13 \ldots \ldots \\
14 \ldots \ldots \\
15 \ldots \ldots \\
16 \ldots \ldots \\
17 \ldots \ldots \\
18 \ldots \ldots \\
19 \ldots \ldots \\
20 \ldots \ldots\end{array}$ & $\begin{array}{l}6.5 \\
6.0 \\
5.6 \\
6.0 \\
5.6 \\
5.6 \\
5.1 \\
5.1 \\
5.1 \\
4.7\end{array}$ & $\begin{array}{r}126 \\
329 \\
235 \\
143 \\
106 \\
91 \\
76 \\
65 \\
58 \\
52\end{array}$ & $\begin{array}{l}21 \ldots \ldots \\
22 \ldots \ldots \\
23 \ldots \ldots \\
24 \ldots \ldots \\
25 \ldots \ldots \\
26 \ldots \ldots \\
27 \ldots \ldots \\
28 \ldots \ldots \\
29 \ldots \ldots \\
30 \ldots \ldots \\
31 \ldots \ldots\end{array}$ & $\begin{array}{r}4.7 \\
4.7 \\
4.7 \\
4.7 \\
4.3 \\
4.3 \\
4.3 \\
3.9 \\
39 \\
1,030 \\
1,690\end{array}$ & $\begin{array}{r}46 \\
42 \\
38 \\
35 \\
31 \\
27 \\
27 \\
24 \\
---- \\
-----\end{array}$ \\
\hline \multicolumn{7}{|c|}{ 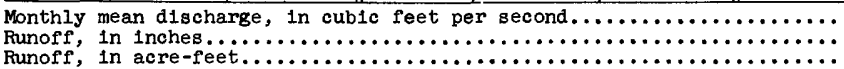 } & $\begin{array}{r}94.7 \\
3.51 \\
5,820 \\
\end{array}$ & $\begin{array}{r}130 \\
4.34 \\
7,190 \\
\end{array}$ \\
\hline
\end{tabular}

Gage height, in feet, and discharge, in cuble feet per second, at indicated time, 1963

\begin{tabular}{|c|c|c|c|c|c|c|c|c|c|c|c|}
\hline Date & Hour & $\begin{array}{c}\text { Gage } \\
\text { helght }\end{array}$ & $\begin{array}{l}\text { Dis- } \\
\text { charge }\end{array}$ & Date & Hour & $\begin{array}{c}\text { Gage } \\
\text { helght }\end{array}$ & $\begin{array}{l}\text { Dis- } \\
\text { charge }\end{array}$ & Date & Hour & $\begin{array}{c}\text { Gage } \\
\text { helght }\end{array}$ & $\begin{array}{l}\text { Dis- } \\
\text { charge }\end{array}$ \\
\hline $\begin{array}{r}\operatorname{Jan} .28 \\
29\end{array}$ & $\begin{array}{l}2400 \\
1200 \\
1600 \\
1800 \\
2000 \\
2200 \\
2300 \\
2400\end{array}$ & $\begin{array}{l}4.31 \\
4.33 \\
4.37 \\
4.48 \\
5.29 \\
5.67 \\
6.31 \\
6.53\end{array}$ & $\begin{array}{c}3.9 \\
4.7 \\
6.5 \\
12 \\
87 \\
143 \\
278 \\
339\end{array}$ & Jan. 30 & $\begin{array}{l}1200 \\
1300 \\
1400 \\
1500 \\
1700 \\
1900 \\
2100 \\
2400\end{array}$ & $\begin{array}{r}11.00 \\
11.80 \\
11.33 \\
10.75 \\
9.01 \\
8.25 \\
7.76 \\
7.35\end{array}$ & $\begin{array}{r}1,870 \\
2,190 \\
2,000 \\
1,780 \\
1,170 \\
908 \\
736 \\
593\end{array}$ & Jan. 31 & $\begin{array}{l}1500 \\
1600 \\
1700 \\
1900 \\
2000 \\
2100 \\
2200 \\
2300 \\
2400\end{array}$ & $\begin{array}{r}12.83 \\
11.80 \\
10.70 \\
9.93 \\
9.97 \\
9.73 \\
9.50 \\
9.68 \\
9.48\end{array}$ & $\begin{array}{l}2,640 \\
2,190 \\
1,770 \\
1,500 \\
1,510 \\
1,430 \\
1,350 \\
1,410 \\
1,340\end{array}$ \\
\hline 30 & $\begin{array}{l}0100 \\
0200 \\
0400 \\
0500 \\
0700 \\
0900 \\
1000 \\
1100\end{array}$ & $\begin{array}{l}6.97 \\
7.17 \\
8.25 \\
8.00 \\
8.02 \\
8.26 \\
8.30 \\
8.98\end{array}$ & $\begin{array}{r}471 \\
531 \\
908 \\
820 \\
827 \\
911 \\
925 \\
1,160 \\
\end{array}$ & 31 & $\begin{array}{l}0300 \\
0400 \\
0600 \\
0700 \\
0800 \\
1000 \\
1200 \\
1300 \\
1400 \\
\end{array}$ & $\begin{array}{r}7.09 \\
7.14 \\
8.34 \\
9.87 \\
11.50 \\
13.42 \\
13.10 \\
13.43 \\
13.17\end{array}$ & $\begin{array}{r}507 \\
522 \\
939 \\
1,470 \\
2,070 \\
2,910 \\
2,770 \\
2,910 \\
2,800 \\
\end{array}$ & Feb. 1 & $\begin{array}{l}0300 \\
0500 \\
0800 \\
1000 \\
1200 \\
1400 \\
1800 \\
2400\end{array}$ & $\begin{array}{l}8.76 \\
8.30 \\
7.84 \\
7.60 \\
7.45 \\
7.47 \\
7.15 \\
6.79 \\
\end{array}$ & $\begin{array}{r}1,090 \\
925 \\
764 \\
680 \\
628 \\
635 \\
525 \\
417\end{array}$ \\
\hline
\end{tabular}


11-4630. Russian River near Cloverdale, Calif.

Location.--Lat $38^{\circ} 52^{\prime} 55^{\prime \prime}$, long $123^{\circ} 03^{1} 15^{\prime \prime}$, in SW $\frac{1}{4}$ sec.14, T.12 N., R.11 W., on left bank at Lambert Ranch, $400 \mathrm{ft}$ downstream from Cummisky Creek and 5 miles northwest of Cloverdale.

Drainage area. $--502 \mathrm{sq} \mathrm{ml}$.

Gage-height record.--Water-stage recorder graph. Datum of gage is $373.44 \mathrm{ft}$ above mean sea level (levels by Corps of Engineers).

Discharge record.--Stage-discharge relation defined by current-meter measurements .

Maxima.--January-February 1963: Discharge, 25,200 efs 1900 hours Jan. 31 lgage height, $21.75 \mathrm{ft}$ ).

1951 to December 1962: Discharge 53,000 cfs Dec. 22, 1955 (gage height, $30.9 \mathrm{ft}$, from floodmarks), from rating curve extended above $21,000 \mathrm{cfs}$ on basis of determination of peak flow at upstream and downstream stations.

Remarks.--Flow slightly regulated by Lake Mendocino (capacity, 122,500 acre-ft).

Mean discharge, In cublc feet per second, 1963

\begin{tabular}{|c|c|c|c|c|c|c|c|c|}
\hline Day & January & February & Day & January & February & Day & January & February \\
\hline $\begin{array}{c}1 \ldots \ldots \\
2 \ldots \ldots \\
3 \ldots \ldots \\
5 \ldots \ldots \\
6 \ldots \ldots \\
7 \ldots \ldots \\
9 \ldots \ldots \\
10 \ldots \ldots\end{array}$ & $\begin{array}{r}177 \\
165 \\
159 \\
151 \\
143 \\
138 \\
552 \\
3,440 \\
2,210 \\
357\end{array}$ & $\begin{array}{r}14,700 \\
6,410 \\
6,380 \\
5,340 \\
4,020 \\
4,440 \\
1,630 \\
1,440 \\
1,950 \\
2,200\end{array}$ & $\begin{array}{l}11 \ldots \ldots \\
12 \ldots \ldots \\
13 \ldots \ldots \\
14 \ldots \ldots \\
15 \ldots \ldots \\
16 \ldots \ldots \\
17 \ldots \ldots \\
18 \ldots \ldots \\
19 \ldots \ldots \\
20 \ldots \ldots\end{array}$ & $\begin{array}{l}243 \\
206 \\
190 \\
177 \\
169 \\
162 \\
156 \\
164 \\
164 \\
162\end{array}$ & $\begin{array}{l}1,590 \\
2,350 \\
2,530 \\
1,790 \\
1,490 \\
1,280 \\
1,170 \\
1,160 \\
2,820 \\
1,500\end{array}$ & $\begin{array}{l}21 \ldots \ldots \\
22 \ldots \ldots \\
23 \ldots \ldots \\
24 \ldots \ldots \\
25 \ldots \ldots \\
26 \ldots \ldots \\
27 \ldots \ldots \\
28 \ldots \ldots \\
29 \ldots \ldots \\
30 \ldots \ldots \\
31 \ldots \ldots\end{array}$ & $\begin{array}{r}159 \\
159 \\
156 \\
156 \\
154 \\
169 \\
177 \\
177 \\
206 \\
6,090 \\
16,200\end{array}$ & $\begin{array}{r}738 \\
570 \\
469 \\
408 \\
360 \\
325 \\
298 \\
275 \\
----- \\
--.-- \\
\end{array}$ \\
\hline \multicolumn{7}{|c|}{ 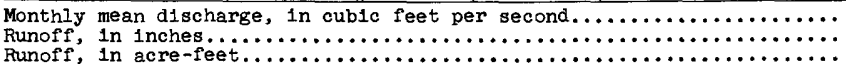 } & $\begin{array}{r}1,067 \\
2.45 \\
65,630\end{array}$ & $\begin{array}{r}2,487 \\
5.16 \\
138,100 \\
\end{array}$ \\
\hline
\end{tabular}

Gage height, In feet, and discharge, in cublc feet per second, at indicated time, 1963

\begin{tabular}{|c|c|c|c|c|c|c|c|c|c|c|c|}
\hline Date & Hour & $\begin{array}{c}\text { Gage } \\
\text { helight }\end{array}$ & $\begin{array}{l}\text { Dis- } \\
\text { charge }\end{array}$ & Date & Hour & $\begin{array}{c}\text { Gage } \\
\text { helght }\end{array}$ & $\begin{array}{c}\text { Dis- } \\
\text { charge }\end{array}$ & Date & Hour & $\begin{array}{c}\text { Gage } \\
\text { helght }\end{array}$ & $\begin{array}{l}\text { D1s- } \\
\text { charge }\end{array}$ \\
\hline $\begin{array}{r}\text { Jan. } 29 \\
30\end{array}$ & $\begin{array}{l}2400 \\
0200 \\
0400 \\
0700 \\
0900 \\
1100 \\
1300 \\
1600 \\
1700 \\
2000 \\
2200 \\
2400 \\
0300 \\
\end{array}$ & $\begin{array}{r}7.03 \\
7.98 \\
9.00 \\
9.88 \\
10.23 \\
11.02 \\
13.18 \\
15.50 \\
15.63 \\
15.10 \\
14.60 \\
13.56 \\
12.22 \\
\end{array}$ & $\begin{array}{r}512 \\
1,080 \\
1,970 \\
2,830 \\
3,200 \\
4,120 \\
7,290 \\
11,200 \\
11,400 \\
10,500 \\
9,580 \\
7,900 \\
5,750 \\
\end{array}$ & Jan. 31 & $\begin{array}{l}0500 \\
0700 \\
0900 \\
1000 \\
1200 \\
1600 \\
1900 \\
2100 \\
2300 \\
2400 \\
0200 \\
0400 \\
0700 \\
0900 \\
\end{array}$ & $\begin{array}{l}11.76 \\
12.47 \\
15.10 \\
16.75 \\
19.25 \\
21.60 \\
21.75 \\
21.58 \\
21.45 \\
21.50 \\
21.50 \\
21.13 \\
19.60 \\
18.24\end{array}$ & $\begin{array}{r}5,080 \\
6,150 \\
10,500 \\
13,600 \\
18,800 \\
24,800 \\
25,200 \\
24,700 \\
24,400 \\
24,500 \\
24,500 \\
23,500 \\
19,600 \\
16,600 \\
\end{array}$ & Feb. & $\begin{array}{l}1200 \\
1500 \\
1800 \\
2000 \\
2100 \\
2400 \\
\\
0400 \\
0800 \\
1400 \\
1800 \\
1900 \\
2400\end{array}$ & $\begin{array}{l}15.92 \\
14.73 \\
14.05 \\
14.10 \\
14.02 \\
13.48 \\
12.79 \\
12.27 \\
11.85 \\
13.06 \\
13.11 \\
12.94\end{array}$ & $\begin{array}{r}12,000 \\
9,810 \\
8,680 \\
8,760 \\
8,630 \\
7,770 \\
6,660 \\
5,830 \\
5,210 \\
7,100 \\
7,180 \\
6,900\end{array}$ \\
\hline
\end{tabular}

11-4632. Big Sulphur Creek near Cloverdale, Calif.

Locat1on.--Lat $38^{\circ} 49^{\prime} 25^{\prime \prime}$, long $122^{\circ} 59^{\prime} 05^{\prime \prime}$, in NW/ $\frac{1}{4}$ sec.10, T.11 N., R. 10 W., on right bank $500 \mathrm{ft}$ downstream from unnamed tributary, 1.9 miles upstream from mouth, and 3.1 miles northeast of Cloverdale.

Drainage area. $--82.3 \mathrm{sq} \mathrm{ml}$.

Gage-helght record.--Water-stage recorder graph. Altitude of gage is 380 ft (from topograph1c map).

Discharge record.--Stage-discharge relation defined by current-meter measurements below $2,900 \mathrm{cfs}$ and by slope-area measurement at $20,000 \mathrm{cfs}$.

Maxima.--January-February 1963: Discharge, 8,680 cfs 1500 hours Jan. 31 (gage he1ght, $13.65 \mathrm{ft}$ ).

1955 to December 1962: Discharge, 20,000 cfs Dec. 22, 1955 (gage height, $22.2 \mathrm{ft}$, from floodmarks), on basis of siope-area measurement of peak flow. 
Mean discharge, in cublc feet per second, 1963, of Big Sulphur Creek near Cloverdale, Callf.

\begin{tabular}{|c|c|c|c|c|c|c|c|c|}
\hline Day & January & February & Day & January & February & Day & January & February \\
\hline $\begin{array}{r}1 \ldots \ldots \\
2 \ldots . . \\
3 \ldots \ldots \\
4 \ldots \ldots \\
5 \ldots \ldots \\
6 \ldots \ldots \\
7 \ldots \ldots \\
8 \ldots \ldots \\
10 \ldots \ldots\end{array}$ & $\begin{array}{l}93 \\
85 \\
82 \\
75 \\
69 \\
66 \\
64 \\
61 \\
60 \\
57\end{array}$ & $\begin{array}{r}2,870 \\
1,500 \\
1,050 \\
670 \\
483 \\
429 \\
393 \\
461 \\
726 \\
735\end{array}$ & $\begin{array}{l}11 \ldots . . \\
12 . \ldots \\
13 \ldots \\
14 \ldots \\
15 \ldots \\
16 \ldots \\
17 \ldots \\
18, \ldots \\
19 . \ldots \\
20 . \ldots\end{array}$ & $\begin{array}{l}55 \\
52 \\
50 \\
49 \\
48 \\
47 \\
46 \\
45 \\
42 \\
42\end{array}$ & $\begin{array}{l}555 \\
885 \\
957 \\
615 \\
515 \\
461 \\
407 \\
363 \\
327 \\
295\end{array}$ & $\begin{array}{l}21 \ldots \ldots \\
22 \ldots \ldots \\
23 \ldots \ldots \\
24 \ldots \\
25 \ldots \\
26 \ldots \\
27 \ldots \ldots \\
28 \ldots \\
29 \ldots \\
30 \ldots \\
31 \ldots \ldots \\
\end{array}$ & $\begin{array}{r}41 \\
41 \\
41 \\
40 \\
39 \\
37 \\
37 \\
36 \\
53 \\
2,810 \\
5,820\end{array}$ & $\begin{array}{r}264 \\
239 \\
218 \\
201 \\
184 \\
172 \\
160 \\
148 \\
- \\
-0 .-\end{array}$ \\
\hline & & & & & & & $\begin{array}{r}328 \\
4.60 \\
20,200 \\
\end{array}$ & $\begin{array}{r}582 \\
7,36 \\
32,300 \\
\end{array}$ \\
\hline
\end{tabular}

Gage height, in feet, and discharge, in cublc feet per second, at indicated t1me, 1963

\begin{tabular}{|c|c|c|c|c|c|c|c|c|c|c|c|}
\hline Date & Hour & $\begin{array}{c}\text { Gage } \\
\text { height }\end{array}$ & $\begin{array}{l}\text { Dis- } \\
\text { charge }\end{array}$ & Date & Hour & $\begin{array}{c}\text { Gage } \\
\text { he1ght }\end{array}$ & $\begin{array}{l}\text { Dis- } \\
\text { charge }\end{array}$ & Date & Hour & $\begin{array}{c}\text { Gage } \\
\text { helght }\end{array}$ & $\begin{array}{c}\text { Dis - } \\
\text { charge }\end{array}$ \\
\hline $\begin{array}{r}\text { Jan. } 28 \\
29\end{array}$ & $\begin{array}{l}2400 \\
1200 \\
1500 \\
1800 \\
2100 \\
2400\end{array}$ & $\begin{array}{l}3.09 \\
\\
3.09 \\
3.14 \\
3.24 \\
3.47 \\
3.84\end{array}$ & $\begin{array}{r}36 \\
36 \\
41 \\
50 \\
82 \\
172\end{array}$ & Jan. 30 & $\begin{array}{l}1400 \\
1500 \\
1700 \\
1800 \\
2200 \\
2400\end{array}$ & $\begin{array}{r}10.75 \\
11.00 \\
10.53 \\
9.89 \\
8.31 \\
7.92\end{array}$ & $\begin{array}{l}5,330 \\
5,600 \\
5,080 \\
4,440 \\
3,000 \\
2,650\end{array}$ & Jan. 31 & $\begin{array}{l}1400 \\
1500 \\
1600 \\
1900 \\
2300 \\
2400\end{array}$ & $\begin{array}{l}13.64 \\
13.65 \\
13.44 \\
12.07 \\
10.30 \\
10.05\end{array}$ & $\begin{array}{l}8,670 \\
8,680 \\
8,430 \\
6,780 \\
4,850 \\
4,600\end{array}$ \\
\hline 30 & $\begin{array}{l}0200 \\
0300 \\
0400 \\
0700 \\
0800 \\
0900 \\
1000 \\
1200\end{array}$ & $\begin{array}{l}4.36 \\
4.89 \\
5.78 \\
7.13 \\
7.05 \\
6.95 \\
7.13 \\
8.49\end{array}$ & $\begin{array}{r}359 \\
605 \\
1,090 \\
2,000 \\
1,940 \\
1,870 \\
2,000 \\
3,160\end{array}$ & 31 & $\begin{array}{l}0200 \\
0300 \\
0400 \\
0500 \\
0700 \\
0800 \\
0900 \\
1100 \\
1200\end{array}$ & $\begin{array}{r}7.65 \\
7.60 \\
7.66 \\
8.05 \\
9.77 \\
11.67 \\
12.29 \\
13.15 \\
13.20\end{array}$ & $\begin{array}{l}2,420 \\
2,380 \\
2,430 \\
2,770 \\
4,320 \\
6,340 \\
7,050 \\
8,080 \\
8,140\end{array}$ & Feb. 1 & $\begin{array}{l}0200 \\
0300 \\
0600 \\
0900 \\
1200 \\
1600 \\
2000 \\
2400\end{array}$ & $\begin{array}{r}10.10 \\
9.90 \\
8.92 \\
8.29 \\
7.78 \\
7.36 \\
7.04 \\
6.77\end{array}$ & $\begin{array}{l}4,650 \\
4,450 \\
3,550 \\
2,980 \\
2,520 \\
2,190 \\
1,930 \\
1,740\end{array}$ \\
\hline
\end{tabular}

11-4639. Maacama Creek near Kellogg, Calif.

Location.--Lat $38^{\circ} 38^{\prime} 25^{\prime \prime}$, long $122^{\circ} 45^{\prime} 45^{\prime \prime}$, in SW $\frac{1}{4}$ sec.9, T.9 N., R.8 W., on right bank $0.5 \mathrm{mile}$ downstream from Redwood Creek and 4.4 miles west of Kellogg.

Drainage area. $--43.4 \mathrm{sq} \mathrm{mi}$.

Gage-height record.--Water-stage recorder graph, except Feb. 7-28. Altitude of gage is $200 \mathrm{ft}$ (from topographic map).

Discharge record.--Stage-discharge relation defined by current-meter measurements below 1,900 cfs. Discharge for Feb. 7-28 estimated on basis of one discharge measurement and records for Santa Rosa Creek near Santa Rosa.

Maxima.--January-February 1963: D1scharge, 7,700 cf's 1000 hours Jan. 31 (gage he1ght, $17.15 \mathrm{ft}$ )

1958 to December 1962: Discharge, 8,100 cf's Feb. 24, 1958 (gage height, $20.6 \mathrm{ft}$, from floodmarks, site and datum then in use).

Mean discharge, in cublc feet per second, 1963

\begin{tabular}{|c|c|c|c|c|c|c|c|c|}
\hline Day & January & Eebruary & Day & January & Eebruary & Day & January & February \\
\hline $\begin{array}{r}1 \ldots \ldots \\
2 \ldots \ldots \\
3 \ldots \ldots \\
4 \ldots \ldots \\
5 \ldots \ldots \\
7 \ldots \ldots \\
8 \ldots \ldots \\
9 \ldots \ldots \\
10 \ldots \ldots\end{array}$ & $\begin{array}{l}40 \\
35 \\
33 \\
31 \\
29 \\
28 \\
28 \\
27 \\
26 \\
25\end{array}$ & $\begin{array}{r}1,020 \\
442 \\
298 \\
221 \\
175 \\
152 \\
125 \\
130 \\
185 \\
205\end{array}$ & $\begin{array}{l}11 \ldots \ldots \\
12 \ldots \ldots \\
13 \ldots \ldots \\
14 \ldots \ldots \\
15 \ldots \ldots \\
16 \ldots \ldots \\
17 \ldots \ldots \\
18 \ldots \ldots \\
19 \ldots \ldots \\
20 \ldots \ldots\end{array}$ & $\begin{array}{l}23 \\
22 \\
21 \\
21 \\
21 \\
20 \\
20 \\
20 \\
18 \\
17\end{array}$ & $\begin{array}{r}145 \\
280 \\
295 \\
200 \\
165 \\
145 \\
130 \\
115 \\
105 \\
97\end{array}$ & $\begin{array}{l}21 \ldots \ldots \\
22 \ldots \ldots \\
23 \ldots \ldots \\
24 \ldots \ldots \\
25 \ldots \ldots \\
26 \ldots \ldots \\
27 \ldots \ldots \\
28 \ldots \ldots \\
29 \ldots \ldots \\
30 \ldots \ldots \\
31 \ldots \ldots\end{array}$ & $\begin{array}{r}17 \\
17 \\
17 \\
17 \\
17 \\
16 \\
16 \\
16 \\
47 \\
1,580 \\
4,110\end{array}$ & $\begin{array}{r}88 \\
81 \\
74 \\
67 \\
60 \\
56 \\
56 \\
52 \\
-\ldots--\end{array}$ \\
\hline $\begin{array}{l}\text { thIy } \\
\text { off, } \\
\text { off, }\end{array}$ & acre- & & & & & & $\begin{array}{r}206 \\
5.46 \\
12,640\end{array}$ & $\begin{array}{r}184 \\
4,43 \\
10,240 \\
\end{array}$ \\
\hline
\end{tabular}


Gage height, in feet, and discharge, in cubic feet per second, at indicated time, 1963, of Maacama Creek near KeIlogg, Cal1f.

\begin{tabular}{|c|c|c|c|c|c|c|c|c|c|c|c|}
\hline Date & Hour & $\begin{array}{c}\text { Gage } \\
\text { he1ght }\end{array}$ & $\begin{array}{c}\text { Dis- } \\
\text { charge }\end{array}$ & Date & Hour & $\begin{array}{c}\text { Gage } \\
\text { height }\end{array}$ & $\begin{array}{c}\text { D1s- } \\
\text { charge }\end{array}$ & Date & Hour & $\begin{array}{c}\text { Gage } \\
\text { helght }\end{array}$ & $\begin{array}{c}\text { Dis- } \\
\text { charge }\end{array}$ \\
\hline $\begin{array}{r}\operatorname{Jan}, 28 \\
29\end{array}$ & $\begin{array}{l}2400 \\
1000 \\
1300 \\
1500 \\
1600 \\
1700 \\
2000 \\
2200 \\
2300 \\
2400 \\
\\
0300 \\
0400 \\
0600 \\
0700 \\
0800\end{array}$ & $\begin{array}{l}2.88 \\
2.88 \\
2.92 \\
3.01 \\
3.09 \\
3.23 \\
3.96 \\
4.90 \\
4.97 \\
5.15 \\
6.96 \\
7.56 \\
7.75 \\
8.13 \\
7.94\end{array}$ & $\begin{array}{r}16 \\
16 \\
17 \\
21 \\
25 \\
31 \\
77 \\
190 \\
201 \\
232 \\
\\
686 \\
904 \\
980 \\
1,130 \\
1,060\end{array}$ & Jan. 30 & $\begin{array}{l}0900 \\
1000 \\
1100 \\
1300 \\
1400 \\
1700 \\
1900 \\
2000 \\
2300 \\
2400 \\
0100 \\
0300 \\
0500 \\
0600 \\
1000 \\
1300\end{array}$ & $\begin{array}{r}8.35 \\
10.31 \\
13.35 \\
11.84 \\
11.50 \\
8.96 \\
9.06 \\
8.25 \\
7.78 \\
7.83 \\
8.09 \\
9.80 \\
12.57 \\
14.73 \\
17.15 \\
14.82\end{array}$ & $\begin{array}{r}1,220 \\
2,230 \\
4,220 \\
3,140 \\
2,940 \\
1,490 \\
1,540 \\
1,180 \\
992 \\
1,010 \\
1,120 \\
1,920 \\
3,640 \\
5,360 \\
7,700 \\
5,440\end{array}$ & Feb. I & $\begin{array}{l}1400 \\
1600 \\
1900 \\
2300 \\
2400 \\
0300 \\
0700 \\
1000 \\
1200 \\
1800 \\
2100 \\
2400 \\
1000 \\
1700 \\
2400\end{array}$ & $\begin{array}{r}15.06 \\
13.13 \\
11.75 \\
10.20 \\
10.30 \\
9.10 \\
8.16 \\
7.68 \\
7.58 \\
6.88 \\
6.70 \\
6.59 \\
6.00 \\
5.79 \\
5.63\end{array}$ & $\begin{array}{r}5,650 \\
4,040 \\
3,090 \\
2,160 \\
2,220 \\
1,560 \\
1,140 \\
952 \\
912 \\
662 \\
617 \\
587 \\
440 \\
388 \\
350\end{array}$ \\
\hline
\end{tabular}

11-4640. Russian River near Healdsburg, Calif.

Location.--Lat $38^{\circ} 36^{\prime} 48^{\prime \prime}$, long $122^{\circ} 50^{\prime} 07^{\prime \prime}$, in Sotoyome Grant, on left bank 2 miles east of Healdsburg, Sonoma County, and 3.5 miles upstream from Dry Creek.

Drainage area. $--793 \mathrm{sq} \mathrm{ml}$.

Gage-he1ght record.--Water-stage recorder graph. Datum of gage is $76.84 \mathrm{ft}$ above mean sea level, datum of 1929 (levels by Corps of Engineers).

Discharge record.--Stage-discharge relation defined by current-meter measurements.

Maxima.--January-February 1963: Discharge, 41,800 cfs 0200 hours Feb. I (gage helght, $20.10 \mathrm{ft}$ )

1939 to December 1962: Discharge, 67,000 cfs Feb. 28, 1940 (gage helght, $30.0 \mathrm{ft}$ ).

Flood in December 1937 reached a stage of $30.8 \mathrm{ft}$, from floodmarks.

Remarks.--Flow slightly regulated by Lake Mendocino (capacity, 122,500 acre-ft).

Mean discharge, in cublc feet per second, 1963

\begin{tabular}{|c|c|c|c|c|c|c|c|c|}
\hline Day & January & February & Day & January & February & Day & January & February \\
\hline $\begin{array}{c}1 \ldots \ldots \\
2 \ldots \ldots \\
3 \ldots \ldots \\
4 \ldots \ldots \\
5 \ldots \ldots \\
7 \ldots \ldots \\
8 \ldots \ldots \\
9 \ldots \ldots \\
10 \ldots \ldots\end{array}$ & $\begin{array}{r}508 \\
486 \\
470 \\
454 \\
434 \\
426 \\
414 \\
1,920 \\
2,570 \\
1,110\end{array}$ & $\begin{array}{r}31,600 \\
10,500 \\
8,600 \\
7,250 \\
5,480 \\
5,820 \\
3,690 \\
2,920 \\
3,510 \\
4,710\end{array}$ & $\begin{array}{l}11 \ldots \ldots \\
12 \ldots \ldots \\
13 \ldots \ldots \\
14 \ldots \ldots \\
15 \ldots \ldots \\
16 \ldots \ldots \\
17 \ldots \ldots \\
18 \ldots \ldots \\
19 \ldots \ldots \\
20 \ldots \ldots\end{array}$ & $\begin{array}{l}615 \\
512 \\
470 \\
458 \\
438 \\
418 \\
406 \\
392 \\
389 \\
378\end{array}$ & $\begin{array}{l}3,420 \\
4,330 \\
6,480 \\
3,890 \\
3,060 \\
2,590 \\
2,350 \\
2,010 \\
2,850 \\
2,820\end{array}$ & $\begin{array}{l}21 \ldots \ldots \\
22 \ldots \ldots \\
23 \ldots \ldots \\
24 \ldots \ldots \\
25 \ldots \ldots \\
26 \ldots \ldots \\
27 \ldots \ldots \\
28 \ldots \ldots \\
29 \ldots \ldots \\
30 \ldots \ldots \\
31 \ldots \ldots\end{array}$ & $\begin{array}{r}375 \\
372 \\
368 \\
361 \\
361 \\
358 \\
364 \\
364 \\
382 \\
8,960 \\
27,500\end{array}$ & $\begin{array}{r}1,680 \\
1,330 \\
1,180 \\
1,080 \\
1,000 \\
940 \\
884 \\
837 \\
---- \\
---1-\end{array}$ \\
\hline \multicolumn{7}{|l|}{$\begin{array}{l}\text { Monthly } \\
\text { Runoff, } \\
\text { Runoff, }\end{array}$} & $\begin{array}{r}1,711 \\
2.35 \\
105,200 \\
\end{array}$ & $\begin{array}{r}4,529 \\
5,95 \\
251,500 \\
\end{array}$ \\
\hline
\end{tabular}

Gage height, in feet, and discharge, in cublo feet per second, at indicated time, 1963

\begin{tabular}{|c|c|c|c|c|c|c|c|c|c|c|c|}
\hline Date & Hour & $\begin{array}{c}\text { Gage } \\
\text { helght }\end{array}$ & $\begin{array}{c}\text { Dis- } \\
\text { charge }\end{array}$ & Date & Hour & $\begin{array}{c}\text { Gage } \\
\text { helght }\end{array}$ & $\begin{array}{c}\text { Dis- } \\
\text { charge }\end{array}$ & Date & Hour & $\begin{array}{c}\text { Gage } \\
\text { helght }\end{array}$ & $\begin{array}{l}\text { Dis- } \\
\text { charge }\end{array}$ \\
\hline $\begin{array}{r}\text { Jan. } 29 \\
30\end{array}$ & $\begin{array}{l}2400 \\
0100 \\
0500 \\
0800 \\
1200 \\
1500 \\
1700 \\
2100 \\
2400 \\
0100 \\
\end{array}$ & $\begin{array}{r}2.44 \\
2.68 \\
3.80 \\
5.38 \\
7.78 \\
10.52 \\
11.78 \\
12.51 \\
12.96 \\
12.88 \\
\end{array}$ & $\begin{array}{r}553 \\
674 \\
1,500 \\
3,380 \\
7,320 \\
12,900 \\
15,900 \\
17,700 \\
18,900 \\
18,700 \\
\end{array}$ & Feb. 1 & $\begin{array}{l}0200 \\
0600 \\
0700 \\
0900 \\
1200 \\
1500 \\
1900 \\
2300 \\
2400 \\
0100 \\
0200\end{array}$ & $\begin{array}{l}12.86 \\
12.02 \\
12.08 \\
13.08 \\
16.00 \\
18.00 \\
18.73 \\
19.83 \\
20.03 \\
20.06 \\
20.10\end{array}$ & $\begin{array}{l}18,600 \\
16,400 \\
16,600 \\
19,200 \\
27,600 \\
34,200 \\
36,800 \\
40,800 \\
41,500 \\
41,600 \\
41,800\end{array}$ & Feb. I & $\begin{array}{l}0500 \\
1100 \\
1500 \\
2000 \\
2300 \\
2400 \\
0800 \\
1400 \\
1900 \\
2100 \\
2400\end{array}$ & $\begin{array}{l}19.81 \\
18.25 \\
16.72 \\
13.40 \\
11.72 \\
11.33 \\
9.73 \\
8.82 \\
8.30 \\
8.24 \\
8.64\end{array}$ & $\begin{array}{r}40,700 \\
35,100 \\
29,900 \\
20,100 \\
15,700 \\
14,800 \\
11,200 \\
9,340 \\
8,310 \\
8,200 \\
8,980\end{array}$ \\
\hline
\end{tabular}


11-4640.5. Dry Creek tributary near Hopland, Calif.

(Crest-stage station)

Location. --Lat $38^{\circ} 53^{\prime} 10^{\prime \prime}$, long $123^{\circ} 09^{\prime 1} 15^{\prime \prime}$, in sec.13, T.12 N., R.12 W., at culvert on State Highway $128,6.5$ miles southwest of Hopland.

Drainage area. $--1.27 \mathrm{sq} \mathrm{mi}$.

Gage-height record.--Crest stages only. Altitude of gage is $800 \mathrm{ft}$ (from topographic map).

Discharge record.--Stage-discharge relation defined by current-meter measurements below $77 \mathrm{cf}$ 's and by computations of flow through culvert at 113, 158, and $189 \mathrm{cfs}$.

Maxima.--January-February 1963: Discharge, $193 \mathrm{cfs}$ Jan. 31 (gage height, $9.38 \mathrm{ft}$ ). 1958 to December 1962: Discharge, $185 \mathrm{cfs} F \mathrm{Feb} .13,1962$ (gage height,
$9.25 \mathrm{ft}$ ).

11-4645. Dry Creek near Cloverdale, Calif.

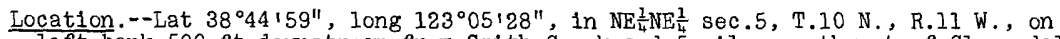
left bank $500 \mathrm{ft}$ downstream from Smith Creek and 5 miles southwest of Cloverdale.

Drainage area. $--87.8 \mathrm{sq} \mathrm{ml}$.

Gage-height record.--Water-stage recorder graph. Altitude of gage is $320 \mathrm{ft}$ (from topographic map):

Discharge record.--Stage-discharge relation defined by current-meter measurements.

Maxima.--January-February 1963: Discharge, 17,700 cfs 1500 hours Jan. 31 (gage height, $17.91 \mathrm{ft}$ ).

1941 to December 1962: Discharge, 17,600 cfs Dec. 22, 1955 (gage height, $17.80 \mathrm{ft}$ ).

Flood in December 1937 reached a stage of about $18 \mathrm{ft}$, from floodmarks.

Mean discharge, in cubic feet per second, 1963

\begin{tabular}{|c|c|c|c|c|c|c|c|c|}
\hline Day & January & February & Day & January & February & Day & January & February \\
\hline $\begin{array}{c}1 \ldots \ldots \\
2 \ldots \ldots \\
3 \ldots \ldots \\
5 \ldots \ldots \\
6 \ldots \ldots \\
7 \ldots \ldots \\
8 \ldots \ldots \\
10 \ldots \ldots\end{array}$ & $\begin{array}{l}50 \\
48 \\
46 \\
44 \\
41 \\
40 \\
38 \\
38 \\
37 \\
35\end{array}$ & $\begin{array}{r}3,860 \\
1,230 \\
690 \\
482 \\
374 \\
322 \\
286 \\
353 \\
556 \\
518\end{array}$ & $\begin{array}{l}11 \ldots \ldots \\
12 \ldots \ldots \\
13 \ldots \ldots \\
14 \ldots \ldots \\
15 \ldots \ldots \\
16 \ldots \ldots \\
17 \ldots \ldots \\
18 \ldots \ldots \\
19 \ldots \ldots \\
20 \ldots \ldots\end{array}$ & $\begin{array}{l}33 \\
32 \\
31 \\
31 \\
30 \\
30 \\
30 \\
29 \\
28 \\
27\end{array}$ & $\begin{array}{l}371 \\
670 \\
655 \\
440 \\
349 \\
289 \\
243 \\
212 \\
189 \\
170\end{array}$ & $\begin{array}{l}21 \ldots \ldots \\
22 \ldots \ldots \\
23 \ldots \ldots \\
24 \ldots \ldots \\
25 \ldots \ldots \\
26 \ldots \ldots \\
27 \ldots \ldots \\
28 \ldots \ldots \\
29 \ldots \ldots \\
30 \ldots \ldots \\
31 \ldots \ldots\end{array}$ & $\begin{array}{r}27 \\
26 \\
26 \\
26 \\
25 \\
25 \\
24 \\
24 \\
47 \\
1,910 \\
8,880\end{array}$ & $\begin{array}{r}159 \\
152 \\
141 \\
133 \\
125 \\
121 \\
116 \\
112 \\
---1 \\
--1-\end{array}$ \\
\hline \multicolumn{7}{|l|}{$\begin{array}{l}\text { Monthly } \\
\text { Runoff, } \\
\text { Runoff, }\end{array}$} & $\begin{array}{r}379 \\
4.98 \\
23,320\end{array}$ & $\begin{array}{r}476 \\
5.64 \\
26,420 \\
\end{array}$ \\
\hline
\end{tabular}

Gage height, in feet, and discharge, in cublc feet per second, at Indicated t1me, 1963

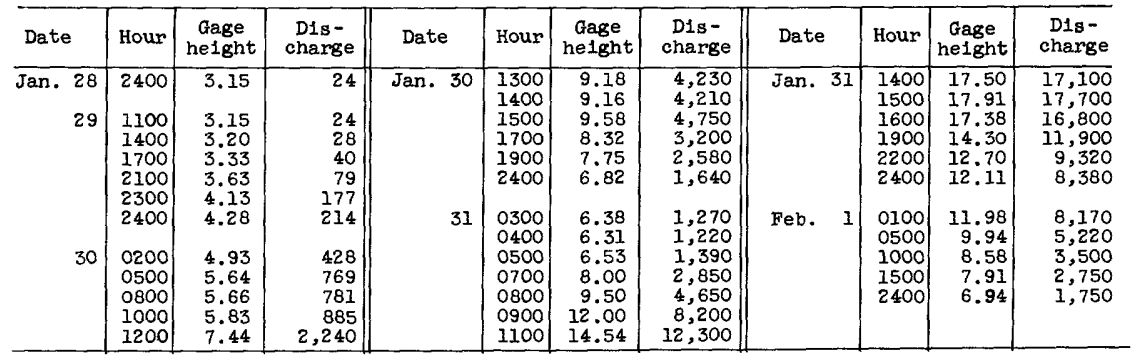


11-4650.5. Dutcher Creek near Ast1, Calif.

(Crest-stage station)

Location.--Lat $38^{\circ} 43^{1} 20^{\prime \prime}$, long $122^{\circ} 58^{\prime} 35^{\prime \prime}$, in Tzabaco Grant, at culvert on Dutcher Creek Road, 3 miles south of Asti.

Drainage area. $--2.25 \mathrm{sq} \mathrm{m}$.

Gage-he1ght record.--Crest stages only. Altitude of gage is $240 \mathrm{ft}$ (from topographic map).

Discharge record. --Stage-discharge relation defined by current-meter measurements below 76 cfs and by computation of flow through culvert at $381 \mathrm{cfs}$.

Maxima --January-February 1963: Discharge, $250 \mathrm{cfs}$ Jan. 31 (gage height, 8.14 ft).

1958 to December 1962: Discharge, $381 \mathrm{cf}$ 's Feb. 16, 1959 (gage height, $9.46 \mathrm{ft}^{\prime} \mathrm{t}$.

11-4652. Dry Creek near Geyserville, Callf.

Location.--Lat $38^{\circ} 41^{\prime} 55^{\prime \prime}$, long $122^{\circ} 57^{\prime} 25^{\prime \prime}$, in Tzabaco Grant, on left bank pier of bridge, $0.3 \mathrm{mile}$ downstream from Pena Creek and 3 miles west of Geyserville, Sonoma County.

Drainage area. $-162 \mathrm{sq} \mathrm{ml}$.

Gage-height record.- Water-stage recorder graph. Altitude of gage is 160 ft (from topographic map).

Discharge record.--Stage-discharge relation defined by current-meter measurements. Maxima.--January-February 1963: Discharge, $25,800 \mathrm{cf}$ 's 1600 hours Jan. 31 (gage

1959 to December 1962: Discharge, 22,500 cf's Feb. 13, 1962 (gage helght, $15.18 \mathrm{ft}^{\mathrm{t}}$.

Mean discharge, in cub1c feet per second, 1963

\begin{tabular}{|c|c|c|c|c|c|c|c|c|}
\hline Day & January & February & Day & January & February & Day & January & February \\
\hline $\begin{array}{c}1 \ldots \ldots \\
2 \ldots \ldots \\
3 \ldots \ldots \\
5 \ldots \ldots \\
6 \ldots \ldots \\
7 \ldots \ldots \\
8 \ldots \ldots \\
10 \ldots \ldots\end{array}$ & $\begin{array}{r}136 \\
126 \\
119 \\
109 \\
100 \\
94 \\
92 \\
87 \\
85 \\
81\end{array}$ & $\begin{array}{r}9,180 \\
2,730 \\
1,780 \\
1,400 \\
1,170 \\
1,020 \\
860 \\
1,020 \\
1,490 \\
1,800\end{array}$ & $\begin{array}{l}11 \ldots \ldots \\
12 \ldots \ldots \\
13 \ldots \ldots \\
14 \ldots \ldots \\
15 \ldots \ldots \\
16 \ldots \ldots \\
17 \ldots \ldots \\
18 \ldots \ldots \\
19 \ldots \ldots \\
20 \ldots \ldots\end{array}$ & $\begin{array}{l}75 \\
72 \\
66 \\
66 \\
62 \\
57 \\
57 \\
54 \\
52 \\
48\end{array}$ & $\begin{array}{r}1,350 \\
1,990 \\
2,000 \\
1,400 \\
1,070 \\
836 \\
670 \\
556 \\
475 \\
418\end{array}$ & $\begin{array}{l}21 \ldots \ldots \\
22 \ldots \ldots \\
23 \ldots \ldots \\
24 \ldots \ldots \\
25 \ldots \ldots \\
26 \ldots \ldots \\
27 \ldots \ldots \\
28 \ldots \ldots \\
29 \ldots \ldots \\
30 \ldots \ldots \\
31 \ldots \ldots\end{array}$ & $\begin{array}{r}45 \\
44 \\
42 \\
42 \\
41 \\
41 \\
40 \\
37 \\
108 \\
5,900 \\
15,300\end{array}$ & $\begin{array}{r}374 \\
330 \\
307 \\
282 \\
251 \\
228 \\
216 \\
201 \\
----- \\
-----\end{array}$ \\
\hline $\begin{array}{l}\text { onthly } \\
\text { unoff, } \\
\text { unoff, }\end{array}$ & $\begin{array}{l}\text { an dis } \\
\text { Inche } \\
\text { ecre }\end{array}$ & & & & & & $\begin{array}{r}751 \\
5,34 \\
46,170\end{array}$ & $\begin{array}{r}1,264 \\
8.13 \\
70,220\end{array}$ \\
\hline
\end{tabular}

Gage helght, in feet, and discharge, in cublc feet per second, at indicated time, 1963

\begin{tabular}{|c|c|c|c|c|c|c|c|c|c|c|c|}
\hline Date & Hour & $\begin{array}{c}\text { Gage } \\
\text { he1ght }\end{array}$ & $\begin{array}{c}\text { Dis- } \\
\text { charge }\end{array}$ & Date & Hour & $\begin{array}{c}\text { Gage } \\
\text { helght }\end{array}$ & $\begin{array}{c}\text { D1s- } \\
\text { charge }\end{array}$ & Date & Hour & $\begin{array}{c}\text { Gage } \\
\text { helght }\end{array}$ & $\begin{array}{c}\text { D1s- } \\
\text { charge }\end{array}$ \\
\hline $\begin{array}{r}\text { Jan. } 28 \\
29\end{array}$ & $\begin{array}{l}2400 \\
1400 \\
1700 \\
1900 \\
2000 \\
2200 \\
2400 \\
\\
0100 \\
0400 \\
0700 \\
1000 \\
1100 \\
1200\end{array}$ & $\begin{array}{l}1.43 \\
1.46 \\
1.57 \\
1.74 \\
1.91 \\
2.63 \\
3.53 \\
4.00 \\
4.94 \\
5.78 \\
5.98 \\
6.10 \\
6.40\end{array}$ & $\begin{array}{r}37 \\
41 \\
57 \\
89 \\
129 \\
362 \\
788 \\
1,100 \\
1,910 \\
2,880 \\
3,170 \\
3,350 \\
3,830\end{array}$ & Jan. 30 & $\begin{array}{l}1300 \\
1400 \\
1500 \\
1600 \\
1700 \\
1800 \\
2000 \\
2100 \\
2400 \\
\\
0400 \\
0600 \\
0700 \\
0900 \\
1100\end{array}$ & $\begin{array}{r}8.05 \\
9.80 \\
10.66 \\
11.09 \\
11.18 \\
10.50 \\
9.15 \\
8.68 \\
7.68 \\
6.90 \\
7.00 \\
7.50 \\
10.10 \\
12.75\end{array}$ & $\begin{array}{r}6,700 \\
20,200 \\
12,100 \\
13,000 \\
13,200 \\
11,700 \\
8,900 \\
7,960 \\
6,020 \\
4,630 \\
4,800 \\
5,700 \\
10,800 \\
16,700\end{array}$ & Jan. 31 & $\begin{array}{l}1400 \\
1500 \\
1600 \\
1700 \\
1900 \\
2400 \\
0200 \\
0600 \\
1000 \\
1500 \\
1900 \\
2400\end{array}$ & $\begin{array}{r}15.28 \\
16.40 \\
16.50 \\
16.45 \\
15.75 \\
13.17 \\
12.72 \\
10.87 \\
9.24 \\
7.93 \\
7.16 \\
6.50\end{array}$ & $\begin{array}{r}22,700 \\
25,500 \\
25,800 \\
25,700 \\
23,900 \\
17,600 \\
16,600 \\
12,500 \\
9,080 \\
6,470 \\
5,090 \\
3,990\end{array}$ \\
\hline
\end{tabular}


11-4658. Santa Rosa Creek near Santa Rosa, Calif.

Location.--Lat $38^{\circ} 27125^{\prime \prime}$, long $122^{\circ} 37150^{\prime \prime}$, in Los Guilicos Grant, on left bank $500 \mathrm{ft}$ downstream from highway bridge, i,500 ft upstream from unnamed tributary, and 4.6 miles east of Santa Rosa, Sonoma County.

Drainage area. $--12.5 \mathrm{sq} \mathrm{mi}$.

Gage-height record.--Water-stage recorder graph. Altitude of gage is $335 \mathrm{ft}$ (from topographic mapl.

Discharge record.--Stage-discharge relation defined by current-meter measurements below $390 \mathrm{cfs}$ and by slope-area measurements at gage heights 11.0 and $13.35 \mathrm{ft}$.

Maxima.--January-February 1963: Discharge, 1,250 cfs 1000 hours Jan. 31 (gage height, $9.53 \mathrm{ft}$ ).

1959 to December 1962: Discharge, 3,200 cfs Feb. 8, 1960 (gage height, $13.35 \mathrm{ft}$, from floodmarks), from rating curve extended above $390 \mathrm{cfs}$ on basis of slope-area measurements at gage heights 11.0 and $13.35 \mathrm{ft}$.

Mean discharge, in cubic feet per second, 1963

\begin{tabular}{|c|c|c|c|c|c|c|c|c|}
\hline Day & January & February & Day & January & February & Day & January & February \\
\hline $\begin{array}{c}1 \ldots \ldots \\
2 \ldots \ldots \\
3 \ldots \ldots \\
4 \ldots \ldots \\
5 \ldots \ldots \\
7 \ldots \ldots \\
8 \ldots \ldots \\
9 \ldots \ldots \\
10 \ldots \ldots\end{array}$ & $\begin{array}{l}11 \\
10 \\
9.8 \\
9.2 \\
8.5 \\
8.1 \\
7.5 \\
7.5 \\
7.2 \\
7.0\end{array}$ & $\begin{array}{r}374 \\
129 \\
81 \\
58 \\
45 \\
38 \\
33 \\
35 \\
51 \\
56\end{array}$ & $\begin{array}{l}11 \ldots \ldots \\
12 \ldots \ldots \\
13 \ldots \ldots \\
14 \ldots \ldots \\
15 \ldots \ldots \\
16 \ldots \ldots \\
17 \ldots \ldots \\
18 \ldots \ldots \\
19 \ldots \ldots \\
20 \ldots \ldots\end{array}$ & $\begin{array}{l}6.7 \\
6.1 \\
5.8 \\
5.6 \\
5.3 \\
5.3 \\
5.0 \\
4.8 \\
4.6 \\
4.4\end{array}$ & $\begin{array}{l}39 \\
77 \\
81 \\
53 \\
43 \\
39 \\
35 \\
31 \\
28 \\
26\end{array}$ & $\begin{array}{l}21 \ldots \ldots \\
22 \ldots \ldots \\
23 \ldots \ldots \\
24 \ldots \ldots \\
25 \ldots \ldots \\
26 \ldots \ldots \\
27 \ldots \ldots \\
28 \ldots \ldots \\
29 \ldots \ldots \\
30 \ldots \ldots \\
31 \ldots \ldots\end{array}$ & $\begin{array}{r}4.4 \\
4.4 \\
4.2 \\
4.2 \\
4.2 \\
4.0 \\
4.0 \\
3.5 \\
6.1 \\
289 \\
771\end{array}$ & $\begin{array}{r}24 \\
22 \\
20 \\
18 \\
17 \\
16 \\
16 \\
15 \\
-\ldots--7 \\
--\ldots-\end{array}$ \\
\hline $\begin{array}{l}\text { MonthIy } \\
\text { Runoff, } \\
\text { Runoff, }\end{array}$ & $\begin{array}{l}\text { an disch } \\
\text { inches. } \\
\text { acre-fe }\end{array}$ & e, & feet & & & & $\begin{array}{r}40.0 \\
3.69 \\
2,460\end{array}$ & $\begin{array}{r}53.6 \\
4.46 \\
2,980\end{array}$ \\
\hline
\end{tabular}

Gage helght, in feet, and discharge, in cubic feet per second, at indicated time, 1963

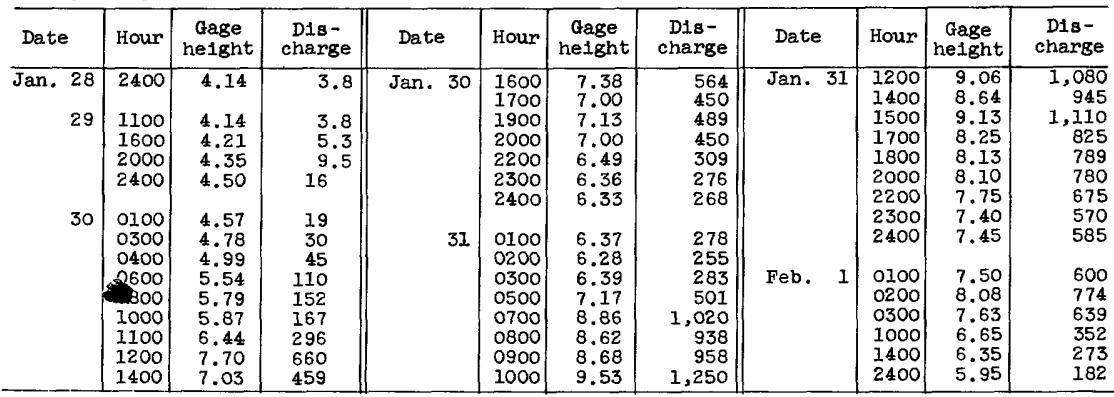

11-4670. Russian River near Guerneville, Calif.

Location.--Lat $38^{\circ} 30^{\prime} 00^{\prime \prime}$, long $122^{\circ} 56^{\prime} 05^{\prime \prime}$, in NE $\frac{1}{4}$ sec.35, T. 8 N., R.10 W., on left bank $0.6 \mathrm{mile}$ downstream from Hobson Creek and 3.4 miles east of Guerneville.

Drainage area. $--1,340 \mathrm{sq} \mathrm{mi}$.

Gage-height record.--Water-stage recorder graph. Altitude of gage is $70 \mathrm{ft}$ (from topographic map).

Discharge record.--Stage-discharge relation defined by current-meter measurements.

Maxima.--January-February 1963: Discharge, 71,800 cf's 0800 hours Feb. I (gage height, $43.70 \mathrm{ft}$ ).

1939 to December 1962: Discharge, 90,100 cfs Dec. 23, 1955 (gage height, $49.7 \mathrm{ft}$, from floodmarks).

Remarks.--Flow slightly regulated by Lake Mendocino (capacity, 122,500 acre-ft). 
Mean discharge, in cubic feet, per second, 1963, of Russian River near Guerneville, Calif.

\begin{tabular}{|c|c|c|c|c|c|c|c|c|}
\hline Day & January & February & Day & January & February & Day & January & February \\
\hline $\begin{array}{r}1 \ldots \ldots \\
2 \ldots \ldots \\
3 \ldots \ldots \\
5 \ldots \ldots \\
6 \ldots \ldots \\
7 \ldots \ldots \\
9 \ldots \ldots \\
10 \ldots \ldots\end{array}$ & $\begin{array}{r}740 \\
700 \\
658 \\
630 \\
604 \\
576 \\
554 \\
1,400 \\
2,970 \\
1,730\end{array}$ & $\begin{array}{r}68,400 \\
39,100 \\
18,900 \\
13,300 \\
9,970 \\
9,140 \\
7,260 \\
5,560 \\
6,410 \\
9,660\end{array}$ & $\begin{array}{l}11 \ldots \ldots \\
12 \ldots \ldots \\
13 \ldots \ldots \\
14 \ldots \ldots \\
15 . \ldots \\
16 \ldots \ldots \\
17 \ldots \ldots \\
18 \ldots \ldots \\
19 \ldots \ldots \\
20 \ldots \ldots\end{array}$ & $\begin{array}{l}810 \\
671 \\
612 \\
576 \\
545 \\
521 \\
505 \\
489 \\
473 \\
465\end{array}$ & $\begin{array}{r}7,500 \\
8,040 \\
15,900 \\
9,840 \\
7,200 \\
5,710 \\
4,820 \\
3,940 \\
4,180 \\
4,680\end{array}$ & $\begin{array}{l}21 \ldots \ldots \\
22 \ldots \ldots \\
23 \ldots \ldots \\
24 \ldots \ldots \\
25 \ldots \ldots \\
26 \ldots \ldots \\
27 \ldots \ldots \\
28 \ldots \ldots \\
29 \ldots \ldots \\
30 \ldots \ldots \\
31 \ldots \ldots\end{array}$ & $\begin{array}{r}457 \\
445 \\
441 \\
433 \\
425 \\
421 \\
425 \\
429 \\
457 \\
14,700 \\
45,300\end{array}$ & $\begin{array}{r}3,080 \\
2,300 \\
1,960 \\
1,740 \\
1,580 \\
1,440 \\
1,300 \\
1,210 \\
-\ldots--- \\
--1-\end{array}$ \\
\hline \multicolumn{7}{|c|}{ 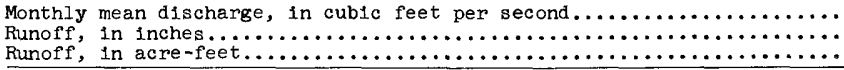 } & $\begin{array}{r}2,586 \\
2,22 \\
159,000 \\
\end{array}$ & $\begin{array}{r}9,790 \\
7.61 \\
543,700 \\
\end{array}$ \\
\hline
\end{tabular}

Gage height, In feet, and discharge, in cubic feet per second, at indicated time, I963

\begin{tabular}{|c|c|c|c|c|c|c|c|c|c|c|c|}
\hline Date & Hour & $\begin{array}{c}\text { Gage } \\
\text { he1ght }\end{array}$ & $\begin{array}{l}\text { Dis- } \\
\text { charge }\end{array}$ & Date & Hour & $\begin{array}{c}\text { Gage } \\
\text { helght }\end{array}$ & $\begin{array}{l}\text { Dis- } \\
\text { charge }\end{array}$ & Date & Hour & $\begin{array}{c}\text { Gage } \\
\text { helght }\end{array}$ & $\begin{array}{l}\text { Dis- } \\
\text { charge }\end{array}$ \\
\hline $\begin{array}{r}\text { Jan. } 29 \\
30\end{array}$ & $\begin{array}{l}2400 \\
0300 \\
0600 \\
1100 \\
1400 \\
1800 \\
2200 \\
2400 \\
0200 \\
0400 \\
0700 \\
0900 \\
1100 \\
1400 \\
1700\end{array}$ & $\begin{array}{r}5.70 \\
8.00 \\
10.25 \\
16.00 \\
20.45 \\
26.00 \\
29.10 \\
29.72 \\
30.01 \\
30.10 \\
30.10 \\
30.47 \\
31.56 \\
34.64 \\
38.20\end{array}$ & $\begin{array}{r}870 \\
2,030 \\
3,640 \\
10,000 \\
16,700 \\
26,000 \\
31,800 \\
33,100 \\
33,700 \\
33,900 \\
33,900 \\
34,800 \\
37,400 \\
45,200 \\
55,400 \\
\end{array}$ & $\begin{array}{l}\text { Jan. } 31 \\
\text { Feb. } 1\end{array}$ & $\begin{array}{l}2000 \\
2400 \\
0400 \\
0600 \\
0800 \\
1000 \\
1300 \\
1800 \\
2100 \\
2400 \\
\\
0600 \\
1200 \\
1800 \\
2100 \\
2400\end{array}$ & $\begin{array}{l}40.50 \\
42.37 \\
43.40 \\
43.65 \\
43.70 \\
43.62 \\
43.27 \\
42.10 \\
40.93 \\
39.35 \\
35.70 \\
31.74 \\
27.88 \\
26.13 \\
24.63\end{array}$ & $\begin{array}{l}62,200 \\
67,800 \\
70,900 \\
71,600 \\
71,800 \\
71,600 \\
70,500 \\
67,000 \\
63,500 \\
58,800 \\
48,200 \\
37,800 \\
29,500 \\
26,200 \\
23,600\end{array}$ & Feb. & $\begin{array}{l}0400 \\
0800 \\
1500 \\
2400 \\
\\
0600 \\
1600 \\
2400 \\
\\
0600 \\
0800 \\
1200 \\
1600 \\
2300 \\
2400\end{array}$ & $\begin{array}{l}23.40 \\
22.48 \\
21.05 \\
19.60 \\
18.82 \\
17.77 \\
17.14 \\
16.77 \\
16.53 \\
15.80 \\
15.36 \\
14.89 \\
14.87\end{array}$ & $\begin{array}{r}21,500 \\
20,000 \\
17,700 \\
15,400 \\
14,100 \\
12,600 \\
11,600 \\
11,100 \\
10,700 \\
9,740 \\
9,170 \\
8,570 \\
8,540\end{array}$ \\
\hline
\end{tabular}

11-4670.4. Ward Creek tributary near Cazadero, Calif.

(Crest-stage station)

Location.--Lat $38^{\circ} 32^{1} 30^{\prime \prime}$, long $123^{\circ} 06^{\prime} 19^{\prime \prime}$, in NW $\frac{1}{4}$ sec.17, T.8 N., R.11 W., at culvert on ranch road, 1.3 miles northwest of Cazadero.

Drainage area. - - $0.11 \mathrm{sq} \mathrm{mi}$.

Gage-helght record.--Crest stages only. Altitude of gage is $490 \mathrm{ft}$ (from tooographic map).

Discharge record.--Stage-discharge relation defined by current-meter measurements below $20 \mathrm{cfs}$ and by computation of flow through culvert at $35 \mathrm{cfs}$.

Maxima.--January-February 1963: Discharge, 24 cfs Jan. 31 (gage he1ght, $10.39 \mathrm{ft}$ ). 1961 to December 1962: D1scharge, 35 cfs Feb. 13, 1962 (gage height, $10.78 \mathrm{ft}$ ).

11-4672. Austin Creek near Cazadero, Calif.

Location. --Lat $38^{\circ} 30105^{\prime \prime}$, long $123^{\circ} 04^{1} 05^{\prime \prime}$, on left bank 0.6 mile downstream from confluence of Blg Austin and East Austin Creeks, 2.3 miles southeast of Cazadero, Sonoma County, and 3.4 miles upstream from mouth.

Drainage area $--63.1 \mathrm{sq} \mathrm{mi}$.

Gage-height record.--Water-stage recorder graph, except Feb. 6-16, 23-28. Altitude of gage is $40 \mathrm{ft}$ (from topograph1c map).

Discharge record.--Stage-discharge relation defined by current-meter measurements. Discharge for periods of no gage-height record estimated on basis of record for South Fork Gualala River near Annapolis.

Maxima.--January-February 1963: Discharge, 11,500 cfs 1800 hours Jan. 31 (gage height, $17.35 \mathrm{ft}$ ).

1959 to December 1962: Discharge, 15,100 cfs Feb. 13, 1962 (gage height,

$20.6 \mathrm{ft}$, crest-stage gage). 
Mean discharge, in cublc feet per second, 1963, of Austin Creek near Cazadero, Calif.

\begin{tabular}{|c|c|c|c|c|c|c|c|c|}
\hline Day & January & February & Day & January & Febmuary & Day & January & February \\
\hline $\begin{array}{c}1 \ldots \ldots \\
2 \ldots \ldots \\
3 \ldots \ldots \\
4 \ldots \ldots \\
5 \ldots \ldots \\
6 \ldots \ldots \\
8 \ldots \ldots \\
9 \ldots \ldots \\
10 \ldots \ldots\end{array}$ & $\begin{array}{l}77 \\
69 \\
66 \\
61 \\
55 \\
53 \\
50 \\
50 \\
47 \\
46\end{array}$ & $\begin{array}{r}2,800 \\
1,300 \\
940 \\
733 \\
610 \\
470 \\
370 \\
400 \\
1,100 \\
1,400\end{array}$ & $\begin{array}{l}11 \ldots \ldots \\
12 \ldots \ldots \\
13 \ldots \ldots \\
14 \ldots \ldots \\
15 \ldots \ldots \\
16 \ldots \ldots \\
17 \ldots \ldots \\
18 \ldots \ldots \\
19 \ldots \ldots \\
20 \ldots \ldots\end{array}$ & $\begin{array}{l}43 \\
42 \\
39 \\
39 \\
39 \\
38 \\
37 \\
36 \\
35 \\
34\end{array}$ & $\begin{array}{r}700 \\
1,050 \\
1,450 \\
800 \\
550 \\
450 \\
351 \\
290 \\
251 \\
223\end{array}$ & $\begin{array}{l}21 \ldots \ldots \\
22 \ldots \ldots \\
23 \ldots \ldots \\
24 \ldots \ldots \\
25 \ldots \ldots \\
26 \ldots \ldots \\
27 \ldots \ldots \\
28 \ldots \ldots \\
29 \ldots \ldots \\
30 \ldots \ldots \\
31 \ldots \ldots\end{array}$ & $\begin{array}{r}33 \\
32 \\
31 \\
31 \\
30 \\
30 \\
29 \\
29 \\
125 \\
3,650 \\
6,820\end{array}$ & $\begin{array}{r}199 \\
174 \\
160 \\
140 \\
130 \\
115 \\
105 \\
100 \\
-\ldots---\end{array}$ \\
\hline \multicolumn{7}{|c|}{ 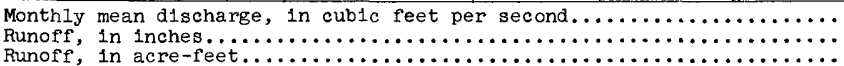 } & $\begin{array}{r}381 \\
6.95 \\
23,400 \\
\end{array}$ & $\begin{array}{r}620 \\
10.23 \\
34,440 \\
\end{array}$ \\
\hline
\end{tabular}

Gage height, in feet, and discharge, in cubic feet per second, at indicated time, 1963

\begin{tabular}{|c|c|c|c|c|c|c|c|c|c|c|c|}
\hline Date & Hour & $\begin{array}{c}\text { Gage } \\
\text { height }\end{array}$ & $\begin{array}{c}\text { Dis- } \\
\text { charge }\end{array}$ & Date & Hour & $\begin{array}{c}\text { Gage } \\
\text { height }\end{array}$ & $\begin{array}{l}\text { Dis- } \\
\text { charge }\end{array}$ & Date & Hour & $\begin{array}{c}\text { Gage } \\
\text { height }\end{array}$ & $\begin{array}{c}\text { D1s- } \\
\text { charge }\end{array}$ \\
\hline $\begin{array}{r}\operatorname{Jan} \cdot 28 \\
29\end{array}$ & $\begin{array}{l}2400 \\
1300 \\
1500 \\
1700 \\
1900 \\
2100 \\
2200 \\
2400\end{array}$ & $\begin{array}{l}3.76 \\
3.76 \\
3.81 \\
3.91 \\
4.10 \\
4.75 \\
5.50 \\
7.05\end{array}$ & $\begin{array}{r}28 \\
28 \\
32 \\
42 \\
69 \\
216 \\
468 \\
1,300\end{array}$ & Jan. 30 & $\begin{array}{l}1300 \\
1400 \\
1500 \\
1800 \\
1900 \\
2000 \\
2100 \\
2400\end{array}$ & $\begin{array}{r}12.38 \\
13.65 \\
13.18 \\
11.45 \\
10.03 \\
9.50 \\
9.83 \\
8.82\end{array}$ & $\begin{array}{l}6,080 \\
7,420 \\
6,900 \\
5,150 \\
3,750 \\
3,270 \\
3,570 \\
2,660\end{array}$ & $\operatorname{Jan} .31$ & $\begin{array}{l}1200 \\
1400 \\
1500 \\
1700 \\
1800 \\
1900 \\
2000 \\
2200 \\
2400\end{array}$ & $\begin{array}{l}14.43 \\
15.15 \\
16.32 \\
16.81 \\
17.35 \\
16.55 \\
15.00 \\
12.92 \\
11.61\end{array}$ & $\begin{array}{r}8,270 \\
9,060 \\
10,400 \\
10,900 \\
11,500 \\
10,600 \\
8,900 \\
6,620 \\
5,310\end{array}$ \\
\hline 30 & $\begin{array}{l}0200 \\
0500 \\
0700 \\
0800 \\
1100 \\
1200\end{array}$ & $\begin{array}{r}8.22 \\
8.80 \\
8.40 \\
8.40 \\
9.45 \\
10.50\end{array}$ & $\begin{array}{l}2,130 \\
2,640 \\
2,280 \\
2,280 \\
3,220 \\
4,200\end{array}$ & 31 & $\begin{array}{l}0300 \\
0500 \\
0600 \\
0700 \\
0800 \\
0900 \\
1000\end{array}$ & $\begin{array}{r}8.45 \\
8.58 \\
9.06 \\
10.07 \\
12.00 \\
13.97 \\
15.46\end{array}$ & $\begin{array}{l}2,320 \\
2,440 \\
2,870 \\
3,780 \\
5,700 \\
7,770 \\
9,410\end{array}$ & Feb, 1 & $\begin{array}{l}0500 \\
0900 \\
1300 \\
2400\end{array}$ & $\begin{array}{l}9.85 \\
9.00 \\
8.45 \\
7.51\end{array}$ & $\begin{array}{l}3,580 \\
2,820 \\
2,330 \\
1,650\end{array}$ \\
\hline
\end{tabular}

\section{GUALALA RIVER BASIN}

11-4673. Wheatfield Fork Gualala River tributary near Annapolis, Calif.

(Crest-stage station)

Location.--Lat $38^{\circ} 40^{\prime} 30^{\prime \prime}$, long $123^{\circ} 15^{1} 12^{\prime \prime}$, at culvert on Stewarts Point-Skaggs Spring road, 7 miles southeast of Annapolis.

Drainage area. $--0.19 \mathrm{sq} \mathrm{mi}$.

Gage-helght record.--Crest stages only. Altitude of gage is $250 \mathrm{ft}$ (from topographic map).

Discharge record.--Stage-discharge relation defined by current-meter measurements below $11 \mathrm{cf}$ 's and by computation of flow through culvert at $49 \mathrm{cfs}$.

Maxima.--January-February 1963: Discharge, $32 \mathrm{cfs}$ Jan. 31 (gage height, $9.23 \mathrm{ft}$ ). 1961 to December 1962: Discharge, $54 \mathrm{cfs}$ Dec. 3, 1962 (gage helght, 9.90 ft).

11-4675. South Fork Gualala River near Annapolis, Cal1f.

Location.--Lat $38^{\circ} 42^{\prime} 14^{\prime \prime}$, long $123^{\circ} 25^{\prime} 13^{\prime \prime}$, in German Grant, on left bank 2,700 $\mathrm{ft}$ downstream from Wheatfield Fork Gualala River and 3.1 miles southwest of Annapolis, Sonoma County.

Drainage area. $--161 \mathrm{sq} \mathrm{ml}$.

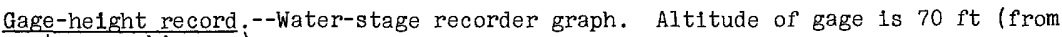
topographic map).

Discharge record.--Stage-discharge relation defined by current-meter measurements below $5,400 \mathrm{c}$ 's and by slope-area measurement at $12,000 \mathrm{cf}$.

Maxima.--January-February 1963: D18charge, 23,000 cf's 1800 hours Jan. 31 (gage height, $16.86 \mathrm{ft}$ ).

1950 to December 1962: Discharge, 55,000 cfs Dec. 22, 1955 (gage helght, $24.57 \mathrm{ft}$, site and datum then in use), from rating curve extended above 13,000 cfs on basis of slope-area measurement of maximum flow. 
Mean discharge, in cub1c feet per second, 1963, of South Fork Gualala River near Annapolis, Calif.

\begin{tabular}{|c|c|c|c|c|c|c|c|c|}
\hline Day & January & February & Day & January & February & Day & January & February \\
\hline $\begin{array}{c}1 \ldots \ldots \\
2 \ldots \ldots \\
3 \ldots \ldots \\
4 \ldots \ldots \\
5 \ldots \ldots \\
7 \ldots \ldots \\
8 \ldots \ldots \\
9 \ldots \ldots \\
10 \ldots \ldots\end{array}$ & $\begin{array}{r}105 \\
85 \\
76 \\
70 \\
63 \\
57 \\
54 \\
52 \\
49 \\
47\end{array}$ & $\begin{array}{r}5,780 \\
2,180 \\
1,440 \\
1,060 \\
829 \\
716 \\
612 \\
724 \\
1,840 \\
2,530\end{array}$ & $\begin{array}{l}11 \ldots \ldots \\
12 \ldots \ldots \\
13 \ldots \ldots \\
14 \ldots \ldots \\
15 \ldots \ldots \\
16 \ldots \ldots \\
17 \ldots \ldots \\
18 \ldots \ldots \\
19 \ldots \ldots \\
20 \ldots \ldots\end{array}$ & $\begin{array}{l}44 \\
41 \\
38 \\
38 \\
37 \\
36 \\
34 \\
33 \\
33 \\
30\end{array}$ & $\begin{array}{r}1,380 \\
1,980 \\
2,800 \\
1,530 \\
1,100 \\
919 \\
764 \\
628 \\
545 \\
468\end{array}$ & $\begin{array}{l}21 \ldots \ldots \\
22 \ldots \ldots \\
23 \ldots \ldots \\
24 \ldots \ldots \\
25 \ldots \ldots \\
26 \ldots \ldots \\
27 \ldots \ldots \\
28 \ldots \ldots \\
29 \ldots \ldots \\
30 \ldots \ldots \\
31 \ldots \ldots\end{array}$ & $\begin{array}{r}29 \\
29 \\
29 \\
28 \\
28 \\
27 \\
27 \\
25 \\
30 \\
6,290 \\
13,000\end{array}$ & $\begin{array}{r}412 \\
352 \\
310 \\
275 \\
250 \\
225 \\
206 \\
190 \\
----\end{array}$ \\
\hline \multicolumn{7}{|c|}{ 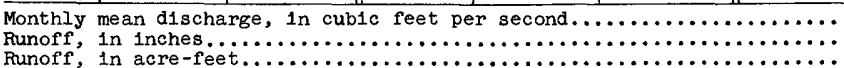 } & $\begin{array}{r}663 \\
4.75 \\
40,790 \\
\end{array}$ & $\begin{array}{r}1,144 \\
7,40 \\
63,560\end{array}$ \\
\hline
\end{tabular}

Gage height, In feet, and discharge, in cubic feet per second, at indicated t1me, 1963

\begin{tabular}{|c|c|c|c|c|c|c|c|c|c|c|c|}
\hline Date & Hour & $\begin{array}{c}\text { Gage } \\
\text { helght }\end{array}$ & $\begin{array}{l}\text { Dis- } \\
\text { charge }\end{array}$ & Date & Hour & $\begin{array}{c}\text { Gage } \\
\text { he1ght }\end{array}$ & $\begin{array}{l}\text { D1s- } \\
\text { charge }\end{array}$ & Date & Hour & $\begin{array}{c}\text { Gage } \\
\text { helght }\end{array}$ & $\begin{array}{l}\text { D1s - } \\
\text { charge }\end{array}$ \\
\hline $\begin{array}{r}\text { Jan. } \\
30\end{array}$ & $\begin{array}{l}2400 \\
0200 \\
0300 \\
0400 \\
1000 \\
1500 \\
1600 \\
1700 \\
2000 \\
\end{array}$ & $\begin{array}{r}3.38 \\
3.70 \\
4.28 \\
5.90 \\
8.60 \\
12.00 \\
12.52 \\
12.32 \\
10.40 \\
\end{array}$ & $\begin{array}{r}56 \\
135 \\
426 \\
1,890 \\
5,370 \\
11,500 \\
12,600 \\
12,200 \\
8,420 \\
\end{array}$ & $\begin{array}{r}\operatorname{Jan} .30 \\
31\end{array}$ & $\begin{array}{l}2400 \\
0400 \\
0500 \\
0600 \\
0800 \\
1000 \\
1400 \\
1700 \\
1800\end{array}$ & $\begin{array}{r}9.37 \\
8.37 \\
8.22 \\
8.24 \\
9.08 \\
12.00 \\
14.90 \\
16.69 \\
16.86 \\
\end{array}$ & $\begin{array}{r}6,630 \\
5,030 \\
4,810 \\
4,840 \\
6,140 \\
11,500 \\
18,100 \\
22,600 \\
23,000 \\
\end{array}$ & Jan. 31 & $\begin{array}{l}1900 \\
2200 \\
2400 \\
\\
0400 \\
0800 \\
1200 \\
1600 \\
2000 \\
2400\end{array}$ & $\begin{array}{r}16.64 \\
13.80 \\
12.18 \\
10.47 \\
9.10 \\
8.28 \\
7.68 \\
7.25 \\
6.82\end{array}$ & $\begin{array}{r}22,500 \\
15,400 \\
11,900 \\
\\
8,550 \\
6,170 \\
4,890 \\
4,080 \\
3,530 \\
2,980\end{array}$ \\
\hline
\end{tabular}

11-4675.6. China Gulch at Gualala, Calif.

(Crest-stage station)

Location.--Lat $38^{\circ} 46^{\prime} 00^{\prime \prime}$, long $123^{\circ} 31^{\prime} 35^{\prime \prime}$, in SW $\frac{1}{4}$ sec.27, T.11 N., R.15 W., at culvert on State Highway 1 , in Gualala.

Drainage area. $--0.54 \mathrm{sq} \mathrm{m} 1$.

Gage-helght record.--Crest stages only. Altitude of gage is $10 \mathrm{ft}$ (from topographic map).

D1scharge record.--Stage-discharge relation defined by current-meter measurements below $11 \mathrm{cfs}$ and by computation of flow through culvert at $112 \mathrm{cfs}$.

Maxima.--January-February 1963: Discharge, 40 cfs Jan. 31 (gage height, $11.66 \mathrm{ft}$ ). 1961 to December 1962: Discharge, $112 \mathrm{cfs} \mathrm{Feb}$. 13, 1962 (gage height, $13.96 \mathrm{ft})$.

\section{GARCIA RIVER BASIN}

11-4676. Garcia River near Point Arena, Calif.

Location. --Lat $38^{\circ} 55^{\prime} 3^{\prime \prime}$, long $123^{\circ} 37145^{\prime \prime}$, in SW $\frac{1}{4} S W^{\frac{1}{4}}$ sec.3, T.12 N., R.16 W., on left bank $0.9 \mathrm{mlle}$ downstream from North Fork Garcla River and 3.5 miles northeast of town of Point Arena.

Drainage area. $--98.8 \mathrm{sq} \mathrm{mi}$.

Gage-height record.--Digital-recorder tape punched at 15-minute intervals, except 0900 hours Jan. 31 to 1600 hours Feb. 1 for which graph was reconstructed on basis of high-water marks in well and several gage readings. Altitude of gage is $50 \mathrm{ft}$ (from topographic map).

Discharge record.--Stage-discharge relation defined by current-meter measurements below 3,600 cfs and by slope-area measurement at $23,900 \mathrm{cfs}$.

Maxima.--January-February 1963: Discharge, 23,900 cfs 2100 hours Jan. 31 (gage helght, $15.11 \mathrm{ft}$, from hign-water marks in well).

1951-56, August to December 1962: Discharge, 26,300 cf's Dec. 22, 1955 (gage helght, $20.75 \mathrm{ft}$, from gage; $20.78 \mathrm{ft}$, from high-water profile, datum then in use), from rating curve extended above $4,200 \mathrm{cfs}$ on basis of slope-area measurement of peak flow. 
Mean discharge, in cubic feet per second, 1963, of Garcia River near Point Arena, Calif.

\begin{tabular}{|c|c|c|c|c|c|c|c|c|}
\hline Day & January & February & Day & January & Pebruary & Day & January & February \\
\hline $\begin{array}{c}1 \ldots \ldots \\
2 \ldots \ldots \\
3 \ldots \ldots \\
4 \ldots \ldots \\
6 \ldots \ldots \\
7 \ldots \ldots \\
9 \ldots \ldots \\
10 \ldots \ldots\end{array}$ & $\begin{array}{l}170 \\
1,58 \\
154 \\
147 \\
141 \\
135 \\
129 \\
126 \\
123 \\
120\end{array}$ & $\begin{array}{r}6,030 \\
1,670 \\
1,090 \\
802 \\
639 \\
555 \\
478 \\
632 \\
821 \\
1,140\end{array}$ & $\begin{array}{l}11 \ldots \ldots \\
12 \ldots \ldots \\
13 \ldots \ldots \\
14 \ldots \ldots \\
15 \ldots \ldots \\
16 \ldots \ldots \\
17 \ldots \ldots \\
18 \ldots \ldots \\
19 \ldots \ldots \\
20 \ldots \ldots\end{array}$ & $\begin{array}{l}114 \\
111 \\
105 \\
102 \\
102 \\
99 \\
96 \\
96 \\
93 \\
90\end{array}$ & $\begin{array}{r}842 \\
920 \\
1,090 \\
831 \\
660 \\
576 \\
499 \\
426 \\
378 \\
342\end{array}$ & $\begin{array}{l}21 \ldots \ldots \\
22 \ldots \ldots \\
23 \ldots \ldots \\
24 \ldots \ldots \\
25 \ldots \ldots \\
26 \ldots \ldots \\
27 \ldots \ldots \\
28 \ldots \ldots \\
29 \ldots \ldots \\
30 \ldots \ldots \\
31 \ldots \ldots\end{array}$ & $\begin{array}{r}88 \\
85 \\
85 \\
83 \\
83 \\
80 \\
80 \\
78 \\
93 \\
3,530 \\
12,000\end{array}$ & $\begin{array}{r}310 \\
290 \\
265 \\
245 \\
230 \\
214 \\
202 \\
190 \\
---- \\
------\end{array}$ \\
\hline $\begin{array}{l}\text { nthly } \\
\text { noff, } \\
\text { noff, }\end{array}$ & acre- & & & & & & $\begin{array}{r}603 \\
7.04 \\
37,080 \\
\end{array}$ & $\begin{array}{r}799 \\
8.42 \\
44,360 \\
\end{array}$ \\
\hline
\end{tabular}

Gage helght, in feet, and discharge, in cuble feet per second, at 1ndicated time, 1963

\begin{tabular}{|c|c|c|c|c|c|c|c|c|c|c|c|}
\hline Date & Hour & $\begin{array}{c}\text { Gage } \\
\text { height }\end{array}$ & $\begin{array}{c}\text { D1s- } \\
\text { charge }\end{array}$ & Date & Hour & $\begin{array}{c}\text { Gage } \\
\text { helght }\end{array}$ & $\begin{array}{c}\text { Dis- } \\
\text { charge }\end{array}$ & Date & Hour & $\begin{array}{c}\text { Gage } \\
\text { he1ght }\end{array}$ & $\begin{array}{c}\text { D1s- } \\
\text { charge }\end{array}$ \\
\hline $\begin{array}{r}\text { Jan. } 29 \\
30\end{array}$ & $\begin{array}{l}2400 \\
0200 \\
0400 \\
0600 \\
0800 \\
1000 \\
1200 \\
1400 \\
1600 \\
1800 \\
2000\end{array}$ & $\begin{array}{l}4.13 \\
4.43 \\
5.31 \\
6.00 \\
6.27 \\
6.64 \\
7.15 \\
7.90 \\
9.34 \\
9.33 \\
9.37\end{array}$ & $\begin{array}{r}158 \\
285 \\
788 \\
1,400 \\
1,700 \\
2,160 \\
2,860 \\
4,030 \\
6,820 \\
6,800 \\
6,880\end{array}$ & Jan. 30 & $\begin{array}{l}2200 \\
2400 \\
\\
0400 \\
0600 \\
0900 \\
1100 \\
1200 \\
1400 \\
1700 \\
2000 \\
2100\end{array}$ & $\begin{array}{r}8.92 \\
8.50 \\
7.75 \\
7.62 \\
8.50 \\
10.70 \\
11.50 \\
12.45 \\
13.10 \\
14.65 \\
15.11\end{array}$ & $\begin{array}{r}5,940 \\
5,120 \\
3,780 \\
3,570 \\
5,120 \\
10,000 \\
12,200 \\
15,000 \\
17,100 \\
22,300 \\
23,900\end{array}$ & $\begin{array}{l}\text { Jan. } 31 \\
\text { Feb. } 1\end{array}$ & $\begin{array}{l}2200 \\
2400 \\
\\
0400 \\
0600 \\
0800 \\
1000 \\
1200 \\
1600 \\
2000 \\
2400\end{array}$ & $\begin{array}{r}14.90 \\
13.50 \\
10.30 \\
9.00 \\
8.88 \\
8.70 \\
8.30 \\
7.75 \\
7.20 \\
6.82\end{array}$ & $\begin{array}{r}23,200 \\
18,400 \\
9,020 \\
6,100 \\
5,860 \\
5,500 \\
4,740 \\
3,780 \\
2,930 \\
2,400\end{array}$ \\
\hline
\end{tabular}

\section{NAVARRO RIVER BASIN}

11-4678. Rancheria Creek near Boonville, Calif.

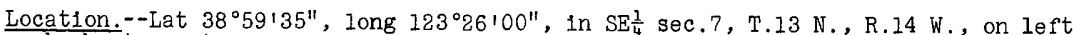
bank at county road bridge, $100 \mathrm{ft}$ downstream from Minnie Creek and $3.7 \mathrm{miles}$ west of Boonville.

Drainage area. $--65.6 \mathrm{sq} \mathrm{mi}$.

Gage-he1ght record.--Water-stage recorder graph. Datum of gage is $427 \mathrm{ft}$ above mean sea level, unadjusted (by Topographic Division).

Discharge record --Stage-discharge relation defined by current-meter measurements below 4,200 cis.

Maxima --January-February 1963: Discharge, 13,900 cfs 1400 hours Jan. 31 (gage height, $18.30 \mathrm{ft}$ ).

1959 to December 1962: Discharge, 9,990 cfs Feb. 8, 1960 (gage height, $15.30 \mathrm{ft})$.

Mean discharge, in cub1c feet per second, 1963

\begin{tabular}{|c|c|c|c|c|c|c|c|c|}
\hline Day & January & February & Day & January & February & Day & January & Febmuary \\
\hline $\begin{array}{c}1 \ldots \ldots \\
2 \ldots \ldots \\
4 \ldots \ldots \\
5 \ldots \ldots \\
6 \ldots \ldots \\
7 \ldots \ldots \\
9 \ldots \ldots \\
10 \ldots \ldots\end{array}$ & $\begin{array}{l}66 \\
64 \\
60 \\
58 \\
55 \\
52 \\
50 \\
50 \\
49 \\
47\end{array}$ & $\begin{array}{r}3,630 \\
1,370 \\
880 \\
692 \\
585 \\
560 \\
507 \\
686 \\
1,010 \\
775\end{array}$ & $\begin{array}{l}11 \ldots \ldots \\
12 \ldots \ldots \\
13 \ldots \ldots \\
14 \ldots \ldots \\
15 \ldots \ldots \\
16 \ldots \ldots \\
17 \ldots \ldots \\
18 \ldots \ldots \\
19 \ldots \ldots \\
20 \ldots \ldots\end{array}$ & $\begin{array}{l}44 \\
43 \\
41 \\
41 \\
40 \\
38 \\
37 \\
36 \\
34 \\
33\end{array}$ & $\begin{array}{l}493 \\
680 \\
585 \\
408 \\
321 \\
284 \\
253 \\
225 \\
200 \\
179\end{array}$ & $\begin{array}{l}21 \ldots \ldots \\
22 \ldots \ldots \\
23 \ldots \ldots \\
24 \ldots \ldots \\
25 \ldots \ldots \\
26 \ldots \ldots \\
27 \ldots \ldots \\
28 \ldots \ldots \\
29 \ldots \ldots \\
30 \ldots \ldots \\
31 \ldots \ldots\end{array}$ & $\begin{array}{r}32 \\
32 \\
31 \\
31 \\
31 \\
31 \\
30 \\
30 \\
57 \\
2,110 \\
7,970\end{array}$ & $\begin{array}{r}161 \\
146 \\
133 \\
120 \\
111 \\
101 \\
97 \\
90 \\
-\ldots--- \\
-\ldots-1\end{array}$ \\
\hline \multicolumn{7}{|c|}{ 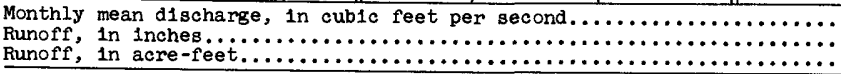 } & $\begin{array}{r}365 \\
6.42 \\
22,460 \\
\end{array}$ & $\begin{array}{r}546 \\
8.66 \\
30,310 \\
\end{array}$ \\
\hline
\end{tabular}


Gage he1ght, in feet, and discharge, in cubic feet per second, at indicated time, 1963, of Rancheria Creek near Boonville, Calif.

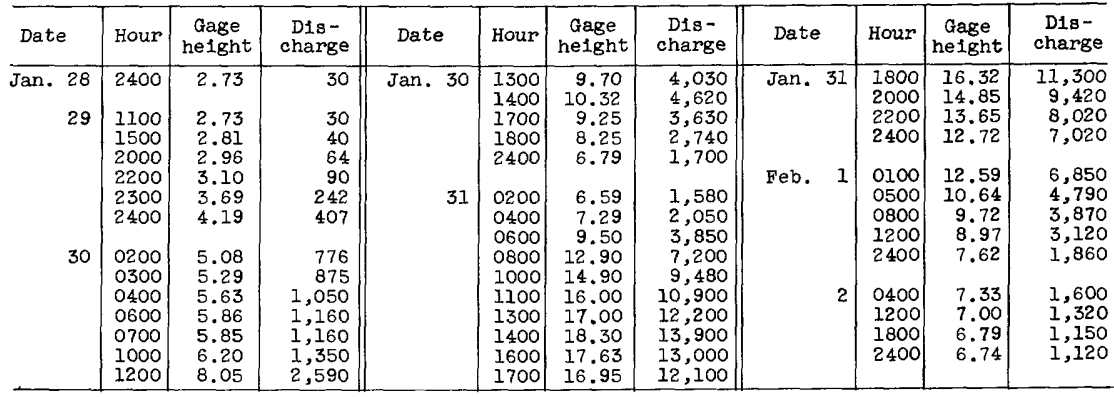

11-4680. Navarro River near Navarro, Calif.

Location.--Lat $39^{\circ} 10^{\prime} 15^{\prime \prime}$, long $123^{\circ} 39^{\prime} 55^{\prime \prime}$, in SE $\frac{1}{4}$ sec.7, T.15 N., R.16 W., on left bank 2.7 miles downstream from North Fork, 5.4 miles upstream from mouth, and 6.6 miles west of Navarro.

Drainage area. $--303 \mathrm{sq} \mathrm{ml}$.

Gage-height record ;--Water-stage recorder graph. Altitude of gage is $20 \mathrm{ft}$ (from topographic map).

D1scharge record. --Stage-discharge relation defined by current-meter measurements.

Maxima.--January-February 1963: Discharge, 33,100 cf's 2100 hours Jan. 31 (gage height, $34.34 \mathrm{ft}$ ).

1950 to December 1962: Discharge, 64,500 cfs Dec. 22, 1955 (gage height, $40.60 \mathrm{ft}$ ), from rating curve extended above $19,000 \mathrm{cfs}$ on basis of slope-area measurement of peak flow.

Mean discharge, In cubic feet per second, 1963

\begin{tabular}{|c|c|c|c|c|c|c|c|c|}
\hline Day & January & February & Day & January & February & Day & January & February \\
\hline $\begin{array}{c}1 \ldots \ldots \\
3 \ldots \ldots \\
4 \ldots \ldots \\
5 \ldots \ldots \\
6 \ldots \ldots \\
8 \ldots \ldots \\
9 \ldots \ldots \\
10 \ldots \ldots\end{array}$ & $\begin{array}{l}171 \\
158 \\
151 \\
146 \\
136 \\
127 \\
122 \\
117 \\
112 \\
110\end{array}$ & $\begin{array}{r}14,000 \\
3,920 \\
2,260 \\
1,530 \\
1,140 \\
884 \\
730 \\
846 \\
1,130 \\
1,960\end{array}$ & $\begin{array}{l}11 \ldots \ldots \\
12 \ldots \ldots \\
13 \ldots \ldots \\
14 \ldots \ldots \\
15 \ldots \ldots \\
16 \ldots \ldots \\
17 \ldots \ldots \\
18 \ldots \ldots \\
19 \ldots \ldots \\
20 \ldots \ldots\end{array}$ & $\begin{array}{r}106 \\
101 \\
97 \\
92 \\
90 \\
88 \\
86 \\
84 \\
82 \\
78\end{array}$ & $\begin{array}{r}1,350 \\
1,170 \\
1,670 \\
1,190 \\
956 \\
802 \\
746 \\
606 \\
536 \\
487\end{array}$ & $\begin{array}{l}21 \ldots \ldots \\
22 \ldots \ldots \\
23 \ldots \ldots \\
24 \ldots \ldots \\
25 \ldots \ldots \\
26 \ldots \ldots \\
27 \ldots \ldots \\
28 \ldots \ldots \\
29 \ldots \ldots \\
30 \ldots \ldots \\
31 \ldots \ldots\end{array}$ & $\begin{array}{r}76 \\
76 \\
76 \\
74 \\
72 \\
72 \\
72 \\
70 \\
74 \\
2,170 \\
15,000\end{array}$ & $\begin{array}{r}434 \\
396 \\
372 \\
345 \\
324 \\
306 \\
291 \\
276 \\
---- \\
---.\end{array}$ \\
\hline \multicolumn{7}{|l|}{$\begin{array}{l}\text { Monthly } \\
\text { Runoff, } \\
\text { Runoff, }\end{array}$} & $\begin{array}{r}648 \\
2.46 \\
39,840 \\
\end{array}$ & $\begin{array}{r}1,452 \\
4,99 \\
80,640\end{array}$ \\
\hline
\end{tabular}

Gage he1ght, In feet, and discharge, in cublc feet per second, at indicated time, 1963

\begin{tabular}{|c|c|c|c|c|c|c|c|c|c|c|c|}
\hline Date & Hour & $\begin{array}{c}\text { Gage } \\
\text { helght }\end{array}$ & $\begin{array}{l}\text { Dis- } \\
\text { charge }\end{array}$ & Date & Hour & $\begin{array}{c}\text { Gage } \\
\text { helght }\end{array}$ & $\begin{array}{l}\text { Dis- } \\
\text { charge }\end{array}$ & Date & Hour & $\begin{array}{c}\text { Gage } \\
\text { he1ght }\end{array}$ & $\begin{array}{c}\text { Dis- } \\
\text { charge }\end{array}$ \\
\hline $\begin{array}{r}\text { Jan. } \\
30\end{array}$ & $\begin{array}{l}2400 \\
0200 \\
0400 \\
0500 \\
0700 \\
0900 \\
1200 \\
1300 \\
1400 \\
1500 \\
1800 \\
2200 \\
2400\end{array}$ & $\begin{array}{r}4.72 \\
4.80 \\
4.95 \\
5.19 \\
6.35 \\
8.68 \\
10.10 \\
10.17 \\
10.11 \\
10.28 \\
11.38 \\
13.29 \\
13.73 \\
\end{array}$ & $\begin{array}{r}92 \\
110 \\
146 \\
207 \\
578 \\
1,630 \\
2,480 \\
2,520 \\
2,490 \\
2,590 \\
3,320 \\
4,730 \\
5,080 \\
\end{array}$ & Jan. 31 & $\begin{array}{l}0100 \\
0200 \\
0300 \\
0500 \\
0700 \\
0800 \\
0900 \\
1000 \\
1100 \\
1300 \\
1400 \\
1700 \\
2000 \\
2100\end{array}$ & $\begin{array}{l}13.82 \\
13.83 \\
13.80 \\
13.40 \\
12.36 \\
12.30 \\
12.32 \\
12.60 \\
15.90 \\
20.60 \\
25.70 \\
30.40 \\
34.00 \\
34.34\end{array}$ & $\begin{array}{r}5,160 \\
5,160 \\
5,140 \\
4,820 \\
4,000 \\
3,960 \\
3,970 \\
4,180 \\
7,100 \\
22,100 \\
17,700 \\
24,600 \\
32,000 \\
33,100\end{array}$ & $\begin{array}{l}\text { Jan. } 31 \\
\text { Feb. } 1\end{array}$ & $\begin{array}{l}2400 \\
0400 \\
0700 \\
1200 \\
1900 \\
2400 \\
\\
0500 \\
1200 \\
1800 \\
2100 \\
2400\end{array}$ & $\begin{array}{l}32.90 \\
28.70 \\
24.75 \\
20.45 \\
16.80 \\
14.77 \\
13.27 \\
11.92 \\
11.11 \\
10.79 \\
10.54\end{array}$ & $\begin{array}{r}29,200 \\
21,900 \\
16,600 \\
11,900 \\
8,000 \\
5,990 \\
4,720 \\
3,690 \\
3,130 \\
2,900 \\
2,740\end{array}$ \\
\hline
\end{tabular}




\section{ALBION RIVER BASIN}

11-4680.1. Albion River near Comptche, Calif.

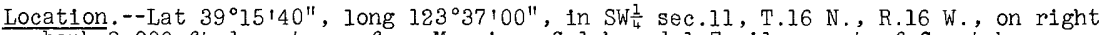
bank 2,000 ft downstream from Morrison Gulch and 1.7 miles west of Comptche.

Drainage area. $--14.5 \mathrm{sq} \mathrm{mi}$.

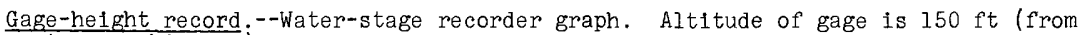
topographic mapj.

Discharge record.--Stage-discharge relation defined by current-meter measurements below $400 \mathrm{cf}$.

Maxima - --January-February 1963: Discharge, 729 cfs 1500 hours Jan. 31 (gage height, $7.53 \mathrm{ft})$

1961 to December 1962: Discharge, $960 \mathrm{cfs}$ Feb. 13, 1962 (gage he1ght, $8.30 \mathrm{ft})$.

Mean discharge, in cublc feet per second, 1963

\begin{tabular}{|c|c|c|c|c|c|c|c|c|}
\hline Day & January & February & Day & January & February & Day & January & February \\
\hline $\begin{array}{c}1 \ldots \ldots \\
2 \ldots \ldots \\
3 \ldots \ldots \\
4 \ldots \ldots \\
5 \ldots \ldots \\
7 \ldots \ldots \\
8 \ldots \ldots \\
9 \ldots \ldots \\
10 \ldots \ldots\end{array}$ & $\begin{array}{l}5.9 \\
5.3 \\
4.9 \\
4.3 \\
4.0 \\
3.7 \\
3.5 \\
3.4 \\
3.2 \\
3.1\end{array}$ & $\begin{array}{r}283 \\
122 \\
71 \\
51 \\
37 \\
32 \\
24 \\
29 \\
47 \\
58\end{array}$ & $\begin{array}{l}11 \ldots \ldots \\
12 \ldots \ldots \\
13 \ldots \ldots \\
14 \ldots \ldots \\
15 \ldots \ldots \\
16 \ldots \ldots \\
17 \ldots \ldots \\
18 \ldots \ldots \\
19 \ldots \ldots \\
20 \ldots \ldots\end{array}$ & $\begin{array}{l}2.8 \\
2.6 \\
2.5 \\
2.5 \\
2.5 \\
2.4 \\
2.4 \\
2.3 \\
2.3 \\
2.2\end{array}$ & $\begin{array}{r}46 \\
53 \\
660 \\
51 \\
41 \\
36 \\
30 \\
23 \\
19 \\
17\end{array}$ & $\begin{array}{l}21 \ldots \ldots \\
22 \ldots \ldots \\
23 \ldots \ldots \\
24 \ldots \ldots \\
25 \ldots \ldots \\
26 \ldots \ldots \\
27 \ldots \ldots \\
28 \ldots \ldots \\
29 \ldots \ldots \\
30 \ldots \ldots \\
31 \ldots \ldots\end{array}$ & $\begin{array}{r}2.2 \\
2.2 \\
2.1 \\
2.0 \\
2.0 \\
2.0 \\
2.0 \\
1.9 \\
3.2 \\
127 \\
426\end{array}$ & $\begin{array}{r}15 \\
13 \\
11 \\
10 \\
8.9 \\
8.0 \\
7.5 \\
6.8 \\
---- \\
--.-1 \\
-.-1\end{array}$ \\
\hline $\begin{array}{l}\text { onthiy } \\
\text { unoff, } \\
\text { unoff, }\end{array}$ & inche & & & & & & $\begin{array}{r}20.6 \\
1.64 \\
1,270\end{array}$ & $\begin{array}{r}43.2 \\
3.10 \\
2,400\end{array}$ \\
\hline
\end{tabular}

Gage height, in feet, and discharge, in cublc feet per second, at indicated time, 1963

\begin{tabular}{|c|c|c|c|c|c|c|c|c|c|c|c|}
\hline Date & Hour & $\begin{array}{c}\text { Gage } \\
\text { he1ght }\end{array}$ & $\begin{array}{l}\text { Dis- } \\
\text { charge }\end{array}$ & Date & Hour & $\begin{array}{c}\text { Gage } \\
\text { helght }\end{array}$ & $\begin{array}{c}\text { Dis - } \\
\text { charge }\end{array}$ & Date & Hour & $\begin{array}{c}\text { Gage } \\
\text { height }\end{array}$ & $\begin{array}{c}\text { Dis- } \\
\text { charge }\end{array}$ \\
\hline $\begin{array}{r}28 \\
29\end{array}$ & $\begin{array}{l}2400 \\
1100 \\
1600 \\
2000 \\
2300 \\
2400\end{array}$ & $\begin{array}{l}2.24 \\
2.24 \\
2.29 \\
2.42 \\
2.65 \\
2.83\end{array}$ & $\begin{array}{r}1.9 \\
1.9 \\
2.4 \\
4.1 \\
9.5 \\
16\end{array}$ & $\operatorname{Jan} .30$ & $\begin{array}{l}0900 \\
1100 \\
1200 \\
1400 \\
1700 \\
2100 \\
2400\end{array}$ & $\begin{array}{l}3.95 \\
3.98 \\
4.50 \\
5.27 \\
4.98 \\
4.80 \\
4.58\end{array}$ & $\begin{array}{r}91 \\
93 \\
143 \\
246 \\
203 \\
179 \\
152\end{array}$ & Jan. 31 & $\begin{array}{l}1100 \\
1200 \\
1500 \\
1800 \\
2000 \\
2200 \\
2400\end{array}$ & $\begin{array}{l}6.55 \\
6.57 \\
7.53 \\
7.09 \\
6.91 \\
6.84 \\
6.48\end{array}$ & $\begin{array}{l}487 \\
491 \\
729 \\
608 \\
566 \\
551 \\
472\end{array}$ \\
\hline 30 & $\begin{array}{l}0100 \\
0200 \\
0500 \\
0600 \\
0700\end{array}$ & $\begin{array}{l}3.11 \\
3.14 \\
3.30 \\
3.43 \\
3.77\end{array}$ & $\begin{array}{l}30 \\
31 \\
41 \\
49 \\
75 \\
\end{array}$ & 31 & $\begin{array}{l}0400 \\
0500 \\
0600 \\
0800 \\
1000\end{array}$ & $\begin{array}{l}4.42 \\
4.46 \\
4.76 \\
5.65 \\
6.38\end{array}$ & $\begin{array}{l}135 \\
139 \\
174 \\
309 \\
450\end{array}$ & Feb. 1 & $\begin{array}{l}0400 \\
1000 \\
1200 \\
1700 \\
2400\end{array}$ & $\begin{array}{l}5.97 \\
5.48 \\
5.53 \\
5.08 \\
4.68\end{array}$ & $\begin{array}{l}368 \\
279 \\
287 \\
217 \\
164 \\
\end{array}$ \\
\hline
\end{tabular}

11-4680.2. Albion River tributary near Comptche, Calif.

(Crest-stage station)

Location. - Lat $39^{\circ} 14^{\prime} 22^{\prime \prime}$, long $123^{\circ} 35^{\prime} 44^{\prime \prime}$, in SW $\frac{1}{4}$ sec.13, T.16 N., R.16 W. , at culvert on Navarro-Comptche road, 1.8 miles south of Comptche and 6.5 miles northwest of Navarro.

Drainage area. $--0.40 \mathrm{sq} \mathrm{mi}$.

Gage-height record.--Crest stages only. Altitude of gage is 350 ft (from topographic map).

Discharge record.--Stage-discharge relation defined by current-meter measurements.

Maxima.--January-February 1963: Discharge, $43 \mathrm{cfs}$ Jan. 31 (gage height, $8.76 \mathrm{ft}$ ).

1961 to December 1962: Discharge, $50 \mathrm{cfs}$ Feb. 13, 1962 (gage he1ght, $8.97 \mathrm{ft}$ ). 


\section{BIG RIVER BASIN}

11-4680.7. South Fork Big River near Comptche, Calif.

Location.--Lat $39^{\circ} 13^{145^{\prime \prime}}$, long $123^{\circ} 27^{\prime} 55^{\prime \prime}$, In sec.19, T.16 N., R.14 W., on left bank $250 \mathrm{ft}$ downstream from Daugherty Creek and 7.2 miles east of Comptche.

Drainage area. $--36.3 \mathrm{sq} \mathrm{mi}$. $\frac{\text { Gage-height record }}{\text { topographic map). }}$. Water-stage recorder graph. Altitude of gage is $500 \mathrm{ft}$ (from

Discharge record.--Stage-discharge relation defined by current-meter measurements.

Maxima.--January-February 1963: Discharge, 2,930 cfs 1500 hours Jan. 31 (gage helght, $10.77 \mathrm{ft}$ ).

1960 to December 1962: Discharge, 2,160 cfs Feb. 13, 1962 (gage height, $9.47 \mathrm{ft}$ ).

Mean discharge, in cuble feet per second, 1963

\begin{tabular}{|c|c|c|c|c|c|c|c|c|}
\hline Day & January & February & Day & January & February & Day & January & February \\
\hline $\begin{array}{c}1 \ldots \ldots \\
2 \ldots \ldots \\
3 \ldots \ldots \\
4 \ldots \ldots \\
6 \ldots \ldots \\
7 \ldots \ldots \\
8 \ldots \ldots \\
9 \ldots \ldots \\
10 \ldots\end{array}$ & $\begin{array}{l}20 \\
17 \\
17 \\
16 \\
15 \\
14 \\
13 \\
13 \\
13 \\
12\end{array}$ & $\begin{array}{r}784 \\
296 \\
201 \\
160 \\
132 \\
105 \\
93 \\
93 \\
99 \\
85\end{array}$ & $\begin{array}{l}11 \ldots \ldots \\
12 \ldots \ldots \\
13 \ldots \ldots \\
14 \ldots \ldots \\
15 \ldots \ldots \\
16 \ldots \ldots \\
17 \ldots \ldots \\
18 \ldots \ldots \\
19 \ldots \ldots \\
20 \ldots \ldots\end{array}$ & $\begin{array}{l}12 \\
12 \\
12 \\
12 \\
11 \\
11 \\
11 \\
11 \\
11 \\
11\end{array}$ & $\begin{array}{l}69 \\
78 \\
73 \\
62 \\
55 \\
52 \\
47 \\
43 \\
38 \\
36\end{array}$ & $\begin{array}{l}21 \ldots \ldots \\
22 \ldots \ldots \\
23 \ldots \ldots \\
24 \ldots \ldots \\
25 \ldots \ldots \\
26 \ldots \ldots \\
27 \ldots \ldots \\
28 \ldots \ldots \\
29 \ldots \ldots \\
30 \ldots \ldots \\
31 \ldots \ldots\end{array}$ & $\begin{array}{r}10 \\
10 \\
10 \\
10 \\
8.3 \\
9.2 \\
8.9 \\
8.0 \\
8.6 \\
104 \\
1,240 \\
\end{array}$ & $\begin{array}{r}33 \\
31 \\
29 \\
28 \\
26 \\
25 \\
25 \\
24 \\
-\ldots-\ldots \\
-\ldots \ldots\end{array}$ \\
\hline \multicolumn{7}{|l|}{$\begin{array}{l}\text { Monthly } \\
\text { Runoff, } \\
\text { Runoff, }\end{array}$} & $\begin{array}{r}54,5 \\
1.73 \\
3,350 \\
\end{array}$ & $\begin{array}{r}101 \\
2.89 \\
5,600 \\
\end{array}$ \\
\hline
\end{tabular}

Gage helght, in feet, and discharge, in cuble feet per second, at indicated time, 1963

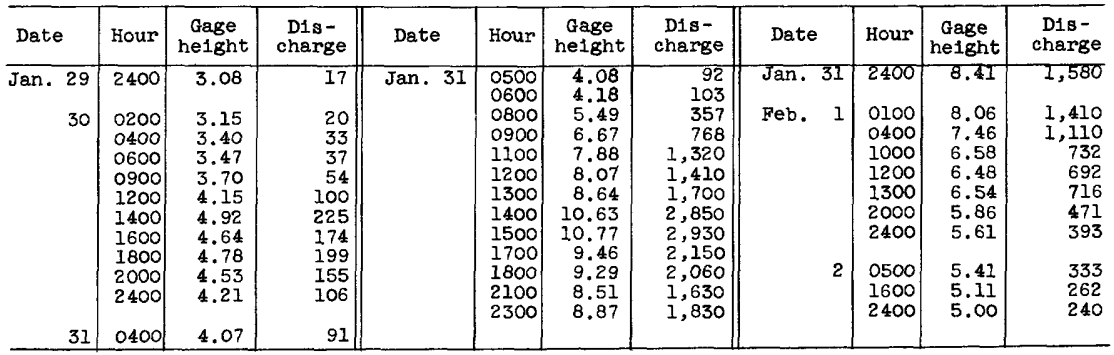

11-4680.85. North Fork Big River tributary near Willits, Calif.

\section{(Crest-stage station)}

Location.--Lat $39^{\circ} 20^{\prime} 50^{\prime \prime}$, long $123^{\circ} 31^{12} 5^{\prime \prime}$, at culvert on State Highway 20 , 10 miles southwest of willits.

Drainage area $--0.43 \mathrm{sq} \mathrm{mi}$.

Gage-height record.--Crest stages only. 'Altitude of gage is $400 \mathrm{ft}$ (from topographic map).

Discharge record.--Stage-discharge relation defined by current-meter measurements below $9 \mathrm{cfs}$ and by computation of flow through culvert at $18 \mathrm{cfs}$.

Maxima --January-February 1963: Discharge, $11 \mathrm{cfs} J a n .31$ (gage height, $12.60 \mathrm{ft}$ ). 1961 to December 1962: Discharge, $18 \mathrm{cfs}$ Feb. 13, 1962 (gage height, $13.35 \mathrm{ft}$ ). 


\section{WARNER CREEK BASIN}

11-4681.5. Warner Creek near Fort Bragg, Calif.

(Crest-stage station)

Location. - -Lat $39^{\circ} 23^{\prime} 13^{\prime \prime}$, long $123^{\circ} 48^{\prime} 42^{\prime \prime}$, in $\mathrm{NE} \frac{1}{4} \sec .36$, T.18 N., R.18 W., at culvert on State Highway 1, 1.5 miles north of Caspar and 4 miles south of Fort Bragg.

Drainage area. $--0.61 \mathrm{sq} \mathrm{mi}$.

Gage-height record.--Crest stages only. Altitude of gage is $50 \mathrm{ft}$ (from topographic map).

Discharge record.--Stage-discharge relation defined by current-meter measurements below $10 \mathrm{cfs}$ and by computation of flow through culvert at $48 \mathrm{cfs}$.

Maxima.--January-February 1963: Discharge, $37 \mathrm{cfs}$ Jan. 31 (gage height, $8.30 \mathrm{ft}$ ). 1961 to December 1962: Discharge, $48 \mathrm{cfs}$ Jan. 19, 1962 (gage height, $8.98 \mathrm{ft}$ ).

\section{NOYO RIVER BASIN}

11-4685. Noyo River near Fort Bragg, Calif.

Location. --Lat $39^{\circ} 25^{\prime} 41^{\prime \prime}$, long $123^{\circ} 44^{\prime} 10^{\prime \prime}$, in SW $\frac{1}{4} \sec .10$, T.18 N., R.17 W., on right bank 0.7 mile downstream from South Fork and 3.5 miles east of Fort Bragg. Drainage area. --106 sq $\mathrm{mi}$.

Gage-height record:--Water-stage recorder graph. Datum of gage is $12.1 \mathrm{ft}$ above mean sea level (planetable survey).

Discharge record.--Stage-discharge relation defined by current-meter measurements.

Maxima $---J a n u a r y-F e b r u a r y ~ 1963:$ Discharge, 5,050 efs 2100 hours Jan. 31 (gage height, $15.83 \mathrm{ft}$ ).

1951 to December 1962: Discharge, $22,000 \mathrm{cf}$ s Dec. 22, 1955 (gage height, $25.64 \mathrm{ft}$ ). from rating curve extended above $3,600 \mathrm{cf}$ 's on basis of slopeconveyance study.

Mean discharge, in cublc feet per second, 1963

\begin{tabular}{|c|c|c|c|c|c|c|c|c|}
\hline vay & January & February & Day & January & February & Day & January & February \\
\hline $\begin{array}{c}1 \ldots \ldots \\
2 \ldots \ldots \\
3 \ldots \ldots \\
5 \ldots \ldots \\
6 \ldots \ldots \\
7 \ldots \ldots \\
8 \ldots \ldots \\
9 \ldots \ldots \\
10 \ldots \ldots\end{array}$ & $\begin{array}{l}82 \\
76 \\
71 \\
67 \\
64 \\
60 \\
58 \\
56 \\
54 \\
53\end{array}$ & $\begin{array}{r}3,110 \\
1,500 \\
898 \\
634 \\
470 \\
370 \\
302 \\
286 \\
278 \\
294\end{array}$ & $\begin{array}{l}11 \ldots \ldots \\
12 \ldots \ldots \\
13 \ldots \ldots \\
14 \ldots \ldots \\
15 \ldots \ldots \\
16 \ldots \ldots \\
17 \ldots \ldots \\
18 \ldots \ldots \\
19 \ldots \ldots \\
20 . \ldots \ldots\end{array}$ & $\begin{array}{l}51 \\
49 \\
47 \\
45 \\
44 \\
43 \\
43 \\
42 \\
41 \\
39\end{array}$ & $\begin{array}{l}260 \\
306 \\
443 \\
400 \\
334 \\
298 \\
270 \\
235 \\
211 \\
194\end{array}$ & $\begin{array}{l}21 \ldots \ldots \\
22 \ldots \ldots \\
23 \ldots \ldots \\
24 \ldots \ldots \\
25 \ldots \ldots \\
26 \ldots \ldots \\
27 \ldots \ldots \\
28 \ldots \ldots \\
29 \ldots \ldots \\
30 \ldots \ldots \\
31 \ldots \ldots\end{array}$ & $\begin{array}{r}37 \\
37 \\
36 \\
36 \\
36 \\
36 \\
35 \\
33 \\
41 \\
366 \\
2,630 \\
\end{array}$ & $\begin{array}{r}174 \\
159 \\
147 \\
135 \\
126 \\
117 \\
110 \\
102 \\
----- \\
--.--\end{array}$ \\
\hline \multicolumn{7}{|c|}{ 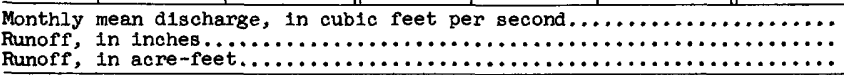 } & $\begin{array}{r}142 \\
1.55 \\
8,740\end{array}$ & $\begin{array}{r}434 \\
4.27 \\
24,120\end{array}$ \\
\hline
\end{tabular}

Gage height, in feet, and discharge, in cubic feet per second, at indicated time, 1963

\begin{tabular}{|c|c|c|c|c|c|c|c|c|c|c|c|}
\hline Date & Hour & $\begin{array}{c}\text { Gage } \\
\text { helght }\end{array}$ & $\begin{array}{l}\text { Dis - } \\
\text { charge }\end{array}$ & Date & Hour & $\begin{array}{c}\text { Gage } \\
\text { height }\end{array}$ & $\begin{array}{c}\text { D1s- } \\
\text { charge }\end{array}$ & Date & Hour & $\begin{array}{c}\text { Gage } \\
\text { helght }\end{array}$ & $\begin{array}{c}\text { Dis- } \\
\text { charge }\end{array}$ \\
\hline $\begin{array}{r}\text { Jan. } 29 \\
30\end{array}$ & $\begin{array}{l}2400 \\
0600 \\
1000 \\
1200 \\
1900 \\
2000 \\
2100 \\
2400 \\
0400\end{array}$ & $\begin{array}{l}2.40 \\
2.83 \\
3.25 \\
3.63 \\
5.47 \\
5.81 \\
5.84 \\
5.74 \\
5.62\end{array}$ & $\begin{array}{r}71 \\
120 \\
184 \\
247 \\
691 \\
793 \\
802 \\
772 \\
736\end{array}$ & $\operatorname{Jan} .31$ & $\begin{array}{l}0600 \\
0800 \\
1000 \\
1200 \\
1400 \\
1600 \\
1900 \\
2000 \\
2100 \\
2200 \\
2400\end{array}$ & $\begin{array}{r}5.68 \\
6.15 \\
7.33 \\
9.35 \\
12.41 \\
14.44 \\
15.60 \\
15.80 \\
15.83 \\
15.68\end{array}$ & $\begin{array}{r}754 \\
895 \\
1,290 \\
2,040 \\
3,330 \\
4,270 \\
4,910 \\
5,030 \\
5,050 \\
4,960\end{array}$ & Feb. & $\begin{array}{l}0300 \\
0900 \\
1500 \\
1700 \\
2400 \\
\\
0500 \\
1000 \\
1600 \\
2400\end{array}$ & $\begin{array}{r}14.41 \\
12.28 \\
10.77 \\
10.53 \\
9.32 \\
8.58 \\
8.03 \\
7.44 \\
6.86\end{array}$ & $\begin{array}{l}4,260 \\
3,280 \\
2,610 \\
2,510 \\
2,030 \\
1,730 \\
1,540 \\
1,330 \\
1,130\end{array}$ \\
\hline 31 & $\begin{array}{l}0400 \\
0500\end{array}$ & $\begin{array}{l}5.62 \\
5.62\end{array}$ & $\begin{array}{l}736 \\
736\end{array}$ & & 2400 & & 4,650 & & & & \\
\hline
\end{tabular}




\section{EEL RIVER BASIN \\ 11-4707. Alder Creek near Potter Valley, Calif. \\ (Crest-stage station)}

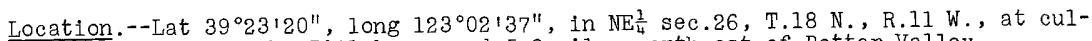
vert on Valley Lake-Pillsbury road 5.8 miles northeast of Potter Valley.

Drainage area. $--1.39 \mathrm{sq} \mathrm{mi}$.

Gage-height record.--Crest stages only. Altitude of gage is $1,650 \mathrm{ft}$ (from topographic map).

Discharge record.--Maximum discharge by computation of flow through culvert.

Maxima.--January-February 1963: Discharge, $149 \mathrm{cfs}$ Jan. 31 (gage height, $54.52 \mathrm{ft}$ ).

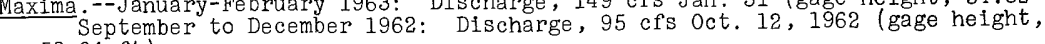
$53.04 \mathrm{ft}$ ).

11-4721.7. Fulweiter Creek tributary near willits, Calif.

(Crest-stage station)

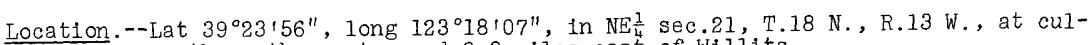
vert on north-south county road 2.8 miles east of willits.

Drainage area. --0.71 sq $\mathrm{mi}$.

Gage-he1ght record.--Crest stages only. Alt1tude of gage 1s 1,430 ft (from topographic map).

Discharge record.--Maximum discharge by computation of flow through culvert at 72 cfs.

Maxima.--January-February 1963: Discharge, $72 \mathrm{cfs}$ Jan. 31 (gage height, $54.84 \mathrm{ft}$ ). September to December 1962: Discharge, $72 \mathrm{cfs}$ oct. 12, 1962 (gage height, $54.85 \mathrm{ft}^{\circ}$.

11-4722. Outlet Creek near Longvale, Calif.

Location.--Lat $39^{\circ} 37^{1} 0^{\prime \prime}$, long $123^{\circ} 21^{1} 20^{\prime \prime}$, in NE $\frac{1}{4}$ sec.1, T.20 N., R.14 W., on right bank 0.2 mile downstream from Bloody Run Creek, 0.9 mile upstream from mouth, and 8.2 miles downstream from Longvale.

Drainage area. $--162 \mathrm{sq} \mathrm{mi}$.

Gage-height record ;-Water-stage recorder graph. Altitude of gage is $1,020 \mathrm{ft}$ (from topographic map).

Discharge record.--Stage-discharge relation defined by current-meter measurements below 9,900 fis.

Maxima.--January-February 1963: Discharge, 19,100 cf's 1600 hours Jan. 31 (gage height, $17.03 \mathrm{ft}$ ).

1956 to December 1962: Discharge, 26,500 cfs Feb. 8, 1960 (gage height, $20.27 \mathrm{ft}$ ).

Mean discharge, in cublc feet per second, 1963

\begin{tabular}{|c|c|c|c|c|c|c|c|c|}
\hline Day & January & February & Day & January & February & Day & January & February \\
\hline $\begin{array}{c}1 \ldots \ldots \\
2 \ldots \ldots \\
3 \ldots \ldots \\
4 \ldots \ldots \\
5 \ldots \ldots \\
7 \ldots \ldots \\
8 \ldots \ldots \\
9 \ldots \ldots \\
10 \ldots \ldots\end{array}$ & $\begin{array}{r}142 \\
120 \\
108 \\
99 \\
90 \\
83 \\
80 \\
74 \\
71 \\
68\end{array}$ & $\begin{array}{r}9,730 \\
4,330 \\
2,470 \\
1,400 \\
835 \\
665 \\
532 \\
585 \\
645 \\
990\end{array}$ & $\begin{array}{l}11 \ldots \ldots \\
12 \ldots \ldots \\
13 \ldots \ldots \\
14 \ldots \ldots \\
15 \ldots \ldots \\
16 \ldots \ldots \\
17 \ldots \ldots \\
18 \ldots \ldots \\
19 \ldots \ldots \\
20 \ldots \ldots\end{array}$ & $\begin{array}{l}64 \\
58 \\
51 \\
51 \\
51 \\
50 \\
50 \\
48 \\
47 \\
43\end{array}$ & $\begin{array}{r}540 \\
1,030 \\
1,090 \\
650 \\
492 \\
440 \\
406 \\
317 \\
272 \\
259\end{array}$ & $\begin{array}{l}21 \ldots \ldots \\
22 \ldots \ldots \\
23 \ldots \ldots \\
24 \ldots \ldots \\
25 \ldots \ldots \\
26 \ldots \ldots \\
27 \ldots \ldots \\
28 \ldots \ldots \\
29 \ldots \ldots \\
30 \ldots \ldots \\
31 \ldots \ldots\end{array}$ & $\begin{array}{r}43 \\
42 \\
42 \\
41 \\
41 \\
39 \\
38 \\
38 \\
56 \\
2,880 \\
11,900\end{array}$ & $\begin{array}{r}235 \\
203 \\
180 \\
164 \\
150 \\
142 \\
131 \\
125 \\
---- \\
---.-\end{array}$ \\
\hline $\begin{array}{l}\text { onthly } \\
\text { unoff, } \\
\text { unoff, }\end{array}$ & \multicolumn{6}{|c|}{ 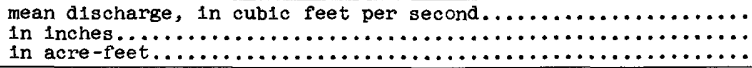 } & $\begin{array}{r}536 \\
3,81 \\
32,940\end{array}$ & $\begin{array}{r}1,036 \\
6,66 \\
57,540 \\
\end{array}$ \\
\hline
\end{tabular}


Gage height, in feet, and discharge, in cubic feet per second, at indicated time, 1963, of outlet Creek near Longvale, Calif.

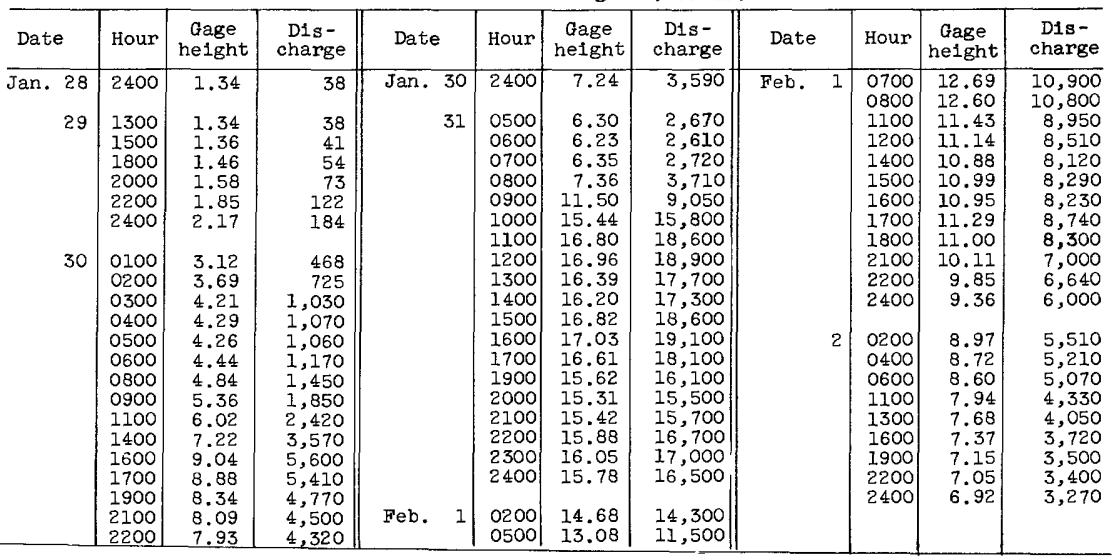

11-4725. Eel River above Dos Rios, Calif.

Location.--Lat $39^{\circ} 41^{\prime} 20^{\prime \prime}$, long $123^{\circ} 21^{\prime} 30^{\prime \prime}$, in SW $\frac{1}{4}$ sec.7, T.21 N., R.13 W., on left bank 1.8 miles upstream from Middle Fork, and 2.1 miles south of Dos Rios.

Drainage area. $-705 \mathrm{sq} \mathrm{mi}$.

Gage-height record.--Water-stage recorder graph, except Jan. 3-29, Feb. 26-28. Oncedaily staff-gage readings Jan. $3-14,16,19,21,23,25,27,29$, Feb. $21,23-28$. Altitude of gage is $950 \mathrm{ft}$ (from topographic map).

Discharge record.--Stage-discharge relation defined by current-meter measurements below 17,000 cfs and by slope-area measurement at 123,000 cfs. Discharge for periods of no gage-height record estimated on basis of records for station below Dos Rios.

Maxima --January-February 1963: Discharge, 59,600 cfs 2300 hours Jan. 31 (gage height, $32.40 \mathrm{ft}$ )

1950 to December 1962: Discharge, 123,0c0 cfs Dec. 22, 1955 (gage height, $45.4 \mathrm{ft}$, from floodmarks), from rating curve extended above $27,000 \mathrm{cfs}$ on basis of slope-area measurement of peak flow.

Remarks.--Flow partly regulated by Lake Pillsbury (capacity, 93,700 acre-f't) and by diversion through Potter Valley powerhouse.

Mean discharge, in cubic feet per second, 1963

\begin{tabular}{|c|c|c|c|c|c|c|c|c|}
\hline Day & January & February & Day & January & February & Day & January & February \\
\hline $\begin{array}{c}1 \ldots \ldots \\
3 \ldots \ldots \\
4 \ldots \ldots \\
5 \ldots \ldots \\
6 \ldots \ldots \\
8 \ldots \ldots \\
9 \ldots \ldots \\
10 \ldots \ldots\end{array}$ & $\begin{array}{l}440 \\
402 \\
352 \\
302 \\
276 \\
268 \\
256 \\
252 \\
244 \\
236\end{array}$ & $\begin{array}{r}39,700 \\
16,400 \\
9,590 \\
6,380 \\
4,360 \\
3,360 \\
2,660 \\
2,490 \\
2,480 \\
4,210\end{array}$ & $\begin{array}{l}11 \ldots \ldots \\
12 \ldots \ldots \\
13 \ldots \ldots \\
14 \ldots \ldots \\
15 \ldots \ldots \\
16 \ldots \ldots \\
17 \ldots \ldots \\
18 \ldots \ldots \\
19 \ldots \ldots \\
20 \ldots \ldots\end{array}$ & $\begin{array}{l}225 \\
214 \\
204 \\
207 \\
203 \\
200 \\
195 \\
190 \\
187 \\
184\end{array}$ & $\begin{array}{l}3,610 \\
3,440 \\
4,210 \\
3,260 \\
2,600 \\
2,230 \\
2,040 \\
1,710 \\
1,470 \\
1,330\end{array}$ & $\begin{array}{l}21 \ldots \ldots \\
22 \ldots \ldots \\
23 \ldots \ldots \\
24 \ldots \ldots \\
25 \ldots \ldots \\
26 \ldots \ldots \\
27 \ldots \ldots \\
28 \ldots \ldots \\
29 \ldots \ldots \\
30 \ldots \ldots \\
31 \ldots \ldots\end{array}$ & $\begin{array}{r}181 \\
180 \\
178 \\
176 \\
174 \\
172 \\
171 \\
170 \\
168 \\
4,130 \\
28,900\end{array}$ & $\begin{array}{r}906 \\
850 \\
805 \\
725 \\
660 \\
593 \\
530 \\
482 \\
-\ldots---\end{array}$ \\
\hline \multicolumn{7}{|l|}{$\begin{array}{l}\text { Monthly } \\
\text { Runoff', } \\
\text { Runoff, }\end{array}$} & $\begin{array}{r}1,279 \\
2.09 \\
78,620\end{array}$ & $\begin{array}{r}4,396 \\
6,49 \\
244,100\end{array}$ \\
\hline
\end{tabular}


Gage height, in feet, and discharge, in cublc feet per second, at indicated t1me, 1963, of

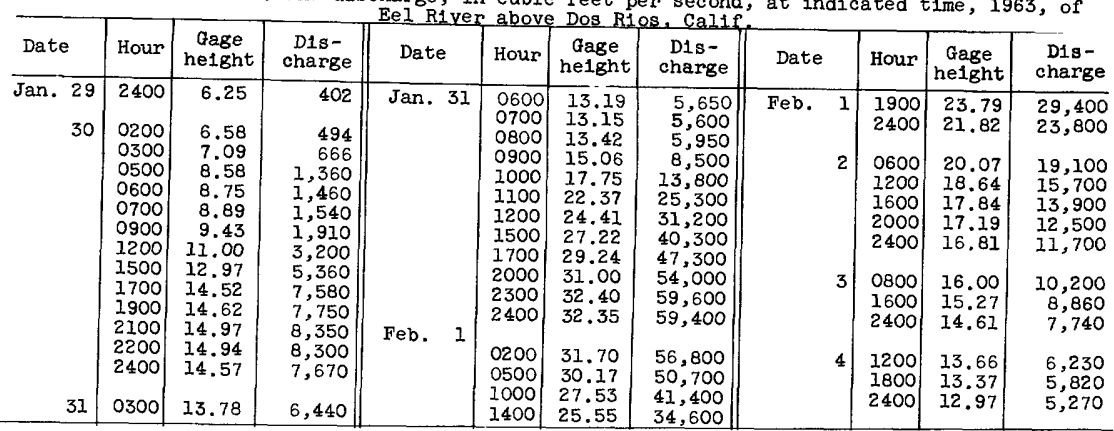

11-4729. Black Butte River near Covelo, Cal1f.

Location. --Lat $39^{\circ} 49^{\prime} 10^{\prime \prime}$, long $123^{\circ} 04140^{\prime \prime}$, in $\mathrm{SE}_{\frac{1}{4}} \sec .28$, T.23 N., R.11 W., on right bank $600 \mathrm{ft}$ upstream from highway bridge, $0.6 \mathrm{mile}$ upstream from mouth, and 9.5 miles east of Covelo.

Dralnage area. $--162 \mathrm{sq} \mathrm{mi}$.

Gage-helght record:--Water-stage recorder graph. Altitude of gage is $1,490 \mathrm{ft}$ (from topographic map) .

Discharge record.--Stage-alscharge relation defined by current-meter measurements below 4,200 cis.

Maxima --January-February 1963: Discharge, 14,900 cfs 1700 hours Jan. 31 (gage height, $17.77 \mathrm{ft}$ ).

1953-57, 1958 to December 1962: Discharge, 25,000 cfs Dec. 21, 1955 (gage height, $35.8 \mathrm{ft}$, from floodmarks, site and datum then in use), on basis of slope-area measurement of peak flow.

Flood of Dec. 11, 1937, reached a stage of $36.2 \mathrm{ft}$, from floodmarks at creststage gage site (discharge, $26,000 \mathrm{cfs}$ ).

Mean discharge, in cubic feet per second, 1963

\begin{tabular}{|c|c|c|c|c|c|c|c|c|}
\hline Day & January & February & Day & January & Febmuary & Day & January & February \\
\hline $\begin{array}{r}1 \ldots \ldots \\
2 \ldots \ldots \\
3 \ldots \ldots \\
4 \ldots \ldots \\
5 \ldots \ldots \\
6 \ldots \ldots \\
8 \ldots \ldots \\
9 \ldots \ldots \\
10 . \ldots .\end{array}$ & $\begin{array}{r}110 \\
103 \\
101 \\
97 \\
88 \\
84 \\
80 \\
75 \\
74 \\
69\end{array}$ & $\begin{array}{r}5,430 \\
2,180 \\
1,550 \\
1,010 \\
740 \\
620 \\
520 \\
513 \\
678 \\
1,330\end{array}$ & 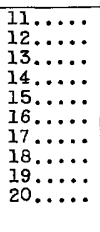 & $\begin{array}{l}61 \\
58 \\
66 \\
66 \\
61 \\
56 \\
54 \\
52 \\
50 \\
47\end{array}$ & $\begin{array}{l}841 \\
783 \\
810 \\
628 \\
548 \\
510 \\
472 \\
412 \\
376 \\
370\end{array}$ & $\begin{array}{l}21 \ldots \ldots \\
22 \ldots \ldots \\
23 \ldots \ldots \\
24 \ldots \\
25 \ldots \ldots \\
26 \ldots \\
27 \ldots \ldots \\
28 \ldots \\
29 \ldots \\
30 \ldots \\
31 \ldots \ldots\end{array}$ & $\begin{array}{r}49 \\
49 \\
47 \\
45 \\
44 \\
43 \\
42 \\
42 \\
47 \\
909 \\
7,580\end{array}$ & $\begin{array}{r}336 \\
291 \\
263 \\
245 \\
233 \\
218 \\
206 \\
194 \\
- \\
-0 .-\end{array}$ \\
\hline \multicolumn{7}{|c|}{ 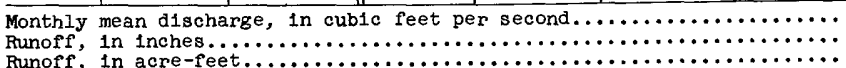 } & $\begin{array}{r}334 \\
2.38 \\
20,530\end{array}$ & $\begin{array}{r}797 \\
5.12 \\
44,250 \\
\end{array}$ \\
\hline
\end{tabular}

Gage height, in feet, and discharge, in cublc feet per second, at indicated time, 1963

\begin{tabular}{|c|c|c|c|c|c|c|c|c|c|c|c|c|}
\hline Date & Hour & $\begin{array}{c}\text { Gage } \\
\text { height }\end{array}$ & $\begin{array}{l}\text { D1s- } \\
\text { charge }\end{array}$ & Date & Hour & $\begin{array}{c}\text { Gage } \\
\text { he1ght }\end{array}$ & $\begin{array}{c}\text { D1s- } \\
\text { charge }\end{array}$ & Date & & Hour & $\begin{array}{c}\text { Gage } \\
\text { helght }\end{array}$ & $\begin{array}{l}\text { Dis - } \\
\text { charge }\end{array}$ \\
\hline $\begin{array}{r}\operatorname{Jan} .29 \\
30\end{array}$ & $\begin{array}{l}2400 \\
0200 \\
0400 \\
0500 \\
0700 \\
0800 \\
1000 \\
1200 \\
1400 \\
1500 \\
1700 \\
1800 \\
1940 \\
2000 \\
2100 \\
2400 \\
0200 \\
\end{array}$ & $\begin{array}{l}3.23 \\
3.50 \\
3.67 \\
3.74 \\
3.76 \\
3.87 \\
4.15 \\
4.69 \\
5.25 \\
6.80 \\
7.41 \\
8.03 \\
8.35 \\
8.44 \\
8.23 \\
7.33 \\
6.71 \\
\end{array}$ & $\begin{array}{r}80 \\
116 \\
145 \\
158 \\
162 \\
185 \\
253 \\
415 \\
620 \\
1,340 \\
1,710 \\
2,080 \\
2,310 \\
2,370 \\
2,220 \\
1,660 \\
1,300 \\
\end{array}$ & Jan. 31 & $\begin{array}{l}0400 \\
0500 \\
0600 \\
0700 \\
0800 \\
0900 \\
1000 \\
1100 \\
1300 \\
1600 \\
1700 \\
1800 \\
2000 \\
2300 \\
2400 \\
0100 \\
0200 \\
0500 \\
\end{array}$ & $\begin{array}{r}6.39 \\
6.36 \\
6.37 \\
6.55 \\
7.31 \\
9.00 \\
11.55 \\
14.27 \\
16.26 \\
17.47 \\
17.77 \\
17.32 \\
15.90 \\
15.60 \\
15.70 \\
15.37 \\
14.48 \\
12.91 \\
\end{array}$ & $\begin{array}{r}1,140 \\
1,120 \\
1,130 \\
1,220 \\
1,650 \\
2,760 \\
5,160 \\
8,710 \\
12,000 \\
14,300 \\
14,900 \\
14,000 \\
11,300 \\
10,800 \\
11,000 \\
10,400 \\
9,020 \\
6,790 \\
\end{array}$ & Feb. & 1 & $\begin{array}{l}0800 \\
1000 \\
1100 \\
1200 \\
1300 \\
1400 \\
1500 \\
1600 \\
1700 \\
1800 \\
1900 \\
2400 \\
0400 \\
0900 \\
1500 \\
1800 \\
2200 \\
2400 \\
\end{array}$ & $\begin{array}{r}11.57 \\
11.11 \\
11.04 \\
10.59 \\
10.59 \\
10.61 \\
10.83 \\
11.11 \\
11.12 \\
11.05 \\
10.89 \\
9.49 \\
8.75 \\
8.35 \\
7.73 \\
7.54 \\
7.38 \\
7.62 \\
\end{array}$ & $\begin{array}{l}5,180 \\
4,630 \\
4,550 \\
4,110 \\
4,110 \\
4,130 \\
4,330 \\
4,630 \\
4,640 \\
4,560 \\
4,390 \\
3,150 \\
2,590 \\
2,310 \\
1,900 \\
1,780 \\
1,690 \\
1,830\end{array}$ \\
\hline
\end{tabular}


11-4730. Middle Fork Eel River below Black Butte River, near Covelo, Calif.

Location.--Lat $39^{\circ} 49^{\prime} 35^{\prime \prime}$, long $123^{\circ} 05^{\prime} 30^{\prime \prime}$, in NW $\frac{1}{4}$ sec.28, T.23 N., R.11 W., on right bank $0.2 \mathrm{mlle}$ downstream from Black Butte River and 8.6 miles east of Covelo.

Drainage area. $--367 \mathrm{sq} \mathrm{m}$.

Gage-height record;--Water-stage recorder graph. Datum of gage is $1,434.33 \mathrm{ft}$ above mean sea level (levels by Corps of Engineers).

Discharge record.--Stage-discharge relation defined by current-meter measurements below 19,000 efs and by slope-area measurement at $89,100 \mathrm{cfs}$.

Maxima.--January-February 1963: Discharge, 60,500 cf's 1700 hours Jan. 31 (gage height, $20.24 \mathrm{ft}$ ).

1951 to December 1962: Discharge, 89,100 cfs Dec. 21, 1955 (gage height, $25.0 \mathrm{ft}$, from floodmarks), from rating curve extended above $19,000 \mathrm{cf}$ 's on basis of slope-area measurement of peak flow.

Mean discharge, in cublc feet per second, 1963

\begin{tabular}{|c|c|c|c|c|c|c|c|c|}
\hline Day & January & February & Day & January & February & Day & J anuary & February \\
\hline $\begin{array}{c}1 \ldots \ldots \\
2 \ldots \ldots \\
3 \ldots \ldots \\
5 \ldots \ldots \\
6 \ldots \ldots \\
7 \ldots \ldots \\
8 \ldots \ldots \\
10 \ldots \ldots\end{array}$ & $\begin{array}{l}372 \\
340 \\
328 \\
313 \\
285 \\
270 \\
255 \\
240 \\
234 \\
220\end{array}$ & $\begin{array}{r}21,300 \\
6,510 \\
5,150 \\
3,280 \\
2,340 \\
1,970 \\
1,680 \\
1,670 \\
2,050 \\
3,410\end{array}$ & $\begin{array}{l}11 \ldots \ldots \\
12 \ldots \ldots \\
13 \ldots \ldots \\
14 \ldots \ldots \\
15 \ldots \ldots \\
16 \ldots \ldots \\
17 \ldots \ldots \\
18 \ldots \ldots \\
19 \ldots \ldots \\
20 \ldots \ldots\end{array}$ & $\begin{array}{l}198 \\
173 \\
188 \\
195 \\
190 \\
178 \\
169 \\
165 \\
159 \\
153\end{array}$ & $\begin{array}{r}2,100 \\
2,080 \\
2,210 \\
1,760 \\
1,520 \\
1,350 \\
1,270 \\
1,100 \\
1,040 \\
977\end{array}$ & $\begin{array}{l}21 \ldots \ldots \\
22 \ldots \ldots \\
23 \ldots \ldots \\
24 \ldots \ldots \\
25 \ldots \ldots \\
26 \ldots \ldots \\
27 \ldots \ldots \\
28 \ldots \ldots \\
29 \ldots \ldots \\
30 \ldots \ldots \\
31 \ldots \ldots\end{array}$ & $\begin{array}{r}155 \\
152 \\
147 \\
143 \\
138 \\
135 \\
130 \\
130 \\
145 \\
2,650 \\
30,000\end{array}$ & $\begin{array}{r}905 \\
810 \\
750 \\
702 \\
636 \\
589 \\
551 \\
518 \\
---- \\
----\end{array}$ \\
\hline $\begin{array}{l}\text { nthly } \\
\text { inoff, } \\
\text { inoff, }\end{array}$ & $\begin{array}{l}\text { in inche } \\
\text { in acre- }\end{array}$ & & & & & & $\begin{array}{r}1,244 \\
3,91 \\
76,460 \\
\end{array}$ & $\begin{array}{r}2,508 \\
7.12 \\
139,300 \\
\end{array}$ \\
\hline
\end{tabular}

Gage helght, in feet, and discharge, in cubic feet per second, at indicated time, 1963

\begin{tabular}{|c|c|c|c|c|c|c|c|c|c|c|c|}
\hline Date & Hour & $\begin{array}{c}\text { Gage } \\
\text { height }\end{array}$ & $\begin{array}{l}\text { Dis- } \\
\text { charge }\end{array}$ & Date & Hour & $\begin{array}{c}\text { Gage } \\
\text { height }\end{array}$ & $\begin{array}{l}\text { D1s- } \\
\text { charge }\end{array}$ & Date & Hour & $\begin{array}{c}\text { Gage } \\
\text { height }\end{array}$ & $\begin{array}{l}\text { Dis- } \\
\text { charge }\end{array}$ \\
\hline $\begin{array}{r}\text { Jan. } 29 \\
30\end{array}$ & $\begin{array}{l}2400 \\
0300 \\
1000 \\
1300 \\
1600 \\
1800 \\
2000 \\
2100 \\
2200 \\
2400\end{array}$ & $\begin{array}{r}3.60 \\
3.98 \\
4.49 \\
5.32 \\
6.86 \\
8.65 \\
10.18 \\
10.21 \\
10.20 \\
9.79\end{array}$ & $\begin{array}{r}225 \\
352 \\
595 \\
1,110 \\
2,420 \\
5,030 \\
7,960 \\
8,030 \\
8,010 \\
7,130\end{array}$ & Jan. 31 & $\begin{array}{l}0400 \\
0600 \\
0800 \\
1000 \\
1200 \\
1500 \\
1600 \\
1700 \\
2000 \\
2100 \\
2400\end{array}$ & $\begin{array}{r}8.68 \\
8.36 \\
8.90 \\
11.60 \\
15.70 \\
19.20 \\
20.15 \\
20.24 \\
18.56 \\
18.25 \\
18.63\end{array}$ & $\begin{array}{r}5,080 \\
4,570 \\
5,470 \\
11,900 \\
33,300 \\
54,300 \\
60,000 \\
60,500 \\
50,500 \\
48,600 \\
50,900\end{array}$ & Feb. 1 & $\begin{array}{l}0200 \\
0800 \\
1300 \\
1500 \\
1600 \\
1700 \\
2400\end{array}$ & $\begin{array}{l}17.57 \\
13.66 \\
12.15 \\
12.01 \\
12.03 \\
11.95 \\
10.60\end{array}$ & $\begin{array}{r}44,500 \\
21,100 \\
13,900 \\
13,300 \\
13,400 \\
13,100 \\
8,960\end{array}$ \\
\hline
\end{tabular}

11-4735.7. Mill Creek tributary near Covelo, Calif.

(Crest-stage station)

Location. - Lat $39^{\circ} 51^{\prime} 20^{\prime \prime}$, long $123^{\circ} 15^{\prime} 45^{\prime \prime}$, in NW $\frac{1}{4}$ sec.13, T.23 N., R.13 W. , at culvert on Covelo-Zenia road, 4.4 miles north of Covelo.

Drainage area. $--0.26 \mathrm{sq} \mathrm{mi}$.

Gage-helght record.--Crest stages only. Altitude of gage is 1,950 ft (from topographic map).

Discharge record.--Maximum discharge by computation of flow through culvert.

Maxima.--January-February 1963: Discharge, $26 \mathrm{cfs}$ Jan. 31 (gage height, $11.80 \mathrm{ft}$ ). September to December 1962: Discharge, 11 cf's Oct. 12, 1962 (gage height, $10.75 \mathrm{ft}$ ). 


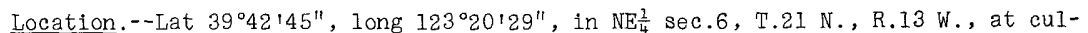
vert on Dos Rios-Covelo road, 0.7 mile southeast of Dos Rios.

Drainage area. $--3.83 \mathrm{sq} \mathrm{mi}$.

Gage-height record.--Crest stages only. Alt1tude of gage is $930 \mathrm{ft}$ (from topographic map).

Discharge record.--Maximum discharge by computation of flow through culvert.

Maxima.--January-February 1963: Discharge, 483 cfs Jan. 31 (gage height, $15.66 \mathrm{ft}$ ). September to December 1962: Discharge, 317 cfs Oct. 12, 1962 (gage height, $14.15 \mathrm{f}^{\prime} \mathrm{t}$ ).

11-4740. Eel River below Dos Rios, Calif.

Location.--Lat $39^{\circ} 44^{\prime} 15^{\prime \prime}$, Iong $123^{\circ} 22^{\prime} 15^{\prime \prime}$, in $\mathbb{N E} \frac{2}{4} \sec .25, \mathrm{~T} .22 \mathrm{~N}$, , R.14 W., on left bank 1.1 miles downstream from Burger Creek, 1.7 miles northwest of Dos Rios, and 2.2 miles downstream from Middle Fork.

Drainage area. $--1,484 \mathrm{sq}$ mi.

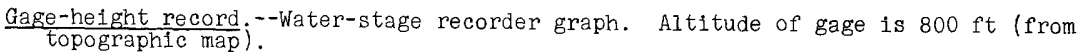

Discharge record.--Stage-discharge relation defined by current-meter measurements. Maxima $--J a n u a r y-F e b r u a r y ~ 1963:$ Discharge, 159,000 cfs 2000 hours Jan. 31 (gage

1911-13, 1951 to December 1962: Discharge, 283,000 ofs Dec. 22, 1955 (gage height, $49.86 \mathrm{ft}$ ), from rating curve extended above $120,000 \mathrm{cfs}$ on basis of a slope-conveyance study.

Remarks, - Flow partly regulated by Lake Pillsbury (capacity, 93,700 acre-ft).

Mean discharge, in cublc feet per second, 1963

\begin{tabular}{|c|c|c|c|c|c|c|c|c|}
\hline Day & January & February & Day & January & February & Day & January & February \\
\hline $\begin{array}{c}1 \ldots \ldots \\
2 \ldots \ldots \\
3 \ldots \ldots \\
4 \ldots \ldots \\
5 \ldots \ldots \\
7 \ldots \ldots \\
8 \ldots \ldots \\
9 \ldots \ldots \\
10 \ldots \ldots\end{array}$ & $\begin{array}{r}1,170 \\
1,040 \\
960 \\
880 \\
792 \\
732 \\
690 \\
660 \\
630 \\
610\end{array}$ & $\begin{array}{r}95,400 \\
37,100 \\
22,600 \\
15,600 \\
11,800 \\
9,190 \\
7,670 \\
7,220 \\
6,950 \\
11,800\end{array}$ & $\begin{array}{l}11 \ldots \ldots \\
12 \ldots \ldots \\
13 \ldots \ldots \\
14 \ldots \ldots \\
15 \ldots \ldots \\
16 \ldots \ldots \\
17 \ldots \ldots \\
18 \ldots \ldots \\
19 \ldots \ldots \\
20 \ldots \ldots\end{array}$ & $\begin{array}{l}572 \\
532 \\
508 \\
512 \\
520 \\
504 \\
488 \\
472 \\
464 \\
446\end{array}$ & $\begin{array}{r}9,090 \\
8,750 \\
10,600 \\
8,080 \\
6,650 \\
5,700 \\
5,320 \\
4,440 \\
3,850 \\
3,500\end{array}$ & $\begin{array}{l}21 \ldots \ldots \\
22 \ldots \ldots \\
23 \ldots \ldots \\
24 \ldots \ldots \\
25 \ldots \ldots \\
26 \ldots \ldots \\
27 \ldots \ldots \\
28 \ldots \ldots \\
29 \ldots \ldots \\
30 \ldots \ldots \\
31 \ldots \ldots\end{array}$ & $\begin{array}{r}439 \\
439 \\
432 \\
425 \\
418 \\
408 \\
400 \\
397 \\
442 \\
8,770 \\
77,500\end{array}$ & $\begin{array}{r}3,170 \\
2,780 \\
2,470 \\
2,210 \\
2,010 \\
1,860 \\
1,680 \\
1,540 \\
--.-- \\
---1-\end{array}$ \\
\hline \multicolumn{7}{|l|}{$\begin{array}{l}\text { Monthly } \\
\text { Runoff, } \\
\text { Runoff, }\end{array}$} & $\begin{array}{r}3,331 \\
2,59 \\
204,800 \\
\end{array}$ & $\begin{array}{r}11,040 \\
7.74 \\
613,000 \\
\end{array}$ \\
\hline
\end{tabular}

Gage height, in feet, and discharge, in cublc feet per second, at indicated time, I963

\begin{tabular}{|c|c|c|c|c|c|c|c|c|c|c|c|}
\hline Date & Hour & $\begin{array}{c}\text { Gage } \\
\text { height }\end{array}$ & $\begin{array}{l}\text { Dis- } \\
\text { charge }\end{array}$ & Date & Hour & $\begin{array}{c}\text { Gage } \\
\text { height }\end{array}$ & $\begin{array}{l}\text { Dis- } \\
\text { charge }\end{array}$ & Date & Hour & $\begin{array}{l}\text { Gage } \\
\text { helght }\end{array}$ & $\begin{array}{c}\text { Dis- } \\
\text { charge }\end{array}$ \\
\hline $\operatorname{Jan} .28$ & 2400 & 6.53 & 400 & Jan. 30 & 1600 & 13.28 & 11,900 & Jan. 31 & 2000 & 36.60 & 15 \\
\hline 29 & 0700 & 6.54 & 404 & & $\begin{array}{l}1800 \\
2300\end{array}$ & $\begin{array}{l}14.66 \\
16.28\end{array}$ & $\begin{array}{l}15,800 \\
21,600\end{array}$ & & 2 & & \\
\hline & $\begin{array}{l}1400 \\
1800\end{array}$ & $\begin{array}{l}6.53 \\
6.62\end{array}$ & $\begin{array}{l}400 \\
432\end{array}$ & & 2400 & & & Feb. 1 & & & 131,000 \\
\hline & $\begin{array}{l}2000 \\
2300 \\
2400\end{array}$ & $\begin{array}{l}6.76 \\
7.12 \\
7.34\end{array}$ & $\begin{array}{l}484 \\
642 \\
792\end{array}$ & 31 & $\begin{array}{l}0200 \\
0700 \\
0800\end{array}$ & $\begin{array}{l}16.02 \\
14.58 \\
14.63\end{array}$ & $\begin{array}{l}20,600 \\
15,600 \\
15,700\end{array}$ & & $\begin{array}{l}1800 \\
2400\end{array}$ & $\begin{array}{l}24.98 \\
23.00\end{array}$ & 68,900 \\
\hline 30 & $\begin{array}{l}0100 \\
0300 \\
0600 \\
1200\end{array}$ & $\begin{array}{r}7.60 \\
7.89 \\
9.12 \\
10.94\end{array}$ & $\begin{array}{l}1,000 \\
1,270 \\
2,620 \\
5,640\end{array}$ & & $\begin{array}{l}1000 \\
1200 \\
1400 \\
1600 \\
1800\end{array}$ & $\begin{array}{l}18.00 \\
23.56 \\
28.60 \\
32.50 \\
35.80\end{array}$ & $\begin{array}{r}29,000 \\
59,600 \\
95,000 \\
126,000 \\
152,000\end{array}$ & 2 & $\begin{array}{l}0600 \\
1200 \\
1800 \\
2400\end{array}$ & $\begin{array}{l}20.77 \\
19.28 \\
18.10 \\
17.47\end{array}$ & $\begin{array}{l}42,700 \\
34,900 \\
29,400 \\
26,600\end{array}$ \\
\hline
\end{tabular}


11-4745. North Fork Eel River near Mina, Calif.

Location.--Lat $39^{\circ} 56^{\prime} 15^{\prime \prime}$, long $123^{\circ} 20^{\prime} 45^{\prime \prime}$, in SW $\frac{1}{4}$ sec.8, T.24 N., R.13 W., on right bank 1.2 miles upstream from Asbill Creek, 2 miles south of Mina, and 8.8 miles northeast of Nashmead.

Drainage area. $--250 \mathrm{sq} \mathrm{mi.}$

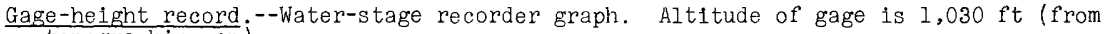
topographic map).

Discharge record.--Stage-discharge relation defined by current-meter measurements below $8,000 \mathrm{c}$ 's and extended above on basis of slope-area measurement at 58,400 cfs.

Maxima.--January-February 1963: Discharge, 26,600 cfs 1600 hours Jan. 31 (gage height, $19.25 \mathrm{ft}$ ).

1953 to December 1962: Discharge, 58,400 cf's Dec. 22, 1955 (gage height, $24.00 \mathrm{ft}$ ), from rating curve extended above $8,000 \mathrm{cfs}$ on basis of slope-area measurement of peak flow.

Flood in December 1937 reached a stage of about $30.7 \mathrm{ft}$ (former site and datum), from information by local residents.

Mean discharge, in cubic feet per second, 1963

\begin{tabular}{|c|c|c|c|c|c|c|c|c|}
\hline Day & January & February & Day & January & February & Day & January & February \\
\hline $\begin{array}{r}1 \ldots \ldots \\
2 \ldots \ldots \\
3 \ldots \ldots \\
4 \ldots \ldots \\
5 \ldots \ldots \\
7 \ldots \ldots \\
8 \ldots \ldots \\
9 \ldots \ldots \\
10 \ldots \ldots\end{array}$ & $\begin{array}{r}158 \\
145 \\
139 \\
131 \\
119 \\
110 \\
104 \\
98 \\
94 \\
91\end{array}$ & $\begin{array}{r}8,670 \\
3,390 \\
2,680 \\
1,830 \\
1,480 \\
1,160 \\
910 \\
975 \\
853 \\
920\end{array}$ & $\begin{array}{l}11 \ldots \ldots \\
12 \ldots \ldots \\
13 \ldots \ldots \\
14 \ldots \ldots \\
15 \ldots \ldots \\
16 \ldots \ldots \\
17 \ldots \ldots \\
18 \ldots \ldots \\
19 \ldots \ldots \\
20 \ldots \ldots\end{array}$ & $\begin{array}{l}85 \\
72 \\
77 \\
76 \\
78 \\
74 \\
70 \\
67 \\
66 \\
62\end{array}$ & $\begin{array}{r}676 \\
977 \\
1,400 \\
975 \\
777 \\
732 \\
777 \\
616 \\
548 \\
532\end{array}$ & $\begin{array}{l}21 \ldots \ldots \\
22 \ldots \ldots \\
23 \ldots \ldots \\
24 \ldots \ldots \\
25 \ldots \ldots \\
26 \ldots \ldots \\
27 \ldots \ldots \\
28 \ldots \ldots \\
29 \ldots \ldots \\
30 \ldots \ldots \\
31 \ldots \ldots\end{array}$ & $\begin{array}{r}62 \\
62 \\
61 \\
59 \\
57 \\
55 \\
53 \\
53 \\
90 \\
2,240 \\
12,500\end{array}$ & $\begin{array}{r}451 \\
399 \\
356 \\
314 \\
288 \\
265 \\
243 \\
222 \\
\ldots-\ldots\end{array}$ \\
\hline \multicolumn{7}{|c|}{ 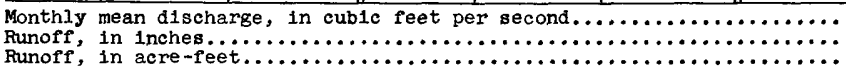 } & $\begin{array}{r}555 \\
2.56 \\
34,130\end{array}$ & $\begin{array}{r}1,193 \\
4: 97 \\
66,280\end{array}$ \\
\hline
\end{tabular}

Gage height, in feet, and discharge, in cubic feet per second, at 1ndicated time, 1963

\begin{tabular}{|c|c|c|c|c|c|c|c|c|c|c|c|}
\hline Date & Hour & $\begin{array}{c}\text { Gage } \\
\text { height }\end{array}$ & $\begin{array}{l}\text { Dis- } \\
\text { charge }\end{array}$ & Date & Hour & $\begin{array}{c}\text { Gage } \\
\text { helght }\end{array}$ & $\begin{array}{c}\text { Dis- } \\
\text { charge }\end{array}$ & Date & Hour & $\begin{array}{c}\text { Gage } \\
\text { helght }\end{array}$ & $\begin{array}{l}\text { D1s - } \\
\text { charge }\end{array}$ \\
\hline $\begin{array}{r}\text { Jan. } 28 \\
29\end{array}$ & $\begin{array}{l}2400 \\
0600 \\
1400 \\
1600 \\
1800 \\
1900 \\
2100 \\
2200 \\
2300 \\
2400 \\
0200 \\
0300 \\
0400 \\
0500 \\
0600 \\
0900 \\
1000\end{array}$ & $\begin{array}{l}3.89 \\
3.91 \\
3.99 \\
4.05 \\
4.19 \\
4.37 \\
4.99 \\
5.12 \\
5.10 \\
5.11 \\
6.30 \\
6.49 \\
6.66 \\
6.91 \\
6.98 \\
6.83 \\
6.84\end{array}$ & $\begin{array}{r}53 \\
55 \\
62 \\
68 \\
82 \\
104 \\
208 \\
235 \\
230 \\
233 \\
\\
620 \\
696 \\
772 \\
885 \\
920 \\
849 \\
853\end{array}$ & Jan. 30 & $\begin{array}{l}1100 \\
1200 \\
1400 \\
1600 \\
1800 \\
1900 \\
2000 \\
2100 \\
2200 \\
2400 \\
0400 \\
0600 \\
0700 \\
0800 \\
1000 \\
1200 \\
1300 \\
1400\end{array}$ & $\begin{array}{r}6.98 \\
7.22 \\
8.28 \\
10.05 \\
11.26 \\
11.55 \\
11.67 \\
11.50 \\
11.07 \\
10.32 \\
9.44 \\
9.17 \\
9.15 \\
9.45 \\
12.00 \\
15.77 \\
17.95 \\
18.72\end{array}$ & $\begin{array}{r}920 \\
1,040 \\
1,680 \\
3,310 \\
4,810 \\
5,190 \\
5,340 \\
5,120 \\
4,560 \\
3,630 \\
2,640 \\
2,370 \\
2,360 \\
2,650 \\
5,770 \\
13,200 \\
20,800 \\
24,100\end{array}$ & Jan. 31 & $\begin{array}{l}1500 \\
1600 \\
1700 \\
2000 \\
2100 \\
2200 \\
2300 \\
2400 \\
0100 \\
0300 \\
0700 \\
1300 \\
1400 \\
1500 \\
1600 \\
1700 \\
1800 \\
2400\end{array}$ & $\begin{array}{l}19.10 \\
19.25 \\
19.00 \\
17.22 \\
16.94 \\
16.92 \\
16.98 \\
17.06 \\
16.93 \\
16.11 \\
14.17 \\
12.57 \\
12.47 \\
12.42 \\
12.62 \\
12.70 \\
12.50 \\
11.22\end{array}$ & $\begin{array}{r}25,800 \\
26,600 \\
25,400 \\
18,000 \\
17,000 \\
16,900 \\
17,100 \\
17,400 \\
17,000 \\
14,200 \\
9,150 \\
6,510 \\
6,380 \\
6,320 \\
6,580 \\
6,690 \\
6,420 \\
4,760\end{array}$ \\
\hline
\end{tabular}

11-4745.7. Wilson Creek near Mina, Calif.

(Crest-stage station)

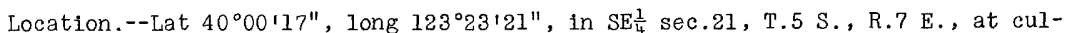
vert on Covelo-Zenia road, 3.2 miles northwest of Mina.

Drainage area. $--2.84 \mathrm{sq} \mathrm{mi}$.

Gage-height record.--Crest stages only. Altitude of gage is $2,550 \mathrm{ft}$ (from topographic map).

Discharge record. - Stage-discharge relation defined by current-meter measurements below $37 \mathrm{cfs}$ and by computation of flow through culvert at $273 \mathrm{cfs}$.

Maxima.--January-February 1963: Discharge, 235 efs Jan. 31 (gage height, $13.17 \mathrm{ft}$ ). September to December 1962: Discharge, $273 \mathrm{cf}$ s Oct. 12,1962 (gage height,
13.55 ft). 
11-4755. South Fork Eel River near Branscomb, Calif.

Location.--Lat $39^{\circ} 43^{1} 09^{\prime \prime}$, long $123^{\circ} 39^{10} 6^{\prime \prime}$, in NW $\frac{1}{4}$ sec.32, T.22 N., R.16 W., on right bank 0.4 mile upstream from Jack of Hearts Creek and 4.7 miles north of Branscomb.

Drainage_area. $--43.9 \mathrm{sq} \mathrm{mi}$.

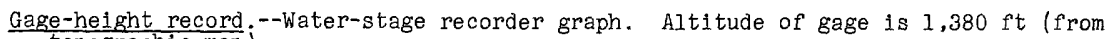
topographic mapj.

D1scharge record.--Stage-discharge relation defined by current-meter measurements.

Maxima --January-February 1963: Discharge 4,090 cfs 2400 hours Jan. 31 (gage height, $8.03 \mathrm{ft}$ ).

1946 to December 1962: Discharge, 20,100 cfs Dec. 22, 1955 (gage height, $16.20 \mathrm{ft}$ ), from rating curve extended above $4,600 \mathrm{cfs}$ on basis of slope-area measurement of peak flow.

Mean discharge, In cublc feet per second, 1963

\begin{tabular}{|c|c|c|c|c|c|c|c|c|}
\hline Day & January & February & Day & January & February & Day & January & February \\
\hline $\begin{array}{c}1 \ldots \ldots \\
2 \ldots \ldots \\
3 \ldots \ldots \\
4 \ldots \ldots \\
6 \ldots \ldots \\
7 \ldots \ldots \\
8 \ldots \ldots \\
9 \ldots \ldots \\
10 \ldots \ldots\end{array}$ & $\begin{array}{l}78 \\
74 \\
69 \\
65 \\
63 \\
58 \\
58 \\
56 \\
53 \\
52\end{array}$ & $\begin{array}{r}2,280 \\
1,060 \\
646 \\
509 \\
409 \\
358 \\
301 \\
283 \\
256 \\
241\end{array}$ & $\begin{array}{l}11 \ldots \ldots \\
12 \ldots \ldots \\
13 \ldots \ldots \\
14 \ldots \ldots \\
15 \ldots \ldots \\
16 \ldots \ldots \\
17 \ldots \ldots \\
18 \ldots \ldots \\
19 \ldots \ldots \\
20 \ldots \ldots\end{array}$ & $\begin{array}{l}52 \\
50 \\
47 \\
45 \\
45 \\
45 \\
44 \\
44 \\
42 \\
41\end{array}$ & $\begin{array}{l}209 \\
256 \\
307 \\
280 \\
250 \\
232 \\
206 \\
181 \\
164 \\
151\end{array}$ & $\begin{array}{l}21 \ldots \ldots \\
22 \ldots \ldots \\
23 \ldots \ldots \\
24 \ldots \ldots \\
25 \ldots \ldots \\
26 \ldots \ldots \\
27 \ldots \ldots \\
28 \ldots \ldots \\
29 \ldots \ldots \\
30 \ldots \ldots \\
31 \ldots \ldots\end{array}$ & $\begin{array}{r}39 \\
39 \\
39 \\
38 \\
37 \\
37 \\
36 \\
36 \\
37 \\
260 \\
2,080\end{array}$ & $\begin{array}{r}136 \\
128 \\
116 \\
110 \\
104 \\
98 \\
90 \\
89 \\
-\ldots---\end{array}$ \\
\hline \multicolumn{7}{|c|}{ 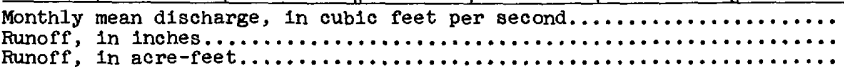 } & $\begin{array}{r}121 \\
3.18 \\
7,460 \\
\end{array}$ & $\begin{array}{r}338 \\
8.01 \\
18,740 \\
\end{array}$ \\
\hline
\end{tabular}

Gage he1ght, in feet, and discharge, in cub1c feet per second, at indicated time, 1963

\begin{tabular}{|c|c|c|c|c|c|c|c|c|c|c|c|}
\hline Date & Hour & $\begin{array}{c}\text { Gage } \\
\text { helght }\end{array}$ & $\begin{array}{c}\text { Dis- } \\
\text { charge }\end{array}$ & Date & Hour & $\begin{array}{c}\text { Gage } \\
\text { helght }\end{array}$ & $\begin{array}{l}\text { Dis- } \\
\text { charge }\end{array}$ & Date & Hour & $\begin{array}{c}\text { Gage } \\
\text { helght }\end{array}$ & $\begin{array}{c}\text { Dis- } \\
\text { charge }\end{array}$ \\
\hline $\begin{array}{r}\text { Jan. } \\
30\end{array}$ & $\begin{array}{l}2400 \\
0500 \\
1000 \\
1000 \\
1200 \\
1400 \\
1600 \\
1800 \\
1900 \\
2000 \\
2300 \\
2400\end{array}$ & $\begin{array}{l}1.40 \\
1.46 \\
1.73 \\
1.88 \\
1.88 \\
2.14 \\
2.56 \\
3.23 \\
3.26 \\
3.44 \\
3.41 \\
3.28\end{array}$ & $\begin{array}{r}42 \\
52 \\
100 \\
133 \\
133 \\
203 \\
329 \\
551 \\
561 \\
626 \\
614 \\
568\end{array}$ & Feb. 1 & $\begin{array}{l}0300 \\
0600 \\
0700 \\
0900 \\
1100 \\
1300 \\
1500 \\
1700 \\
1900 \\
2200 \\
2400 \\
0500\end{array}$ & $\begin{array}{l}2.88 \\
2.74 \\
2.83 \\
3.55 \\
6.00 \\
6.87 \\
6.98 \\
7.65 \\
7.36 \\
7.68 \\
8.03 \\
6.75\end{array}$ & $\begin{array}{r}432 \\
387 \\
416 \\
670 \\
2,170 \\
2,880 \\
2,980 \\
3,670 \\
3,360 \\
3,700 \\
4,090 \\
2,780\end{array}$ & Feb. & $\begin{array}{l}0900 \\
1300 \\
1400 \\
1600 \\
1700 \\
2000 \\
2400 \\
1400 \\
2400\end{array}$ & $\begin{array}{l}6.26 \\
5.60 \\
5.67 \\
5.51 \\
5.70 \\
5.28 \\
4.94 \\
4.18 \\
3.86\end{array}$ & $\begin{array}{r}2,380 \\
1,850 \\
1,910 \\
1,790 \\
1,930 \\
1,630 \\
1,390 \\
\\
970 \\
810\end{array}$ \\
\hline
\end{tabular}

11-4756.9. Steep Creek near Laytonville, Calif.

(Crest-stage station)

Location.--Lat $39^{\circ} 45^{\prime} 41^{\prime \prime}$, long $123^{\circ} 32^{\prime} 22^{\prime \prime}$, in center of sec.16, T.22 N., R.15 W., at culvert on U.S. Highway $101,6.0$ miles northwest of Laytonville.

Drainage area. $--2.90 \mathrm{sq} \mathrm{mi}$.

Gage-height record.--Crest stages only. Altitude of gage is $1,480 \mathrm{ft}^{\prime}$ (from topographic map).

Discharge record. --Stage-discharge relation defined by current-meter measurements below $39 \mathrm{cf}$ and by computation of flow through culvert at 843,973 , and $1,090 \mathrm{cfs}$.

Maxima,--January-February 1963: Discharge, 1,090 cf's Jan. 31 (gage height, $22.67 \mathrm{ft}^{\prime}$ ).

September to December 1962: Discharge, $843 \mathrm{cfs}$ Oct. 12, 1962 (gage height, $20.63 \mathrm{ft})$. 
11-4757. Tenmile Creek near Laytonville, Calif.

Location.--Lat $39^{\circ} 45^{\prime} 45^{\prime \prime}$, long $123^{\circ} 32^{\prime} 30^{\prime \prime}$, in NW $\frac{1}{4}$ sec. 16 , T.22 N., R.15 W., on right bank 0.1 mile downstream from Step Gulch Creek and 6.0 miles northwest of

Laytonville.

Drainage area. $--50.3 \mathrm{sq} \mathrm{mi}$.

Gage-height record; - Water-stage recorder graph. Altitude of gage is $1,450 \mathrm{ft}$ (from topographic map)

Discharge record.--Stage-discharge relation defined by current-meter measurements below $4,300 \mathrm{cfs}$ and by slope-area measurement at $16,300 \mathrm{cfs}$.

Maxima.--January-February 1963: Discharge, 9,530 cfs 1400 hours Jan. 31 (gage height, $16.63 \mathrm{f}^{\mathrm{t}}$ )

1955 to December 1962: Discharge, $16,300 \mathrm{cfs}$ Dec. 22, 1955 (gage height, $22.9 \mathrm{ft}$, from floodmarks), on basis of slope-area measurement of peak flow.

Mean discharge, in cubic feet per second, 1963

\begin{tabular}{|c|c|c|c|c|c|c|c|c|}
\hline Day & January & February & Day & January & February & Day & January & February \\
\hline $\begin{array}{c}1 \ldots \ldots \\
2 \ldots \ldots \\
3 \ldots \ldots \\
4 \ldots \ldots \\
6 \ldots \ldots \\
7 \ldots \ldots \\
9 \ldots \ldots \\
10 \ldots \ldots\end{array}$ & $\begin{array}{l}62 \\
58 \\
54 \\
50 \\
46 \\
44 \\
43 \\
41 \\
40 \\
38\end{array}$ & $\begin{array}{r}2,770 \\
1,140 \\
737 \\
571 \\
425 \\
366 \\
257 \\
282 \\
254 \\
242\end{array}$ & $\begin{array}{l}11 \ldots \ldots \\
12 \ldots \ldots \\
13 \ldots \ldots \\
14 \ldots \ldots \\
15 \ldots \ldots \\
16 \ldots \ldots \\
17 \ldots \ldots \\
18 \ldots \ldots \\
19 \ldots \ldots \\
20 \ldots \ldots\end{array}$ & $\begin{array}{l}36 \\
33 \\
31 \\
31 \\
30 \\
30 \\
29 \\
27 \\
26 \\
25\end{array}$ & $\begin{array}{l}177 \\
493 \\
407 \\
247 \\
200 \\
212 \\
191 \\
157 \\
142 \\
139\end{array}$ & $\begin{array}{l}21 \ldots \ldots \\
22 \ldots \ldots \\
23 \ldots \ldots \\
24 \ldots \ldots \\
25 \ldots \ldots \\
26 \ldots \ldots \\
27 \ldots \ldots \\
28 \ldots \ldots \\
29 \ldots \ldots \\
30 \ldots \ldots \\
31 \ldots \ldots\end{array}$ & $\begin{array}{r}25 \\
25 \\
24 \\
23 \\
23 \\
22 \\
22 \\
21 \\
50 \\
1,120 \\
5,290\end{array}$ & $\begin{array}{r}122 \\
110 \\
100 \\
92 \\
84 \\
79 \\
73 \\
70 \\
---- \\
---2-\end{array}$ \\
\hline $\begin{array}{l}\text { onthly } \\
\text { unoff, } \\
\text { unoff, }\end{array}$ & \multicolumn{6}{|c|}{ 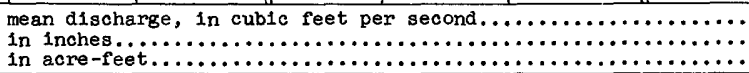 } & $\begin{array}{r}239 \\
5.49 \\
14,720\end{array}$ & $\begin{array}{r}362 \\
20,110 \\
\end{array}$ \\
\hline
\end{tabular}

Gage he1ght, in feet, and discharge, in cub1c feet per second, at indicated time, 1963

\begin{tabular}{|c|c|c|c|c|c|c|c|c|c|c|c|}
\hline Date & Hour & $\begin{array}{c}\text { Gage } \\
\text { helight }\end{array}$ & $\begin{array}{c}\text { Dis- } \\
\text { charge }\end{array}$ & Date & Hour & $\begin{array}{c}\text { Gage } \\
\text { height }\end{array}$ & $\begin{array}{c}\text { Dis- } \\
\text { charge }\end{array}$ & Date & Hour & $\begin{array}{c}\text { Gage } \\
\text { helght }\end{array}$ & $\begin{array}{c}\text { Dis- } \\
\text { charge }\end{array}$ \\
\hline $\begin{array}{r}\text { Jan. } 28 \\
29\end{array}$ & $\begin{array}{l}2400 \\
1400 \\
1700 \\
1800 \\
1900 \\
2000 \\
2100 \\
2200 \\
2300 \\
2400 \\
0300 \\
0400 \\
0500 \\
0600 \\
0700 \\
0800 \\
0900\end{array}$ & $\begin{array}{l}2.97 \\
2.99 \\
3.06 \\
3.11 \\
3.22 \\
3.52 \\
4.12 \\
4.38 \\
4.47 \\
4.78 \\
5.60 \\
5.78 \\
5.79 \\
5.77 \\
5.76 \\
5.84 \\
6.12\end{array}$ & $\begin{array}{r}23 \\
24 \\
29 \\
33 \\
43 \\
72 \\
141 \\
177 \\
193 \\
259 \\
494 \\
552 \\
555 \\
548 \\
545 \\
571 \\
667\end{array}$ & Jan. 30 & $\begin{array}{l}1200 \\
1300 \\
1500 \\
1600 \\
1700 \\
2000 \\
2400 \\
\\
0400 \\
0500 \\
0600 \\
0800 \\
0900 \\
1000 \\
1200 \\
1300 \\
1400 \\
1500 \\
1700\end{array}$ & $\begin{array}{r}6.93 \\
7.18 \\
8.97 \\
9.16 \\
9.05 \\
8.34 \\
7.14 \\
\\
6.30 \\
6.25 \\
6.51 \\
8.38 \\
11.15 \\
14.30 \\
16.45 \\
16.49 \\
16.63 \\
16.48 \\
15.01 \\
\end{array}$ & $\begin{array}{r}972 \\
1,090 \\
2,120 \\
2,250 \\
2,180 \\
1,710 \\
1,070 \\
730 \\
713 \\
804 \\
1,740 \\
4,050 \\
7,200 \\
9,350 \\
9,390 \\
9,530 \\
9,380 \\
7,910 \\
\end{array}$ & $\begin{array}{l}\text { Jan. } 31 \\
\text { Feb. } 1\end{array}$ & $\begin{array}{l}1900 \\
2000 \\
2100 \\
2400 \\
0300 \\
0500 \\
0600 \\
0800 \\
1100 \\
1200 \\
1400 \\
1500 \\
1600 \\
1700 \\
2000 \\
2400\end{array}$ & $\begin{array}{r}14.12 \\
14.25 \\
14.17 \\
13.12 \\
11.21 \\
10.55 \\
10.15 \\
9.92 \\
8.92 \\
8.85 \\
9.13 \\
9.67 \\
9.49 \\
9.52 \\
8.54 \\
7.84\end{array}$ & $\begin{array}{l}7,020 \\
7,150 \\
7,070 \\
6,020 \\
4,110 \\
3,450 \\
3,090 \\
2,880 \\
2,080 \\
2,040 \\
2,230 \\
2,660 \\
2,510 \\
2,540 \\
1,830 \\
1,420\end{array}$ \\
\hline
\end{tabular}




\section{REFERENCES CITED}

Bodhaine, G. L., 1963, Indirect measurement of peak discharge through culverts: U.S. Geol. Survey open-file report, $49 \mathrm{p}$.

Dalrymple, Tate, and others, 1938, Major Texas floods of 1936: U.S. Geol. Survey Water-Supply Paper 816, $146 \mathrm{p}$.

Grover, N. C., 1937, New England rivers, pt. 1 of The floods of March 1936: U.S. Geol. Survey Water-Supply Paper 798, $466 \mathrm{p}$.

Hofmann, Walter, and Rantz, S. E., 1963, Description, pt. I of Floods of December 1955-January 1956 in the Far Western States: U.S. Geol. Survey Water-Supply Paper 1650-A, p. Al-A156.

1963, Streamflow data, pt. 2 of Floods of December 1955-January 1956 in the Far Western States: U.S. Geol. Survey Water-Supply Paper 1650-B, p. BI-B580.

Johnson, Hollister, 1936, The New York State flood of July 1935: U.S. Geol. Survey Water-Supply Paper 773-E, p.233-268.

Kindsvater, C. E., Carter, R. W., and Tracy, H. J., 1953, Computation of peak discharges at contractions: U.S. Geol. Survey Circ. $284,35 \mathrm{p}$.

McGlashan, H. D., and Briggs, R. C., 1939, Floods of December 1937 in northern California: U.S. Geol. Survey Water-Supply Paper 843, 497 p. (1940).

Rantz, S. E., and Harris, E. E., 1963, Floods of January-February 1963 in California and Nevada: U.S. Geol. Survey open-file report, $74 \mathrm{p}$.

Rantz, S. E., and Stafford, H. M., 1956, Floods of 1952 in California: U.S. Geol. Survey Water-Supply Paper 1260-D, p.531-575.

Rostvedt, J. 0., 1965, Floods in the United States during 1960: U.S. Geol. Survey Water-Supply Paper 1790-B, p. Bl-B147.

U.S. Geological Survey, 1953, Floods of November-December 1950 in the Central Valley basin, California: U.S. Geol. Survey Water-Supply Paper 1137-F, p. 505-789 (1954).

1954, Floods of November-December 1950 in western Nevada: U.S. Geol. Survey Water-Supply Paper 1137-H, p. 897-956.

1963, Summary of floods in the United States during 1958: U.S. Geol. Survey Water-Supply Paper $1660-B, p$. Bl-B97. 
Adobe Creek near Kelseyville, Calif... A4li Alameda Creek, at Union CIty, Calif... near Niles, Calif.

tributary No. 1 near Warm Springs

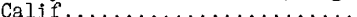

Alameda Creek basin, records......55, 166-17 Alamitos Creek near New Almaden, Calif.

Albion River, near Comptche, Calif.... tributary near Comptche, Calif...... Alder Creek (tributary to Eel River) near Potter Valley, Calif.........

Alder Creek (tributary to Prosser Creek) near Truckee Calif.

Alder Creek (tributary to South Fork American River) near Whitehall, Calif...

Alec Canyon near Morgan Hiij Cajif....

Almaden Reservolr near New Almaden, Calif ....... at Fair oaks Calif... American River, at Fair Oaks, Cal
Middle Fork, at French Meadows. Calif.

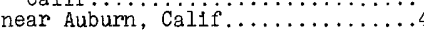

near North Fork, at North Fork Däm, Calif.

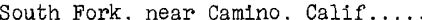

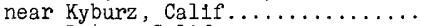
near Lotus, Callf...

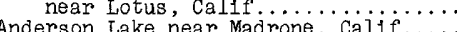

Antelope Creek (tributary to North Fork Mokelumne River) near West

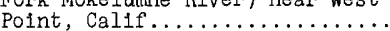

Antelope Creek (tributary to Sacramento Riverl near Red Bluff, Cal1f.

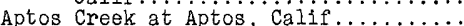

Arroyo Calero tributary near New Almaden, Calif..

Arroyo de la Cruz near San Simeon,

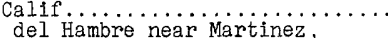
Calif........................

Arroyo Mocho near Pleasanton, Cäiff... Arroyo Seco, near Greenfleld, Callf..

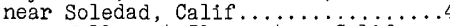

Arroyo Valle, at Pleasanton, Calif....

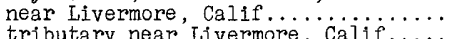

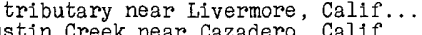

Bass Lake near Bass Lake, Calif....... Battle Creek below Coleman Fish Factory, near Cottonwood, Calif.

Bear Creek (tributary to Cache Creek), near Rumsey, Calif............

tributary near Wilbur Springs

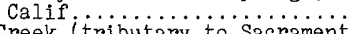

Bear Creek (tributary to San Joaquin River, lower), near Lockeford, Cal1f...

tributary near valiey Springs

Bear Creek itributary to sä joàuin River, upper), near Catheys

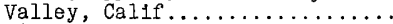

tributary near Catheys Valley,

Bear Mountain Creek near Squaw valiè, Calif..........

Bear River iributary to Feather River), near Auburm, Calif.....

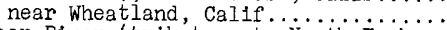

Bear River (tributary to North Fork Mokelumne River, near Salt Springs Dam, Calif.

Beardsley lake near Strawberry, caiji. $\mathrm{Blg}$ Canyon Creek near Dublin, Calif...

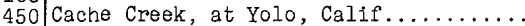

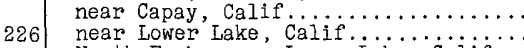
North Fork, near Lower Lake, Calif.. 322 Calaveras River, at Jenny Lind, Calif.. below Hogan Dam, $\mathrm{Cal} 1 \mathrm{f}$

419 North Fork, near San Andreas, Calif.. South Fork, near San Andreas, Calif. . 418 Calaveritas Creek near San Andreas,

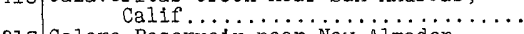

317 Calero Reservoir near New Aimaden, Calif.................... 156

Camp Creek near Somerset, calif......... 299

286 Canyon Creek below Bowman Lake,

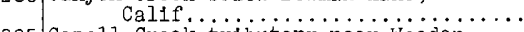

1 Creek tributary near Wooden

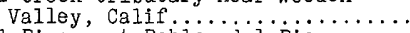

Carmel River, at Robies del Rio,

236

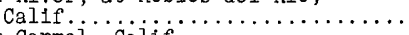

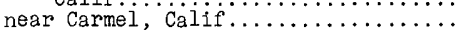
237 Carson River, East Fork, below Markleeville Ćreek, near Markleeville,

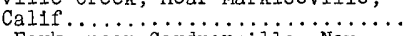
West Fork, at woodfords, Calif........ 42,96 Carson River basin, records.........5i, $91-97$ 290 Cascade Creek near Pinecrest,

268 Calif................... 266

167 Cedar Creek near Beil Station, Caijf... 131 
Central-coastal California, records... AlO Alo, $19,52-56$, i i5-178 Cherry Creek, below Cherry Valley Dam, near Hetch Hetchy, Calif.......

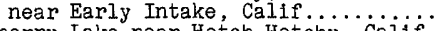
Cherry Lake near Hetch Hetchy, Calif. Chesbro Reservoir near Morgan Hill, Calif.

China Gulch ät Guajaia, cäif.

Chiquito Creek near Bass Lake, Cajif."

Chowchilla River, at Buchanan damsite,

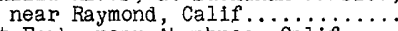

East Fork, near Áwwahnee, Calif.....

Middle Fork, near Nipinnawassee, Calif.

West Fork, near Mariposa, Calif.....

Churn Creek near Redding, Calif........

Clavey River near Buck Meadows, Cailf

Clay Creek near Ione, Calif..

Clear Creek (Carson River basin) near

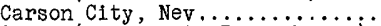

Clear Creek (Sacramento River basinj),

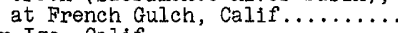

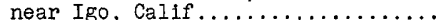

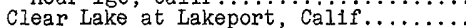

Coho Creek near White River, Calif....

Cole Creek near Salt Springs Dam,

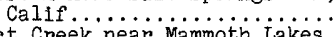

Convict Creek near Mammoth Lakes,

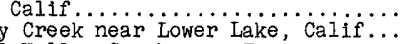

Copsey Creek near Lower Lake,
Corral Hollow Creek near Tracy,

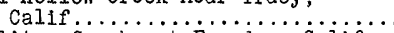
Corralitos creek, at Freedom, calif...

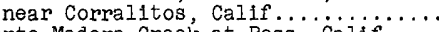

Corte Madera Creek at Ross, Calif.....

Cosgrove Creek near Valley Springs, Calif...

Cosumnes River, at McConneii, calif...

at Michigan Bar, Calif.............43 Middle Fork, near Somerset, Caifi... North Fork, near El Dorado, Calif...

South Fork, near River Pines,

Calif .....................

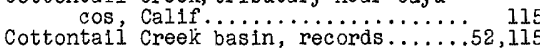

Cottonwood Creek, Middle Fork, near Ono, Calif....

near Cottonwood, Calif

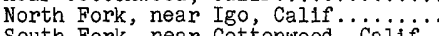

South Fork, near Cottonwood, Cailf.

tributary near cottonwood, Calif...

Courtright Reservoir near Nelson Mountain, Calif...................

Cow Creek (Sacramento River basin)

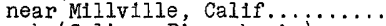

Cow Creek (Salinas River basin) near

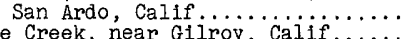

Coyote Creek, near Gilroy, Cailif.....

near Madrone, Calif ............ 164

Coyote Creek basin, records.... . 55,163

Coyote Lake near San Martin, Calif.... calif ...................

Data, explanation of.

Deer Creek (tributary to Cosumes River), near Shingle Springs, Calif , near Shingle Springs,

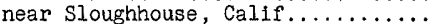

Deer Creek (tributary to Sacramento River (, below Slate Creek, near Deer Creek Meadows, Calif....... near Vina, Calif.

Deer Creek (tributary to Yuba River) near Smartville, Calif.........

Del Puerto Creek, near Patterson,

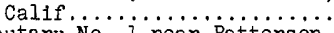

tributary No. i near Patterson,

tributary No. 2 near Patterson,

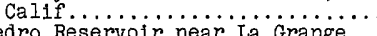

Don Pedro Reservoir near ia Grange,

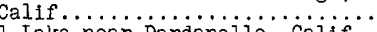

Donnell Lake near Dardanelle, Calif... Donner Creek at Donner Lake, near

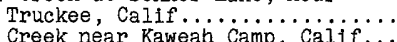
Dorst Creek near Kaweah Camp, Caijf... Doud Creek near Carmel, Calif........

198
Dry Creek (tributary to Russian River),

234 . near Cloverdale, Calif........44,44

313 near Geyservilie, Cálif.............. 448

258 tributary near Hopland, Caijf......... 447

298 Duncan Creek near French Meadows,

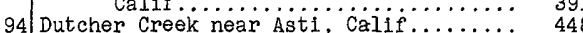

311 Eagle Lake tributary near Susanville,

312 East Walker River. above Strosnider

415 East Walker River, above Strosnider

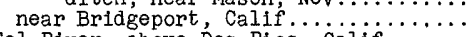

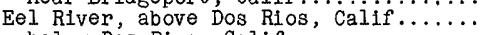

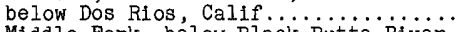

Middle Fork, below Black Butte River,

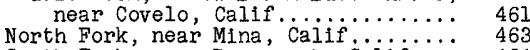

279 South Fork, near Branscomb, Cailf.... 464

140 Eel River basin, records.........70,458-465

139 Elder Creek, at Gerber, Calif........ 326

436 near Paskenta, Calif............... 326

Eldorado Creek at Mountain Ranch,

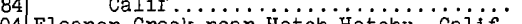

304 Eleanor Creek near Hetch Hetchy, Calif.

, 302 Esperanza Creek near Mokelumne Hill,

$301 \quad$ Calif ...............

Falls Creek near Hetch Hetchy, Calif... 250

301 Feather River, at Bidwell Bar, Calif... 350

at Nicolaus, Calif.............. 382

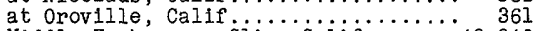

Middle Fork, near cijo, Caijf.......43,340

near Merrimac, Calif............ 34]

318 North Fork, at Pulga, Cailf........... 359

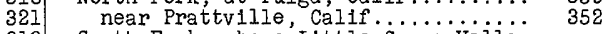

319 South Fork, above Little Grass Valiey

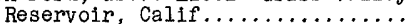

at Enterprise, Calif.............

below diversion dam, near straw-

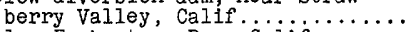

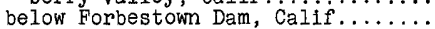
below Little Grass Valley Dam,

Calif..................... 344

below Ponderosa Dam, Calif........... 349

West Branch, near Paradise, Caiff.... 360 near Yankee Hill, Calif............. 360

-165 Feliz Creek near Hopland, Calif........ 443

163 Flood discharge, determination......... 45

Flood frequenciés . . ............. 38

261 Flood stages and discharges, summary... 50 Floods, damage................ 33

46 Floods, general description.......... 15

Florence Lake near Big Creek, Cajif.... 218

Folsom Lake near Folsom, Calif........ 408

303 Forbes Creek, North Fork, near Dutch

303 Flat, Calif.

Forest Creek near Wiliseyvilie, cailf...

329 Fresno River, near Daulton, Calif ......

329 Fulweiter Creek tributary near wiilits,

378

Galena Creek near Steamboat, Nev.......

250 Garcia River near Point Arena, Caijf...

Garzas Creek near Gustine, Caiff......

249 Gerle Creek below Loon Lake Dam, near

249 Gilmore Creek near Lodoga, Cailf......... Goforth Creek near Dos Rios, Calif.....

262 Gold Run tributary near Nelson, Calif..

265 Golden Trout Creek near Cartago,

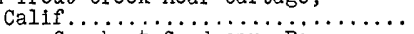
99 Goodyears Creek at Goodyears Bar,

119 Granite Creek near Tobin, Cailf........
350

345 45
48

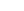

0


Great Basin, records.......

Green Creek near Bridgeport, Calif...

Green Valley Creek near Corralitos, Calif c..... tributary near Eik

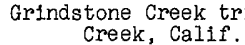

Grizzly Creek near Cedar Grove Caijf Guadalupe Reservoir near New Almaden, Calif.

Guadalupe River at San Jose, Calif.. Guadalupe River basin, records....55, i55-162 Gualala River, South Fork, near Annapolis, Calif.............

Wheatfield Fork, tributary near Annapolis, Calif...

\section{ear} $70,451-452$

Haypress Creek near Sierra City, Calif

Hayward Creek near La Grange, Cailf...

Helms Creek below Courtright Dam, Calif...........................

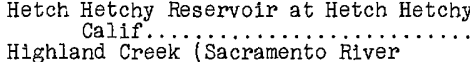
basin) above Highland Creek Dam, Calif...

Highland Creek (San Joaquin River basin) below Spicer Meadows Reservoir, Callf....

Honey Lake basin, records............. i13-

Horse Creek near Clayton, Calif....... Huling Creek tributary at ono, Calif. Hunter Creek near Reno, Nev........... Huntington Lake near Big Creek.

$$
\text { Calif ..................... }
$$

Ice House Reservoir near Kyburz, Calif. Independence Creek below Pinyon Creek, near Independence, Calif........

Indian Creek, near Crescent Milis, Calif.

near Taylorsvilie, Caiif..............

Indlan Valley Creek tributary near

Valleton, Calif............
Isabella Reservoir near Isabeila,

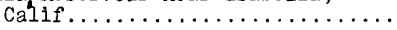

Jack Creek near Templeton, Calif Jackass Creek near Bass Lake, Calif.. Jesus Maria Creek near Mokelume Hili, Callf......................

Kaweah River, at Three Rivers, Calif.. below Terminus Dam, Calif......... East Fork, near Three Rivers, Calif. Marble Fork, at Potwisha Camp, Calif.

Middle Fork, near Potwisha Camp,

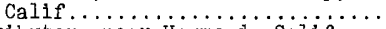

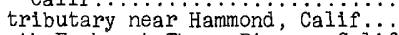

South Fork, at Three Rivers, Cailf. Kellogg Creek tributary near Byron,

Calif......................

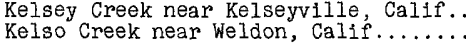
Kern River, at Kernville, Calif......... below Isabella Dam, Calif............. below Kern Canyon powerhouse, near neakersfield, Calif. . Democrat Springs, Calif.......... near Kernville, Calif.............42,181 near quaking Aspen Camp, Calif ........ 178 South Fork, near Olancha, Calif..... near onyx, Calif.

tributary near Miracie Hot Springs, Calif

Kings River, above North Fork, Caiif.. below North Fork, Calif............ below Pine Flat Dam, Calif............ North Fork, above Dinkey Creek, at

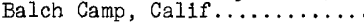

below Dinkey Creek, near Balch

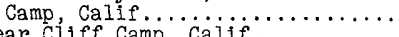
near Cilff Camp, Cailif.

Kingsbury Creek near Twain, caijf..... Kirkwood Creek near Silver Lake, Calif........................ Lahontan Reservolr near Fallon, Nev..... 9696

8 Lake Almanor, near Prattville, Calif .................... 351

141 tributary near Aimanor, Caijf........ 351

Lake Berryessa near Winters, Calif.... 427

331 Lake Eleanor near Hetch Hetchy, Cailf.. 254

202 Lake Elsman near Los Gatos, Calif..... 159

157 Lake Hennessey tributary near Rutherford, Calif.................. 431

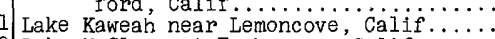
Lake McClure at Exchequer, Calif ........ 246

lake Success near Success, Calif....... 193

Lake Tahoe, at Tahoe City, Calif........ 98 tributary at Tahoe City, Calif........ 97 tributary near Meeks Bay, Calif...... 97

Lake Thomas A. Edison near Big Creek, Calif.................... 219

Laurel Creek near Laurei, Cailf........ 142

366 Lee Vining Creek near Lee Vining,

247

Lexington

Little Chico creek tributary near Forest Ranch, Calif...

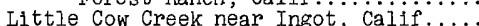

Little Grass Valley Reservoir near

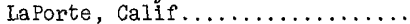

Little Kern River near Quaking Aspen

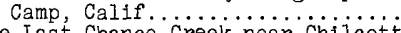

Little Last Chance Creek near Chilcott, Calif.

178
318
106

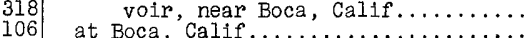
at

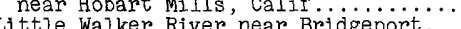

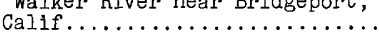

404

5 Iong Canyon Creek near French Meadows,

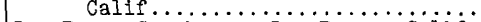

Los Banos Creek near Los Banos, Calif..

355 Los Gatos Creek at Los Gatos, Calif...

354 Los Trancos Creek tributary near Stanford University, Calif.......

122 Lost Creek, above Sly Creek Reservoir, Calif...................... 346

186 near Clipper Milis, Calif............ 34

Lower Twin Lake near Bridgeport, Cailf.

121 Lyons Creek tributary near Lakeport,

Maacama Creek near Kellogg, Calif..... McCloud River above Shasta Lake.

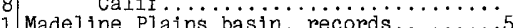

$\ldots \ldots 52,115$

197 Magnolia Creek near Auburn, Calif...... 380 Mammoth Pool Reservoir near Blg Creek, Calif.................. 222 Mariposa Creek near Catheys Valley,

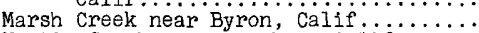
Martis Creek near Truckee, Calif $\ldots .$. Masterson Hollow Creek near Newvilie, Matadero Creek at Paì Aito, Cailf.... Maxwell Creek at Coulterville, Calif... Melones Reservoir at Melones Dam,

Merced River, at Bagby Calif ...........

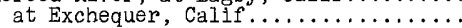
at Happy Isles Bridge, near Yosemite,

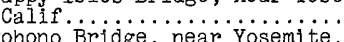

at Pohono Bridge, near Yosemite,

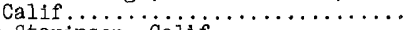

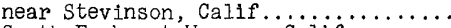
South Fork, at Wawona, Cailf...........

near El Portal, Calif................

202 Merced River Slough near Newman.

Miami Creek near oakhurst, cailif........ Middle Tuolumne River at Oakland

210 Middle Yuba River, above Oregon creek,

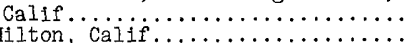

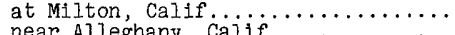

Mill Creek (tributary to Kings River)

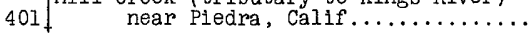

237

305
100 
Mill Creek (tributary to Middle Fork Eel River) tributary near Covelo, Calif.................... Mill Creek (tributary to Sacramento River) near Los Molinos, Creek) near Quincy, Calif.

Millberry Creek at Markleeville, Calif.

Millerton Lake at Friant, Calif......... Mokelumie River, at Lancha Plana,

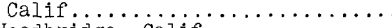
at Woodbridge, Calif.

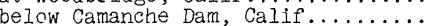
Middle Fork, at West Point, Caiji... near Mokelumne Hill, Calif.........

North Fork, below Salt Springs Dam, Calif.

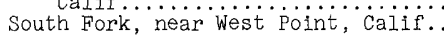
Mon Canyon Creek near Oildale, Calif.

Mono Creek below Lake Thomas A.

Edison, Calif.................... 220

Mono Lake basin, records............50,76-77

Moro Cojo Slough tributary near

Castroville, Calif.

Morrison Creek near Sacramento, Calif

Mountain House Creek, near Midway,

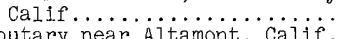

tributary nar A.

Nacimiento River, below Nacimiento Dam, near Bradley, Calif.......

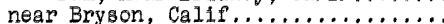

Napa River, near Napa, Calif.........

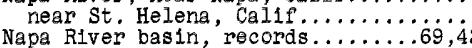

Navarro River, near Navarro, Cäij.

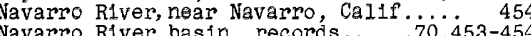

N1casio Creek near N1casio, Calif....

North-coastal Calffornia, records......

North Shirttail Creek near Dutch Flat Calif .................................

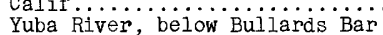
Dam, Calif: :

below Goodyears Bar Caj $\ldots \ldots \ldots \ldots$

tributary near Goodyears Bar Caij.

Novato Creek near Novato, Calif......

Noyo River near Fort Bragg, Calif.....

Oak Run Creek near Oak Run, Calif.....

Onion Creek, near Soda Springs, Calif.

tributary No. 1 near Soda Springs,

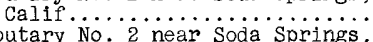
Calif No. 2 near Soda Springs,

tributary No. 3 near Soda Springs,

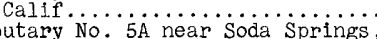
Calif No. SA near Soda Springs,

tributary No. 7 near Soda Springs,

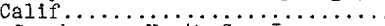

Oregon Creek near North Sä Juan, Calif..

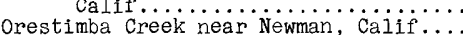

outlet Creek near Longvale, Calif....

Owens Lake basin, records..........50,72-75

Pacheco Creek, near Dunneville, Calif.

Pacheco Creek basin, records......56, 175-177

Packsaddle Canyon Creek near Fairview, Calif................. 180

Pajaro River, at Chittenden, cailf.... 139

near Gilroy, Calif................ 134

Paradise Creek near Paradise Camp. Calif.........................

Pardee Reservoir near Valley Springs,

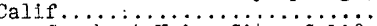

Patterson Creek at Union City, Calif..

Paynes Creek near Red Bluff, Calif....

Pescadero Creek, near Pescadero, Calif.

tributary near La Hönda, Caijf....... 147

Pescadero Creek basin, records....54, 146-148

Petaluma River at Petaluma, Cai if..... 435

Phipps Creek near Lower Lake, Calif...

Picayune Creek near Coarsegold, Calif.
Pilot Creek, above Stumpy Meadows Res-

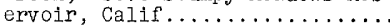
below Mutton Canyon, near Georgetown, Calif................. Bishop, Calif............................

356 Pine Flat Reservoir near Piedra. Calif....................... 215

Pinole Creek, at Pinole, Calif.......... 174

30 Pinole Creek basin, records.......56,174-175

Pit River near Montgomery Creek, Calif................... 308

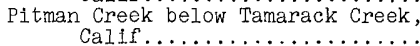

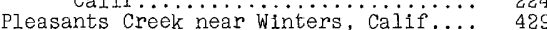

Poorman Creek near Wastington, Calif... 375

Pope Creek near Pope Valley, Calif..... 425

8 Poso Creek near Oildale, Calif........ 189

92 Precipitation.................. 4-9

Prosser Creek, at Hobart Milis, Cailf.. 100

near Boca, Calif................. 101

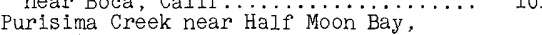

Putah Creek, near Guenoc, Calif......... 148

near Winters, Calif............. 428

tributary near Whispering Pines, Calif.................. 422

287 tributary No. near Winters, Calif.. 428

86 Pyramid and Winnemucca Lakes basin, records.................51,97-112

Pyramid Lake near Nixon, Nev............ 97

124 Rancheria Creek near Boonville, Cal1f., 453

23 Rat Creek near Lucia, Cal1f........... 117

Red Bank creek near Red Blufi, Cailf... 324

Red Clover Creek near Genesee, Cal1f...

Redwood Creek (tributary to corte

Madera Creek) near Tamalpais

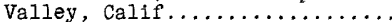

Redwood Creek (tributary to Napa creek) near Napa, Calif....................

Redwood Creek (tributary to San Francisco Bay) at Redwood City.

Calif...................... 149

Redwood Gulch near Jolon, Cailf......... 117

370 Rheem Creek at San Pablo, Calif......... 173

368 Robinson Creek at Twin Lakes Outiet,

435 Rock Creek (tributary to North Fork

435
457 $\begin{aligned} & \text { Rock Creek (tributary to North Fork } \\ & \text { Kings River) at Dinkey Creek, }\end{aligned}$ Kings River at Dinkey Creek,

314 Rock Creek (tributary to North Fork Yuba River) at Goodyears Bar, Calif Creek (tributary to Owens River)

386 Rock Creek (tributary to Owens River Bishop, Calif.

Roscoe Creek near Bode............. 72

384 Ross Creek at San Jose, Calif......... 158

Rubicon River, at Rubicon Springs, near Meeks Bay, Cal1f.......... 392

near Foresthill, Calif............ 398

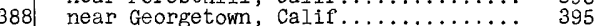

South Fork, below Gerle Creek, near.

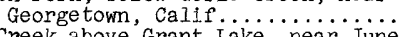

48 Rush Creek above Grant Lake, near June

Lake, Calif ............. Calpelia, Calif..

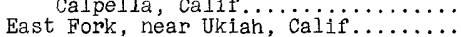
tributary near Potter Valley,$$
\text { Calif. }
$$

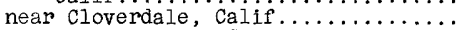

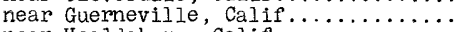

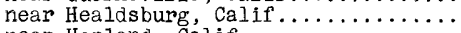

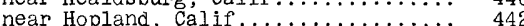

near Ukiah, Calif................ 439

73 Russian River basin, records........69,439-451

294 Sacramento River, at Butte City, Calif. 334

171 at Colusa, Calif.............. 335

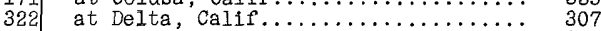

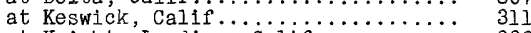

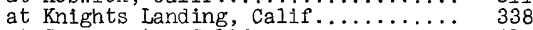
at Sacramento, Calif.............. 410

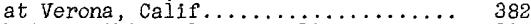
below Wilkins Slough, calif........... 337 near Red Bluff, Calif............ 323

in

\section{a}

\section{4} 政

8


Sacramento Valley, records $\ldots \ldots \ldots \ldots$ Page 27, Sacramento weir spill to Yolo bypass near Sacramento, Calif Sagehen Creek near Truckee, Caijf...... Salinas River, near Bradley, Calif.... near Spreckels, Calif...

382

103

130

Saliras River basin, records.......53,i21-130

Salmon Creek (tributary to Kerm

River), tributary B near Fairview, Calif...

tributary C near Fairview, calif...

tributary E near Falrview, Calif...

Salmon Creek (tributary to Pacific

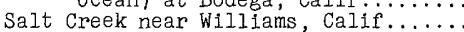

Salt Slough near Los Banos, Calif.....

Salt Springs Reservoir near West Point, Calif ..................

San Antonio Creek (tributary to Alameda Creek) near Sunol,

San Antonio Creek (tributary to South Fork Calaveras River) near San Andreas, Calif.

San Antonio River, at Pleyto Cailf.

at Sam Jones Bridge, near Lockwood, Calif....

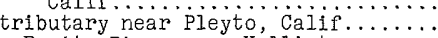

San Benito River near Hollister, Calif.

San Domingo Creek near San Andreas

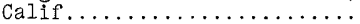

San Franc1squito Creek, at stanford University, Calif.............. University, Calif...................

tributary near Stanford University,

San Francisquito creek basin, records.

San Joaquin River, above Shakeflat Creek, near'Big Creek, Calif.... above Wiliow Creek, near Auberry, Calif.

at Fremont Ford Bridge, Calif........

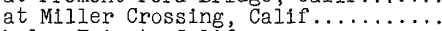
below Friant, Calif.................. below Kerckhof $f$ powerhouse, near

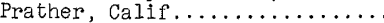

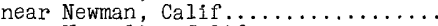

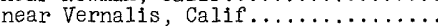
South Fork, near Florence Lake, Calif.

182
182
182

439

338
234

234

287

166

66

280
125

124
126

126

138

279

153

150

151

54 ,

0-153.

222

226

217

217
230

229
248

248
278 calif ...................... 218

San Joaquin River basin, records . 58,217-306 San Joaquin Valley, records $\ddot{2} 3, \ldots \ldots-63 \hat{6}, 178-306$.

San Lorenzo Creek (tributary to Salinas River) below Bitterwater Creek, near king City, Calif...

San Lorenzo Creek (tributary to San Francisco Bay) at Hayward,

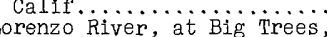
Calif.....

tributary near Boulder creek, Cailf.

San Lorenzo River basin, records.....

San Luis Creek near Los Banos, Calif..

San Marcos Creek tributary near Paso Robles, Calif.

San Ramon Creek, at San Ramon, Cailf..

at Walnut Creek, Calif.............

Sand Creek near Paraiso Springs,

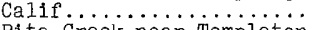

Santa Rita Creek near Templeton.

Santa Rosa Creek (tributary to Pacific Ocean) near Cambria, Calif.

Santa Rosa Creek (tributary to Russian River) near Santa Rosa, Calif...

Sapaque Creek tributary at Bryson, Calif.

Saratoga Creek at Saratoga, Cailf.....

Scott Creek above Little Creek, near Davenport, Calif.

Scotts Creek near Lakeport, Cailf..... Sharon Creek near Menlo Park,

123 ocean) at Bodega, Calif....

below Ladera damsite, near stanford

tributary, near Bitterwater, Calif...
Shasta Lake near Redding Palif .......... Pag Shaver Lake near Big Creek, Calif....... 225 Shingle Creek near Shingletown, Calif.. 317

Shirley Creek tributary near Alta Sierra, Calif............... 183

Silver Creek (Carson River basin) below Pennsylvania Creek, near

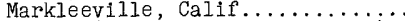

Silver Creek (Sacramento River basin) below Camino diversion dam, Calif.

South Fork, near Ice House, Calif....

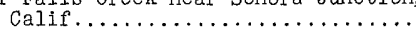

Silver Lake outiet near Kirkwood,

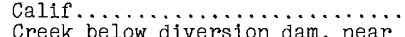

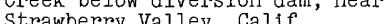

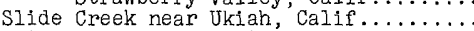

Slinkard Creek tributary near Topaz,

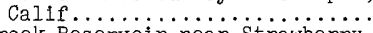

Sly Creek Reservoir near Strawberry Valley, Calif...

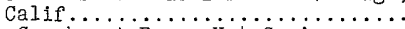

Sonoma Creek, at Boyes Hot Springs,

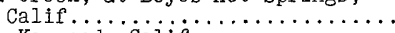

near Kenwood Calif .............

soquel Creek, at Soquei, Calif.......... 143

West Branch, near Soquel, Calif........ 142

Soquel Creek basin, records.......54,142-143

South Cow Creek near Millville,

Calif.................. 314

South Honcut Creek near Bangor, Calif.. 362

South Yuba River, at Jones Bar, Calif.. 376

near Cisco, Calif................. 372

near Washington, Calif........... 374

tributary near Soda Springs, Calif... 371

Spanish Creek, above Blackhawk Creek,

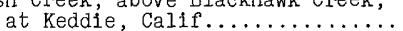

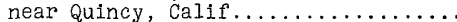
Ferry, Calif................. 277

below Melones powerhouse, near

Sonora, Calif.............. 276

Clark Fork, near Dardaneile, Caiłf... 264

Middle Fork, at Hells Half Acre Bridge, Calif................ 267

at Kennedy Meadows, near Dardaneile, Calif.

at Sand Bar Fiat, near Avery, Cailif.

below Beardsley Dam, Calif.........

North Fork, below Ganns damsite,

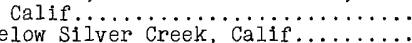

below Silver Creek, Calif........ 270

near Avery, Calif..............43,273

tributary near Lake Alpine, Calif.. 269

South Fork, at Strawberry, Calif..... 274

128 near Long Barn, Calif............. 274

Steep Creek near Laytonville, Calif.... 464

Stevens Creek Reservoir near Monte

Vista, Calif............... 154

Stone Corrai Creek near sites, Cailf... 338

144 Stony Creek, below Black Butte Dam,

144 near Orland, Calif............ 333

near Fruto, Calif ................ 332

near Hamilton City, Calif............ 333

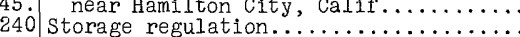

Strawberry Creek near wawona, Caijf.... 243

122 Sugarpine Creek near Long Barn, Calif..

175 Sulphur Creek near St. Helena, Calif...

176 Sulphur Springs Canyon near Jolon,

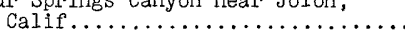

9 Summit Creek near Mineral, Calif....... Susan River at Susanville, Calif.......

121 Sutter Creek near Sutter Creek, Caijf.: Swager Creek near Bridgeport, Calif....

116 Sweetland Creek near North San Juan,

449 Sycamore Creek above Pine Fiat Reser-

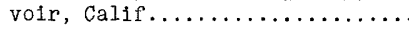

162 Tamarack Creek, South Fork tributary

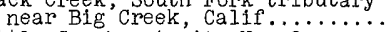

146 Teakettle Creek, at site No. 3 , near Patterson Mounta in, Calif........ tributary No. I near Patterson Mountain, Calif...............
Smoky Jack Creek near Yosemite Viliage,

belous River, at Ripon, Calif..... Woodwin Dam, near Knights

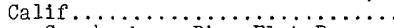

(1)

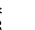

4
2
6
74
1

78

(1)

\begin{tabular}{l}
74 \\
748 \\
\hline
\end{tabular}

54

3

33

36
243

260

430
400 
Teakettle Creek, tributary No. 2 near Patterson Mountain, Calif...... tributary No. 2A near Patterson Mountain, Calif.

tributary No. 7 near Patterson

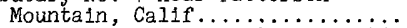

Tenmile Creek near Laytonvilie, Caijf.

Thomes Creek, at Paskenta, Calif..... tributary at Paskenta, Calif........

Topaz Reservoir near Topaz, Calif....

Truckee River, at Farad, Cálif........

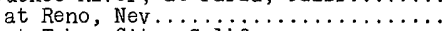

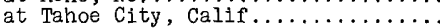

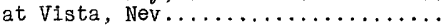
below Derby Dam, near Wadsworth,

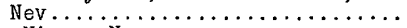

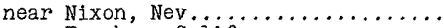

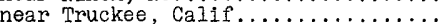
tributary near Truckee, Cailf

Tulare Lake basin, records........57,i

Tule River, below Success Dam, Calif.. Middle Fork, North Fork of, near

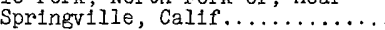

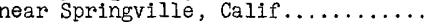

North Fork, at Springvilie, Caiff... South Fork, near Success, Calif.... tributary near Success, Calif.......

Tulloch Reservolr near Knights Ferry, Calif $\ldots \ldots \ldots \ldots \ldots$ near oildale, calif..

Tumbleweed Creek near Oildale, Calif
Tuolumne River, above La Grange Dam, near La Grange, Calif..........

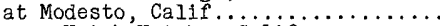

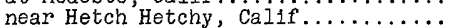
North Fork, above Dyer Creek, near Tuolumne, Calif

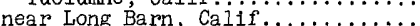

South Fork, near Oakland Recreation

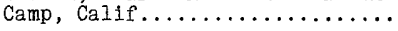

Union Valley Reservoir near Riverton,

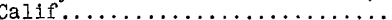

Upper Castle Creek at Soda Springs,

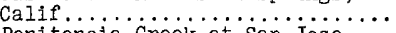

Upper Penitencia Creek at San Jose,

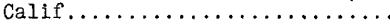

Upper Twin Lake near Bridgeport, $\mathrm{Cal1f} . \ldots \ldots \ldots \ldots \ldots \ldots \ldots \ldots$

Uvas Creek, above Uvas Reservoir, near

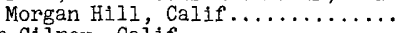

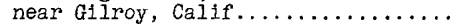

Uvas Reservoir near Morgan Hili,

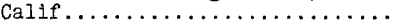

Vale Gulch tributary near Red Bank,

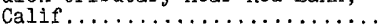

Page

A207 Walker Creek near Tomales, Cal1f...... 438

208 Walker Lake, near Hawthorne, Nev ......... 77 Walker Lake basin, records.........50,77-90

206. Walker River near Wabuska, Nev......... 90

465 Walnut Creek at Walnut Creek, Calif.... 177

328 Ward Creek tributary near Cazadero,

328

88 Warner Creek near Fort Bragg, Caij....

Wellman Creek near Smartvilie, Calif...

West Walker River, at Hoye bridge, near

7 West Walker River, at Hoye bridge, near at Leavitt Meadows, near cöjevilie,

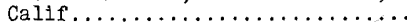

below Iittle Walker River, near Cole-

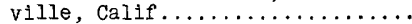

111

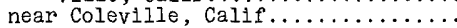

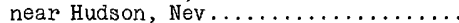
Whiskey Creek near Termo, Calif....... Whites Creek near Steamboat, Nev...... Willow Creek (tributary to Middle Fork Feather River), tributary near

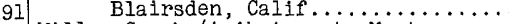

W11low Creek (tributary to Montgomery Creek) near Round Mounta1n, Calif

5 W11low Creek (tributary to San Joaquin

277 River) at mouth, near Auberry

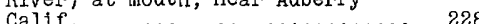

North Fork, near Bass Irake, Calif.... 227

262 Willow Creek (tributary to Susan River)

252 tributary near Susanville. Calif .....................

260 Willow Glen Creek near Rackerby,

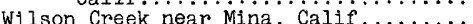

Winding Creek near Camp Nelson,

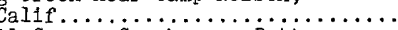
Windmill Canyon Creek near Patterson,

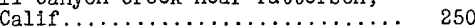

Wishon Reservoir near Cilff Camp,

371 Calif.................. 204

Wolf Creek near volita, Caijf........... 239

165 Woodruff Creek at Goodyears Bar,

Calif....................... 367

9) Woods Creek near Jacksonvilie, caijf... 261

Wyman Ravine tributary near Pálermo,

135 Calif.................... 362

Yolo bypass near Woodland, Calif...... 422

36 Yuba River, at Englebright Dam, Cailf... 377 near Marysville, Callf........... 379

324 Zayante Creek at Zayante, Callf....... 144 